Dr. M. Ralijí

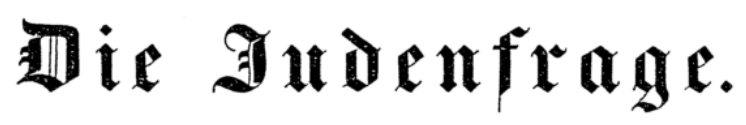





\section{Bir Эuturnfrage}

\section{in ifrer wahren Bedeutung}

fün $\mathfrak{x} \mathfrak{x} \mathfrak{e n} \mathfrak{e} \mathfrak{e n}$

bolt

Dr. At. 船

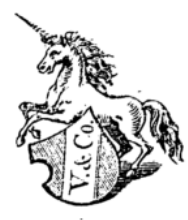

跬就

Berlag vou $\mathfrak{B}$ eit \& Somp.

1860. 


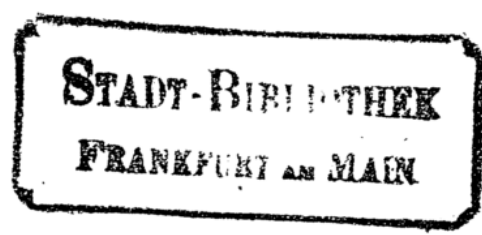

m[ mben. 


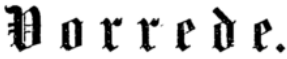

Der Dberrabbiner $\mathfrak{A}$. Sutro in Münjter hatte Samenz feiner (5lau=

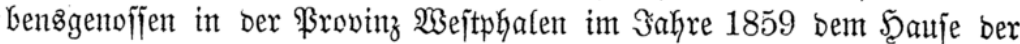

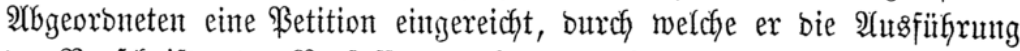

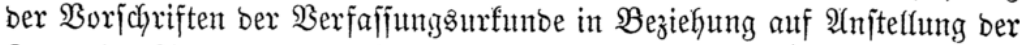

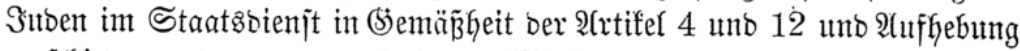
werichiebener, bem entgegenjtehenber Minijterialrejfripte bezmedte, alz mit

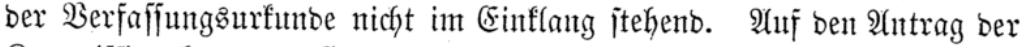

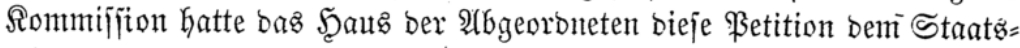
minijterium zur berïffichtigung itbermiejen. Unter bem 6. Februar 1860 hat mun Betent feine \$etition wieber in Amregung gebradyt, uno

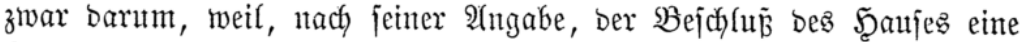
Errebigung nicht gefunben. Die Sonmiffiton hat nut abermals sie \$etition

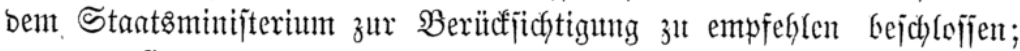

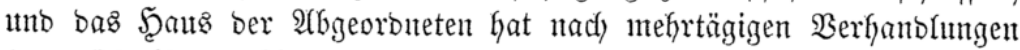

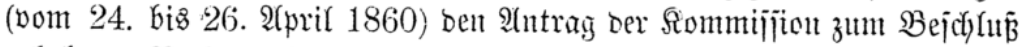

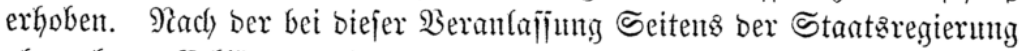

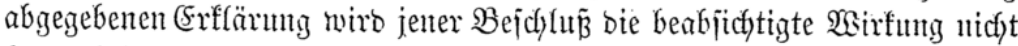
hervorbringen; und bie atsfüfyrlichen Erränterungen, welche bie Şerren

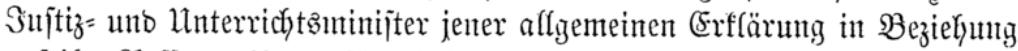

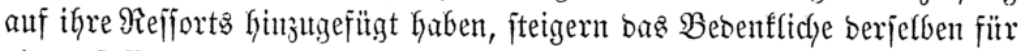

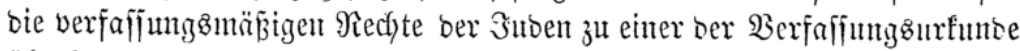
überhaupt brohenoen siejahr.

In ber Siommiffiton waren bie bei ber Petition betheiligten Mintifter

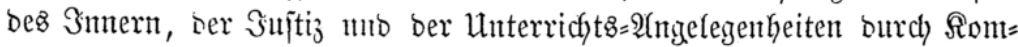
miffiarien bertreten, uno won biejen warb folgente Erflärung abgegeben: 
"Die Staatzregierung habe aus $\mathfrak{A} \mathfrak{n}$ la

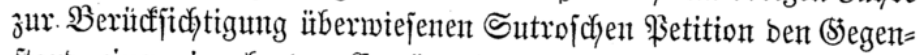
ftant einer eingehenben (Exwägung unterzogen. Nach Dent Ergeb=

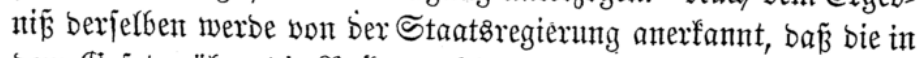

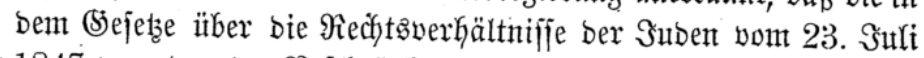

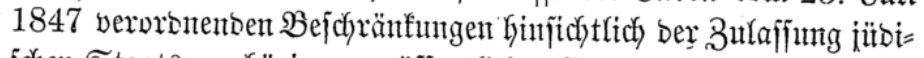

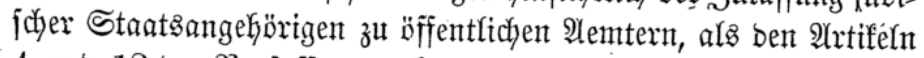
4 und 12 ber \$Berfafiungsurfunbe zutwiber(anfent, butrd bie lets:

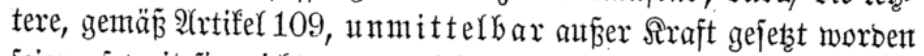
jeien, jowneit jie nicht anberweitig; wie namentfich) int $\mathfrak{2}$ rtifiel 14 ,

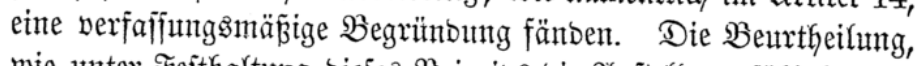

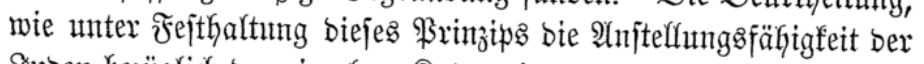

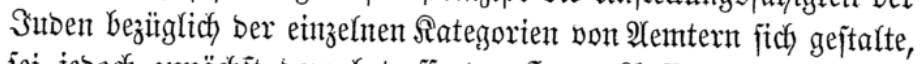

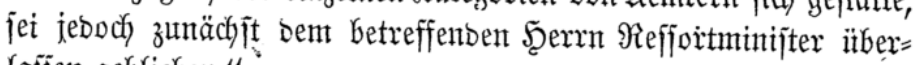
lafjen geblieben."

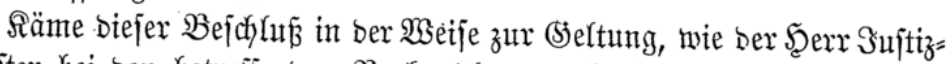

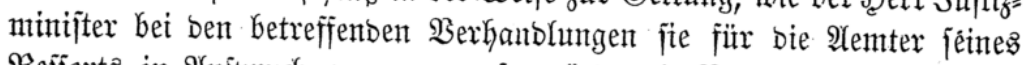

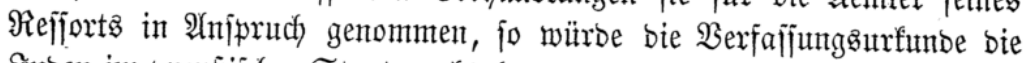

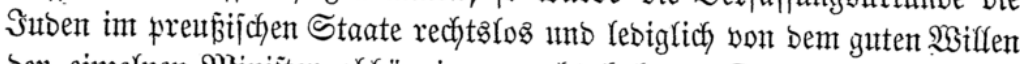
Der einzełnen 9)linijter abhängig gemadyt haben. Die 2rrtifel 4 unb 12

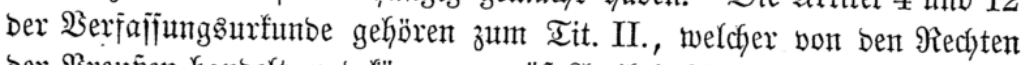

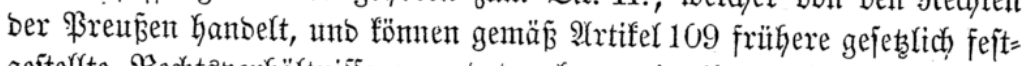

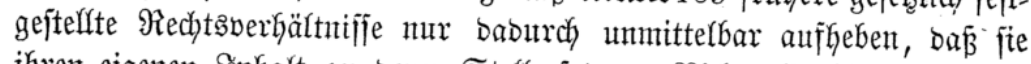

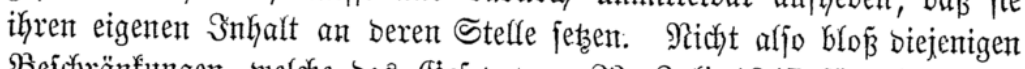

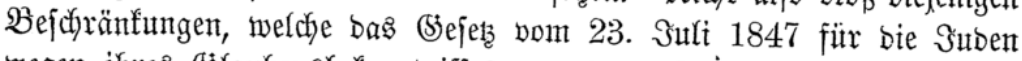

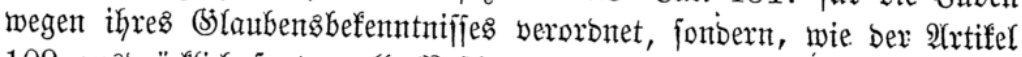

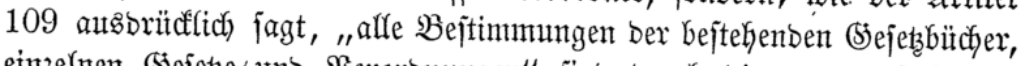
einzelnen Brefetse und Berorbmungen" find burch bie entgegenjtehenben İrtiffel 4 unt 12 ummittelbar aufgehoben; und es fann fein 2 imt ferner geben, welches - wenn es nicht, jeiner eignen Patur nach, bem Dienjte

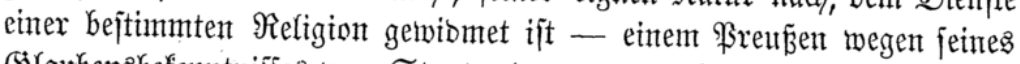

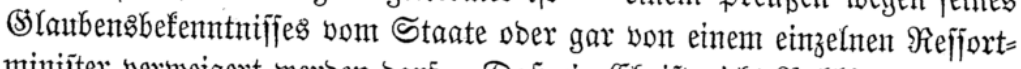

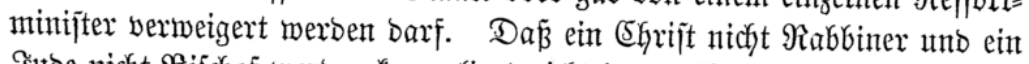

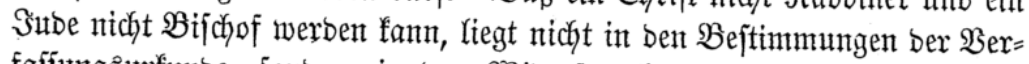
faffung

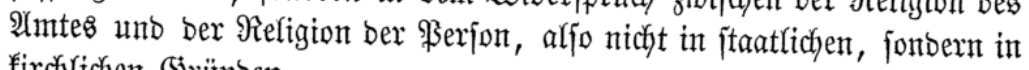
firchlichlen (strünben.

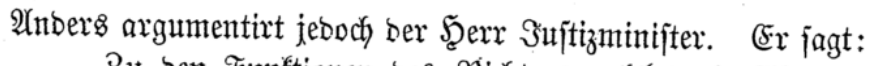

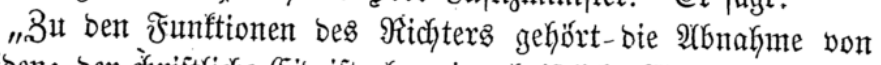
siben; ber chriftliche (sib ift aber eine dyriftlidje (sinridytung, anf 


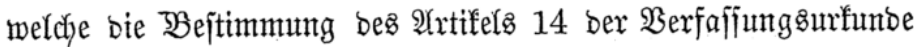
zu bezieken ift. - - Man hat zwar bejtritten, bas bie sibes=

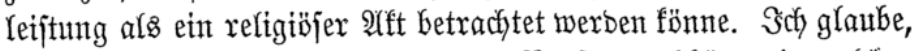

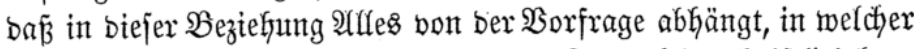

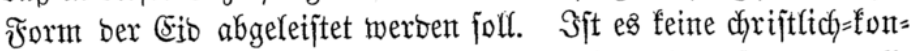
feifïnelfe Form, in weldher ber (Fid erhoben wirs, fo treten afle

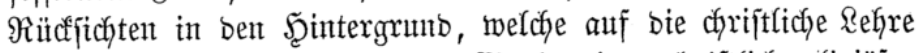
zuriüffweifen. Went aber ber (5ib in einer doriftlich)refigiöjen Form erkgben wirb, bann hat er nach ber Gerrjchenden $\mathfrak{A}$ nficht, wie ich glaube behaupten zu fönnen, bie Eigenfichaft einer religiöjen,

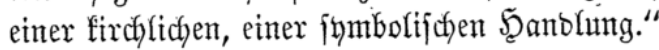

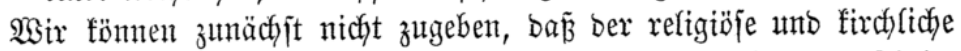

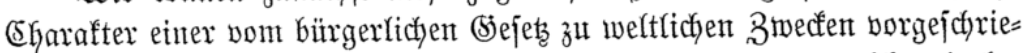
benten Scanblung bon ber fonfeffitonellen Form abjängt, in welche bie be= treffento jtaatliche Einrichtung jene F̧andung geffeibet hat. Sit bie Eibes=

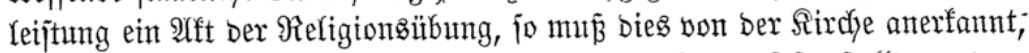

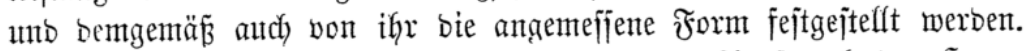

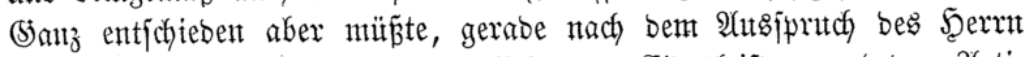

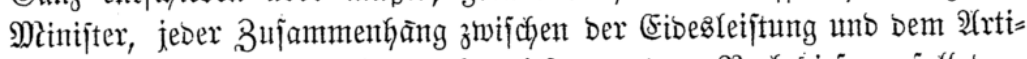
fer 14 ber $\mathfrak{B}$ erfajfung jenigen Einxidytungen Des Staats, weldye mit ber Religionsübung im 3ujammenhange jtehen, bie chriftliche Religion zu (Srunbe gelegt werben,"

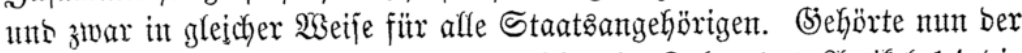
(sib ju benjentigen Einrichtungen, melchen in Folge bes $\mathfrak{2}$ rrtifel 14 bie

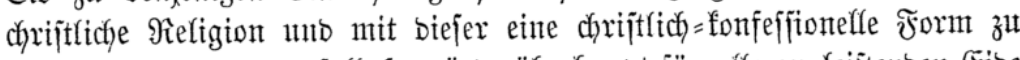

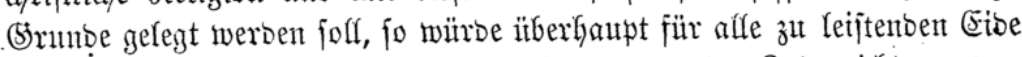

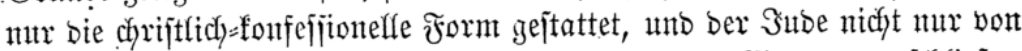

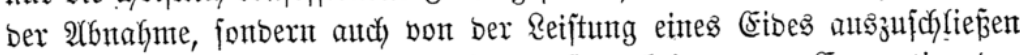

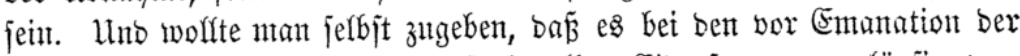
Berfaffung fejtgejtellten nichtfonfeffionelfen Eibesformen vorläufig ber=

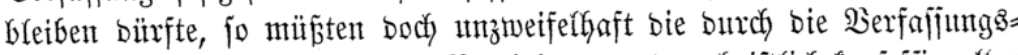

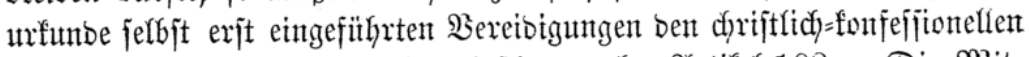

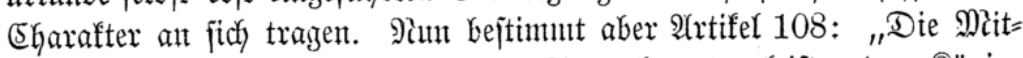

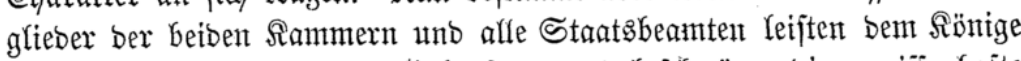
bent (5ib ber Trente unb bes \$ehorjams unb bejdyören bie genifjenthafte

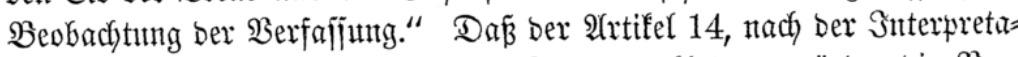

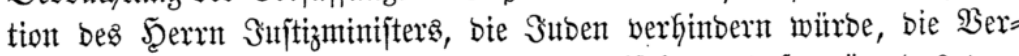
faffunt zut "befdywären, wirb nientand bezweifeln; unt fo wäre bas ber=

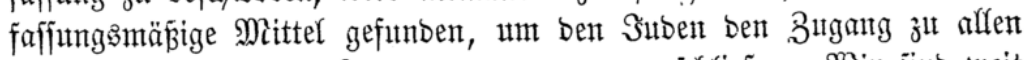
Staatgämtern und zur Ranbeşvertretung zu verjoblief̧en. Wir jint weit 


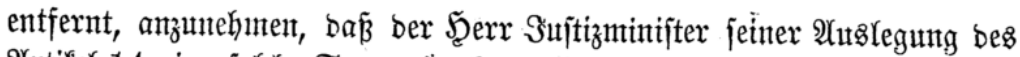
Artifer 14 eine folche Tragmeite hat geben wollen; aber bie Miöglichleteit einer foldyen Ronjequenz barf nicht ïberjehen werben.

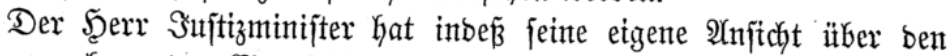

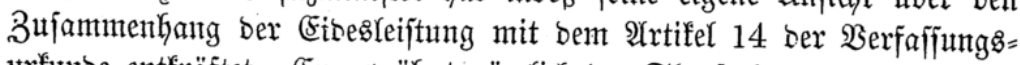

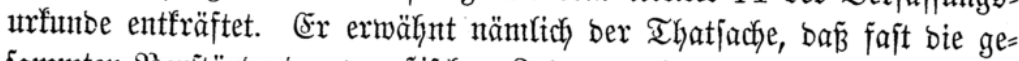

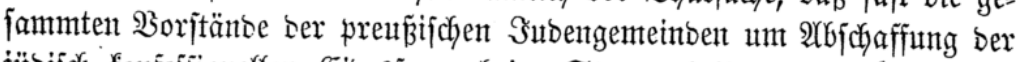

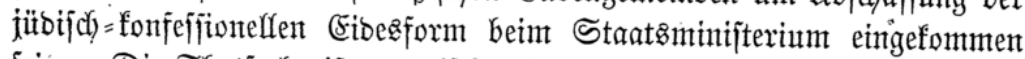

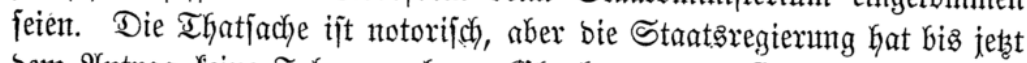

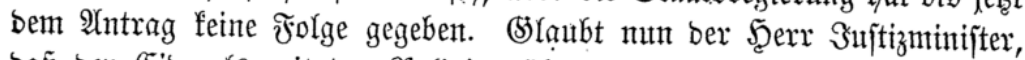

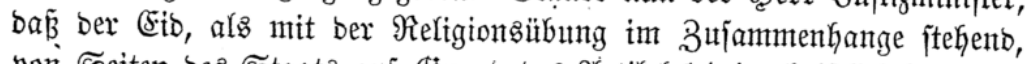

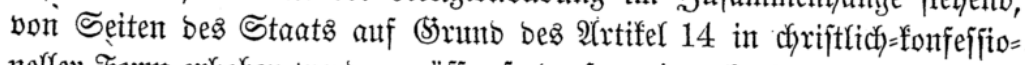
neffer $\mathfrak{r}_{0 m}$ erkoben werben mitffe, jo barf er einen fonfeffioneff $=$ jübifchen (5ib gar nicht mefyr zulaffen, noch wentiger aber biẹ Suben, gegen ihre alfein berechtigte refigiöfe $\mathcal{H}_{e}$ berzengung unt gegen ifren auf bieje Heber= zengung gegrünbeten Âtntrag, zwingen, ihren Eibent bie jübifche Religiont zut Strumbe zu regen.

Wir mitiffent utns aber erlautben, nody einen Sdyritt meiter zut gehent. Wenn es eine ftantliche Einrichtung giebt, welche burch ifgre hiftorifiche

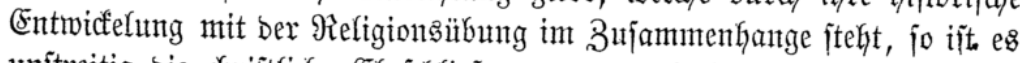

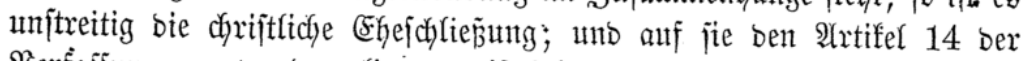
Serfaffung anzumentoen, liegt gemiñ fefr nake. Uno boch hat ber Seerr

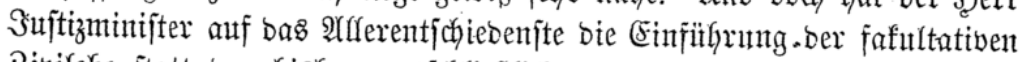

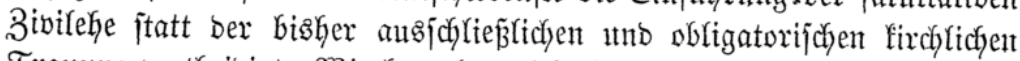

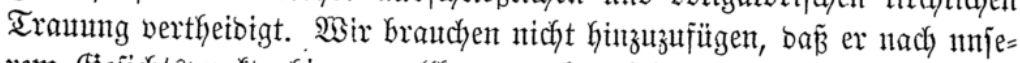
rem (Sejichtspunfte fierzu wolffommen berechtigt war; benn wir fteffent.

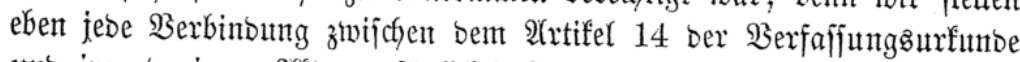

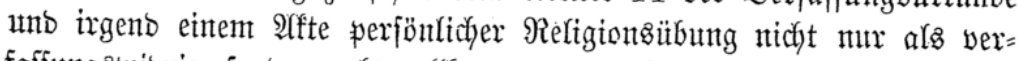
faffungsiovibrig, fonbern als wolffommen untoenfbar in 2rbrebe. Die Âta

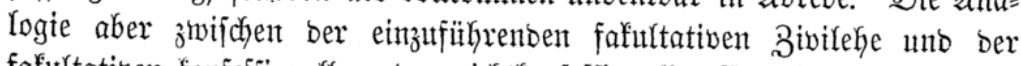
fafultation tonfeffionellen ober nidytfonfeffitonelfen Gioesleiftung verbient barum Kervorgefoben zu werben, weil Yeţtere bei ber Sereibigung auf bie

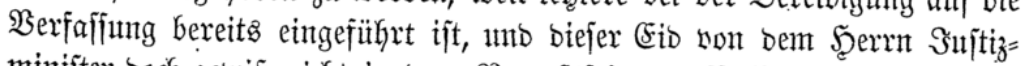

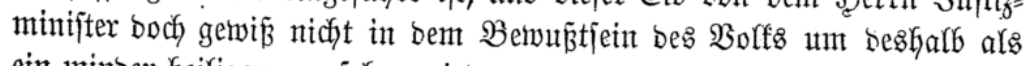
ein minter heiliger angejeken wirb.

Es möchte baher wohl nicht zu getwagt exjcyeinen, ment wir gläuben,

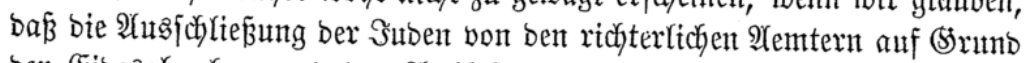

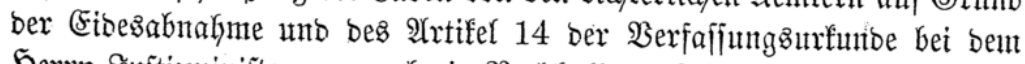

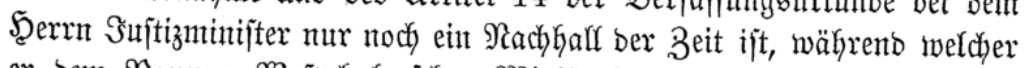

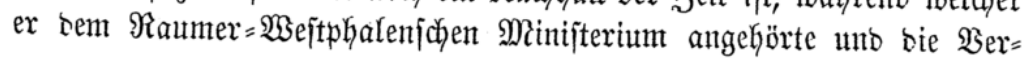




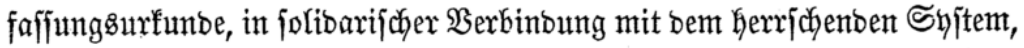
nicht nach ben Snterpretationąregeln eines borffommen jelbjtftänbigen

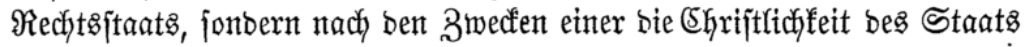

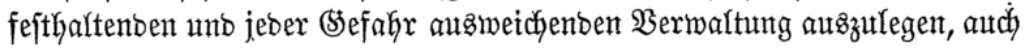

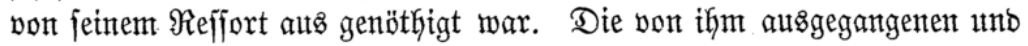

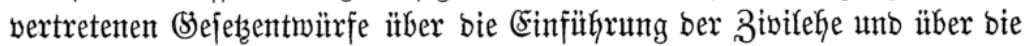

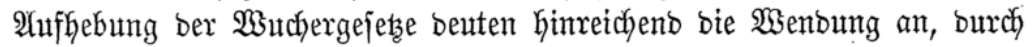
weldye es ifhn möglidy geworben, ein Mitglieb bes gegentwärtigen Staatz= minifteriums zu fein. Mebr als in einer tief wutzzelnden leberzeugung möchte vieffeidyt in ber Entidyitebenheit, mit weldyer gerabe ber ફ̧err Sujtiz=

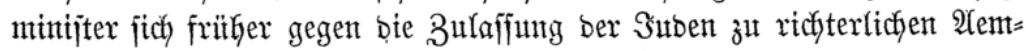
tern ausigefprochent, ber Srumb liegen, ber ifn verfintort, unmittelbar uno lebiglich. auf ben (5rumb einer ßetition ben entgegengejeţten $\mathfrak{W e g}$ einzu= fdylagen uno getwiffermazen fich felbit zut bejavouiren. Die fortichreitente

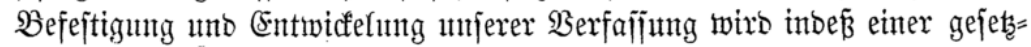

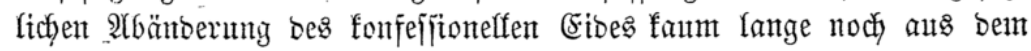
Şege gehen fönnen; bas wahre religiöfe (s)efïhl, welchem bie Benuthung firchlicher und refigiöjer Formen für rein bïrgerliche Zwedfe miberjtrebt,

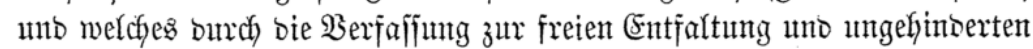

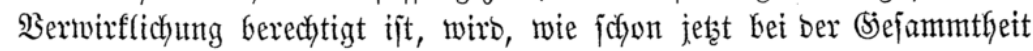

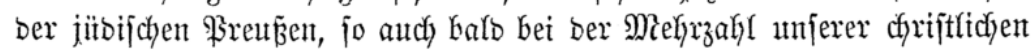

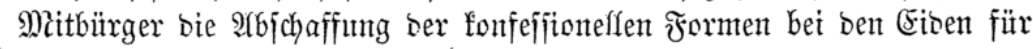

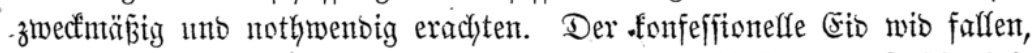

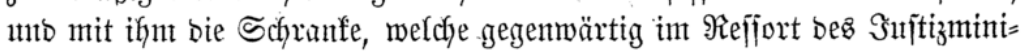

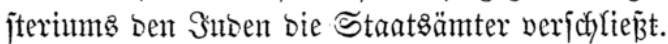

Bebenflicher als ber religiö

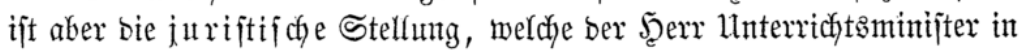

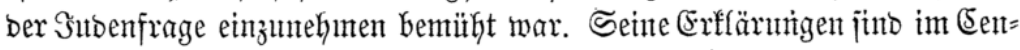
tralblatt für bie gejammte Unterridytzuernaltung, Maifheft 1860 von einem offizielfen $\mathfrak{A}$ rtiffel begleitet, Dem mir folgentbe Stellen entnehment:

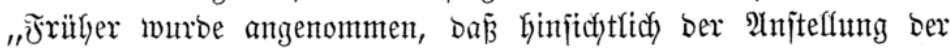

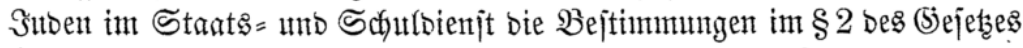

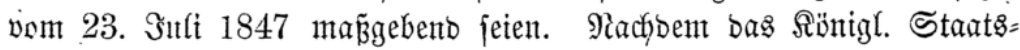
minijterium bejhlofifen hat, ben $\$$. 2 bes (Sejetzes vom 23. Sult 1847

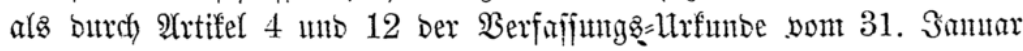
1850 -aufgefoben anzujeken, jo ergeben jich), unter Beritcfïchtigung

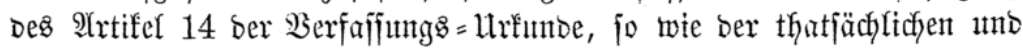

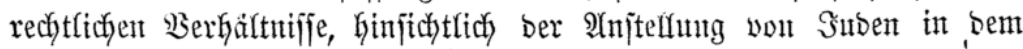

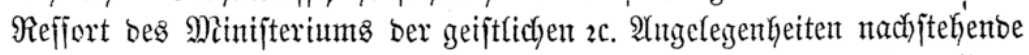

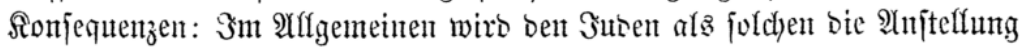




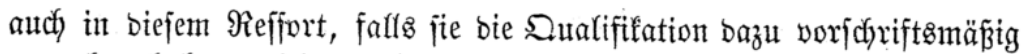
ermorben haben, nicht verjagt merben fönnen, fofern ifre Refigion fie

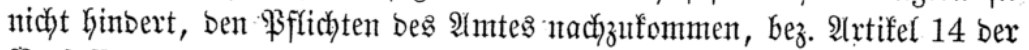
Serfaijungsinfunde nidyt entgegenfteht. Sn miefern Yeţteres ber Falf

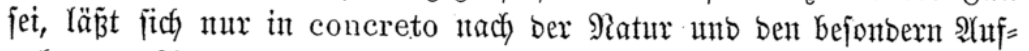

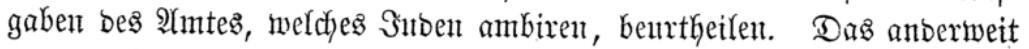

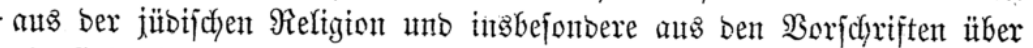
bie Jeeilighaltung bes Sabbaths und ber. jïbijchen Feiertage fich er=

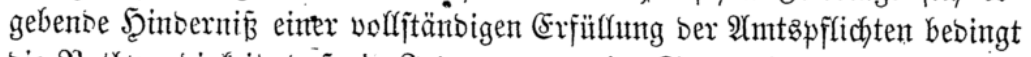

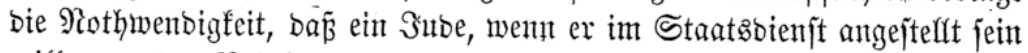

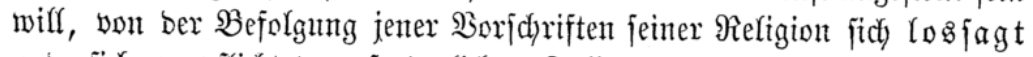
unto fich verpflichtet, erforber(idyen Farfz aud) am Sabbath und an

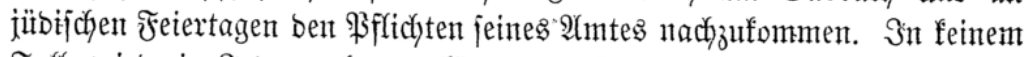

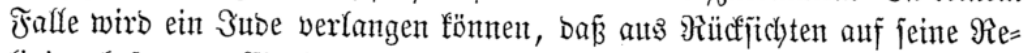
ligion bejonbere Einridftungen befufg feiner Bertretung ant Sabbath ge= troffen werben. Der Staat beriudfichtigt in B̉etreff ber religiöfen Feier=

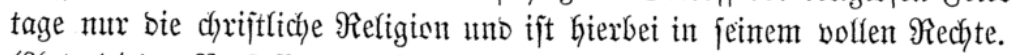

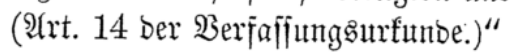

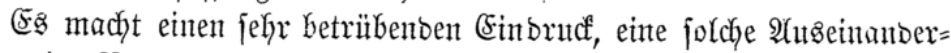

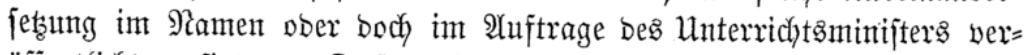

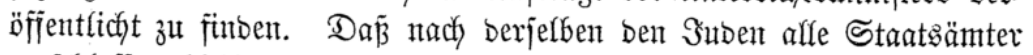
verīglofien bleiben müffen, liegt auf ber Şanto; bann trete man aber offen hervor uno erffäre: "Es liegt uns fein Mittel zu fern, um es gegen.

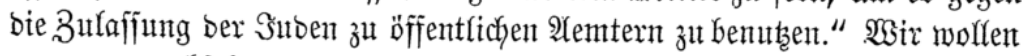

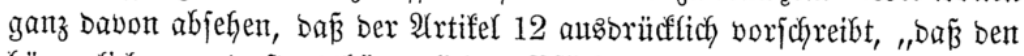

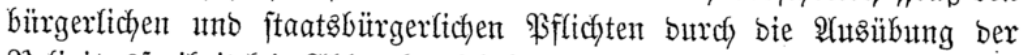

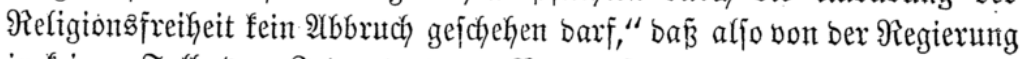

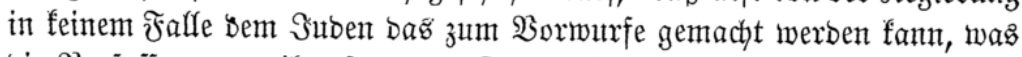
bie Serfajiung von ifm forbert. Soer joll etrwa ber 2 rtriffel 12 in feinem leţten Satze bas wieber alfgefoben haben, was er in ben vorangegan= genen gemährleiftet, unno was fich nach Rage ber Sache boch wohl nur auf

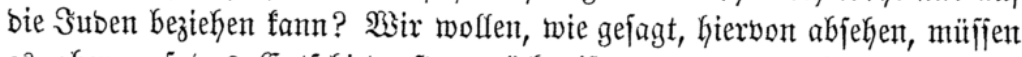
es aber anf Das Entfchiebenjte zurüftweifen, wenn der Berfaffer jenter

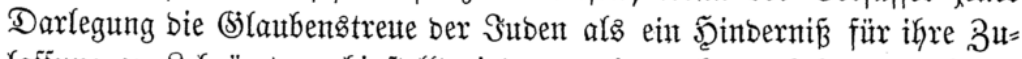
lajfung zu Rehräntern hinjtellt, inbem, wie er herborkebt, "ein Sube,

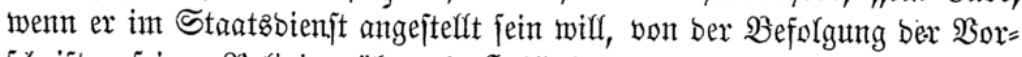

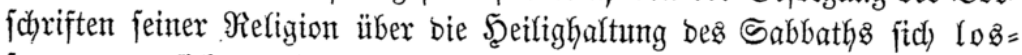
jagen und jich verpflichten mura, erforberfichen Faffs aud am Sabbath

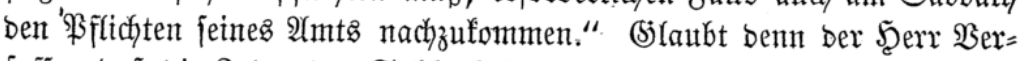
fajfer, baj bie Suben ben Sabbath fahlafent ober nidytgthueno ober ourch 
Sdywelgerei unb finnliche Rujtbarfeiten heiligen? Weí er es benn nicht, Dá̧ gerabe bie Rehrthätigfeit bet ihnen bazu beftimmt ift, am Sabbath bie

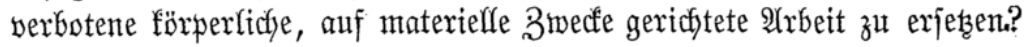

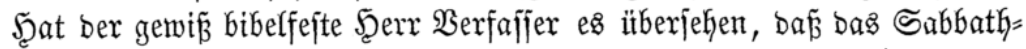

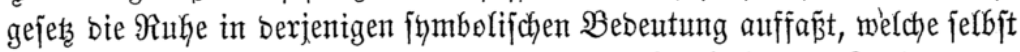

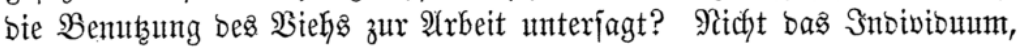

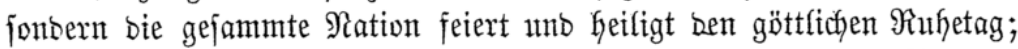

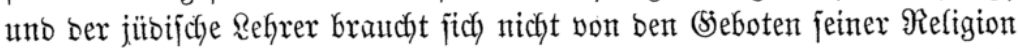

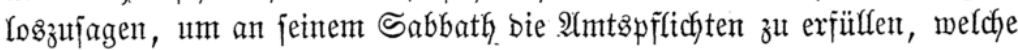

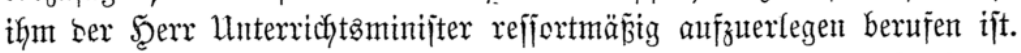

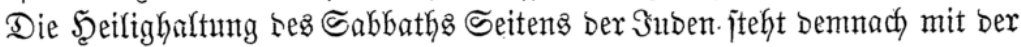

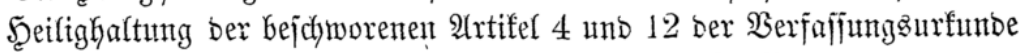
Seiteng bes Şern Unterrichteminifters in vollem Einflang.

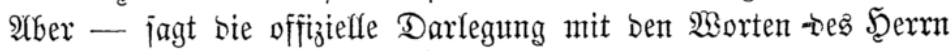
Minijiters: -

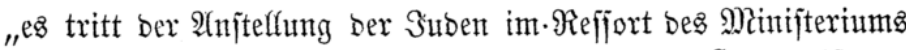

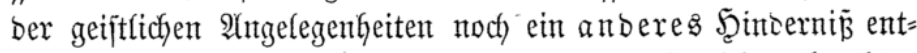

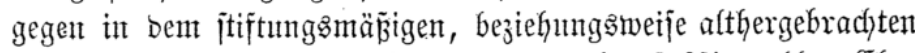

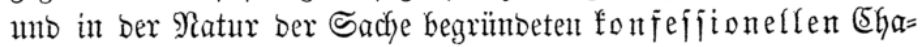

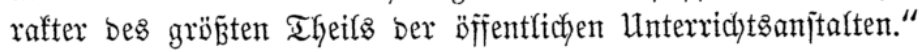

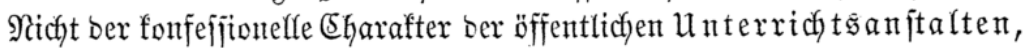

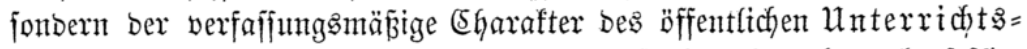
wejens ift hier majgebent; unt bie ₹rage ijt eben bie, ob ber fonfeffito= nelfe (5harafter, weldfen ber Şerr Interrichtamminifter für bent größ̈ten Theil jener $\mathscr{A}$ niftalten als einen nod) jeţt bered)tigtent erf(ärt uno als ein

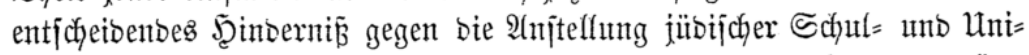

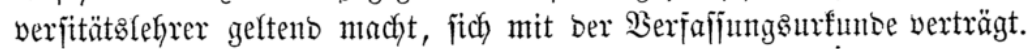

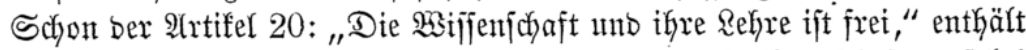

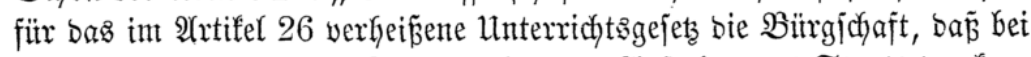

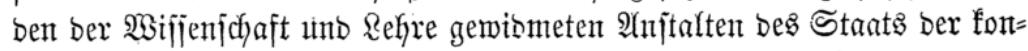

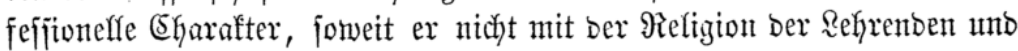
Rernentoen in nothmentigem $3 \mathfrak{u}$ jammentyange fteht, weber für bie Schüler,

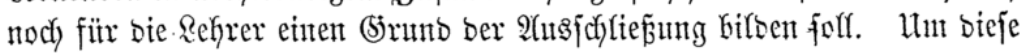

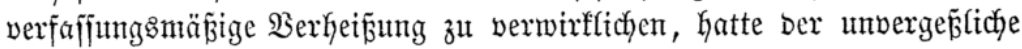
Minijter v. Rabenberg einen entiprechenden (Sejetzentmurf ausgearbeitet;

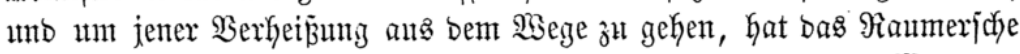
Minifterium utidyt nur jenen Entwurf bejeitigt, jonbern anf bem $\mathfrak{W}$ ege ber

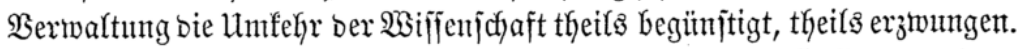

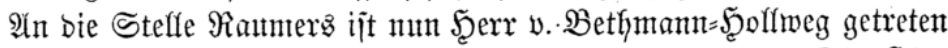

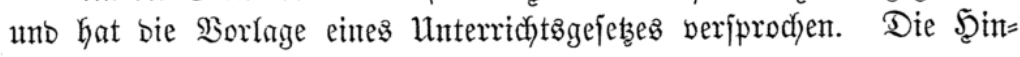


beutung, welche er bei biefer Belegenlyeit auf bie "gefcheiterten Beftre=

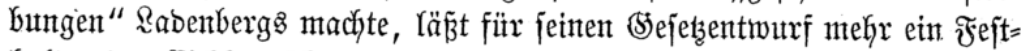

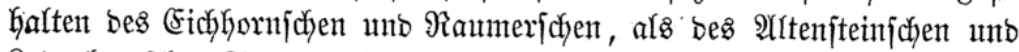
Rabenbergicyen Stantounfts vorautifehen; uno went wir audf mit Sicher= heit vorkerjagen fömtnen, baß ein foldcher (\$) ejetzentwurf mur auf ben Irüm=

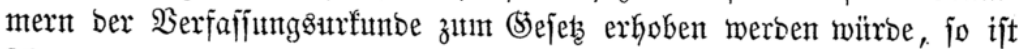

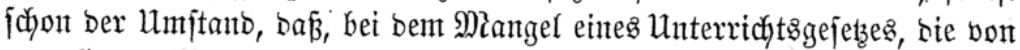
Den Şerrn Minifter anggefprochenen unt auf bent Berwaltungginege get=

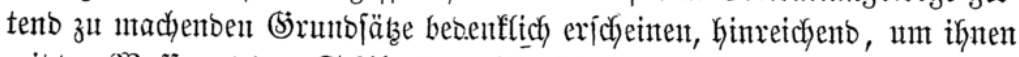

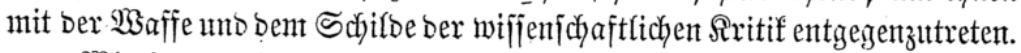

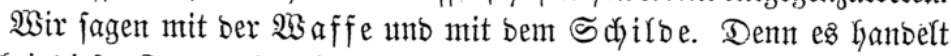

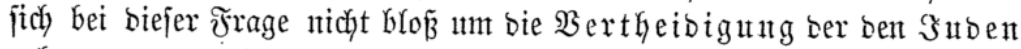

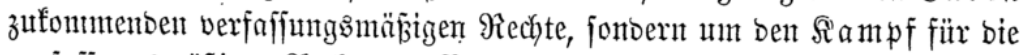

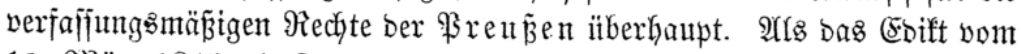

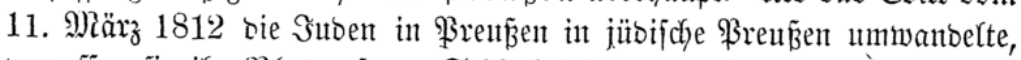

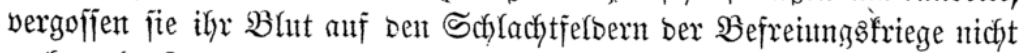

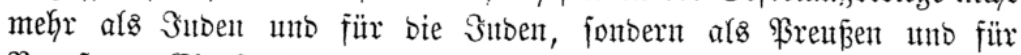

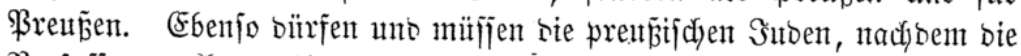

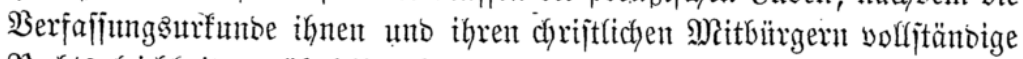

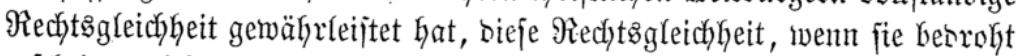

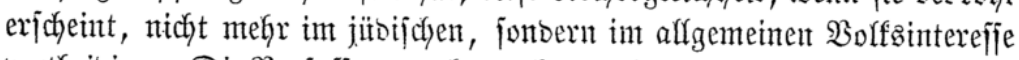

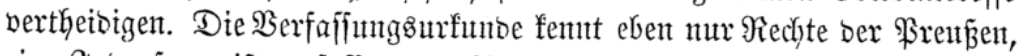

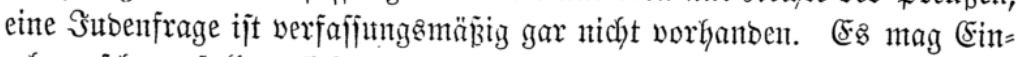
zelnen fajwer fallen, fich in bie groß̧en Sonjequenzen zut fügen, welche bie

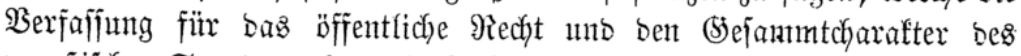
preupifictyen Staats notǵtwentig herbeigefühgrt hat; bies änbert aber in ber

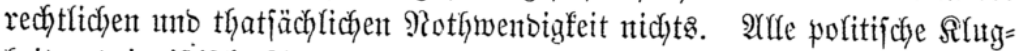
Geit und juriftifiche Spiffindigfeit fam Gier feine Bermittelung ber begriff= lichen 19 iberipritche zut Stanbe bringen. 3wifchent ber Berfaffing

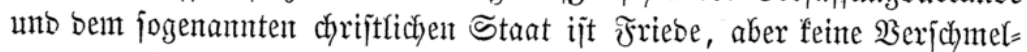
zung möglich. Bofffomment ridytig, fonjequent mo umerjefyitterlich hat

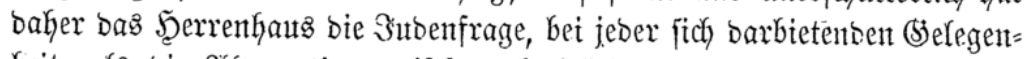

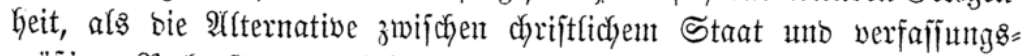

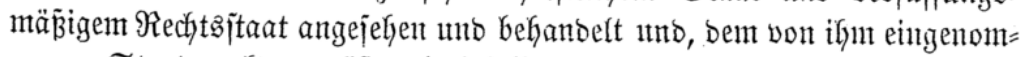

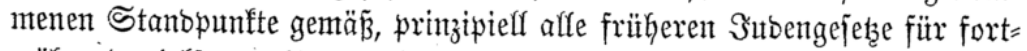

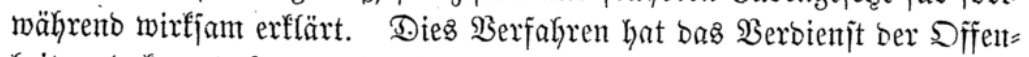
Geit und fann baher burch fich felbjt beurtheilt weroen. Der vont Serrat Unterridfteminijter eingejd)lagene $\mathfrak{B}$ eg ijt bagegen ein gewunbener unb verbecfter; unt burch biejes Rabarinth faun uns unr ber 2 triabnefaben ber gefdyidytlichen Thatjacken mit Sicherkeit leitent. 
Diejen Faben zu finben, habe idy midy reblich bemüht, und ifn bem

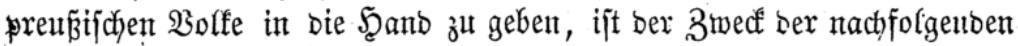
Schrift. Man wiro ihr bie jahrelange 2 trbeit und bie milhebolle For=

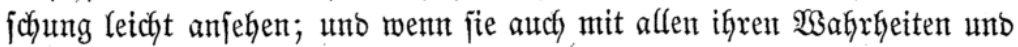

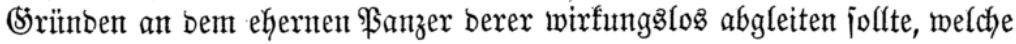
aus Parteintereffe nicht ïberzengt werben, wollen: fo wirb jie boch min= bejtens benjenigen, welche fich berufen fühlen, für bie fortjchreitente (Ent= widfelung bes prenfifichen Staates und $\mathfrak{B}$ olfes auf bem $\mathfrak{W}$ ege ber gejets= lichen Freiheit mit ben $\mathfrak{W}$ affen bes Bjeiftes zu fämpjen, ein ebenjo umfajien= bes als zunerläjfitges Material barbieten. Dá̉ ein folches mir mur ourch

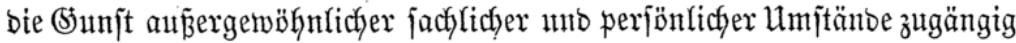
gemacht werben fonnte, bebarf faum ber Errwähnung, bieje aber näher an= zugeben, wifl ich) für jeţt unterlaffen, um jelbjt Den Sdjein ber (Fitelfeit zu vermeiben. Dagegen halte ich es für feine, ober boch für eine erlaubte (5itelfeit, wenn idy meinem Buthe, im Intereffe ber Sacthe, bie wahrelich

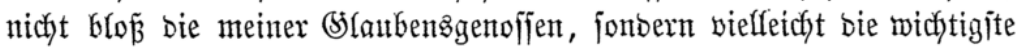

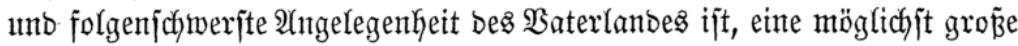
Berbreitung unb Theilnahme münjhe. Der Rampf für bas Recht ber

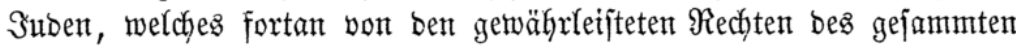

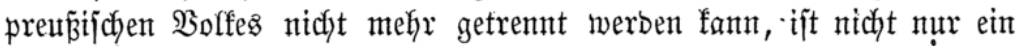

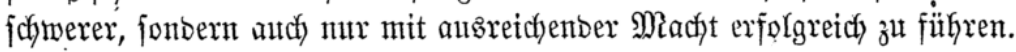

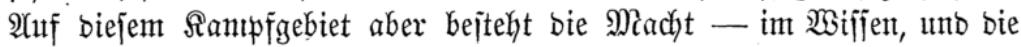

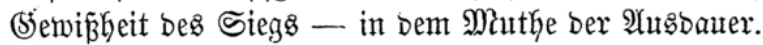

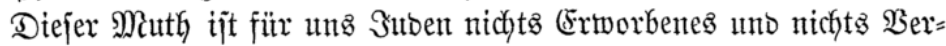

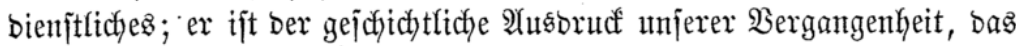

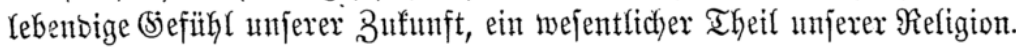

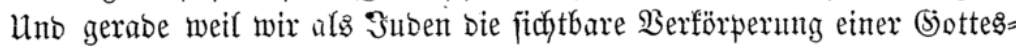

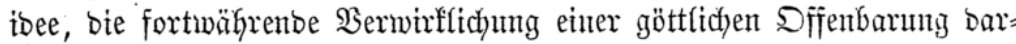
jteffen, bürfen unt müijen wir audy bie göttliche Mifijion ses SGgrijten=

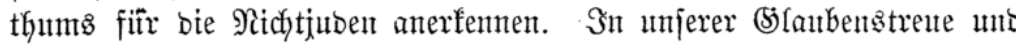
(S) Taubensfejtigfeit haben wir jtets bie Ginreidfenbe Sidferheit gejumben,

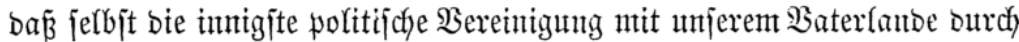

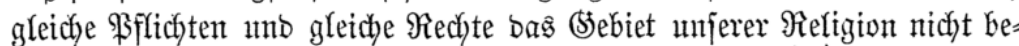
rïfren und nidht verleşen-twerbe. Solfte es aljo twohl nicht mefir ein Beichent bes mangelnden Selbjtbertrauens, als ein Berveis ber jtat männifchen $\mathfrak{B}$ orjicht jein, wenn man von ber Bulajïung einiger jübijcher

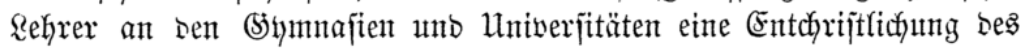
preupifcyen Solfes fürdftet? Die Suben benfen hierin dyriftlicher, und weil jie bies thun, befürchten fie nicht, bá im গamen eines nicht excifiti=

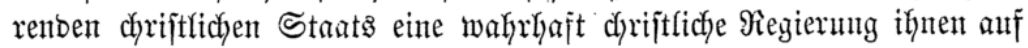




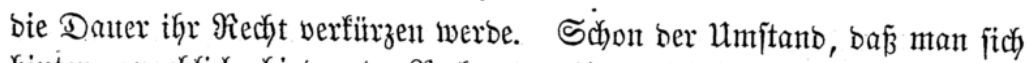

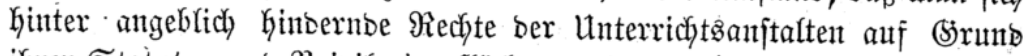

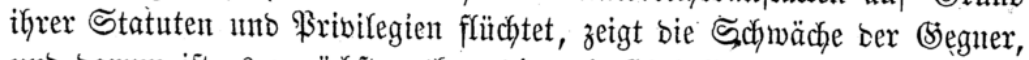

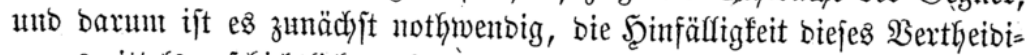

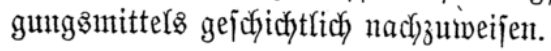

Berlin, im アuni 1860.

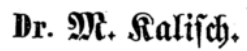




\section{$\mathfrak{3} \mathfrak{n} \mathfrak{h} \mathfrak{a} \mathfrak{l} t$}

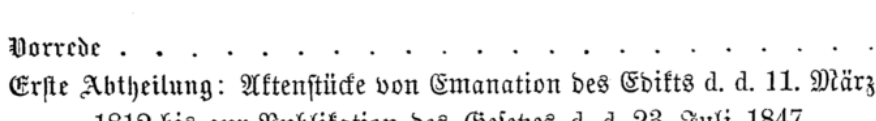

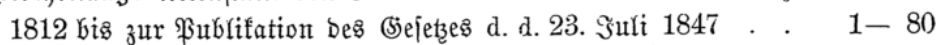

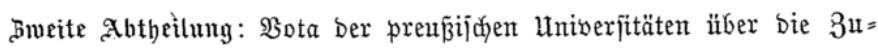
laffung jübijdyer Rehrer nad) Dent (5)ejeţ vom 23 . Suli 1847 . . 81-232

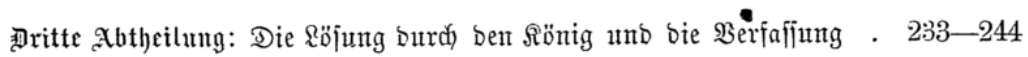

Dierte Abtheilung: Đas (5)ifft vom 11. Märj 1812 umb jeine $\mathfrak{A b}=$

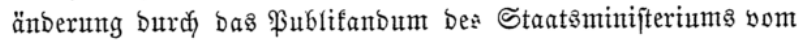
4. Dezember 1822 . . . . . . . . . . . . . . . . . 245-306

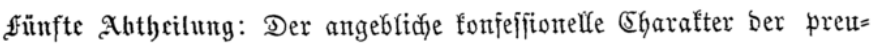

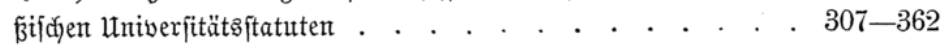

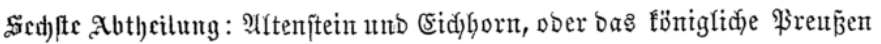
unb ber dyriftlide Staat . . . . . . . . . . . . . . . . . . . 363-410

\section{Beridytigung.}

Seite 5, Beile 5 von oben ftatt (E) $i$ (t) B orn lieŝ v. Alltenitein.

"184, "4 von oben fitatt 1947 lieŝ 1847 .

"309, " 8 von unten ftatt 1. Miär子 Yies 4. Dejember. 

Errte $\mathfrak{a b t h e i l u n g}$

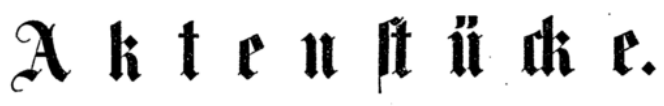

Bon Emanation bes Subenebiftż d. d. 11. März 1812 biz

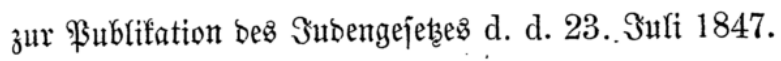





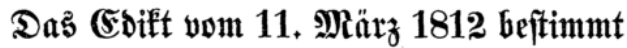

\author{
§. 1 .
}

Die in Mnjeren Staaten jeł̧t mohnhaften, mit Sieneral= \$rivilegien, Raturalijations = Batenten, Sdyutbriefen uno Eoncejitonen verjefenen

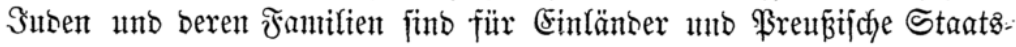
bürger zu achtent.

\section{§. 7.}

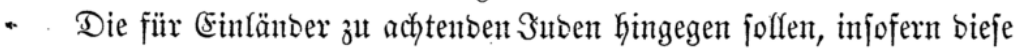

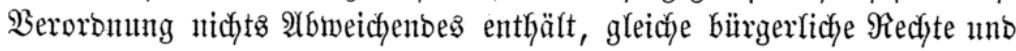

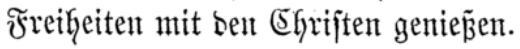

\section{§. 8.}

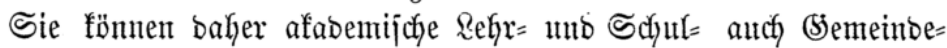

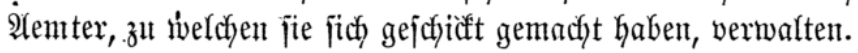

\section{§. 9 .}

In wiefern bie Snben z̆ anberen öffentficten Bebienungen unb

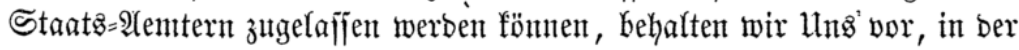
Folge ber 3eit gejeţfich ơl bejtinmen.

\section{अublifandum vom 4, Dezember 1822.}

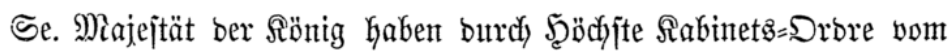

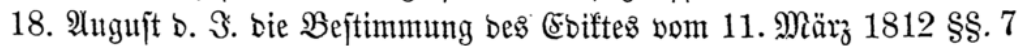
unt 8 ,

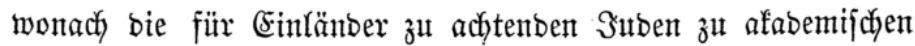

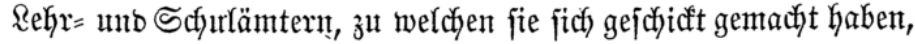
zutgelajfen werben follen, 


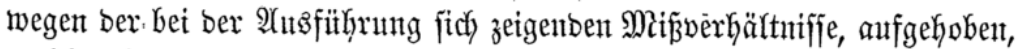
welches fierourch befannt gemadyt wirb.

Bertill, ben 4. Dejember 1822.

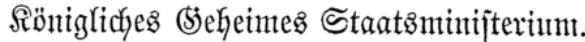

v. 3o

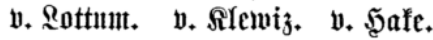

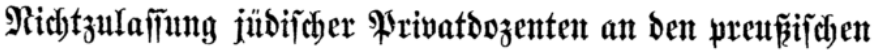 Untwerfitüten 1826.}

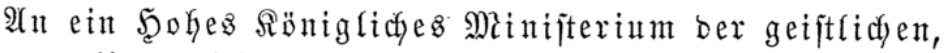
Unterridyt: uno Mebizinal= 2 ngelegenfeiten.

Der Doctor philosophiae M. R. Jr., aus Braunfdyetg gebürtig

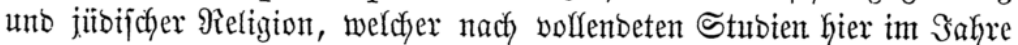
1823 promovirte und nach bent Frotofolfen feines Examents bejonbers in ber Mathematif gründoliche Senutnifje bejitzt, jucht bei ber unterzeidyneten prito=

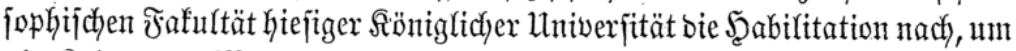

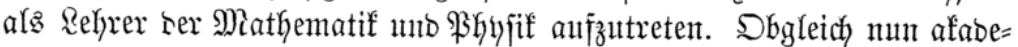
mifche ßrivatlefyrer nicht als angejtellt z̆ betrachten fint, unto bie Sïnigliche

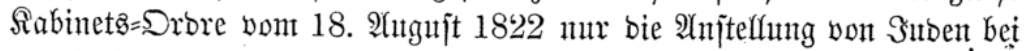
Den Univerjitäten unterjagt, fo fürchtete body bie ₹afultät, wenn aud

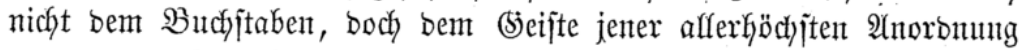
entgegen zut hanbeln, went fie einen Snben als \$riwatbozenten zuftejpe.

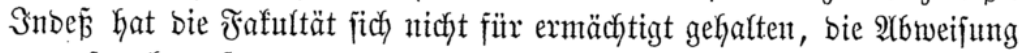

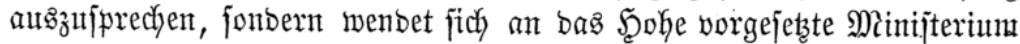
mit bent gehorjamjten $\mathfrak{A}$ njuchen, gnäbigit enticheiben zu wolfen, nicht blog

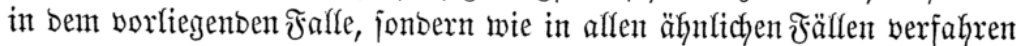
werben jofl.

B̉ertin, ben 4. Februar 1826.

Defan und ßrofefforen ber phitofophificyen Fafultät.

(unterjajriften.)

\section{Serfïnuntg +}

Das Minifterium exöffnet ber philofophifçen Fafultät auf iłre $\mathfrak{A} \mathfrak{n}=$

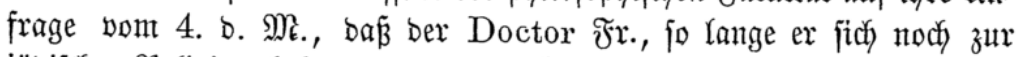

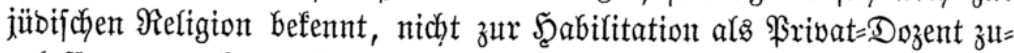
gelajīen werben fann. Die Fafultät hat baher ben $\mathfrak{F}$. auf fein beşfallfigez

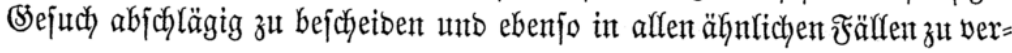




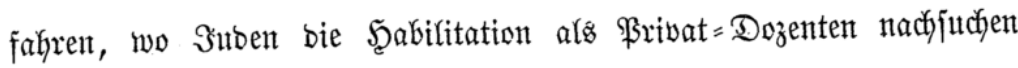
jollten.

Berlin, Den 16. Februar 1826.

Der Minifter $2 c$.

(Eidulgrat.

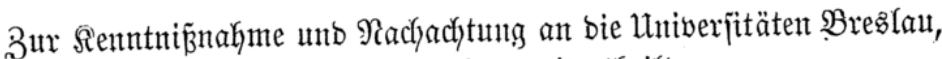

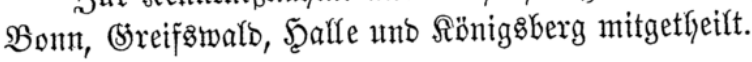

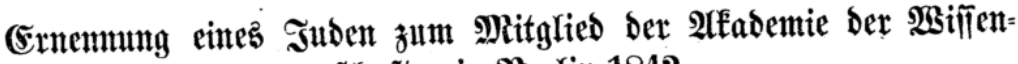 (j) aften in $\mathfrak{B e r l i n} 1842$.}

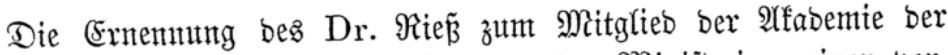
Wiffenfchaften fiel gerabe in bie Beit, wo bas Minijterimm einen bor $=$

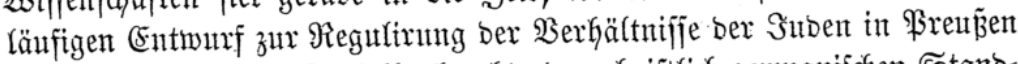

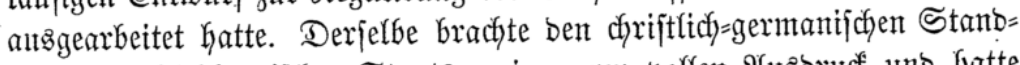

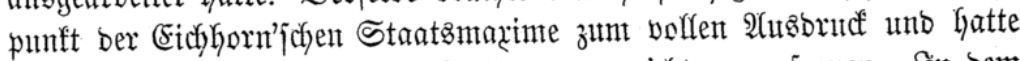
fich) beshalb ber siöniglichen Bufftimmung nicht zut exfreuen. Sn bem

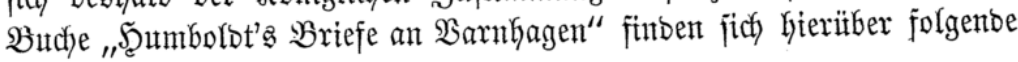
Notizen:

"Whumbolot an $\mathfrak{B a r u h b a g e n .}$

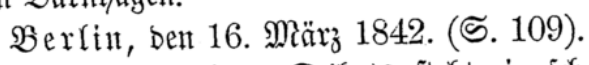

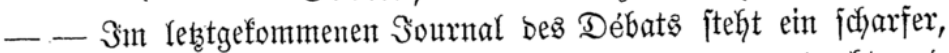

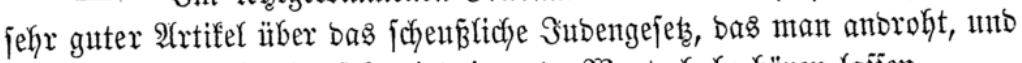

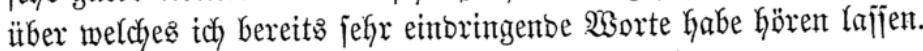

Mittwodys.

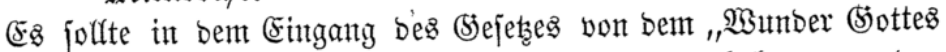

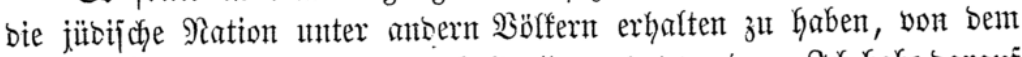

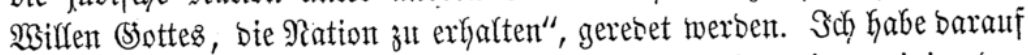
geantwortet: "Das (5ejets ift mit affen Frinzipien einer einigenten

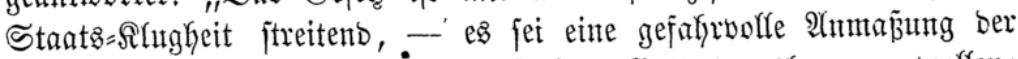

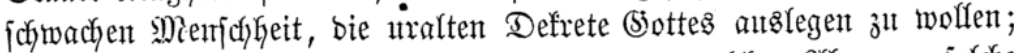

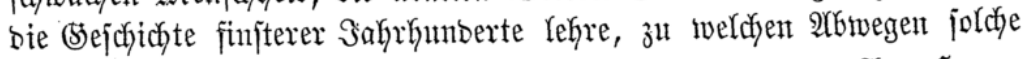
Dentungent Matth gebent."

$\mathfrak{A}, \mathfrak{y} \cdot \mathfrak{g}$.

B̉erlin, ben 7. Irpril 1842. (ธ. 119).

- - Sab bin Keute nidyt nady \$otabant gegangen, inm bie

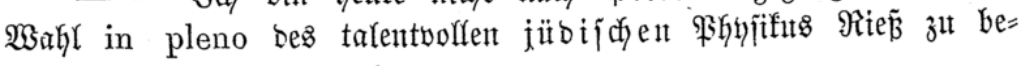


treiben. Sie ift für bie âffabemie jehr ehrentwoll anggefalfen, mur brei

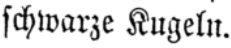

Domeritag Radyt.

A. $\mathfrak{v}, \mathfrak{y}$.

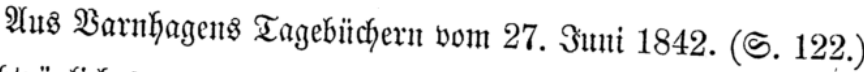

Rachträgliches von gejtern: Şumborlot erzählte mir, ex habe ben

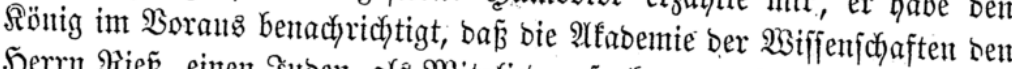

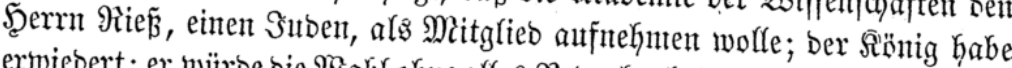

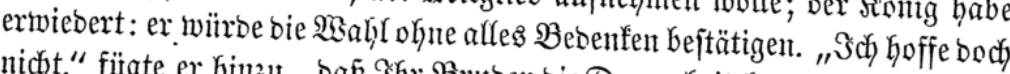

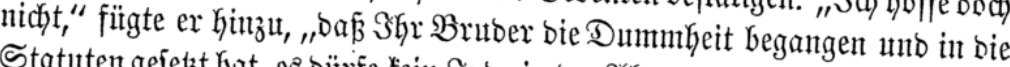
Statuten gejetzt Kat, es bürfe fein Sube in ber Alfabemie jeit." Der Mintijter

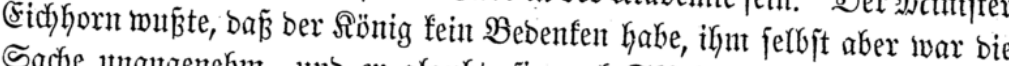

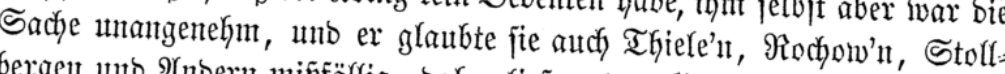

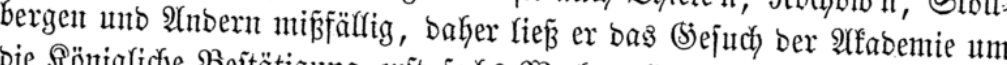

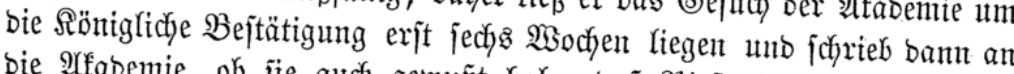

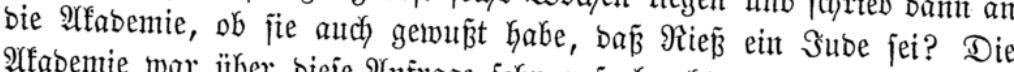
Affabemie war über bieje Anfrage fehr aufgebrad)t unt antwortete ein= ftimmig, fie halte fict an ifre Statuten, habe nach biejen getwäblt unt weije bie Frage bes Minifters als eine ungegörige zurïh, ohne fie zut

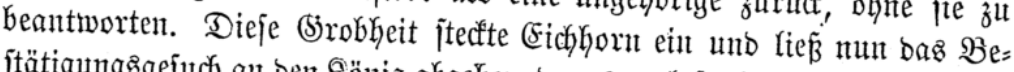

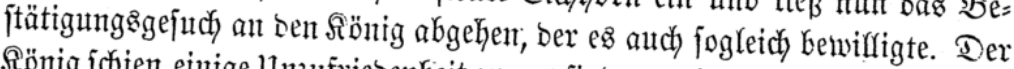
Rönig fchien einige Unzufriebenkeit zut empfinben, als er inne warb, ba getwährte, was Friebrich ber (\$rnß̨e verfagt hatte, nämlidy bie 3ulafjung

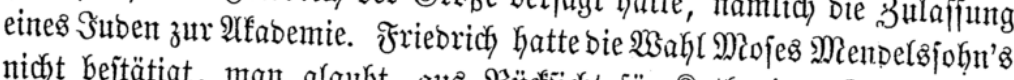

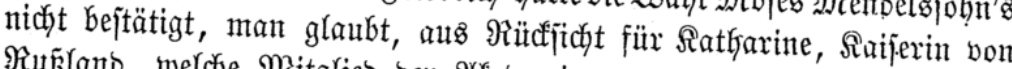

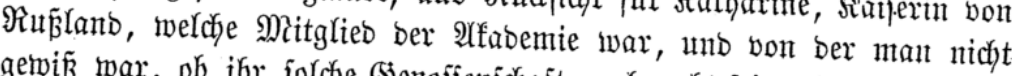

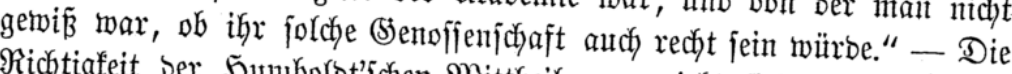
Richtigfeit ser 5̧umboldt'jchen Mittheilung ergiebt fich aus ben nach= folgenben, biejen (Siegenjtant betreffentien Ifftenjtücfen.

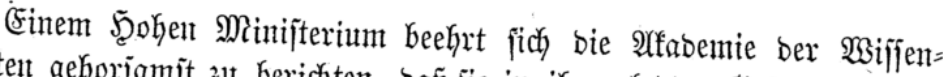

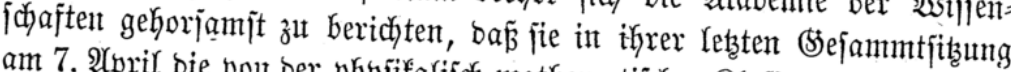

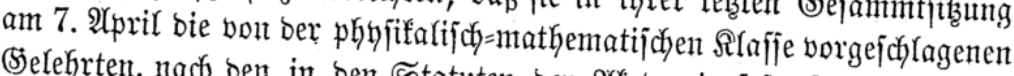
(selehrten, nach ben in ben Statuten ber Affabemie feitgejebzten Beftim= mungen gewählt hat, nämlich zut vroentlichen Mitgliebern ber phyjiffalifoc)=

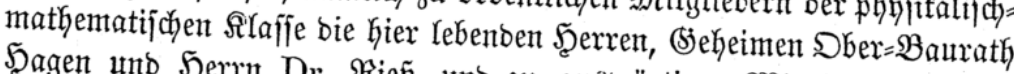

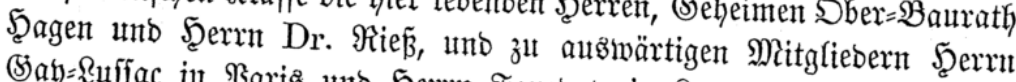
(5a) $=\mathfrak{R}$ fffac in ßaris unt Serm Farabay in Ronbon. Die Alfabemie

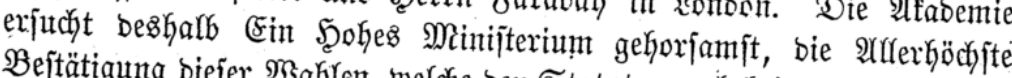
Bejtätigung biejer Wahlen, weldye ben Statuten nady bei ben orbentlicken 


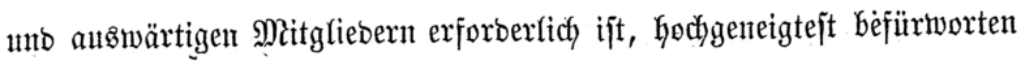
zut wolfent.

Berlin, ben 11. Ilpril 1842.

Die Rönigliche Arfabemie ber Mifijenjidyaften.

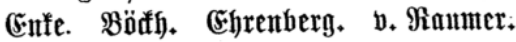

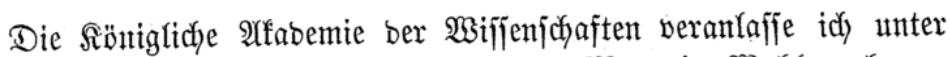
Bezugnahme auf ben Bericht vom 11. v. M., bie $\mathfrak{W a h l}$ mehrerer (5)elehrten zut orbentlichen unto rejp. auswärtigen Mitgliebern ber mathe=

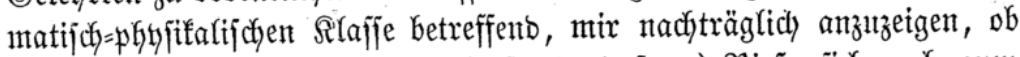

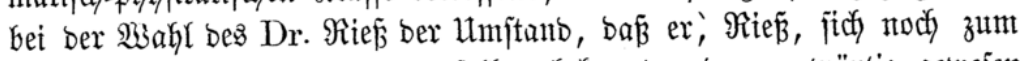

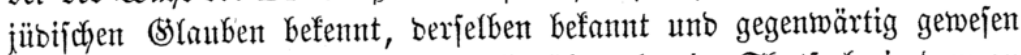
ift, intoen idh es für nöthig halte, Gierüber als eine IThatjactje in bem an Se. Majejtät zut erjtattenden $\mathfrak{B}$ ericht mich mit $\mathfrak{B}$ ejtimmtheit äuñern zั łönnen.

Berlin, ben 29. Mai 1842.

Dex Minijter.

(Eidfyort.

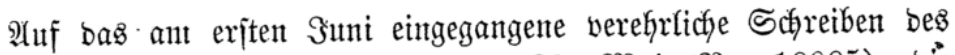

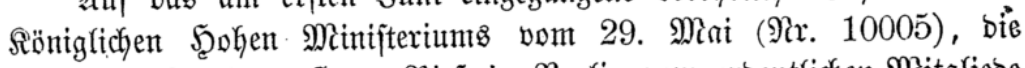

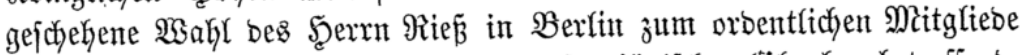

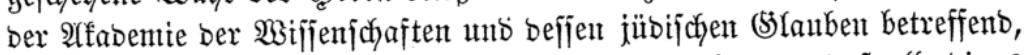

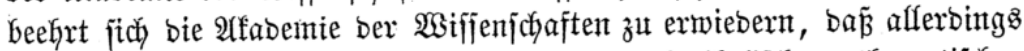
von biejem Unitanbe vor ber $\mathfrak{W a g l}$ in ber phyjifalifich=mathematifichen

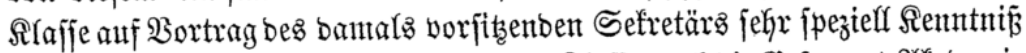

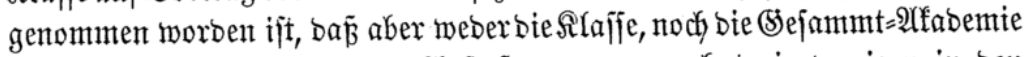
und um jo weniger baran $\mathfrak{A}$ njto

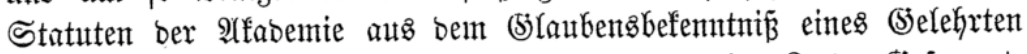
irgend ein \$räjutoiz gegen jeine $\mathfrak{3 a ̈ h l b a r f e i t ~ h e r b o r t r i t t . ~ S n ~ b e r ~ ( S ) e f a m m t = ~}$ Irfabemie ift vor ber $\mathfrak{W a h l}$ bieje Angelegenheit nidyt fpeziefl verhanbelt worben, aflein es unterltegt feinem Zweifel, ba

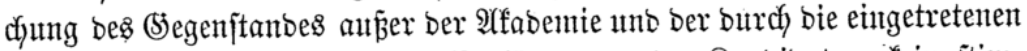
Ferien bamals ftattgefuntenen $\mathfrak{D}$ erlängerung ber Ranbibatur, feit jtim= menbes Mitglieb ofne bas $\mathfrak{B}$ etwuß̄tiein jenes Umjtanbes war. Sebenfallz ijt ber Wahlactus ganz in gejetzlicher Form vollzogen worben, unb bie Ertwähnung ber reltgiöjen Ronfeffion hätte nur bann bei ber $\mathfrak{W a h l ~ i n ~}$ pleno vorfommen fönten, wenn irgent einer ber $\mathfrak{A}$ (ntwejenten Gätte glautben

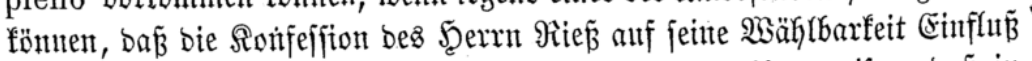

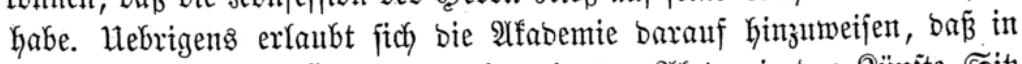

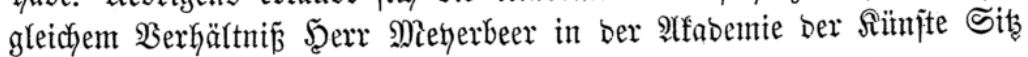
utito Stimme hat. - 


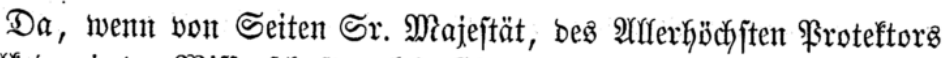

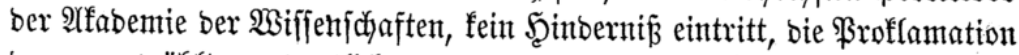
ber netterwählten orbentlidjen unb auswärtigen Mitglieber in ber öffent= lichen Sitzung am Reibnitz'juen Sahrestage, ben 7. Suli, ftattzufinoen

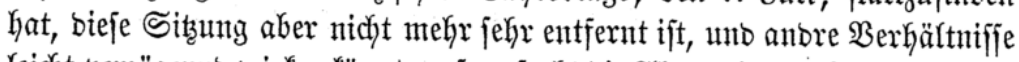

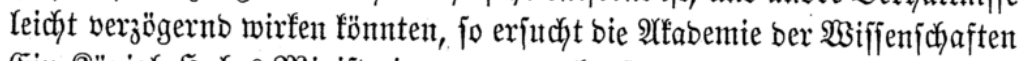

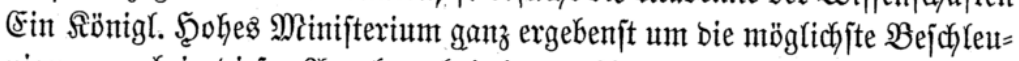

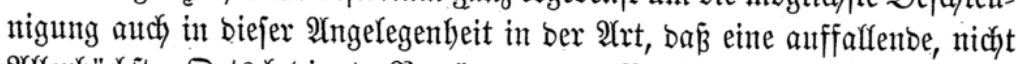

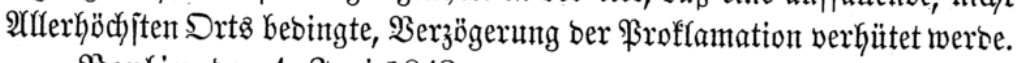

Berlin, ben 4. Suni 1842.

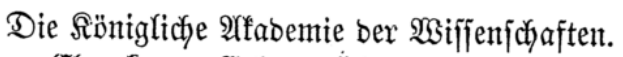

Ebrentierg. Confe. Böath. vo. Miaumer.

\section{An Se. Majeftät ben $\Re$ önig.}

Die Alfabemie ber Miffenffhaften hierjelkft hat in ihrer sejammt=

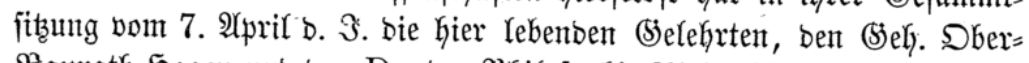

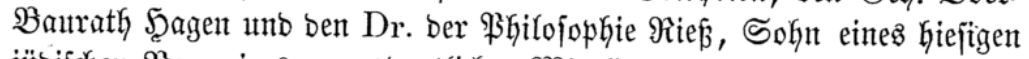
jübifchen Banquiers, zut orbentlichen Mitgliebern ber phyfifalifac)=mathe=

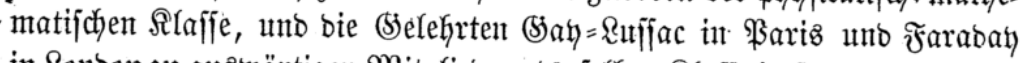

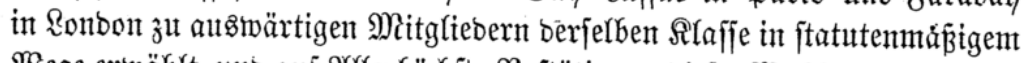

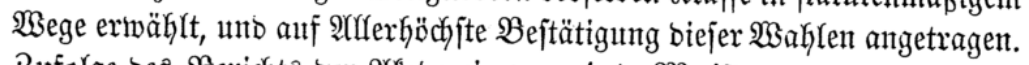

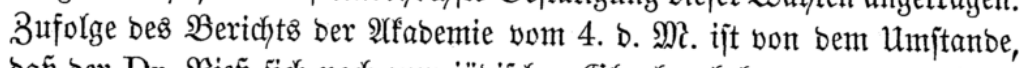

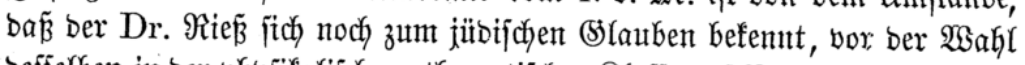

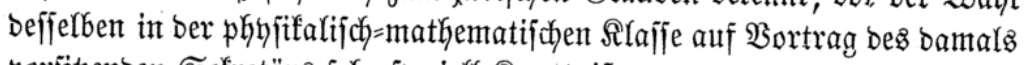

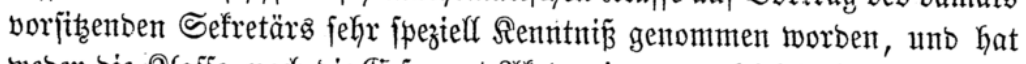

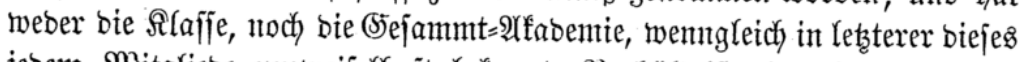

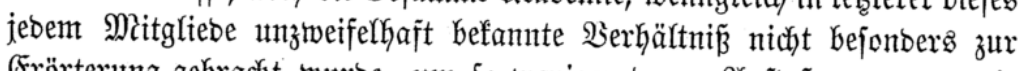
Erörterung gebracht wurbe, um fo weniger baran 2 (ñ

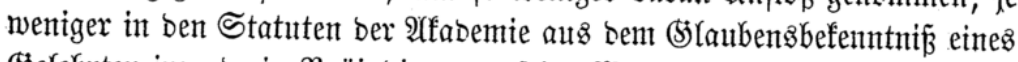

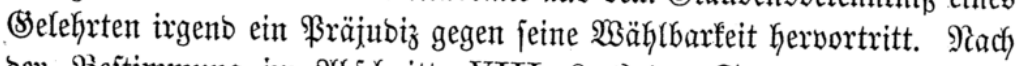
ber Beftimmung im 2rbjhnitte VIII. \$. 2 ber Statuten ber hiefigen

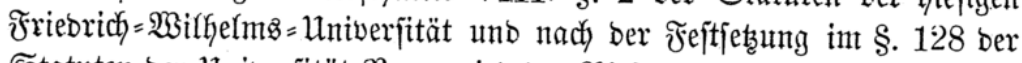

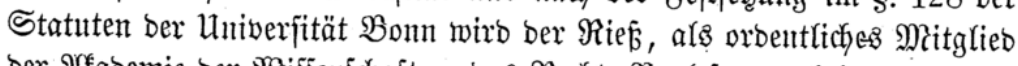

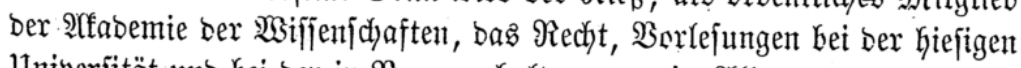
Untwer fität unb bei ber in Bont zu halten, zwar im Âfrgemeinen erwerben,

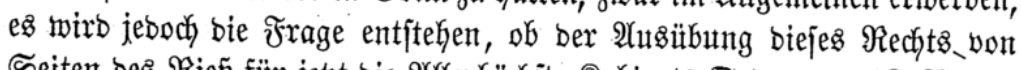

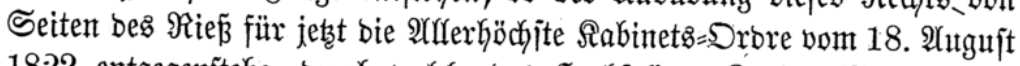
1822 entgegenjtehe, burch welche bes Şochjeligen Riöntigs Majejtät bie

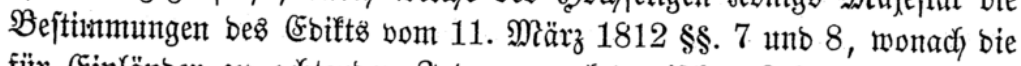
für Ginlänber zut achtenben Эubent zu afabentifden Rehr = unb Schull= 


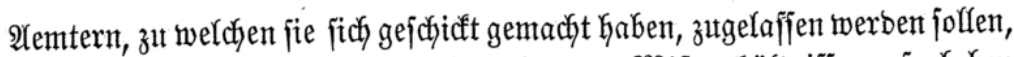

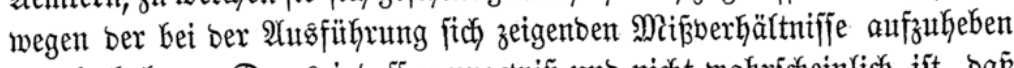

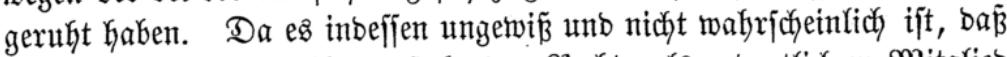

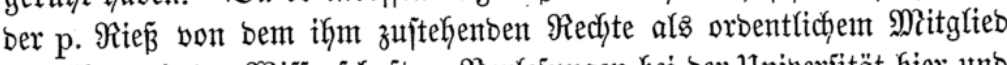

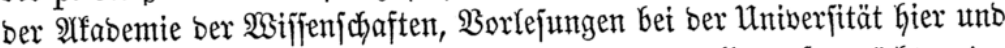
in Bonn zu Kalten, werbe (S)ebraud mathen mollen, jo mödyte eine

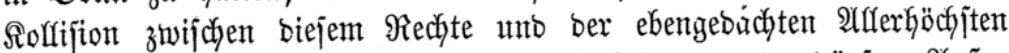

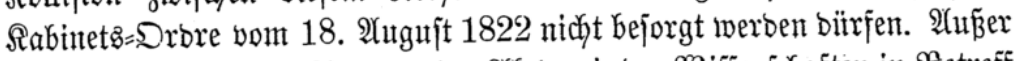

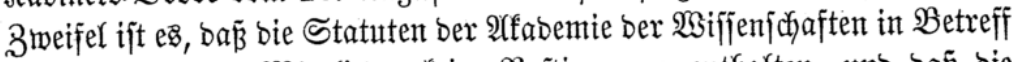

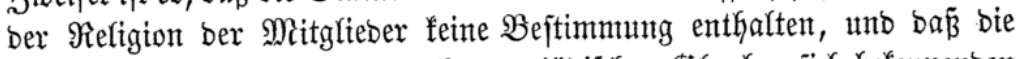

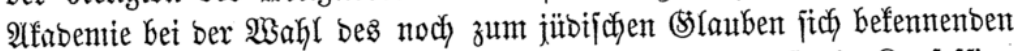

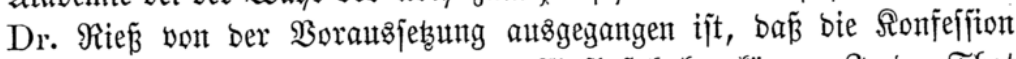

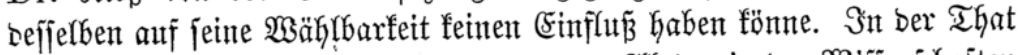

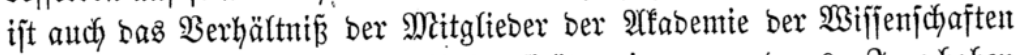
unt ber öffentlichen Regrer an Univerjitäten ein ganz anberes. Sente haben in 2Ufjicht auf Bildoung ber Sugent für ben Dienjt bes Staats und ber

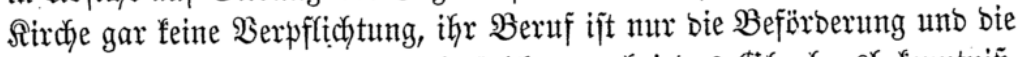

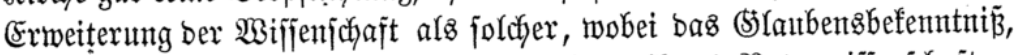

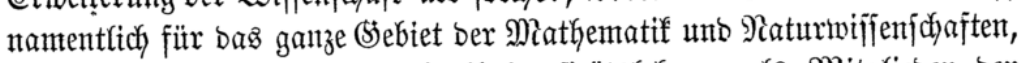
ohne Einflus ijt, währento bie Univerjitätzhehrer, als Mitglieber ber

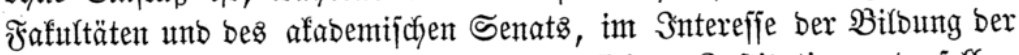
Sugent fïr Staat und Sirche und bie pojitiven Injtitutionen berjelben auth) ganz bejontere Berpflichtungen haben, fïr welche bas (STaubens=

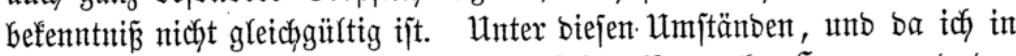

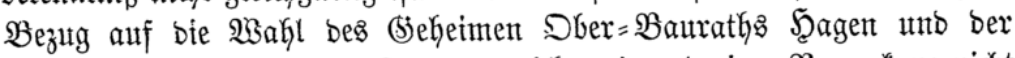

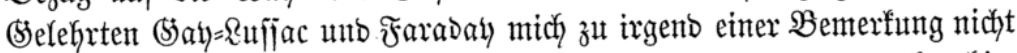

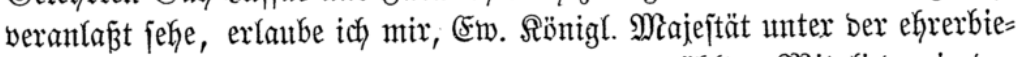
tigen $\mathfrak{A}$ nzeige: Dá bie ßroffamation ber neu ermählten Mitglieber in ber

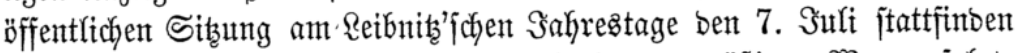
wirb, afferunterthäntigit zu bitten, bie in jtatutenmä̋̈itgem Wege erfolgte

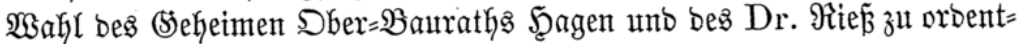

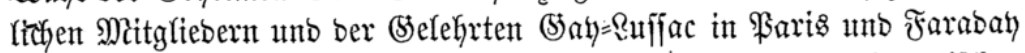

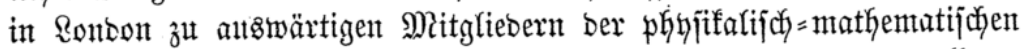

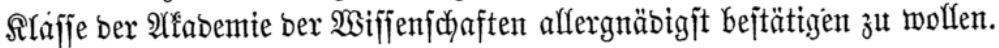

Berrin, ben 9 . Sunt 1842.

(Eidillorit.

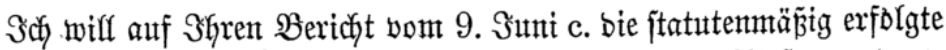

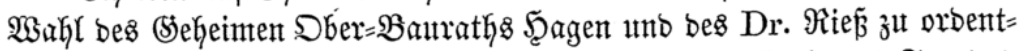

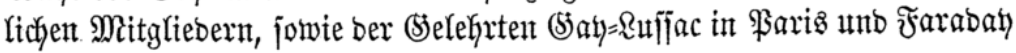


in Ronbon żt auswäntigen Mitgliebern ber phyjiffarij(b)=mathematijdyen

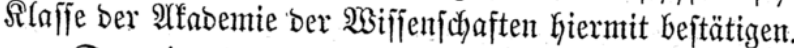

Danzig, Den 28. Suni 1842 .

Ât ben Staatsminifter (sid)lyorn.

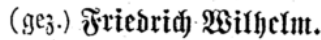

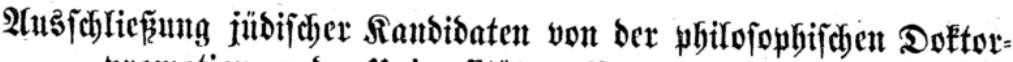

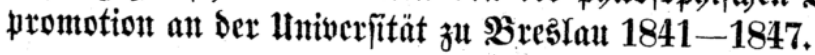

Eingabe bes jübifchen Stemeinteborjtanbes zu Breslau wegen verjagter

Bromotion jitbifcher Ranbibaten zu Doftoren ber Bhitojophie.

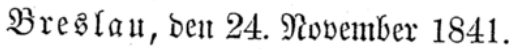

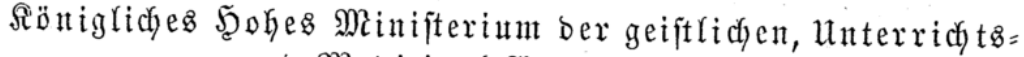
und Medizinal=ängeregenheiten!

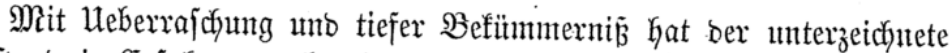

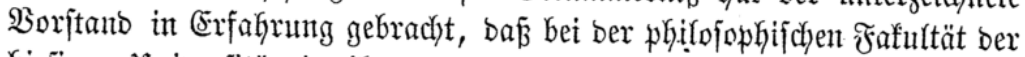
Giefigen Univerfitüt in ifhrem neutent Statut bie Bejtimmung fejtgefetżt wurbe, bã ein Seber, welcher von berfelben ben Srab eines Ricentiaten ober Doftors erlangen wolle, bem dyriftlidjen (5)auben angehören mïffe,

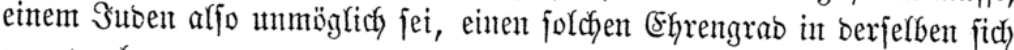
zu ertwerben.

\$3ix fonnten bies anfangs um fo wentiger glauben, alz an alfen

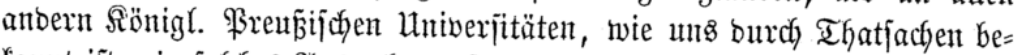

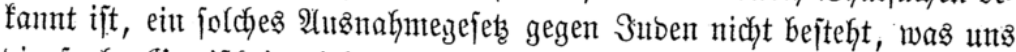

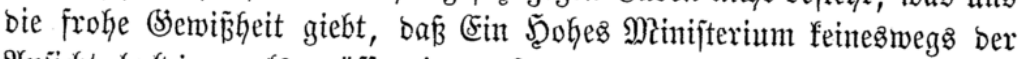

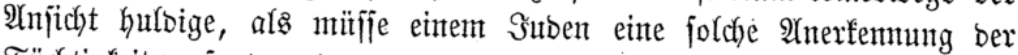
Titchtigfeit verjagt werben.

Der Einblicf in bas Statut ber Breslauer Univerfität verfchaffte uns jebody bie Ueberzengung, bas bie hiejige philojophifche Fafultät wirf= (ich) mit einem foldyen $\mathfrak{Y}$ usinahmegejes behaftet ijt, oas man jonjt nirgents fent.

Sn ben Beiten, ba man nod weit entfernt war, eine humante $\mathfrak{B} e=$ hanblung Den Эuben zu Theil wersen zut laffen, fam man boch nicht alf ben Stebanfen, ben vorzïglich SBegabten ben Bemeis ber Anerfenmmg zu

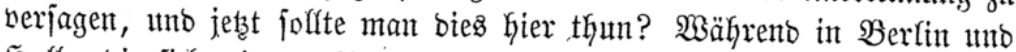
Scalle, bie jich mit ber hiejigen Ulniwerjität wohl in jeber Beziefunt ver=

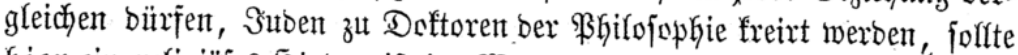

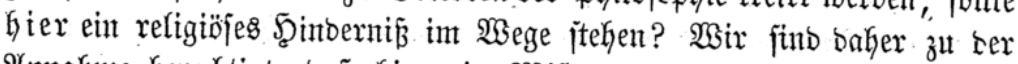

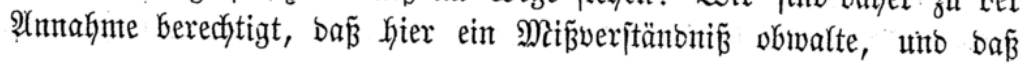


viefleidyt aus ben fritheren Statuten jene ber 3eit jo wenig angemeijene Beftimmung irrtfïmlicherweife in bie nenen Statuten ïbergegangen ift.

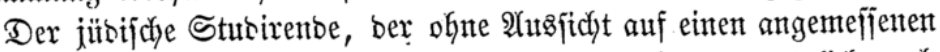
Wirfungafreig fich bem gelehrten Stanbe wiomet, fann unmöglich aud

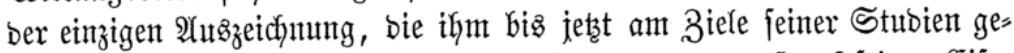

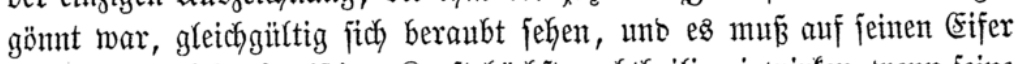
in ber Entwiffelung geiftiger $\Omega$ rajt hödjit nachtheilig einwirfen, went jeine

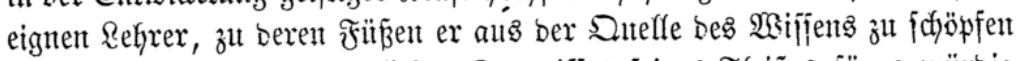

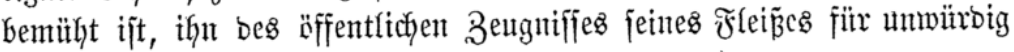
halten.

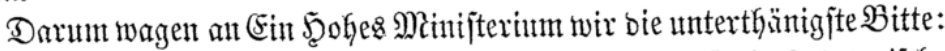

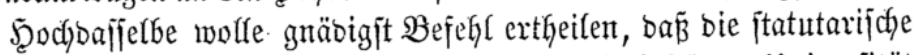

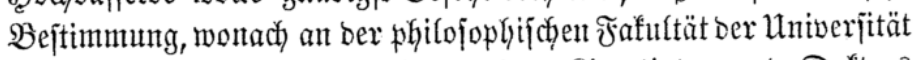
z̆ Breşau ein Sube Den (5rad eines Ricentiaten uno Duftors nicht erlangen fönne, altfgefoben iwerbé.

Sn tiefiter Eghruturdyt verharren

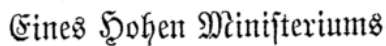

ganı unterţänigiter

Boritant ber Giejizen jürifaten (Stemeinto

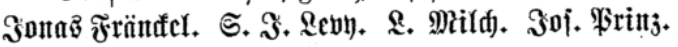

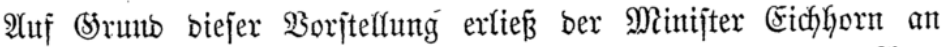

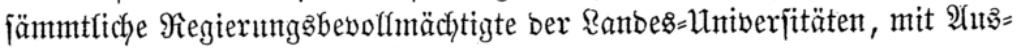

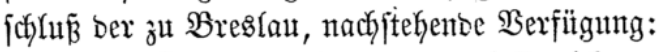

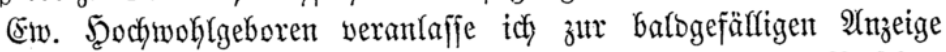
barïber, ob fich bei ber philojophifchen Fafulttät ber Univerjität $\Re$. fchon Suben mit bem (Sejuthe, zu Doftoren Der \$sGilojophie freirt zut werben, gemelbet haben, ferner, wie bergleityen \$sejutye etwa bisher bon ben Faful= tätẹn behanbelt worben finb, voer farlz bergleichent (\$sejuche bei berjelbent bis jeţt noch nidht vorgetommen, ob bie Fafultü̈t im eintretentoen Falle barauf einzugehen fidc befugt hält, infofern in ben Univerjitätşjtatuten bie Ertangung ber phitojophijchen Doftortwitrbe nicht ausbrituflich bon bem

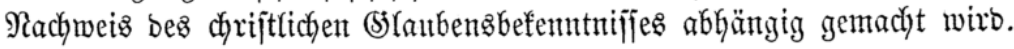

Berlin, ben 12. Dezember 1841.

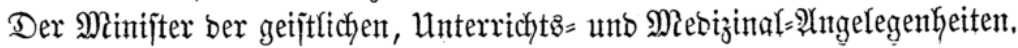

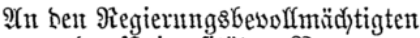

(Eid)fortt.

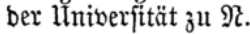

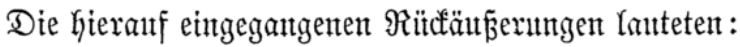

Erw. Excellenz beehre idy mich anf bie fehr geehrte Berfitgung vom 12. Dezember pr., nach vorkeriger Sonmunifation mit ber phitojophijchen 


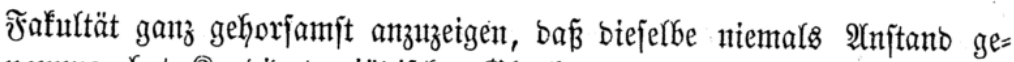
nommen hat, Sanbibaten jübijchen Sthaubens, wenn fie fich fonjt mur fähig

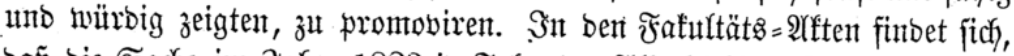

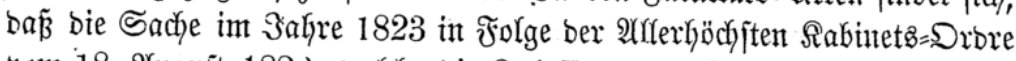

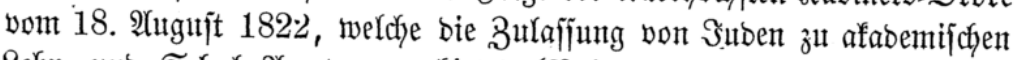

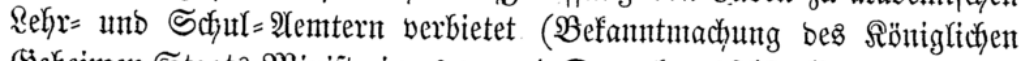
(5eheiment Staats=-Ninijteriums vom 4. Dezember 1822, Siejeţianmlung für 1.822 ऽ. 222) zur Sprache gebracht worben ijt. Da bie \$romotion von biefer গllferhöchiten Anorbmung inbeffen nicht betroffen wurbe, fo hat

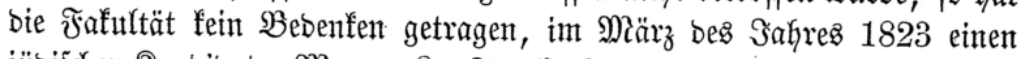
jübijchent Ranbibaten Marcus Reo Franfentyeim zum Doftor zut promoviren.

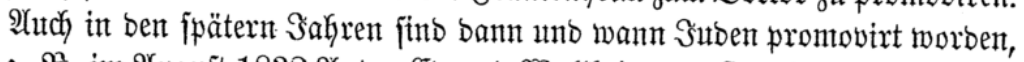

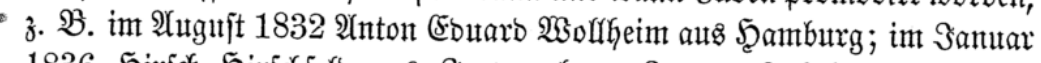

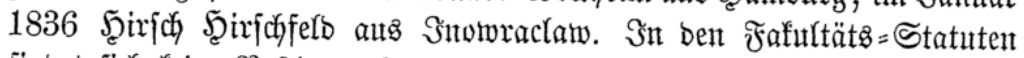
finbet fich feine Bejtimmunig, woburdy bie Ertangung ber phifofophifchent

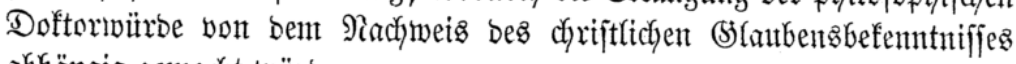
abjängig gemacht wïrbe.

Berlin, ben 6. Sanuar 1842.

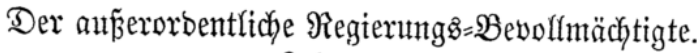
Radentberg.

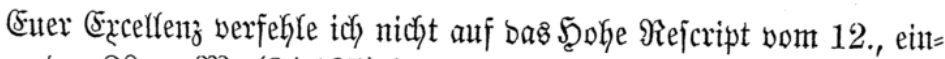

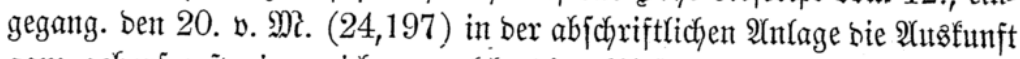
ganz gehorjamit einzureichen, welche bie philojophifche rafultät iiber bie

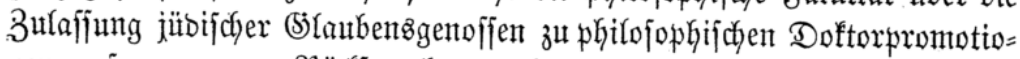

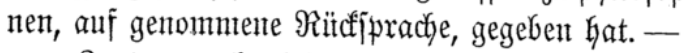

Sn ben nod's nicht ausbrüdflich aufgehobenen, boch ganz veralteten unt außer (jebrautch gefommenen Statuten ber phitojophifichen Fufurtät Rap. 13, welche in Rodf's Sammlung 2bo. I. S. 608. abyebrutft fint,

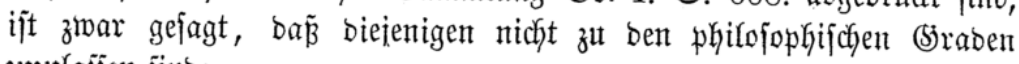

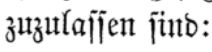

quorum mens polluta et fascinata est falsis opinionibus, et

a consensu catholieae ecclesiae Christi alienis,

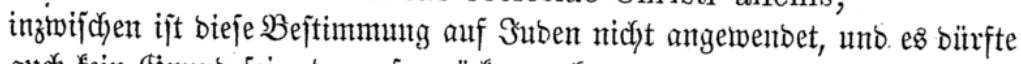
auth fein (Srund fein, barauf zuritd zu geben. -

ア̊̈nigsberg, ben 8 . Janum 1842.

gieufid.

\section{Anlage.}

Einem p. p. Geehrt jich bie gehorjamit unterzeidynete Fafultät ber am 28. Dezember pr. Godhgeneigt an fie erlaffenen $\mathfrak{A}_{4}$ fforberutg gemäß 
bie Fromotion ber Suben efrerbietigit zu berichten. Sbgleich bie $\mathfrak{B e r}=$

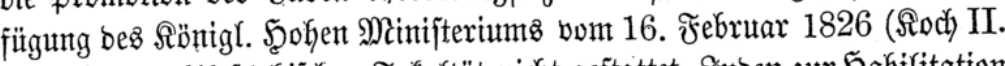

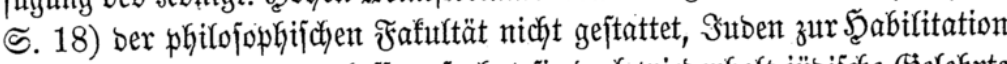

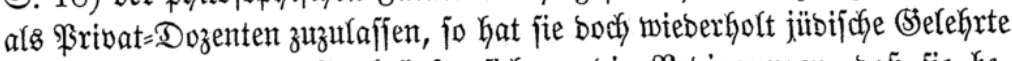

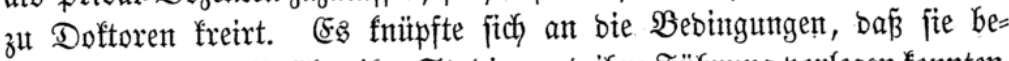
friebigende Zeugniffe über ifye Stubien unb ifyre Fithyung vorlegen fonnten,

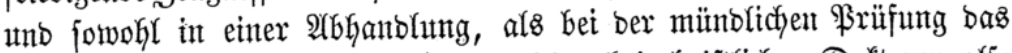
Exforberfiche leijteten. Der Eis, weldyer bei chriftlichen Doftoren aljo lautet: „Juró, ita me Deus adjuvet et sacro-sanctum ejus Evangelium " bejchränftt fich nach ber Weohen Minifiterial=

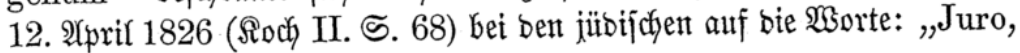
ita me Deus adjuvet."

Rönigsberg, Den 3. Santar 1842.

Die phitojopgijache rafultät.

Drumtant, D. z. Defan.

(5w. Şodyinohigeboren

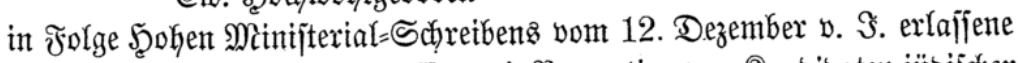

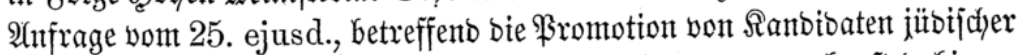
Sonfeffion, beeilt fid bie unterzeidynete Fafultät ganz ergebenjt bafin-zut Geantworten, bá fie feinen 2 nnjtand genommen hat, am 5 . Maa 1835 den

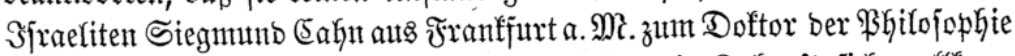

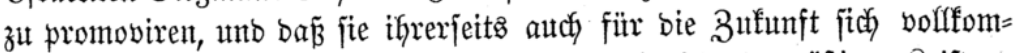
nten befugt halte, gelehrten Yuben, weldye bie ftatutenmä̈̈igen Reiftun= gen exfüffen, ebenjo unbebenfflich wie gefehrten (Shrijten einte rein wijīen=

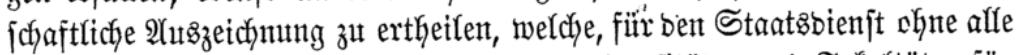
Folge, nidyt nur bas Beifpiel anberer Univerjitäten unt Fafurtäten für

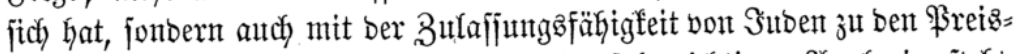

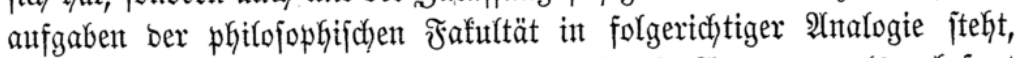
jeitens ber Statutent aber nichyt burch bie minbejte 2futbentunt als unbefugt ericheint.

B̊nn, bent 4. Santar 1842.

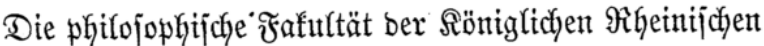

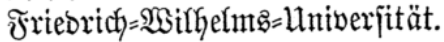

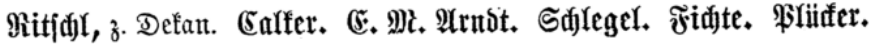

(Ew. Scocfiwohlgeboren beehrt fich sie philojophifiche Fafultüt anf bie

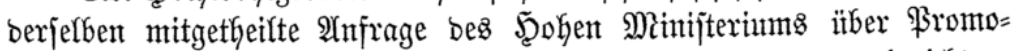
virung won Suben zu Doftoren ber \$hilojophie ganz ergebenit ju berichtent:

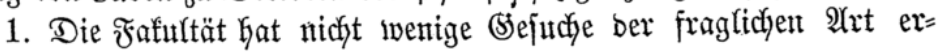


Galten unb fie niemals anbers behanbelt, ałz bie (Siejudye von chriftlichen Sindibaten.

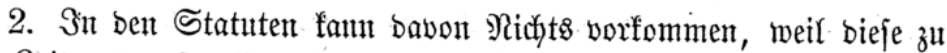
einer Zeit entworfent fint, in welcher mant fdywerlich hieran bachte. Die

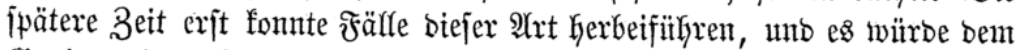
(Sientits biefer ßeit wentig angentefjen gewejen jein, went bie Fafuttlät, welche fein. Serbot bejaryänfte, unto weldye fich ber Serbienjte eines

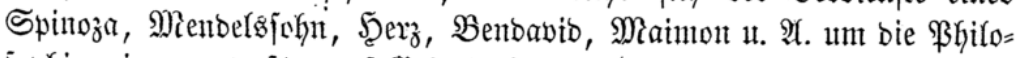
jophie erimern muste, auf (S)efuctje jübifcher Sanbioaten einzugehen ver=

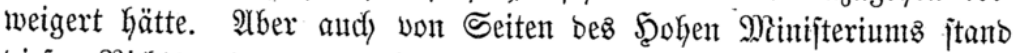

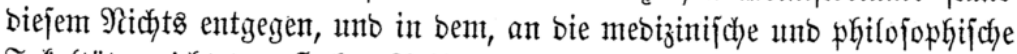

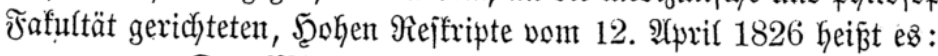

"Da: Minifiterium fintet fich betwogen, Gierburch fejtzujetsen,

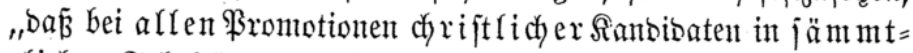
"Yichen Fafultäten bem (Eib bie Dbjtriftiongformel: ita me Deus "adjuvet et sacro-sanctum ejus Evangelium, wie fich gehärt, ,şltgefïgt werben jolf. Bei \$romotionen jitoifdyer Ransibaten "in benjenigen Fafultäten, wo jie jtattfinben fönuen, "genügt bie $\bigcirc$ bitriftionbformer: ita me Deus adjuvet."

Unverfennbar liegt es Gierin, baj nur in ber theologifonen und juriftifchen

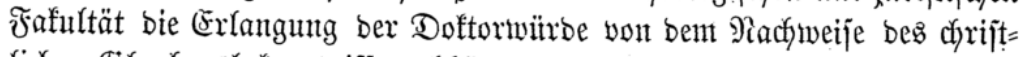

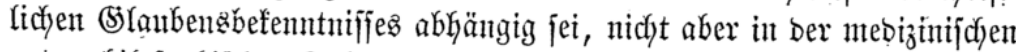

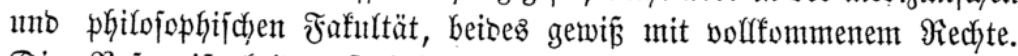

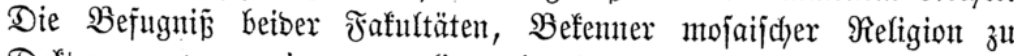
Doftoren zut promoviren, wwterfiegt aber hiernach wohl feinem Zweifer.

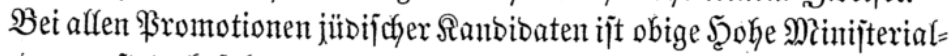
Serorbmung jtetz befolgt worbent. -

J̧alle, Den 29. Dezember 1841.

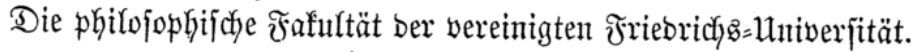
Grnther, b. z. Defan.

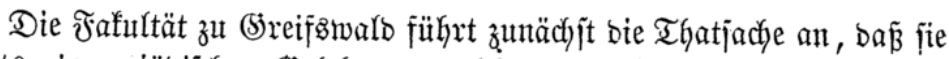

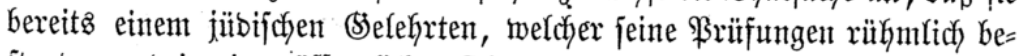
jtanben unb in einer öffentlicfen Disputation bie von ber Fafultät appro= birten Thejes vertheibigt hatte, zum Doftor ber \$̧Gilojophie mit (Serieh= migung bes Fürjten=Sanzlers freirt habe, und fährt bann fort: Was bie Injichten betrifft, weldje bie Frafultät bei biejem \$romotions=(\$)ejuch ge= leitet haben, unb von benen fie fich in Beziefing anf bie \$romovirung jübifdyer ßhilojophie Stubirentęr ïberkaupt leiten laffen wirb - jo lange ein Şokes Minijterium nicht bejonbere, biejen Siegenjtand betreffenbe, 
Berorbnungen zu erlafjen geruhen jollte, - fo urtheilt jie, ba in ihren Statuten bie \$rommsirung jübijcher Stubirenber nicht unterjagt ijt, unt bie (Srabuirungen jübijujer Me e bizin Stttoirenber nicht jelten borfommen,

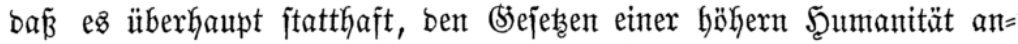

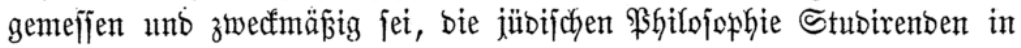

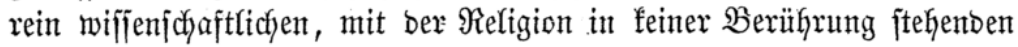
Fächern bet Exprobtheit bouffommener Tüdhtigfeit bie Doftormürbe fich erwerben zu Lafjen unb, wenn biejes ein $\mathfrak{A}$ nfeuterungsmittel ber gelehrten Thätigfeit biefer Pation jein fönnte, fie baburch, fo lange jie noch in ifrer Sonfefition jteyt, auf bem Wege ber Entwickehung ber Yntelligenz uno bes

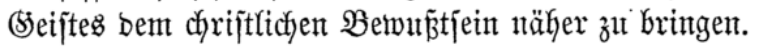

(5)eifzmald, Den 30. Dezember 1841.

Die phitofophifche Fafultüt.

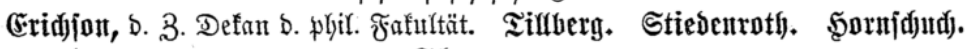
S(d)เmant.

Trots biejer übereinjtimmenten ben jübijchen Ranbibaten ber \$̧illo=

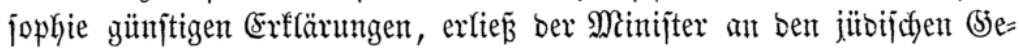
meinbeborjtand ben nachfolgentoen ablehnenten

\section{Beifleito.}

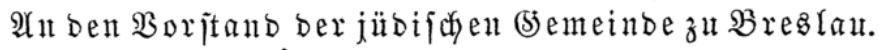

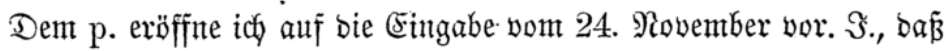
bie in ben neuen Statuten Der phitojophifchen Fafurttät ber bortigen Univerjität enthaltene Bejtimmung, nach welcher bie Erlangung bes

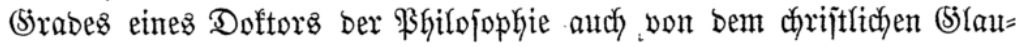
bensbefenntnis anhängig gemadjt worben ijt, für jeţ̧, nachbem jente Sta=

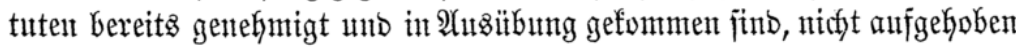

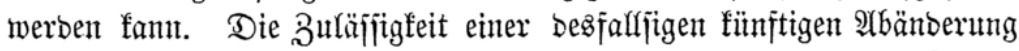

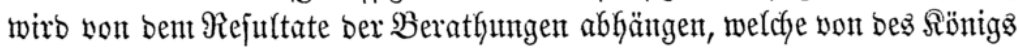

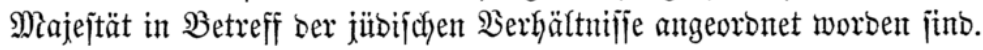

Berlin, ben 12. Februar 1842.

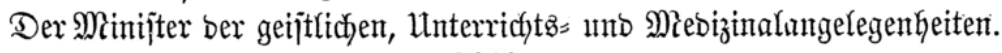
(sid)lyorn.

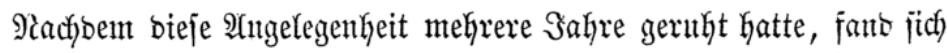

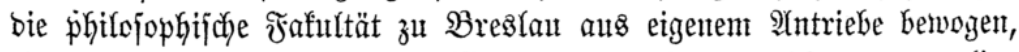
eine ähnliche Gingabe an ben Minijter zut ridjten, weldye ber bamalige Regierungsbevolfmächtigte (S) heimrath Şeinfe mit nadjitehenbem befïr= wortenben $\mathfrak{B}$ egleitjchreiben einfante: 


\section{Şerr Minijter!}

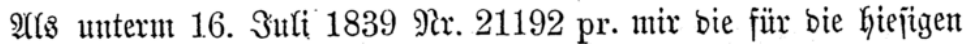

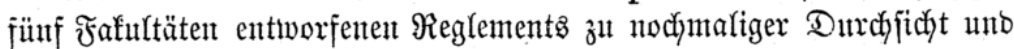

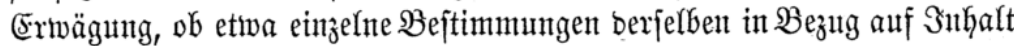

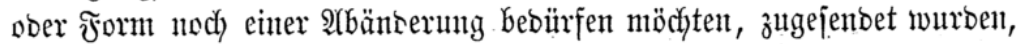

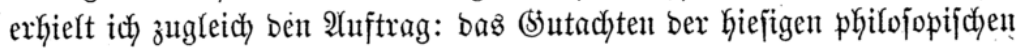
Fafultät bariitber einzıżęen:

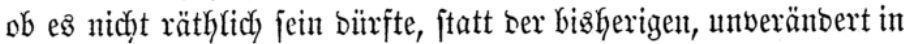
ben $\Re$ eglements= (5ntwurf aufgenommenen Forberung bes bei feier=

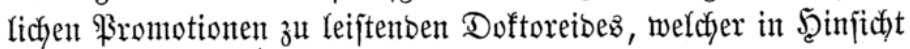
auf Form und Snhalt nidyt unberenflich jei, bie ben Statuten ber Fafultät zu Berlin angehängte Sponjionşormel zu mählen?

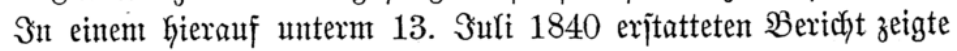
id) am Sdylujje beffelben ganz gehorjamjt an, bá fajt alle Mitglieber ber Fafultät fich für bie Sponjionsformel ber Berliner whilojophijdyen Fafull= tät erflärt gehabt,

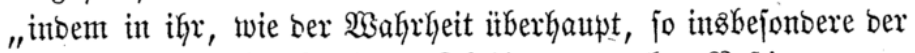

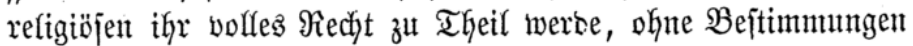

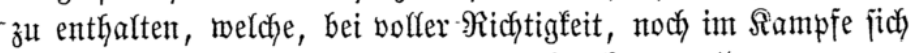
befinbende junge Meänner verlegen machen fönnten."

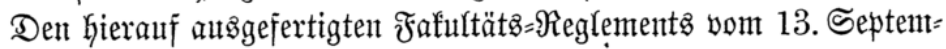
ber 1840 war aber bennody nidyt bie Sponfionsisormel ber Statuten ber

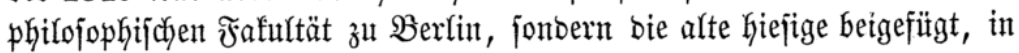
iweldyer bie Worte borfomment:

postremo confiteor, me abhorrere a fanaticis opinionibus, et sancte promitto juroque, me consensum et doctrinam ecclesiae christianae in scriptis propheticis et apostolicis traditam constanter retenturum perpetuoque defensurum. Ita me Deus adiuvet et sacro-sanctum ejus Evangelium.

Wahrjalytidy war bieje sibesformel, burch weldye alfe Befenner

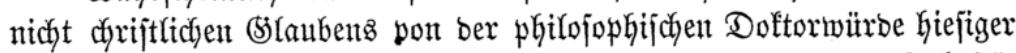

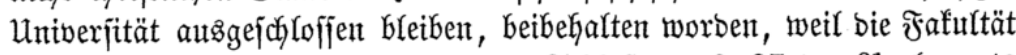

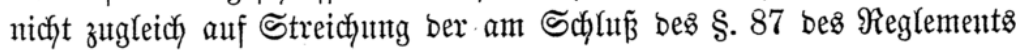
enthaltene $\mathfrak{B}$ eftimmung angetragen hatte, welche bahin lautet:

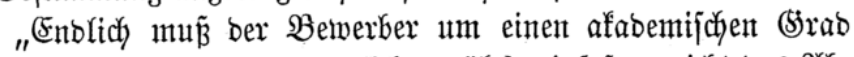

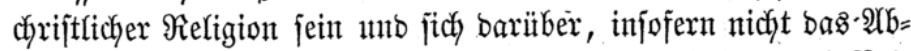

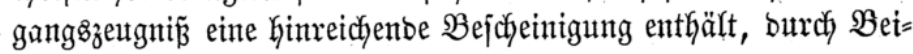
bringung bez Taufzeugnifjןez aużweijen."

Die Sunbe von ber Beibefaltung biejer Bejtimmung gelangte balb 


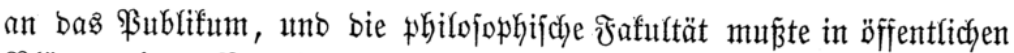
Blättern Karte $\mathfrak{B}$ ormürfe barïber Gimuebmen.

(S)egenwärtig wïnicht biefelbe mit Âtanahme einer einzigen Stinune, unt zwwar ber bes hodjbejahrten Dr. Pioforwafty, bie Alufhebung jener $\mathfrak{B} e=$ ftimmung, unb ich habe bie Ejhre, Em. Excelfenz in ber Ünlage eine hier=

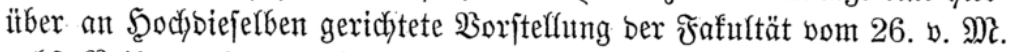
nebjt Beilage mit bem ehrerbietigen $\mathfrak{A}$ nheimiteflen zu überreidjen:

ben barin gejtellten 2 Anträgen gnäbigit zu wiflfahren, uno bem=

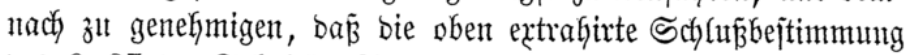

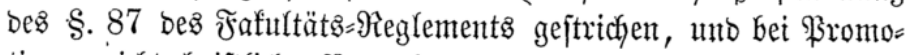
tionen nicht dyriftlicher Benverber um bie philojophifiche Ricentiaten= ober Doftormintbe bie Sponfionsformel ber Berliner philo=

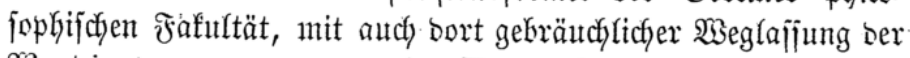
SOorte: et sacro-sanctum ejus Evangelium, gebraudfyt werbe.

B̉reslat, Den 4. Dejemtber 1845 .

Der Fegierungabevollmächtigte $2 c$.

פeitte.

Der Minitïter antwortete:

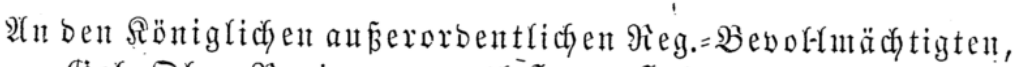

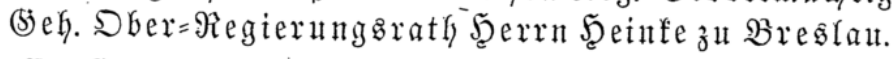

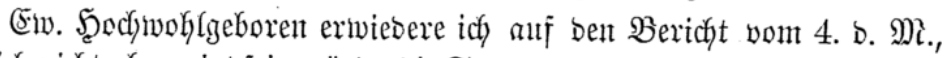
Dá̃ ich) nicht abgenteigt jein witroe, bie Statutent ber bortigen philojop fijichen

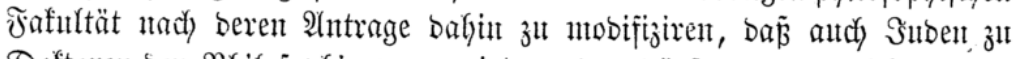
Doftoren ber \$rgitojophie promtovirt werben bïrfen, went nicht gegen=

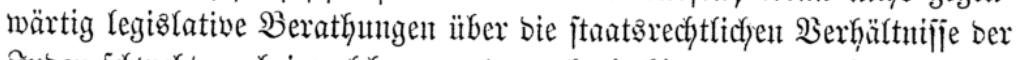

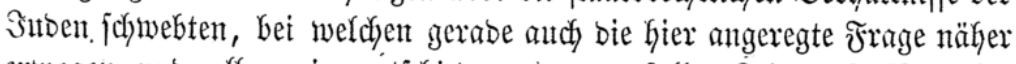

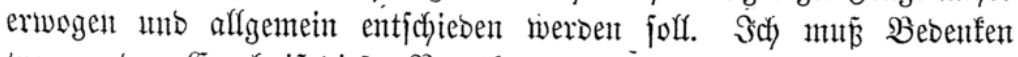

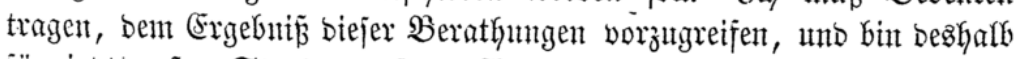
für jeşt aufer Stanto, auf bent $\mathfrak{U}$ ntrag Der gebachten Fafultät in bem

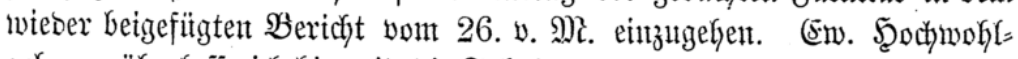
geboren itberlafje ich Giermit, bie Fafulttät z̆t bejcheiben.

B̉ertin, Den 21. Dezember 1845 .

Der Minifter ber geiftlichen, Unterrichts = unt Mebizinalangelegentyeiten. (Eidjlyorn.

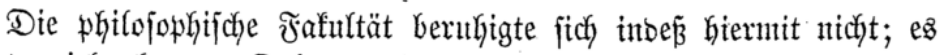
richtete viefmehr ber Defan berfelbent wentige Mionate fpäter an ben Minijter bie nachjtehende $\mathfrak{B o r j t e f f u n g : ~}$ 


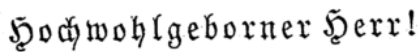

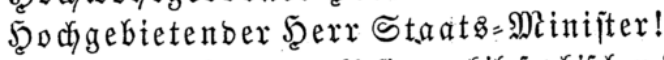

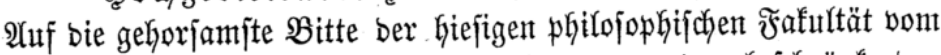

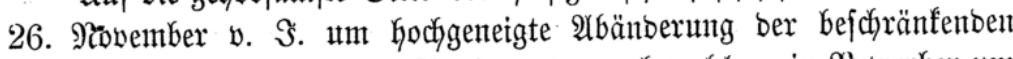

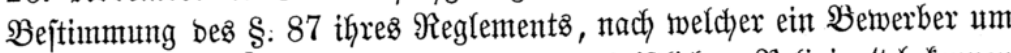

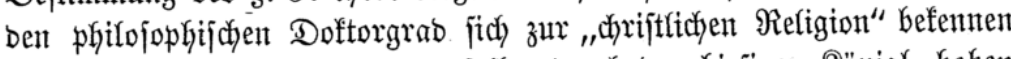
müiffe, haken En. Exceflenz berjelben burch ben hiejigen Rönigl. Gohen

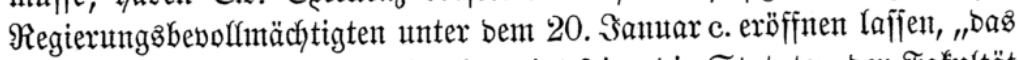
hoke Minifterium würbe nicht abgeneigt jein, bie Statuten ber Fafultät

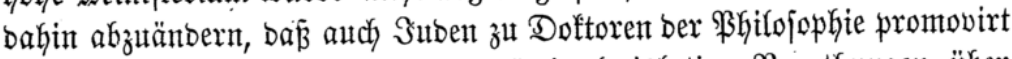
werben bürfften, wenn nicht gegenuärtig legialative Berathungen über

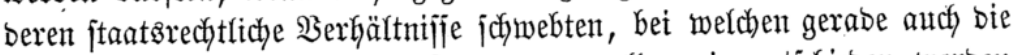
Gier angeregte Frage näher eriwogen und affgemein enticjieben twerben jolle. Das hohe Minijteriun habe baher Bebenten getragen, bem Ergebni biejer Berathungen vorzutgreifen, unb mitjfe ez für jeţt ablehnen, auf ben Ântrag ber Fafultät einzugełen."

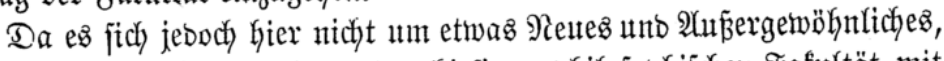

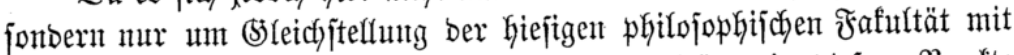
Denen anberer preußificjen und beutjchen Mniverjitäten in biejem ßunfte Ganbelt, bie in Berfin 'idnwebenton Berathungen vieffeidyt noch lange bautern bürften, und alfo auth ber hier beregte (stegenjtand nody geraume

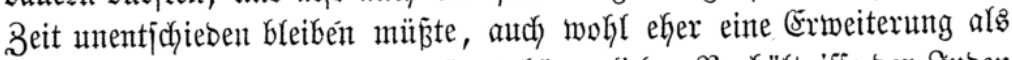

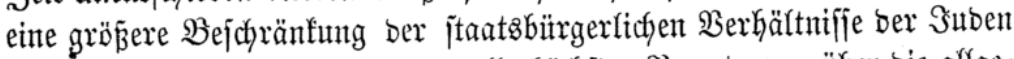

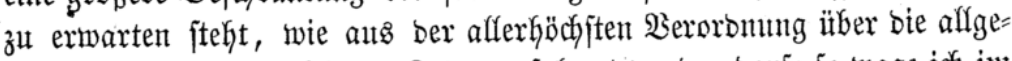
meine Mititärpflichtigfeit ber Suben gefolgert werben barf: fo wage idy int

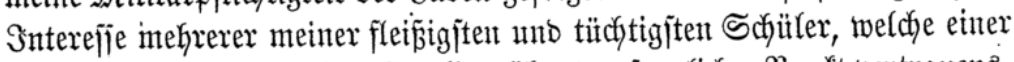

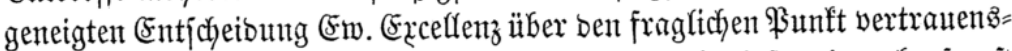
boll entgegengejehen haben, Şodjoiejerbe jo ehrerbietigit -wie gehorjamit

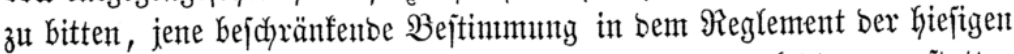

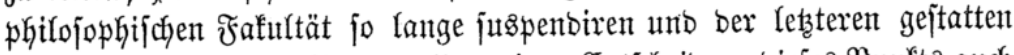

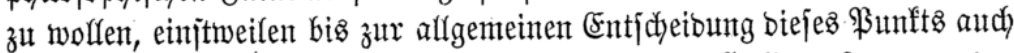

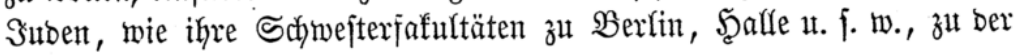
Bromotion zulaffen zu bürfen.

Meine eifrigiten unb tïdytigiten 3uhyörex fint hier fehr häufig jübijiche Stubirenbe, beren vorzugameije Bejchäftigung mit ben alttejta=

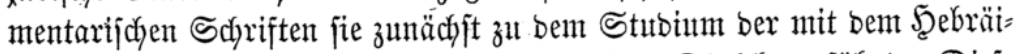

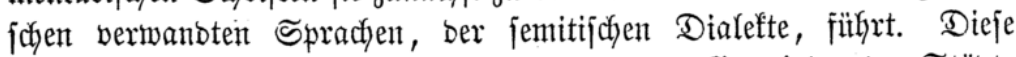
Stubirenben fint nun genöthigt, oa bie gröferen \$semeinben ber Stäbte

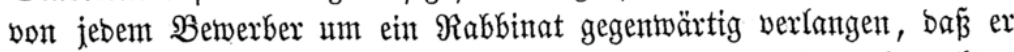
promovire, intoem fie biefen $\mathfrak{A f t}_{\mathrm{ft}}$ als eine $\mathscr{U}$ rt Staatzprüfung betrachten 


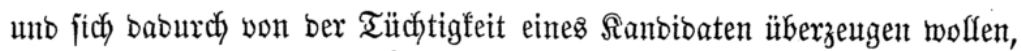

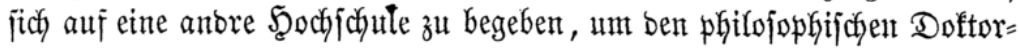
grab zıt erwerben, welchen ihnen bie Univerjität igres \$seburtżlanbes, álf

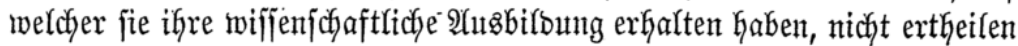

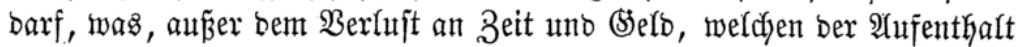

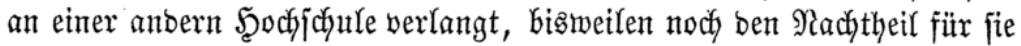
hat, Daß̉ fie, ben Examinatoren gänzlich fremb, gerabe in ihrem Scaupt= factje weniger icharf unb grünblich geprïft werben, je nachoem bas jemitijche Sprachgebiet auf ber Univerjität, nach meldyer jie jich begeben, vertreten ift.

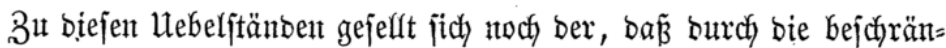

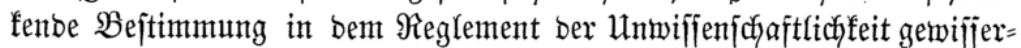

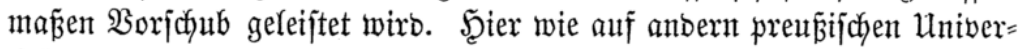
jitäten mú nämlich ein Berverber ım ben philojophifchen Doftorgrab

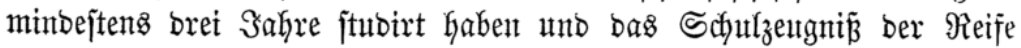
beibringen, wonach auf vielen beutfdyen Univerjitäten gar nicht verlangt wirb. Da nun bie jübijchen Ranbibaten Giex zux \$romotion nidjt gelangen fönnen, fo fangen fie jetzt an, fich wentger als frïher um bas Zentgniz ber

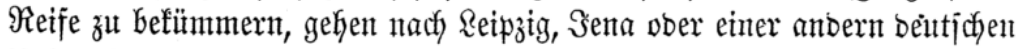
Univerjität, werichaffen fich bort ben Doftortitel unb jtehen bann in ben $\mathfrak{A}$ ugen bes 20 olfes auf gleicher Stuje mit benen, welche jichy ben Doftorgrad nach mefrjährigen $\mathfrak{A}$ jtrengungen rite erworben haben. Rönnten fie biefen. Strab hier erlangen, fo würben fie ifgn ge=

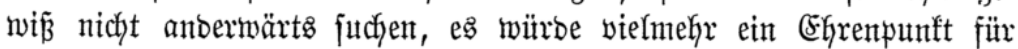

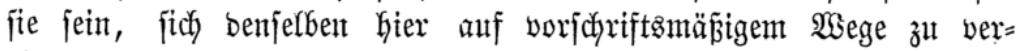
bienen.

Solften Erw. Excelf́enz fich inbeffen burch bie von mir bargelegten (Sitünde nicht bewogen fühlen, bie sben ausgejprodyente Bitte zu erfüffen, fo erlaube ich mir nody bie gehorjamite Âtnfrage: ob, went

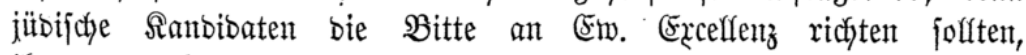

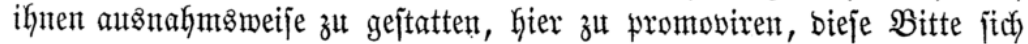

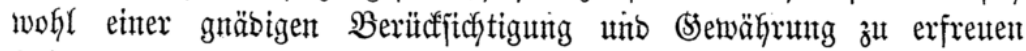
haben würbe.

Bresłan, Den 14. Alpril 1846.

\section{Mit größ̈ter Eqgrerbietung \\ (5iv. Excelfenz \\ unterthänigit gehorjamfter \\ Bernitein,}

Deržeitiger Defan ber phitofopgifdyen Fafuluttät. 


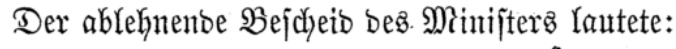

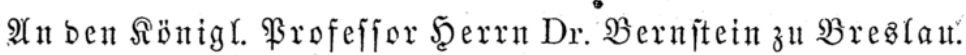

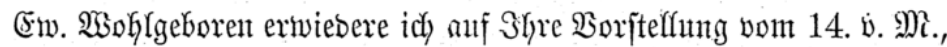

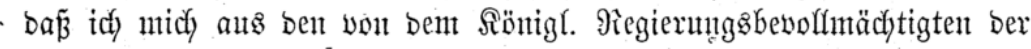

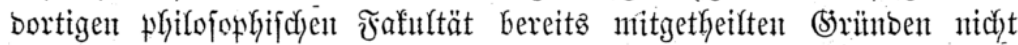
bewogen finben fant, gegenwärtig auf eine Abänberung berjentigen Beftim=

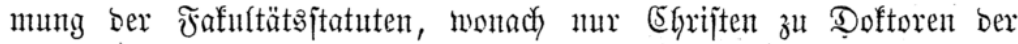

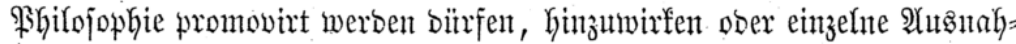
ment bon benferfent jut gejtatten.

Berlin, ben 2. Niai 1846.

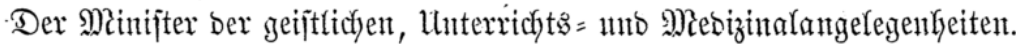

(Eid) yorts.

Şiergegen war nun freilich nidhts tweiter zht thun; faum war aber

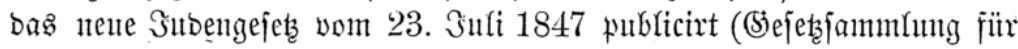

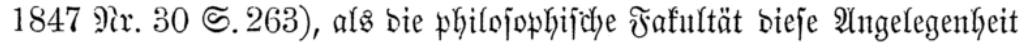
jofort mieber burdy folgente singate anregte:

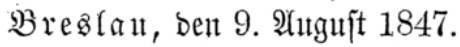

Şodyebietender Feer Minijtex.

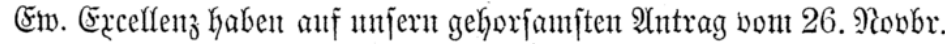

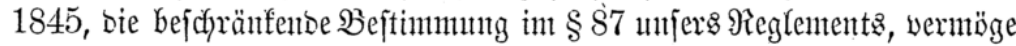
beren ein B̧ewerber un ben philojophifdyen Ricentiaten = ober Doftorgrab

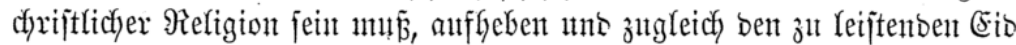

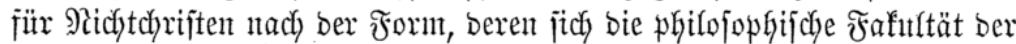

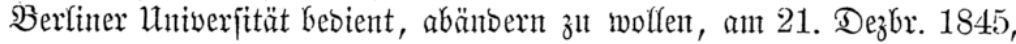

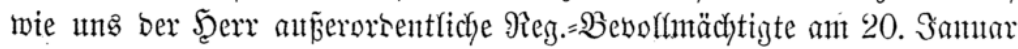

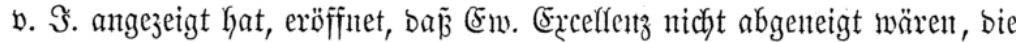

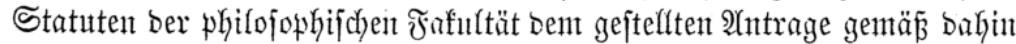

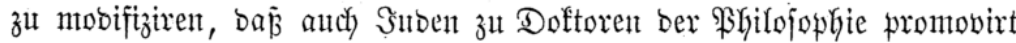

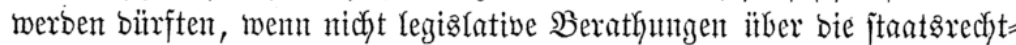

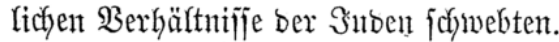

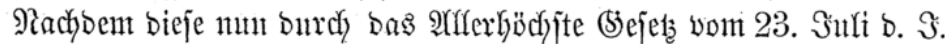

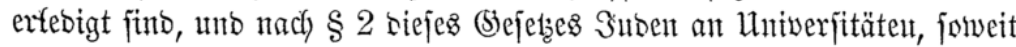
beren Statuten nicht enfgegenftehen, als \$riwatbozenten, autzerorbentfidyo unb orbentliche Brofejpren ser ntebizinifchen, mathematifchen, natır=

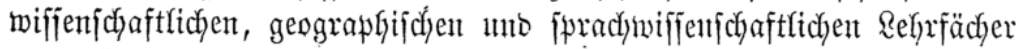
zugelaffent werben föment, fo bitten wir (En. Exceffenz elyrerbietigit, unjerm frühern geforjamen $\mathfrak{A}$ ntrage vom 26. 9lovbr. 1845 nach, nummefyr bie

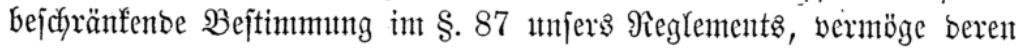


eit Bewerber um ben philofopfifchen Ricentiaten = ober Doftorgrab cyrift=

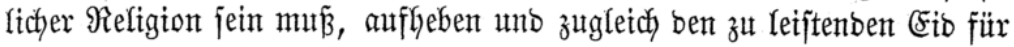
Nidutchriften nach ber Form, beren jich bie philojophifiche Fafulttät ber Berriner Untiverjitüt bebient, Gọd)geneigtejt abänbern zu wolfen.

Die philojopgifche Fafulttät ber Sönigfiçyen Univerjität.

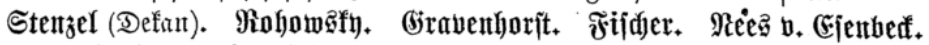

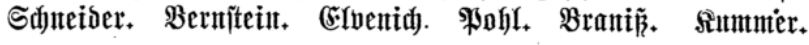

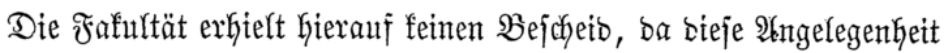
burch) bie Circularverfügung vom 28. Septbr. 1847 Dem Minifterium errebigt zut fein fofjien.

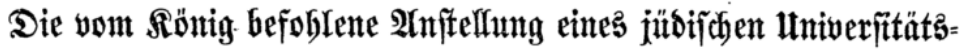 lehters int Sabte 1847.}

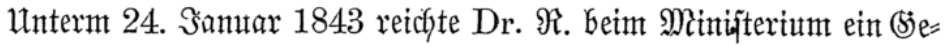

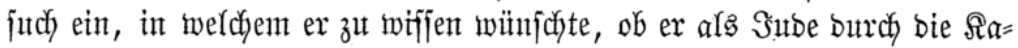

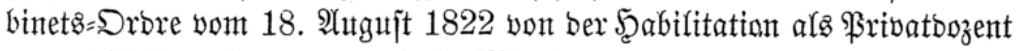

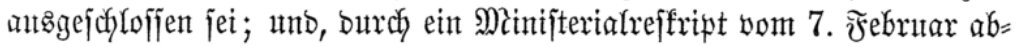

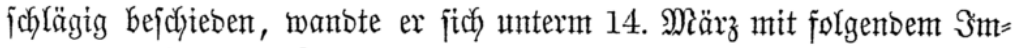
mebiatgejutch ant bent R̈̈nig.

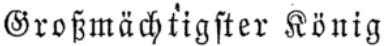

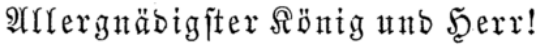

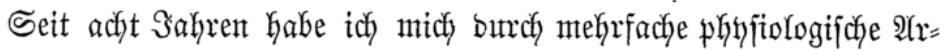
beiten unb burch Frtwatworträge, welchen jelbjt afabemijche Rehrer ifre

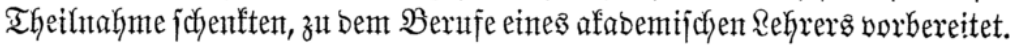

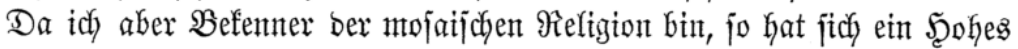
Mintijterium ber geiftlichen, Unterrichts = unt Mebizinalangelegenheitent

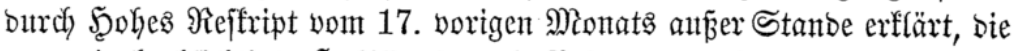
von mir beafjichtigte F̧abilitation als ßrivatbozent bei ber medizinifichent

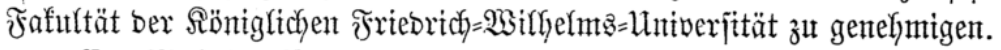

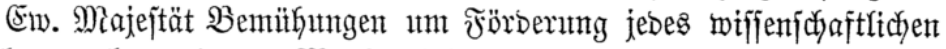
Strebents geben mix ben Muth, bieje 2(ngelegentheit an bie Stufen bes Thrones zu bringen, unb laffen mich fït bie folgenben 9 Semerfingen, beren

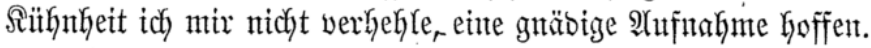

Wem bie gejammten Befenter ber ntojaifchen Religion, jumal in

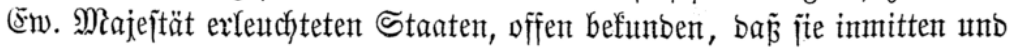
mittels ber chrijtliçen Bitloung ifyent feit lange erjartarten religiöfent unb

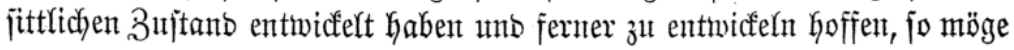




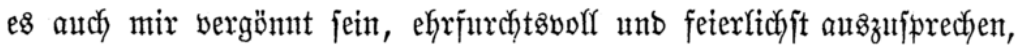

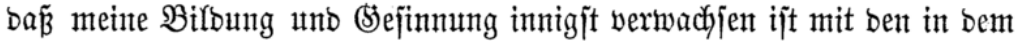

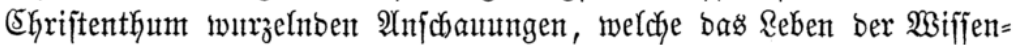
jufaft unt bes Staates burchbringen. Dieje ibeeffe Hebereinjtimmung icheint ben formelfen Utebertritt zun (5hriftenthum eher zut exjdyweren alo zu erleidytern. Die geringere politijhye Berechtigung raubt wor Arllem bie

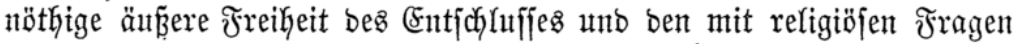

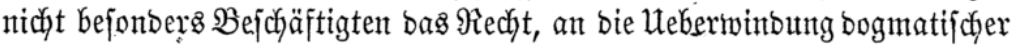
Sdymierigfeiten zu benfen. Sener befannte anfreie Uriprung bez $\mathfrak{H}$ eber= tritts erzengt zumeift bie zweifelfafte joziale Stelfung ber Wlebertretenten, werche ifgre Wirffamfeit verfïnmert unb anbere, nicht äunerlich Ângeregte

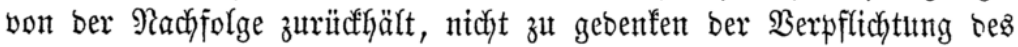

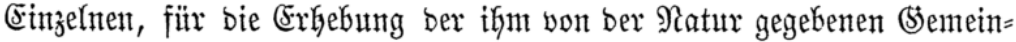
jdhaft zut wirfen, anjtatt zu eigenter, menngleidy jelbit intuerer Befriebigung in eine antore (S)meinjidaft zut treten.

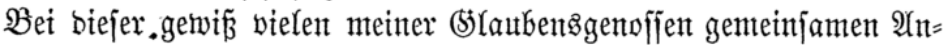
ichaumng fehe ich mich ber Mëglichfeit beraubt, meine Sräfte in bollem.

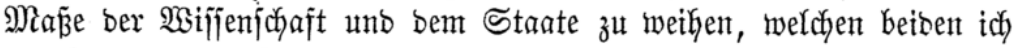
angehöre und mit Eifer ergeben bint.

Daker wage ich an Fw. Majejtät bie alferunterthänigjte unt ehr $=$

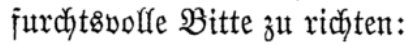

eڤ möge (5w. Miajejtät affergnäbigit geruthen, biejenigen $\mathfrak{A}$ norb= nungen zut verfügen, welche meine Şabilitation als \$rivatoozent

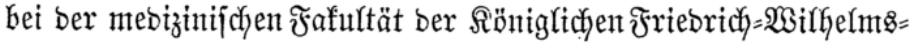
Univerjität möglidy machent wïrben.

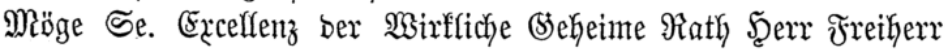
v. Scumboldt, bet weldhem meine $\mathfrak{A}$ rbeiten ftets Sntereffe erregt haben,

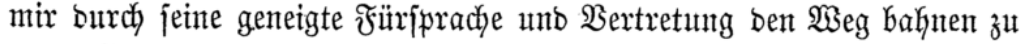
bem afferuntertfänigjt erbetenten Wirfintgghreije, für befjen affergnäbigite Berleifung ich meinen Dant betfätigen werbe burch gemifjentyafte Exfüffung meiner Sffichten zur Eshre Bottes, zum Frommen bes Staats und zum (5)ebeiken ber Wiffenfdyaft.

Berfin, ben 14. Meärz 1843.

Эn tiefíter -

Dr. $\mathfrak{R}$.

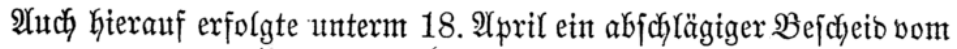

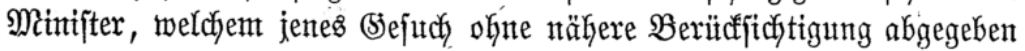
worben war, wie benn überhaupt alfe ähnlidyen Эnmebiat=(S) ejuthe (jo von

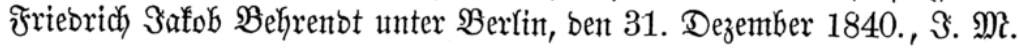




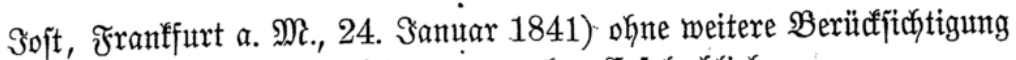
an bas Minifferium zurüffigingen uno ohne Erfolg blieben.

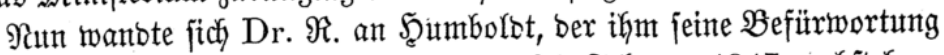
beim $\Re$ önig verfprach, und reichte unterm 24. Februar 1847 nachjtehen=

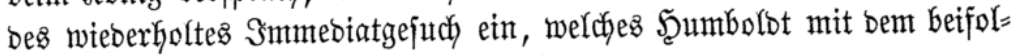
genben Begłeitfahreiben an ben @önig beförberte:

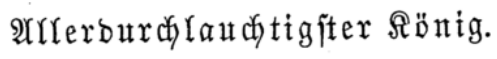

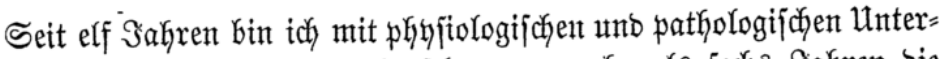

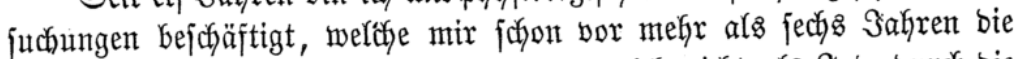
afabemijche Rauf̣ahn eröffnet hätten, wäre ich nicht als Sube burch bie

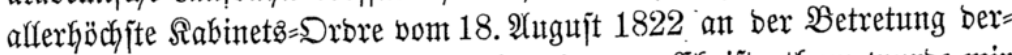
jelben verfinbert worben. Der Hebertritt zum Shriftenthum wurbe mir burch bie Drthoboxie meiner Eltern, Denent ich ßietät und Riebe fdyulbe, unmöglich gemacht. গ̛luch habe ich won jeher ben größ̈ten Wibermiflen

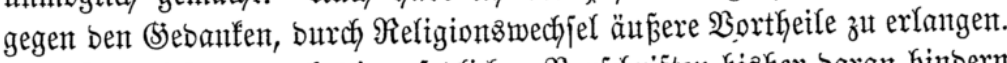

Da mich bennach bie gejestidchen Borjdyriften bisker baran Ginbern mürben, in bie Reifye ber afabemijchen Refyrer zu treten, fo wage id bie aflerunterthäntigite $\mathfrak{B}$ itte ant (Erm. Majeftät:

mir allergiäbigit zu geitatten, bei einer ber inlänbijadjen Utniverji= tätent eine afabemijiche Ref̧riftefle antretent zu bürfent.

Se. Excelfentz Şerr Freih̆err v. Şumborbt will bie Snabe haben,

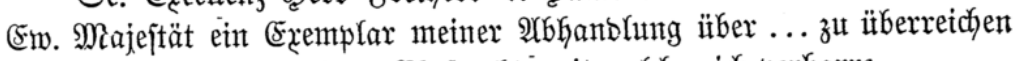

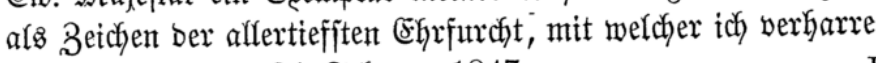

Berlin, ben 24. Jebruar 1847.

Dr. $\Re$.

\section{(Em. $\Re \ddot{n} n$ iglidye Majejtät}

haben gerufft, fich auf eine fo beftimmte unt fo hulbreiche Weife gegen mich zu äupern, als ich ЭGnen in meinem Namen unb bem meiner be=

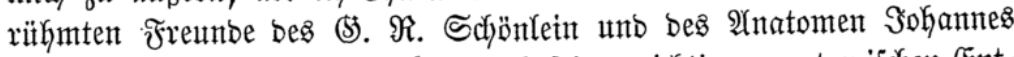
Müfler von bem Schicffale bes burch jeine midytigen anatomijchent (Ent=

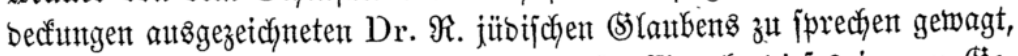

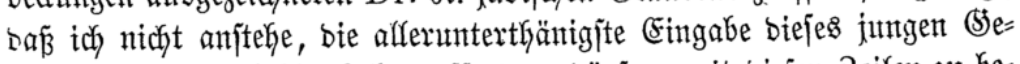
lehrten, zut ber ich ifhn habe aufforbern bitrfen, nit biejen 3eilen zu be= gleiten.

Der Dr. $\Re$. ijt vont jübifchen, fehr orthoboxen unbemitteltent Ertern geboren. Schon auf ber hiefigen Univerjität hatte 1835 eine \$reisfdyrift

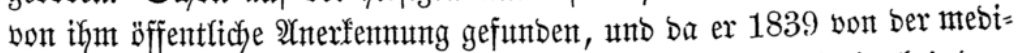

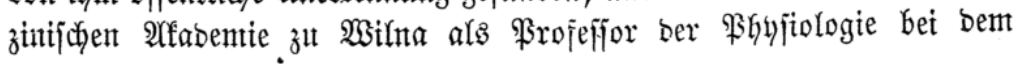


ruffifichen Minifteriunt in Borjdylag gebractyt wurbe, empafaht ich ifh,

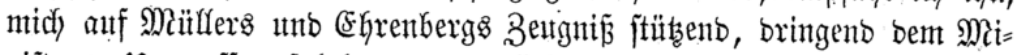
nijter v. Utvaroff, erfolglos wegen religiöjer, undyrijtliçer Sntoleranz, bie

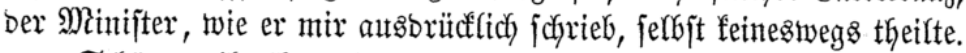

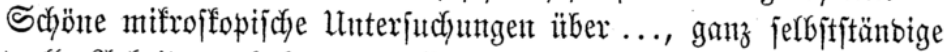
talentwolfe $\mathfrak{A}$ rbeiten, haben ben Biekeinuath Scyönlein betwogen, ben

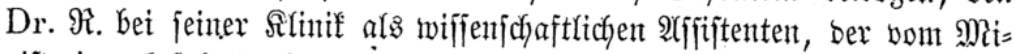
niftertum bejolbet wirb, auzuttelfen. Seit 1843 nehmen bie 3uffürer bes (Stekeimmath Schöntein Theil an jeinen Demonjtrationen in ber (Sharité.

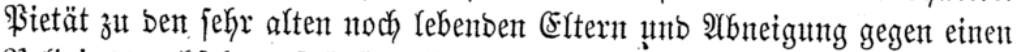
Religionsinedyjel, auf äunere Bortheile gegrünbet, entjernen einen nidyt

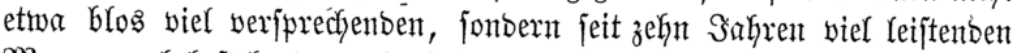

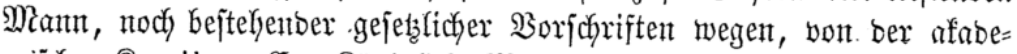

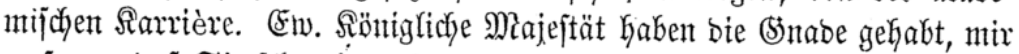

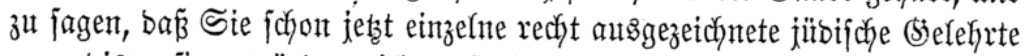
gern bispenjiren wïrben; ich barf aljo bie unterthänigite $\mathfrak{B}$ itte ernentern:

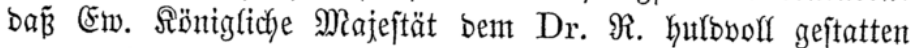
ntögen, bei einer ber inlänbijđ̆en Untuerjitäten eine afabemijche Rehritelfe antreten zut bilnfent.

Die anliegenbe Schrift über... ift auth in ärztlicfer patfologifocher

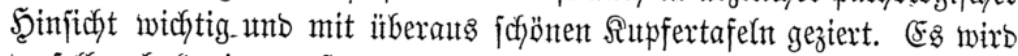
berjelben barb eine größ̈ere folgen, zut ber biele anatomijche Tafeln bereitz

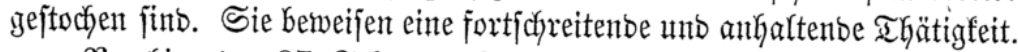

Berlin, ben 27. Februar 1847.

Sn tieffiter (Egyrfurdyt erfterbe ich

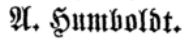

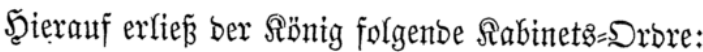

Da bie Frage über bie Bulafjung ber Suben zu öffentfichen Rełr:

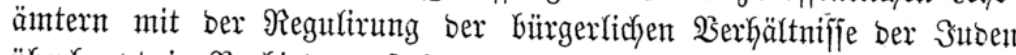

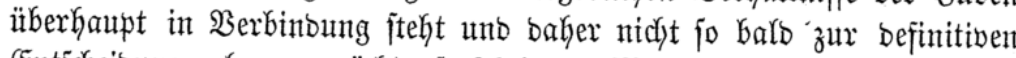

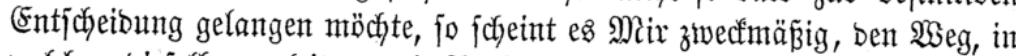

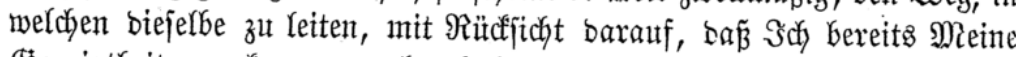
Seneigtheit zu erfennen gegeben habe, bie Suben bon biejem 3weige öffent=

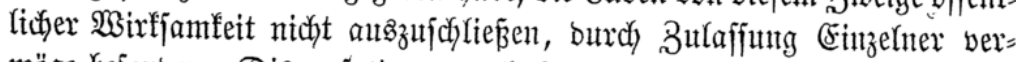
möge bejonberer Dispenjation, anzubahnen.

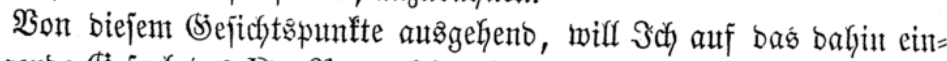

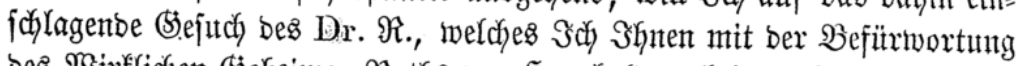

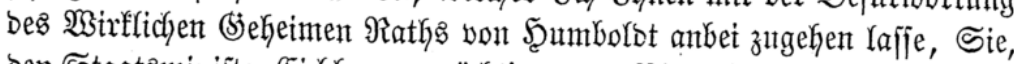

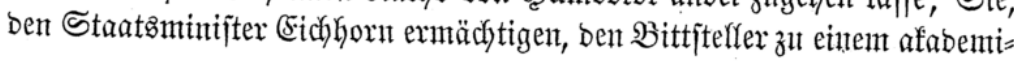




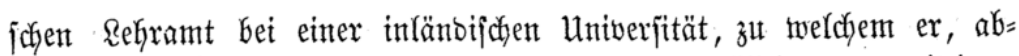
gejeblen von ben fonfefïioneflen Bebingungen fich qualifizirt, zu abmittiren, infofern Sie nicht bejonbere, èventuell anzuzeigenbe Bebenten bagegen habent.

2̧erlin, ben 8. Märrz 1847.

$\mathfrak{A} \mathfrak{n}$

(gę.) Fritebrid) Willhelm.

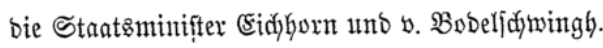

Die Bulaffung ber Suben zu afabemifjyen Rehrifelfent war aljo bereits ant 8. März 1847, Demnaç vor Eröffnung bes Erften Bereinigten Rano= tages vom Söntge nidyt nut prinzipiefl ausgefprodyen, fonbern and that=

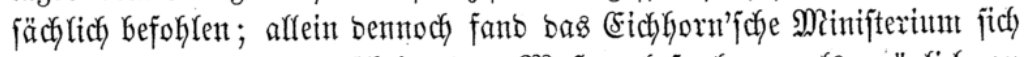
bewogen, mit biefer enticheibenben Mafregel fo lange als möglich jut

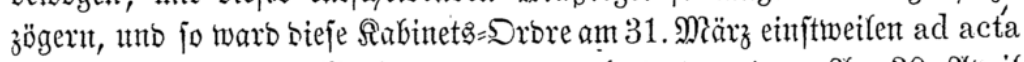

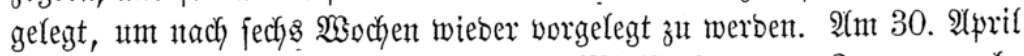

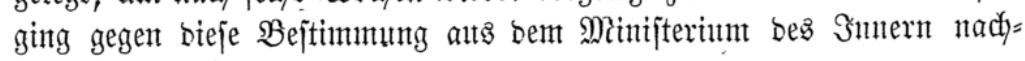
jtehenbes Votum ein:

\section{Votum,}

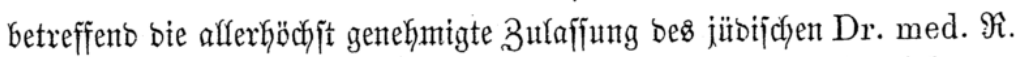

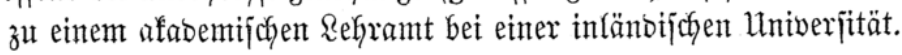

Sr. Excellenz bem $\Re$ önigl. Staatzmintijter ber geijtlichen,

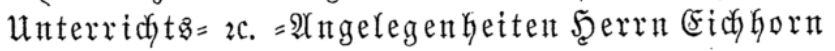
borzulegen.

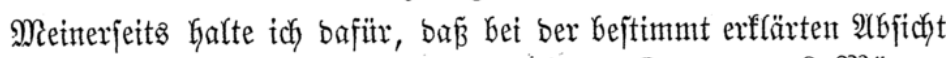

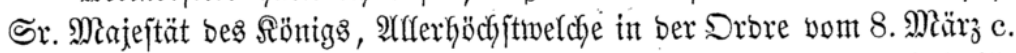

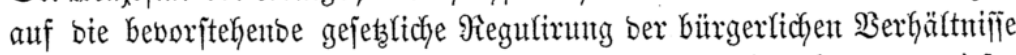

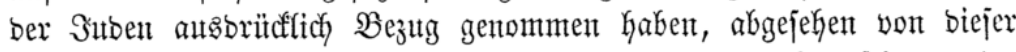

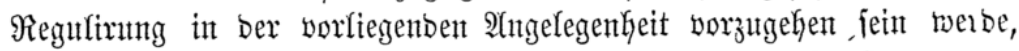
unb jtefle baher ganz ergebenjt antheim, bas 2 seitere geneigtejt jut veran=

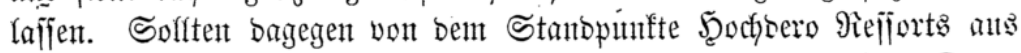

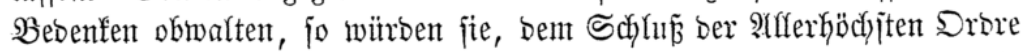

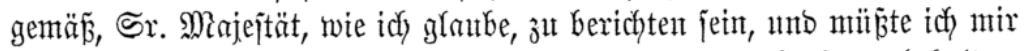
in biejer Beziefung event. meine Aenferung ganz ergebenjt vorbehaltent. Berlit, bent 30. Ilpril 1847.

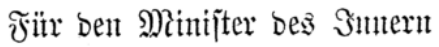
Sm $\mathfrak{A}$ luftrage Mathis.

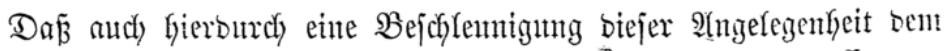

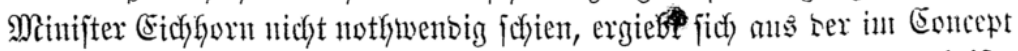

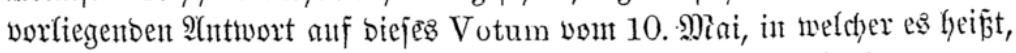

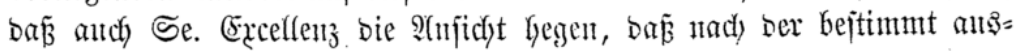




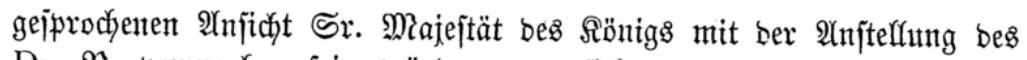

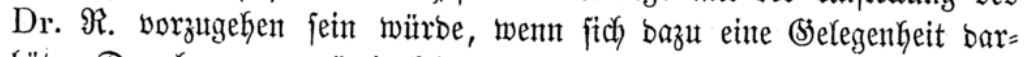
böte. Da aber gegentuärtig feine Stefle ber $\mathfrak{A}$ rt bei einer Univerfitüt z̆t

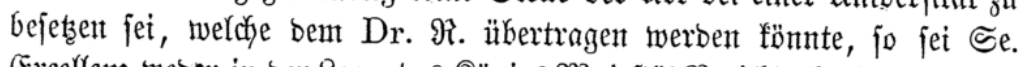

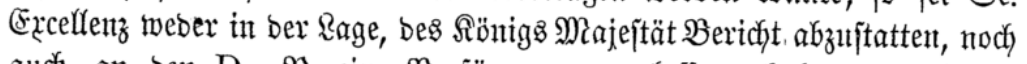

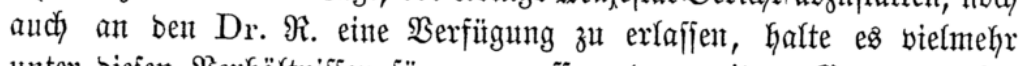
unter biejen Berhältniffen für angemeffen, ben weitern Stang ber $\mathfrak{B} e=$

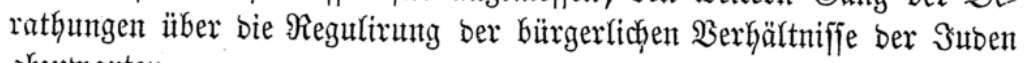
abzumarten.

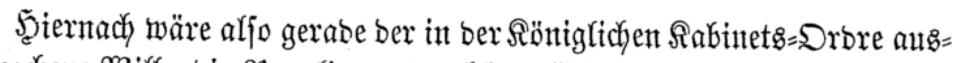

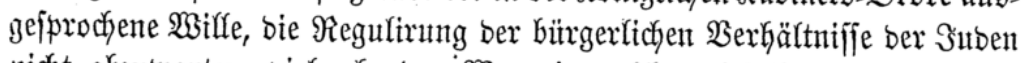

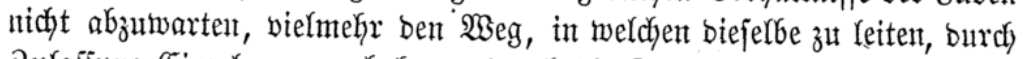

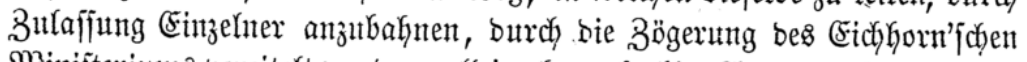
Minijteriums vereitelt worben; affein ehe noch obige 2̂ntwort abgejcyrieben

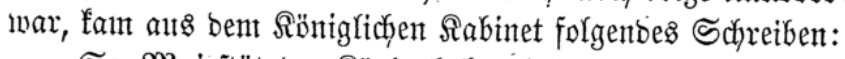

Se. Majeität ber Rönig haben beim gejtrigen 20 rtrage eines frühe= ren Befehls an Ew. Exceeflent Erwähnung gethan, bie Berleifung eines

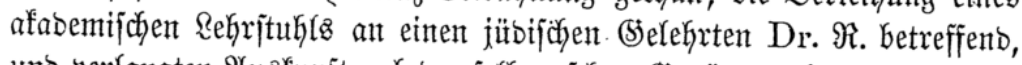

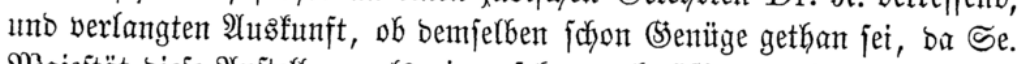

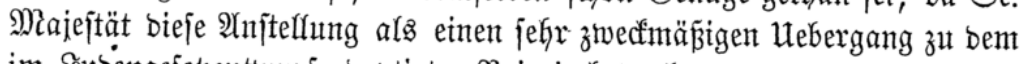

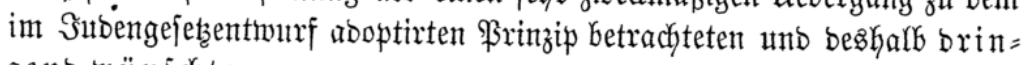
gent wit njoten.

Da niv bieje Sache bißker ganz unbefannt gewejen ift, fo fann idy

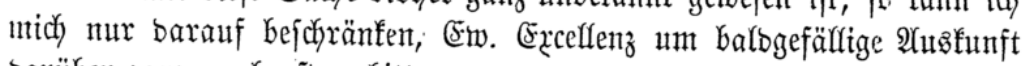
barïber ganz ergebenjt zut bitten.

Berlin, ben 15 . Mai 1847.

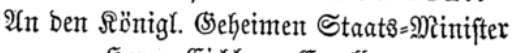

Şerrn (Eid)horn Eָcelllenz.

Thile.

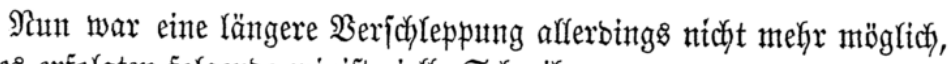
unb es erfolgten folgende minifterielfe Schreiben:

I.

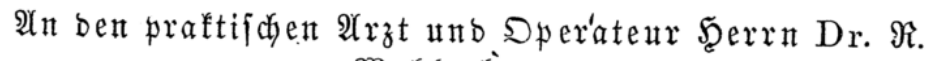
Wohlgeboren.

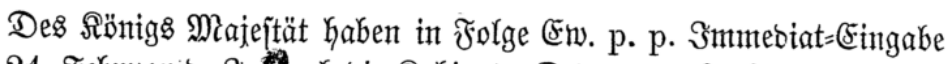

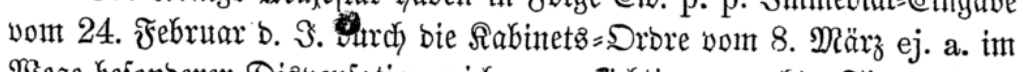
Wege bejonberer Dispenjation mich zut ermächtigen geruht, Sie zu einem afabemijchen Rebramte bei einer inlänbijchen Univerjität, zu welchem Sie 
jich, abgejełen won bent fonfeffitonelfen ḃebingungen, qualifizirt haben,

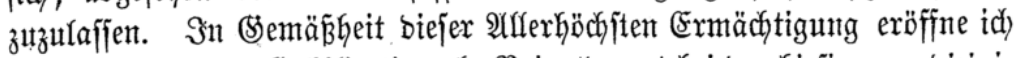

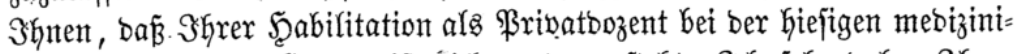

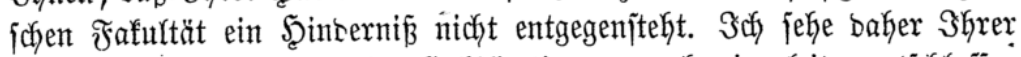

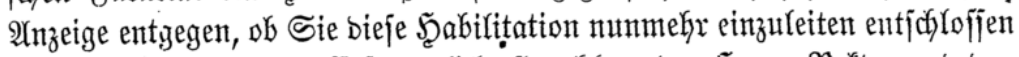

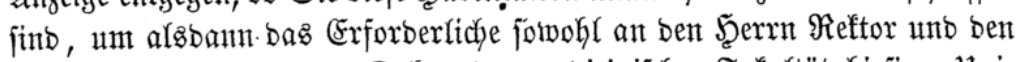
Senat, als auch an ben Defan ber medizinifchen Fafulttät hiejiger Uni= verjittät 孔̆t verfügen.

Berlin, ben 23. Maa 1847.

\section{Der Mintiter.}

Eidhorn.

\section{II.}

Ân Des $\mathfrak{A o ̈ n i g s ~ M a j e j t a ̈ t . ~}$

(5ww. Rönigl. Majejtät verfehle ich nicht, allerunterthänigit anzuzeigen,

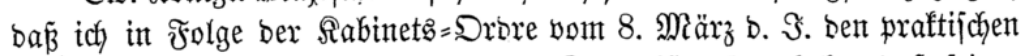

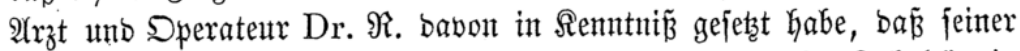

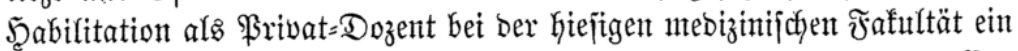

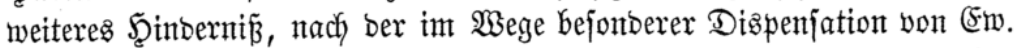

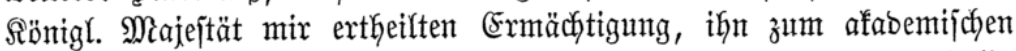

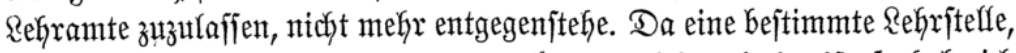
weldye bem Dr. $\Re$. ïbertragen werben fönnte, nicht erfebigt ijt, jo habe ich mich auf bieje Eröffinung um fo mefyr bejcyränfen müffen, als ich wohl

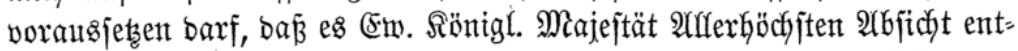

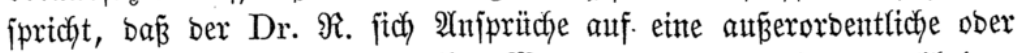

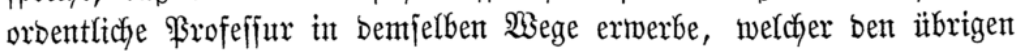
Betwerbern um afabemij̄che Ręrämter geöffnet ijt.

Berrin, ben 23. Mai 1847.

Der Mintiter.

(5idulyorn.

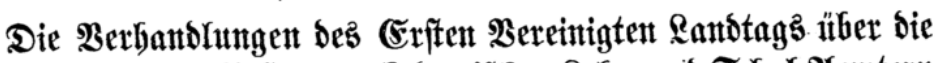

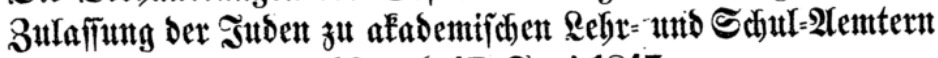

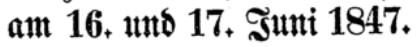

Der bem Bereinigten Ranbtag vorgelegte Sejetsentmumf bejtimnte

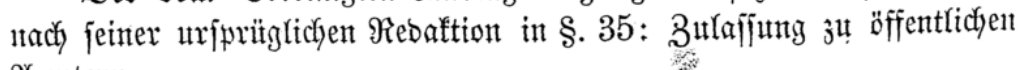
OCentern.

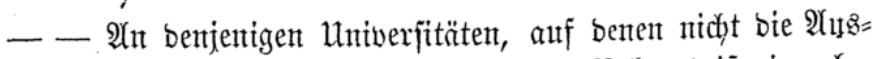

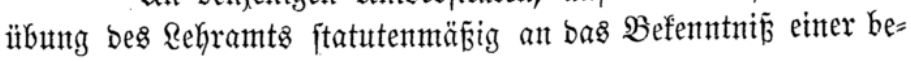




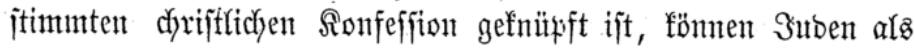
Sribatbozenten unb anferorbentliche Profefforen ber mathema=

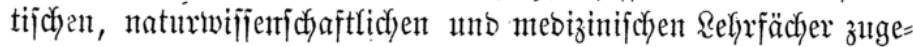
lafient twerbent.

Die Berkanblungen ïber biefe Bejtimnntug fanben in ber. Serrent= furte am 16. unt in ber Furte ber brei Stänbe am 17. Sunt 1847 ftatt, wobei nad) ben ftenographifdyen Beriçten folgenbe (Erflärungen abgegeben twitroen.

\section{A. In dor farrenliurie.}

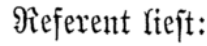

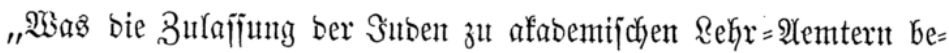

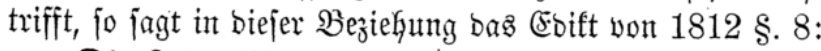

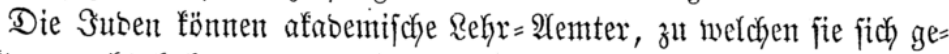

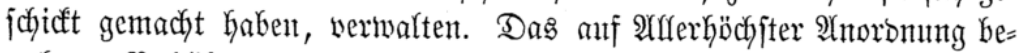

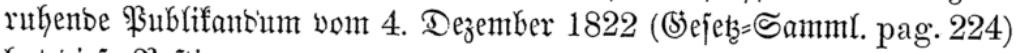
Yat bieje Bejtimumung,

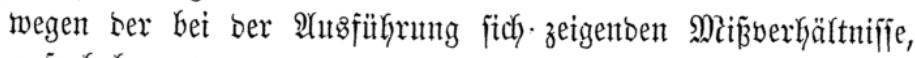
aufgefyoben.

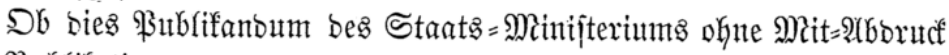

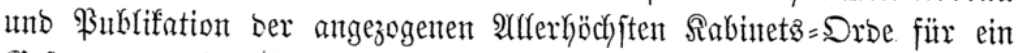
(5iejets zu erachten ijt, was bie burdh bie Bumbezafte garantitte (5)ejetz=

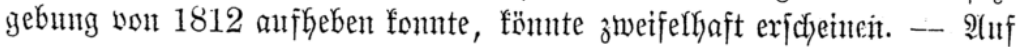
Der anbern Seite fönnen bie blo faum enticheiben.

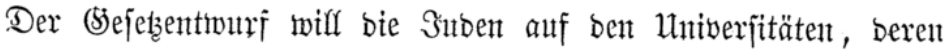
Statuten es gejtatten, mux als \$ribatbozenten unb aunerorbentliche \$iro= fejīoren in ben mathematifichen, naturwijientichaftlichen unb mebizinifichen Rehrfächern z̧utals̈ent.

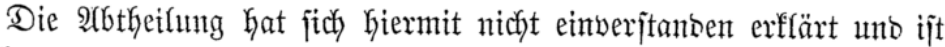

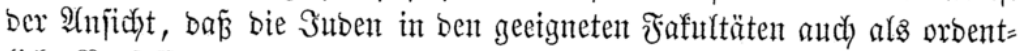
liche \$rofefijorent angejtellt anb zugelafjen werben müffen, wenit anter:

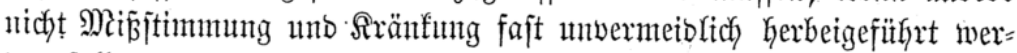
Den joff.

- Man verjetze jid in bie Rage eines foldhen auperorbentlichen $\$$ iro

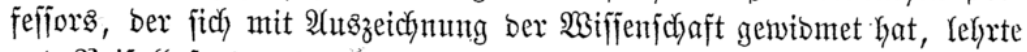
uno Sheifall fant and bann nie ein wirfficher \$rofeffor werben forl, und

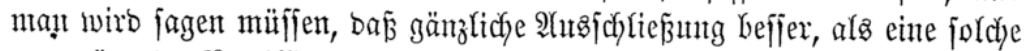

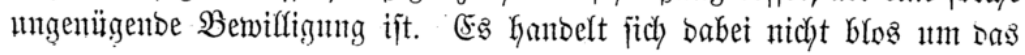


(5)ehalt; ba lieje fich nachlyelfen. Der Staat fönnte bie auperorbentlichen \$rofejforen jübijchen (silaubents ausfömmlidy unb befjer befolben, als bie

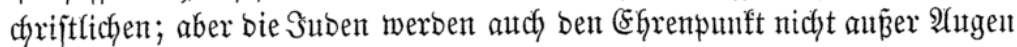

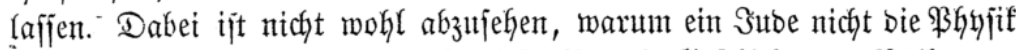

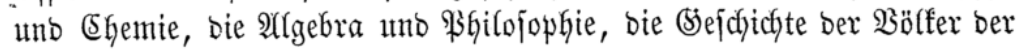

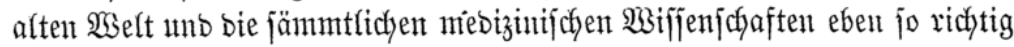

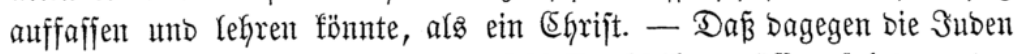
vont ber theologifchen ₹rafultät autsgejchlofijen bleiben mülfien, folgt ans ber 9iatır ber Sache. Bweifelhajter erjcheint beren 3ulafiung bei ber jurijti=

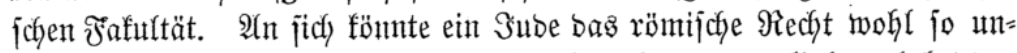
befangen rehren, als ein Shrijt; es ijt aber allgemeiner Bsebrauch bei tent

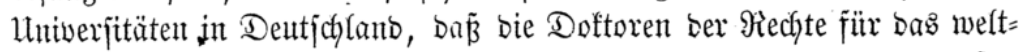
fiche unt fanonifiche Piecht zugleich promovirt werben, unb nur in nenejter

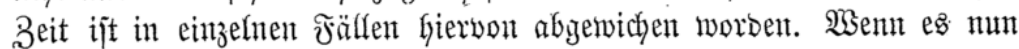

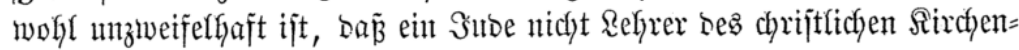

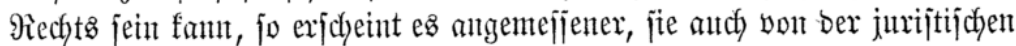
Fafultät auģ̧ı

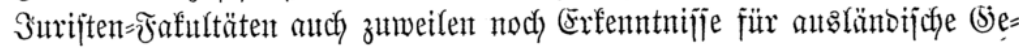

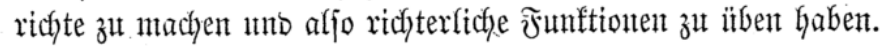

Die 2 (btheilunty trägt baher mit 6 gegen 1 Stimme bahin an:

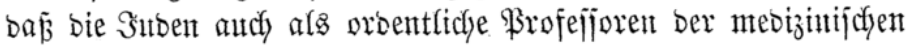

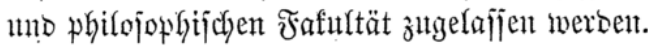

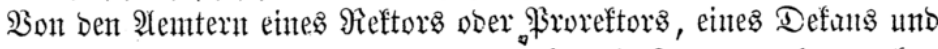

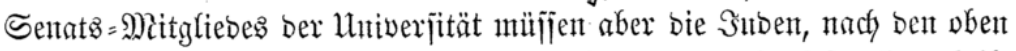
entwiffiften \$rinzipien, ausgejdylojien bleiben; benn mit biejen jüt theil= weis ridjterliche unb polizeiliche Funftionen über bie Stubentent verbunben.

Die Spezial=Statuten fajt allex prenpipifyent Hniverjitäten, abgejehen

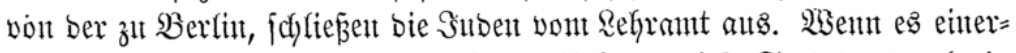
jeits nidyt bie âbjicht bes (Sejeţgebers jein fant, bieje Statuten burdy ein

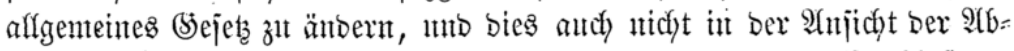
theifuntg liegt, fo fönnen antoererjeits bieje Statuten burth bejuftur ber Untwerjität unto $\mathfrak{B}$ ejtätigung bes Ranbeghern geänbert werbent, unto einer

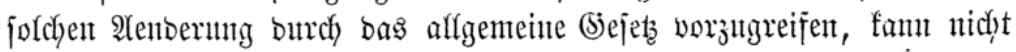
rathfam erfcheinent. Die betreffende Steffe bes (Sefelzes wirb baher anders,

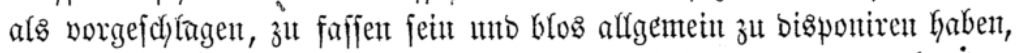
ohne bes Statutax= Redyts zat gebenten, was befanntlich jtets nebent ben

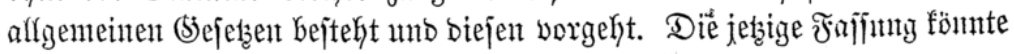
eine für bie Sache verfänglidje genaunt reerben."

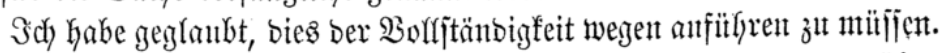

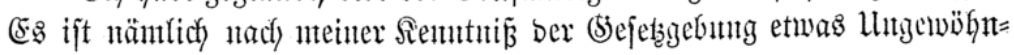




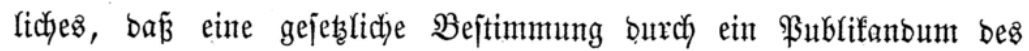

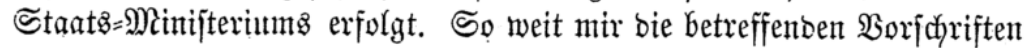

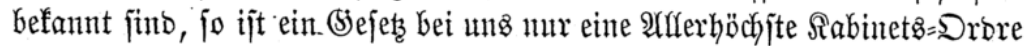

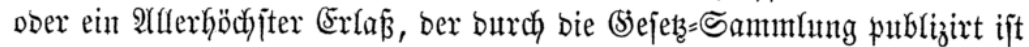

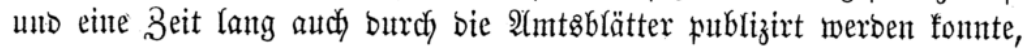

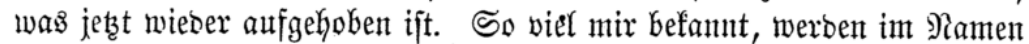
bes Stant: = Minitifertums in ber \$ejess=Sammlung mur Sorrefturen von

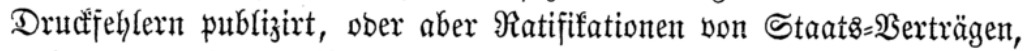
welche von geringerer Bebentung fint. Şh habe, wie gejagt, bies nur ber Bolljtändigfeit wegen anführen wolfen.

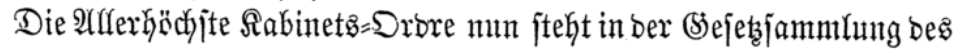
Эafles 1822 und lautet jo:

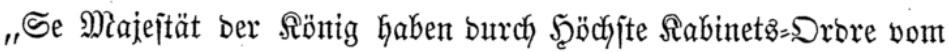

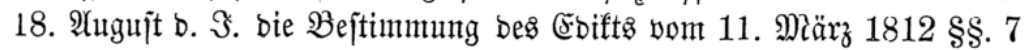
unt 8 ,

wonach bie für Eintänber zu achtenden Suren zut afabemijchen

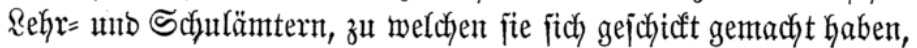
zugelajfen werben follen,

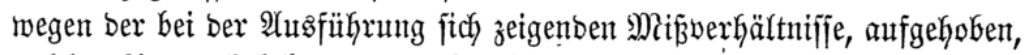
weldes Gierburch befannt gemadyt mirb.

Berlin, ben 4. Dezember 1822.

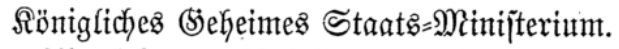

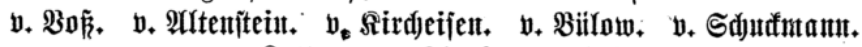

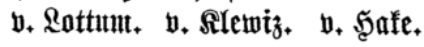

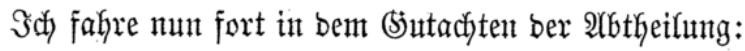

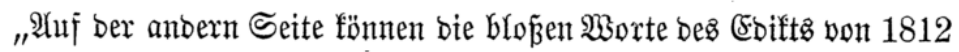
Gier audh faum enticheiben.

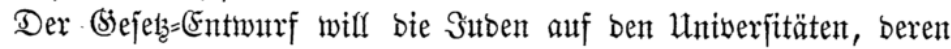
Statuten es gejtatten, nux als \$rivat=Dozenten und aurerorbentliche

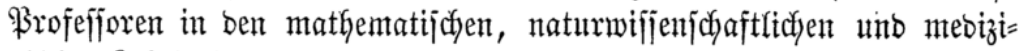
nij̄ben Rehrfächern zulafijen.

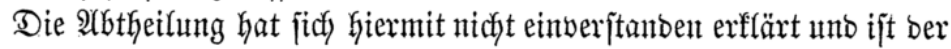
श्unjicht, ba

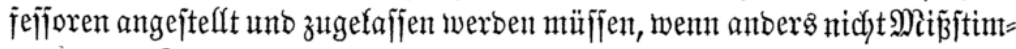
mung und Rränfung fajt unvermeiofich herbeigefühyrt werben folfen. Man

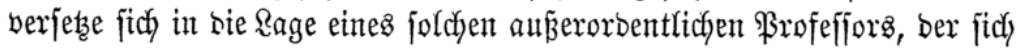

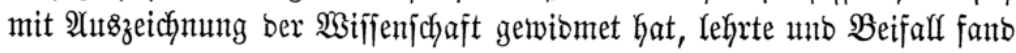
unb bann nie ein wirfficher Profeffior werben foll, unb man wirb jagen

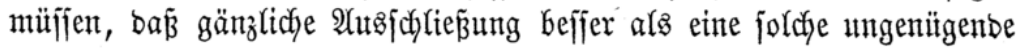




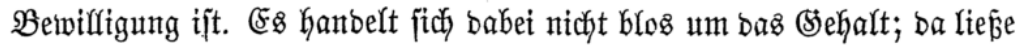
fich nachberfen. Der Staat fönnte bie auperorbentlichen \$rofefforen jübifchen (\$)laubens ausfömmlich uno befifer bejolben, als bie chriftlichen;

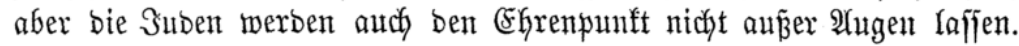

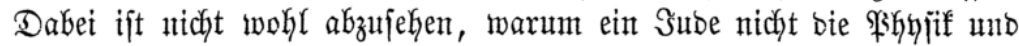

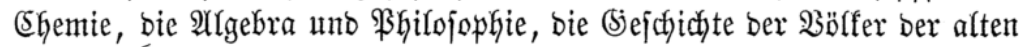

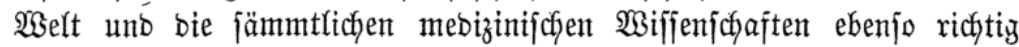
auffaffen und lehren fönnte, alz ein Shrift. - Dẩ Dagegen bie Suben von ber theologifichen Fafultät ausigejchlofien bleibent muijfien, folgt aus ber Natur ber Sache. Zweifelgafter erfoheint beren 3ulafjung bei. ber

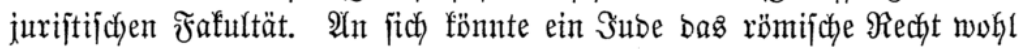
fo unbefangen lehren, als ein (Shrijt; es ift aber aflgemeiner (Siebrand)

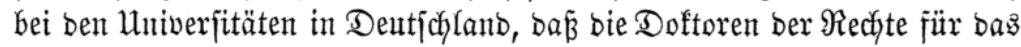

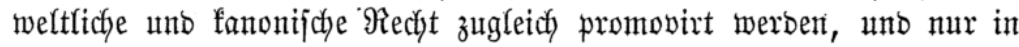
neuejter $3^{\text {eit }}$ ijt in einzelnen $\widetilde{x a ̈ l e n ~ h i e r w o n ~ a b g e m i c h e n ~ w o r b e n . ~ W e n n ~}$

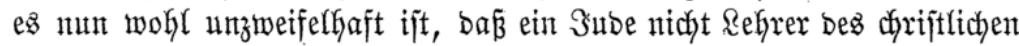

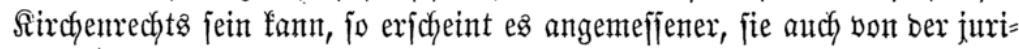

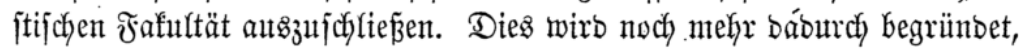

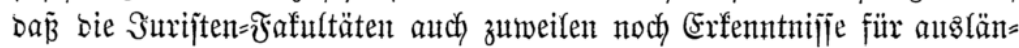
bifche (Sierichte. zu machen unb alfo ridjterlidje ซunftionen zu üben haben."

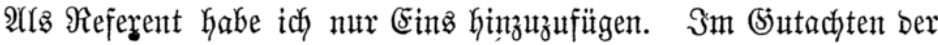

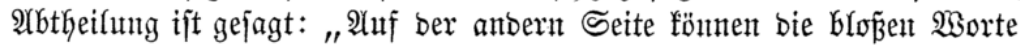

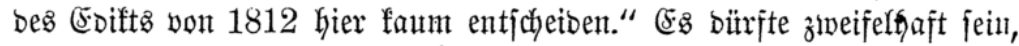
wie bas zut verjtehen ift. Эch, meines Dafürkaltens, meine es jo. Das (5ifift won 1812 ift jehr alfgemein und unbejtimmt gefajt, ich habe bie

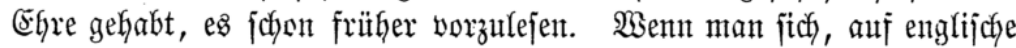

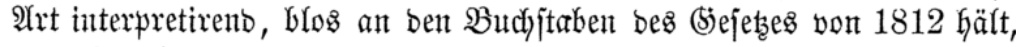
fo ift fein (5runt abzulekgen, warunt ein Sube nidfyt audj verfangen f̈̈mte, als \$rofeffor ber Theologie zugelafjen zu werben, bent ez jteft.barin: "Die

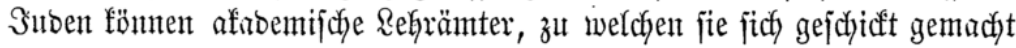
haben, verwalten"; unt ein \$rofeffor ber Theologie befleibet ein afabemi=

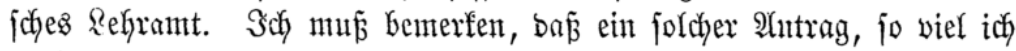

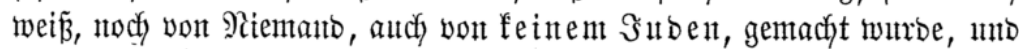
ich, meines Dafürthaltens, würbe auch eine foldje Anjteflung eines Subèn

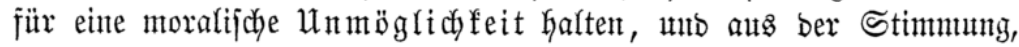
welche fich hier fundigab, afz idy bie betreffente Stefle bes (5utachtens

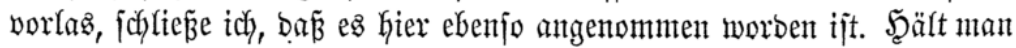

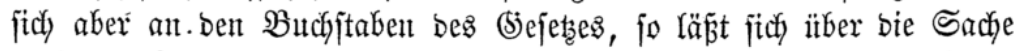
ftreitent. F: fönnte ant Enbe Einter jagent, ich fajfe bie Theologie objeftiv auf, ich werbe jie fo gut lehten, wie ein (Shrijt. Sch glanbe aber, baf man 


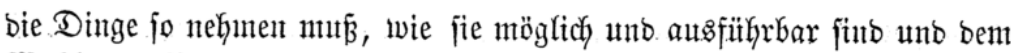

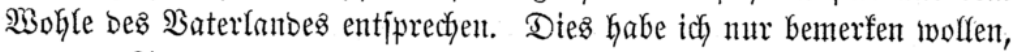

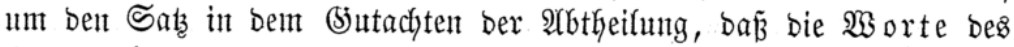

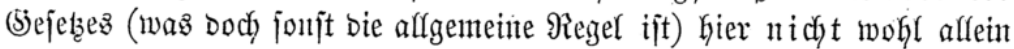
utä́gebent jein f̈̈mnen, zu rechtfertigen. Die 2rbtheifung trägt baher mit (b geyen 1 Stimme an: "bá bie Suben aud) als orbentliche Profeijoren

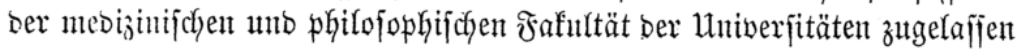
werben."

Minijter (Eich)horn: Die verefrliche Atbtheilung hat zuterit ben 3weifel

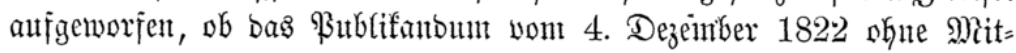

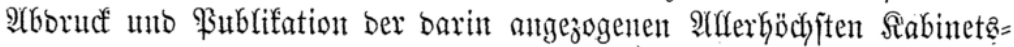

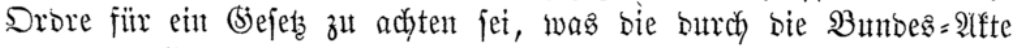

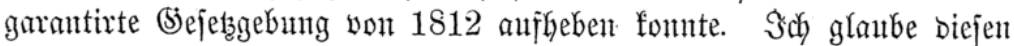

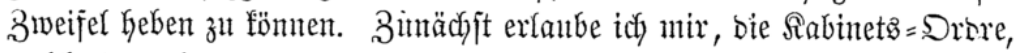
weldhe bantals ergangen ijt; borgulejent. Sie lautet wie folgt:

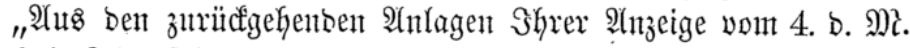

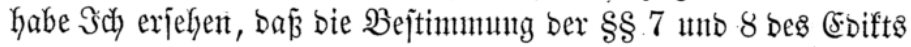
vom 11. März. 1812, nach twelcher bie für Snltäntber z̆l achtenton

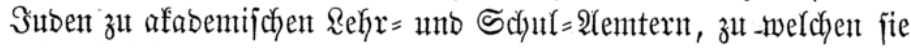

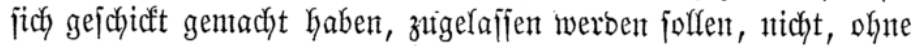

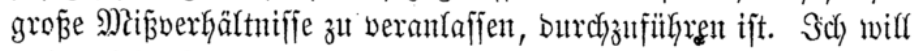

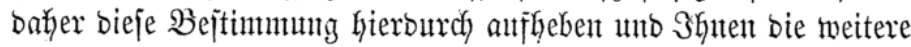

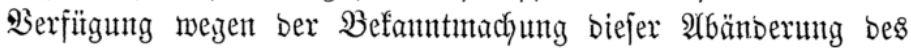
gebact)ten (biejeţes antheingeben.

Tepltis, ben 18. 2)

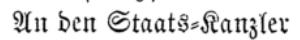

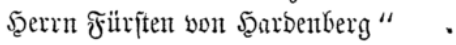

Der Fïnjt bon Şarbenberg hat mun folgenbez Sdyreiben an bag

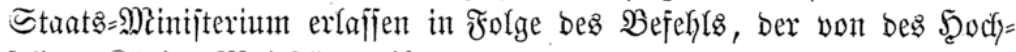
fetigen Sünigg Mlajejtät an ilyn ergangent war;

„Seine Majętät ber Sïnig haben burch bie unterm 18. Pugujt

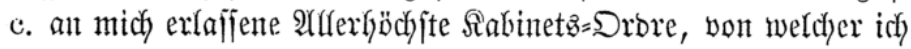
quo ad passum concernentem eine beglantbigte $2(6 j$ dyrift bier

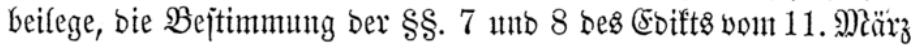
1812, wonady 3uben zut afabemifchen Rehr $=$ und Schut=2(emtern zugelaijen, werben, aufalkeben gerulgt, unto mix bie weitere $\mathfrak{B}$ er= fitgung wegent ber $\mathfrak{B}$ efauntmachung biefer 2 bänberung bes erwähn= tent Bjejetzes antheingereben.

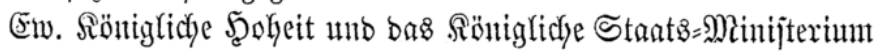


éritche idy. Giernach gehorfamit unt ganz ergebenjt, jene angeorb= nete Befanntmachung gefälligit zut berwirfen.

Berona, ben 19. Dftober 1822.

$\mathfrak{A}_{\mathfrak{n}}$

ein $\Re$ ïnigl. Staatßs=\$inifterium."

(gez.) wont Satroentberg.

Machbent bas Staats: Minifterium biejes Schreiben bez Staats=

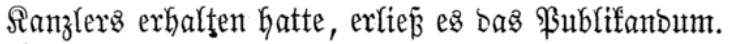

Die Sache liegt aljo jo: Se. Majejtät ber F̧odjeltge Röntig. Kaben

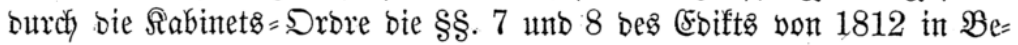

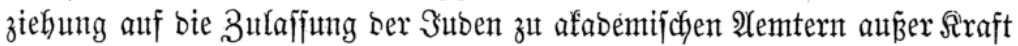

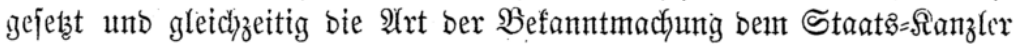
ïberlaffen. Der Staats= Sanzler hat bas Staats=\$Minifterium erjitcht, bic

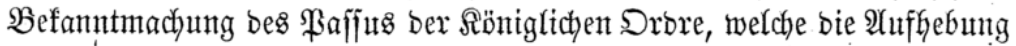

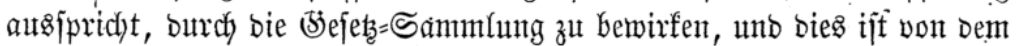
Staats= Minifferium geidjehen. Nun erlanbe ich mir zu erinnern an bie werichiebenen Forment ber ßublifation @öniglicher ßeroronungen in frühe= ren Beiten. Es giebt eine groß̉e Sammlung, welche unter bem Ramen

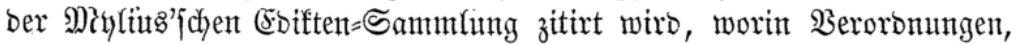
von bem $\Re \ddot{n} n i g$ ferbjt volfogen, enthalten jint, bann fint Berorbmungen, welche von einigen ober auty von mefreren Minijterien zujammen auf

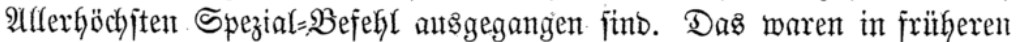

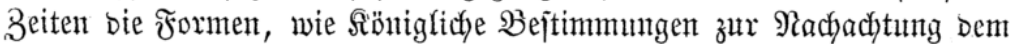
\$ublifun mitgetheilt murbent. Wejentlich war bie Äufnahme, wie man e\&

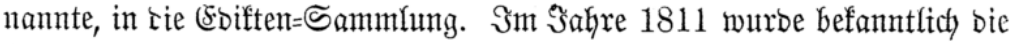

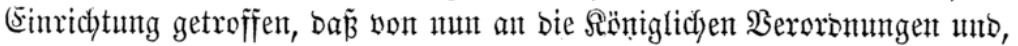

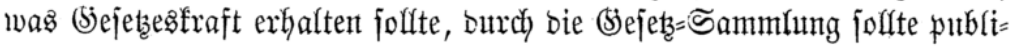
zirt werben; aber alth in ben erjten Beiten nady ber Exfdyeinumy ber (Bie=

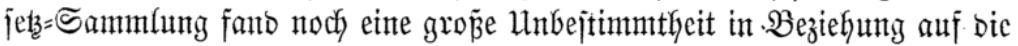

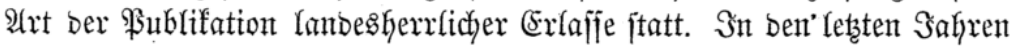
ijt bie Sache zum Biegenftant einer ausfühyrlichen ß̧erathung gemacht, uno auf (5rumb eines bon bem Staats = アiath erjtatteten (5itachtens ijt bas

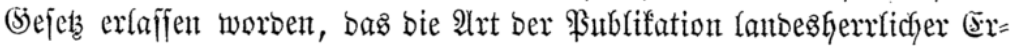
lajie für bie Buftnft fejt regelt. Nie hat man bezweifelt, baßs, was früher=

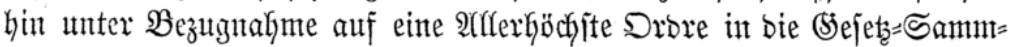

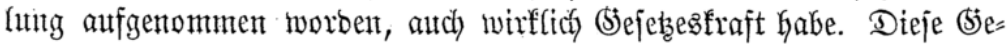

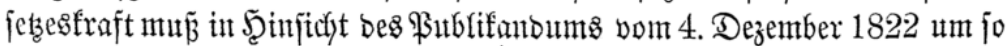

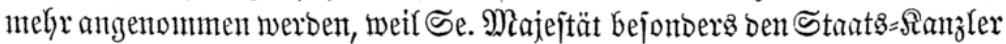
angenviejen hatten, wegen ber AYrt ber Befanntmadyung bie weiterent $\mathfrak{B} e r=$

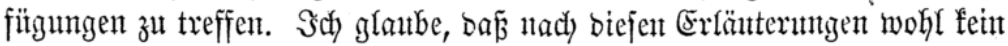




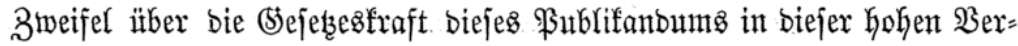
jammlunty jtattfintoen fantn.

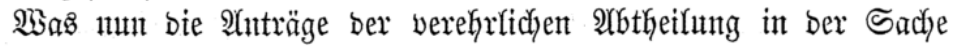
betrifft, fo möchte es fajt iiberflüffitg fein, itber bas $\mathfrak{W}$ ejen unferer Univer=

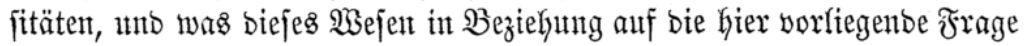

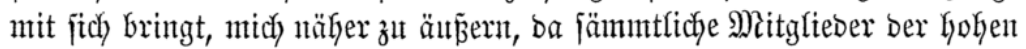
Berfanmulung unjre Untwerjitäten genau fennen uno bem größ̄eren Theile nach aud auf benfelben jtubirt haben. Sch glaube aber meiner bejonbern

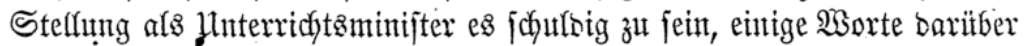

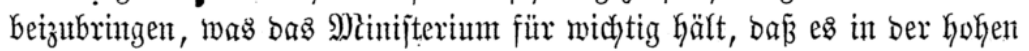
Berjanmlung nidyt ohne Beachting bleibe. Sch glaube unt jo mehr bazu verpfliçtet z̆t jeilt, als unjre Sönige bie Hniverfitäten bes Ranbes inmer

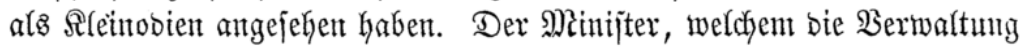

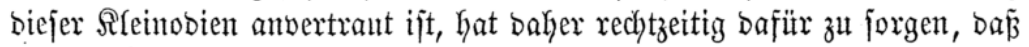

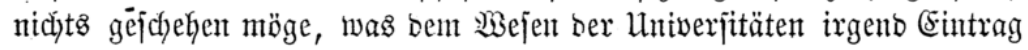
than fönnte.

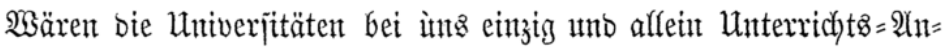
ftalten, fo witroe bie Frage, ob Suben zuzulaffen ober nicft, weniger

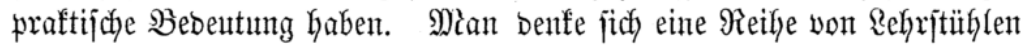
neben eitanber aggregirt, einen bejonbern Refritulgl für jebe bejonbre Dis=

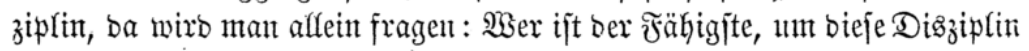
borzutragen? Das find (Sifaubenşachen. Freifid) wirb man audf benjeni= gen, ber bie Dişziplin ber chriftlid)en Dogmatif vortragen will, fragen:

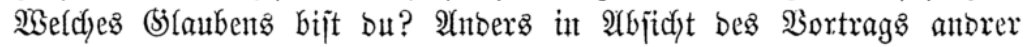

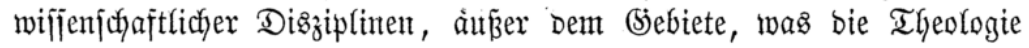
berithrt. Ese exiftiren in \$aris Refritizfle neben einanber; ba twäre es in

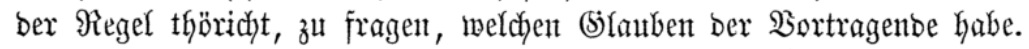

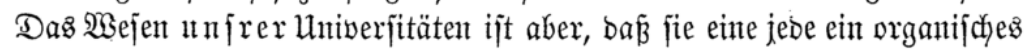

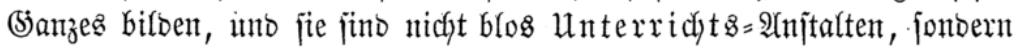

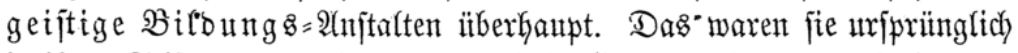

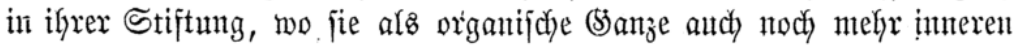

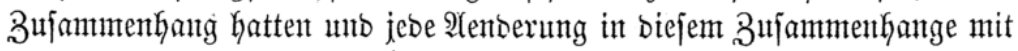

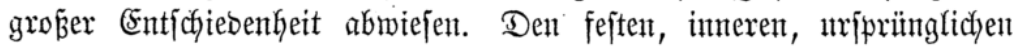
3ujammentang haben z. $\mathfrak{B}$. noch in England bie bortigen Univerjitätent,

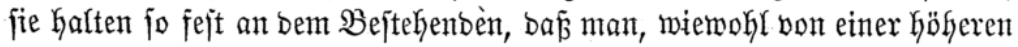

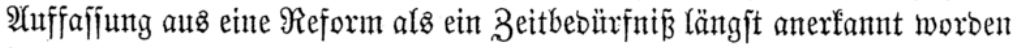
ift, bentod) groze Sdyeu getragen hat, eine Reform vorzınehmen. Der forporative $\mathfrak{B}$ ejtand unfrer Univerfitäten ijt im Raufe ber ßeit lax geworben, fie haben in Fulge veränberter Berkärtniffe uno Beobürfniffe felkit viełe Yenterungen erfahren, aber immer ift biejer (5harafter fejtge= 
Galtent worben unb wirb auth ferner fejtgehalten werben milfjen, ba organiface (\$anze uno nicft blos für ben Unterridyt, fonbern fitr bie Bifloung bez höherent geiftigent Rebens im Stanzen bejtimmt fint. Die

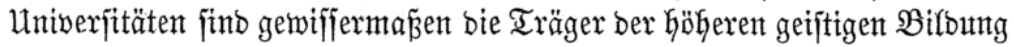
unjres $\mathfrak{B}$ olfees. Es: ijt barum autdy ben Univerjitäten bie Dizziplin anber= traut, in Beziefung auf bie Stubirenbent, ja nidft blos in Beziegung auf

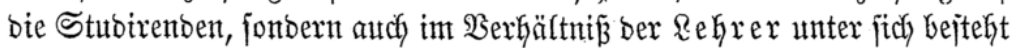

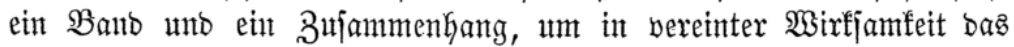
gefammte hökere geiftige Reben, burdh Bifbung ber Yugent an Tiefe und

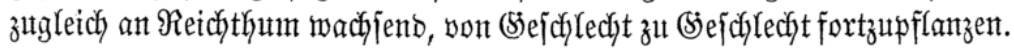
Wie aber jdyon in ben vergangenen Tagen ber Berathung bemerft worbent,

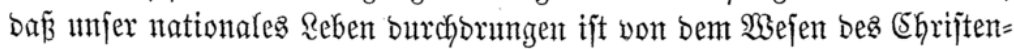

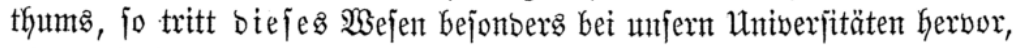

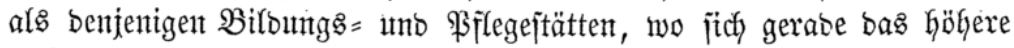

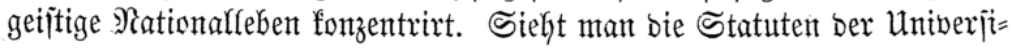
täten an, felbjt berjentigen Untwerjitätent, werdje gegrünbet jint nacty ber Reformation, fo nefment jie bis anf bie neutere Beit alfe Bez̧ug anf bas

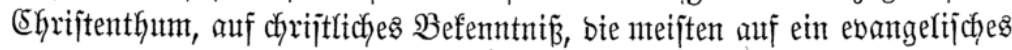

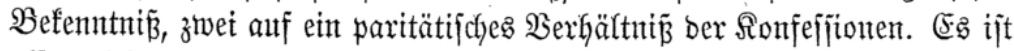

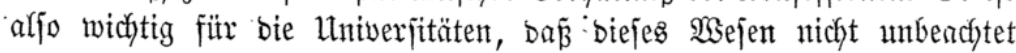

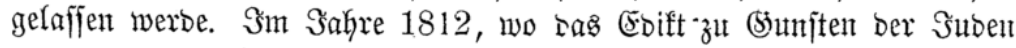

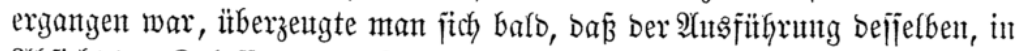

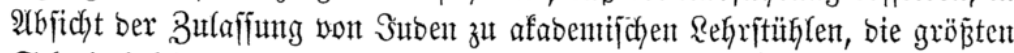

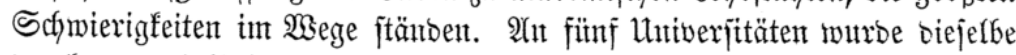
burch atsobrüffliche Bejtimmungen ser Statuten verhinbert. Merfwïr=

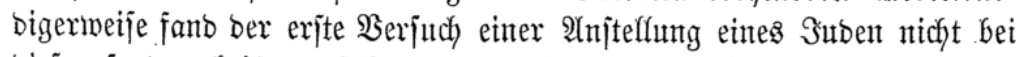

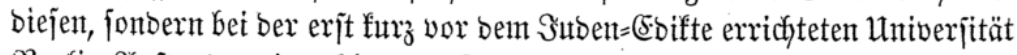
Berfin $\mathfrak{A n j}$ tand, wienohl beren Statuten über ihren refigiöjen $5 \mathfrak{G a r a f t e r}$ ichweigen. Man fragte gleich nach bem Exfyeinen bes Esifts, was bebeuten int bem $§ 8$ :

"Die Эuben fönnen afabemijche Rehr=2(emter, zu weldyen jie jid gefdicft gemadyt haben, werwalten", bie Worte:

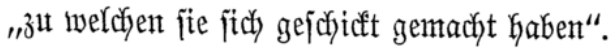

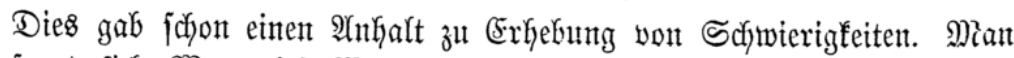

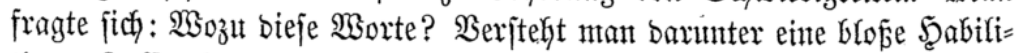
tirung? Es fant aber überfaut Nientanb angejtelft werben bei bent

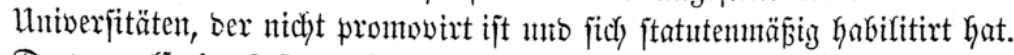

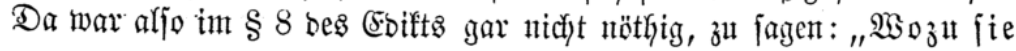




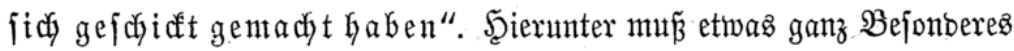
gemeint feint.

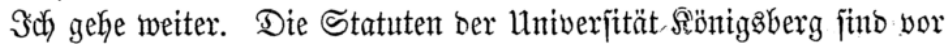
einigen Эahren revibirt worben. Der bortige Senat uno bie Fafultät wurben aufgeforbert, in $\mathfrak{b} e z u g$ auf bie 2 (bänberung biejer Statuten bie

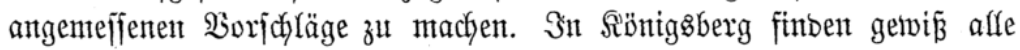

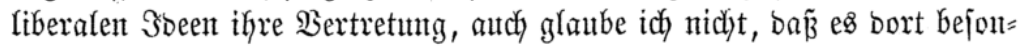
Dere Subenfeinbe giebt, unb bennody hat ber Senat ben aften Sharafter ber

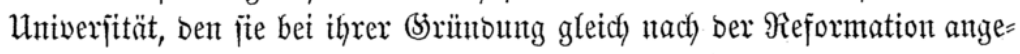

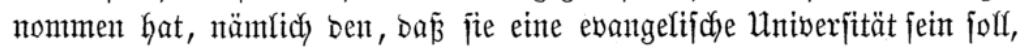

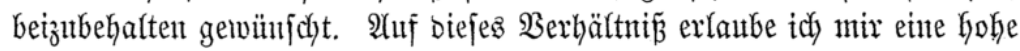
SBerfammlung nur aus Dent Bejicftöpunte aufmerfjam zu machen, um bie Ueberzengung zu genvinnen, $D a \tilde{B}$ Das Unterridyt $\mathrm{g}=$ Minijterium in jeiner

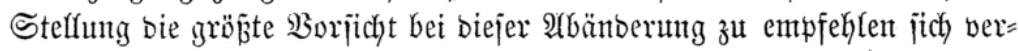

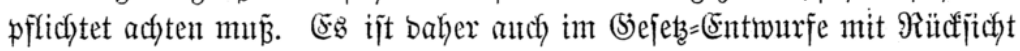
auf bie von bem Unterrichts = Minifterium vertretenen Mionente bie $3^{\mathfrak{H}=}$

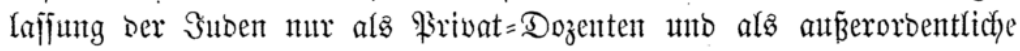

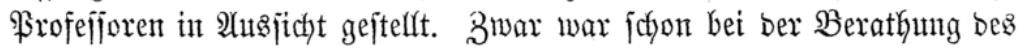
(5)ejetzes int Staats= Minitifterium bie Frage gejtelit, ob man bie Suben

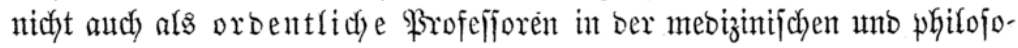

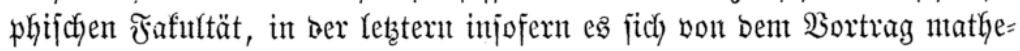

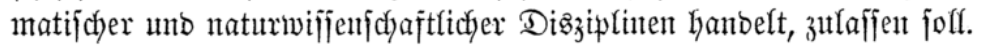

Mian erwieberte aber, went fie als orbentliche \$rofejioren in biejen

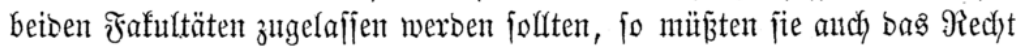
Gaben, an ben Senats= Siţungen Theil zu nehmen, fie mitß̈ten $\mathfrak{A}$ njpruch auf bas Defanat, ja autch barauf haben, Siroreftor zut werbent. Da über=

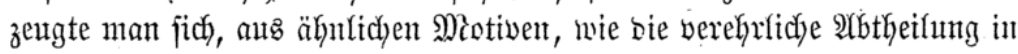

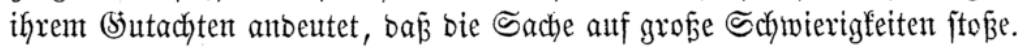
Man glaubte, bie antigebehnte 3ulafiuntg gleich wieber burch eine nente

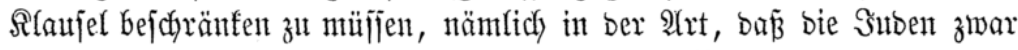

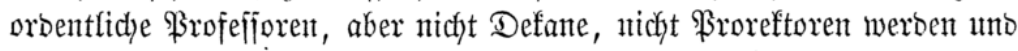

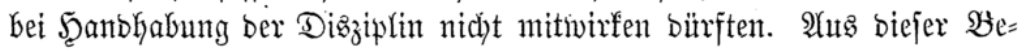
trachtung hat man fich samit begnïgt, in bem (S)efetzes=20 orichlage nur bie

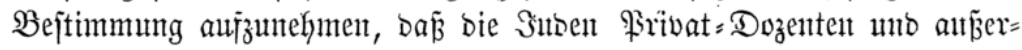
orbentliçe \$rofeffioren werben fömen.

Utebrigens freue ich midh, in bent (S)utachten ber verefyrlichen Arbthei=

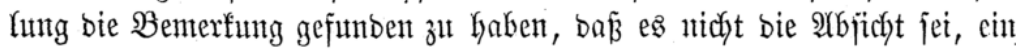
(Sejes anzurathen, in welchem gerabezut ein Strich burch bie Statuten

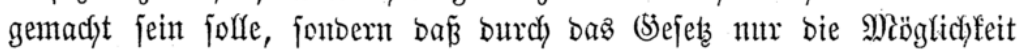
gegeben werben foll, infofern feitens ber Univerfitüten feine erkeblichen 


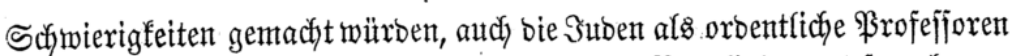

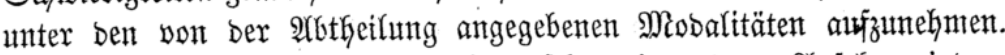
Daburch gewinnt bie Sache alferbings ichon ein anberes 2 Anjehen, inbem bie Bulfaffung bon einex zuftimmenden Mitwirfung. ber luniverjität felbjt, als Sorporation, abbängig gemacht mirb.

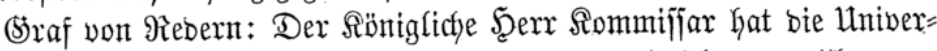
jitütent als Sleinobien bezeichntet, eine Bentennung, bie ich) nux vollfommen

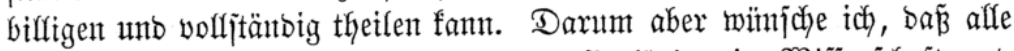

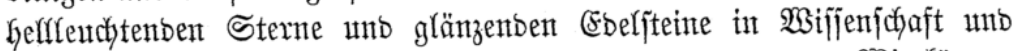

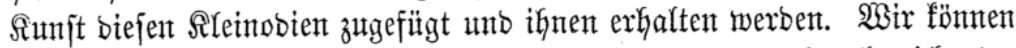

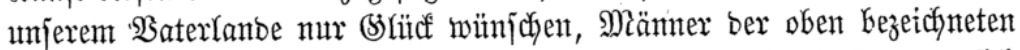

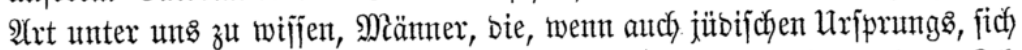

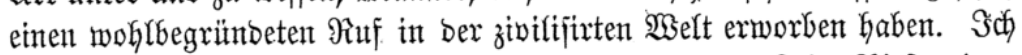

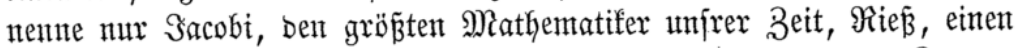
autzgezeidyneten \$hyjiffer, Metyerbeer und Menbelşohn, beren Rompo= fitionen weit über Guropa Ginaus extönen. Sn ben Familten ber Reţtge= nannten finben win in früherer Beit einen herborragenben \$̧Gilofophen, in neuerer Zeit B̉eifpiele ebler $\mathfrak{S o h y t h a ̈ t i g f e i t ~ u n b ~ h o h e r ~ S a t e r l a n b a l i e b e ~ i n ~}$

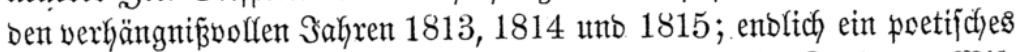

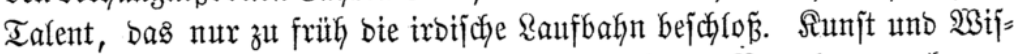
jenjchaft fennen nidyt bie engen (5)ä̈nen bes eignen 2 aterlanbes, łennen

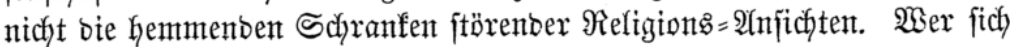

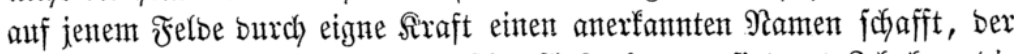
fann jidyer jein, ïberall eine günjtige $\mathfrak{A}$ ufnahme zut finten. Sch hege bie

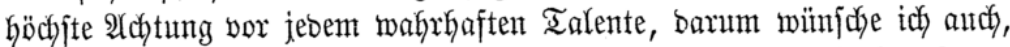

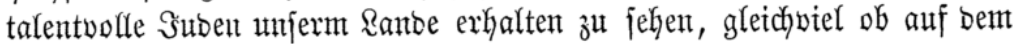
Ratheber, in ben ફ̧örjälen ber Untwerjitäten ober in ben ber Aunjt geweiften

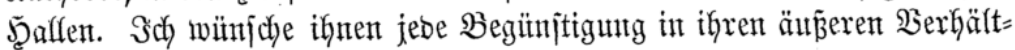
niffien und wollte baher meine Bitte an bie hohe Sinte riduten, jie möge

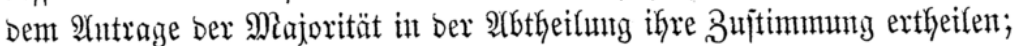

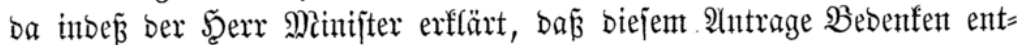
gegenjtändon, fo fann idy mur bie Bitte an ihn richten, bieje Bbebenfen nach

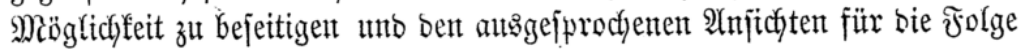
z̆t gentïgett.

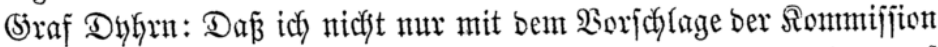
übereinftumme, fonbern über ben Sorjallag noch Ginangehen möchte, barf id) nach meiner gejtrigen âtitimum unt nach bem, was idf) geitern aus = gefprochen habe, wohl nidyt exjt befürmorten. Sch nehme mir bie Jreifheit,

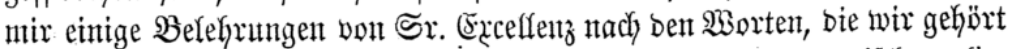

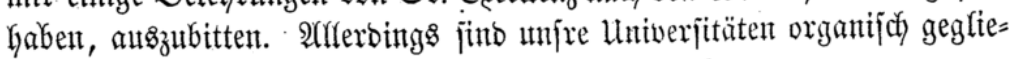




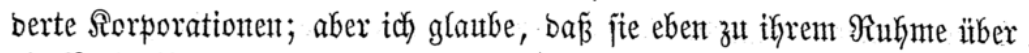
bie $\mathfrak{B} a j i$ ' Ginatsgegangen fint, alf ber jie int Mittelalter errichtet worben

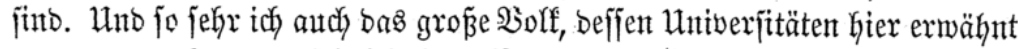

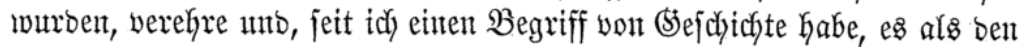
ältejten Sohn ber Freiheit immter verehrt habe, fo mut idy bod geitehen,

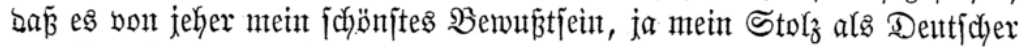

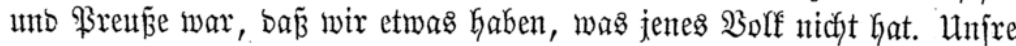
Univerjitäten itberragent nach meiner Âtrficht bie englijchen fo hody, wie mandhe anbre Eturichtung in Englant vielleidyt unfre Eintridtung überragt.

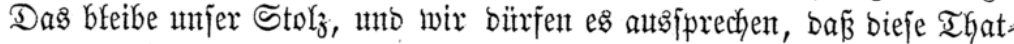
fache ber (stunt ijt, warum man bei feinem anbern $\mathfrak{B}$ olfe jo viele wahithaft gebilbete Mienjchen finbet, als bei uns. Sch fage: Menjichen; benn es fann jehr viele gebilbete Engländer, Franzofent, Deutjche geben, aber bie

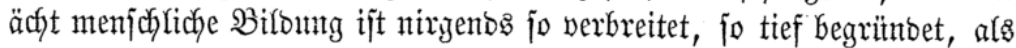
in Deattjchlant. Und wem verbanfen wir bag? Meine Seerren! Das ver=

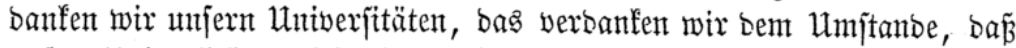
unjere Uniberjitäten nicht ein fo alfgenteines Ranbesinjtitut getworbent finto,

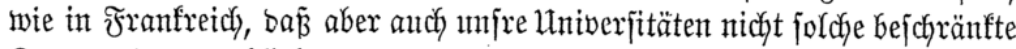

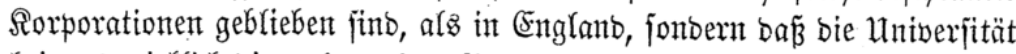
bei unt wirffich bie universitas literarum gemorben ijt. Das ijt umjer

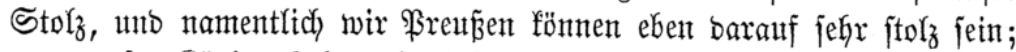

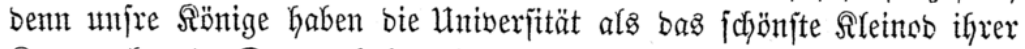
Srone erfannt. Darum habent jie fich eben biefes gebilbete $\mathfrak{B}_{0}$ lf erzogen; Se. Majejtät felbit hat bie Freube uno ben Stolz, ber SBeherricher bieje:

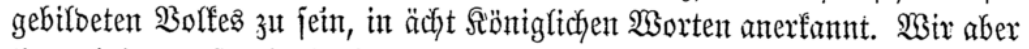

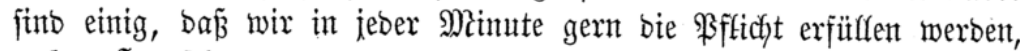
unjern Şerrichern zut zeigen, baf jie nidyt umjonjt Gahrhumberte lang bieje

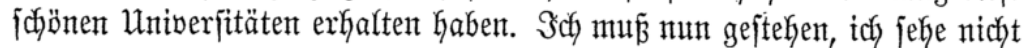

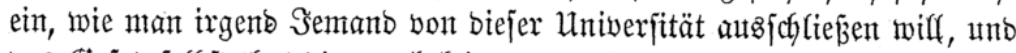

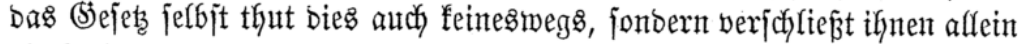

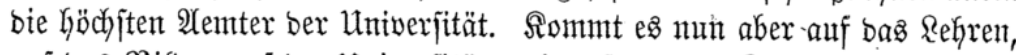
auf bas $\mathfrak{B i} i$ bent anf ber Utniverjitüt, wie gejagt werbèn ijt, befonbers an, fo, glaube ich, fann eit \$rivatbozent eben jo viel wirfen ober, wenn Sie lieber wolfen, eben fo viel jufaben als ein Professor ordinarius: $\Im(f)$ habe in meiner vierjährigen Stubienzeit hier in Berlin ben Saal mand Professoris ordinarii leer gejehen, und ich habe bent Saal bes eben zum (5hriftenthum übergetretenen Priwatoozenten \$ans nie- Yeer, fonbern gewöhn=

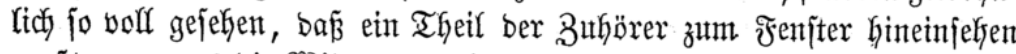

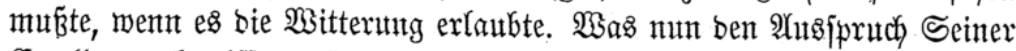
Frcellenz anbetrifft, bá 
YYemter bes Reftorats und Defanats verjajlöfie, und er fie barum gar

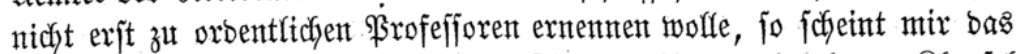

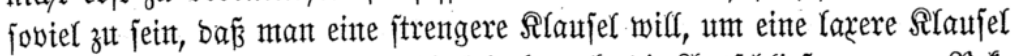
auģuf

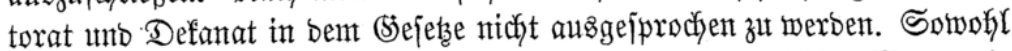
ber $\Re$ eftor als ber Defan werben von bem Sentate getwählt. Went wir itum auth ben Suben bie Beredytigung geben, orbentliche ßrofefiforen zu werben, fo hängt es nody immer bon ifyren Solfegen ab, ob fie Defane, ob

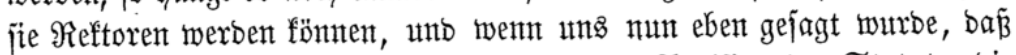

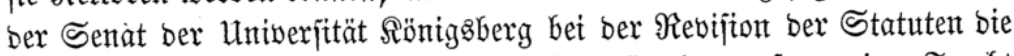

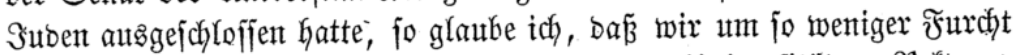

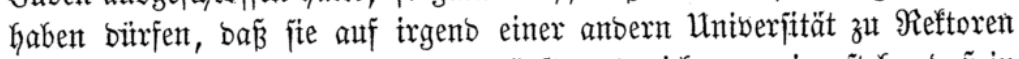
voer in ben Sentat getwählt werben bürften, ba ich gern eingejtehe, bã in

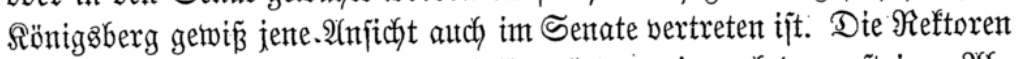
Gabent ïbrigens ęrefittive (semalt, 'aljo mitroen wir nach ber geftrigent $\mathfrak{A l b}_{b}=$

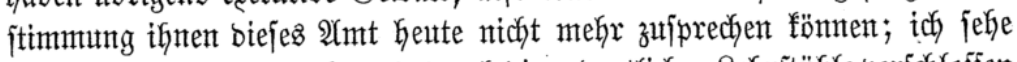

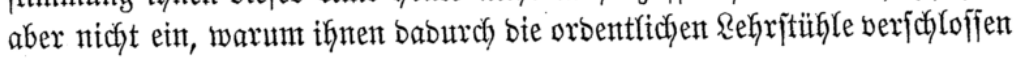
jein jolfent.

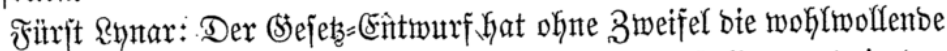

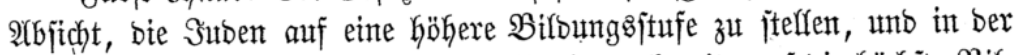

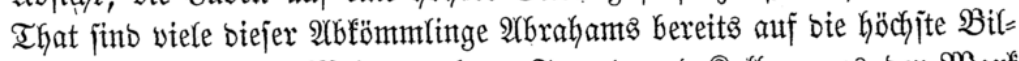
bungsitufe getretent. Mein verehrter Freutto unt Solfege aut ber Marf

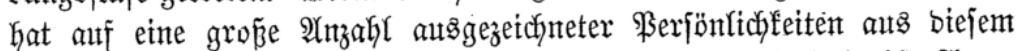

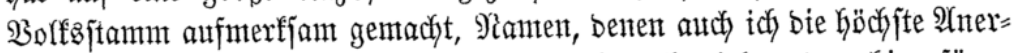

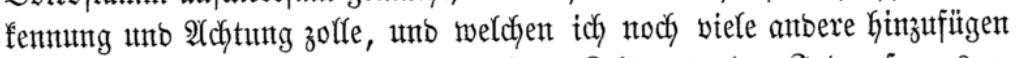

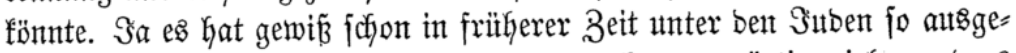
zetchntete Miänner gegebent, es giebt beren noch gegentuärtig viele, uno ę

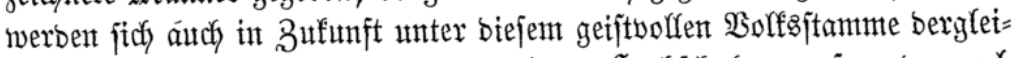
dyent finben, welche bie Zierbe einter jeben Şodjichute gewejen ober nod)

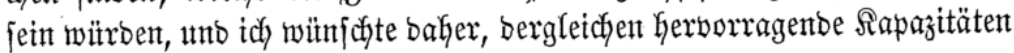
für bie Sifijenjchaft zu geminnen.

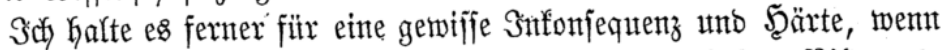
mant einerjeits 2

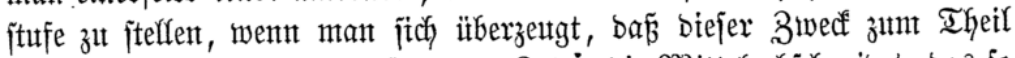

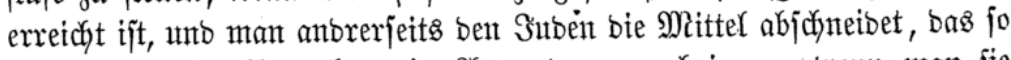

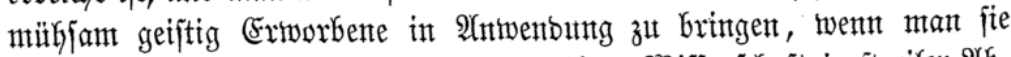

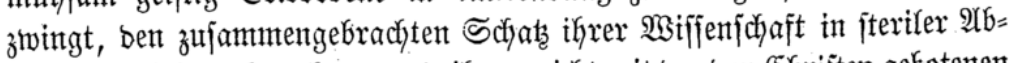

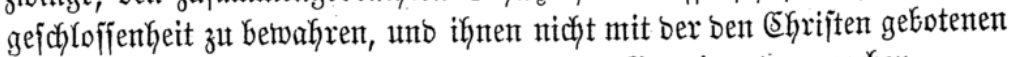

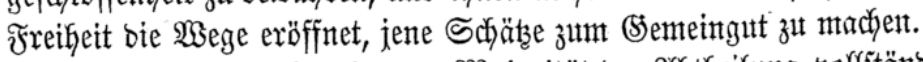

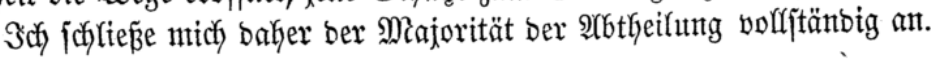




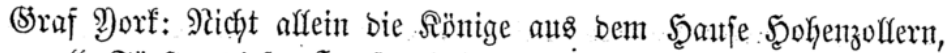
jonbern alle Fürjten biejes Şanjes Gaben von jeher mit Gohem Sinne bie

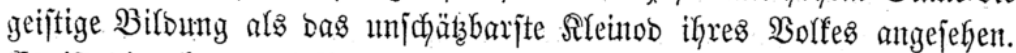

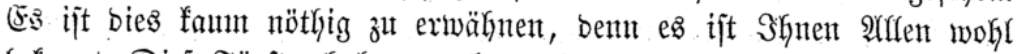
befannt. Dieje F̈̈rrjten haben co aber auf bie geiftige, nicht alfein geiftliche

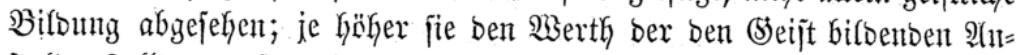
italten jtellten, bejto geiftig freier wursen fie Gintgejtelll. Wenn nun ber

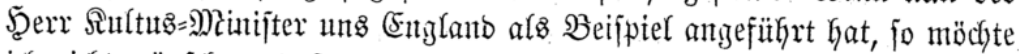

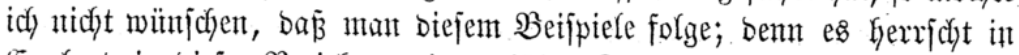

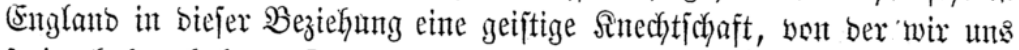
irei gehalten haben. Das liegt, meines Exadjtens, Darin, dá̉ man bie Univerjitäten bon ber Goken Stufe, bie jie einnehmen folfen, Kerabgejetżt

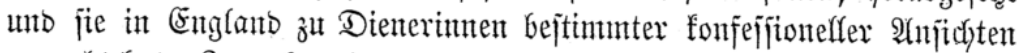
gemadyt hat. Se mehr wir biejen Boben eintehmen, bejto mehr wirb ber

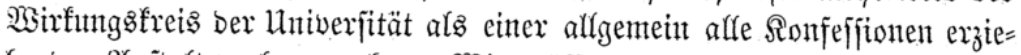

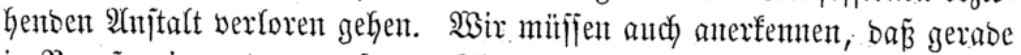
in \$renten im entgegengejetztent Simne gehantbelt morben ift. Sch erlaubc mir bas ßBeijpiel anzufïfyren, beffen idy bei ber Berathung biejes (S)egent=

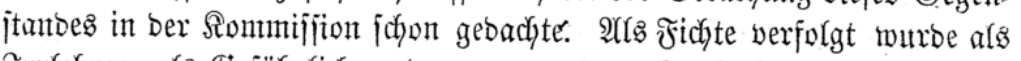

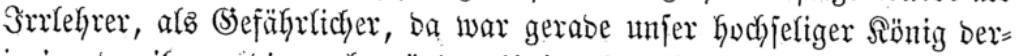

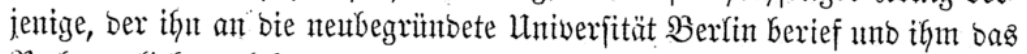

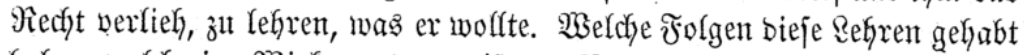

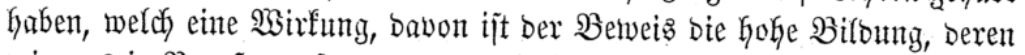

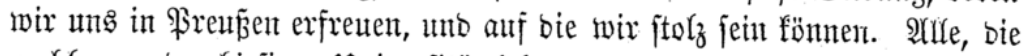
nadhfer-aut ber Giefigen Univerjität Yehrten, alle berithnten ?amen, Scegel

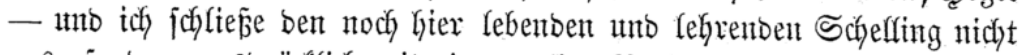

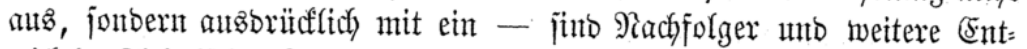

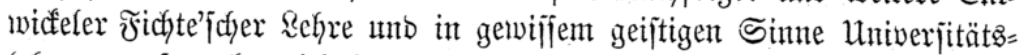
legrer genejen, aber nicht in bem Simne, wie in Gnglanb, wo bie Uniwerjität

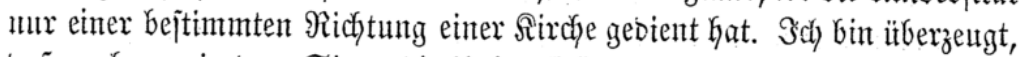

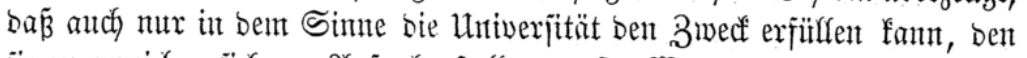

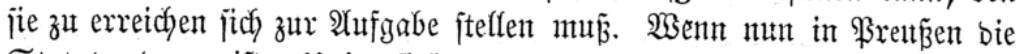
Statuten ber meijten Uniwerjitäten, trots ber von mir für jie bintizirten geijtigen Freiheit, bem entgegenjtehent, jo hat bies feinten wahren (Stunto

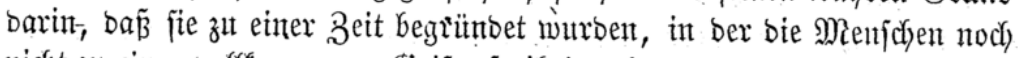

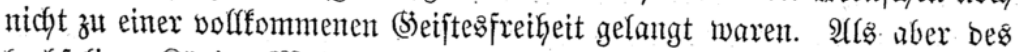

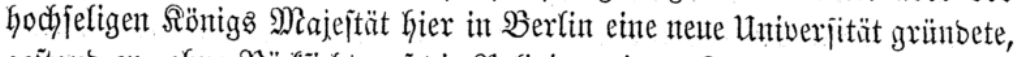

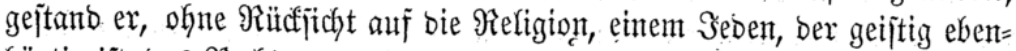

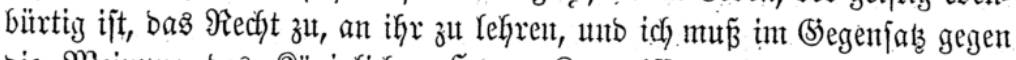

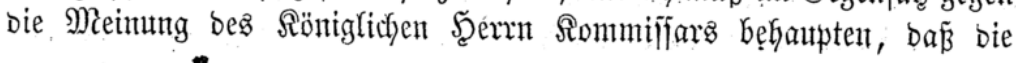




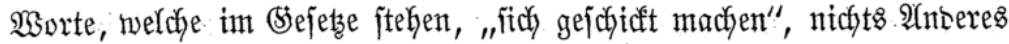

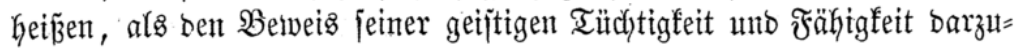

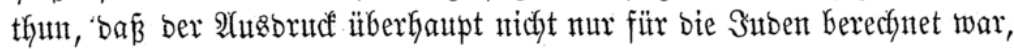

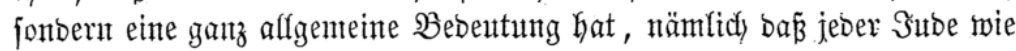

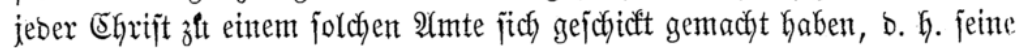

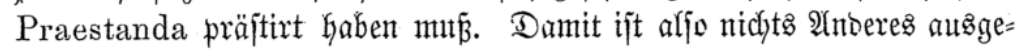

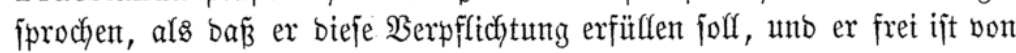

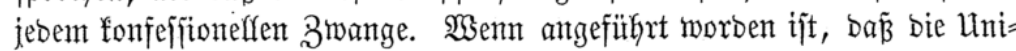
verjität ein organifches (Sanze fein joll, fo gebe ich bies gern uno vollftänbig

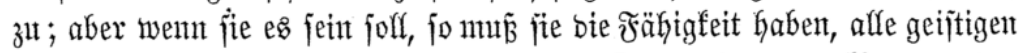

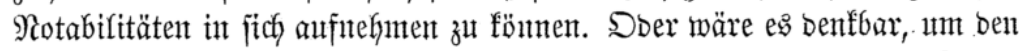

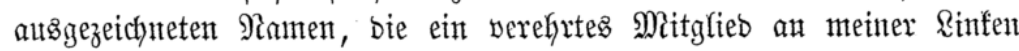

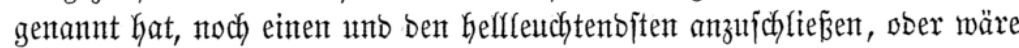

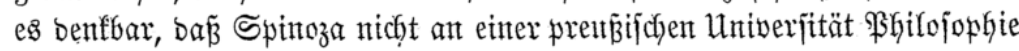

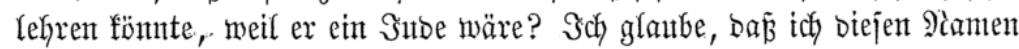

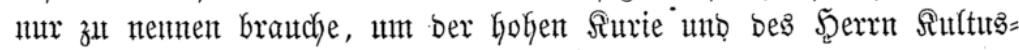

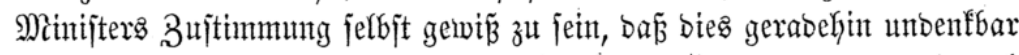
wäre. Dieje Univerjität, bie nach ber $\mathfrak{2}$ njicht bes (5ounernements und nad) meiner eigenen ein organijabes (sanze. jein jolf, mur auch bie Fä̆higfeit haben, in fich ein Reben zut entwiffeetn, umb bamit jie bieje habe, mur jie nitugt äน

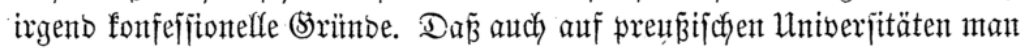

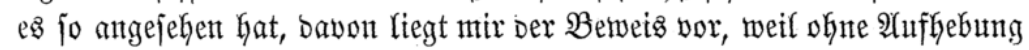

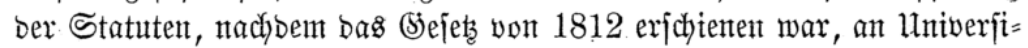
täten, bie nicht bon bemt dyriftlichen Befenntnifje abjtrafitren, wie bie Giefige,

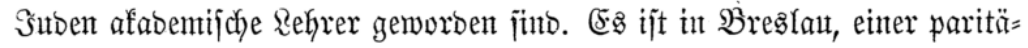
tifchen Untiverjität, ber Frall zweimal, wenn idf) nicht irre, jogar breimal vorgefommen. Zwet biejer Regrer find, wenn ich nicht irre, fpäter zum (5hriftentfum ïbergetretent. Der britte, ein nody in Breslan Yebenber ange=

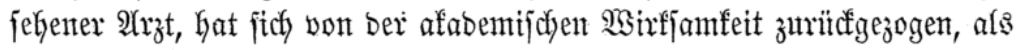

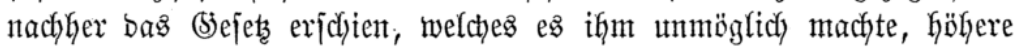

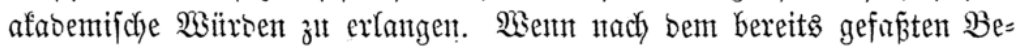

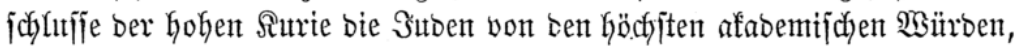

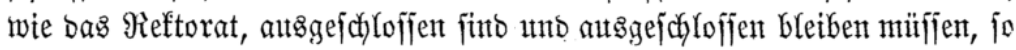

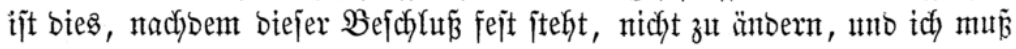
bies anerfenten, fo jehr ich es bebaltere.

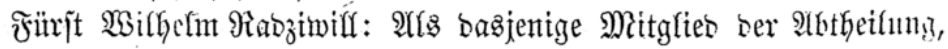

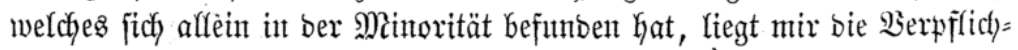

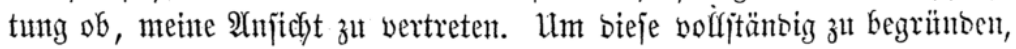

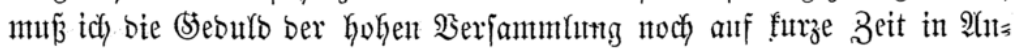


forud nefynen und furz anf bie geftrige Debatte zurürdfonmen, infoweit

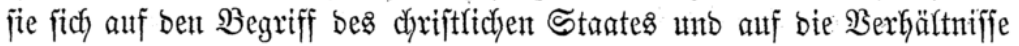
jwifdyen Staat unt Sirdje, bie gejtern berïlgrt worben fint, bezieft. Sch wifl mich nidyt auf eine theoretifye (Entwicfelung biejer Soee eintaffen, man

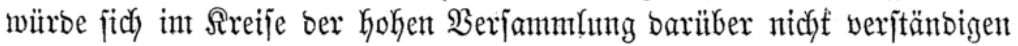
fönten. Sch wifl bieje Soee mutr infofern berïhrent, als fie fich auf bie hier

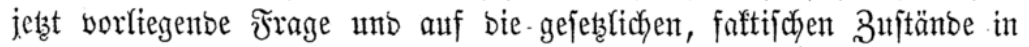

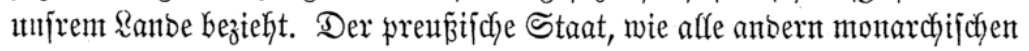
Stanten in Deutjoylant, berulgt nody auf ber alten aus bent bentichen

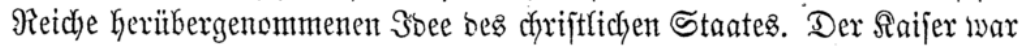
erjtents Schirmboigt ber Sirche, unb zweitens hatte er bas dominium mundi, bie oberjte weltliche (Stewalt. Diejer Begriff ber Soutveränetät

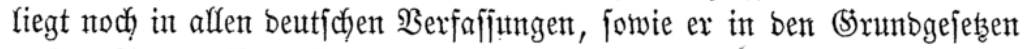

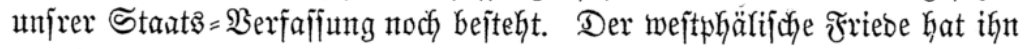

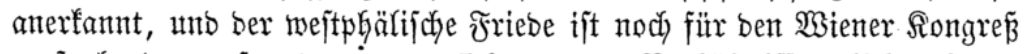

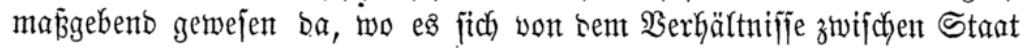
unb Sirche gehanbelt hat. Alus biejem Begriffe, jo jehr er aud in ben

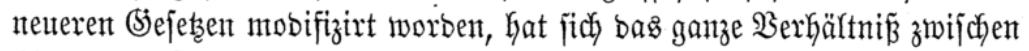
Staat und Sirche entwidfelt. Sommt mun in unjerem Staat noch bie Drga=.

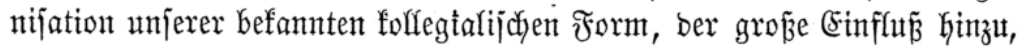
ben mit biejer Form bie inbivibuefle Mleinung Gaben twirb, fo. liegt barin und in ber Schutspflidyt, bie ber Staat gegen bie Sirche übernommen hat,

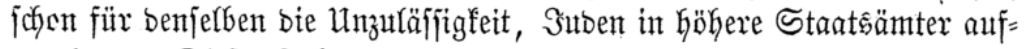
zunehmen. Diejes Faftum ijt gejtern burch bas $\mathfrak{B}$ otum ber fioken Surie anerfannt worben, es mü̈̈te eine völlige Trentung von Sirche unb Staat erfolgen, weun bem entgegen gehanbelt werben fönnte, neben biejer Irent= mung mü̧̈te ber ganze (Seijt unjrez Beamtenthums, jeine ganze Drganija=

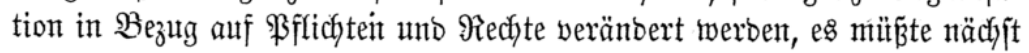
ber. Trenmung von Strat und Sirche bie franzöjif dye Minifterial = und Bräfeften = simrichtung, eine ftrenge Scierarchie ant Unteroronung bes

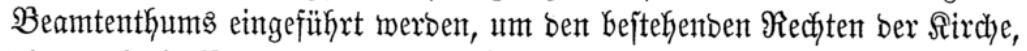
bie burch bie Beamten bes Staates vertreten wirb, nidyt zut nabe treten. Nurr nach einer foldhen Trennung fömte einte völfige Emanzipation ber

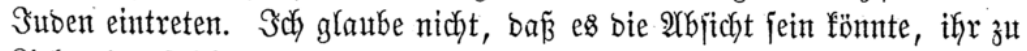

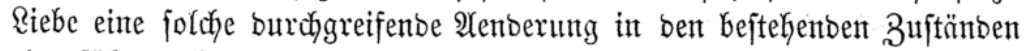

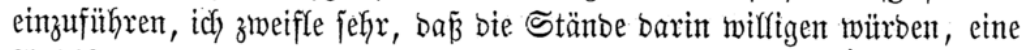

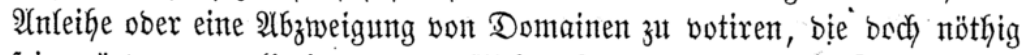
fein mürbe, um alfe in bem preusijichen Staate anerfannten Sirchen bolf = ftänoig zu botiren, eine Dotation, bie erfolgen mil̈ß̄te, wenn eine volfytänoige Trenumg zwifdsen Sirche uno Stant ftattfinden follte. Sn Franfreids), 


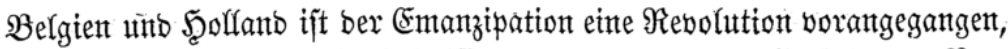

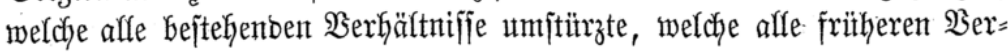

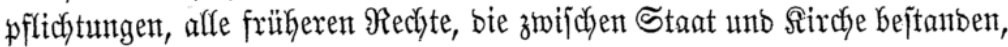
auflöjte. $\mathscr{A}$ itf eine jolche tabula rasa fonnte in Franfreich, wie in Belgien uno 5̧offano, bie Emanzipation ber jeşt bejtehenden Berfafjungen uno in

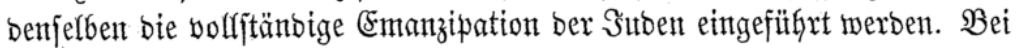
unz soäre jie nicht butrdzufïhren, ofne bie mejentlichjten Theile bes bejtehen= ben Staatoredyts zut veränbern. Diefes Staatzrecht, bie in Folge beffelfen bejtekente Schutspflicht bes Staates gegen bie anerfannten Rirchen, fommt mun bet ber Drganifation ber Rehranitalten wejentfich zur Spradje. Scl

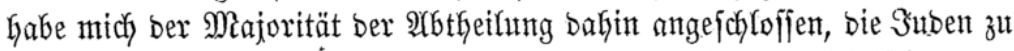

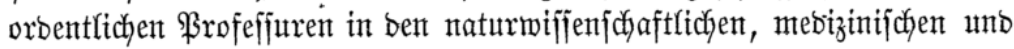
mathematifchen Rehriächern zuzulaffen; ich habe mich aber gleichzettig

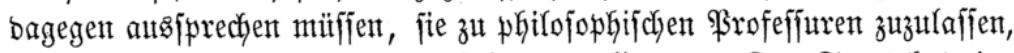
unt ich ftelfe biefen 9 intrag aus folgenbem Sirumbe. Der Staat hat eine Univerfität zat $\mathfrak{B e r}$ (in, burdy beren Statut nidyt bejtimmt ift, weldyem

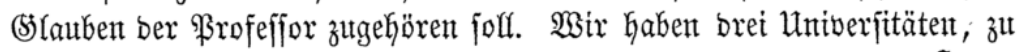

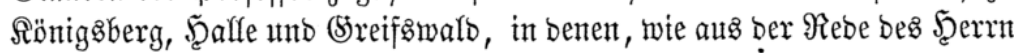

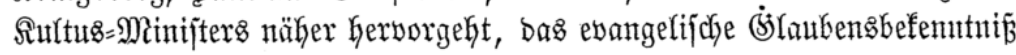
eine Bebingung für bie Bulajjung zur ßrofeffur ift.

Db für bie èbangefijchen Univerjitäten ber Staat geneigt jein möchte,

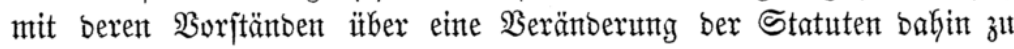

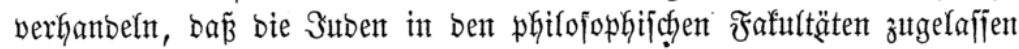

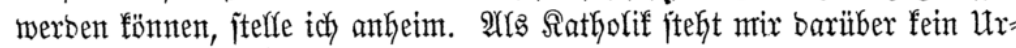
theil zut. Wir haben zwei paritätijche Ulniverjitäten, Bonn unt $\mathfrak{B} r e \mathfrak{l}$ ant, bie ant ber Stelle von brei aufgehobenten, rein fatholifduen Rehramitalten gegrïnbet finto; bieje finto zutm Theil mit beren $\mathfrak{B}$ ermögen botirt unt funbirt

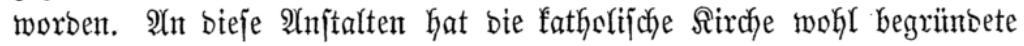

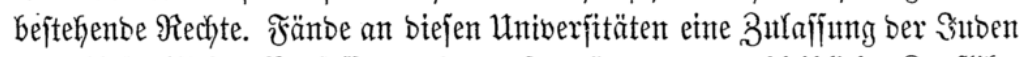

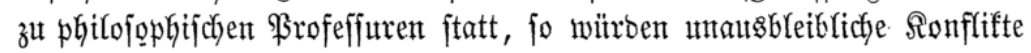

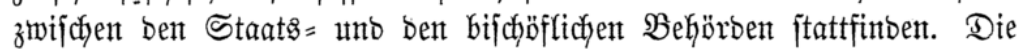

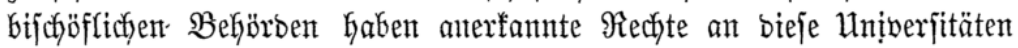
uno witrben, went philojophifiche Profefiftren an benfelben ben Suben

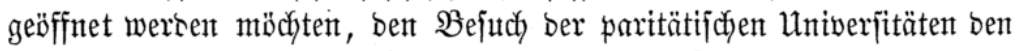
fatholijchen Stubiofen ber Theologie unterjagen. Die nädyjte Folge bavon witrbe feilt, baß̧ fie rechtlich an ben Staat bie Forbernng mürben fteffen

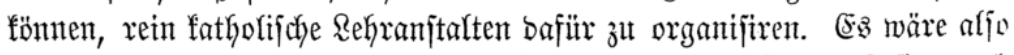

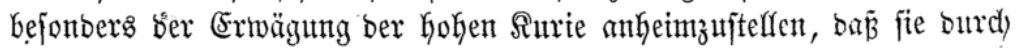

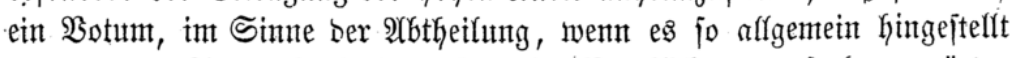
witrbe, bem Staate in Folge beffen eine $\mathfrak{B}$ expflichtung auferlegent würbe, 


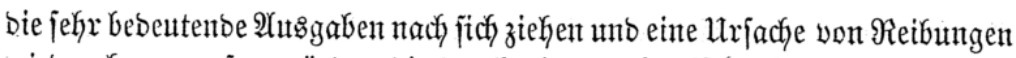
wieber Gervorrufen witrbe, bie burdh bie geredyte Beriuffichtigung ber be=

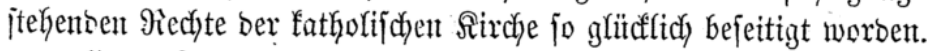

(5raf Botho zut Stolberg: 33 ir haben vorfin won einem verehrten Mnitgliebe alts Sdylejien fehr itberzengento barfteffen hören, auf weldyem

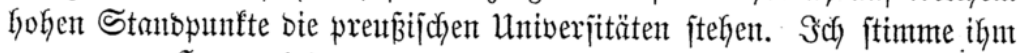

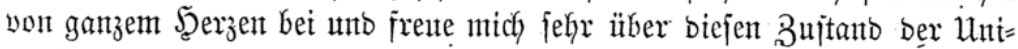
verjitäten; ich frage aber, auf welcher (strundage berutht eben ber brïhenbe

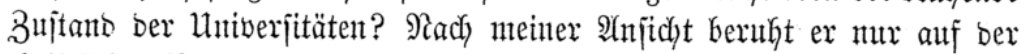
chriftlichen Bifloung unt (Sejittunty, bie alles bies hervorgebracht hat. Sch

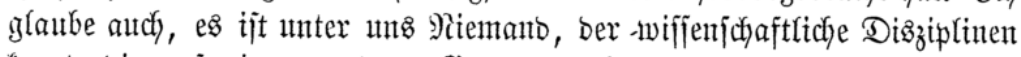
fennt, bie auf einemt anbern Srumbe in jeţiger Deit beruften unb zu

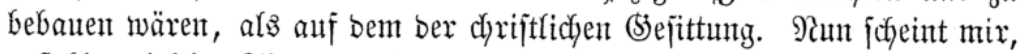

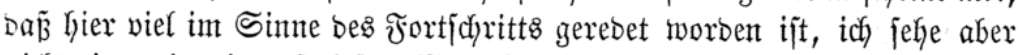
nicht ein, wie wir auf biejem 2 ege Fortjdyritte madyen, wenn noch andre

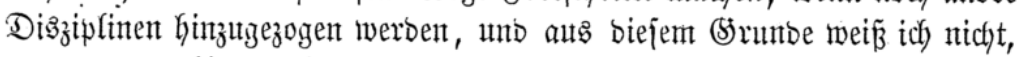
warunt man hier noch bejontors bie jübifichen $\mathfrak{B} e f e n t e r$ Ginzuziegen foff.

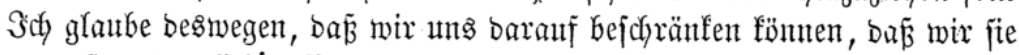

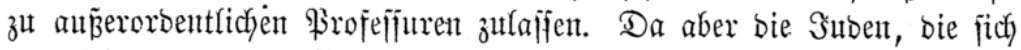
atszeichnen, meitter Mleinung nach, fich immer auth bann auzzeidynen,

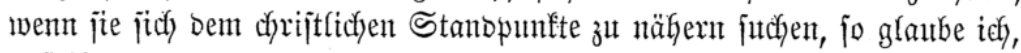

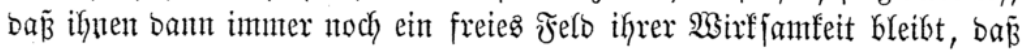
wir aber nicht weiter zu gehen brautchent.

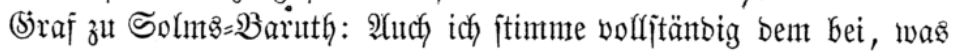

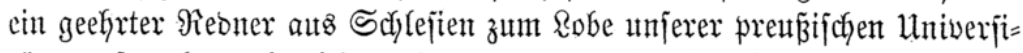
täten gejagt hat; aber idh mache gerabe barauf aufmerffam, baj bieje unt=

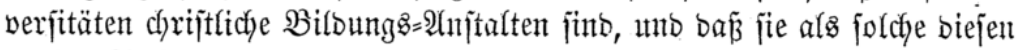

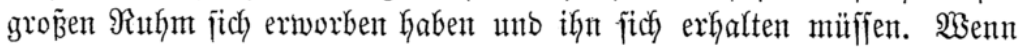

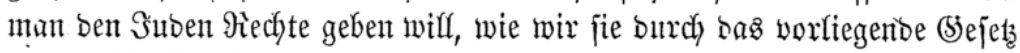

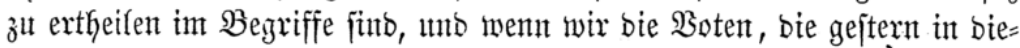

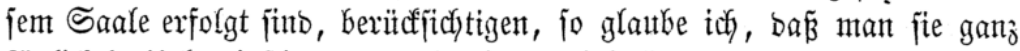
fïglich in Uebereinjtimmung mit biejem chriftlichen Funbamente, welches

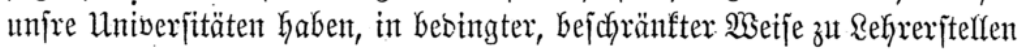
an benjelben zulafijen fann, weldhe ihnent eine Theilnahme an ber alfgentei=

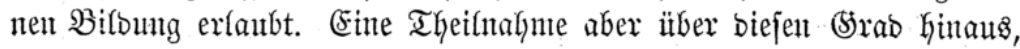
bie, glaube ich, fann man ifhent nicht einräumen, wenn man nicht gerabc

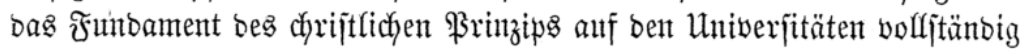
verändern rivill. Dem jtehen mehrfache, jehr begrünbete Schnierigfeiten

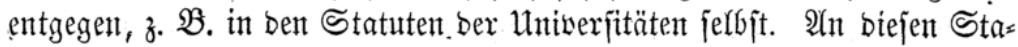
țteten hat man nach jorgfältiger Früfung in ber PYTbtheiluntg geglaubt, 
Durchaus nicht rütteln zut bürfen. Ebenjo hat ber Exfolg, ben bisher bie Untiverjitäten gehabt haben, bie AYbtheitlung bahin geführt, gerabe bei ben

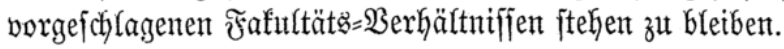

-29lı biejem Srumbe möcfte ich ber hohen Berjammtlung anrathen, fich)

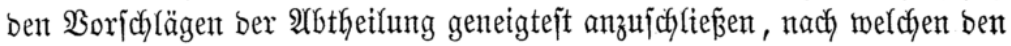

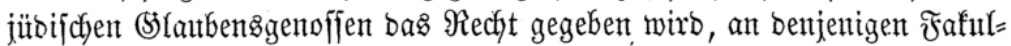

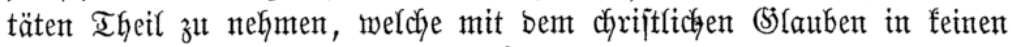

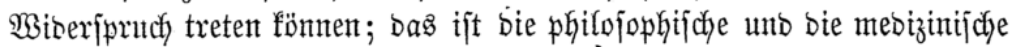

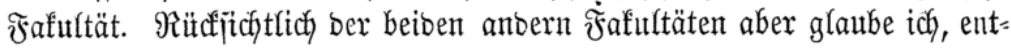

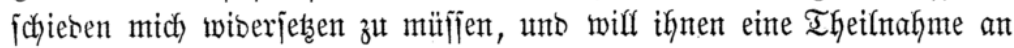

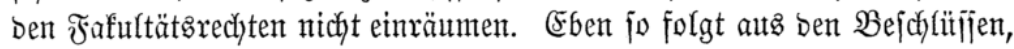

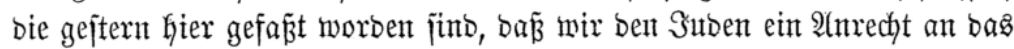

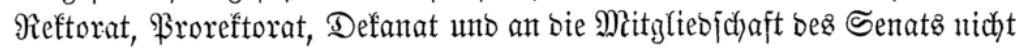
zutgeitehen bürfen, weil biejen Funftionen gewiffe Bsewalten anbängen,

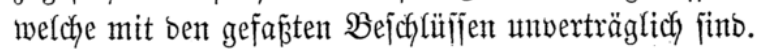

(5) raf zu Dokna=Rauf: Âtuch ich bin jothon lange ber Meinung gemejen,

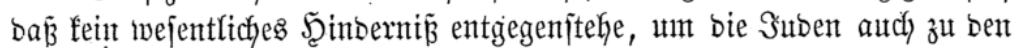

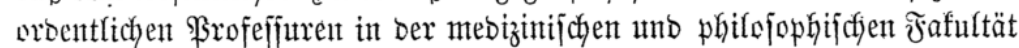

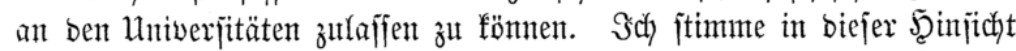

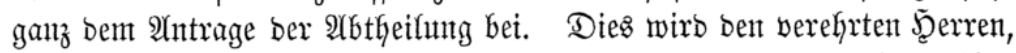

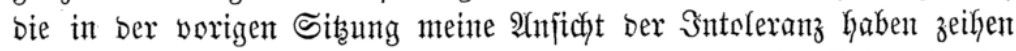

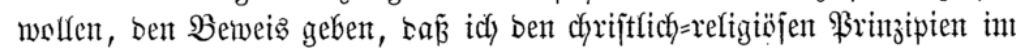

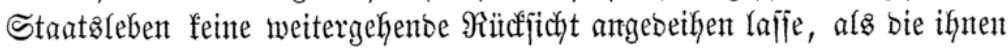

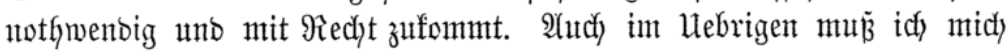

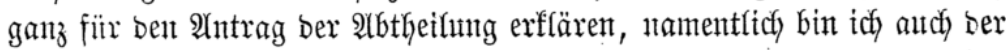

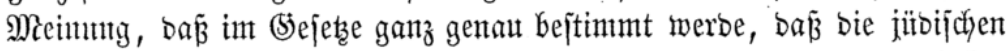

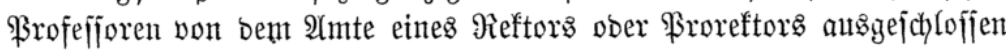
bleibent. Sch mb̈chte nicht wie mein geehrter Freutb ants Schlejien jagen,

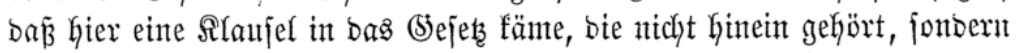

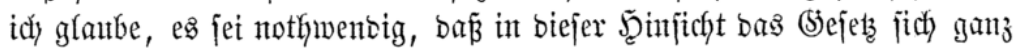

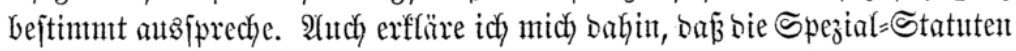

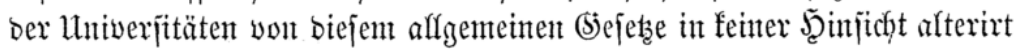

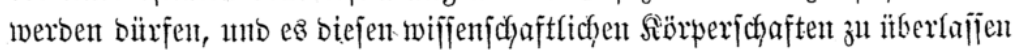

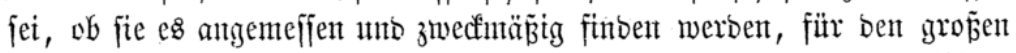

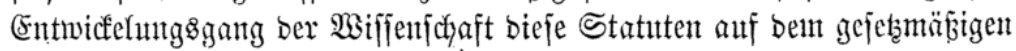

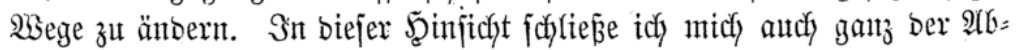
theilunty ant.

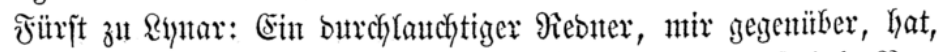

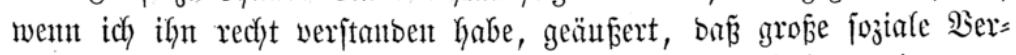

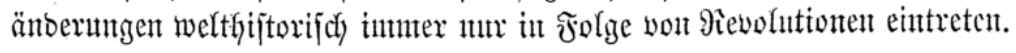




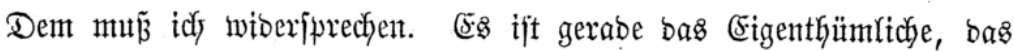

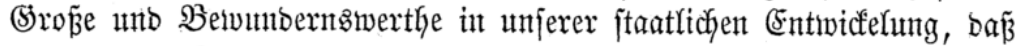
bie burch bie 3eit gebotenten Beränberungen bei unz nidft auf bent jturn=

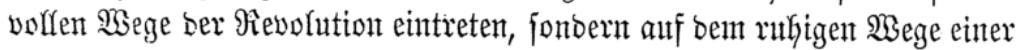

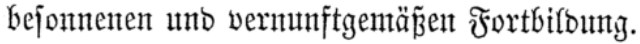

Feint affer Exidjittterungen, wollent wir fïx affe Beitent burch bieje

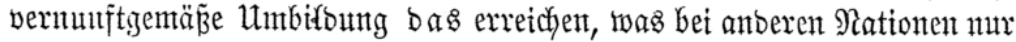

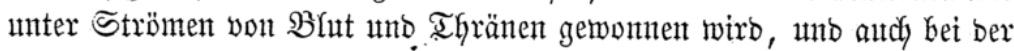
vorliegentoen $\mathfrak{B e r a n l a f j u n g ~ w e r b e n ~ w i x ~ a n e r f a n n t e ~ H e b e l i ̈ t a ̈ n t o ~ b u r c h ~ e i n e ~}$

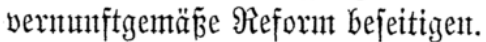

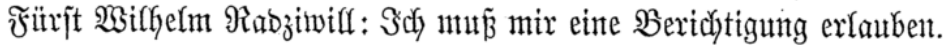

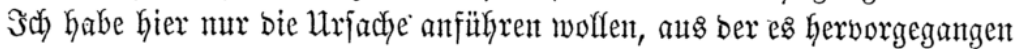

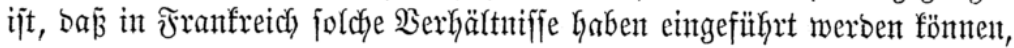
wie, fie bei mts praftijch noch nicht möglich fint, weil eben bet unts noch)

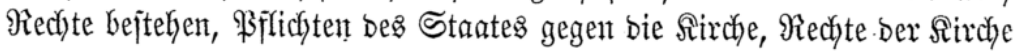
int Staate, bie tangirt werbent witrben, went wir ben Suben bie antsge=

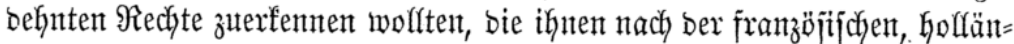

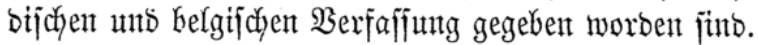

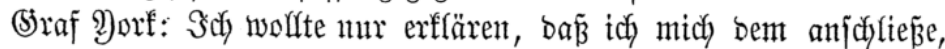

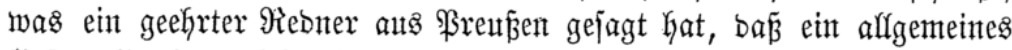
Siejeł alferbings nicht bie Statutent ber einzelnten Mniverjitäten aufGebent fant, und baj mạn vont biejen $\mathfrak{B}$ thoung

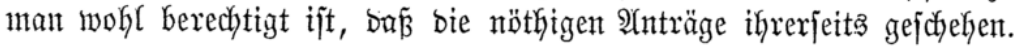

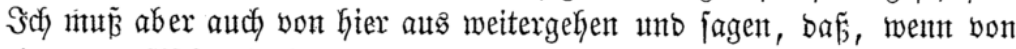

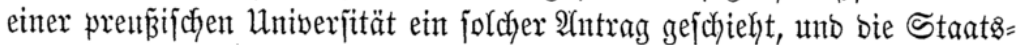
regierung barauf eingugehent für gut eracfstet, mir es bann böllig richtig

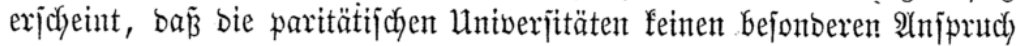

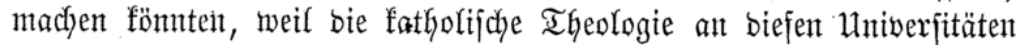
auch gelehrt wirb. Fis ift bann nutr bie Forberung zu fteffen, bie ald int

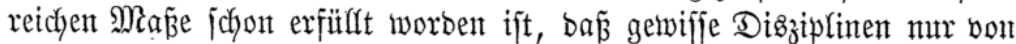

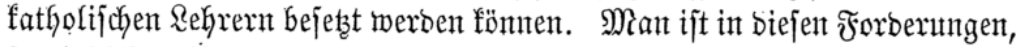

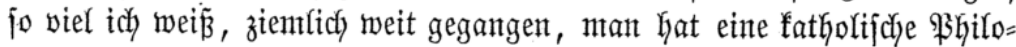
fophie, eine fatfoliffje stejchichte verlangt, unto, fowiel mir befannt, ijt bas (Souvernement auf affe biefe Forberungen eingegangen unb hat befonbere

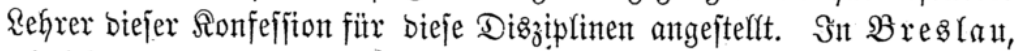

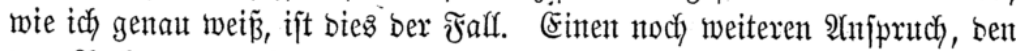

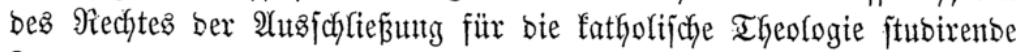

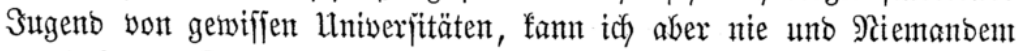
zugejteken. Dies wollte ich mir nody, anjdyliejento an bas, was ber

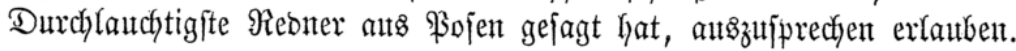




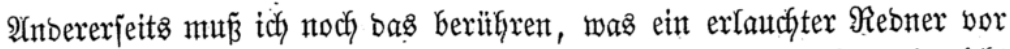

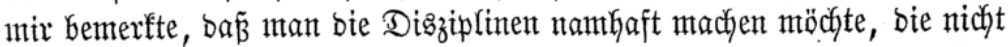

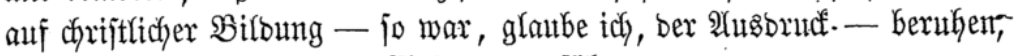
unt barauf ertaube idy mir Einiges anzuführen.

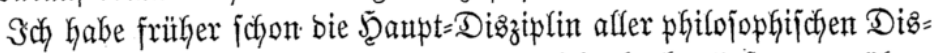
ziplinen, bie \$̧Gilojophie jefbjt, genannt, unt ich glaube, bas̃, went ïber= Gautpt eine Dizziplin philofophifd fein joll, fie, unabfängig bon einem Befenntni $\tilde{\beta}$, jich jelbjt bejtimmento jein mura. Sch fönnte mich baraur ein=

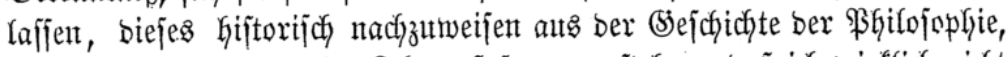

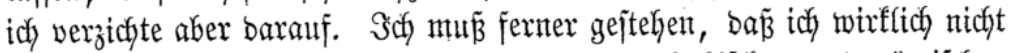
begreife, wie bie dyrijtfictye

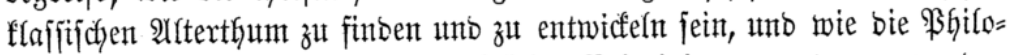

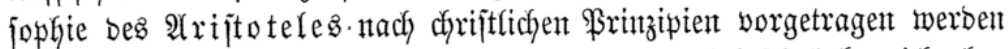

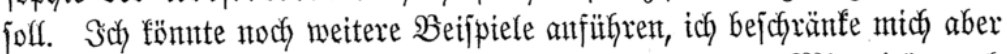

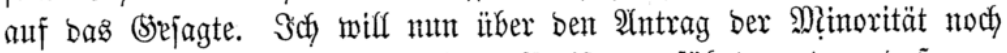

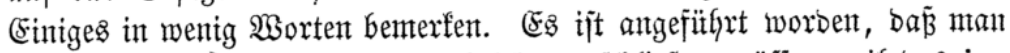

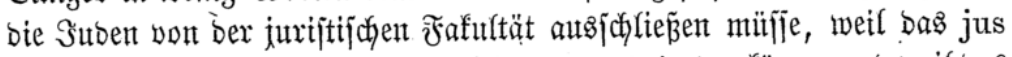
civile von bem jus eanonicum nidyt getrennt nexben fönne, unb weil bas Siatheber nur an einen Dr. juris utriusque zut itbertragen jet. Eas jino

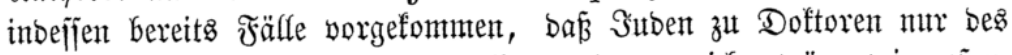

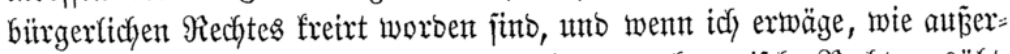

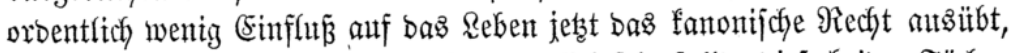

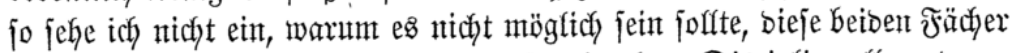
zht trennen, ba man, abgejęen von biejer einzelnen Disziplin, alle anberen jurijtijchen vortragen fann, ohne (5hrijt zu jein. Esa ijt mir jogar befannt, Dás es fehr bebentente Rechtalehrer gegeben hat, bie, went man auf ben

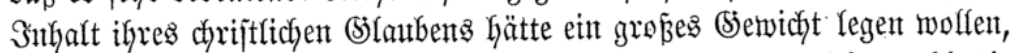
und biejen fïr unumgänglidh nothwendig exadjtet hätte, nicht wohl bie

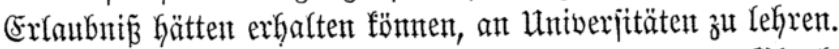

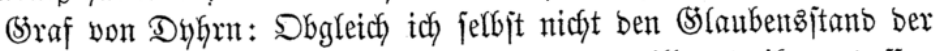

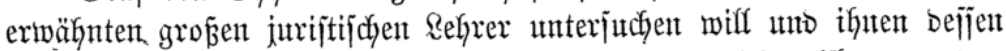

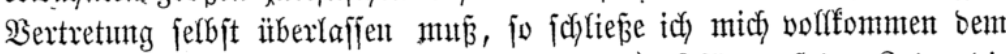

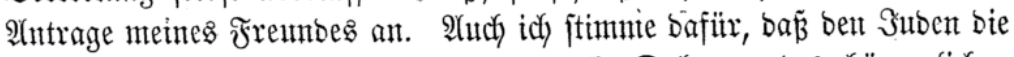

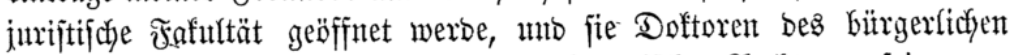
Rechtes werben fönnent, ohne Rehrer bes fantonijodyen Rechtes jut jein.

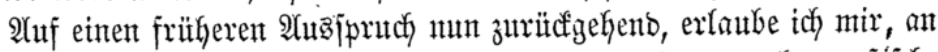

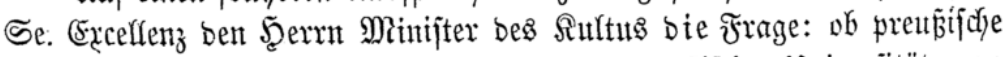

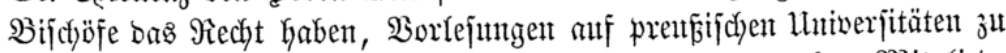
verbietent? Es ij̆t nämliç vorfyin von einem ehrentwerthent Mitgliebe

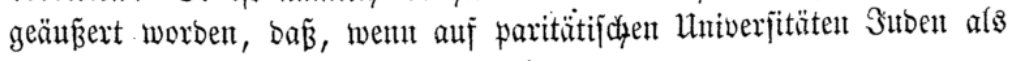




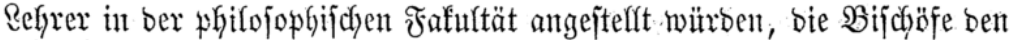
jungen fatholifdyen Theologen bann bie Borlejungen biefer Rehrer verbieten witrben. Butr philojophijichen Fraftultät gefören aber bie mathematijche

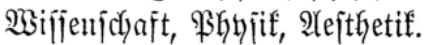

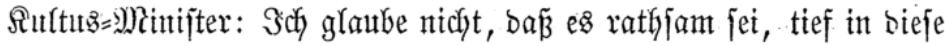

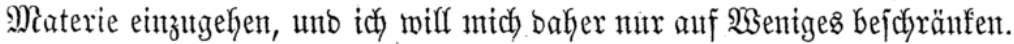

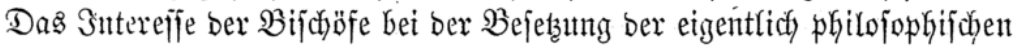

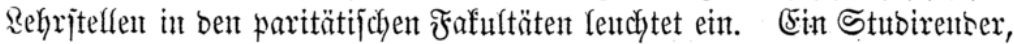

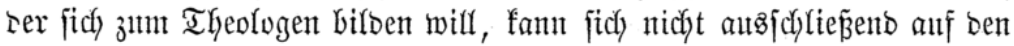
Sreis ber Disziplinen, welche nut in ber theologifchen Fafultü̈t getehrt werben, bejdyränfen, jonbern er mur audy philojophifche Sollegien hören,

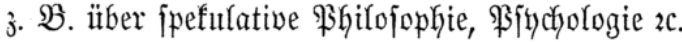

(braf bon Dhym: Dbgleidy idy burchaus nicht gebeten habe, eine Belehrung über bas Retztere zut erhalten, fonbern.mur eine ganz furze Frage über ein Faftum an Se. Excellentz ben Scerrn Minijter richtête, bie mir aber nicht beantwortet worben ift, fo wifl ich boch auth ntidyt tiefer in bieje Materie eingehen. Sch habe blos eine einfache ofrage gejtellt, unt aller=

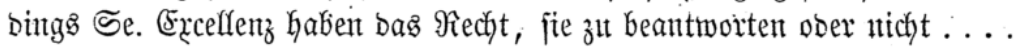

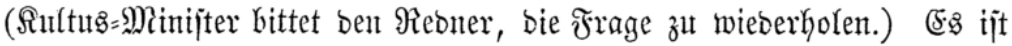
bie Frage, auf bie idy. mir eine Ântwort erbittent wollte, ob bie fatholifeden

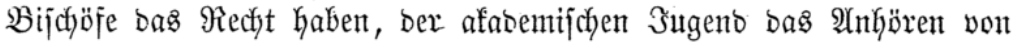

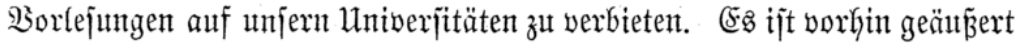

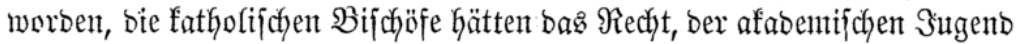
zut verbieten, Borlejungen beizutwohnen.

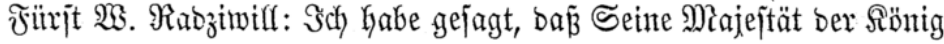
in Seiner Weizheit uno (Serechtigfeit geruht haben, ben B̉ijdjöfen auf

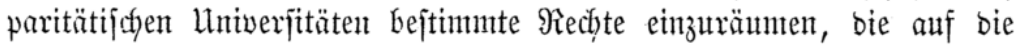

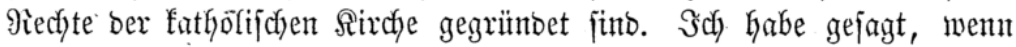
Suben als \&ehrer auf joldyen paritätifdyen Univerjitäten zutgelafjent werbent,

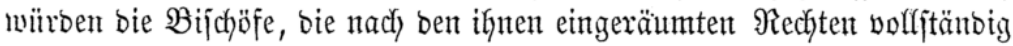

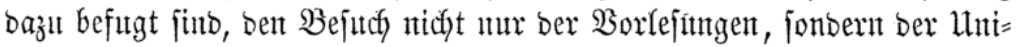
verjitüt felfjt ben Stubiojen ber fatholijcyen Theologie verbieten. (5: werben baraus fojtbare Berpflidytungen für bent Staat kervorgehen.

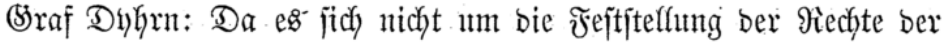

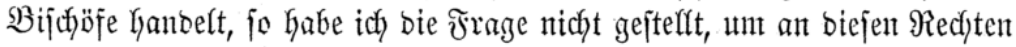

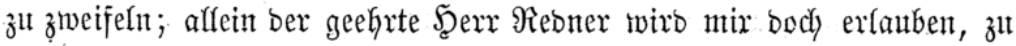

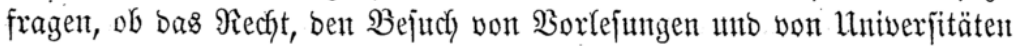

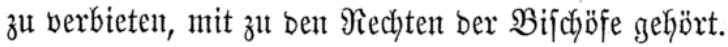

Sinltus = Minifter: Dieje Vejonbere Frage fann beantwortet werben, ohne bie allgemeine Frage zur Erörterung zu, bringen, weldye giech te ben 


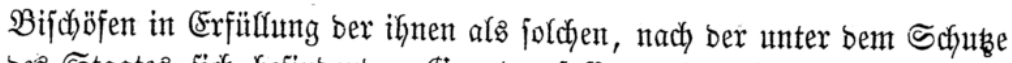
bes Staates fich befinbenten Brunbserfafiung ifrer Sirche offiegenden,

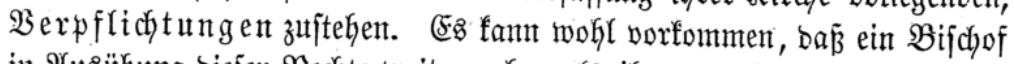

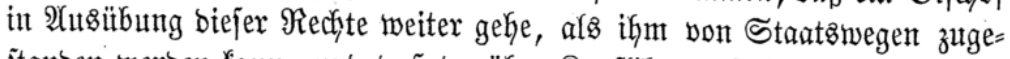

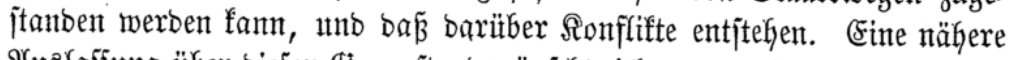

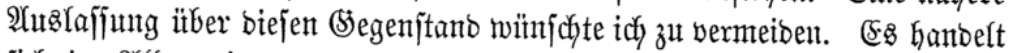

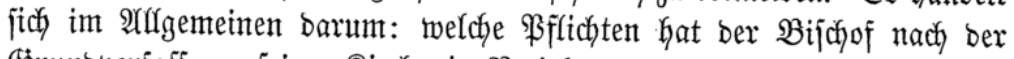
Brunbverfaffung feiner Sirche in Beziehung auf bie jungen Theologen, sie fïr feine @irche gebilbet werben foflen, uno welche Finmirfung hat ihm ber Staat, in Folge biejer bem BBiftyofe obliegenten $\mathfrak{B} f$ ficften, einerjeit: vermöge bes einer öffentlich amerfanten Rircje gebïfrentent Schuțes,

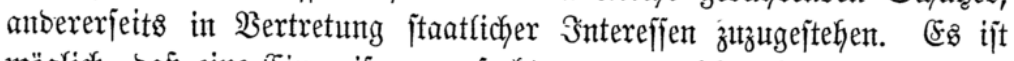

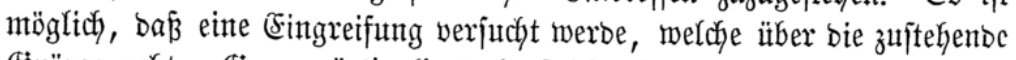
(5ränze geht. (Siegentwärtig liegt ein foldfer Falf nidjt vor. Das $\mathfrak{B}$ er=

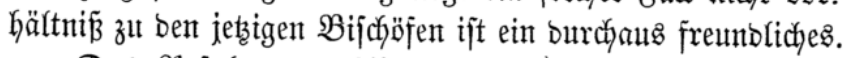

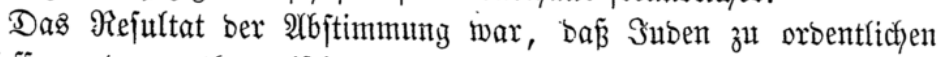
Profeffuren ber mathematifchen, naturwiffenfd)aftlichent, merizinifichen uno phitologifachen Rebrifücher zatgelajịen werben jollten.

\section{B. In der Eiturie der drei stünde.}

Regierungs= Siommiffiar Brïggemann: Эch merbe fogleich, wenn ich miç) im Arfgemeinen über bie vorfiegenbe Frage auşprechen werbe, auch) auf bie ftatuturijçen $\mathfrak{B}$ eftimmungen ber einzelnen Uniwerjitäten fommen, ich) mollte nur abwarten, ob viefleidyt noch) (siner ober ber Altibere aus ber

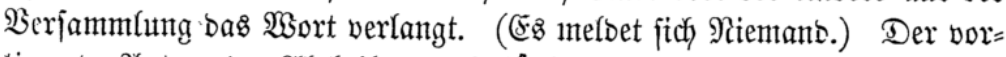
liegende $\mathfrak{A}$ ntrag ber $\mathfrak{A}$ btheitung geht insbejonbere bahin, bie in bem (5oifte

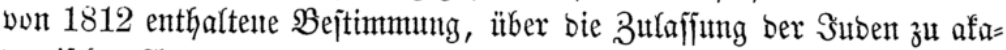

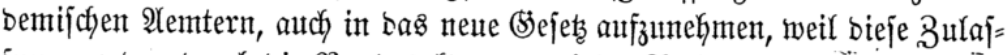

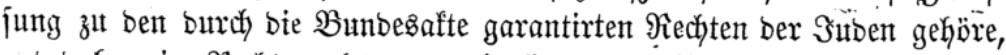
unb baher eine Rechtsverleţung barin liege, wenn jenes $\Re$ echt in bem nenten Stejeţe eine Schmälerung erleiben follte. Das Eoift bon 1812 ipricht

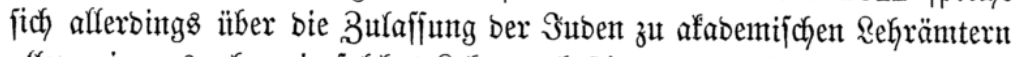

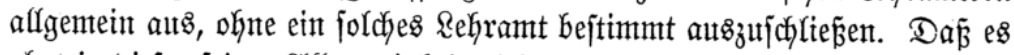
aber in biejer feiner arffgemeinkeit nidyt hat angemenbet werben foffen uno fömen, bas zeigt fich fofort, wenn jene bejtimmung auf bie theologifuse Fufultät bezogen wirb und auf biejentigen Disziplinen in anberen Fafult=

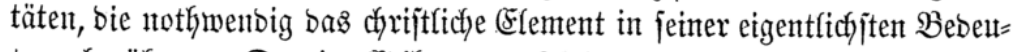
tung berithren. Der im (5obifte von 1812 enthaltene $\mathfrak{p a r a g r a p h}$ besurfte

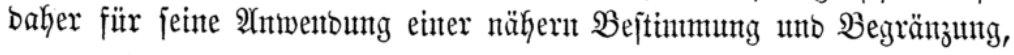


unb eben bei sem erjten Falfe, in weldyem er bei ber Giefigen Uninerjität

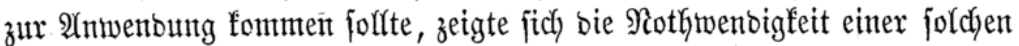
Bejcyränfung, bie bann freilich ftatt einer riähern $\mathfrak{B e j t i m m u n g ~ u n b ~} \mathfrak{B} e=$ fadränfunt in eine $\mathfrak{A}$ ufhebung bes ganzen ßaragraphen im Эahre 1822

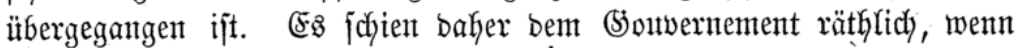

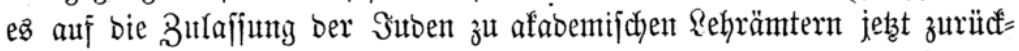
zuffonmen für angemeffen eradjtete, in ber baritber zu ertafjenden Beftim=

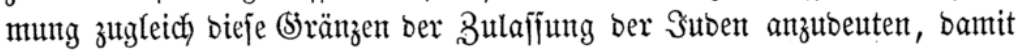
forvuhl bie wirffich) eingeräumte Bulaffung um fo weniger fpäter einem Zweifel ober einer weitern Dentung unterliegen fönnte, als auch ber

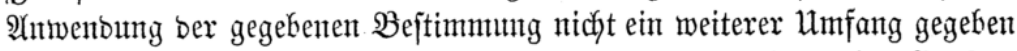
witrbe, als in ber neuen gejetzlichen aljo barauf an, in bem \$ejetz=ভnttvurfe jelbjt bieje Bränzen anzuteutent.

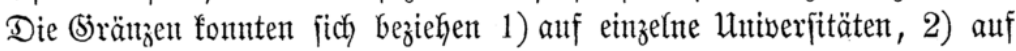
einzelne Frafultäten, 3) auf einzefne Dioz̧iplinen in einzelnen Fofultü̈tent, 4) auf bie berfdjiebenen Stufen ber afabemifchen Rehrämter.

$3 a$ a bie 3ulafjung zu Den einzelnen Univerjitäten im 2rffgemeinent betrifft, jo hat ber Bejetz=entwurf bie in biejer Beziefung eintretente $\mathfrak{B} e=$

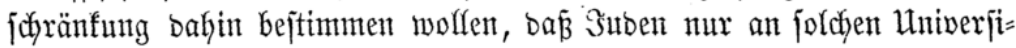
täten zugelaffen werben jolfen, an weldyen nicht jtatutenmäß̈̈tg bas $\mathfrak{B} e=$

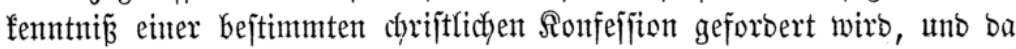
eben getwünjadt worben ift, z̆l erfahren, wie weit bieje jtatutarifachen $\mathfrak{B} e=$ fitimmungen bei ben einzelnen Mniverjitäten reichen, fo nehme ich hier eben

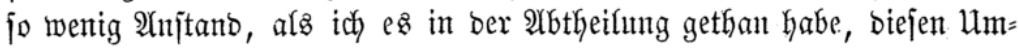

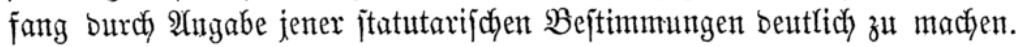
Eine von ben Univerjitäten, welche nicht ein bejtimmtes chriftliches (5) \{au= bensbefenntniz wout ben Rehrenden forbern, ijt bie Univerjität (S) reif $z$ walo

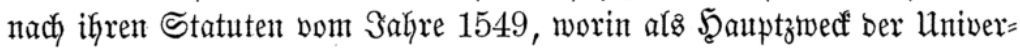
jität angegeben wirb, ut juventus ad pietatem adsuescat et doctrina

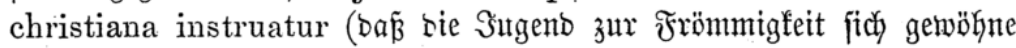

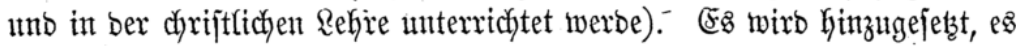

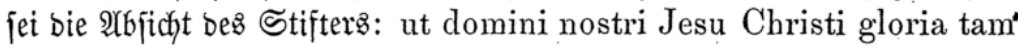

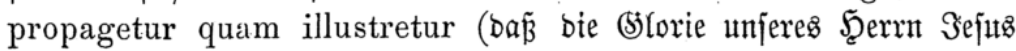
(5hriftus fowohl verbreitet, als erhöht werbe). (Es folgen jobann $\mathfrak{B} e$ ftim= mungen, weldye allen Rehrenben bie Theilnahme an bem afabemif hyen Stot=

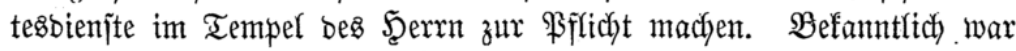

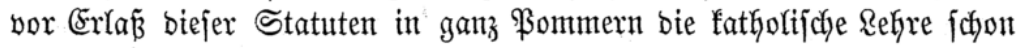

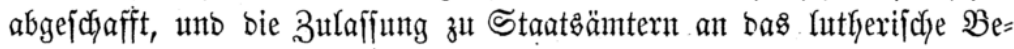
fenntnís gefnüpft, uno Suben waren in Rante gar nicht geburbet. Der neunte

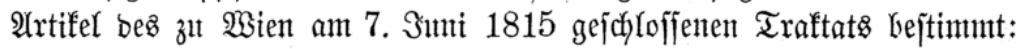


Sa Majesté le roi de Prusse s'engage, à maintenir les établissements et notamment l'académie de Greifswalde dans leur état

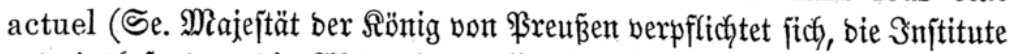
unb insbejonbere bie Affabemie zut Sreifsivald in iłrem gegentwärtigen

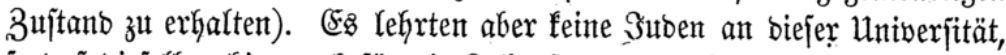
fo bá biejelben Gier autch für bie 3ufunft von ber Zutajjung zu afabemt=

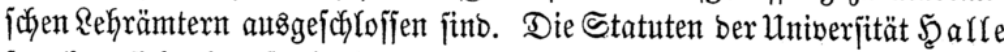
fiprectyen fich eben fo bejtimmt aus, inbem fie voriffreiben: praecipue autem consensus sit inter omnes et singulos professores in religione christiana et evangelica, scriptis prophetorum et apostolorum et augustana confessione comprehensa.

Die Rehrer jolfen hiernach ïbereinjtimmen in ber dyriftlidyen unto ebangelijfyen Rehre, wie. fie in ben Schriften ber \$ropheten uno ber Apojtel unb in bem augaburgifchen Ronfeffitonsbefenntniffe entfyalten ijt. Die

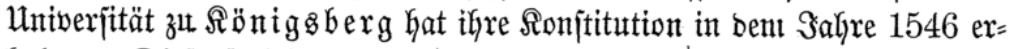

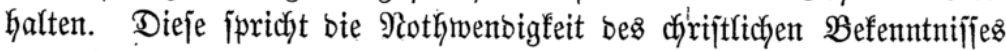

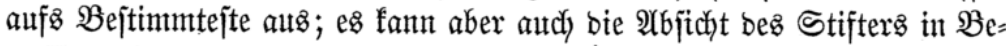
treff bes bejtimmten ebangelijdyen Befenntniffes nidyt zmeifelhaft jein. In

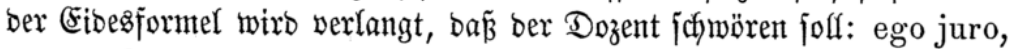
me amplecturum veram ac puram Evangelii doctrinam, quam uno spiritu ac voce $e^{z}$ ana ecclesia dei catholica profitetur, nec corrup-

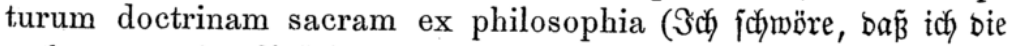
wahre unt reine. Religion bes (Evangeliums annehmen und bie heifige

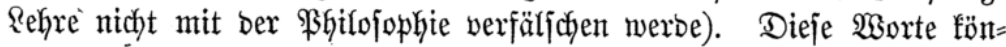
nen nicht antbers, als nach bem \$lauben bes Stifters veritanden werben,

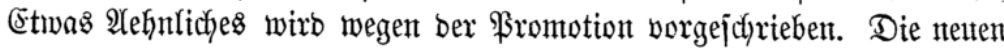
Statuten vom 4. Maa 1843 fprechen baher aus: Der urjprünglidjen Stif =

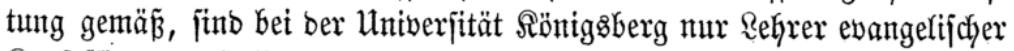
Sionfefition anzujtellen.

Die Statuten ber Univerjität 子ł $\mathfrak{B}$ onn, weldye ben 18. Dftober 1818 gegrünbet worben $i j t$, fint unter bem 18. Dftober 1834 ertheilt worben. (5: Keißít in benjelben: Die Univerjität ift in $\mathfrak{B}$ eziehung auf bie Refigions:

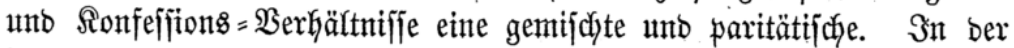

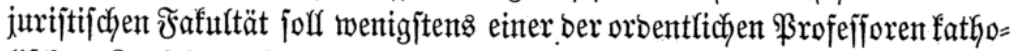

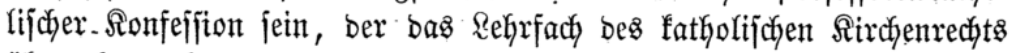
iibernebmen fann; ingleichen foll in ber philofophifłen Fafultät immer

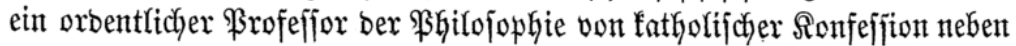

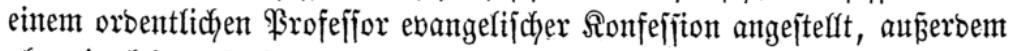
aber in feiner Fafultät, bie beiben theologifchen autsgenommen, auf bie

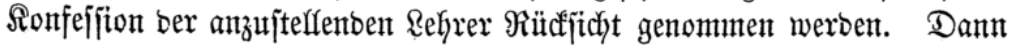




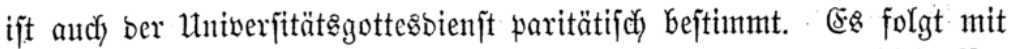

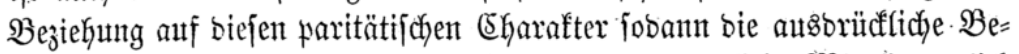

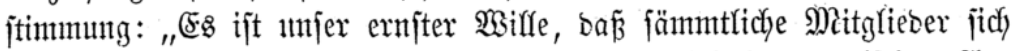

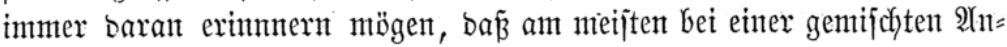

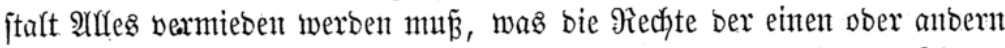

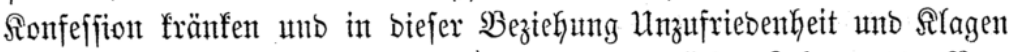

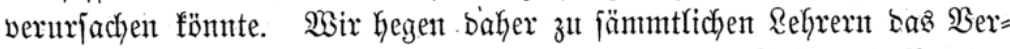

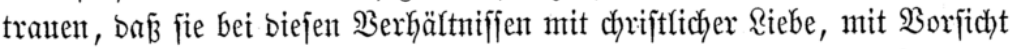
unb zarter Schomung verfahren it. \{. w." Die Ulniverfität zat Boonn ift alfo eine paritätifche Univerjität, weldye für einzelne Stellen Refrer fatbo=

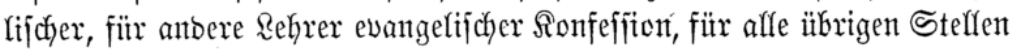
aber Miänner verlangt, bie fich entweber zur fatbolifdyen ober ebangelijchen

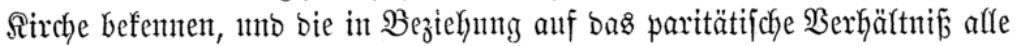

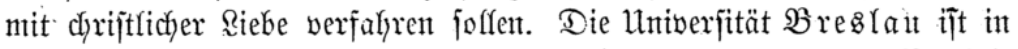
ifher jeşigen (Sejtalt burch bie unter bem 3. 2tugujt 1811 erfolgte $\mathfrak{B}$ ereini= gung ber fatholifchen Reopolos=Lniverjität ju Breslau unt ber reformirten

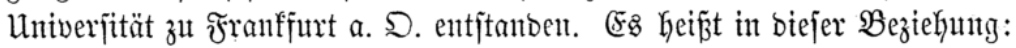

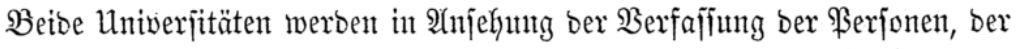
mit ihnen verfnüpften Stiftungen, bes Bermögens und ber Einfïnfte zit einemt (Sanzen verbunbent.- Diejer Sereinigntng entfpredyen bann autdy bie folgenten jtatutarifdyen Bejtimmungen, in weldyen bas paritätifche $\mathfrak{B} e r=$

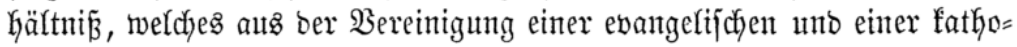

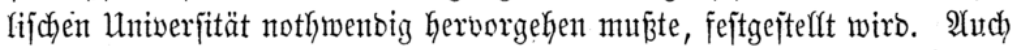

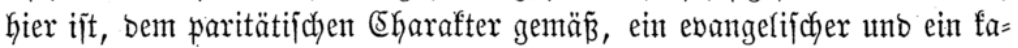
tholifcher Untwerjitäts = \$sottesbienjt angeoronet worben, aud hier ber

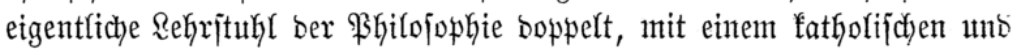
ebangelifchen Rehrer, bejetzt, währento cs bet bent itbrigent Rehriftellen, mit

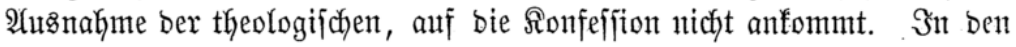

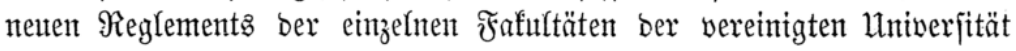
zu Breslaut vom 13. Septemtber 1840 ift inbeffen, unzmeifelfaft wegen

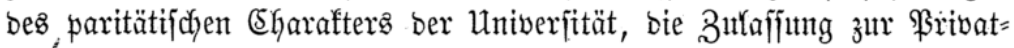
Dofftion in alfen Fafultäten von bem chriftlichen \$5laubensbefenntniffe $a \mathfrak{b}=$ hängig gemadft worben; es bïrfen audch, mit $\mathfrak{A}$ uğnahme ber mebizinif dyen Fafultät, nur SGriften promovirt werben. Das Statut ber Utniberjität łu Berlin, exfolgt unter bem 16. Âtugut 1809, enthält nichts, worauz auf bas Exforbernićs bes chriftliçen $\mathfrak{B}$ efenntniffes für einzelne Dozenten ge=

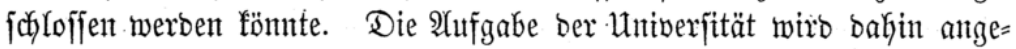
geben, bie alfgemeine unb befonbere wiffenfchaftliche Bilbung gehörig vorbereiteter Sïnglinge... fortzufetzen unt fie z̆um sintritt in bie ver=

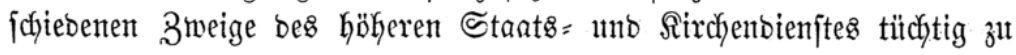




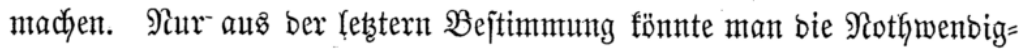

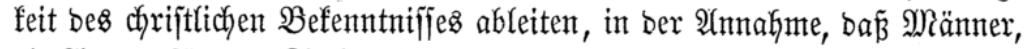

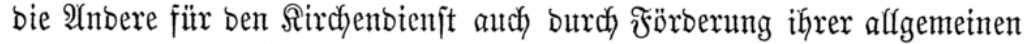
wiffenjdyaftlichen Billoung vorbereiten jollen, aud jelbjt ber dyriftlichen Sitrche angefören mitijen. Rach ben in ben Gier in Betradyt fommenten

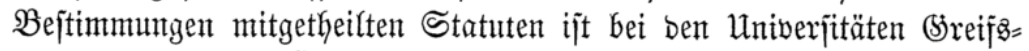

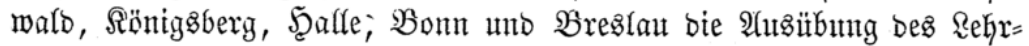
amtes an ein bejtimmtes chriptliches $\mathfrak{B}$ efenntni bieje Univerjitäten burdy bie jtatutarifchen Bejtimmungen alz joldye be= zeichnet, auf welchen Suben zu einem afabemifachen Rehramte nicht zuge= laffen werben fönnen, fo Daß̧ bie Univerjität zu $\mathfrak{B}$ erlin alfein als eine foldye übrig bleibt, an melcher bie Suben nicht fichen burch bie Statuten ber Univerjitüt augigejchlofjen jüno.

Das ift es, was ich über bie in Beziehung auf bie Bulaffung ber Sttben zu afabemifchen Rehrämtern an einzelnen Univerijtäten jtatuten= mäpig eintretente Bejcyräntung mitzutheilen hatte. Sch will mich hier auf eine Begrïnoung bes Erforberniffes eines dyriftliduen Frinzips in ben

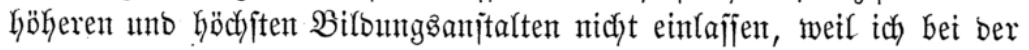

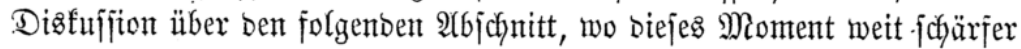

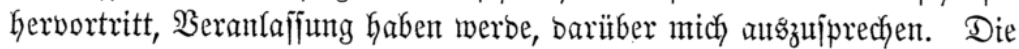

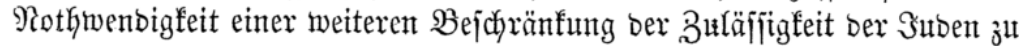
afabemij̄chen Rehrämtern fönnte in bent einzelnen Fafultüten gefunben

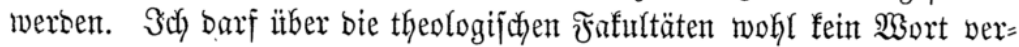

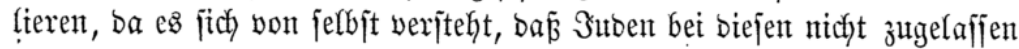
werben bitrfen. $\mathfrak{W a s}$ bie jurijtifđje Fafurtät betrifft, fo ift in ben

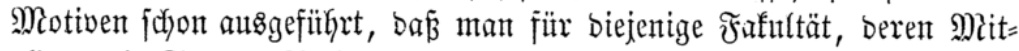

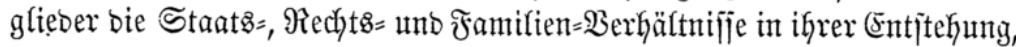

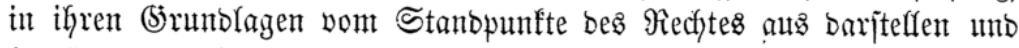
begrünben, weldye von bemjelben Stanbpunfte aus ber Ssejetzgebung in

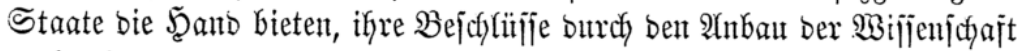

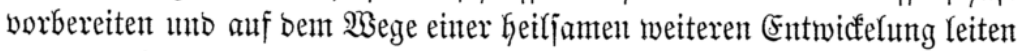
unb unterftütsen, bie fünftigen Diener Dcs Staates füt jeine richtende und

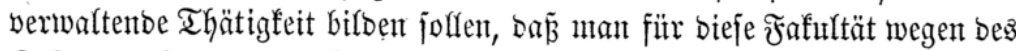

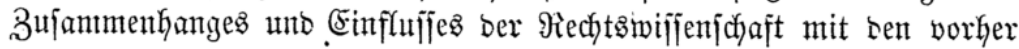

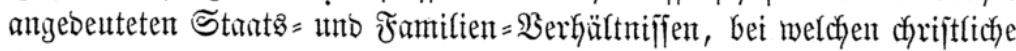

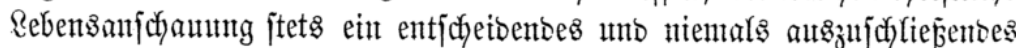

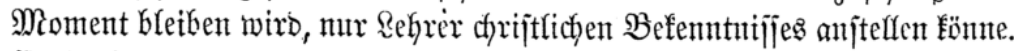

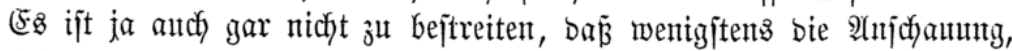

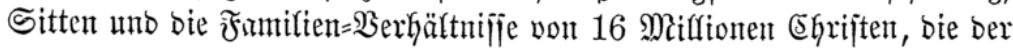
Staat zut feinen Unterthanen zählt, im dyrijtlidyen wie im germantijdhen 


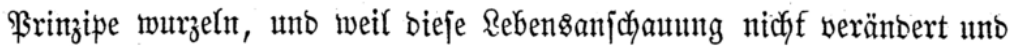
getrübt werben foff, fo ift hinreidfenber Strutt borkanben, eine foldye Trïbınt berjelken burch bas Gintreten von Männern, bie einer anberen refigiöfen unb nationalen $\mathfrak{A}$ nfichaunng folgen, Gier entjchieben fern zu Galten.

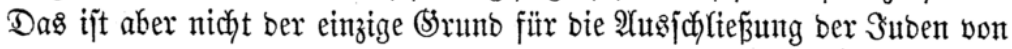

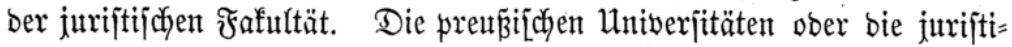

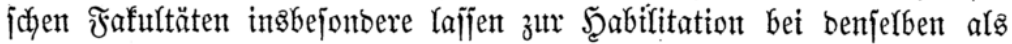

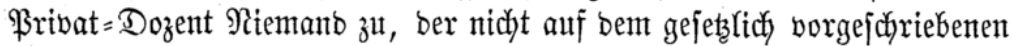
Wege das Doftorat utriusque juris ermorben hat. Diefes Doftorat

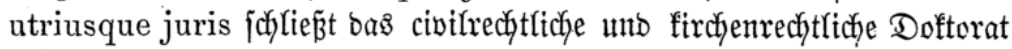
in fich. Das firchenredftlidje ift von ief̧er, und insbejonbere füfrt auch

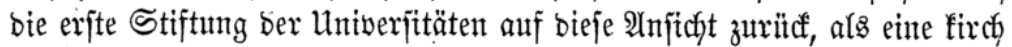
liche $\mathfrak{B u ̈ r b e}$ angejeken worben. (Fs ijt aud bon ba an bis jetzt bas $\mathfrak{D o f}=$ torat utriusque juris als untfeiffar betractytet worben, unb bie inländifdjen Univerjitäten haben jich, fo viel ich weís, weber zu einer Theilung bes Doftorats entichlieânen fönnen, noch audy bas Doftorat utriusque juris an bie Suben ertheilt, welche (id) baburch zu Pribat=Dozenten in ber juri= jtijdyen Fafulttüt fühig madyen mollten; ob ez an joldye ertheilt ijt, bie jich baburch blos einen Titel ertwerben wollten, vermag idy nicht zu jagen. In neutefter ßeit, aber nicht früher, als bie Frage yon ber Emanzipation ber

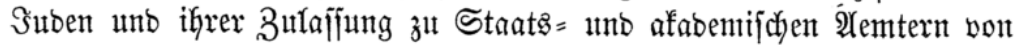
alfgemeinterer Bebeutung geworben ijt, find einzelne, aber bod' nur jehr

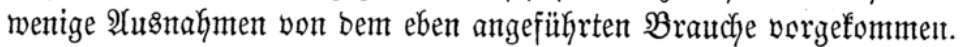

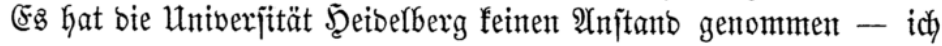

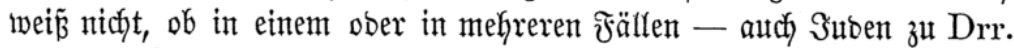
utriusque juris zu ernemen; andere Uniberjitäten, weldje bas für bebent= lich hielten, haben verjucht, bas bisker untrennbare Doftorat zu theifen unb einen Эutben zum Dr. jur. fähig z̆t mact,en, wie bies alf ber Univer=

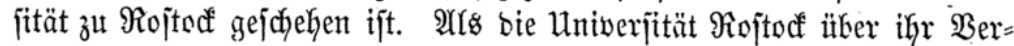
fahren zut einer Erffärumg aufgeforbert murbe, hat bie jutriftifiçe Fafulttät fich bahin erffärt, fie habe geglaubt, einen Эuben nur zum Dr. juris civilis, aber nicht zum Dr. utriusque juris ernennen zut fönnen. Da ber Doftor

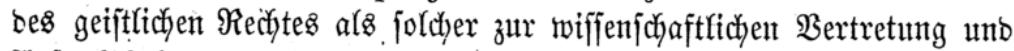
Alufredthaltung ber chriftlich=firchlichen Rechtsuerfaffung verpflidytet jei,

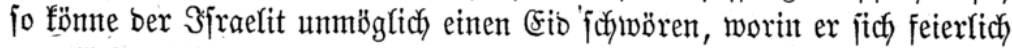

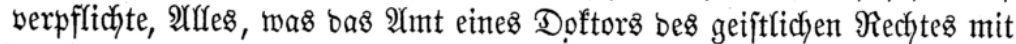
fich bringe, auf's Sienviffenthaftefte zu erfüflen. Würbe er alch viefleicht

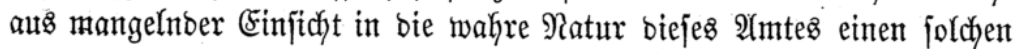
Doftor = Eit ableijten, fo würbe es ifm bennody in ber Folge nicht jefwer werbent, von jebem $\Re a b b i$ biejes (Fibes entbunben zu werben, wogegen jelbjt 


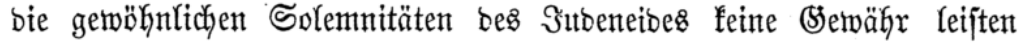
würben, abgejehen von bem SWiberiprudte, burch Şülfe ber Synagoge uno

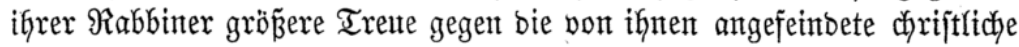
- Sirche erzmingen zat wollen. Darum habe jie jenten , Suben mur zum Dr.

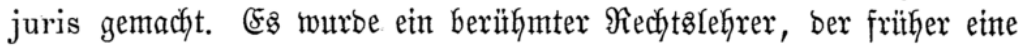
Zierbe ber Untwerjität 子u Sï̈ttingen war unb fpäter unjerem Staate an= gehörte, aufgeforbert, feine Meinung über bas bon ber Frafultät befolgte

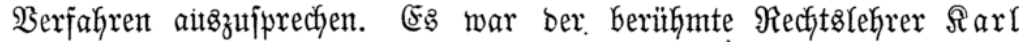

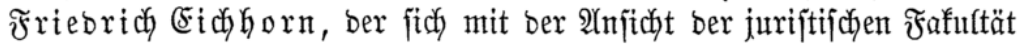

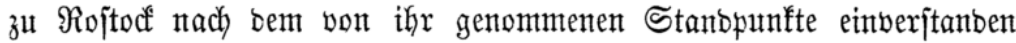

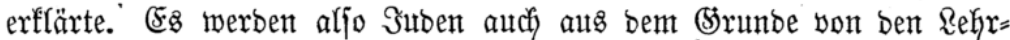

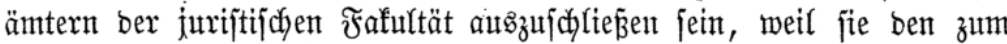

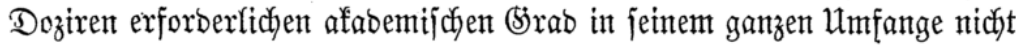
erwerben fönnen. Bon ber mesizinifchen Fafultät rebe id nidut, ba ber

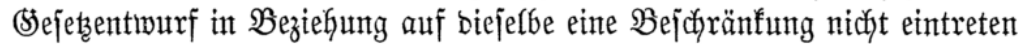

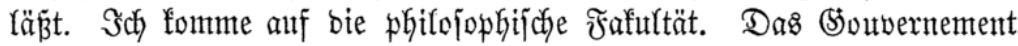
hat jich bentitht, gerabe bet ber Bulaffung ber Suben zum 2 mt eines

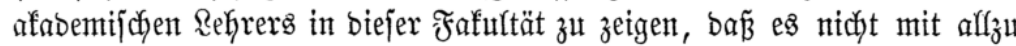

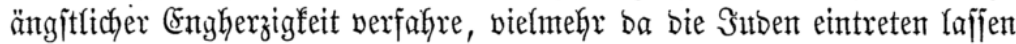

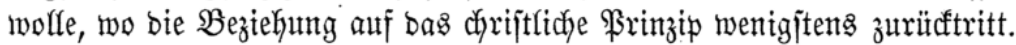

Heber bie Gier zu ziełenten Stränzen zwifłyen ben einzelnen Dis= ziplinen, bei welchen ein mehr ober wentiger tieferez Eingreifen bes d)rijt= fichen \$rinzips jtatffinbet, baritber fanm man alferbings verfffiebener Meinung jeint.

Es ijt ben Subent ber Sortrag für bie mathematijchen unb naturr= wiffenjichaftlidyen Disziplinten eingeräumt worben, uno ba idy nicht voraus=

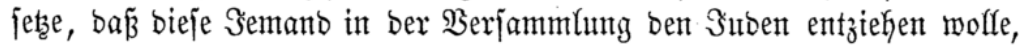

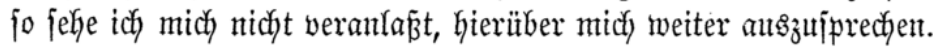

Die widftigite hier in Betradyt fommenbe Disziplin ijt wohl bie

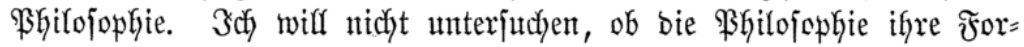

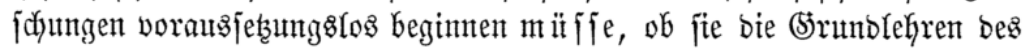

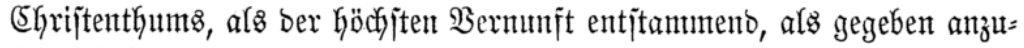

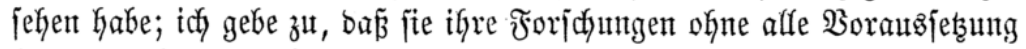

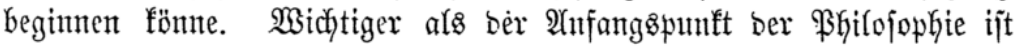

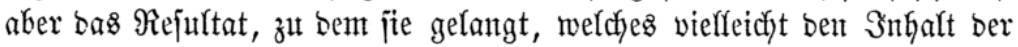
dyriftlichen Refren nicht erreidyt, ofne ifnen jeoody zut wiberipredyen, aber audy mit benjerben in bireften Wiberfprudu treten fann, wobei bas Urtheil

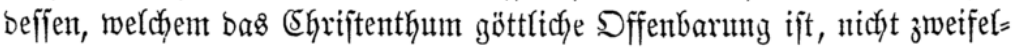
haft fein fant. Der freien wifjenjchaftlichen Forjchung folf eine Schranfe nicht gejeţt werben; aber barum hanbelt es jich; ob Demjentigen burch bie 
Ylutorität bes Staates bas philojophifche Rehramt übertragen werben joll,

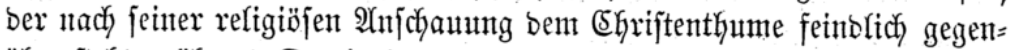
über jteht, währento Demientigent, ber im Ehriftenthume geboren uno unter ben Segnungen beffelben aufgetwadjent und jeine Rebensanfdyaungen unto

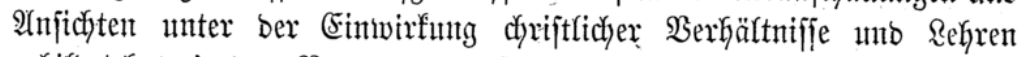
gebilbet hat, in bem $\mathfrak{B} e r t r a u e n, ~ b a \tilde{B}$ er bem (shrijtenthume nidyt feinblich entgegentreten werse, weil bie wahre \$rgilojophie ifhn nicht wiberjprechen

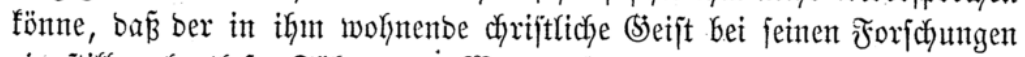

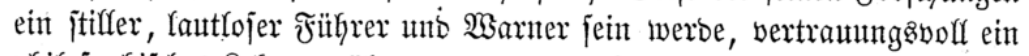
philojophijches Rehramt ïbertragen werbent fant.

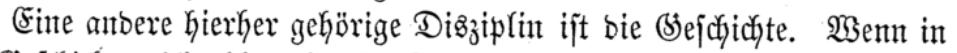
ser (b)ifjichte nicht blos eimzelne Thatjachen erzäh(t, fonbern autd nadj= gewiejen werben foll, wie Sott bie Schidffale Einzelner und ganzer $2 B ̈ b l f e r$ ifyrem Biełe entzegenfïhrt, mie bie Siefchichte mit göttlicher Dffenbarung beginnt, bie Erfcheinung bes Shrijtenthumb vorbereitet unb, nachbem bajfelbe in bie $\mathfrak{S e l t}$ gefommen, unter feinem Einflujfe alfe $\mathfrak{B}$ erbältniffe Des Rebens iffer Umgejtaltung und weiteren Entwicfelung entgegengeführt worben, fo witroe es body einem Suben wohl unmöglidy werben, bie \$te $=$ icjichte in biejem Sinme anf

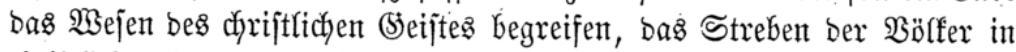
chriftlicher Staaten=Billoung, die Rämpfe des Staates und ber Sirche richtig auffaffen unt würbigen fömnen? Wie fann man einen Mann für bie Rehrtanzel ber (jefdyichte berufen, ber verntöge feiner religiöjen lueber=

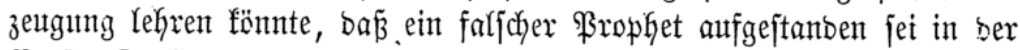
Perjon Desjenigen, ben bas (shriftenthun göttlich verehrt, unb ourch beffen Rehre bie fümftigen Diener bes Staates uno ber Sirche gebilbet werben

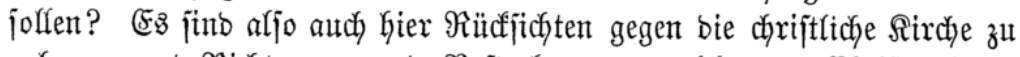

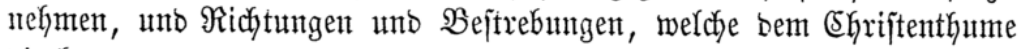
Direft entgegentreten, fern z̧t halten. (5: find in bem (5)utachten ber Abtheilung aud) bie linguiftifdyen Dizzziplinen berithrt, won benen bie

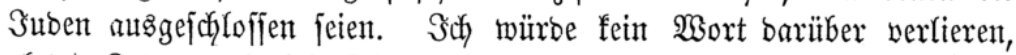
ob ben Эuben aurd) bieje Disziplinen zu überlafjen jeien, wenn man bloz

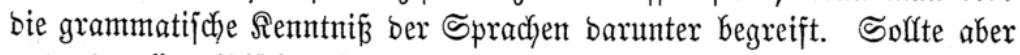
unter ben linguiftijdyen Disziplinen aud bas ganze philojophiface Sebiet,

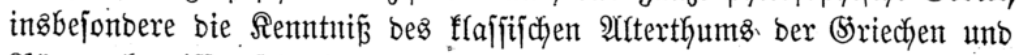
Römer, begriffen fein, fo berïfyrt bieje Dizziplin bie ganze geijtige Biloung Des Menfchen. 'Es fommt fierbei nicht blos auf ßenntníz ber alten Spractyen, fonbern ganz bejonbers auf bie (Finfïfyrung in ben ganzen (Steijt

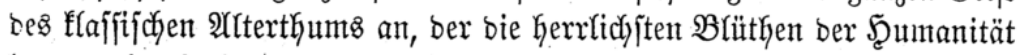
herborgebradyt hat, ber nicht blos ridytig uno tief, fonbern mit bem höblyjten 


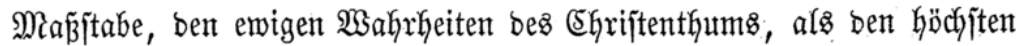
- Srinzipien, aufgefaß̧t uno beurtheilt twerbent mú

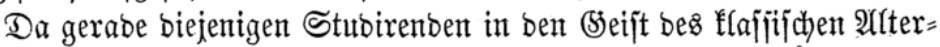
thums eingefïlfyt werben folfen, welchen fünftig bie Billoung ber djriftlichen

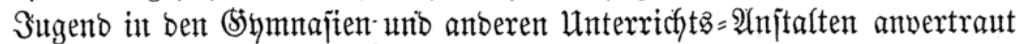

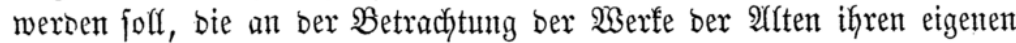

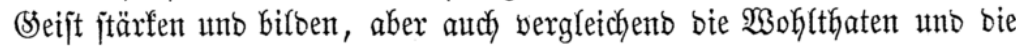
Segnungen bes (Shriftenthums fchätzen lernen jollen, beşhalb glaubte man

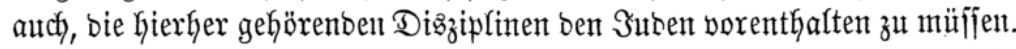
Waz bie meitere $\mathfrak{B} e j$ chränflung betrifft, jo hängt bieje mit bem alfgemein

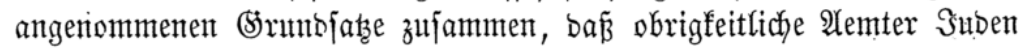
nicht anvertraut werben folfen. Da aber ohne Bejclyränfung ber Suben

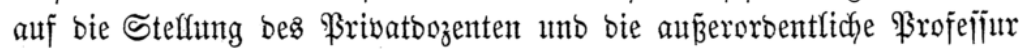

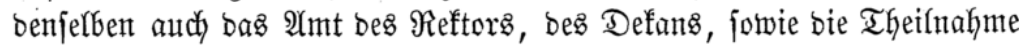
an ben Senatsrecten, mitfin an ber $\mathfrak{A}$ usübung ber Sittenpolizei unb Surtisbiftion, zujteken würbe, fo jujen jene Bejcyränfung nothmendig.

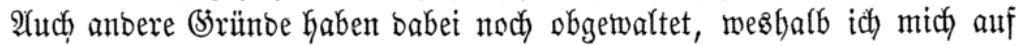
bie Denifjarift beziehe. Wenn man aber Darin eine Zurürffetsung ber

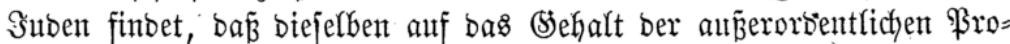

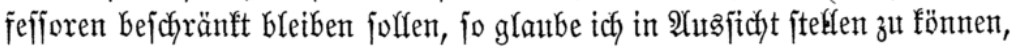

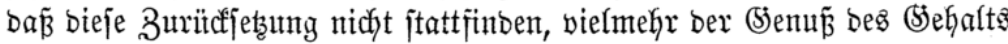
auth) bei ben jübifchen Dozenten ïber jene \$ränze Ginaugageḩen werbe.

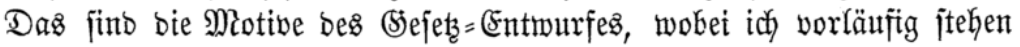
bleiben will.

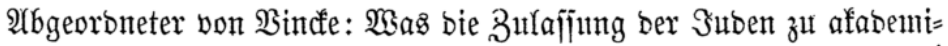
ichen Refrämtern betrifft, fo fann idh aflerbings, wenn idy bas (5oift vom Yahre 1812 unbefangen erwäge, in bem neuten Sejets=Entwurf mur

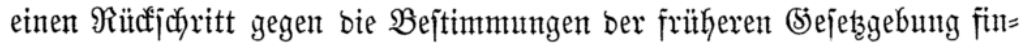

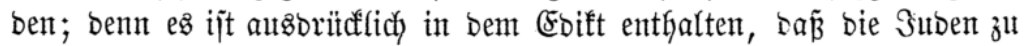
aflen afabentijchen 2 (lemtern zugetajien jein jolfen, zu benen jie jich gejdjicft gemacht haben. (5: fann aljo nach meiner Afnjicht nur barauf anfommen,

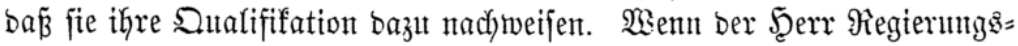

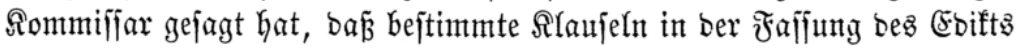
entffalten jeien, jo jtimme idj bem zwar bei, benn es fann ein Sarbe jidy alferbings nidyt qualifizirt machen zur Beffeibung einer \$rofeffir ber

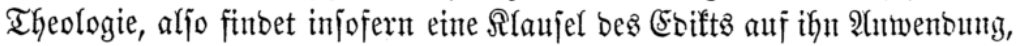
währento er jidy zut allen anbern Disziplinen, weldye nidyt bas chriftliche Befenntnití voratıjetzen, unbebingt gejujift machen faun. Er fann bie

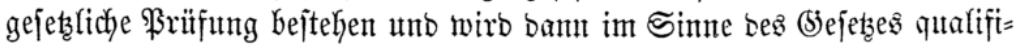
zint fein. Snjofern bie Rabinets= Drove von 1822 jene $\mathfrak{B e j t i m m u n g ~ a u j =}$ 


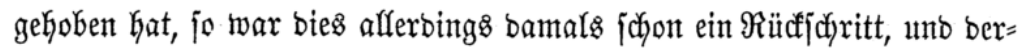
jelbe mit ber Bejtimunung ber $\mathfrak{B}$ unbeg̊afte, bie ben 3 uben alfe $\Re$ edjte.

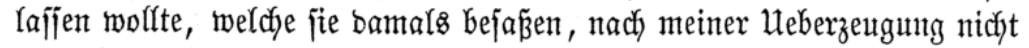

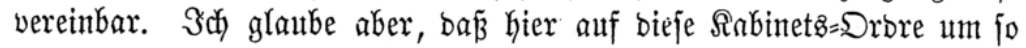
weniger hingewiejen werben barf, als nady ber Minifterial= Denffarifit bieje $\mathfrak{B}$ ejtimmung nidyt auf bem gejetzlichen $\mathfrak{W}$ ege publizirt morben ijt,

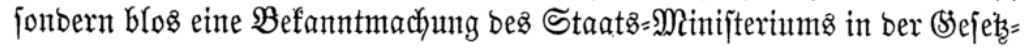
jammlung barauf $\mathfrak{B}$ ezug genommen hat, unb fowohl nach ber heute zu Recht bejtehenben Siefezgebung, als nach ber früheren eine Befaunt= machung bes Staats= Minifíteriums bie Araft eines (Sejetzes nidyt be=

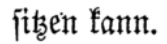

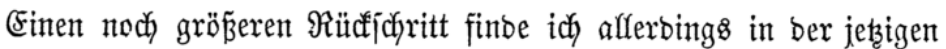
Bejtimmung, worin ausbrüdflich gejagt ijt, baß fie nur zu bejtimmten

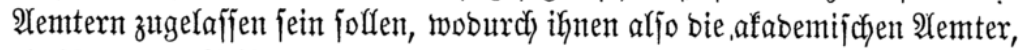
bie iłnen bas Goift von 1812 einräumt, nieber entzogen worben finto. Es

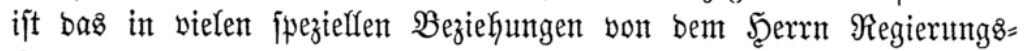

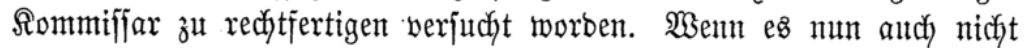
möglich ift, einem jo vollftänbig auzిgearbeiteten $\mathfrak{B}$ ortrage in allen einzelnen Worten und Buchitaben zu folgen, fo wifl idh bod verjutchen, vom allge= meinen Stantopunfte einige biejer Behauptungen zu beleuthten. Ueber bie Theotogie habe idy mich eben geäunert. Sch glaube, baj es jich von jelbjt

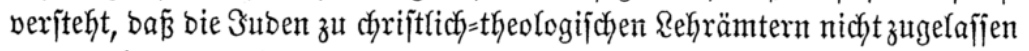

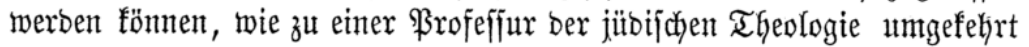

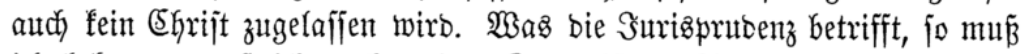

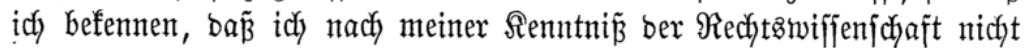

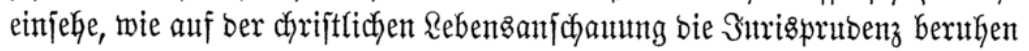
fann, namentlich wie bie dyriftlidye Rebensanfdyaunng bem ßanbeftenredyt

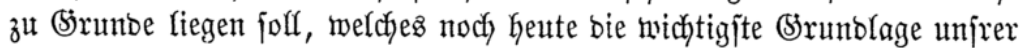

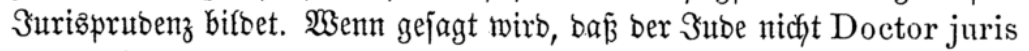
werben fönne, weil er nicht ben vorgejdyriebenen Eio leiften unb bie barin

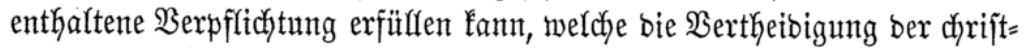

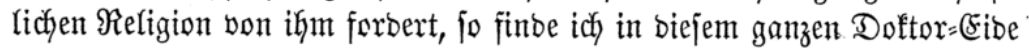
auch mux ein Ueberbleibjel mittelalterlicher Formen, was idy jeţt für

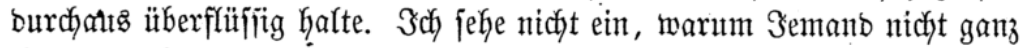
einfady ein Examen bejtehen fann, worin er jeine Befähigung zur \$rofeffur nadyweift, warum es nöthig ift, ifhn in bie Formen einer Doftorpromotion 孔 bannen. Das ift eine leere Spielerei mit Formen, auf bie autch, fo viel idy)

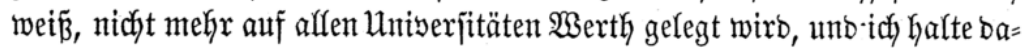
her um fo meniger bafür, bã man von bem Erfitflen einer foldjen, im Raufe Der Yahrhunberte ganz leer geworbchen Form bie Ertangung ber ßrofeffur 
abhängig machen foll. Will man bennody bie Spielerei beibehalten, jo jteht ja nidyts entgegen, ben Eib in ber Synagoge abzunehmen uno bie Fajfung zu mobifizixen.

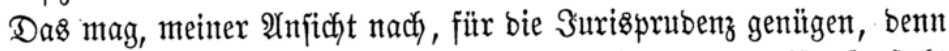
wenn von ber $\mathfrak{B r o f e f f u x}$ bez Sirchenrechts gefprodfen worben ift, fo jteht nid)tz entgegen, obgleidy audy bas Sirchenredyt nidyt wejentlidy mit bem

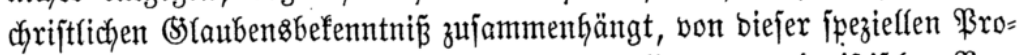

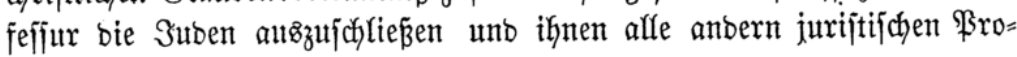
fefīuren zutgänglich) zut madyen.

Es ijt ferner bavon bie Rebe gewejen, baßj fie nicht ßrofefforen ber

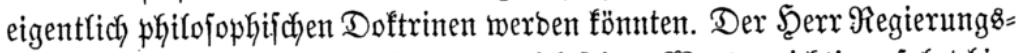
Sommiffar hat aber jelbjt gejagt, wenn ich jeinen Worten ridjtig gefolgt bin,

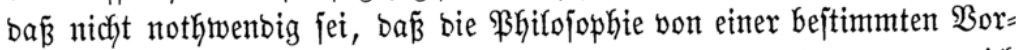
ausfetzung ober von einer fonfeffitoneflen (Strumblage ausgehe, uno wenn id')

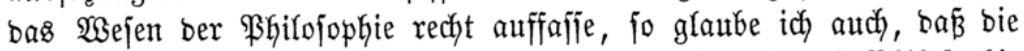

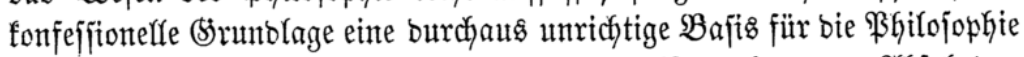

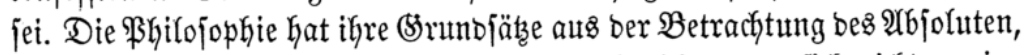
aus ben affgemeinen (Sejetzen bes Denfens abzulleiten unb jid') nidyt an eine

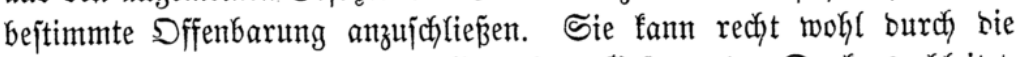
Folgerungen, bie jie auz ben allgemeinen Sejetzen bes Denfens ableitet, zu benjelben $\Re$ ejultaten, wie bie pojitive Dffenbarung, gelangen, obgleid')

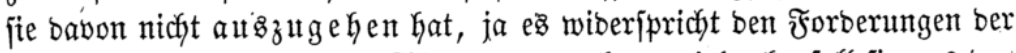
\$̧ilojophie, von pojitiven Sätzen atsazugehen, vielmehr foll fie aus ben affgemeiten Srumbjätzen bes Seins und Denfens ihre Theorieen ent=

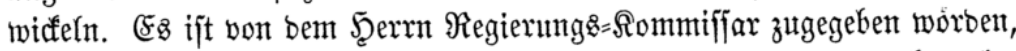

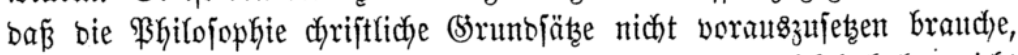

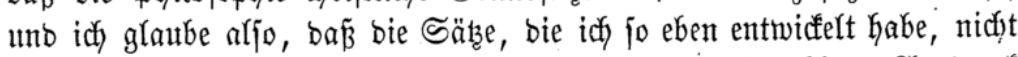

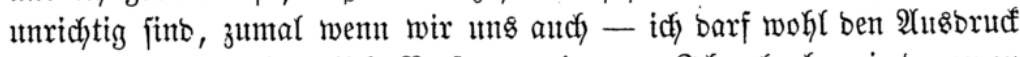

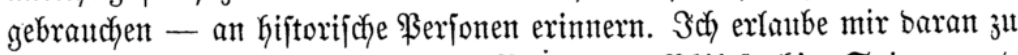

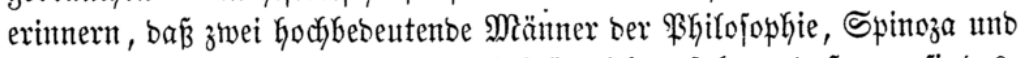
Menbelsjohn, Sttoen waren, unb idy habe nicht erfahren, baß man fie bes:

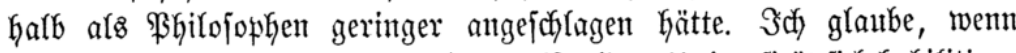

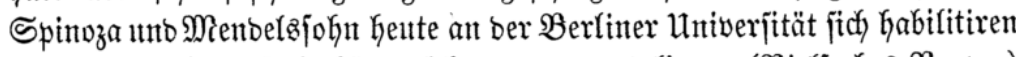

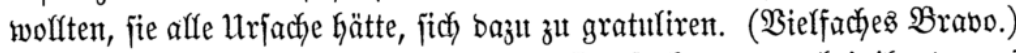

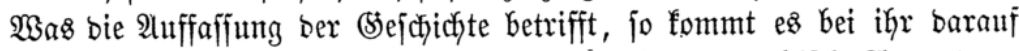

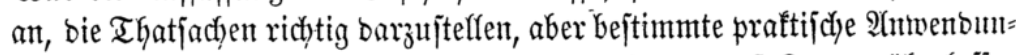

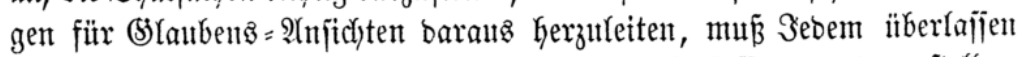
bleiben. Die (5)efchichte ift mur rein objeftib aufzufaffen unb barzujtelfen, uno ber Rehrer ber (Sejefjidyte hat jich mur mit ber objeftiven Auffafiung

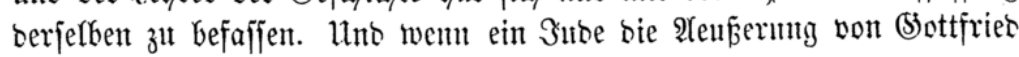


von boutlfon zu referirent hätte; fo wirb ex fie boch wohl nicht anbers referiren, als jie gethan worben. Sidy wifl ihm überlaffen, was er baraus folgert; fitr mich genitgt es, wenn er bie I Ifatjache richtig mittheilt, mag er bie Sirone nur als Srone anfehent ober jie mit ber Dornentronte ver=

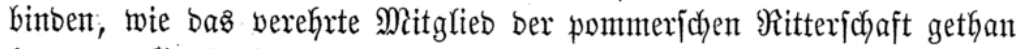

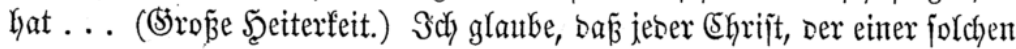

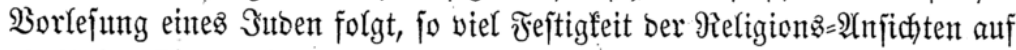

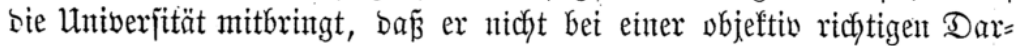
jtelfung, an bie ber Dozent eine falfche, eine unrichtige Folgerung anf nuthpt,

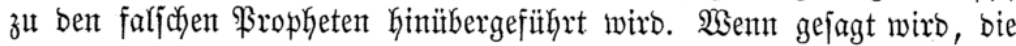

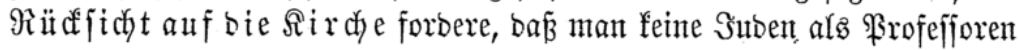

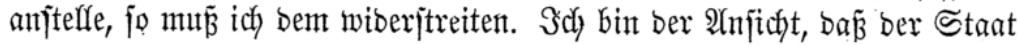

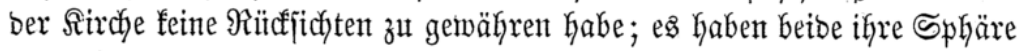

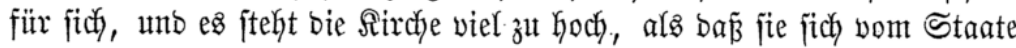

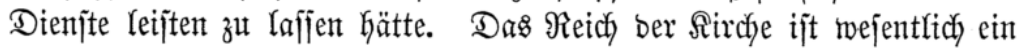
inneres, auf bie intere Heberzengung gegrünbet, unb jebe innere Meber= zentgung eines Menjchen thut mix Yeib, went jie erjt burch ben Staat'ge= währleiftet werben foll. (Stürmifches Bravo.) Sie mur in ihm vor=

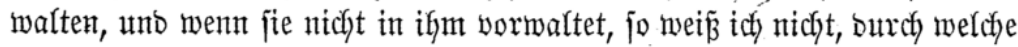
innere 3 wangsmittel bes Staates bie innere Heberzengung probuzint wer= ben jolf. (অren jo jtarfes Bravo.)

Die geographifchen Diszziplinen fino ben Suben nachgelaffen moroen,

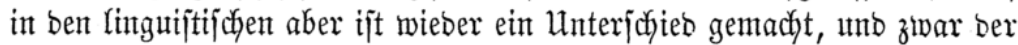
zwifhen ben Borlefungen über Brammatifalifchez unb benen über ben

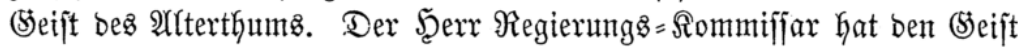

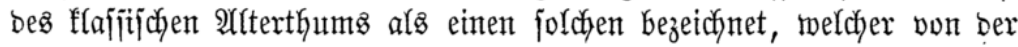

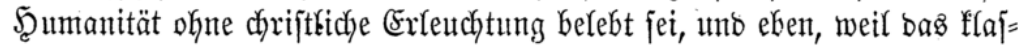

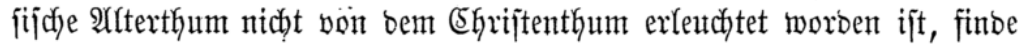

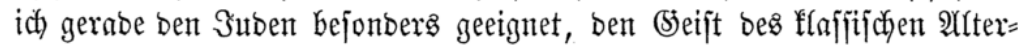
thums unbefangen barzufteflen, weil er biejen \$seijt objeftio auffap̧t, ofne

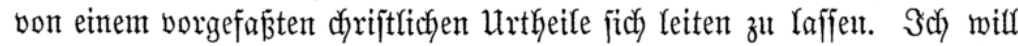

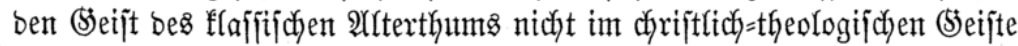

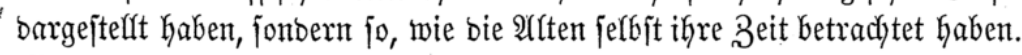
Wer bas Âterthum benutsen wifl, um firchliche. Theorieen baraus zut ent= widfeln, ber wirb bei bem Ziele vorbeifchiezßen uno ben (Seijt nicht treffen,

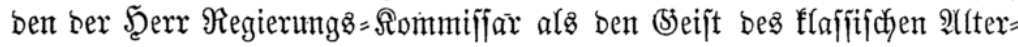

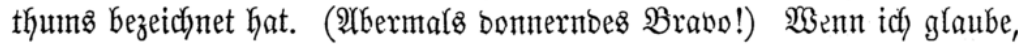

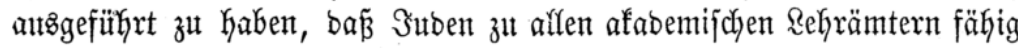
jeien, fo jehe idy nidht ein, warum man jie nicht bes $\mathfrak{B}$ orzugs theilkaftig

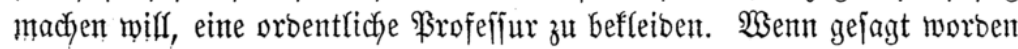




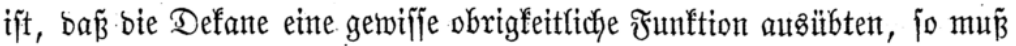

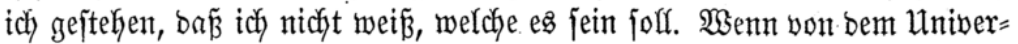

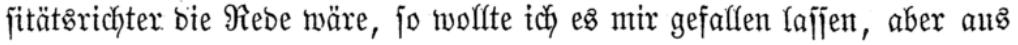

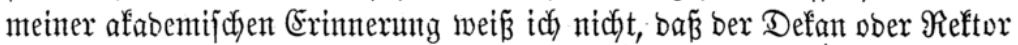

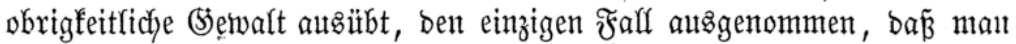

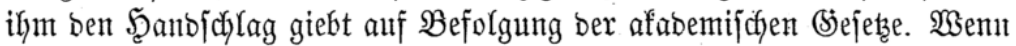
es aber zlt Sontrabentionen fommt, fo tritt ber Uniberjitütżrichter ein. Das ijt bie einzige Dbrigfeit, welche bem Stubenten entgegen tritt, wem

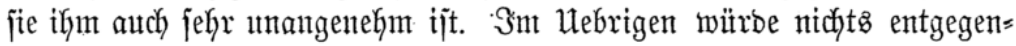

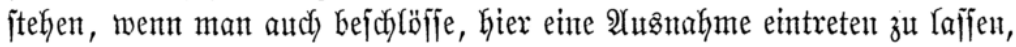

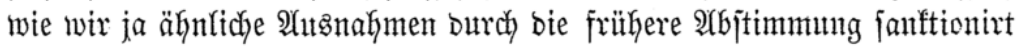
haben. Sebenfalfs ijt bie obrigfeitfiche Funftion ber Defane jehr unbe= beutent. Wollte man aber autch Gier ben angenommenen Strumbjatzerlafjen, fo würbe ez boch eine unridytige Folgernng fein, wenn man bie Suben

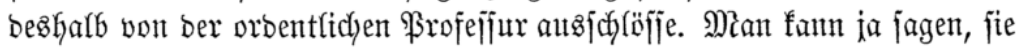
foflen orbentfiche Frofefijoren werben, nur nicht in ben Senat getwähit werben unb nidyt Defane uno Reftoren jein fönnen. Warum man aber ifnen beshalb, weil jie nidyt Defane unb $\Re$ eftoren werben follen, auth bie

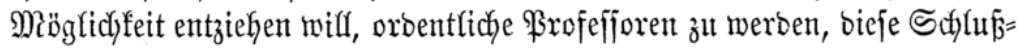

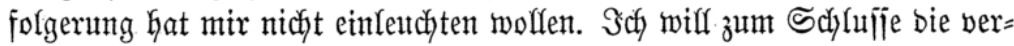
ehrte $\mathfrak{B}$ erjammlung nur an sent Srumbjats erintern, zu bem jie jich bei mehreren (Selegenheiten in überwiegender Mekrheit befannt hat, an bent (5)runbjats, fonfeffitonefle Uunterffyiebe nidyt bahin zu bringen, wo jie nicht Gingehören, unb nidjt ba, wo es fidy nidht um Religion hanbelt, fonbern

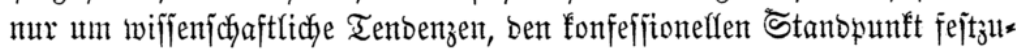
halten. Wenn man bas bei ben (ETementarjd)ulen fejtgejtellt hat, wo ber

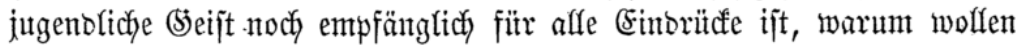

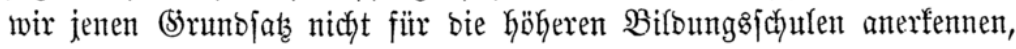

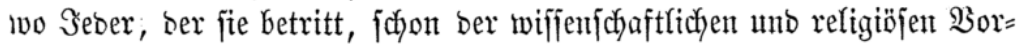
bereitung jich) zut erfreuten gehabt hat, in ben S(hoor ber Sirche alz errwact)= jener Mienfich alfgentommen worbent uno vor allen Eintwirfungen gefichert

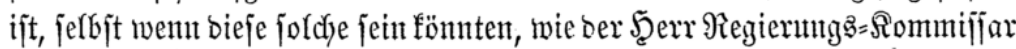
fie bezeichntet hat. Darum halten wir fonjequent an bem Brumbjats fejt,

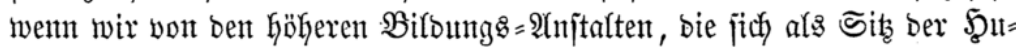

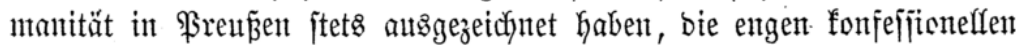

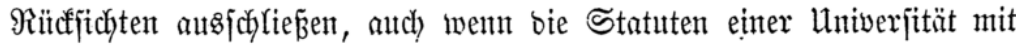
biejem (5runbjatze nicht in Einflang jtehen folftent. Eas ijt uns aber in

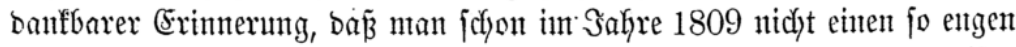
Stänopuntt einnahm, unb bie Statuten ber Berliner Univerjität meijan feinen jo engen Stanbpunt auf .... (Donnembes Brabo!) Souft haben 


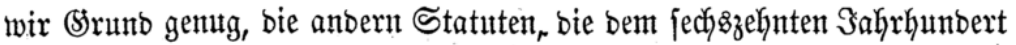
angefören, aus bem Stantopunfte bes neunzegnten Sahrfhunberts zu beleutc)=

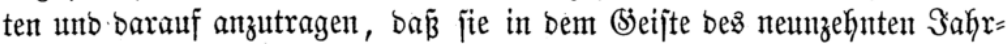

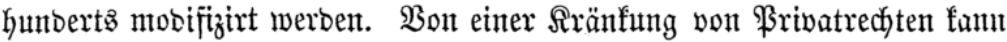
babei wohl nicht bie Rebe jein, bent bie Stifter unjrer Univerjitäten finto bie Ranbesherren felbjt getwejen. Sie haben jie zum alfgemeinen Bejten bes ganzent Rantoes gejtiftet, gejtiftet als unt Şumantität, unb jie jind baher autdy wohl befugt, ihre \$rivilegien im Sinne bes neunzegnten Sahrhunberts zu mobifiziren. (Ungemein groperer Beifallaruf unt lang anthaltenbes $\mathfrak{B r a v o}$ !) -

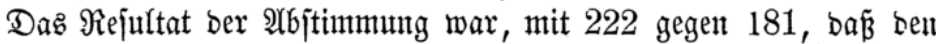
Suben alle afabemifhen Refrämter ïbertragen werben fönnen, welche nicht

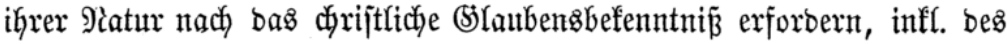
Defanatz, Proreftoratz uno Reftoratz.

Merfwürbigerweije war in ber ganzen $\mathfrak{B}$ erjammlung nux ein einzigę Mitglied, weldes ben Exfolg biefer Âtbijtimmung als iflujorifd) erfannte,

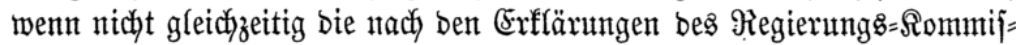

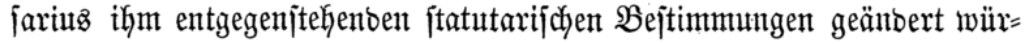
Den. Es jtelfte nämlich ber 2 (bgeorbnete von Dominiersłt folgenden Intrag:

„Meine Werren! Sie habent aus bem Munte bes Rönigfichen Şerrn

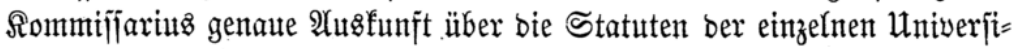

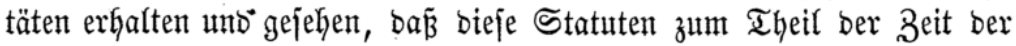

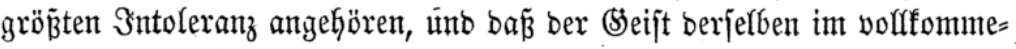
nen. 2 Siberjprudy jteft mit ber jo eben erfolgten $\mathfrak{A b j t i m m u n g , ~ u n o ~ w e m ~}$

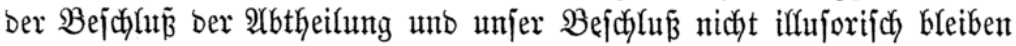

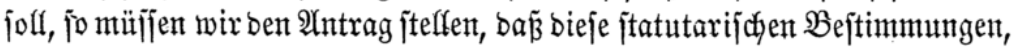
bie bem Mittelalter angefören, fo balb als möglidy umgearbeitet witroen, uno idf erfaube mir biejen Ifntrag zu jtelfen."

Der Ranțtaggmarichafl erf(ärte jeboch biejen $\mathfrak{A}$ ntrag für verjpätet

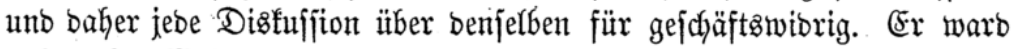

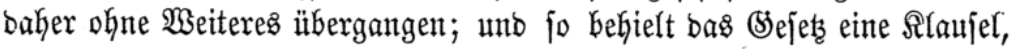
welche es bem Minijter möglidy madyte, bie Suben nicht nux nady

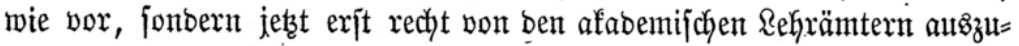
ichließrent.

Für: bie Mittheilung ber betreffenben jtatutarif dyen Beptimmungen

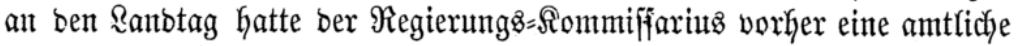
3ufamunenjteflumg berjelben angefertigt. Dieje lautete: 


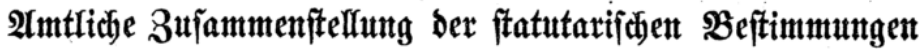 ber preußił selyrer betreffent.}

(5)eifżmald, Den 17. Dftober 1456 mit päbjtlicher Beftätigung eröffnet, von Şerzog Philitipp 1539 mieberkergejtellt.

Statuta yon 1545.

Deinde cum scholae omnis doctrinae honestae et virtutum officinae esse debeant, et praecipue opera danda sit, ut juventus ad pietatem adsuescat et doctrina christiana instruatur. -

Nos igitur quum nihil perinde in hac schola nostra constituenda spectemus, quam ut Dei optimi maximi aeterni patris, Domini nostri Jesu Christi gloria tam propagetur quam illustretur.

Itaque statuimus, ut et professores et studiosi dominicis diebus sacris caerimoniis et concionibus diligenter intersint. - Quisque igitur professorum in templo suo loco - adsint, sacras conciones audituri.

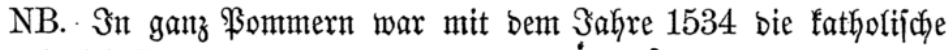
Rehre abgejchafft.

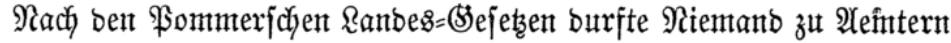

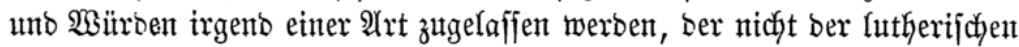
Ronfeffion zugethan war: Suben wurben gar nidyt im Ranbe gebuldoet.

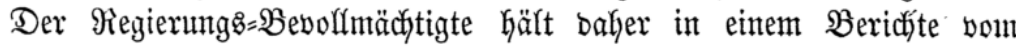

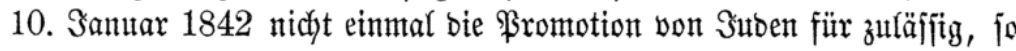
lange bie provinzialredyttichen $\mathfrak{B}$ eftimmungen nicht aufgehoben fino.

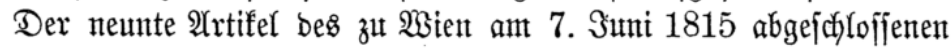
Traftats bejtimmt: Sa Majesté le roi de Prusse s'engage à maintenir les établissements, et notamment l'académie de Greifswalde, dans leur état actuel.

Scalle: S̈tatuten vom Rurfïrit Friebrich III. 3h Branbenburg, ertheilt ben 1 . Эult 1694 .

Praecipue autem consensus sit inter omnes et singulos professores in religione christiana et doctrina evangelica, scriptis prophetarum et apostolorum et augustana confessione comprehensa.

Pariter ab omnibus christianae religioni et honestati contrariis opinionibus sibi temperent.

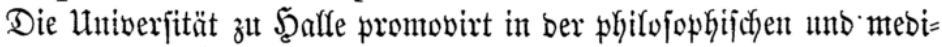




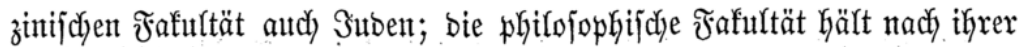
Heuperitrg vom 29. Dezember 1841 bie Promtotion ber Suben in ber

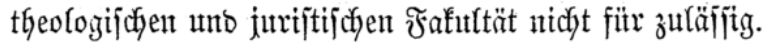

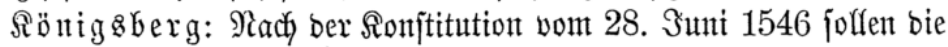
अrofefforen fdumören:

Ego juro - me amplecturum veram ac puram Evangelii doctrinam, quam uno spiritu ac voce una ecclesia Dei catholica profitetur, nec corrupturum doctrinam sacram ex philosophia.

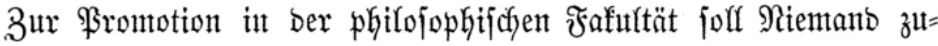
gelajfen werbent: cujus mens polluta et fascinata (verjtrifft) est falsis opinionibus et a consensu catholicae ecclesiae Christi alienis umb body promobirt man zu Röniggberg alted Sttbent.

Die neuten Statuten bom 4. Mai 1843 jeţen $§ 105$ fejt:

Der uriprünglidyen Stiftung gemäß finb bei ber Univerjität zu $\Re \ddot{b}=$

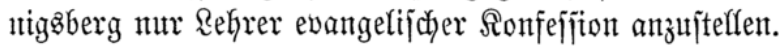

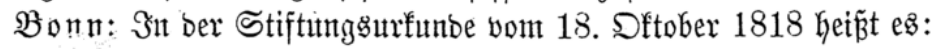

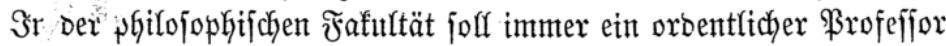

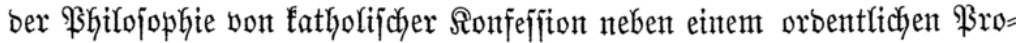

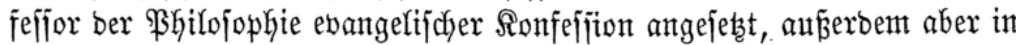
feiner Fafultät, bie beiben theologifchen ausgenommen, auf bie Sonfeffiton ser anzultellenben Rehrer $\Re$ ï

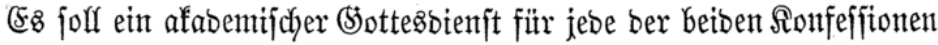
bejontberz jtattfinton.

\section{Statuten bom 18. Dftober 1834.}

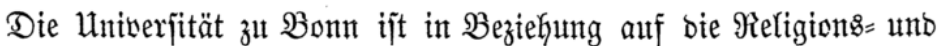

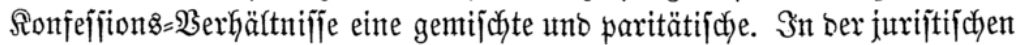
Fafulttüt joll wentigitens einer ber orbentlichen \$rofefjoren kathodijdyer Sonfeffion fein, ber bas Rehrfach bes fatholifichen Sirchenrectits inber= nefimen fann, ingleichen joll in ber philojophijçen fafultät immer ein

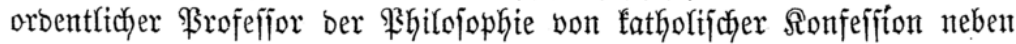

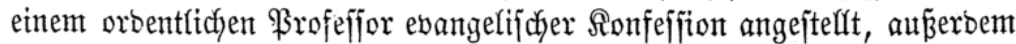
aber in feiner Fafulttät, bie beiben theologifdjen auzgenommen, auf bie

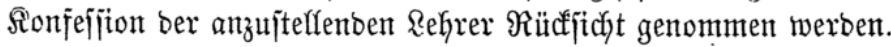

Für jebe ber beiben Ronfeffitonen ift ein afabemifcher Bottesbienjt

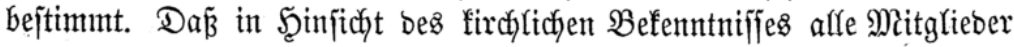
ber Univerjität gleishe Redjte haben, folgt jogon aus unjeren allgemeinen (S) jefzen, wiro aber hier nody bejontors fejtgejetzt. "Es ijt unjer ernjter

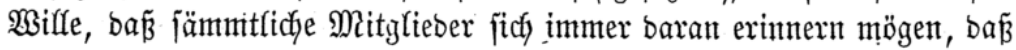

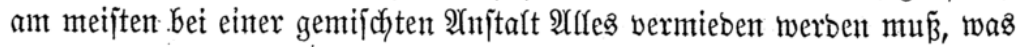
bie Recffte ber cinent ober antern Ronfeffiton fränfen unt in biejer $\mathfrak{B} e=$ 
ziefung $\mathfrak{U n} \mathfrak{n}$ uffriebenkeit und $\mathfrak{A}$ lagen verurjachen fönnte. Wir hegen baher

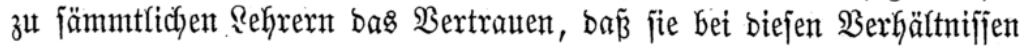
mit chriftlicher Riebe, mit Borjicht unt zarter Schomung verfahren, uno

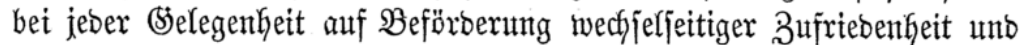
guter (Eintracht bebacfl jein werben."

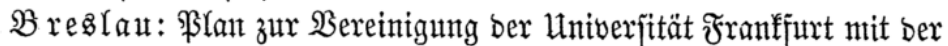

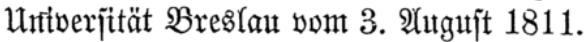

Beibe Untwerjitäten werbent in $\mathfrak{A}$ njehung ber $\mathfrak{B}$ erfafjung, ber $\mathfrak{B}$ er= fonen, ber mit ifnen verfnüpften Stiftungen, Des Sermögens unt ber Einfïnflte z̆t einem Sanzen verbunbent.

Uebrigens folf zur $\mathfrak{b e r u h i g u n g ~ u n j e r e r ~ f a t b o l i j c t i e n ~ u n t e r t h a n t e n ~ b e r ~}$

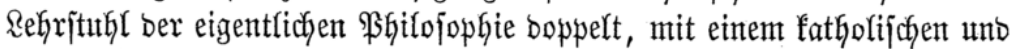
eiriem protejtantifdjen Rebrer bejetż jein.

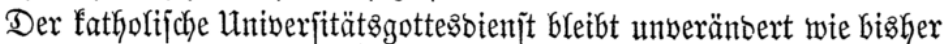

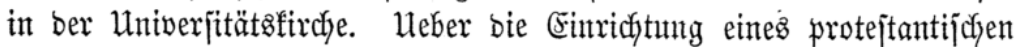

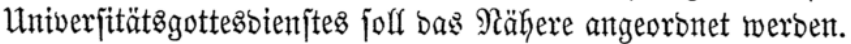

Uebrigens aber machen alle \$rofejforen, Dozenten, Dffizianten unt Stubirente ber Untwerjität ohne Unterfwieb ber Ronfefifion ein \$ban= zezి aนtร.

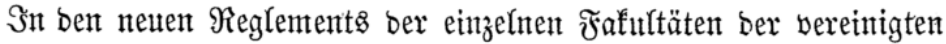

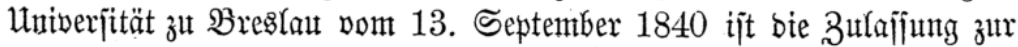

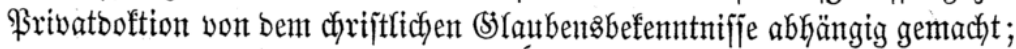

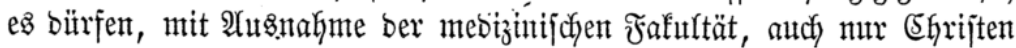
promovirt werben.

Berlin errichtet burch Afferfyöchjte Drore vom 16. 2Augujt 1809. Die Statuten ber Untuverjität finto vom 31. Oftuber 1816, Die Statuten ber

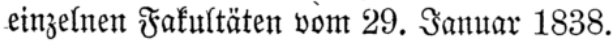

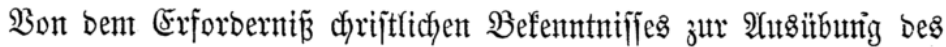
Rebiramts ijt in ben Statuten ntidyts zut fintoen; in ben Statuten ber Uni= verfität ift mux als Bwect angegeben, bie alfgemeine unb bejonbere wifjen=

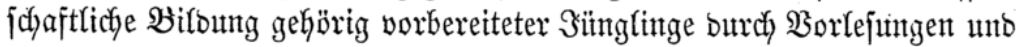
anbere afabemiface Hebungen fortzufeşent unto fie zum Eintritt in bie ver=

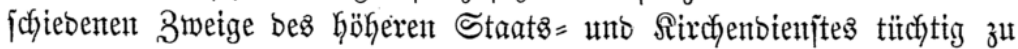

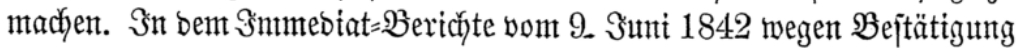

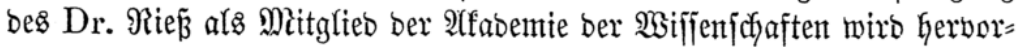

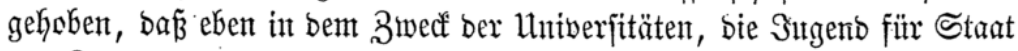

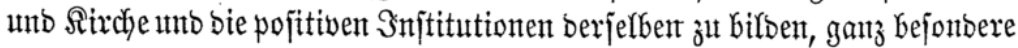

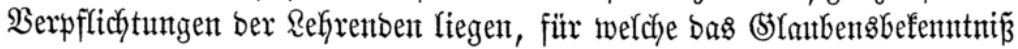
nicht gleidfgültig ift.

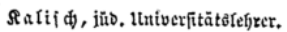




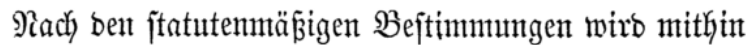

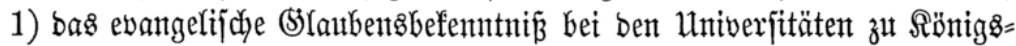
berg, Scafle und bitreifgiwalo,

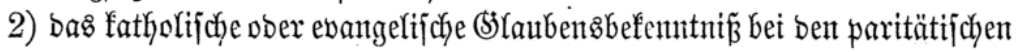
Untiverjitäten $\mathfrak{B}$ resłan unt Bom verlangt.

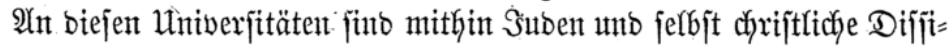
benten wegen bes Exforbernififes eines beftimmten dyriftliçen (Slaubens:

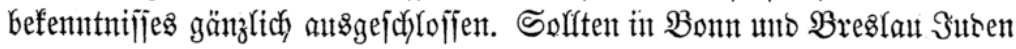

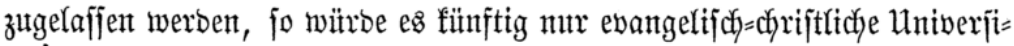

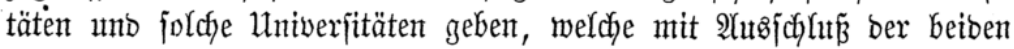

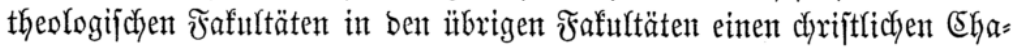

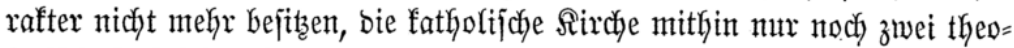
logifłbe Fafultäten bejiz̧en an Univerjittäten, welche übrigens sen doriftlichen (sharafter nicht mefyr feptyalten.

Unmittelbar nuch bem Salufje bes Bereinigten Ranbtags unb nodh

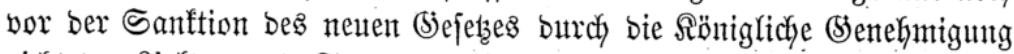

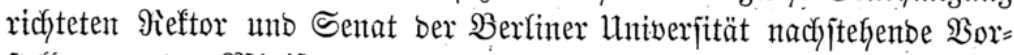
fteflung an ben Mlinifter:

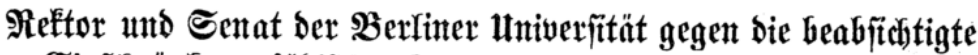

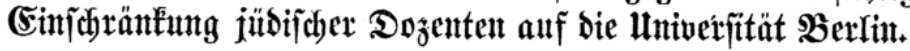

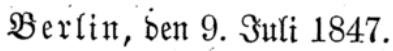

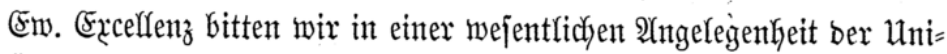
verjität, bas Folgenbe mit ber Egrrerbietung vortragent zu bürfen, werche

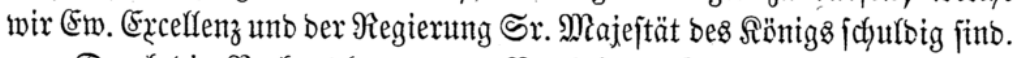

Durch bie Berhanolungen bes Bereinigten Ranbtages (alfg. Preñ.

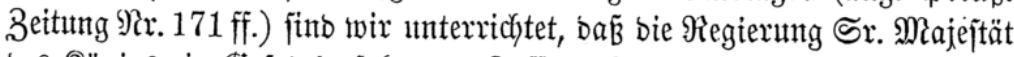

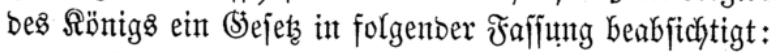

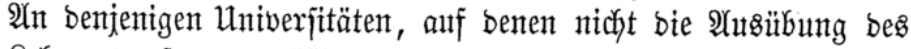

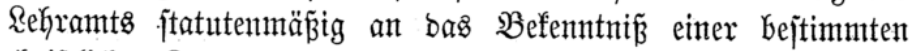

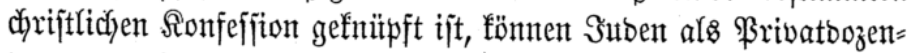
ten unt aukerorbentlicje \$rofefforen ber mathematifchen, natur= wififenfdyaftliçen uno mebizinifchen Rehrfächer zugelaffen werben.

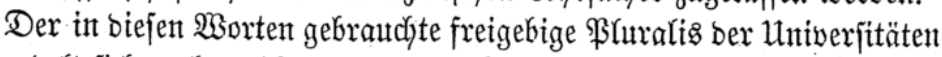

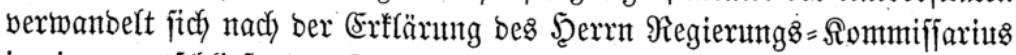

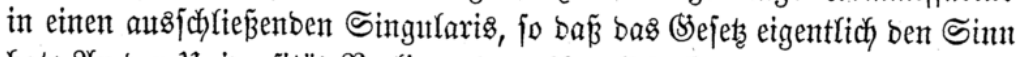
hat: $\mathfrak{A} \mathfrak{n}$ ber Univerfität $\mathfrak{B e r l i n}$ unb an ify allein fönnen Suben zugelaffen werben. (5: wirb baburch, genaut genommen, bas alfgemeine Ranbegigejets 


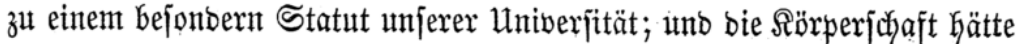

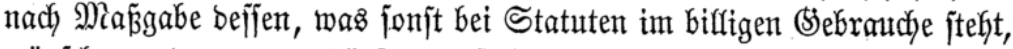

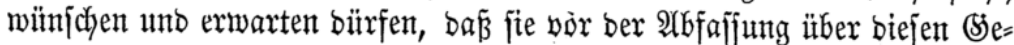

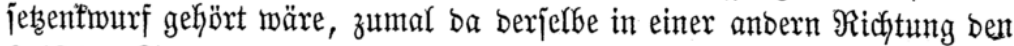
$\S 43$ ber. Statuten ber philofophijđjen Frafultät burchjadneibet, wie erkeffen wirb, wenn man bie zu bem Sejets= Entwurf gegebenen Erfflärungen mit jentem $\S$ vergleicfyt.

Die Univerjität SBerfin hat mitten in ber Ueberfülllung ber ßrofejp= ren, an. weldjer fie reibet, alfjtrebenben Sräften von wifjenjichaftlidjer Türdytigfeit nie ein Şinberni $\tilde{\beta}$ in ben $\mathfrak{B} e g$ gelegt, junbern ifnen immer

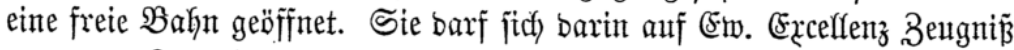

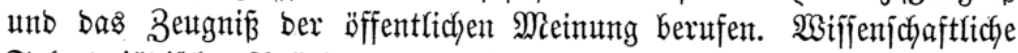

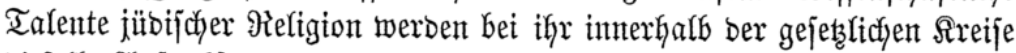
biejelbe $\mathfrak{A}$ uffnahine finben.

Wenn bie Regierung, wo es inmmer jei, hemmente Schranfent wirflich und affgemein wegräunten wiff, jo wirb bie Univerjität $\mathfrak{B}$ erlin j̣tetz bereit

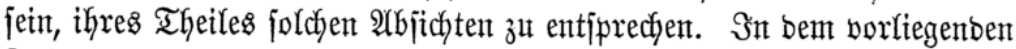
Fafle, in welchem ein julyeinbar alfgemeines (jejest in ber That auf bie Untwerjität Berfin eingejdyränft wiro, iłt jiein bejien ihrer Rage wohl ein=

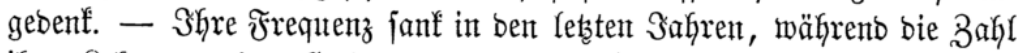

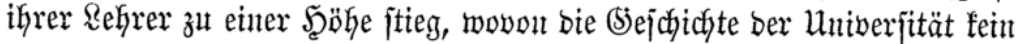
'Beifpiel hat. Sie zăhlt gegenwärtig 170 \&ehrer bet 1378 immatrifultirtent Stubenten, alfo ungefähr einent Rehrer auf 8 Stubirenbe, währent e⿱ Zeiten gab, in welchen bas Berbältniç noch einmal jo gïnjtig jtant. Sie erfennt,

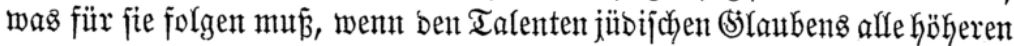

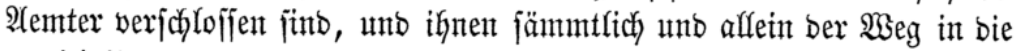

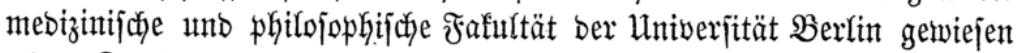

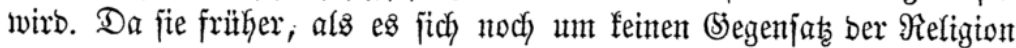

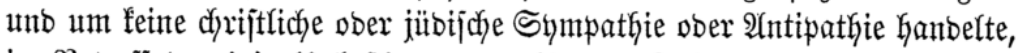

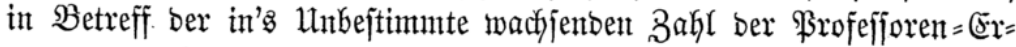
nennungen efyrerbietige Borjteffung nicht verjäınte, fo bürfte fie muth jeşt, ba ifr ein 3ubrang zugeleitet wirb, an bie vorbanbene, wie an bie brokentbe Uleberfïfluntg erimtern. SAGer wir wolfent gern bieje Seite überjehen unb bie Sache zugleidy im Sinte berer anffaffen, Denen ein freier Spielraum ifyer Thätigfeit und eine Raufbahn ifyres Rebens an unjrer Untwerjität foll geöffnet twerben.

Die Untiverjität $\mathfrak{B}$ erfin ijt, wie anerfannt worbent, mit $\mathfrak{B r o f e j p o r e n t}$

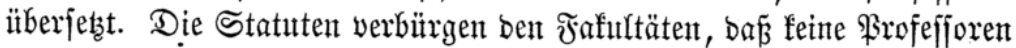
gegen bas $\mathfrak{B}$ édürfniţ ernannt werben tönnen. Wenn baker für lange Beit

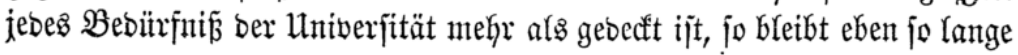




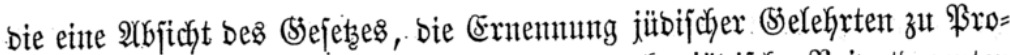
fefforen, unerreidyt. Es merben jich bejto mehr jübijche \$ribatbozenten

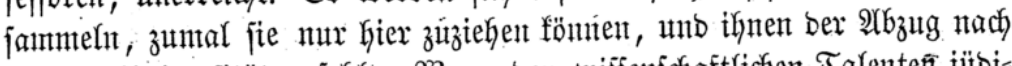

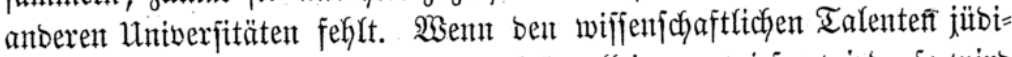

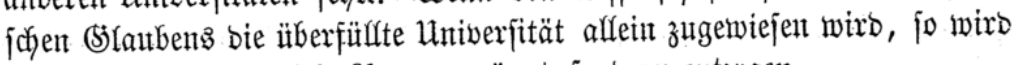
ihnen eben baburch nicht $\Re$ aum gegönnt, fonbern entzogen.

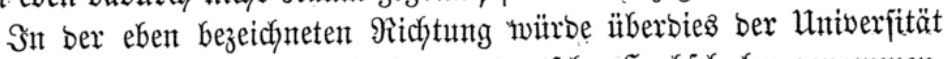

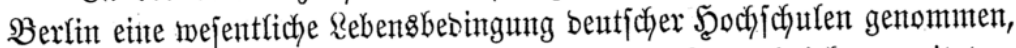

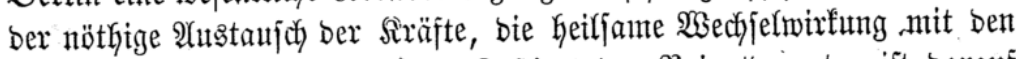

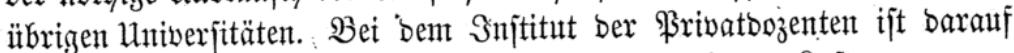
gerechnet; und es nütrbe ben Univerjitäten zur brüuffenden \&ajt, wenn man bont worn Kerein, jtatt 3 sege zu offnen, einem guten Theil ber Dozentent bie Wege veriperren wollte.

Unter biejen Unijtänben mag es̊ uns gejtattet jein, "auf bie Strünbe

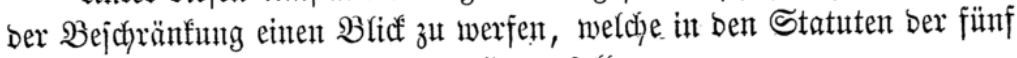
anberent prentifif

Der philojophijchent Fafultät an ber-2lfabemie zut Mänjter ijt in ben Berkanblungent nicht erwähnt worbent. Da in ben Statuten ber Affabemie

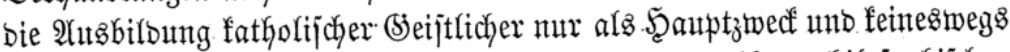

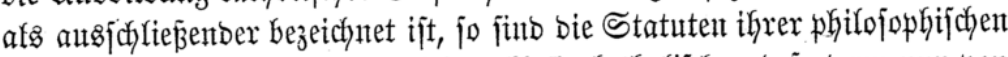

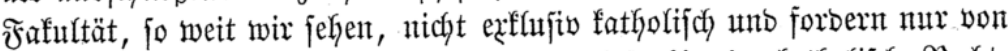

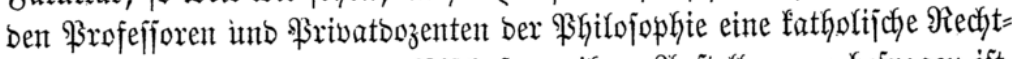

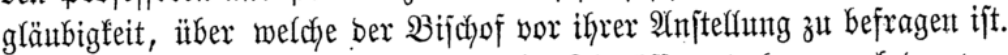

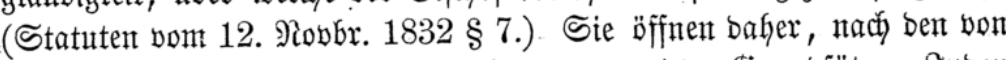

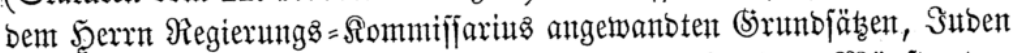
einen Bugang, ba ïbrigens bie philofophijche Fafultät zut Münjter bent

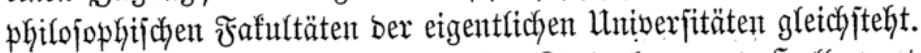

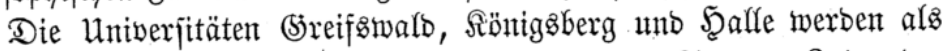

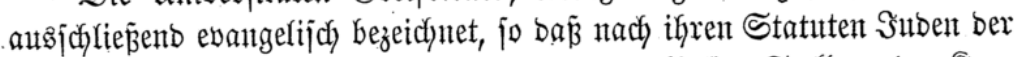

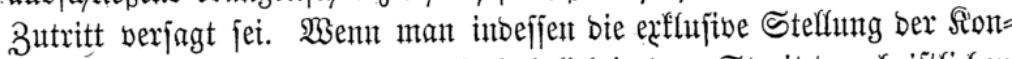
feffion hijtorifol anffapt, fo ijt jie lebiglicy in bem Streit ber dyriftlicyen Sirchen entftanben unb baher wiber bas gegenïberjtehente fatholiface $\mathfrak{B} e=$

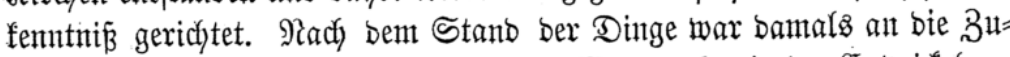
lafjung jübijacher \$elehrtent nicht gebacht. Went baher in ber Entwicfelung

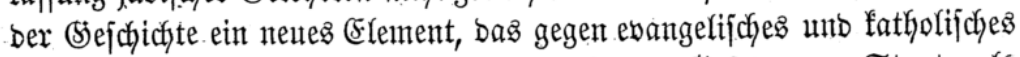

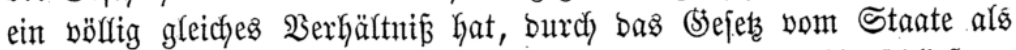

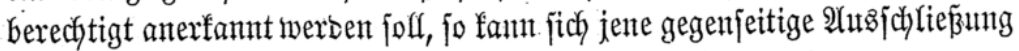
ifrem Giftorifajen Sinne nady nidyt gegen biejes britte wenben.

Die Suben jtehen zu bem ebangelijchen ober fatholijdyen Befenntnif

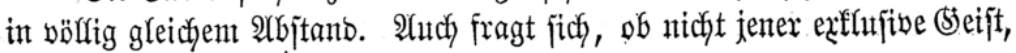




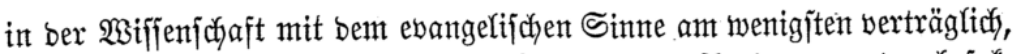

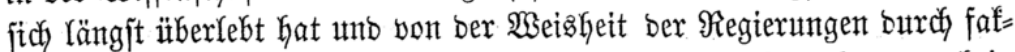

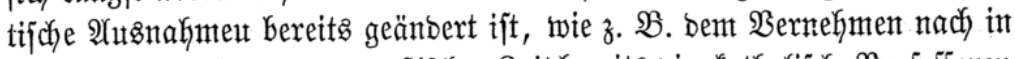

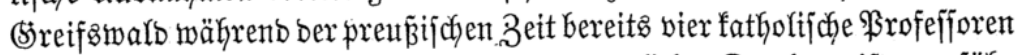

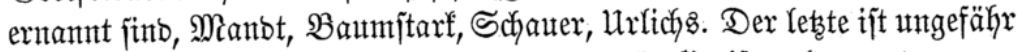
in benjelben Tagen, in welchen bie Hntwerjität Sreifsmald von bem von

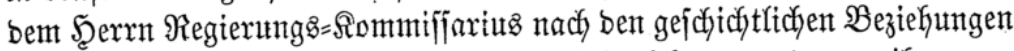

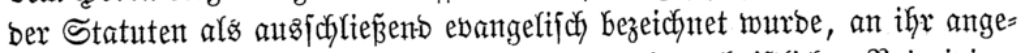

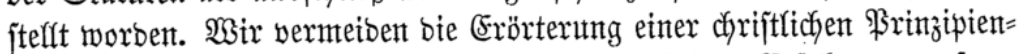
frage, aber bürfen nach ber fiebenumboreiß̧igjährigen Erfahrung unjerer

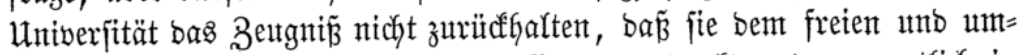
fajfenbent Steijte ber Statuten mur (S)utes verbanft und namentfich in

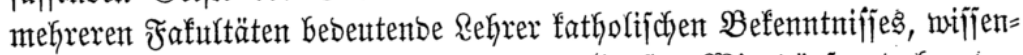

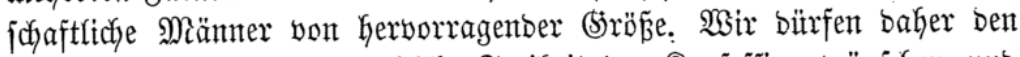

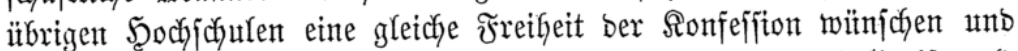

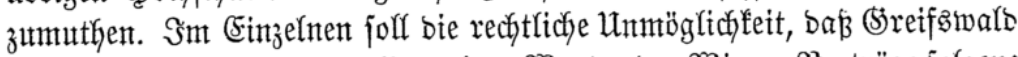

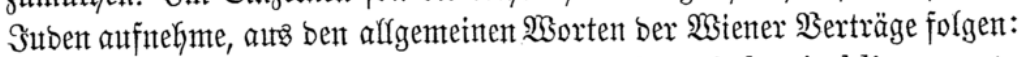
Sa majesté le roi de Prusse s'engage à maintenir les établissements et notamment l'académie de Greifswalde dans leur état actuel. Der

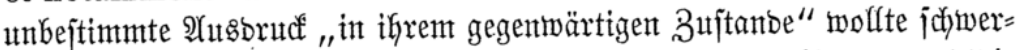
lich ber Univerfität Streifäwalo einen jtarren Bejtand verbïrgen, unb bie

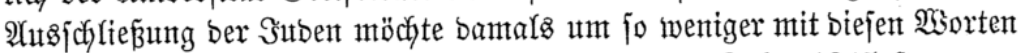

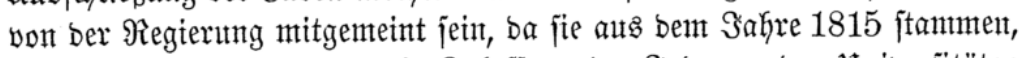

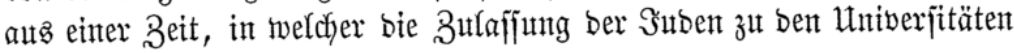
Maxime ber Megierunt war.

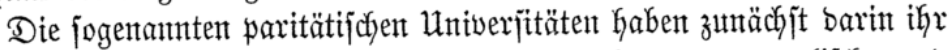

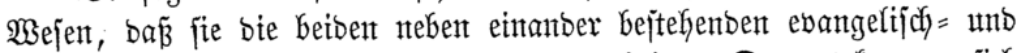

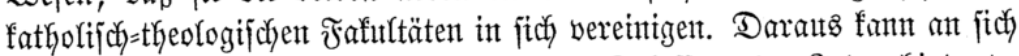

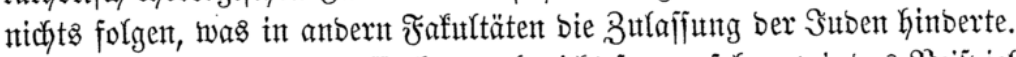

Frither hat man es offenbar audy nicht fo angejehen, wie bas Beijpied

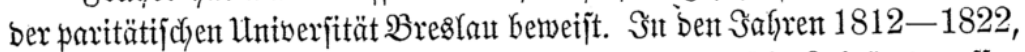
in welchent bent Suben nady bent Ranbesgejes afabentijche Refrämter offent ftanbent, waren bort, wie wentigjtenis (5raf gort anfithyrt (affy. \$reun.

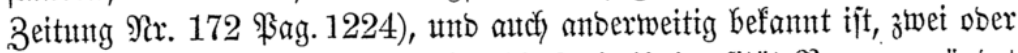

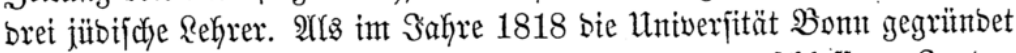

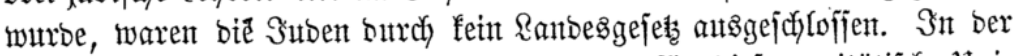

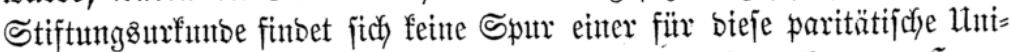

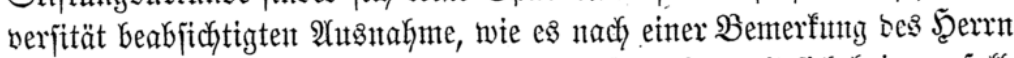

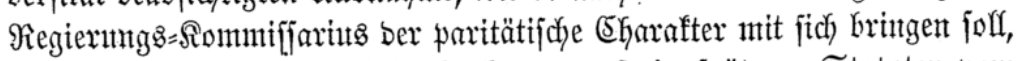

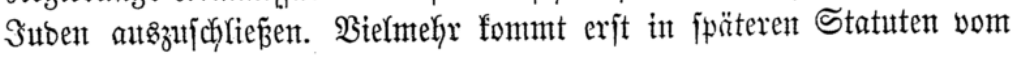




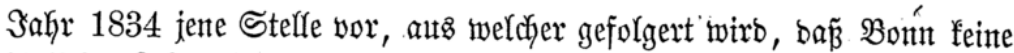

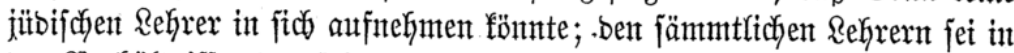
bent $\mathfrak{B e r h a ̈ l t n i f f e n t ~ b e r ~ f i c h ~ t r e n t e n t o e n ~ f i r c h l i c h e n ~ B e f e n n t n i f f e ~ b i e ~ g e m t e i n = ~}$

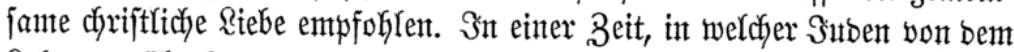

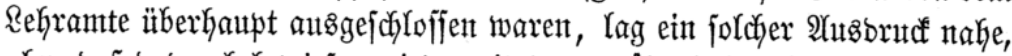

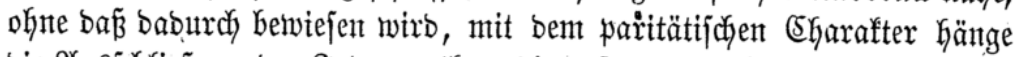

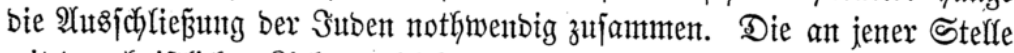
mit ber dyriftlichent Riebe zugleich entpfohlene $\mathfrak{B o r f i c h t ~ u n t ~ z a r t e ~ S c h o u n n g ~}$

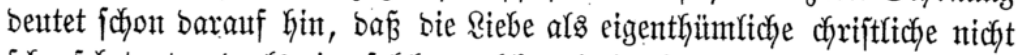

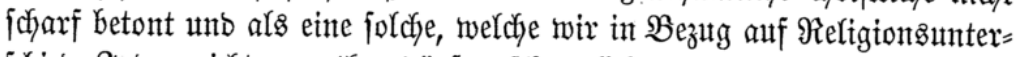

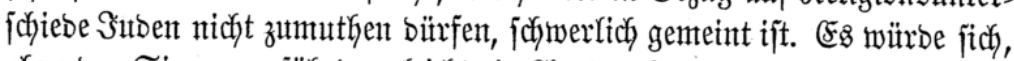

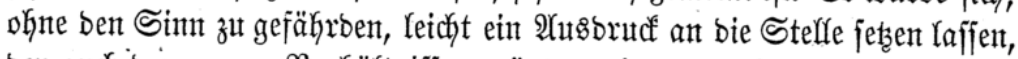

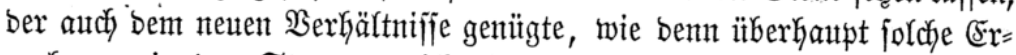
mahnung in ben Statuten nidyt füglich als jtatutarifache Beftimnnung gelten fiann.

Wir fönnen nidyt anbers untheilen. Faftifd haben gegentwärtig alle

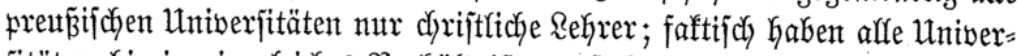

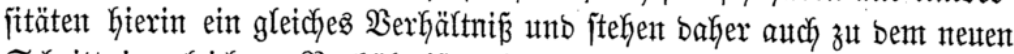

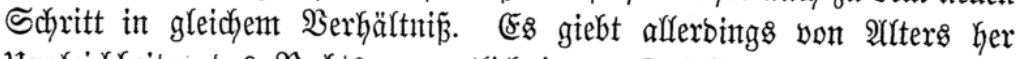

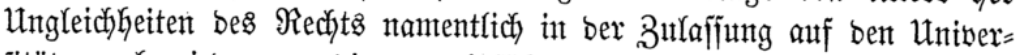
jitäten; aber jebe neute, bie man einführen mödyte, ift gegent ben (Seijt ber

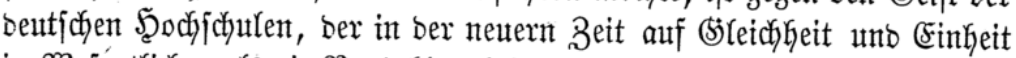

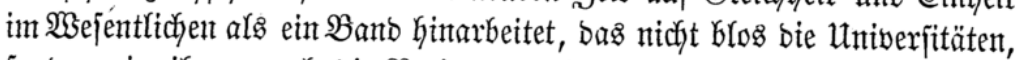

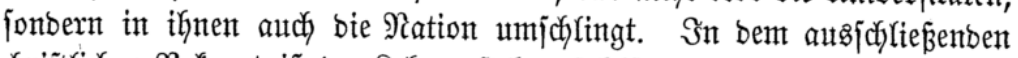

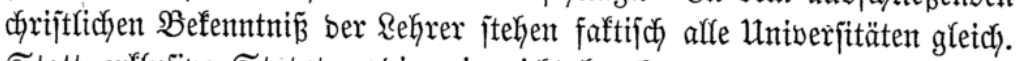
Statt exffujibe Statuten, bie wix nicht begehrent mürben, gilt bet uns

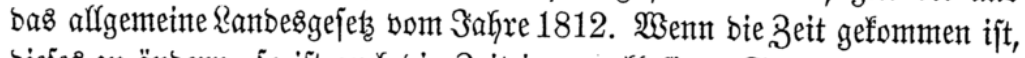

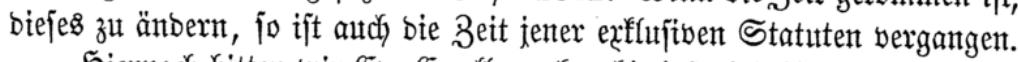

Şiernach bittent wir Ew. Exzeffenz efrerbietigit, bet Sr. Majeftät bem Rönige bahin wirfent zu wollen,

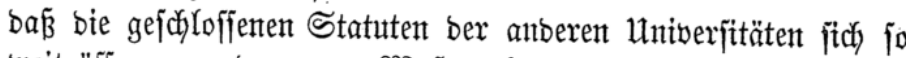

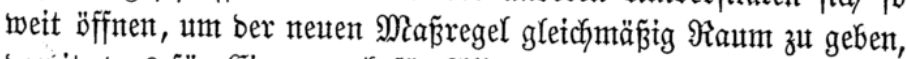
banit, was für Einen, autch für Îlfe gelte.

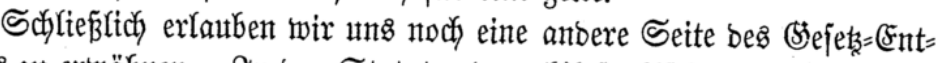

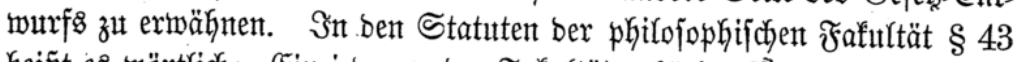

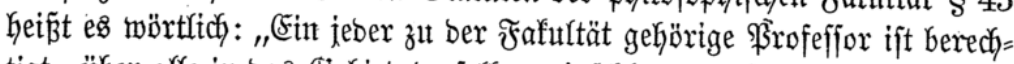

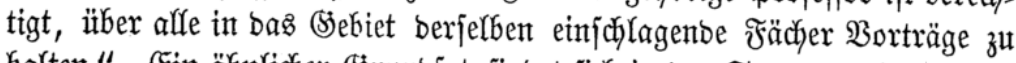

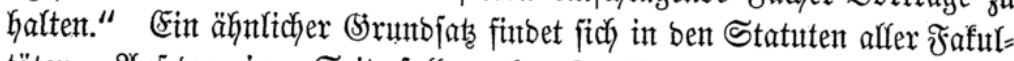

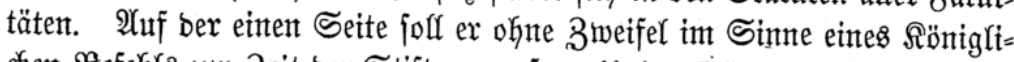
chent Befehlz zut Beit ber Stiftung unjerer Untwerjität bem, ,Mimonopolien= 
geijt in ben Wifjenjchaften" entgegen arbeiten unb auf ber anbern ben

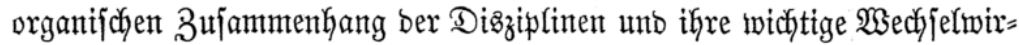

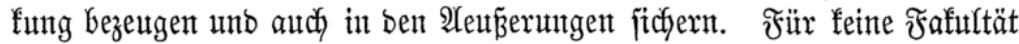
ift indeffen biejer (stuntojats wejentficher alz für bie philojophifache, bie recht

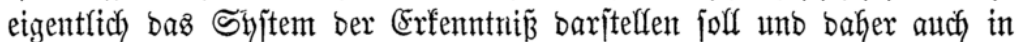

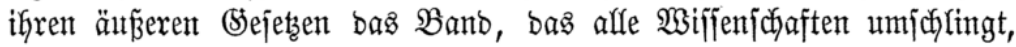
nicht gefähroent barf. Wenben wir mun bieje $\mathfrak{B}$ ejtimmunt auf joldje $\mathfrak{P r o}=$ fefforen jübifiden (STaubents an, weldje nach bem (Entwurf für mathe = matijche ober naturwififenjchaftliche Rehrfächer ernannt worben: jo jinto jie ofne Frage berechtigt, auth itber anbere Dizziplinen ber philojophifdyen

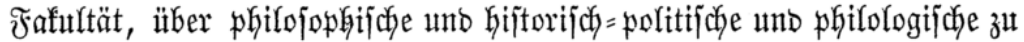
lejen. Die Fafultät, ihren moglbegrïnbeten Statuten getreat, fann und

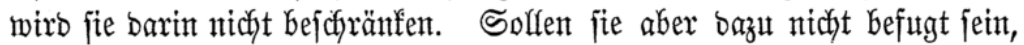
wie freilich bie zu bem Entwurn gegebenen Erffärungen voraugajeţen: jo ijt bantit ein twejentlicher unt aflgemeiner Srumbjats"ber Statutent burchbrochent.

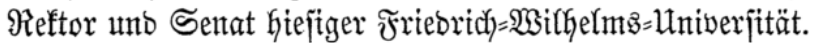

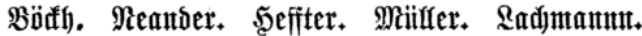

\section{Şierauf erging folgenter $\mathfrak{B}$ eichetb.}

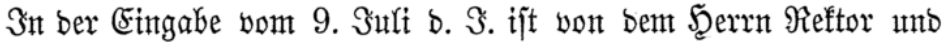
Senat eine bantals noch in ber $\mathfrak{B e r h a n b l u n g ~ b e g r i f f e n t e ~ u n d ~ g e j e r s f i c h ~ n o c h ~}$

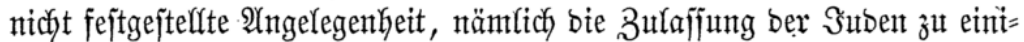
gen afabentifhen Rehrämtern, näher erörtert worbent. Es war yon yorn

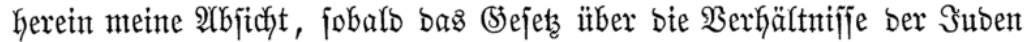

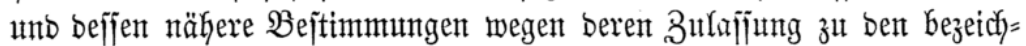

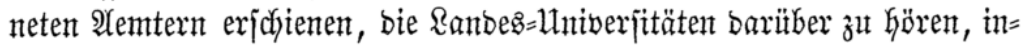

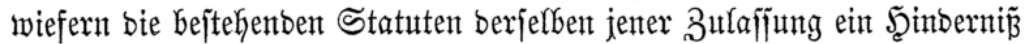
entgegenjtellen, and ob, went bies ber Fall jei, eine Mcobififfation berjelfent

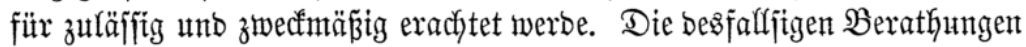

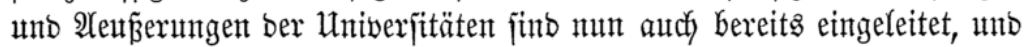
ich fehe baher zur Zeit noch feine Şeranlafjung, auf bie in ber Eingabe

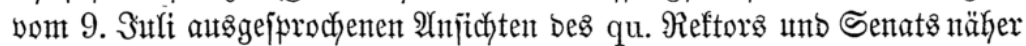
einzıtgehen, bejadyänle midy vielmełr barauf, einen am Schlujije ber Eingabe berïfyten Bunft zu berichtigen. Der Şerr Reftor unt Sent jutto ber

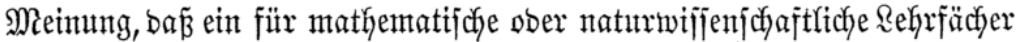

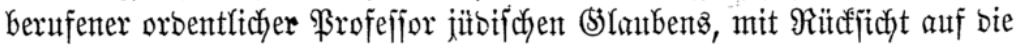
in ben Statuten alfer Fafinltäten enthaltene Bejtimmunty, bá jeber jut Fafurtät gehörige \$rofeffor Geredytigt fei, ïber alfe in bas \$sebiet berjelbent

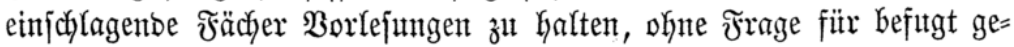

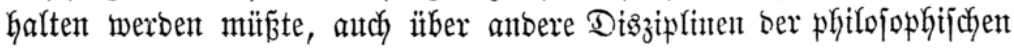




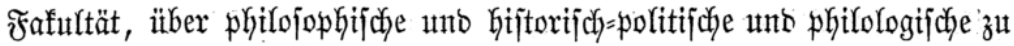

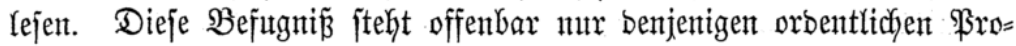
fefforent zut, welche auf bent Brutto ber bejtehenben Statutent ohne bejon= Dere Befdyränfint berufen uno angejteflt worben. Werben bagegen

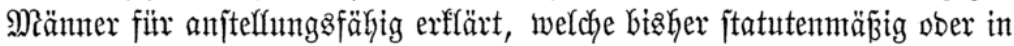
Jolge alfgenteiner gejetslicher Beftinmunngen von berartigen Âtnjtellungen

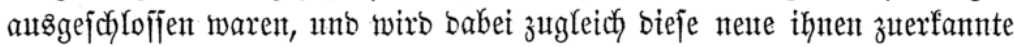

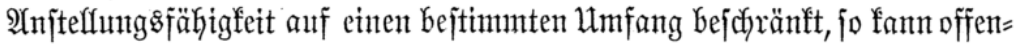
bar bieje bejchränfte 2Anjteflungafähigfeit, welche auf einem bejonbern Siejetse beruht, nicht vermöge einer in ben Statuten enthaltenen Bejtinnnutng ïber biejen $\mathfrak{H}$ mfant auggebehnt werben, unt ebenfoiventig wirb baburch ein twe

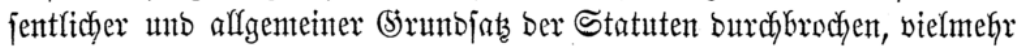
bleibt berjelbe für alle Diejenigent bejtehen, für weldye er bisker gegolten hat.

Berlin, Den 28. September 1847.

Der Minipter ber geiftlichent, Itnterrichts= ant Mebizinal= 2̂ngelegenheiten.

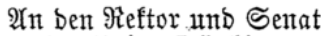
(cid)horti.

Der Untuerfität Gier.

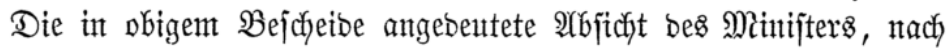

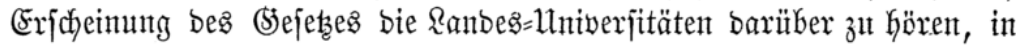
wiefern bie bejtehentent Statutent berferbent ber Bulajfung Der Yntben ein

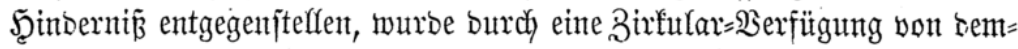
ferben Datum in's 2 Serf gejetşt. Diejelbe lauttete:

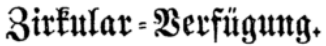

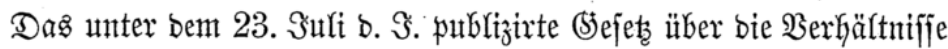

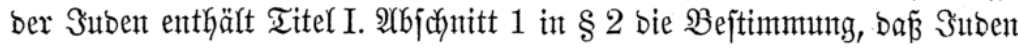
an Uniberjitäten, joweit bie Statuten nicht entgegen jtehen, als \$ribat=

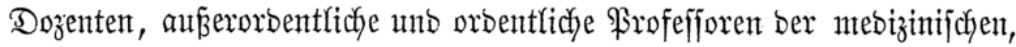

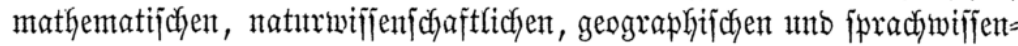

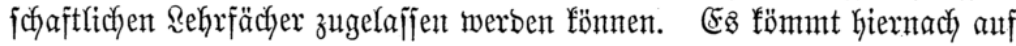
eine gründliçe Erörterung an, ob bie bejtełenden Statuten ber Untuerfität

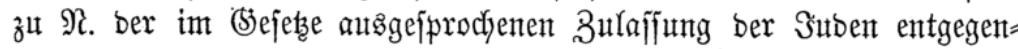
jtehen ober biejerbe gejtatten. Frw. Scodywohigeboren erjuthe idy baker,

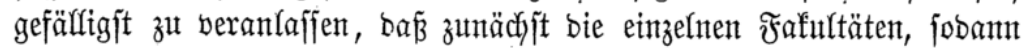
autc) $\Re$ eftor unb Senat barüber,

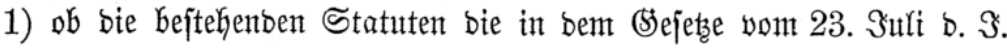

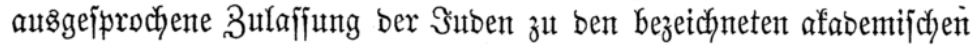
Rebriächern geitatten ober niç,t, und 
2) ob, wenn bie Statutent bieje Bulafjung nicht gejtatten, eine Modi= fif́ation berjelben für zuläffitg und angemefjen zu eradjten jei, näher berathen uno jich äufern. Bei ber Wichtigfeit ber Sache ifjt nichtos

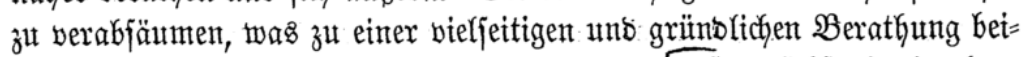

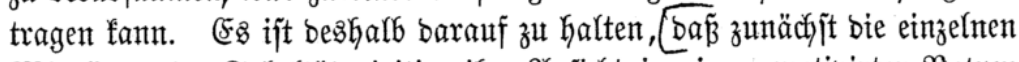

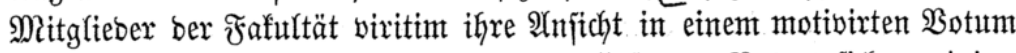

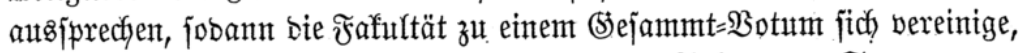

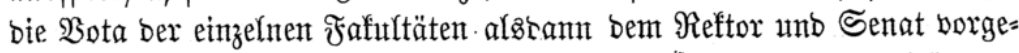
legt werben, welche zulleţt bie Sache in ihrem, bie ganze Itniverfität um= fajfenben Bujammenhang, unter Beriüffichtigung ber in ben einzelnen Fafultäten abgegebenen Singular= und (Sejammt=(5)utachten, z̧山 ertwägen,

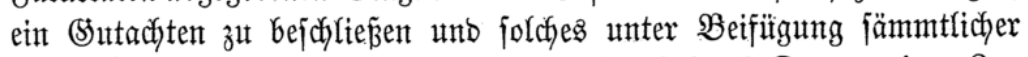
vorausgegangenter Berkanblingen einzureichen habent.] Da von einer $Z^{\mathfrak{t}=}$

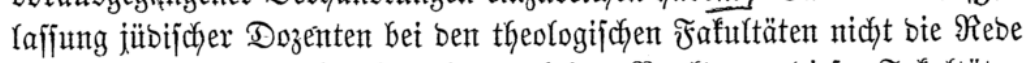
fein fant, fo fint bie oben bezeidyneten beisen \$untte von biejent Fafultäten

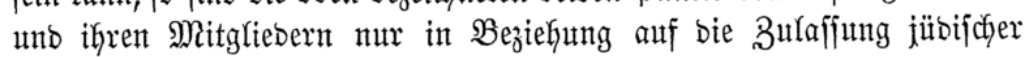
Dozenten bet ber Utniwerjität überfaupt zu berathen unb zu beantworten.

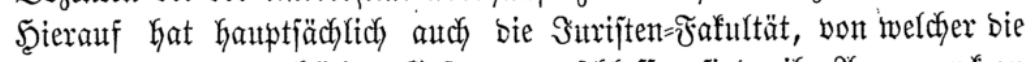

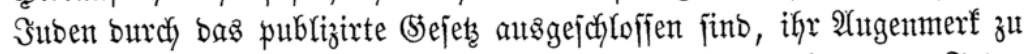

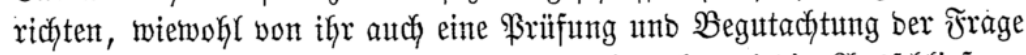

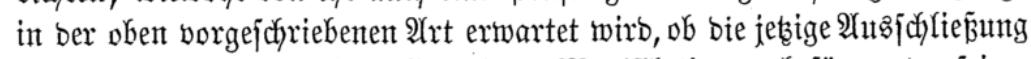

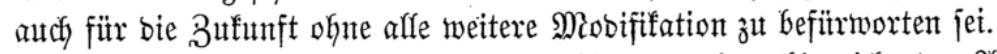

Эnjofern bie gegentwärtig geltenben Statuten einen finreidjenten $\mathfrak{A}(\mathfrak{n}=$ halt zur Beantwortung jenter \$unfte nicht ergeben, ijt auf bie älteren Sta=

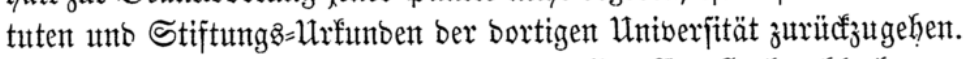

Die jämmtliç̧en SBerḩanblungen molfen (Fw. Şodjwohlgeboren mir unt żwar \{pätejtens nad) bret Monaten gefälligit vorlegen.

Berlin, ben 28. September 1847.

Der Minifter ber geiftlichen, Unterridyts= und Mebizinal= Îtrgelegenheiten.

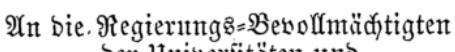

(Eid)hyornt.

ber Intuiverjitïten und

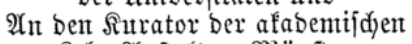

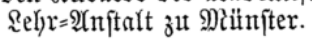

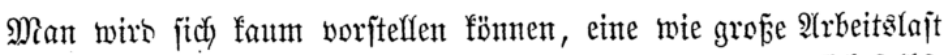
bas Minifterium butrdy bieje Mafiregel ben Univerjitäten uno fich felfit auffitrbete; baffelbe ergriff fie aber mit grofem $\mathfrak{B} e b a d y t$, ja es fant in ifgr

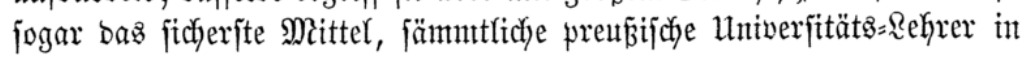




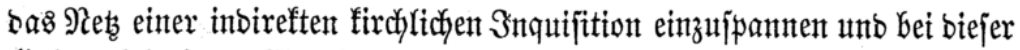
Selegentheit jeben Einzelnen zu zwingen, feine ächt dyriftlidfe \$ejünung

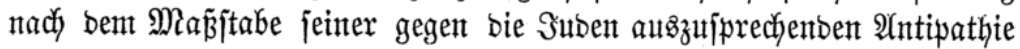
mehr ober mintor zut betwährent. Der 3 weed bes Minijters mitroe nach

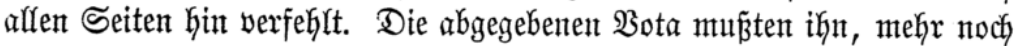

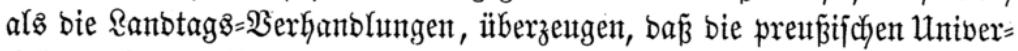

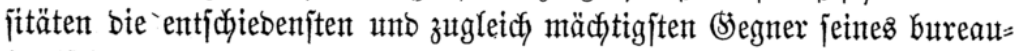

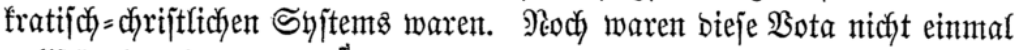

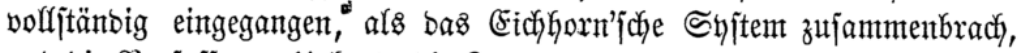

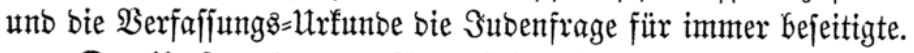

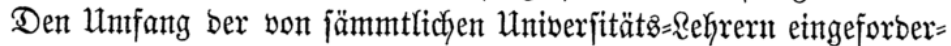

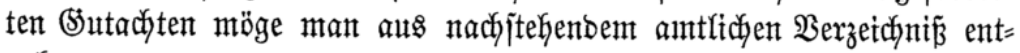
nebmen. 


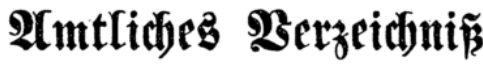

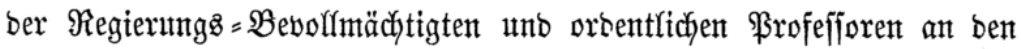

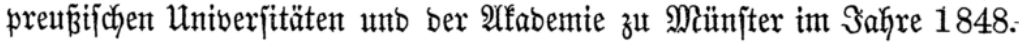

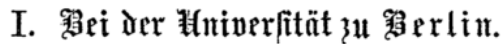

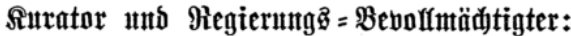

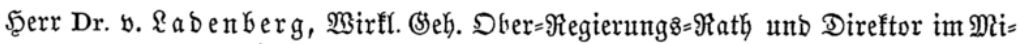

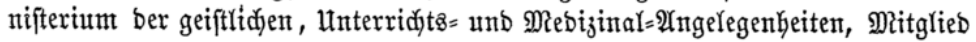
bes Staats̊ratḩs.

\section{Theologifde $\mathfrak{F} \mathfrak{a}$ furltüt.}

Seerr Dr. Reanber, Dber=Ronfiftorial=

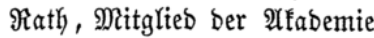
Der $\mathfrak{B i f i f e n}[$ dafter.

$==\mathfrak{T}$ weften, $D$ ber $=$ Ronfiftorial $=$ Rath.

$==\operatorname{Str} \mathfrak{a} \mathfrak{u} \tilde{B}, \mathfrak{B i n f l}$. Sber $=\Omega_{\mathfrak{o n}}=$

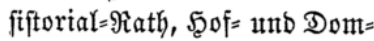
prebiger.

$==$ Sengftenberg.

$==\Re i t z i d, \quad D b e r=\Omega o n f i f t o r i a l=$

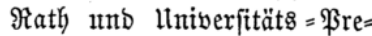
biger.

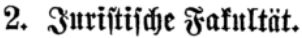

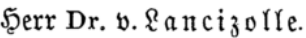

$=$ = Feffter, (Jeh. Dber $=\mathfrak{T r}$ ribut $=$ nal $8=\Re$ iath.

$=\quad$ 5gomeyer, (5eh. Dber $=\mathfrak{T} r i=$ butals=ఇath.

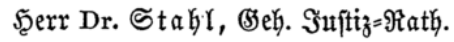

$==$ Ruborff.

$=$ Reller.

$==$ Riduter.

$=$ = Seydemann.

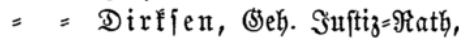

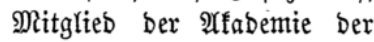
खiffenjuaften.

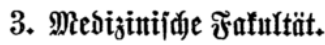

Seerr Dr. \&i.nf Mitglied Der $\mathfrak{A} f a b e m i e$ ber खifienfidaften.

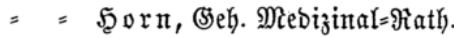

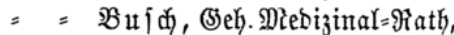
Direft. D. Entbinbungåanftalt.

$=$ = Sab̈uleit, (5eh. Dber=:Die= bizinal = Rath, Reibarzt Sr. Maj. Desి Rünigs, Direftor Der

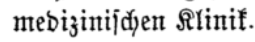


ફ̧err Dr. Mï̈rfer, (5eh. Mebizinal= Rath, Direftor ber anatomi= fajen Sammlung und bez ana= tomifdyen Theaters, Mitglied Der $\mathfrak{X}$ fabentie ber $\mathfrak{W} i f \mathfrak{e n}=$ (d)aftent.

$==$ Sdlemm.

$==$ (5. 5ृ. 5 d) $u l$ th.

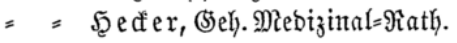

$=$ = Süngfen, (Sel). Mebizinal= 丹ath.

$=$ = Easper, (5eh. Mebizinal=

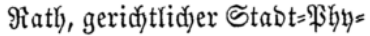
fifłıs.

$=$ = Eranberg, Mitglieb und bejtänbiger Sef́retär Der $\mathfrak{2} \mathfrak{f} \mathfrak{a}=$ bemie ber sisifenjuaften.

$=$ = Mitfderlidj.

$==$ Romberg, Direftor bes poli $=$ flinijoden Snftituts Der-Univer= fität.

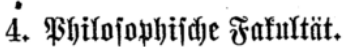

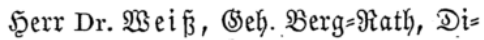
reftor ber Mineralien= Sanm $=$ lyung, Mitglieb ber $\mathfrak{A}$ abemie Der $\mathfrak{W}$ ijjenjd)aften.

$=\quad=$ b̈ đfh, (jeh). Regierung: Rath, Direftor Des philolo= gijden Seminars unb bes $S_{e}=$ minars für gelehrte Sd)ulen, Ephorus Der Яurmärfijden Stipendiaten, Mitglied und beftänbiger Sefretair ber $\mathfrak{2} \mathfrak{f} \mathfrak{a}=$

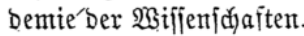

$=$ = mie ber \$ifijenjdaften.

$=\quad$ \&idytenftein, (5)eh. Mebizi $i=$ nal= $=\Re a$ th, Direfter ber zoolo= gifden Sammlung, Mitglied

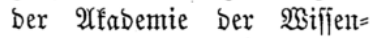
fduaftent.

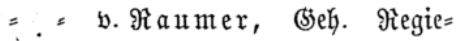

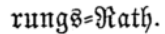

$=\quad$ = Beffer, Mitglieb ber Mfábe mie ber Mifijenjdaften.

$=$ = v. D. Seagen, Mitglied Der Ŷfabemie ber \$̇iffenjajaften.

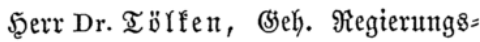

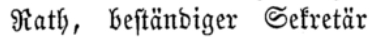
und Mitglieb Dez Senats Der भrfabemie Der Rïnfte, Direftor ber antiquarijdyen Arbtyeifung besิ Mư

$=$ = Dirf́fen, Mitglieb ber $\mathfrak{A} \mathfrak{a} \mathfrak{a}=$

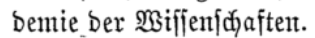

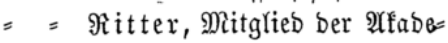

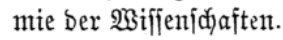

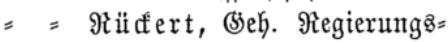
গath.

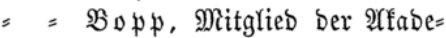
nie ber $\mathfrak{B}$ iffenjdjaftent

$=\quad=$ Mitidjerlidy, (5eh. Mebizi $i=$

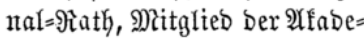
mie ber $\mathfrak{3 i j j e n j d ) a f t e n . ~}$

$=\quad=\quad \mathfrak{a} \mathfrak{d} \mathfrak{m} \mathfrak{a} \mathfrak{n}, \mathfrak{M i t g}$ Yied ber $\mathfrak{A} \mathfrak{a}=$ Demie ber $\mathfrak{x i f f e n j d y a f t e n . ~}$

$==\Re \mathfrak{n} t \mathfrak{h}, \mathfrak{S i c e}=$ Direftor Des botanijaden (5artents, Mitglied ber $\mathfrak{A} \mathfrak{f} a$ bemie ber $\mathfrak{B i f j e n =}$ jdjaften.

$=\quad=$ Seuber.

$==\Re \mathfrak{a} \mathfrak{f} \mathfrak{e}$, Seifturiograph bez Preupijdyen Staats, Mitglied Der Urfabemie ber $\mathfrak{3 i f f e n =}$ [d)aftent.

$=$ Dieterici, (5eh. Dber $=\Re i e=$ gierungs $=\Re$ ath, Direftor Des ftatiftifden $\mathfrak{B u ̈ r e a u s ~ u n o ~ M i t = ~}$

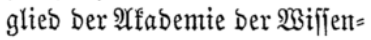
\{d)aften.

$==\$ \mathfrak{a} \mathfrak{a} \mathfrak{b}$ ler.

$=$ = b. Wenning.

$=$ = $\mathfrak{T} . \mathfrak{R} \mathfrak{p}[\dot{e}, \mathfrak{M i t g l i e b}$ ber $\mathfrak{A} \mathfrak{A} \mathfrak{a}=$ bemie ber \$ijijenjuaften.

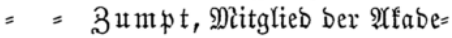
mie ber $\mathfrak{W i f j e n j d j a f t e n . ~}$

$=\quad$ Trendelenturg, Mitglied ber $\mathfrak{U} \mathfrak{f} a$ bemie ber $\mathfrak{B i f f e n}=$ (d)aften.

$=$ = \$5. $\mathfrak{A} \mathfrak{0}[\mathrm{e}, \mathfrak{M}$ itglied ber $\mathfrak{A} \mathfrak{A} \mathfrak{a}=$ bemie ber $\mathfrak{B i f j e n}[d) a f t e n$.

= Rejenne Diridylet, Mit=

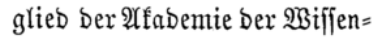
fdjaftent.

$=\quad \mathfrak{D h} \mathrm{m}$. 
Seerr Dr. (5) elzer.

$=$ = Endfe, Direftor ber Rönig= lidjen Sfermmarte.

$=$ = (5)rharb, 2Trdäolog bes Röniglidjen Mu[euntzి], Mitgl. ๖. Âtabemie D. Wifjenjafaften.
Şerr Dr. Dut ve, Mitglieb ber $\mathfrak{X}$ fabemie ber $\mathfrak{B}$ ifjenjuaftent.

- = $\mathfrak{M a g n u} \bar{b}, \mathfrak{M i t g l i e b}$ ber $\mathfrak{A} \mathfrak{f} \mathfrak{a}=$ Demie ber $\mathfrak{B}$ ififenfdaften.

$=$ Franz.

= Repjius.

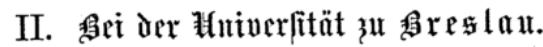

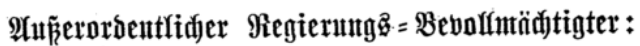

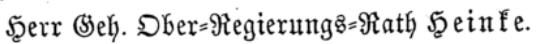

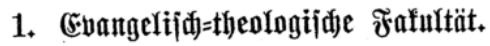
Jeerr Dr. Sd) $u I_{z}$.

$=$ = Mibbelborpf, Dber $=$ Ron $=$ fiftorial = $\Re$ iath.

$==\mathfrak{T} \mathfrak{a} \mathfrak{h} \mathfrak{n}$.

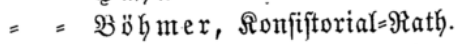

$==$ (5) a $\downarrow p$, Ronfiftorial= Rath.

$=$ Defler.

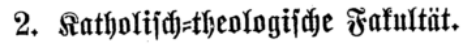

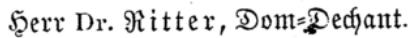

$=\quad$ Baltzer, Domberr.

$=$ = Demme.

$=$ Moverg.

$=$ = $\mathfrak{B} \circ \mathfrak{l}$.

= Ric. theol.: Friebrieb.

3. Juriftijade ซafulultät.

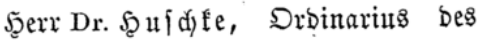
Sprud)= Rolfeginms.

$=$ = $\mathfrak{A}$ begg.

$=$ = Megentredt.

$=\quad=$ (5) a thp .

$==$ Wilba.

\section{Mesiżintijade ซึafulthät.}

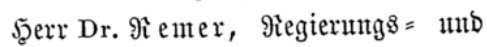
(5eh). Medizinal= Rath.

$=$ = Senedict, (5eh). Mebizinal= গiath.
Serr Dr. \$ứrinje.

$=$ = Sentdel.

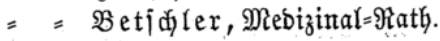

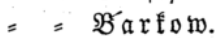

$=$ SBppert.

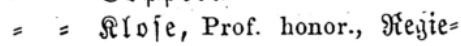

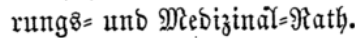

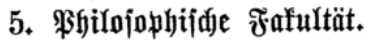

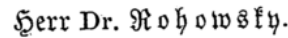

$=$ = $\mathfrak{T h i l o}$.

$=$ = (5raventorft, (5eh. Fofrath.

$==\mathfrak{F i}$ ider.

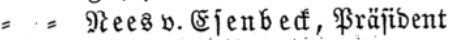
ber f́aijerl. Seopolb. = Earol. $=$ Iffabemie ber ?aturiorjdjer.

$=$ Sdneiber.

= Bernftein.

$=$ = Stenzel, (5el). Ardjiorath.

$=$ = Elventd.

$=$ = Pohr.

$=$ = Srofer.

$==\mathfrak{B r a n i \tilde { \beta }}$.

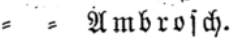

$=$ Rummer.

$=$ Selafoto

$=$ Dr. $\Omega$ utzen.

$=$ Stentifer.

$=\quad$ Jea $\mathfrak{a} \mathfrak{e}$.

$=$ = Terfímpi. 


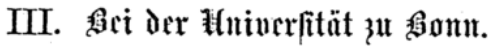

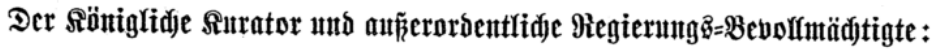

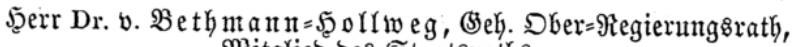

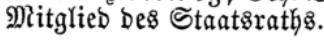

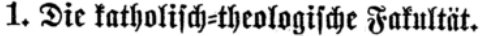

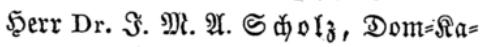

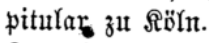

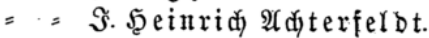

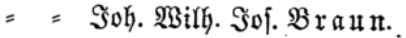

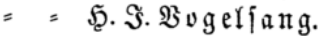

$==\mathfrak{F r a n} \mathfrak{z}$ aver Dieringer.

$=$ = B. S. Şilgerฎ.

$=$ = Eomrab Martin.

\section{Die evantgelifid = thenlogi $i \mathfrak{d}$ e} ซึafulttüt.

5ૃerr Dr. Friebr. Bł

- fiftorial= $\Re$ ath.

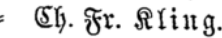

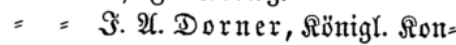
fifforialrath unb Mitglieb Dez

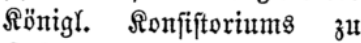
Roblenz.

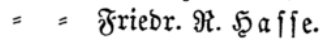

3. Die jurifitifđje Fafuluttüt.

Şerr Di. F. $2 \mathfrak{G} \mathfrak{a l t e r}$.

$==\mathfrak{F r} . \mathfrak{B} \mathfrak{1}$ ume, (jeh. Suftizrath.

$==$ E. Bö ofing.

$=$ = Pet. Fr. Deiters.

$=$ Sarl Serr.

$=$ = Slem. PertheB.

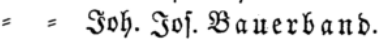

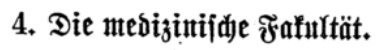

Şerr Dr. Shrift. F̛r. $\mathfrak{F} \mathfrak{a} \mathfrak{r} \mathfrak{l}$ e $\mathfrak{\beta}$.
Şerr Dr. Fr. Эof. ․ Mayer.

$==\mathfrak{F r}$. $\mathfrak{A} \mathfrak{a}\{\mathfrak{e}$.

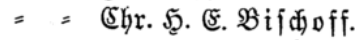

$=\quad=\mathfrak{M}$.

$=$ = $5 . \mathfrak{M}$. $\mathfrak{M}$ tzer.

$==\mathfrak{h} . \mathfrak{F r} \cdot \Omega i \Upsilon i \mathfrak{a n}$.

$={ }^{\prime}=\mathfrak{R}$. $\mathfrak{S} \cdot \mathfrak{M e b e r}$.

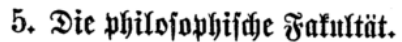

Serr Dr. Fr. Th. $\mathfrak{i}$ el fơ er.

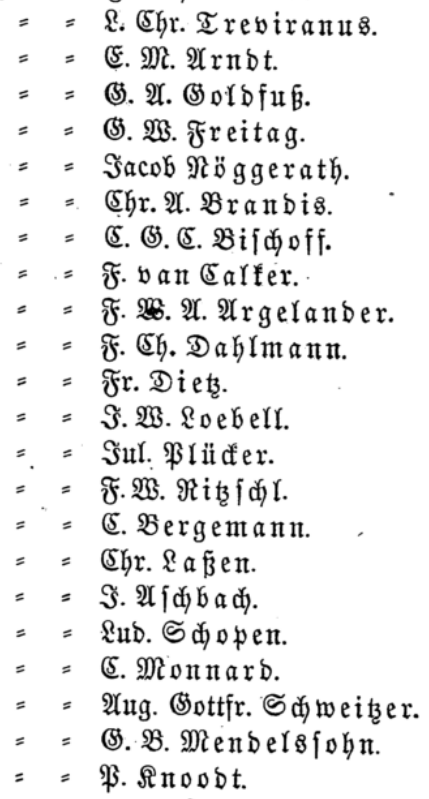

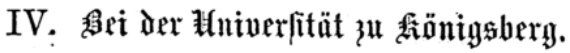

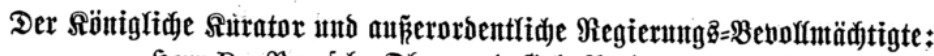

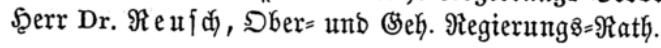

1. Theologifde Fafultüt.

Şerr Dr. Se bjer, Euperintendent.

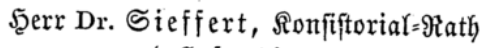
und S.ofprebiger. 
Seerr Dr. Rehree bt, Ronfiftorial= Rath und Superintentent.

\section{Sutrifitifđje $\mathfrak{g} \mathfrak{a}$ fulttüt.}

Seerr Dr. Sd) we eif ar bt, Tribunals= 凡ath.

$=$ Sanio.

$==\mathfrak{b} \cdot \mathfrak{B} \mathfrak{u d} \mathfrak{h} \circ \mathfrak{l t g}$.

$=$ Sacobjon.

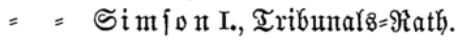

$=$ Miejer.

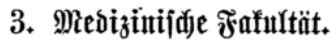

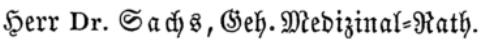

$=$ = Seerig, Mebizinal= Rath.

$=\quad$ Rathlé, Mebizinal= $\mathfrak{i}$ ath.

$=$ = Eruje.

$=\mathfrak{F}_{\operatorname{ta}}[\dot{d}$.
Şerr Dr. Şayn, Direftor ber Şebammen $=\{e$ hranjtalt.

$=\mathfrak{B} \mathfrak{u} \boldsymbol{x} \mathfrak{b} d)$ II.

\section{4. \$hilojpphifłe Fafultüt.}

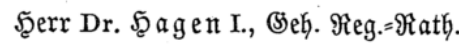

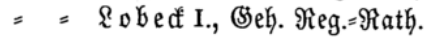

$==\mathfrak{D} \mathfrak{r} \mathfrak{m} \mathfrak{a} \mathfrak{n}$.

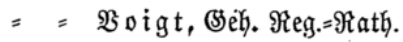

$=\quad$ Sdubert, (5eh. Reg.= Rath.

= Meyer.

$=\quad=$ Dult.

$=$ = $\mathfrak{T a g e n}$ II.

$=\quad=$ Reumann.

$==$ Rojenfranz.

$==$ v. Rengerf́e.

$=$ Mojer.

$==$ Ridelot.

$=$ Sehra.

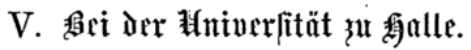

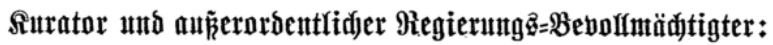

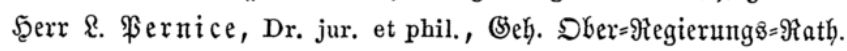

\section{Thenfngifude $\mathfrak{a}$ afultüt.}

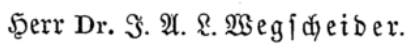

$==\Re . T_{\mathfrak{G}} \mathfrak{l l}_{0}$, Ronfiftorial $=\Re a+h$.

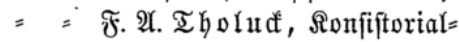

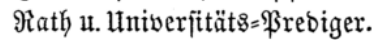

$==$ (5h. F. Fritzide, Superint.

$=\quad$ S. Mürler.

$=$ =

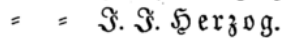

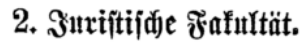

5err Dr. . $\mathfrak{B}$ itte.
ร.. $\mathfrak{2}$. E. Şente.
D. (3) B̈โder.
⿰冫. $\mathfrak{B} \mathfrak{n}$ berlid.

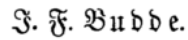

\section{Medi}

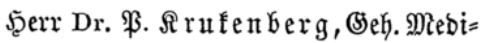
zinal $=$ Rath.
R. 5.. Friebränber.
(E. b'थिton.
E. $\mathfrak{B} \mathfrak{I} \mathfrak{a}\{\mathfrak{i} \mathfrak{i} \mathfrak{B}$.

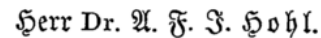

$==\mathfrak{A} . \mathfrak{B} . \mathfrak{B}$ olf $\mathfrak{m} \mathfrak{a} n$.

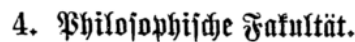

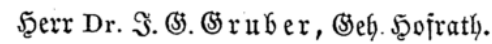
$=$ = (5. W. Bertad.
$=$ = Э. S. E. Sdyeigger.
$=$ =. ঋ. \$. (Eifelen.
$=$ = E. F. (J) ermar.

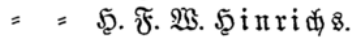
$==\mathfrak{M}$. F. E. Meyer.
$==$ (5. Berngarbi.
$=$ S. Rev.
$=\mathfrak{A}_{\text {. }}$ Rofenterger.
$==$ R. (5.) Blanc.
$=$ = D. R. F. v. Sdjledtendal.
$=$ E. Möbiger.
$==\mathfrak{A}$. $\mathfrak{F} \cdot \mathfrak{P o t t}$.

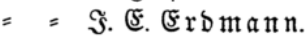
$==\mathfrak{R}$. S. Solnde.

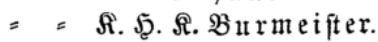
$=$ R. $\Re \circ$.
$==\Re . \mathfrak{F}$. Mardanb. 


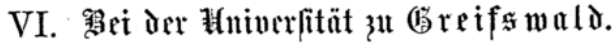

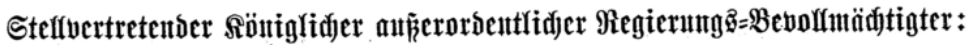

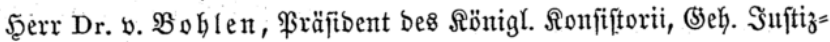

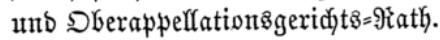

- 1. Theologifide $\mathfrak{a}$ afulttüt.

ફ̧err Dr. $\Re \mathfrak{v}$ fegartert.

$==$ Sdirmer, Ronfiftorialraty.

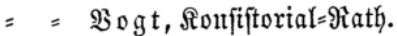

$=$ Semifid.

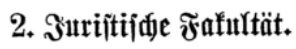

Şerr Dr. Niemeyer.

$==\mathfrak{B} \mathfrak{a r f i t w}$.

$=$ Befeler.

$==\Re \mathfrak{i} \mathfrak{n} \mathfrak{d}$.

$=$ Fütter.

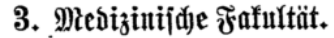

F̧err Dr. Sđdulţe.

$==$ Bernbt, (Beh. Mebizinatrath.
Şerr Dr. $\mathfrak{B a \mathfrak { t }} \mathfrak{m}$.

$==\Omega i t z \mathfrak{m} \mathfrak{a n n}$.

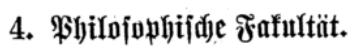

Şerr Dr. Tirrberg.

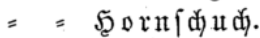

$=\Xi \Phi_{d} \ddot{b} \mathfrak{a} \mathfrak{n} \mathfrak{n}$.

$=$ Stiebenroth.

$==$ Eridjin.

$=$ = Sirutert.

$=$ = $\mathfrak{y}_{\text {it neferd. }}$.

$==\mathfrak{B} \mathfrak{a}$ rthold.

$=\quad=\mathfrak{B} \mathfrak{a} \mathfrak{u} \mathfrak{m} \mathfrak{f} \mathfrak{a r} \mathfrak{k}$.

$=$ = Matthies.

$=$ Sovefer.

$==\mathfrak{u} \mathfrak{r} \mathfrak{i} \dot{d} 8$.

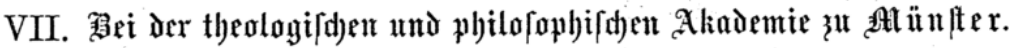

\section{Rurator :}

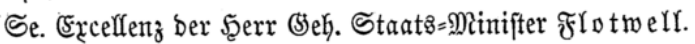

\section{Theologifide $\mathfrak{x} \mathfrak{a f u l t a ̈ t . ~}$}

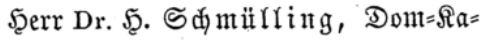
pitular.

$==\mathfrak{A} . \mathfrak{B e r l a g e}$.

$==$ R. Reinfe.

$=$ = B. Diedifoff.

$=$ = A. Eappenberg.

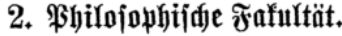

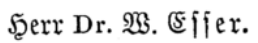

$=$ = $\mathfrak{B}$. Se. (5) rauert.

$==$ Fr. 2̇interos

$=\quad=$ (5hr. (5) udermann.

$==\mathfrak{F} \cdot \operatorname{Dey} \mathfrak{d}$. 
3meite $\mathfrak{A}$ tbtheilung

\title{
Hota
}

Der preubifaen univerfitäten

\author{
iiber

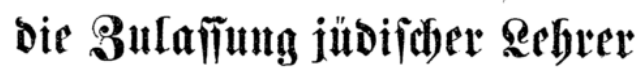

nady Dem Sieję̧ voun 23. Öuli 1847. 



\title{
Dnz Öefeç vom 23. Suli 1847 beftimmt
}

\author{
Titel I. Ábjunitt 1. §. 2.
}

SYn Univerjitäten fönten Suben, foweit bie Statuten nicht entgegen=

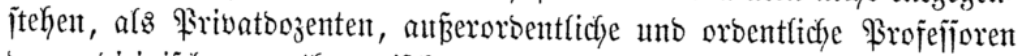
ber mebizinifdyen, mathentatifden, naturivifijenjchaftlicfen, geographijchen

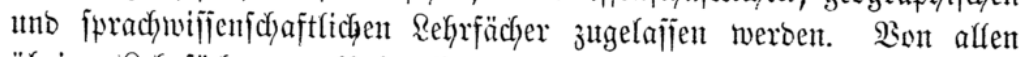

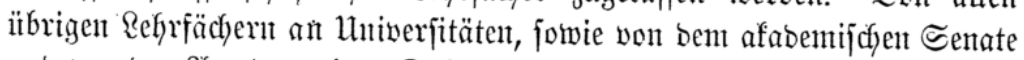

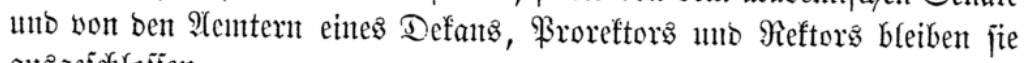
aแถ่ge

Ueber bieje Bejtimmung folften mun nady ber Berfïgung vom 28. September 1847 bie Ranbesıniverjitätent, unb zmar zunächjt bie eint=

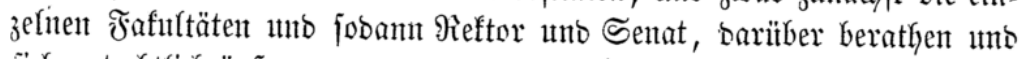
jich) gutacdyt(fich) äıñern:

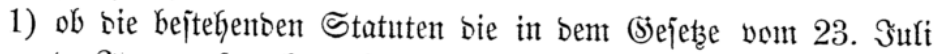

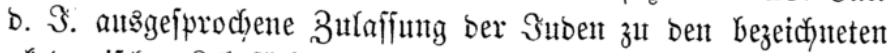
af́abemijchen Rehrfïchern gejtatten ober nicht, unto

2) ob, went bie Statuten bieje 3ulajiunty nicht gejtatten, eine 9)?obi= fifation berjelben für zutläfïtig uno angemeijen zu eract)ten jei.

(S)leicyseitig wünjcyte ber Minijter, ja, er Yegte ein bejonberes (S)envidyt

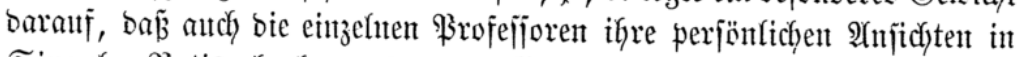

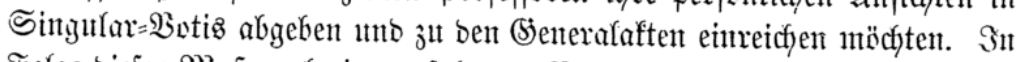
Folge biejer Miafregel gingen folgento Bota uno Berichte eint. 


\section{Fota ìr Zniwerlitüter.}

\section{Son ber llutwerjitüt $\mathfrak{u} \mathfrak{S} \mathfrak{S} a l l e$.}

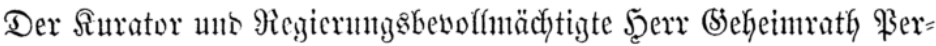

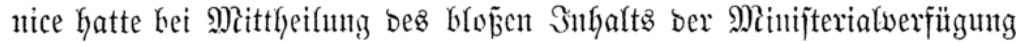
an bie bortige Surijtenfafultü̈t ausbrütffich biejelbe auf Rap. I. § 2 ber

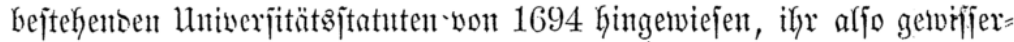

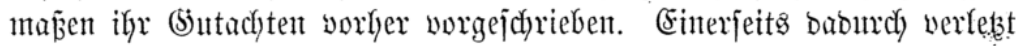

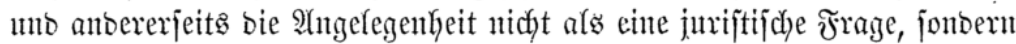
als eine politifuche Mafirenel eradjtent, hielt fie bie Sermittelung bes

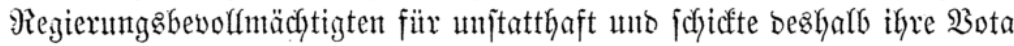

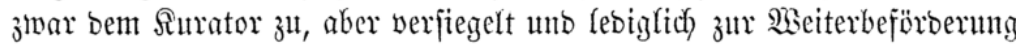

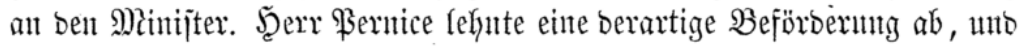

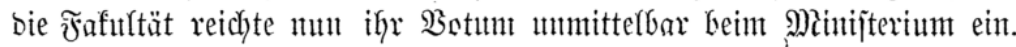
Dieję̧ Yautete:

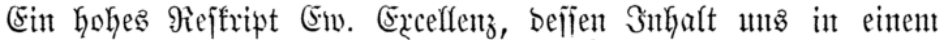

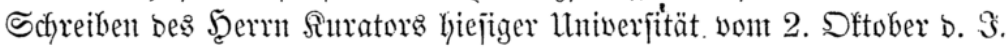

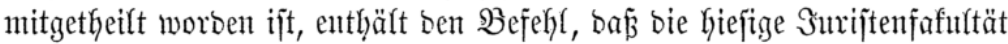
jich berathen unt äuñern jolle, ob

Sap. I. § 2 ber Gejtehenben Univerjitätştatuten von 1694 bie in

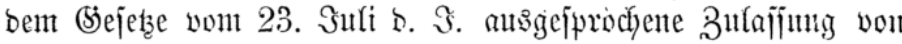

Sitbent zul bent bezeichyneten afabemijchen Refrämtern gejtatte?

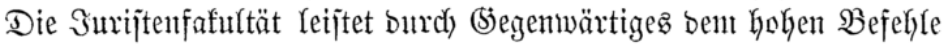

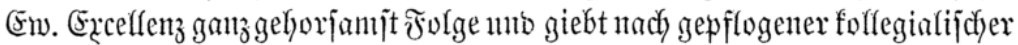

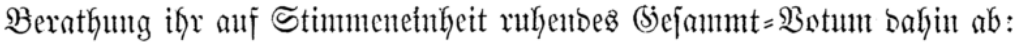

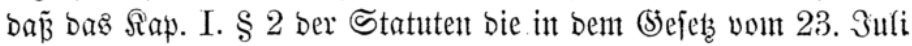

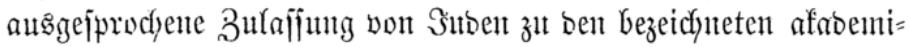
idjen Selyrämtern nicht gejtatte.

Dent bie Morte ber angezogenen Stefle ber Statuten Yauten folgent= Dermẩen:

Praecipue autem conseǹsus sit inter omnes et singulos professores in religione Christiana et doctrina evangelica, scriptis prophetarum et apostolorum et augustana confessione comprehensa.

Şalle, ben 17. Noventber 1847.

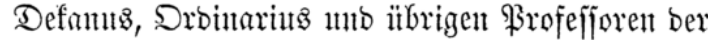

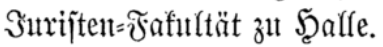

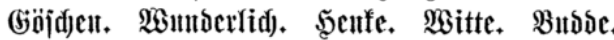




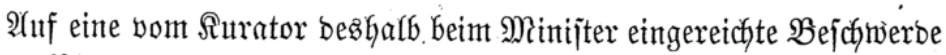

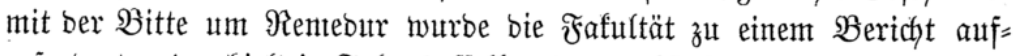
geforbert und erfielt in Folge befifelbent ben nachjtehenben Bejueib:

\section{Berlin, Den 12. Samtar 1848.}

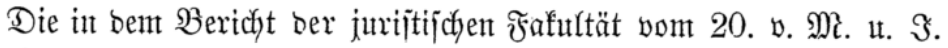

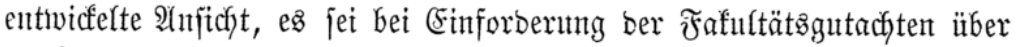

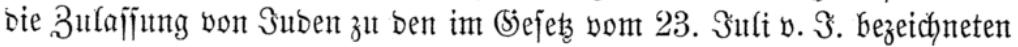
afabemijachen Refrämtern meine Intention bafin gegangen, über bie in Der Berfïguntg vom 28. September v. $\Im$. gejtellten Fragen $\mathfrak{B r i b a t =}$ äน

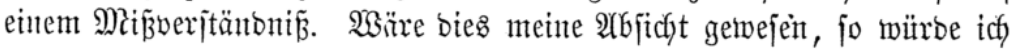
von ben einzelnen Fafultä̈ts= Mitgliebern uno nicüt von ben Fafultäten (Sutachten erforbert buben. Went idy aber für bie Berathung ber in ber Berfütgunt vom 28. Septentber v. Э. anfigejtelltent Jragen bejtimmt habe,

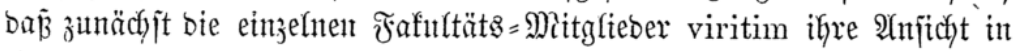
einem motivirten Sotunt ausfprechen, fobann bie Fafulttăt jìch zut einem (5ejammt= mittheile, banit biejer von feinem Stanbpunfte ans ein (sutachten abigebe unto nit fämmtlichen Berfanofungen einreiche, fo ijt bieje, von bent gemöhn=

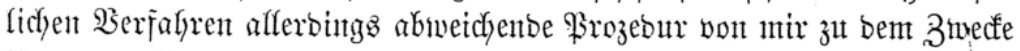

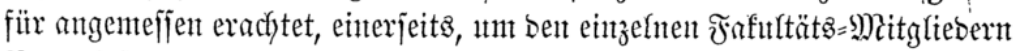

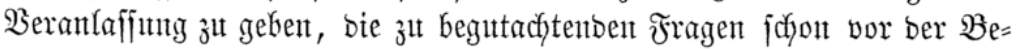

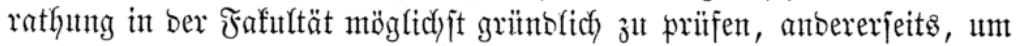

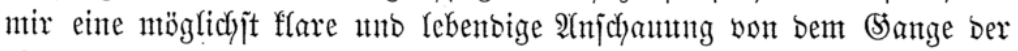

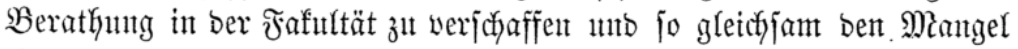

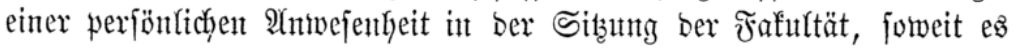
antigeft, jut erferent.

Die Fafuttät mirb, went fie bie 9 Angelegenkeit von biejem (s)ejichts:

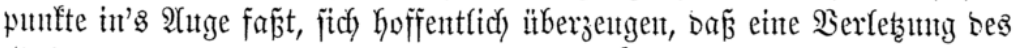

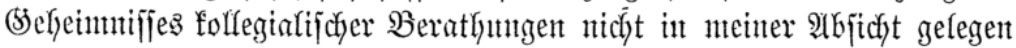

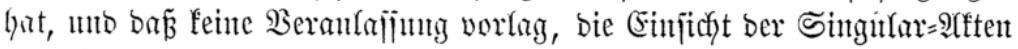

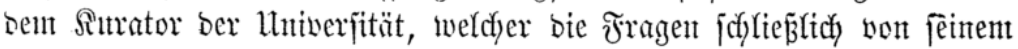
Stanbpunfte ans, unter Beritdfichtigntng fümmtficher Singutar = unto

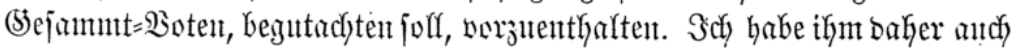

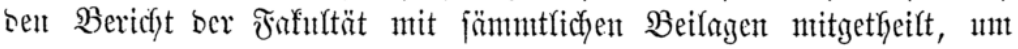

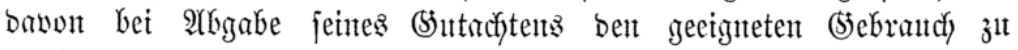
machen.

In bie juriftijadje Fonfinttït

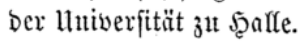

Der Mintifter.

(Eid)horn. 
Die Derftimmung ber Fafurtät waro burdy biejen Befcheio nicht

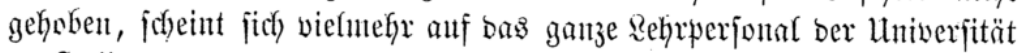

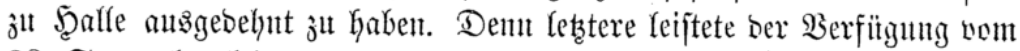
28. September Keine weitere Folge, mo bie Märzereigniffe iiberlyoben jie ber weiteren Arbjtimnuttig mo Miríregefung.

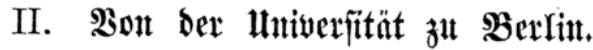

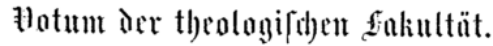

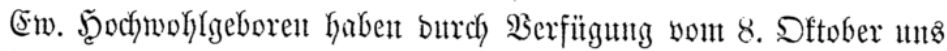
Den $\mathfrak{A}$ uftrag ertheilt, ïber bie sragent:

1) ob bie bejtehenton Statnten ber Mniverjität bie in bent (5iejetze über bie

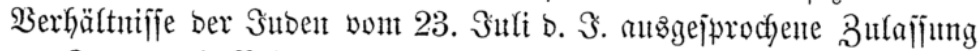

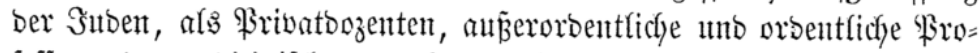

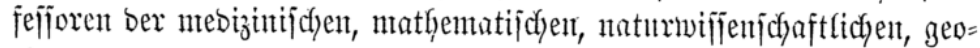

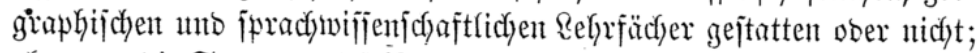

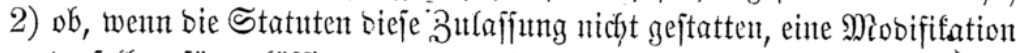
- Derjelben für zultäjīig unto angemejijen zu erachten jei?

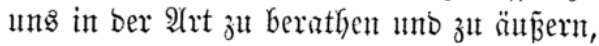

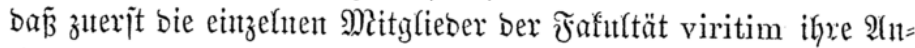
ficht in einem motivirten 3 otum altzzujpredjen, unb jobaum bie Fafultät fich) zul einem (Sejanmmotum zut vereinizen gabe.

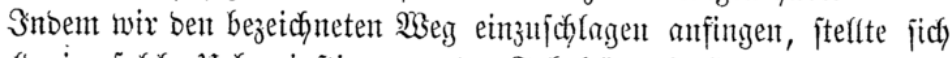

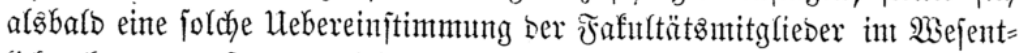

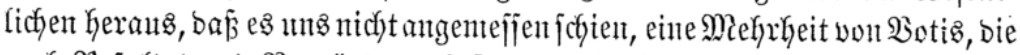
nad) Rejultat unt Begrünoung fajt mur baffelbe entfyalten fomnten, an:

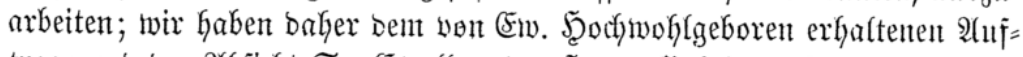

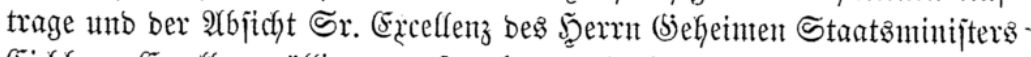

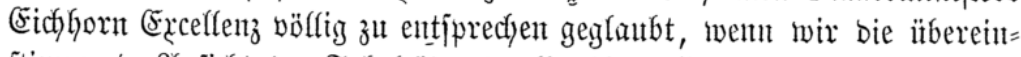

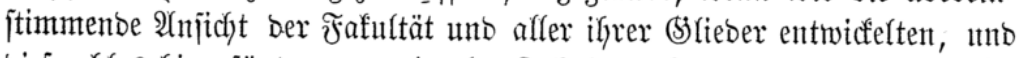
biejer blos hinzufügten, was einzelne Fafultäts=-9iitglieber noch bejondors ber höhern (Frwägung glaubten anhein geben z̆t miiffen.

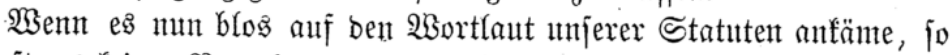

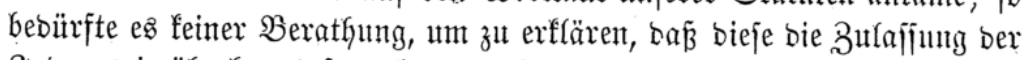

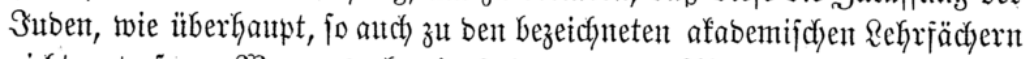

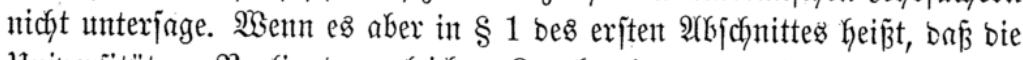

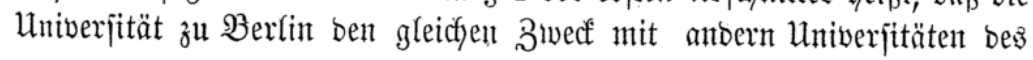


Staates Gabe, nämlidy bie allgenteine unt bejonbere mifjenjuaftlidje $\mathfrak{B i l}=$ oung geförig vorbereiteter Süntglinge fortzufetzen uno fie zum sintritt in

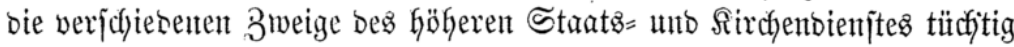
3u madyen: fo liegt barin body, baj aud unjere Univerjität nicht bloz jein

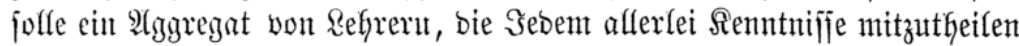
berufen fint, wobei Biwecf unt Stantbpuntt bent inbibibuellen Befieben

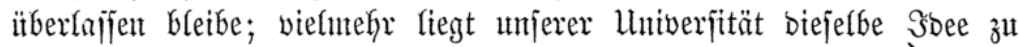

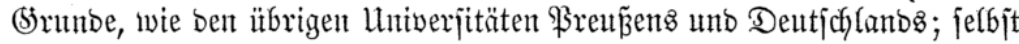

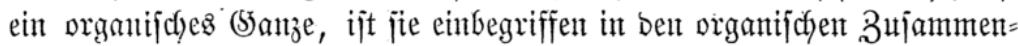
Gang ber jämmutlichen Refranjtalten unt zielt mit biejen gemeinjodaftlich $\mathfrak{a b}$ anf bie Bifloung Derjenigen, weldye bereinjt an ber Reitung unjeres

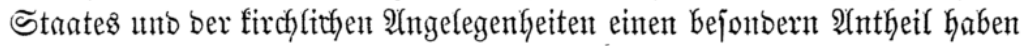
werben, und zwar bentent bie Statuten, inbem jie von Staats= nt no Sir= chentienjt, nidfyt von Staats= ober Sirchentienjt jprectyen, alf jene innige Serbintung unt Durchbringung von Stuat unt Rirche, bie in ber Bse= jajichte, wie in unjerm ganzen Reben zut tiej begrïnbet ijt, als baj jie burch iene Abjtraftionen, in welchen einige Beitgenojien beibe zlt trennen lieben,

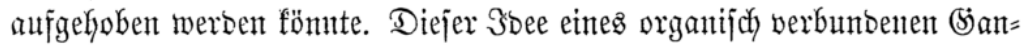
zent gemäß werben auth fowohl alle Borlejungen unter ber $\mathfrak{A}$ utorität ber

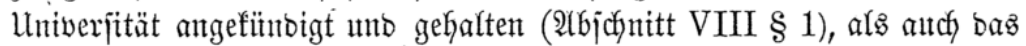

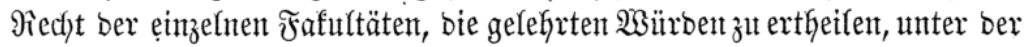

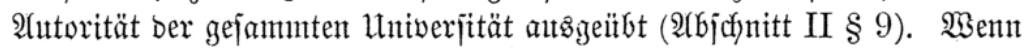
es baher auty Refrifächer giebt, bei benen ber Bujammenfyang mit ber (5ie= janmtheit ber im Beij̄te unjerer nationalen, bürgerfiçen und refigiöfent

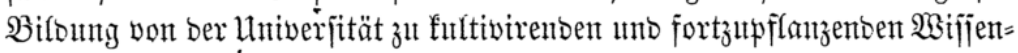

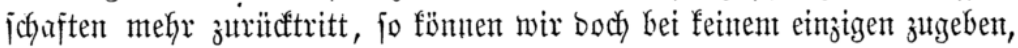

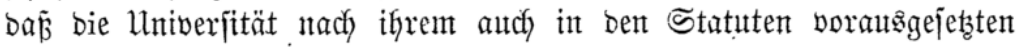

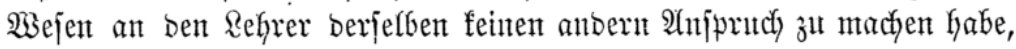

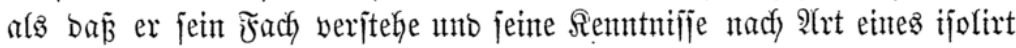

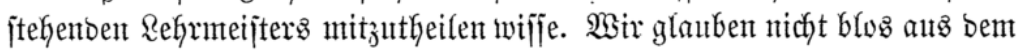
Stanbpuntt ber theologijchen Fafultät, fonbern alts bent eines integriren=

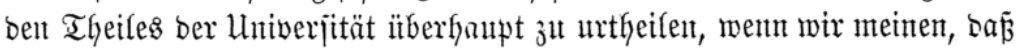

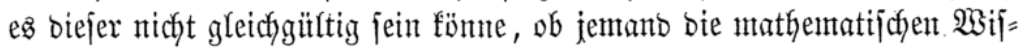

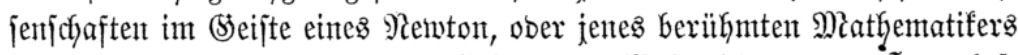

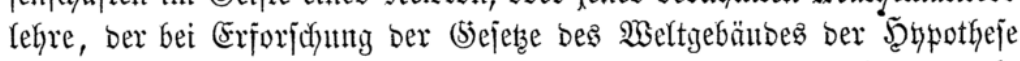
einer orbnenten \$ottheit nie beburft zul haben erffärte, ob jemant als

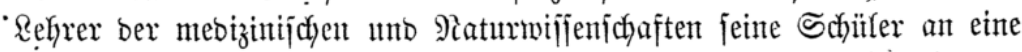

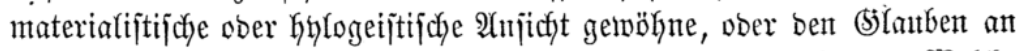
eine injterbliche Seele wenigjtens nicht als Thorkeit verfpotte. Welche

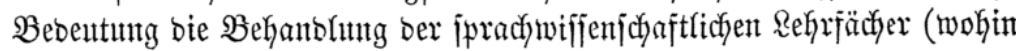


Dody wohl bie ganze flaffifdye unt orientalijche \$shifologie gerechnet wirb)

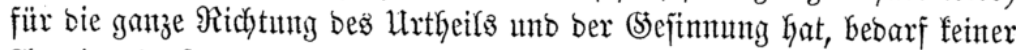

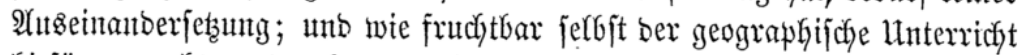
hiefür gentadyt werben föme, zeigt bas B̉eifpiel eines Mannes, bent wix

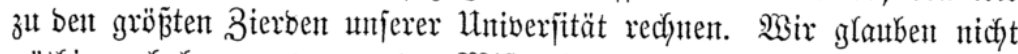

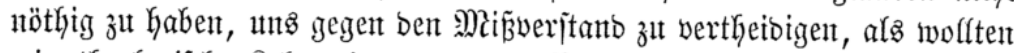
wir theologifdye Refrmeinungen zun Niąjitab ber Beutrtheifung ïber

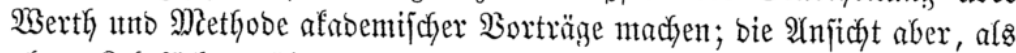
vb es Refyriächer gäbe, bei benen bie refigiöfen (5runbjätze bes Dozenten

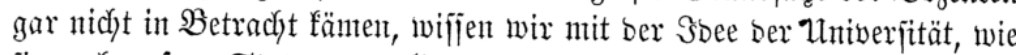
fie aud unfern Statuten zu (5runbe liegt, nicht zu vereinigen. $3 i r$ itber=

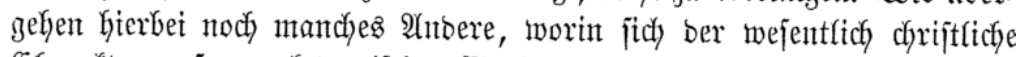
(5Garafter unjerer afabemifchen Einrichtungen ausfpridyt, z. B. bet Ber=

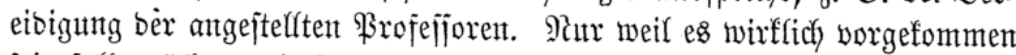

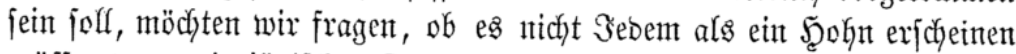
miijie, wenn ein jübifdjer Dozent aus bem ihm als Subent zufommenten Rechte folgern wollte, feine Borlejungen audh am Sonntage haltent fit bürfen?

Waa bie Frage betrifft, ob eine Yenberung ber Statuten, um in bent

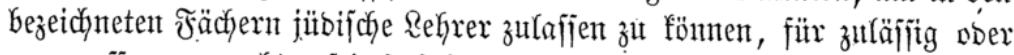

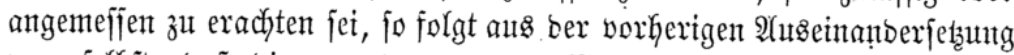

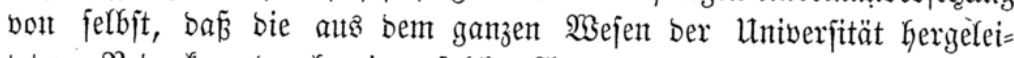
tetent Bebenfen burch eine folche Yenberung nidfyt gehoben werben

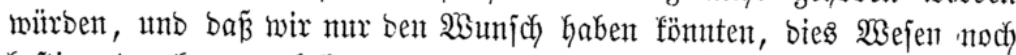
bejtimmter herborgefoben zu jeken, als es in umjern Statuten ge= forjegt:

Dem ßorjtehentoen glaubt ber Dr. Reanber noch Ginzufü̈gen jut

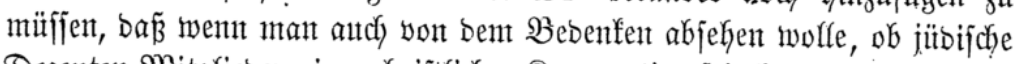
Dozenten Nitglieber einer cyriftlidyen Sorporation feit tönntent, als weldje bie 1tniverjität baburdy anerfannt worben, baj jie ihren eigenthünnlichen

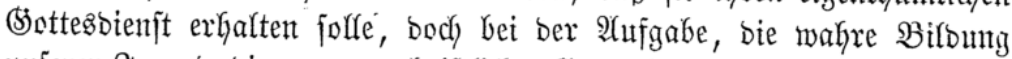

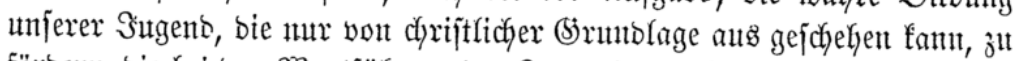

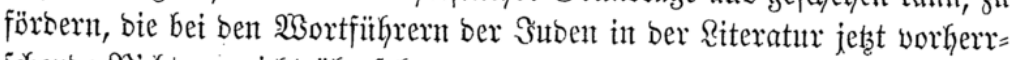

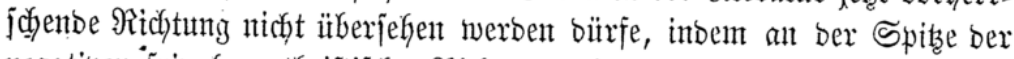

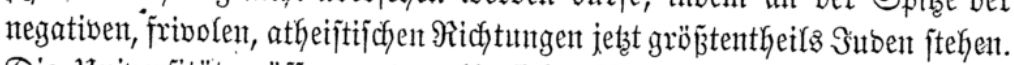

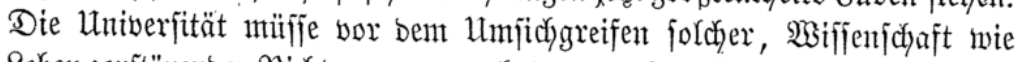
Reben zerftörenten গitchtungen vertwahrt, uno baher Affres vermieben werben,

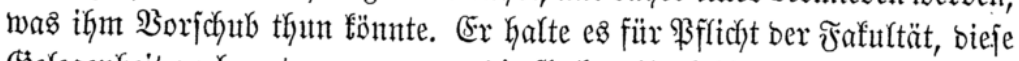

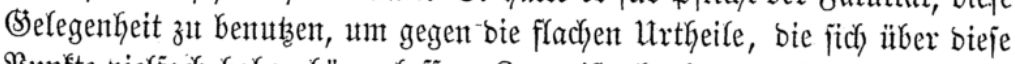

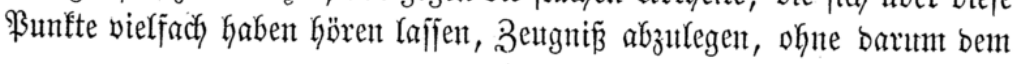


Sntereffe ber chrijttiçen Riebe an bem wahren Bejten ber Suben jelbjt z̆ nake zut treten. -

Bertin, Den 6 . Dezember 1847.

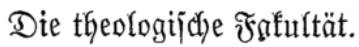

(1tnteridjriften.)

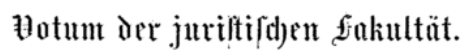

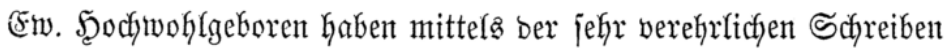
bont 8. Dftober uno 19. November c. bie unterzetdnete Suriften=予afultät zu einer Beratfung unb gutachtfichen 2 (euferung ïber bie brei Fragen altfgeforbert:

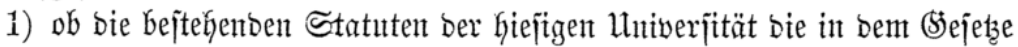

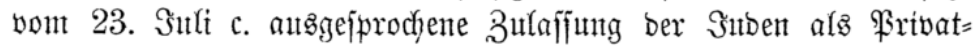
Dozenten, auzerorbentliche und orbentliche Brofejiforen ber mathemati=

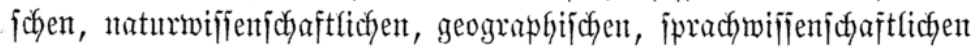
unb mebizinifichen Refrefächer gejtattent ober nicht;

2) ob, wenn bie Statuten bieje 3ulajīung nicht gejtatten, eine Mrobififation Derjelben fït zuläfifity unb angemefijen z̆t erachten;

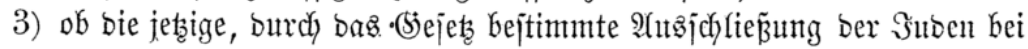

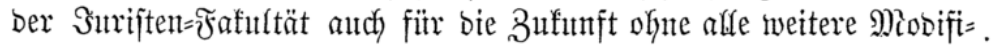
fation zu befürtworten jei?

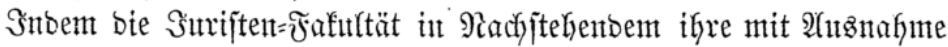
einer Stimme eintheffige Ueberzengung ïber bieje bret Jragen antşz iprechent jidy beehrt, erfanbt jie jich, bie leţte, jie jelbjt betreffentoe, voran zut jteflen.

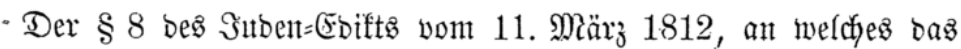

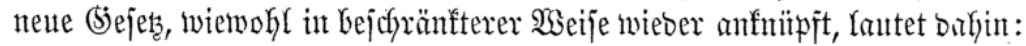
"Sie (bie Sttben) fönten baher afabemijaje Rehr= mo Schuts,

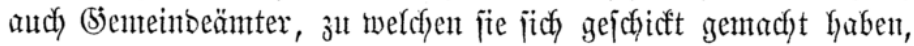
vertwaltent."

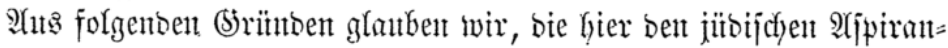

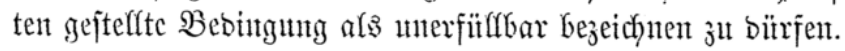

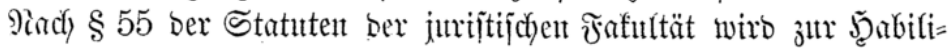
tation fïr ein juriftij(yes \&ehrant, nach) $\$ 8$ zum (sintritt eines berufenen

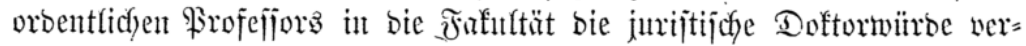

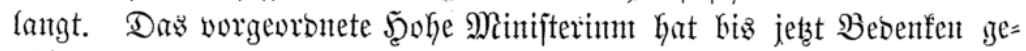

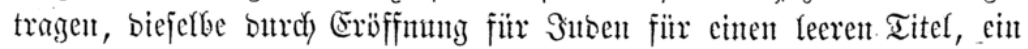

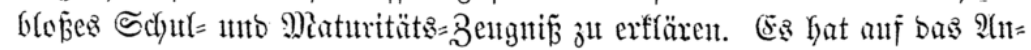

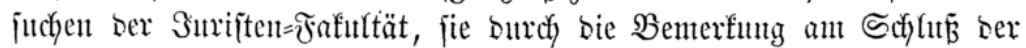
Fafultüts= Statıtten : 


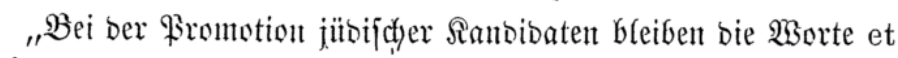
ejus sacrosanctum Evangelium 1veis,"

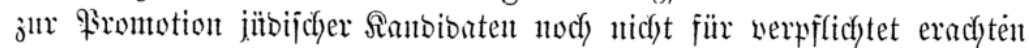

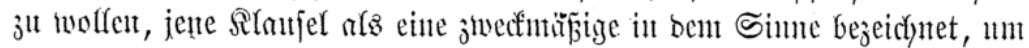

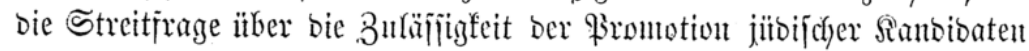

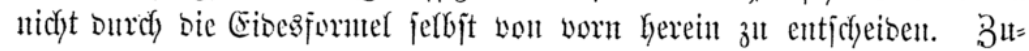

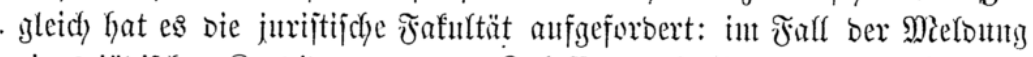

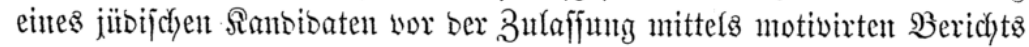

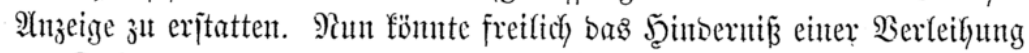

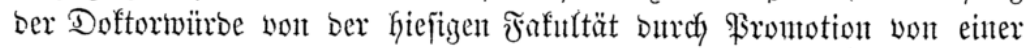
answärtigen in Serbinoung nit einer Dispenfation bes vorgeorbneten Minifterints, nad) bent mefiührten $\$ 55$, alfenfalls umgangen werben.

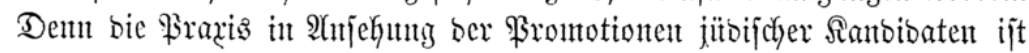

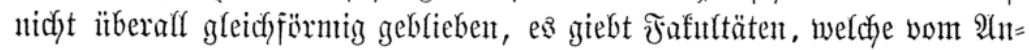

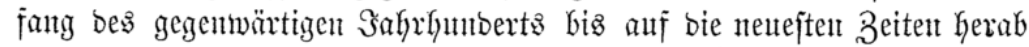

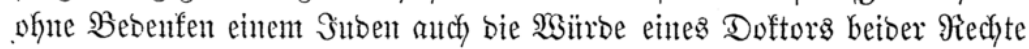
ertheilt haben, weil jie aud in bent fantonifdyen Doftorgrabe feite $\mathfrak{B} e r=$

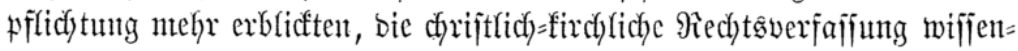

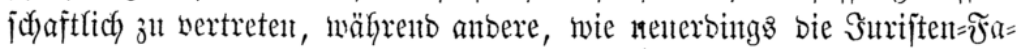

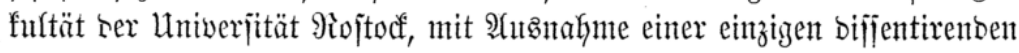

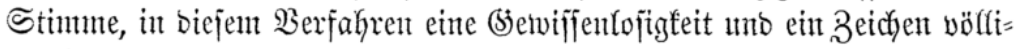

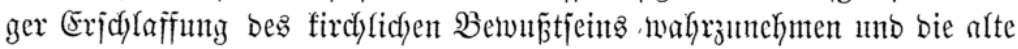

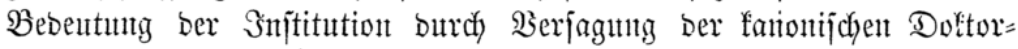
würoe bei ber \$romotion jübijcher Ranbibaten ehren zu mitjjent geglantbt

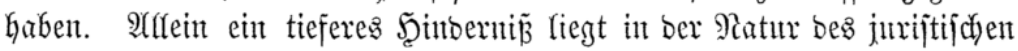
Rehramtes jelbjt, z̆t weldyent ber Doftorizrab ben Butgang eröffnen folf.

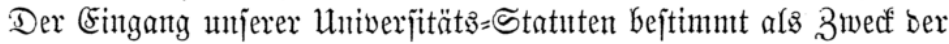

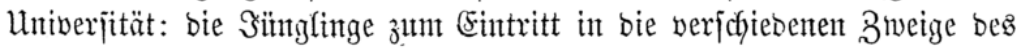
höhern Staats= uno Sirchenbienjtes tïchtig zu machen. Snjonberkeit ijt

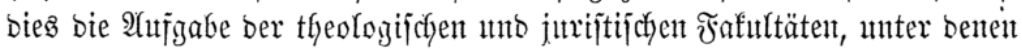

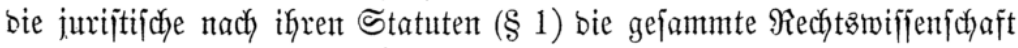

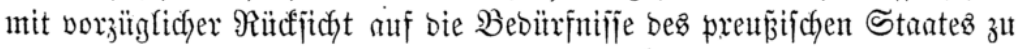

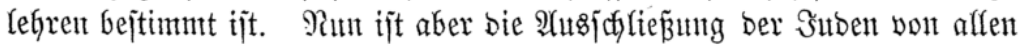

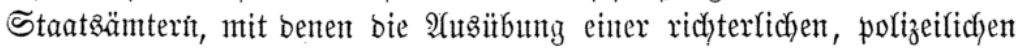

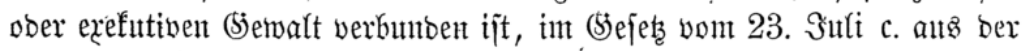

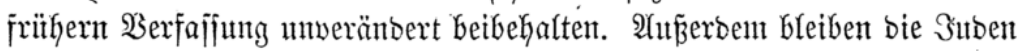

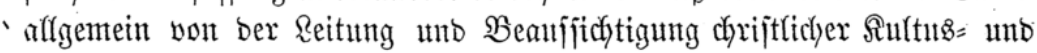

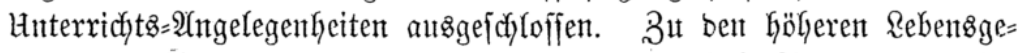

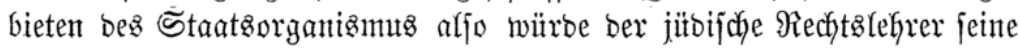

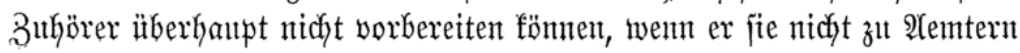


tïtchtig madhen foll, bie zu begleiteit er felfjt und zwar wegen jeiner

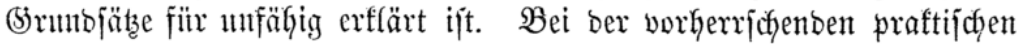

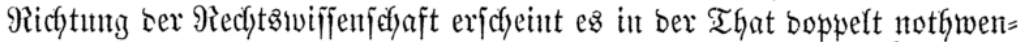

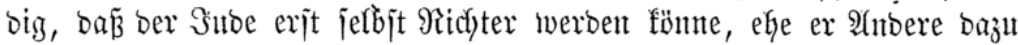

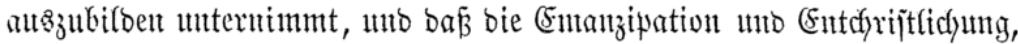

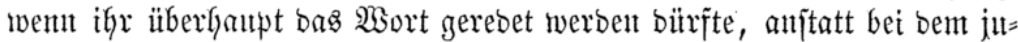

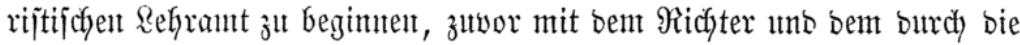
B̉efähigumy zum 9iddyterant bebingten Sachwalter=\$Beruf anfange, bamit bie in bemferbent gejanmelten wraftiphen Exfahrungen ber jtibirenben

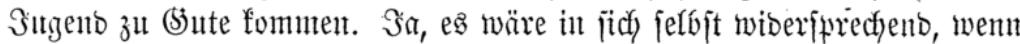

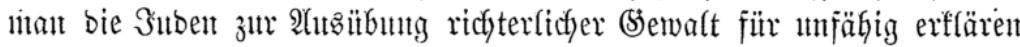

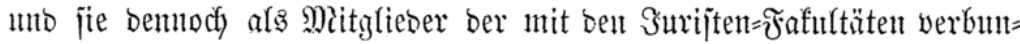
Denen Spruthfolfegien an ber 2 fusübung ber biejent ïbertragenen Jurisdictio mandata Theil mehnten lajien wollte. -

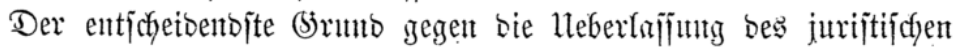
Reframts an $\Re$ idd

IAtch) in anbern Regrgebieten gejtattet ber afabemijche Refrrberuj eine

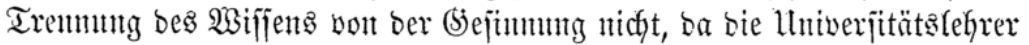

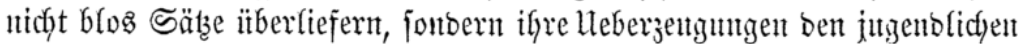

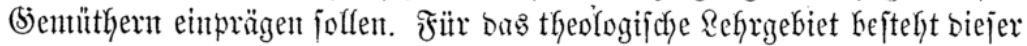

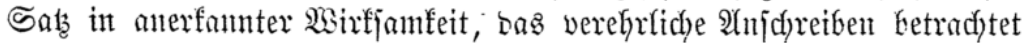

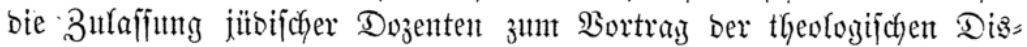

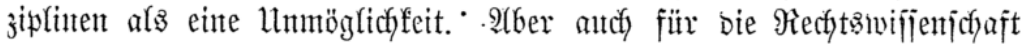

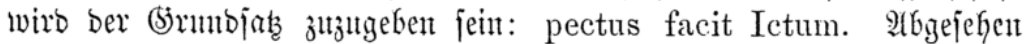

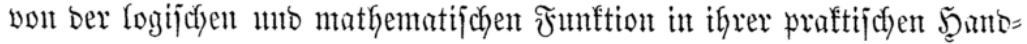

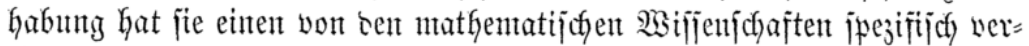

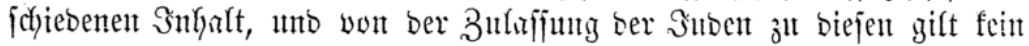

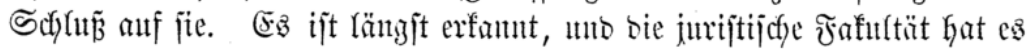

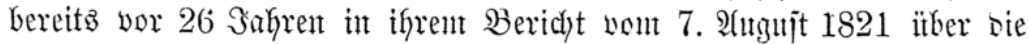

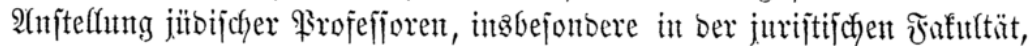
mtsgejprochent, ba

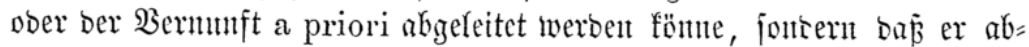

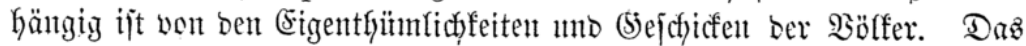

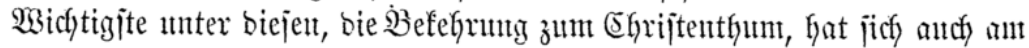

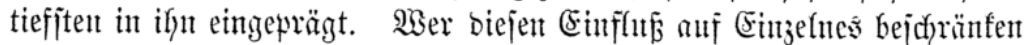

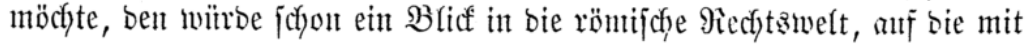

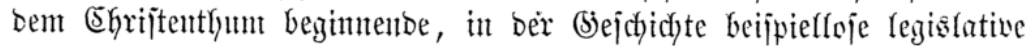

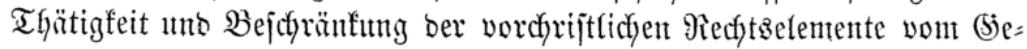
gentheil ïberzentgen mitifen, uno unter sen Bölfern germtantichen Stan=

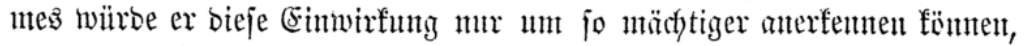




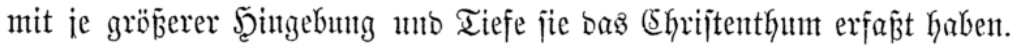
Siun joll zwar nidyt verfannt werben, ba

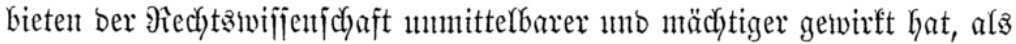

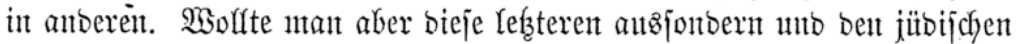

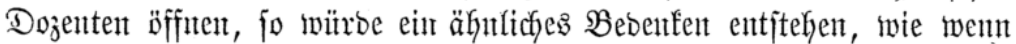

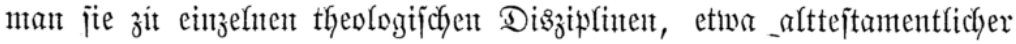

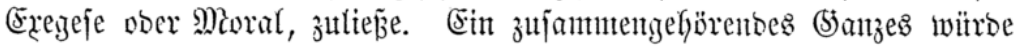
unnatïrlich zerrifjent, bie Statuten ber jutrijtijchen Fofulttüt, welche jesem

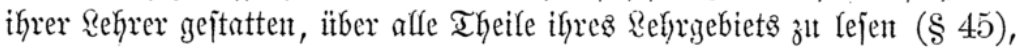

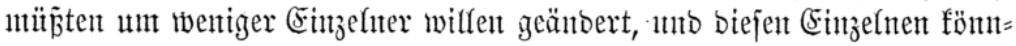

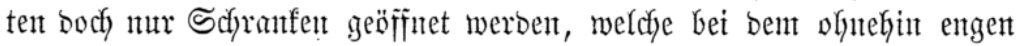

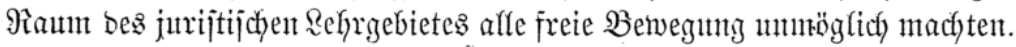

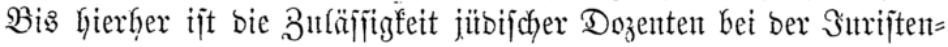
Fafulttüt mutr atts bent (jejichtopuntte iGrer Untauglichfeit zum Reframt in=

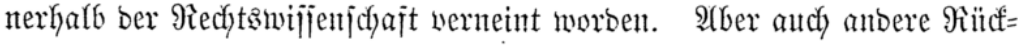

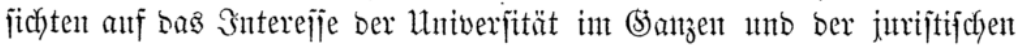
Fafultuät insbejonsere bürften benjelben entgegen jtehen. İngentommen,

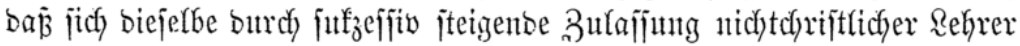

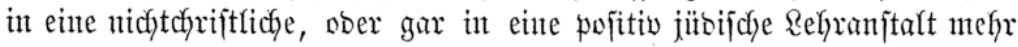

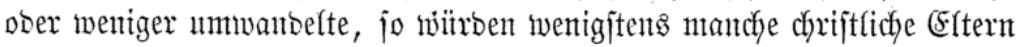
Sebenfen tragen, ihre Söhule ifrr anzutwertrattent, und gerabe bie Surijten=

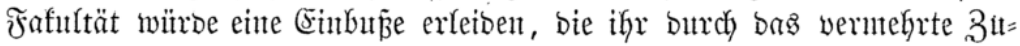

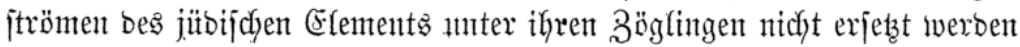
biurite.

Snbem wir uns mumehr ber Frage zutwentoen :

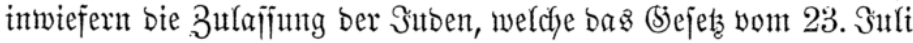
1847 Tit. I \& 2 für bie Refrrfächer ber Medizin, Mathentatif,

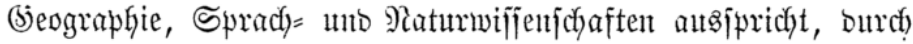
Die Statutent ber Giefigen lutiverfität antsgejdyloffen fei,

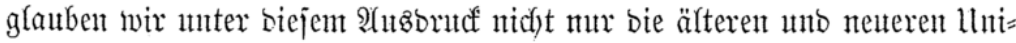

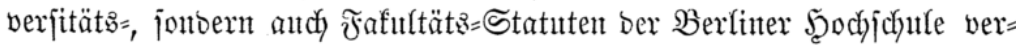

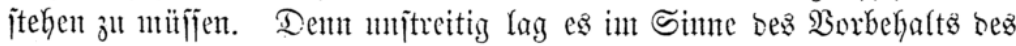

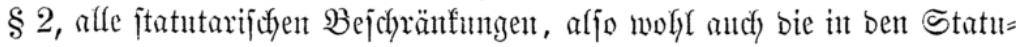

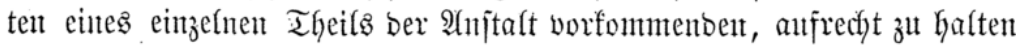
und mur in - Stelle bes $\$ 8$ bes Sitbentebifts vom 11. Miärz 1812 eine neute

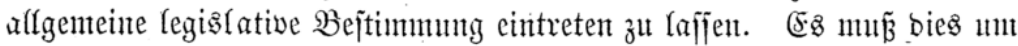
fo mefr angenomment werben, als bie von bem vorgeorbneten Minifterinm

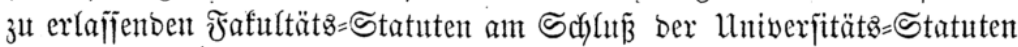

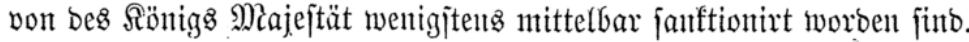

Die allgemeinen Statuten ber Univerjität Bertin, vollzogen am 
31. Dltober 1816, fâllen in eine Beit, in mèldjer nach bem Butchjtaben

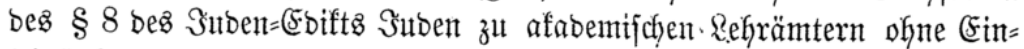

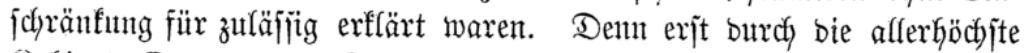
Siabints=5 Drore vout 4. Dezember 1822 murbe bieje Bulafijung, wegen ber

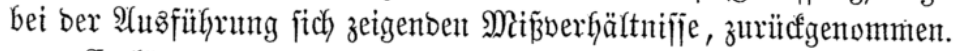

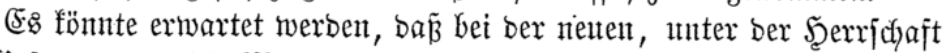

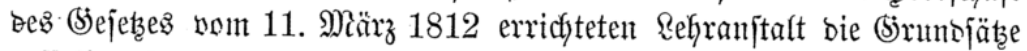
Defierben fofort eine umfajfente praftijace Âtuentung gefunben Gätten,

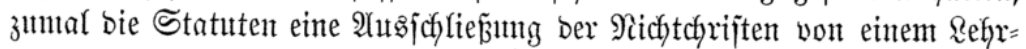
ant irgend welcher Fafultät ober irgent weldyen (5rabes nirgends auts=

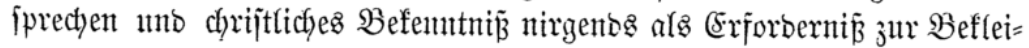
bung eines afabemijchen Reframtes aufitellen.

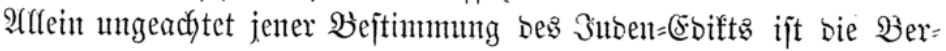
finer Uniwerfität gleidy ihren Schwejtern bis alt bie neuejte (siejebgebung

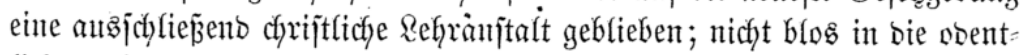

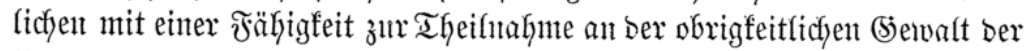
Univerfität verbumbenen Sefyrämter, nicht blos in bie theologijdje unt ju= rijtifche Fafultät ijt nientals eit jïbijd)er sehreer alfgenomment worben,

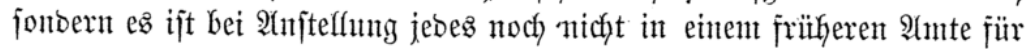
ben prenfifichen Staat in Eib und siflicht genommenten Profejiors of ne

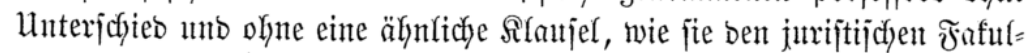

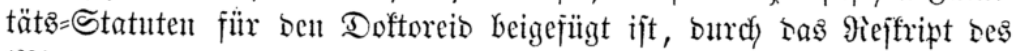

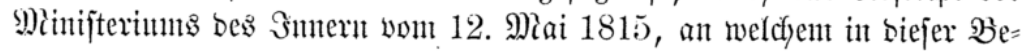

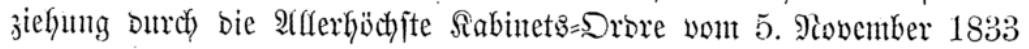

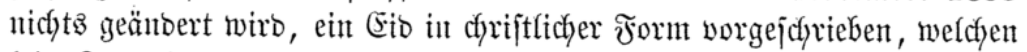
fein Snbe leijtent faum, unb ber einem joldyen ben Eintritt jerbjt in ein

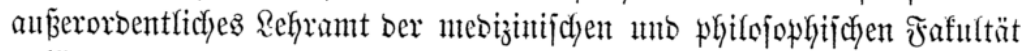

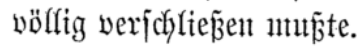

Dies 2(fles mutroe eben fo jehr als jelbjtuerjtandon angentonnten, ars

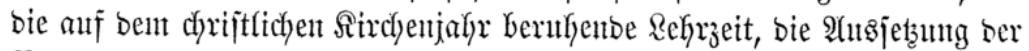
Borlefung ant Sountag, nidft ant Sabbath, mo ant ben Feiertagen be: (f)riftlichent unt nidyt bes jïbifdyen sirchenjahres.

Die Statuten ber phitofophifchen Fafultät enthalten fogar eine ans: brïuffictye Bejtinumung, weldye, jo lange jie ungeänbert bejtefyt, mit ber 3ultafjung ber Befemer mojaijcher 9iefigiont nidfyt int Einffang ijt. Sint . $\$ 43$ biejer Statuten fintoet fiđd nä̉nllidy ber, mit ber eben anz ben jurijti=

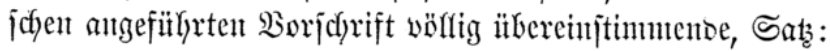

"Ein jëber zut ber Fafurttät gehörige \$rofejijor ijt beredstigt,

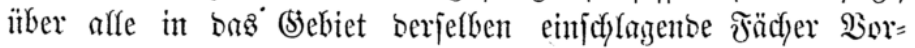
lejumgen jut haltent. 


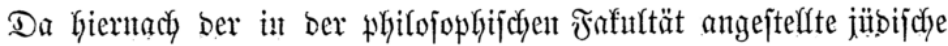

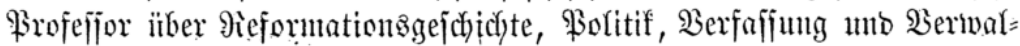
tung bes prentijichen Staates at. j. w. Borlejungen halten barf, währento Das (Sejets woun 23. 3nlti, abgejehent won (Sieographie, Miathematif, Sprad)=

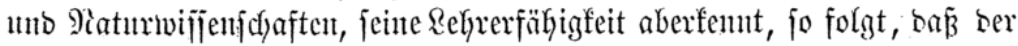
angezogene $§$ ber Stntuten, fo lange er in untgehinoerter 2 sirffamfeit be= jteht, unb nidyt fïr bie anzujteflenten jübijchen \$arofejporen eine, bei bem

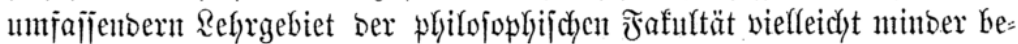

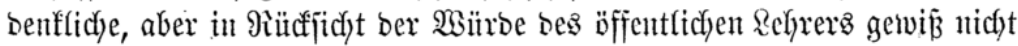

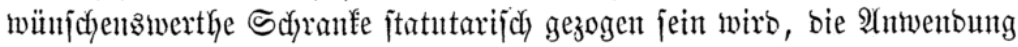

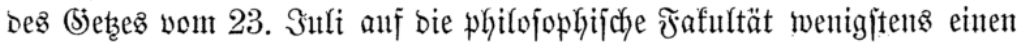
vorläufitigen $\mathfrak{A}$ njtant fintoen bïrfte.

In ber hiernach nod, ïbrig bleibentoen Frage:

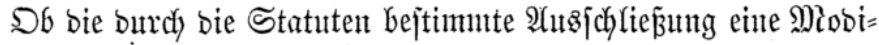
fitifation gejtatte uno angemeijen exicheinen laije, Ganbelt es jich baher Yesiglich ant ben Fortbejtano bez etwa in $\$ 43$ ber

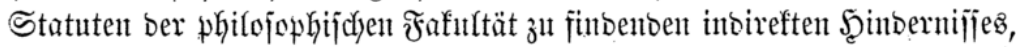
oa ber bisherigen Praçis, weldye bie jitbijdyen Dozenten affgemein ans=

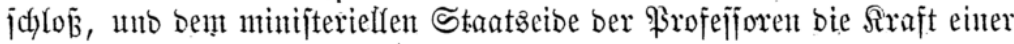

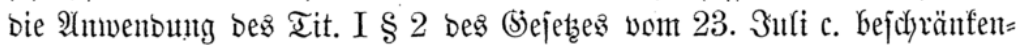
Den jtatutarifchen Beftimmung nicht' beizumejien ift, ein anber'weites

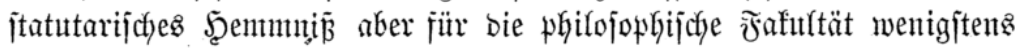
nicht bejtegt.

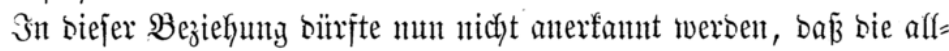
gemeine, im Eingang ber Uniberfität = Statuten aujgejtellte Bejtinmmung Der Univerjität:

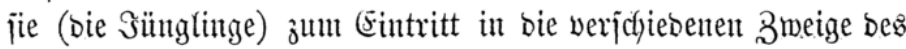
höhern Staats= mo Sirchenbienjtes tüudytig zu machen,

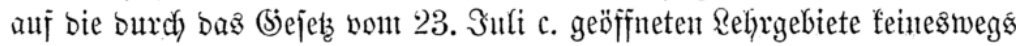

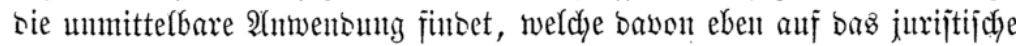
gemacht worbent ijt, unb ebenjo vermtöge bes erwähnten Sirchenbienjtes anf

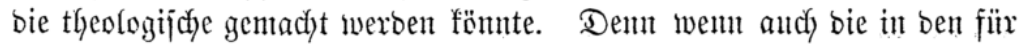

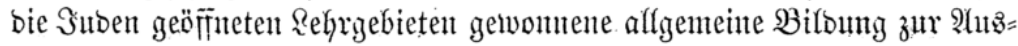

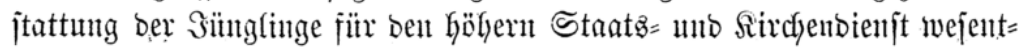
fich beitragen mag, jo ift bieje 2 sirfjamfeit body inmer nur eine vorberei=

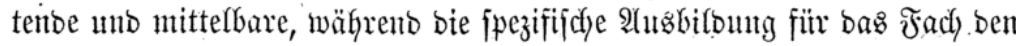

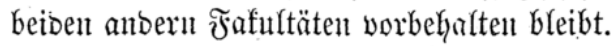

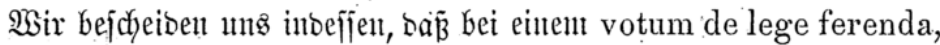

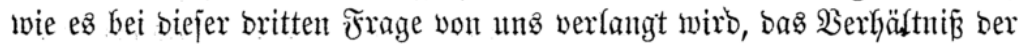

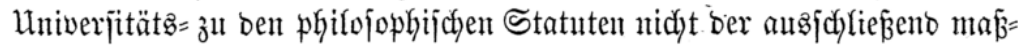


gebentoe (Siefichtopuntt fein wirb, fonbern ba

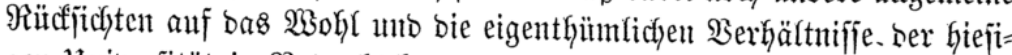
gen Univerfität int Betradyt fommen mögen, weldje, fo lange an anderen

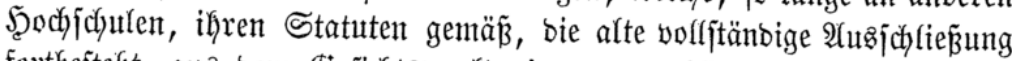
fortbejtejt, aus bem (Sefichtspunft einer verberbficfen Bermefrung ses

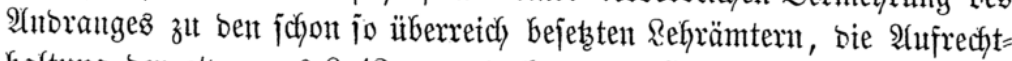
Kaltuntg ber etwa aus $\$ 43$ zut entnehmenten \$cemmniffe eines 3ujant=

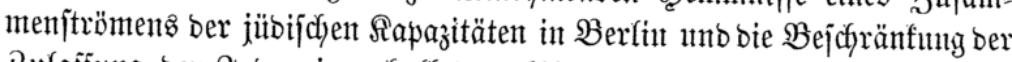

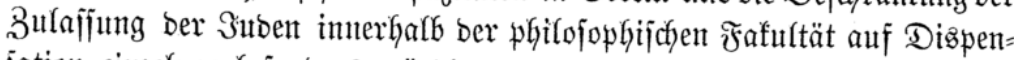
jation einzelıer bejonbers würbiger uno tüchtiger Snoivioualitäten unter ihnen räthlich madyen fönnten.

Berrin, ben 12. Dezember 1847.

Die jurifitijche Frafultät.

(Unterid)riften.)

\section{Sepurat-zotum ies Frofeflor Dr. faffer.}

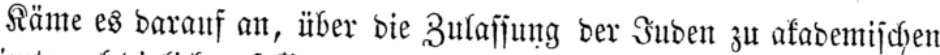

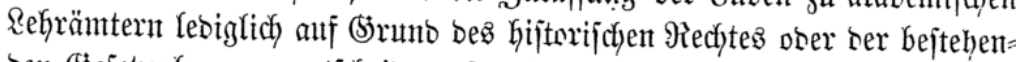

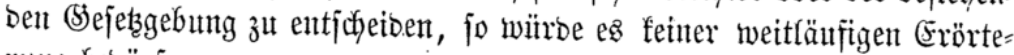
rutng bebürfent.

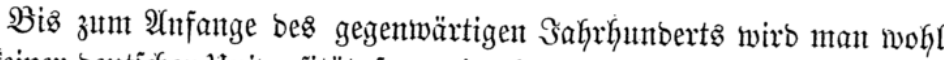

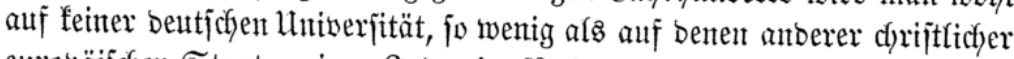

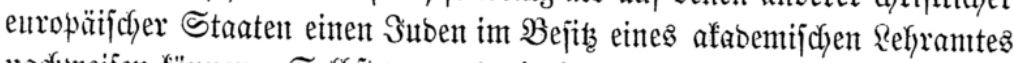

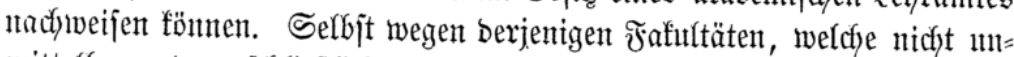

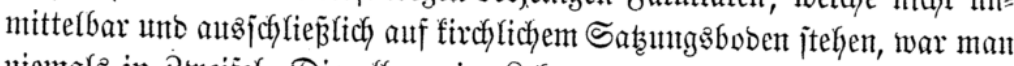
niemals in Simeifel. Die affgenteine Rehre max:

Judaei nec in doctores juris, vel medicinae, nec in tabelliones sive notarios publicos creari possunt, quia portae dignitatum ipsis sunt clausae.

Hannius, de Judaeis Marp. 1629. p. 9. Kaestel, de Judaeis Altorf 1645 th. 26. Lud. Roman, Singular 1679 in princ. Ziegler, de jurib. Judaeor 1684. cap. II § 2. Wiltragel, de Judaeor. receptione. Jen. 1700. thes. 12.

unto fo alfe frïiłgern utno fpätern Sutrijten.

Der (5runo Kierbon unar, wie es ber jtercoti)pe Saţ felbjt ausorïldt,

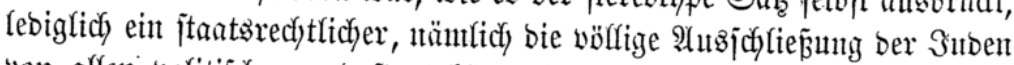

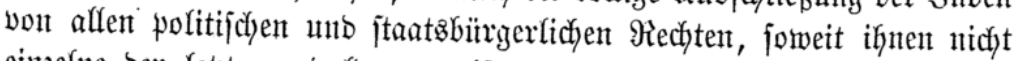

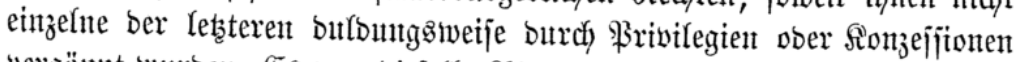

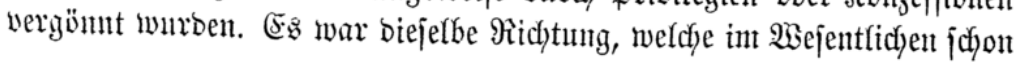


sas rönif men hatte.

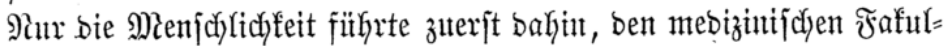

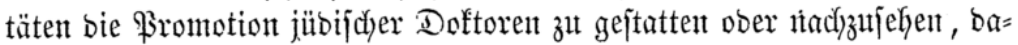
mit jübifche Unterhanent ober Schutizverwandte fich geeigneten Mebizinal=

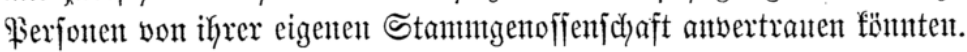

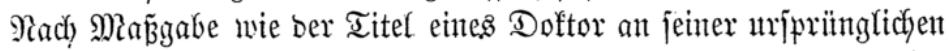

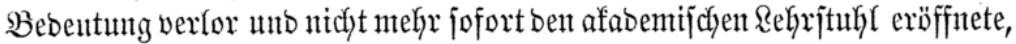

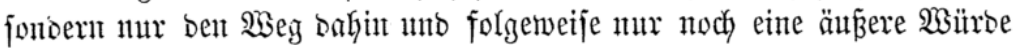

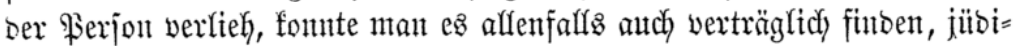
jchen (5elefyrten in anberent Fafultü̈ten, als ber mebizinifchen, ben Doftorfhut 3u ertheilent, joweit bas Sonffeffindefle niclyt hinberfich in ben $\mathfrak{W e g}$ trat,

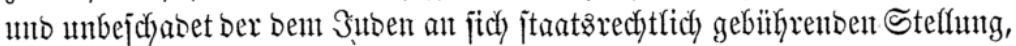
woritber ign natïrfich anthy ber Doftorlyut nicht erfeben fonnte. So ijt

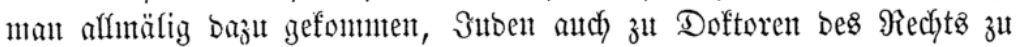

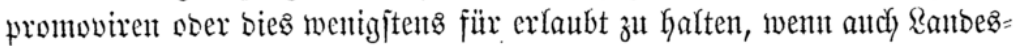
gejetze feine Sergünftignng baju, weber bireft noch inbireft ertheilen jolltent. So gab bie Untwerjität z̆t (5öttingen an 25 . Dftober 1799 einem Ittben Yaron (5)mpredyt, nachben er feine Difjertation de sequela territoriali vertheidigt hatte, uno bie Univerjität zut $23 i e n$ am 18. 2Yutgujt 1800 bem

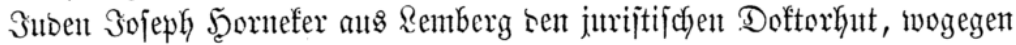

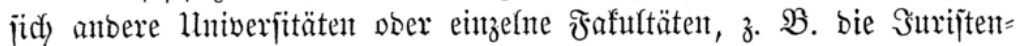

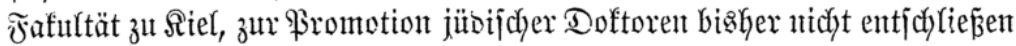

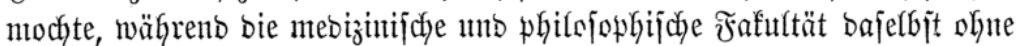

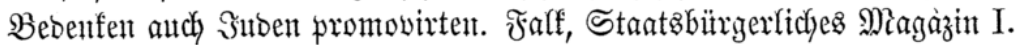
Seite 813.

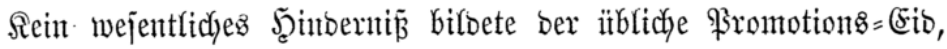

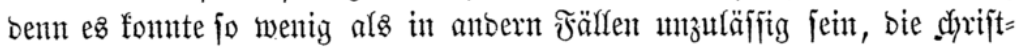

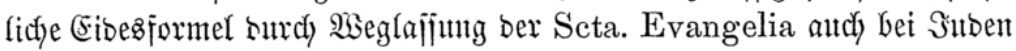

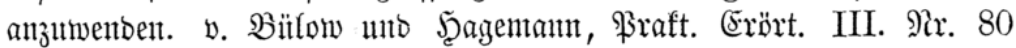
5. 452 .

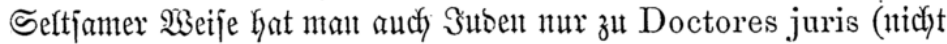

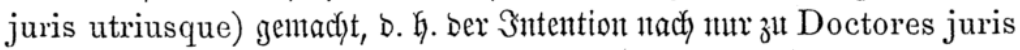
civilis; - eine offenbare Snfonjequenz, ba ę ein jus civile ohne ba: jus canonicum gar nicht mefyr giebt.

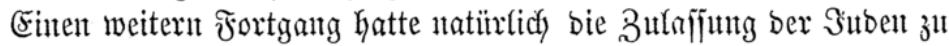

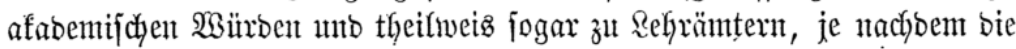
jogen. bürgerfiche Serbefferung ber Sitben in eimzetnen Ränbern vor fich

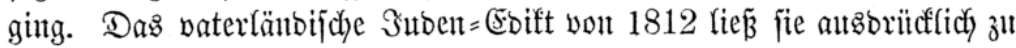

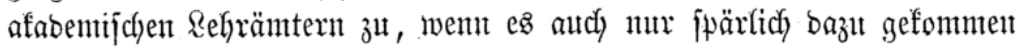




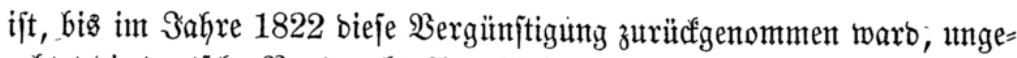

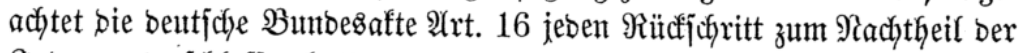
Эuben ausgejd)lojien hatte.

Dagegen verfieb bie furbefifiche Beroronung vom 29. Dttober 1833

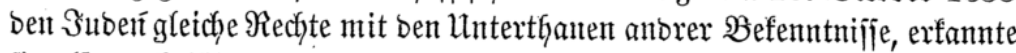
jie aljo auch fütr anjtellbar auf ber Ranbes=Uniberjität. In ber That wurbe

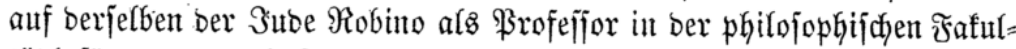

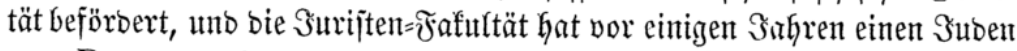
zum Doctor utriusque promovirt.

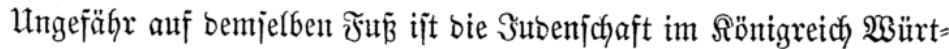
temberg gejteflt.

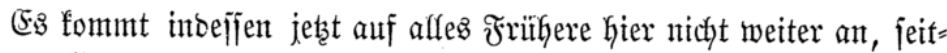

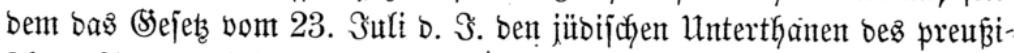
ichen Staates bejtimmte Berechtigungen aud in Betreff afabemijader Rehrämter ertheilt hat. Es: fonmt barauf an, ben föniglichen lanbesväter=

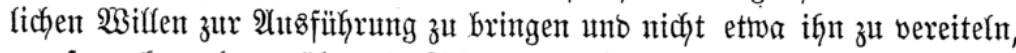
um fo mehr, als barüber bie Stimme bes Ranbes vernommen tworben ijt.

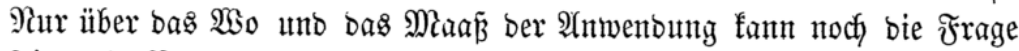

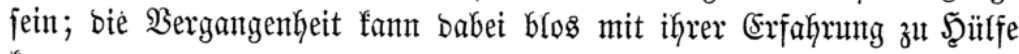
fommen.

Stefle ich nun zuerjt bie Alufgabe, zu unterjucken, ob bie bejtehenten Statuten ụmjerer Univerjität unto bie barauf gegrünbeten Statuten ber

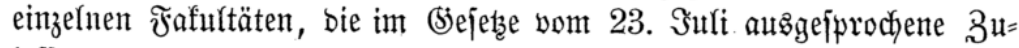

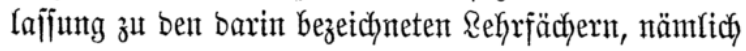

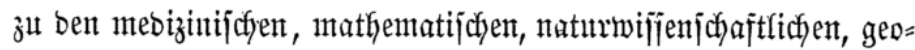

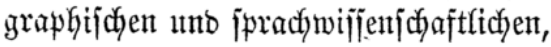

wirffich geitatten ober nicht? jo jehe ich auth nidft bent entferntejten (sirunb, ber für bie Berneinung geltend gemadyt werben fönnte. Sirgenbs erforbern die Statuten für bie gebachten Rëhrfächer ein bejtimmtez Befenntnití, auch ericheint ein jolches überall nidyt als natïnlidfe \$orausjeţutng für biejel=

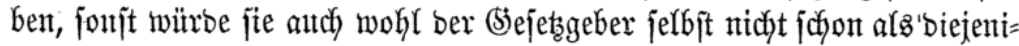
gen bezeidynet habent, bie einem Suben anvertraut werben fönnten. Der

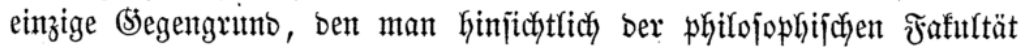
anfüfhren hört, bejteht barin, baß zufolge ihrer Statuten jeber bazu gehö=

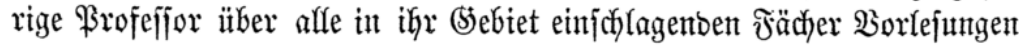

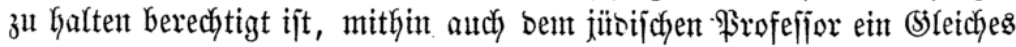
gejtattet werben, ober - eine ant jich nidft zu bebortwortenbe Äbänberung ber Sfatuten in biefem Stütof erfolgen num.

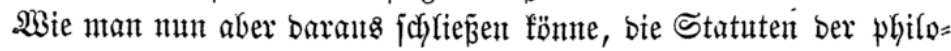

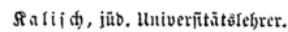




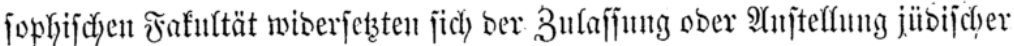

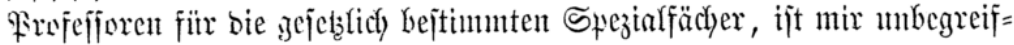
fic). Die Statuten finto afferbings ein Spejialgejeds für bie Univerfität

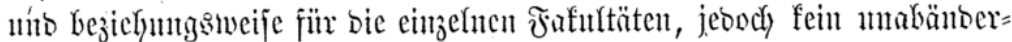

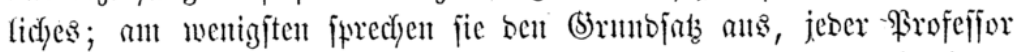

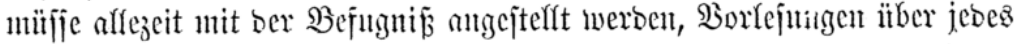

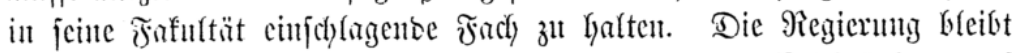

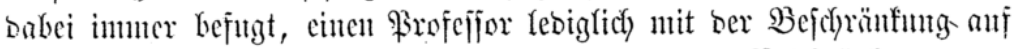

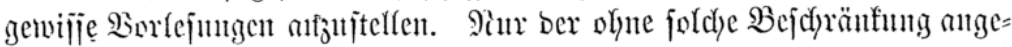

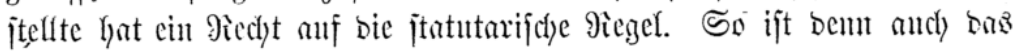

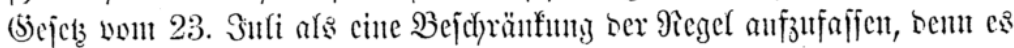

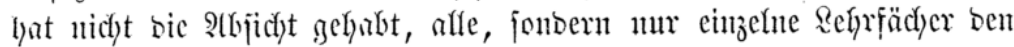

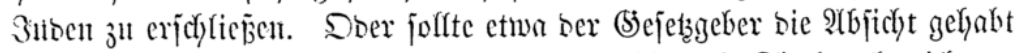

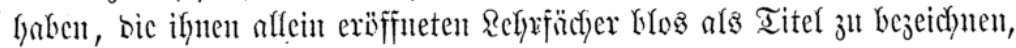
auf werdye hin cin Shbe bei ben Uniwerjitäten angejtellt werben fïnnte,

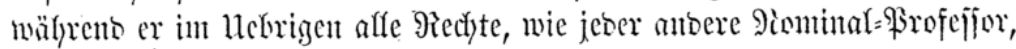

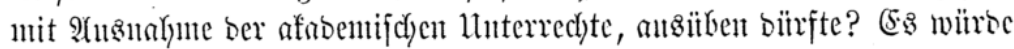

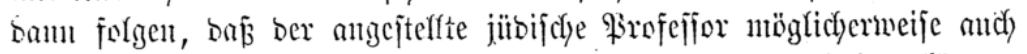
Sorrejungen nus ben (bebiet jeber anberen ซafulttät halten. fümute.

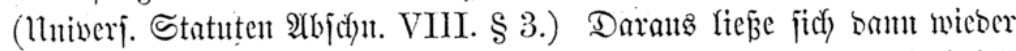

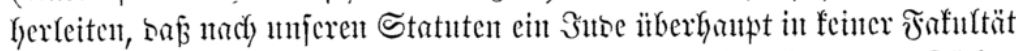

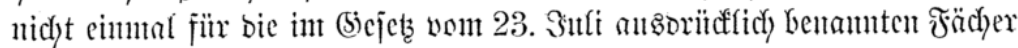

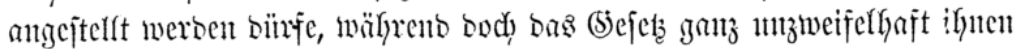

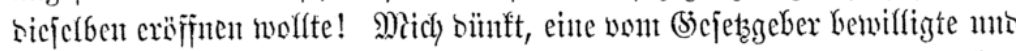

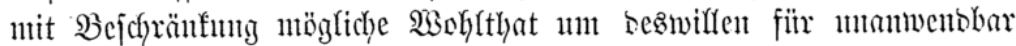
lyalten, ober wegbenten, weil bie $\mathfrak{W o h}_{\mathrm{f}}$ hat nicht unbejdyränft gegeben

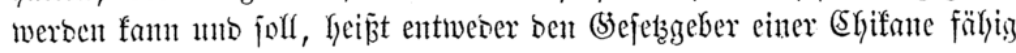
lyalten, ober bas (S)ejełz chiffaniren!

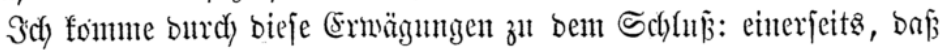

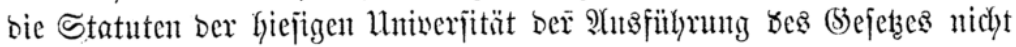
wiberjtreben, anbererjeits aber auds, baj jich bie fitnftig anjuftelfenben

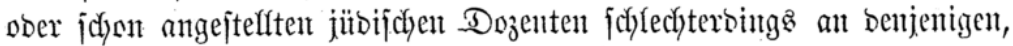

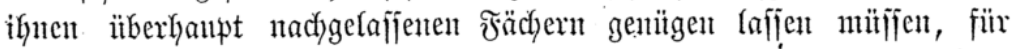
werdye jie jich habilitirt haben ober afis srofejforen bejtelft worbent fint;

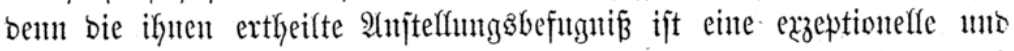

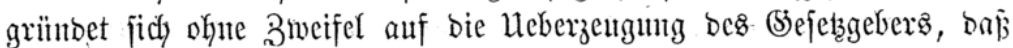

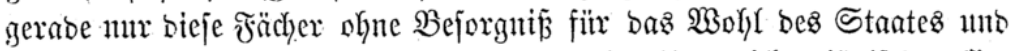

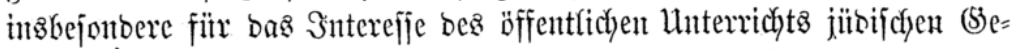
lehrten antwertraut werben fönnent. (5: wiro Sache jeber betreffenton

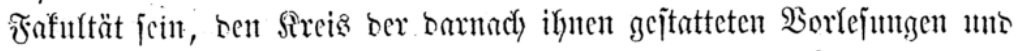


Uebungen zu überiwad)en unb allenfalls reglementarifd) zu bejtimmen ober bejtimunen zut laffent.

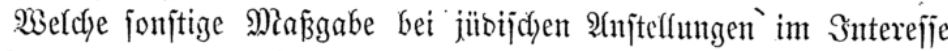
Des Stnates unt ber Univerfitäten zu ergreifen fein mödyten, barauf werbe

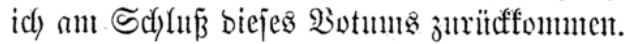

(E⿱

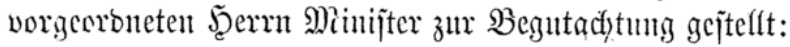

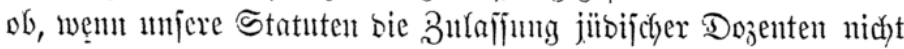

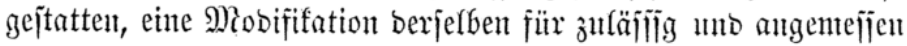
zut erachtelt jei,

ober, wie cas an einer anteren Stefle ber vereffrlichen Mlittheifung beś

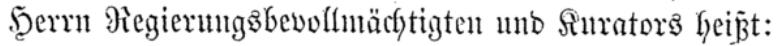

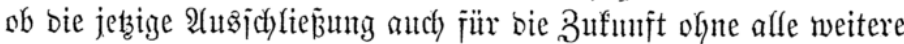
Miosifitation zit besortworten jei?

Sofern bieje żwei Fragen mur auf ber Unterjteflung rubcu, baj jich

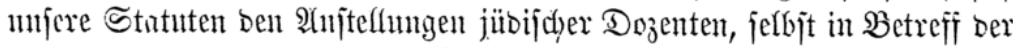

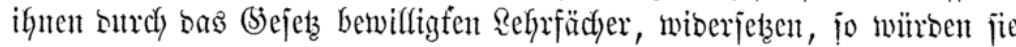
nach bent Origent feiner weiteren Errebigung bebiliren; benn ez ijt jitjon barizelegt, bus eine Sollifion nicht jtattfintoet, ober body im Sinne oes

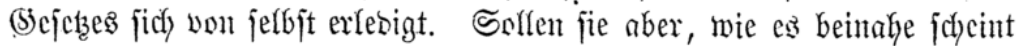
mo namentfid) sie Ábjicht ber zweiten Frage gewejen jein bürfte, sie

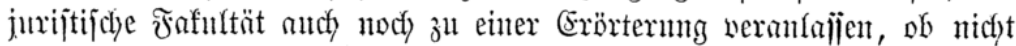

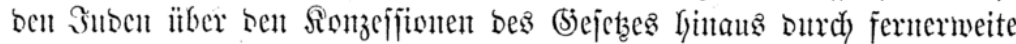

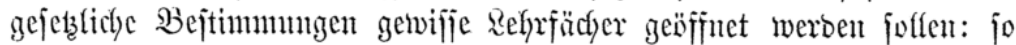

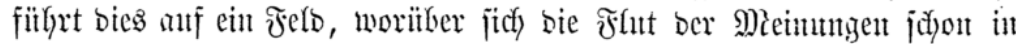

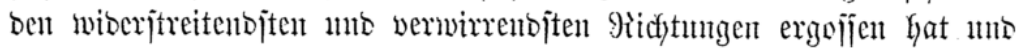

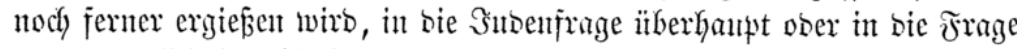

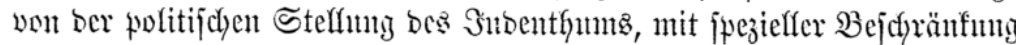

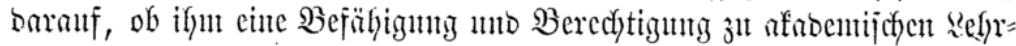
ämtern im âtfgemeinen, unt insbejonbere ju welcyen? - jugejtanben

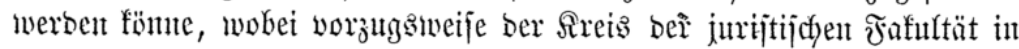
Betradyt zul mefymen ijt.

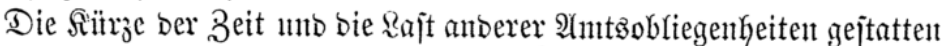

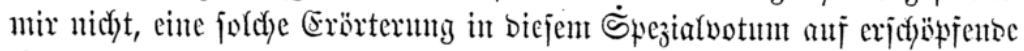

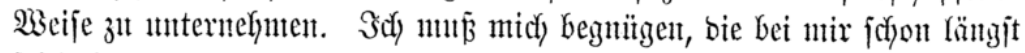

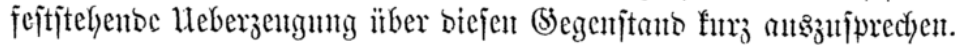

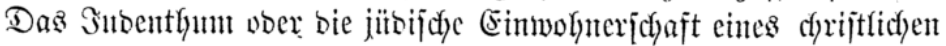

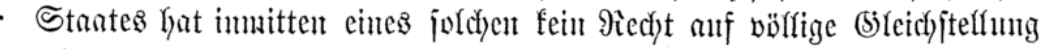

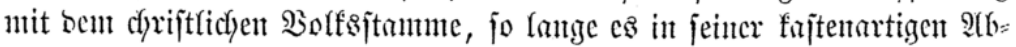

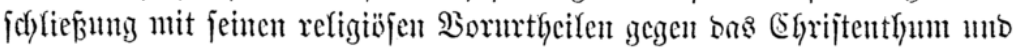


mit feinen Arbweidyungent von dyriftlicher Sitte bejteht. "Gine vollfwmmente Staatżgemeinjiłaft ijt hier jo unsenfbar, als bie angegebene Divergenz, jelbjt in ber milbejten Fornt auşgebritcft, auf (Strunb bes in bem jübifichen

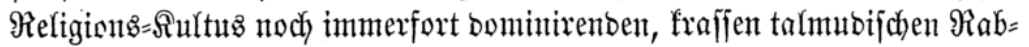
binißmus, nady ben eigenten Bengniffen jübifcher Schriftjtelfer, wirflidy fortbejtejt.

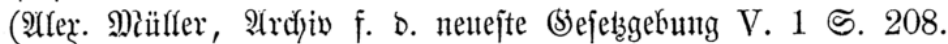
VI. $1.170 \mathrm{fif}$.)

Dies barf jeboch feine Beranlafjung werben, in ber Dulbung unt in Der Erfü̈flung ber \$rfflidyten chriftlicher Menfdyentiebe zu ermüben, fo

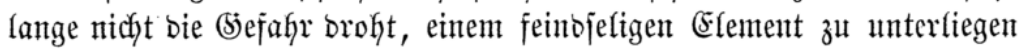

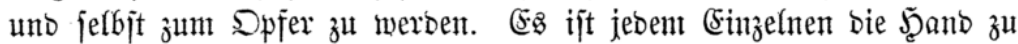
reichen uno. \$jemeinjdyaft zut genähren, ber jich mit unjerem Staat ver= tragen ober ibentifiziren will unb bafüir Bürgjedaft giebt, bã er, wenn auch gläubig unb fejthaltent an feinem $\Re$ ultus unb. Dogment, fich bennod) von ben frajjen Sonjequenzen bejierbent emanzipirt unb lozjagt. Nar auf biejer (S)unblage faun bie bïrgerliche uno politifche Emanzipation ber Juben angebahnt werben; jie ijt jogar eine $\mathfrak{B f f i c h t}$, wenn mant jie andererjeits zu Den Rajten bes Staatzberbanbes Keranzieht.

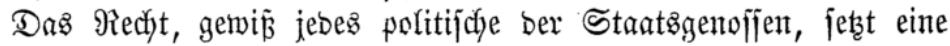

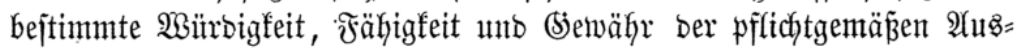

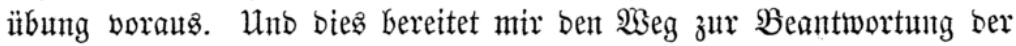
Spezialfrage:

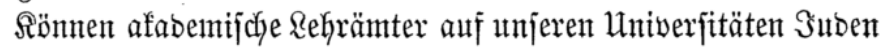
anvertrant werben? and welche?

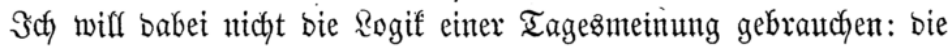

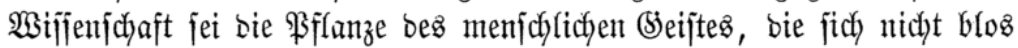

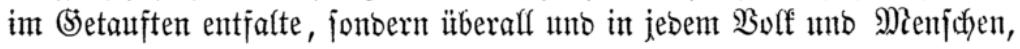

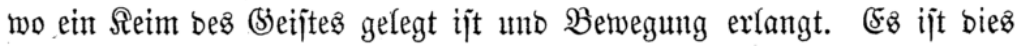

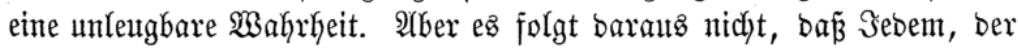
jich wifjenjajaftlidy bejuäftigt uno bejtrebt, audy bie freie Rehre ober gar ber Unterridgt ber Эugend eröffnet werben miijfe.

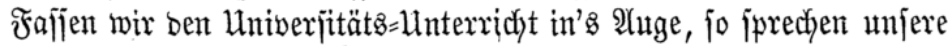
Statuten bom 31. Dftober 1816 bejiflt 3ivecf bahin alts:

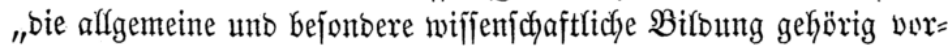
bereiteter Sünglinge burch Sorlejungen uno anbere afabemifche Hebungen fortzujetzen und fie zum (Fintritt in bie verjujiebenen 3weige bes höheren Staatz= unt @irchenbienjtes fähig zu machen."

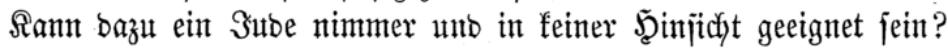
$3 \mathfrak{u}$ ber 3 eit, wo jene Statuten gemadyt unb jantitionirt wurben, zweifelte 
man mokyl im atrfgemeinen nidyt baran, benn bas tamala noch in biefem

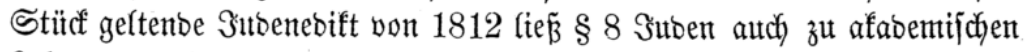
Rehr $=$ unt Schutümtern zu, für welche fie fich gefchicft gemacht haben

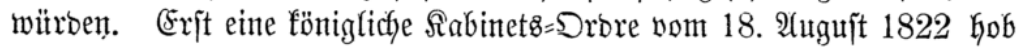

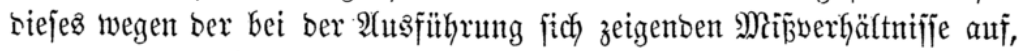

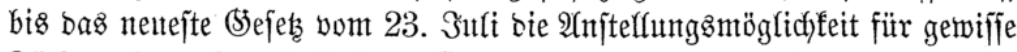

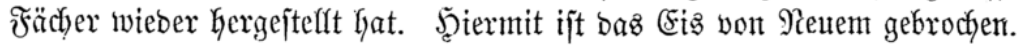
Das nämliche Prinzip, welches bei biejer theifweijen Sonzeffion geleitet hat, fann aber wohl aud nodh bei anberen Rehriächern antwentbar jein.

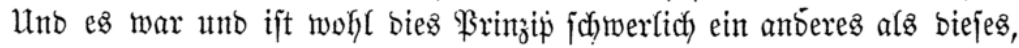

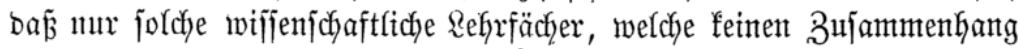
mit ber chriftlichen Staats, Sirchen- unto Sittentegre haben, folglich auth

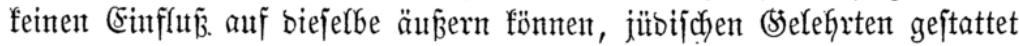
jein jollen. Sj̈ biejes ridytig, unb ijt es in ber That bas Minnmum, was

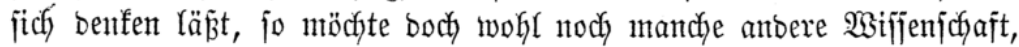

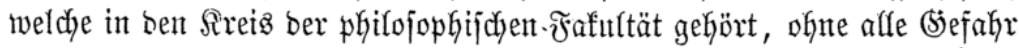
einem Sitton anvertrant werben bitrfen. IUtf jeben Fall jinto bie ver=

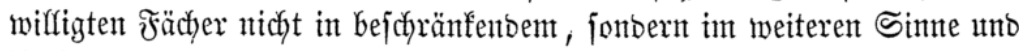
Umfang zu verjteken, wenn ich es auch gerabe hier nidyt unternefymen witl,

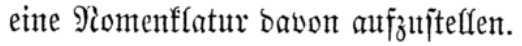

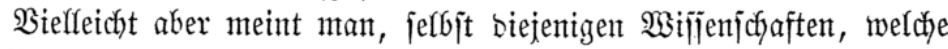

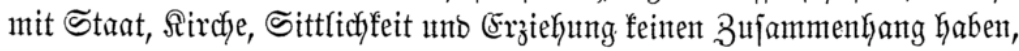
fönte bodf, nadjoent jie eimmal in ber entropäifdyent Sphäre eine Errungen=

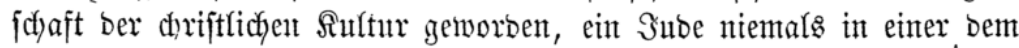

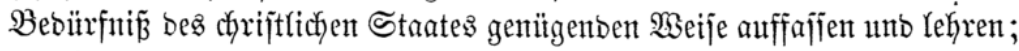

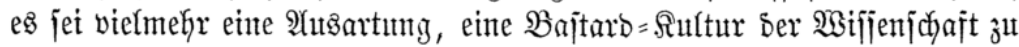
befürchten, wenn fie einter frembartigent refigiöfen Denfweije anheimgereben

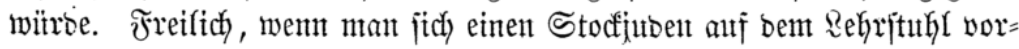
jteflt, bem ber Talmub ber Snbegriff alles 2 siffens ijt, unto ber wie ber Bater bes Salomon Maninton (jieke befien Rebensigejdyjute, Berlin 1792)

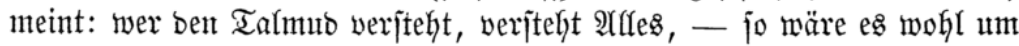

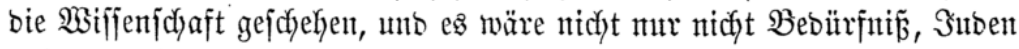
jich) baran bethätigen zu laffent, fonbern ntan mitfite jie jeţt anto immerbar

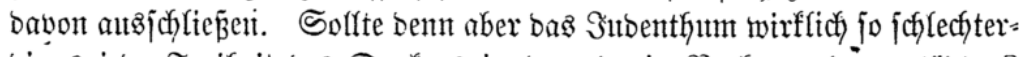
bings jebe Freikeit bes Denfens in bem barin Serharrenben ertöbten?

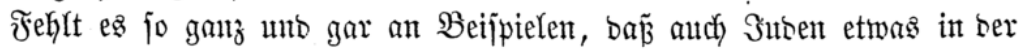

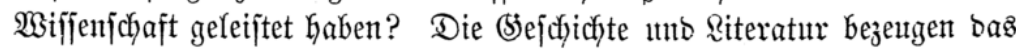

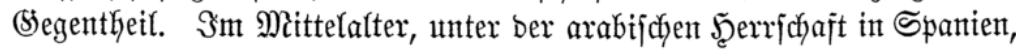

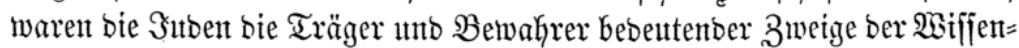
¡chaft, ber Arriftotelifchen \$̧Gilojophie, ber Afjtronomie, ber Mathematif 


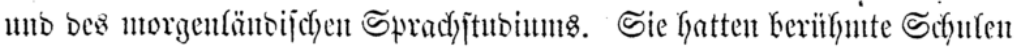

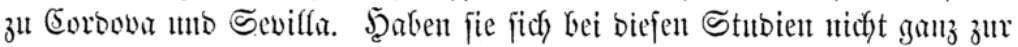

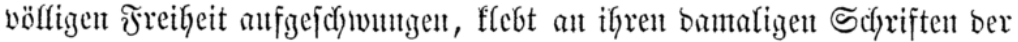

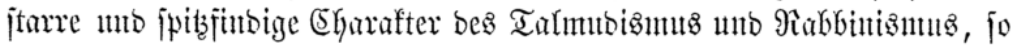
bradyten jie in iffrer Siseije eben mur ben Tribut ber wifjenfdyaftfichen

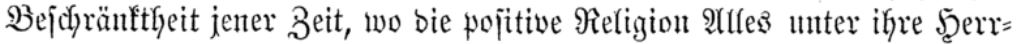

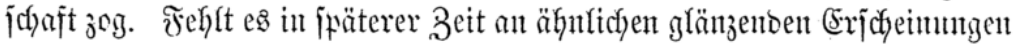

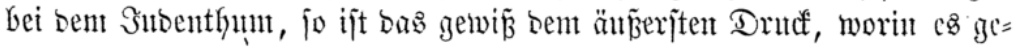

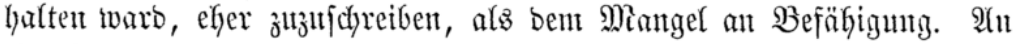

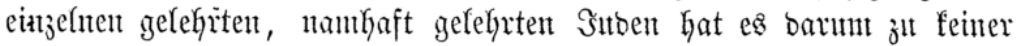

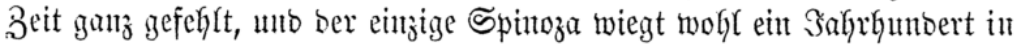

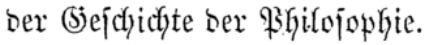

Wier vermïchte mut wohl mit wahrer. interer Heberzentgung bem

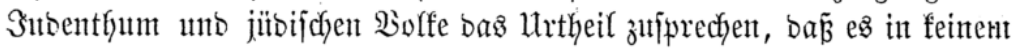

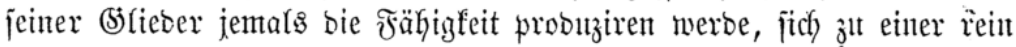

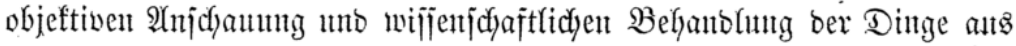
bent Sdylamm bes frajien Talmubismus zut erheben? Sch follte bentent,

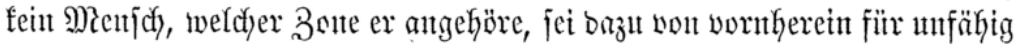

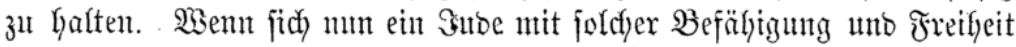

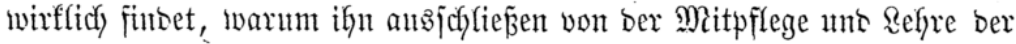
2ijijenfichaft?

Dreier(ei wiro man vieffeicht eintwerfent und entrgegenjetsent. Maan

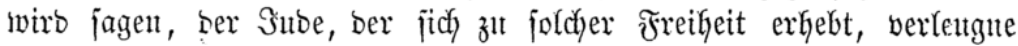

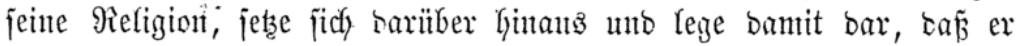
feine গieligion habe. Man wirb jich ferner auf ben dyriftlichen Staat berufen, ber nur bon dyrifttich (Sejunntent getragen werben sürfe; man wirb entlich jagen, ber doriftlidye Staat habe wentigitens

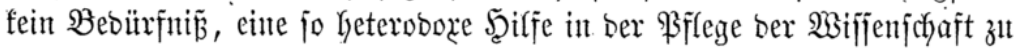
gebrautchent.

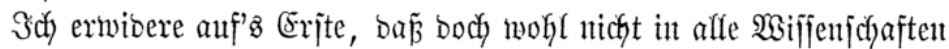
jübijdyes Sorurtbeil Ginemipielt, itberbies and nidyt Seber, ber in ber

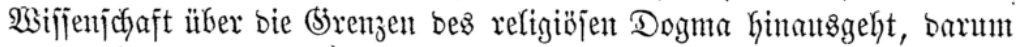

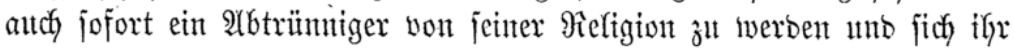
als untrüglidger Selbjtoenter gegenitber jut ftellen nöthitg hat. Waa abcr

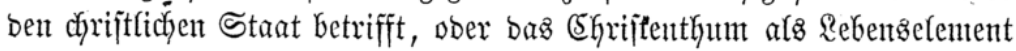

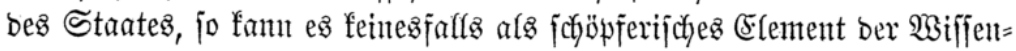

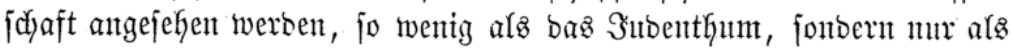

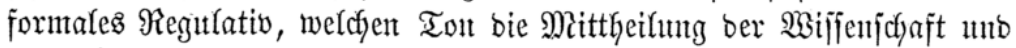

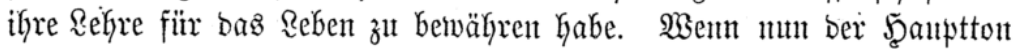

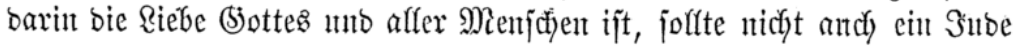


jich finton, ber bawon beritgrt wïrbe, obgheich bas nationale Dognta ifyn

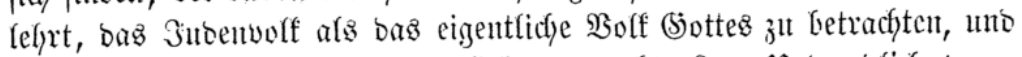
ihyn gejtattet, jebe antore 9iationafität zu veradjten? - Uno enoliç, wenn

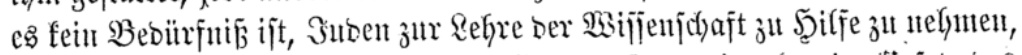

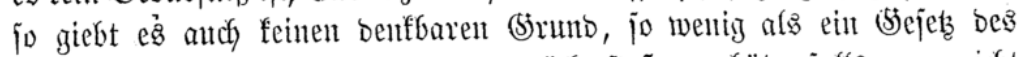

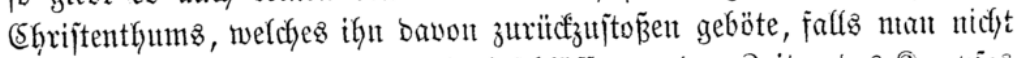

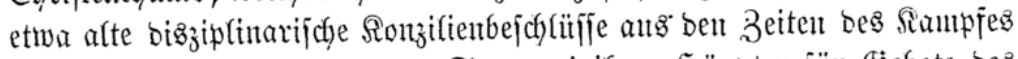

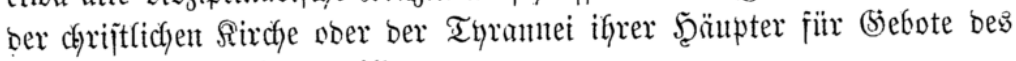
(5hriftenthums erflëren will.

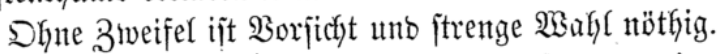

(Fin wejentlich dyriftlicher Stant fann weber einten $\mathfrak{A}$ lnfänger bes

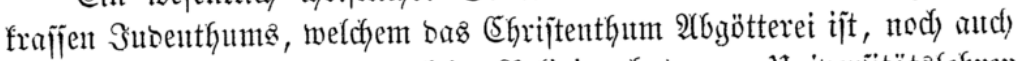

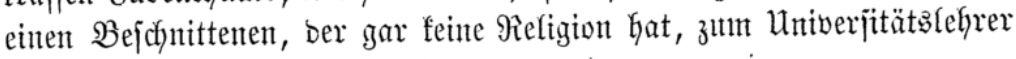
berufen.

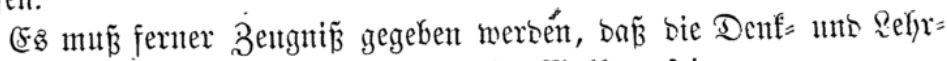
woije mit Sitte und \$sejes bes Stantes im Einflang jei.

(5.

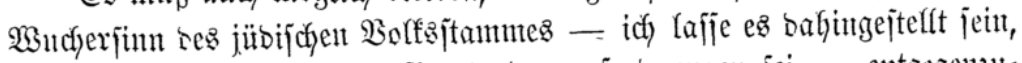
ob ex ifm won ?atum eingepflanzt ober aufgebrumgen jei - entgegenju=

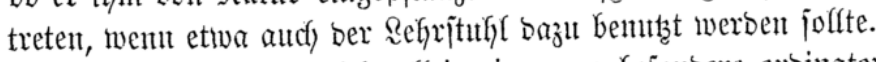

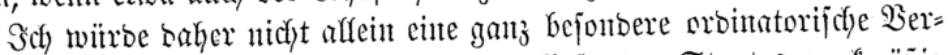

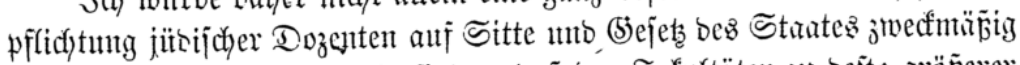

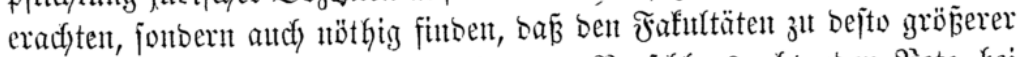

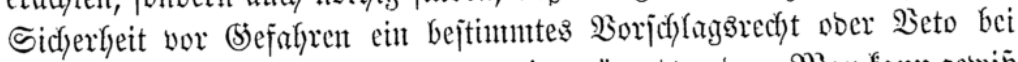

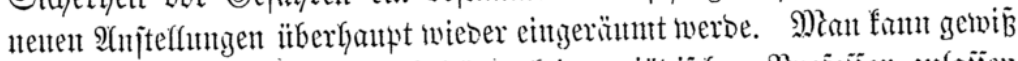

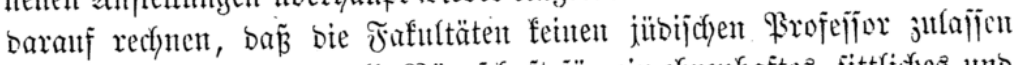

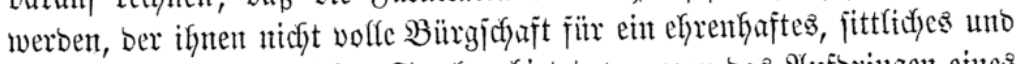

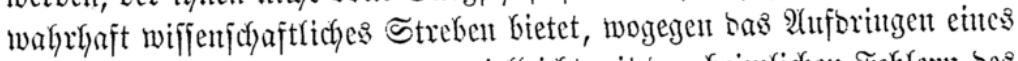

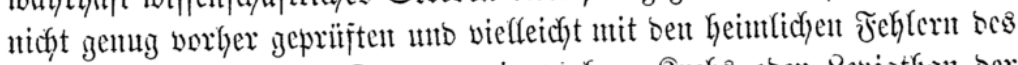
Subenthums Gehafteten Dojenten ein warhrer firebs ober Revinthan ber

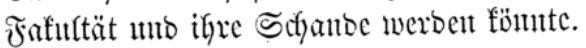

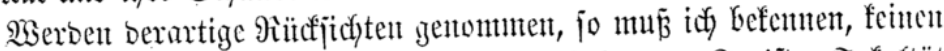

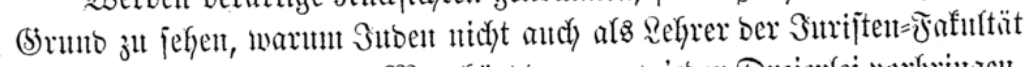
beigejeflt werbent fümntent. Man hört bagegent wieber Dreicrlet worbrintzent.

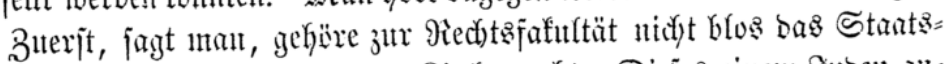

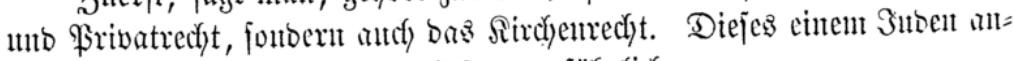

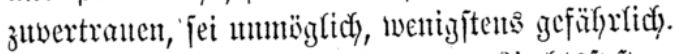

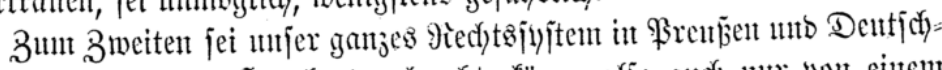

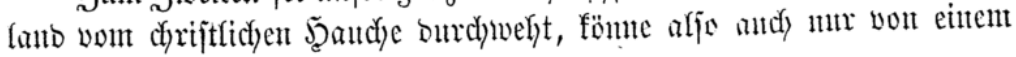
Eshriften begriffen und getehrt werben. 
3um Dritten feien unfere Mntiverfitäten wejentlich bazu bejtimmt, Sünglinge zum Eintritt in bie verffyiebenen Bweige bes Göheren Stantz= unb Rirchenbienjtes tïchtig ju madyen. Untjere Suben fönnten aber zeither weber in bent einten, noch anberen eintreten, folglich fönne autch ein jübijcher

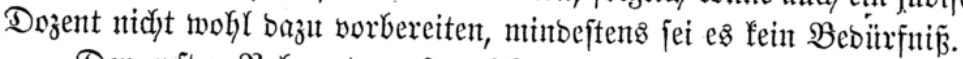

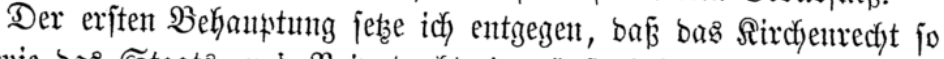
gut tvie bas Staats= 1utb Frivatredyt einte äunerlidje Erfentbarfeit hat und einer rein objeftiven Durd bringung fäbig ijt. Sie fino fertige (5)e

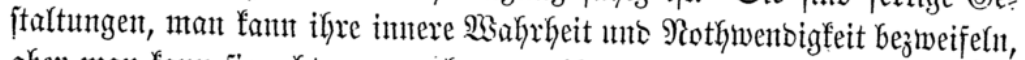

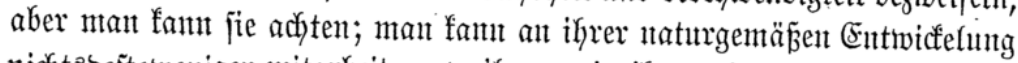

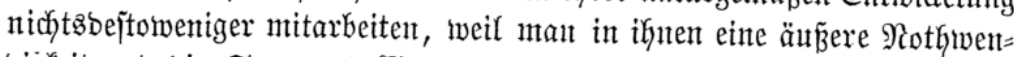
bigfeit unt bie - Surrogat=(Eigenjchaft für tiefer liegente (sejetze erfennt. \$ir gejtatten bem Brotejtanten, fatholijches @irchenrecht zu Yehren, bem

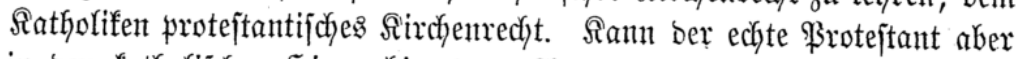

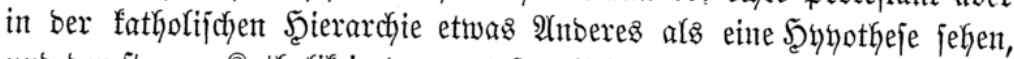

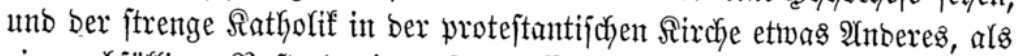

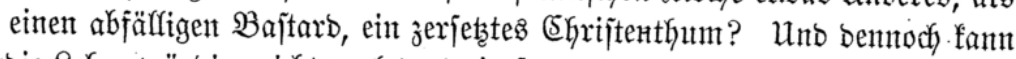
bie Refre mürbig, nidyt verleţent, ja jogar förbernto jeint.

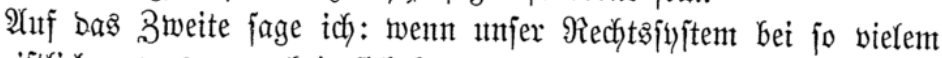
Undefyriftlichen, was es nody in jich hat, bennoch ein dyriftlidjes ift, fo liegt

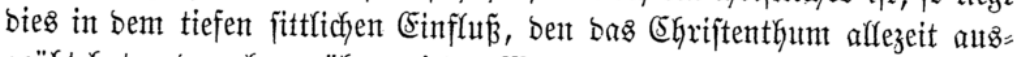
geübt hat unb noch ausübent tvirb. Warum follte bas autch ein Jutbe nicht erfennen unb entwidfeln helfen?

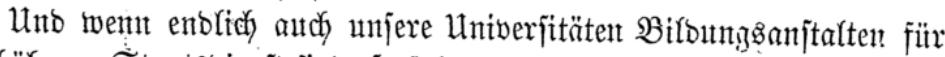

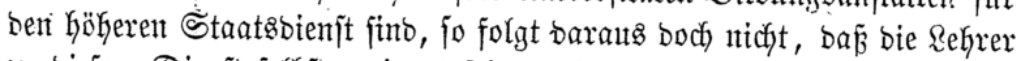

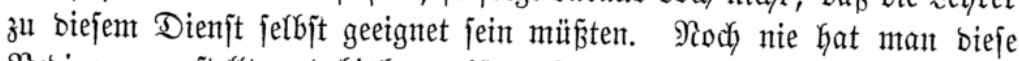

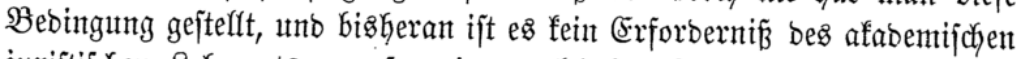
juriftifchen Rehramts getwejen, int praftijchen 3ujtizbienjt geitanton zu haben. Uteberbies möchte es nody nicht jo autsegemacht jein, ob ben Suben

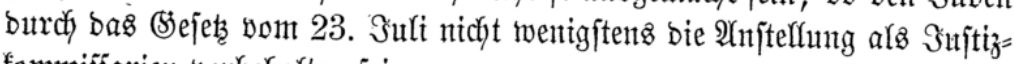
fommijifarien vorbehalten jei.

3ch bin baker ber Meinung, wenn überkaupt nody weitere Scfyritte

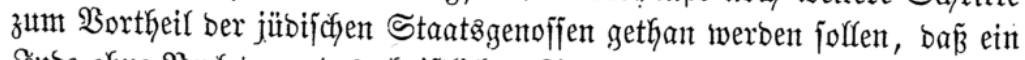
Jube ofne Serletzung bes dyriftlichen Staates unt ohne Eintrag fïr bie Wiffenfdyaft Dozent für alfe juriftifichen Fädher merben fönne, went er bie obigen moralifichen Staranticent giebt unt Finer ijt voit Denent, quibus ex meliore luto finxit praecordia Tytàn.

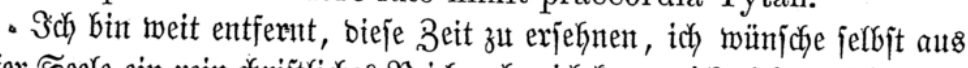
tiefer Seele ein rein dyriftliches $\Re$ eich; aber ich fant midy nicht entichließzent, (Etwas ber offẹnbaren Möglichleteit zumiber zu behautpten, utno idy erfente 


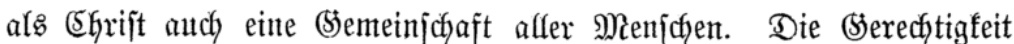
fagt: Theile mit Dem, ber nach gleichem Ziele auf recjtem Wege jtrebt;

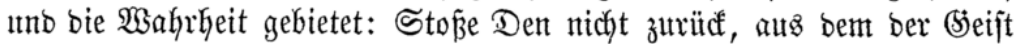

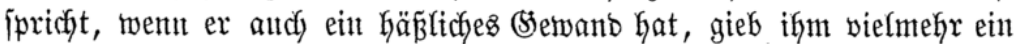

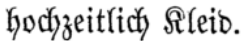

So fann idy nidut andera!

Berlin, am 20. Dezember 1847.

A. $\mathfrak{W}$, $\mathfrak{b e f f t e r}$.

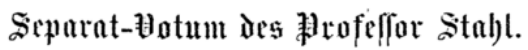

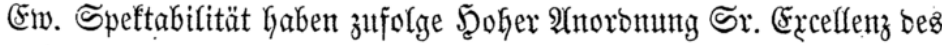

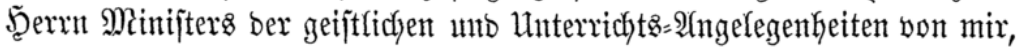
wie von jebem Mitgliebe ber Fafultät, ein (S)tadhtent ïber bie Zulajīung

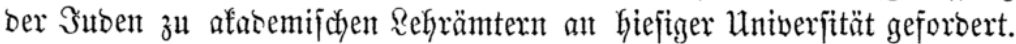
$3 c$ entfpredye siejer $\mathfrak{A}$ nforberung in Folgenbent:

Die hief̣ige Univerjität ijt bei ifrer (arridytung, eben fo wie alle

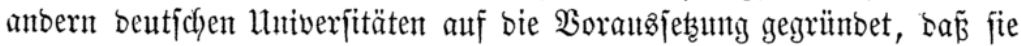

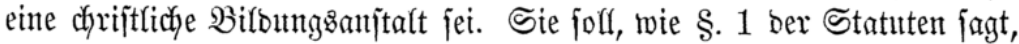

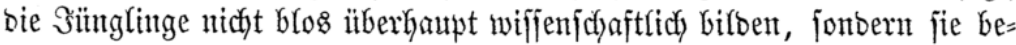
jonbers zum sintritt in bie verjefiedenen 3iweige bes höheren Staats= uno Sirchenbienjtes madyent. Unter bem Dienjt ber Sirche ijt hier aber ohne

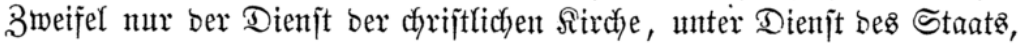
nur ber Dientit bes Staats gemeint, ber ben chriịtliçen EGarafter trägt, uno -

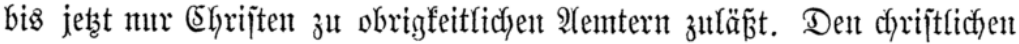
Eharafter ber Untiverjität, wie er burch ben ganzen Entroidelungägang ber

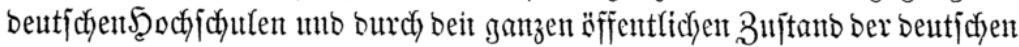
Staatent, unb instefonbere audy bes prentipifyen, gegeben ijt, jeşent beshalb

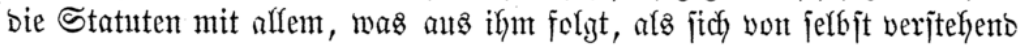
überall voraus uno erffären ifgnt nicht mit $\mathfrak{B o r t e n t . ~ D e a ̆ h a l b ~ n a m e n t l i c h ) ~}$ iprechen jie autch nicht bas Erforbernis d)rijtlidyen Befenntniffes für bie

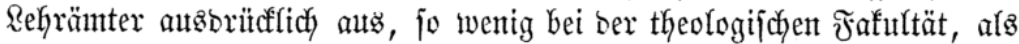
bei ben anbern, weil an ein (Entgegentgejeţtes gar nicht gebadyt wurbe. Es

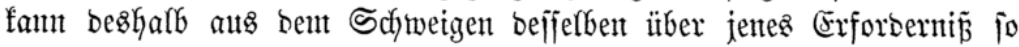
wentig ein Berżicht alf bafjefbe gefolgert werben, alz aus bem gleichen

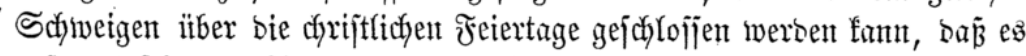
gejtattet fei, bent Sonntag zu ben Borlejungen unto bent Somtabent jum Feiertage zit bejtimment.

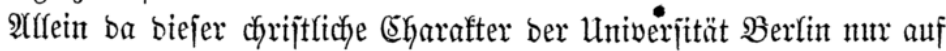
ben alfgemeinen dyriftlichen (5harafter bez ganzen ëffentlichen Buftantoez

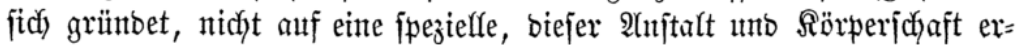




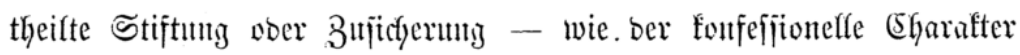
anbern Untwerjitäten in joldyer \$seije ertheilt ijt --: jo ijt berfelbe ant()

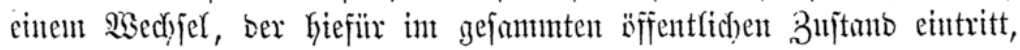
innterbar offen, unto wenut bahjer Se. Sïnigl. Majejtät burch ein allge=

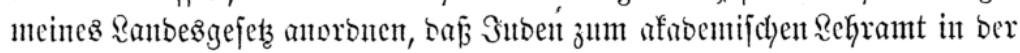

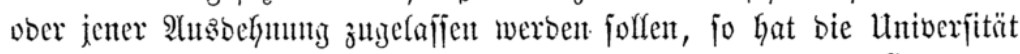

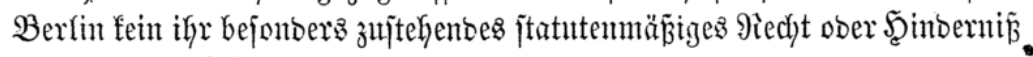
bagegent vorgubringent.

Wenn Yiernach ber Einfiührung bes (5ejeţes bon 1847 bic Statuten

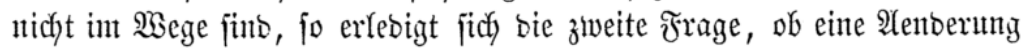
ber Statuten wünjchensinerth, von jelbit.

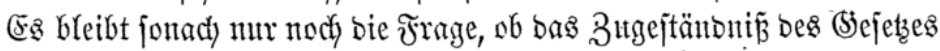

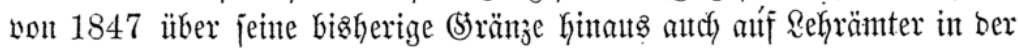

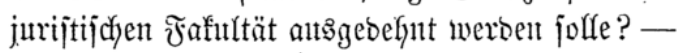

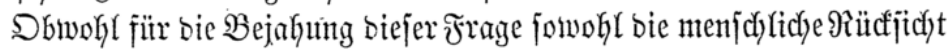
auf Ermeiterung ber freien Berufgrwahl uno ber $\mathfrak{B r}$ irfungsfreife für bie

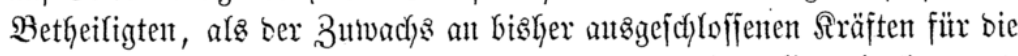

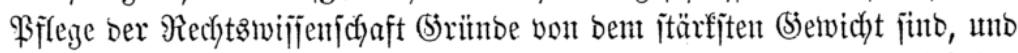

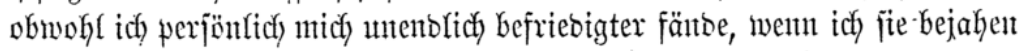
bürfte, jo fam idh bod nicht anbers als midh für bie Serneinung ber=

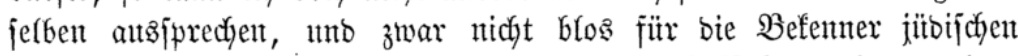
(5) anbens, für weld)e jie gejteflt ijt, fonbern für bie Befenter irgent eines

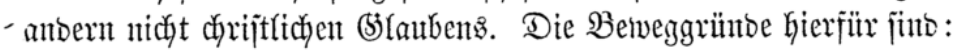

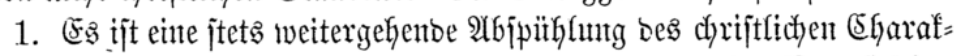

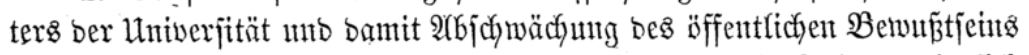

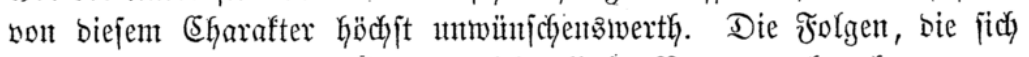
hieraus ergeben witrben, finto gar nidyt affe im 20 raus zut berechnen.

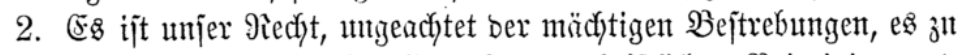
entchriftianifiren, bennody überall nody won dyriftlidyen Brinjipien unt Miotiven burdybrungen, bas gilt nidjt blos vom Sitrchentrechte, bas feiner

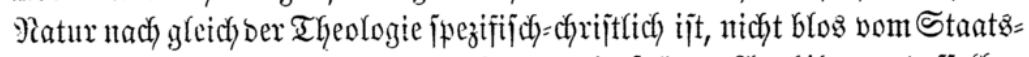

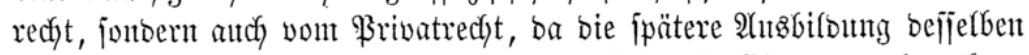

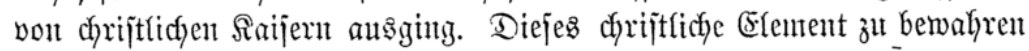

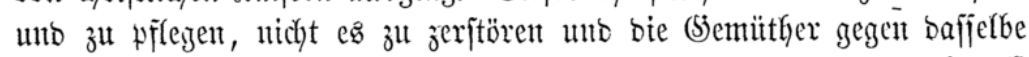

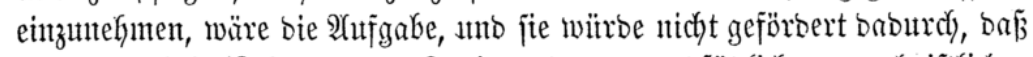

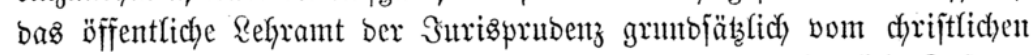

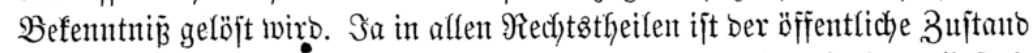

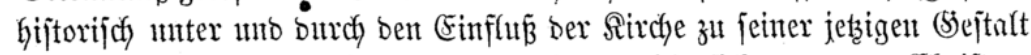

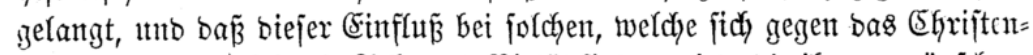
thum befennen, nidyt bie Riebe unt \$ietät finton wirb, bie igm zu wïnjchen, 


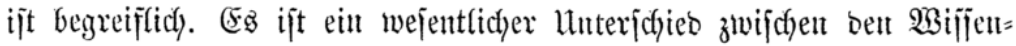

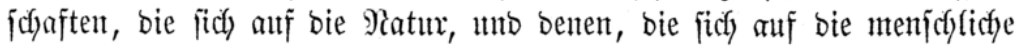
Sozietät beziehen, bie leţteren funo von bem 3ujanmentang mit ber (5e)ittung, baher tiefer von bent religiöfen (E)Lement nidyt völlig zu trement.

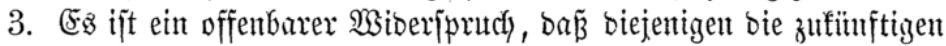

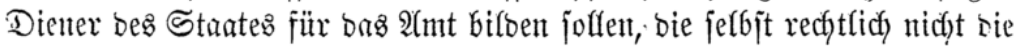

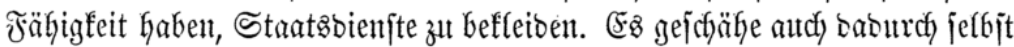
ber Digntiät bes Refrers Eintrag, ber alfo jeiten Bubürern gegenüber jtäutbe. (5) gelyt in biejer ફ̧injicht bie unts vorgelegte Frage gleich) antoen

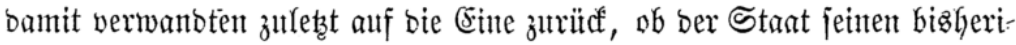
gen djrifttichent EGarafter behaupten ober anfgeben folle. Şierïber habe

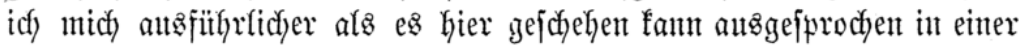

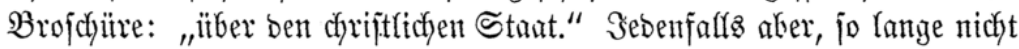

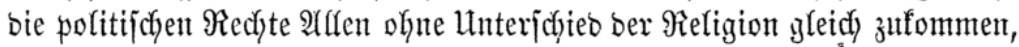

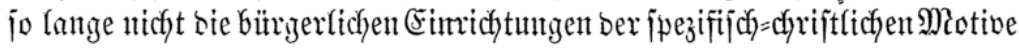

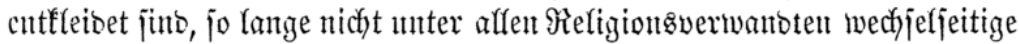
Berkeirathung jatt hat, fitr, jo lange nidyt ber Staat bie Snbifferenz

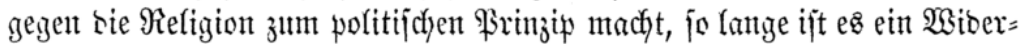

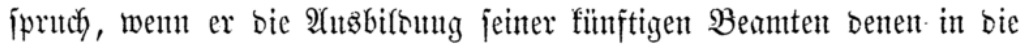

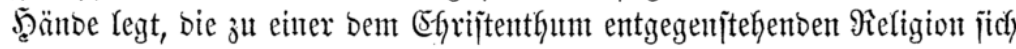
befénten.

B̧errin, im Dezémber 1847.

Stahl.

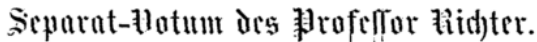

Bereits in ber mitndfichen Berfyandlunty, ans weldyer ber gejtern von

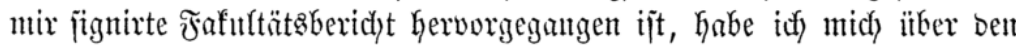
Stanbpunft geäuñert, wou weldyent ans ich) bie Subenfrage in ifjer jpezieflen

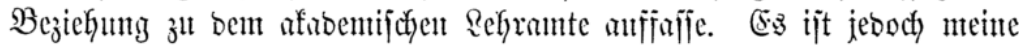

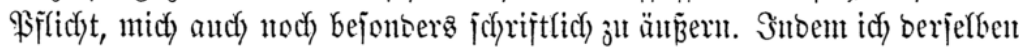

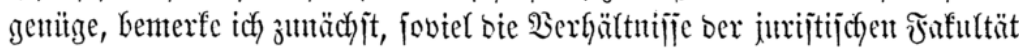
anlangt, ergebenjt Folgentoes:

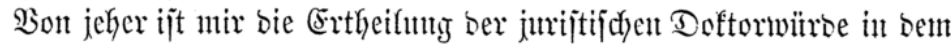

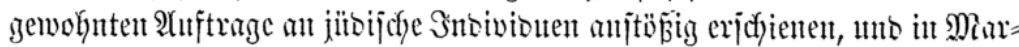
burg bin ich ber Eimgige getwejen, ber im Salfre 1842 ber Theilnafyme an

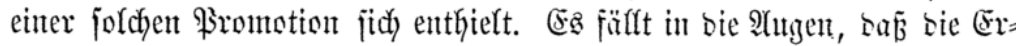

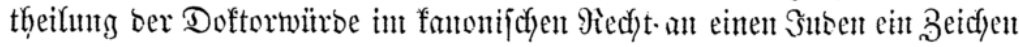

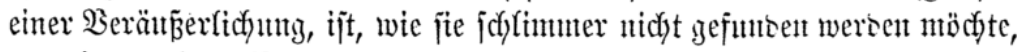

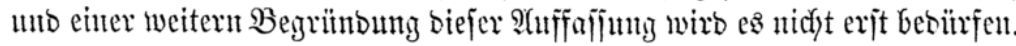

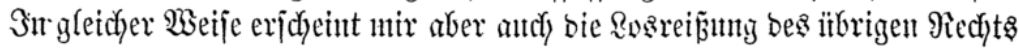




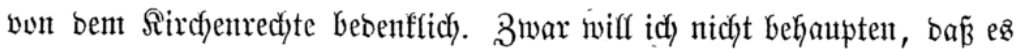

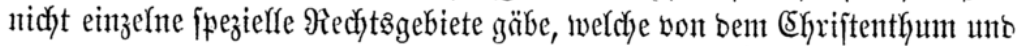

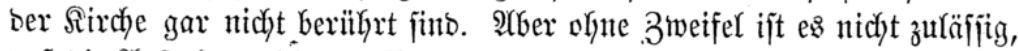

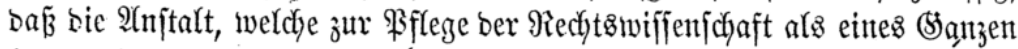

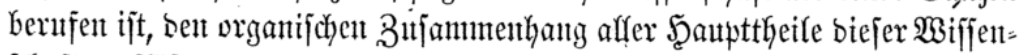

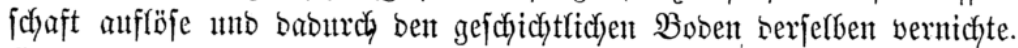

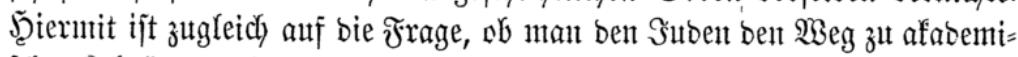

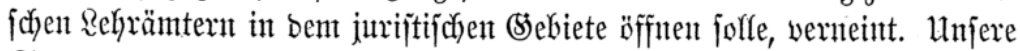

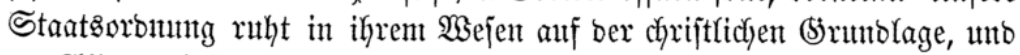

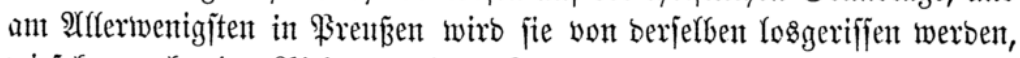

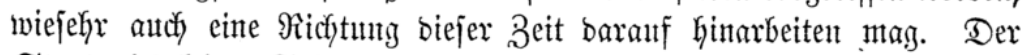
Staat wirb feinen Selbjtmorb begehen. Sjt aber jener Bulfanmenhang ber

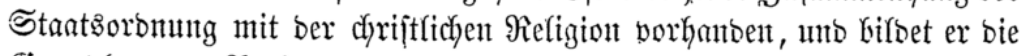
Strunblage bes 9iegiments, fo miijīen wir fortern, baj biejentigen, melche

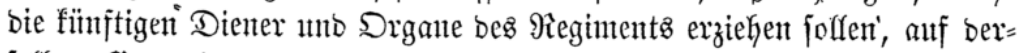
jelbent Srunblage jtehen, auf ber Staat und. Aiegiment errichtet finto. Sie fint es, weldje burdy ifyren Unterridyt hier vorarbeiten unb bem Stante

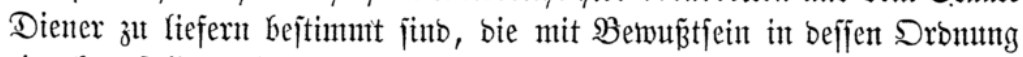
eingehent follent. Sine Scheibung ber Diszziplinen halte idy auth hier für

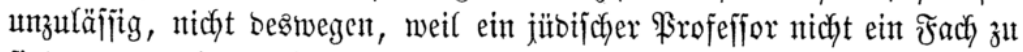
finben verntëchte, weldyes altzerfalb ber Beritfyrung mit bem (Ehriftenthum

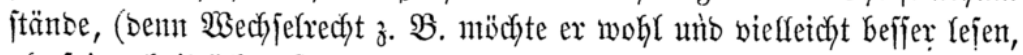
als jeine chriftlicyen Sollegent), jonbern weil ber Staat nicht burch) bie $\mathfrak{A}_{11}=$

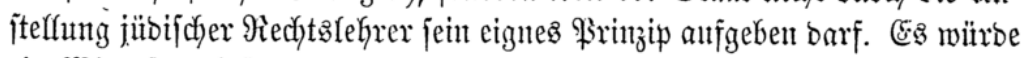
ein $\mathfrak{B}$ iberfpruch fein, auf ber einen Seite von ber jurifitifchent Fafulttät zu forbern, baß jie int Sinne biejes \$rinzipz lehyre, unto auf ber anbern Refrer

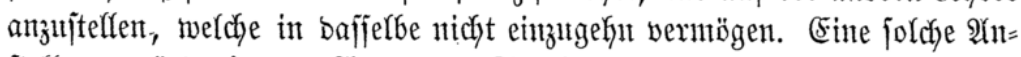
jtelfung witrbe in ben 2 (tigen ber Stubirendent einem praftijchen Stegen=

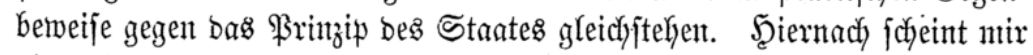
bie unbebingte Fejthaltunt beffen, was unfere Statuten auşprechen, fehr. wïnjchensiwerth. Die Statuten ber mebizinifachen unb phitojophifchen

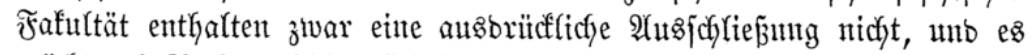

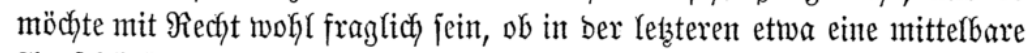

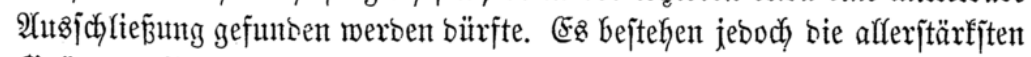

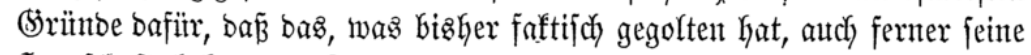

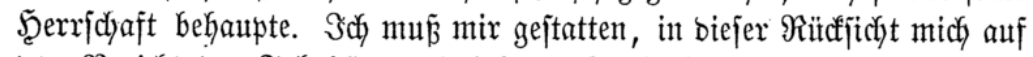
Dén Bericht ber Frafultät zu beziehen. Bugleich aber interlajfe idy nicht auf einen $\mathfrak{B u n f t}$ hinzubeuten, ber ber $\mathfrak{B}$ eherzigung fehr werth fein bürfte.

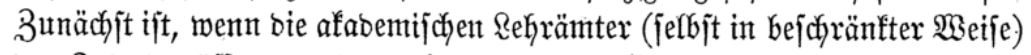

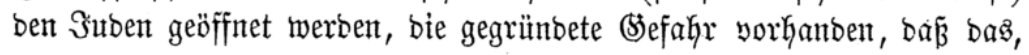




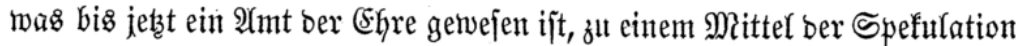
werbe, bie in bem afabemijchen Reben eine vöflig unleibliche Ericheinung ijt. Sn Marburg hatten wir brei jitbijche Dozenten, von benen zwei bieje Befhauptung völfig beftätigten, ber eine in ihrem alfervollften Umánange. Inskefondere fam aber gefragt werben, welche battung von Suben ber

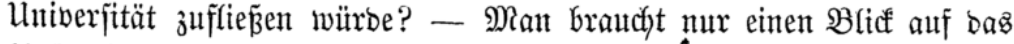

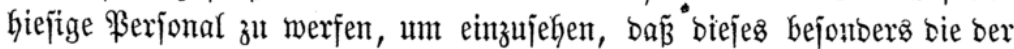

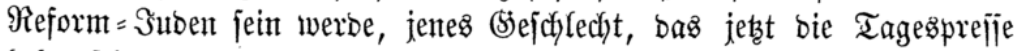

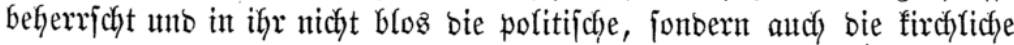
Bolemif führt. (5s würbe gefährlich jein, bieje wibertwärtigjte afler liebera=

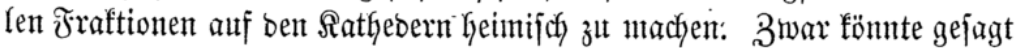

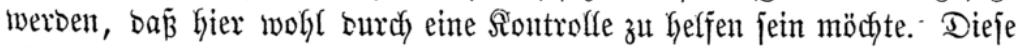
ijt aber theils im âtlgemeinen untangfüthrbar, theils, wenn jie in einem

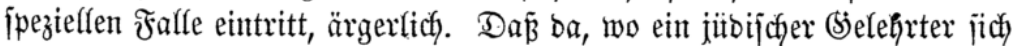
ganz bejonbers auszeichnet, er im 23 ege ber Dispenjation zut eintem jpeziellen

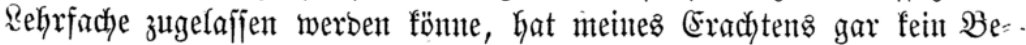
benfert. In gegentuärtigen Falfe aber Gantelt es jidy um éin \$rrinzip und

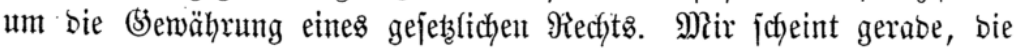
Univerfität $\mathfrak{B}$ erlin witrbe bie leţtere tief z̆ beflagen haben.

Berlin, Den 16. Dezember 1847.

Piid)ter.

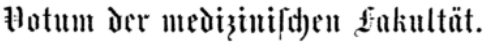

Berliti, ben 28. Dezember 1847.

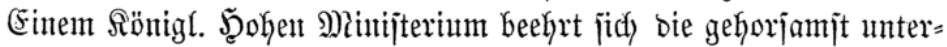

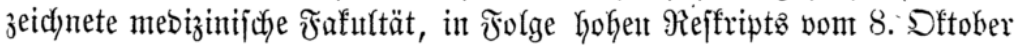

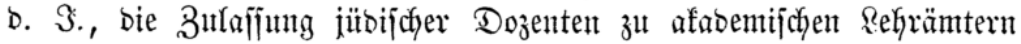

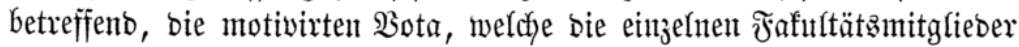
viritim abgegeben haben, in originali z̆t ïberjentent unb babei in $\mathfrak{B}$ etreff

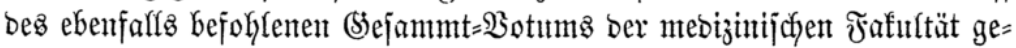
horjamjt zut bemerłent:

Wag zuerjt bie Frage ad 1 betrifft: $\mathfrak{o b}$ bie bejtehentent Statuten ber

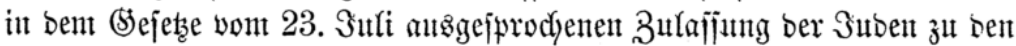
bezeichneten afabentijchen Sebräntern geftatten ober niddyt? jo enthalten bie Statuten ber Kiejigen mebizinifa)ein Fafulttät feine $\mathfrak{B}$ ejtimmung über biejen

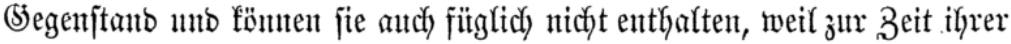

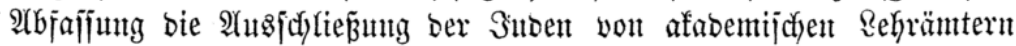
ïberhautpt als eine unbejtrittene Thatjache galt. Went mut and Giernady

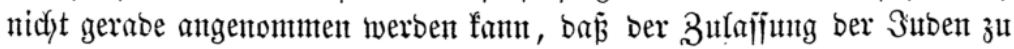
afabenif(yen Refyräntern barum nidyts int 23 ege jtehe, weil bie Statuten 


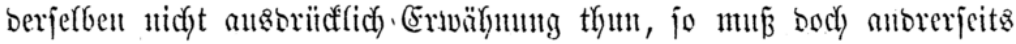

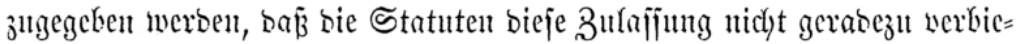

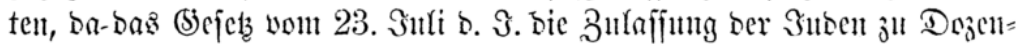

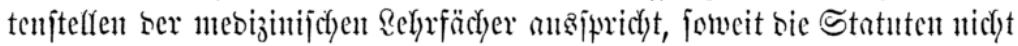

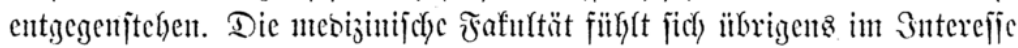

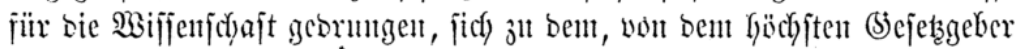

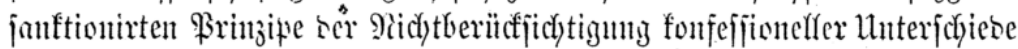

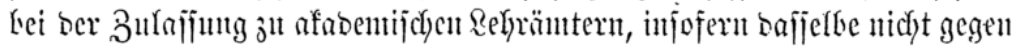

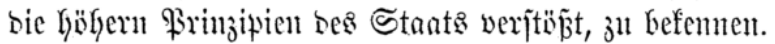

Einer Aenfermity ither bie Frage ad 2: v6, wem bic Statuten ricje

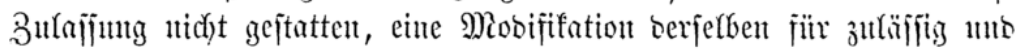

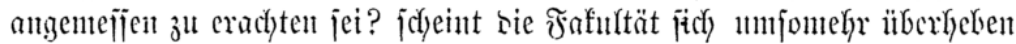

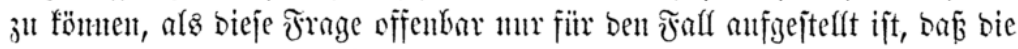

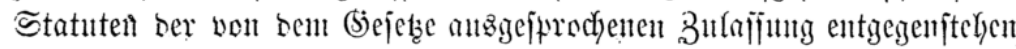

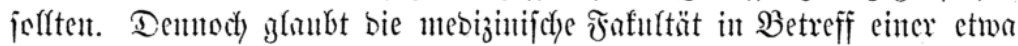

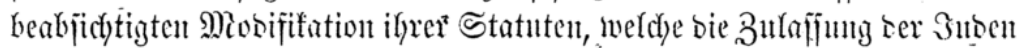

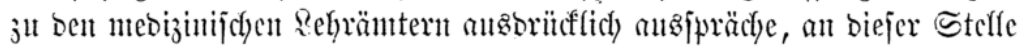
auf̃ bic Folgen anfmerffom machen ju miijjen, weldye bas Eintreten ciner

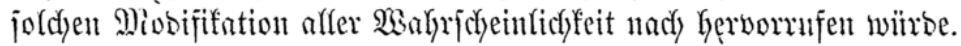

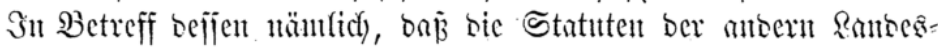

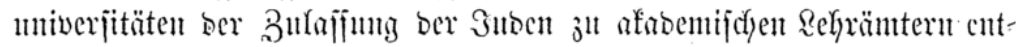

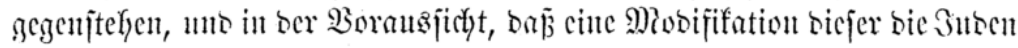

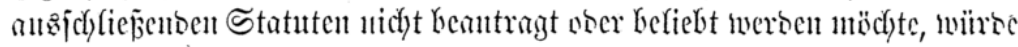

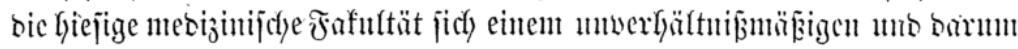

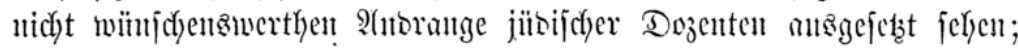
cinmal meil bie fiefige Fafultät vielleicht bie einjige ift, beren Statuten. bie Bulajpung Der Gnben nicht verbieten, mo jueitens, weil gernoe Bertin

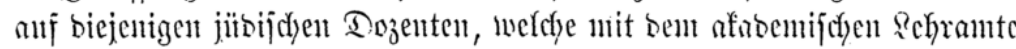

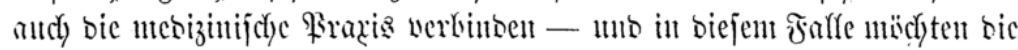

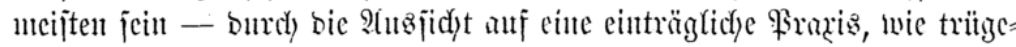

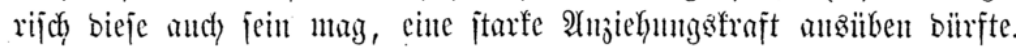

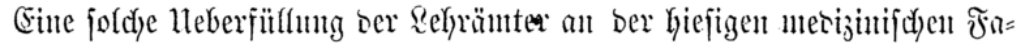

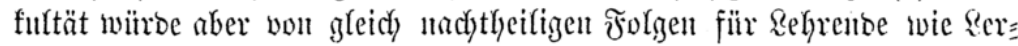

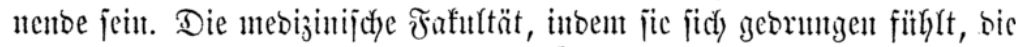

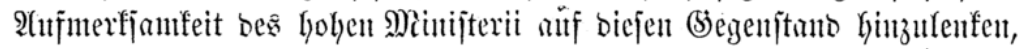

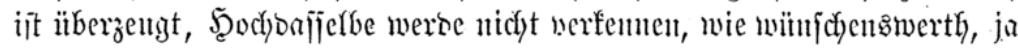

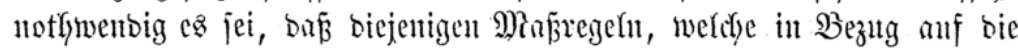

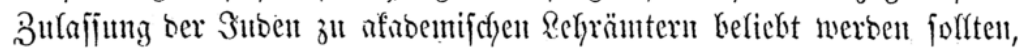

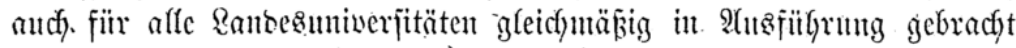

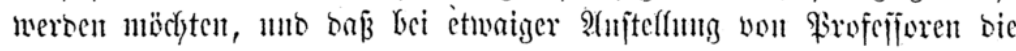




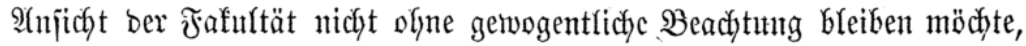
weldye ifyrerjeits mehnx als je, nädyjt ber @uafifitation ber Sanbibaten, ganz

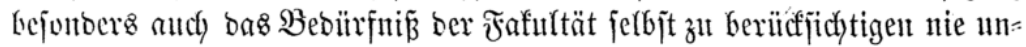
terlafjell mirt.

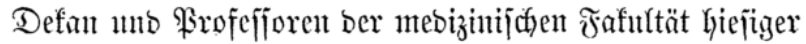

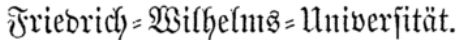

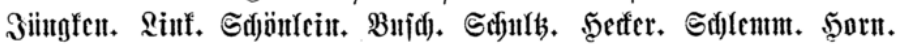

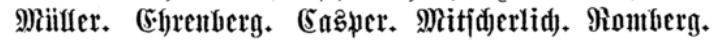

\section{Separat-\#otum des Alofeffor Atlïller.}

Micines BSijjen entharten bie Statuten ber Univerjität Ber(in nichts,

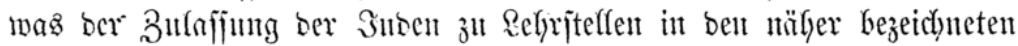

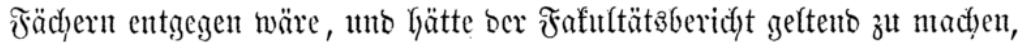

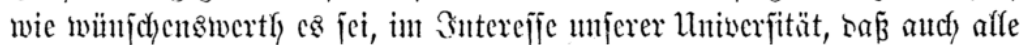

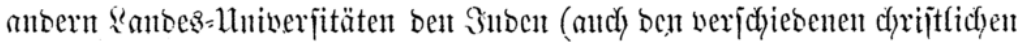
Sonfeffitonent, wo . fie ez nod) nidyt jinto) geüffnet werbent.

Berlin, bent 22. Oftober 1847.

Miirler.

Einverịtanton.

3uiff. Den 26. Sftober 1847.

(5)anz einveritanbent.

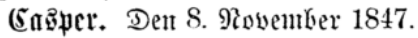

Einverjtantert.

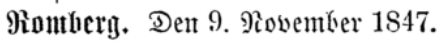

Dezgleidyen.

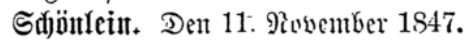

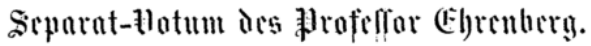

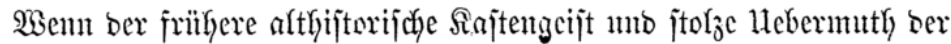

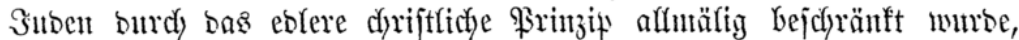

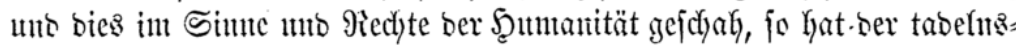

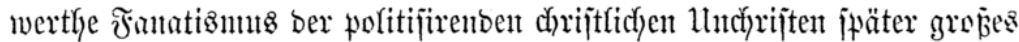

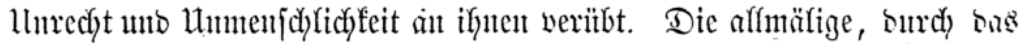

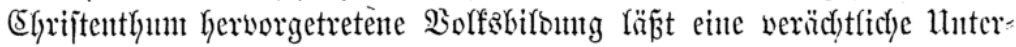

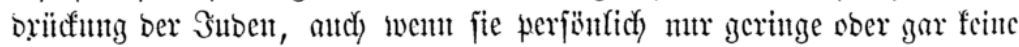

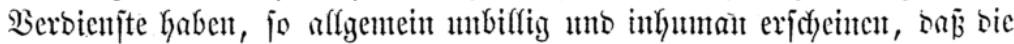

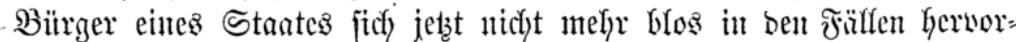
ragenber Snteflizentz, jonbern in Mirfie foţänten, went bie Snben im

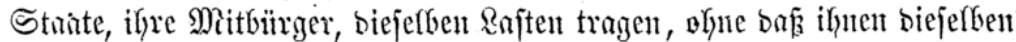

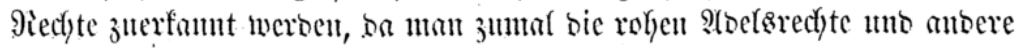




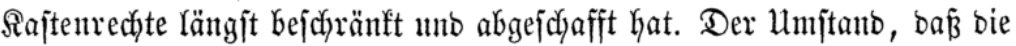
Statuten ber $\mathfrak{B}$ erliner Univerjität ben Sntoen ben 3utritt in bie Refrämter:

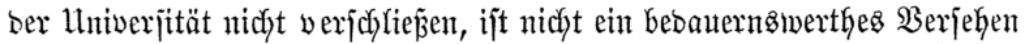

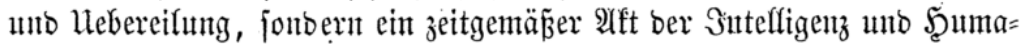

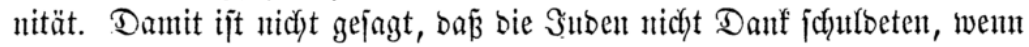

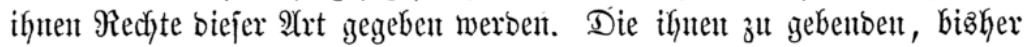

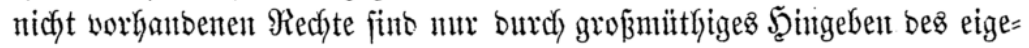
nen Erwerbs ber EGriften unt burdy Sdyaben unt Mnbiffigfeit gegen bis:

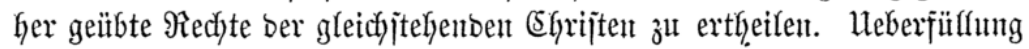

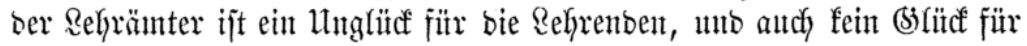
bie Rernentoen, wie eine grope Bibliothef bem Sdyüter und aud bem Stu= Denten nicfsts taugt.

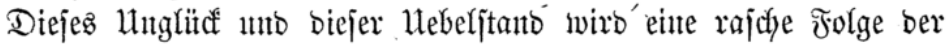

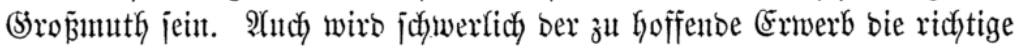

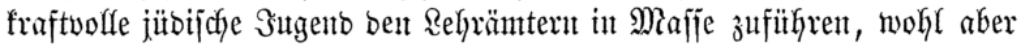

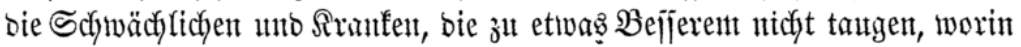
idf feinen Bormurf für bie खation anşprechen will, ba es affgemeinere

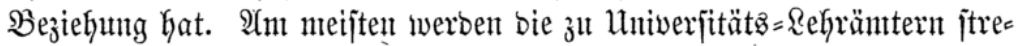

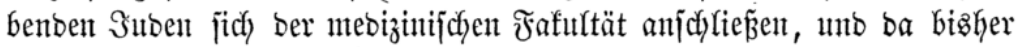
mur bie Berfiner Univerjität feine Bejchräntung fïr jie hat, jo niro bie

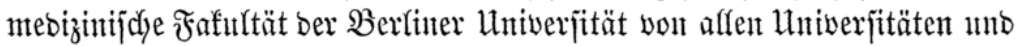

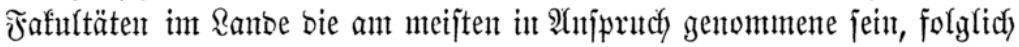

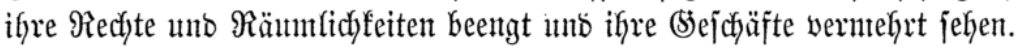

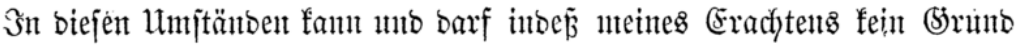

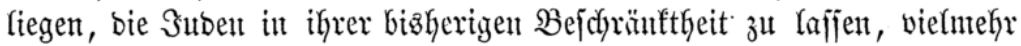

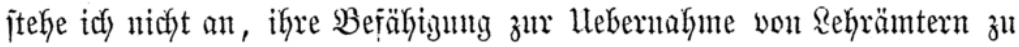

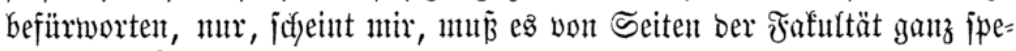
ziell bem hohen vorgejetsten Minifterinm empfohlen werben, burch Berall=

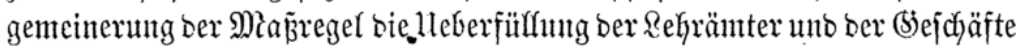

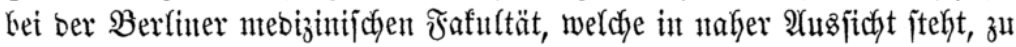
verhü̈tent.

Berlin, ben 27. Dftober 1847.

\section{(E)tentherg.}

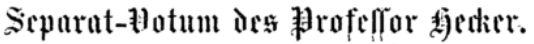

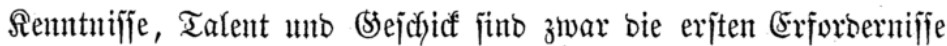
eines afabemifonen Rehrantes, fie reichen aber nicht hin, went fie nicht

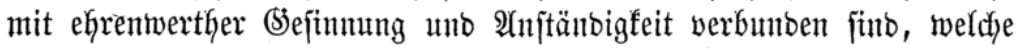
burch gute, ich meine nicht bloz surch glatte, jonbern ourdy moralijaje (Ex:

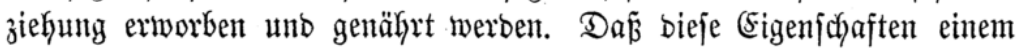




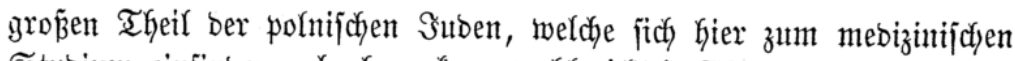
Stutbium einfinten, abgeken, fann wohl nicfit in Abrebe gefteflt werben.

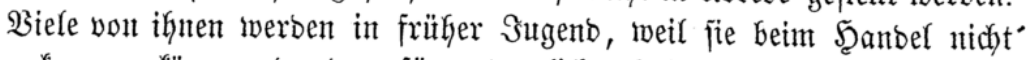
allfommen fönnen ober bagu fïr untaugfich gehalten werben, fajt ofne alle Mittel utb ausgejtattet mit bem moralijchen (Sefithl, bas im Elent bes

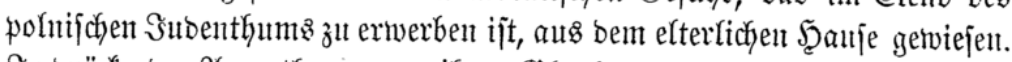

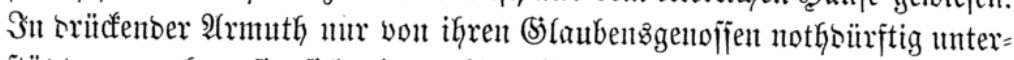

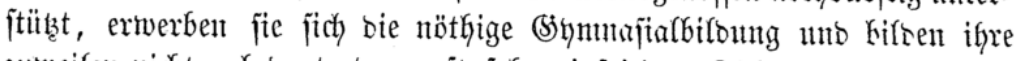
zuneilen nicht unbebententen, oft jef̧r einjeitigen Fähigfeiten mit zäher Beharrlicyfeit ans. Ebenjo gegt es auf oer Univerjität, wo fie ifgren $\mathfrak{u}_{n}=$ terhalt zum Theil boburch ertwerben, bã fie jich won jitbificjen Riteraten

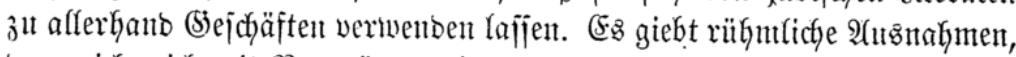
berent ich mich mit Bergntïgen eriunere, unb mandyen tüthtigen uno ệren= haften jiibififen Stubirenton bin ich währent igrer Stubienzeit wie nachber

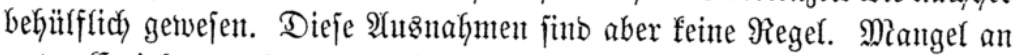

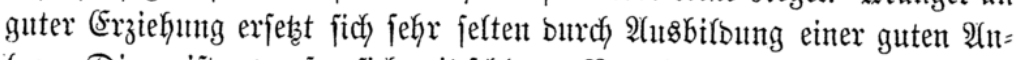
lage. Die meijten merfen fich mit julatter Berectynng fo auf bie Mebizin,

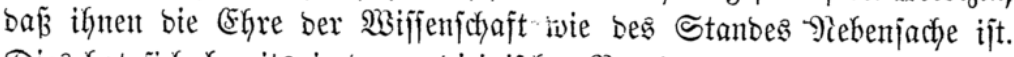
Dies hat jidy bereitz in ber mebizinifichen \$rax̧iz gentrgant ergeben, bie fier unb ba eint wahrer Şaufithantoel gemorben ijt.

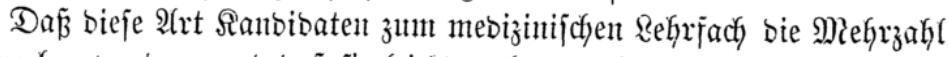

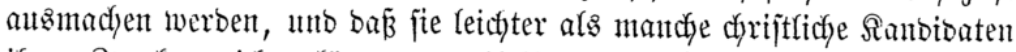

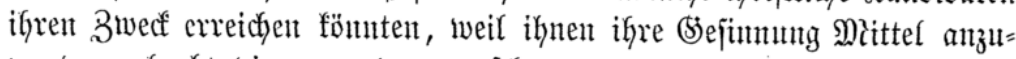
ivenben erlaubt, bie bon anberen gejchent werben, wie z. B. Servifität bei

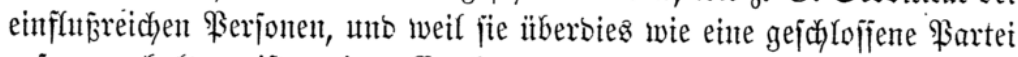
zujammenthalten, ijt meines Eradytents ebenjonentig in Âbrese zu jtelfen,

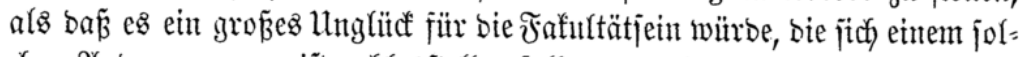

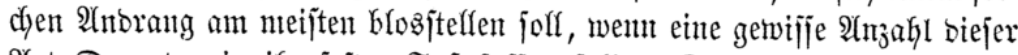

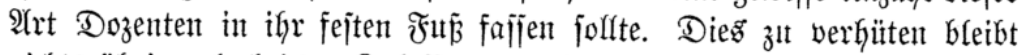
nichts itbrig, als bei ber 马utaffung von \$rivatoozenten ïberbautpt nie bas

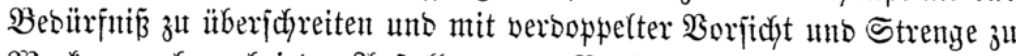

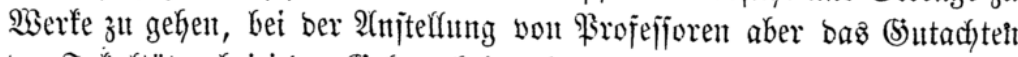
ser Fafultäten bei jeber (selegentyeit geltent zu machent.

Bertin, ben 1. November 1847.

†ุetécr.

\section{Sipurnt-flotum dos fofrofellor Sit)ult?.}

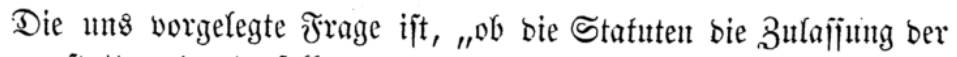
Suben geftatten ober berjelben entgegenftehen", unb wie es fdyeint in ber

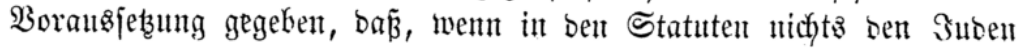


Entgegenjtehentes ijt, anzuntehmen jei, baß̧ bie Statuten bie Zulajiung ber Suten gejtatten. Diefe Borausfetzung halte idy für nidht ridhtig, ba bie Berliner Statuten, obgleidy jie ben Snben nidht entgegenjtehen, weil fie

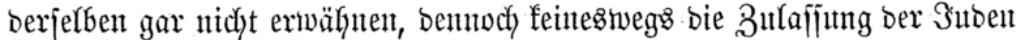

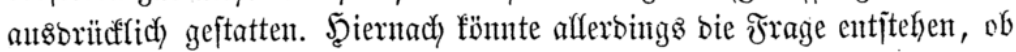
nicht nach bent \$unft sub 2 eine Mobififation ber Statuten notfinentig

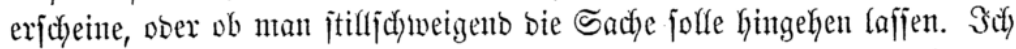
glaube jedod, baj wir Gierin nicht jut voreilig fein, fonbern viefntehr bas

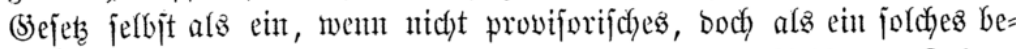

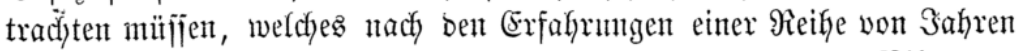
nuobifizirt werben fönnte. Die befürdytungen, welche ans bem $\mathfrak{B}$ illoungs: jujtand und ben bem Subenthumè entipwechenden SGarafter ber Suben fïr

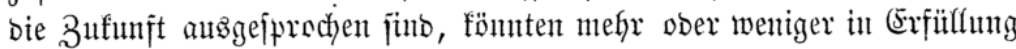

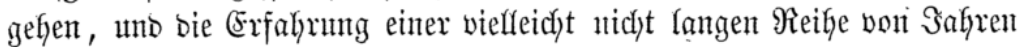

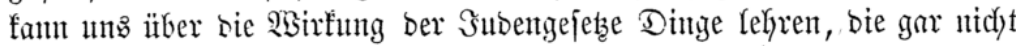
voratşzujehen warent. Dinge, bie bahin führen fönten, bas (5 Ghriftenthun unb bie dyriftliche humane Bifbung (bie bod) Strumblage aller bejonberen

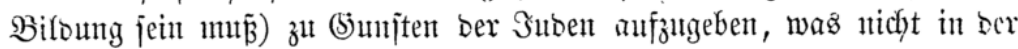
Abjicht bez (Siejetzes liegen fann. Sch jtimme baher bafür, bie Fragen jo. 3u beantworten:

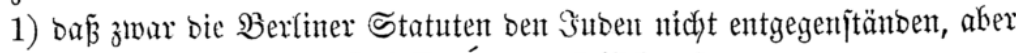

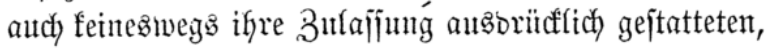

2) Dá̧ man Kiernach zmar an cine Micoififiation ber Statuten benfen

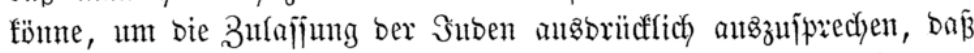
aber eine joldye Mlobifitation uns jeb̧t nody nidyt räthlidy exfdyeine, on

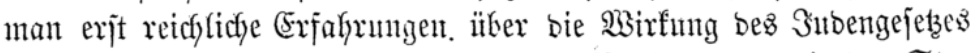

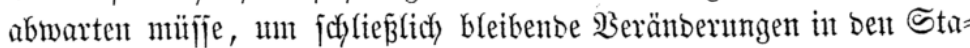

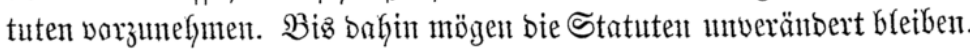
$\Im m$ Uebrigen bin ich and bafür, baj bie übrigen Uniwerjitäten von ber

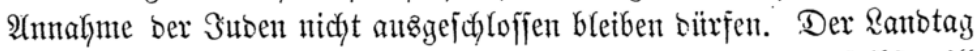
hat affen ïbrigen Sorporationen Suben aufgebintoet, mur er jelbit mill fie nicht Gaben, wartm follen wir nidft in bempelfen Sinne hanbeln?

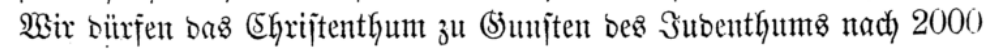
- Gafren nidyt preizgeben.

Berliu, Den 2. Powember 1847.

Sdulth.

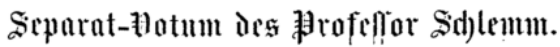

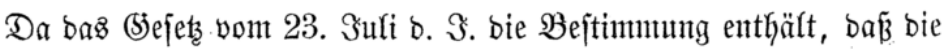

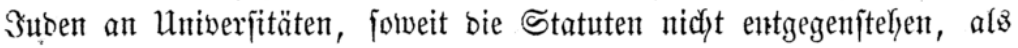




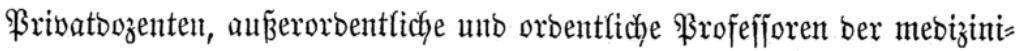
fchen Fafultät zugelajfen werben fönnen, fo wiro ber Âtnbrang ber Suben ohne 3rweifel zumeift an ber Giefigen Univerjität, ber einzigen, wie mir befamt, weldye in igren Statuten bie 3ulajïung ber Suben nicht verbietet,

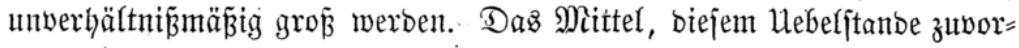
zufommen, fcheint mir inber von ber hiejigen Fafultät nicht burdy baz

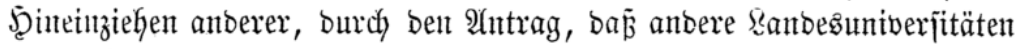
eine $\mathfrak{A b a ̈ n b e r u n g ~ i f r e r ~ S t a t u t e n ~ v o r n e h m e n ~ j o f l t e n , ~ g e j u c h , ~ w e r b e n ~ z u ~}$ miijien, jonben ith halte es jür natürlicher uno oer Sachlage angemefiener,

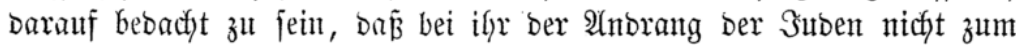

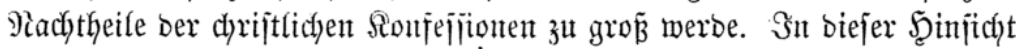
mïnjche ich, baß bas hohe vorigejetste Minifterium gebeten werbe, unjere Statuten bafin abzuäubern, baß̉ biejelben bie Suben zmar jür zuläfjig

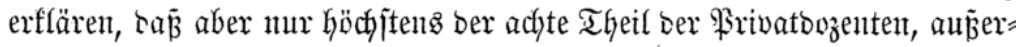

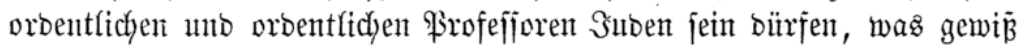
Der Billigfeit angemefjen ijt, wenn man bie Seelenzahl ber Sonfejijionen

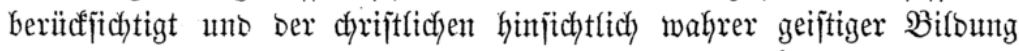
nicht jut nahe treten will. Bubent halte idf bie Einfïbruing einer fo burchs=

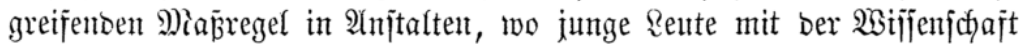
zugleich) inmer von bem (5)eifte uns Sharafter ber sehrer ihren 2 tntheif

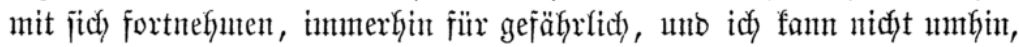

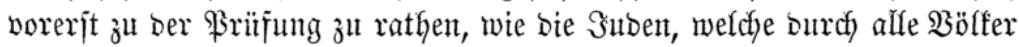
und Beiten Gindurch igren eigenthümlichen sharafter aufrecht exha!ten Gaben, senjefben bei ber größ̈eren iłnen gewährten Freiłgeit bethätigen, in

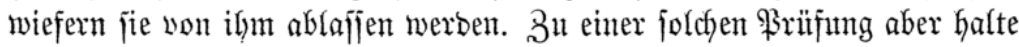
id) Den von mir gemadyten Sorjdylag vorerjt für Gintreidjent.

Berlin, ben 3. November 1847.

Sdjlemm.

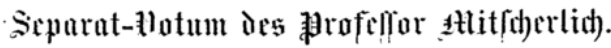

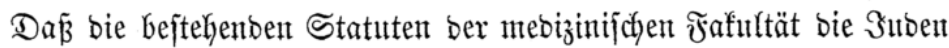

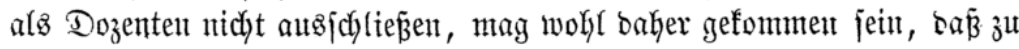
ber Zeit, als fie entworfent ulo genefmigt wurben, in \$rentien feine Juben

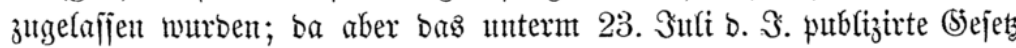

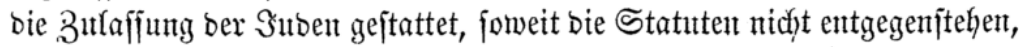

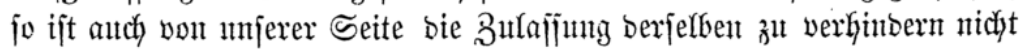

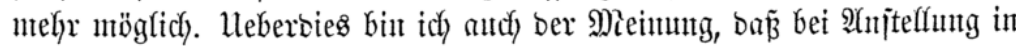

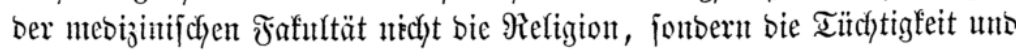
Mioralität allein berï̌ffichtigt werben mïjijen. Die Iitchtigfeit aber fann man ber jübifchen ?ation nidjt abjpredjen, uno ift in bem SGharafter 


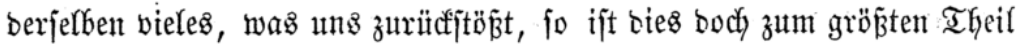
eine Folge bes Dructez, in bem fie getebt haben, weldyes fich baher bei befjerer Steflung allmälig verlierent wirb. Die vielen Эuben eigenthüm=

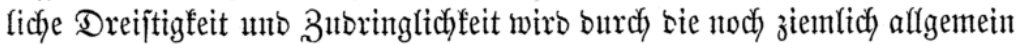
bejtegende $\mathfrak{A}$ ntipathie gegen biejelben himreicheno in Sdyranfen gehalten werben. Son nadytheilizem Einflus fant es aber auf bie Berliner Hniver=

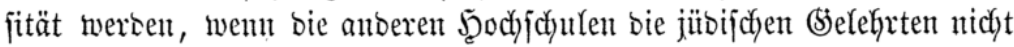

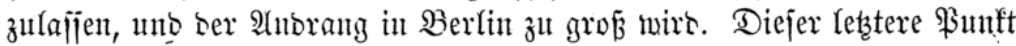
bürfte baher in bein (5)utadyten genau zu erörtern unb alz widstig herwor=

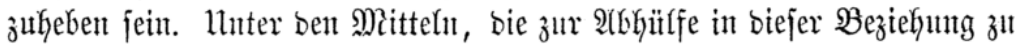

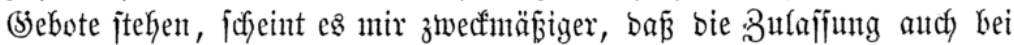

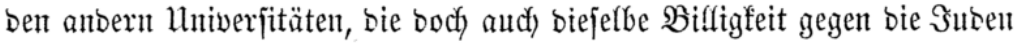
zu üben haben, erfolge, als burdy Bejtimmung ser Bahl ber jübifdyen

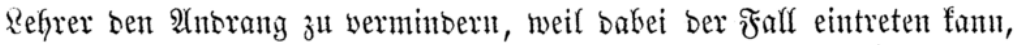

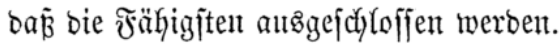

Berlin, Den 5. Nowentber 1847.

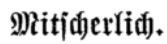

Scpurnt-Hotum des Jrofellor farm.

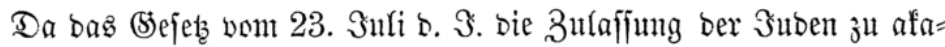
bemifchen Regrerjteffen ausoriteffich vorichreibt, unb bie Statuten ber Berliner Univerjität folche nicht ausfjchließ̧en, fo fann unfrerjeitz gegen zeren Bulajfung nichts weiter gefdyełen, als ein hohes sminifterium zu bitten, bie erforberlicye Mobififation ber Statuten ber itbrigen Mniverfi=

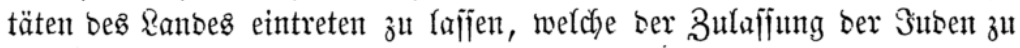

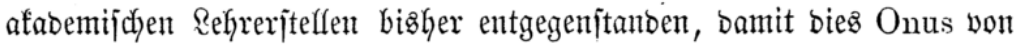
allen gletdymäß̈tg getragen merbe.

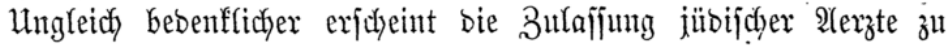

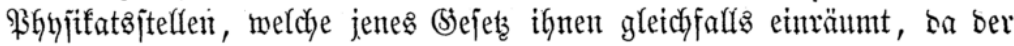

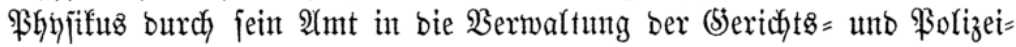
beförben unmittelbar eingreift unt nicht nux, wie ber afabemifche Refjrer,

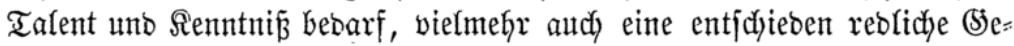

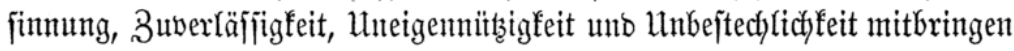

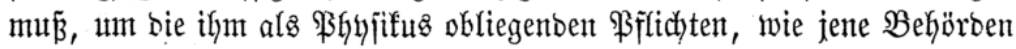

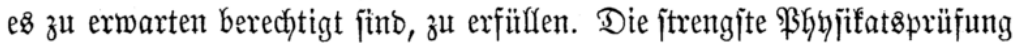
twirb wohl oft ben 3tweifel nidht Keben fönnen, ob bem Ranbibatent bieje

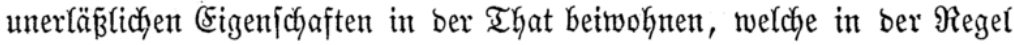

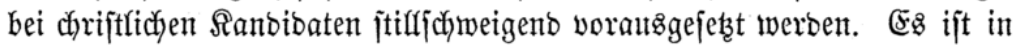

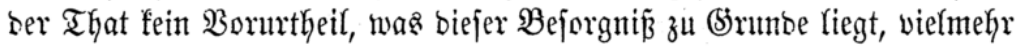




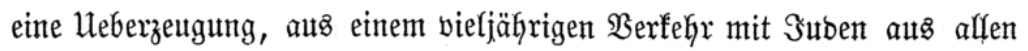
Rlaffen unt ßrovinzen bes Ranbes Kervorgegangen.

Berlin, Den 7. Nowember 1847.

ந̊ort.

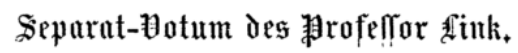

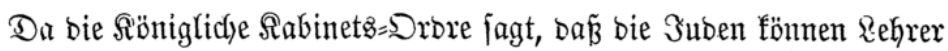
ber Meoizin werben, wenn bie Statuten oer Univerjität nichtz bagegen

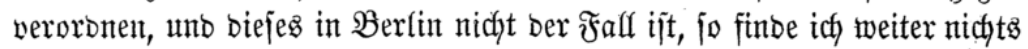
hinzzนzufügen.

Berlin, Den 15. Rovember 1847.

Sinff.

\section{Fotum Der philofophirctere Eakultät.}

(5m. Şodjwohlgeboren haben vermittelitt verehrlichen Schreibens vom

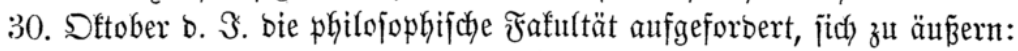

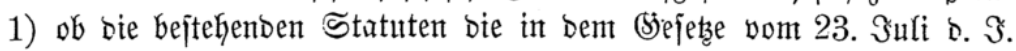
außgejprochene 3ulajijung ber Suben zu Den bort bezeidyneten afabemi= ichen Rehrfä̈chern gejtatten ober nicht, uno

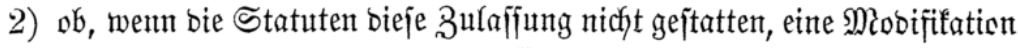
Derjelben für zuläfifig uno angemejien zu erachten jei.

Die Frafultät hat hierüber in ifrer Siţung vom 23. Dftober b. $\Im$.

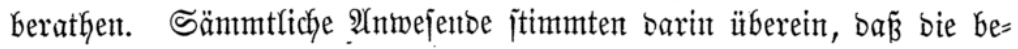
jtehenben Statuten bie 3ulajiung von Эubent alz Rehrer bet ber hiefigen

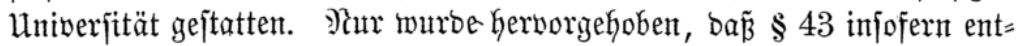
gegenjtehe, als biejer jeben zux Fafultät gehörigen Profeffor berechtigt, ïber alle in bas (S)ebiet berjelben einfchlagenden Fächer Borlejungen zu

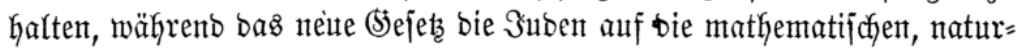

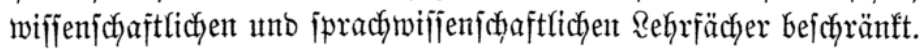

Bei joldber (sinjtimmigfeit jojien eine weitere Arbjtimmung nidft noth=

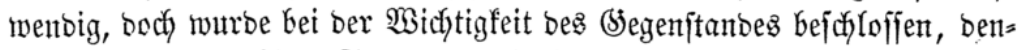

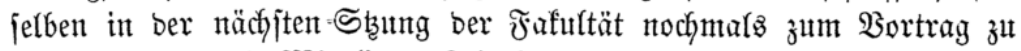

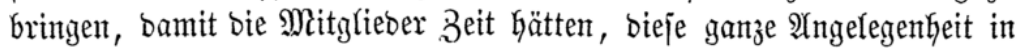

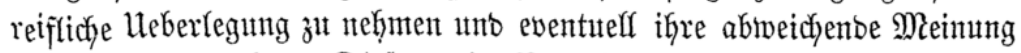

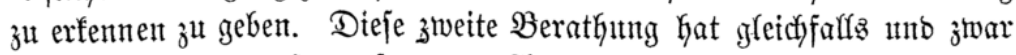
am 25. November jtattgefunten. Nuch futo biejentigen Mitglieber ber

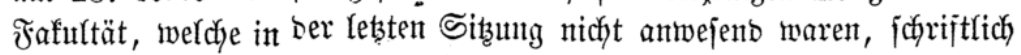

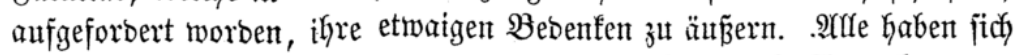

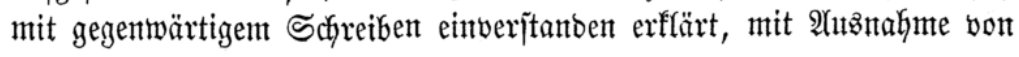




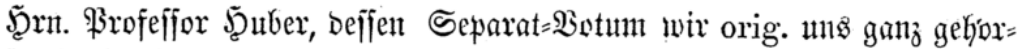
famit Gier beizufïtgent ertauben.

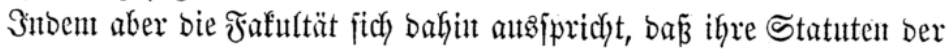

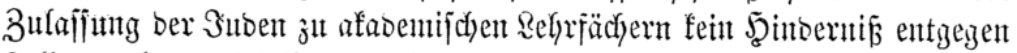

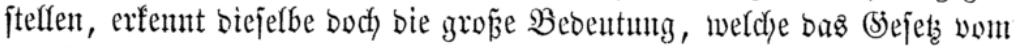
23. Sult fïr jie hat, unt in welchem Miaa fie werben fann.

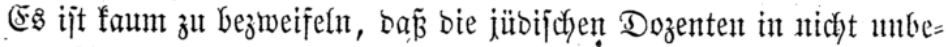

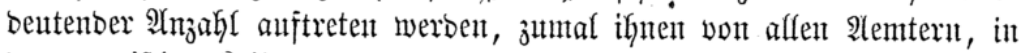

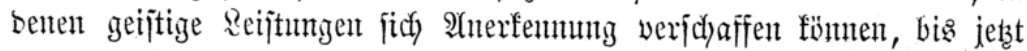
nur bas afabemijatye Refyrfach ju ergreifen verjtattet ijt. Wenn bieje Do= zenten jidy anf bie verfocjiebenen Univerjitätent vertheifen, entweber gleid)=

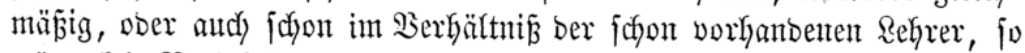

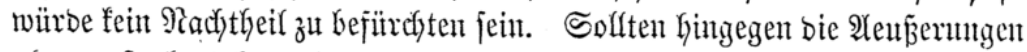

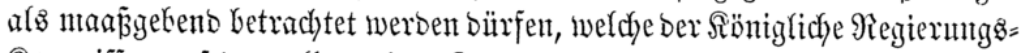
Sommiiffar auf bem affgenteinen Ranbtage gentadft hat, nach benen fämmt=

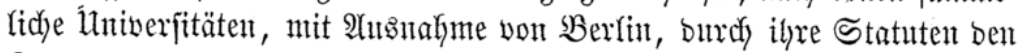
Snben verfaclofjen jüt, bann würbe bas \$sejets vom 23. Sufi son unbe= rechenbarent Folgen für bie hiejige Uniberjität werben, benn bieje würoc alfein baju bejtimmt jein, bie jübijchen Dozenten aus bem ganzent Staate

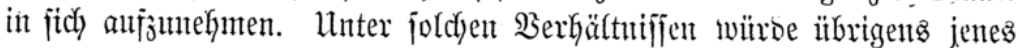

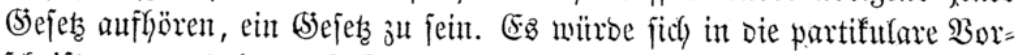
ichrift verwandeln, saj Suben Dojenten an ber $\mathfrak{B} e r(i n e r$ Untiverfität

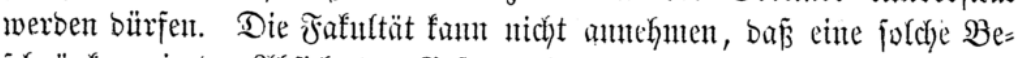

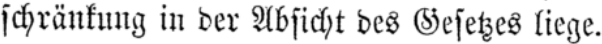

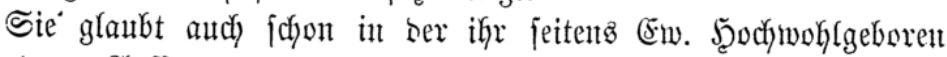

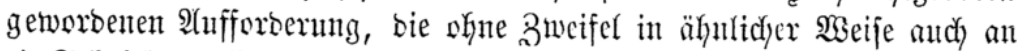
bie Fafultäten aller anberen Univerjitäten ergangen ift, ben erjten Schritt

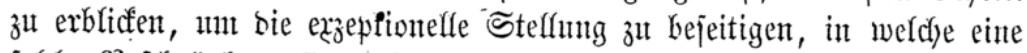
joldye Befchränfung fie verjetzen wilnbe, unt jie erfennt barin bie weife

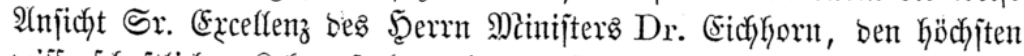

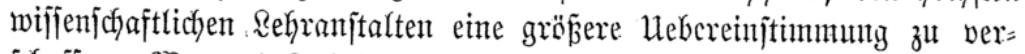

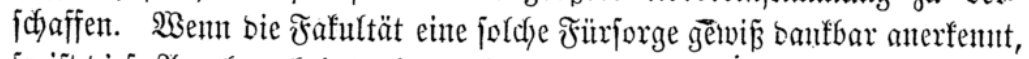

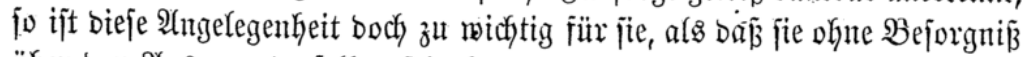

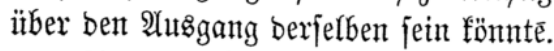

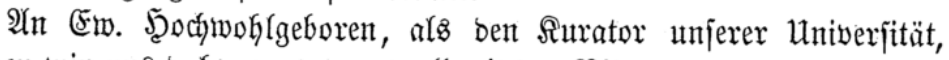
wenben wir uns baher vertratensyoll mit ber $B$ itte:

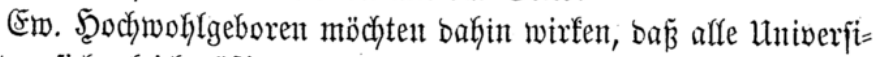

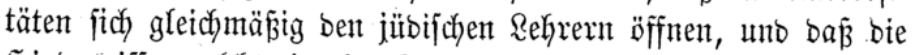
Şindernifje, weldye eimzelne Statuten barbieten, bejeitigt werbent. 
Die Fafultät glaubt, da $\mathfrak{B}$ es feiner Motive bebarf, um bieje ehr erbietige Bitte zu unterjtützen. Sie hat bereits wieberholt unt namentfid) in einer unmittelbar an Se. Ercellent ben Şerrn Minijter Dr. Eidhyorn unter bem 5. Âguit 1843 geridyteten singabe, fo wie in einem Schreiben voun 13. Suni 1846, welches Duraf ben Senat an ben Şerm Minijter unter been 17. Suni 1846 beförbert worben iit, bie ?achtheile bargelegt, weldye burch Ueberfitflung an Rehrem theils-brohen, theifs jich fidon herauggejteflt haben. Sn wie bedertendem Maaze jidy bieje Heberfüflung jteigern wirb, wenn bie hiejige Univerjität allein ben jübijđjen Dozenten

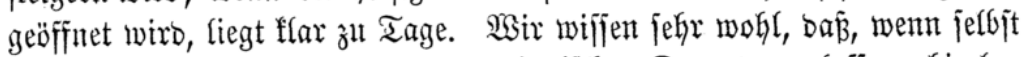
fümmntliçye andere Univerjitäten bie jübijiçen Dozenten zulajien, Gierher.

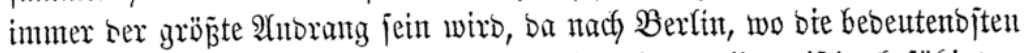

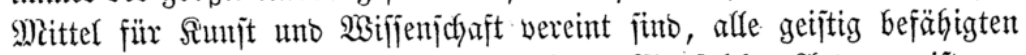

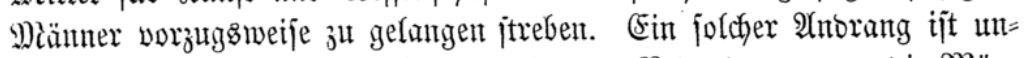
verneiblidy. Er ift aber aud won geringerer Bebeutung, wenn bie Mäg=

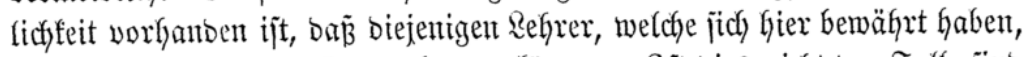

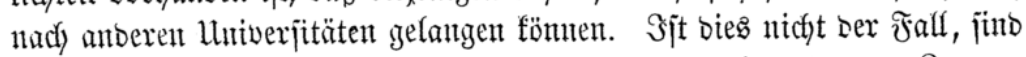

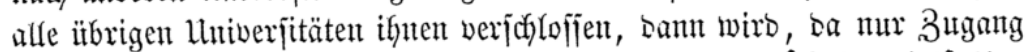

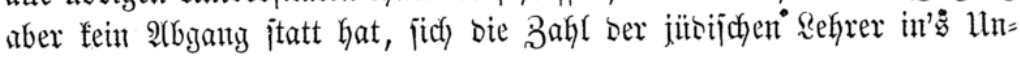
bebingte Gier vermefren.

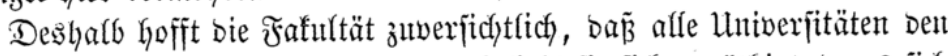

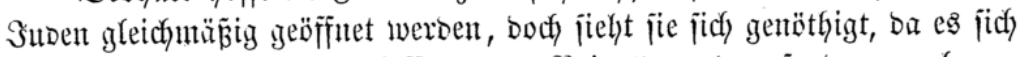

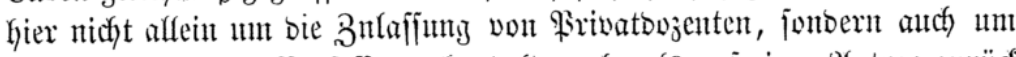

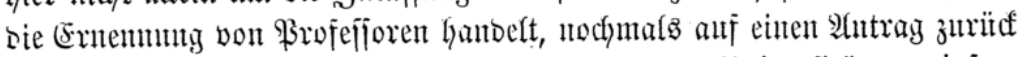

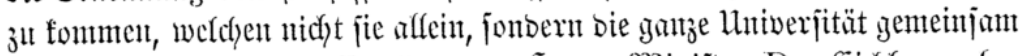

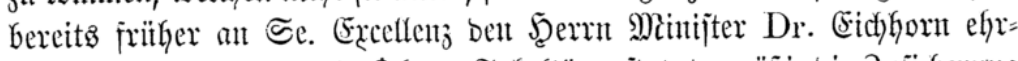

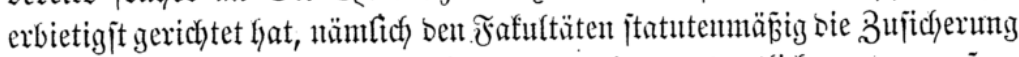
jut ertheifen, baf jie vor ber Ermentung eintes vroentlicfen voer anjer=

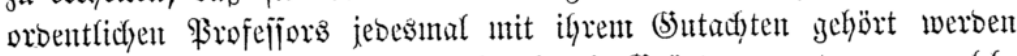

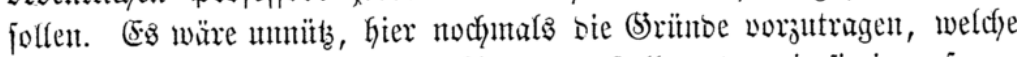

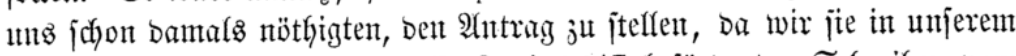
Durc) Den Senat unter Den 17. Sunt 1847 bef̈̈rberten Schreiben vom

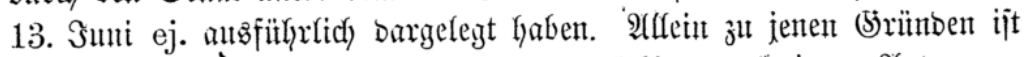

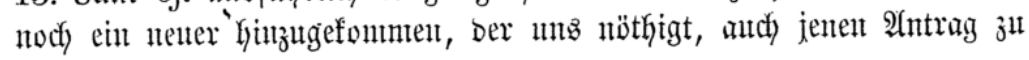
ernenern.

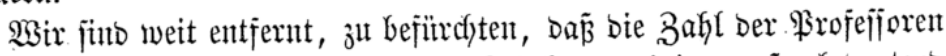

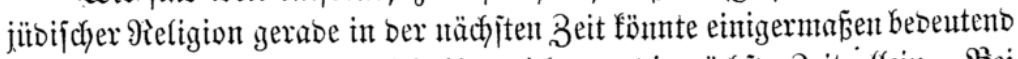

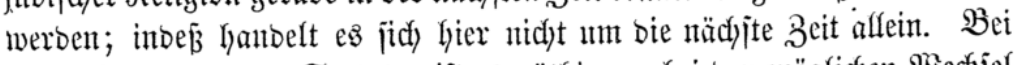

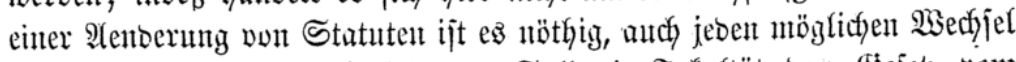

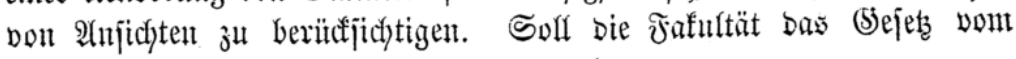




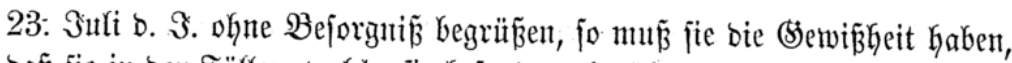

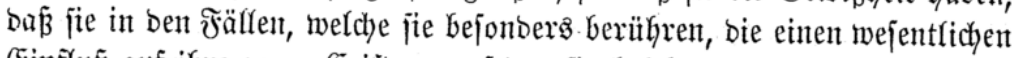
(5influz auf igre ganze Exijtenz, auf ben fie berebenden forporation tseift üben, etwas mehr als eine willents= uno meinungslofe Zuj juatuerin bleibe.

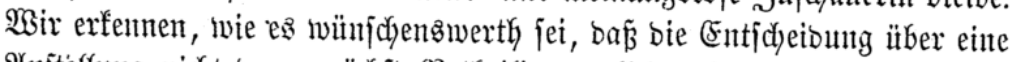
Anjtelfung nicht ben zunächj̣t Betheifigten affein überlaffen breibe. Wir fïgen uns gern ben Ânorbinungen einer umfidytigen Berwaltung, allein

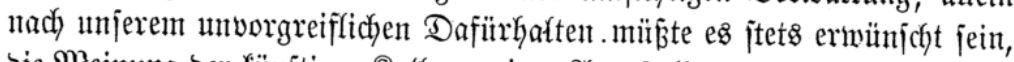

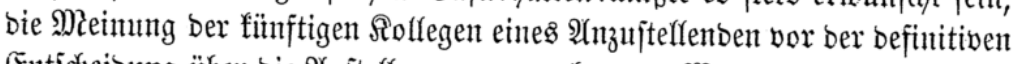

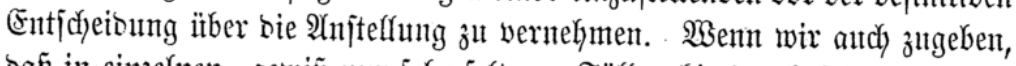

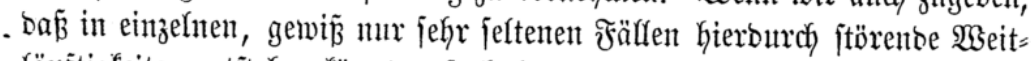

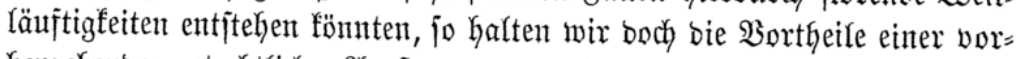

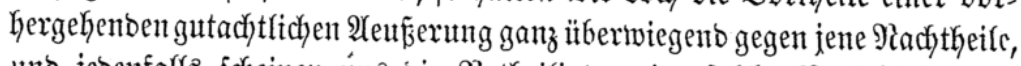
unt jebenfalfs fcheinen uns bic Betheifigten eine folche Berütffichtigung 3tt verbienten. Denn fie vermïgen einterjeitz am bejten zu beurtbet(en, weldye Rücfen in ben verjchiebenten Rehrfächern vorhanben fint, unt weldye Bewerber bie meijten $\mathfrak{A n}_{\text {nf }}$ ritche bejitzent, anbererfeits ijt ein eintiges, reges,

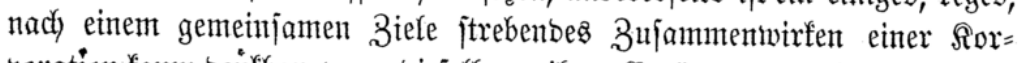
poration faum benffbar, wenn biefelbe an ifyer Ergänzung gar feinen 2lntheil hat. Bei ber jetzt ertweiterten Bulafjung bon Profefforen glautben wir beshalb bie gehorjamjte Bitte ehrerbietigit hinzufügen zu müffen, baş:

(5w. Scodjwohlgeboren jich auch bahin verwentoen möchten, baß

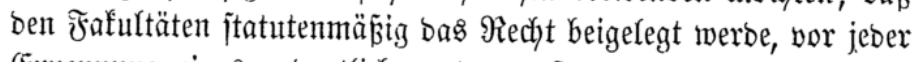
(Ernennung eines orbentliçen ober außerorbentlicben Frofefifors gutachtlich gehört zut merben.

Berlin, ben 6. Dezember 1847.

Die philojophifuche rafuttüt.

(Unter[dyriftent.)

\section{Fotum des 铻ktors und Sinnts.}

Berlin, Den 7. Februar 1848.

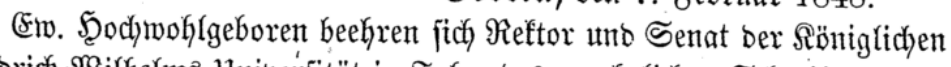

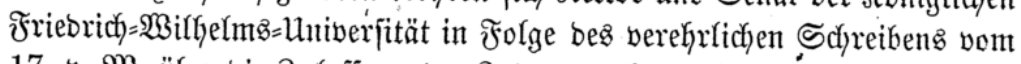

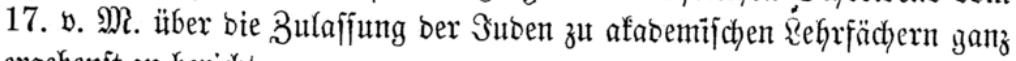
ergebenit zu berichten.

Ueber- bie Frage, ob bie Statnten ber ßönigl. Univerfität, bie in bem

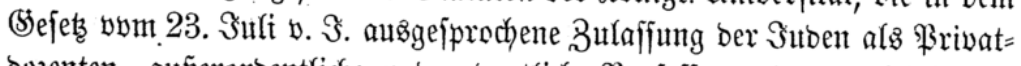

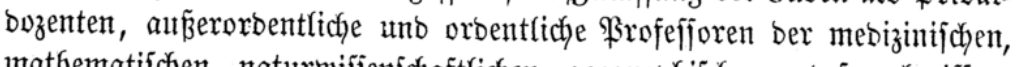

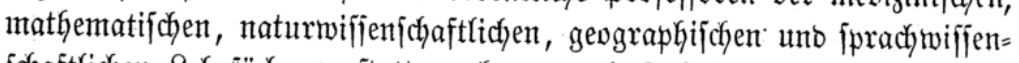

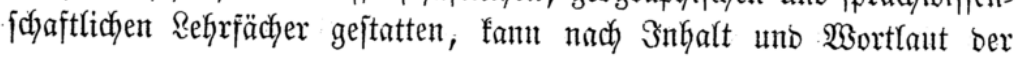


bejtefyenden Statuten fein Zweifel jein, unb beantwortet ber Senat bieje

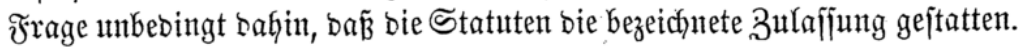

Die zweite ber vorgelegten fragen fällt nit ber Bejahung ber erjten von jelbjt weg.

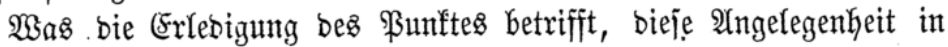
iryrem bie ganze Uniberjität auffaffenden 3ujammenhange, unter Beriớc= fichtigung ber in sen einzelnen Frafultäten abgegebenten Singular = unt (S) jammtgutadgten zu ermägen und zu begutacften, fo hat ber Senat bereits

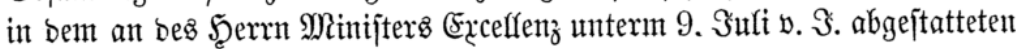
Beridyt bie fraglidye $\mathfrak{A n g e l e g e n h e i t ~ i n ~ i h r e m ~ b i e ~ g a n z e ~ U n i v e r j i t a ̈ t ~ u m f a ́ = ~}$ fenben 3 uammenhange einer ausfiutyrlichen (Exörterung unterworfen, unt hat baker bie vorkererwähnte 2 ufgabe, foweit jie bem Senat obliegt, ihre voll= ftänbige (Erlebigung gefunben. Ein neues \$sutachten hat ber Senat nicht

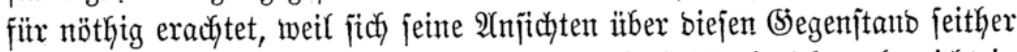

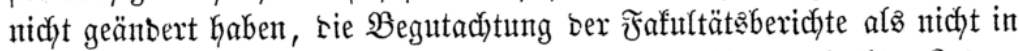
ber Stelfung bez Senats Yiegend unterlajien zu mitjjen geglaubt. Sntoem wir uns baher auf umjern Beridyt vom 9. Suli v. S. feinem ganzen Эn= halte nady beziehen, ïberreidyen wir (5w. Scodyohlgeboren ganz ergebenit bie jämmtliçen biskerigen-Berbanthungen Kierbei zurüct.

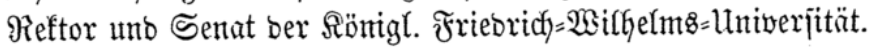
Miifler.

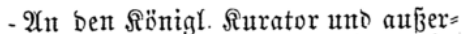

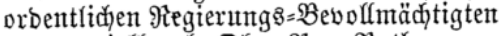

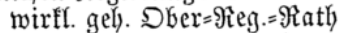

Serrn Dr. v. Labenberg, 5ెod) mohlgeb. Kier.

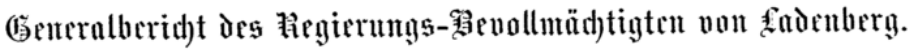

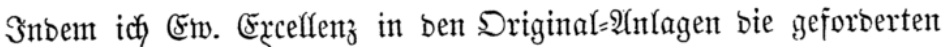

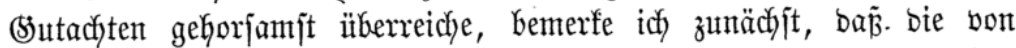

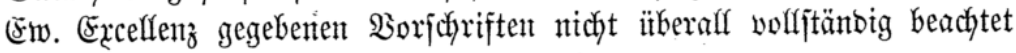
worben finto. Es fintot jicty nämlich jut erimern:

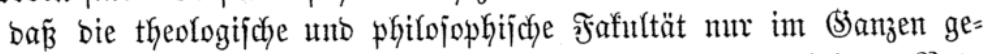

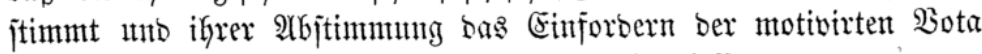
ber einzelnen Mitglieber nicht habent worangehen lajpen.

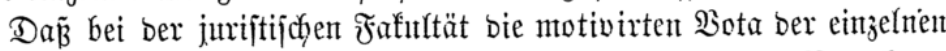
Mitglieber jum grö̈pten Theife exjt nach) ber alfgenteinen Berathung atzgearbeitet wurben, jtatt berjelben vorkerzitgefen unb bie Unterlage

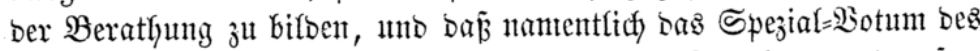
Profeffor Dr. p. p. Seeffter erjt nach biejer Beratfunty entworfen, uno baburcdy ber Fafultät bie Miöglickffeit entżogen norben, wie von (5w. Exceflenz beabjichtigt wurbe, fich ïber biejes $20 t u m$ int Einjelnent 


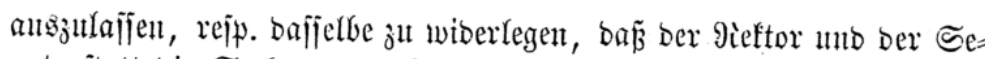
nut, itatt bie Sache Inter Berüuffichtigung ber, in ben einjefnen $\mathfrak{F} a=$

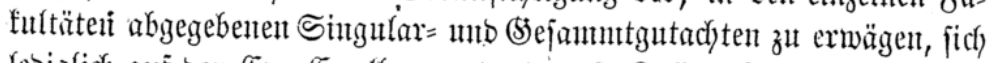

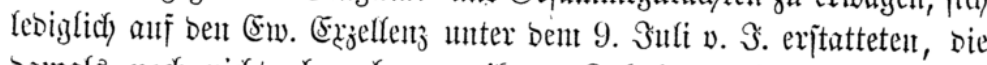
sannals ntody nidyt abgegebenten, ifyrent 3ntgalte nach ivejentfich ver= ichiebenen Spesial= unt (5tejanmutgutachten ber Fafultäten feines=

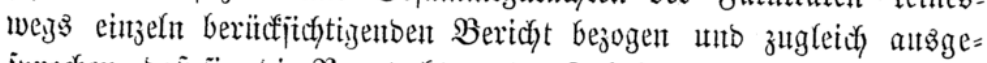

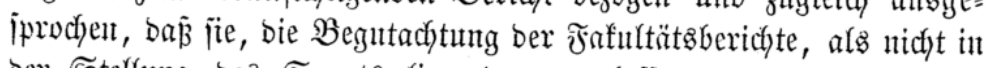
ber Stelfung bes Senats liegent, unterlaffen zu milffen geglaubt habent. -

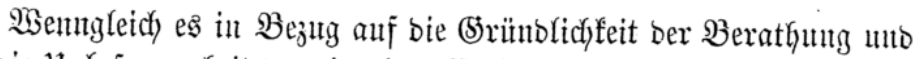

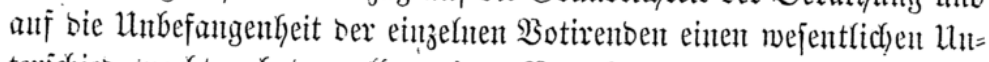
terichico inacht, ob ber aflyemeinen Berathung bie $\mathfrak{A}$ tusarbeitung ber motivirten Bota ber Eimzehnen vorkergeget, biefer fulm Srutube gelegt,

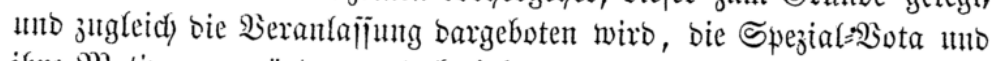

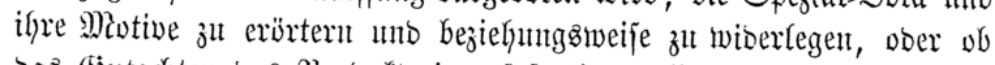
Das (5utachten bas \$robulft einer fofortigen affgemeinen Befprectung

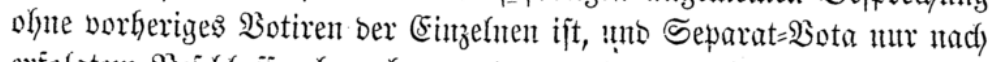
erfọlgtent Bejchluije abgegebent werben, unto wentugleich id) es fïr un=

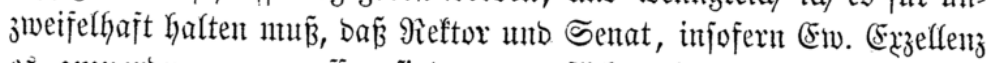

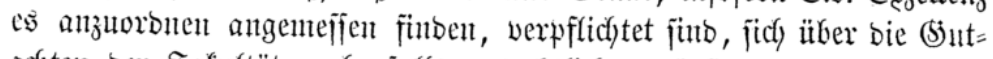

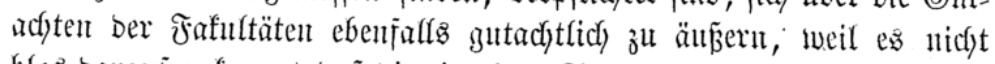

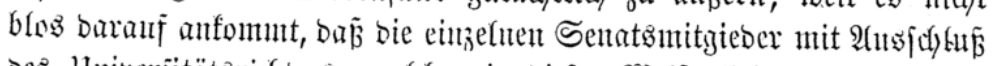

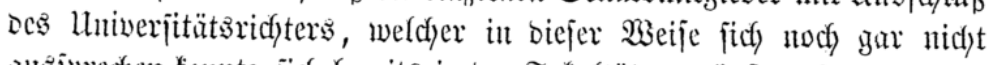

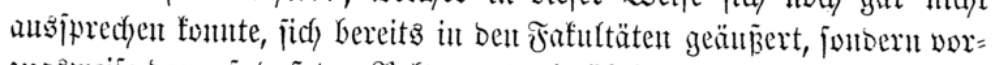

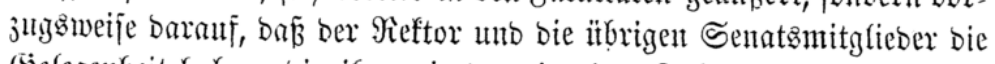

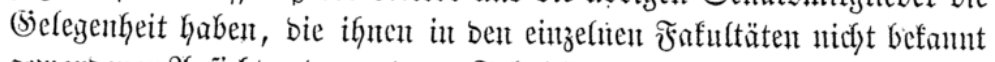

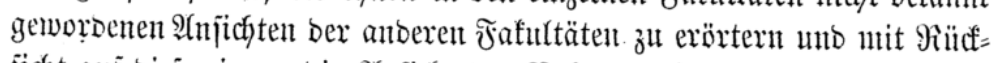

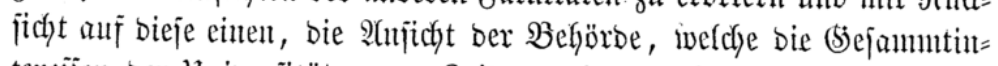

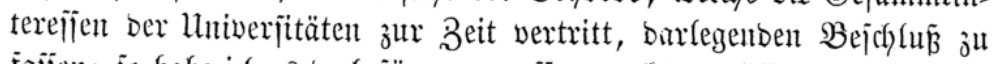

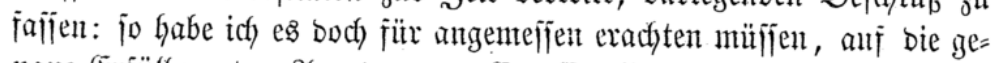

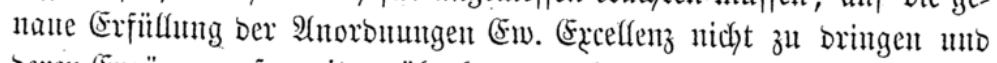
Deren Exgänzung, jo weit es übergaupt nod mögfich gewejen wäre, nicht

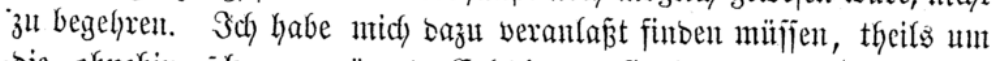

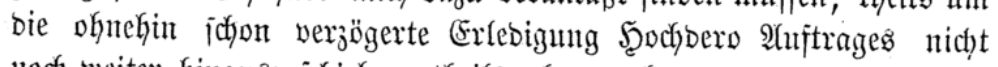

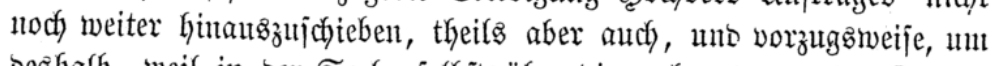
Deshalb, weil in ber Sache felfit ïber bie zu beantwortentent Fragent

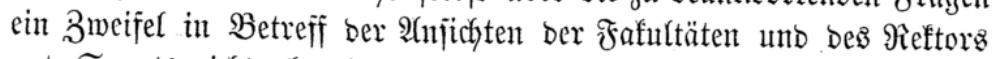
uno. Eenats nicht obwaltete, unt eine nähgere (Exörterung injofern mir

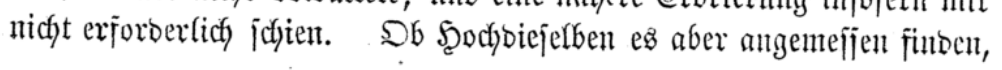




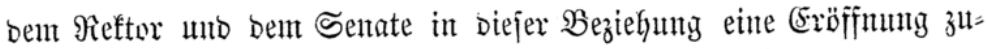
gehen zul lajjen, habe ich ganz gehorịamit anthein zu jtellen.

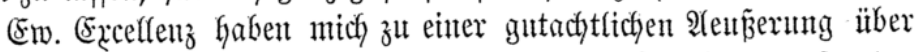

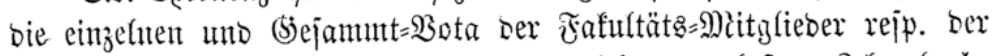

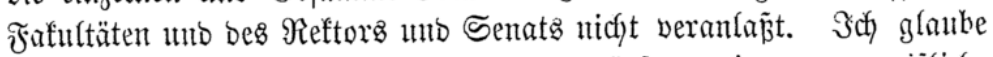
mir baher ganz gehorjamit vorbehalten jul bürfen, meine mnorgreif̧liche

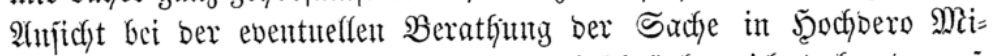

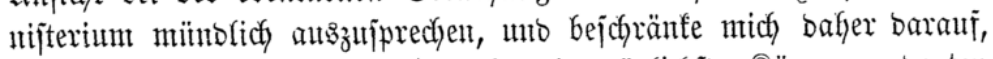

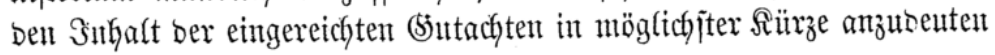
wie folgt:

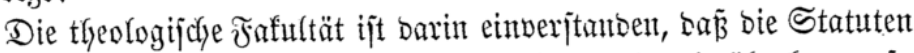

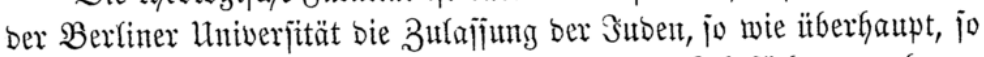

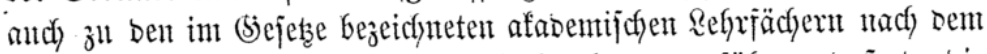

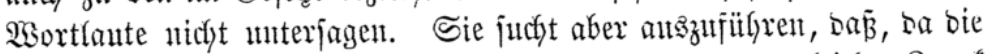

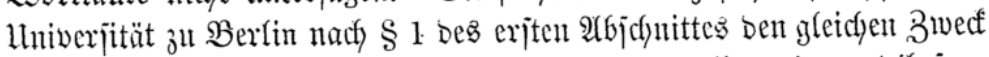
mit anberen Univerjitüten bes Stants Gabe, bie allgemeine mb bejon=

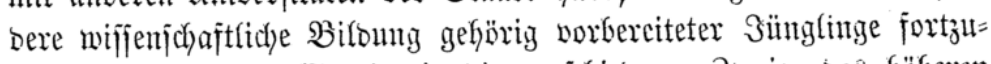
jeţen und fie zum (sintritt in bie verjufiedenen 3weige Des Gäheren

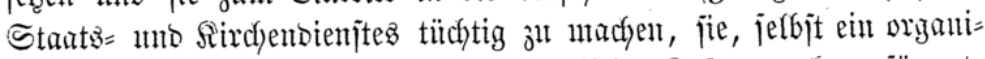

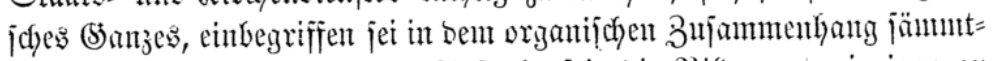

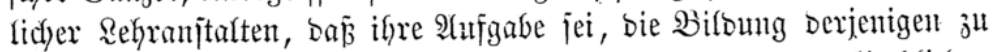
förourn, welche bereinft an ber Seitung ber Staats= mo firdflidyent Antzelegentjeiten einen bejondern $\mathfrak{T}$ ntheil haben werben, Daj bie Sta =

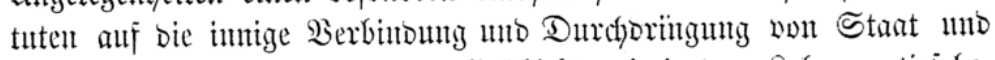
Sirclye fintoenten, weldye in ber (bejdyichte wie in bem Reben ju tief be=

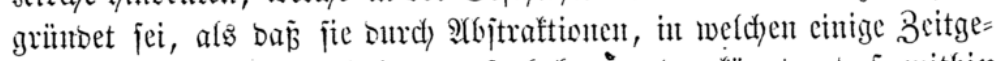

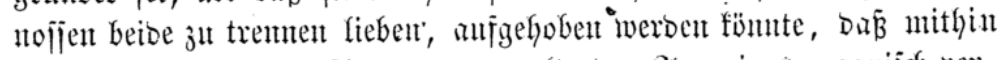

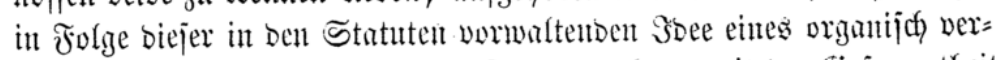
bunbenten (S)anzen, went and ber 3ujammenthang mit ber (Sejammutheit

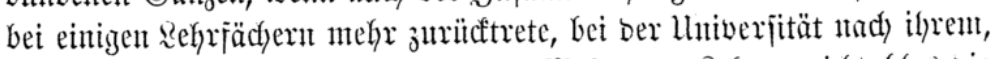

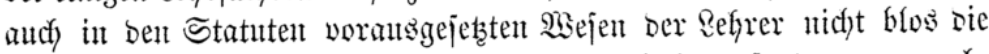

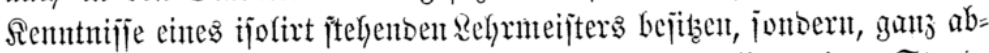
gejehen won theologifdyen Regrmeinumgen, ans oem alf gemeinen Stanb= punfte ber llniverjitï̈t verlangt werben Mitijie, Daj ber Iojent vout

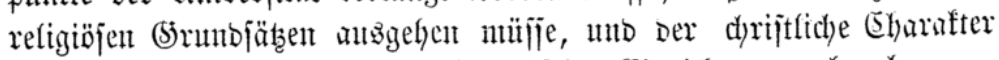
ihm beiwohne, auf weldyen bie afabemijchen Eimridytun gen bernthent.

$\mathfrak{A}$ tris biejer Deduftion ber theologifichen Fafultät folgt ser, in ihrent (5utachten nidft bejonsers hervorgehobente Sallus:

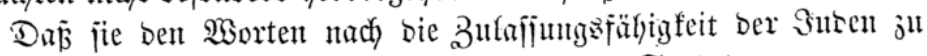

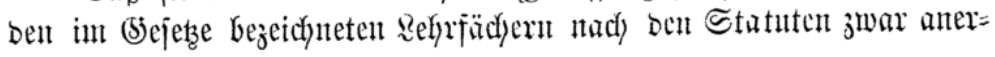


fenuen miifife, mit oem (S)eifte berfelfen unb bem $23 e j e n$ ber in innig= iten 3 ufanmentyange mit ben übrigen gleidartigen Rebranjtalten ftehen: ben Giefigen Univerjität biefelbe aber nidjt für vereinbarlich erachte. -

Sn $\mathfrak{B}$ ez̆tig auf bie Frage:

ob eine 2Yentberung ber Statuten, um in ben bezeichneten Fächern jïtoifche Refrer zulaijen zu fömen, für zuläfifig ober angemeffien zut eractlent jei,

bemerft bie theologifdye Fafultät, bã eine jolche Aentoerung bie aus bem gamzen 2 Bejen ber Univerfität Gervorgehenten Bebenfen nicht bejeitigen

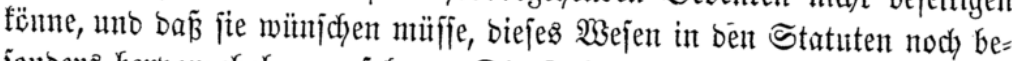
jonbers hervorgehoben zu jehen. Die Fafultät erffärt jïch mithin gegen

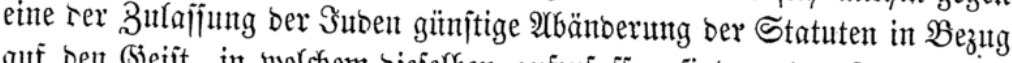
auf bent (5)eift, in welchem biejelbent aufzufafjen finto, unto auf ben fie bie Berneinung ber erften Frage gebaut hat, audh madyt fie forfieflich noch

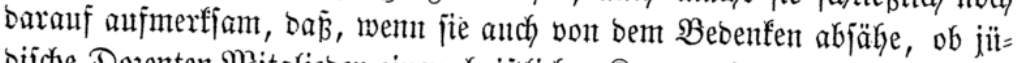
bijche Dozenten Mitglieber einer dyrijtlictyen Sorporation, welche alz jolche noch nenterlicy burch bie Errichtunty eines eigenthïmnlichen Sottesbienites anerfannt worben fei, fein fömnten uno jie bem Sntereffe ber cfriftlicfjen Riebe an bem wahren Bejten ber Suben nicht zu nake tretent wolfe, rodh

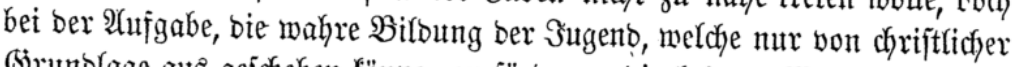

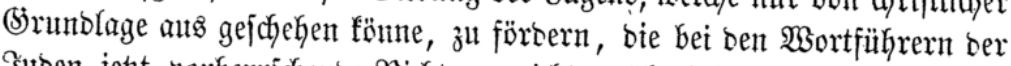

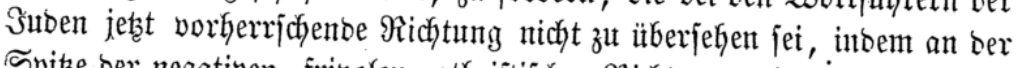

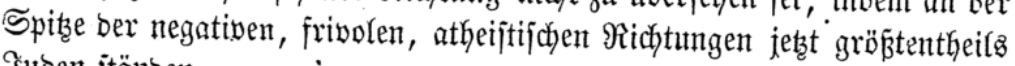
Эubẹn jtänben. -

Die philojophifche rafurttät

hat jich in ifrem (sutachten einjtimmig (nit alfeiniger $\mathfrak{A}_{118 \mathrm{n}}$ ahme bes

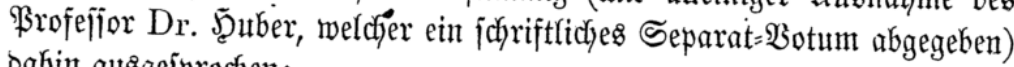
bahin ausigeiprocten:

Dã bie bejtehenben Statuten bie Zullafjung von Suben als Rehrer

bei ber Giejigen Univerjität gejtatten,

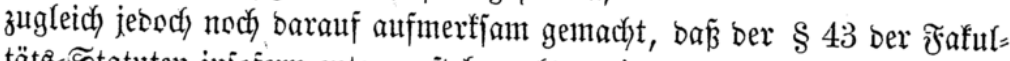
tätz= Statuten injofern entgegenjtehe, als er jeøen zur Fafultät gehörigen

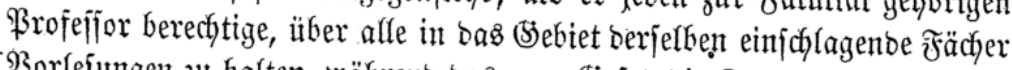
'Borlefungen zu halten, währent bas neue Bejets bie Suben auf bie mathe=

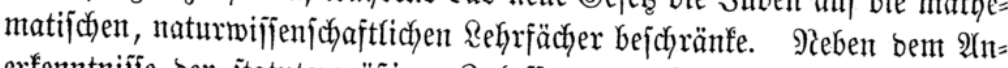

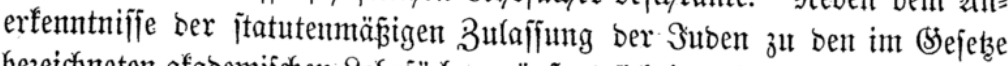
bezeidyneten afabemijchen Rehrrächern, äurert jich jeboch oie gebachte Faful= tät, über bie ifgr von Eiv. Excellenz vorgelegte Frage hinautsgehent, über

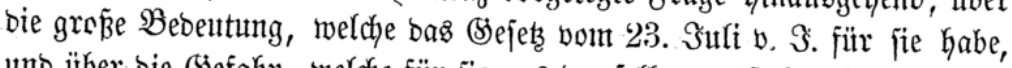
uno über bie Befahr, weldye für jie aus bemjelben entitehen fönte. Sie 


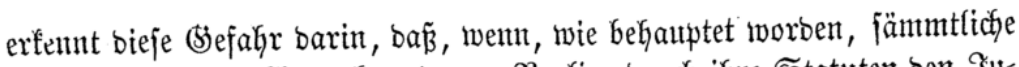

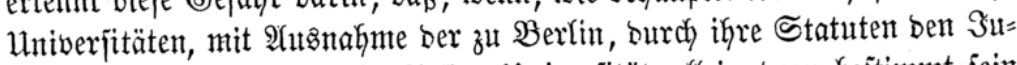
Den verjchlofijen feien, bie hiefige Univerjität allein bazu bejtimmt jein witrbe, bie jübijchen Dozenten aus bem ganzen Staate in jidy aufzumehmen.

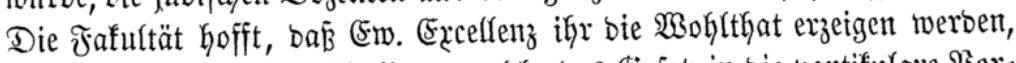

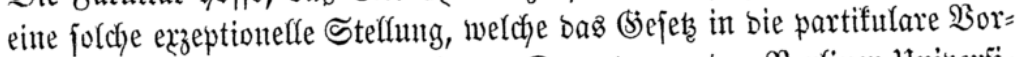

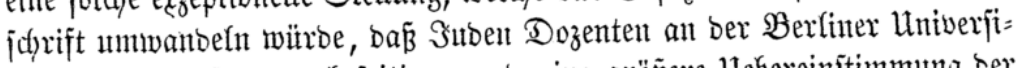
tät werben bürfen, zu bejeitigen unt eine größ̄ere Hebereinjtimmung ber

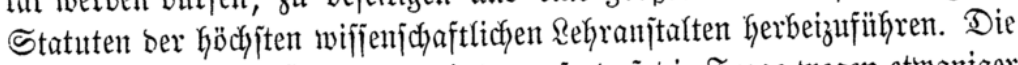

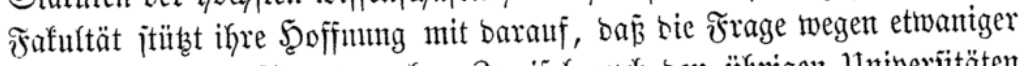

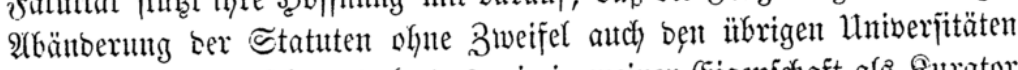
vorgelegt worten jei, uno legt es mir in meiner Eigenjuaft als Surator ber Univerjität noch bejonders an's Şerz, buhin ju wirfen,

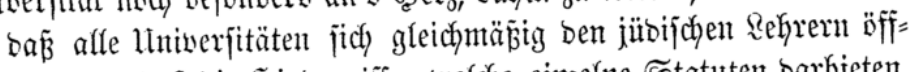

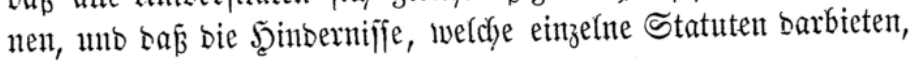

bejeitigt werbent. -

Die Fafulttät nimmt $\mathfrak{b}$ ez̆tg anf frithere, an (Ew. (Excellenz gerichtete Eingaben, worin fie bie Madytheile gejdyilbert habe, welche alts ber lleber= füflung ber Utniverjitüten mit Rehrern erwadjjen, uno madyt barauf aufmerf=

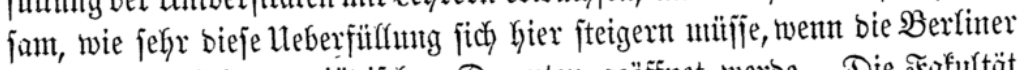
Univerjitüt alfein ben jübijchen Dozenten geöffnet werbe. Die Foufultüt

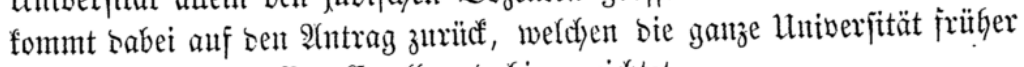
gemreinfichaftlich an (5w. Excelfenz bafin gerichtet,

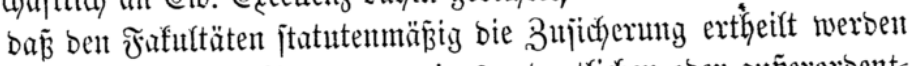
mïge, jie vor ber Ernenumng einte orbentlichen ober auzerorbent=

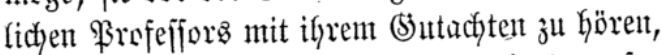

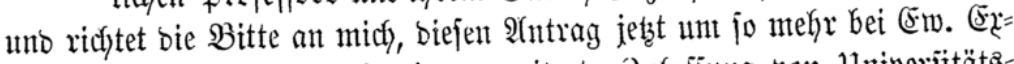
ceffenz z̆t befïrtworten, a a lehrern unt insbejonbere beren Shermefrumg burch Juben, bie affgemeinen

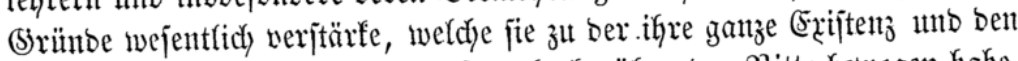
jie Gelebentoen furporativen (Beift jo nahe berithrentoen Bitte berwogen habe.

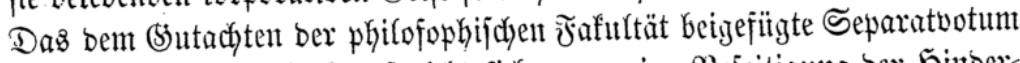

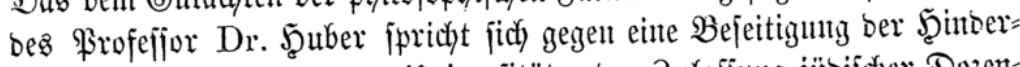

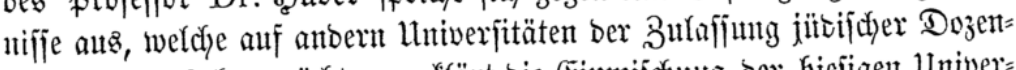

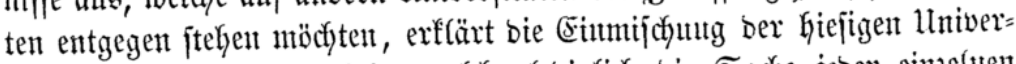
jität in eine Angelegentgeit, welche lebiglidy bie Sache jeber eingeltuen betheiligten Fafultät jei, für eine unbejugte unto unberufente unto jayliē̄t

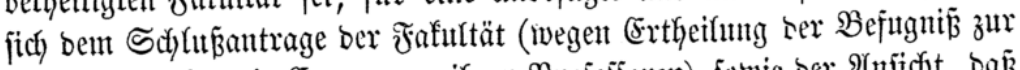

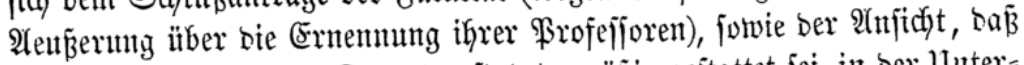
bie Zulajfuntg jübifdjer Dozenten jtatutemuäp̈ig gejtattet jei, in ber Unter= 


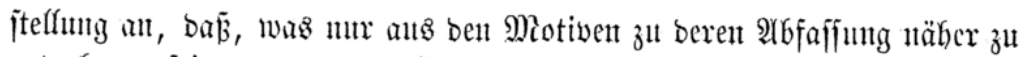
entnefnen fein werbe, bas (5)eftatten, o. h. bas 9?idytuerbieten, als einc pojitive 3ultajintug gebentet werben fömue. -

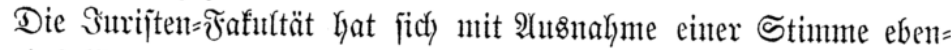
falls eintlyeflig autsgefprochen. Die ihr vorgelegte Frage:

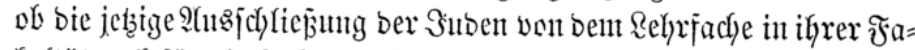

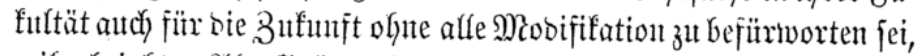

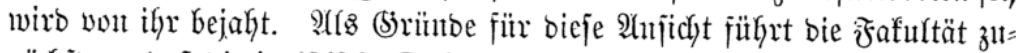

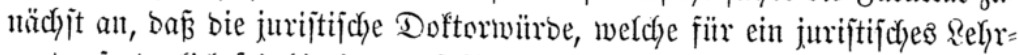

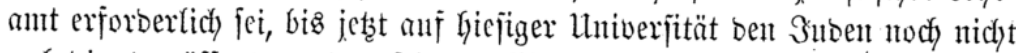

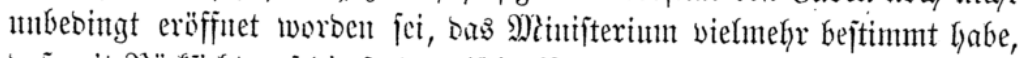

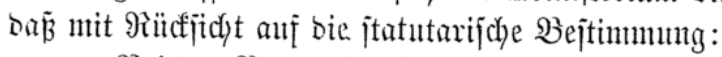

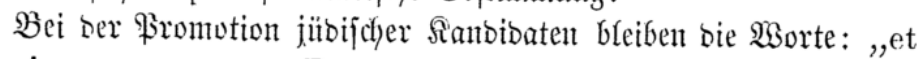
eius sacrosanctum Evangelium" weg,

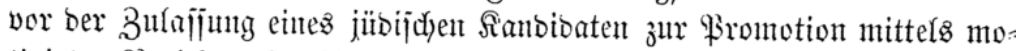

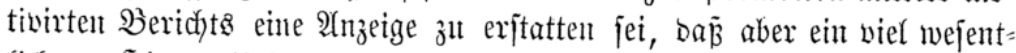

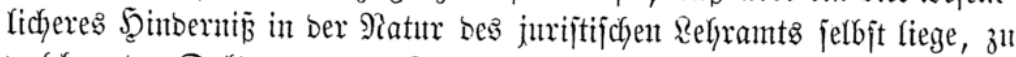
weldyem ber Duftorgrab ben Zugang erüffnen folfe. In biejer Bejiebung fïlyrt bie jurijtijche Fafultät in Hebereinjtimmung mit ber theologifdjen

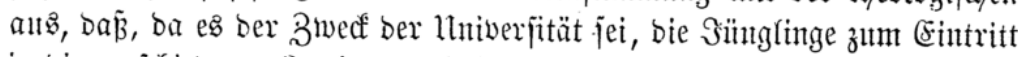
in bie, werichiebenten 3iveige bes hïhern Staats= unt Sirchentienjtes tüchtig

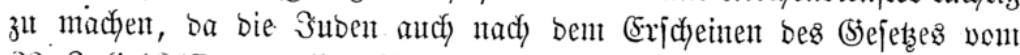

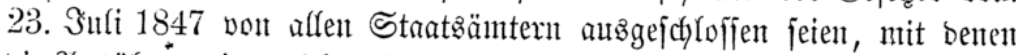

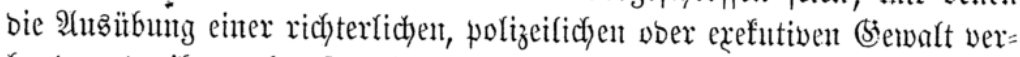
bunben, ba ifnen eben jowohl bie Reitung uno Beauffichtigung djriftlicher Sultus=

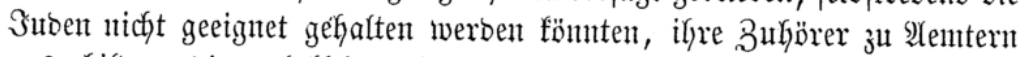

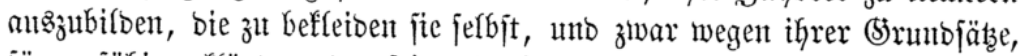

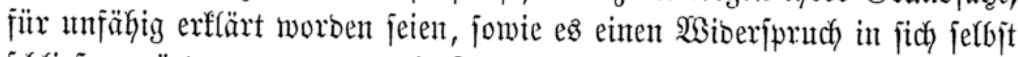

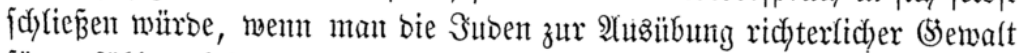

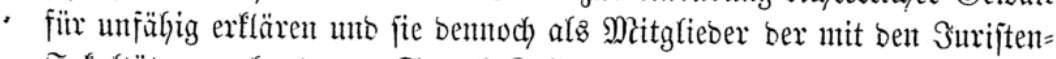

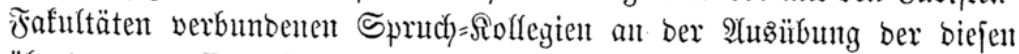
übertragenen Jurisdictio mandata Theil negmen laffen woffte. $\mathfrak{A}(\mathfrak{B}$

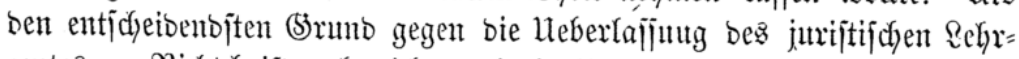

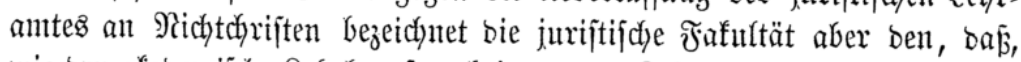
wie ber afabemijd) Refreberuf andy in mbern Rehrgebieten eine Tremung

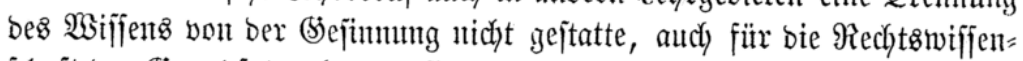

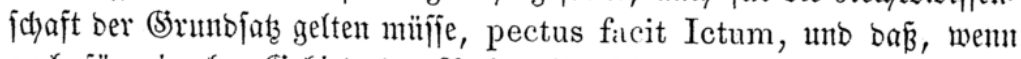

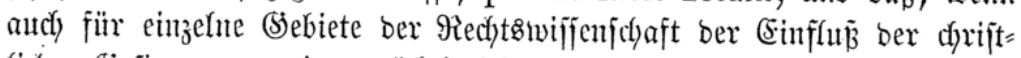
fichen (bejinunng meniger mächtig fein möge, alz für anbere, einc Schjei= 


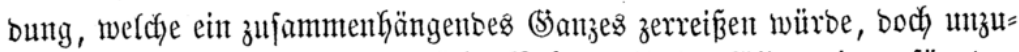

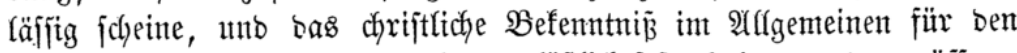

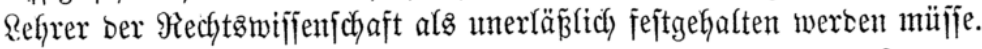

Die Frage betreffend, in wiefern bie 3ulafintug ber Эuben, fo meit jie bas (siejets bom 23. Suli 1847 ausjprectye, ourch bie Statuten ber B̧erliner Utniverjität autzgejchlofjen jei,

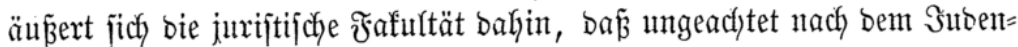

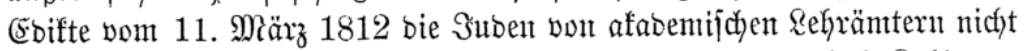

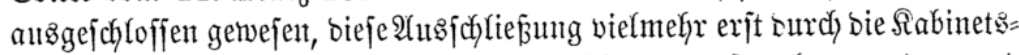
Srore vom 4. Dezember (18. Atugut) 1822 ausgejprodyen worben, uno in ben affyemeinen Untiverjitätştatuten vom 31. Sftober 1816 ein Serbot

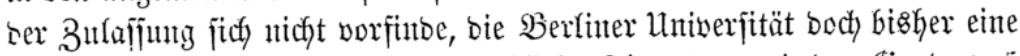

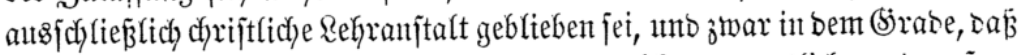
ber vorgejcyriebente sio in dyrijtlidjer Form, welchen orbentlidje unb aurer= orbentfiche \$rofefioren Leijten muşten, uno welchen ein Sube nicht leijten

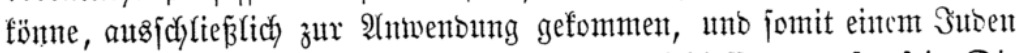

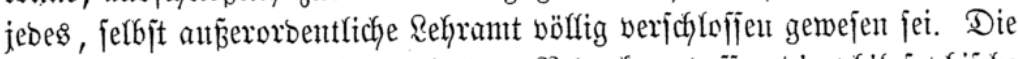

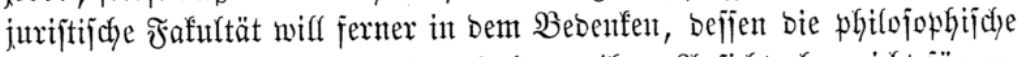

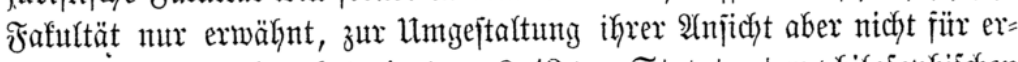
Geblich genug erachtet hat, in bem $\$ 43$ oer Statuten ber phitofophifichen

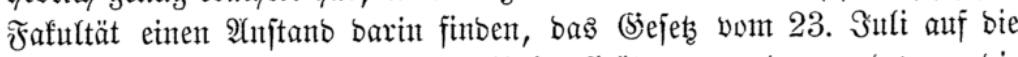
whitojophifache Fafultät ber hiefigen Univerjitüt anzumenten, uno went bie

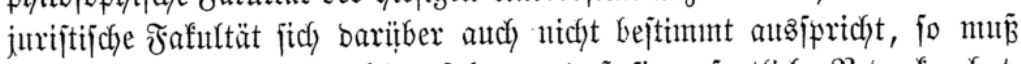

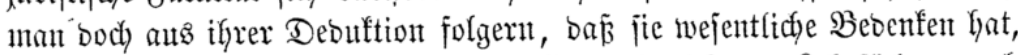

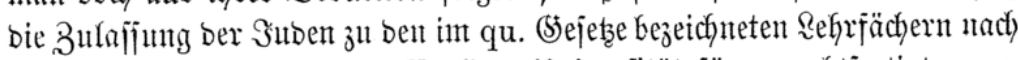

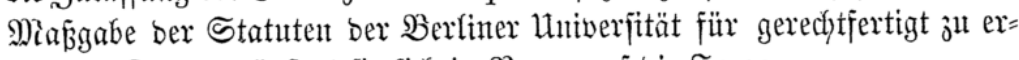

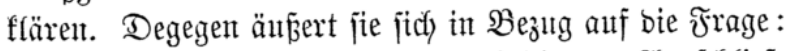

ob bie burch bie Statuten bejtinmte $\mathscr{U}$ tsichlitefung eine Mobifi= fation gejtatte unto angentejfen exfojeinen lajie,

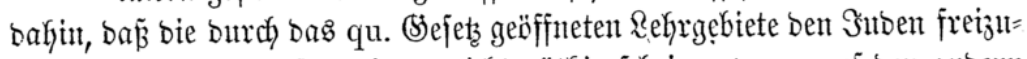
laffen fein bitrften, fo weit ez nidfyt nötfig icheine, went auf bent anbern

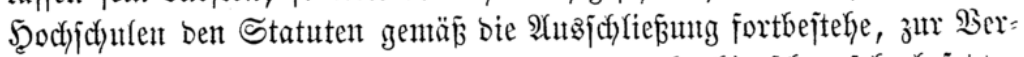

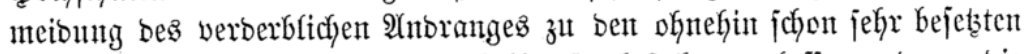

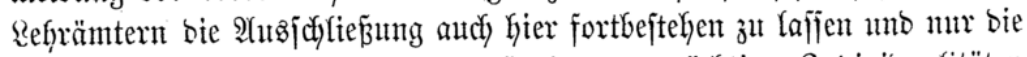

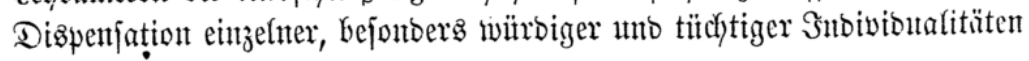
z't geftattent. -

Die oben ermähnte eine Stimme, weldye mit bem (5)tatadent ber

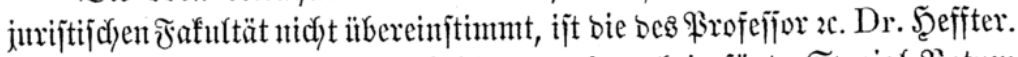

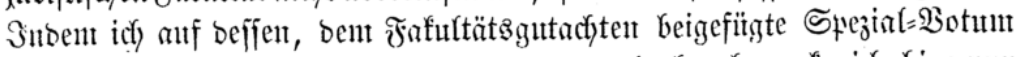

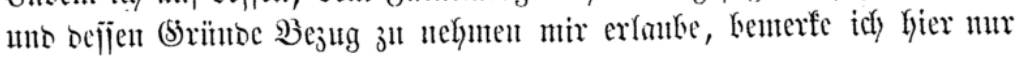




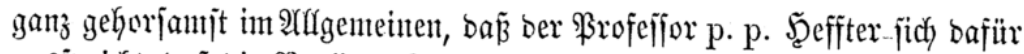

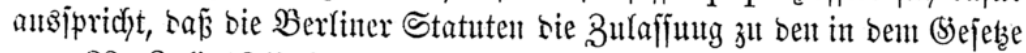

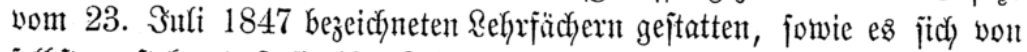
jelbjt verîtehe, bã fie ihre Rehrfähigfeit nicht neiter ausbefnnen bürften,

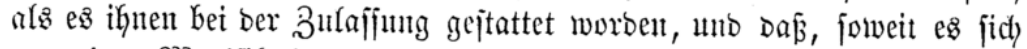
von cinter Mobififation ber Berfinter Statuten ïberhaupt noch hanbele,

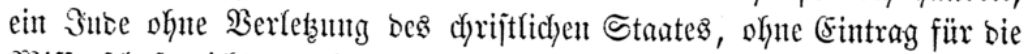

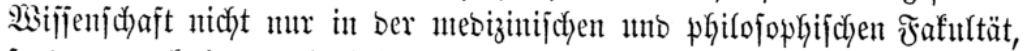
jonbern auch in ber jurijtijchen Dozent für alfe Fädjer berjelbent werbent

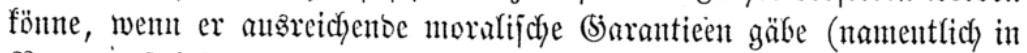
Bejug auf bejtinmte refigiöje Anjichten uno eine Denf= unt Rehrweije, weldye nit Sitte mo (sejeţ ses Stantes in Einf(ang jei). Eine ivejent=

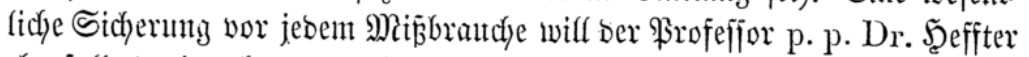

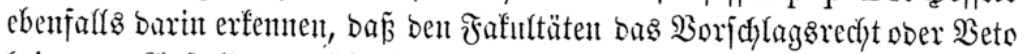

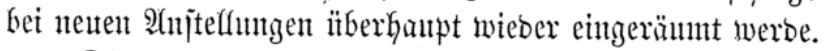

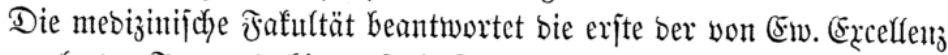

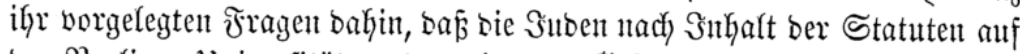

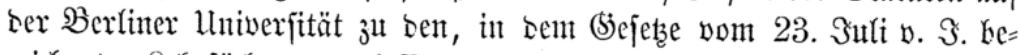

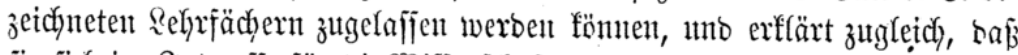

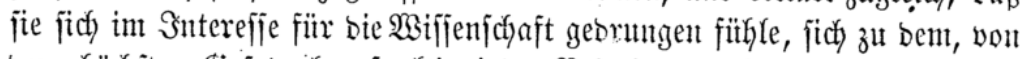

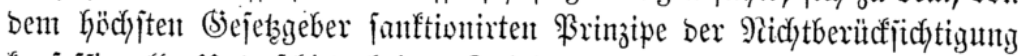

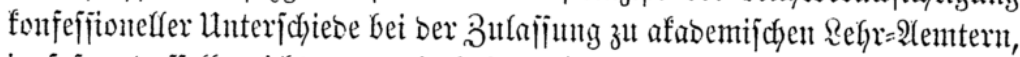

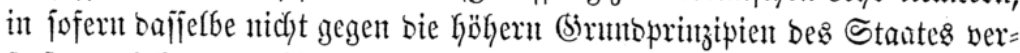

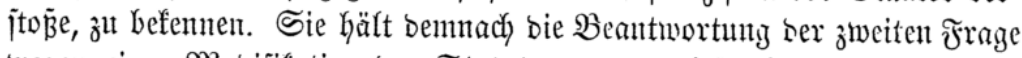
wegen einer Mobififation ber Statuten, wem siefe bie 3ulafjung ntdyt gejtatten joulten, für überflüffig, benterft aber, ba beabjichtigten Miobififfation iffrer Statuten bie ふultajiung ber Subent zu

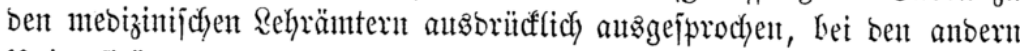
Univerjïtäten bagegen, beren Statuten biejer Bufafjung entgegenjtehen, eine joldye Mobififationn nicht beliebt werbe, bie hiefige mesizinifche Fafultät, unb zwar insbejonbere bei ber hier vormaltenten, wenn gleidy tritgerijchen

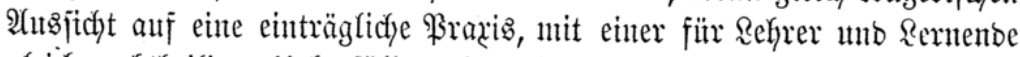
gleid) nachtheifigen Ueberfitflumy bebrwht werben wïrbe. Die mebizintifdye

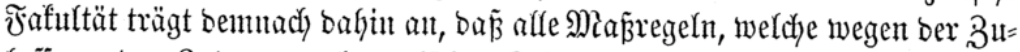

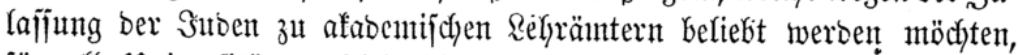

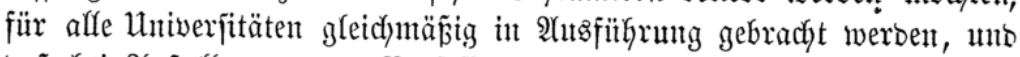

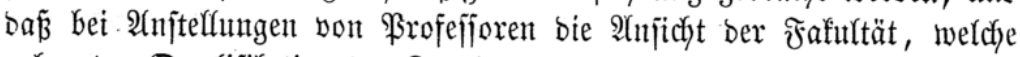

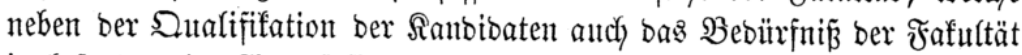

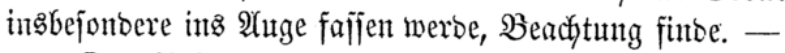

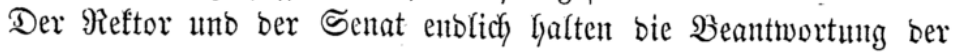


erjten Frage für unzweifelfaft und äuneen fich bahin, baß̧ bie Statuten

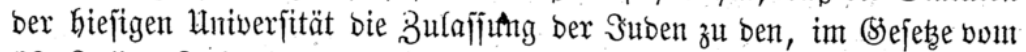

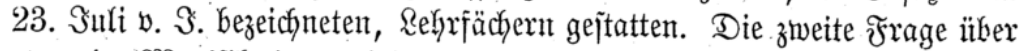
etwantige Modififfationten bei entgegenítehenden Statuten erffären fie für wegfallent Durch bie Bejahung ber eriten Frage unb beziehen fich im Uebrigen auf bie ausfüblfiche Erörterung, welcher jie biefe Angelegentheit

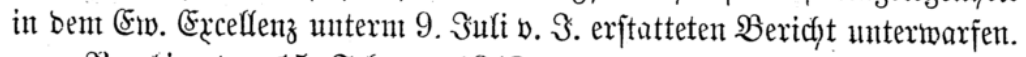

Berlin, Den 15. Februar 1848.

Rabenuerg.

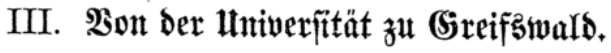

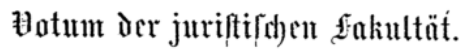

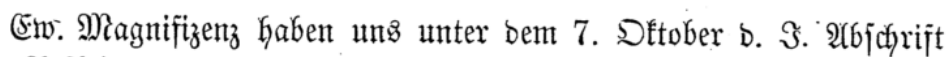

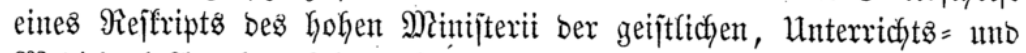
Mebizinal=2Angelegentyeiten, betreffenb bie Zulajinng ber Sntoen zu afabe=

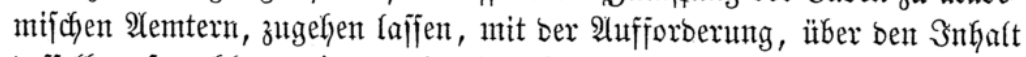

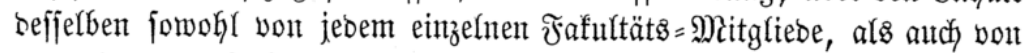
Der gejammten Fafultät, eis: Sutacfiten abzufaffen. Wir verfehlen nicht, in bem Folgendent jowohl bie $2(n j i c h$ ten ber einzelnen Mitglieber, als bag (S) faumtgutaçten ber Fafultät zujammen zu jtellen uns gehorjamjt vorzulegent.

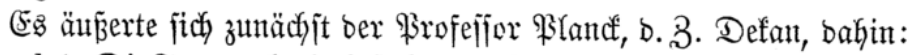

ad 1. Die Frage, ob bie bejtehenten Statuten ber Univerjität (Streif

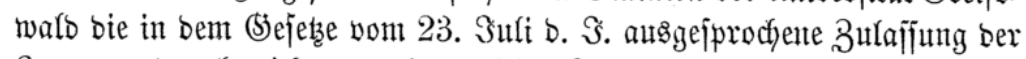
Suben zut ben bezeichnetent afabemijchen Rehrfächern gejtatten, ijt meines

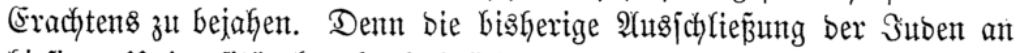
Giejiger Uniberfität Gerufyt lebiglich auf bem Suftand ber affgemeinen

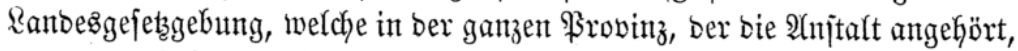
von beren Stiftung bis auf bie neutejte Deit bie Hnfähigfeit ber Şuben $3 \mathfrak{u}$ Staatßämtern überkautpt fejthielt. Die bejonberen Statuten ber Univer=

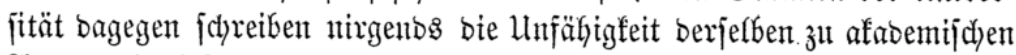
Aemtern insbejonbere vor. 3war enthalten bie Statuten von 1545 (abge $=$

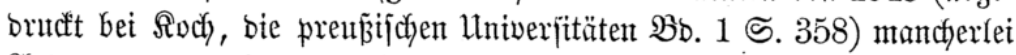

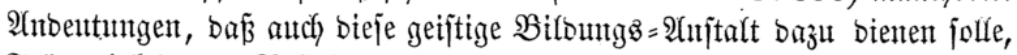

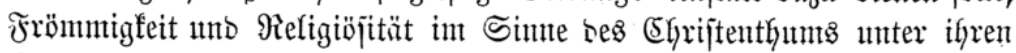

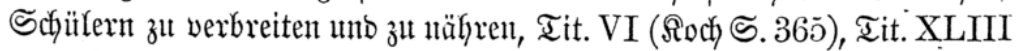

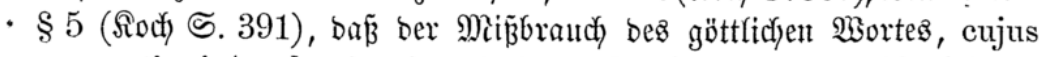
venerationi Academias imprimis studere decet, forgfältig bet ben 


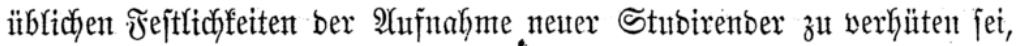
Tit. IX (

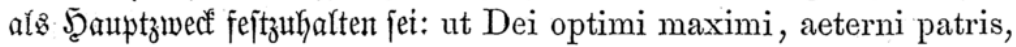
Domini nostri Jesu Christi gloria tam propagetur quam illustretur, Tit. XVII ( §od) ऽ. 372).

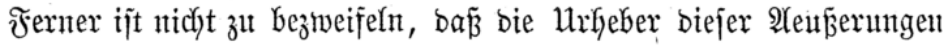

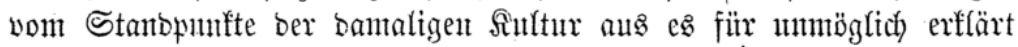

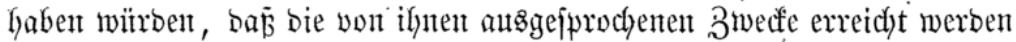

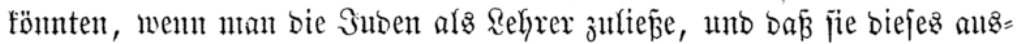

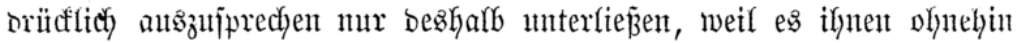

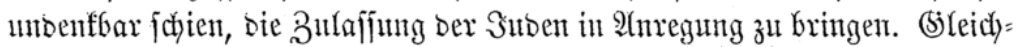

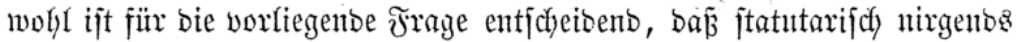

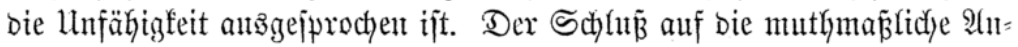
ficht ber frïhern (biejetggeber, weldyer surdy bie obigen Steflent kegrünoet

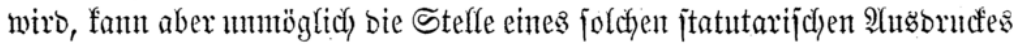

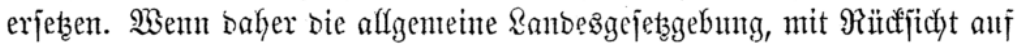

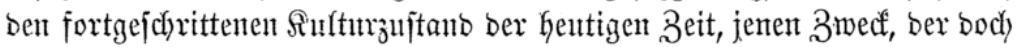

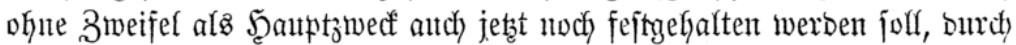

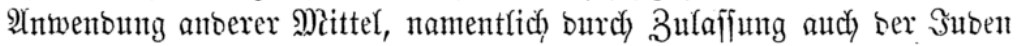

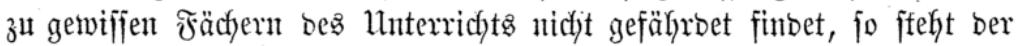

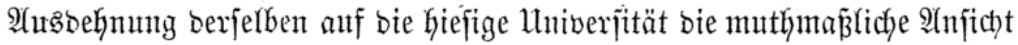
früherer (S)ejęzgeber über frïhere Beiten nidyt im sisege.

ad 2. Die Beantwortung ber zrweitent Frage ijt nad) bem jo eben (5e)= jagten bon jefbjt errebigt.

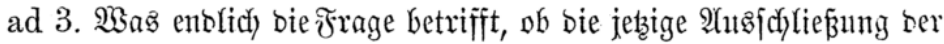

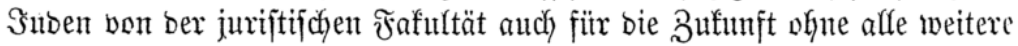
Modififation zu befürworten jei, fo fann biefelke meines (5radjtens mur

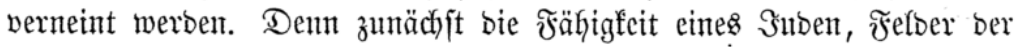

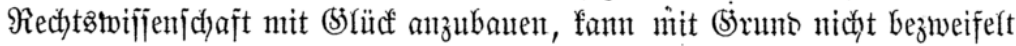

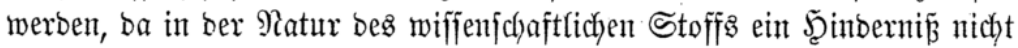

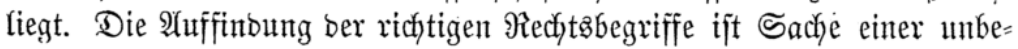

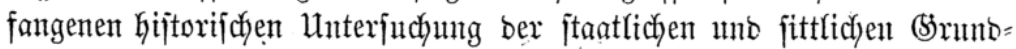

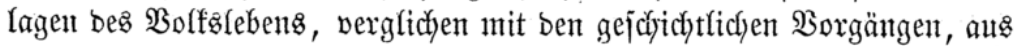

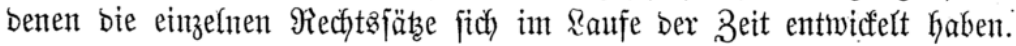
Die Fähigfeit zur Sornahme einer joldhen fam aber bem Snben un fo weniger abgefprodyent werben, aโz eళ bazu nidyt eines Mitbringents einer be=

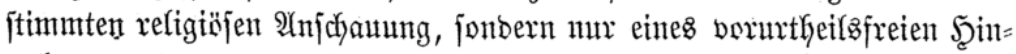
gebens an ben zu unterjuchenden Stoff bebarf ${ }^{1}$ ). (Dagegen läß̈t fich auch

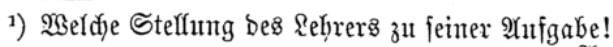

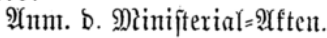


nidjt eintwenton, baj jener Stoff felbjt zum Theil herborgerufen unt

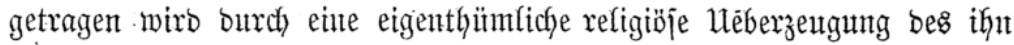

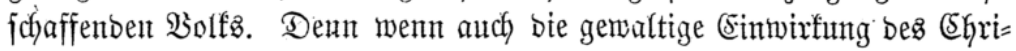

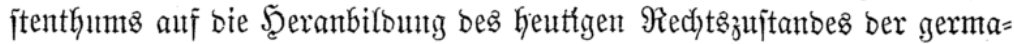

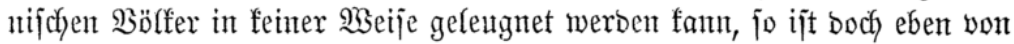

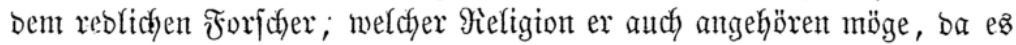

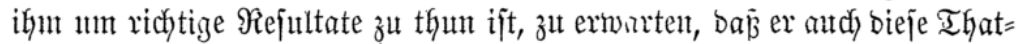

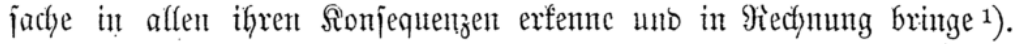

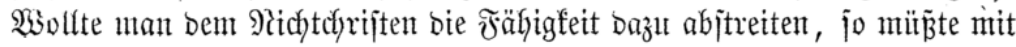

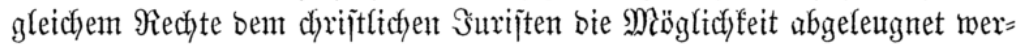

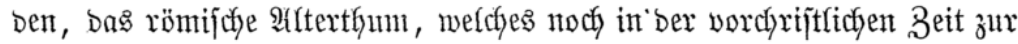

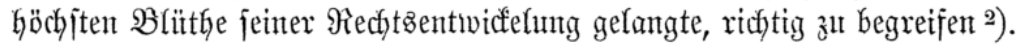

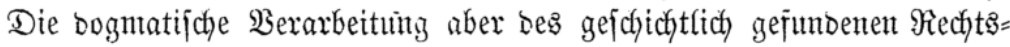
begrififs ijt Sache bes richtig benfenden Berjtandes, welcher bent Menjchen als jolchem, abgejehen won jeiner religiöjen Heberzengung, beinohnt.Dagegen bie (Bsefahx, weldje ans bem Mangel eines guten Willens auf

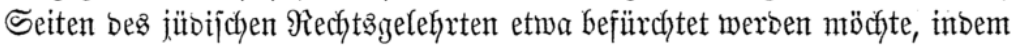

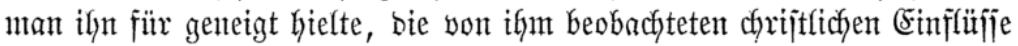

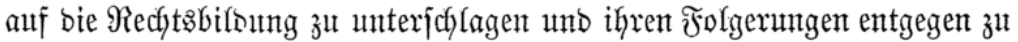

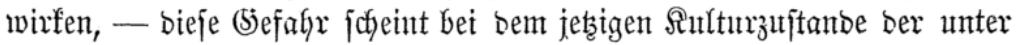

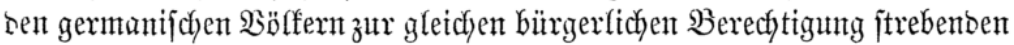

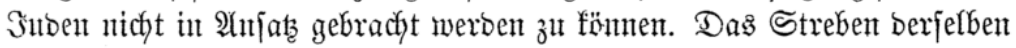
geht nicht bahin, ant bie Stelle bes unter ber ફ̧erridafaft bes (E) rijtenthums

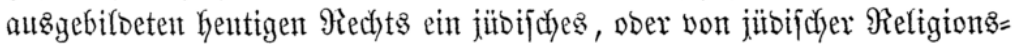

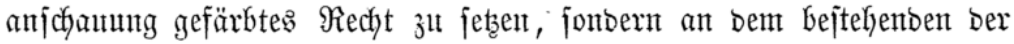

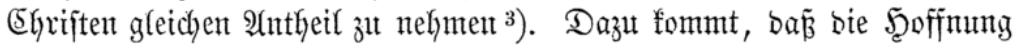
auf Erfolg eines joldyen wiberjintigen Strebens fofort niebergejdhlagen

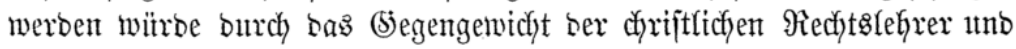

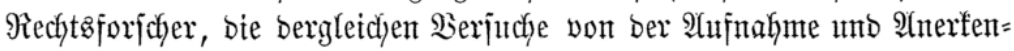

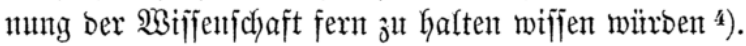

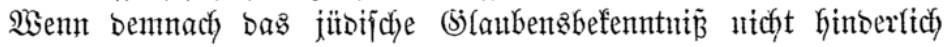

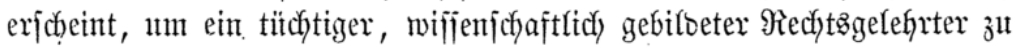

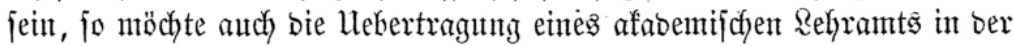

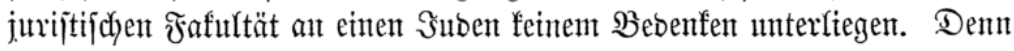

1) Auty ber Sube?

2) פigeldse Roujequenj!

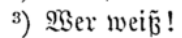

4) Sönten bic Snben red)tlid) jugelaffen merben, fo faut autd) bie ganje Fafinltät eine jübijdje twerben.

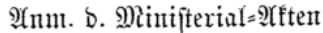

Inm. ๖. Mininiterial= $\mathfrak{A}$ ftert.

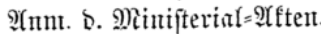

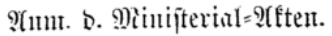


wem es mit feiner 3 Sifjenjchaft wahrer (Ernjt ijt, ber wirt aud) biejelbe in

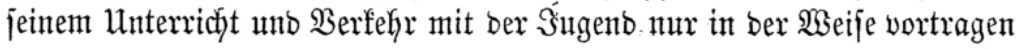

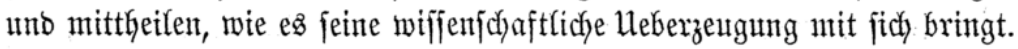

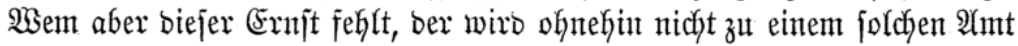
Deş Sertrattenz yon Staat berufent werben.

Der Einwant, weldher gegent bas Siejagte von Dem Umitande herges

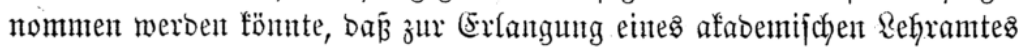
in ber juriftifchen Fafultät bie অigenjchaft einez Doctor juris utriusque tam civilis quam canonici bisher erforberlidy ijt, jajeint jich einfady $b a=$ burch) zut erfebigen, bas, wemn man einmal ben Fortjchritt in ber Sache will, bie Form nicht länger im 2 Sege jtehen faum, fowenig alg bie. Einfïlyrung eines neuen (Siejetzes burch bie Exijten cines älteren entgegenjtehenben ge=

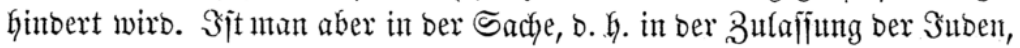
einig, fo wirb eine nene Form bald aufzufinsen fein, welche bie entgegen= jtehenbe ältere erjeţt.

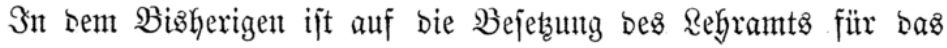

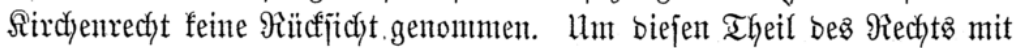

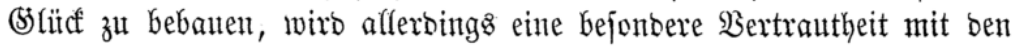

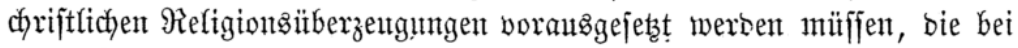

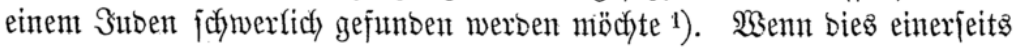

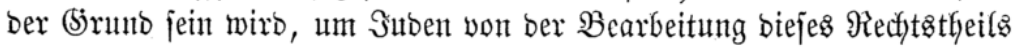

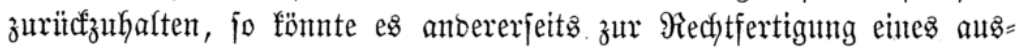

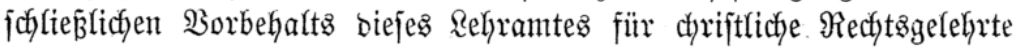
benuţt merbent.

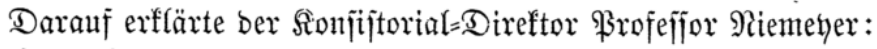

Miein Botum geht oahin:

ad 1. Die Statuten ber Giejigen Lniverjität uno ihrer einzefnen Fafultäten (natürlich) mit $\mathfrak{2}$ ušnahme ber theologifchen), von ben ältejten

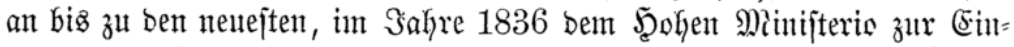

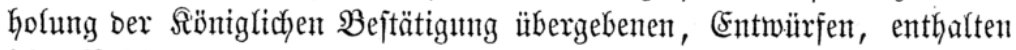

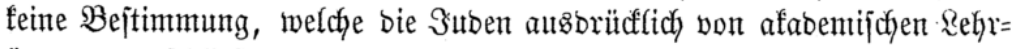

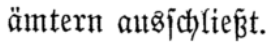

ad 2. (5z bebarf baher feiner Mobififation biejer Statuten, um jie

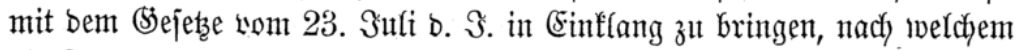

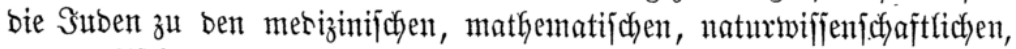

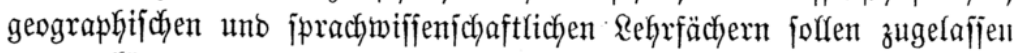
werben fönnen.

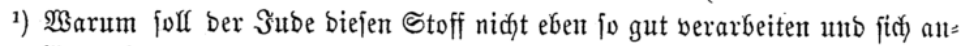
eignen fönnen?

Âm. ๖. Minifterial=9lften. 


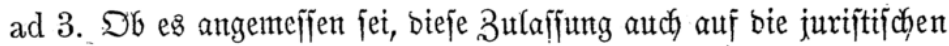

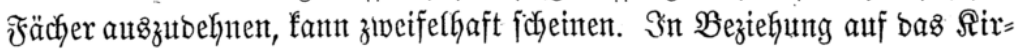

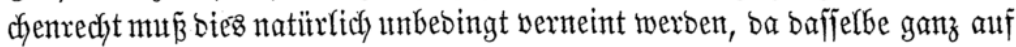

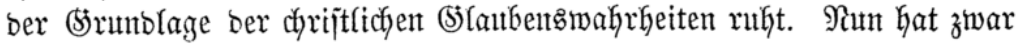

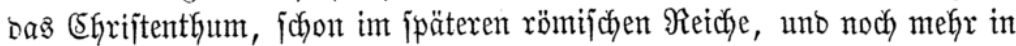
bent netterent europäifdyen Staaten, audf) auf bie Entwidétung ber ïbrigen

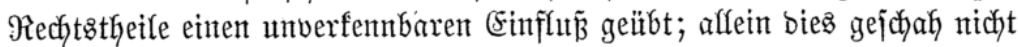
jowohl butrch fein Dogma, als vielmtefr butch Berbreitung bon biejem untabfängiger, reinever uno geläıterter fittliḑer Sruntojätze, welche \$se= nteingut bes gejamunten $\mathfrak{B}$ offes getworben fint, einen Theil umjerer Keutigen

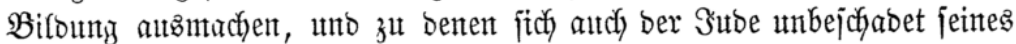
(5) fantbens befentent fann. Derjelbe wirb autch baher int Stantoe fein, bie=

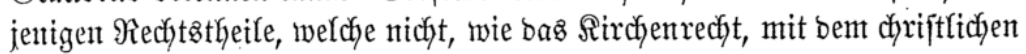

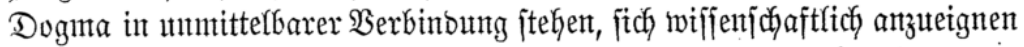

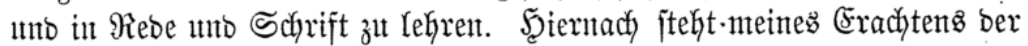

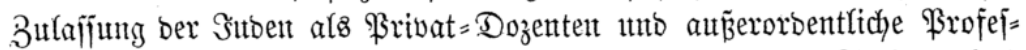

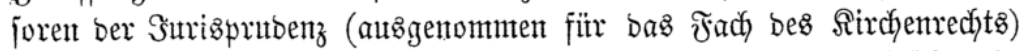
nidyts entgegen; bent bieje 2Yemter fint auf bas reinte Rehrwejen bejayränft.

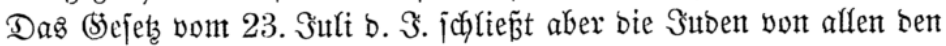

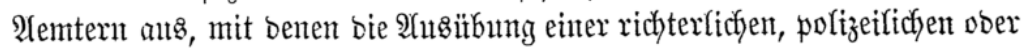

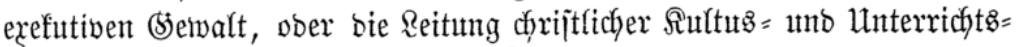
Ángelegentyeiten verbunben ijt. Sie follent baher in Betreff gemifijer Rehr= fächer zuvar auth als orbentliche \$irofefforen zutgelafjen iverben, aber nicht

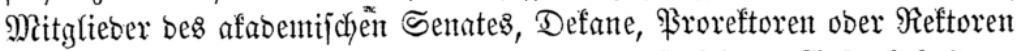

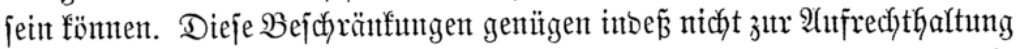

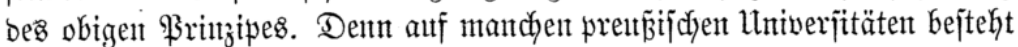
neben bem Senate auch ein ans, alfen orbentfichent Brofejporen zuf ammen=

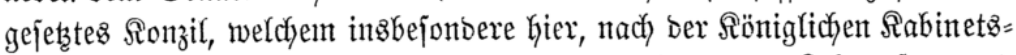
Drore nont 15. Meärz 1835, it. A. bie Beanfïidytigung bes Rehrwejenz unt

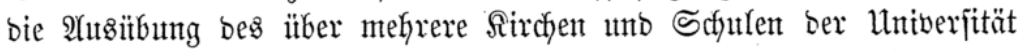

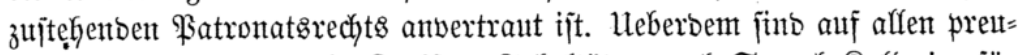

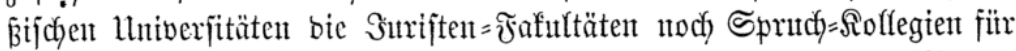

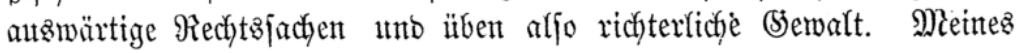

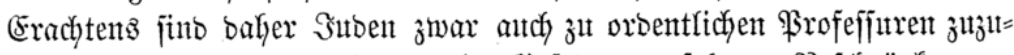

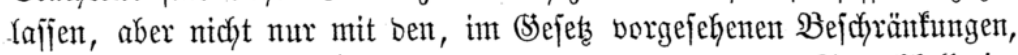

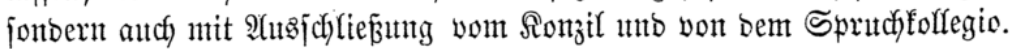

Şiernady aljo fpredye idy midy_im âtlyemeinen fïr bas \$rinzip aus,

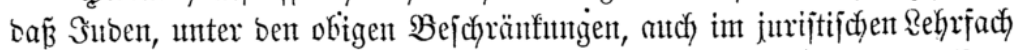

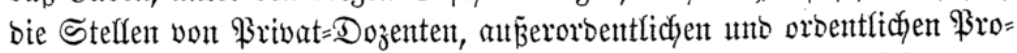

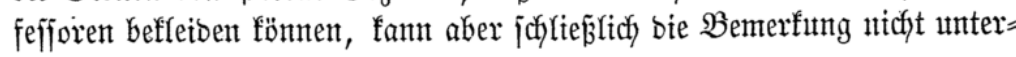




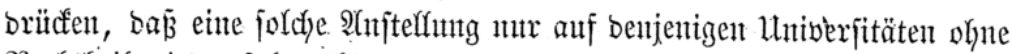

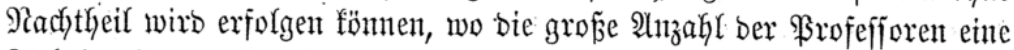

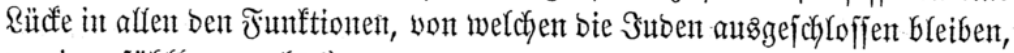
wentiger fïrylbar mady, ${ }^{1}$ ).

Sobaum benterfte ber Seheime Suftizrath \$rofejifor Barfor:

ad 1. Seit jefyr frühen Zeiten uno bis tief inz 18. Sahrhunbert

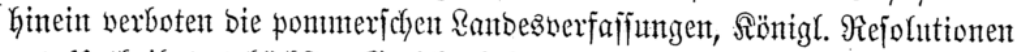

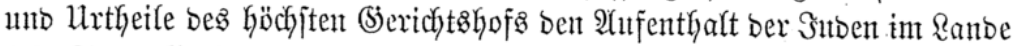

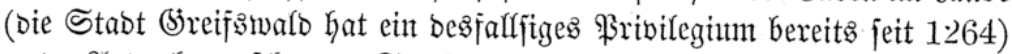
unter Allorohung fidwerer Strafen gegen biejelben.

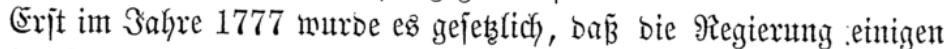

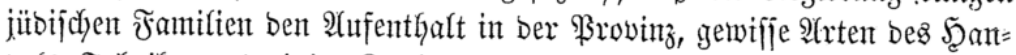
Defa, Fabrifen und cinige 3 weige Des 2 erfehrs gejtatten bürfe; aber ferbjt

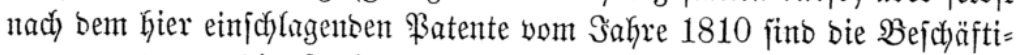
gungen, Denten bie fo fonjefifionirten Suben jich wibmen bürfen, auf

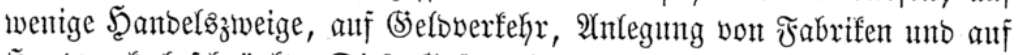

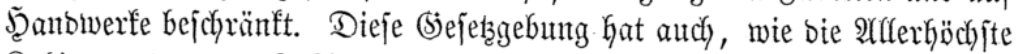

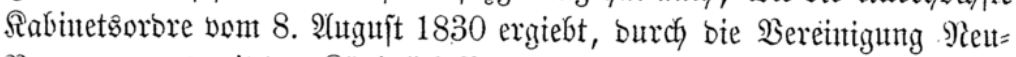

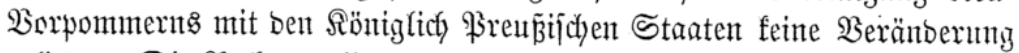
erlitten. Die Rechtįutelfen, woralts bieje Sätze fich ergeben, fint ver=

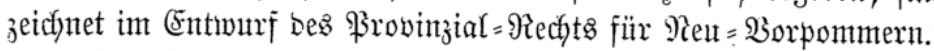

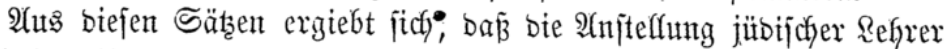
bei hiefiger Univerjität, von berent Strünoung ab bis zu ben neuejten Zeiten,

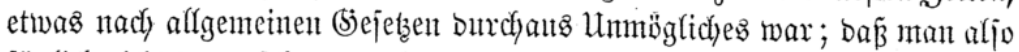

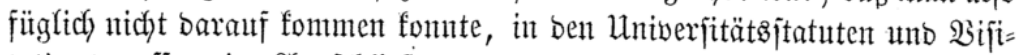

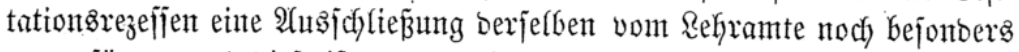
3u verfügen, unt bieje ijt bent aud nirgentos in beftimmten 2 orten alts=

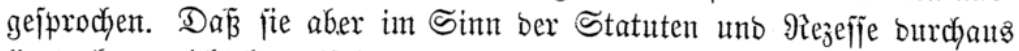
fiegt, fann nidjt bezineifelt werben, unb ergiebt jich mittelbar aus vielent

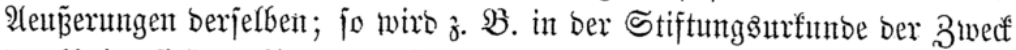
ber Uniberfität bahin angegeben, jie jolle bienen ad augmentum fịdei catholicae (Dähnert Thl. 2 S. 743), uno noch in bem neuejten (5runto=

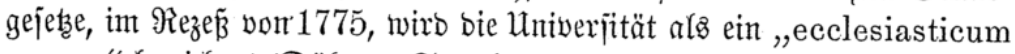
corpus" bezeidfnet (Dähnert Supplentente Ifl. 2. S. 121). Sener 3wed

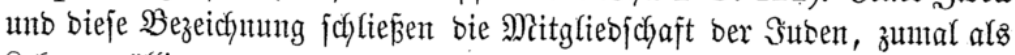
Refirer, bölfig auts.

ad 2. Da nach bem Błejagten bie Srunbgejęze ber hiejigen Mniwer=

1) Rienteyer mödte fie aljo Dod' eigentlidy nidjt ju Rollegen haben.

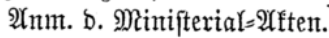




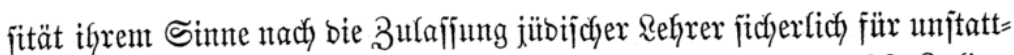

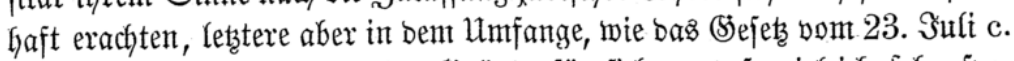

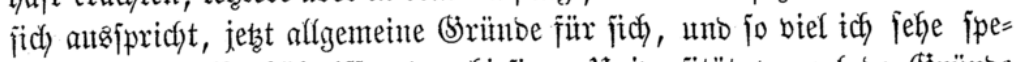

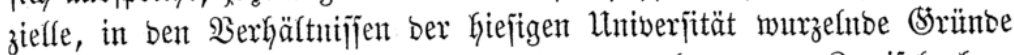

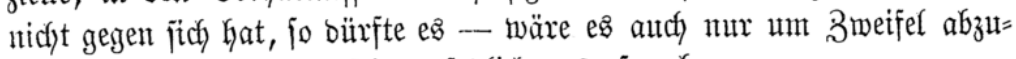
jdyneiben - angemeijen fein, gejetzlich ausizufprechen: :

bã bie int Sinne ber Struntogejetze unt Statuten Giejiger Univer=

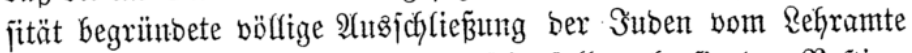
an berjelben injoweit aufgehoben jein jolle, alz jie ben Beftim=

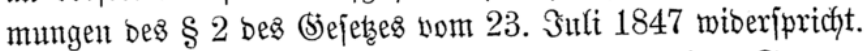

ad 3. Sn $\mathfrak{B}$ eziehung auf bie $\mathfrak{B}$ eantwortung ber britten Frage mú zunächjt fejtgehalten neerben, Dá̉ es fich nidyt um bie affgemeine wifjen=

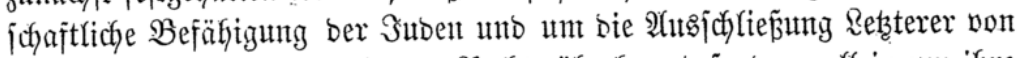

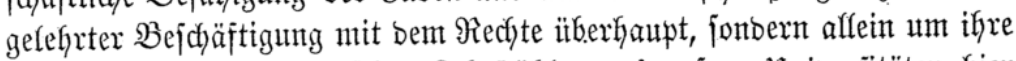

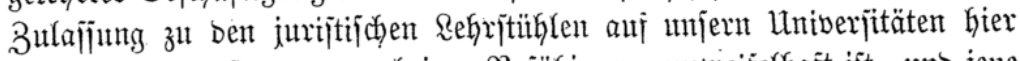

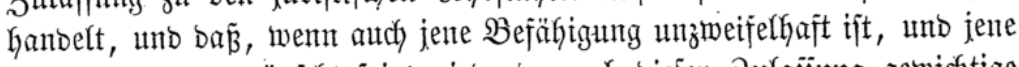

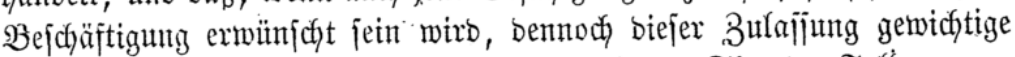

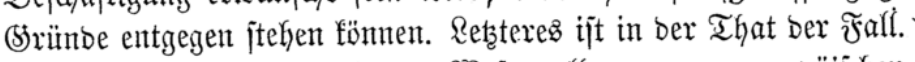

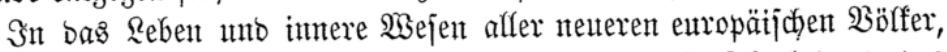
ganz bejonbers aber ber germanifłen Stämme, ijt ein jehr bebentendes

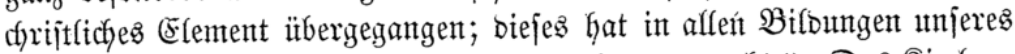

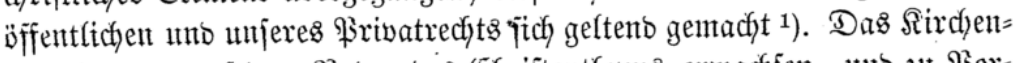

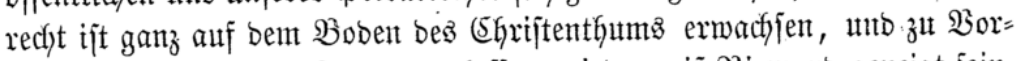

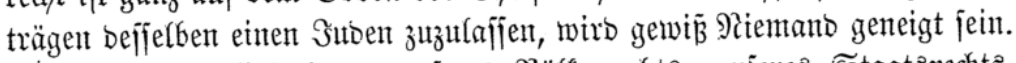

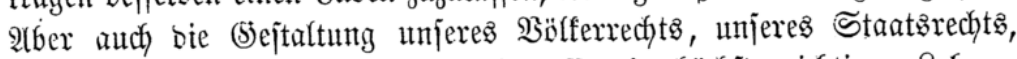
unjeres Sriminalrechts, unjeres \$rozejies in höchjt widftigen Rehren,

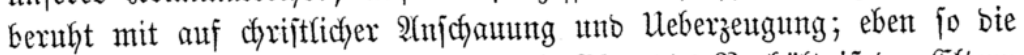

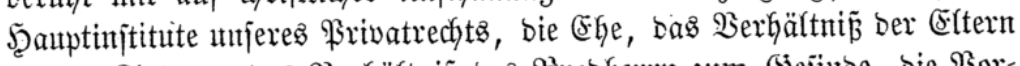

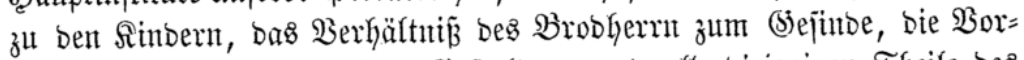
muntofuaft in ifrer heutigen (s)ejtaltung und alle biejenigen Theile bes

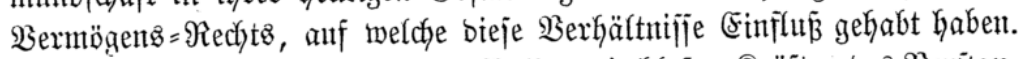

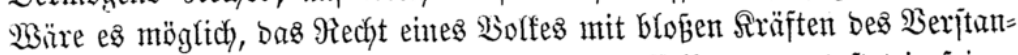

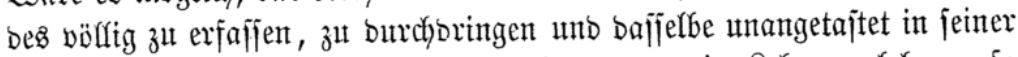

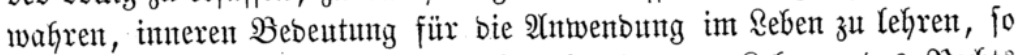

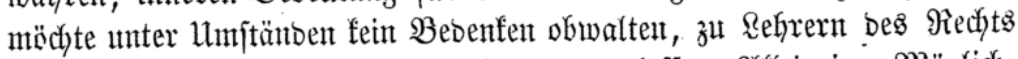

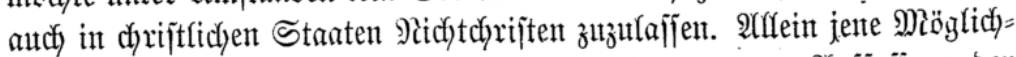
feit ift meines (Erachtens nicht vorkanben, fonbern zur Âuffajiung oer

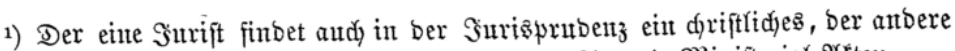

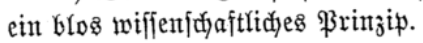

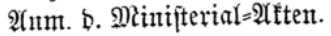




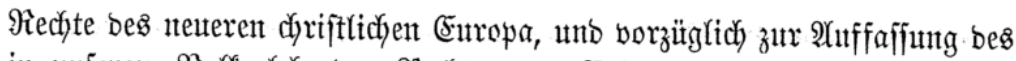

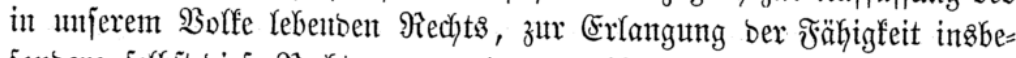

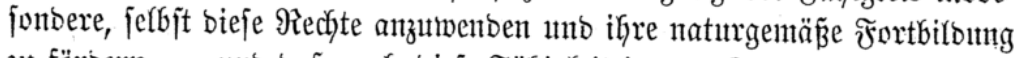

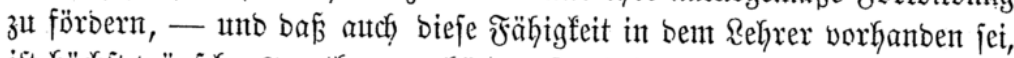

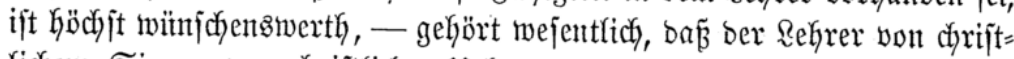
richent Sinte, won dyriftlicher Heberzengunts, von chriftlichent Silauben

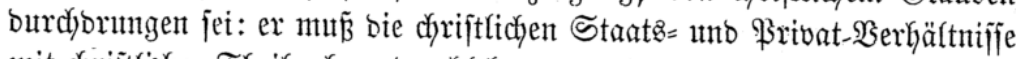
mit dyriftlictyer Theilnahme burchlebt ober mit djriftlidjer $\mathfrak{A}_{11 f}$ affung be= trachtet haben. 2 n allem biejen aber wirb es bei bem rechten Silten mangeln, unb eben besivegen fann feine Butlafjung als \&efrer ber bei uns

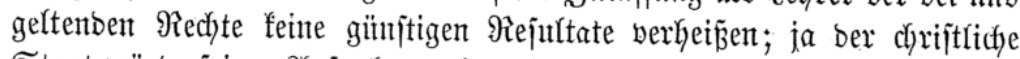

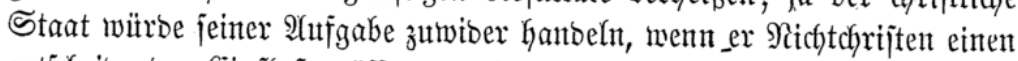

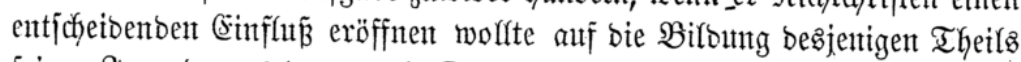
feiner Эutgent, auts bent er bie Drgane nimmt zut Exreidfung feiner nidd)=

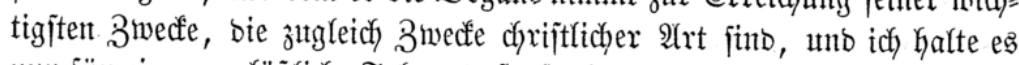
nur für eine unerläß̆

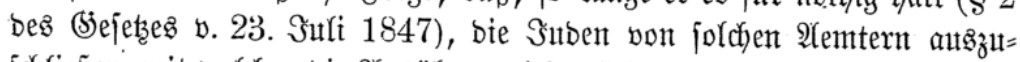

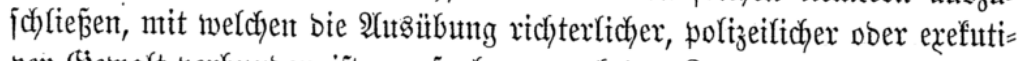
ber (Semalt berbunben ift, er fo lange autch ben Suben unterfagent müffe,

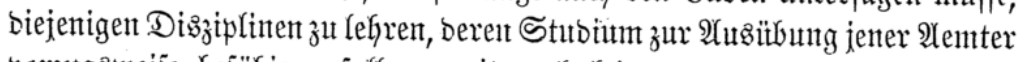

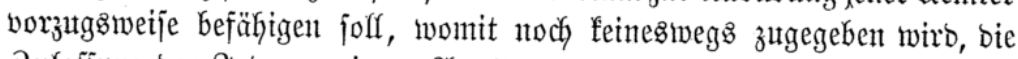

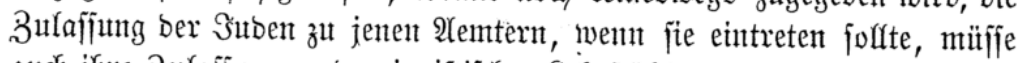

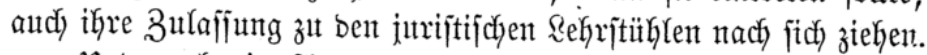

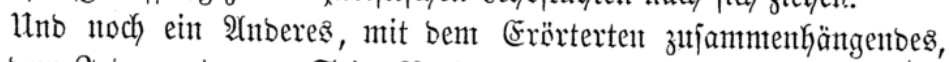

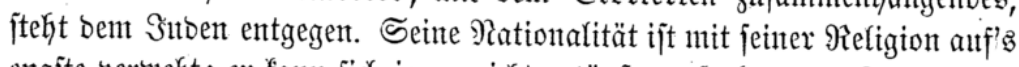

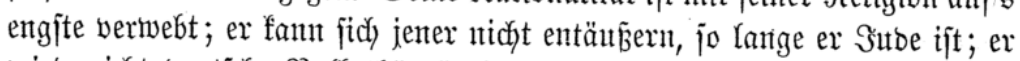

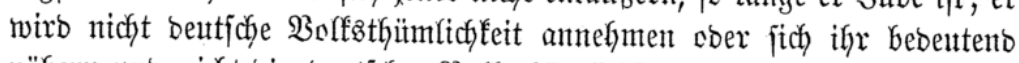

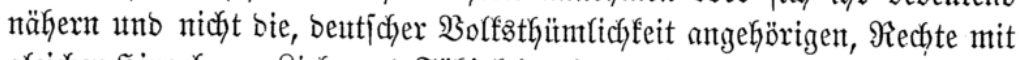
greicher Șingebuntg, Riebe unt Fähigfeit wie ber Dentjche ergreifen, pflegent unt Yehren; wie benn bie Erfahrung bejtätigt, ba $\mathfrak{\beta}$ nur berjentige in bie

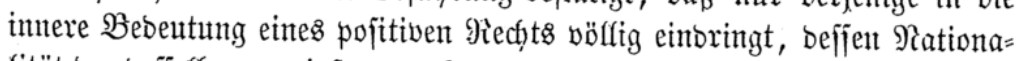
lität ber: beffelben wentigiten: nahe verwanot ijt.

3war fönte mant gegent bas \$sejagte einwentoen, es werbe Jutoen

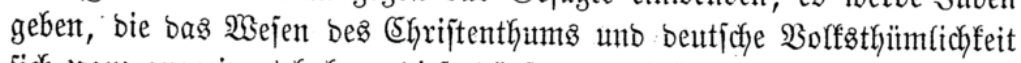
jich 'ganz ạngeeignet haben, bieje bürften wentgitens nicht aussgejd)loffen

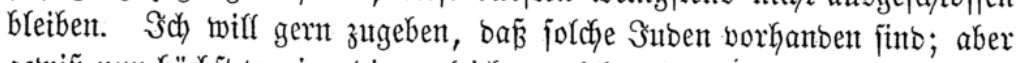

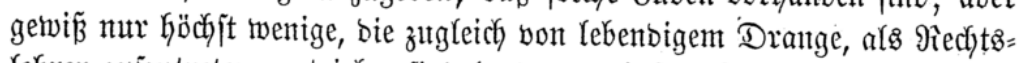

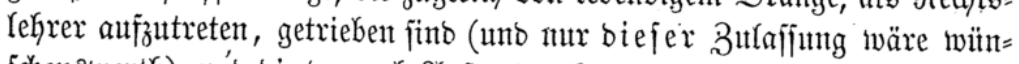

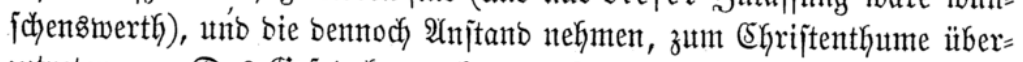
zutreten. - Das Stejes fant aber bie Bulafjung nur von Eigenjchaften 


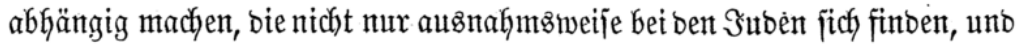

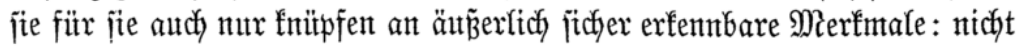
alfo an innern dyriftlichen Sinn unb an beutiche Befininung, beren $\mathfrak{A} b=$ jenfeit zwar wahrgenommen, beren Ânmejenheit aber nicht nachge $=$ wiejen werbent fann.

(Fin fernerer (Finmunt gegen bie Gier vertheibigte $\mathfrak{A}$ njitht wäre ber,

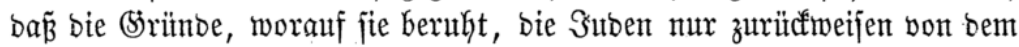

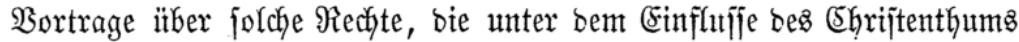

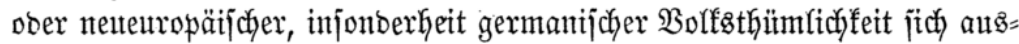

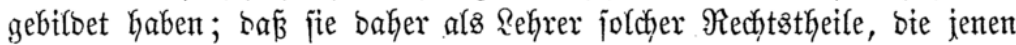

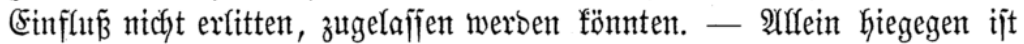

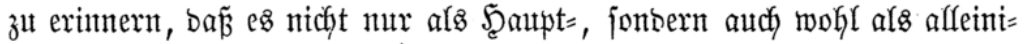

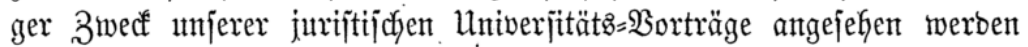

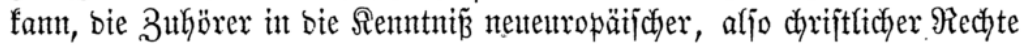

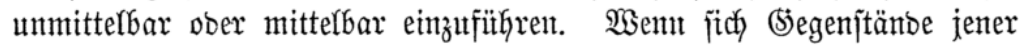
Borträge finben, auf weldye EGhriftenthum unb (serritantenthum nicht ge=

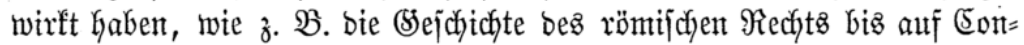
jtantin, ober bieje ober jente-Materie ba ijt, auf weldje ber Einflutis jener

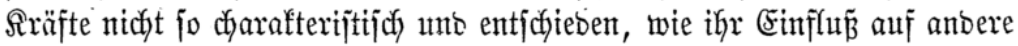
Materien Kerbortritt, wie $\mathfrak{z}$. $\mathfrak{b}$. einzelne Theile bes $\mathfrak{B}$ ermögenzrechta ber

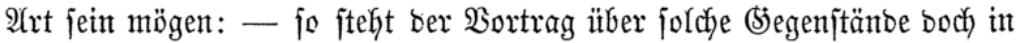

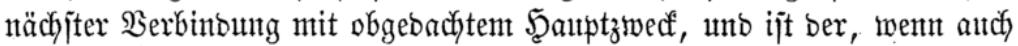

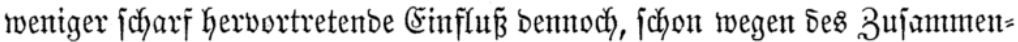

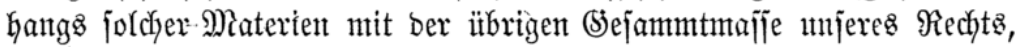

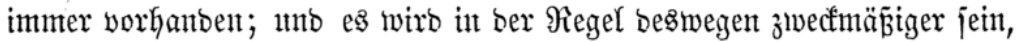
bem (5Griften bie Darjteflung in ben Untverjitäts=\$Sorlejungen vorzube=

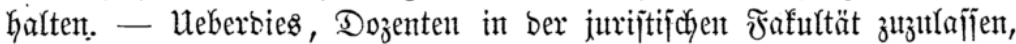

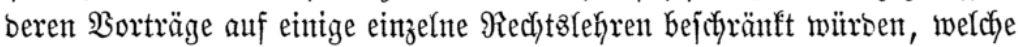
nach ber (sintichtung unjeres Rurjus integrirenbe Theile anberer, umfaj=

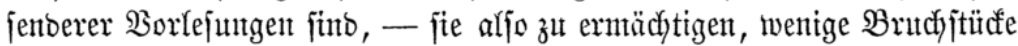

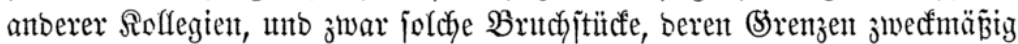

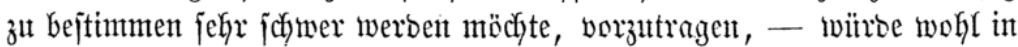

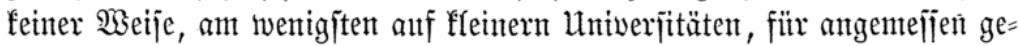

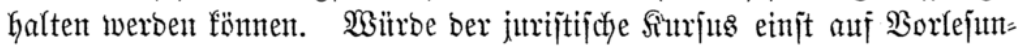

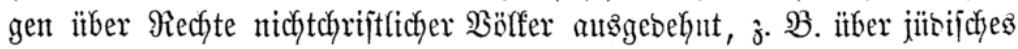

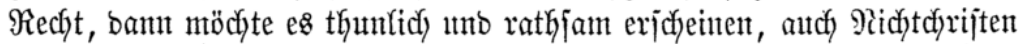

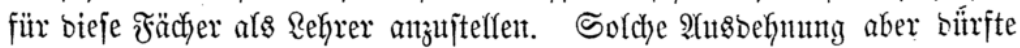

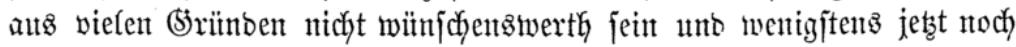

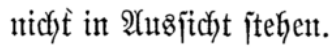




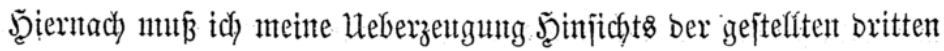
Fraige bahin attsfpredyen :

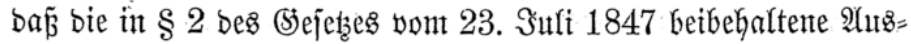

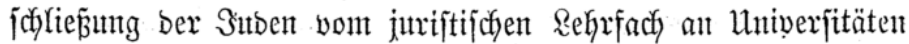
altch für bie Buffunft ohne weitere Midobifif́ation zu befütworten jei. -

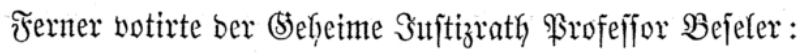

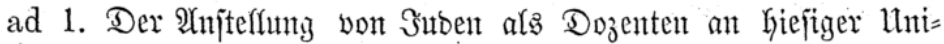
verjität jtehen meines (Erachtens bie Statuten berjelben nitcht entgegen.

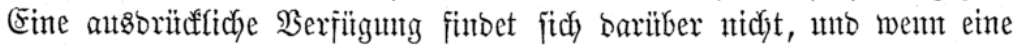

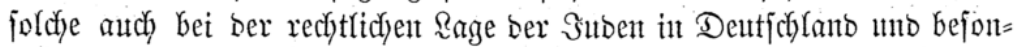
bers in biejer Provinz frühyer fïr untöthig gefalten jein mag, fo fehyt es

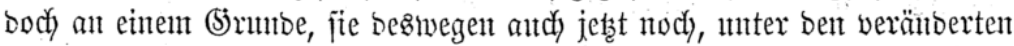

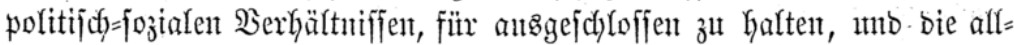
gemeine Begünjtigung, welche iłnen bie Ranbeågejeł̧gebung getwährt hat,

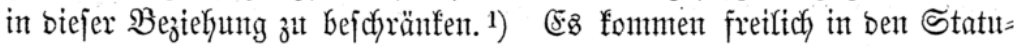

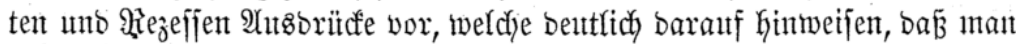
oie Univerjität für eine dyrijtliche Sorporation angejegen hat, affein bas

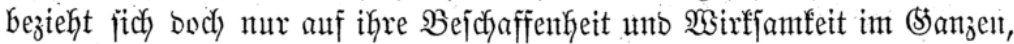
shne baß man berechtigt wäre, fïr einzelne Mitglieber und Rehrämter

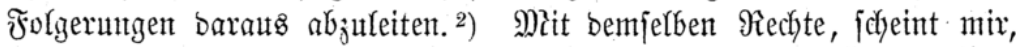

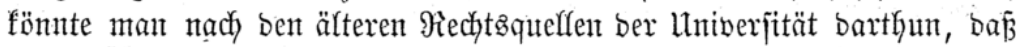

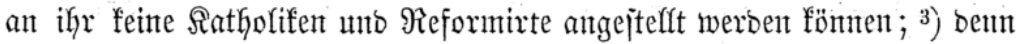

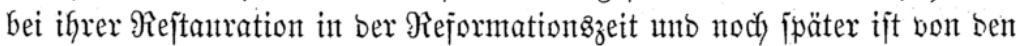

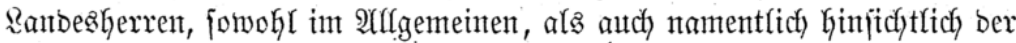

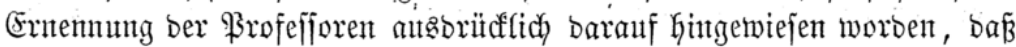
es bejonbers auf bie Befürberung ber reinen Rehre ber Alugsburgifthen

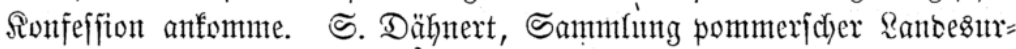

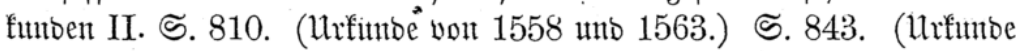
von 1627.) Seite 964. (Urfunbe von 1739.) -

So wie aber in neterer Zeit unter Berïffifchtigung ber veränberten

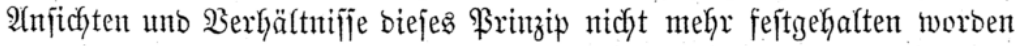

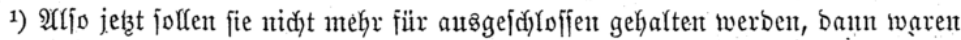
fie Dod) bis bahin ausigeid)lofien.

Anm. ๖. Minifterial $=\mathfrak{\mathscr { C }}$ ftent.

2) Wenn man für einzelne Mitglieber bies nidyt folgern fann, bann. bleibt fie im

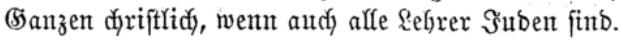

3) அYUerbing .

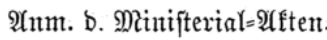

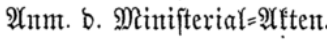




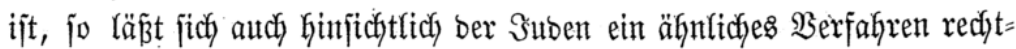
fertigen. $\left.{ }^{1}\right)$

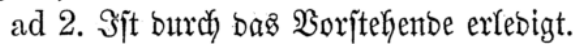

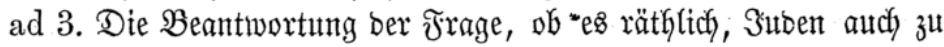

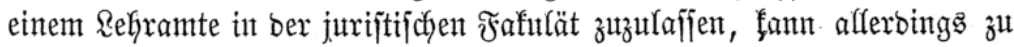

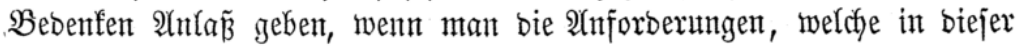

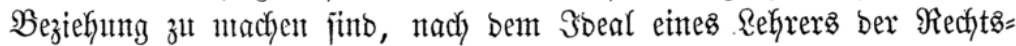
wiffeniflyaft abmefjen wilf. Ifffein, went mant unbefangent prïft, was benn

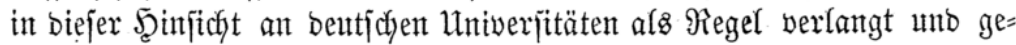

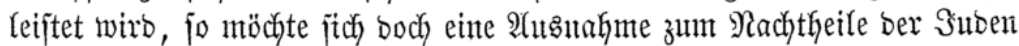

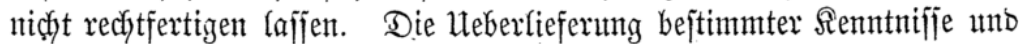

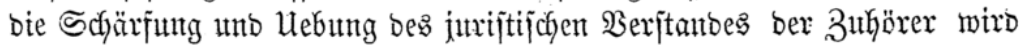
man auch bon ignen erwarten binfen, unt baranf werben, fo viel ich jege,

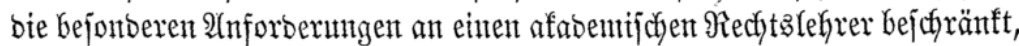

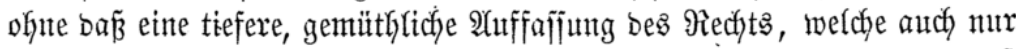

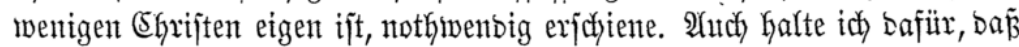
unan jelbjt bieje einem Stuben nidyt unbebingt abjprechen barf. Die nadjhal=

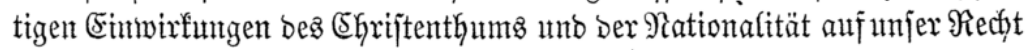

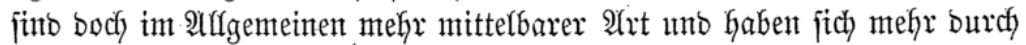

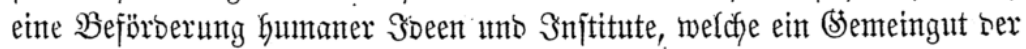
(sebtlbeten getworben jint, als burch eine jo ipezifitche (siejtaltung bes

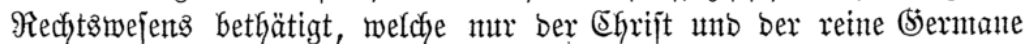

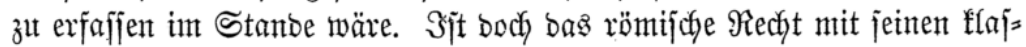
jijchen Surijten ein \$robuft bes Setbenthums, weldyem bas dyrijtliche

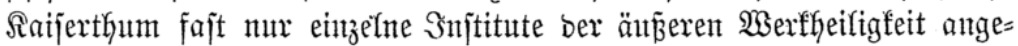

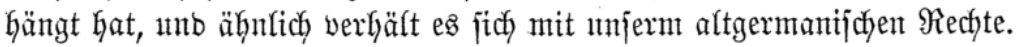

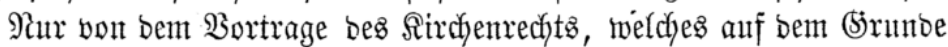
Des CGriftenthums gelehrt inerben mus, wïrben meines Erachtens bie

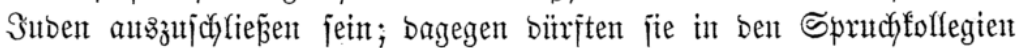
unbebentflidy funtgirent fönnen, ba bieje, bei ifyer Thätigfeit nady aunent Kint,

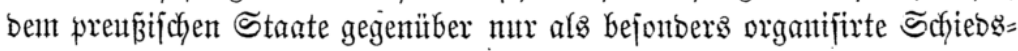

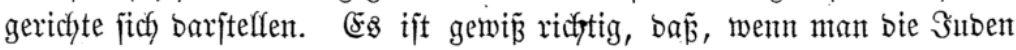
eimmal zat bem afabemifchen Refyramte zulaiffen wifl, jie möglidyjt free umb

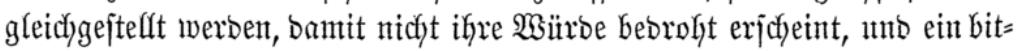

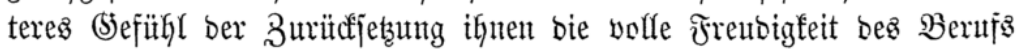
¡ç)

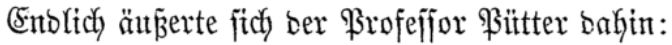

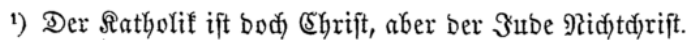

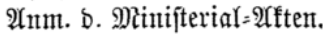




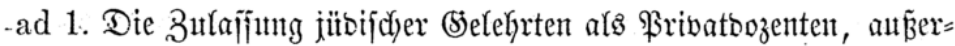

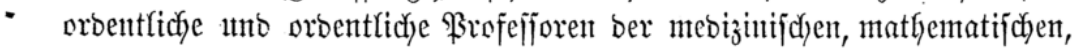

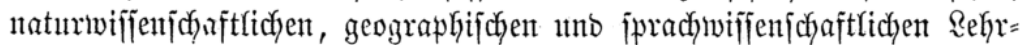
fächer ijt butrch fein Statut"unjerer Univerjität verboten, fonbern burch bie alfgemeinen Ranbesgejetze von Reuvorponmern verwehrt, welche ben $\Im_{11}=$

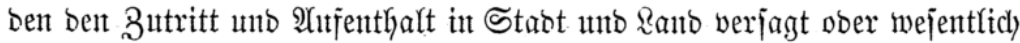

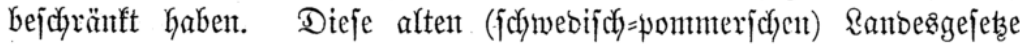
werben aber burch bas alfgenteine föntigl. preupijiche Rantosigejęs vom

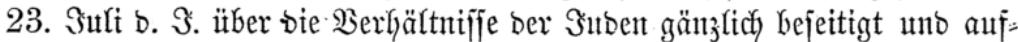
gehobert.

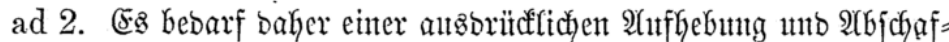
fung ber affremeinent bejetze in ihrer bejonbern beziehung auf unjere

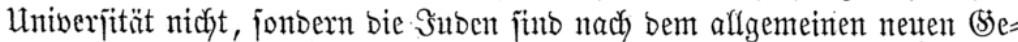
jetze autch hier zutläfïig. Das cinzige Bebenfen, was gegent bie Anjfteflung

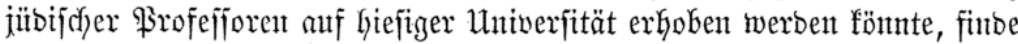

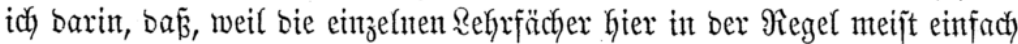

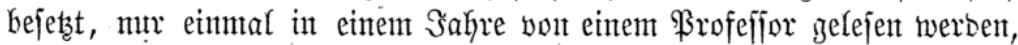
bie Stubirenton genẗtgigt jeit würben, bei bent Einen jïbijchen Regrer bie betreffenten Borlejungen zu Gören, wenn fie ihnen gerabe nöthig ober be= jonbers nützlidy unb förberlich in ifyren Stnbien find. 1) -

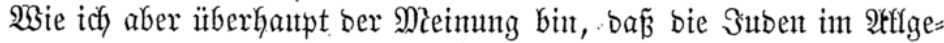
meinent und jeber (sinzelne mur burch bas 2 Bertrauten ber chrifttichen Mit=

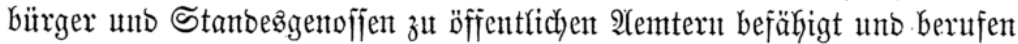

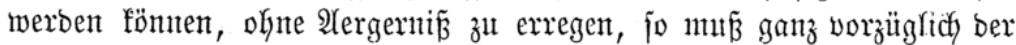
itudirenten Sugent bie Freikeit erhalten unb gejichert werbent, bei einem jübijchen Rehrer, ben jie nicht lieben unto leibent mögen, nicht hören zut müijen. ${ }^{2}$ ) $\mathfrak{W o}$ bagegèn ztwei ober mehrere Profejīoren biejelben $\mathfrak{B i f j e n =}$

- ichaften lehren, icheint mir bie 3uttaffung eines Suben unter ifynen ganz unbebenflidy.

ad 3. Die jeţige $\mathfrak{A}$ uş

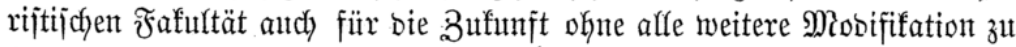
befürmorten, fann ich mich burch bie gewöhnlich bafütr angeführten (Srü̈nbe

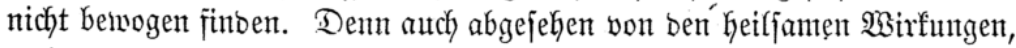

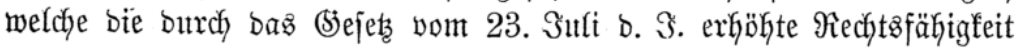

1) $\mathfrak{B a s}$ [djabet benn $b a z$, wenn bie Suben ïberhaupt tüdytig jein fokfen zur Doftion.

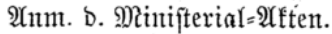

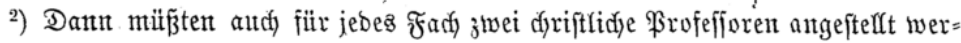
Den, benn ber Stubirenbe fann viefleidyt ben einent nidyt Yeiben.

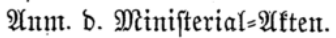




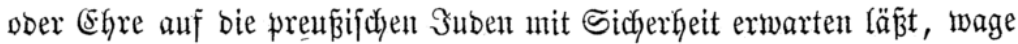

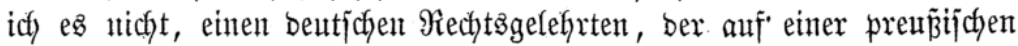

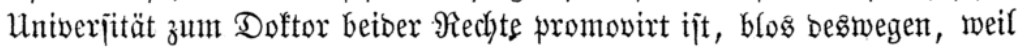
er ein Sube ift, für unfähig ober unwürbig zur $\mathfrak{B}$ erwaltung eines rechts= wifijenjchaftliçen \&ehramtes zu erffärent. -

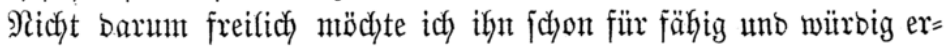
achten, weif ex etwa bie gelehrten Sentnifije unb einen jufarfen ausgebil=

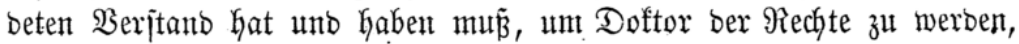

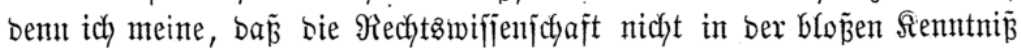

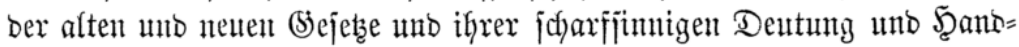

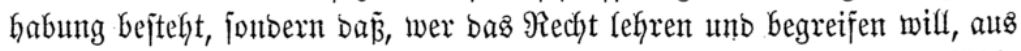

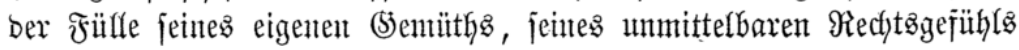

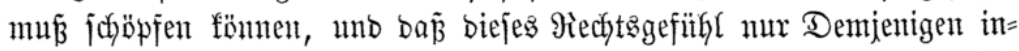

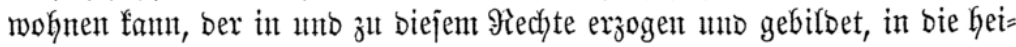

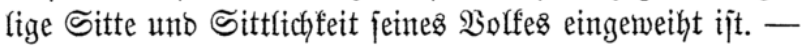

Man hat mun ben Suben bie Fähigfeit ju ben afabemijchen Rehräm=

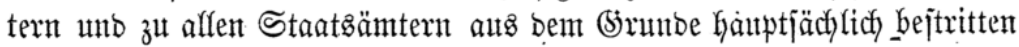
unb abgejprocken, weil jie als ein frembes in jich abgejchlofienes Bolf

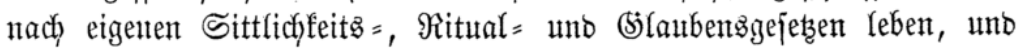

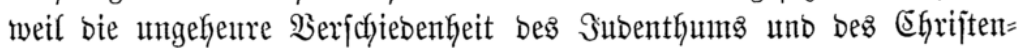

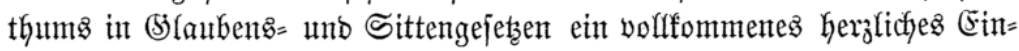

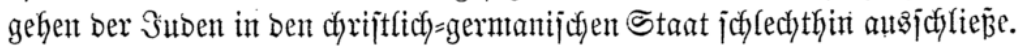

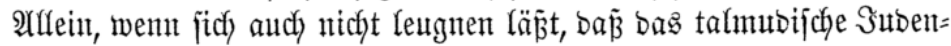

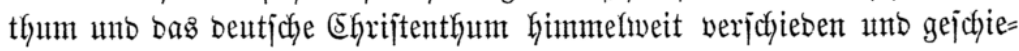

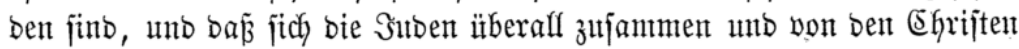

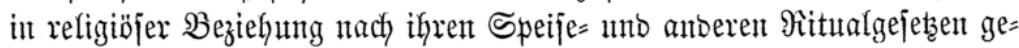

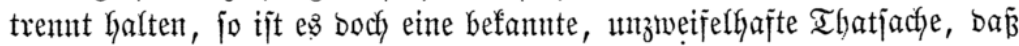

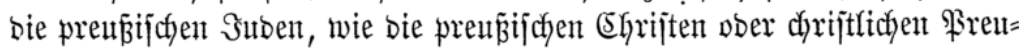

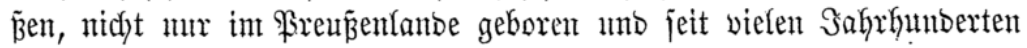
einheimifich, fontoen audy in unjerm dyriftlichen Staate erzogen unto zu un=

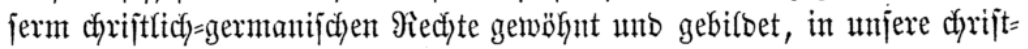
liche (s)ejittung unt Bsejumung eingegangen futto. -

Zwoar halten fie, aber aud viele (Shrijten mit ihnen, bie chriftliçen

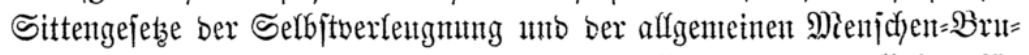
ser=Riebe unb bie baraus folgenton jittlidyent (Srunbjätze unto (5ebote jür etwas alfgentein Menjchliches, ber vernïnftigen Menfdyennatur inte=

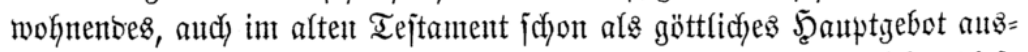
gefprodyentes; affein bieje ungejdyidytliche $\mathfrak{A}$ njicht Ginbert jie nidyt, bieje

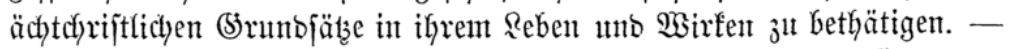

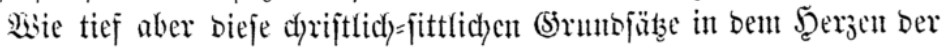




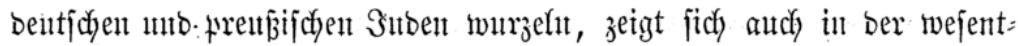

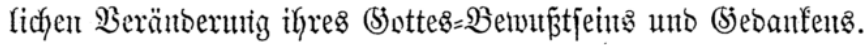

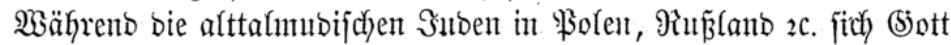

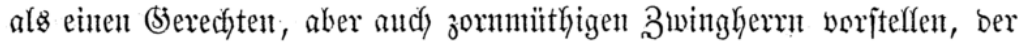

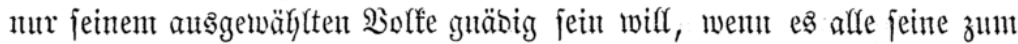

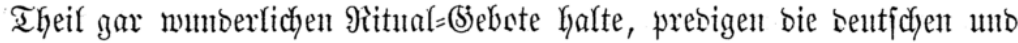

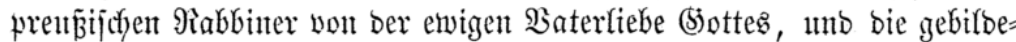
tent Suben glauken, baj (Sott bie Riebe jei uno jich alz jolche im alten Tejtament uno jonjt offenbart habe: ein gewiés mur eigenthïmlich (5hrijt= ‘iches! -

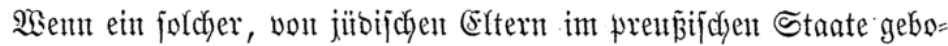
rener unb jittlich erzogenter, auf unfern Schulen unb (bymuafien verorb=

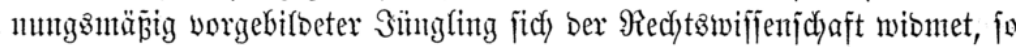

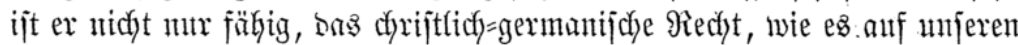
Univerjitäten gelehrt wirb, wolffommen aufanfaffen unb zut verjtehen, jon= bern and in bie Tiefen ber $13 i f f e n f(h) a f t$ einzubringent unb nene Fortfdyritte

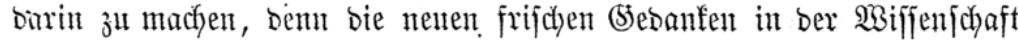

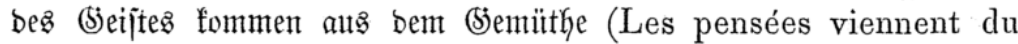
coeur) jagen jogar bie Franzojen.

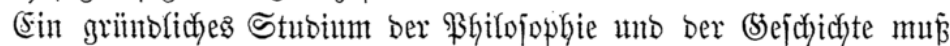

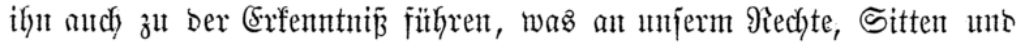

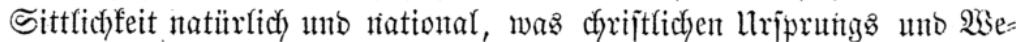

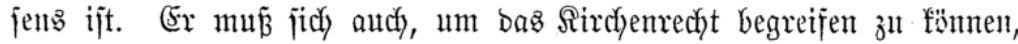

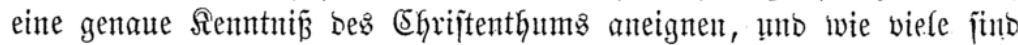

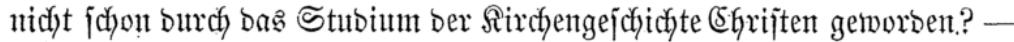

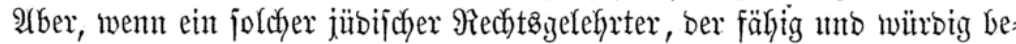

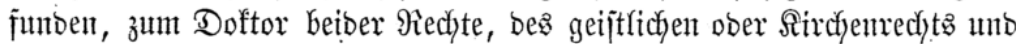
Dez weltlichen (jourt mur (Sivils) Rechts erfoben zut werben, auth nicht

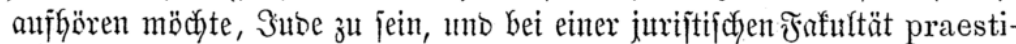
tis praestandis mit beren (\$ienehmigung $\mathfrak{B}$ orlejungen über (nicyt fircyen=)

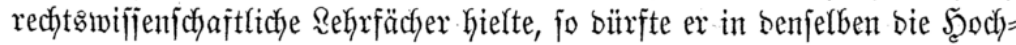
achtung, welche bem EGriftenthum uno - ben Ehriften, bie er unterrichten

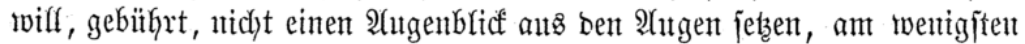
offen obcr berifteft bagegen reben, es Kerabmürbigen wollen. Denn jelbjt joldhe Stubenten, welche jonjt nicht jehr baranf achtent, würbent won einem

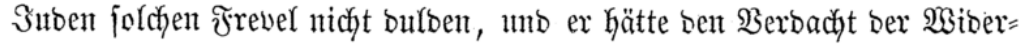
d)riftlichfeit won vorn herein gegen fich, wenn er irgent etwas anberes ars Rob barïber auşfpräcte. -

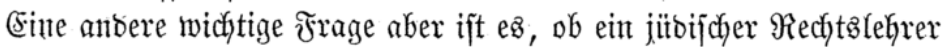
nidht aud bas Borurtheil ber Rollegent unb ber Stmbirentent wiber fidt) 
Gaben unb baburch in einer jonjt vieffeicht jegensreichen Winfjamfeit ge= Gemmt fein twitrbe und 9 (nd bere Gemmte? -

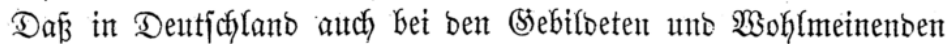

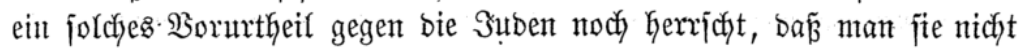

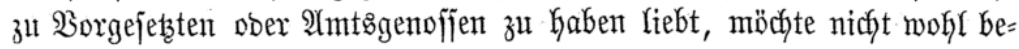
jtritten werben fönnen. Es mürbe baher unb weil bie Ehrijten bas Selbjt=

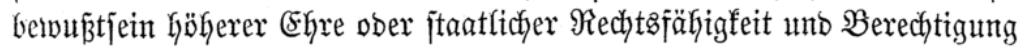

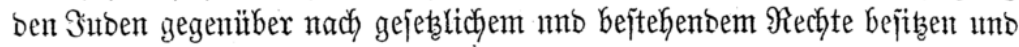
gettent machen, afferbings nicht woht gethan jein, went bie Regierung

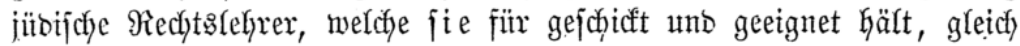

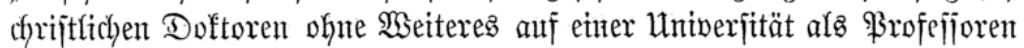

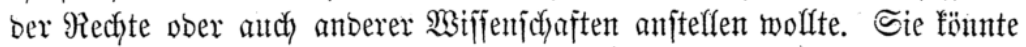

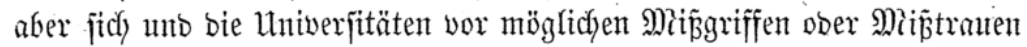
jictyern, wenn jie nidyt mur, wie jodon oben Kervorgehobelt, bajïr jorgte, oaj neben joldyem jïbijchen gechtalehrer immer nody einer ober mehrere dyrijt=

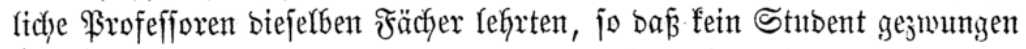
wäre, bet bem jübijøen zut hören, fonbern aud vor jeber joldfen 2(njteflung

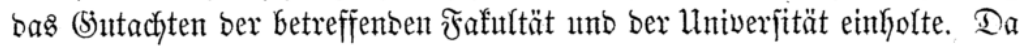

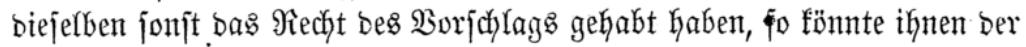

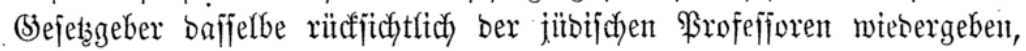

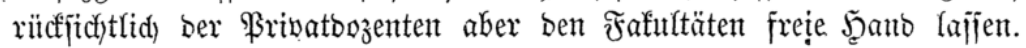

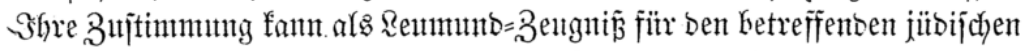

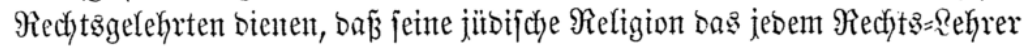

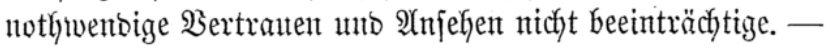

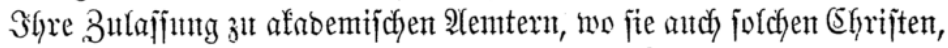

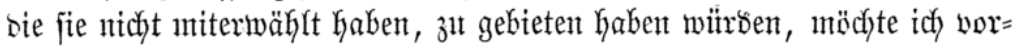
räufig noch nidbt befïrtwortent. Dagegen hat ihre Theilnahme an ben

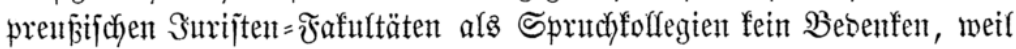

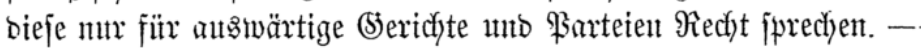

Rach biejen Soten ber einzelnen Mitglieber vereinigte fidy bie Fafultät jobann zu forgentent (5ejantmtvotum:

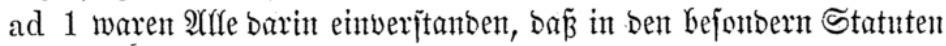

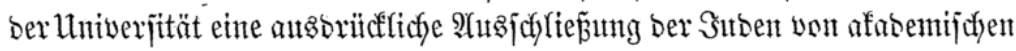

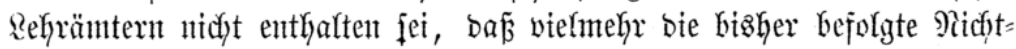

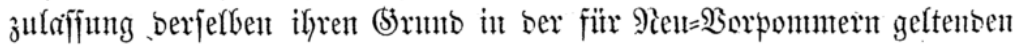

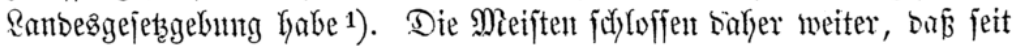

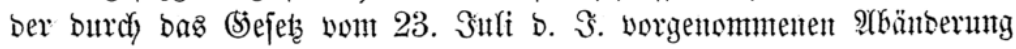

1) Ias ift nidyt gefraigt worben, fonbern ob bie Statuten ber Mnftellung entgegen ftelsen.

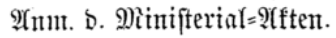


jenter affyenteinen Ranbesgejetsgebung ein ferneres rechthiches Bebenfen

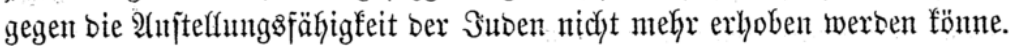

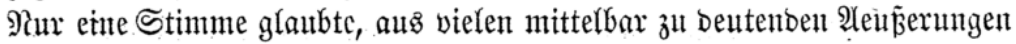

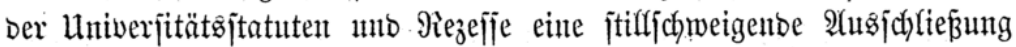

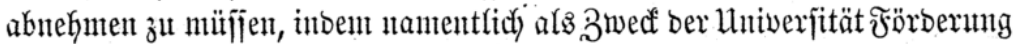

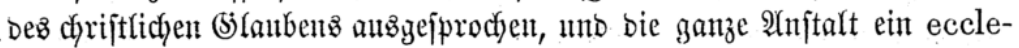
siasticum corpus genamnt werbe. Âffein ragegen warb einerjeits geltent

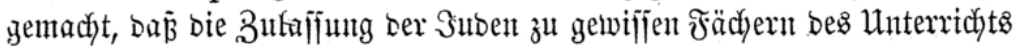

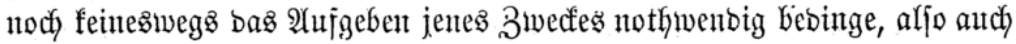

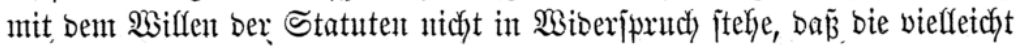

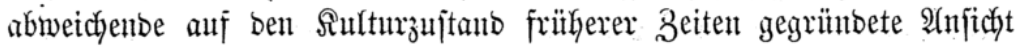

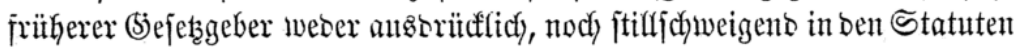
erflärt worben jei. Fernter wurbe anbererjeits erinnert, bá bie bezeichnung ber Univerjitüt als ciner dyrijtlidjen Sorporation jidh nur auf ifje $\mathfrak{b e}=$

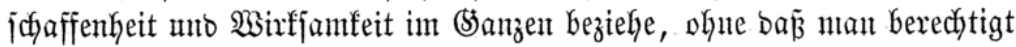
wäre, für einzelute Mlitglieber ober Rehräunter Folgerungen baraus abzıt= leiten. Es beanttwortete bemnad bie Fafultät bie vorgelegte erjte ₹rage:

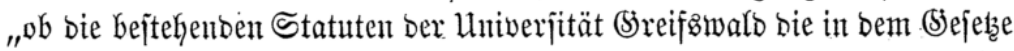

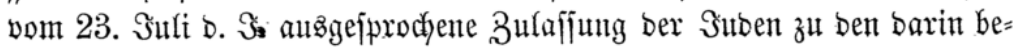
zeichneten afabemijchen Rehrämtern gejtatte",

mit vier gegen eine Stimme bejakent. -

ad 2. (Es'mar hierourch bie Mlajorität für bie zmeite Frage nach ber

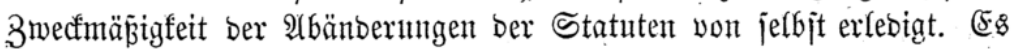
erf(ärte jich inber auth bie bifịentirente eine Stimme unbebingt für bie

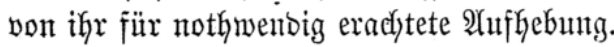

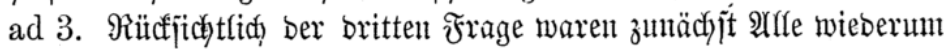
barin einig, baß̧ von bem Refyrant Des Sirchenredhts bie Suben nach wie vor auszuf eine Stimme senjelben (s)runbjats fejthalten zu müjfen. Denn zunächjt jei in Das Recht Der germanifdyen Stämme ein jefy. bebeutentes chrijtliches

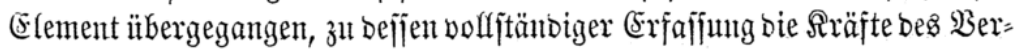

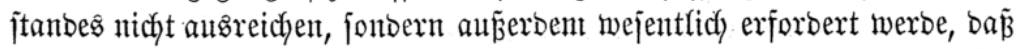

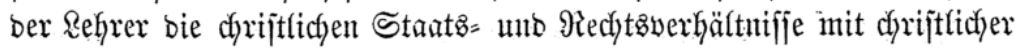

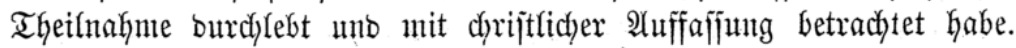

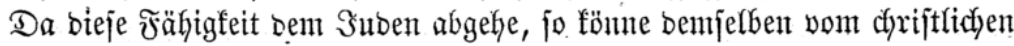

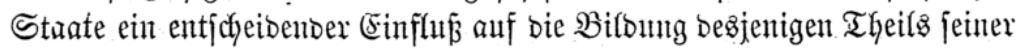

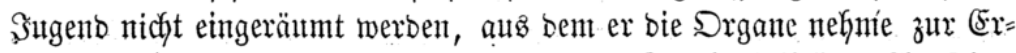

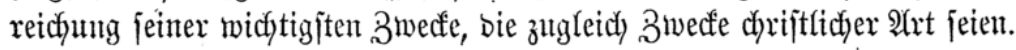

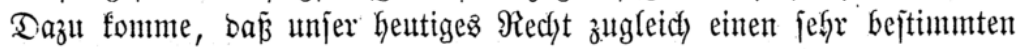

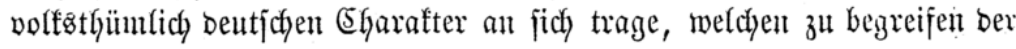




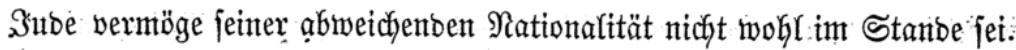

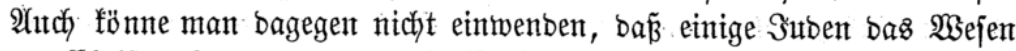

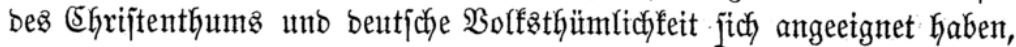

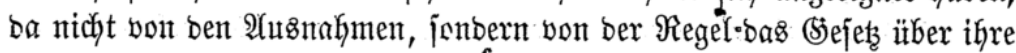

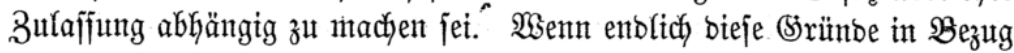

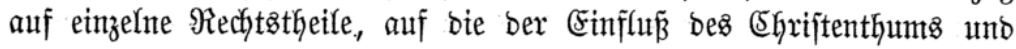

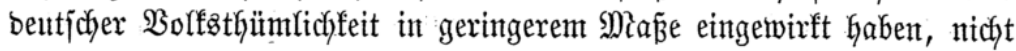

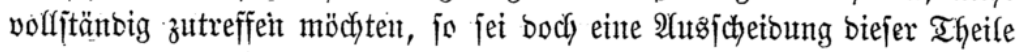
von ber übrigen Bejammtmajie, um jie jübijchen Rehrern anzuvertrauen, theils wegen Störung ofez Dufammenthanges, theils wegen Zerreinung

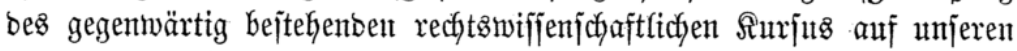
Univerfitäten feinešnegg zu empfehlent. - Dagegen warb von ben Mit=

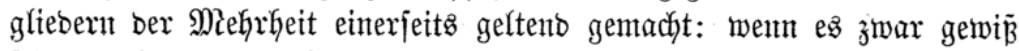

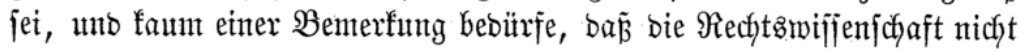

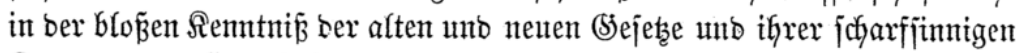

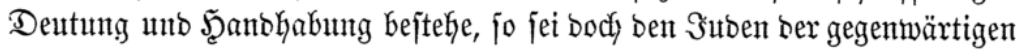

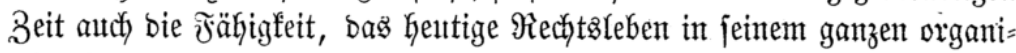
idjen 3 ujanmenthange auffufajfen, unt bas in bemjelben wirfjant gemorbene chriftliche (stement zut begreifent, nicht abzujprectjen, weil es zur richtigen

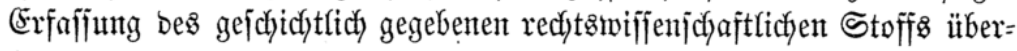
haupt nicht jowohl bes Mitbringents einer bejtimmten religiöjen $\mathfrak{M e b e r =}$

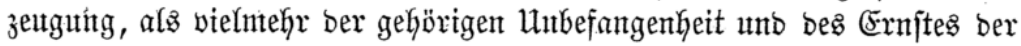

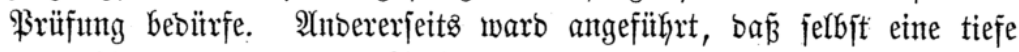

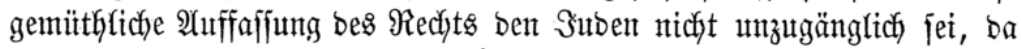
bie vorker hervorgehobenen Einnirfungen bes Ehriftenthums unt ber

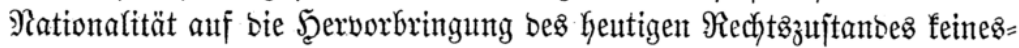

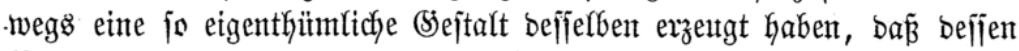

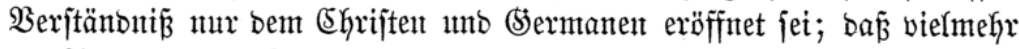

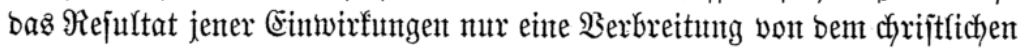

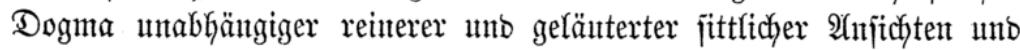
Snjtitute fei, weldye alz ein Sienteingut aller Bebilbeten ber Keutigen Zeit, Into jomit audy ber Sltben betractstet werben mirjfe. So jeien namentlich

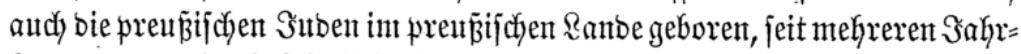

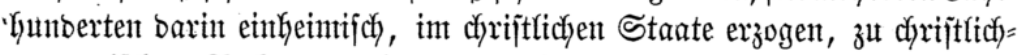

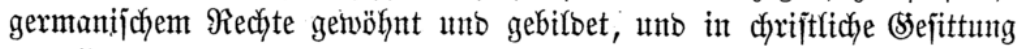

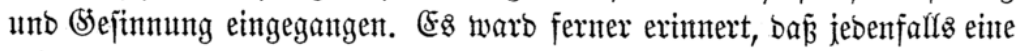

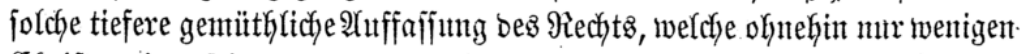

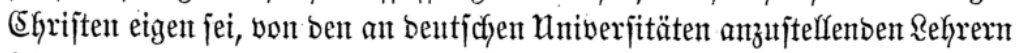
feinesiweges unumgänglich) geforbert z̆t werben pflege, währenb bie Meber= lieferung beftimmter Senntniffe und bie Schärfung unt llebung bez

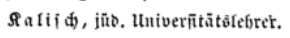




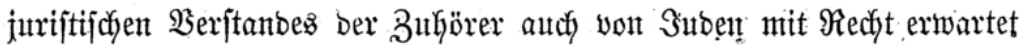

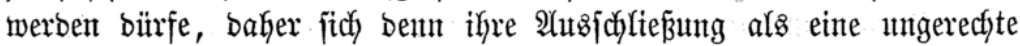

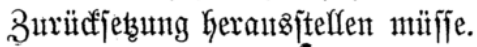

Das von einer" Stinme foban Kervorgehobene Bebenten, ob bie

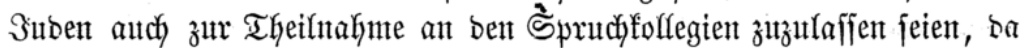

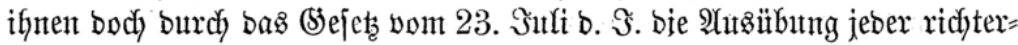

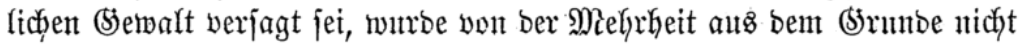
getheilt, weil bie Spruth follegien bei igree Yebiglich nach aurent gerichteten 33irfjanteit bem prentifichen Staate gegenïber num als bejonbers organi= jirte Schiebsggerichte fid barjtellent.

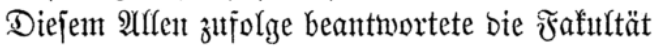

mit vier gegent eine Stinme bie britte Frage bahin: baß einer vom

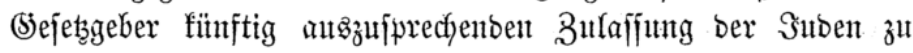

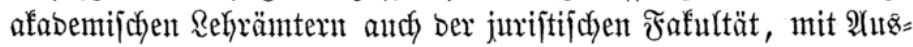
nahme bes Sirchenredytz, ein wejentlidjes $\mathfrak{B}$ ebenfen nidyt ent= gegentifeke. -

(5) reifsmald, ben 20. Nowember 1847.

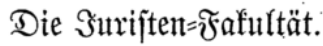
(Unter[j)riften.)

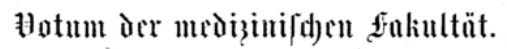

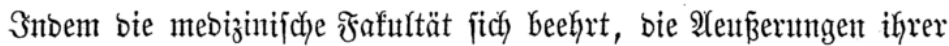
einzelnen Mitglieber über bie aufgeftelften żwei Fragen z̆ ïberreidyen,

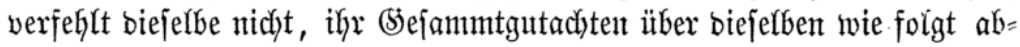
zugeben:

$3^{\text {wwei }}$ Mitglieber ber Fafultät, bie $\mathfrak{B r o f e f f o r e n ~ S d y u l t z e ~ u n t ~ B e r n o t , ~}$

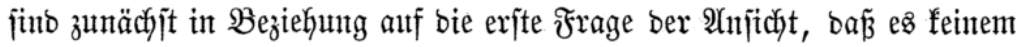

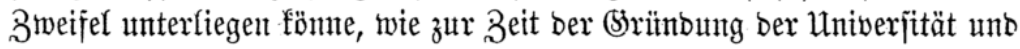
nach bem Sinme ifrer Statuten fowohl Refrer alz Stubirenbe bem chrift=

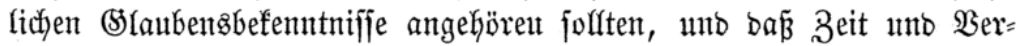

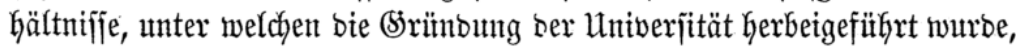

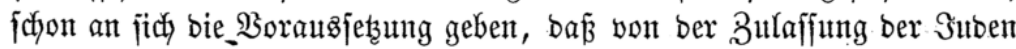

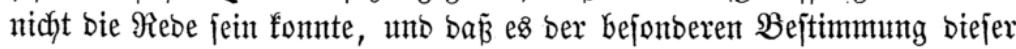

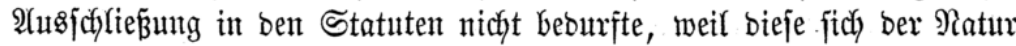

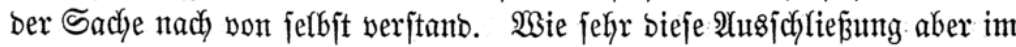
Sinne jener Zeit unt überhaupt ber Şerzöge von \$ommern gewejen ijt, geht aus Dähnert $\mathfrak{B}$ b. II. pag. 251 hervor, wo in Beziefung auf bie $\mathfrak{S}_{\mathfrak{u}}=$

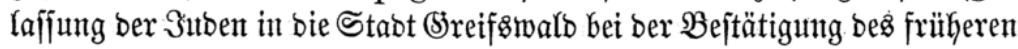
ßrivifegiums wörtlich gejagt ijt: „Repellimus etenim et fugamus perfidissimos Judaeos et irredituros judicamus." 


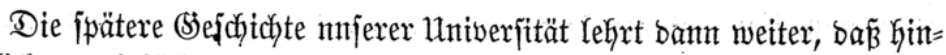

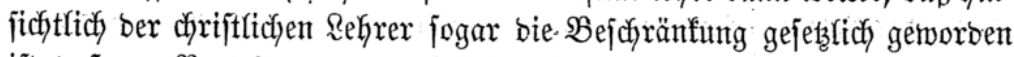

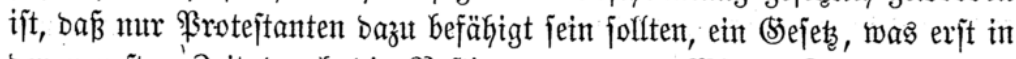
ber neutejten' Beit burch bie Beftimmungen bez $\Re$ Sienter Aongreffes auf=

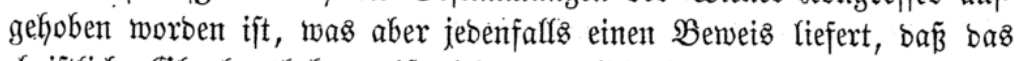

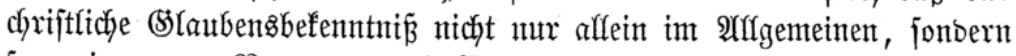
fogar in engerer Begrenzung als Erforberni $\tilde{\beta}_{\text {z }}$ ur Rehrerbefähigung erachtet worben ift.

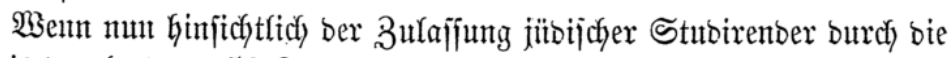

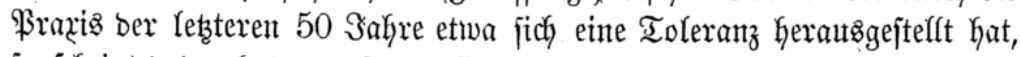

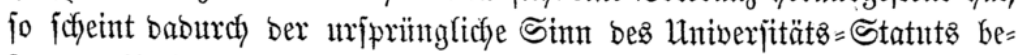

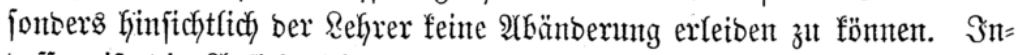
befien ift bie-Ânjidyt itber bie fortbejtehenbe Biftigfeit bes Statuts in

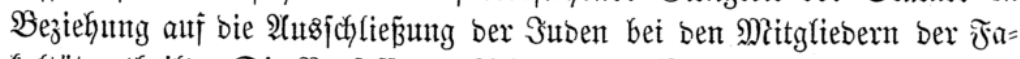
fultät getheilt. Die ßrofefjoren Sdyuthe uno Bernot fint ber Meinung,

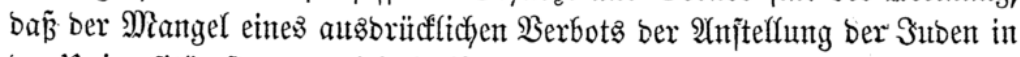

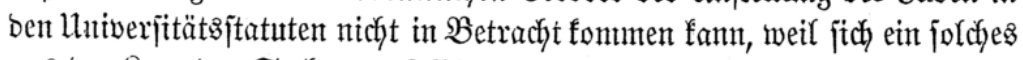
atts ber Rage ber Sache von felbjt ergab, unto bas (Siegentheil nicht füglich

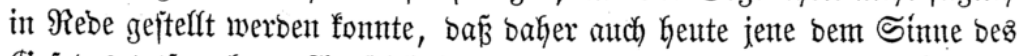

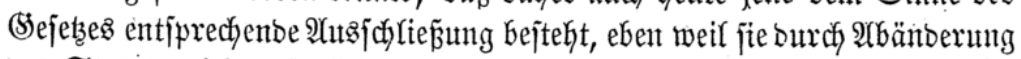
Des Statits nicht gefetzlich aufgehoben iit.

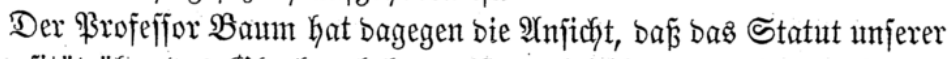

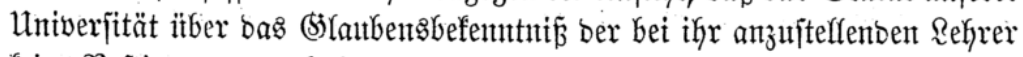

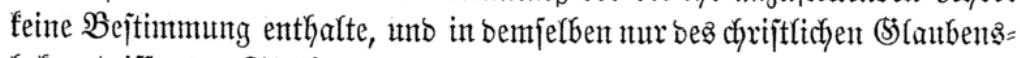
befenntnifjez ber Stutirenben gebacht werbe, biejer Theil bez Statuta aber

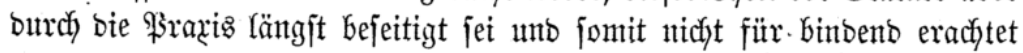

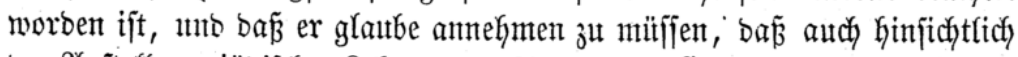

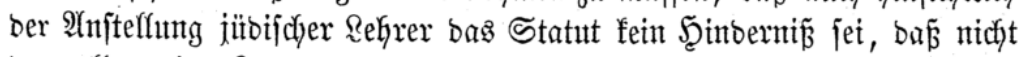
bas affgemeinte Ranbesgefets autch bei ber hiefigen Itniverjität in firaft treten fönne.

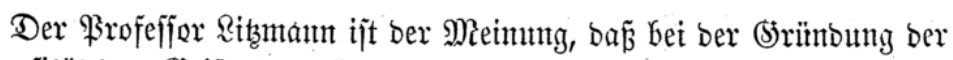

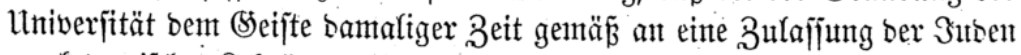

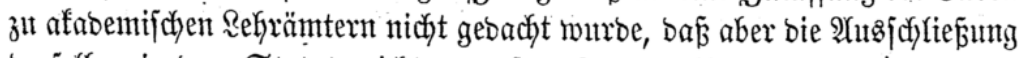
berjelben in bem Statute nicht autgegefprochen, bie Kieranf bejügliche Frage

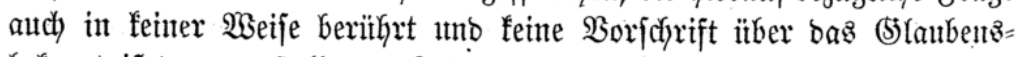

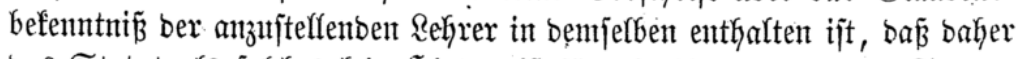

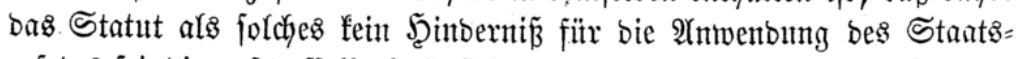

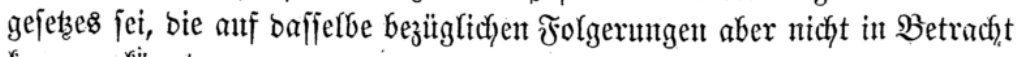
fommen fö̀nten.

Went nun Giernady bie \$rofefforen Schutbe uno Bernot affein nody 


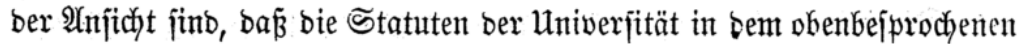

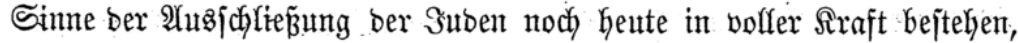

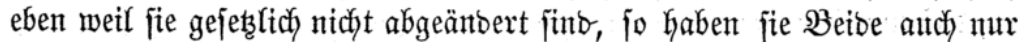
ïber bie zweite Frage, bb bie Mobififation ber won ihnen angenomment

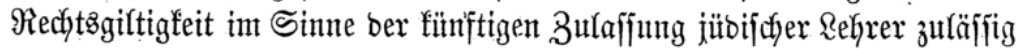

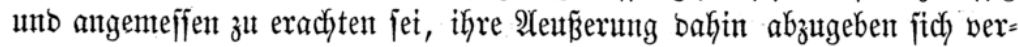
pflichtet gefiüglt:

baß bieje গ̛̃

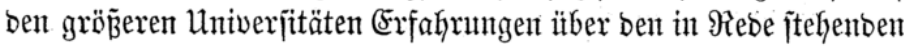
Funft gemonnen fino, für bie mebizinifłue Fafultät ber hiefigen

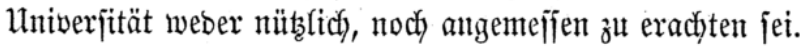

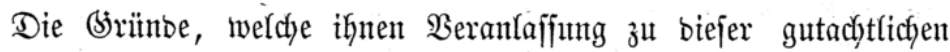
Aleurering gegebent haben, jint folgenbe:

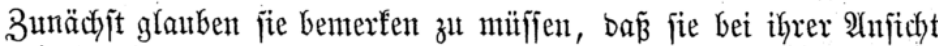

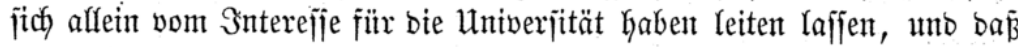

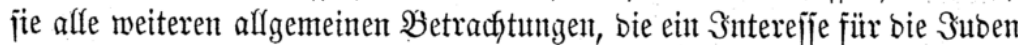
begrïnben fönnen, hier ganz glaubent übergeken z̆t muitfjent.

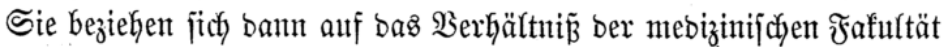
bei einer f́leinen Univerjität, bei weldyer itberhautpt mtr 4 orbentliche Fro $_{\mathrm{r}}=$ fejforen unt für jebes Fach) mur ein Refirer angejtellt ijt, unt glauben be= merfent zat müjfen, ba

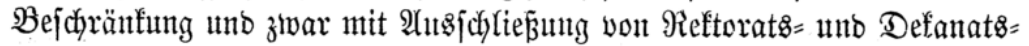
Sèrwaltung, fdyon wegen bes abzunehmenten dyriftliçen Eibes exfolgen

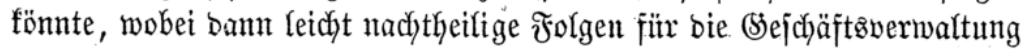
in ber Fafultät entiłtehen bürften, wem sie Şertvaltung bes Defanatz

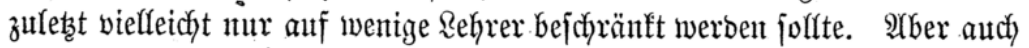

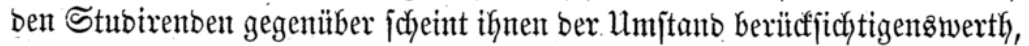

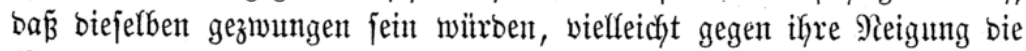
Borlejungen jübijajer Refrer zu bejutyen, eben weil biejelben nur von biejen affeịn gefalten würben. Şei ber im Alfgemeinen nod) vorwal= tenben, gegen bie Suben gerichteten Stimmung bürfte biejer Umitano wenigitens auf unjerer fleinen Univerjität nicht außzer $\mathfrak{A}(\mathfrak{d}) \mathrm{t}$ gelaffen wer= ben bïrfen.

Enblicy aber glauben jie hervorkeben zu miiffen, bå̉ Seitenz ber

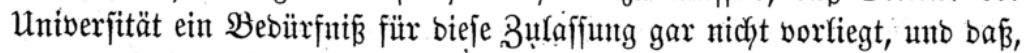

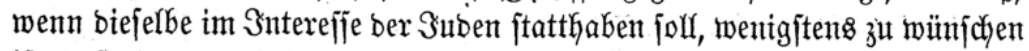

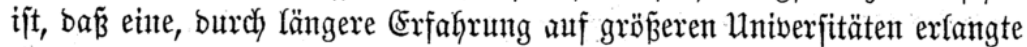

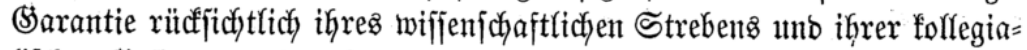

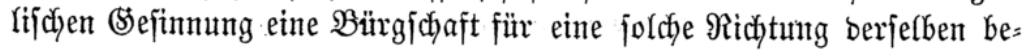


grïnbe, bie nidyt jtërento wirft, was gerabe aber bei ben fleinen Univer= fitäten am leichtejten uno jtärffíten herbortreten möchte.

(5) reifzatwalb, ben 28. Nowember 1847.

Die medizinifłche rafultuät.

Berntt, Defan. Dr. Sdulthe. Baum. Ribmant.

\section{Fotum der pljilo[ophirchen fakultät.}

Ueber bie in ber Şoken Minifterial=ßerfügung vom 28. September

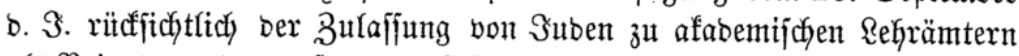

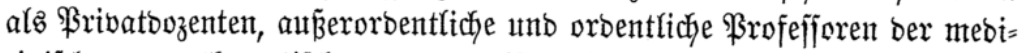
zinifchen, mathematiftyen, naturwifijenjcyaftlichen, geographifcyen uno

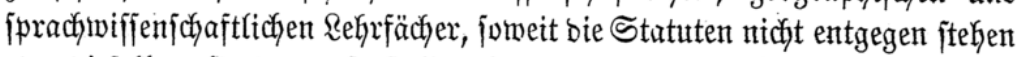
ober biejelbe gejtatten, aufgejtellten beiben Fragen hat jich bie unterzeichnete philofophifche Fafultät zu bem folgenben (s)utachtent, vereinigt.

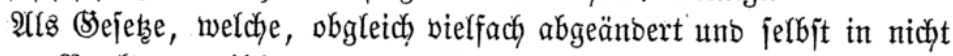
wenigen ßunften ungiltig geworben, für bie philojophifche Fafultät gegen= wärtig noch ftatutarif̧ce (siltigfeit Gaben, fönmen alfein betrachtet werben:

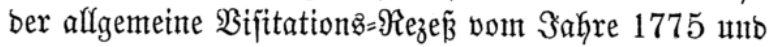

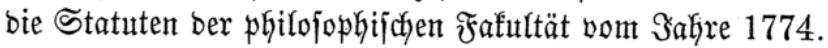

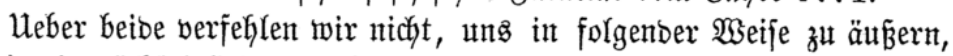

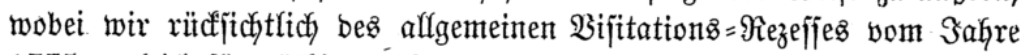
1775 zugleich für nöthig erachten, auch auf bie frühere seffyicfte unferer

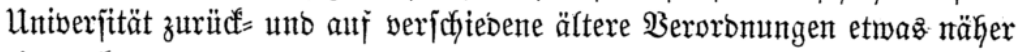
einzugehent.

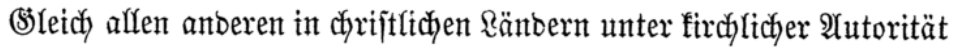
geitifteten Şodjichuten hatte audy bie unjrige bei ifhrer Entitehung ben

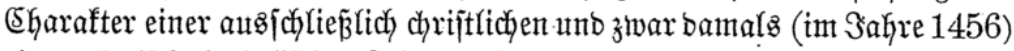
einer römijch = fatholijchen Rehranjtalt, unto es verjtanto fith in jener Beit

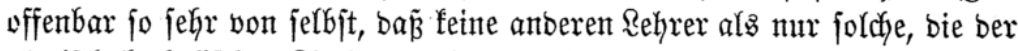

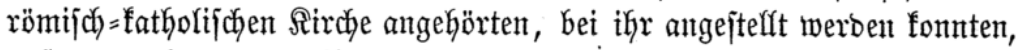

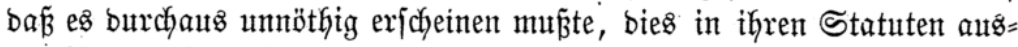
brürffich) żt bemerfen. Daher enthält audy bie Stiftungsbutfle unjerer

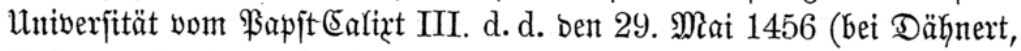

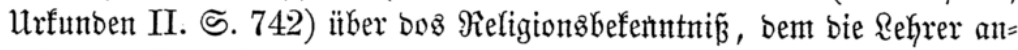

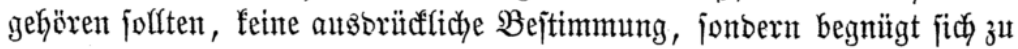
jagen, bá bie Untiverfität gefitiftet jei ad augmentum fidei orthodoxae,

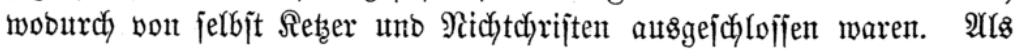

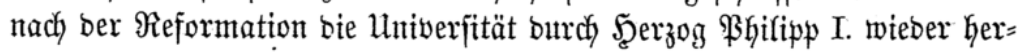
gejtellt murbe, verjtand es ficd) unter ben bamaligen Berbältnififent von

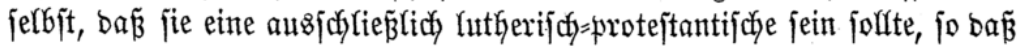




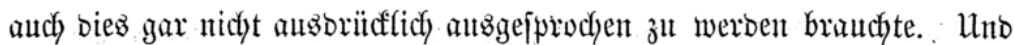
in ber That fintet jidy autch Dariiber Sidyta, weber in ben Statuten vom

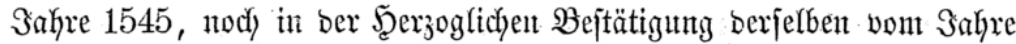
1547 (bei Däh̆tert, Urfuntoen II. S. 770 unb 807); "unr in eiter Ultumbe

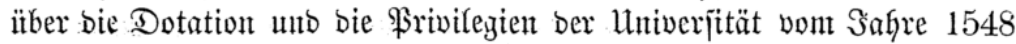

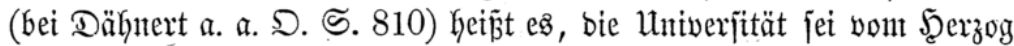
氶 filipp I. ad testificationem gratae mentis pro laetissima revelatione sacrosanti Evangelii, cujus lux cum primordio imperii ipsius felici auspicio luculentissime affulsit, ad omnipotentis Dei gloriam et ecclesiae ac rei publicae salutem botirt roorben, fowie fpäter=

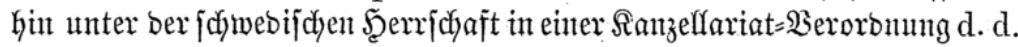

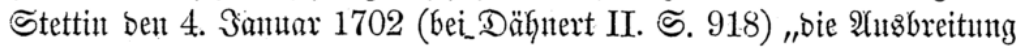
bes Gellen evangelifdyen Ridytes" als bie vornehmliche B̧ejtimmung ber

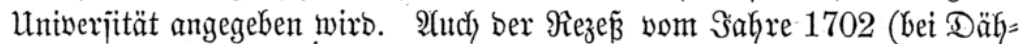
nert a. a. ‥ ऽ. 924) erwähnt int $§ 4$, wo er von ber @ua alififiation ber anzujtelfenten Rehrer hanbelt, ber Sonfeffiton nicht, offentbar, weil ez ałs

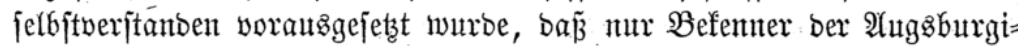

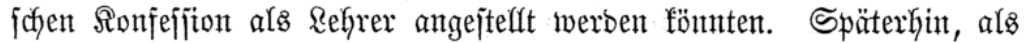

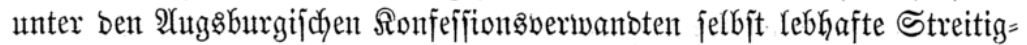
feiten entítanden waren, in welchen fich ein fiejiger \$rofeffor ber I Keologie,

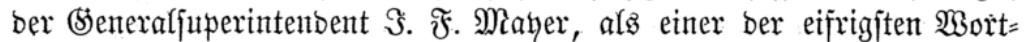
fïfrer ber bantals' jidy für allein rechtgläubig haltenben \$artei hervor=

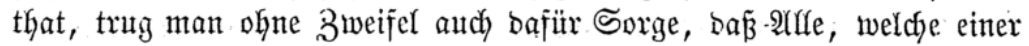

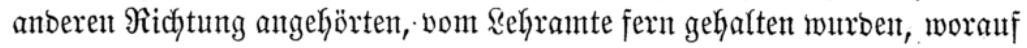

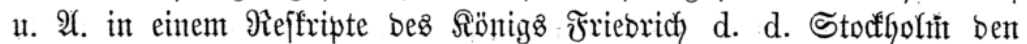

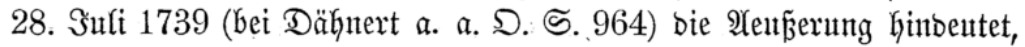

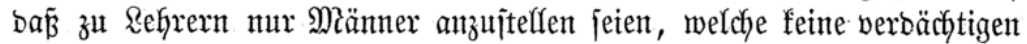

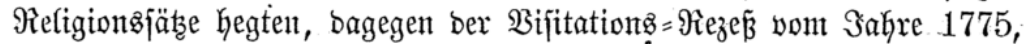

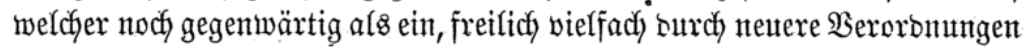

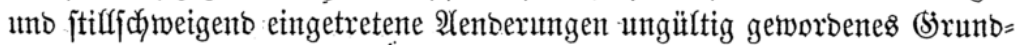
gejes fïr unjere Untiverfitüt gilt, auf welches jeber neut angejtellte \$rofeffor verpflicytet wiro, verlangt nichts meiter als:

rechtichaffene, vernünftige, won $\mathfrak{B o r u r t h e i l e n ~ f r e i e ~ u n d ~ i n ~ g u t e m ~}$

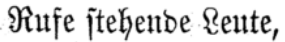

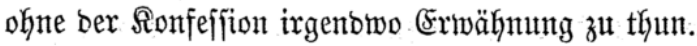

Wå nun ferner bie gegentwärtig affein nod) mażgebenben Statuten

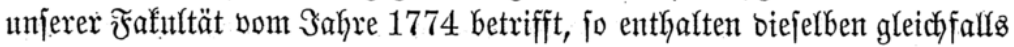

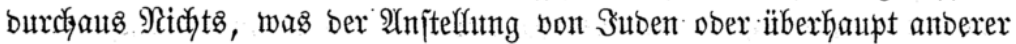

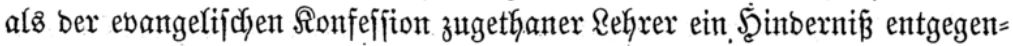
fteflen fönnte. 
Tit. II. § 10 uno $\$ 16$ fteflt für Errangung ber facultas legendi et disputandi feine aubere Bebingung als ben gradum philosophicum.

Tit. II. § 17 fdureibt in Bezug auf bie perjënlidfe @ualififiation zux

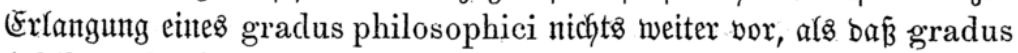
(philosophici) publici non nisi dignis et ad eos capessendos idoneis fonferint werben follen unb bürfen.

Tit. III. § 2.jeţt als \$rumbbebingung ber Errangung einer orbent=

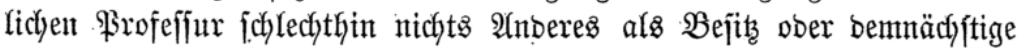
İneignuty bes gradus magistri.

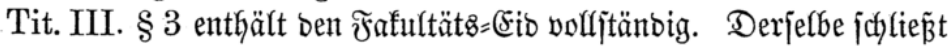

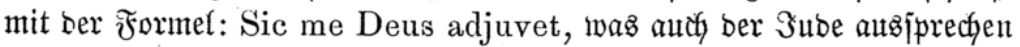
fann unt barf, nicht etwa mit ber jonjt wohl bei EGhriften gemöhnlichen Formel: Sic me Deus adjuvet ejusque sacrosanctum Evangelium.

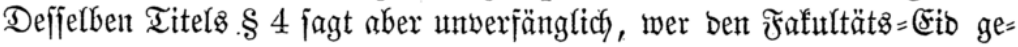
leiftet habe, jei Mitglieb ber Fafultät.

Tit. IV. § 1 jagt baffelbe, was Tit. II. § 10 enthält, und § 2 madyt

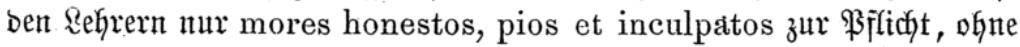

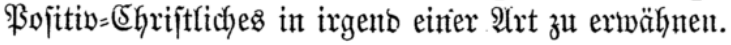

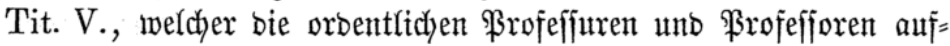
zählt uno ebenio erjtere dyarafterifirt wie lebztere injtruirt, enthält eben jo

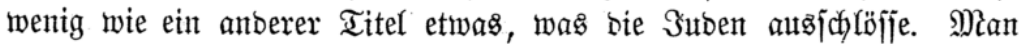
wiro fictherlich ben $\$ 12$, weldjer voriffreibt, diebus festis, in quibus sacra tractari debent, lectiones, disputationes et declamationes philosophicae omnes quiescant, nicft gegen bie Bulajiung ber Suben anmentent fömen, ba er in ber That fein Şinbernin if́t.

Tit. VII. § 1 unt 2 bezeidfnet biejenigen Rategorien von \$erjonen, welchen bie 3ulajiung zu bem gradus zu verjagen jei; Sitben find nirgends

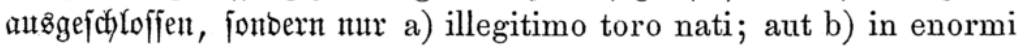
excessu vel gravi facinore deprehensi; c) quive albo hujus universitatis inscripti non sunt; d) vel etiam praeceptoribus suis non satisfecerunt; e) vel denique in disciplinis philosophicis suum non habent profectum.

Enblich ift in ben Statuten nirgends ein Doftor= (Fib geforbert ober autch) nux erwähnt.

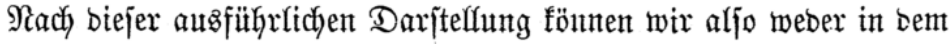

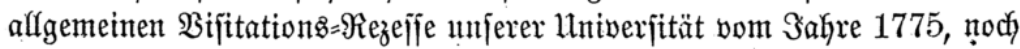
in' ben Statuten unferer Fafultät vom Эorare 1774, welche bie einzigen

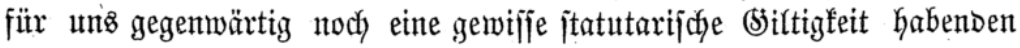

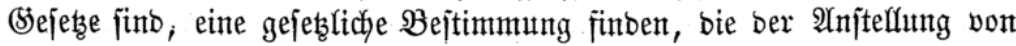

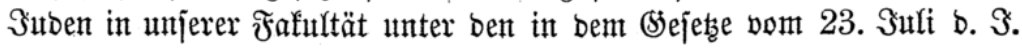




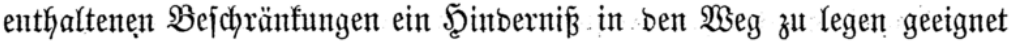
twäre, mit welcher (Exflärung wir zugleich bie erjte ber beiben aufgejtefllten Fragen gentïgent beantwortet zut haben glauben.

Was num abex ferner bie zweite ber beiben aufgejteflten Fragen be= trifft, fo fällt biefelbe für bie hiejige philojophijche Frafultät von jelbjt meg, ba nach bem Dbigen bie in ifr gemachte $\mathfrak{B o r a u s j e t z u n g ~ a u f ~ u n a ~ f e i n e ~} 2 \mathfrak{n}=$ wenbung fintet.

(5)eifinald, ben 31. Nowember 1847.

Die philojophifche Fafulttät.

(unteridyriften.).

Separnt-yotum von fiofeflor saum/tark.

Die zur Begutachtung vorliegente Frage ift nach iłren beiben Seiten folgenbe:

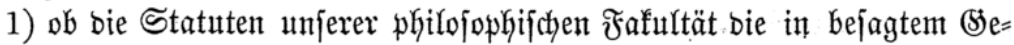

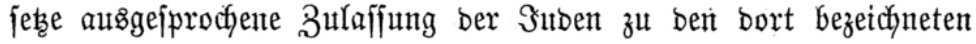

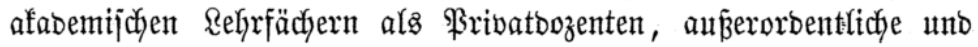
orbentliçye Profefjoren gejtatten ober nicht, unto

2) ob, wenn bie Statuten bieje 3ulajpung nidft gejtatten, eine Mlobifitation berfelben für zuläjifig unb angemefijen zu erachten fei.

Bei Beantwortung biefer Fragen mich rebiglidy an bie Statuten unjrer Univerjität v. $\Im .1774$ haltend, weldje, objchon veraltet, body ber

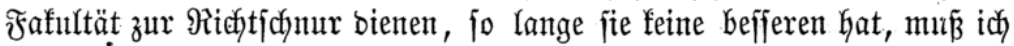
mich in $\mathfrak{B}$ ezug auf bie Frage unter 1, ofne ben geringiten Biveifel bejałent

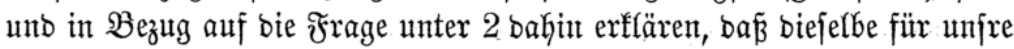
philojophifiche Fafultät aljo ganz Ginwegfallen mus. Meine Enticheioungas= grünbe fint folgende:

1. Tit. II $\S \S 10$ uno 16 unjerer Statuten vom $\Im .1774$ ftellt für ⿷r: $=$ langung ber facultas legendi et disputandi feine anbre $\mathfrak{B}$ ebingung, al\$ ben gradum philosophicum.

2. Tit. I. § 17 jafreibt in Bezıtg auf bie perjönliche Dualififation

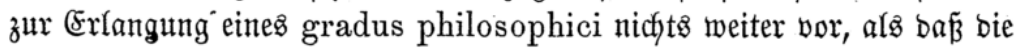
gradus publici non nisi dignis et ad eos capessendos idoneis fon= ferirt werben jollen und bürfen.

3. Tit. III § 2 jeţt alz \$runtbebingung ber (Ertangung.einer orbent=

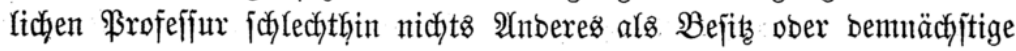
İneignung bes gradus magistri.

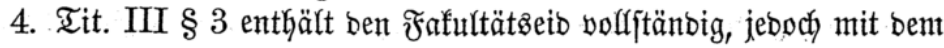

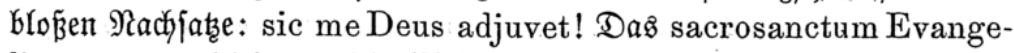

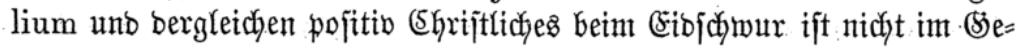


ringiten erwähñt. Sic me Deus adjuvet fann unb muß audy ber Sube

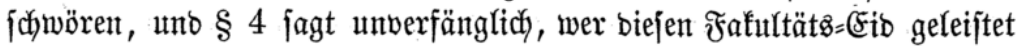
habe, jei Mitglieo ber Fafulttät.

5. Tit. IV § 1 jagt bajfelbe, was ber Tit. II $\S 10$ enthält, unt $\S 2$ madft ben Rehreern mur mores bonestos, pios et inculpatos, ohne pofi=

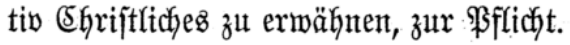

6. Tit. $V$, weldjer bie orbentlidjen \$rofeffuren und \$rofejforen auf= zählt und ebenjo erjtere charafterifint wie lebztere injtruirt, enţält ebenjo

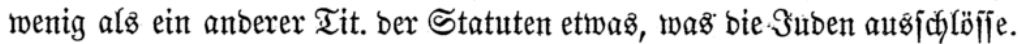
Man wirb jicherlicidy ben $\S 12$, ber ja vorjareibt: diebus festis in quibus sacra tractari debent, lectiones, disputationes et declamationes philosophicae omnes quiescant, nicht gegen bie 3uläffigfeit ber $3 u b e n$ anwenten fönnen ober mögen, ba er in ber That fein Şinberni

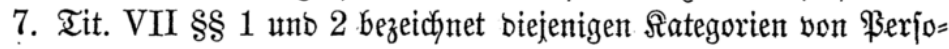

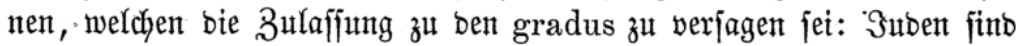
nirgentos ausgef enormi exeessu vel gravi facinori deprehensi, c) quive albo hujus universitatis inscripti non sunt, d) vel etiam praeceptoribus suis non satisfecerunt, e) vel denique in disciplinis philosophicis suum non habent profectum. Enblich ijt in ben Statuten nirgenb ein Doftor= (Fib geforbert ober jelbjt aud nur erwähnt. Soweit nach) ben Statuten vom Sabre 1774.

Эm Эahre. 1836 wurbe ein Entwurf von neiten Statuten ausgearbei= tet und zur $\mathfrak{B}$ ejtätigung vorgelegt, aber bis jeţt nicht bejtätigt, wiemolil aucd) nicdyt zurürofgetwiejen.

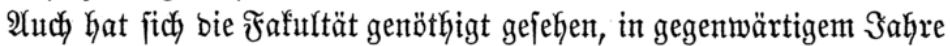

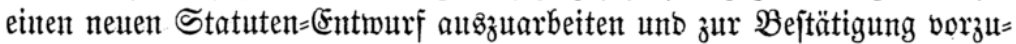
legen. Affein in feinem biefer beiben Entrwïrfe ijt etwas enthalten, was

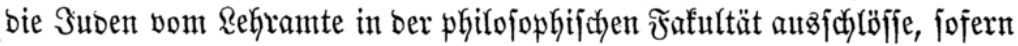
jie nur wie jeber (5hrift praestanda im wiffenjchaftlichen Sinne prae-

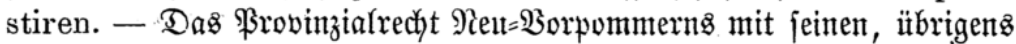
ferbjt jehr wentg zureichenben, bie Stben in Erwerbung von Srunbbejits

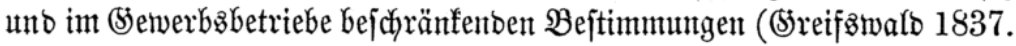

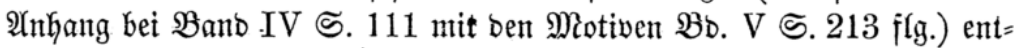

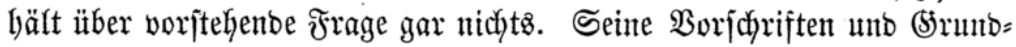

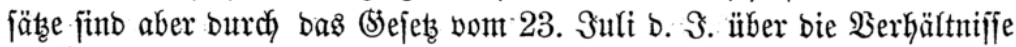
ber Guben § IV flg. aufgehoben, foweit es ben \$etwerbabetrieb ut. f. w.

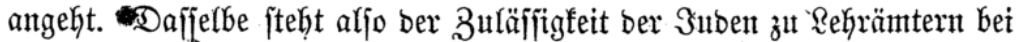

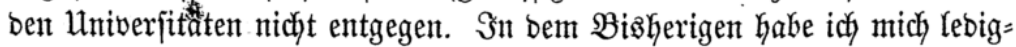

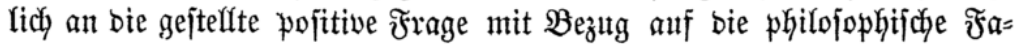


fultät gefaltent. Bon bem Refrante in ben Staati= uno Sameralwifien=

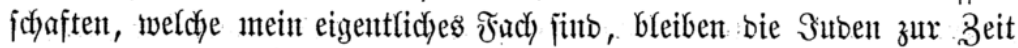

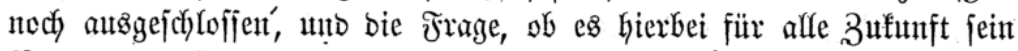

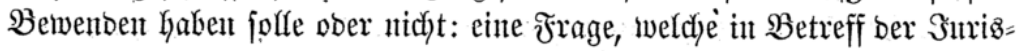

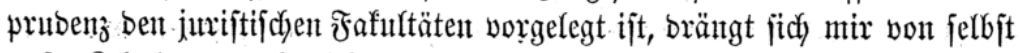
auf. Sch fant auth nicht umfiut, midh, uach reifficher lleberlegung ber Srrünbe für mb miber bie Emanzipation ber Sttben in biejer ß̧eziefung,

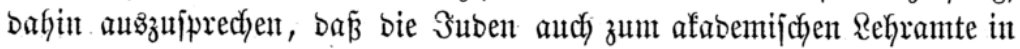

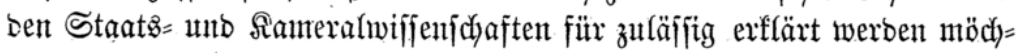

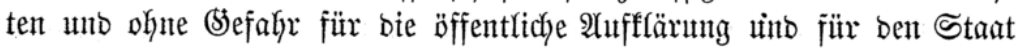

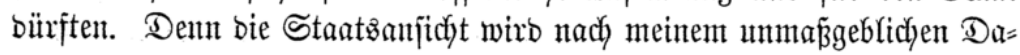
fürbalten baburch im Bolfe utb bei ben Staatsbeamten ifyren dyriftlichen

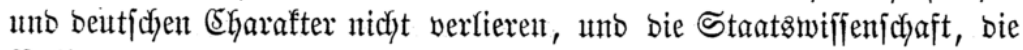

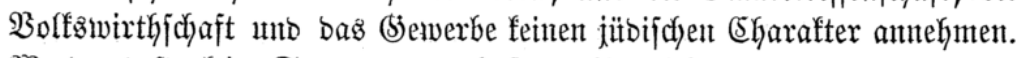
23erben bejtufftive Tenbenzen aud fernerhin nidyt ganz verfdywinben, jo

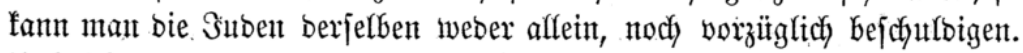
Unhaltbare, ungejdyichtfiche uno irrationeffe Staatstheorien eines bizarren, ftörrifchen, Gefrittelnben Subenthums jteflen jich gerabe in Rehroortrage

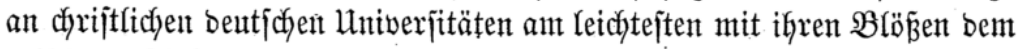

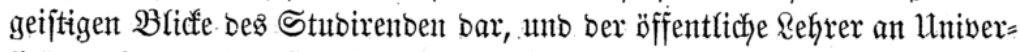
fitäten fann ohne ફ̧altbarfeit uno (Srrünolichfeit jeiner Rehren auf bie

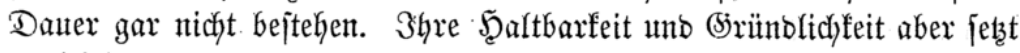

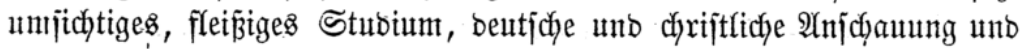
bauternoe 'Anerfenmung ber 3uförer von biejen Stanbpunften boraus.

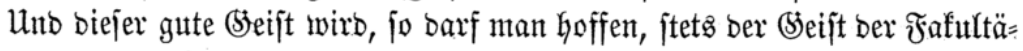

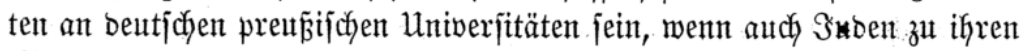

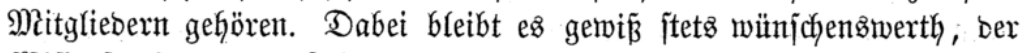
Wifjenjichaft und bem Rehramte eine möglichjt freie Ronturrenz ber geiftigen Siäfte unto Talente zu jichern.

(5) loena, ben 22 . Dftober 1847.

(E. Baumttarf.

\section{Gotum des Felitor und Sentits.}

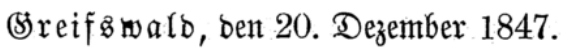

Em. Excellenz

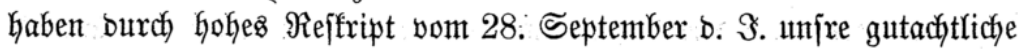
IXeurerung barüber zu verlangen geruht:

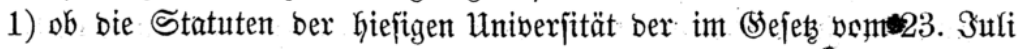

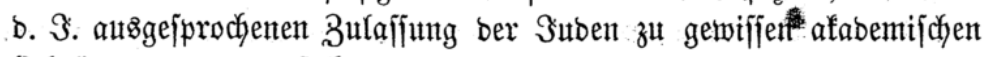
\{ehrämtern entgegenjtełen, unt 
2) ob, went bie Statuten bie 3ultafjung nicft gejtatten, eine Mlobifitation - Derjelben fïr zultäffig uno angemefien zu eracten fei.

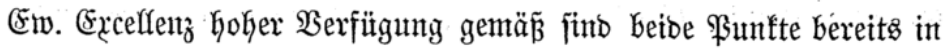
bent einzelnen Fafulttäten Biegenftand reiffiçer (Erörterung getworbent, uno wir beehren uns, bie $\mathfrak{B}$ ota ber einzelnen Mitglieber ber Fafultüten, forwe

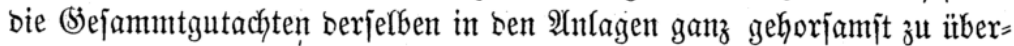
reichen. ' $\mathfrak{A} u f$ (5rundiage biejer $\mathfrak{B e r h a n b l u n g e n ~ h a t ~ m u t ~ a u d ~ b e r ~ a f a b e m i = ~}$ iche Senat bie Sadje zum (Segenftant feiner Berathung gemadjt, unto

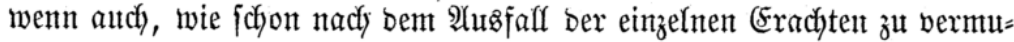
theit war, feine wolfe $\mathfrak{H}$ ebereinjtimmung ber $\mathfrak{A}$ njichten zut erzielen gemejen ijt, fo hat jich boch eine Mehrheit ber Stimmen zu bem bejd)luz vereinigt:

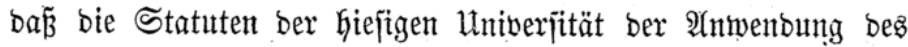

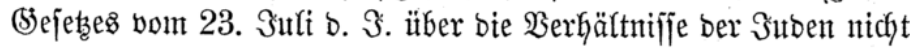
entgegentitełent.

(Es fommt Kier vor Affem ber Umitant in Betracht, baj bie Statu= ten, worunter wir alle bie Ulniverjität betreffenden geję̧liçen $\mathfrak{A}$ norbmungen

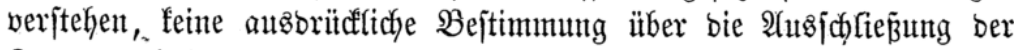
Suben enthaltent. Dagegen wirb nun freilich, in Hebereinjtimnung mit bem (Exadyten ber philojophijchen Fafultät, jowie eines Mitgliebes ber jurififichen und zweier Mitglieber ber medizinifđhen ₹afultät, Kerborgeboben,

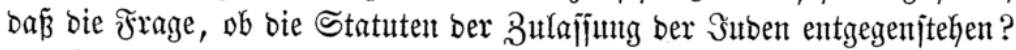

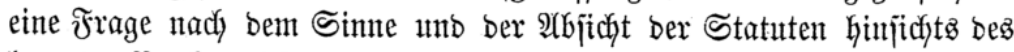

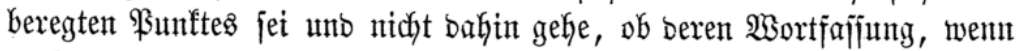
audf) gegen beren Simu, möglicherweife bem (sejetze vom 23. Suli jid affommobiren Kafje? Jene Arbjicht jei aus ber (Sejammtjajiung ser Sta=

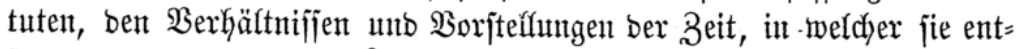

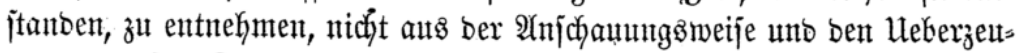
gungen unjrer Tage. - Zu jener Zeit mun hätten bie Ranbesgejeţe bie Suben vom Ranbe, bejonbere \$rivilegien ber Stabt Breifgtwald jie von

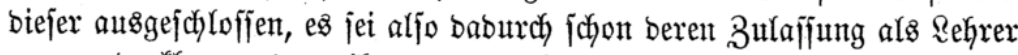

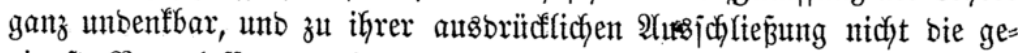
ringite $\mathfrak{B e r a n l a f f u n g ~ v o r h a n t e n ~ g e w e j e n , ~ o b w o h l ~ m a n ~ f i e , ~ w i e ~ v o m ~ R a n t b e ~}$ utto von ber Stabt, fo aud nothwendig von ber Univerjitüt fern halten

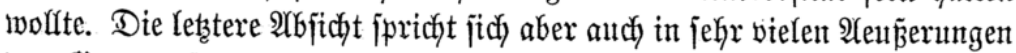

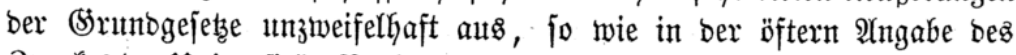
3 wecf́es ber Univerfität, Berbreitung ber „fides catholica“, „quo gloria individuae trinitatis propagetur", ,ad ecclesiae utilitatem", , ut sit 
seminarium ecclesiae", Zwedfe, beren F̈̈rberung man bem jübijdyen

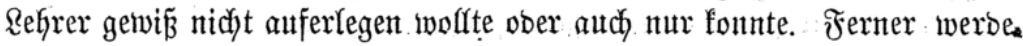
bie Untwerjität bezeidynet alz ein corpus ecclesiasticum, ben fämmtliçen unb einzelnen Refrern jura clericorum ertheilt, von ifnen jtrenge $\Re i r d$ = lichfeit ant ein Fejthalten an ber augustana confessio geforbert, audf verlangt, bã $\tilde{\beta}$ alfe Scholastici aliquid studii ponant in verbo divino et summa doctrinae christianae, was affes nur unter $\mathfrak{B o r a u s f e t ̧ u n g ~}$

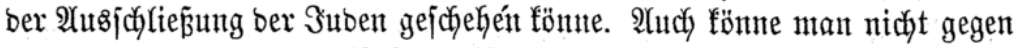
ben, von bem geforberten $B$ efenutnif ber augustana confessio hergenom= menten Bemeis einwenton: barnach mütiten auch bie Satholifen ausige= \{d\}lojfen bleiben, bie bod, jeţt zugelafjen. würben, benn ber Reţteren

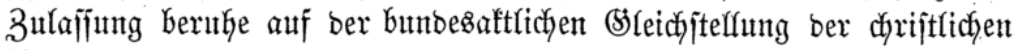

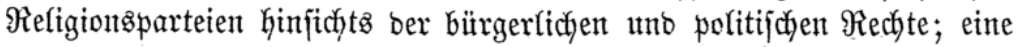

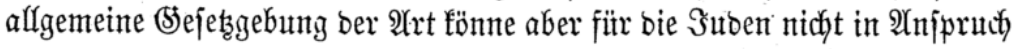
genommen werben.

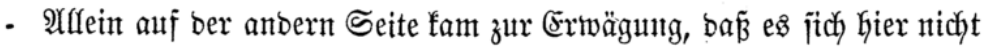

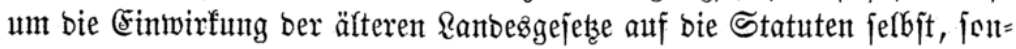

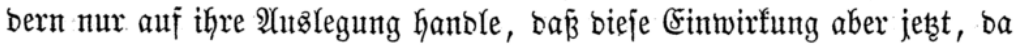
bie alfgemeine \$sejęzgebung veränbert worben, ifre Bebeutung verloren

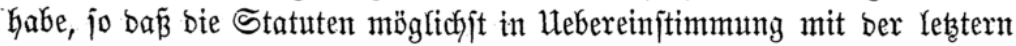

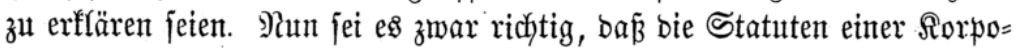

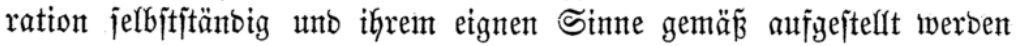
müijent, unb $b a \tilde{\beta}$ mant biejem, wenn es jich um bie Snterpretation hanble, feinen 3 wang anthun bürfe, um ihn mit ber übrigen Bejeţgebung in હin= flang zu bringen. Afflein ez gelte fier ja nidyt eine rejtriftive Erfflärung

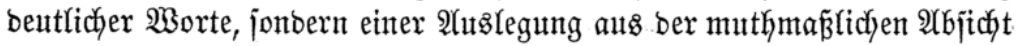

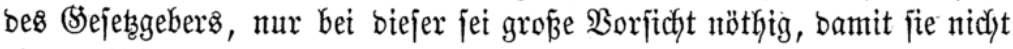
einer willfütrlicfen $\mathfrak{A}$ uffaffung auggefest werbe. In fritheren Zeiten habe man bie Univerjitätżangelegenheiten vom Stanbpunfte ber bantals vor=

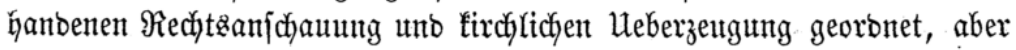
wenn man benjelben nidjt legizlatorif d) fejtgejtellt Gabe, fo jei nicht anzu=

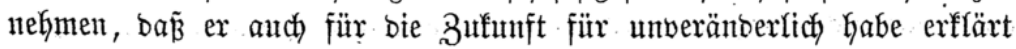
werben joffen, nur ben legislativen Fortjdyritt und ber jtiffen Eintwirfung

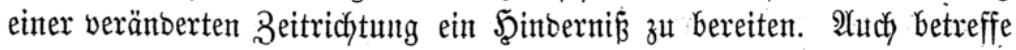

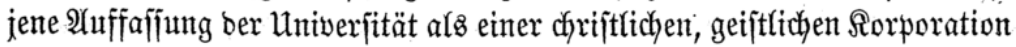

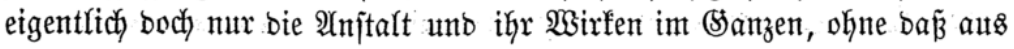
biejem rieber auf bie $\mathfrak{A n f o r b e r u n g e n ,}$, weldye an alfe einzelne Mitglieber unb Refrämter zu jtellen, ein Sdjlús gezogen werbent bïrfe: Der alfge=

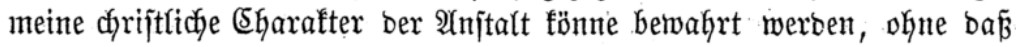


alle Rebrämter gerabe mit Shrijten bejeţt zu fein brauduten. So jei aud frïther in ben Statuten von ben Stubirenten Miandjes verlangt tworben,

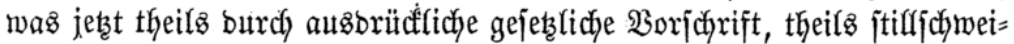
gent in 2 bnahme gefommen, unb autch ber in ben Statuten ausboüufflich fejtgejteflte proteftantifche SGarafter ber Univerjität habe in neuerer Beit nicht mełhr aufredfyt exfyalten merben fönnen, ungeadytet bie Beftimmung in $\mathfrak{A}$ rt. 16 ber beutichen $\mathfrak{B}$ unbesalfte, welcher nur ein allgemeines politi=

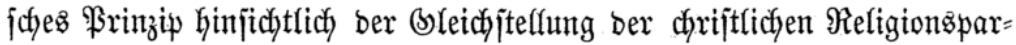
teien ausfprectye, auf bie bejonberen Berhältnijןe einzelner Sorporationen nidyt antwentbar erjacheine.

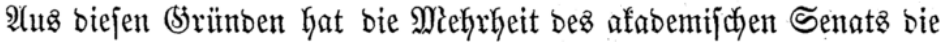

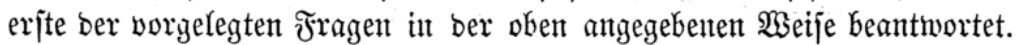
Da mun bie zweite Frage mur eventuell gejtellt worben unb butrch bie vor= gehente Exörterung ifre Erlebigung gefunten, jo haben wir uns nicht

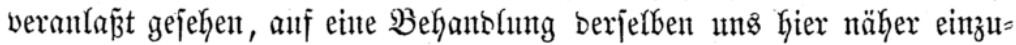

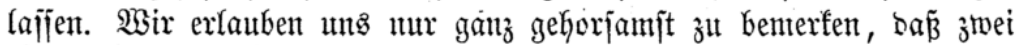
Mitglieber ber theologifdjen unto ein Mitglieb ber jurijtijcyen ₹afultät,

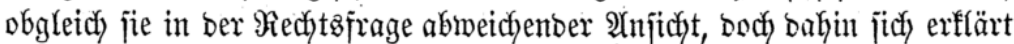

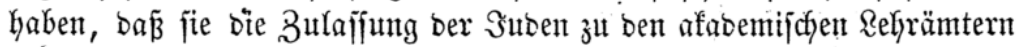

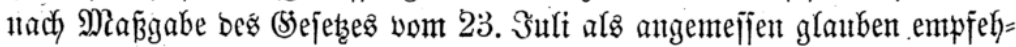

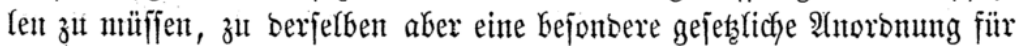
nötfig Galtent.

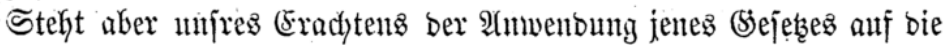
Giefige Univerjität redytlich nidyts entgegen, jo jïhlen wir unz body ge=

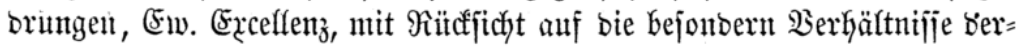
felben in ber hier behanbelten Frage, eintge ganz geborjamjte Bemerfungen

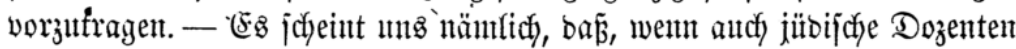

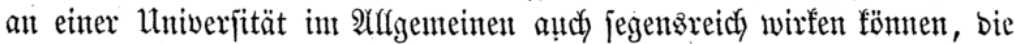
Zahl berjelben boch immer nur eine verhältniphnäpig geringe jein barf,

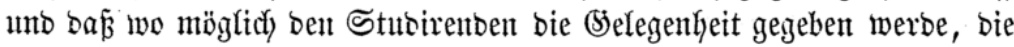

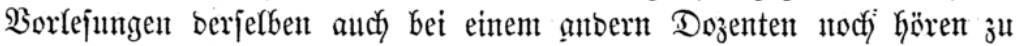

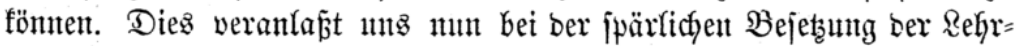
ämter an hiejiger Mniverjität zu ber ganz gehorjamjten Bitte, baß̃ Erw.

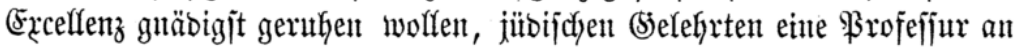
berjelben nur ans?nahmsiweife uno mur bum, wenn eine joldye in bemjelben Fach, Gereits von cinem Ehrijten werjehent wirb, ïbertragen ju woflen.

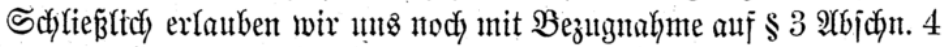

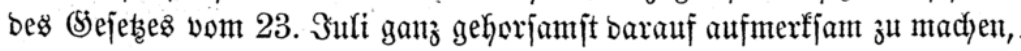

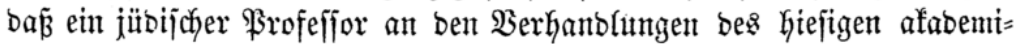

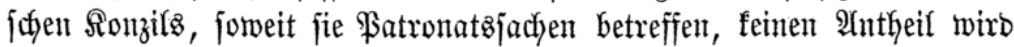


neł̧men fömen, obgleich ex int âffgemeinen von bemjelben nicht att:ge= juslojijen tworben ${ }^{1}$ )

Reftor unb Seniat hiefiger Univerjität.

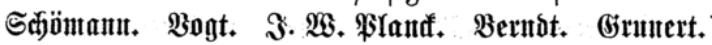

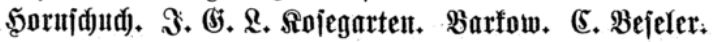
Baum.

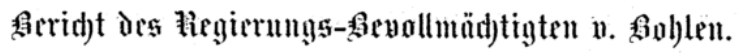

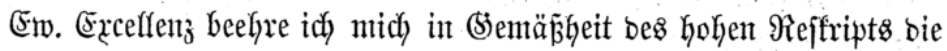
geforberten $\mathfrak{S o t a}$ ganz gehorjamjt borzultegen.

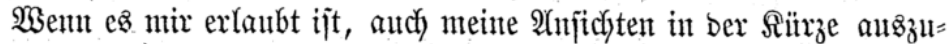
iprectyen, fo bürite ez

ad 1 feinem 3 weifel unterliegen, bå̉, wenn bie in bem $\$ 2$ Iit. I

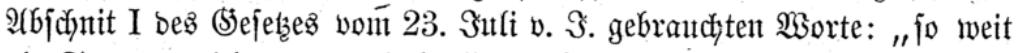
Die Statuten nidyt entrgegenjteken", beñ Sinu Kaben:

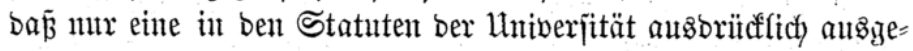

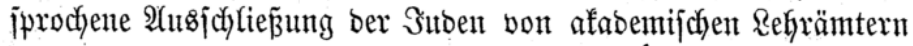
Darunter verjtanten ift,

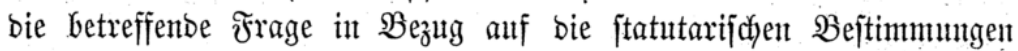

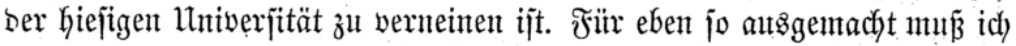
ez halten,

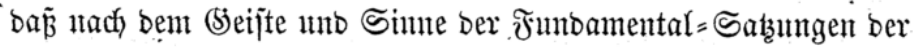

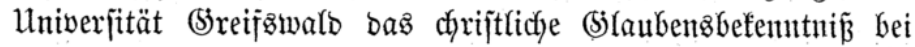

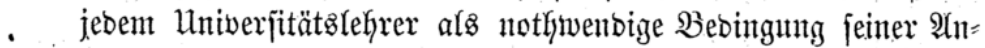

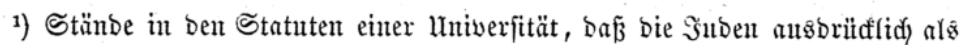

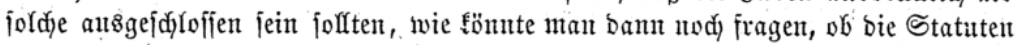
Der $\mathfrak{A}$ utfelfung ber Sitben entgegenftełen? Der Simn biefer Frage fam aljo nur fein,

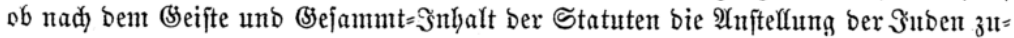

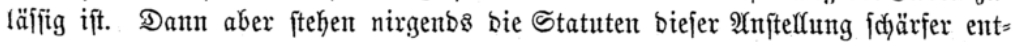

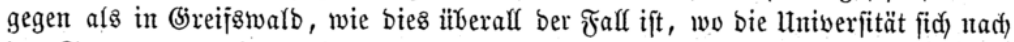
Den Statuten als eine d)riftlidje ober fonfejitonell d)riftlidje ergiebt. Der djriftlidje

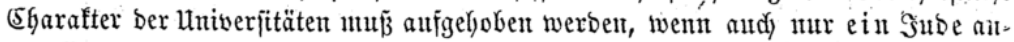

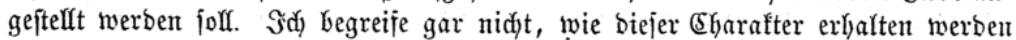

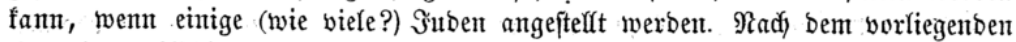

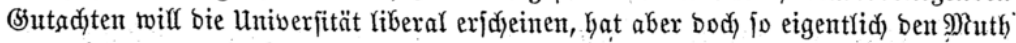

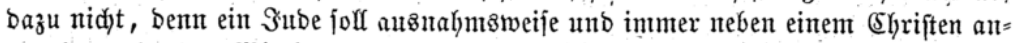

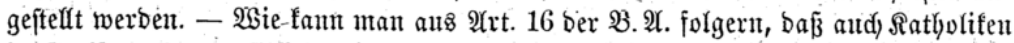

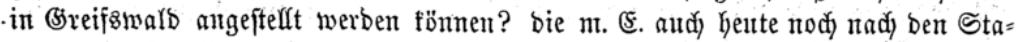
tuten ausigeid) Ioffen find.

Den 14. Эamuar 1848.

Anmerfintg in ben Âften. 
ftellung vorgejdyrieben ift, unb eben baburch bie Suben ausgese jubloffen jinto.

Solfen alfo fünftig bie Subent audf hier in ben in bem gebacfiten

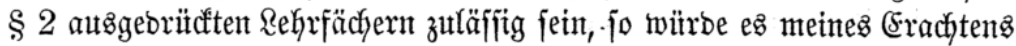
biejerhalb jebenfalls einer ausorïaffichen gejeşlichen Sanftion bebürjen, ba bie Frage, ob bie hiefigen Statuten ifnen entgegenftehen, minbejtens

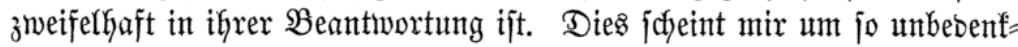

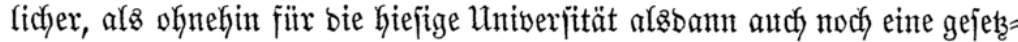
liçje $\mathfrak{B}$ ejtimmung bafin nöthig wirb,

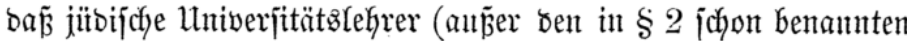
Untiverfitäts = 2 (emtern, beren jiẻ nidjt fähig jein follen) autch von

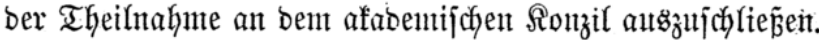

Die Motfinenbigfeit einer foldhen Beftimmung geft baraus fervor,

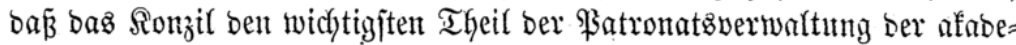

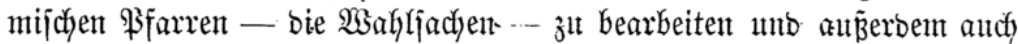
bas gejanmte Rehrwejen ber Univerjität jul beaufjichtigen hat.

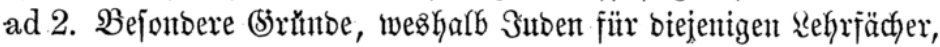
in benen jie nach bem $§ 2$ auf altbern Untwerjitäten als ReGrer zugelajjen

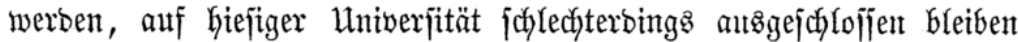

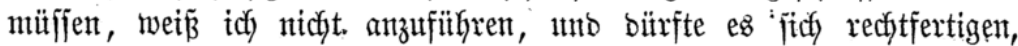

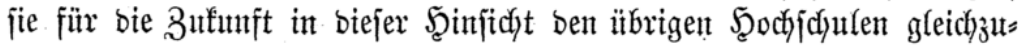
jteflent.

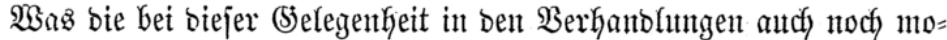
tivirte Frage betrifft:

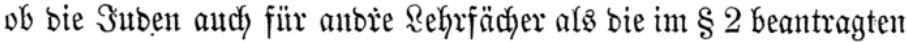
zuzulaffent feien?

jo laffe ich es bafin gejtellt fein, ob ifre Beantwortung itberall in ber

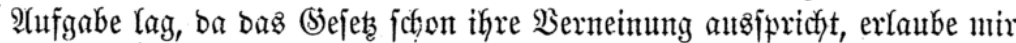

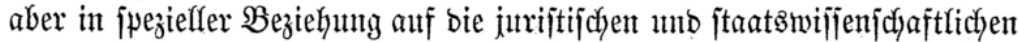

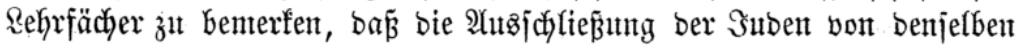

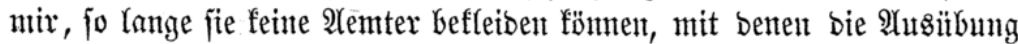
einer ridyterlichen, polizeilichen ober exefutiven \$setwalt verbunben ijt, jichon

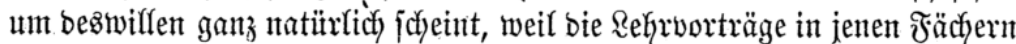
ja gerabe zut Bilbung fünftiger Beamten biejer $\mathfrak{A}$ rt bejtimnt fint. Seben= falls witrben Sttben biz bafin altch wohl immer vont ber Theilnahme an

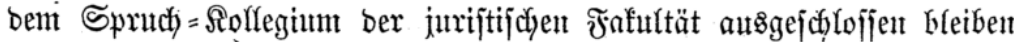
müffen.

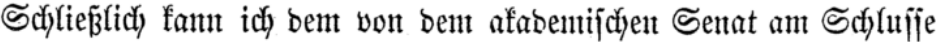

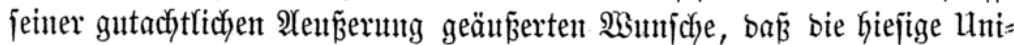

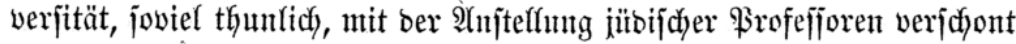


bleibent möge, nur beitreten, ba eine Mehrzzahy foldyer Rehrer Gier reidft einen anberen unb umfafjenteren Einfluß gewinnen fọnnte, alz auf grö= Beren Univerjitätent.

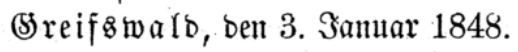

v. Boblett.

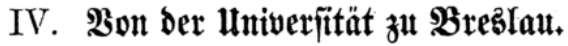

Fotum der kutboli[(d)-tbeologi (d)en fakultät.

(Fw. J̧odfwohlgeboren beehrt fich bie unterzeidgnete Fafultät alf bie beiben Fragen beß Şohen Minifiteriun:

A. $\bigcirc \mathfrak{b}$ bie bejtehentent Statuten ber Giefigen Univerjität bie in bem

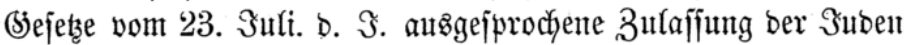
z̆l ben bezeichnteten Regrfächern gejtatten ober nicht? unt

B. wenn bie Statuten bieje Bullafjung nidjt gejtatten, ob eine Mobi=

- fiffation berjelben für zuläfjig unb angemefijent zut eracfften jet?

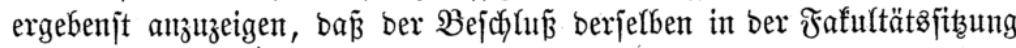
einjtimmig negatib augigefalfen ift. Die benfelben motivirenton Sirünbe wollen Scochbieferken atz ben beifolgendent fünf Spezial=(\$)utachten ent= nehmen.

Bresian, Den 19. Dezember 1847.

Die fatholifidy=theologifache Frafultät.

(Unterid)riften.)

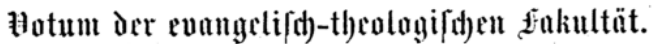

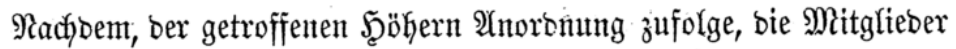
unjerer Fafultät iGre $\mathfrak{A}$ inficht über obige Fragen zutürberjt virition in einem -motivirten Botum ausgejprochen, haben biejelben fich mumehr zu einem (bejammt=\$otum vereinigt, was um fo wentiger jajwierig war, als

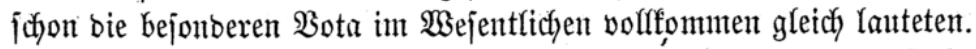

Wå bie erjte Frage betrifft, fo futto alle Mitglieber ber Fafultät

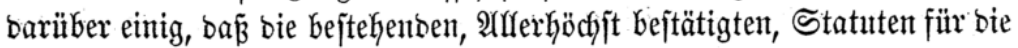
Uniberjität zu Brezlan d. d. B̧erlin, ben 21. Februar 1816, feine bie

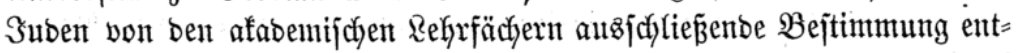
halten, unb von ben afferbings entgegenjtehenben $\mathfrak{B}$ ejtimmungen ber auf Sruno jenter Statuten von bem vorgeorbneten Minijterium ber geijtlidjent,

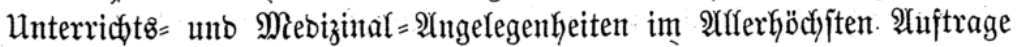
unter bem 13. September 1840 ber mebizinifchen unb phillojophifichent 


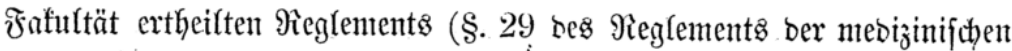

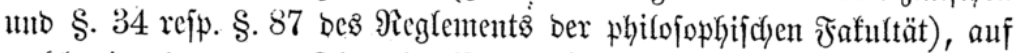
welche in einem ber Singular $=3$ sota Kingenviejen morben ift, glaubt bie Miehrzahl der Mitglieber deshalb ganz abjehen zul bürfen, weil in rem

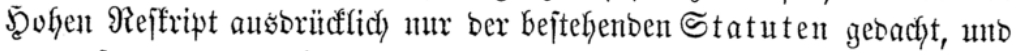

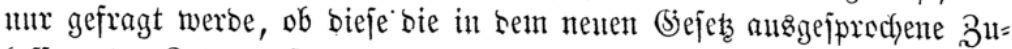
laffung ber Suben geitatten ober nidyt.

Was bie zweite Frage betrifft, ob wenn bie Statuten bie in bem (5)e

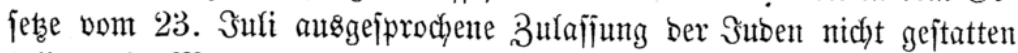
fullten, eine Modififiation berjelben für zuläfïtg unb angemejīen zu eracțten fei, fo wiro bieje Frage von jämmtlichen Mitgliebern ber unterzeichneten

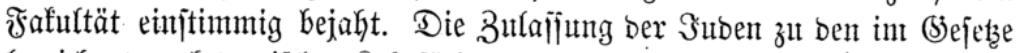
bezeichnteten afabemijchen Refyrfächern erjcheint uns angemeifen

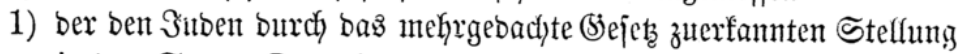
in bem Staats= Drganismus, bie jie forthin zu bem Eintritt in alle

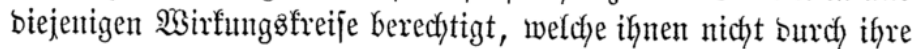

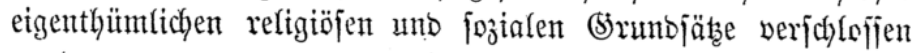
werben;

2) Dem Zwecfe ber bezeichneten afabemifchen Rehriächer, welche mijife

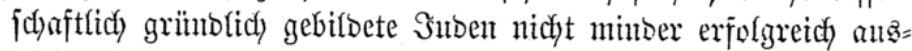

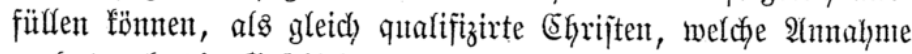

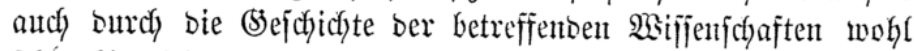
ithon finreidyent gered tiertigt niro.

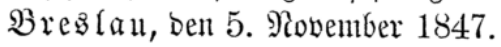

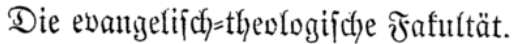
(unterid)riften.)

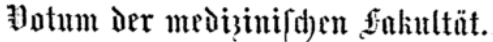

Breşau, ben 13. Deženber 1847 .

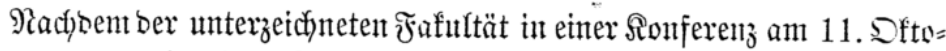

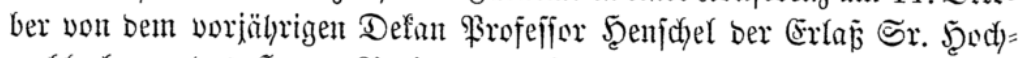

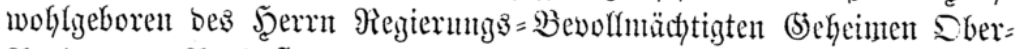

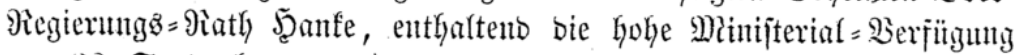
vout 28. September vorgetragen, unt ber gegennärtige mitunterjeichnete Defin am 18. Dftober fein Sotum abgegeben, haben bie vont bent holyen Minifterium zur Beantwortung vorgelegten beiben Fragen, betreffent bie

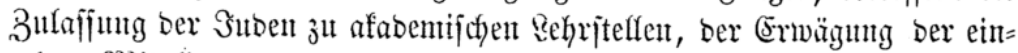

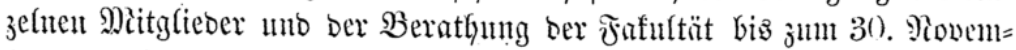

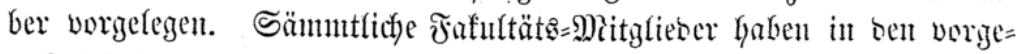




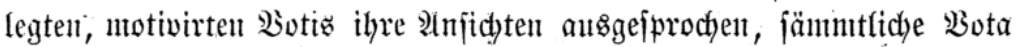
fint alsbann von ঐeuem ber Fafultät surch ben Defan, mit einem zmeiten

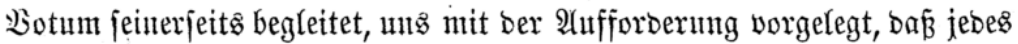

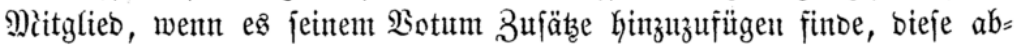
gebent möge, und unter $930 r b e h a l t$ feiner eigenen viefleicht noch abjugeben= Den Erffärungen, - went in sen etra nod zł erwartenben Bujätzen Neues zur Spradje gebrad)t werben jollte. Siene Exf(ärungen muroen von feinem Mitgliebe abgegeben. Sein Mitglieb trat von jeinem Sotum

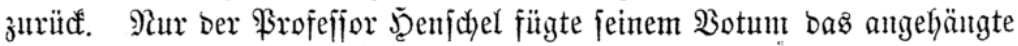
Pustscriptum bei, unt ber (Steheimrath benedict gab fpäter einzetnen Stellen feines Botunts eine etwas veränberte Fajīung, weldhe leţtere von

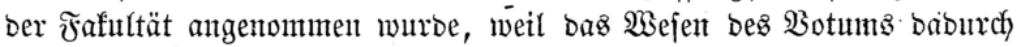
nicft veräntoert erfacjien, unt in bem (sange ber Berkanblungen nichts unffar gemad, wurbe. -

Das hohe Minifterium hat in biejer 9 nngelegenheit einen bisker

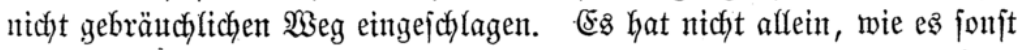

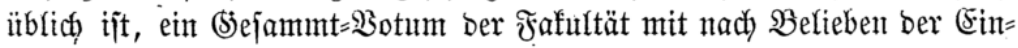

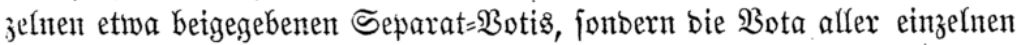

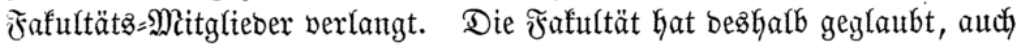
in bem Sange ihyer Serhanblungen feine Rürfe laffen zut bitrfen. Sie hat

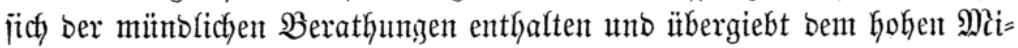

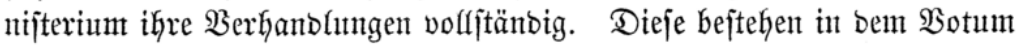

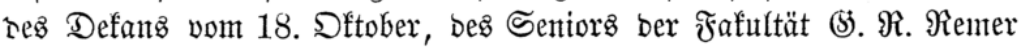

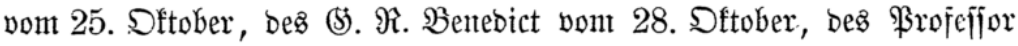
Burfinje vom 29. Oftober, bez \$rofefjor Senjafel von 1 . Yovember nebjt

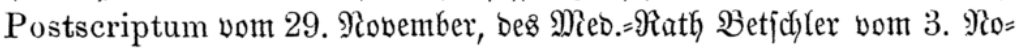

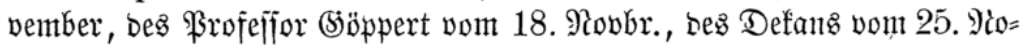

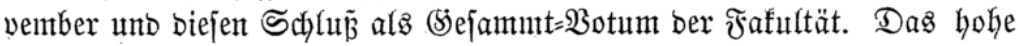
Minifterium verlangt von ber Fafultät bie Beantwortung zweier ซragen.

1) $\mathfrak{O b}$ bie bejtekenden Statuten ber Fafultät bie in bem (5jejets vom

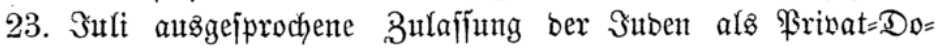
zenten, auperorbentlidje unb orbentliche Profefijoren geftatten ober nicht?

2) $\mathfrak{D}$, wenn bie Statuten bie Bulaffung nicht geítatten, eine Midobifi= fation berjelben für zuläfïig und angemeffen (nicht angenehm, wie es

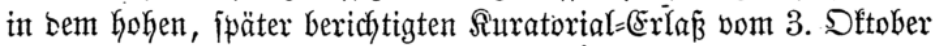
Gieß̧) zu erachten jei?

Die erite Frage fam bie Fafultät nur bahin beantworten, bå bie

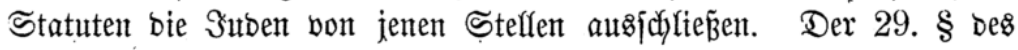
Reglementz ber Fafultät jagt: wer jict) als \$rivat=Dozent bei ber Fafultät 


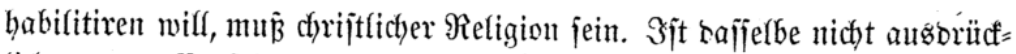

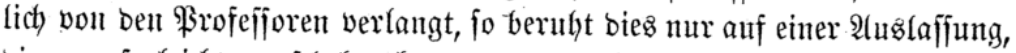

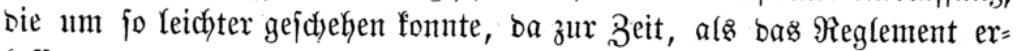
laifen wurbe (im Safhre 1840), bie Suben fdhon burd) bie allgemeinen Staatżgefeţe von ben \$rofefîuren ausigejchlofien waren. Es wäre ein

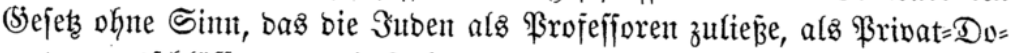

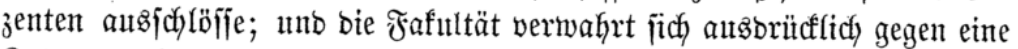

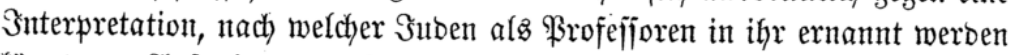

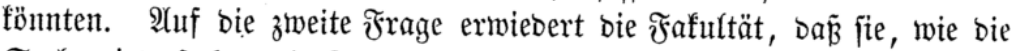
Sachen jeb̧t jtehen, bie Bullaffung ber Suten als \$riwat=Dozenten, aujer= orbentliçye und orbentliche Srofeiforen weoer für zuläfifig, noch für ange= mefīen erachtet. Sie lehnt ihre Mitmirfung zur Erreichung biejes 3 wedfes unb jebe Berantwortfichfeit für bie Folgen, bie aus ber 3ulaifung ber Suben erwachjen f̈̈mnten, ab. Sie betradjtet bie Srünbe, melche gegen bie 3ulajfung ber Suben fprecten, als itberwiegent, verweift jeboch in biejer Begiehung auf bie beiliegenben Bota, welche bas hoke Minijterium jelbjt hat fentmen unt prüfen wollent.

Die Fafultät vertraut, Dá bas hohe Minifterium mur nach eigener

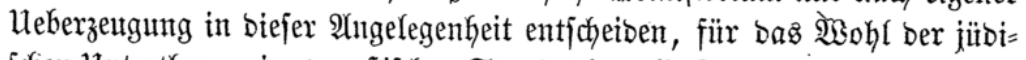
fdjen Unterthanen in prenkifchen Staate bie bolle Sorge tragen, aber anth nicht minoer es in bie reiflichjte Ueberlegung zieken wirb, inwiefern bei

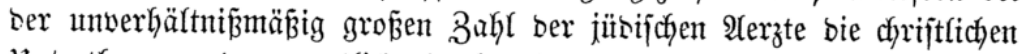

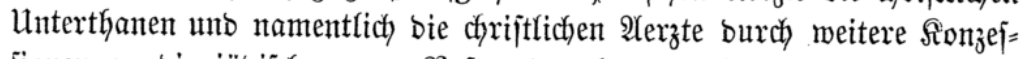

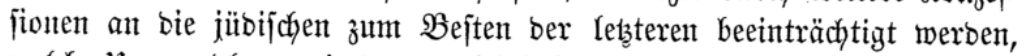
weldye Ummanblung mit ber mesiżinifchen ₹rafultäat burch 3ulaffung ber

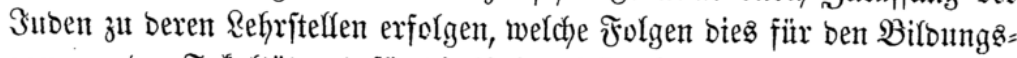
gang an ber Fafultät uno für bie Univerjität überkaupt haben fann.

Die medizinifche Frafuttät.

5. Barfow, Defan. Pienter. Furfinje. Fenider. BetifjIcr. (5öppert. Bentebitct.

\section{Sepurat-\#lotum uon \#rofellor farkom.}

Das hohe Minifterial $=$ ieffript vom 28. v. M. verlangt von ber me= sizinif̧)en Fafultät bie Beantwortung ơneier Fragen:

1) $\mathfrak{D b}$ bie beftehenton Statuten ber Fafultü̆t bie im Siejeţe vom

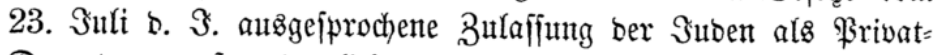
Dozenten,. auf̧erorbentliche und orbentlicje \$rofefiforen gejtatte ober nicht?

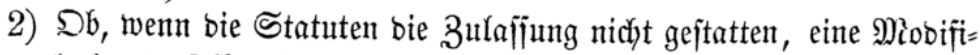

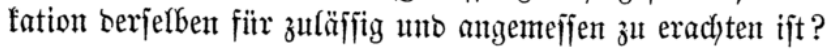




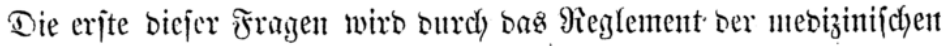
Jafultät in Brestau pag. 15 2(bjdyn. III. \$29 beantwortet, wo es heipt:

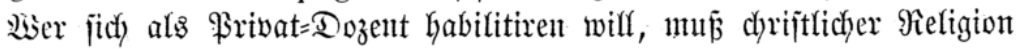
jeint. -

Meine Anfidyt in Betreff oer zweiten Frage beehre id midh in Fod gcubem autsanfiprechent:

Das Subentfunt ift jwar meiner Mieinung nad) nod) nidjt beredytigt, wall bem Ehriftenthum Emanzipation zu verlangen, benn ein jitbifcher Strat wïrbe dyrijtlidyen Unterthanen nidyt genuähren, was jïsifdye Unter=

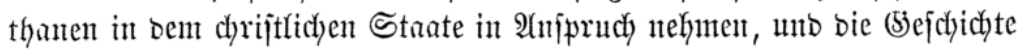

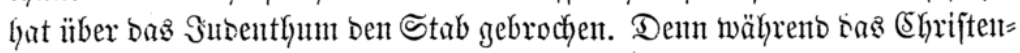
thum fich itber bie (Erbe ausgebreitet hat, hat bas Subenthum es bahin gebradyt, beim (E)rijtenthum bie Emanzipation nadyzufuchen. atber bie (5ejchicfle hat es and gezeigt, ba

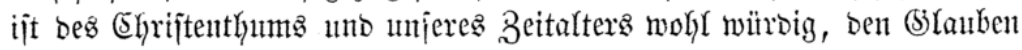

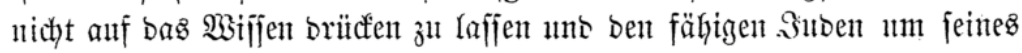

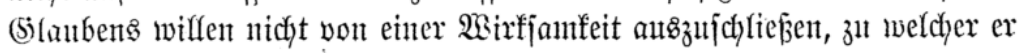
jonjt Bieruf hat.

Эch fann nich aber bemungeadytet nidyt unbebingt für bie Bejeitignng oer bejtehenben Schranfen anspipredyen, weil idy bie Ucberzengung habe,

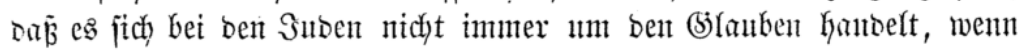
and) nur won biejent bie ?ese ift.

Dwei Brüber, beibe Suben, fint für bas Stubium bejtimmt. Der

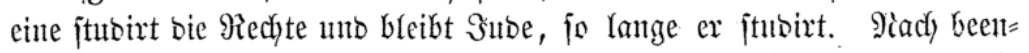

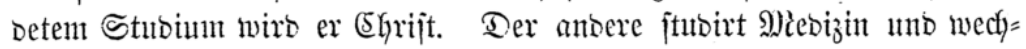

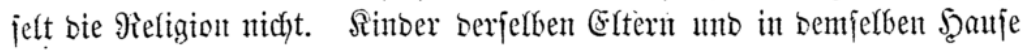
erjogen, befolgen beibe meiner Ueberzentgitntg nach biejelben (bruntojäz̧ze.

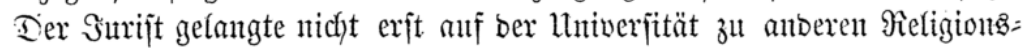

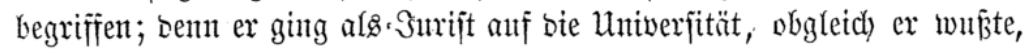

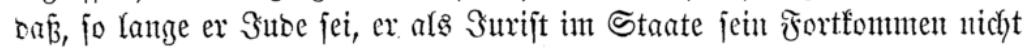

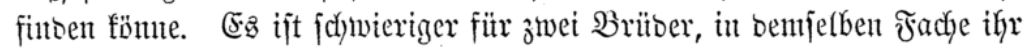
Fortfonmen zut finben, weil bei einem geringen Unterfohiebe ber Saljre

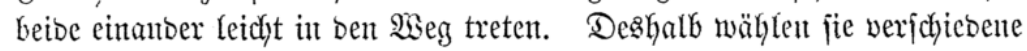

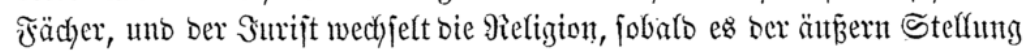

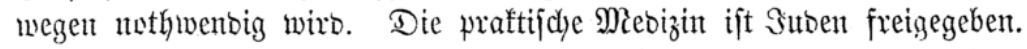
Der jübifdye $\mathfrak{A}$ rzt finbet bei Suben leichter (Eingang, als ber d)rijtiche, uno es ijt bies ein widytiges Mlotiv an einem Drte, wo fich eine reiche

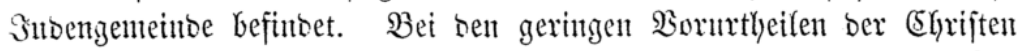

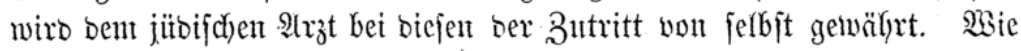

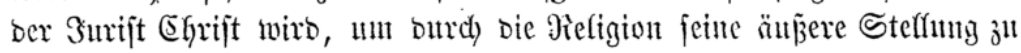




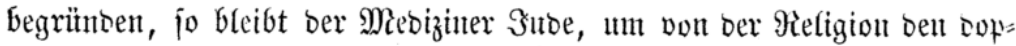
pelten Sieninn zu ziehen.

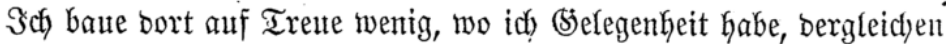

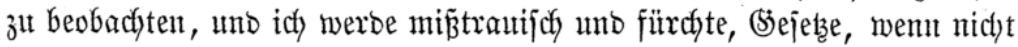

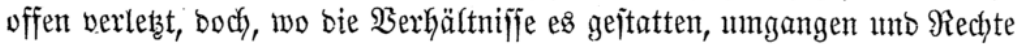
angetajtet zut jefgen, bie zu achten, ein inneres Pfflichtgejüh) jonjt gebieten miïpte.

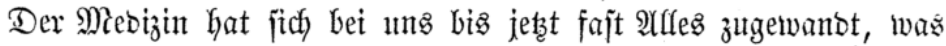

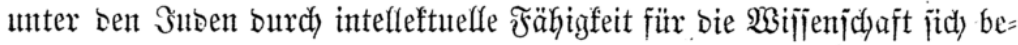

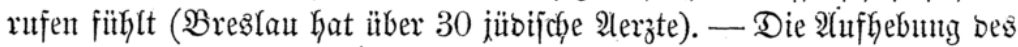

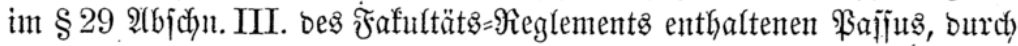

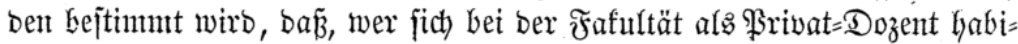

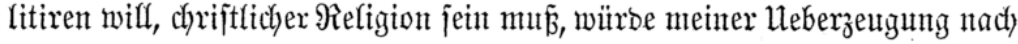

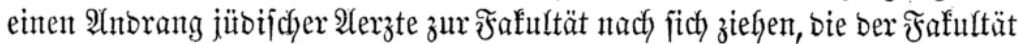
nicht alfein im Göchjten (S)rabe läjtig werben, fonbern fie einer umuter=

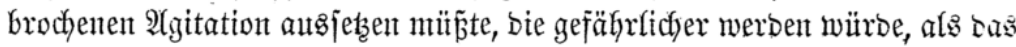

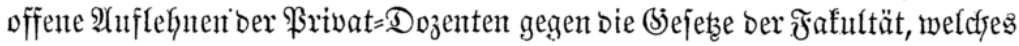

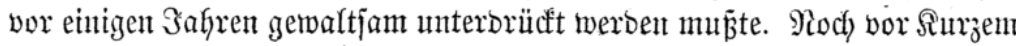

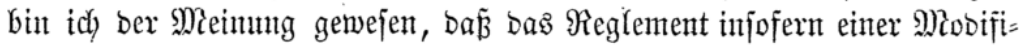
fation unterworfen twerben fönnte, bas auf einen befonbern 2intrag nad) Albgabe eines jpeziellen (Sutachtens ber Fafultät, wenn bieje bie volfe (5a)

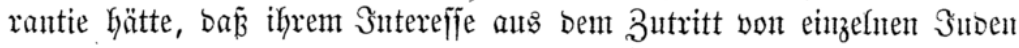

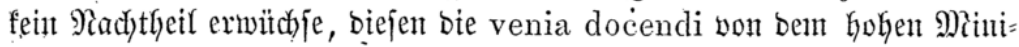
fterium ertheilt werben fönne. Die aber janon jef̧t wirfenbe Mgitation

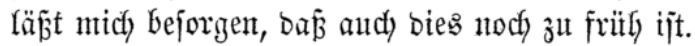

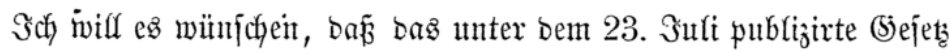

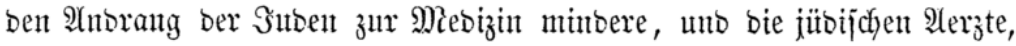

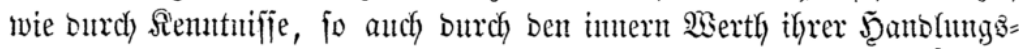

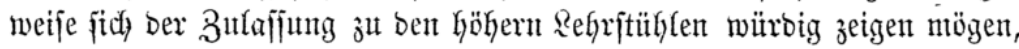
aber idy) faum boch ṇtr bahin ftimmen:

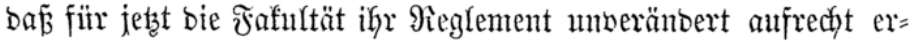
Galte, nidft baran rittele unb es erjchüttere, fonbern bie Folgen

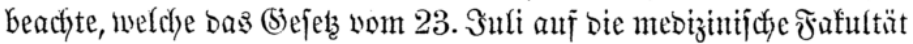
in Berfin ausüben wirb, beren Statuten ben Suben nidd) entgegen

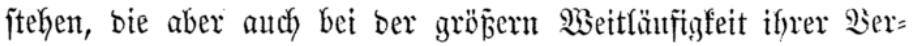

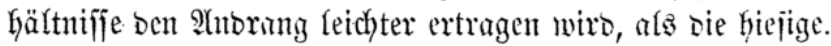

$\mathfrak{B}$ reglat, bent 18 . Sftober 1847.

5. Barfuw. 


\section{Siparat-Zotum vou 租rofeffor. Aiemer.}

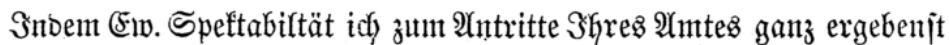

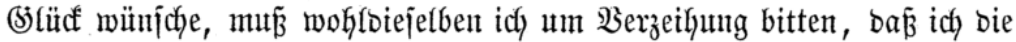

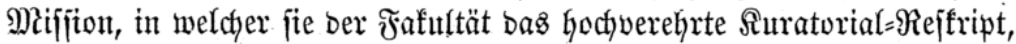
die Subenfrage betreffent, vorgelegt haben, gez̧wungen getwejent bin, bis heute zurütf zu halten. Midh haben anderweite Dienitgejdjäfte auf eine eben jo unaufichiebbare als zeitraubente 2 seije gefinbert.

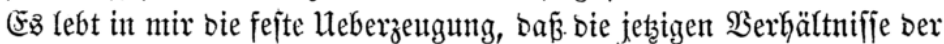

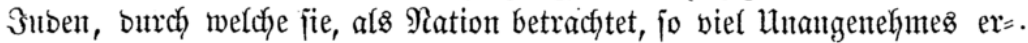

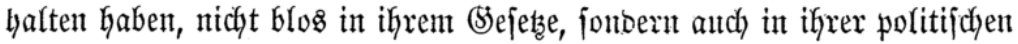
Rage ihren (stumb haben.

Alferbings trennt jein (5eję̧ ben Suben vollitänbig von allen andern

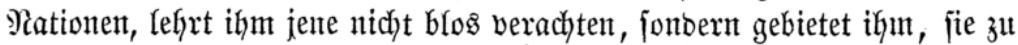
meiben unt zu vertilgen, wenn $i$ hm baz bie Miacht gegeben wirb. (5. fam bas Reţte nidyt mehr, weil er unter bem joywerjtent Drucfe lebt, bent

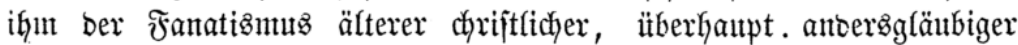
(z. B. mohamebanifcher) Nationen auflegte, aber anfeinben, inteiben,

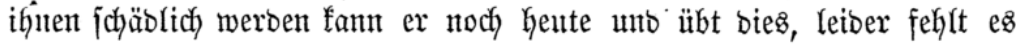

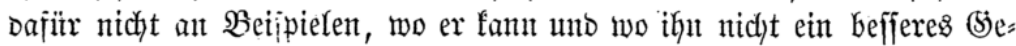
fühl keitet, autch in wolfem Maáze.

So elyrentwerth auf ber einen Seite bie Trente ift, mit welcher ber Sttbe, ungeachtet ber Schwere bes Drutfes, weldyer auf ifhm lajtet, an jeiner Bäter (Blaubent uno Beję̧ noch hente hängt, jo nadytheilig ijt jein

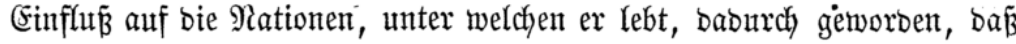
ihm jebes Mittel, auf welches er jidh auf Sojten jener bereidyern fann, bas richtige, bas zu ergreifente erfacheint, mitfin von ifym benutzet mirb.

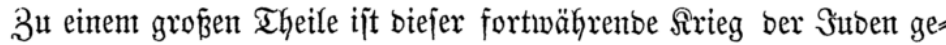

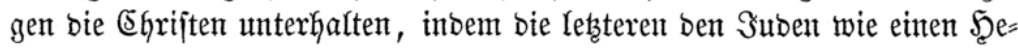
loten behanbelten, ja zum Theil nod) behanbeln. Sch erinnere an bas Ghetto!

Das Freigeben ber Sfllawen ift ein Schritt, weldyer ihn allerbingz beffern, ifhn moralifł erhöhen fann. Die fortbauternbe Sflaverei hindert unbedingt unt bleibent jebe moralijche Erhebung.

Daher bin ich auf bie entichiedenjte 2 Beife für bie Emanzipation ber

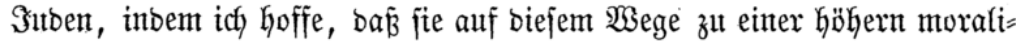
idhen Steflung gelangen und zu einem Friebenşchluffe mit ben Shyriften gefïfrt werben werbent.

Soll biez aber geidjehen, fo mus bie Entanzipation eine vollftänbige jein, nicht eine halbe, nidyt eine joldje, weldye auf ben (5)arafter ber Sutben 
einen Flecfen fallen läß̈t. Unto biez leţte gejdyiegt, wenn ich mid) nidyt jefr irre, burch bas fie betreffende Befets.

(5: jchließ̧t bie Suben nicht bloz von allen foldhen $\mathfrak{B}$ eziefungen aus, bei welchen bas (5Griftentfyum in Frage fommt, wie bies natürlid), noth= wentig uno eben jo wenig verlezzent ijt, als es oen riatholifen verleţt, wenn er über Âtngelegenkeiten, bei benen ez jich um bie protejtantijache Rehre hanbelt, nidyt enticheibent barf, fonbern es verjalliest ify audy alle ridyterlichen $\mathfrak{A}$ emter, bei benen ez fich boch nur um bas Siejets Gandelt. Scier Greibt ber Sube ein ફ̧elot.

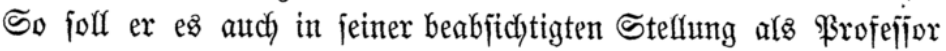

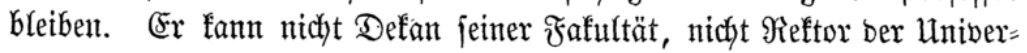
fität, nicht Senator werben. Eş haftet alfo auf ifgm ber alte Flecten, ben fein Bsejeţ iłm unter uns aufprägte, er bleibt ber verachtete Sube, man

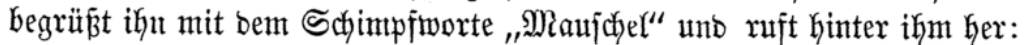

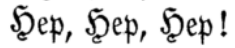

So lange bies $\mathfrak{B} e r \mathfrak{a} \mathfrak{a} l t n i \tilde{\beta}$ bautert, bleibt bie alte Stellung, ber nur abgeholfen werben fann, wenn bie (Fmanzipation eine vollitändige ift.

Alferbings fann fich, wenn bie Berbältnifje ez begünftigen, bann,

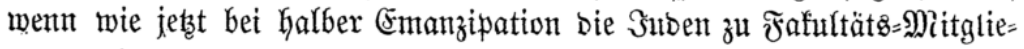

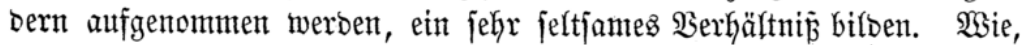
wenn bie Fafultät einjtenz auz lauter Suben bejtänbe? fie fönnte bann im Senate nicht repräjentirt werben, fie fönnte feine \$romotion mehr vor= nehmen, weil fie feinen Defan haben fömte.

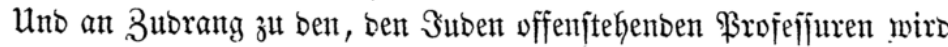

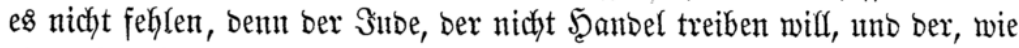

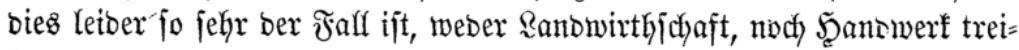

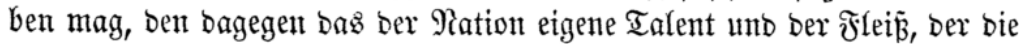

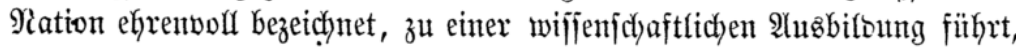
wirb begierig nach einer folden Anjteflung jtreben unt wirb fie erlangen, wie er $\mathfrak{A l f}$ es erlangt, wonad) er einmal fein $\mathfrak{B}$ ejtreben gemendet hat. Iie Wifjenfchaft wirb barunter nicht leiben, wie wir bies an Beifpiele jo vieler tiefgelehrter S̈loen genügeno jehen fönnen.

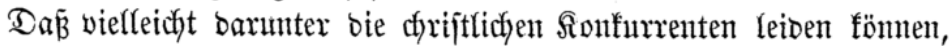
will ich, mus ich nachgeben, aber zugleich) aus inmiger Heberzengung bie

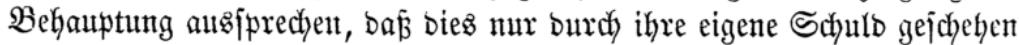
wiro.

Unjere Statuten fddreiben $\$ 29$ vor, Dẩ nux Ehrijten Frivat=Do= zenten weroen fönnen, nirgends aber verlangen jie bas Shrijtentbum nom Frofeffor, ohne anzugeben, Dá auferorbentlidye uno orbentlidje, Gervorgehen fönnen, was and nidyt ju 
mïnj]dyent wäre. Şier ijt eint Hiatus in ben Statutent, welcher nicht jtatt= fintben jollte.

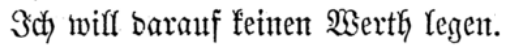

Ebenjo wifl idy bie ärgerliche (Sefdyidhte, weldye bie F̧erren Doftoren

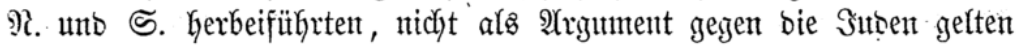
lajpen. Sie waren ja beibe getauft, alfo EGrijtent.

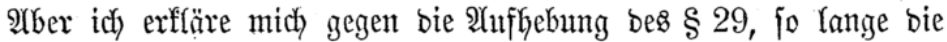
Subeit nidyt vollytäntoig emanzipint fino, ๖. h. jo lange iłnen nidyt alle Aemter im Staate, alfe Berbültnifje in unt zut bemfelben offen jtehen, bei

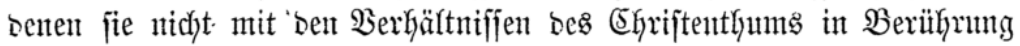
fomment.

B̧reslat, ben 25. Dftober 1847.

Dr. Menter.

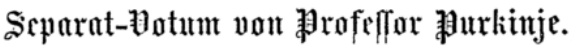

Snbem ich meine Meintung ïber bie Bulajfintg ungetaufter Suben

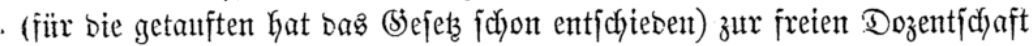

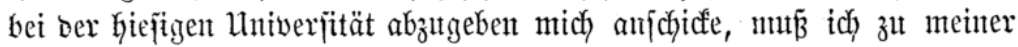

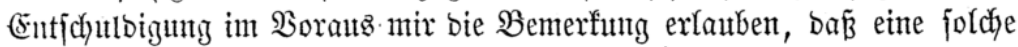
Denfinufgabe weit. itber meine Sräfte geht, intem mir weber bie Gierzut

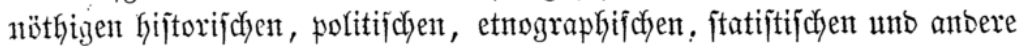
Erfahrumgen zu (bebote jtehen, nod) id) midh) (in rubiger Betrad)tung ser immer wahren ?atur vertieft) in jozialen und noch bazu fo fomplizirten Begrifffen mein Uththeil z̆t bewegen gewantot fïflele.

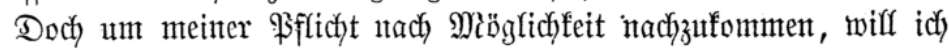
Den Bebantengang barlegen, ben bie bon einem hohen Mintifterium mir vorgelegte Frage in mir erzengt hat.

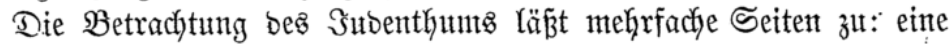
anthropologifache, eine internationale, eine religiöje, eine foztale uno leicht

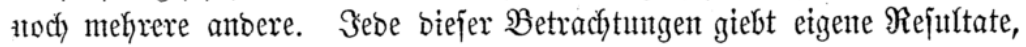
fegt eigene praftifabe $\mathfrak{B r o b l e m e}$ vor, unto erit alfe zufanment geben bie $\mathfrak{B} e=$

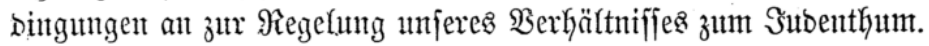

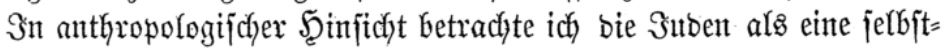

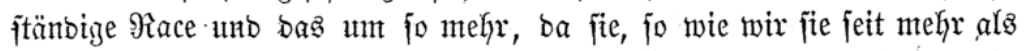
Taufend 3ahren unter uns fenten, jich butth Şeirathen unter einanber in

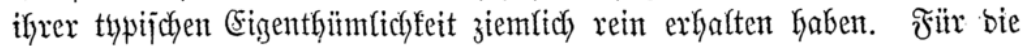

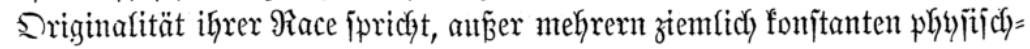

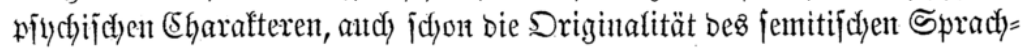
ftammes.

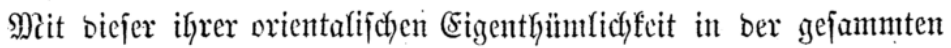




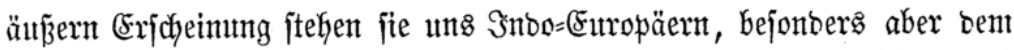
gemeinen Mant beś innern Feftlantos, befjen whyjïognomijajer Sinn nod) nicht burch ben grelliten Wechjel verjudebenartiger \$shyjiogntomieen abge= ftumpjt ift, fremb, ja in vielen oäflen abjto

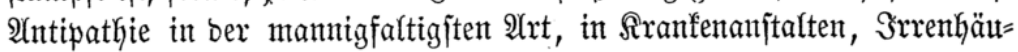

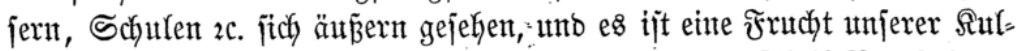

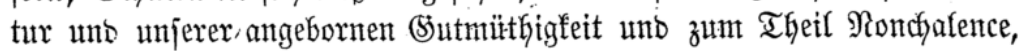

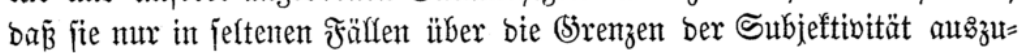

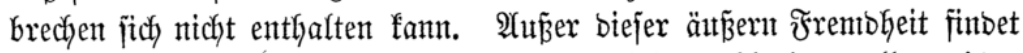
fich noch eine innere pigdyologif he. - Es giebt wohl einen alfgemeinen Typus für bie Drganifation ber menfjhlichen Seelen. Dod) hat aurer=

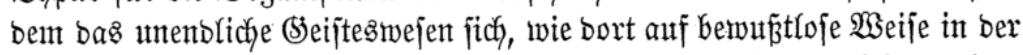

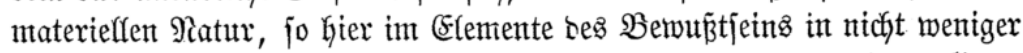
mannigfartigen pitychifdyen Bifoungen ausgefpochen uno baburch ben Siang

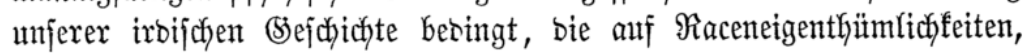
Bölferanlagen unb attzerwähyten Beiftern zur Entwidelung ber gejamm=

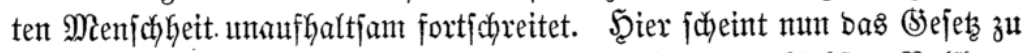

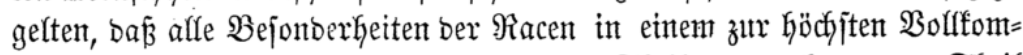
menkeit temperirten Mienjuheitabiloe zum. Theil untergeken, zum Theil

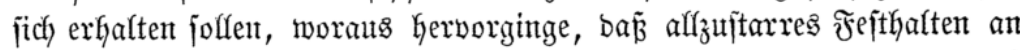

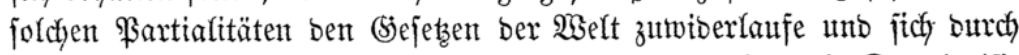
unnatürfiche Entwidfelungen unb perennirenbe Forterbung, ja Deteriorifi $=$

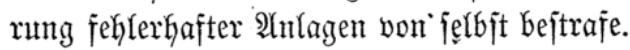

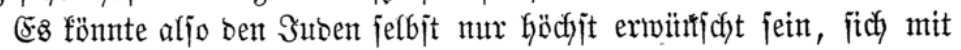

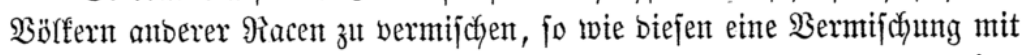
bem an jich eblen Sitbenjtamme vortheilfaft wäre, um nette regenterirte

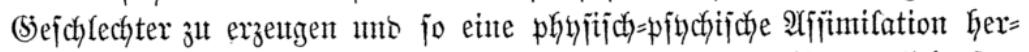
beizufïhren, in beren Folge jebe Frembkeit unt $\mathscr{U}$ (ntipathie am jicherjten

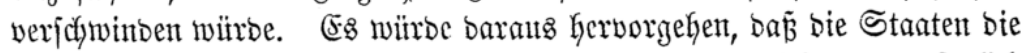

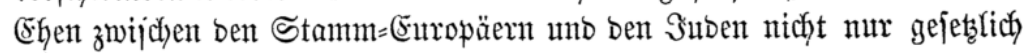
ertauben, jonbern aucich beginijtigen jollten.

Wag bie internationale Frage betrifft, fo fann man bie Sitbent, als eine emige ober fejtgenorbente (Entgration betradfent. So jtellen fie fich uns

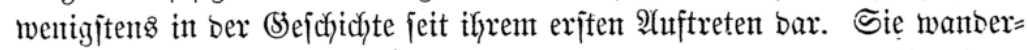
ten in Egypten ein, und, nachbent fie bort fremb getworbent, zogen fie wieber

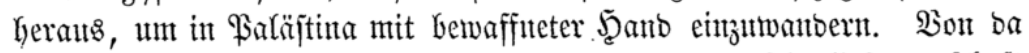

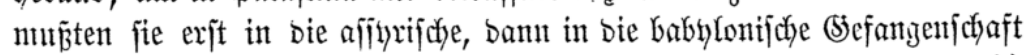

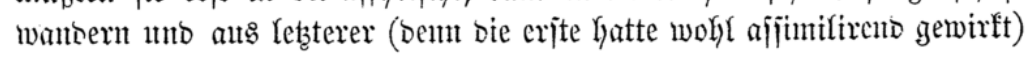
it ifje Şeimath wieber jutriict.

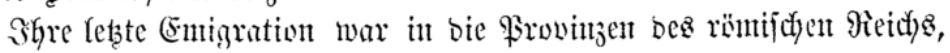


volt bent wir fie als (Erbtheil mit anderem (5)utent und Schlimmen iiber= fommen haben. (S)gentwärtig ift es eine Entigration ohne Enbe gemorben,

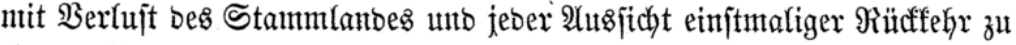

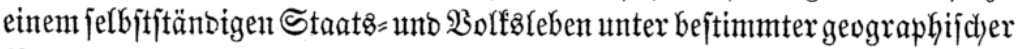
Begrenzung. Sie, bas ältejte hijtorifube $\mathfrak{B}$ olf, haben zul alfererjt einen jol=

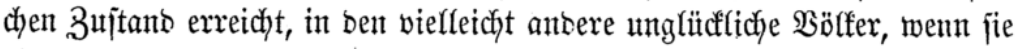
ebenfo jtarr in ifrer Eigenthümlidsfeit beharren, erjt Gineingerathen wer=

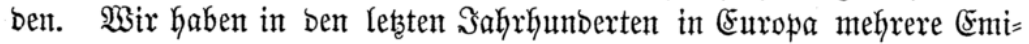
grationen auf Der Büfne ber $\mathfrak{B}$ eltgejuchichte auftreten jehen. Sie haben fich mit bent Stammlande verjöhnt, ober haben fich in ber Frembe grö $\tilde{\beta}=$

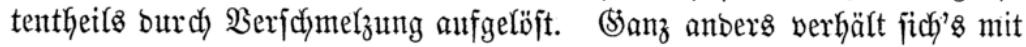
ber jübijchen Emigration: Durch Fefthaltung an ber Untwermifatheit ihrer

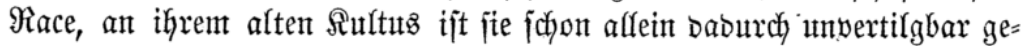

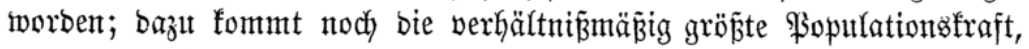
woburch bie Erfhaltung ifyres phyfifchen Dajeins für alle Bufunft gefichert fajeint. Durch ben Trieb nach Sammlung und $\mathfrak{A}$ nhäufung bes (selbes

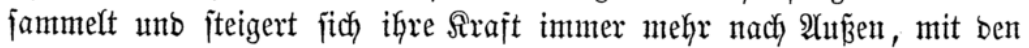

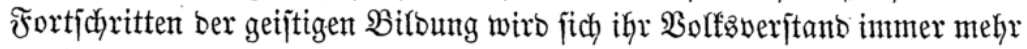

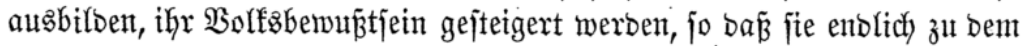
Srabe bes Selbjtgefühls gelangen fönnten, alle alfifimilation zu ver= fchmähent unt jich als bas auserwählte Bolf (5ottes zu behaupten. Und welche anbere Pation fönnte ifnent barin Unredyt geben? Will fich ja jebe für bie ausermählte halten uno fich neḅen unb trotz ben anbern aufreidt

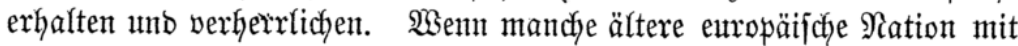

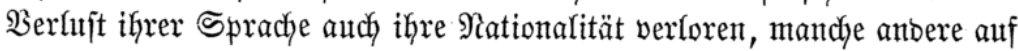
biejem $23 e g e$ fie zut verlieren bebroht wirb, haben bie Sitben zwar ihre alte Pationalfprache vergeffen, find (Senoffen aller fultivirten Sprachen gewor=

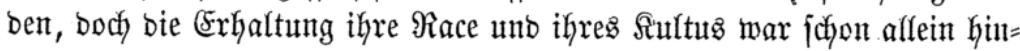

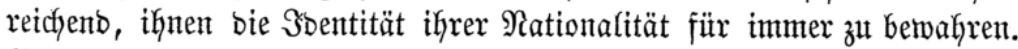

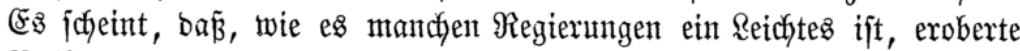

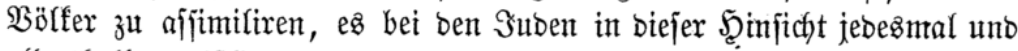

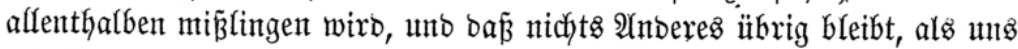

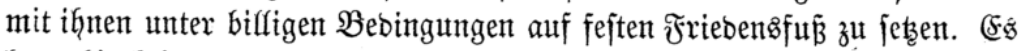

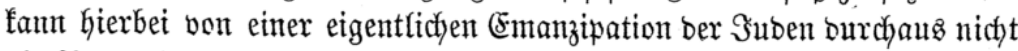

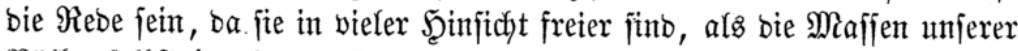
Bölfer jelbjt, ja wir zum Theil jelbjt in ifyrer (Stewalt fint. Es fieht baher ziemlich jonberbar auz, bå fie, bie Stürmenten, unjer Mitteib zu erregen juchen, um ungefinbert affe unjere fejten Steflungen einzunehmen, bá̉ fie, Die nichtgelabenen (Sä̈lte, jịch) bei uns zum vollen Tijche fetzen unt bie Sin= Der bes Şaujes an ben leţ̧ten Ort brängen voer gar vertreibent. - 


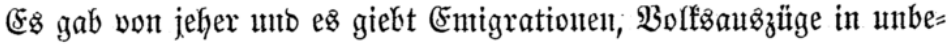

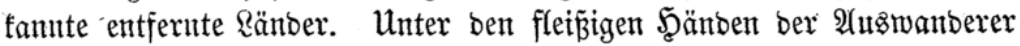

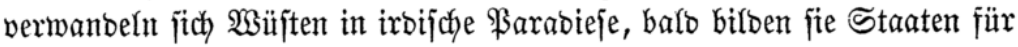
jich, ober bleiben im $\mathfrak{B} e r e i n$ mit bem Mutterlanbe, ober jie begeben fich an benachbarte mächtige Staatenvereine uno verjadmelzen mit biejen zu gleicher Sitte, Sprache und Regierung. Solche Injtinfte icheinen bem hebräi=

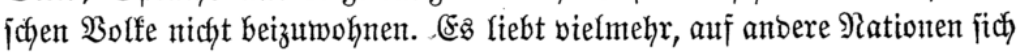
nieberzulajien, fie alz jeinen Srumb unb Boben auszubeuten, in alle

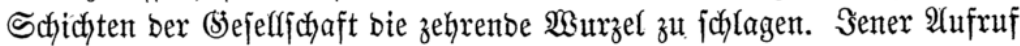

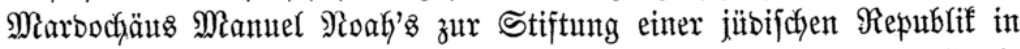
Norbamerifia ging, wie zu erwarteu war, in \&ächerlichfeit auf. Sollte je

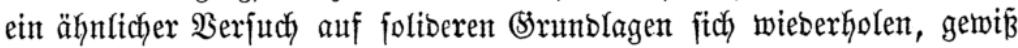
würben $\mathfrak{B i e l e ~ v o n ~ u n s ~ g e r n ~ i h r ~ S c h e r f l e i n ~ b a z u ~ b e i t r a g e n , ~ u m ~ b i e ~ j u ̈ b i j c h e ~}$

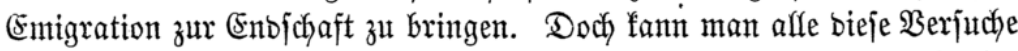
in vornherein als vergeblich betrachten, uno es mirb immer bie unabweis= are $\mathfrak{A}$ ufgabe bleiben, mit ben mun einmal unter uns Wohnenden auf gïn= jtige Bebintgungen zu paftiren. In älterer beßppotijcher Zeit wanbte man allerlei (setwaltmafregeln an. So hat fich benn mandjes Rand ber jübi= ichen Emigration entlebigt, freilich geichah biez meijt auf $\mathfrak{U n}_{\mathfrak{n} f o j t e n}$ anderer

- Siölfer, bie jie aufnahmen, und bie bann jpäter ifhre \&iberalität bitter zu bereuen hatten. Innjere Beit abhorrirt jolche Mittel. Der Begrifif ber Şumanität, bie Anerfemung angeborner Menjchenrechte forbern anbere Maß̧regeln. Die älteren Sonjtitutionelfen haben ben Suben beinahe vöflige

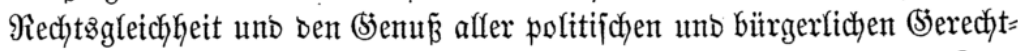

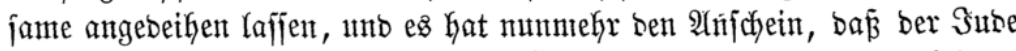
im Snbivibuum immermehr in ben F̧intergrumb treten, bie mächtigere

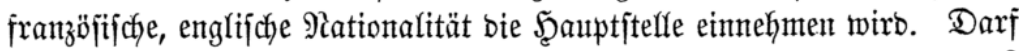
man biez aber aud won ber beutjchen, flavijchen Nationalität erwarten? Sint bieje aud jodyon fräftig gentu, um bas fo zähe, jo heterogene Element

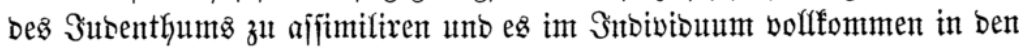
Şintergrund z̆ brängen?

Unt bie jübijche, ober jonjt einte möglidye (Emigration an ifyren $\Re$ edf)

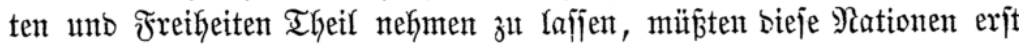
jelbjt volffonmen frete Injtitutionen bejişen und in biejen burch) längere Zeit gefräftigt fein, um fo was ohne ঐad)theil magen zu bürfen. So lange bie Sinber bez end bringen, bie Fremben bollanf zu jättigen? Dody joldye jumb bie ge=

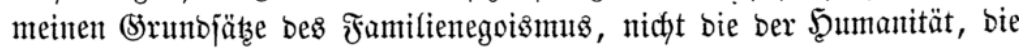
Des (Ehriftenthums. Safjen wir jeboch genuähren. Durch Einräumung

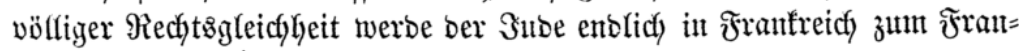




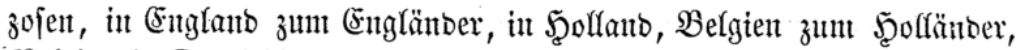

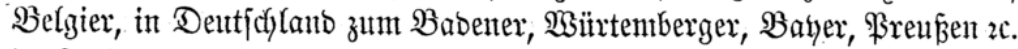

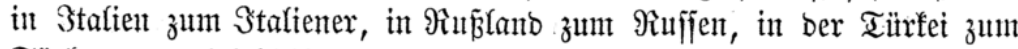
Titrtent 2c., Dabei bleibe er bod, Stlbe bem Stamme unt ber gieligion nad).

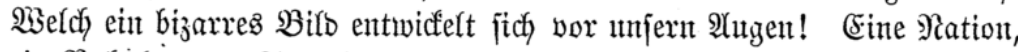
ein Babylon von Sprachen fprechent, von jeber Stammgenofjenfdyaft hat

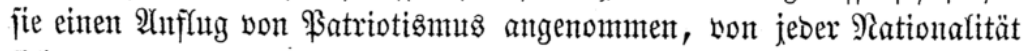
iid) etwas jugeeignet, babei jeboch bilbet jie eine grope, zerworfene, ourch unvertilgbare Banbe verbunbene, zu erneuter Fintgung jtrebende Mafje.

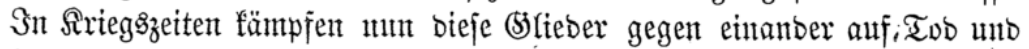

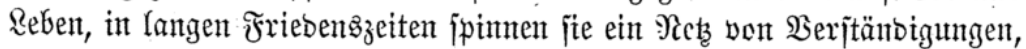

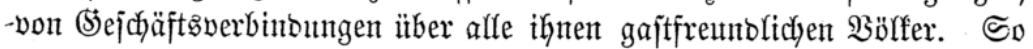

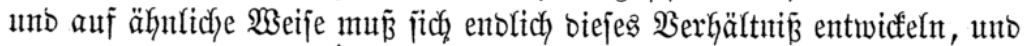

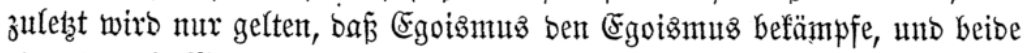
einamber bie \$aage Galten.

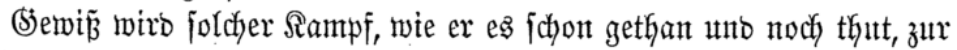

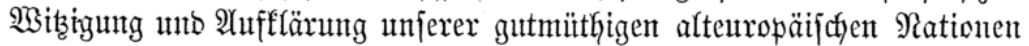
nicht mentig beitragen, ooch wiro es auth auf Unfojten unjerer Sitte, unjerer

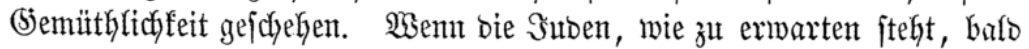

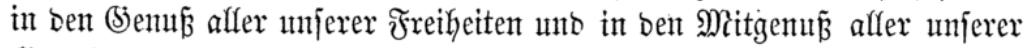

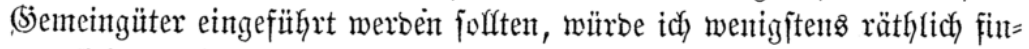

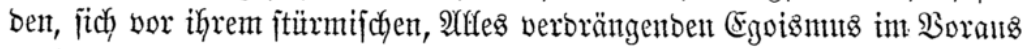

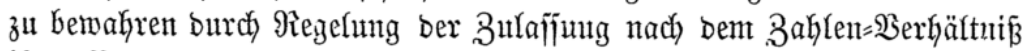

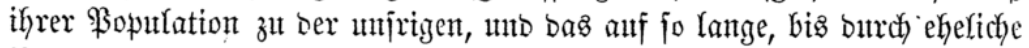

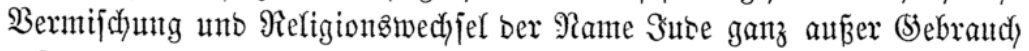

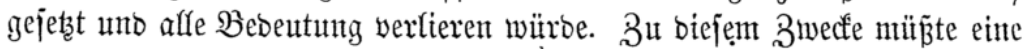
genaute Statijtif ifrer Erwerbsarten erhoben, uno bieje balomöglichjit mit

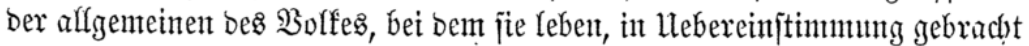

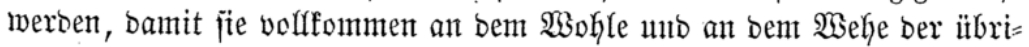
gen Siafien Theil nehmen.

Die Religion war in frithern Zeiten ber Dedfmantel, Ginter werdyen jitc) aufer ber religiöfen, audh bie Ântipatbie gegen bie Stanm= $141 \mathrm{~b}$ Rational=Eigenheit ber Suben, io wie alle Eiferfïthtelei auf ihre Sit=

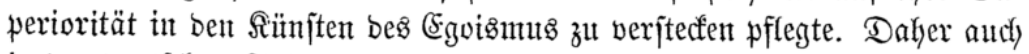

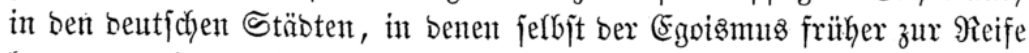
fam uno mit bem jübijdyen in Evalfipion gerieth, bie heftigjten $\mathfrak{B}$ erfolgun=

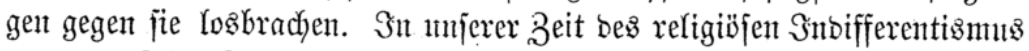
unb zum Theil Riberalismus läß̈t ntan ben Deismus ber Suben getuälyren.

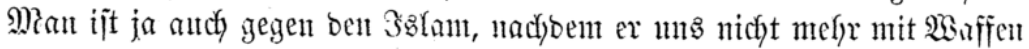

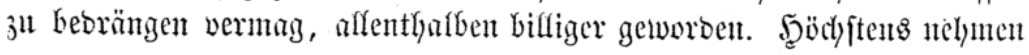




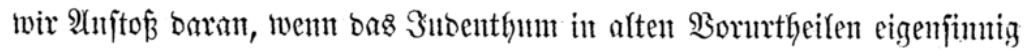
verbarrt, fo wie uns bergleichen bei (Éfriften aud nidyt erfreut. Sa wir intereffiren uns fïr bie neutern Beftrebungen ber Snben, ifren Anttus zu ernenern, unb ihn mobernen Begriffen uno (S)efdmadfe anzupaffen. Rängit

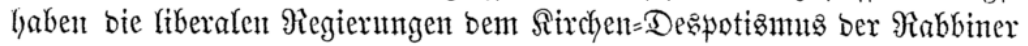

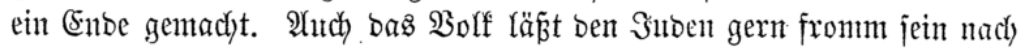
feiner $\mathfrak{W e i j e , ~ m e n n ~ e s ~ n i c h t ~ f u ̈ n j t l i c h ~ f a n a t i j u r t ~ w i r b , ~ u n t ~ f i t h r t ~ i h n ~ j o g a r ~}$

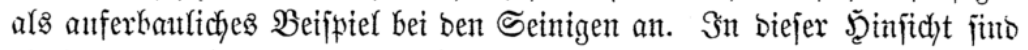

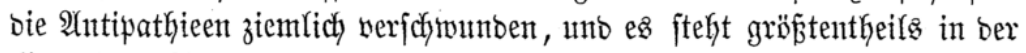

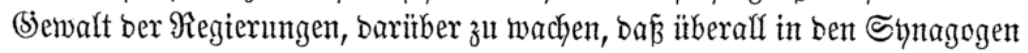

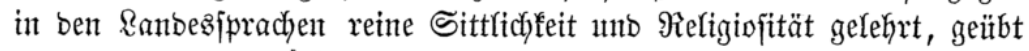

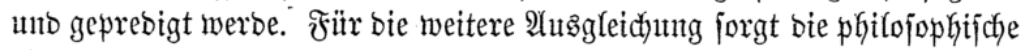

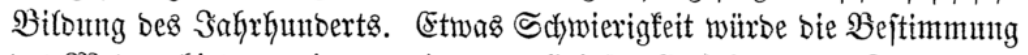
Des Miobus bieten, wie es mit ber religiöjen (Er riehung ber Sinber aus

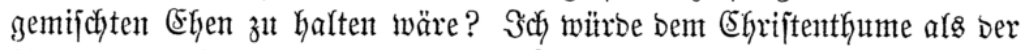

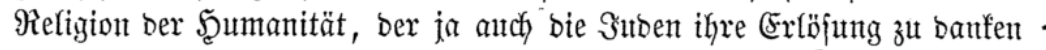

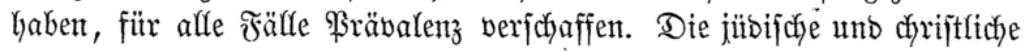
Theologie ließ̧en in Betreff ber Bsegenftänbe ber Stubien eine groß̧e

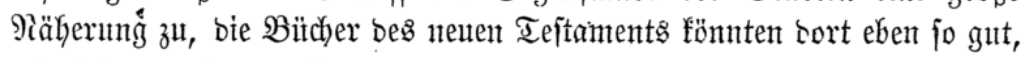
wie bei uns bie bes Arten, zur Errorfochung eingefüfrt werben. Es tönte nux bazu bienen, bie wechjelfeitige $2(d)$ tutng in geiftlichen Dingen zu nähyren

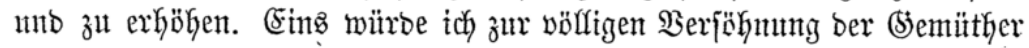
von einem etwaigen jitbifchen Sankebrin verlangent: eine ëffentfiche be= friebigenbe Erffärung itber bas (5hriftenthum, worin z̧um wentgiten eine N(chtuntg vor bemjelben ausigebrïtft wïrbe.

Dies mitroe um fo mekr exforbert werben fömten, ba mur babutrdy ehelidye $\mathfrak{B}$ erbindungen beiber $\mathfrak{F a r t e i e n t}$ eine moralijcye (5runtolage erlangen witiben.

Âtı biejen Betrachtungent, bie id hier abbreche, geht fachon Kerwor,

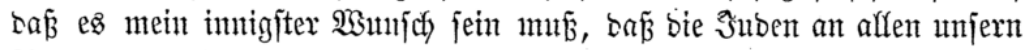

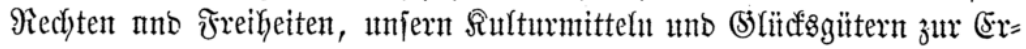

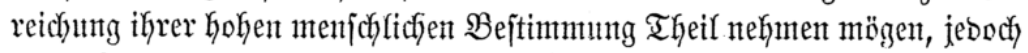

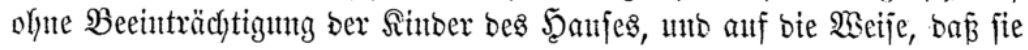

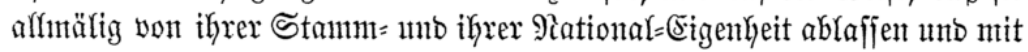
ums völlig zut einem 2 off veridymelzen mögen. Wenn burdy bie \$sirfung ant=

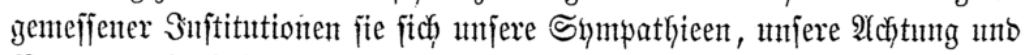
Sertrattent in Gäberm Brabe afs bisher mo weiterem Umfange eriverben

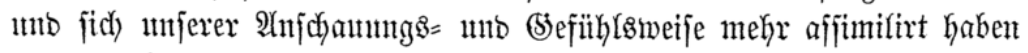

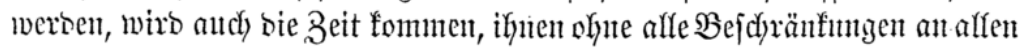

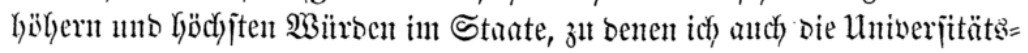




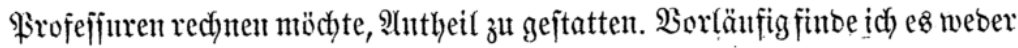
juläjfïg, noch angemeffen, von ben bizherigen Statuten unjerer Univerfität in Diejer beeziefung abjutgehent.

$\mathfrak{b} \mathfrak{e} \mathfrak{g} \mathfrak{l} \mathfrak{a}$, Den 29. Dftober 1847.

Fiurfinie.

\section{Sepurat-Yotum von 角rofeffor Esmedict.}

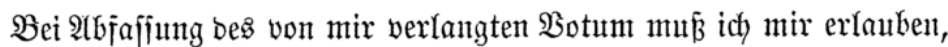
einige Bemerfungen über bie fogenannte Subenemanziłation uno über bie

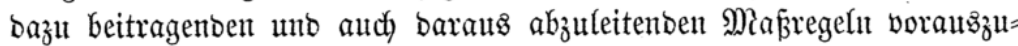

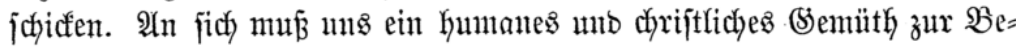
förberung biejer Sataftrophe aufforbern. So wie inbefjen bie Theorie jo felten mit ber Braris im menfdylidyen Reben übereinfommt, fo wie fich bie Berkältniffe auf bem $\mathfrak{S e g e ~ b e r ~ E r f a h r u n g ~ g a n z ~ a n b e r s ~ h e r a u t b j t e l l e n , ~ f o ~}$ ift biez audy bei biejer Angelegenheit ber Faff.

Bei bem jeţigen Stante bes Subenthums und bes Siemerbes ber

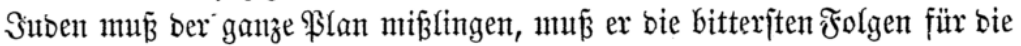
(5hriften uno inbireft aud für bie Inton veranlafjen.

Die Subenemanzipation fann nur gelingen, fobalo ber Sabe felbjt

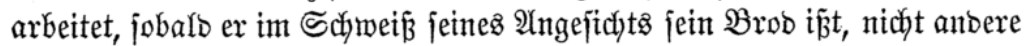

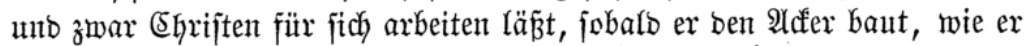
es vor Ehrifti Zeit gethan hat, - jobald er ein efritichez Şandwerf be= treibt, jobalb er nicht von bem ben (shriften abgenommenen (setwinn unb von

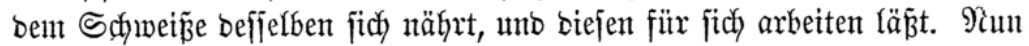

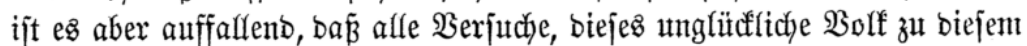
beffern unt zut ber Selbitarbeit anzuleiten, welche beinake von affen $\Re e=$ gierungen in ben Ränbern, wo bie Suben zahlreich find, mit redlichem Sinne

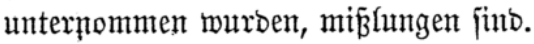

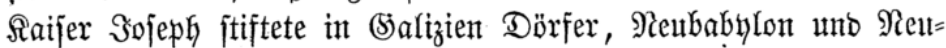
jerujalem, bejetzte jie mit jübijchen Sioloniften, gab ihnen $\mathfrak{B i e h}$, Saatforn,

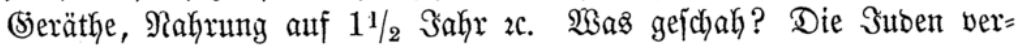

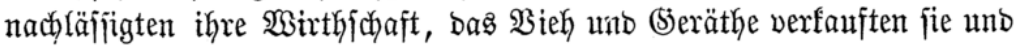
fchlenberten bann als Schacherjuben im Ranbe herum. Der Monard)

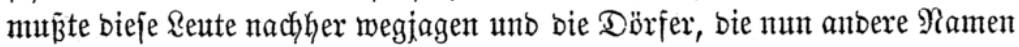

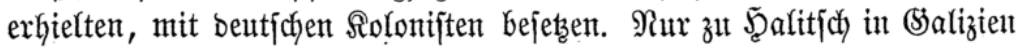

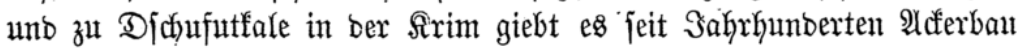
unb Şanbwerf treibende Şraeliten, bies find aber Fiaraiten, bie ben Talmub verwerfen und von ben anbern Şraeliten töbtlich gehafist werben, und id'

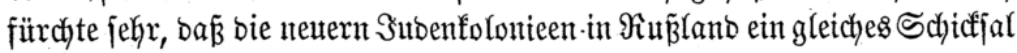
haben, falfz nidyt ber אaifer in jebem Dorfe zwei Unteroffiziere anjtellt, 
bie burch brei Menf(f)enalter Ginburch bie Rente thätliç uno tägrich zum Alferbau an= unb won bem Schacher abhalten.

Uno fo werben ähnlictje $\mathfrak{B e r j u c h e , ~ b e n ~ S u b e n ~ z u ~ e i n e m ~ o r b e n t l i c j e n ~}$ Bauter zu machen, jeberzeit miß̧̧lingen.

(86)en fo gefft es mit bem Betriebe ber Şanbwerfe, wenn idy etwa

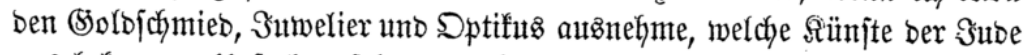
aus befannten $\mathfrak{u}$ rjachen jebr gern betreibt. Bu anbern Şanbmerfen hat

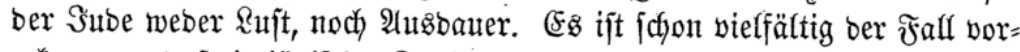

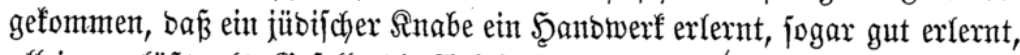

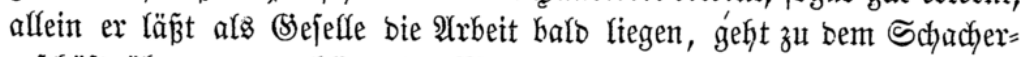
gejchäft ïber ober etablirt eine Meubles= ober Rreiberhandlung, wo bie

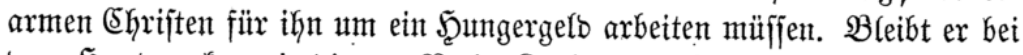

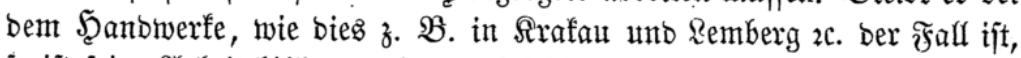
fo ijt feine 2 rrbeit bifliger, aber aud jojlechter, wenigitens verjichern bies

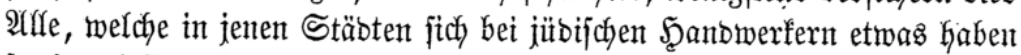

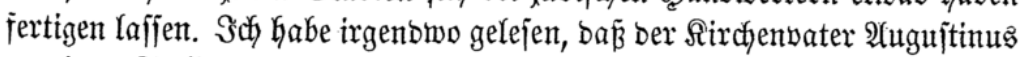
an einer Stelfe fagt: Die Эuben gehen vor bem (SGrijtentfuim voraus, um

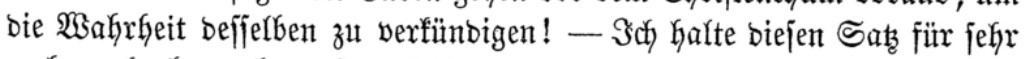
wahr, glaube audy, bẩ berfelbe wahy bleiben werbe bisz zur Endgfeit; benn eben biejer unglücffliche, alfe $\mathfrak{B}$ erbefferungen abtweijente 3 ujtand bes

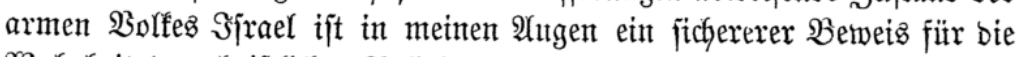

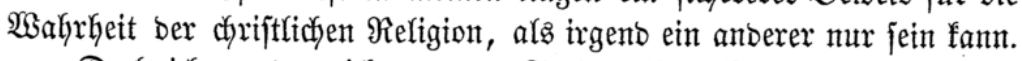

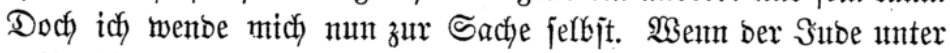

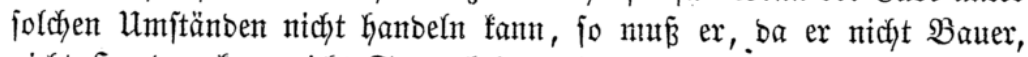
nidjt \$̧anbmerfer, nicht Tagearbeiter jeint mag, zu jeinem Unterhalt ein anderes (Sterverbe ergreifen. So wirb ex ein Mafififus ober ein Iajanenfpieler, Bänfeljänger oder (Srimacier, - ich) habe in allen biejen Erwerbszotwen Subent gejehen. Doer er wirb ein Âgent, ein jogenannter Faftor, unb nähert in

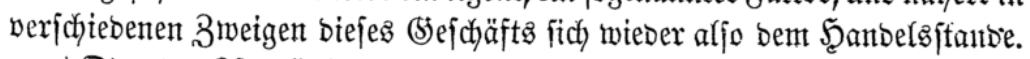

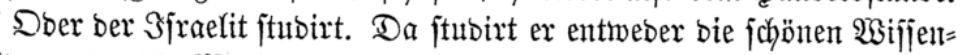

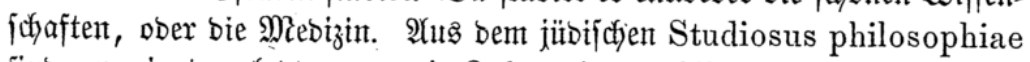

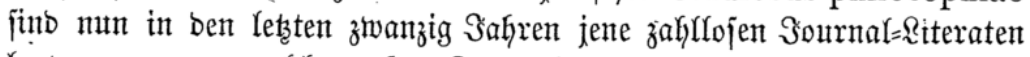
hervorgegangen, welche unjere Soumale unt Zeitungen gröftentheifs in.

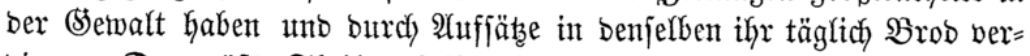
bienent. Der gröbite Theil berjelben bejitzt bie Sraft, ïber Alfes mit bem größ̧ten Ungejtüm herzufallen, was ifhnen entgegen ijt, uno itber alfe ifgre (5iegner bie fdyimpflichjten Snweftiven zu beren Bernichtung logazulafien. Unter ber Zahl biejer Riteraten befinbet fich bie größjte Zahl ber jeşt umjer politifches Reben auf gleiche 2 seife untermithlenben politifchen 2agitatoren

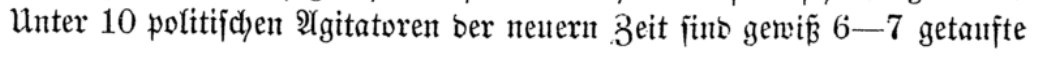




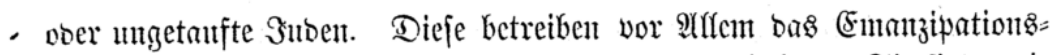

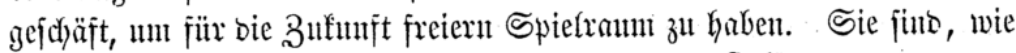
theilweije jobon ermiejen ijt, zum Thyeil bie trenen \$celfer ber unter uns

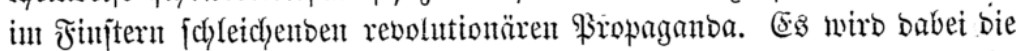
antidyriftliche Tentoenz biejer \$arteien inmter flarer, wie ber boppelte

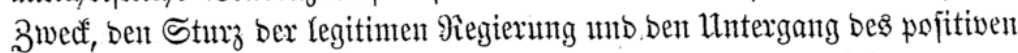

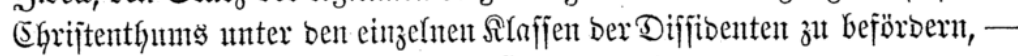
inbent beibe 3wedfe einanber in bie Seältbe arbeiten.

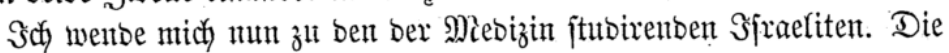
ehemalize Signtoria zu Senesig hat zuerjt alf ber Mniverjität zu ßabua biejes Stubium ben Suten eröffnet, und von ba aus ijt biejes aud in bem ïbrigen Europa Sitte getworbent. - Unter ben bie Miebizin ftubirenton

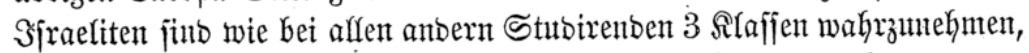

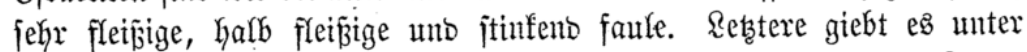

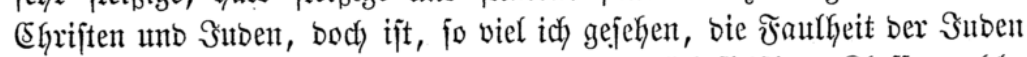

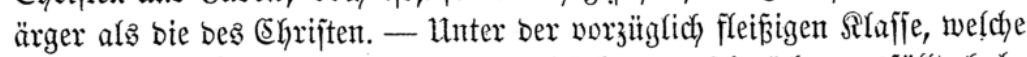

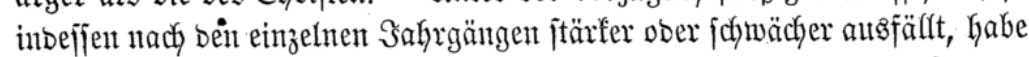

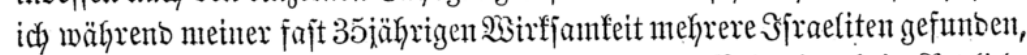

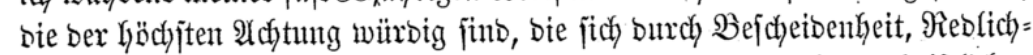

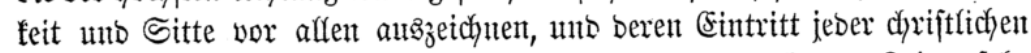

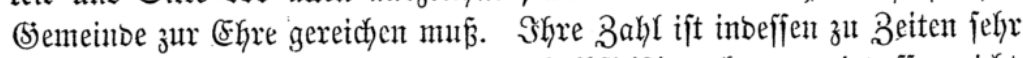
gering. Unter ben anbern ganz= unb halbfleifitgen fomment inbeffen nicht

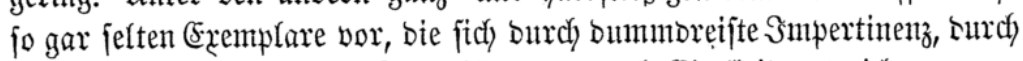
\$erfibie gegen Rehrer und Siommilitonen, burch (sitelfeit anģzeichnen.

Der jetsige Sahrgang, ben idy um midy zu fehen bie (shre habe, hat indefjen bayon noch nichts bemerfen lafjen.

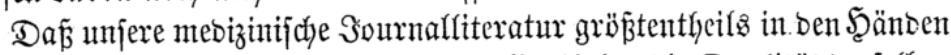
unjerer jübijđjen Sollegen ijt, wifjen wix alle. Ueber bie @ualität berjelben Da jie uns allen befannt ijt, enthalte ich mich bes Uartbeils.

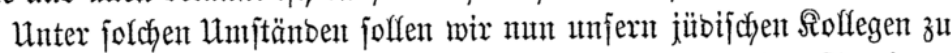
(S)efallent ben $\S 29$ unjerer Statuten umänbern? Da unter unjern Stubiren= ben ber Medizin wentigitenis $3 / 5$ S צraeliten fint, fo würben bie meijten unjerer dyrijtlichen Siollegen f́etn Solfegium mełx zut Stanbe bringen, ba bie

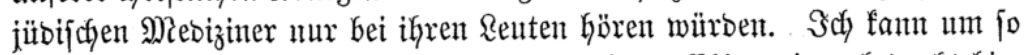
eher hierüber \{prechen, ba id) für bas Fach ber (Shirurgie unbebroht bin, welches bent Siraeliten weniger zujagt unb mu won ben bejten unb tïldytig= ften unter ifnen fultivirt wiro.

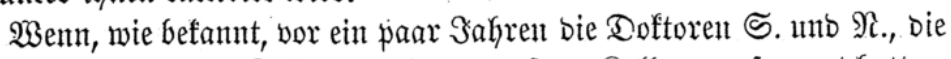
boch getauft waren, bie Sollegia mehrerer unjerer Solfeyen gefprengt hatten, wie foll es unz erjt ergehen, wenn bie wahren Suben zu Lejen anfangen! - 
abgejełen von ben übrigen @utalitäten ber jich gemelbet habenben :ipi= ranten.

Sch fitimme bafer für jtrenge Beibefaltung bea § 39 ber Statuten. Wiaf einer von bent Şebräern Dozent werben, unt er hat ben Beifall bez Ordo gratiosus, fo mag er fich taufen lafjen.

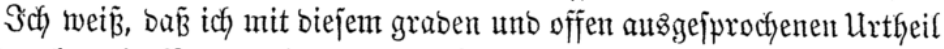
unto burch mein 2 sotum einen gresenen Rärm veranlaffen werbe. Allein two

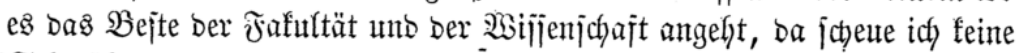
'Sodymäfung, auch bie in ber (Senträzeitung nicht.

Błreslau, ben 28. Oftober 1847.

Benesict.

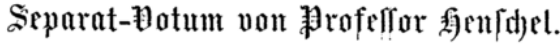

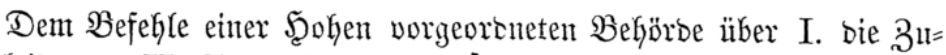

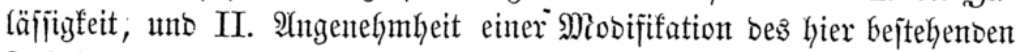

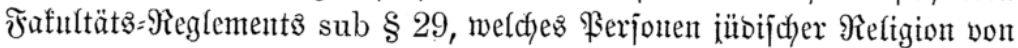

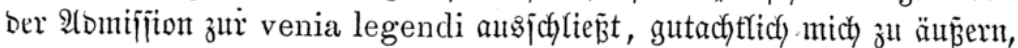

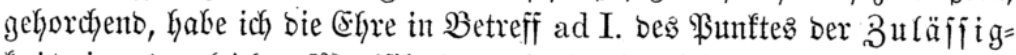

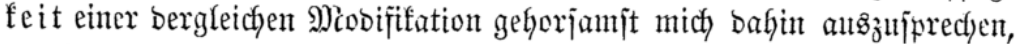

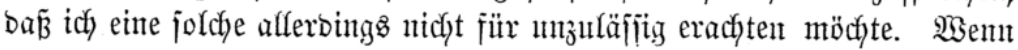

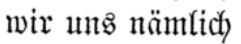

1) nicht etroa auf ben ultrantontanen $r$ eligiöjen Stanbpunft eintes

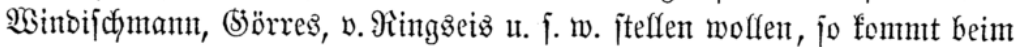

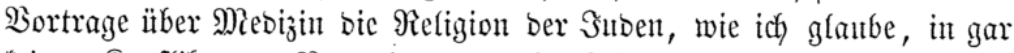

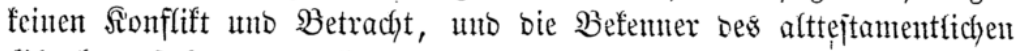
(5) (aubens jtehen, wemn jie überbaupt zu afasemijchen Funftionen geeignet

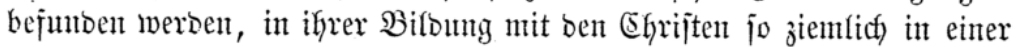

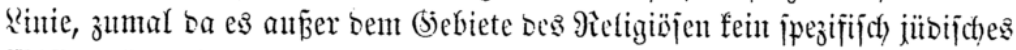
wsijןen für jich, fonbern mur ein allgemein menjolylides giebt, bejonbers aber bešnegen, weil unjere ganje Bifsumb, felbjt bie jïbijdye, hentjutaje

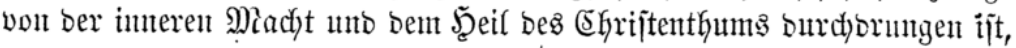
Dem in ifm leben, weben unt funt wir:' - Die Sache

2) vom a bitraft

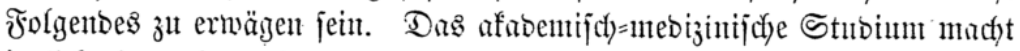
in jich bie nothwentige \$rätenfion, bis jut feinem (5ipfel, bent Doftorate,

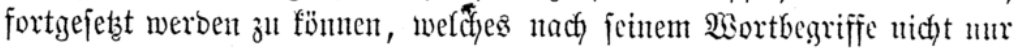

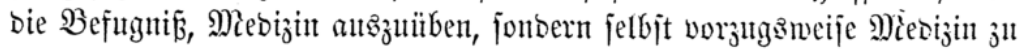

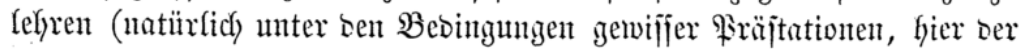

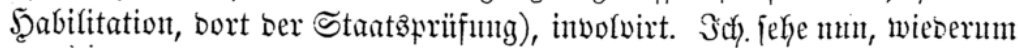

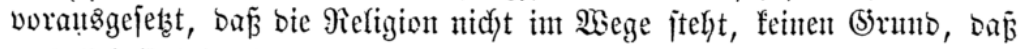




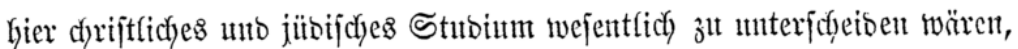

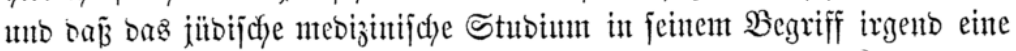

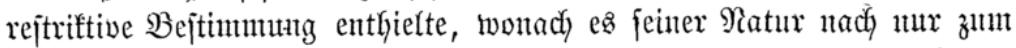
Doftorat als \$raxis, nicht zum Doftorat als Rehrbefugnif́ fütyren fömue.

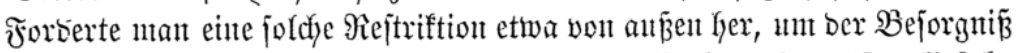

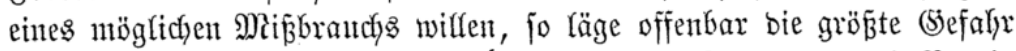

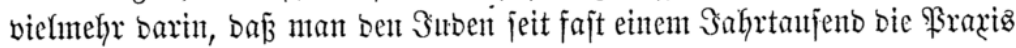
uno jomit ben wekrlojen franten Reib ber EGrijten of ne Bebenten preis= giebt, währenb bie 23ijjenjagaft uno Rehre, won ihnen bebroht, fich boch

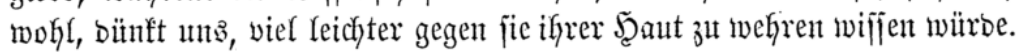
- Die Sadje

3) entolich won bent afabeni $j$ chen, unb zwar

a) bem afabemi $i c h=$ legalen Stanbpunfte erwogen, hat ebenfalfs

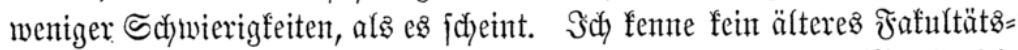

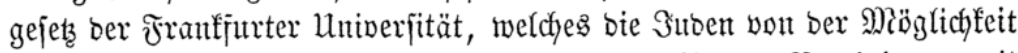
ber venia docendi ausfatöfije. Sn ben alten bis zur Bereinigung mit

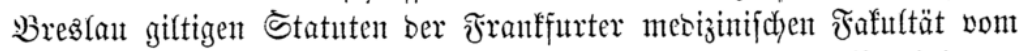

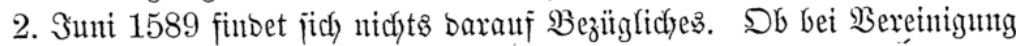
ber テranfjurter uno B̧restauer medizinifchen Fafulttät ein neuer hierin Den Suben ungïnjtiger \$affus in bie Statuten Kinteingefonmen, weíß id) nidyt; wäre es aber audy ser ₹all, jo wäre er. Durdy bas ofne Borbehalt gejtellte Sönigliche Snben = Ebift won 1812 effeftio aufgehoben. Dagergen

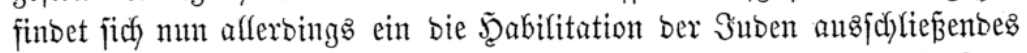

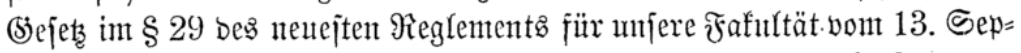
tember 1840, allein es ijt bieje \$sejetzesjtelfe offentar nur in fonjequenter

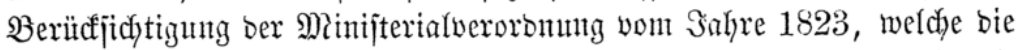

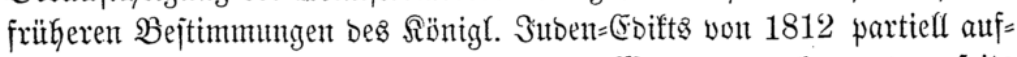

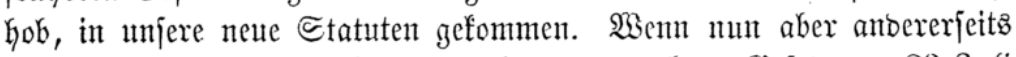

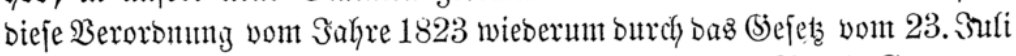

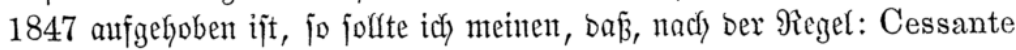
causa, cessat effectus, hiernit nun aud ber (5) runt weggefallen fei, aus

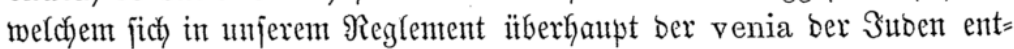
gegenjtełente Biejtimmungen befinben. Da auperbem in unjerem gegen=

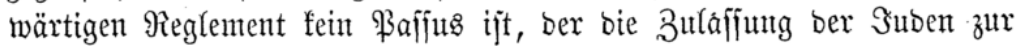
Müroe einę professor extraordinarius unt ordinarius berböte, fo entjteht baburd) ber feltiame Wiberfpruch, są bie ßulfajiung zur höheren Sürbe geftattet, zux geringeren aber verboten ift, fo bá bie holge bor=

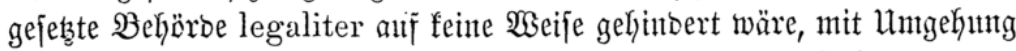
ber verbotenen, aber autd nicht nothwendig erforberfichen \$rivatoojentur

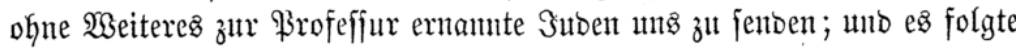




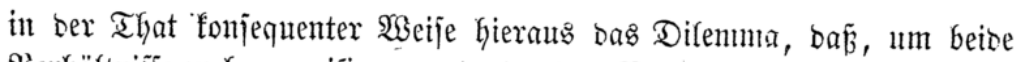
Berbältnifje zu harnonifiren, entweber das Betreffento bes $\$ 29$ unjerts

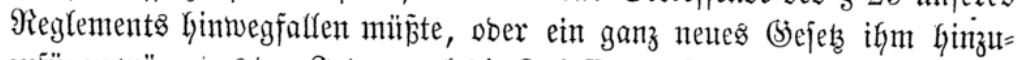

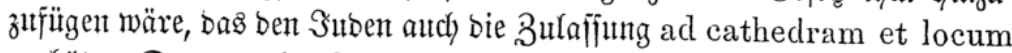
verböte. Da nut aber Rețteres gleichfarfo nicht möglich ijt, ba es jich mit

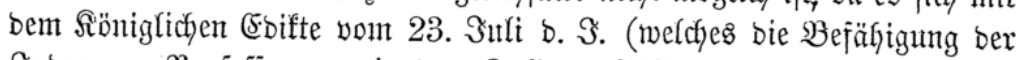

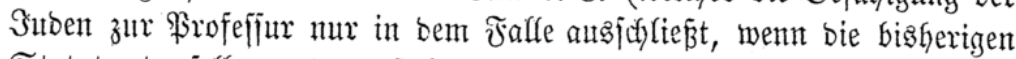
Statuten benjelben entgegenjtełen, was hier nur bezüglich̆ jtattfintot) in

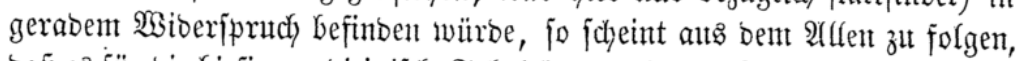

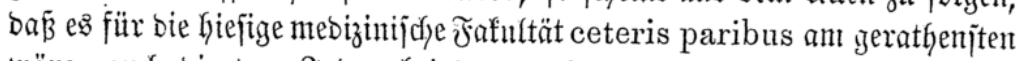
wäre, auch bie bent Juben bei ber venia privatim docendi entgegen=

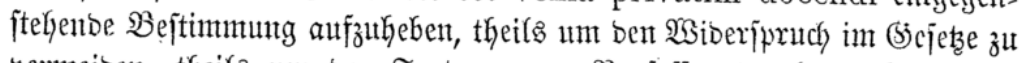
verneiben, theils um ben Fortgang jur \$rofeifur burch bie Stufe bęr Frivatiogentichaft zut jichern, theits um unjere afabentijdjen (S)jetze mit bent Staatggejetzent in Einflang zut bringen, um fo mehr, ba burd) leţtere (bas

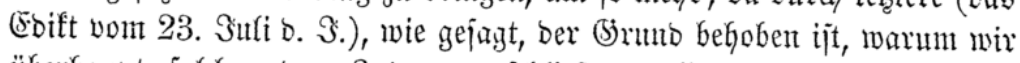

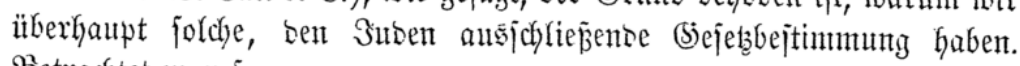
Betrachtet man ferner

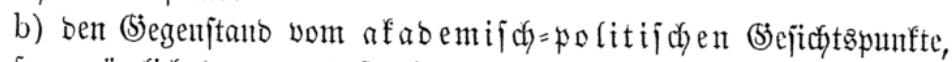
intwiefern nämlich Darauts, Daj alttejtantentarijche Befenter jut Göherent

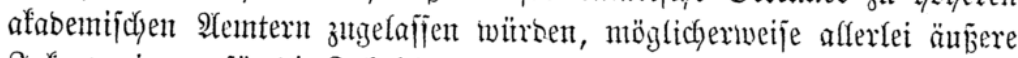
Эnffonventienzen für bie Fafultät uno Univerjität erwadjjen fönnten, fo bit

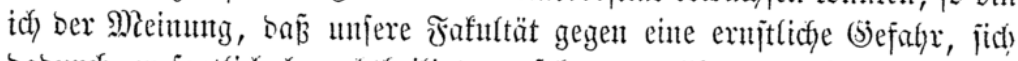
baburch wejentfich bentadytheiligt ju jehen, vollfommen imb vieffältig

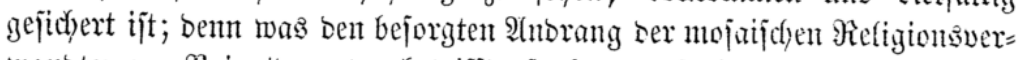
wanbten zux Friwatoozentur betrifit, fo hat bie Fafultüt ein fouberaines

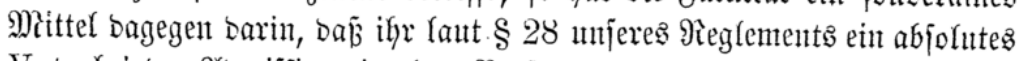

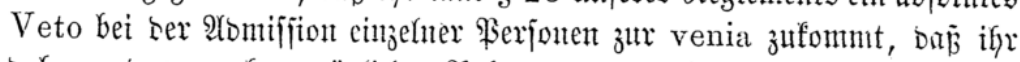

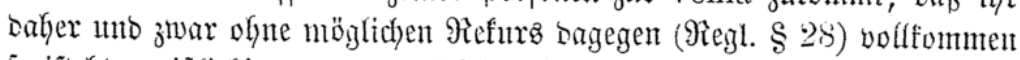

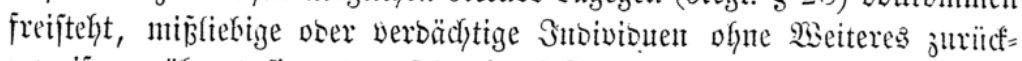

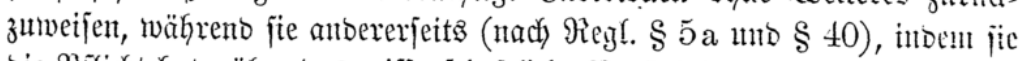

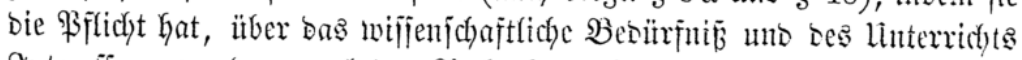

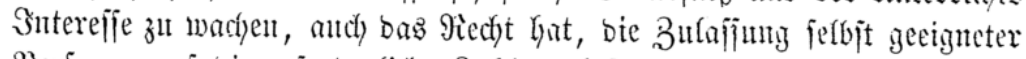

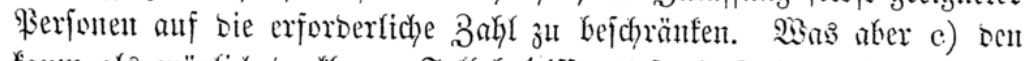
faum als möglich) benfbaren Fall betrifft, baj bie Fafuttät jemats an: lauter inbefanablen \$erjonten bejtänbe, unb weber in Sente repräjentirt

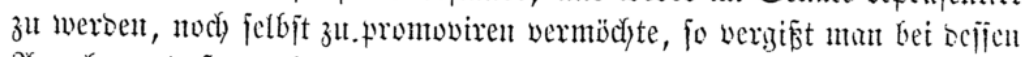

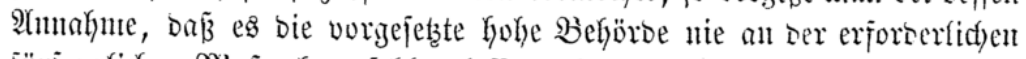

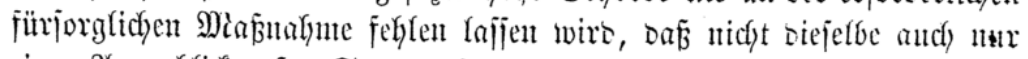

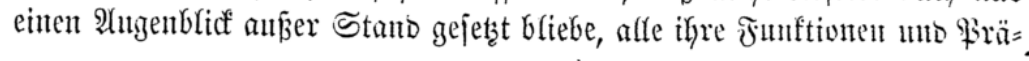




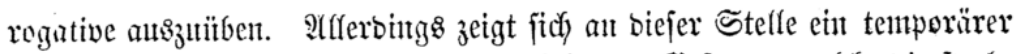

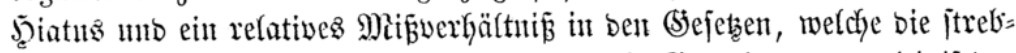
jainen jübijd)en Süntglinge gleidyfam wie nit (Sewalt ben mebizinifhen

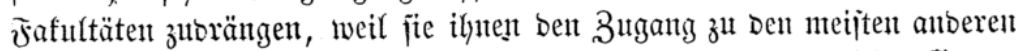
Blacirungswegen verjagen; idh) glaube aber nicht, baj ein logifd)er (Strund

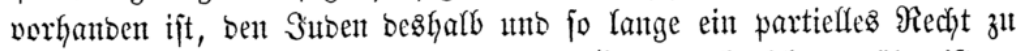
verweigern, als ihnen unb weil ifnen bas (șanze nody nidyt gewälyt ift.

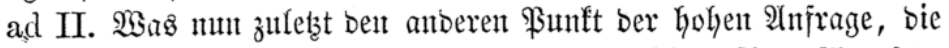

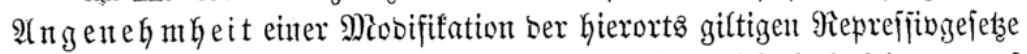

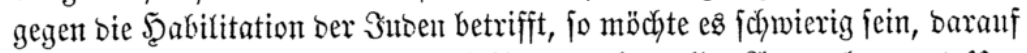

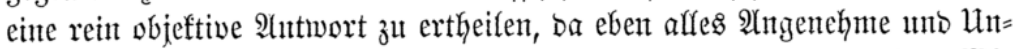
angentehme in bas (Sebiet Des Subjeftivent unt ßerfünfidyen fällt.- Wie

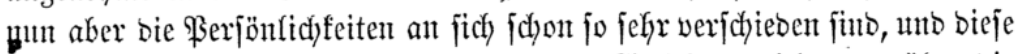
bier insbejonbere von jehr mantigfaltigen $2(n j$ jichten nidyt nux itber bie

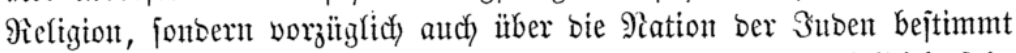
werben, fo möchte bie hoke Behërbe über bie beregte Frage vieffeid)t fehr heterogente $\mathfrak{A n t w o r t e n}$ erhalten, bie jie inbefjen nady bem Merthe unb oer

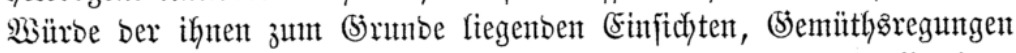

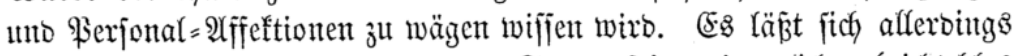

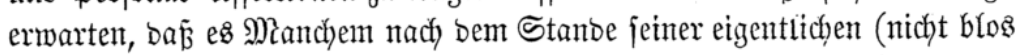
gelehrtent) Bilbung, feiner \$räoffupationen unb inbivibuellen Stimmungen jefr unangenefun erjchenten bürfte, in consessu ordinis.neben einem Suben fitsen zo minffen, wogegen anbere vielleicht fich weniger baburd) beunruffigt finben witroen, unt es wirb nur baranj anfonuten, in wieiveit joldyen perjönlidyen Empfintungen ïberhaupt Folge jut geben, im grof́ent (5)anzent bas Staatżgejes, dem Einzelnen fein (Senvifien gejtatten wiro. Mir nun für meine \$ierjon gebietet, glaube idy, meine (5hriften= und

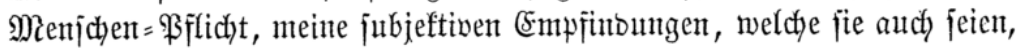
jo weit irgeno möglich, mit meiner 9 bernunft in Einflang jut bringen, unt Da num, ben oben vorange fdjifftent Errwägungen zufolge, eine Mlobififation

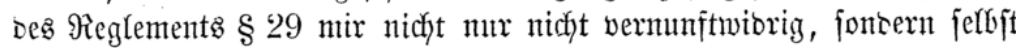
zuläffig uno angemeffen erfdyeinen bürfte, jo mïb)te es mir audy bentgemän nicht unangenehm fallen, went vorbehaltfid) bes ßechtes ber Fafultät gegen bie Einzelnen bie venia docendi bei uns nicht nothwentig an bie Refigion

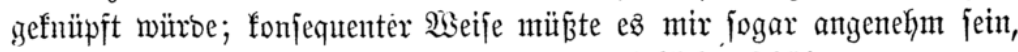

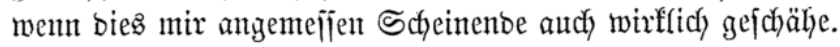

$\mathfrak{B r e s} \mathfrak{a} \mathfrak{a}$, Den 1. Nowember 1847.

benidjel.

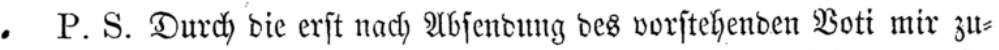

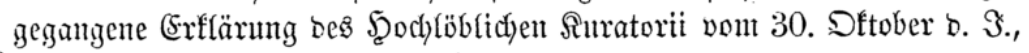


bá

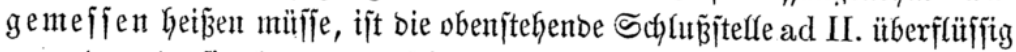
gemorben, ba fie eben mux auf jenem, mix exjt pä̈terf̧in zur Renntni fonmenen Schreibfehler bajirt.

Brezlau, Den 29. 2lovember 1847.

ફ̧enidjel.

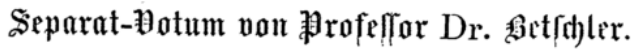

Bei Brantwoirtung ber von einem Şoken vorgeję̧ten Minijterium unts vorgelegten beiben orragen glaube ich ben mebizinifichen. Stanbpuntt

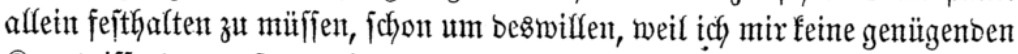

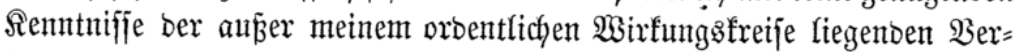
hältnifije zutrauen $\mathfrak{k} a$ nn.

Die erite Frage:

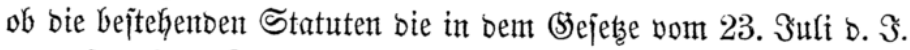

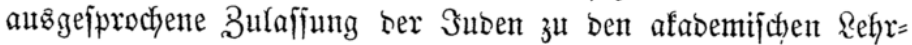
fächern gejtatten ober nidgt?

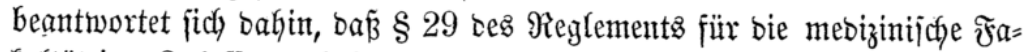

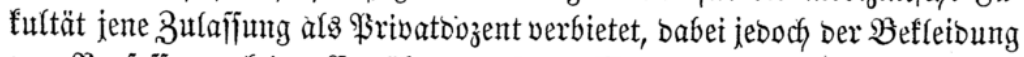
von \$rofefifuren feine Erwähnung thut. Wenn barauts gejdlofijen twirb,

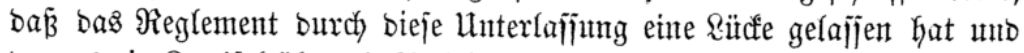

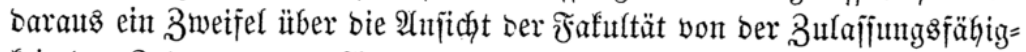

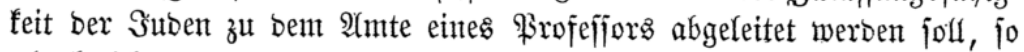

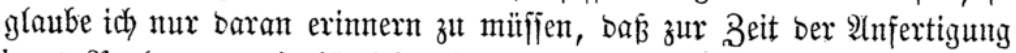

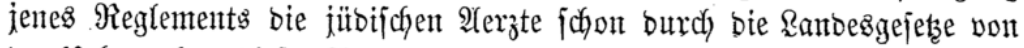

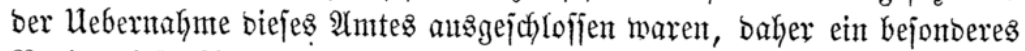

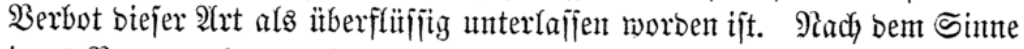
jenes \$aragraphen möchte beshalb wohl zu fdyliefen jein, baj auth bieje Bejtimmung auf bie ßrofefjoren angenventet twerben folfe, unb baj mithin bie zweite frage:

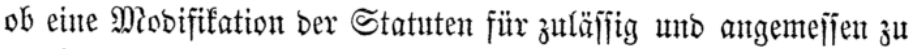
erachtent jei?

zur Erörterunt gelangt.

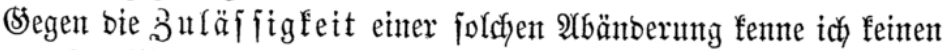

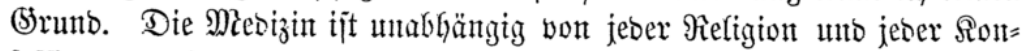

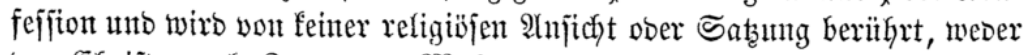

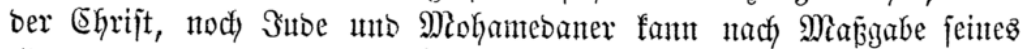
(5) antbens irgent eitent Theil berfelben bejonders beanjprudyen, bent fie ijt

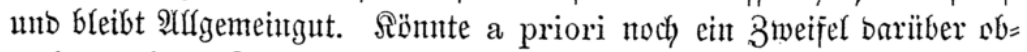

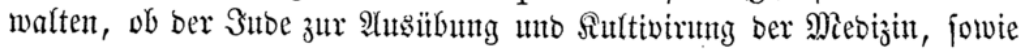




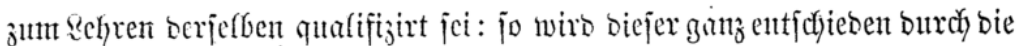

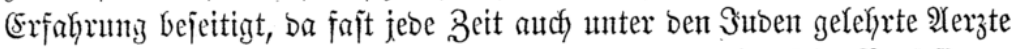
aufjumeijen Gat, unb jerbjt bie nentejte non ber Exijtenz jitbijcher \$rofelforen

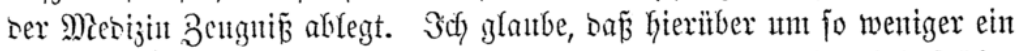

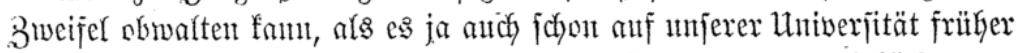

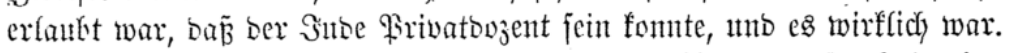

Mit weit geringerer Bejtinntyeit möchte bie ânge me f jen heit einer

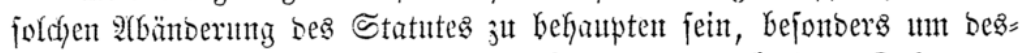
milfen, weil jübijchen \$rofejioren bie Beamtuntg als Sieftor,"Defan und

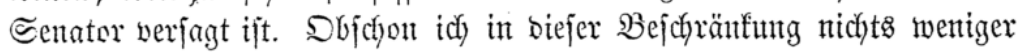

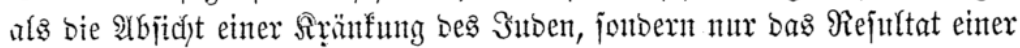

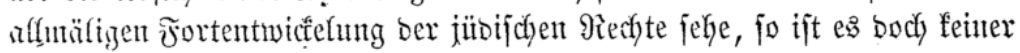
Fafultät ju verargen, went fie jid weigert, Mitiglieber in jich aufjunteynten,

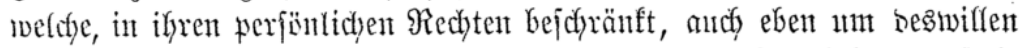

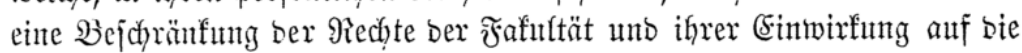

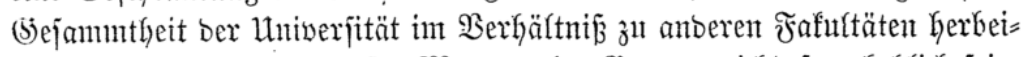

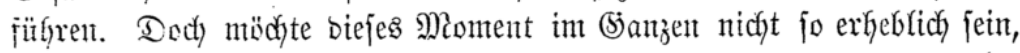

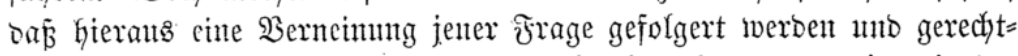
fertigt erfdeinen bürfte, weil es immer noch mefre ober wentiger in ber Macht Des Staates, wie in ben Şändent ber Fafultät liegt, bie Zah ber

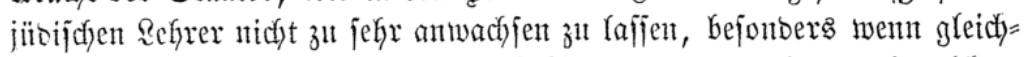
jeitig für bie 2 (ufred)thaltung bes $\$ 28$ Sorge getragen wiro, nach welchem

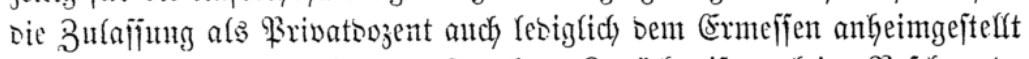
iit, uno gegen bie von ify ausgefprochene Butrïfweijung feine Bejchwerbe bei einer höheren $\mathfrak{B}$ ehörbe jtattfinbet.

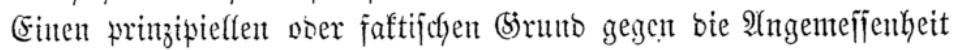
einer Modififation bes \$ 29 mijeres Meglements fentue idy ïberhant nicht, wohl aber theile id mit ben meiften meiner Şerren Soffegen einen aus ber

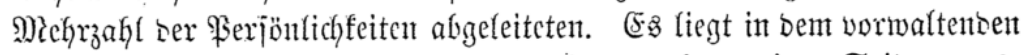

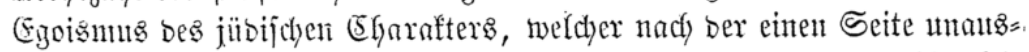
iterlidye $\mathfrak{A}$ rroganz uno (Eitelfeit, nach ber anberen aber eine Betriebjamfeit erjengt, weiche jux Erreidjung bes vorgeftedten Zieles feine humane

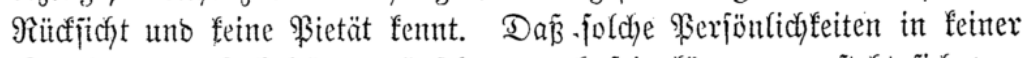

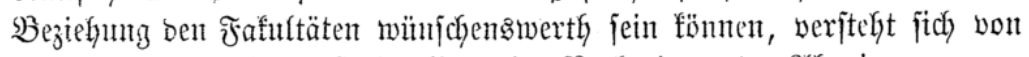
jelbjt, uno beşalb gemiñ bie affgemeine Berbreitung ber âbneigung gegen

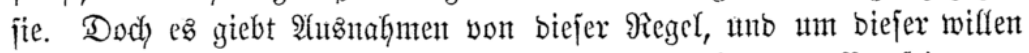
mörste bonn bie in Frage ftełyenbe Mosififfation auch angemeffen fein.

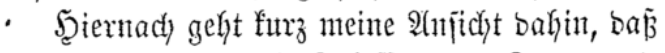

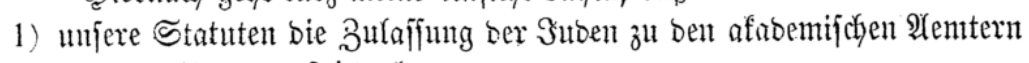
jouar verwieten, báz jebody 
2) eine Meobififation berjelben zuläjiłig, jelbjt angemefien jei, falls ber

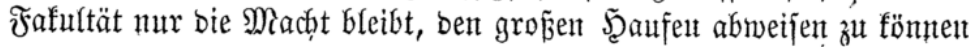

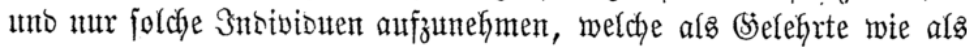
Menjchen gleich achtungsinerth uno biejer $\mathfrak{A}$ uzzeichnung würbig fint.

$\mathfrak{b r e s} \mathfrak{l} \mathfrak{a}$, ben 3. Nowember 1847.

Dr. Betijuler.

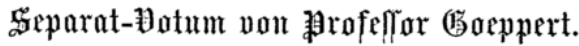

Der $\mathfrak{A}$ ufforberung eines hohen Minifiteriums, mich über bie fünftigen

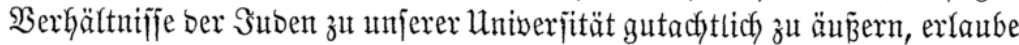

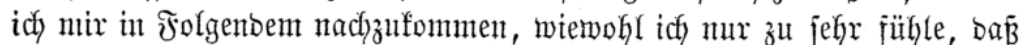
zut einer umfajfenden Beurtheilung biejer Berbältnifje noch ganz anbere Renutnifje und Erfahrungen gefören, alo ich mir in meiner nur ber $\mathfrak{B} e=$

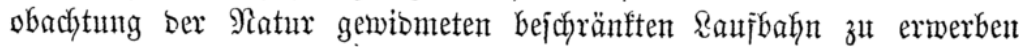
vermodyte.

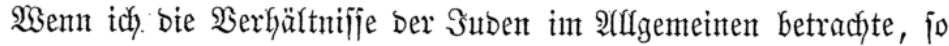

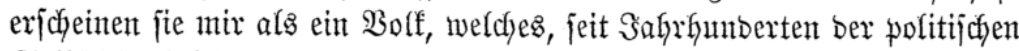

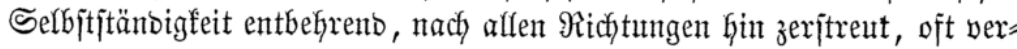
folgt unt jtets unterbrürdt, eben burch bieje traurige rage jich genöthigt fah, mit allen ifm etwa noch zu (sebote jtehenben Mitteln für (5rhaltung

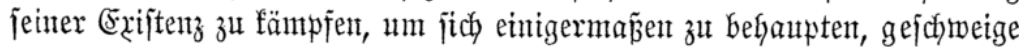

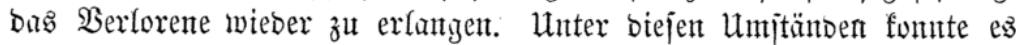
nicht feglen, aber ben aujmerfjamen B̧eobachter nicht überrajchen, bá bie

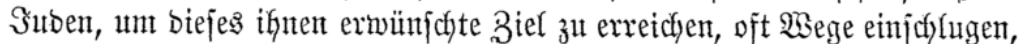
weldye jich bon bem Stanbpunfte ber Moral ano Sittlichfeit nicht immer rechtfertigen liejen, woourdy ber (s)unt zu bem weitberbreiteten Wioer= wiflen gelegt murbe, ber fajt überall bem (S)ebanfen an igre Emanzipation

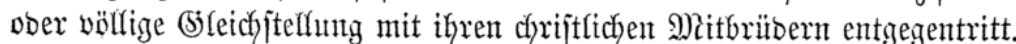

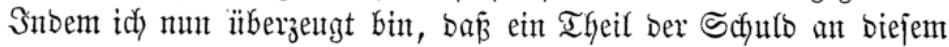

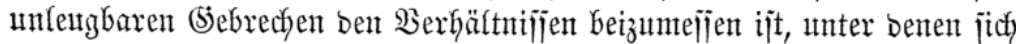
bie Suben befinton, bie iłnen nux eine einfeitige Entwiffelung ber ent=

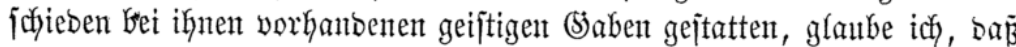
nur burd) eine vöUrize Emanjipation berfelben eine Bejeitigung oiejer Uebel= ftänbe erlangt werben fanm, bie uns jelbjt oft jachon empfintolich beriifgrten.

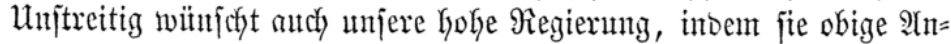
frage an uns fteflte, biejelbe alljubahnen, und ich halte mich baher boppelt verpflidytet, von, meinem Stanbpunfte aus aud baz̆ beijutragen.

Unffäfijg alfo, won bent Stanbpunfte, bent mich bas (şrijtentfum lefyt, ben Suben als meinen Mitbitrgern bie gleiche Berechtigung zur

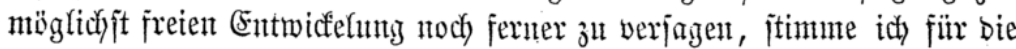




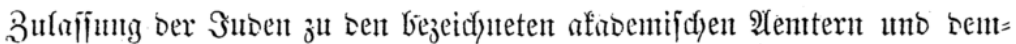

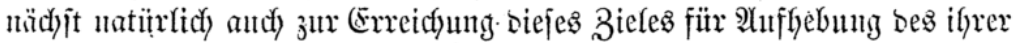
Tufnahme entgegenjteḩenoen \$aragraphen unjerer Statutent.

Bresiall, ben 18. Poventber 1947.

(socppert.

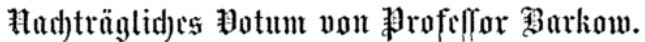

Rach) Einjicht jämmtlicher an 20. D. Mi. eingegangenen Sota Der

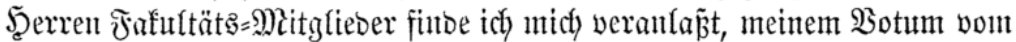
18. Oftober Foligentoes beizufïizen.

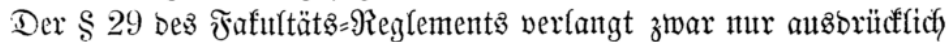

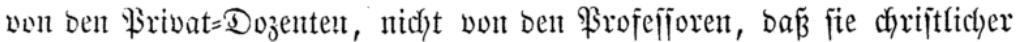

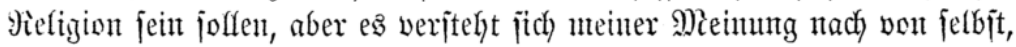
Dußs man bem bie höhere Steflung hat verfagen woulfen, bem than bie niebre nid)t bentlligen zu töntuen geglaubt hat.

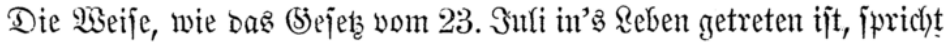
and) unverfentuar hierfür. $\mathscr{A}(\mathfrak{B}$ es bem erjten vereintigten Rantotage vor=

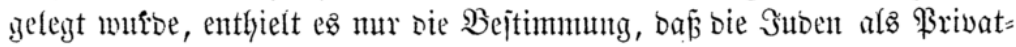
Dozenten und auferorbentfiche Sirofefforen zugelaffen werben fömutent. Das Droinariat murbe erjt jpäter lyingugefiiłyt, wäfrent bie Senatur=

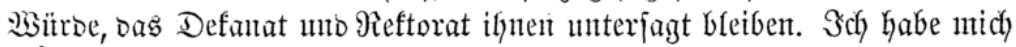

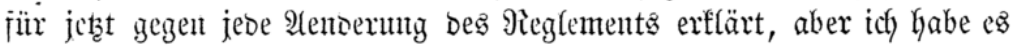

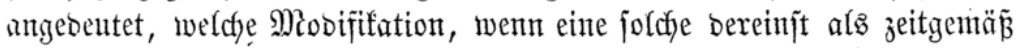

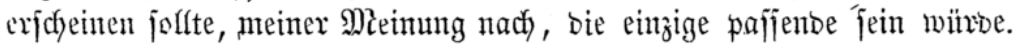

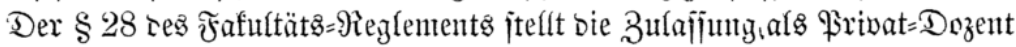

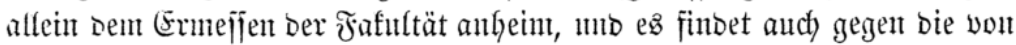

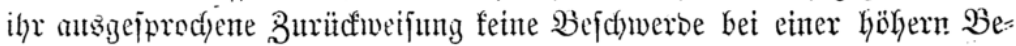

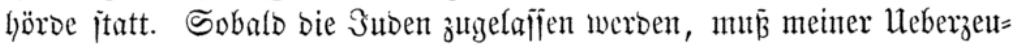
guntg nad) biejer § geänbert worben. Wags bei (Shrijten auŝreicht, genügt

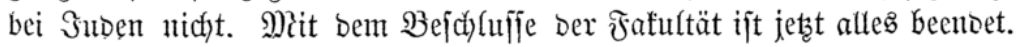

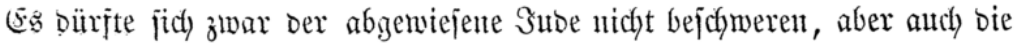

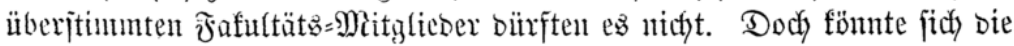

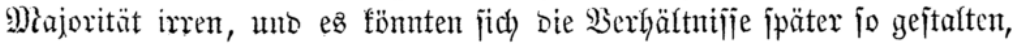
Daj bie Lלerautwortlid)feit gaulz ober jum Theil auf Mitglieber ber Faful= tät überginge, welche in Der Minurität geblieben. Deshalb wïnjache ich für

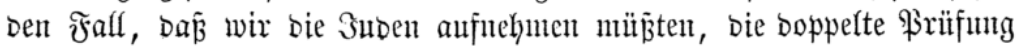
surch bie rafultät unt burch bas hohe Minifterium. Die verneinenoen

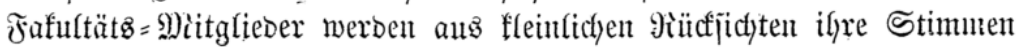

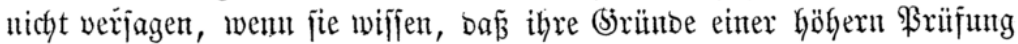
untertiegen, bie bejahenden werden nur um jo wadyjamer fein, und bas 
Bano fann ez bem Goken Minifterium, welchez feine $\mathfrak{A}$ ngelegentheiten leitet,

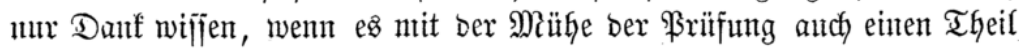
Der Serantwortliçfeit übernimmt. Die Fafultät würbe mit bem $\S 28$

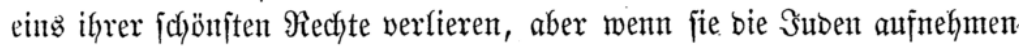

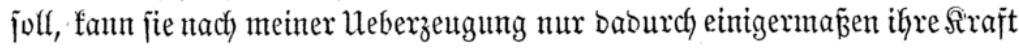
bewahren, baj jie ber Madyt entjagt, jonjt bitrite es mur zul (eid)t eine

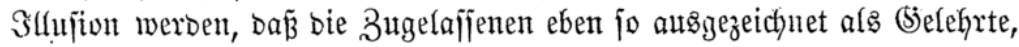
wie als Menjchen feien.

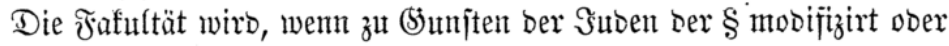
aufgehobent werben follte, es nicht allein mit bem groß̉en Şaufen jübijcher

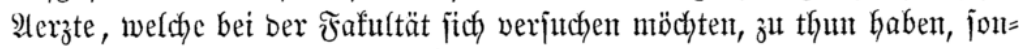

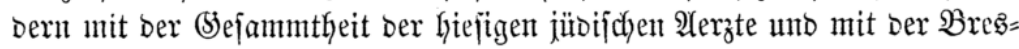

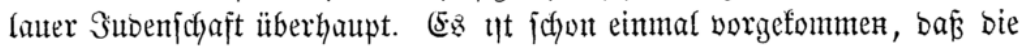

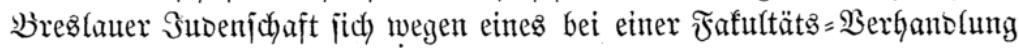

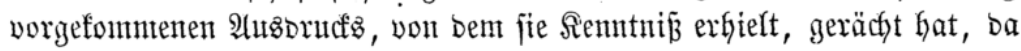

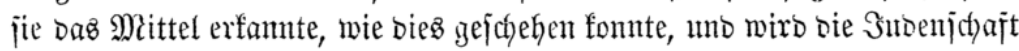
erjt glauben ein Niecht an ber Fafultät ju haben, jo wiro jie bieje als ein ausoritcflich) fïr jie angebahntes, ihyem Betriebe ïberwiejentes ơelo be=

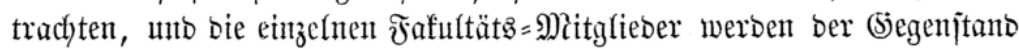
Der Bearbeitung feit. (5: ift nicht jchwer, im Borans zu jehen, was bei

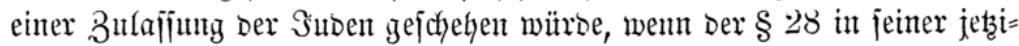
gell (5)ejtalt bliebe.

Bei einer Bejeţıng ber Fafultät, wie bie Kentige ijt, würben vier Stimmen 孔l gemvimnen fein; vier Stimmen find bie Miajorität, bie Miajo=

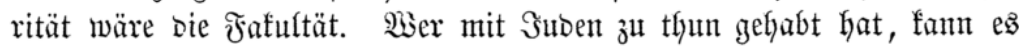
wifjent, wie falwer es hält, jïh) ihyer zu erwehren, wenn jie etwas erlangen

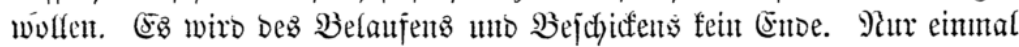

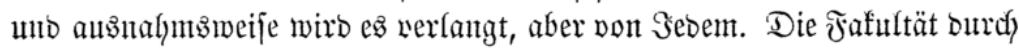

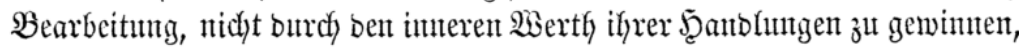
würoe bie 2 Uufgabe fein.

Durcty bie Sota ber ïbrigen Fafultüts = Mitglieber bin idy in meiner

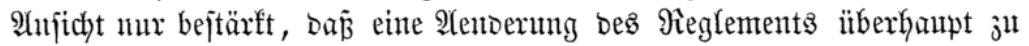

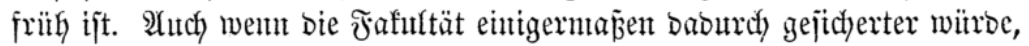
Dás jie einten 9iürfflalt an bem hohen Minijterium erhielte, fo witrde jie bod) bei bent (5rabe, in welchem bie jitbijd)en 2 Serbintungen fier in bie

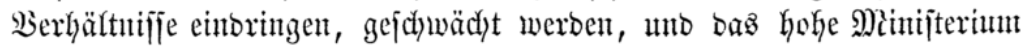

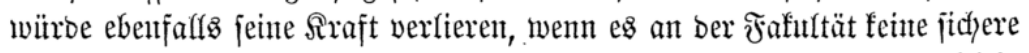

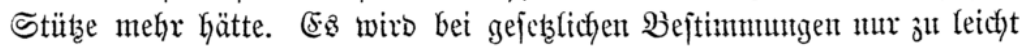
etwas ïberjefyen, unt went ber Simn aud nody fo flar wäre, fo mitroen

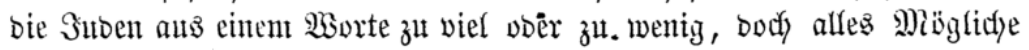


interpretirent. Die Siejetze verfagen bei ben Fafulttätşftelfen ben Sutben

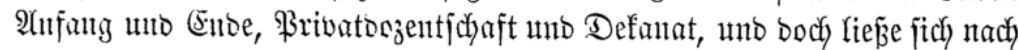

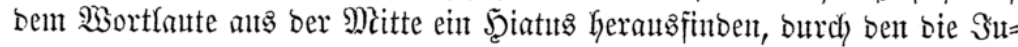

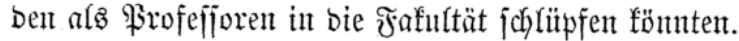

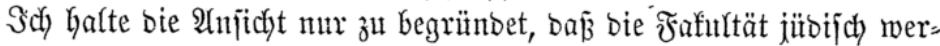
ben wirb, ment bie Schranten gefodert merben jollten, fo lantge ber jeşige (S)eift unter ben Suben fortbautert; unb idd fann für ihye Bulaffung nidst

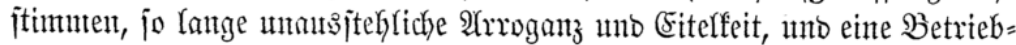
fanteit, weldje jur Erreidyung ifres vorgejtedten Ziels feine humane

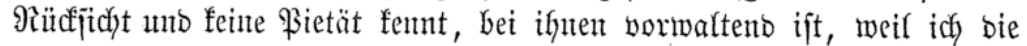

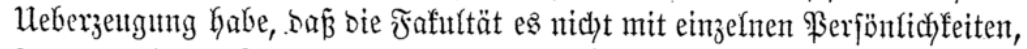

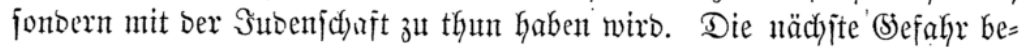

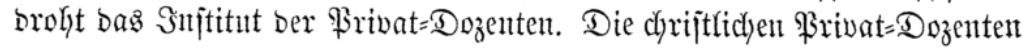
weroen bei ber $\mathfrak{B} e t r i e b j a n f e i t$ ber jübijcyen bie fionfurrenz mit ben jübi=

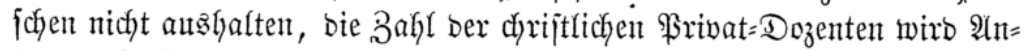
fangs abnelymen, uno bann wirb bas 3njtitut jübijdy werben.

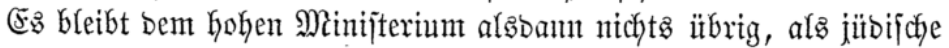

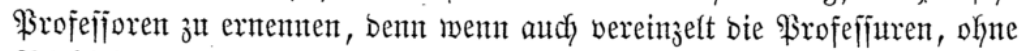

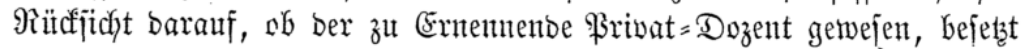

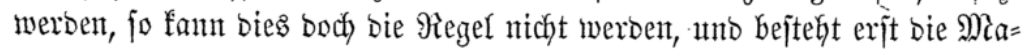
jorität aus Sulten, fo wirb bieje vorfommenton Falles alle Bejtrelungen Der chrijtlidyen Mintorität paralyjiren, unb ber chrijtliche Defan hätte bie jïbijche Fofultä̈ zu repräjentiren.

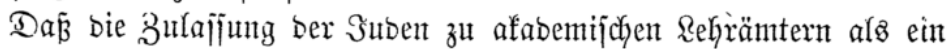
Sorreftionsmittel für ihren Sharafter angenentet werbe, mun ith als un=

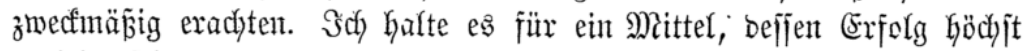
umjicfyer jein, ber wahrjd)einlich ausbleiben wirb, uno aus ben angefithrten (S)rïnden für ein gejährliches Experiment. Die Scumanität verfenne ichs

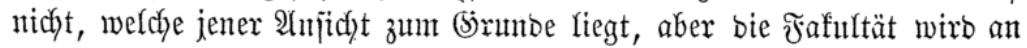

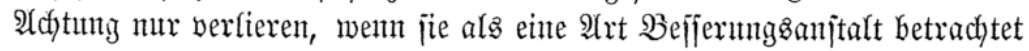
rerben follte.

Bieslau, Den 25. 9ronentber 1847.

5. Barfow.

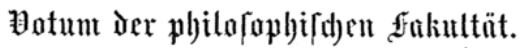

(5n. Seodywohlgeboren beehrt fich $2 c$.

Was bie erjte Frage betrifft:

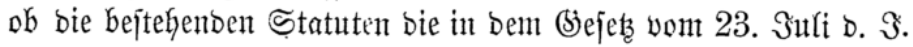
ausgefprochene .̉ulafjung ber Suben zu ben bezeidhneten afabe= mijchen Rehriächern gejtatten ober uicht, 
jo. befeunt fich bie unterzeidynete Fafultät mit bebentenoer Stimmenmegr = heit zu Der Mieimung: Dẩ bie @tatuten bom 21. Febr. 1816, weil bie= jelben in Hebereinjtimmung mit bem oamals in Iraft bejtehenden und erjt

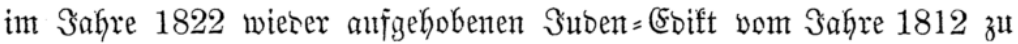
interpretiren fino, bie quäst. 3ulajīung ber Suben gejtatten; was un jo

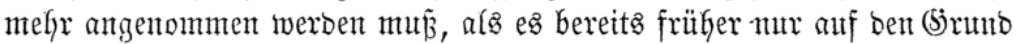
Des erwähnten sobiftz von 1812 und ber Daburch geforberten Snterpreta= tion ber Statuten einem jübijcyen (Sielehrten, Dem jez̧igen Sanitäts=?ath Dr. (5)uttentag, möglich getwejen ijt, Bribatbozent. in oer medizinijacten Fafultät hiefizer lniverjität zu jein.

Die ziveite đrage:

ob, weun bie Ctatuten bieje 3ulajpung nicht gejtatten, eine Modi=

fifation berjelben fïr zuläfijig uns angemefien zu exachten jei,

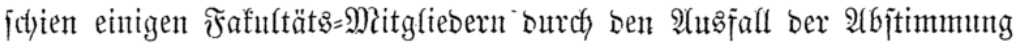
ïber sie erjte Frage fdyon von felbjt erlebigt. Da jeboch bieje Injicht bejtritten murbe, jo fam audic bie zmeite Frage nach bem angejitifrten Wort= laute zur bejonbern भibjtimmung, aus ber jidf ergeben hat, baj bie unter= zeichnte Fafultät in oer Mehrzahl ifrer Mitglieder eine Mrodififation ser Statuten in bent Gypothetijdy angenomntenten Falle für zuläjïg und angentejen erachtet. Die Fafultät bejabet aljo mit Stimmenmebrkeit bie

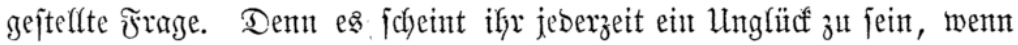
ein Staat berjafiedenartige B̈̈lfer, ober in bemjelben Solfe jo jtarfe

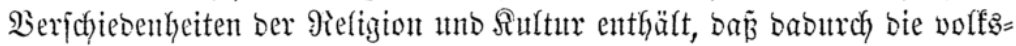

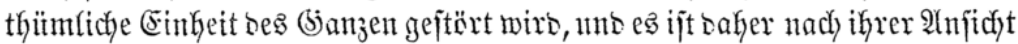

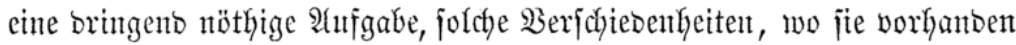

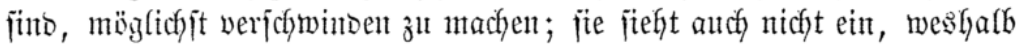

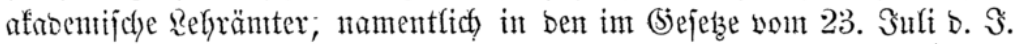

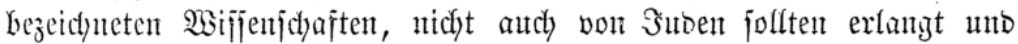

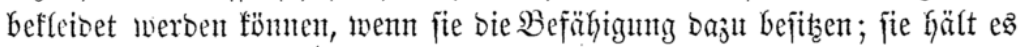

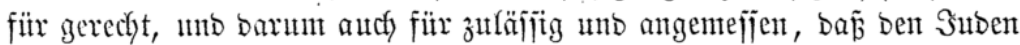

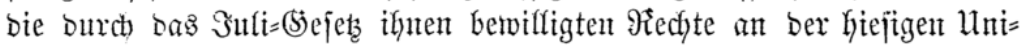
verjität nidyt ferner verjdyränft bleiben; fie vermag barin and eine

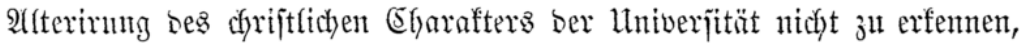

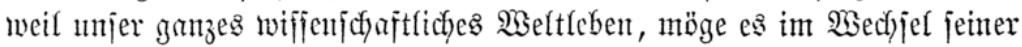

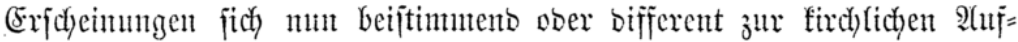

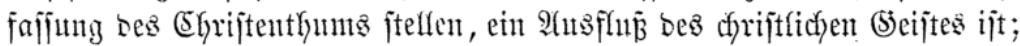

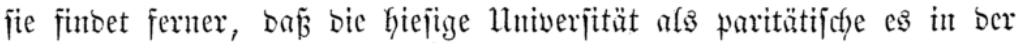

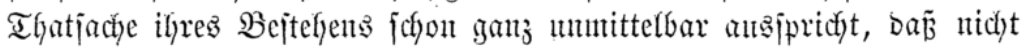

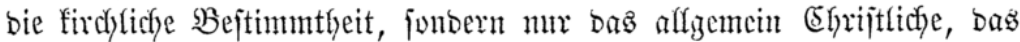

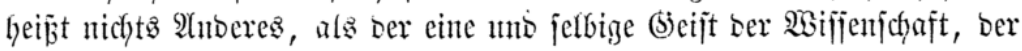




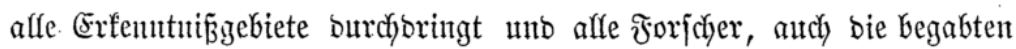

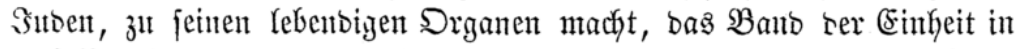

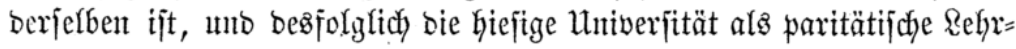

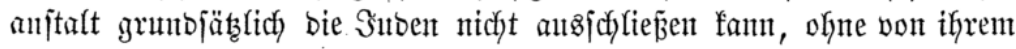

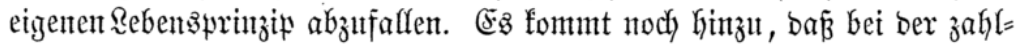

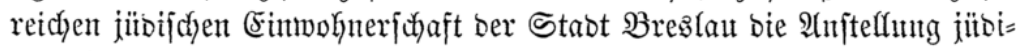

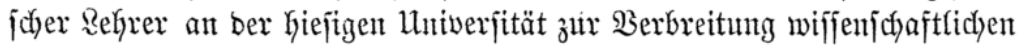
Snterefīes unter ben Suben nidft wentig beitragen bïrfte, unb bar anberer=

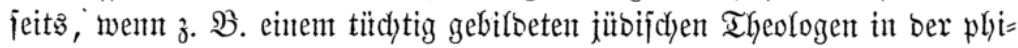

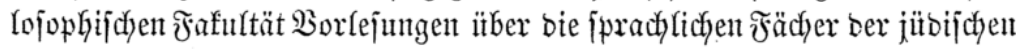
Thevlogie, bent Talmub unb bie fpätere jübifche Riteratur. zu halten ver= jtattet witroe, aud ben dyrijtlichen Theologen und Drientaliften bie (Erwer=

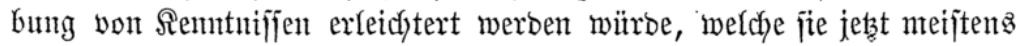

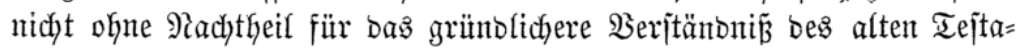

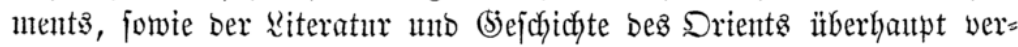
nach) (äfïizen. Dies aljo jüto bie Strïnbe, aus benen bie unterzeichnete

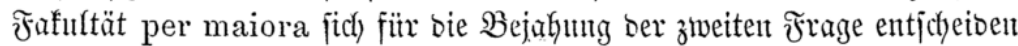

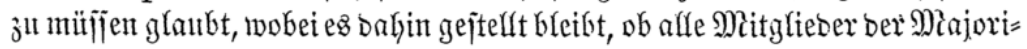

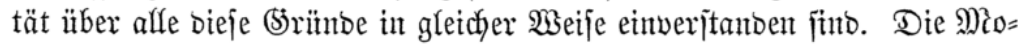
tive ber Mincrität für iłre entrgegengejetzte Mreinung find in ben Separat=

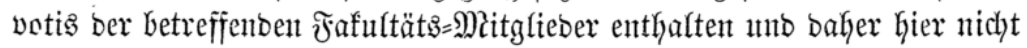
mit aufgenomumen worben.

Anlangent bie britte Frage:

ob bie Bejtimmung im Reglement ber philofoplifichen Fafulttät, nach welcher bie 3ulajiung zut Doftor=\$romotion von bem chrijt=

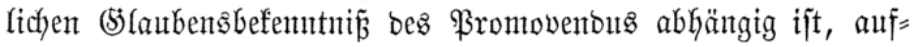

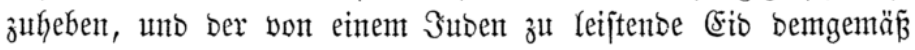
a ğ uänoern jei,

fo glaubt bie unterzeidfnete Fafultät, ihren bieģälfigen 2 (ntrag vom

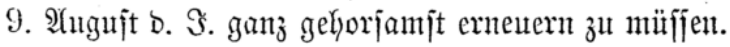

błregla u, ben 20. November 1847.

Die philojophificue Fafultüt.

(Unteridjuiften.)

\section{Motum des lackitor und Senuts.}

Breśa au, ben 31. Jamar 1848.

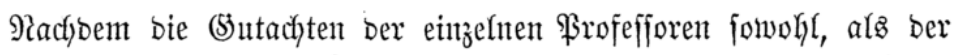
sejaumten Fafultäten aflen Mitgliebern bes afabemijchen Senats nach ber

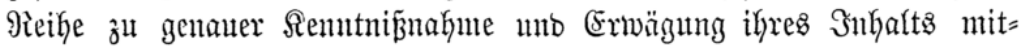


getheilt worben waren, wurbe in ber Siţung vom 22. Samuar jolgentes Senat $=$ =(Sitachten beich)lofien.

Da ber Senat unter bejtehenben Statuten ber Giejigen Univerjitüt nutr bie im Эałre 1816 von Sr. Majejtät berjelben ertheilten Statuten verftehen zut bïrfen glaubt, und in biejen nicht mur nichts ser 2 njifellungs: fähigfeit jïbifduer Dozenten Şinberlidyez entfyalten, fonbern aud anju=

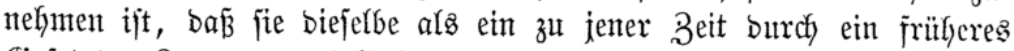

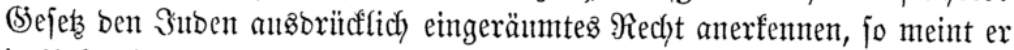
in Ulebereinjtimmung mit ber Mebrzahl ber Fafultäten sie erjte Frage:

ob bie bejtehenben Statuten ber hiejigen Mniverjität bie in bem

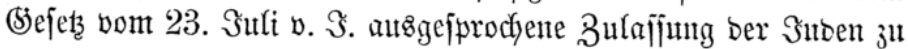
ben bort bezeichneten afabemijchen Rehrämtern gejtatten ober nicht, bejaken zat nuitffen. Diejer Meinung war bie Şälfte ber 14 Mitglieber,

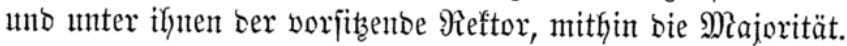

Die alts ebenfalla 7 Mitgliebern bejtehende Minorität meinte ba=

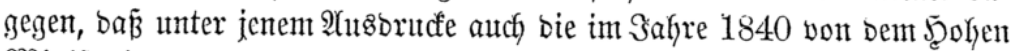

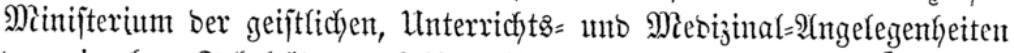

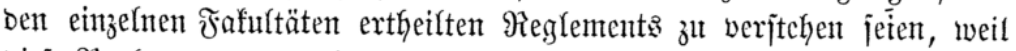

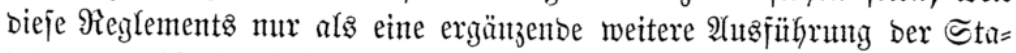

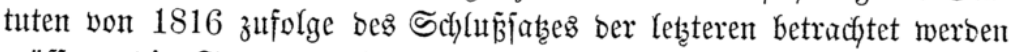

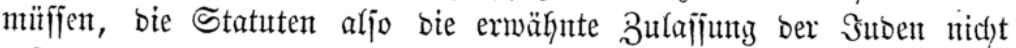
gejtatten.

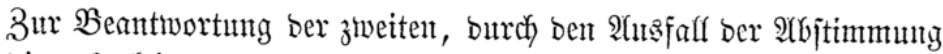
iiber bie erfte feineşwegs jabun erresigten Frage:

ob, went bie Statuten bieje 3ulajintung nidht gejtatten, eine Mabi=

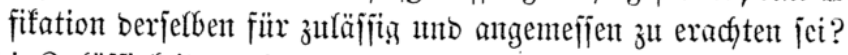

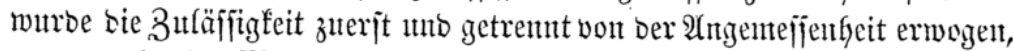
unto burch) eine Majorität von 9 Stimmen angenommen, baj in scm voratıgejeţten Falle eine Mobifitation ocr Statuten jutläjifig jei, ba in ben Statuten, was man aud) unter biejem 2 hasbrude verjtehen mag, nichts

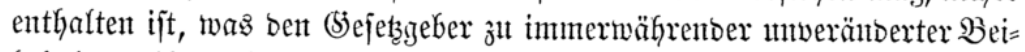
behaltung ifyrer Bejtimmungent nöthigen fünnte. Dagegen nurbe bic 2 tu= gemejēenfyeit einer folchen Mrobififfation mit einer Majorität von 8 Stim=

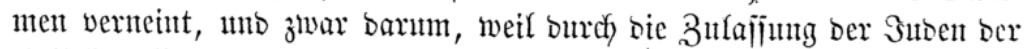

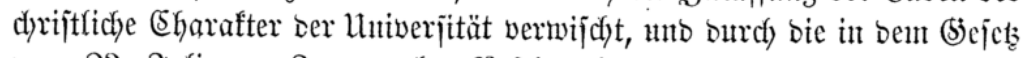

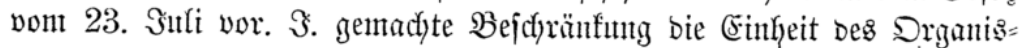

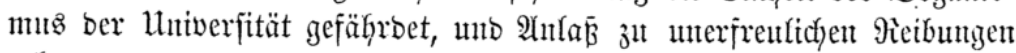
gebent werbe.

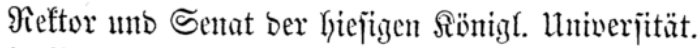

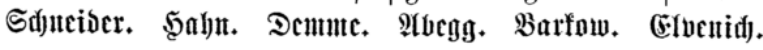




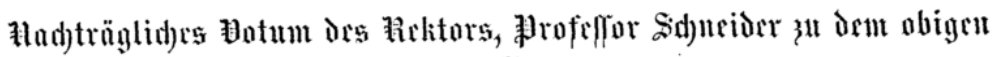 Senuts-Botum.}

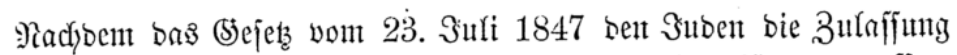

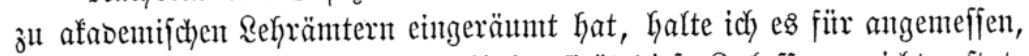

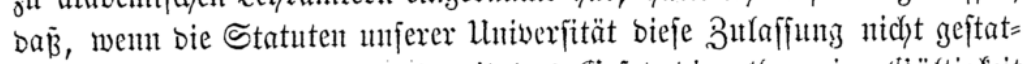
ten, fie abgeäntoert werben, bamit bas Biefeş bie allgemeine (5)ïltigleit

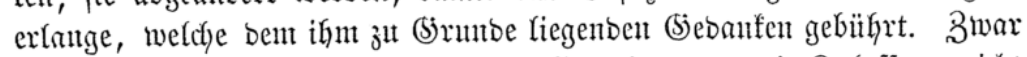

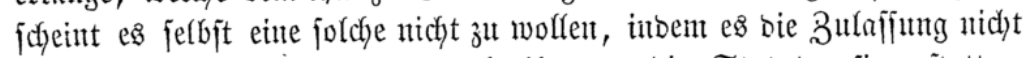
unbebingt, fonbern: nur ba vorjdyreibt, wo bie Statuten fie gejtatten,

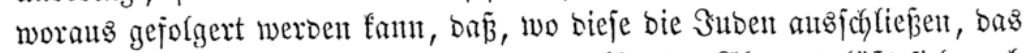

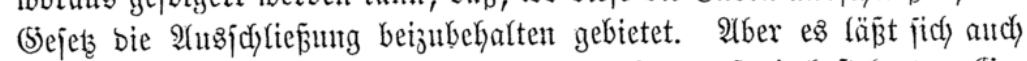

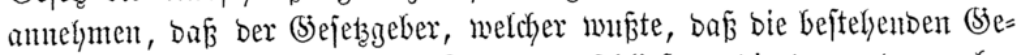

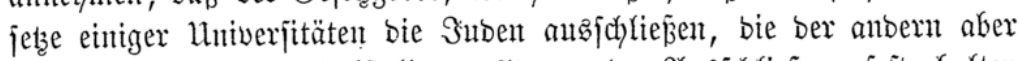

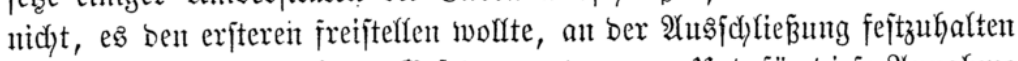

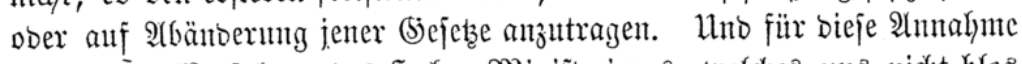

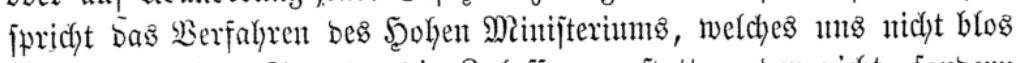
fragt, ob unfere Statutent bie Bulaffung geftatten ober nicht, fonberut auch, ob wir, wenn fie jie nidft gejtatten, eine Aenberung berfelben fïr

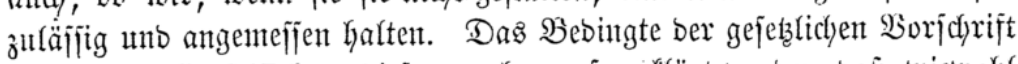

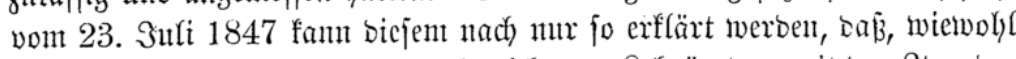

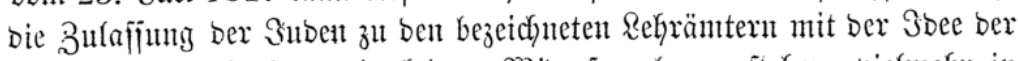

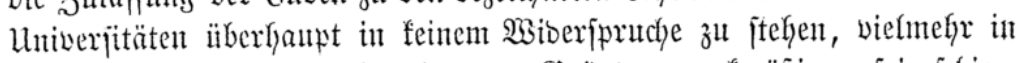

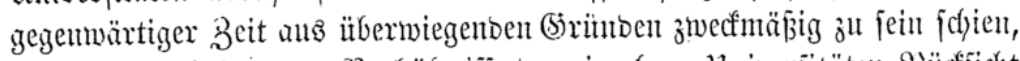

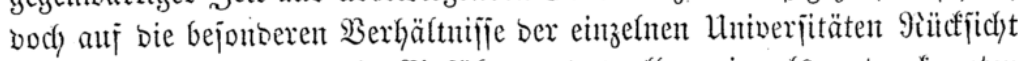

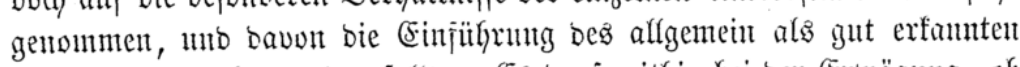
abgängig gemadyt werben jollte. (5s barf mithin bei ber Erwägung, ob

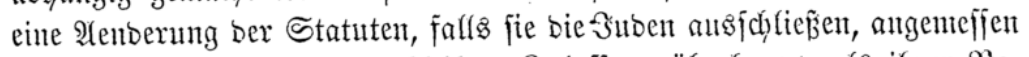

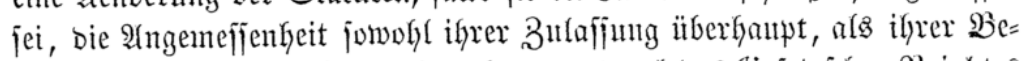

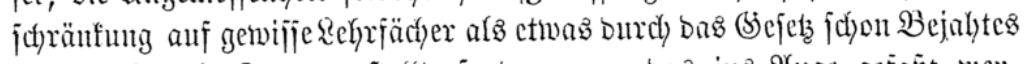

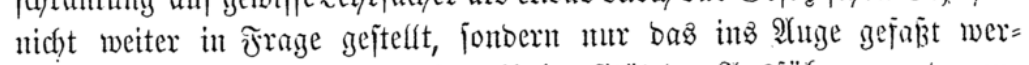

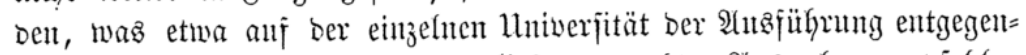

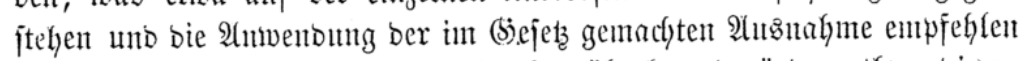

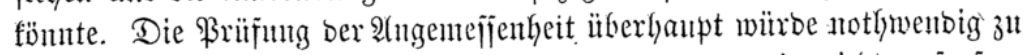
ciner Brüfung bes Befetzes jelfjt führen, zut ber wir nicht aufgefor= Dert finto.

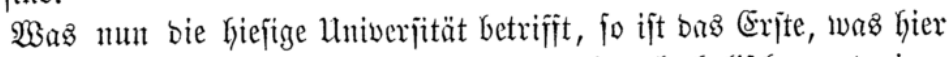
in Betracht fonmen fam, biejes, oñ jie, aus einer fatholif́cyen unto einer evangefifhen hervorgegangen, in ihrer (sinridytung auf beibe sonfeffionen 


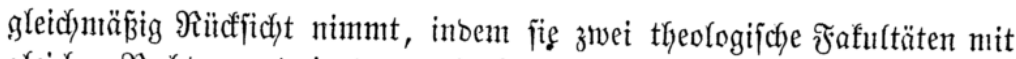

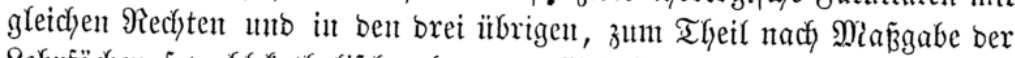
Relyrfächer, fowohl fatholifche als evangelijche \$rofefforen hat. Der Ziwed hierbei ift, beiben Sirchen ifyr Bejtehen injofern zu fichern, alz biejentigen, bie fich Den $\mathfrak{B i f f e n f c h a f t e n t ~ t w i b m e n t , ~ i n ~ a l l e n ~ F a ̈ c h e r n ~ f o l d h e ~ R e g r e r ~ v o r = ~}$ finben, bie, mit ifnein einerlei firchlichen (s)lauben habeno, aud ¿as, was

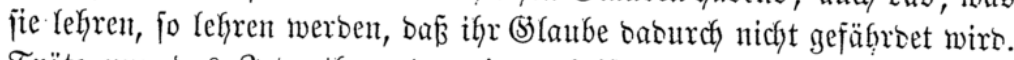
Träte mut bas Subentfyum ber einen chriftlidyen Sionfeffion megr ent=

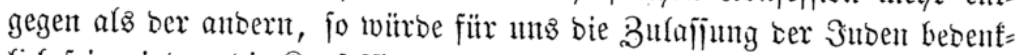

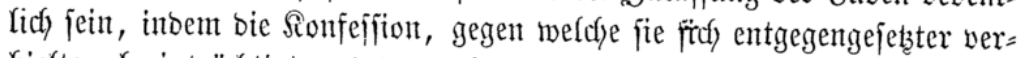
Gielten, beeinträchtigt, unb buburd; bas bei uns beabjichtigte (3) feich)gemidyt

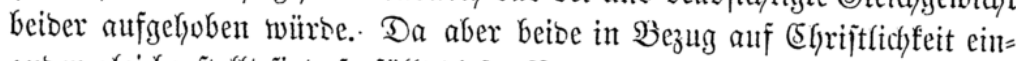
anber greich)gejtelft fint, fo fällt biejes becenfent hintweg. Demjentgen aber, weldyes, wenn"es ftatthaft wäre, won beiben Sonfeifionen gemeinj(d)aftlid'

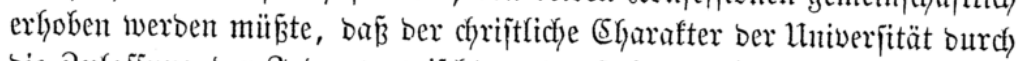

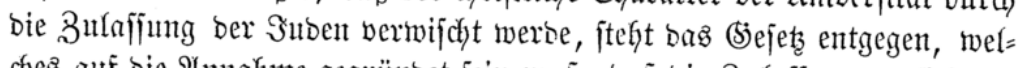

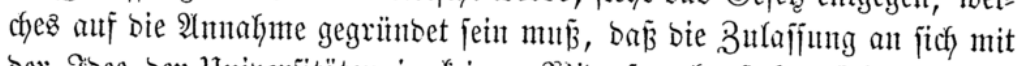

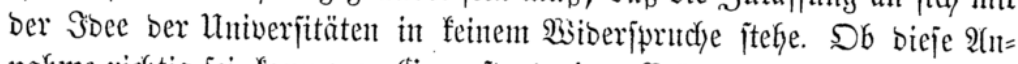
nahme ridjtig jei, faum zum (Siegenitand einer Erörterung, eine foldye $5 x=$ örterung aber nidyt zum Snfyalte bes erforberten (Sittachtens gemacidt werbelt.

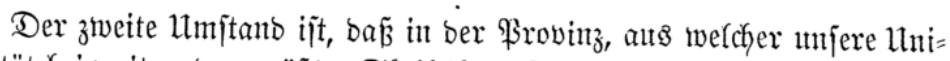

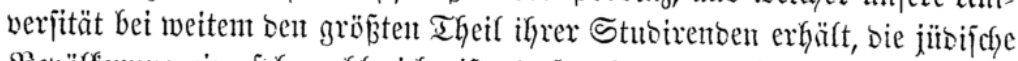

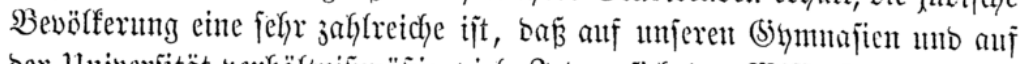

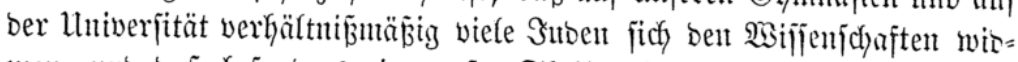

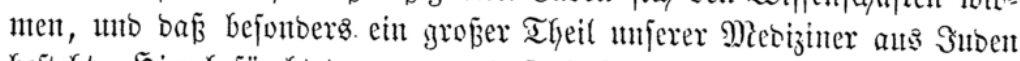

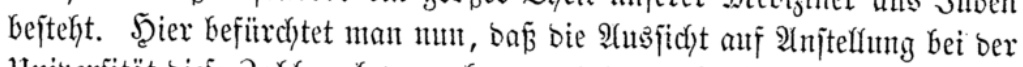

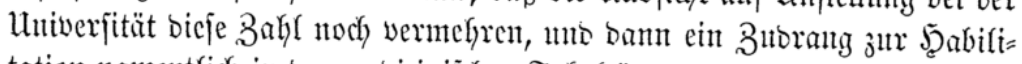

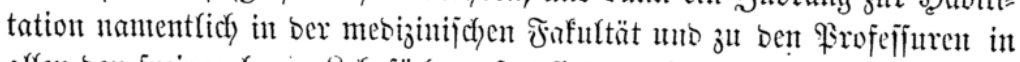

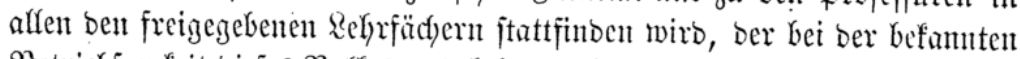

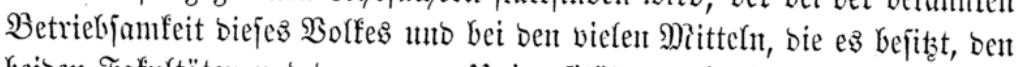
beiben Fafurttäten uno ber ganzen Univer jität mancherlei Untbequemtic)feit

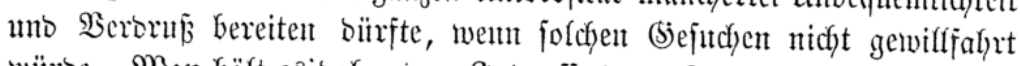
würoe. Man hält es'baher oem Sntereffe ber gefanmuten luniverjitüt fïr

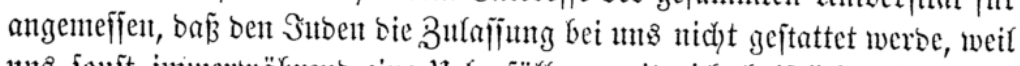

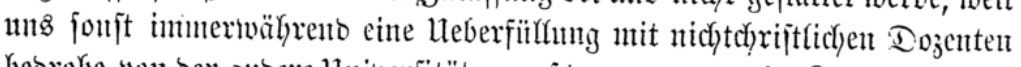
bebroke, won ber anbere Univerjitütent, anf benten mur wenige Snben jtutoiren,

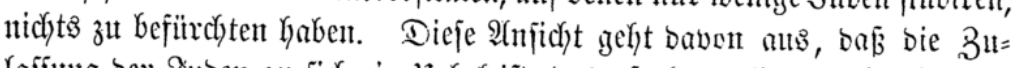

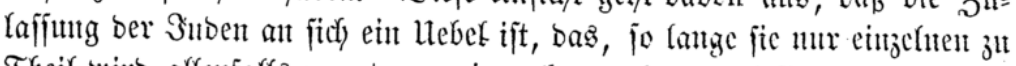
Theil wirb, affenfalfa jut crtragen, je mefyrere afer jugchijent werben, bejto 


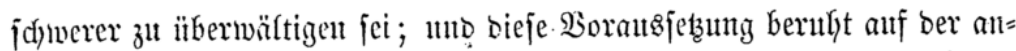
genommenten Unwerträglichfeit bes jübifchen uno chriftlichen (sharafters, bie von bent (Siejetze nicht angenommen rvirt. Mebrigens ijt gerabe

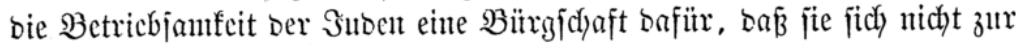

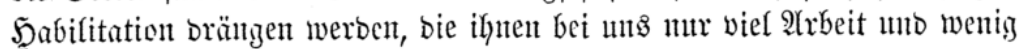

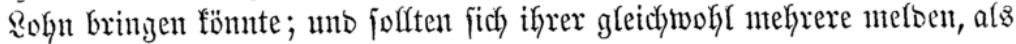

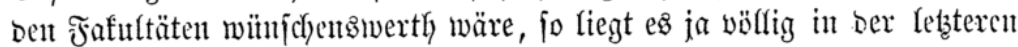

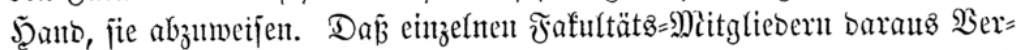

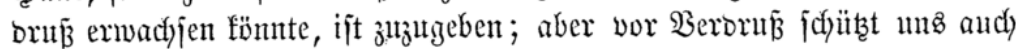

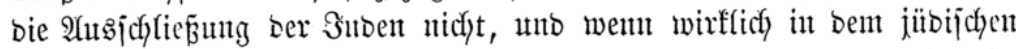

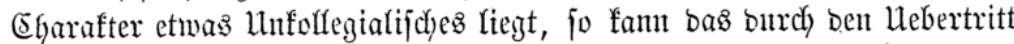
jum (5)rijtenthyum nidyt jo getilgt werben, baj man wohyl mit getauften, aber nicht mit ungetauften Suben in erminlifder (Eintracht jul leben hoffent bitrfte. $23 a \xi$ aber ben 3ubrang zu ben \$rofejïmen betrifft, fo ift biejer

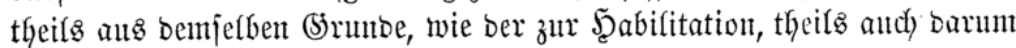

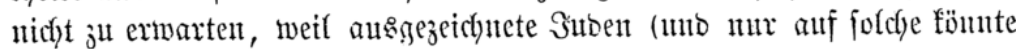

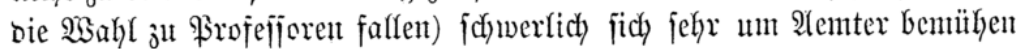
weroen, bie jie nur unter Befchränfuntyen erłhalten fömuten, burdy weldye

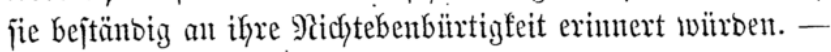

- Bregla ben 10. Februar 1848.

Frofeffor Eduteioer.

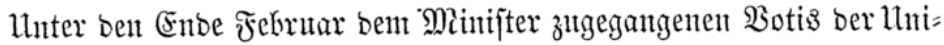

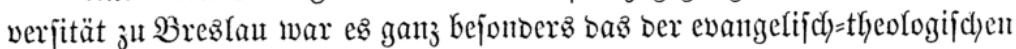

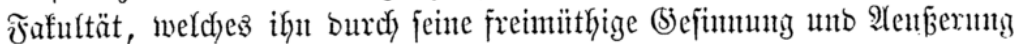
verleşte. Die Folge hierwon war bie nachjtehenbe gejdidytlid) mertiviir= bige Sorrefponbenz, merfwürbig ourch) bas Tatum ber minifterieffen Ser= fütgung, merftnüroiger nody burdy bas Datum unb bie 2(brefje ber ab:

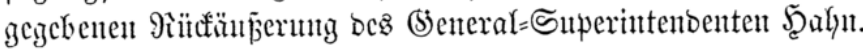

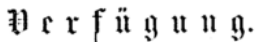

Berlin, Den 18. März 1848 .

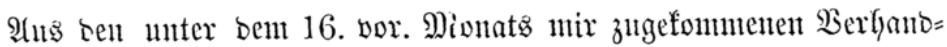
\{ungen ber bortigen Univerjität in Betreff ber Bulafjung jübijd)er Dozenten und Brofefforen bee berfelben nady ben Bejtimmungen bes

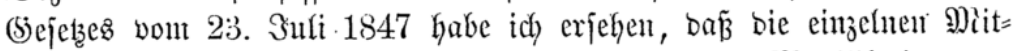

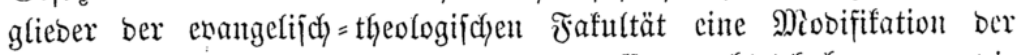
Statuten zu (siunjten Der Suben für angeneffen erad)tet haben, wem die

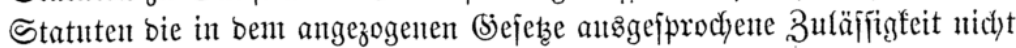

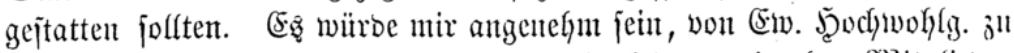

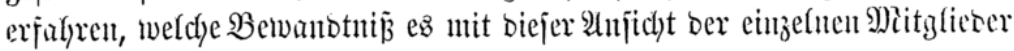


unb ber gauzen Fafultät habe, ba-biejelbe meine bejonbere $\mathfrak{A}$ (ufmerfjamfeit um fo mefr zu erregen geeignet war, als bie einzelnen $\mathfrak{B}_{\text {ota }}$ nicht tiejer in bie Sache eingekent.

$\mathfrak{A} n$ ben (Seneral $=S_{1}$ perintenbenten Dr. $\mathfrak{S a h n , ~}$

5od)nohlgeb. in B̊reslau.
Der Minifíter 2c.

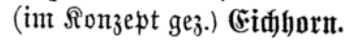

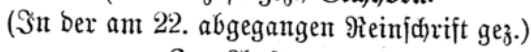

$\Im \mathfrak{m} \mathfrak{A}$ uftrage:

v. Rabentberg.

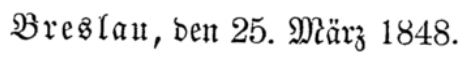

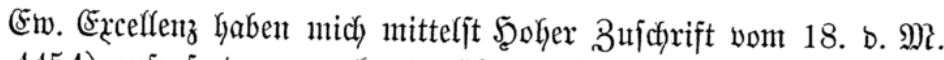

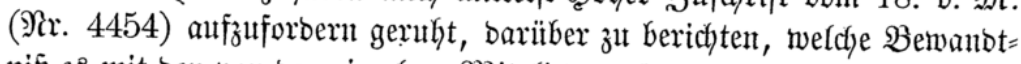
ní̧ es mit bent von belt einzelnen Mitgliebern fo wie bann bon ber ganzen

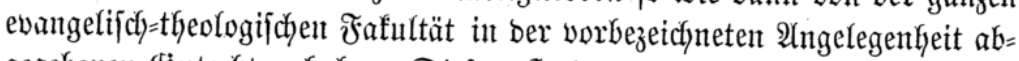

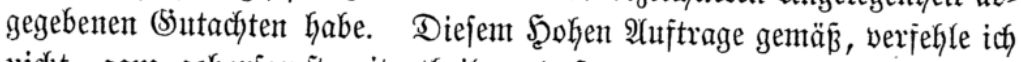
nicht, ganz gehorjamit mitzutheilen, baj won bem jtatt bes erfrantten

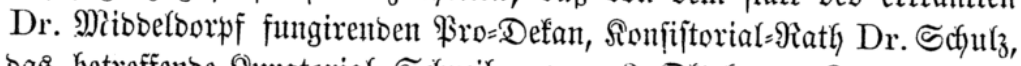
bas betreffende Simatorial=Schreiben nom 3. Dttober v. Э. unter bem 7. ej. in Ulmlauf gejetzt unb bemfelben fojort bon ben einzelnen Mlit= gliebern ifgre Butadyten beigefügt 'wurben, wie fie Ew. Excellent werbent vorgelegt worben feit. Da balb barauf ber Defanatz=\$2edjfel eintrat, jo wurbe auf Grumb ber im 2 Sejentlichent itbereinjtinmenten Singular=2ota bie Faffung bes (Sejammt=(Sutachtenz unter meinem Borjit von jämmt=

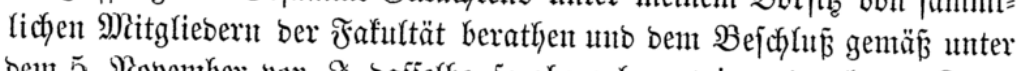

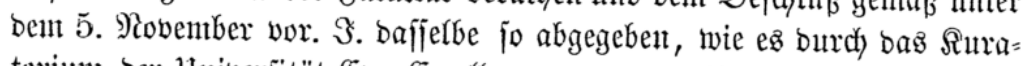
torium ber Univerjität Giv. Exceflentz zugegangen ift; eine irgent wejent= liche Berichiebenheit ber Meinungen ifit bei biejen Berathungen ber Fafultät nicht hervorgetretent.

Dieje trat jeboch in anderṇ Fafultäten, bejonbers aber bei ben all= gemeinen Berathungent int Sent herbor, unb Gier wurbe burch bie.

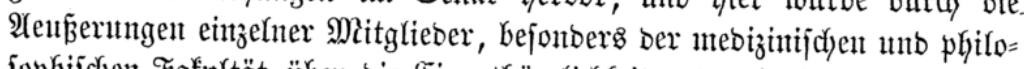

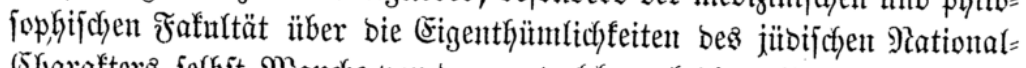
Eharafters ferbjt Mianche von benten, welche unbebingt fïr bie Bulajiung jiibijucher Dozenten geftimunt hattent, wie idy jelbit, an ber von ihnent

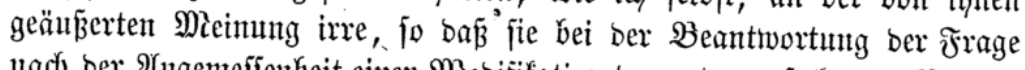
nady ber $\mathfrak{A}$ ngemeffenkeit einter Mobififation ber entgegenjtelyenben $B$ ejtim=

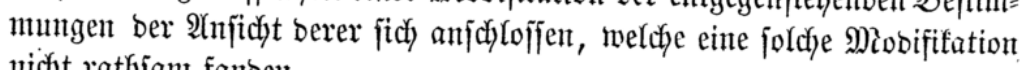
nicht ratbjant fanbent.

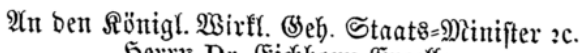

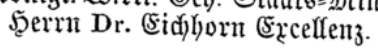

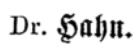




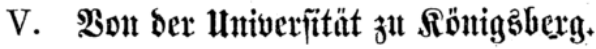

Botum ior modiziniliden fankultät.

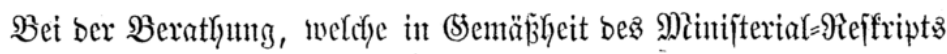
wom 28. Septentber 1847 won ber ntesizinifchen Fafitttät gehalten morben ijt, jtimuntent in Seziehung anf bie erjte ber beibent Fragen, weldye biejem Meffript juffolge beantwortet werben folltent, bie antwejenben Mitglieber ber

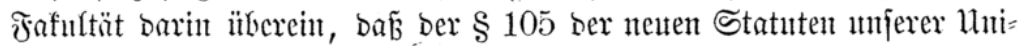

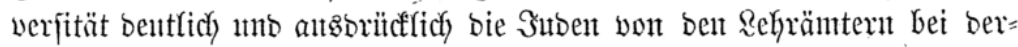

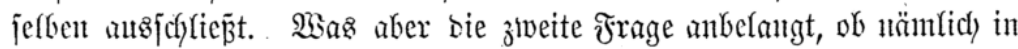
bem Fralle, baj bie Statuten eine Zullajfung ber Suben zut ben afabenti=

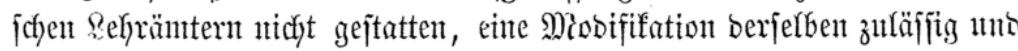
angenteffen jut erachten jei, jo erffärten jid żwei Mitglieber ber Fafutttüt,

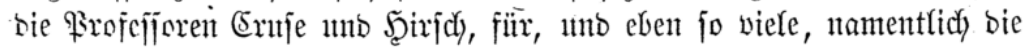

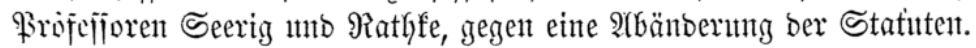

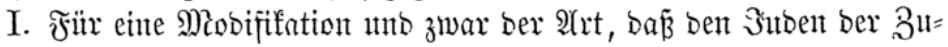
tritt ऊut ben Rehrë̈ntern an ber hiefigen Un niverjitüt frei gegebent werben midste, witrbe bejenters geltento gemadyt:

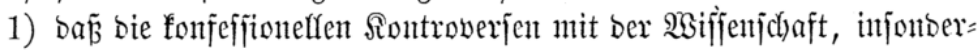

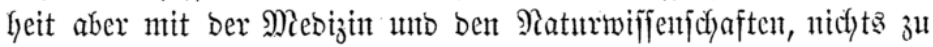

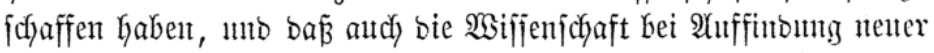
Baahrheiten fich faftifdy nie sarum gefïmmert hat, weldyer Sonfejfion Der Entoecter angehörte;

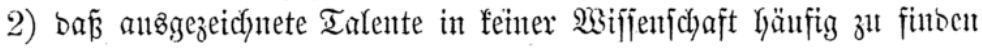

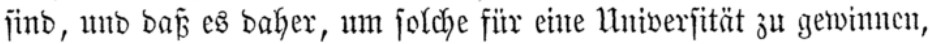

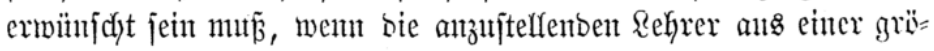

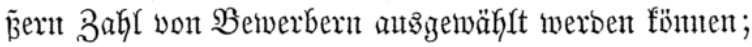

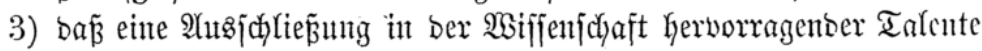
von ben Rehramte bez (S)

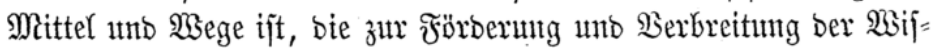

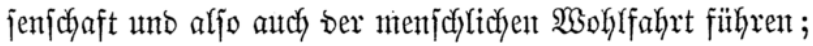

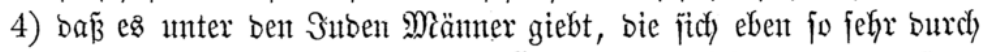

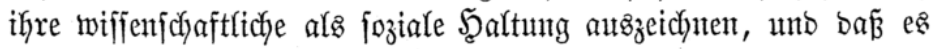

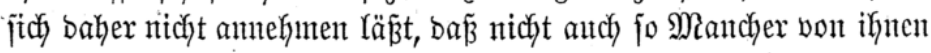

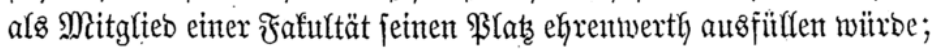

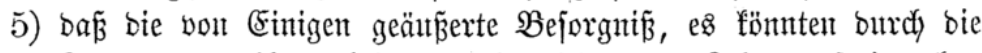
Suben, wenn ifnen bei ben Univerjitn̈ten bas Regramt freigegeben würbe, bie Chyriften baraus mehr ober wentiger verbrängt werben, 


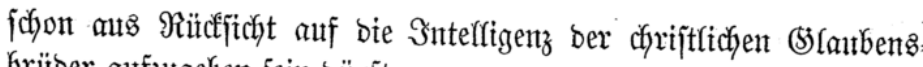
brïber autfugeben fein bïrfte.

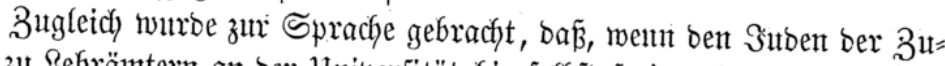

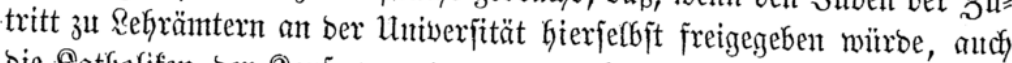

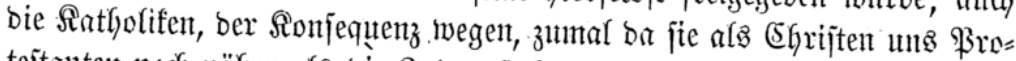

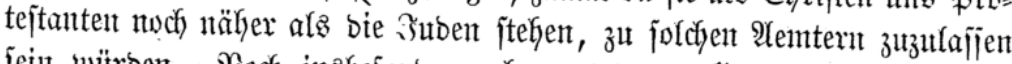

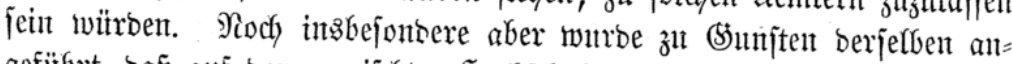

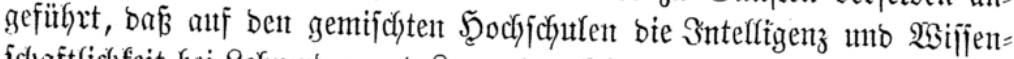
fd)aftlichfeit bei Rehrenten und Rernenben feinesiwegs etwa niebriger jtefye, alz bet ber unfrigent.

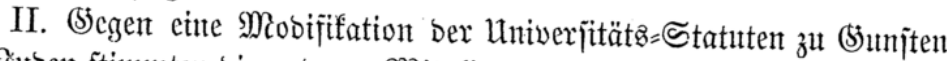

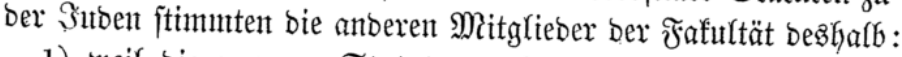

1) weil bie neuteren Statuten unferer Mniwerjität mur exít vor vier

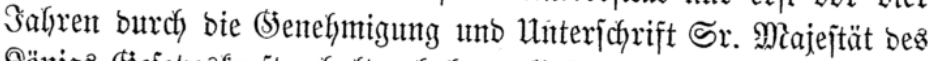

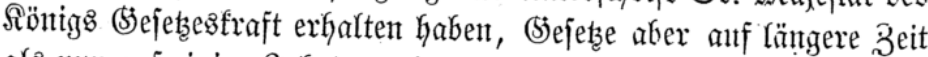

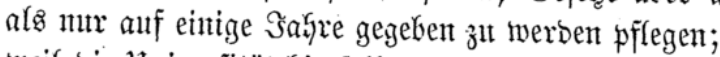

2) weil bie Univerjität hierjerbjt ben 3medfent bes Staats unto bent $\mathfrak{U}_{11}=$

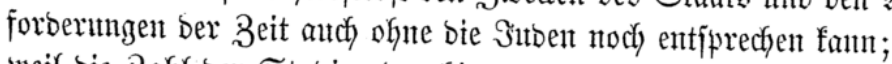

3) weil bie ßahl ber Stutbirentoen Kierorts jut gering ijt, als baj eine rajche SSermefyrung ber Dozenten, bie mux zu bald eintretent würoe,

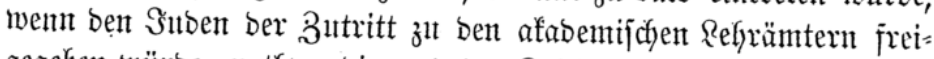

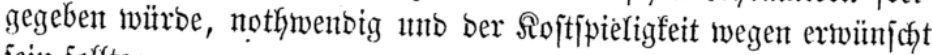
feitt follte;

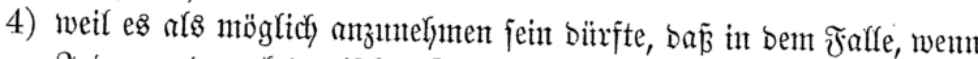

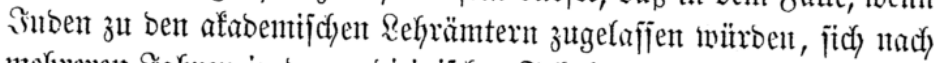

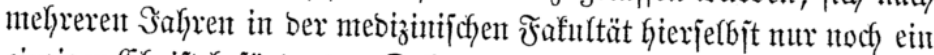

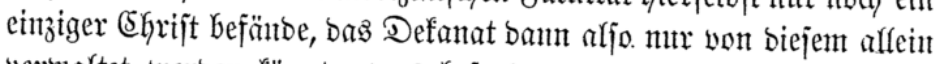
verwaltet merben fïnnte, was Gejonbers ben Ueberjtant zur Folge

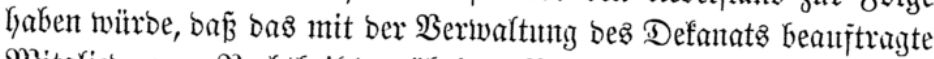
Mitylieb, zunt Racththeil ber itbrigen Berpflictutungen, bie ifym als afabentifyen Sehrer obliegent, vont jeinent wifjenjichaftfichen Stutoien

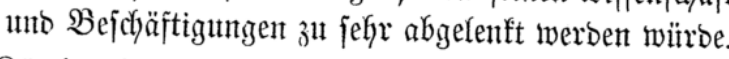

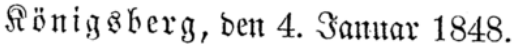

Die mebizinifice Fafultät.

Piathlfe. Secrig. $\mathfrak{W}$. (Eruje. Girijd.

\section{Siparat-kotım von flofofinor sceriy.}

Frei von eigennithigen Symtpatbien vber Ânthipathien, bie möglicher=

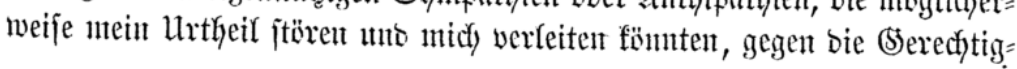




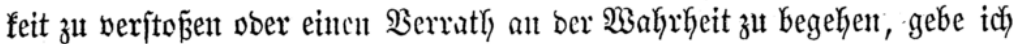

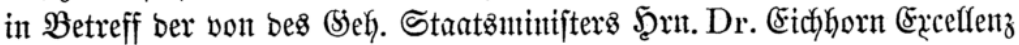
vorgelegten Fragent meitte Mieinung bahin $\mathfrak{a b}$,

1) Dá̉ bie bejtehentben Statuten ber hiejtgent föntigfichen Univerjität bie

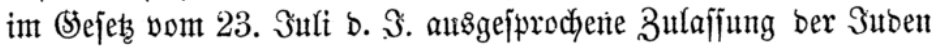
zlt Untiverfitäts=?egrämtern nicyt geftatten, weil bie Stiffung ber

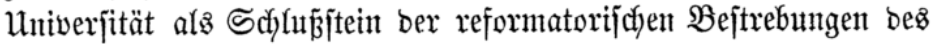

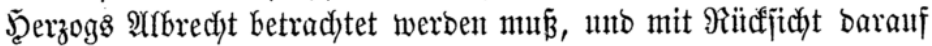

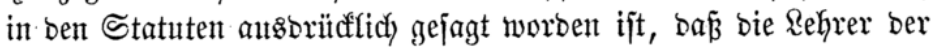
Giejigen Univerjität evangelifiden (St)aubens fein jollen. Sind hier= nach bie Satholifent von ber Zulajpung als Rehrer bei ber Giejigen

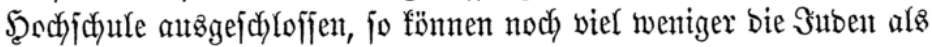
zulafjungąähig eradytet werben, ba fie nidyt mux wie jene jidy nicht reformiren laffen, fonbern reformirent unb regieren noflent.

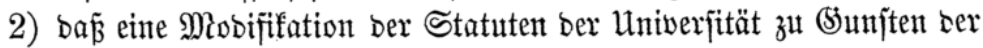
Subent nidyt wokl zuläffig jein bürfte: Der Staat, welcher an

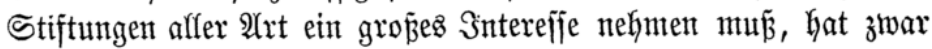

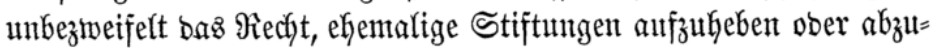
änbern, boch madyt berjelbe nur bann von biejem jeinem Rechte (Sie= brautch, went Stiftungen nicht mefr ben 3iwectent bes Staates ent= fprechen ober mit bem (Steijte ber Beit in Wicerjprutd) jtehen follten.

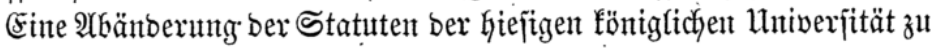

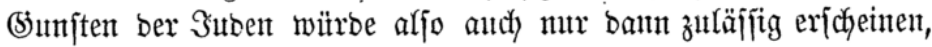
wenn bie Univerjität nidyt mehr ohne bie アuben ben 3 medfen bes Staatz und ben 2 nnforberungen ber Zeit entfprectjen follte. Beibez aber ift nicht ber Fafl. Die Univerfität entipricht zur Beit noch bem ibeałen wie bem materieflen Intereffe, ben Forberungen ber $\mathfrak{W}$ iffen= fdhaft, fo wie benen bes auf (5)erwinn gerichteten äuñerent Rebenz, bem praftijchen Zwecte, gite unb brautchbare Staatzbitrger Geran= zubilben, aljo bem 3ruedfe bes Staats unt ben 2 (nforberungen ber Zeit zugleich, und es ijt mithin, wenigitens auf Seiten ber Rehrer, fein Srunb yorḩanben, eine $\mathfrak{A b a ̈ n b e r u n g ~ b e r ~ S t a t u t e n ~ b e r ~ h i e f i g e n ~}$

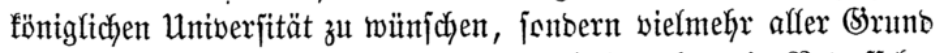
vorhanben, bie hochweife Fürjorge bez \$sejezgebers in Betreff be=

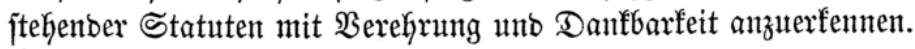

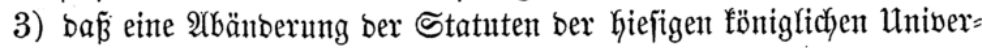

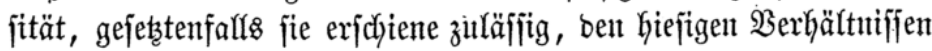
nicht angemeffen jein würbe, ba eines I Theilz bie Zahl ber Stubi=

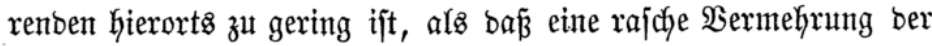
Zahl ber Dozenten, bie nur zu balb eintreten würbe, nothwendig 
uno ber Rojtipieligfeit wegen erwünidft jein-jollte, unt anbern Theils eben beshalb, weil bas Dozententhum z!̣ geringe materiefle Bortheile barbietet, befürchtet werben muñ es habe ïberhaupt ber Antrag ber Suben auf $3 \mathfrak{u l a j p u n g ~ z u ~ a l l e n ~ S e d j o j d y u l e n ~ e i n e n ~ g a n z ~}$ anberen (Srunt, als bent gleicher Befähigung, gleidher Begeijterung mit ben dyriftlidyen Männern ber Wifjenjchaft, nämlidy unter bem

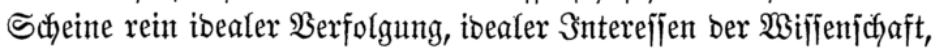
eine noch oppofitioneflere 5̧altung gegen ben Staat einnehmen zu fönnen, als jie bereitz angentommen haben. Nach ben voritełenten (5rörterungen glaube idf mux gegen bie 3 ulaffung ber Suben zur

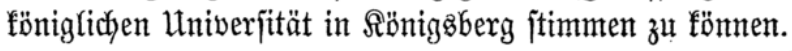

Seerig.

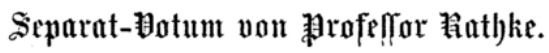

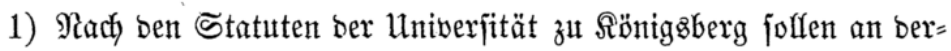
jelben nux Brotejtanten eine $2 \mathfrak{n}$ jteflung als Rehrer erfalten fönnen. Dieje Statuten aber haben erjt vor vier Sahren burch bie Unterichrift Sr. Maj. bez Sïnigg (\$ejęzesfraft erhalten. \$ar zu frühe an ber Zeit bürifte ez baher jein, jeşt jefon einen 2 ntrag zu jteffen, jie unzuänbern unb zumal eine ifrer wejentlichiten Bejtimmungen, wie es bie oben angeführte ift, auf̧uheben; benn (Sejeţe pflegen auf eine längere Z̉eit, alz anf wentige Sahre gegebent zat wertent.

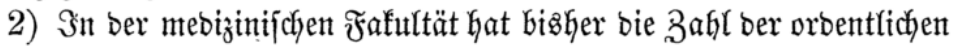
Profefioren Gödjitens 5 ober 6 betragen, und es bürfte baher nicht wahr=

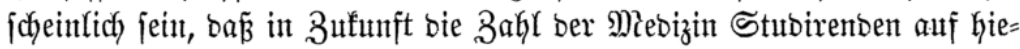

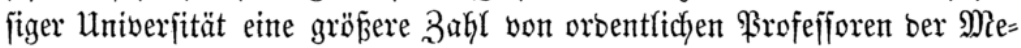

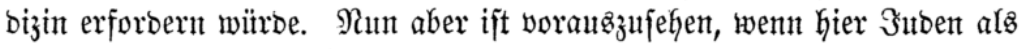

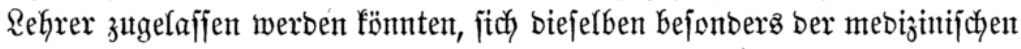
Fafultät zumenton witrben. $\mathfrak{A}\left(\mathfrak{s}_{8}\right.$ möglich bürfte es baker anzutehmen

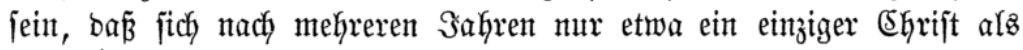

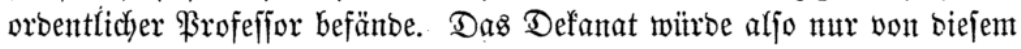
alfein werwaltet werben fömuen, ba nach bem (sejetze vom 23. Sult c. Su= ben ein Defainat nidht folfen ïbernefmen fünnen. Ein joldyer Fall aber

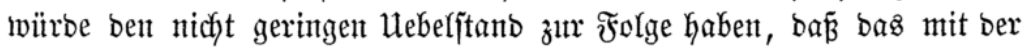
Berwaltung bes Defanatz beanftragte Mitglieb, theils burch bie vielfälti=

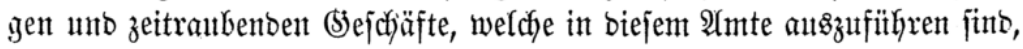
zum Rachtheil ber Berpflidytungen, weldye ifm als (Rehrer) afabemijobem Dozenten obliegen, von feinen wijijenjchaftlicyen Stubient unto B̉ejcyäfti= gungen zut fehr abgelenft werben witrben, theils aud burch biejes $\mathfrak{A}$ mt in ben $\mathfrak{A}$ ngelegenheiten ber Fafultät leidjt ein zu bebeutenbes Uebergenticht 


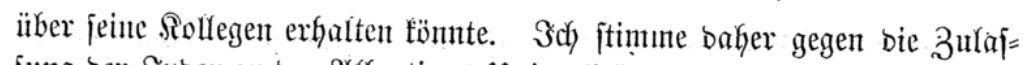

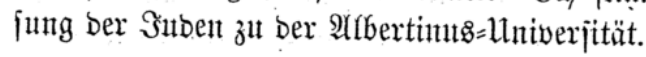

9intljfe.

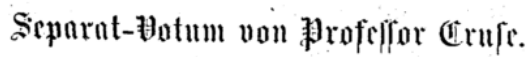

Sie hat bie : (3)eburt, Saterfant, (Slaubent ifrer Träger gemeffen; wo ein förbernoer

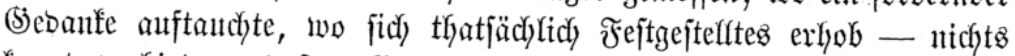
fonnte verhintorn, baj Hriprung fein, weldyer er wollte. Nitigends in Reben hat fich biefer rein

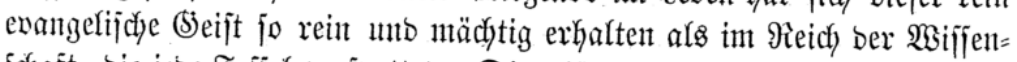
f(f)aft, bie jeoc Feffel werfpottet. Dies ijt ber (Bjeift, in weldyent unjere

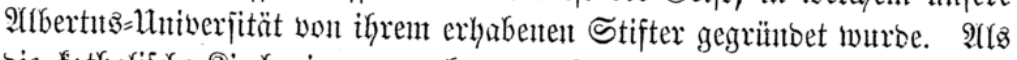

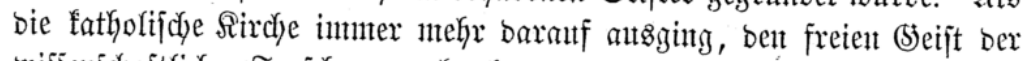

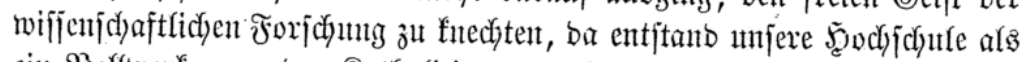

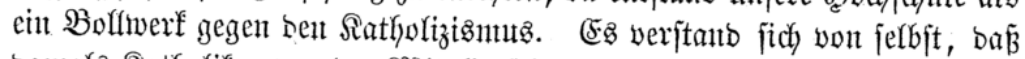

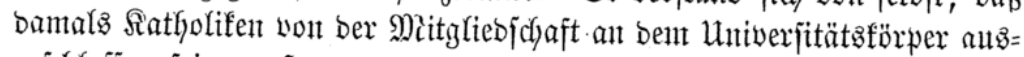

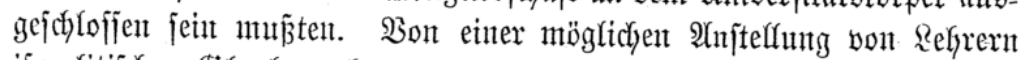

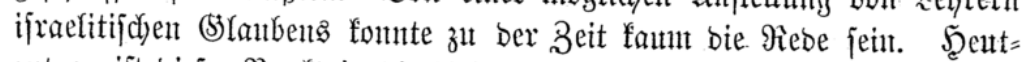

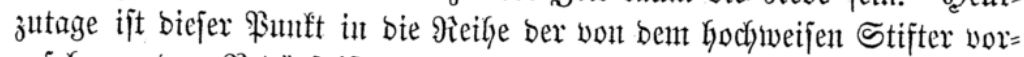

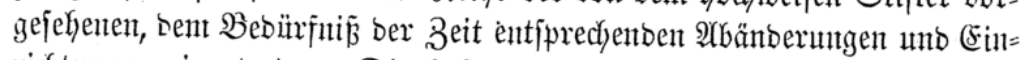
ricftungent eingetretent. Die holge vorigejełzte Behörbe hat bies erfannt

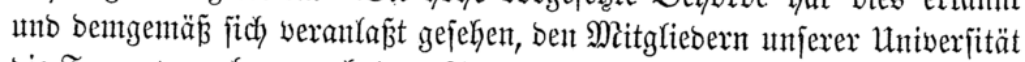

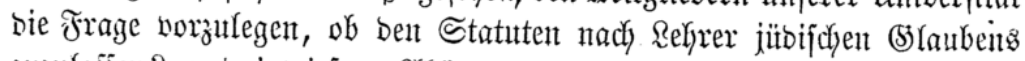

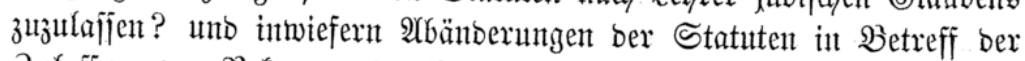

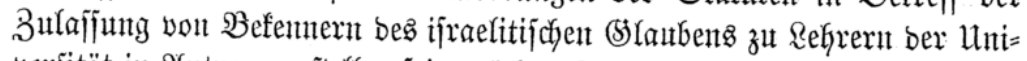
verjität in $\mathfrak{2}$ (ntriag zu jteffent jein möchten?

Sn Bejug auf bent erjten \$inft beịagen bie Statuten $\S 105$ gant

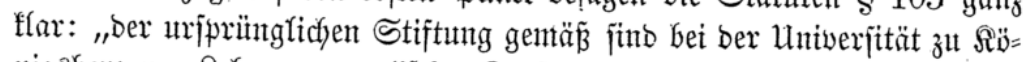

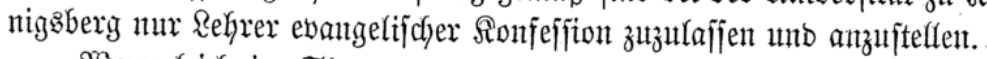

Wenngleich int Sinne ber urfprünglictyent Stiftung bamit vffenbar

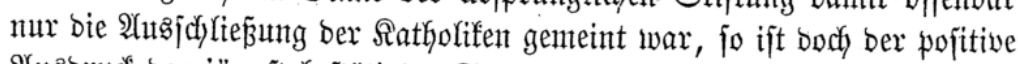

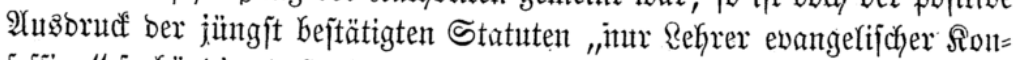

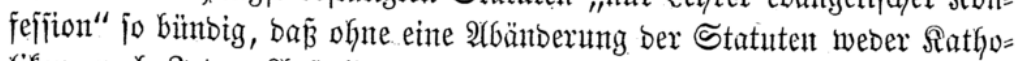

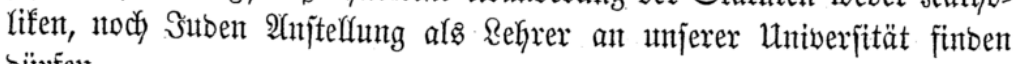
bürfent.

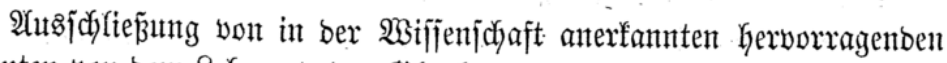
Talenten von bent Rehrant, Des BSIaubens ivegen, ijt aber einte Bejdjrä̀t=

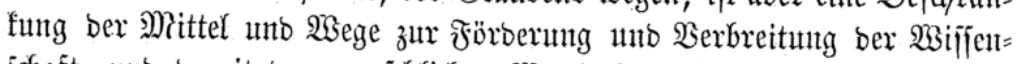

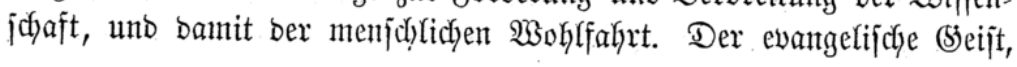


in bem unjere Şodjichule gejtiftet wurbe, fant es niemals billigen, wenn

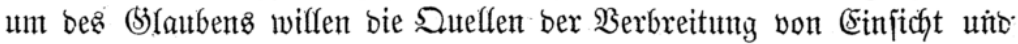

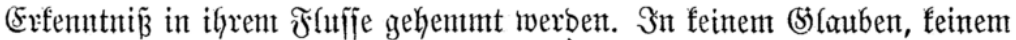

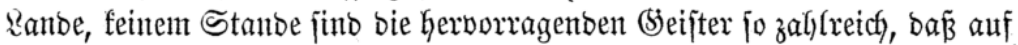

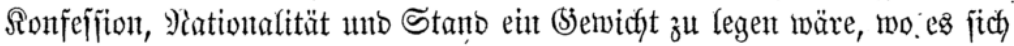

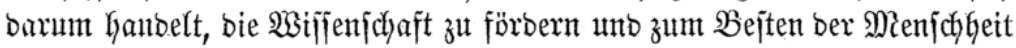
3t verbreiten. Unter unferen Mitbïrgern jübijcyen (S)Laubens Gaben wix

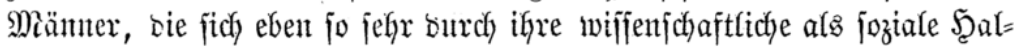
tunty alszzeicfynelt, bie fich) bes öffentfichen Bertrauens unt ber alfgemeinen

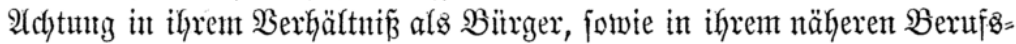

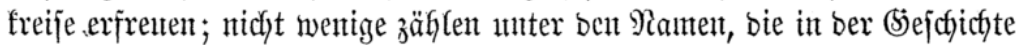

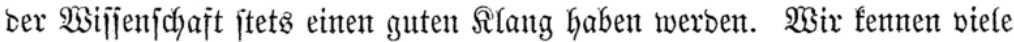

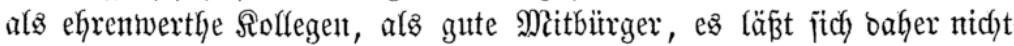
annelyment, bã nicht autch jo mantcher berjelben als Mitglieb ber Fafultüt

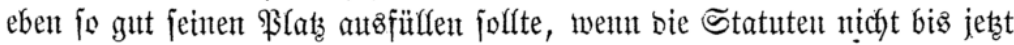
Der $\mathfrak{B}$ etheiligumg von Suben an bem afabemijchen Unterridyt entgegen=

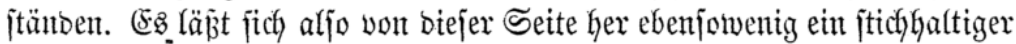

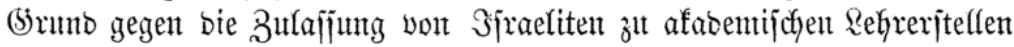
geltento machen, als jich aus bem alfgemeinen (jejichtspuntt iiberbaupt

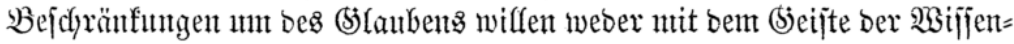

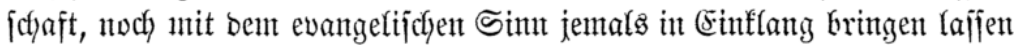
werben. Mein Sotun geht benmadh bahin, baj ber beregte \$affus im \$ 105 unferer Statuten getifgt, unt bant nidyt affein bent Sitben, fonbern

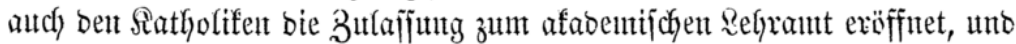

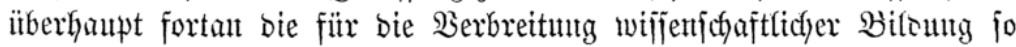

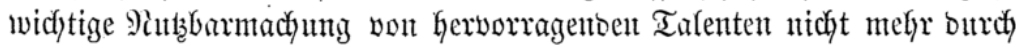

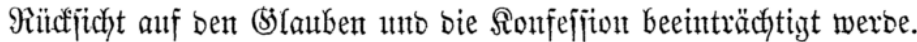

Eritic.

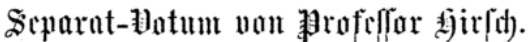

Dem $\mathfrak{B} e f e h($ einez $\mathfrak{h} 0$ hen Mintifteriums, mich in einent motivirten (S)utachten barïber jut erffärent: 1) ob bie bejtehenbent Statuten unferer

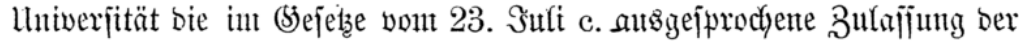
Shbent zut ben bejeidyneten afabentijchen Rehriächern gejtattent ooer nicht, unt 2) wenn bie Statuten bieje 3ulajïung nicht gejtattent, eine Mlobififiation

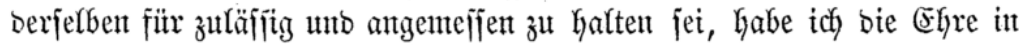
Madjfolgenbent jut entfprechen. Was bie erjte Frage betrifft, fo fant es feinem Zwweifel unterltegen, bar biẹ Stefle int $§ 105$ unjerer Statutent

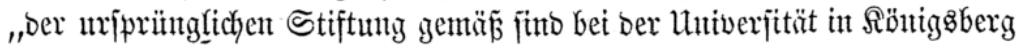

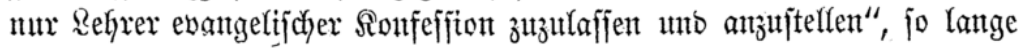




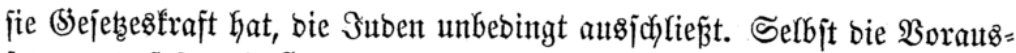

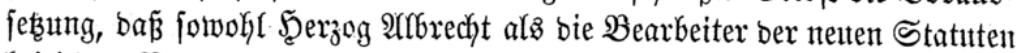
bei jener Bejtimmung gar nicht an bie Suben gebacht, jonbern nur bie

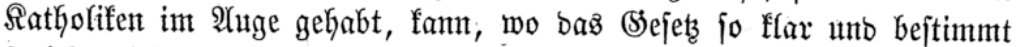

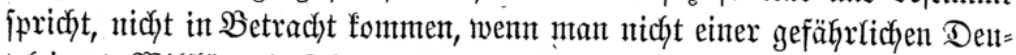
telei unt $\mathfrak{W}$ ifffiin bie Thore öffnent wifl. Was bagegen bie zlveite Frage betrifft, "ob eine Miobififiation ber Statuten für zut zäffig mo angemeffen zu halten jei", fo jtehe ich nidyt an, jie nach reiflicher Hebertegung mit einem unbebingten "Эa" zu beantworten. A2ffe Bebenfen wegen ber $3^{\mathfrak{t}=}$

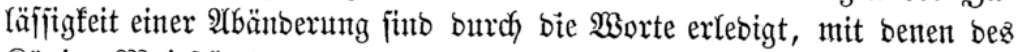
Rönigs Maajejtät ben gegentwärtigen Statuten bie gejeţliche (5eltumg zu

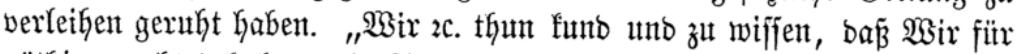
nöthig geadjtet haben, bie Statuten ber von unferem in Sbott ruthenten Borfahren, Marfgrafen Mrbrecht geftifteten Ranbes=Univerjität 孔̆ Sïnigg= berg revibiren zut laffen unb, wie von bent Stifter in sen Sonjtitutionent uno Statuten ausbrürffich vorgefdrieben worben, bie bem Beoürfnifije ber

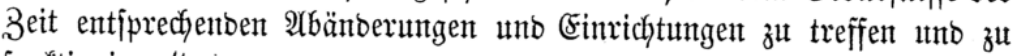
fantftioniren."

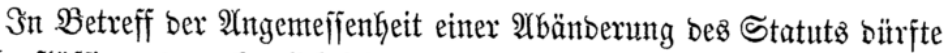
eร Suben aufzujuctyen, ba inbivibutelle Buneigung für ober Afbneigung gegen bie 3uben bet biejer widftigen ßrinzipienfrage nicht in Betradyt fommen fünnen, unb es fich burchauts nicht um eine bejonbere Berechtigung für oie

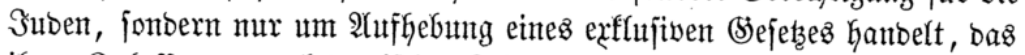

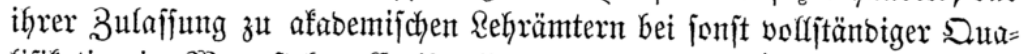

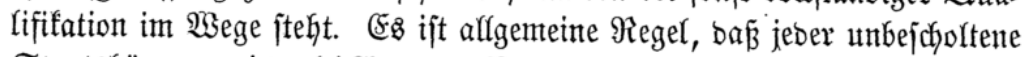

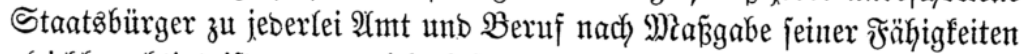

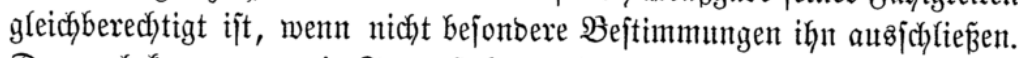
Demnady fann es nur in Frage jtehen, ob in vortiegenben Fall zur $\mathfrak{2}$

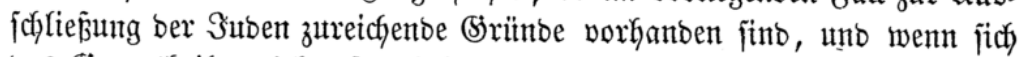

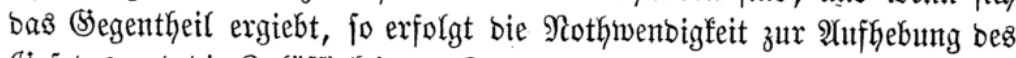

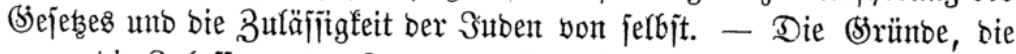
gegen bie 3ulaffung ber Suben zut afabentifctjen Rebrämtern beigebrad)t worben find ober beigebracht werben fönten, fint folgento:

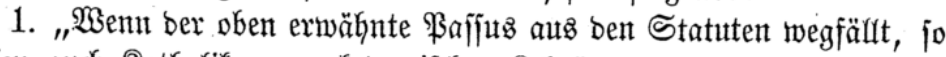

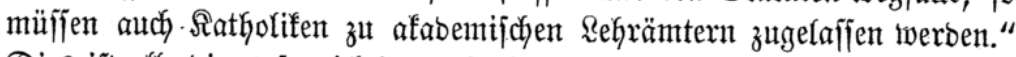

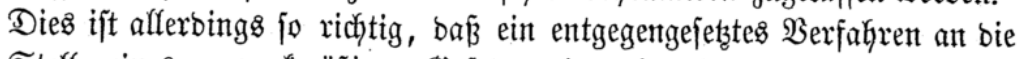

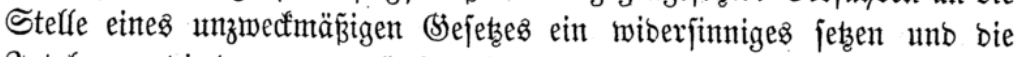
Intoleranz, bie bem gegentwärtigen innewohnt, nicht bämtpfen, fonbern aıf

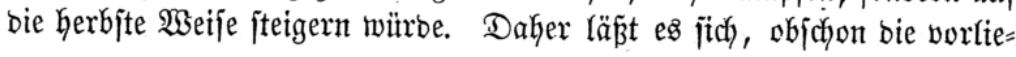


genbe Frage fich mur auf eine 2 (entorung bes Statuts rïffichts ber Suben bezieht, nicht umgehen, aud bie Buläffigfeit ber Ratholifen in Erwägung

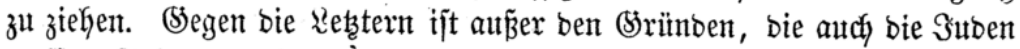

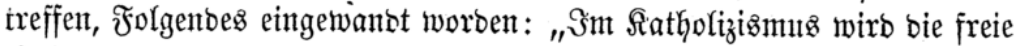
Wiffenfchaft burch bie röntifche Surie bebormunbet unb gefnechtet, unb jebe

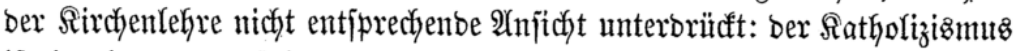

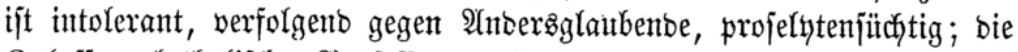

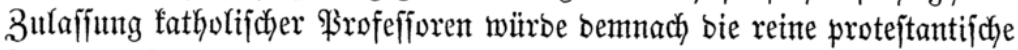

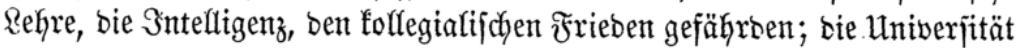
Rönigsberg barf iłyen urfprünglichén (Sharafter nicht berlieren, ba jie um

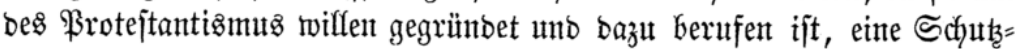

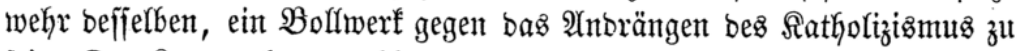
fein. Das Reţtere famu wohl nux fo viel Keipent, bá bie geltenben Statu=

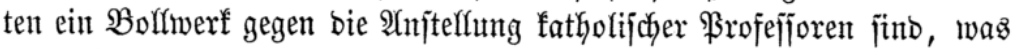

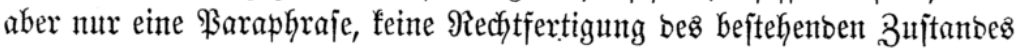

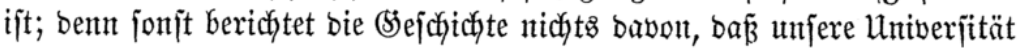

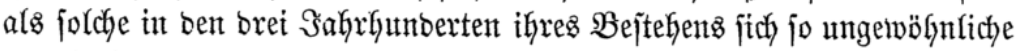
Berbienjte um ben \$rotejtantismus erworben habe. Es ijt aber fogar un=

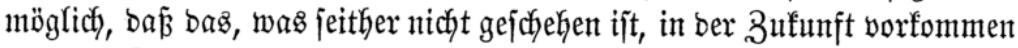
fönnte. Die theologifche Fafultät, bie jelbjtrebeno ben protejtantifchen

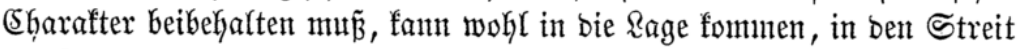

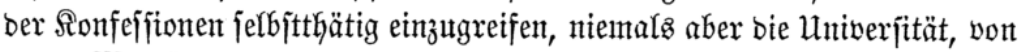

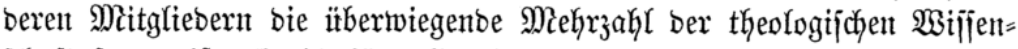
ichaft fremb iit; jie ift fïr alfe theologifdent Streitjragen volffomment infompetent, uno bie Frofefforent ber brei Yetzten Fafultäten werben jich in

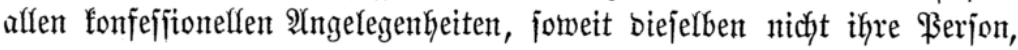
fontern ihr $\mathfrak{2}$ mt betreffen, gleich intifferent verhalten, mögen jie $\mathfrak{B r o t e}=$

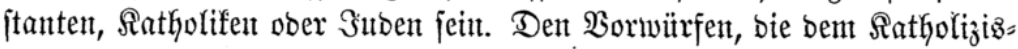
mus jelbjt gemuad)t werben, fann idy als ebangelijcher (Shyijt nux beijtimmen, finde es aber burchaus verwerflich, ben einzelnen ßatholifen es entgelten

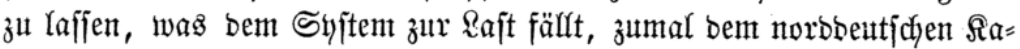
tholifelt, ber unter protejtantifchen $\mathfrak{B r i t b e r n}$ frieblich aufgetwachjen, mit

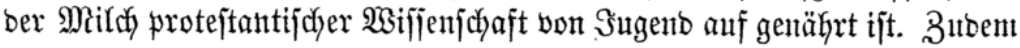

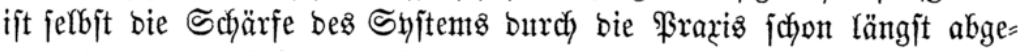

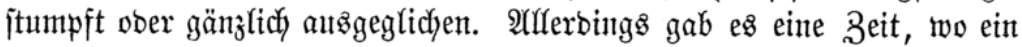

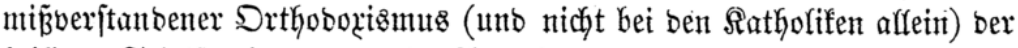
Geiligen Schrift eine normative $\mathfrak{A}$ utorität für sie $\mathfrak{B a h r k g e i t e n t ~ b e r ~ \Re a t ı r = ~}$ funbe unb anterer profanent 2 Siffenjodyaften beilegen formte uno jebe ent= gegenjtehente 2 nnjidyt verwarf. Sie ift aber längit vorïber, unt man hat

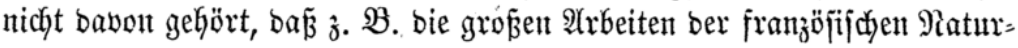


foricher, bie boch meijtens fatholifdy find, won Seiten ber Sirthe wären

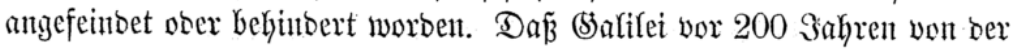
Snquifition eingeferfert mutbe, weil er bie Berwegung ber Erbe un bic

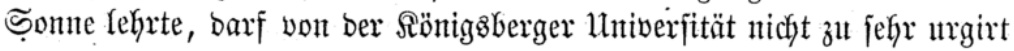
werben, bent fayon längit wirb auf alfen fatholifdyen Schulen bas Syjtem

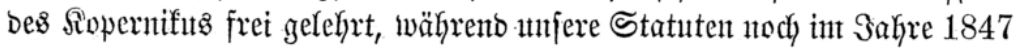
Den Sopernifus felbft, went er erjt jetzt als Domkerr von Frautenburg in

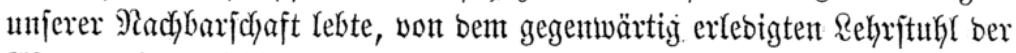

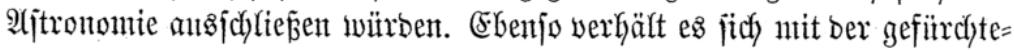

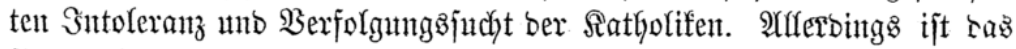
fïr(f)terliçye haereticis non est servanda fides befannt, afferbings weijt

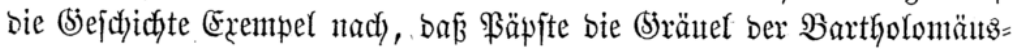
nautst gutgeheipen, Unterthanen won ihrem Eibe gegen ifyen sanbesherrn lozgefprodyen ober gar żtm Söntgantorb angeregt haben; aber trotzbem

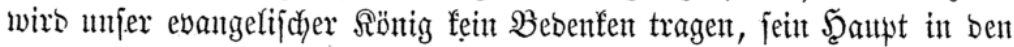

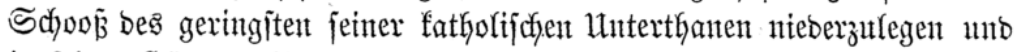

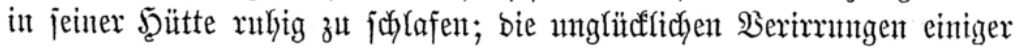
Bolen beruthten nicht auf fonfeffionelfem, fontoent anf nationalem 3wiejpalt:

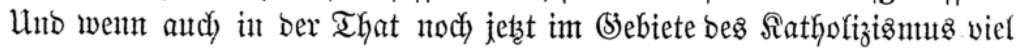

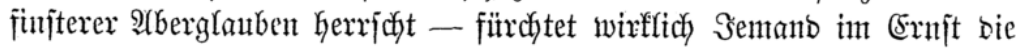
brutale Dogntatif uno Moral eines Rijfaboner (\$)alfego ober eintes vene= tianifichen $\mathfrak{B r a b o}$ bei einem bentichen \$elehrten twieber zut finben? - 9icht mekr hat es aud mit ber (stefpenjterfurcht vor bem Эejutismus auf jich,

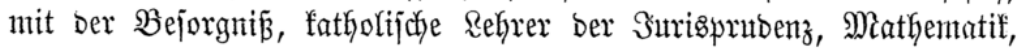

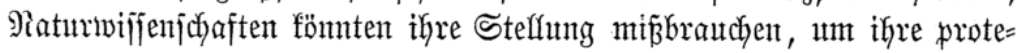
jtantijçen Schüler zu \$rojelyten bes Ultrantontanismus zu machent. Man

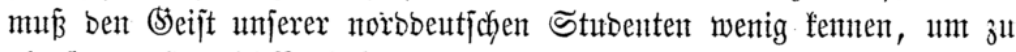

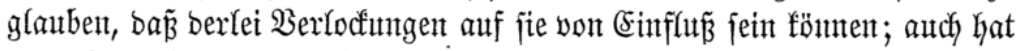
man faum je bavon gehört, bá ein protejtantifdjer Stubent auf einer gentijchten Univerjität, ober einer ber vielen juntgen Miesiziner, bie nach

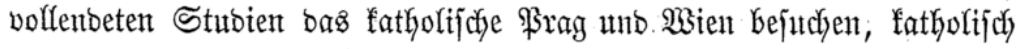

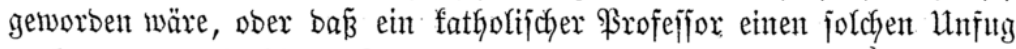
auch mur verjucht hätte. Sa eş ijt wohl ber Falf nod) ntidyt vorigefommen,

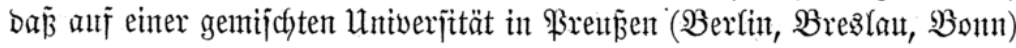

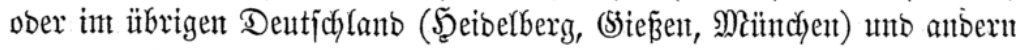

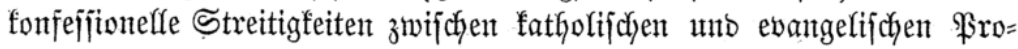

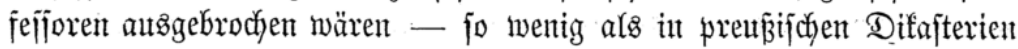
ober in ber $\mathfrak{A}$ rntee, wo fein Unterficyied ber Sonfeffionen jtattfintet, ber=

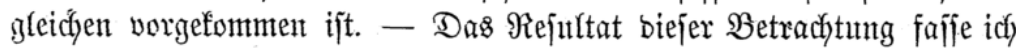
in ben Satz. zujamment: Wenn man nidft betweijt, baß ber ebangelijdye 


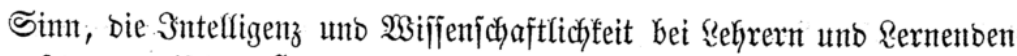

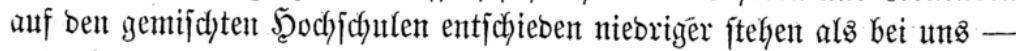

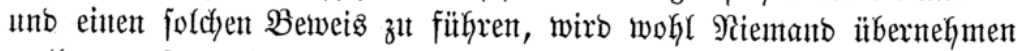
wollen - fo binxte es an ber Zeit fein, unfer \$rivilegium, feine fatboli= fichen Refirer zuzultafjen, entjchiedent. aufzugeben.

2) "Die \$̇iffenfchaft forbert einen religiöfen Sinn, bie moberne

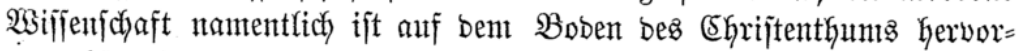
gewwadyjent, ift chriftlicher. Ratur unt fann folglich won Suben nicht gelefyrt werben." Dẩ bie Bottjeligfeit, wie bei allen Dingen, fo audy bei $\mathfrak{2} u \tilde{j}=$

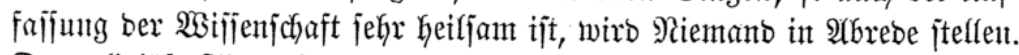

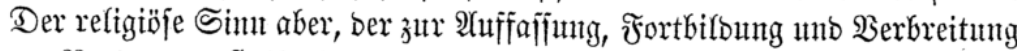

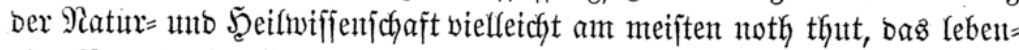
bige Bemuñ

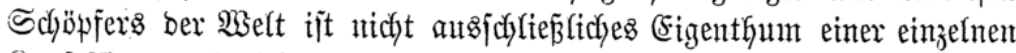
Sonfeffion, aud') nidyt einnal bes (Shriftenthums, fonbern (5emeingut jeber

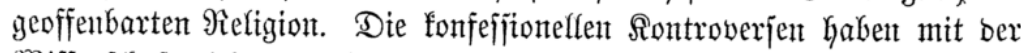

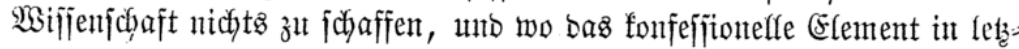

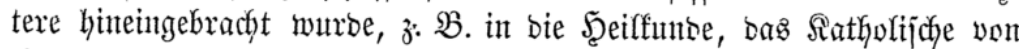

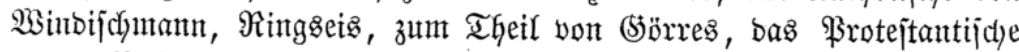

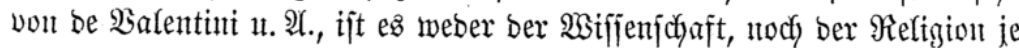

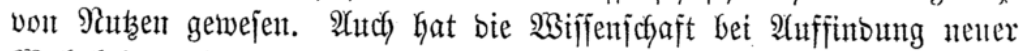
Wahrkeiten fich faftifdy nie barum gefïnmert, welcher Ronfejition ber

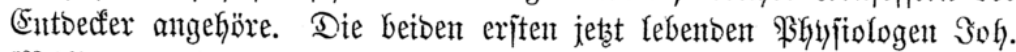

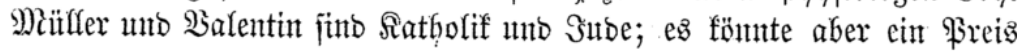
baranf gejetzt werbent, int ifren Schriften auth mtr eine Zeile alf bie vont Stanbpunft ifrer Ronfeffiton ans gefdyrieben wäre, unto bie ber

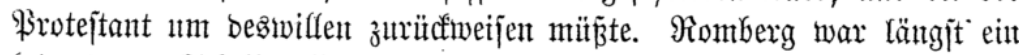

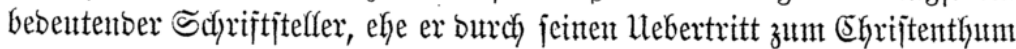
befähigt wurbe, \$rofefior in Bberlin zu werben: er hat aber um biejes

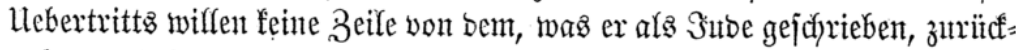
nebmen bïrfen. - Dieje Ioleranz ber Wifjenjchaft tijt aber feinesinegs

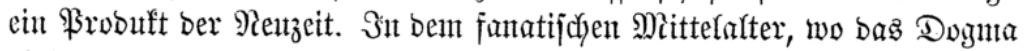

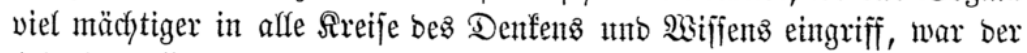

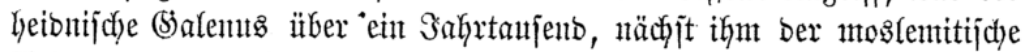

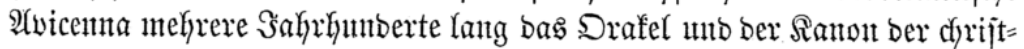

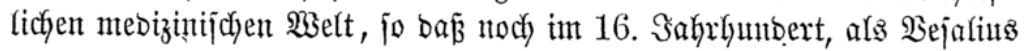
mebrere Srrthümer ber galenifdyen Rehre anfbectte, Siele behautpteten, jie

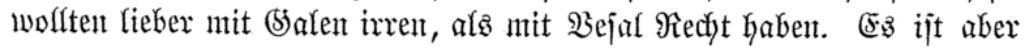

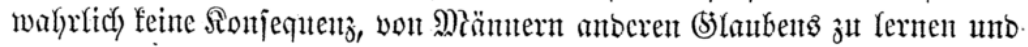

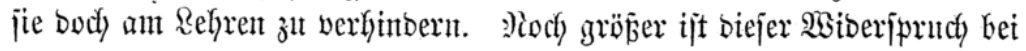




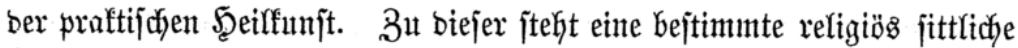

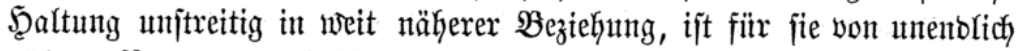

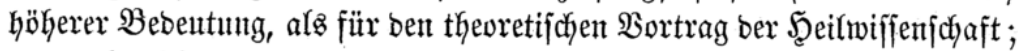

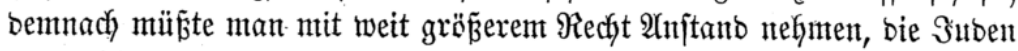

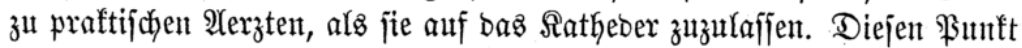

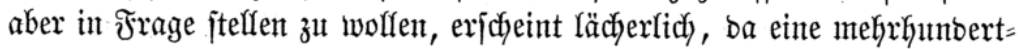
jäbrige Exfahrung barïber entjojteben hat, uno wohl in jeber größzeren!

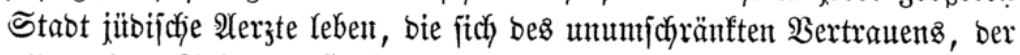
alfgemeinen Riebe unb f̧odgachtung ifyrer dyriftlichen Mitbürger erfreuten. Wenn aber ber Sube bie Mebizin mit \$slür uno zu alljeitiger 3ufrieben-

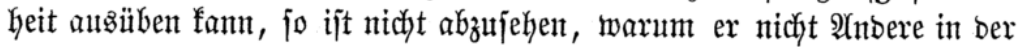

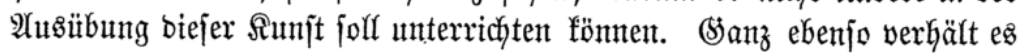
jich nicht blos mit ben excaften unb ben ïbrigen im Stejes vom 23 . Suli

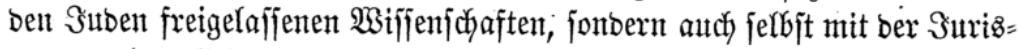

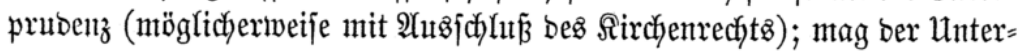

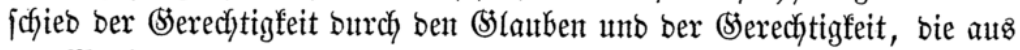
ben $\mathfrak{W e r f e n ~ f t a m m t , ~ n o d y ~ f o ~ g r o z ~ f u ̈ r ~ b a s ~ i n n e r l i c h e ~ R e b e n ~ u n o ~ f u ̈ r ~ b a s ~}$

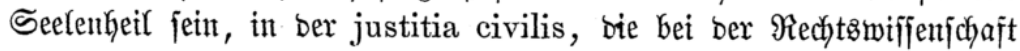
allein in Frage fommt, fällt jebe berartige Different fort, uno bie heioni=

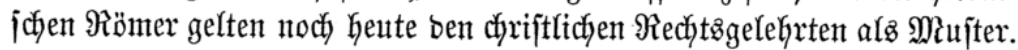

3) ,"9kber," fönnte ferner eingemantot werbent, "bie jogenannten gebil= beten Suben, bie fich affein um Refrämter betwerben witrben, find im Serzen feine $\mathfrak{A}$ nhänger bez mojaijchen \$Slaubens, jonbern Deijten, Spi= nozijten, Âtheiften; bieje bürfen auf einer dyrifftlichen Univerjität nicht

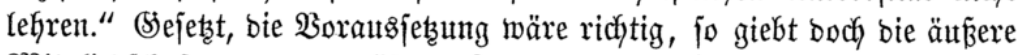
Mitgliebjchaft ber evangelifchen ßirche feinerlei \$arantie gegen bie ge=

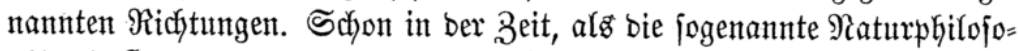

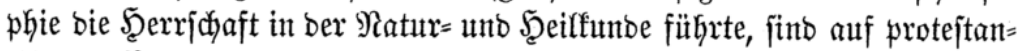
tifduem Boben mur zu oft ber trangzenbente (Sott unb bie perjönliche Unjterblichfeit in Frage geftellt worben. Sn ber neuejten Zeit aber werben

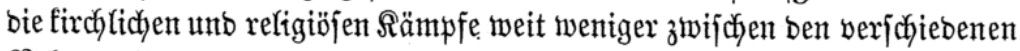

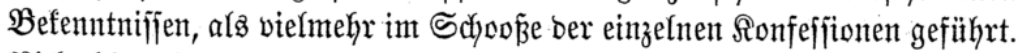
Nidyt blos bie fathodijchen, protejtantifchen uno jübijchen Diffibenten fynt= patfijitren untereinanber, jonbern nody taujent aibere, bie mit ihnen über= einftimmen, ohne jich gerabe äußzerfich won ihrer angejtammten sirche zu trennen. Demnach wäre eв eine reine $\Im$ flufion, alfe in ber protejtantifdyen Sirche gebornen uno nicht aus ify ausgetretenten Mitglieber burch eine went auch noch fo meite Einkeit bes STlaubens verbunben zut benfen. $23 e n n$ aljo ber Staat nicht von jeben anzujtellenben Uuniwerjitätệfehrer ein bejtimmtes \$ilaubenzbefenntni 
lich) wäre unb bie furdytbarjte Sorruption nady fidf ziehen mürbe), fo fann

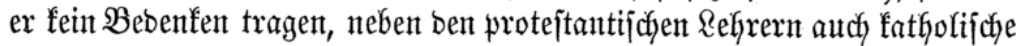

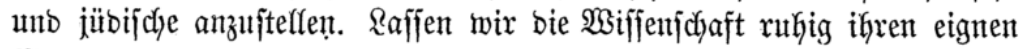

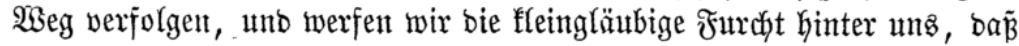

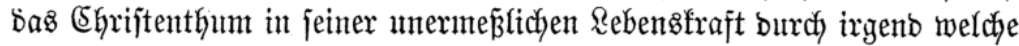

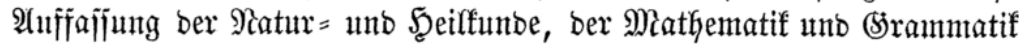
gefähroet werben tönne.

4) Ferner ift angeführt worben, „e' feien nody immer affe \&ehrerjteflen

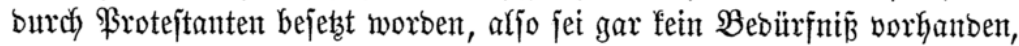

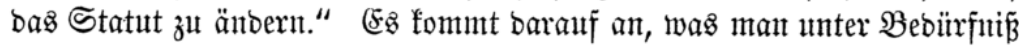
veriteft. Sidfer werbent jich immer Snbivibuen zun Bejetzung jeber etatis=

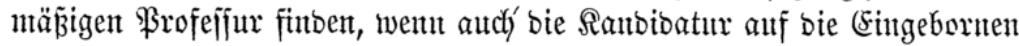

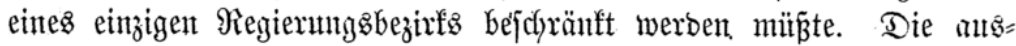

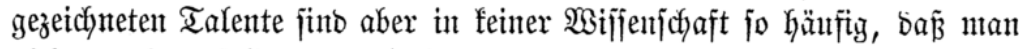
nicht trachten jollte, Das (sebiet, in bem jie gefunben werben fö̈nten,

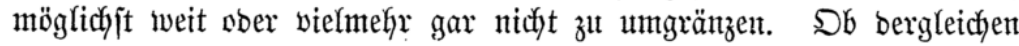

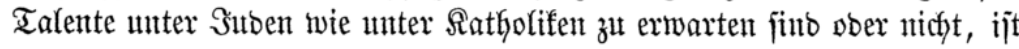

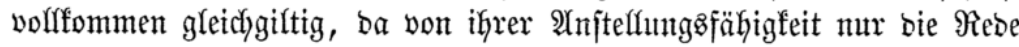

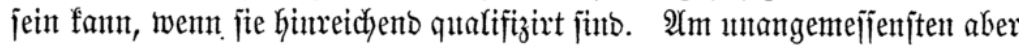

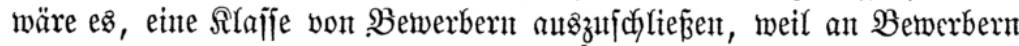
aus anberen $\mathbb{R}(a j j e n t$ Ueberfluz ba ift.

5) Endlich ift auldy bie Bejorgni

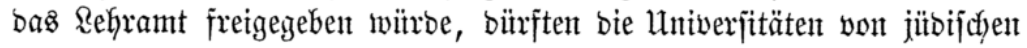
Profefforen jo überjaywentunt werben, ba baraus verbrängt werben würben." (5: ijt oft behautptet worben, baj im

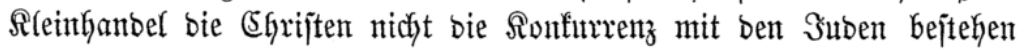

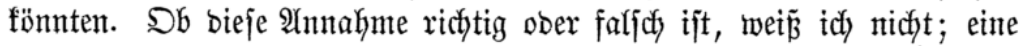

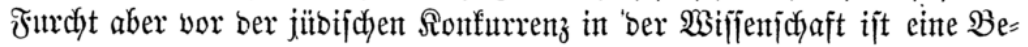

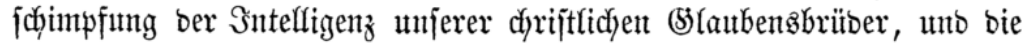

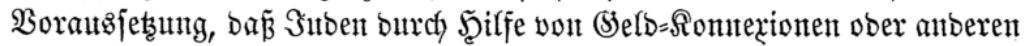

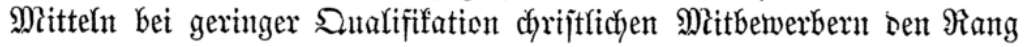
ablaufen fönnten, wäre eine Beleibigung unferer Staatßregierung, beren

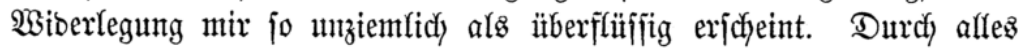

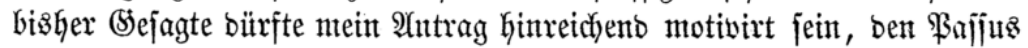
int § 105 ber Statuten, bentzufolge bei ber Univerjität Rönigg̨berg nur

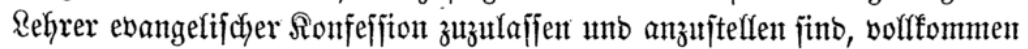

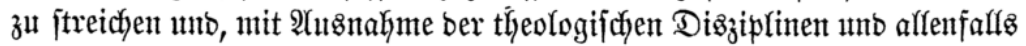

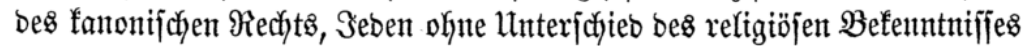
zum Rehramt zuzulaffen, forweit bie affgemeinen Staatzgejetze es geftatten.

Siridi. 


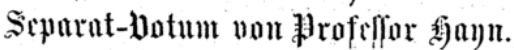

Die neuten Statuten ber hiefigen Univerjität enthalten inn $§ 105$ bie

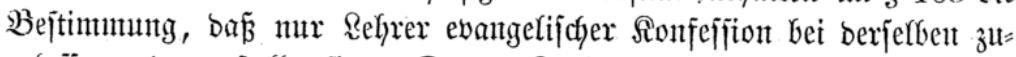
zulaijen unt anzujtelfen füto. Da unn Ratholifen zut Refyrämtern in anberein WSifienfdyaften alz in ber ebantzelifchen Theologie unzweiferfaft in bempelben (5irno befähigt fein fömten, als foldhe, weldye ber ebangelifdyen Sonfeffion

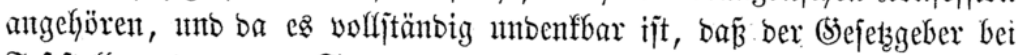
Feitfteffung ber neuen Statuten eine bent Befemernt irgento einer ber cfrift=

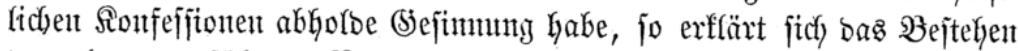

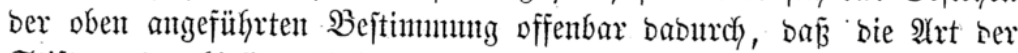
Stiftung ber hicjigent Untwerjität, anf welche ber antgefiifhrte \$aragraph

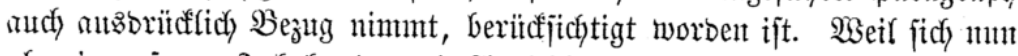

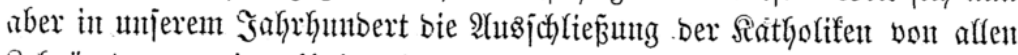

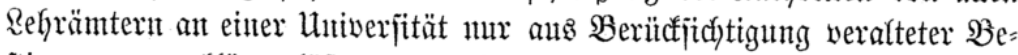

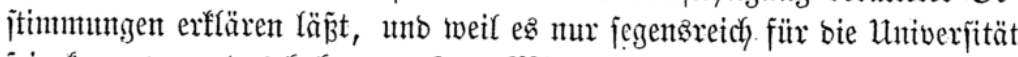
jcin famt, went bas hohje vorgejetzte MRinijterium bie anzujtelfenton Refrer

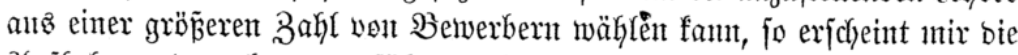

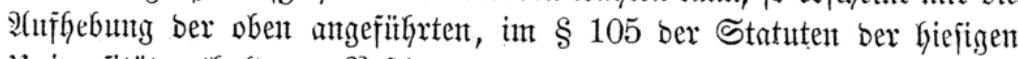
Univerjität entfyaltenen, B̉ejtimmumg wïnjchenșmerth.

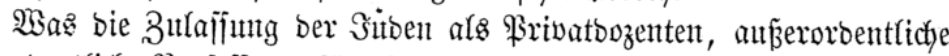
unto oroentliche \$rofefforent fïr bie mebizinif dyen \&ehrfächer antangt; fo ijt

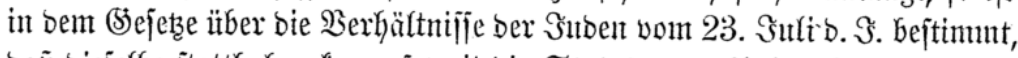

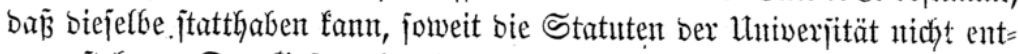

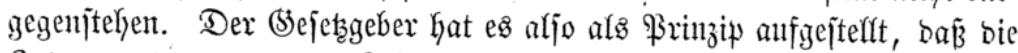

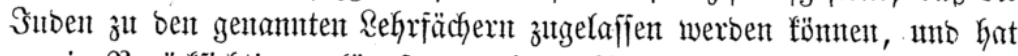

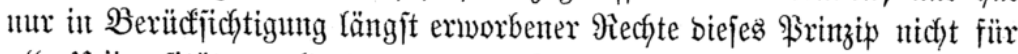

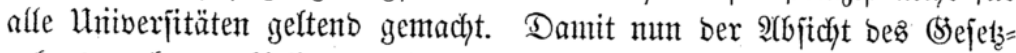
sebers auth an hiefiger luniverfität entifrodyen werbe, fdyeint es mir

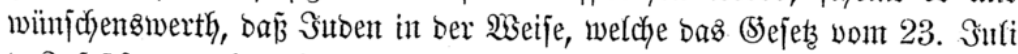

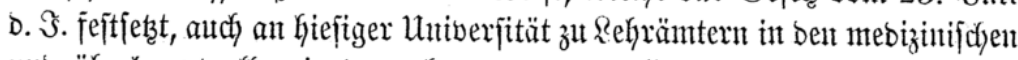
unt itberhaupt affen in bem ebent genanten \$sejetze antgefithrtent Fächern

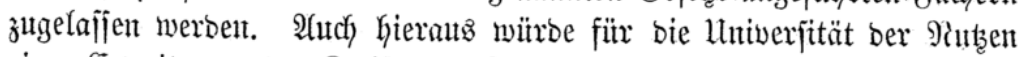
einer (Erweiterung bes Sreifes ber Ranbibatent bes \&ehramts entitehen; ein Radjtheil fönnte aber unt fo wentger barats hervorgeken, ba ja bas hohe

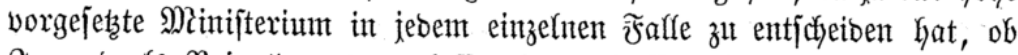
Semant als \$riwatbozent zugelaffen ober als \$rofeffor angejtelft werben joll ober nicht.

Mein Botum geft arfo bafin:

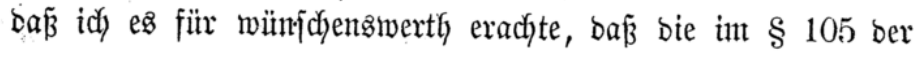


Statutent Kiefiger Utniberfität enthaltene Beftimmung, ber zufolge

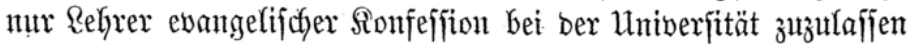
unt anzuftellen finto, alffgehoben werbe, und baj bie allgemeinen

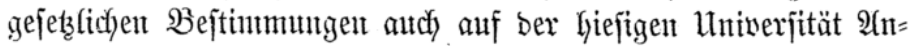
mentung finten.

$\mathfrak{g a \mathfrak { n } t .}$

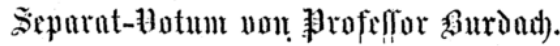

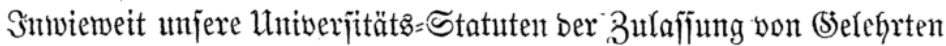

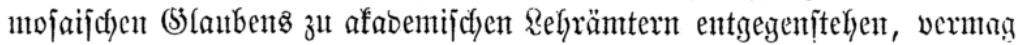

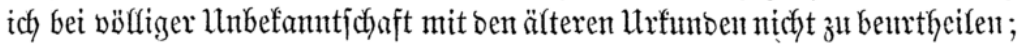
idy bin jebodh ber Mieimntg, baßs, wenn aud ben evangelifden (Ehrijten

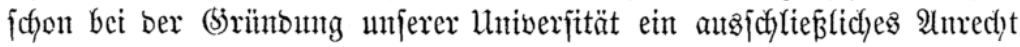

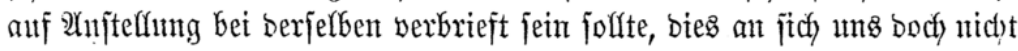
verlyintoent bürfte, freinuilfig eine joldye Beborrechtung ben Ratholifent unt

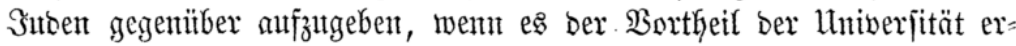
heif(d)te; Denn bie ergabenent (5rrünber und Förberer unjerer Univerjität

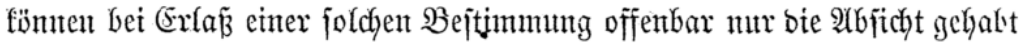

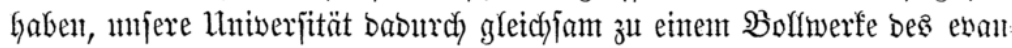

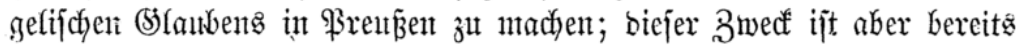
zutr (Stenïge erreicht, ba ber \$rotejtantismus im Raufe ber Beit jo erjtarft ijt, baj er fernerfint bejtehen unt gebeihen wirb, wenn auddy alfe gegen anbere giefigionsparteien anțgeführte Schranten niebergerifjen werben jollten.

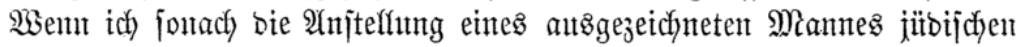

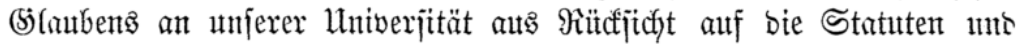

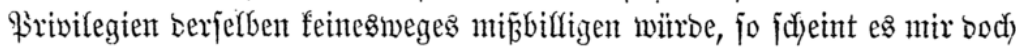
eine ganz anbere Sbewantntin mit ber Frage zu haben, ob unter bent gegent=

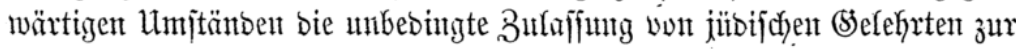

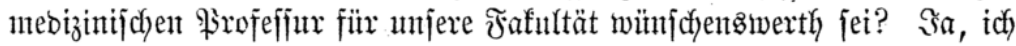

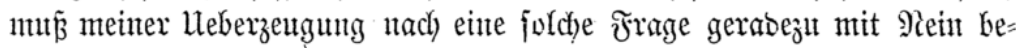

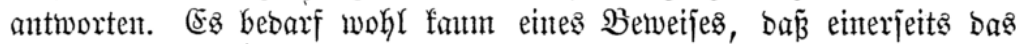

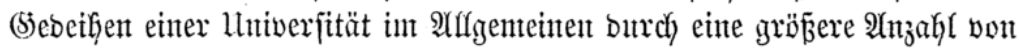
Dozenten geförbert wirb, baß a aber anbererjeits bei einer fleinen Untwerjität

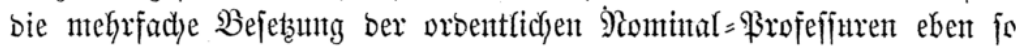

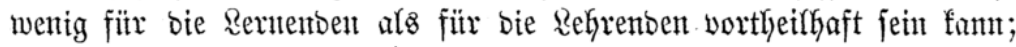

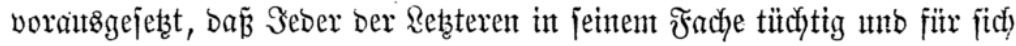
allein bas ifm anheingegebene Miaterial int Sortrage zut betwältigen im

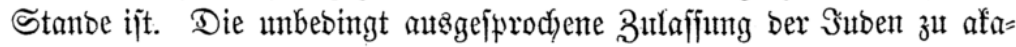
bemifdyen Rebrexptelfent witrbe num, fo glaube ich, eine nachtheilige $\mathfrak{H e b e r}=$ füflung unjerer Fafulttät mit \$rvefefforen zur Folge habent. Ess verjtegt 


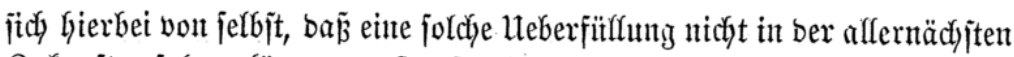
3ufutuft exfolgen fömnte, baß aljo bie gegentuärtigen Droinarien umjerer ซafultüt, bie ja alle bå mittlere Rebenzalter erreicht haben, biejelfe nidjt

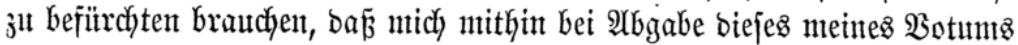

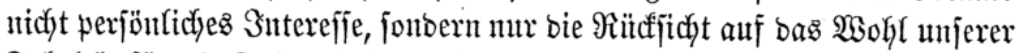

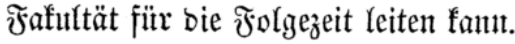

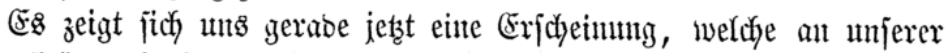

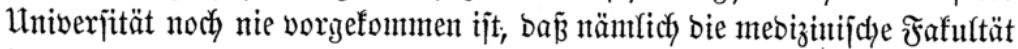
innerfalb 12 Mionaten einen Butwach so von 5 Privatbozenten theilz erfalten hat, theils nody erihalten wirb. Went wir and bei ben betreffentoen fünf angehentoen Dozenten rein wifjenjchaftliches Streben unt ben Błeruf zum

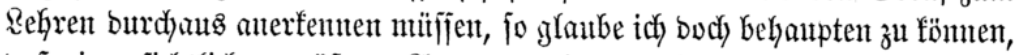

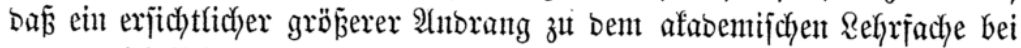

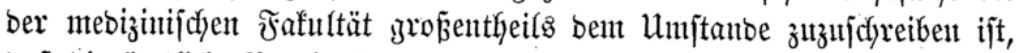

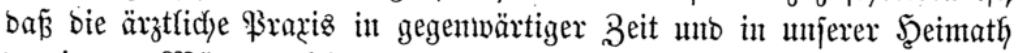

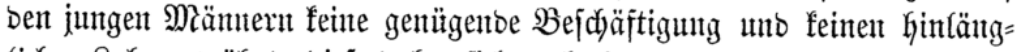

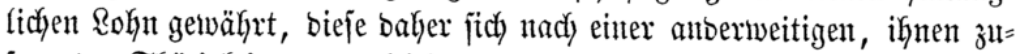

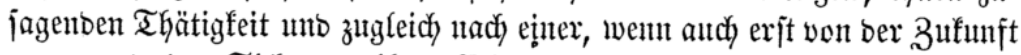

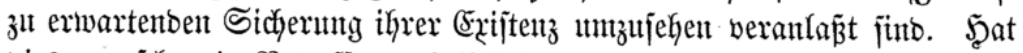

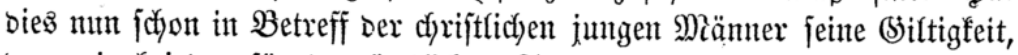
benen ja bei ben für bent ärztlichen Stano anerfannt untüntutigen Beit=

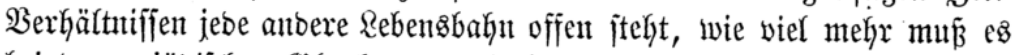

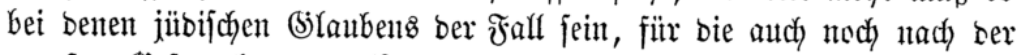
neuejten Bejetgrebung ber Beantenjtant fajt ganz verjchlojien ijt, unt fïr

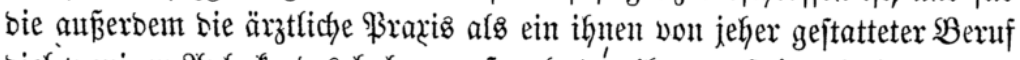

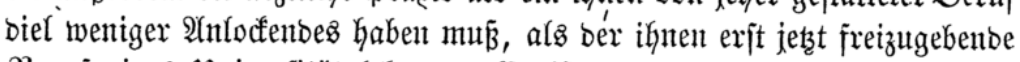
Beruf eines Univerjitätß̊lehrers. (5: ijt baher gar nicht zu bezmeifeln,

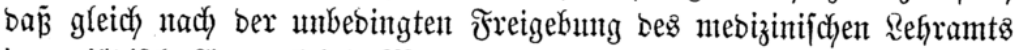
junge jübijche $\mathfrak{A}$ (erzte fich) in Mlenge alz Dozenten Gabilitirent werben. Diez würbe mun alferbings fein Schabe jein; ein Uebeljtani aber liegt barin,

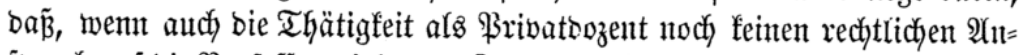

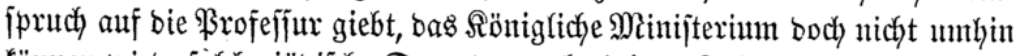

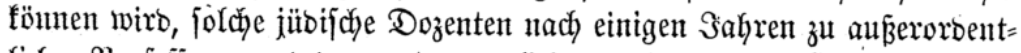

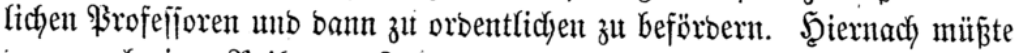

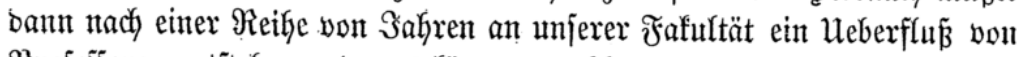
Brofefforen entjtehen, ober es fönnten wohl gar, um einem jolchen vor=

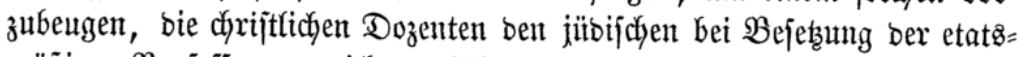
mäß̄igen ßrofeffuren weichen müfjen. Das Retztere exjcheint mun ebenjo wenig wie bas Grjtere wünjdyenşwerth; beun wenn fich in ber Fafultät eine gleiche ober wohl gar nod) überwiegende Bahl bon $\mathfrak{B r}$ rofefforen jübifchen 
(5) antbens befünoe, fo ivitrben nidyt nur bie chriftlictyen burch bie von ifnen alfein jul verwaltentoen, bei uns mur jehr geringen pefuntären Bortheil

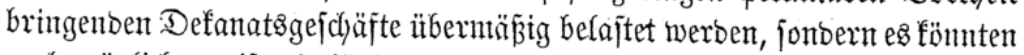

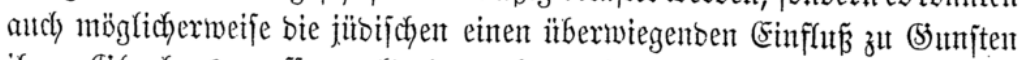

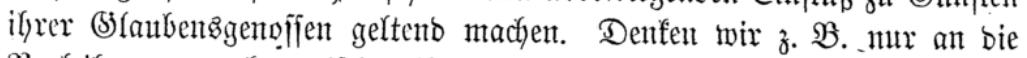
Berteifung von afabemifden $\mathfrak{B}$ enefizien, auf welche, wenn einmal bie un=

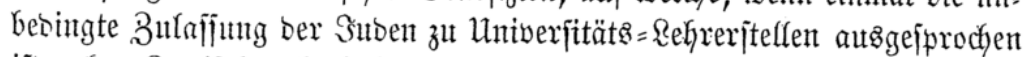

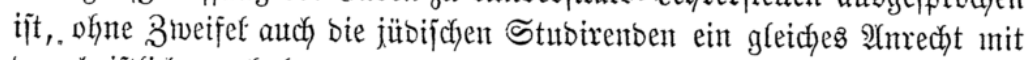

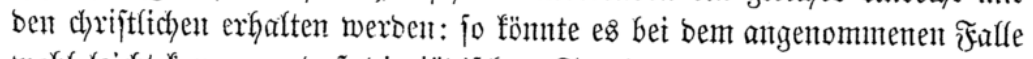

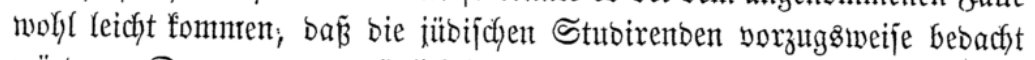

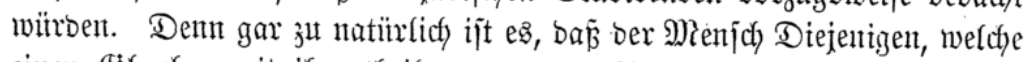
einen BSTatben mit ifn theilen, bor ben $\mathfrak{A}$ ntbersglaubenden begünjtige,

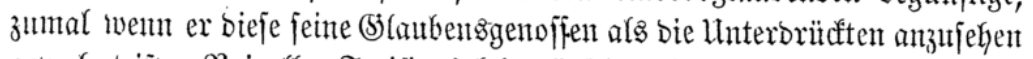
gewohnt ijt. SBet afler Freijunnigfeit bitxiften wir aber boch wohl bie $\mathfrak{b} e=$

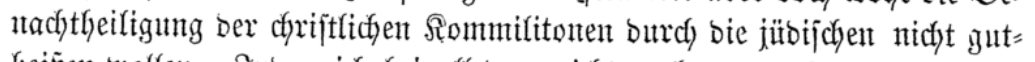

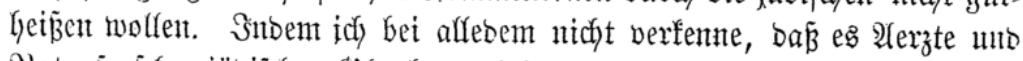

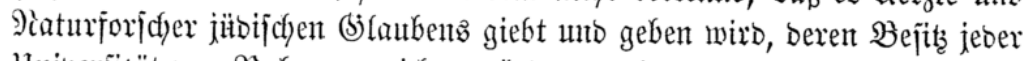

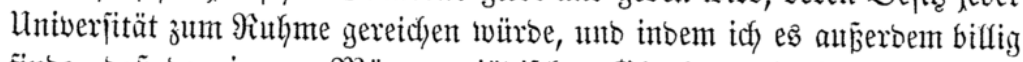

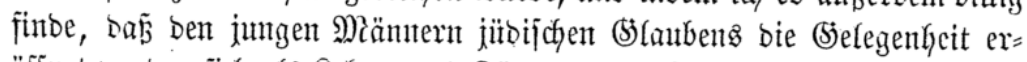
z̈ffnet werbe, jich afs Rehrer unb F̈̈rberer ber $23 i j$ fenf

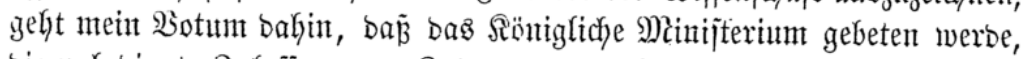

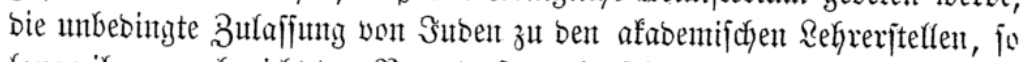
lange ihnen noch nicht ber Beamtenitant in jeinem ganzen Umfange fret= gegeben ift, für unjere Mniverjität nicht auşziprechen, ongegen zu be= ftimment, $\mathrm{D} a \tilde{B}$

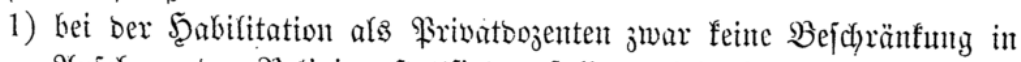

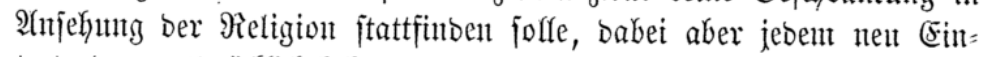
tretenton atsorituffich befannt gemacht werben minffe, wie er burch jeinte Reijtungen als Dozent in feinerlei $\mathfrak{B}$ eife eine gegrïnbete $\mathfrak{A}$ ntwartjdyaft alf eine \$rofejifur erhalte;

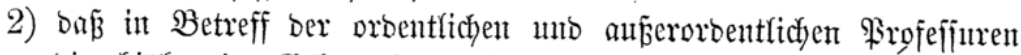

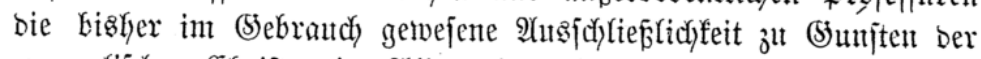

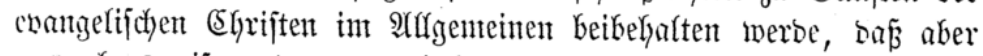
anbuabmsmeife mb mur nad) bejonberer Befütrwortung von Seiten

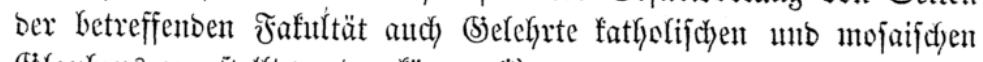
(3) faubents angejtellt werben fönnent. *)

Buroad).

*) Sntcreflant bürfte jut biejent 2 stum folgenbe Stelle ans ber Selbjtbiographie Des Saters biejes sotranten jeit :

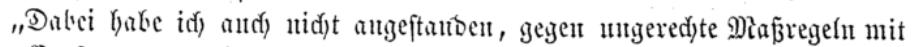

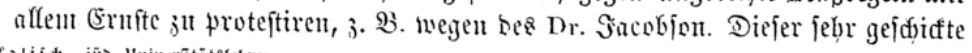

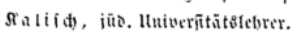




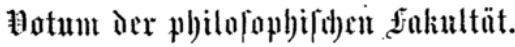

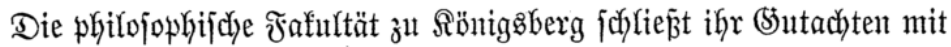
folgenben $\mathfrak{A}$ (nträgen :

1. Der Schlutfjat bes $\$ 105$ mijerer Statuten ift zut jtreichent.

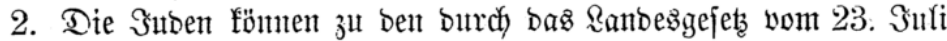
1847 bezeidyneten Rehräntern zutgefaffent werbent.

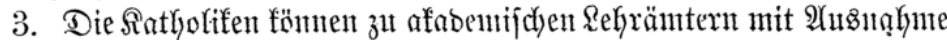

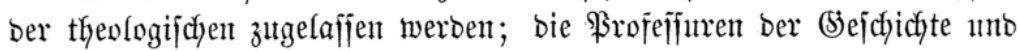
Bhitofophie fönten aber nie einjeitig von Ratholifen bejeţt fein. Das Reftorat ober Broreftorat fam nidgt von einem Ratholifen verwaltet twerben.

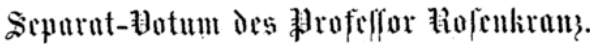

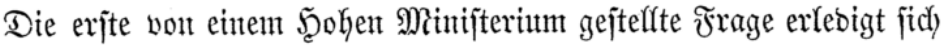
burch unjere Statuten von jelbjt. Die zweite Frage aber ift ž bejaken,

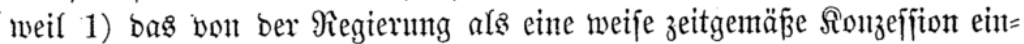
mal emantirte (sejess ba ift, ba Snben unb Subenfremtbe alfo von mun ab

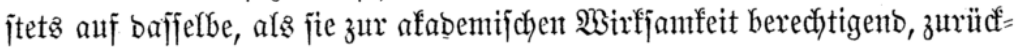
fonmen unto gegen jebe in biejer Şinficht ntact) borkantone Sctyranfe ant=

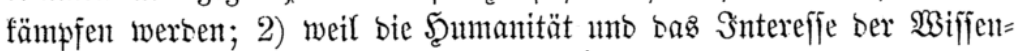

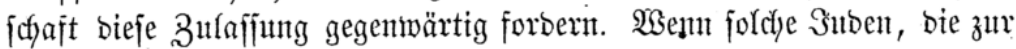

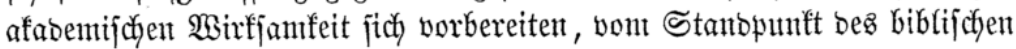
ober ridytiger talmubijoyen Subentfunts nicht mefre Suben, went fie viel=

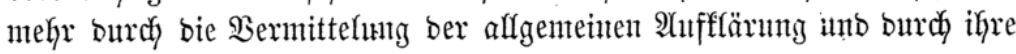

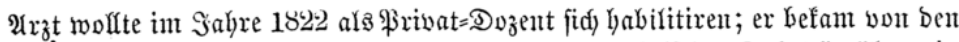

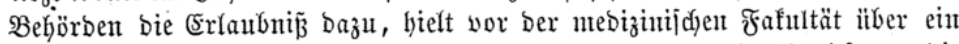

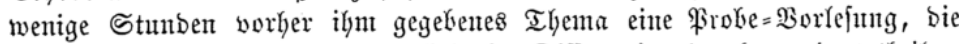

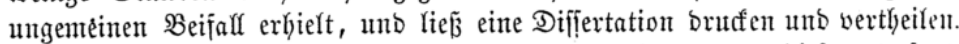
$\mathfrak{U}_{\mathfrak{m}}$ 20. Dezember, ałs bem $\mathfrak{T}$ age vor ber Disputation, wurbe biefe unterjagt, weil bas (sefets, weldjes ben jübifdjen Blaubesgenofien bie Erlangung afabe= mijajer \&ebrämter geftattete, eben aufgeboben worben war. Dieje Sile ber Reaftion - Fürft Şarbenberg war an 26. Rovember in Semua geftorben -

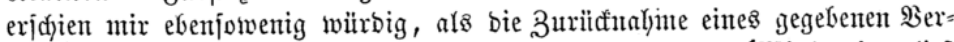

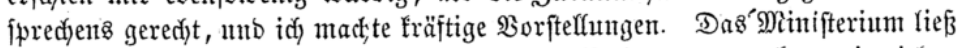
Gierauf ben Dr. Gacobjơn burd) bie Fafultät aufforbern, anzugeben, wie viel er

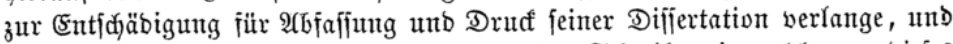

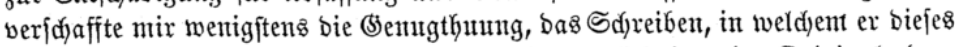
 Minifterium z̆

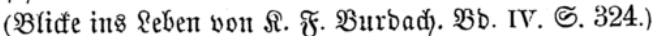




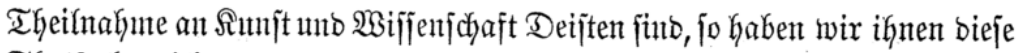
Thatjache nidyt vorzunerfen, fonbern einfach anzuerfennen; ja wir, won

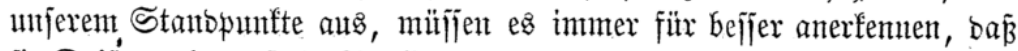

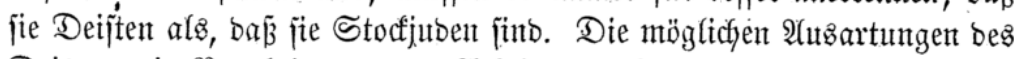

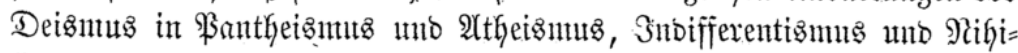

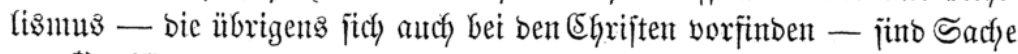
Des (Stwiffents des Einzelnen, worüber wir nicht zu richten Gaben, uno

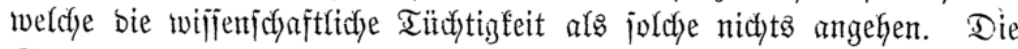

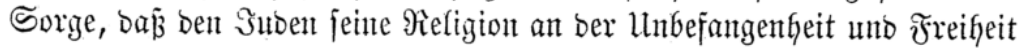

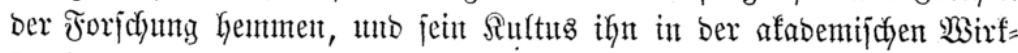
janteit an jeiner \$rflichterfüluntg hiutbern nerbe, gehört ebenfalls igm, nicht uns. Uns fommt $e$ s nux zu, ihm, nachbent einmal bie futtur=

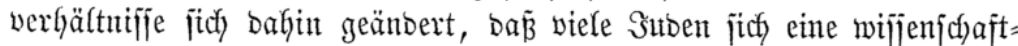

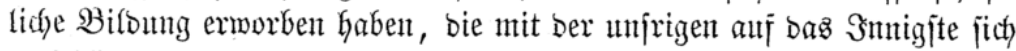
verichlingt, wie namentlich bie Ringuiftif uno Mebizin bisker gezeigt haben,

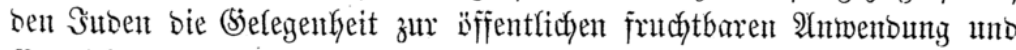
Entwidfeetung berjelben nidyt ferner vorzuenthalten. Der sBefürdytung,

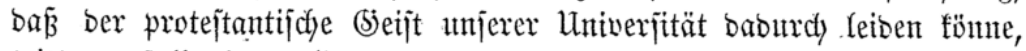
tritt - faffs jener beijt ïberfaupt fo jofwady und fo leicht ju ver= nichten wäre - objeftiv bie b̉ejchränfung des (biejeţes anf gemijie in

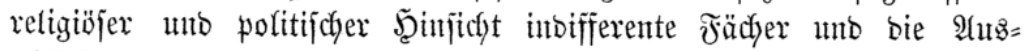

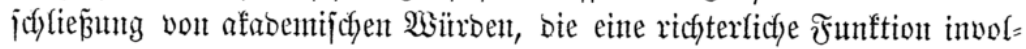
viren, gentitgent entgegent. Daj bie Frage über bie Zullafint ber Siatho= lifen, bie anj ben meijten Uniwerjitäten junon feine mehr ijt, für bie umjere

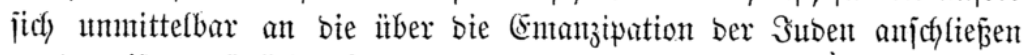
werbe, ijt natïrlidy. Sie ijt ebenfalls uno fajt auts ben nümlidyen (Sritnben ju bejaken. Da jebody jtatutennäpig unjere Untwerjitüt einen

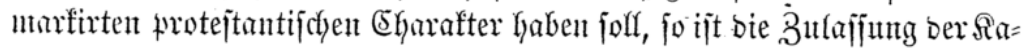
tholifen mur interbalb serfelben Schrantfen, wie bie ber Suben, zuzugejtegen, weil miter biefer Bebingung affe Bebenfen einer formution bes evan= getijchen Sinnes unt einer Sejuttentyerrfchaft bei uns fortjallent.

אïniggberg, bent 12. November 1847.

Rojenfranz".

\section{Fotum dis Concilium generale.}

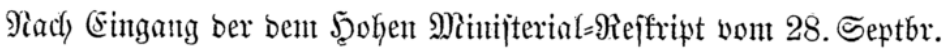

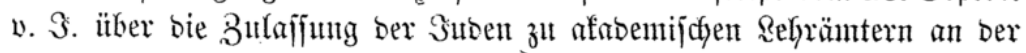

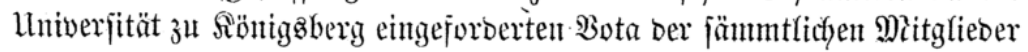

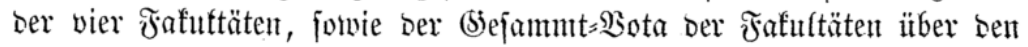
betreffenton (Segenjtand, ijt bie für bie fiefige Univerjität gan bejonbers 


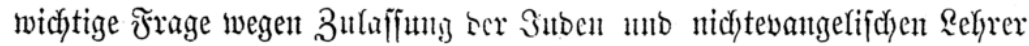
$3^{\mathfrak{y}}$ afabentifchen Rehreämtern in żwei Siţungen bes Concilium generale

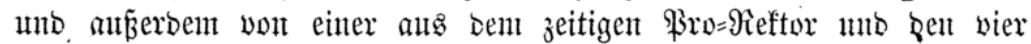

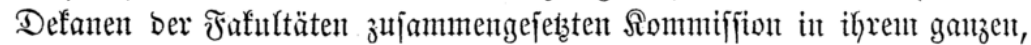

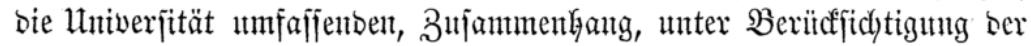

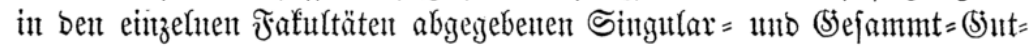
adytent, erwogen unb beratben worben.

Da ber $\S .105$ ber ant 4 . Mai 1843 von Sr. Majejtät bem アönig

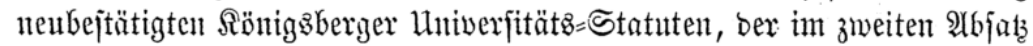
aljo linutet: .

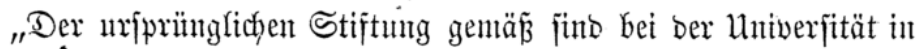
Sionigsberg mur Refrer evangelifyer Sonfeffion zuzulajien uno autzititeflen"

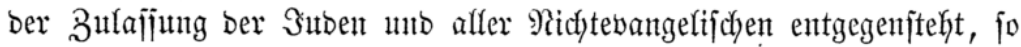
muşte zuerjt bie Frage entitehen: ob anzer ber int erwähnten § beftimun=

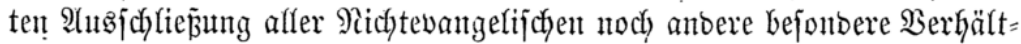
nijije bei ber hiejigen Univerjität ber $\mathfrak{A}$ nuventbbarfeit bes unter bem

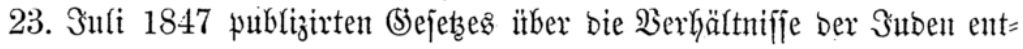
gegenjtäntben? Die Frage wurbe beinake ganj einftinnmig bahin beant=

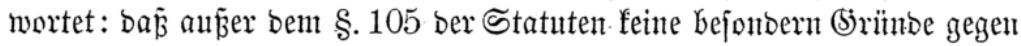
bie $\mathfrak{A n t w e n b u n g ~ b e s ~ e r m a ̈ h n t e n ~ B ̉ e j e t ̧ e s ~ b e ~ h i e f i g e r ~ H u t v e r ~ j i t a ̈ t ~ v o r f i e g e n t . ~}$

Da jomit ber $\S .105$ ber Univerjitäts: Statuten ber $\mathfrak{A}$ (nwentumg bez Subengejeţes vom 23. Sulf 1847 auf ber hiefigen Mniverjität als bus

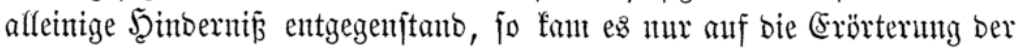
zwei. Fragen an: 1) ob ber $\$$. 105 ofne $23 e i t e r e s$ anjatheben, und alfo

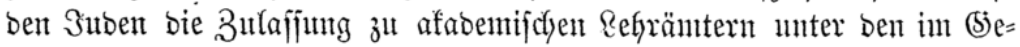

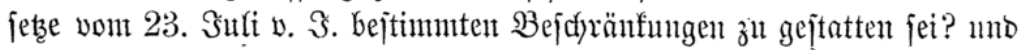
2) ob, wenn ber $\$ .105$ aufgehoben werbe, für gichtevangelijdye (Satho=

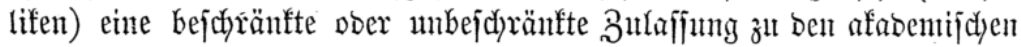
Sehrämtern hiefiger Univerfität z̆l gewuähren jei?

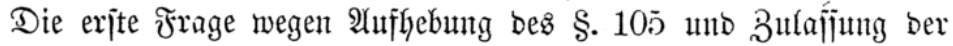

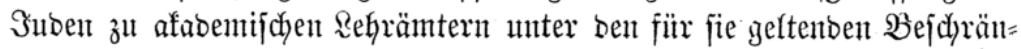
funge̊n murbe, wie fdyon burch bie Mehrzahl ber Stimmen in bent vier

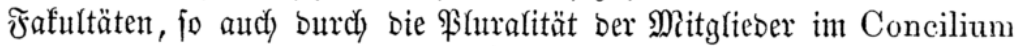

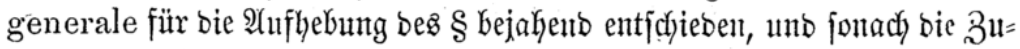

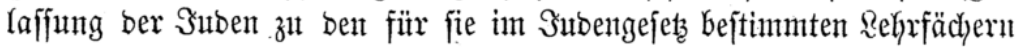
für angemejifen befunben.

In Betreff ber zwweiten Frage megen befchränfter ober unbefdyränfter

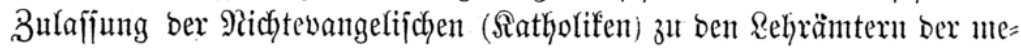

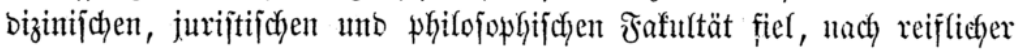




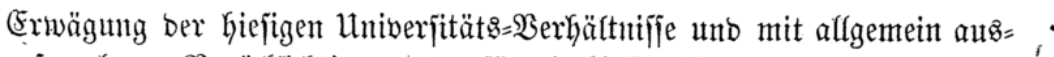

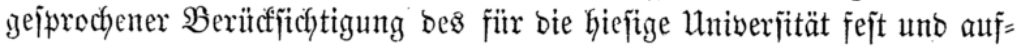
recht zu erfaltenben protejtantifichen (Sharafters berjelben, bie Enticheibung nach) Mefrkfeit ber Stimment im Concilium generale bafin aus, bá in Stelle bes §. 105̆, went ex aufgehuben werbe, ein in jolcher Weife mobi=

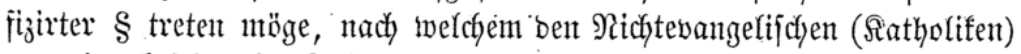

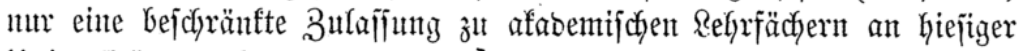
Univerjität getuährt werbe.

Itun nun bie Fruge in nähere Errwägung z̆ żeken, unter welchen $\mathfrak{B} e=$

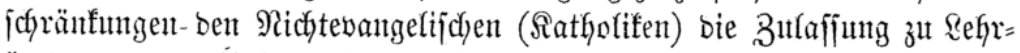

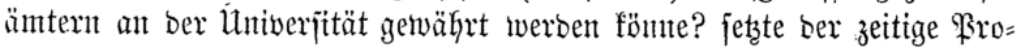
Reftor einte. unter jeintent Borfizze aus ben Defanten ber vier Fafultäten beitelyento Sontuniffiton nieber, weldye nach umjidytiger Erörterung aller zu

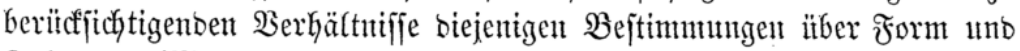
Snthalt ber Modififation entwarf, weldfe in bie Stelle bes aufgefobenen $\S 105$ treten unögen.

Dieje entworfenen $\mathfrak{B}$ ejtimmungen murben hierauf am 14 . Samuar ๖. Э. in einter abermafigen Siţung bem Concilium generale borgelegt uno

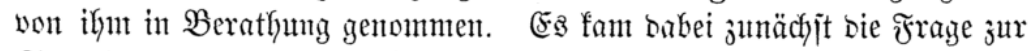

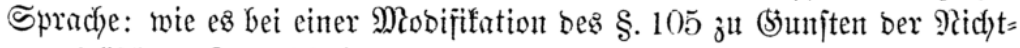

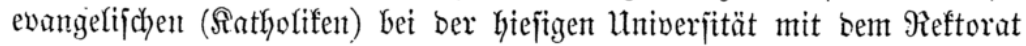

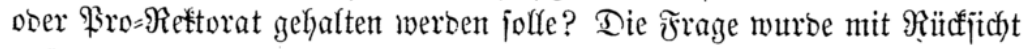
auf ben aufrectht ju erhaltenben protejtantifchen (5harafter ber Univerjität mit ïberwiegenber Majorität ber Stimmen bahin entijujeben, ba $\mathfrak{\beta}$ an

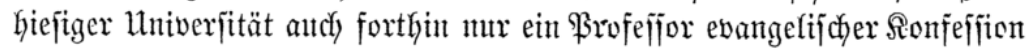

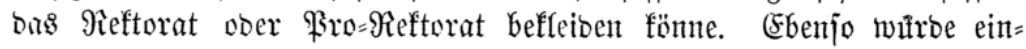
heclig bafïr gejtimmt, bå unter bem eigenthümlichen (5harafter vieler

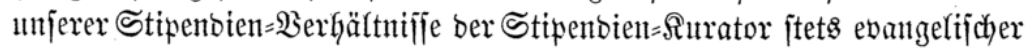
Sionfefiion fein mitffe. Die Frage bagejen: of bie Defanatz=:2emter bei

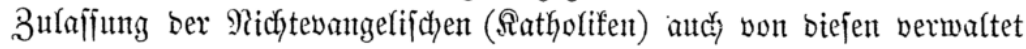
werben fönnten, wurbe burch bie Mehrbeit von einer Stimme (von 13 gegen 12) beiakent entichiebent.

Rachbem hierauf bie erwähnten, von ber Sommiffion entworfenen, Beptinumungen in einigen Einzelheiten nody einer Mobififation unter= worfen waren, faj̧te man bie Rejultate ber Berathungen in folgentem (5)utad)tent zufanmen:

1) Die Beftinmmung ber Statuten ber Mniverjität zu §öntigsberg vom

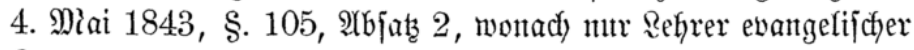
Sonfeffion bet ihy z̆tzutlaffent unb anzulfteflen jeien, möge alz auf $=$ gehoben Getradytet werben. 


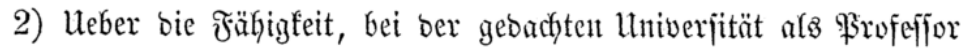
noer \$ribat= Dozent eimzutreten, witroen fomit bie affgemeinen Ranbegigejeze entjcheibent jein.

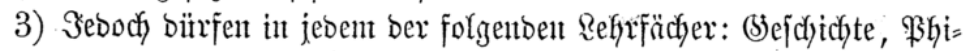
lojophie, Staats= unt Sirchentedyt bie 3ahl ber nitht jut ber evangelifchen Sonfeffiton gegörigen Rehrer bie Zahl ber für bie einzelnen Fädyer zutgelaffenten evangelif̧hen Rehrer bes gleidyen

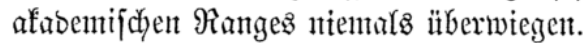

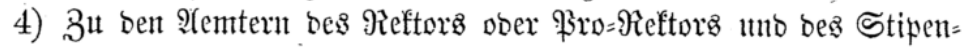

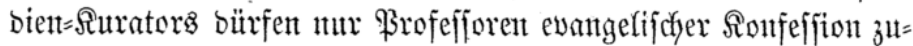

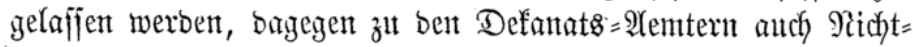
ebangelifiche ( Ratholifen) gelangen.

Rönigzberg, Den 31. Samtar 1848.

Concilium generale ber ß̊̈nigl. Utniverjität.

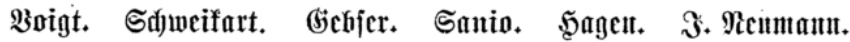

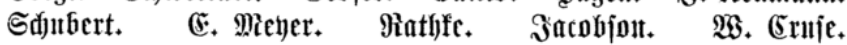

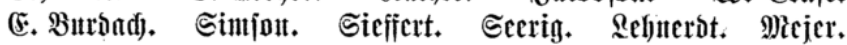

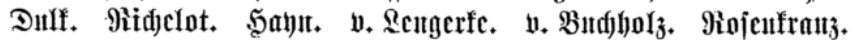

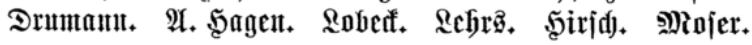

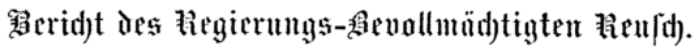

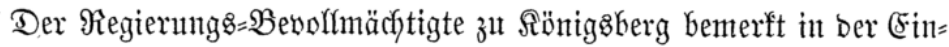

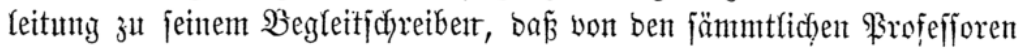

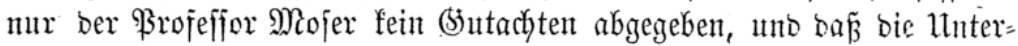

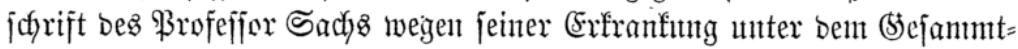
(5)utachtển bes Concilii generalis fehle.

Wenn (Ew. অrcelfent, fährt er bann fort, mir erlautben, mich in biejer

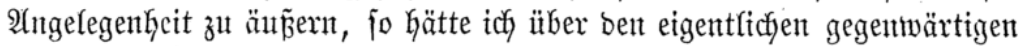
Stanbpunft berjetbent Folgentoes anzuführen:

Die Frage, ob unb wiefern Suben zu afabemijchen Rehrämtern zugelaffen werben joffen, ift bei bem vereinigten exjten Ranotage vielfeitig

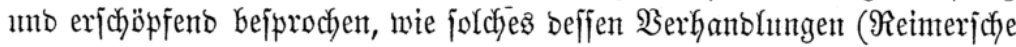

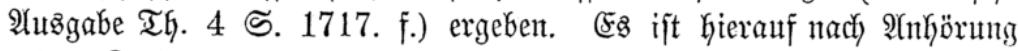
beiber Rurien bes vereinigten Ranbtages das \$5ejets wont 23. Suli 1847

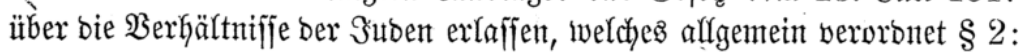

Bei Univerfitäten fönten Suben, foweit bie Statutent nicht ent= gegen jtehen, als ßribatbozenten, außerorbentliche uno orbentliche Brofefforen ber mebizinifchen, mathematifdyen, naturwiffenjdyaft=

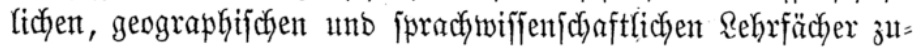
gelaffent werben. $\mathfrak{B}_{0}$ affen übrigen Sebrfächern an Untwerjitäten, 
jo wie von bem afabemijchen Senate unt von ben $\mathfrak{A}$ emtern eines

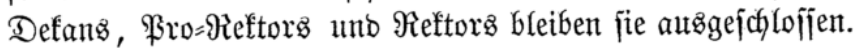

So wie es bei biejem bejtehenten biejetse nicht anf tweitere allgemeine

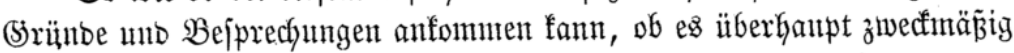
gewejen, Suben zu afabemifchen Sefrämtern zuzulajfen, jo folgt aus ben

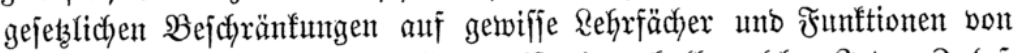

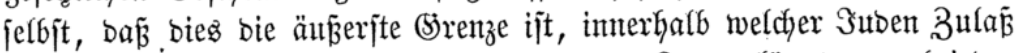
finben. Die Bejorgni

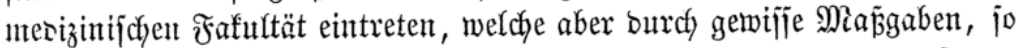
wie burch bie barauf geridytete $\mathfrak{B}$ orjorge ber ber Univerjität vorgejeţtent

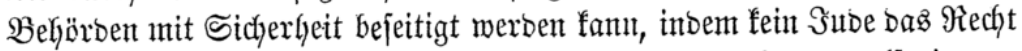
hat, bie $\mathfrak{A n}$ fteflung bei einer bejtimmten Fafulttät zut verlangen, aljo inmer

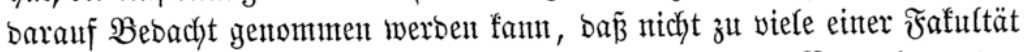
zugetwiejen merben, ¿amit noch mehrere Mitglieber zur Bertwaltung ber Den. Suben verjagten Defanatššüfrung bisponibel bleiben.

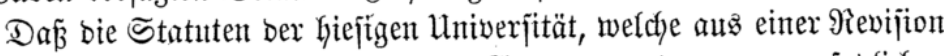

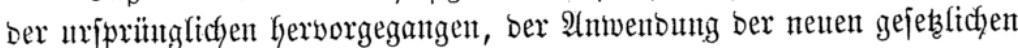
Bejtimumutg entgegenjtehen, ijt bereits bem vereintigten Ranbtage von bem

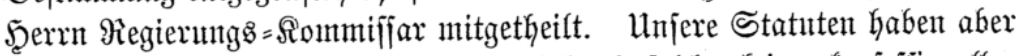

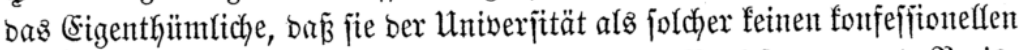

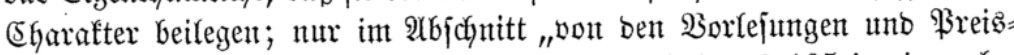

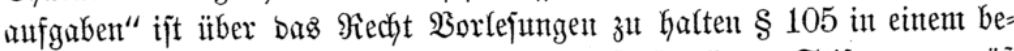

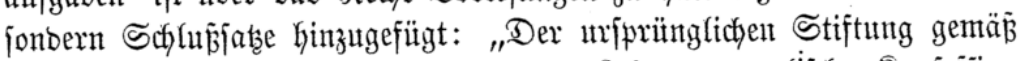

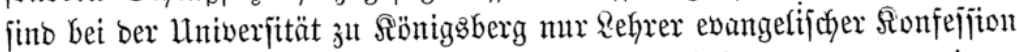
zužllajien unt anzujtellen." - Mant fömute bieje B̧ejtimmungen an einem nicht paffentoen Drt für fugitiv halten, was jie jeboch nicdyt jint.

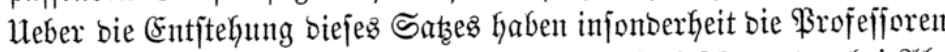

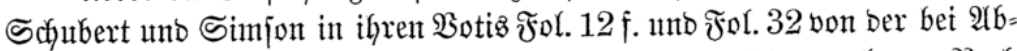

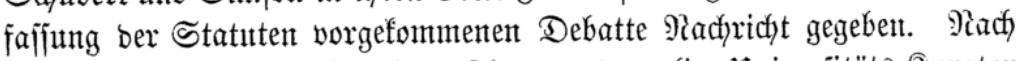

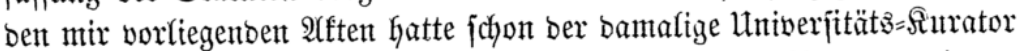

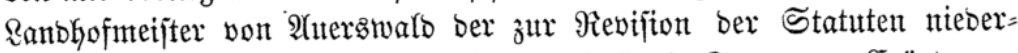
gejersten Sonmiffiton bent 18. Dftober 1817 bie Frage zur Erörterung

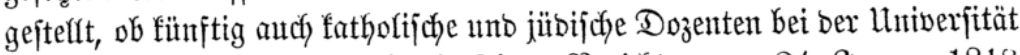

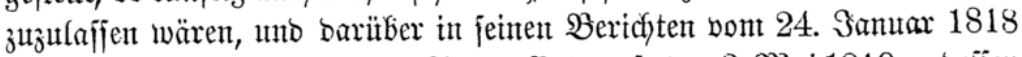

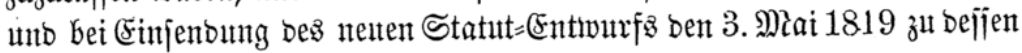
$\S 144$ angefithrt:

Die it peinen frithern Bemerfungen aufgetworfene orage über

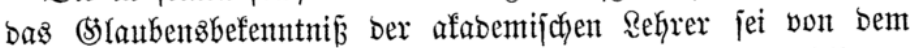
Senat furzweg bahin beantwortet, bar jie nach ber Stiftung

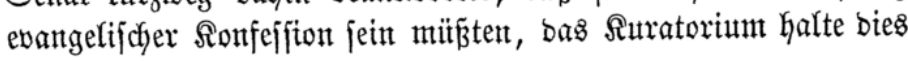




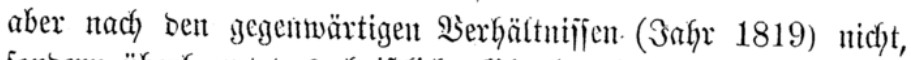

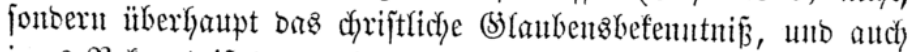

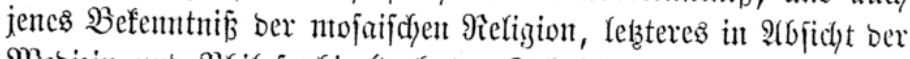

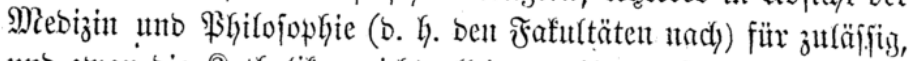
und zwar bic Ratbolifen nicht allein, weil bes Seinnigs Majẹtät

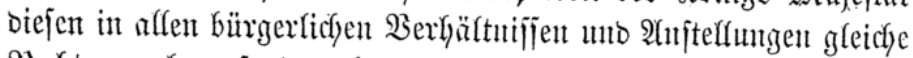

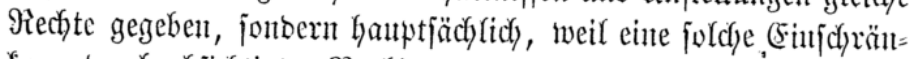

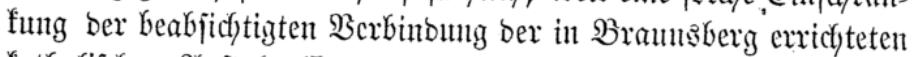
fatholifdyen 2̂njtalt (Lyceum Hosianum) mit ber Univerjität entgegenftehen witrbe, bie Butaffung ber Suben Gerutye aber in

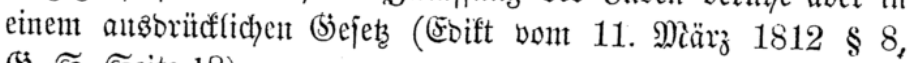
(5). = S. Seite 18). -

Der Rurater hatte bereits bie gelehrten. Erörtermmgen itber bie in

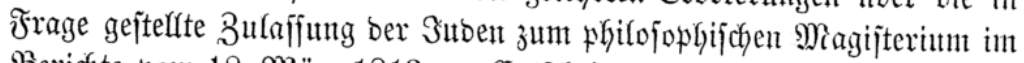
Berichte voun 18. Miär, 1813 zur Entfjeibung bes hohen Minifteriums, Departements für ben Unterricht unb Яultus, gebracht, welches biejelbe aber nach Dem Befdyeibe vom 23. Sult 1813 vhne ?ammer Gis zut ein= tretenbem Fall ausigejeţt lię̧. 2)(

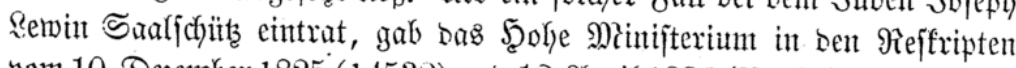

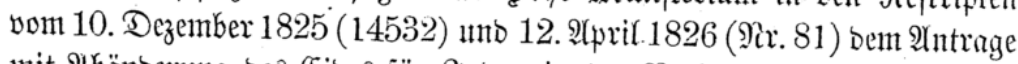
mit MGänberung bes (5ibes für Suben in ber. Bethenterungsformel: ita me Deus adjuvet, wie folche noch gebräuchlich ifit, nach). Schon frither

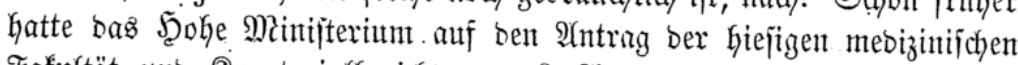
Fafultät uno ßumatorialbericft vom 8. 2(ugujt 1817 in bem Befdeioe

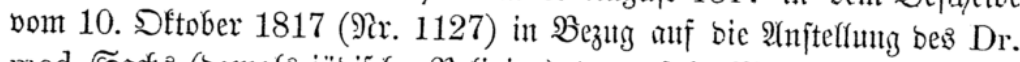

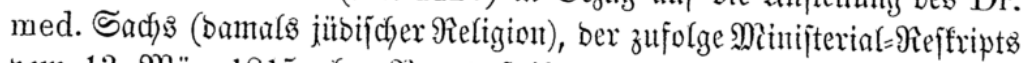

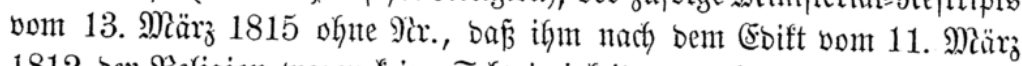

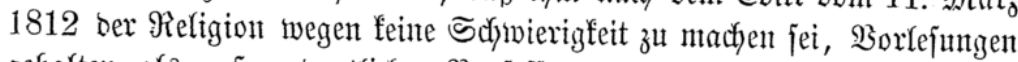
gefalten als aufierorbentlicfer \$rofeffor oer Mebizin, erffärt, baß̃ bie

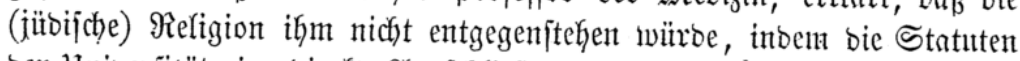

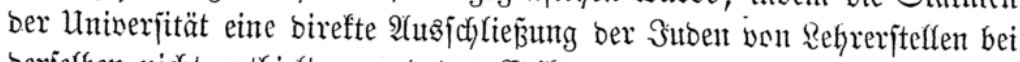
berjelben nicht enthielten, uno bas Ebift vom 11. Mär 1812 afle barin nidjt bejtätigten (Sejebze uno Boxjdyriften für anfgehoben erffärt habe. Da

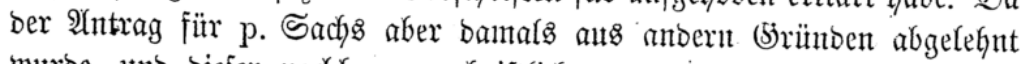
murbe, unb biefer nadjher jur dyriftlidyen uno evangefijchen Sonfefïion

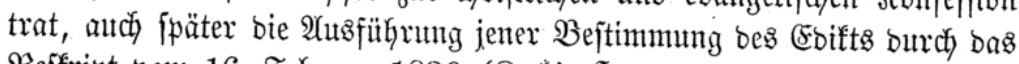

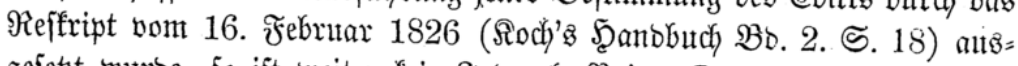
gefetst murbe, fo ift meiter fein Sube als \$riwat=Dozent, vielwentiger als

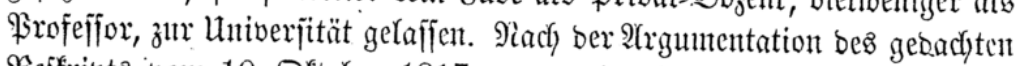

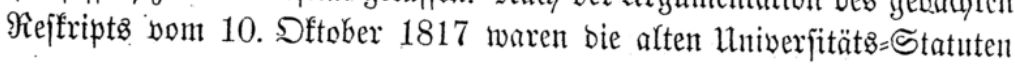


abgejchafft, ob. bie Suzpenjion ber besfallfigen Borjdyrift bes (5obifts vom

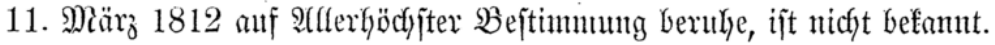

SGegen ber Ratholifen hatte bas bamalige Mniver jitüts= Siuratorimn

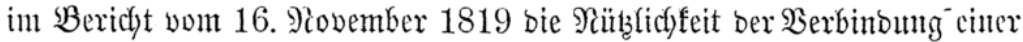

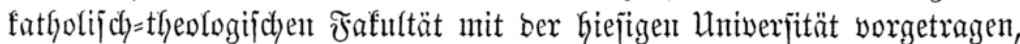
worain aber f́ein $\mathfrak{B} e$ ijcheib eingegangen ift.

Auf bent vorerwähnten Beridyt vom 3. Mai 1819 fanto befauntlids

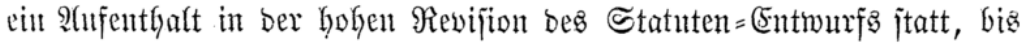

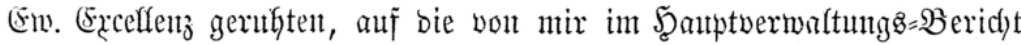

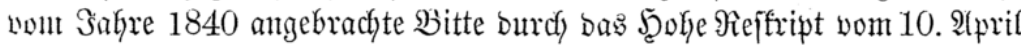

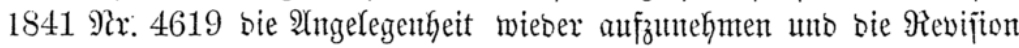

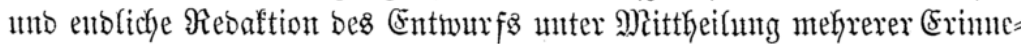

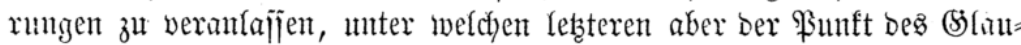

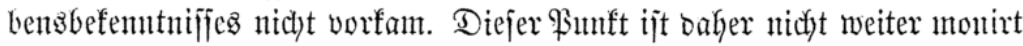
worben, unt in ben ant 15 . November 1841 eingereichtent unto nad) ber

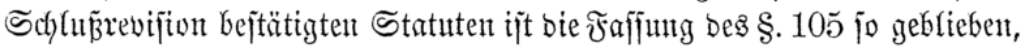
als bie bes frühern §. 144 war.

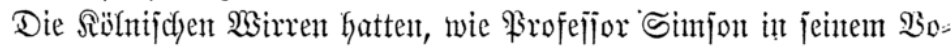

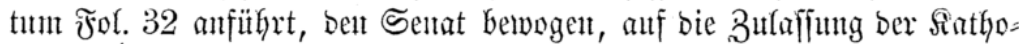

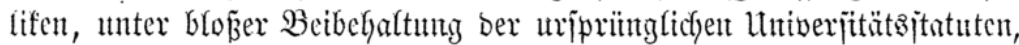

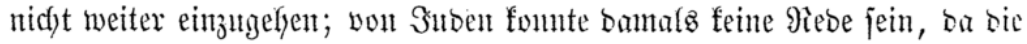

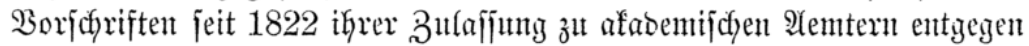
jtanbent.

Die Fejtietzunt ber hiejigent Statuten ijt baker, fo wie es in rer

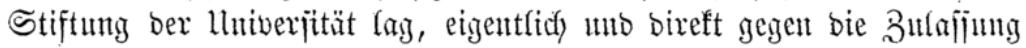

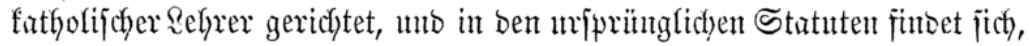
wie bas oben angefitfyrte 9iejtript vom 10. Dftober 1817 richtig bemerft,

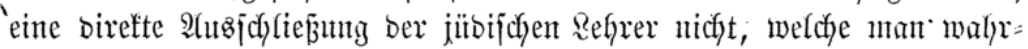

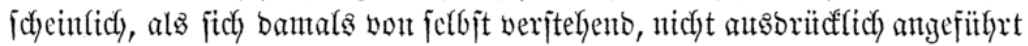

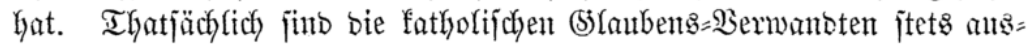

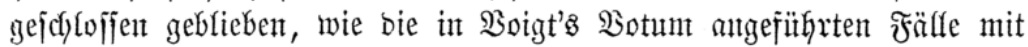
v. SBaczlo, Rubin und v. Siebold nachueifen.

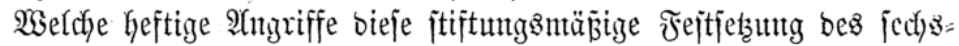
jefnten Safhrfunbertz bei bom Sereinigten Ranbtage herburgerufen hat,

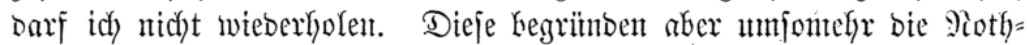

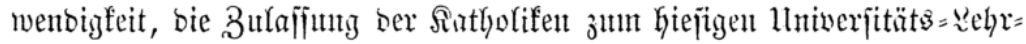

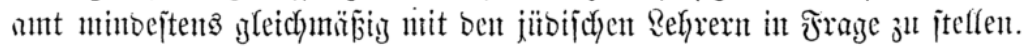

Die von Fiv. Excelfenz verfangte Beantwortming ber jweiten Frage

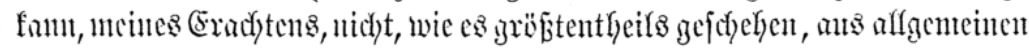
(bründen genomntent werben, fontern, fo wie Statute bejonbere, ants sen 


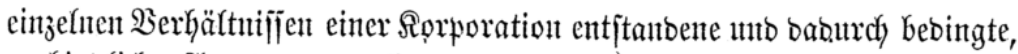

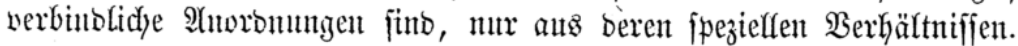
E: unterliegt aljo ber Erörterung, ob bei ber Kiefigen Univerfität $\mathfrak{B} e r=$ bältniije jtattfinben, welche bie Beibehaltumg ber jebst jtatutarifchen ₹ejt=

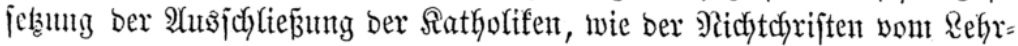
ante erforberlich machen.

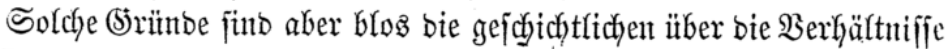

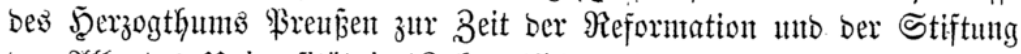

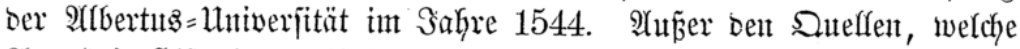

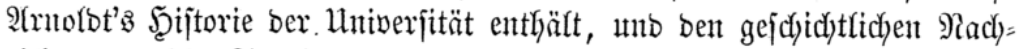

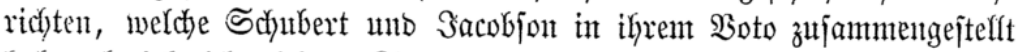

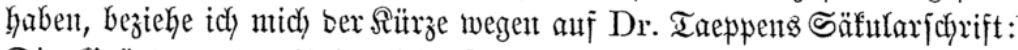

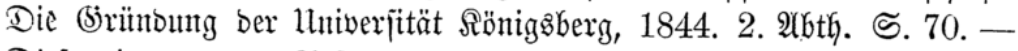
Dieje ginty alts ber Яeformation bes Ranbes hervor, follte bieje unter= ititizen, aber audh bas Rano mit protejtantifdyen (seiftlichen uno Refrern,

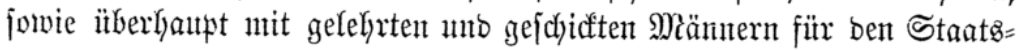

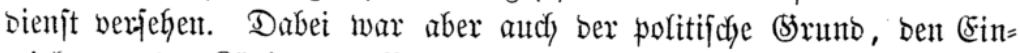

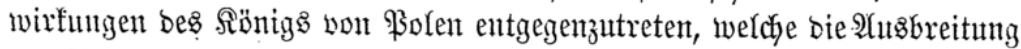

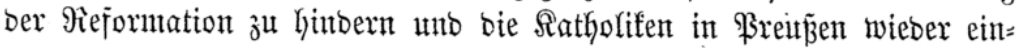
zufiüfrent bemilfyt warent.

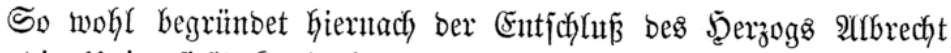
war, bie llniverjität fiöniggberg mur mit protejtantifchen Rehrern zu

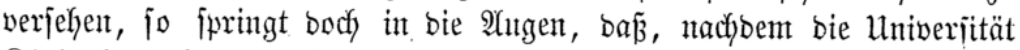

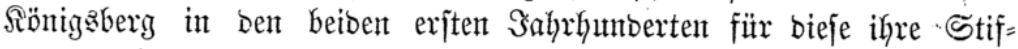

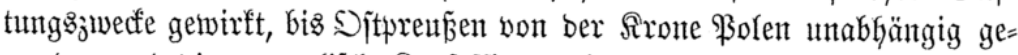

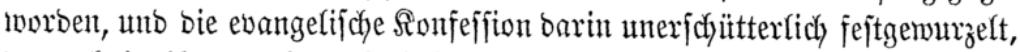

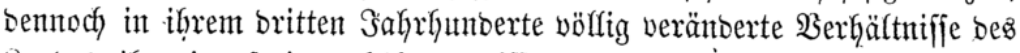

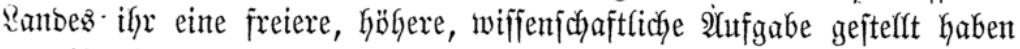

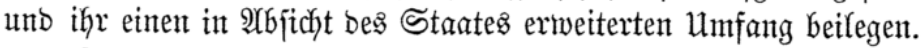

In Bezug auf bie gejchidstlichen unb jtatijtijchen Darjtellungen

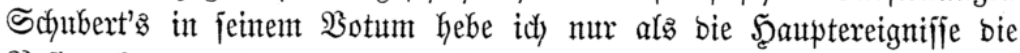

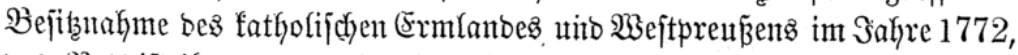

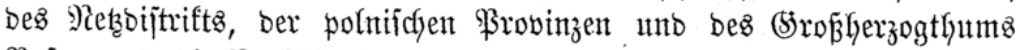

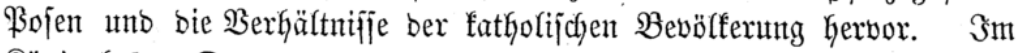
Sïniggberger Departement weijet bie jtatiftifche Tabefle für 1846 nad):

$$
\begin{aligned}
& \text { ebangelijd)e (Ériften . . . . . . . . . . 662,144 }
\end{aligned}
$$

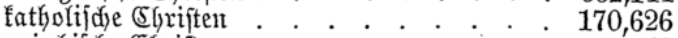

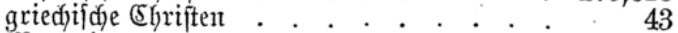

$$
\begin{aligned}
& \text { Menoniten . . . . . . . . . . . . . . } 385
\end{aligned}
$$

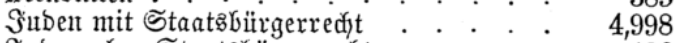

$$
\begin{aligned}
& \text { Snben vhne Staaţbïrgerredt }
\end{aligned}
$$

Finwohner: Summa 838,322 
Fiit bieje (s)ejamuntbesölferutg, wogut bie brei anberen preukifchen

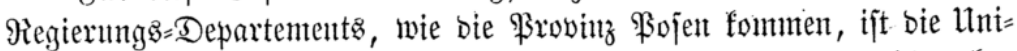
verjität in ber hägern Bilbungaffufe zut jorgen berufent. Dazu gehört aber

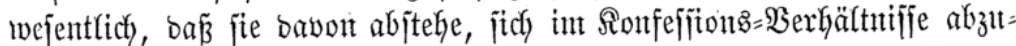

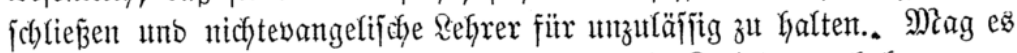
perjöntich unbequem jein, fatholifdje uno jübijche Sidlegen zut haben, mag man eitte unfremtolidye Stellung bejorgen, wie jie überall ftattfintet, wo die Sonfeffitonen gentifyt wohnten, wie fie Keiber bet uns feit ber bon ben Ratholifent gegen bie Evangelijchen angenonmtenen ftrengerent F̧altung ntehr hervorgetreten ift, fo ficheiten bieje (5ritnto bod), als alfgemeine unt nicht

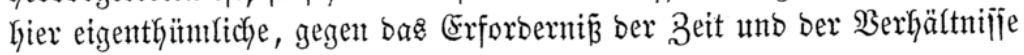
nicht vont (semvicht. -

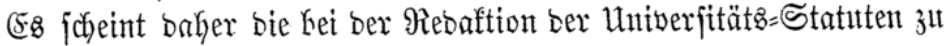
jtarf Gerborgebobente Pietät gegent bie Stiftttig, beim Mangel anberex we=

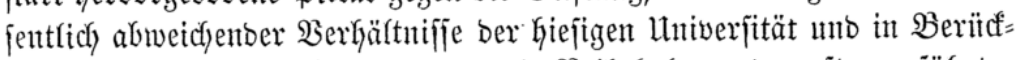
jichtigutng ber neuturn (5iejebsgebung, bie Beibehaltung bes oft angejührten Sd)

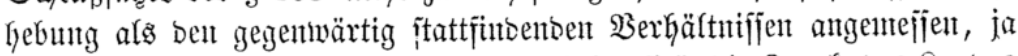
als nothwentig barzujtellen, bamit bie Uniwerjität bie Ziwede bes Randes exfitfle.

Das Concilium generale hat baher, meines (Frachtents, ntit vollem

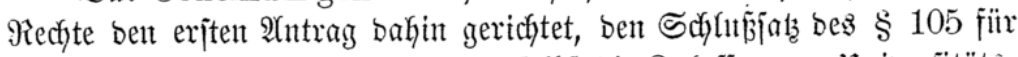

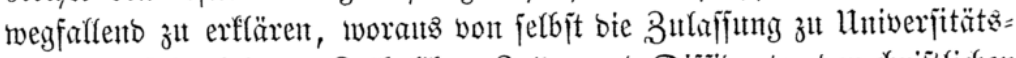

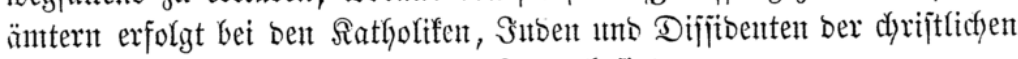
Sirche, jobalo jie fidt) in gejetşictyer Form befindent.

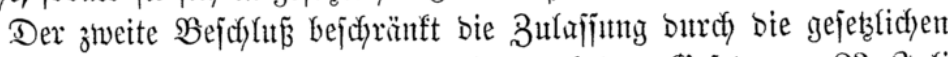
Beptimmungent. Bei ben Suben ift bies nad) Sem Stejets vont-23. Julti v. $\Im$, von jelbjt flar, inbent barin nidyt mtr bie \&eforfächer bejtimnt jint, weldye ifnen offen, affe anbern aber, fo wie bie Berwaltung bes Reftorats, Bro=9ieftorats unt Defanats, wie bie Mitgliebjedaft bes Sentatz, verfagt bleiben. Die Theiluahme am Concilium generale breibt ifnen barnact) gejtattet.

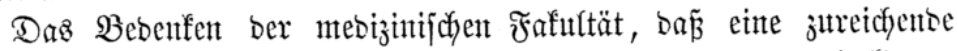

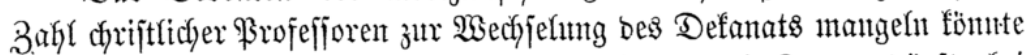

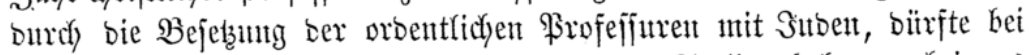
fleinern Untiverjitüten, bie wentge Drbintarient= Stellent haben - bei

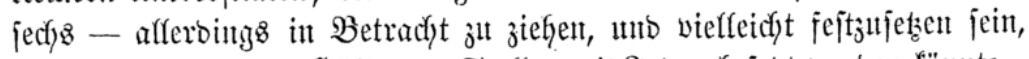

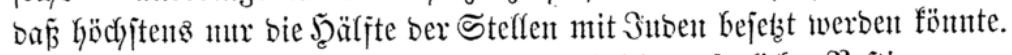

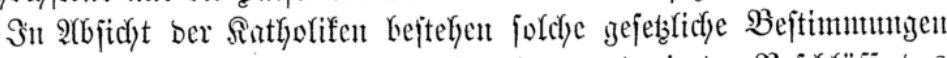

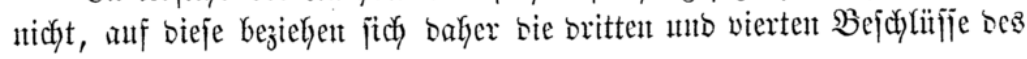




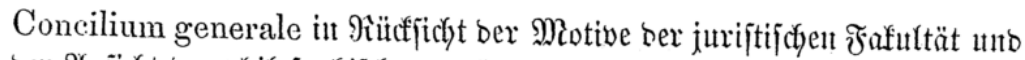

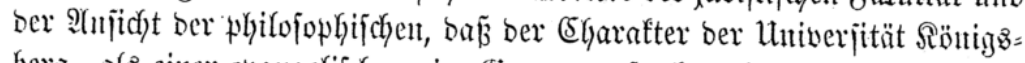
beriz, als einer evantgelifchen, im (5)anzent anfrecht erhaltent werbent miiffe.

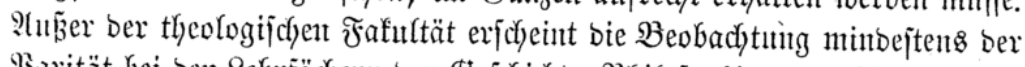

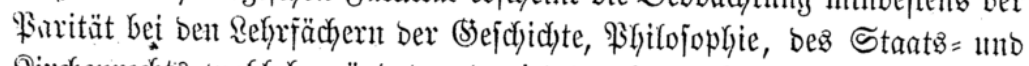
Rirdyenredyts wohl begrüntot uno wiro burch bas Statut ber Univerfität

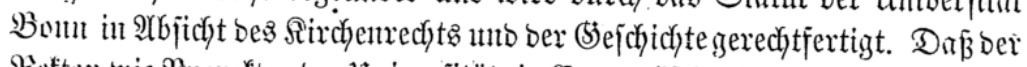
Meftor mie \$roreftor ber Univer jität ein (Evangefifd)er bleibe, bitrfte man zur

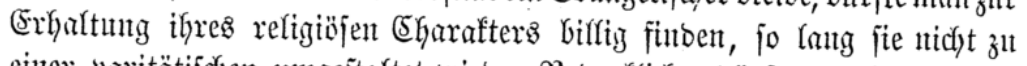
einer paritätifdyen amgejtaltet wirb. Bebenfflicher bürfte $e 8$ aber jein, ob

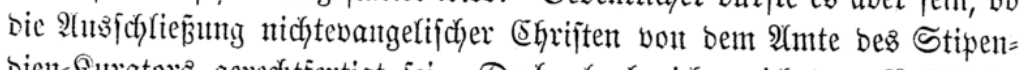

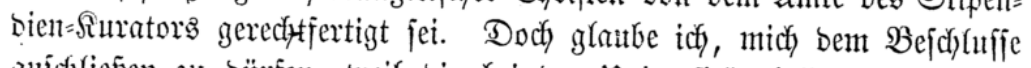

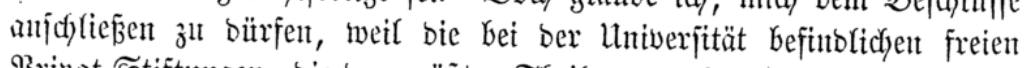

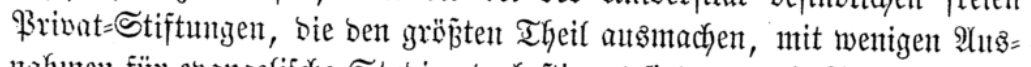
nukmen für ebangelifdye Stutbirente bejtimnt fint, unb bie Stifter, iverdye

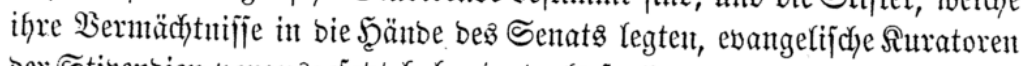

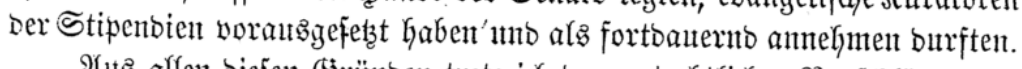

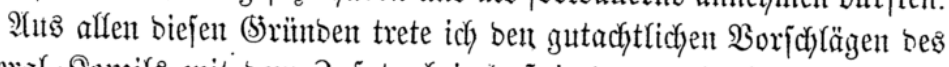
(5)eneral= Sonzil

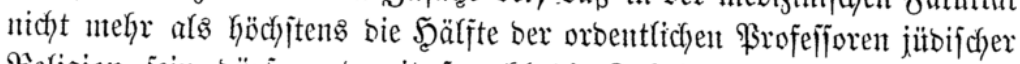
Religion fein bïrfen, bant fowohl bie Fafultät bei ber $\mathfrak{B a h l}$ zum

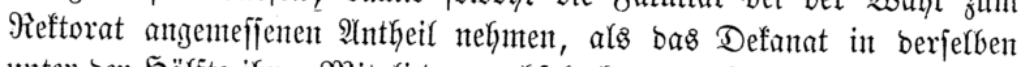
unter ber Şälfte iGrer Mitglieber: wechfeln faum, autef eine Bertretung im

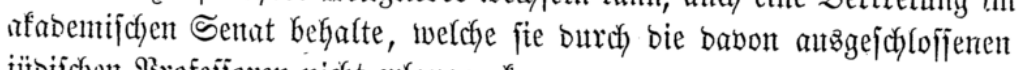
iübifchen Brofefijoren nicht erlangen fannt.

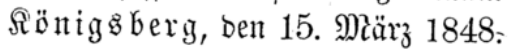

アietifid.

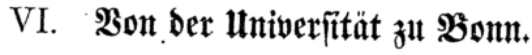

(Gefummt-motum der medizinifoden Enkultät.

Erite Frage:

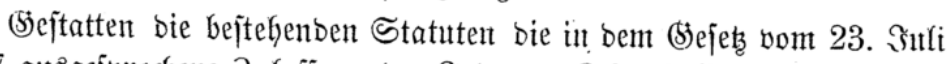

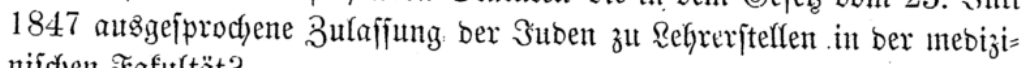
nifd)en Fafılttät?

Fïr $\Im \mathfrak{a}$ jtinnment

Raumant. Bukcr. Silian. Meber.

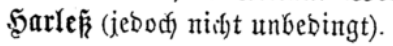

\section{Antwort:}

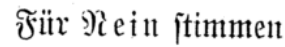

Matacr. Maific. Bijdoff. 


\section{3weite $\mathfrak{i r a g e :}$}

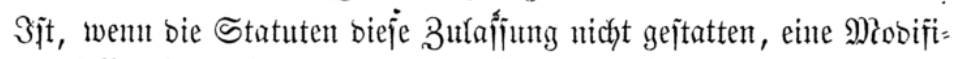

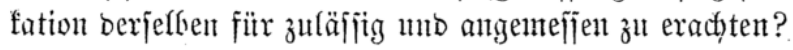

Für 9) Mobififation jtinmen bie \$rofefijoren:

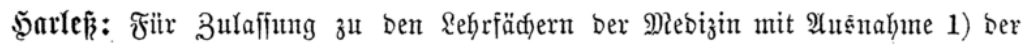
Staatzarzzneifunbe, 2) Der Şugieine umb Diätetif, 3) ber Direftion ber

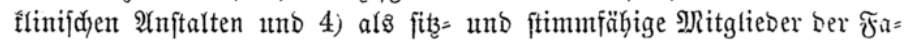
futttät.

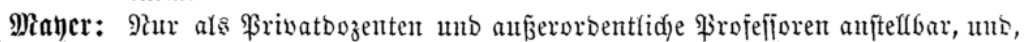

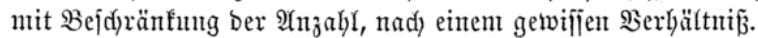

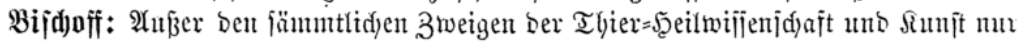
fiir bie $\mathfrak{M}$ natomie bes Menjdjen anfterrbar.

Boun, Dent 21. Nowember 1847.

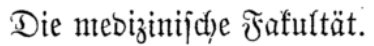

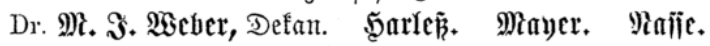

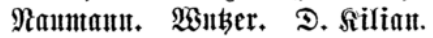

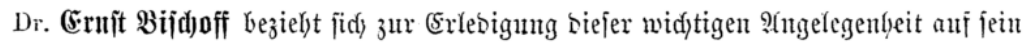
ipeziefles (3) tataditen.

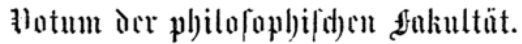

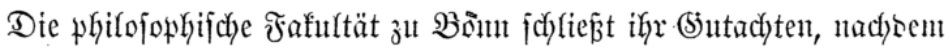

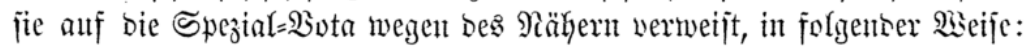

(5: hat fid einjtimmig bie ganje Fafultät für bie Bulafinng oer 3uben, refp. für bie 3uläifigfeit Der Medobififiation ber Statuten ju (5) miten ber Snben anıgefprochen. Die Fafultät, weldye mit an Ein=

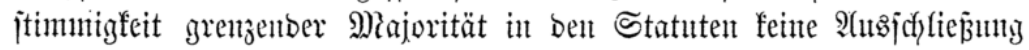

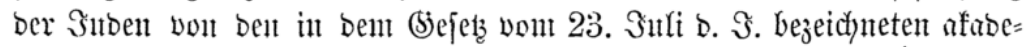

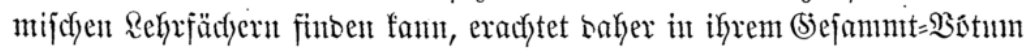
fajon baburch bie jweite Frage fïr 'erlebigt, fo baj felbjt okne Mobifita= tion ber Statuten bie mit Stimmen= Eintgeffigfeit gebifligte Zulajiung oer Suben zut ben geoachten Rehrfächern itattfinden fantm.

Bonn, Den 22. Dejember 1847.

Die whilojophif dye Fafultät.

(ltuterid)riftent.)

Sepurnt-thotum von Arofellor 雪uncrbant.

Die son ben R̈̈niglichen Minijter ber geiftlidyen uno Unterrichto:

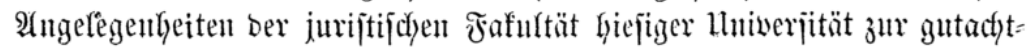




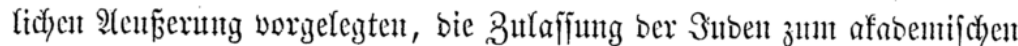

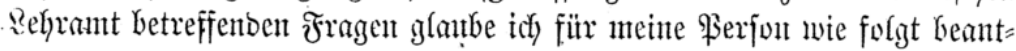
worten z̆ miijijen.

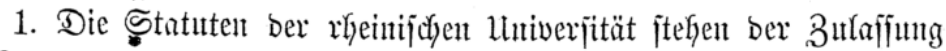

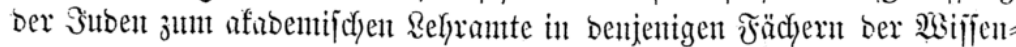

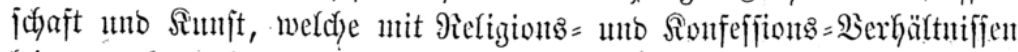

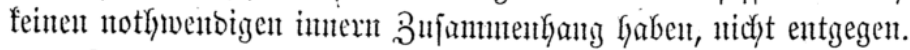

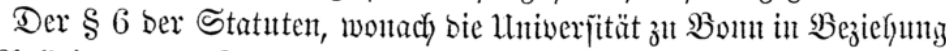

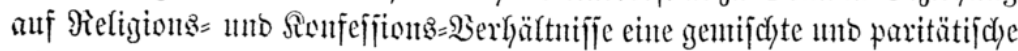

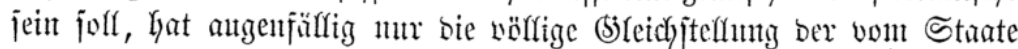

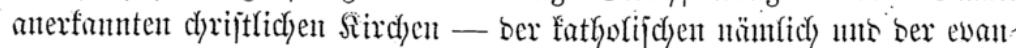

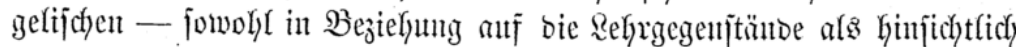

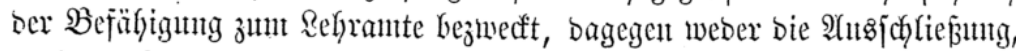

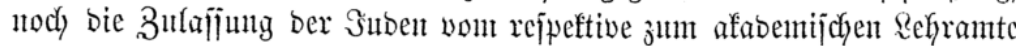

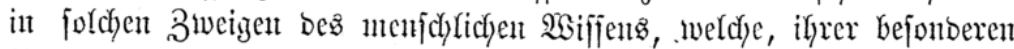

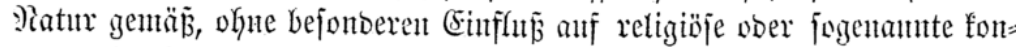

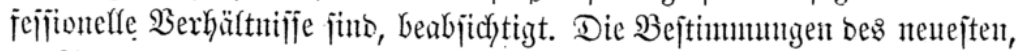

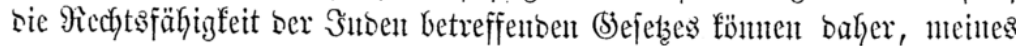

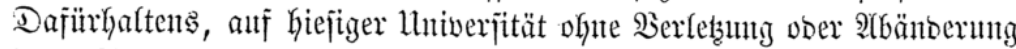

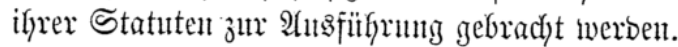

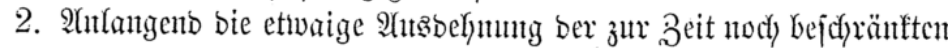

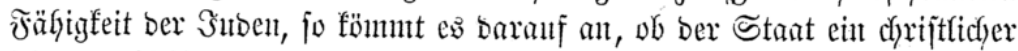

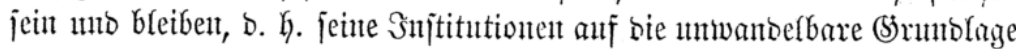
ber chriftlichen Rehre funtoirt, ober untabgängig vout ben fich vitntals iviber=

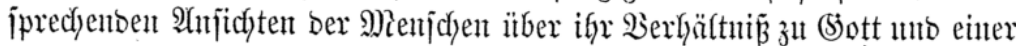

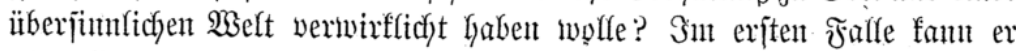

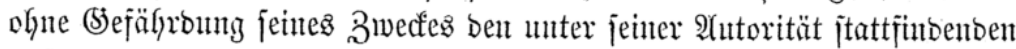

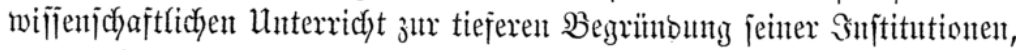

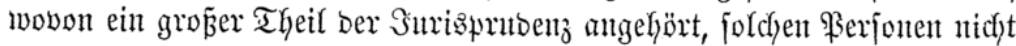

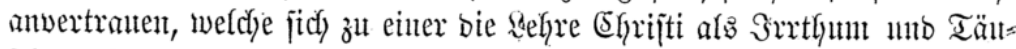

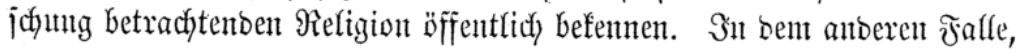
ober wenu ez etwa gar nicht möglidy jein follte, jid ïber bas șejen ber Rehre Shrijti - joweit biejelbe bejtimmte ?orment für bie Scantohngent ber

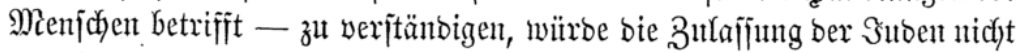
nur, jonbern aud affer jonjtigen (jegne ses wirf(idyen ober vermeintfichen

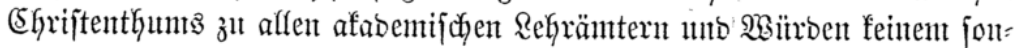
berlichen Bebenfen unterliegen, ber Staat aber audy feinent weitern Beruf

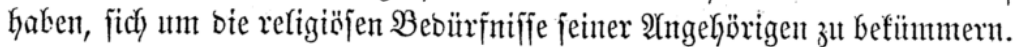
Bonn, ben 30. Rovember 1847.

Baucrbanto. 


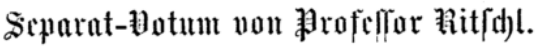

Die Beantwortung Der Frage, "ob bie Statuten unjerer Univerjität

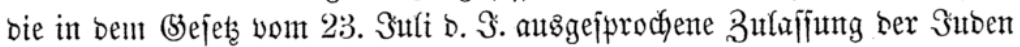
3u atabemifchen Eehrifächern gejtatten ober nicht", jujeint mix jo einfact) wie mögliç. Der § 6 Der Statuten bejtimmt: "Die Untverjität 孔̆t $\mathfrak{B}$

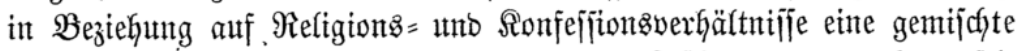

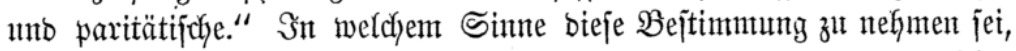
geht aus bent ummittelbar folgenten Fejtjeţungen hervor, nach wetchent fowohl eine evangelifche als fatholijche Fafultät fütr Theologie unto zwor

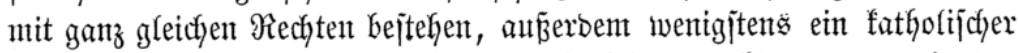

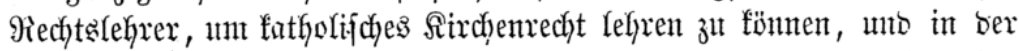
phitojophifchen Fafultät ein fathofifdyer \$rofefior ber \$Gjilojophie neben

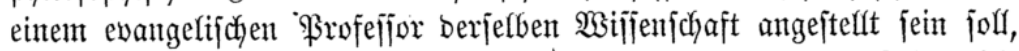
fjierwon aber abgejehen auf bie Sonfeffionen ber anjujteflenden Rehrer fei=

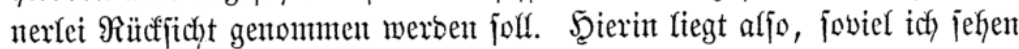

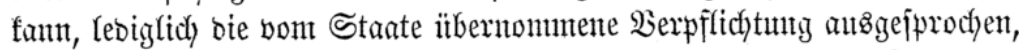

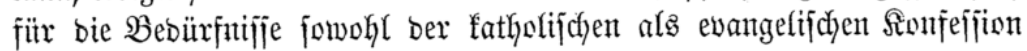

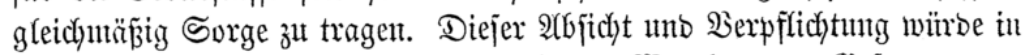
Beziehung auf nette 2 njtelfungen, nad) bem $930 r t f a n t$ bes (5ejeţes, mux bann nicht entiprodyen werbent, wenn für einent ber jpejieff namhaft gemach)=

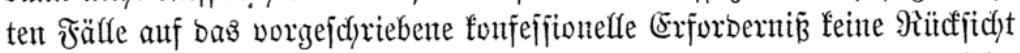

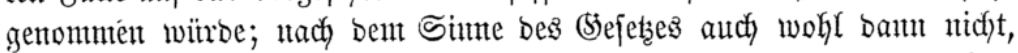

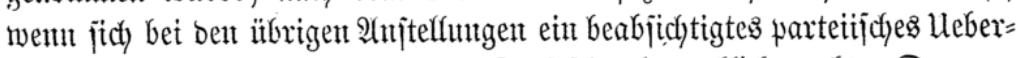

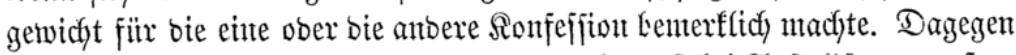

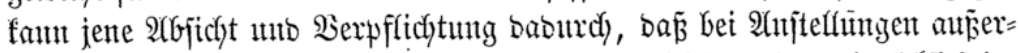

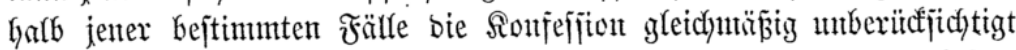
bleibt, itberbant gar nicht beriihyt werben, weil jie Gierburd) weber bejär=

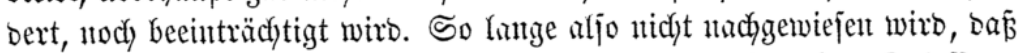

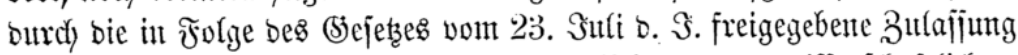

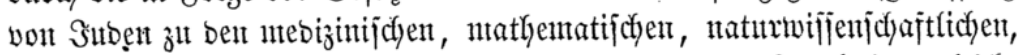

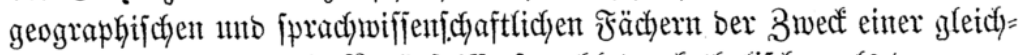

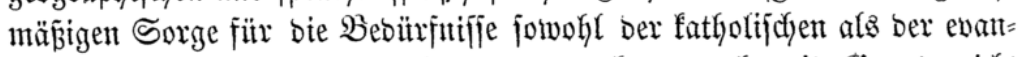

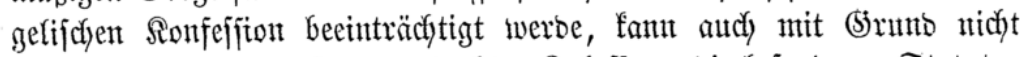
Gehauptet werbent, bá ber gebadjten Butlajiung bie bejontberen Statuten

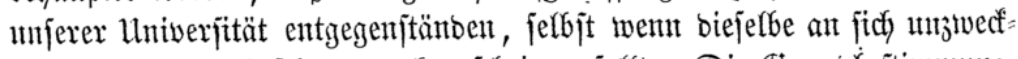

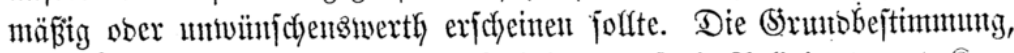

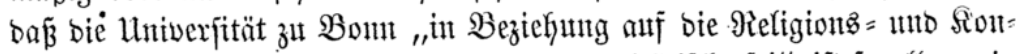

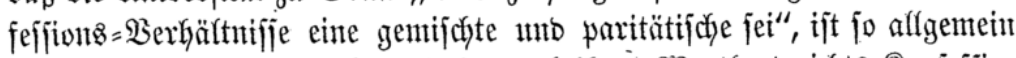

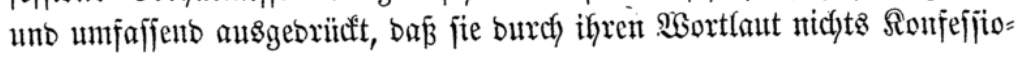




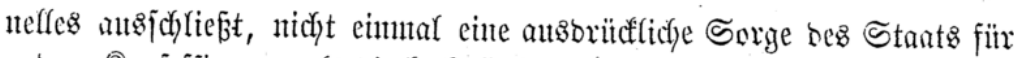
mbere Ronfefïinent, als bie fatblyolifdye unb evangelifdye, ober für anbere

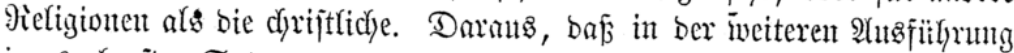

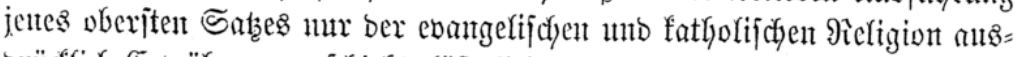

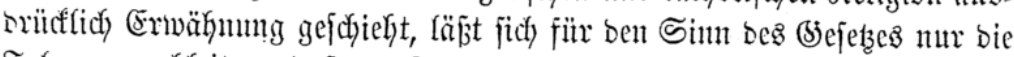

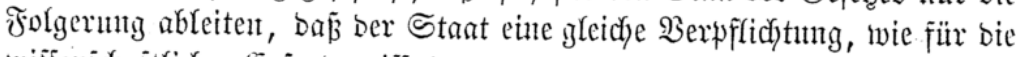

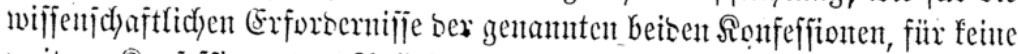

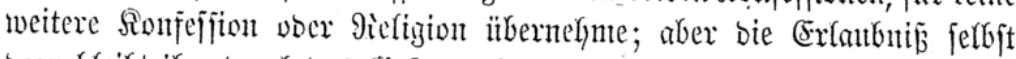
baju bleibt ihnt burch) bas (siefeţ unbenommen. Lun wie vier mefr arfo bie

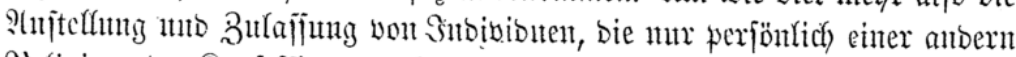

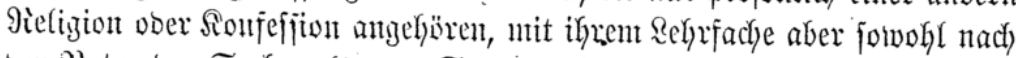

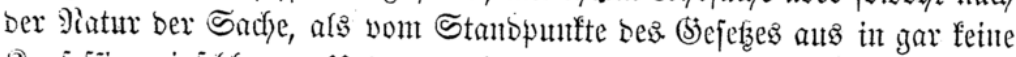

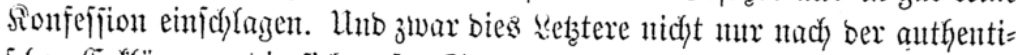

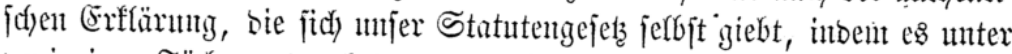

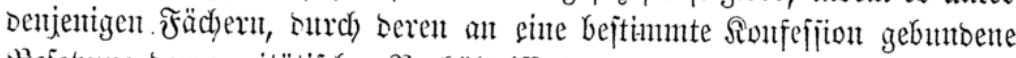

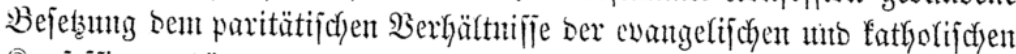

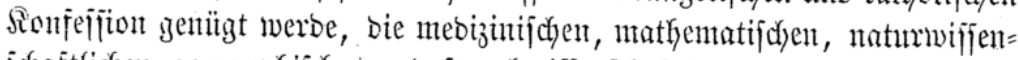

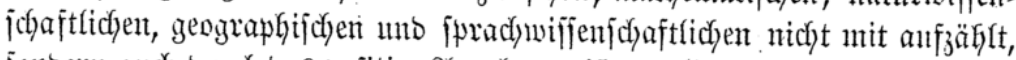

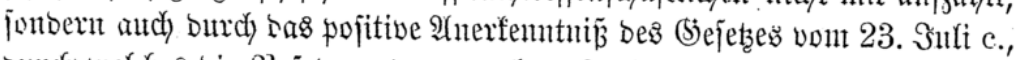

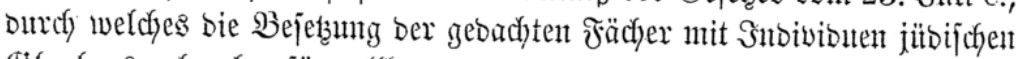
(5) autbens untentgbar für volffonmment verträgliç) mit bent allgenteinent wifjent= ichaftlidjen 3ivecfen chriftlicher lniwerjitäten erflärt worben ift.

Jïr benjentigen, ber bie erfte Jrage bejaht, ift bie zlweite won jelbjt erlebigt, unto barf fich berjelbe ebent barum ber näheren Motivirung ïber=

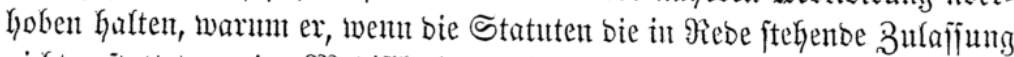
nicht gejtatteten, eite Miobififiation biejer Statuten für ebenjo zulüffïg al: a!ngemeffen eradyten mitrbe.

Boult, ben 26. Dftober 1847.

F゙. Ritifd).

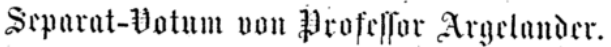

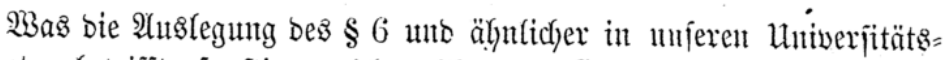

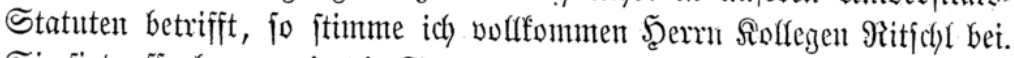
Sie fint offenbar nut in bie Statuten aufgenommen, um atsoriluffich jut

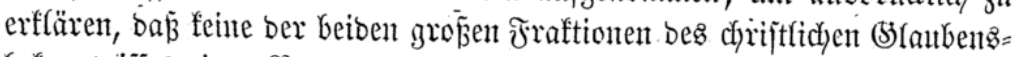
befenntniffez einen Borrang wor ber anberen haben folfe. Es twar bies

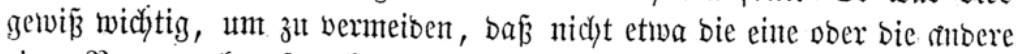

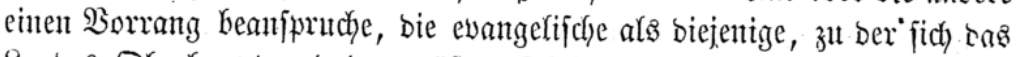
Ranbes= Dberkant unb ber gröpere Theil ber Unterthanen befeme, sie

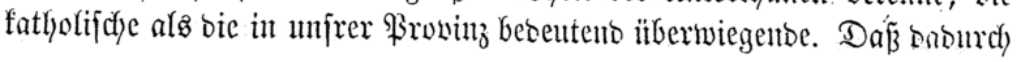


Suben nidyt augbritcflich) ausgejof logie gemäß aus § 106 unb ähnlidyen, worin ben Stubirenben ein chriftlich religiöjer Wanbel anempfohlen, und zur $\mathfrak{B}$ elebung befjelben auf ben dyrijt=

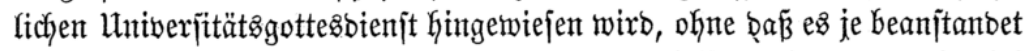
worben ift, autch Sutben zur Smmatrifulation zuzutafient. 2(uch bürfte Gierbei

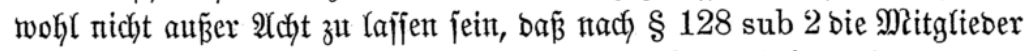

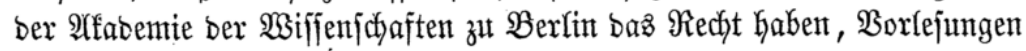

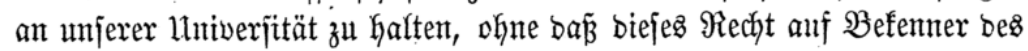

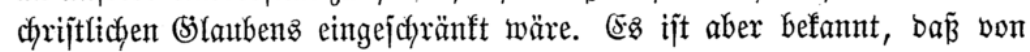

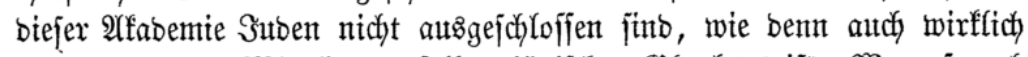
gegentwärtig ein Mitglieb berjelben jübifichen (Silaubens ijt. Wenn fonach

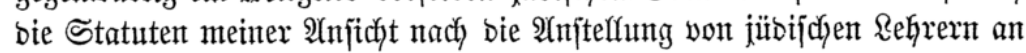

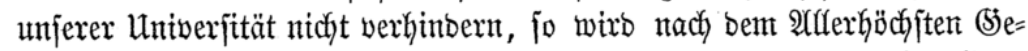

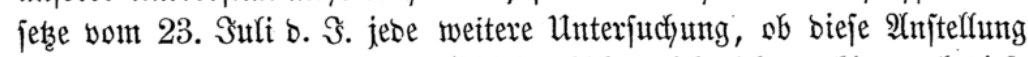

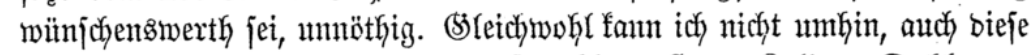
Frage zu bejaken, uno zwwar alts ben jowohl von ફ̧errn Fiollegen Dahlmann

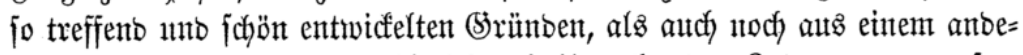

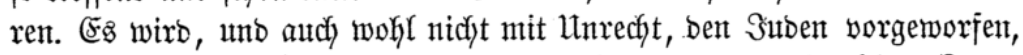

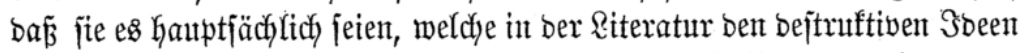

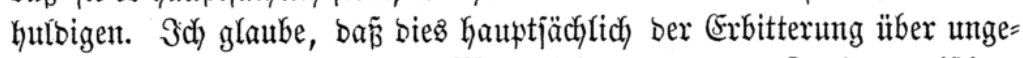

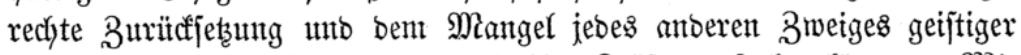

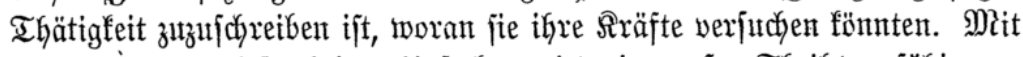

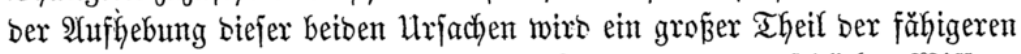

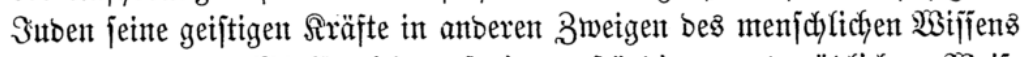

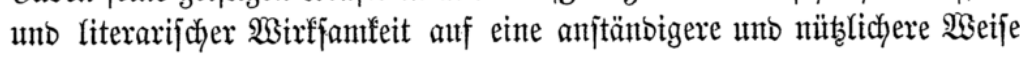
anwentinen.

Bont, ben 1. November 1847.

\section{Frr. $\mathfrak{A} \mathfrak{r g e l a n d} \mathfrak{e r}$.}

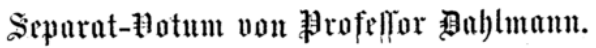

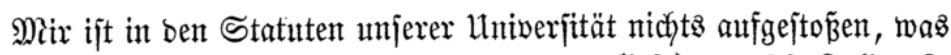

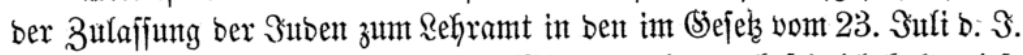
bezeichneten ซä̌chern entgegenjtäntbe. Wie bem aber auț jei, ich halte bieje

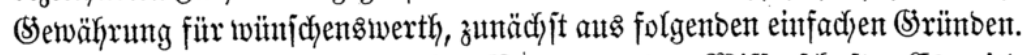

1. Sm Sntereffe ber freien Beswegung ber $\mathfrak{W}$ ifjenjichaft. (5: nirb

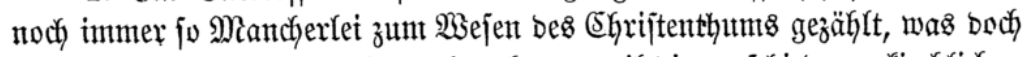
fafon barmm fahwerlidy bafür gelten fann, weil bie verichiebenten firchlichen

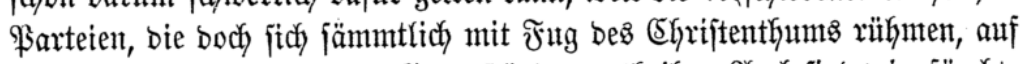

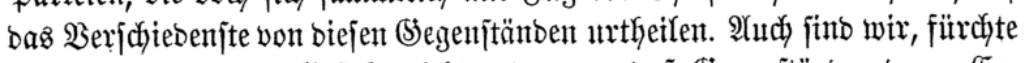

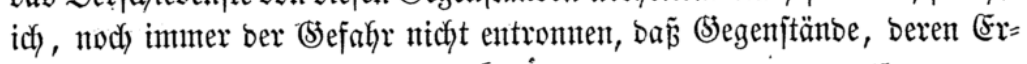




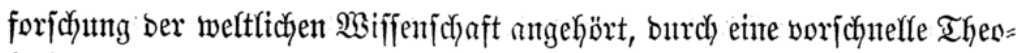
logie bogmatifirt unt fo ber freien Forjchung entzogen werben möchten.

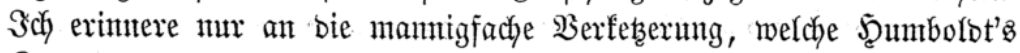
Rosmos neuterbings exfahren hat. Num aber, glaube ich, barf fich berjentige eines tieferen Sifaubens rilfmen, ber bie Heberzengung hest, baj (5ott, ber biejen rajtlojen Trieb ber Forjchung in bie Mienf(hentrujt gelegt hat, iful

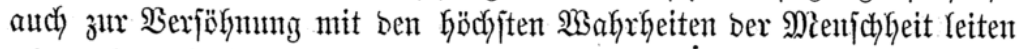

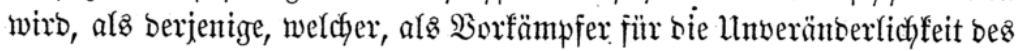

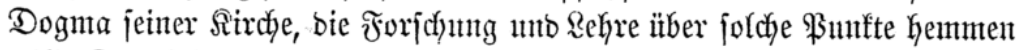

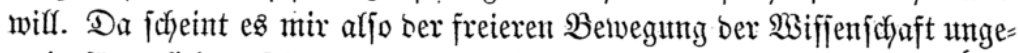

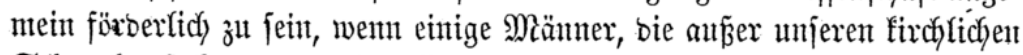
Schranfen jtehen, uns bieje Brefahr jtets gegentwärtig exhalten. Sollten bieje Männer unabweisbare $\mathfrak{B a h r h e i t e n ~ e n t b e c t e n ~ u n o ~ r e h r e n , ~ b i e ~ g e g e n ~}$ unjer firchliches Syjtem anjtofent, fo wirb uns bas in ber Afnerfenmung

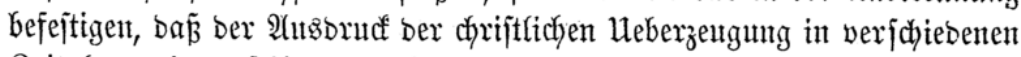
Beitaltern ein berjudebener jein bïrfe.

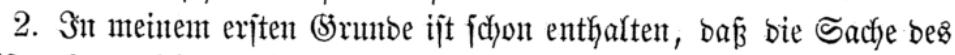
(5Griftenthums feinen 2(bbrutch burch biefe (Sejtattung erleiben wirb. Das ijt nicht (shrijtenthum, was bie Unterjuchung zu fürchten hat. Mleine Ueberzengung wärbe ben jonjt befäfigten Şjraeliten nidyt einmal von

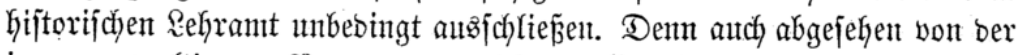

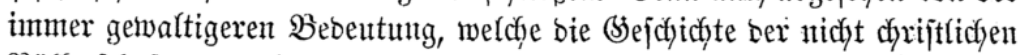

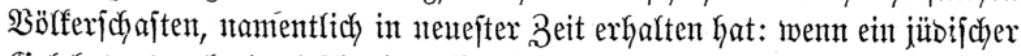

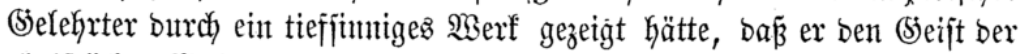

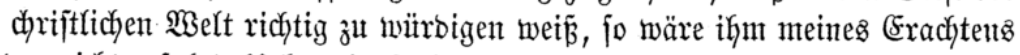

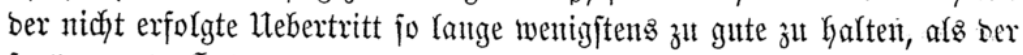

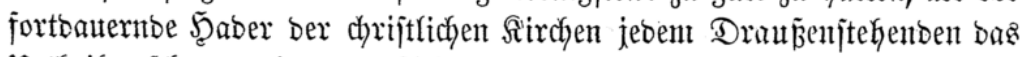
Urtheil exjcywert, in bem Schoope weldyer von ifnen ber affein wahre

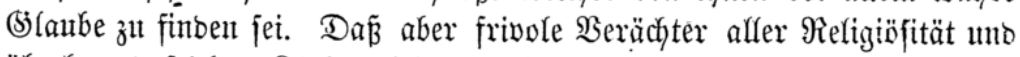
ïberhaupt feichte Söpfe nicht zur Feabilitation, gefdyweige benn zur

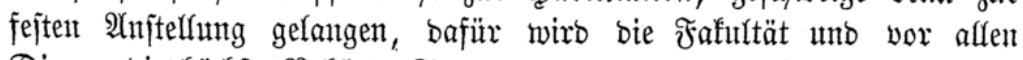
Dingen bie höchjte $\mathfrak{B}$ ehörbe Sorge zu tragent miffen. Enolid) barf baum autch wohl

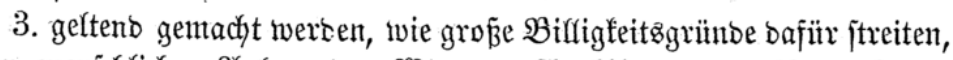

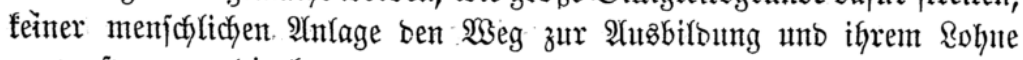

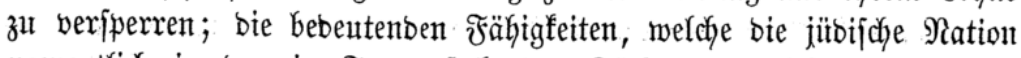
namentlich in bent in Frage ftehenben-Fäcyern entwidfelt, fint aber unbezmeifelt.

Bonn, ben 24. Oftober 1847.

Dahlmant. 


\section{- 227}

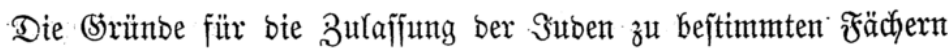
bes afabemifchen Reframts, bie bom \$rofejijor Dahlmann aufgefteflt

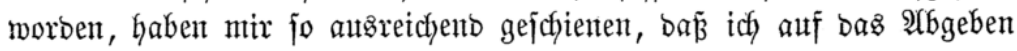
einez bejonbern Botunt verzichte, inbem idf einfach biejem Borbotanten

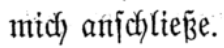

$\mathfrak{B}$ onn, ben 24. Sttober 1847.

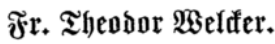

Gotum des kikltar und Sennts.

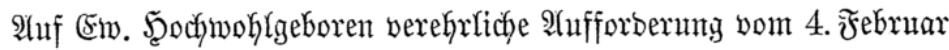

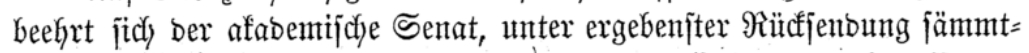

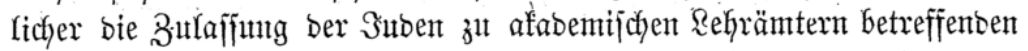

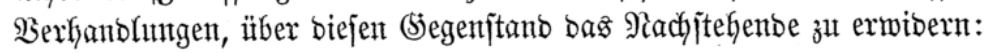

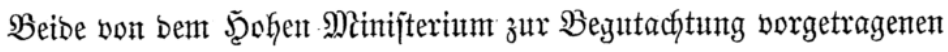
Tragen:

1) $\mathfrak{o b}$ bie bejtehenton Statuten unjerer Untwerjität bie in bem (5ejeş

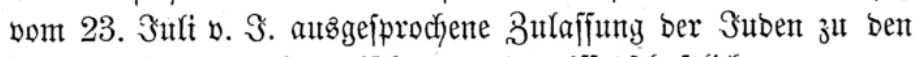

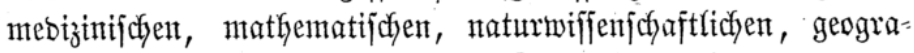

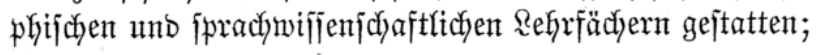

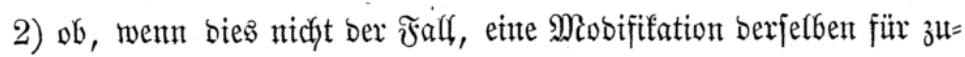
läfifig und angemeffen zu eraçten $j e i$,

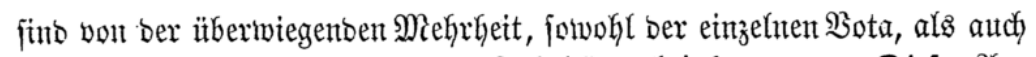
ber SSefammt=(Sutachten ber fïnf Fafultäten bejaht worbent. Diejer $\mathfrak{A} \mathfrak{n}=$

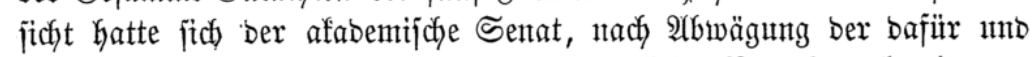
bagegen gettend gemachten (Stïnbe, in müntlicher Berathung bereits an=

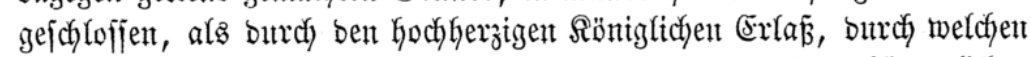

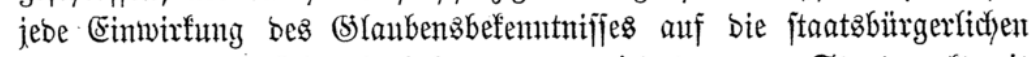
Rechte vorausficdtlid anf

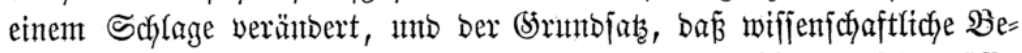

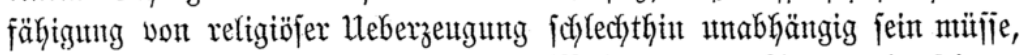

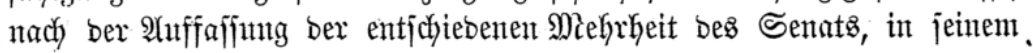

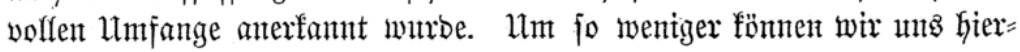

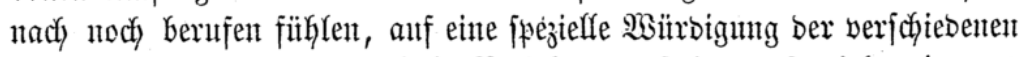
(5)efichtspuntte einzugehen, bie in $\mathfrak{B}$ eziehung auf ein um fo viel geringeres

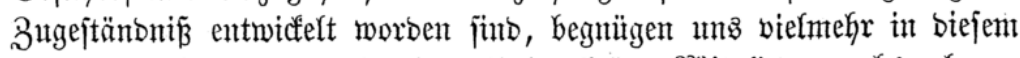
Betracyt, bie von ben einzetnen Univerfitäts = Mitgliebern abgegebenen (5)utachten für jitch jelbjt jprechent zu "Iajjen. Die britte unts vorgelegte 
Frage, welche mur bie juriftiche Fafultät berilhrt, erlebigt fich Giemach in entiprectyenter $\mathfrak{W e i j e . ~}$

$\mathfrak{B}$ onn, ben 4. Âprif 1848.

Reftor unt Senat.

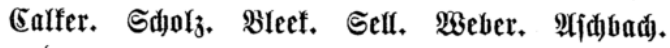

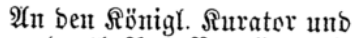

außzerorbentl. $\Re$ eg. $=2$ Bebolfmädytigten

S.errn (5eh). Dber $=\Re$ Reg. $=9$ iath

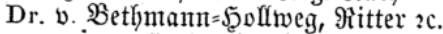

5.odiwoblgeb.

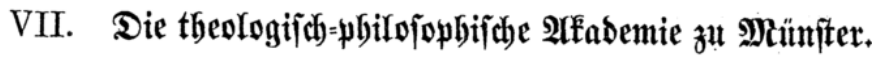

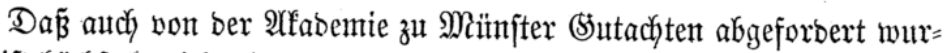
ben, ift höchjt bezeichneítb, ba bieje nach bem §. 1 ifrer Statuten autobrüd lich bie Bejtimmung hat: biejentgen Sïnglinge, weldye fich bem geiftlichen

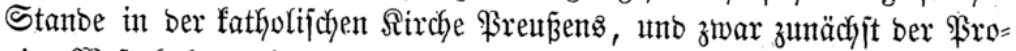
vinz Şejtphalen, wiomen wollen, wifjenjchaftlich und religiös jittlich aus=

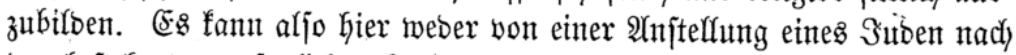

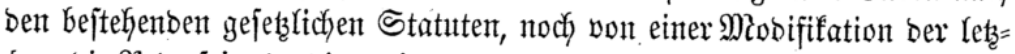

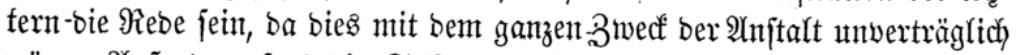

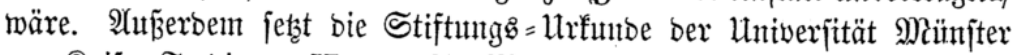
von Raifer Ferbinant II. vom 21. Mai 1631 fejt: „ङs folle in feiner ber "vier Fafulttäten irgento (siner angeftelft werben f̈̈nnen, ber niçft früher

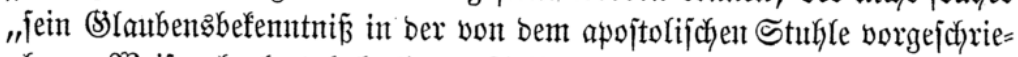
"benen Seije abgelegt habe." - Selbjt bie Ertheilung ber afabemijachen

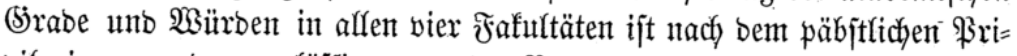

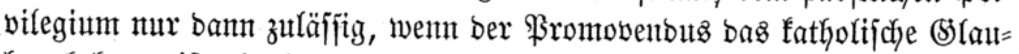

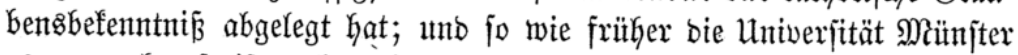
es war, eben fo ijt auch nody hente bie Alfabemie zu Münjter, weldye alts

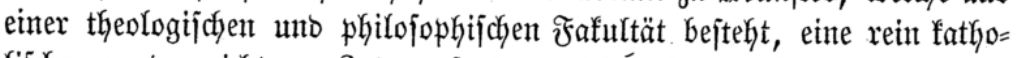

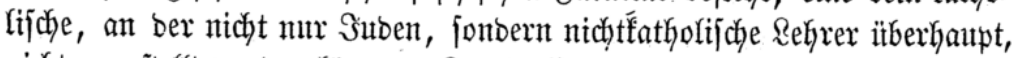
nicht angejtelft werben fönnen. Sa bie (s)ejdjidjte ber Univerjität Mänjter

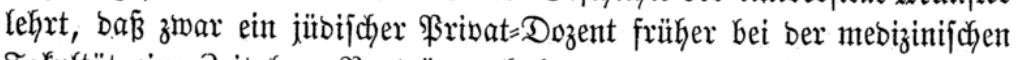

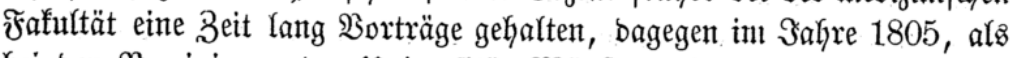

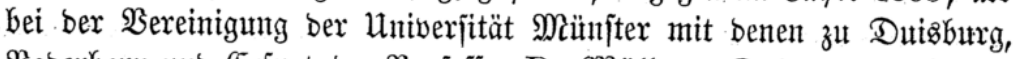

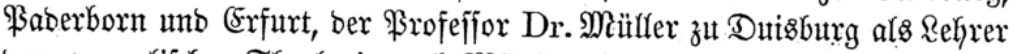
ber evangelifichen Theologie nad) Münjter berufen werben follte, ber ba=

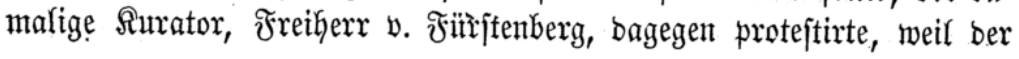




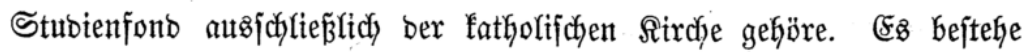

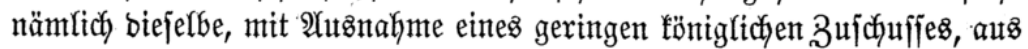
Den Bütern bes 1773 aufgehobenten Sejutterorbens unt aus benent bes in

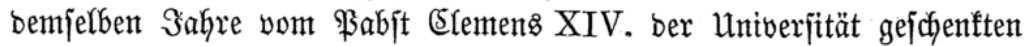
Frauenflojters Ueberwajfer uno follte befanntlicis mur zum Bejten ber

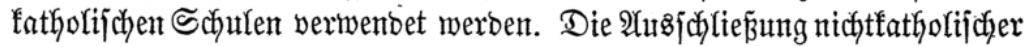
Refrer murbe baher auch bis jeşt fo fonjequent burchgeführt, ba Folge ein in jeber Şinjicht paffender Mann als afabemifijer Rehrer ber Mufil von bem Minijteritm abgemiejen murbe, weil er ber ebangelijdjen Sirctye angefïrte.

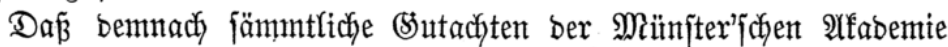

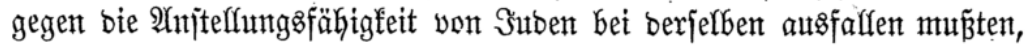
war burchauts untrmeifelfaft; und es fann bem Minijterium bet feiner bes= farffigen $\mathfrak{A}$ ñ

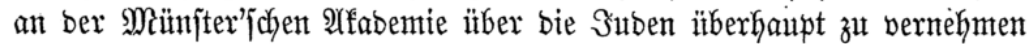

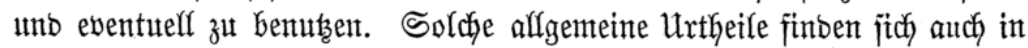
ber That in ben eingegangenten $\mathfrak{B o t i}_{\text {s. }}$

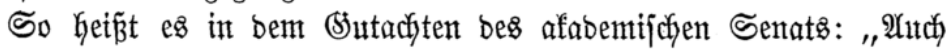

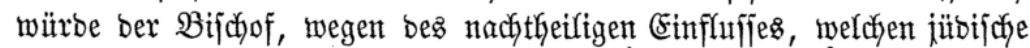
Dozenten auf bie religiöfe Bsefinnung mur zu Yeidjt Gaben, feinen Diöze=

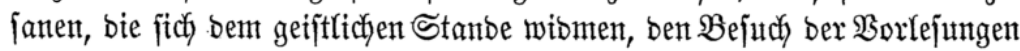
bei benfelben ichwerlich gejtattent. Wenigftenz feglt es nicht an einem

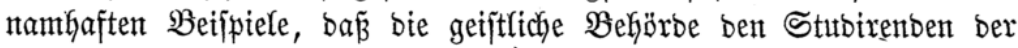
Theologie ben Bejuch ber Sorlejungen bei einem jübifchen Dozenten unter=

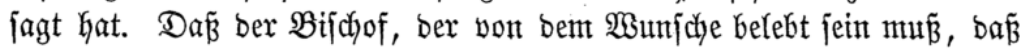

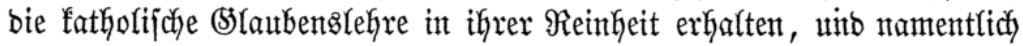
won ben Stutirentben ber Theologie, bie jich) zu bem geiftlichen Stanbe vorbereiten, Arfres fern gehalten werbe, woburdy ber (5)lanbe an bie

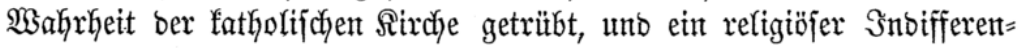

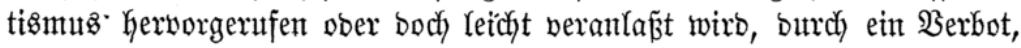
bie $\mathfrak{B o r l}$ ejuntgent ber jübifchent Dozenten .zu bejuchen, nux etwas, feinem erhabenten $\mathfrak{B} e r u f e$ Entfprechentes und 2 Ingemeffentes thun würbe, wirb

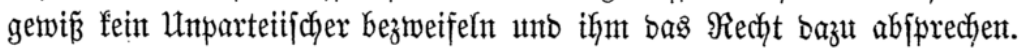

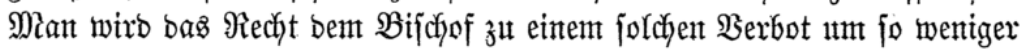

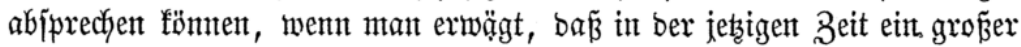

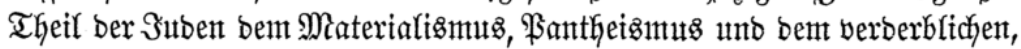

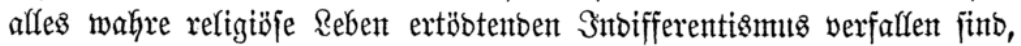

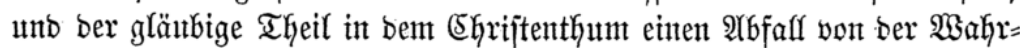
heit annimmt unt baffelfe baher für unberechtigt, vertwerflich und vor (Sott verabjheuntngsinürbig Gält. Mit weldhen Blasphentieen bie Suben 
bent Stifter bes SGriftenthums, beffen Rehre unt Diener überhäuft haben,

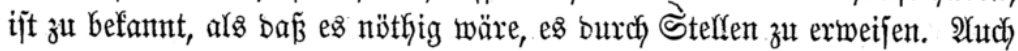

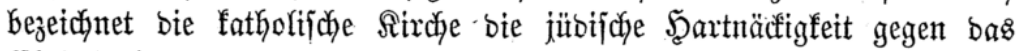
(5hrijtenthum alz eine Perfidia unt bittet \$ott am Tage bez Siretzestobes Des Stifter: : ut Deus et dominus noster auferat velamen de carnibus eorum, ut agnita veritatis luce, quae Christus est, ex suis

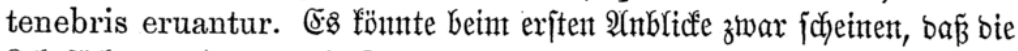
Rehrfächer, z̆t benent bie Sutben nur zugelaffen werben fönnen, in feiner Beziehung zut bent Ehrifitenthum ftehen, uno Daher bie Doftion berjelben

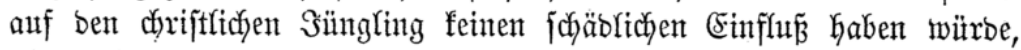
alfein bies ijt nicht ber Fafl. Daß̧ bie jitbifchen Dozenten insbejondere in Betreff ber Spract = unt naturwiffenfoldaftlichen Rehrfächer nachtheilig auf bie religiöfe Ueberzengung ber bem geijtlicken Stanbe fich mibmenten Sünglinge einwirfent f̈̈mtent, unterliegt nicht bent minbejtent $\bigcap_{\text {weifel. }}$ Wą zuerjt bie Sprachivifjenfchaft betrifft, jo ift alfgentein befannt, baß̉ ber $\Re \mathfrak{a}=$

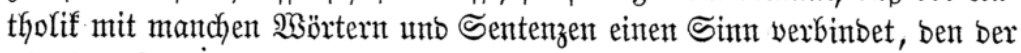

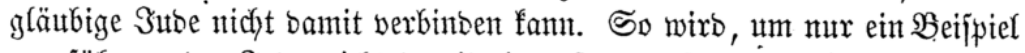

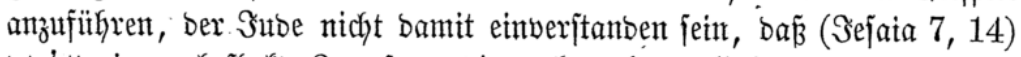

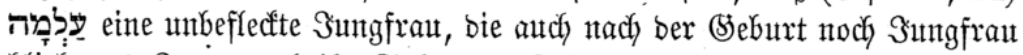
blieb, unt Smmanuel, ihr Sohn, ben Stifter bes Ehriftenthums bezeichne. Und boch ift biejes bie Heberzengung bes (Evangelijten Matthäus unt alfer

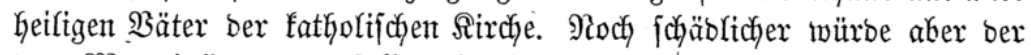
Dem' Materialigmus verfalfene jübiffye Dozent wirfent, benn ein foldher müroe ben Uriprung ber Sprache imaterialiftifich auffaffent unb baburdy zur Berbreitung ber verberblichjten Эrrthÿmer nicht mentg beitragent. Da bie Sprachmiffenidjaft einen bebeutenbent unt widftigen phitofophifchent Theil Gat, wenn fie ïber bas blos Mectyanifde unb bie Sritif ber Frormen hinaugegeht, fo witrbe ber jitbifche Dozent feine bem Shriftenthum ent= gegengejeţten 2 njichten über bie Spractje autch in biejem Theile vortragen fönnten.

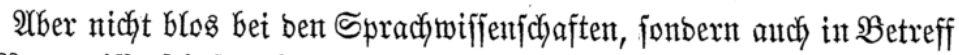

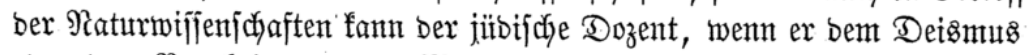

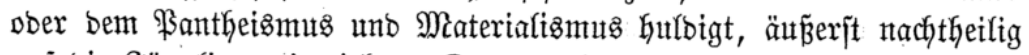
anf bie Sinnglinge einmirfen. Denn nach bem \$antheisnuts unt Mate=

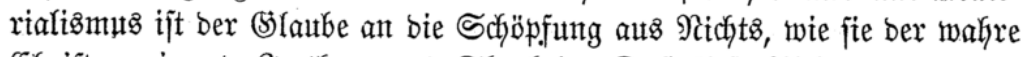

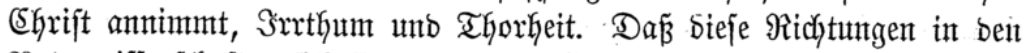
Paturmifijenjulyaftent fich finton, ijt zur \$senitge befaunt. Sn Betreff ber Seographie focheint ztwar bie Bulaffunt ber Suben eher zutäffitg, aber bei näherer Beachtung ber neutern Behanbluttg berjelben, inzbefontore feit

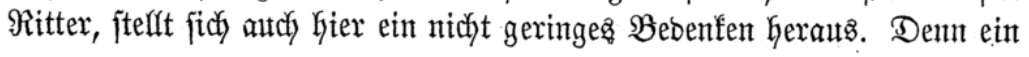




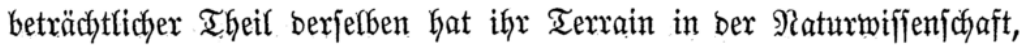
und ihn Sortrag fann baher bieferben Stefahren haben, wie bei jenter.

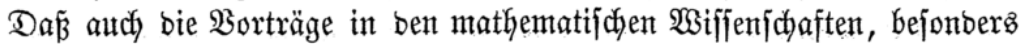
fo weit fie fich auf bie alfitronomie erjtrecten, fïr bie religiöfe Heberzengung eines d)riftlichen Sünglings gefäburlidy werben fönnen, fann ebenfalla nicdyt

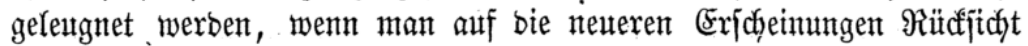
nimmt.".

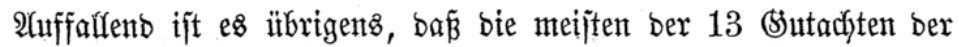

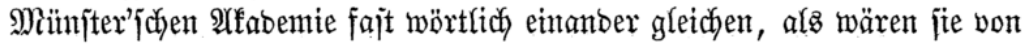

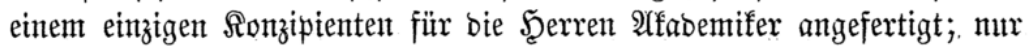

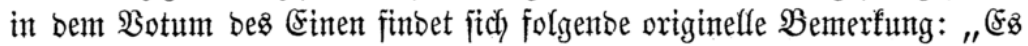
wäre wohk hinreidfent, bie Suben nad wie vor bei ben Univerjitäten uno

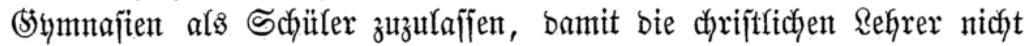
bermaleinjt nöthig hätten, gegen ben im Hebermaß̧e jich verbreitenten

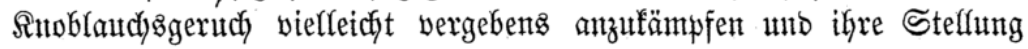
aufzugeben."

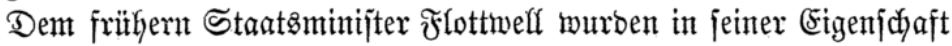

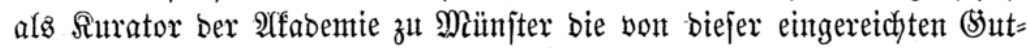

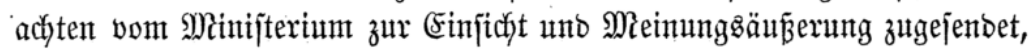
unt berjelbe äuferte jiḑ barüber wie folgt:

"En. Excelfenz beehre ich mich; bie mix mit bem gefälfigen (Extajie vom 21. v. M. mitgetheilten 13 (5)utact)ten ber Mitglieber bes afabe= mifłon Senatz, fowie ber beiben Fafultäten unb bes Sentats jefbjt oer

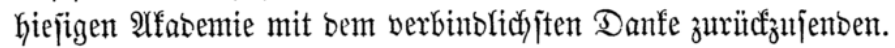

Da bieje Rehranjtalt hauptjädylid) mur bie Billoung fatholijcher Theo=

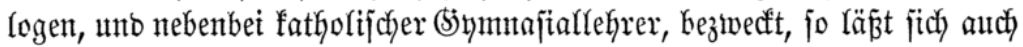
bie Uebereinftimmung ber (S)utachten gegent bie Bullafiung jübifcher Do= zenten für gewiffe Rehrfächer nidfyt nur erflären, fonbern aud aus bem angenommenent Stanbpunfte recthtfertigent.

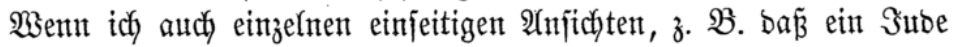

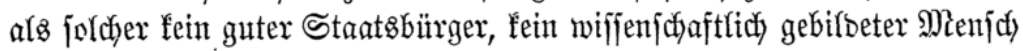
fein uno bie erforberlicfyen fittlidyen @ualitäten nidyt in jidy vereinigen fömte, bie man von bent gebilbeten Manne erwarte, f́eineşwega beitretent fant, fo erachte idh es body auth mit ber Tenben unt Steflung biejer

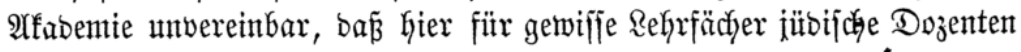
zugelajien werben.

Aluf eine nähere Erörterung ber (5)utachten barf wohl unter ben ob= waltensen Berhältnifjen nidyt weiter eingegangen werbent.

Müṇ̂ter, ben 15. Februar 1848.

F̊nttivell. 
(5s haben afferbigas nidyt affe \$rofefforen motivirte (5)utachten zut bent Ifften eintgereidyt, aber es fint autch won bent abgegebenten Sotis viele hier weggelaffen worben, theils um Wieberholungen gleicher Argumente mit

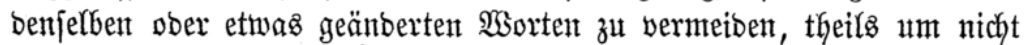

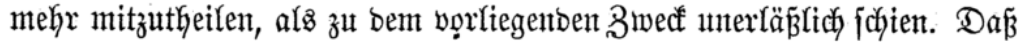

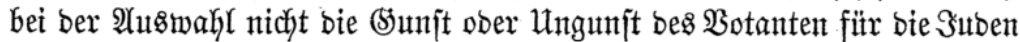
ma ẩgebent war, wirs man gejekent haben, boch bürfte barauf hingeniejen

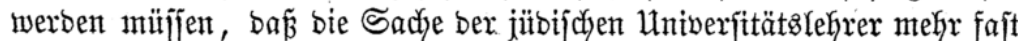
burch bie Stinment ifyer (5egner, als burdh bie igrer Freunbe geförbert worben. Die Sriüne, welche bie Snben von ben afabemifchen Rehrämtern

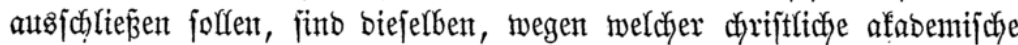

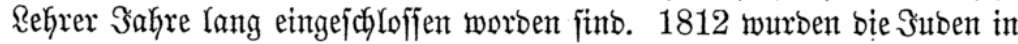

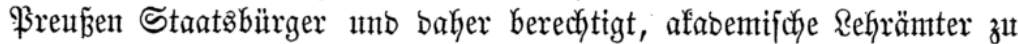

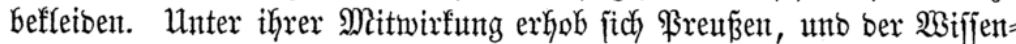
fchaft wurben neute Pflanziduten erridjtet. 1819 wurbe in Rarlabab ben Univerjitäten ifre frete Bemegung gentommen, uno bamit im Bujammen= hang 1822 ben Suben ihr Recht zum Reframt. 1848 warb wieber bie

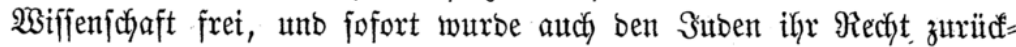
gegeben, twie biez aus ber nadffolgenton britten Arbtheilung fich ergiebt. 
Dritte $\mathfrak{Y}$ btheilung

\section{gip fäluny}

\section{Durdh Den Sönig und die Berfận!}

Bom Sejets d. d. 6. 2Tpril 1848

biฐ

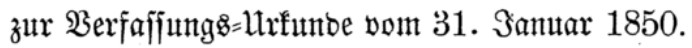





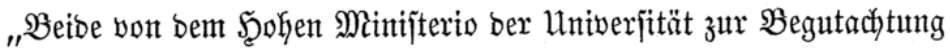
vorgelegten Fragen:

1) $\mathfrak{o b}$ bie bejtehenben Statuten umjerer Univerjität bie in bem Stejets

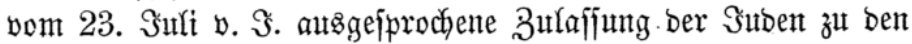

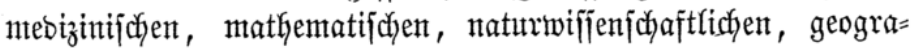

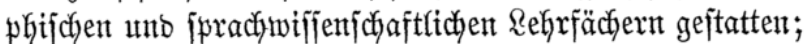

2) $\mathfrak{o b}$, wenn bies nidyt ber Fall, eine Mobififfation berfelben für zuläfifig unt angemefjen zut eractytent jei, fint wont ber itbermiegentben Mehrkeit, fowohl ber einzelnen 20 ota, als ber

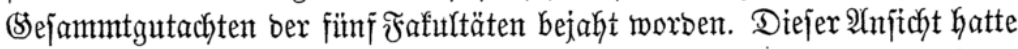

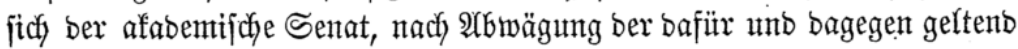

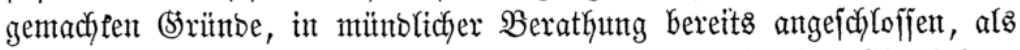

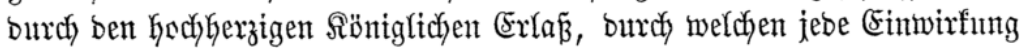

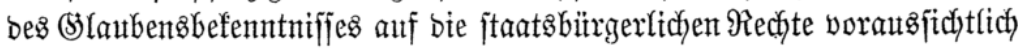
aufgehoben werben wirb, ber ganze Stanbpunft mit einem Schlage ver=

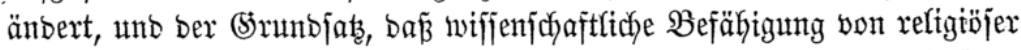

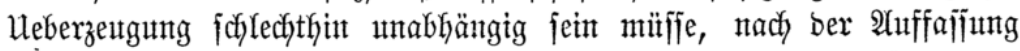
ber entichiebenen Mehrbeit bes Senats in feinem volfen Umfange an= erfant tultrbe."

Dies war, wie wir oben gejehen haben, bas (5ejanmt=23otım, tweldyes

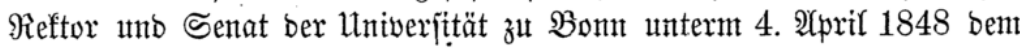
Regierung $=$ =

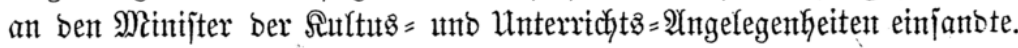

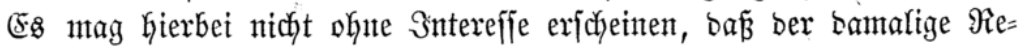

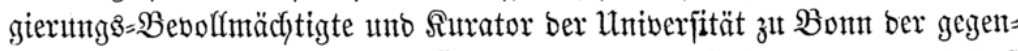

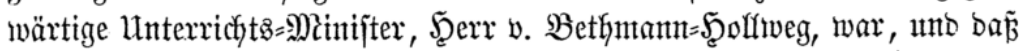
ber bamalige Unterrichts= Mintifter, (5raf Sctywerit, gegentwärtig Mintijter Des Эntuern ijt. 


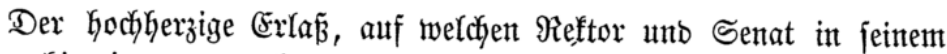
Botum Kintwies, war nactjphentioer

\section{Allerböchjter Röniglicber $\mathfrak{A}$ ffruf an bas Ration, betreffent die fünftige Stantz=\$erfa fumg,}

vom 21. März 1848.

Mit Bertrauten fprach ber Sönig vor fünfunboreişig アafhren it ben

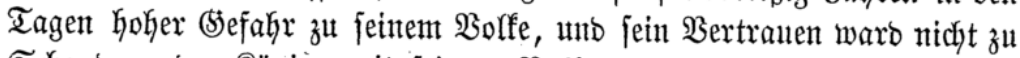

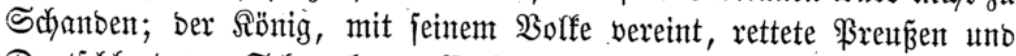
Deutichlant von Schntact uno Erniebrigung.

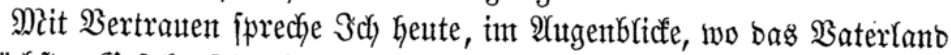
in hödjiter (5efahr jajwebt, zu ber beutfchen Pation, unter beren ebelite

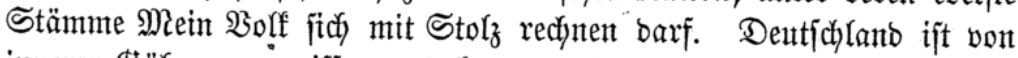
innerer (\$ährung ergriffen unb fant butch äunere \$sefahr von mehr alz einer Seite bebroht werben. Rettung auts biejer boppeltent bringenben

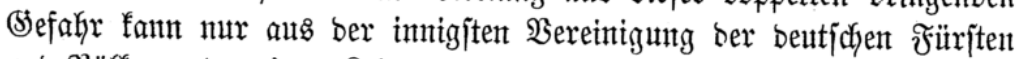
unt Böffer unter eitter Reituntg Gervorgekent.

Sch ïbernehme heute biefe Reitung für bie Tage ber Stefahr. Mein

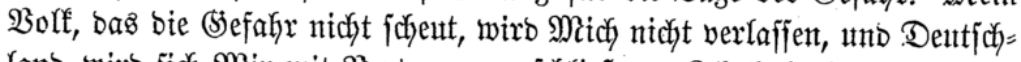
lanb wirb jith Mir mit Bertrauten anjdylezent. Sch habe Geute bie alten beutichent Farben angenommen unt Mitid unt Mein Solf unter bas

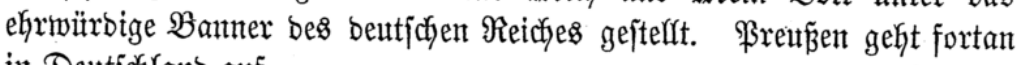
in Deutjollanto auf.

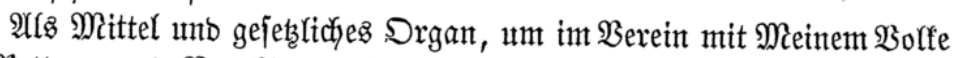

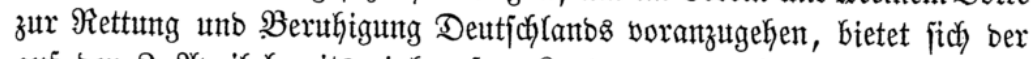

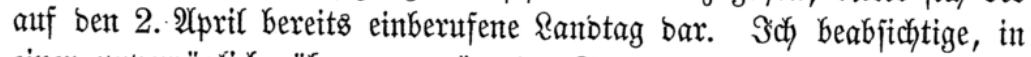

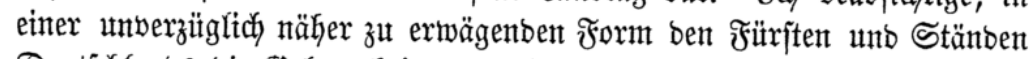
Deutfichlands bie Sielegentheit zut eröffnen, mit Drganent biejez Ranbtags

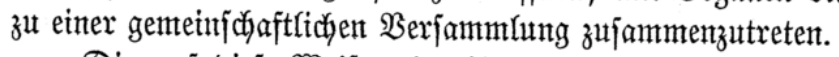

Die auf bieje Meije zeitmeilig jich bildonbe bentiche Stänbe= Ber= jammlung wirb in gemeinfamer, freter Berathutg bas Erforberliche in

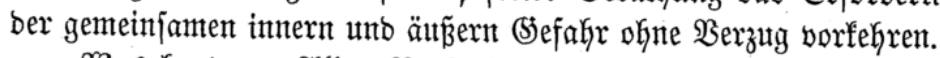

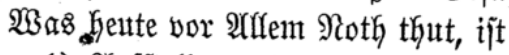

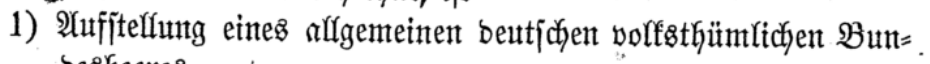
besheeres,

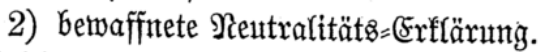

Solche vaterländijçe Rïjtung und Erfläruntg merben Europa

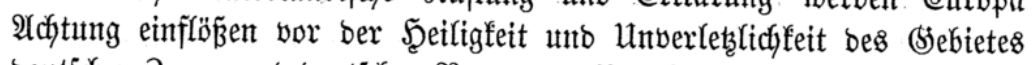

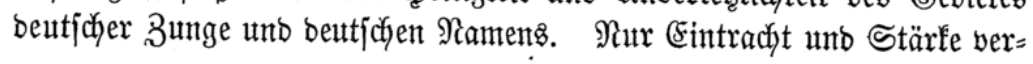


mögen heute ben Frieben in unjerm joÿnnen, burch Scanbel unb Sienverbe blïhenden Sejammt=QBaterlanbe zut erhalten.

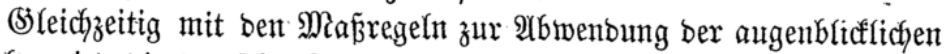
(Sefahr twirb bie beutjche Stände= 2 Serjammlung über bie \$iedergeburt uno (s)rïnoung eines neuten Deutichlanos berathen, eines einigen, nicht ein=

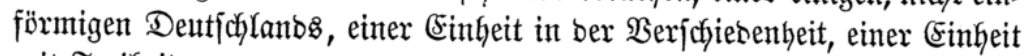
mit Freiłyeit.

Alfgemeine Einführung wahrer fonjtitutionefler $\mathfrak{B e r f a f j u n g e n , ~ m i t ~}$

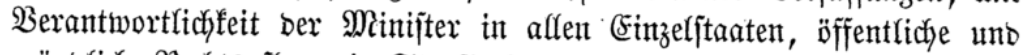

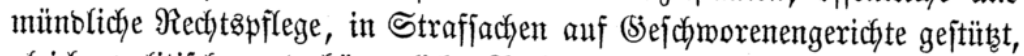

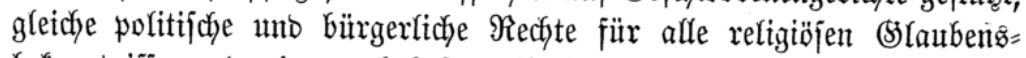

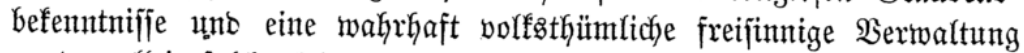
werben alfein foldye fichern unb innere Einheit zu bemirfent uns zut befeptigen iin Stanbe jein.

Berrin, Den 21. Miär 1848.

Friedrid $\mathfrak{W}$ illyelm.

(3raf') Arnim. siilnte.

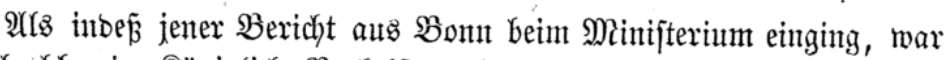

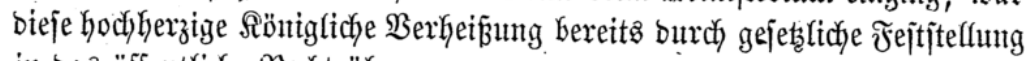
in bas öffentlictje Recht übergegangen, unb zwar burch bie

\section{Seronomung Berfafinนtม \\ bou 6. April 1848.}

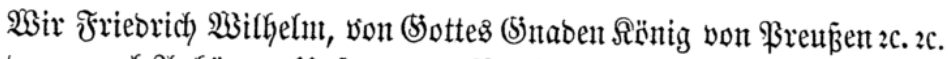
veroronen, nact $\mathfrak{A}$ nhÿrung $\mathfrak{U n}$ jerer zum Siereinigten Ranbtage verfammelten

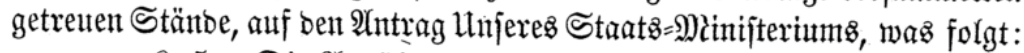

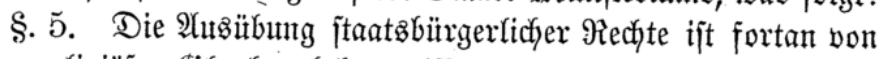
bem religiöfen \$Slaubensbefenntnifife unabhängig.

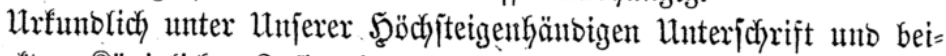

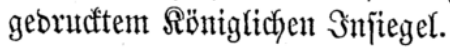

(Segeben zal \$otzo am, ben 6. April 1848.

\section{(L. S.) Friedrid $\mathfrak{B}$ irfhelm.}

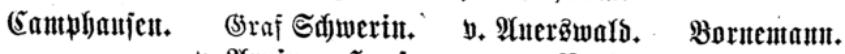

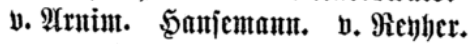

Man wirb nidyt in arbrebe ftelfen wolfen, bá bieje Berorbnuth sub

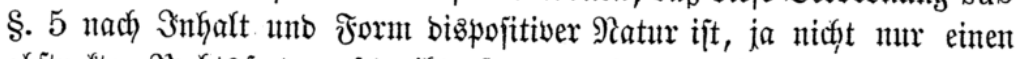

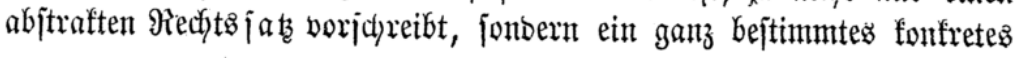




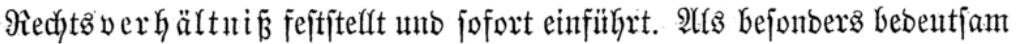

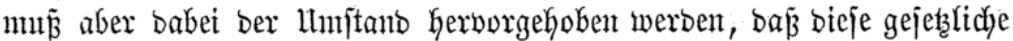

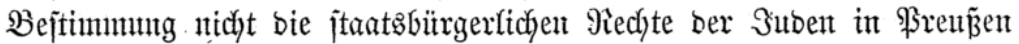
erweitert, ober überhaupt von ben fünftigen ९eedytguerhältniffen ber Sutoen

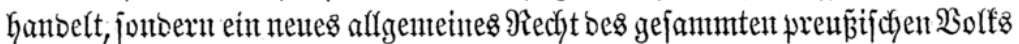
proflantirt und jofort in's Reben ruft. Den jübifdyen Sreunen, weil jie Suben

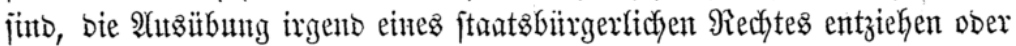

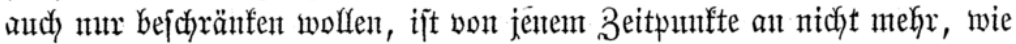

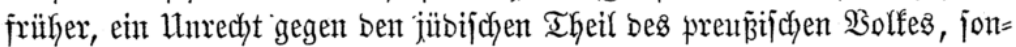
Dern bie Ber Rechtâ.

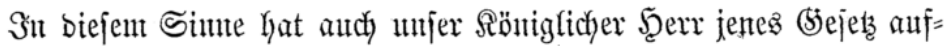

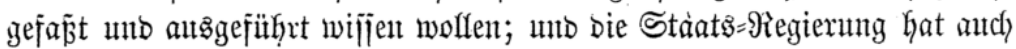

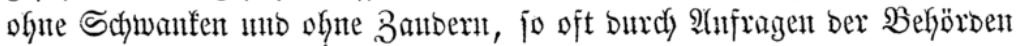
(5)elegenfyeit bazal fich barbot, ihye Entficheibungen getroffen uno burch

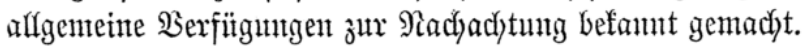

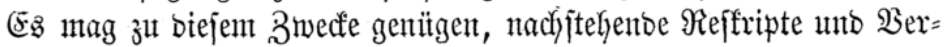
fügungen ber verfohiebenen Minifterien bis zur Emanation ber פer= fajpunġurfumbe mitzutheilen. Man wiro aus benjelben exjegen, baß

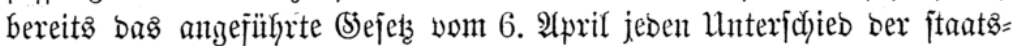

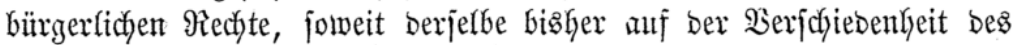

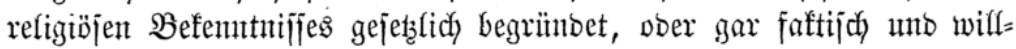
fitrlich von ber Serwaltung Geliebt worben wax, volfjtänbig anfgeknben

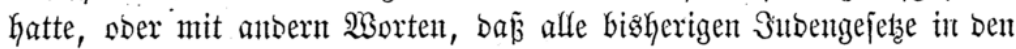
nenen allgemeinen Srenßemrechten anfgegangen waren.

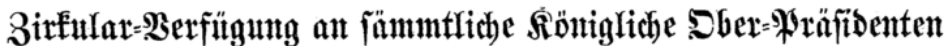

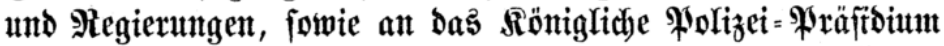

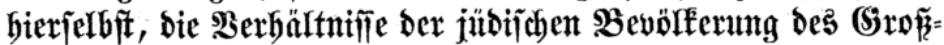 herzogthums अojen betreffent,}

wom 8. פaai 1848.

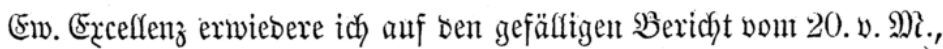

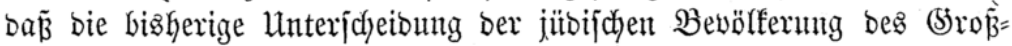

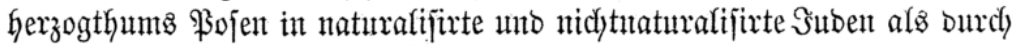

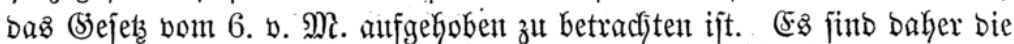

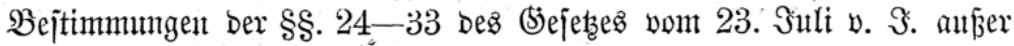
Rraft getreten. Dagegen fint bie Borfdyriften bez $\S .34$ in Betreff ber

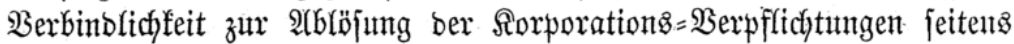
ber negaieheriben jübifdyen (5emeindeglieber in ber \$rovinz \$ojen nady wie vor zur $\mathfrak{A}$ nuventoung zu bringent. 
Borítehenter Errlaß̧ ifjt ben übrigen Sূerren Dber=\$räfibenten uno

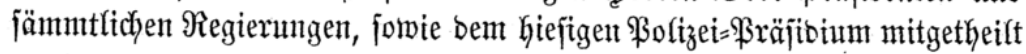
worben.

Berlin, ben 8. Mai 1848.

Der Minițter beß Sัunern. b. 2Titeräwald.

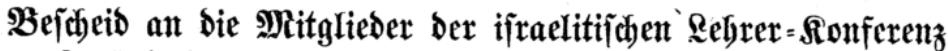

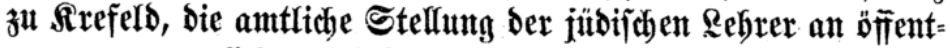 Yichen und \$riwatĩchulen betreffend,}

bont 26. Mại 1848.

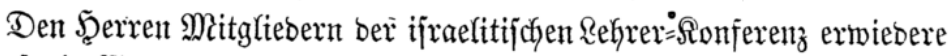

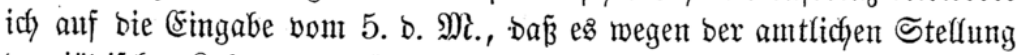
ber jübifchen Rehrer an öffentfichen unb \$rivatidyulen, nach bem bereits

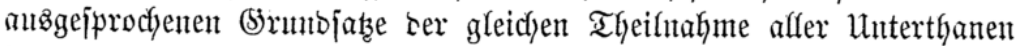

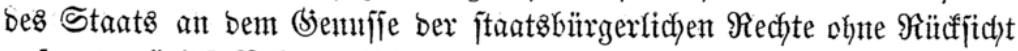
auf Das religiöje $\mathfrak{B}$ efenntni $\tilde{\beta}$ berjerben, injofern einer weitern $B$ Bejtimmung nicht bebarf, als ber amtlid)e (Sharafter ber jitbifdyen Rebrer jich, wie bei

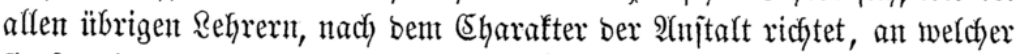
jie fungiren, und jie banach entweber öffentliche Rehrer an Staats = ober

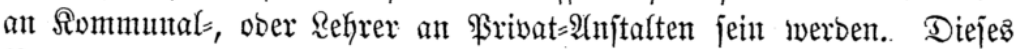

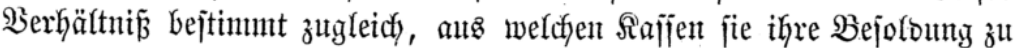
beziehen Gaben.

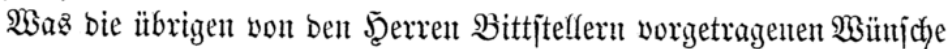

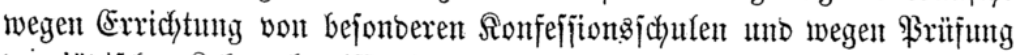

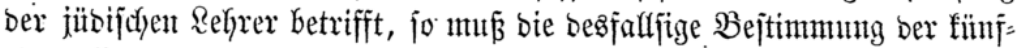
tigen SEejetzgebung worbehalten bleiben.

Berlin, ben 26. Mai 1848.

Der Minifter ber geijtlichen, Unterrichtés= uno Mesizinat=2(ngelegenheiten.

(3riaf Sdjweritr.

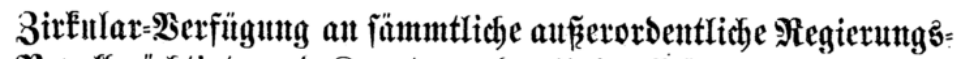
Bevolfmächtigte und Sitratoren ber llniverjitüten, fowie an ben

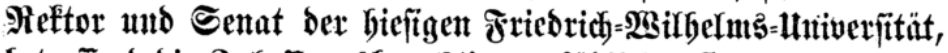
betreffent die 3 ula afabenijōyen Rehrämtern,

vom 14. Sutti 1848.

In Folge einer an midy geridyteten $\mathfrak{A}$ nnfrage wegen ber Bulajïmtgs=

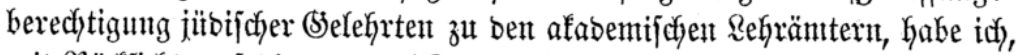

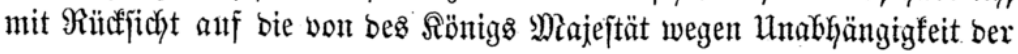




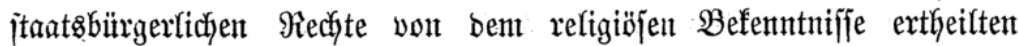

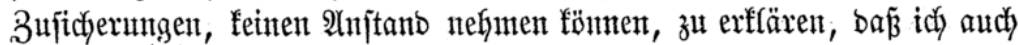

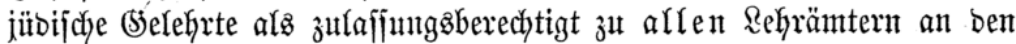

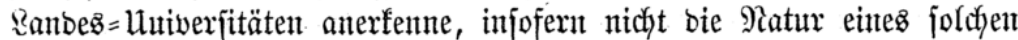
Rehrants bas chriftliche Befenutuís nothwenbig vorausfetze.

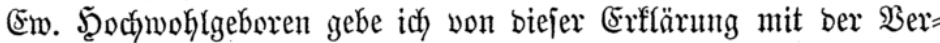

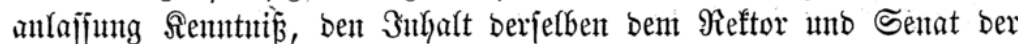

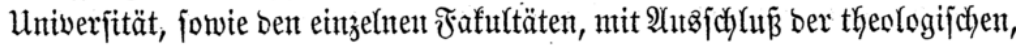
zur Sienntniß̋nahme und Bead)tung mitzutheilen.

Berrin, ben 14. Sulti 1848 .

Für Den Minifiter ber geiftlichen, Mnterrichtos= uno

Mecizinat=9ingelegenheiten.

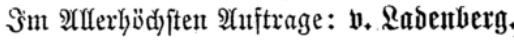

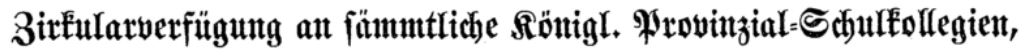

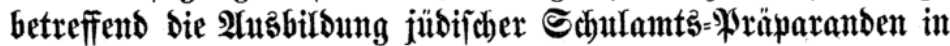 Seminarien,}

vom 19. September 1848 .

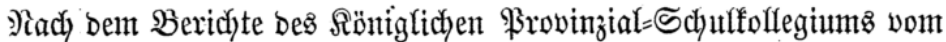
3. ๖. M. Kat baffelbe bie in neuejter Zeit mehrfach vorgefommenten 2 nnträge

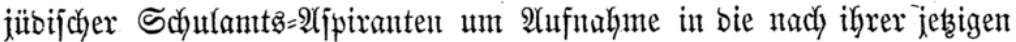

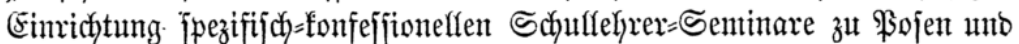

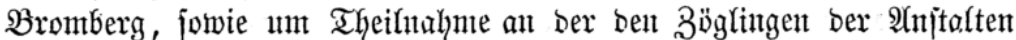

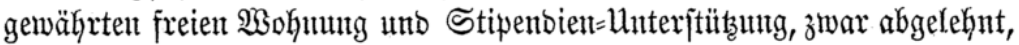
Dagegen ben Bittiftelfern bie unentgettliche Theilutahme an bem Semintar= Unterridyt gewährt.

So lange bie Seminarien in iłyer jetzigen sinnidytung alz fonfej=

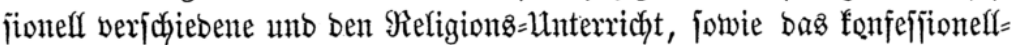

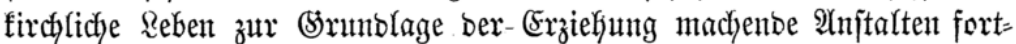
bejtehen, fann ich mich mit bem von bem Sïniglichent ßrovinzial=Schul=

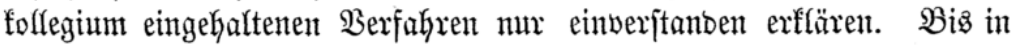

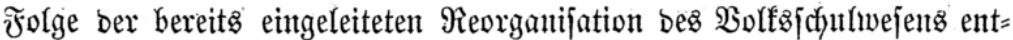
weber für jübijche Schulamtz=\$räparanben eigene Seminarien eingerichtet, ober bie bereitzz vorkanbenen jo geftaltet worben fint, baj in biefelben ohne

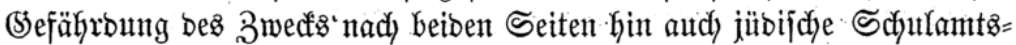

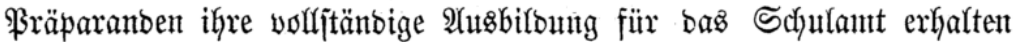
fönnen, wolfe baher bas ̊öntiglidye \$rovinzial=Sdyuffollegium, joweit ez

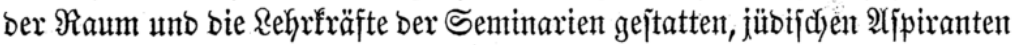

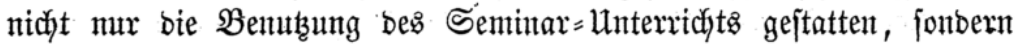

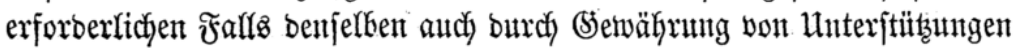




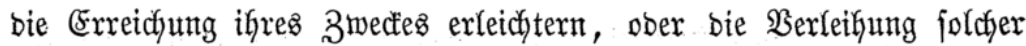
Unterftüthutngen bet mix beantragen.

Berlin', ben 19. September 1848.

Für ben Minijter ber geiftlichen, Unterrichtes= und

$\mathfrak{A} \mathfrak{n}$

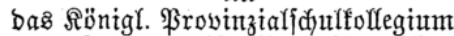

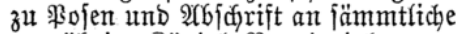
iibrige Rönigl. \$rovinzial=

Sd)ulfollegien zur ßenntnif̧ahme unt Nad)adjtung. .
Medizinal=记nelegenbeiten.

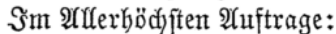

v. Radentberg.

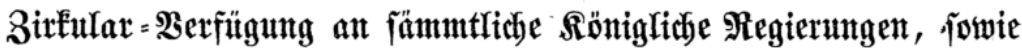

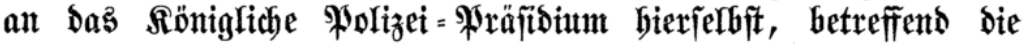

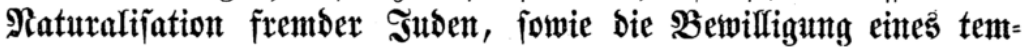

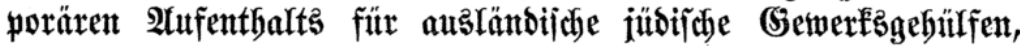
(Sejellen, Rehrlinge ober Diemitboten,

vom 13. Dezemtber 1848.

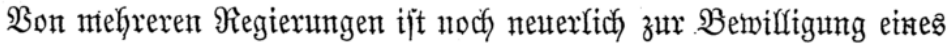

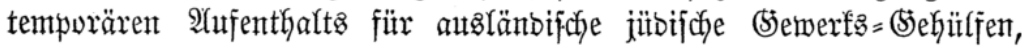

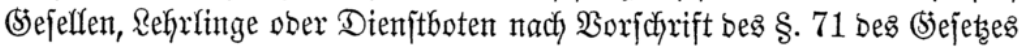

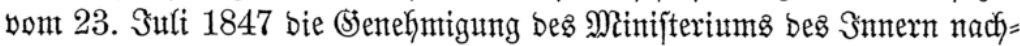
gejutcht morben.

Rach ber gegentwärtigen Rage ber \$ejetzgebunt jütb bie Regierungen jeboch befugt, bieje (senefimigntng zu ertheilen.

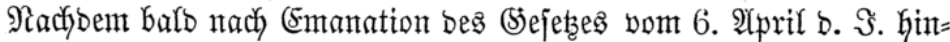

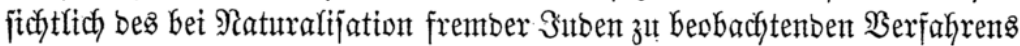
.3weifel angeregt worben, hat bas Minijteritm $\mathfrak{B}$ eranlajjunt genommen, über biejen (Stegenjtand an Des ̊önigs Majejtät Bericht zut erjtatten,

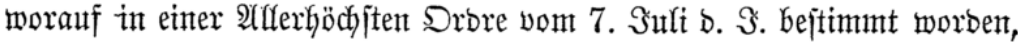

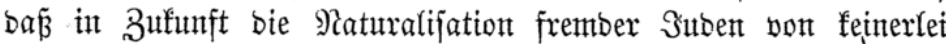

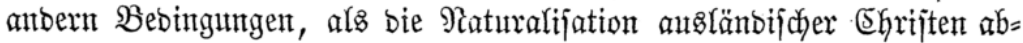

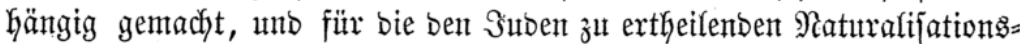
Urfunto feinen häheren Stemtpel als für anbere jolche Urfunben verwenbet werben jolfen.

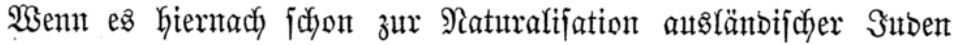
ferner nicht mefyr ber bieffeitigen (senefymigung bebarf, fo ift leţtere um

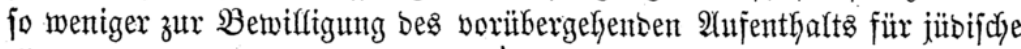

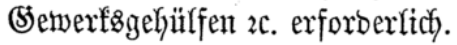

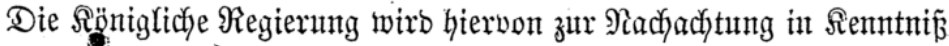
gefetzt.

Berlin, Den 13. Dezember 1848. Minijterium Des Эnnern.

•Erfte $\mathfrak{A b t b e i l u n g : ~ \mathfrak { v } . ~ \Re u t t f a n m t e r . ~}$

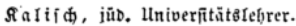




\section{Serfügung an ben Proreftor und Sentat ber Univerfitüt $\mathfrak{u} \mathfrak{\Re}$,

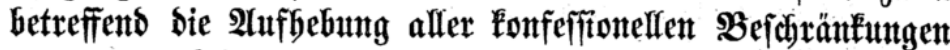

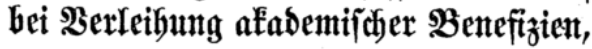

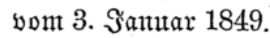

Da in Betreff ber $\mathfrak{B}$ ergebung ber bet ber bortigen Univerjität be=

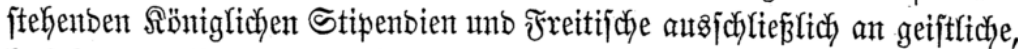
beziehungsmeife evangelifdye Stubirente feine eigentlichen Funbations=

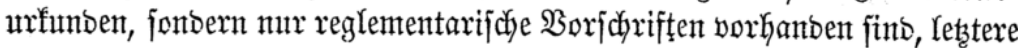

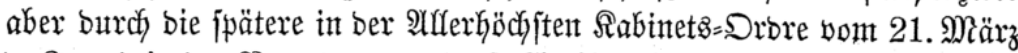

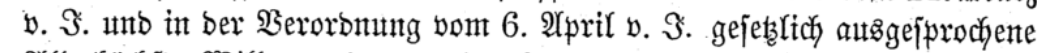
श्uferbächjte Wiffentsmeinung als abgeänbert zu betrachten, aud mit ber

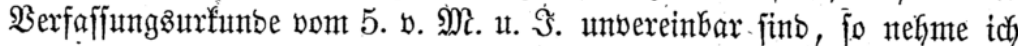

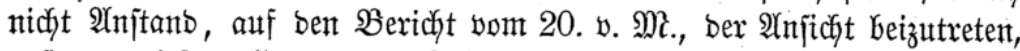

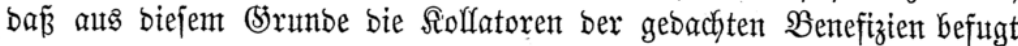

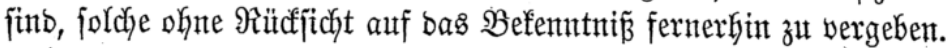

Dem Serrn Froreftor und bem Senate gebe idy bie weitere $\mathfrak{B e r}=$ anlafiung Giernach antheim.

Berlin, ben 3. Эantuar 1849.

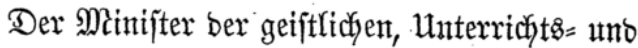
Mesizinal=29ngelegenkeiten.

\section{b. :adenberg.}

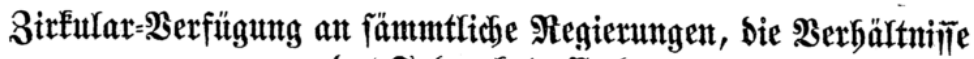 Der Intoen betreffent, \\ vont 5 . Sunt 1849.}

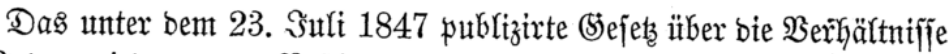

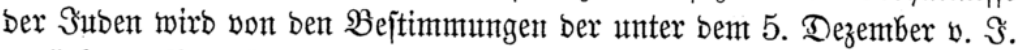

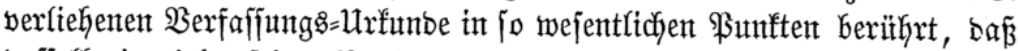
baffelbe in vielen feiner $\mathfrak{B o r j} d$ riften als aufgehoben unb nur in benjentigen als fortbejtehento zu betradjten ift, welche mit ber $\mathfrak{B}$ erfafjungs=U1rfumbe

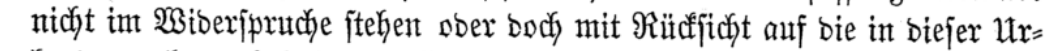
funbe noch vorbehaltenen Befetse und Beroromungen einjtweilen noch

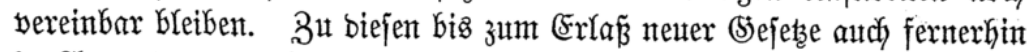

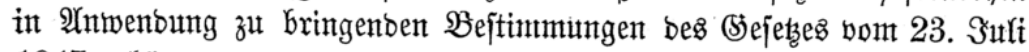
1847 gehören:

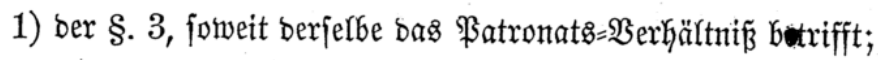

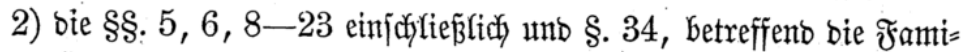

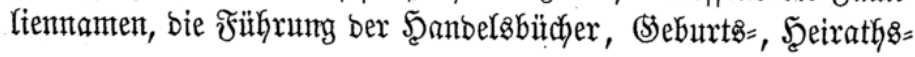




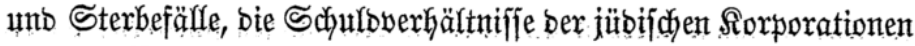

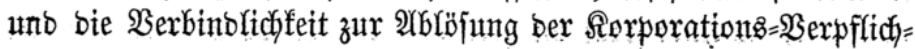
tungen;

3) Die $\S \S .59,60,61$ unt 63 , betreffent bie $9 \mathfrak{r m e n}=$ unt Aranfen=

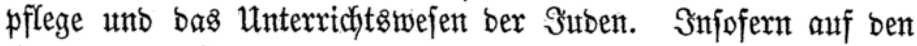
(5rumb bes Siefezes vom 23. Sult 1847 einzelne Synagogen= Semeinben errichtet und organifirt morben fint, bletben bie $\mathfrak{B} e=$

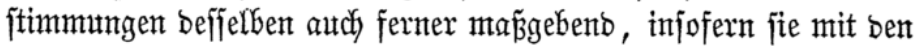
Bejtimmungen ber Berfaifung

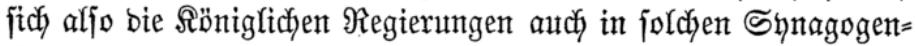

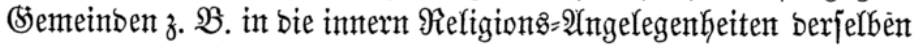
nicht ferner zut mifichen ober bie Etats ïber bie zur Durdffüblyung

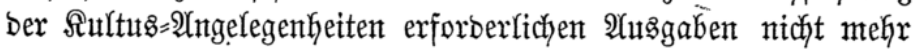
zu prïfen, feitzuftelfen unb nöthigenfalfs int Wege ber Arominiftra= tion einziehen zu lafjen haben.

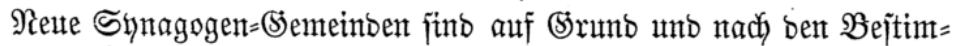

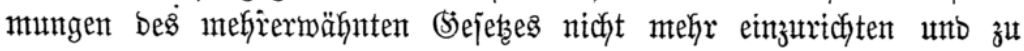
organifirent.

Berlin, Den 5. Funt 1849.

Der Minifiter ber geiftlidjen, Unterridyts $=$ unt Mebizinal=2(ngelegentheiten.

$$
\text { v. } \mathfrak{R a d e n t b e r g} \text {. }
$$

Der Minifter Dez Snnern.

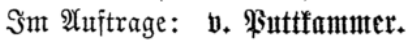

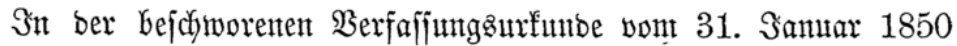

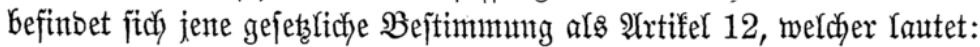

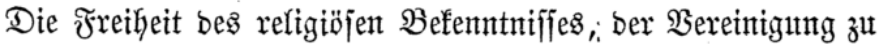

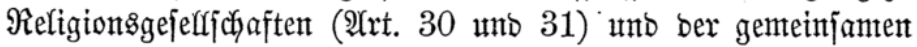

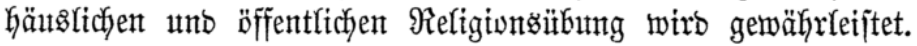

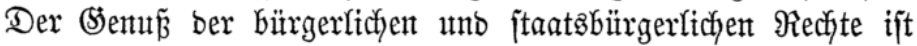
anabhängig von bent religiöfen $\mathfrak{B}$ efenntnifje. Dent bürgerlicyent

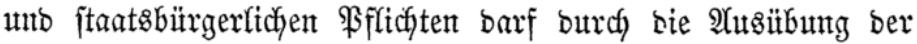
Refigionsfreikeit fein 2rbbruch gejchehen. -

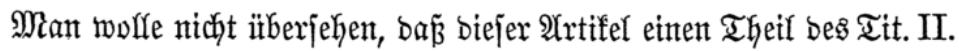

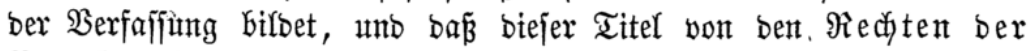

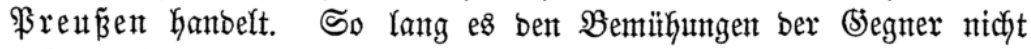

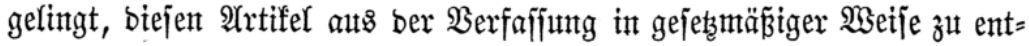




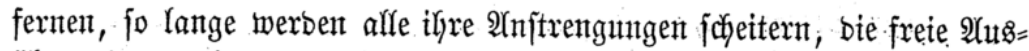

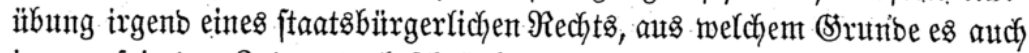

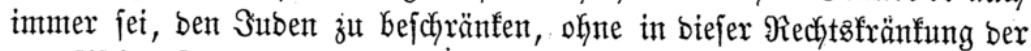
preupijchent Suben zugleidy bie nicht uur ben jübijchen \$reuren, fonbern

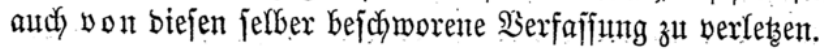


Bierte $\mathfrak{U}$ (rtbeilung.

\section{Fug Tulenedit}

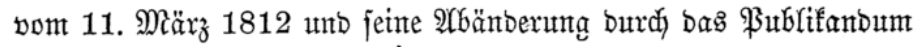
vom 4. Dezember 1822. 

$\mathfrak{M}_{\text {ofes gab feinem }} \mathfrak{B o l f f e}_{\text {nete }}$ unt mit ber Rebensweife ber anbern

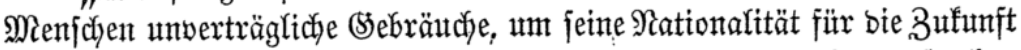

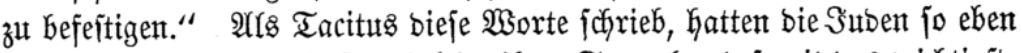

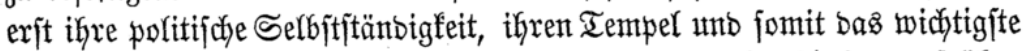

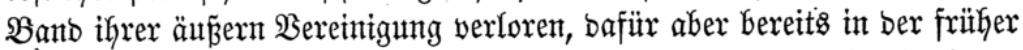

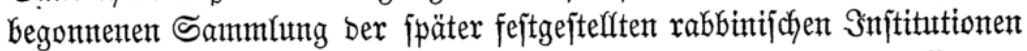
eine neute Araft getwonnen, weldhe bie Trümmer eines zeritörten (Spottes= ftaats in bent (5trumbjtein bes allnuälig auffutbautenben Sottes reiches verwan=

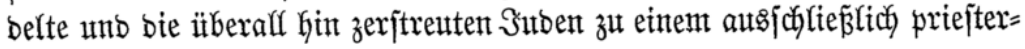
licyent 20 offe verbanto.

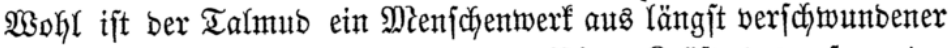

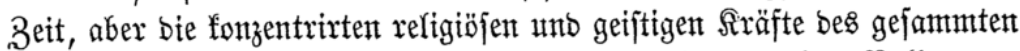

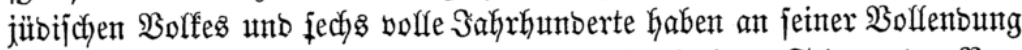

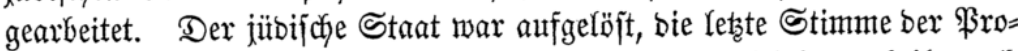

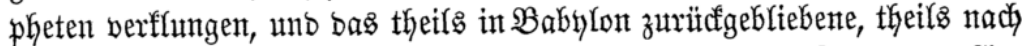

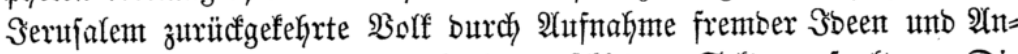
eignung ber griectifichen Spractje in verifjiebente Seften geipartent. Die

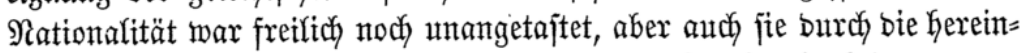

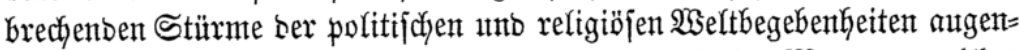

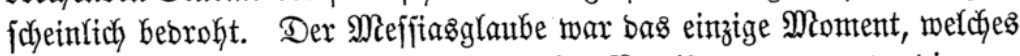

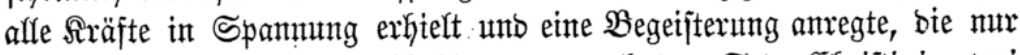

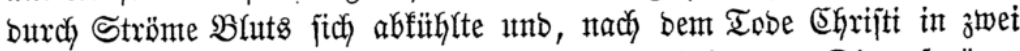

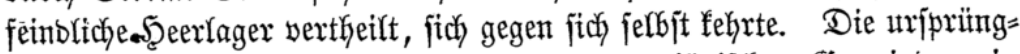

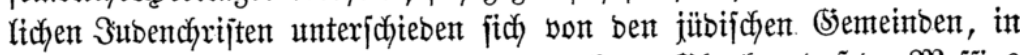

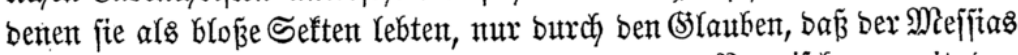
in EGrifito bereits gefommen; aber ifgre fpätere $\mathfrak{B}$ ermifidung mit ben 


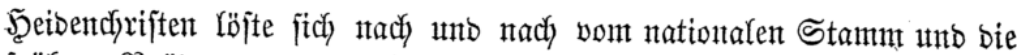
frïfern $\mathfrak{B}$ ritiber wurbent jidf bie bitterjten Feinbe. Doch mit wie ver=

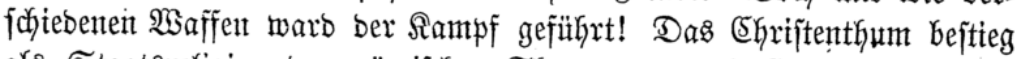

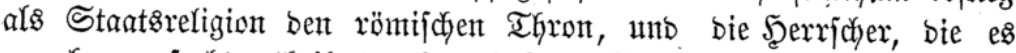

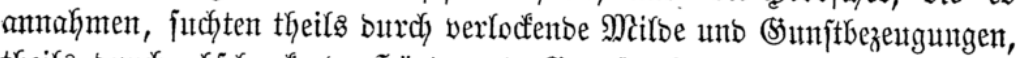

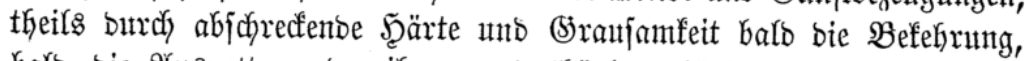

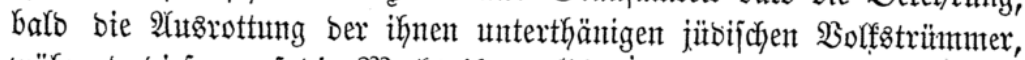

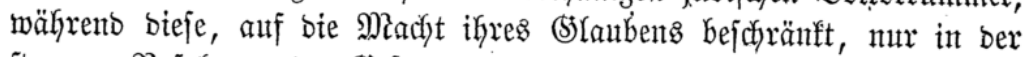

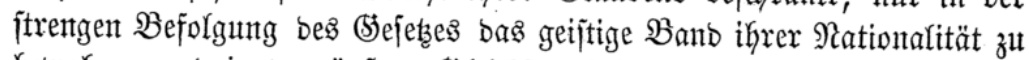

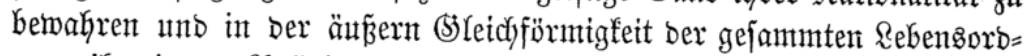

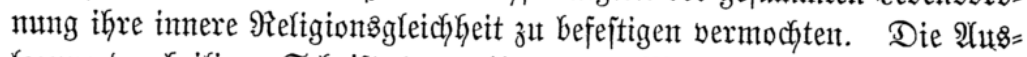

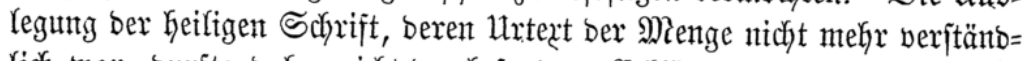
lich war, burfte baher nidjt ber bejonbern Erffärung ber zerftreuten (5)e= meinten unt ifyer ReGrer itberlaffen werben, unt ebenjo mentig bie gejantmte

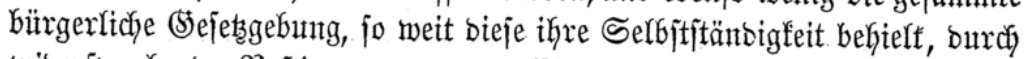
wiberipredyentoe Bejtinmungen ben SGyarafter ber nationalen Einkeit verlierent.

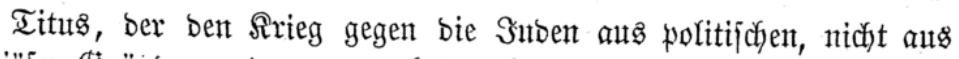
religiöfen (Srüitben unternommen hatte, begnügte fich mit ber Berftörung ihrer Şauptitabt und ifyres Iempela, liể aber bie in anbern Stäbten

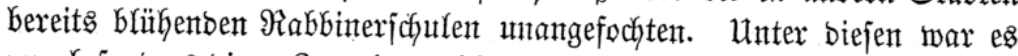

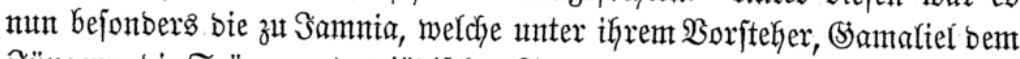
3üngern, bie Trïmmer bes jübijchen Staats burch Beibefaltung ber alten Stemeinbeverfaffuntg zu erfalten unb zu fräftigen unternahm, babei aber

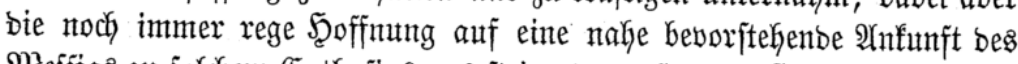

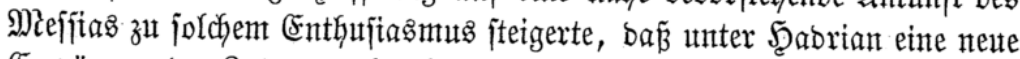

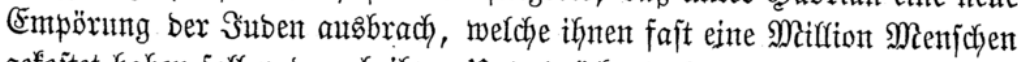
gefojtet haben forl uno nach ifyer Unterbrïcfung ein fitrenges Berbot gegen

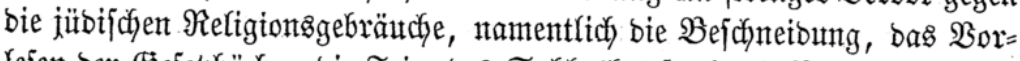

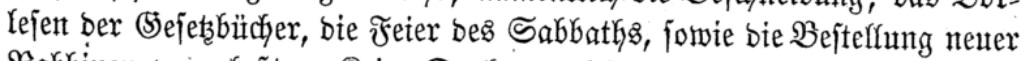

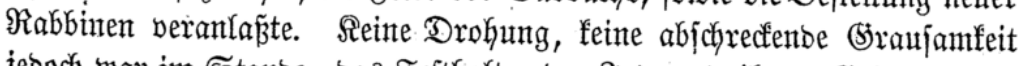

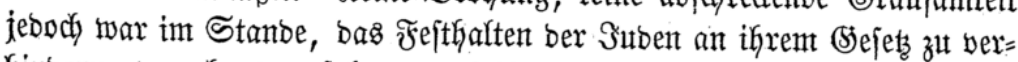
finbern; vergebents verfolgten nacheilenbe Solbaten bie Rabbinen, welche

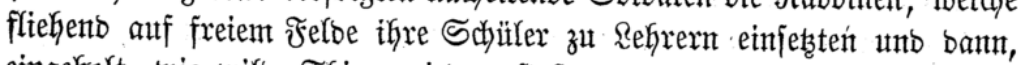
eingeyolt, wie milbe Thiere niebergeftopen wurbent. Da gab man bent bie $\mathfrak{B}$ exfolgung auf unt jutchte burch Mitbe zu erlangen, was man burch

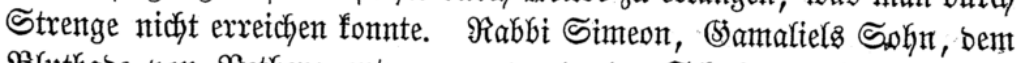

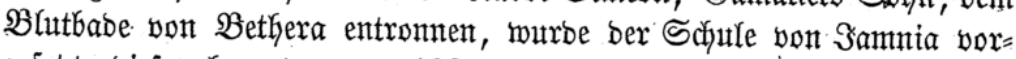
gejetzt, bieje aber etwa um 180 nach Iiberias verlegt. Seter warb bie

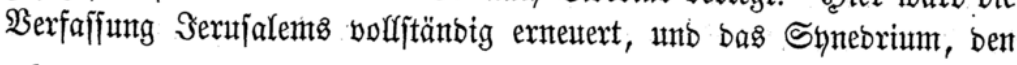


Nafi an ber Spize, erfannte mieber als hödjfter (Seridytshof. über alle

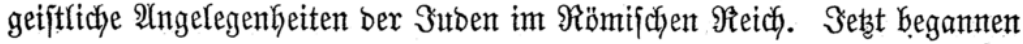

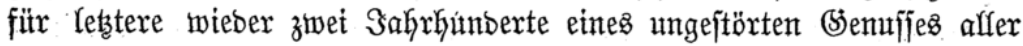

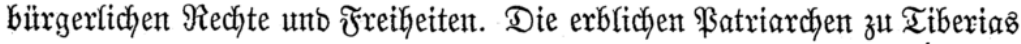

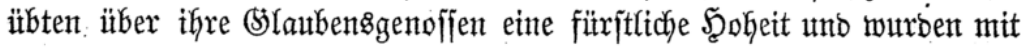
Den Egrentiteln belegt, welche nadh benen bes Raijers bie hödjpten waren.

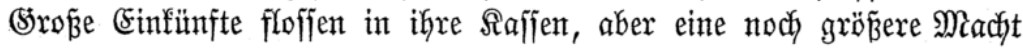

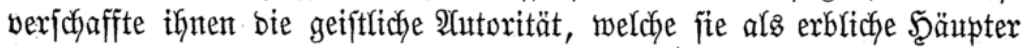

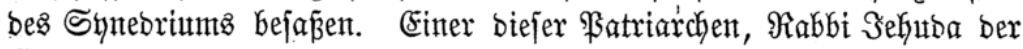

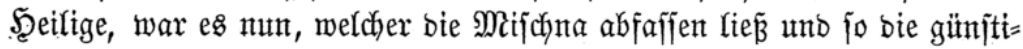
gen Zeitwerfältutiffe benutste, um gegent bie erwarteten झ̆pätern Drangfale eint nationalez $\mathfrak{B}$ offmerf zu errichten.

Unt in ber That twar bie Mijidna faum abgeidylojien, fo murbe auth fduon eine Erweiterung berjelbent baburch nöthig, baj bas (Ehriftenthum

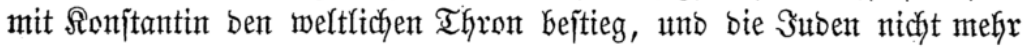

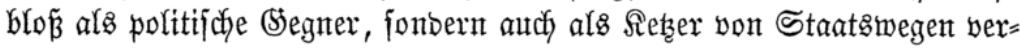
folgt wurben. Nicht ihr bürgerfiches \&eben, fonbern ihr religiöjes maro nutn angefochtent, und felbit bie ausbrütfficjen Befehle Der Raifer zum Schutze ber Synagogen fonnten bie Beritörung Derjelben nidft mebr werhintorn. Unt boch war bie jübijche Religion biz jeţt burch fein Staatsgejets berboten, wie bent itberfautpt ben jübifchent Unterthanen nichto zur Rajt gelegt merben fonnte, moburch eine Sdymälerung ifyrex $\Re$ echte zut

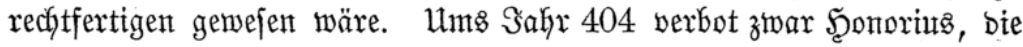

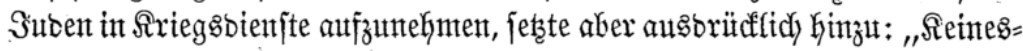

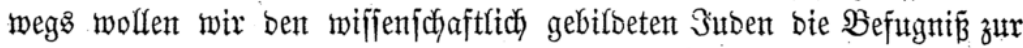

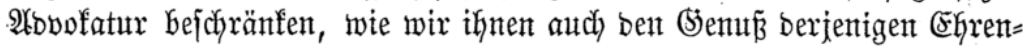

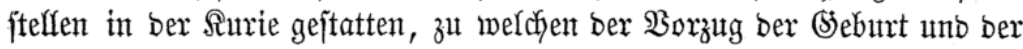
(Slanz ihrer Familie fie berechtigt. Da ifnen bies genug jein mufa, fo

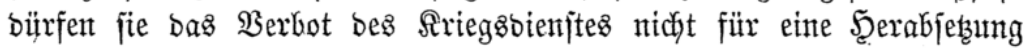

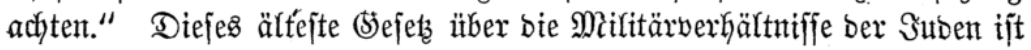
in boppelter $\mathfrak{B}$ ez̧ielyung widhtig, Denn erjtens betweijt

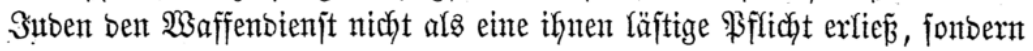
als ein von ifnen in $2 \mathfrak{2}$ ifprud

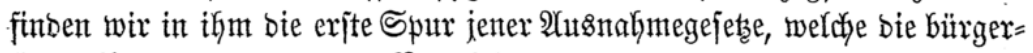

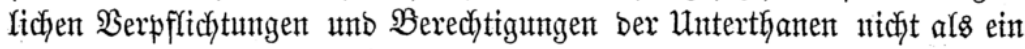

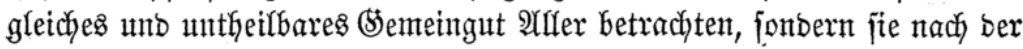

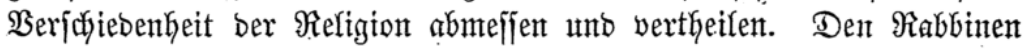
entging bies unt fo wentiger, als fie bereits feit Sonjtantins Uebertritt

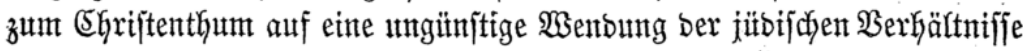
gefajt warent. Sie fahen es baher gern, als mit Samaliel IV. etwa 


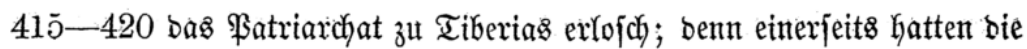

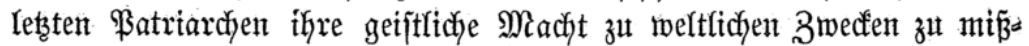
brauchen angefangen, währent anbererjeits bie bon ben (Shriftenfaijern

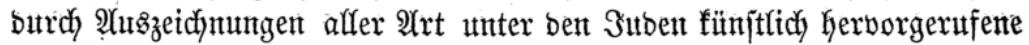

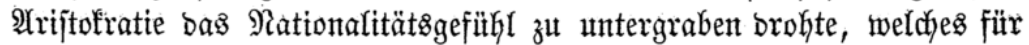
bie Buffunft bas einzige ßaflabium ifrer religiöfen Einkeit birben fonnte. Man berpflanzte baher bas in Tiberias begonnene. Serf in bie babylont=

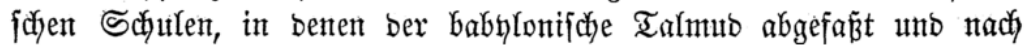

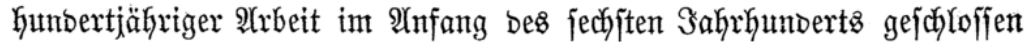
warb. Bon nun an blieb biejer als unverbrïdhliche 2 Autorität ben jpätern

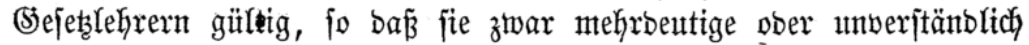

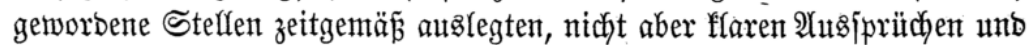

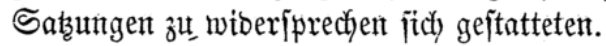

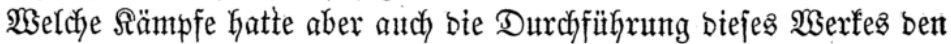

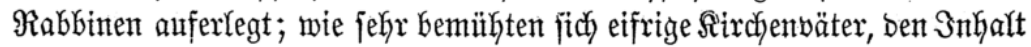
beffelben barb lächerlich, balo verbächtig zu madjen, unb twie erfolgreid ftrebte bie bereits bie jdywadhen (5hriftenfaijer beherridhende Şierarchie,

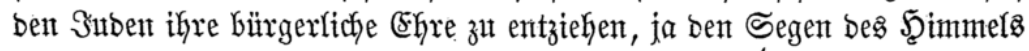

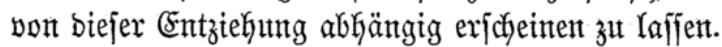

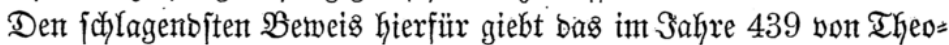
bofius H. und Balentinian erlafjene \$5efes, welchez als \$endepunft ber bişherigen unt als Strunblage ber fpätern jübifchen bürgerlidjen $3 \mathfrak{u}$ jtänbe betrachtet werben fann uno nidyt nur barum hier vollijtänbig mitgetheilt werben joff, fonbern auth wegen bes gewi

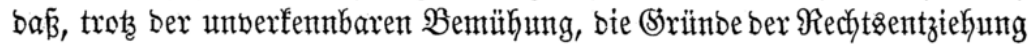
exjdyp̈pfend anzugeben, bennody nidjto barin vorfommt, was in bürgerlicher Beziefung ben Suben afs Bormurf angeredynet würbe. Das \$sejeţ Lautet:

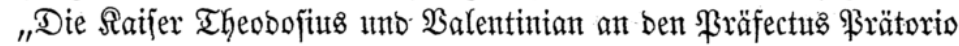
Florentius:

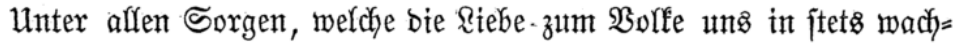

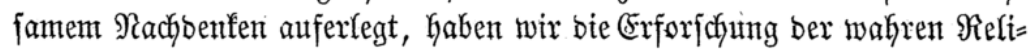

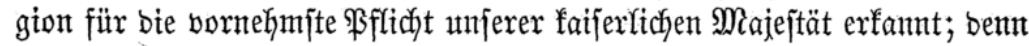
wenn wir ifren Dienjt aufredyt zu erhalten im Stanbe finto, fo eröffnen

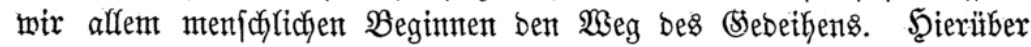
belehrt burch bie Erfahrung eines langen Rebens, haben wir mit gott=

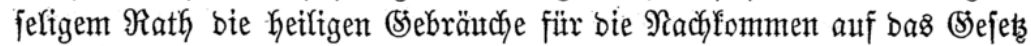
ber Unveränberlichfeit zu grünben bejd)loffen. Denn, wer follte jo wahn=

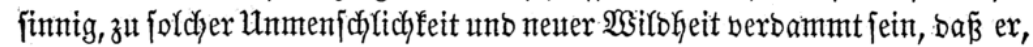

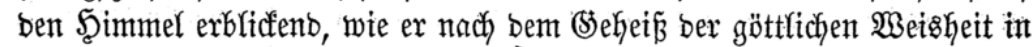

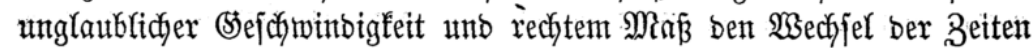


volfentbet; ben Rauf Der Bejtirne, welcher bie Arrbeiten unb Stenüjje bes Sébens orbnet, bie mit Frïdjten begabte Erobe, bas frömenbe Meer und

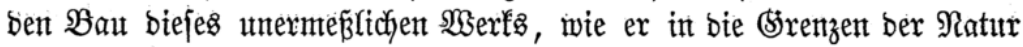

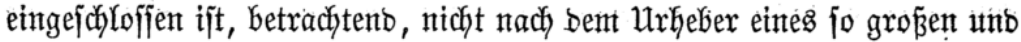

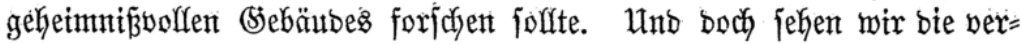

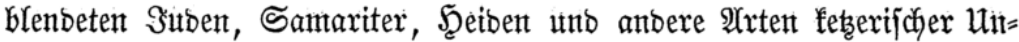
gehenter biejes jich unterjtehen! Wonn wix es aljo unternehnten, fie burdy

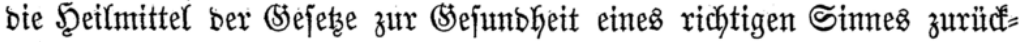
zubringen, fo werben fie felbjt bie Schuld unjerer Strenge tragen, intent

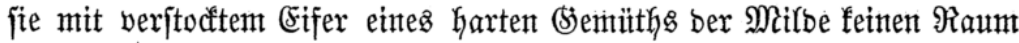
laffen. Da muth, nach einem alten Sprutche, bei verzmeifelten Srălffyeiten

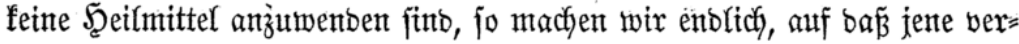
berbenbringenben Seften jich nidht, unjerer Beiten ganz bergejjen, gleichjam ofne Unterfajeibung bes SHFaubens ungezügelter in bas Reben verbreiten,

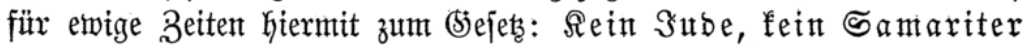

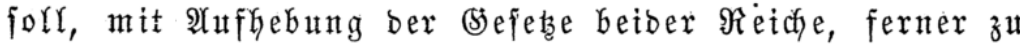
Alemtern und $\mathfrak{W}$ üben zugelafjen werben, feinem bie $\mathfrak{B} e r=$ waltung ftäbtifder Dorigleit offen jteken, nidyt einmal ber Dienjt eines Bertreters ber Stäbte bon ifnen berfehen wer=

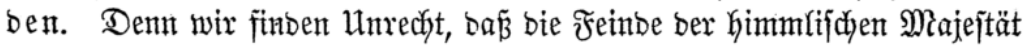

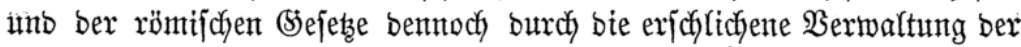

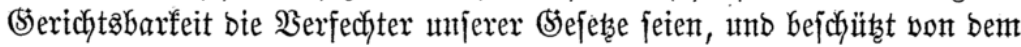

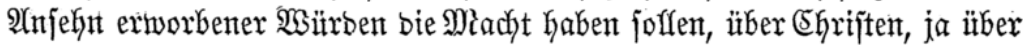

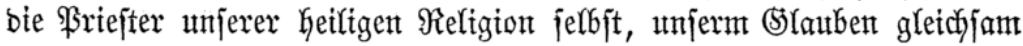

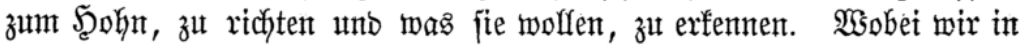
gleidyem betradft nody fejtfetsen: Daß feine Synagoge in neutem Baue fith erhebe, jeboch bie Unterjtittsung ber alten, bie von Baanfärrigfeit bebroht jinb, gejtattet jei. Diejem fügen wit hinglt, baj, wer einen Sflaven ober Freien wiber feinen $\mathfrak{W i f f e n}$ ober burch jtrafbare Heberrebung won bem Diente ber chriftlichen Reltgion zu jenen jtrafbaren Seften unb sese

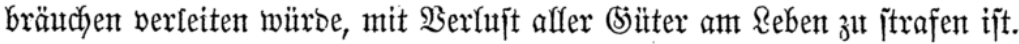

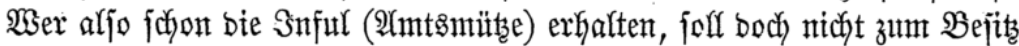
ber erworbenen Würbe gelangen, und wer eine Sinnagoge erbanten würbe,

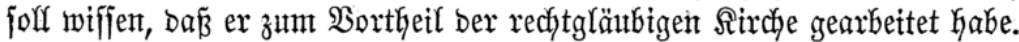
Wer fich bennody in ein $\mathfrak{A}$ mt einjdyleicyen witrbe, forl boch wie borker in bem nieberjten Stanbe bleiben, went ex autd fêrbjt bent Titel einer ber Gökern Witrben fich ertworben hätte. Wer aber bent $\mathfrak{B a n t}$ einer Synagoge

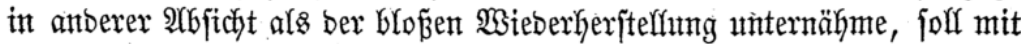
einer Strafe von 50 Pfunt Sold fein Unterfangent vereitelt fehen. Heber=

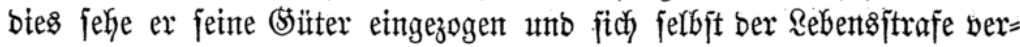




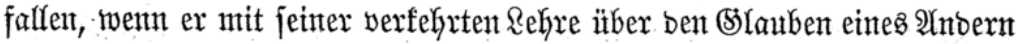
gefiegt Gaben jollte. Uno weil es ber faijerlichen Majejtät geziemt, mit

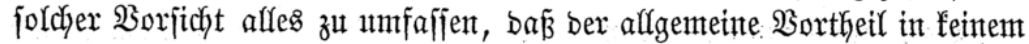

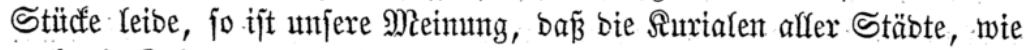

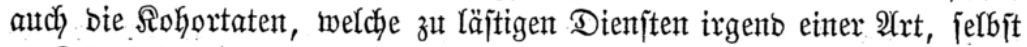

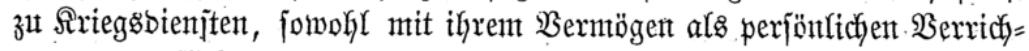

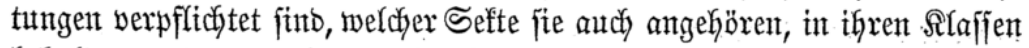
behalten werben, bamit es nidjt jcheint, als Gätten wir ben abjcheutwïroigen Menjicten, weldye wir Sraft biejes \$ejeţes bejtrafen wolfen, vermöge

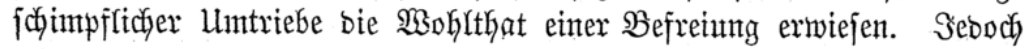

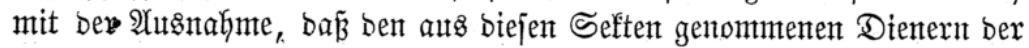

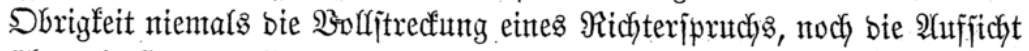
ïber bie Şut ber Sefangenent anvertrant merbe, bamit nicht bie EGriften, wenn fie, wie es zutweilent geichieht, eingeiperrt werben, burchy bent $\mathfrak{W} a \mathfrak{a}$ ber

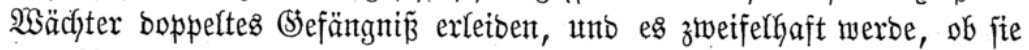
mit Recht eingefdylofien finto. Ferner hat unjere Snabe erwogen, ba

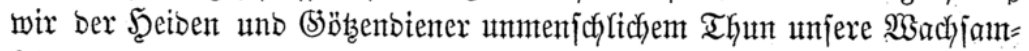
feit entgegenjetzent mitifjent, als welche, mit antgeborner Thorhett unto Fred)=

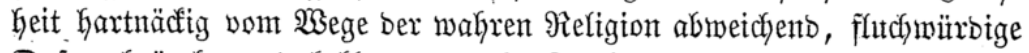

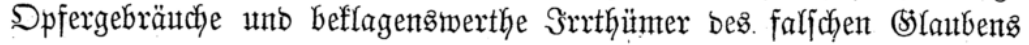
in abgelegenter 3 erborgenteit zut übent jich nicht entblöben, wenn nicht ifyre Berbrechen zur Beleibigung ber göttlichen Majejtät und zum \$̧ohn umferer Beiten burch bie B̉efdyaffentheit iłhres Wanbels an ben Tag fämten, weil nicht bie taufend Sdyrecten ber erlaffenen (stejesce, ntidyt bie Strafe ber angebrohten Berbaunung jie, went aud nidjt zux Sinnesänberung, body wentigitens zur Mintorung ifrer zahliojen Serbrechent unt Enthaltung vont Der Befubelung burch Dpfer haben nöthigen fönnen. Biermehr wirb mit

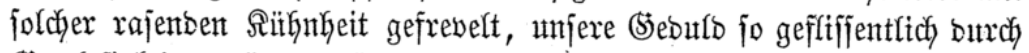
(Bottlojigfeit ermitbet, baj , wenn fie auth zut vergeffen geneigt ijt, fie boch nicht fdyweigen fant. Daher, obgleich bie Riebe ber Religiont inmer

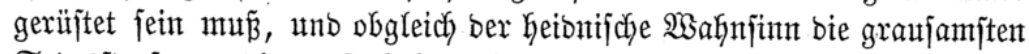
Tobesftrafen verbiente, fo haben wir boch, unjerer angeborenen Rangmuth

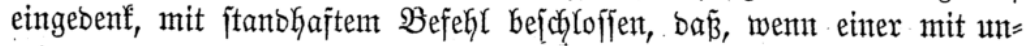
reinem and beflecttent Sinm, wo ę aud jei, bei einem Đpfer ergriffen würbe, unjer Zorn fich wiber fein Ssut und Bhyt erheben folf. Denn

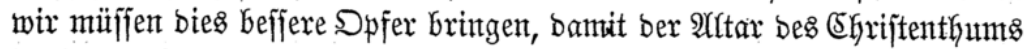

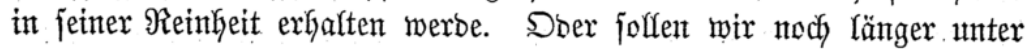

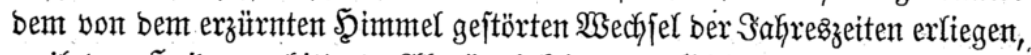

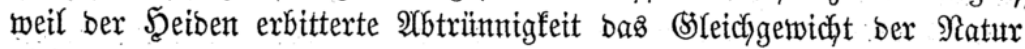

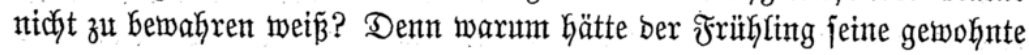


Milbe abgejumorent? Warum hätte ber Sommer beş arbeitjamen Rantb=

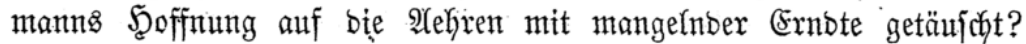
Warum hätte bes Winters unmäßjiger (5ximm bie freigebige Eroe burch

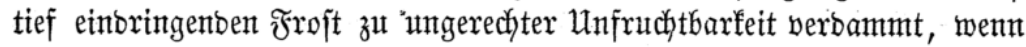

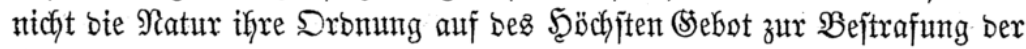

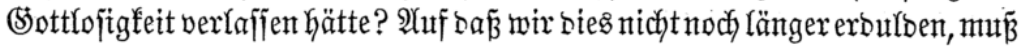
burch friebenbringende $\Re$ ache, wie oben fejtgefetst ift, bie anbetungghnürbige Majejtät bes höchjiten Wejens verjöhnt werben. Hebrigens, werthejter

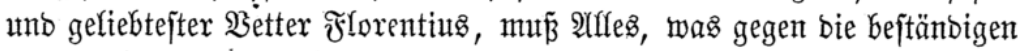

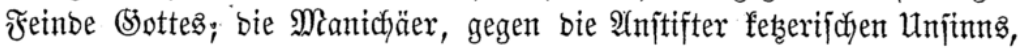
bie Eunnmianer, gegen bie Montanijten, Satafrigen, F̌otinianer, Bris= ciflianijten, 2 scobrogen, Şyoroparajtaten, Borboriten uns Dphiten in unzähligen $\mathfrak{B}$ erorbnungen befohlen ijt, nummehx ohne ferneres Säumen

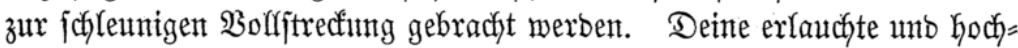

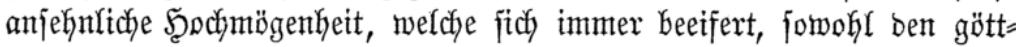
richen als fürytlictyen Befehlen ihren Dienjt zu wibmen, wirb alfo bas,

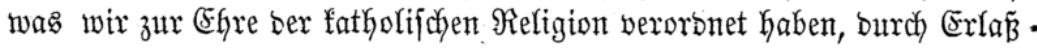
Der gemöhnltichen (Esifte Deiner Exccellenz zur alfgenteinen fumbe bringen.

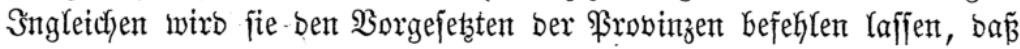
mit gleidjer Bïnfttlicffeit bas, was wir zu veroronen nöthig gefunben, jämmtlichen Stäbten unb \$rovinzen befannt gemacht werbe. Stegeben

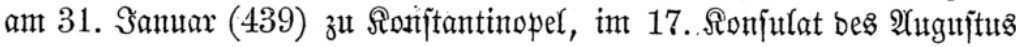
Theodofü, und bes nody zu ernennenben."

War aber audy bie Macht bes Talmutos unto bie 2 (utorität ber bent=

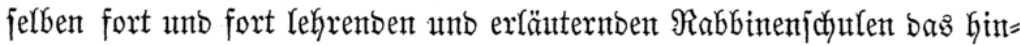
reichenbe Mittel, um bie ibeale Nationalität ber ïberalfyin zerftrenten

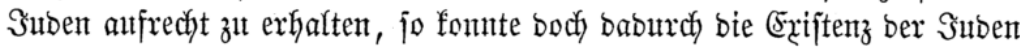

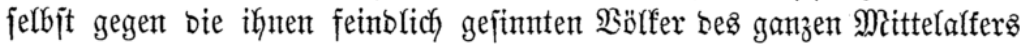
nicht gejichert werben; unb ber jübif̧je Stamm wäre gemic wäfrent jener trautrigen Эahrhumberte von ber Erboberfläche bertifgt worben, wenn nidyt

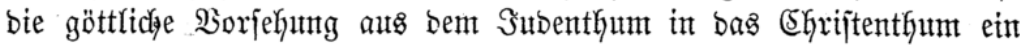
Moment itbertragen Kätte, weldyes bas erftere fïn bas lețtere fo lange unentbefrlich madjte, bis eine Gökere Stufe ber Sinilifation unb eine

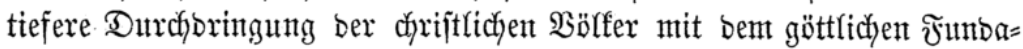

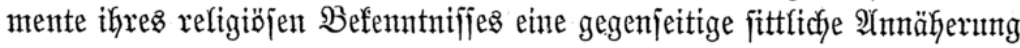
anbahnte.

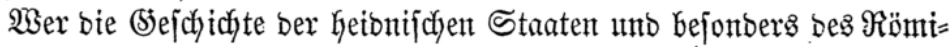

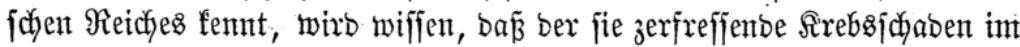

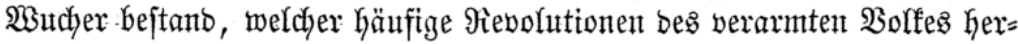
beiführte unto-burch bie jtrengiten . Sejetse immer nur temporär nieber= 


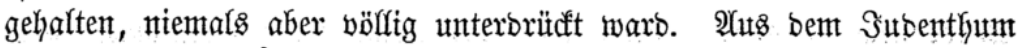

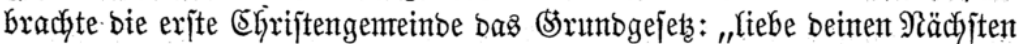

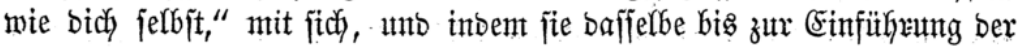

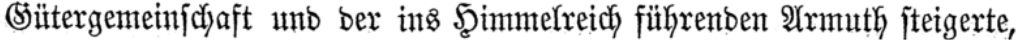

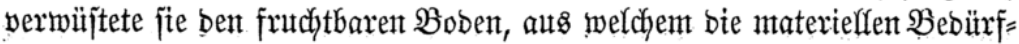

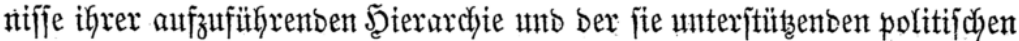
Mradyt Gätten bejtrittent werbent fönten. So warb ein auker ber (SG)riften=

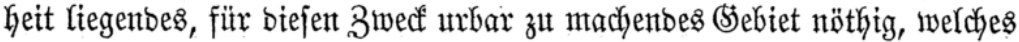

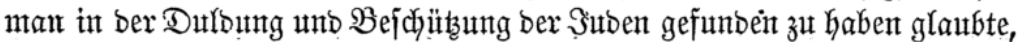

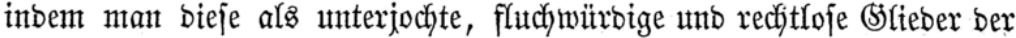

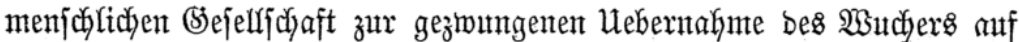

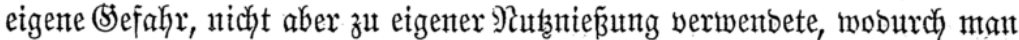
ben dyrijttidyen Britbern, saien unt Unterthanen, recht gut und ohne (5es= wiffengffrumel ihr (S)elo abnehmen fonnte, ba bies burch bas Fittrum eines

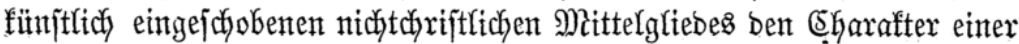

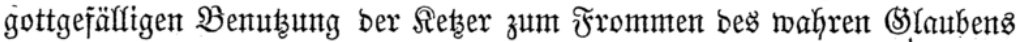
- erfielt. Nidut als ein ofnefin ganz unerflärficjes Borrecht, fonbern als

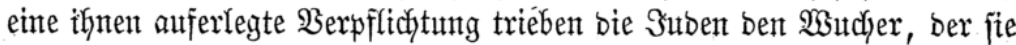

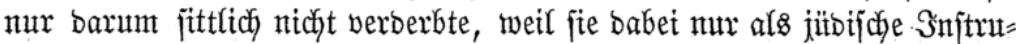
mente in chriftlichen Şänben thätig waren.

Diejer 3uftant hat int 2ffrgemetnen währento bes Mittelalters feine

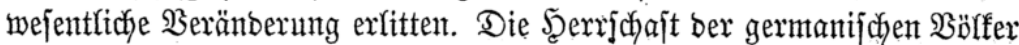

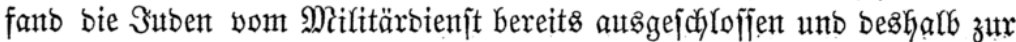
Errlangung von Strunbeigenthum unfähig; affein bie Saijer betrachteten

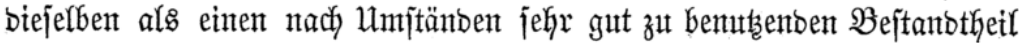
ber von Tituz überfonmenten (Erbjhyaft (jo jagt ber Schmabenfpiegel Sap.

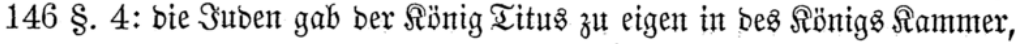

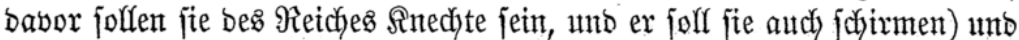
erffärten je für ifyr perjönliches (Eigenthum, weldyes. jie nady ifyrem wills= fürlidjen (Ermeffent pflegen ober vernichten bïrften. Uno bies thaten fie

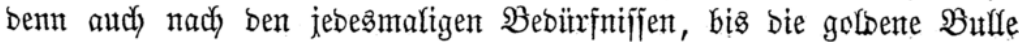

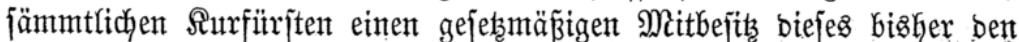

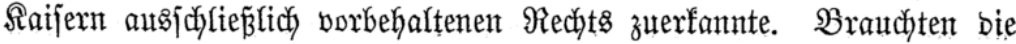
Regierungen religiöfen Fanatismus, fo murben Subenverfolgungen auş=

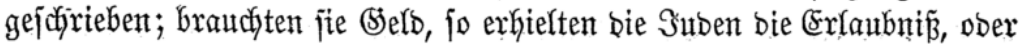
vielmehr ben $\mathscr{A}$ uftrag, auf hohe Binfen zu leihen, geftohlenes (5) zut fanfen

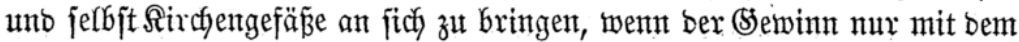
Regenten chrijtlich getheilt warb; brauddent jie aber viel (Selb, Daun mupisten

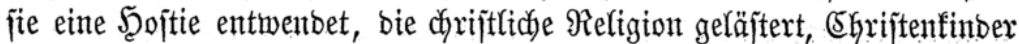
heimlich befdynitten haben, um wie augigepreẩe (5)elbichnänme weggejagt 


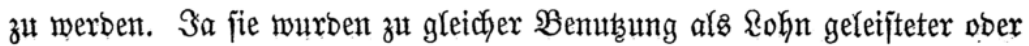

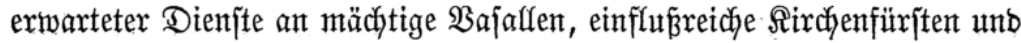
unabhängige Stäbte verichenft, verpfänbet ober verfauft, unb noch heute grünton eintige ber letztern iffre vermeintliche $\mathfrak{B e r e d}$ tigung zur freien $D i s=$

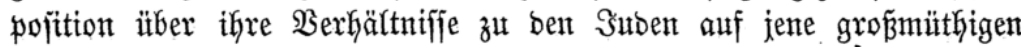
Schenfungaintumben ober auf bie erhaltenen \$rivilegien, feine Suben aufnehmen zu mitjien, wenn bie Rehnsherrn etwa aus ber Errlaubniz bazu

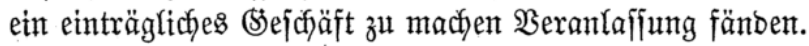

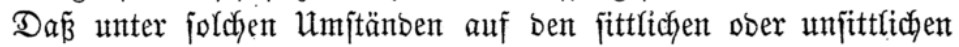
Sharafter bes Subenthums jelfit bei ben mannigfachen Röpungen ber

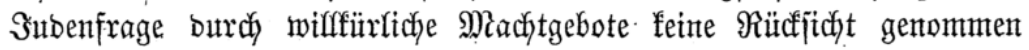
worben, ift wohl nicht zu bejtreiten, ebenjo wentig fann man inber ber $=$ fennen, bå ein in jeinem Uriprunge chriftliches, aber aud borffommen

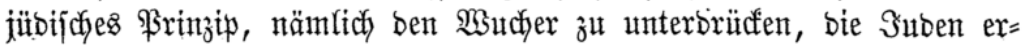
halten hat, benen man, freilich mit undyriftlicher $\mathfrak{A}$ uslegung, jentes

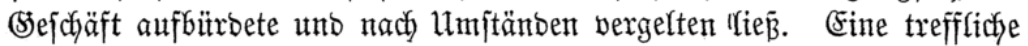
Uteberficht ber Sdjidfjale, weldye bie Suben im breizehnten unb vierzehnten Эahrhunbert erfahren haben, finbet fich in bem

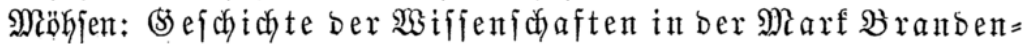

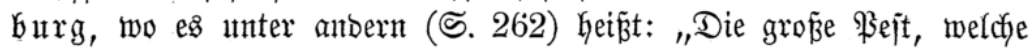

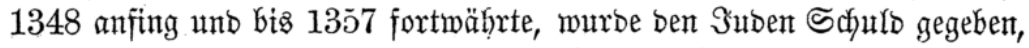

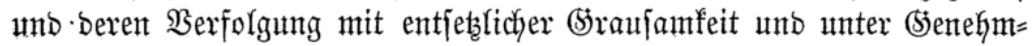
haltung ber Drrigfeit "und fajt Der ganzen (Seijtlidjfeit bejchloffen und veranjtaltet. Die \$ijeiftlichen waren mit Den アuben nidyt zufrieben, weil fie fich mehr and mehr in ben Stäbten augbreiteten uno bie Einfünfte ihyer Sirchjprengel fonmälerten; zumal ba jie burch fürjtliche Binaben= briefe ihrer weit autgebreiteten geiftlichen (jerichtobarfeit entzogen wur=

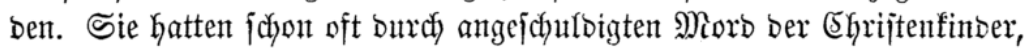

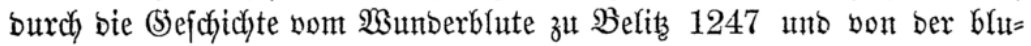

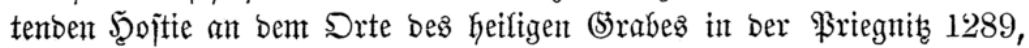

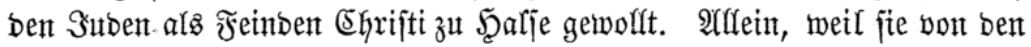

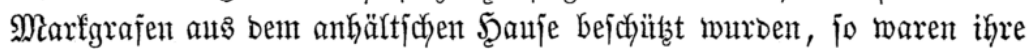

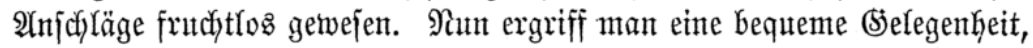

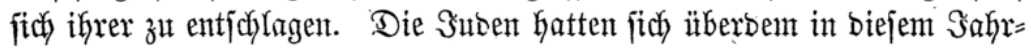

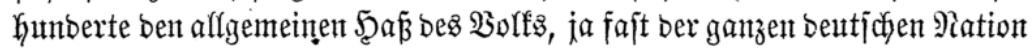

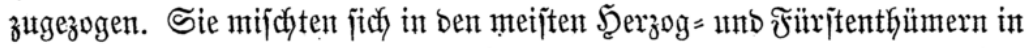
Das Finanzmejen und hatten bie Steutn, 3̈̈lle und 2 (Kgaben gepachtet ober (Stelo im Borjant baranf gegeben, und zogent bie Zimjen aus ben (s)eälfen, bie fie ohne $\mathfrak{A}$ njegn ber \$erjon einforbertent. Sie hatten nente 2Yuflagen erbacht unt angegeben, bie ben Unterthanen bejay werfich fielent. 
Weil fie fich zut fehr auf bie \$nabe ber Fürften verliepen, fo murben fiè ftolz und ïbermüthig. Sei bem Scanbel unb Berfauf, weldyen bie (Seift=

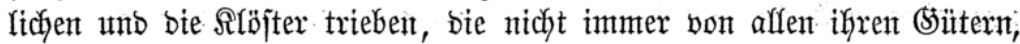
Sorneinfünften unt \$robuften zolffuet waren, faken fie nicht fo burds bie

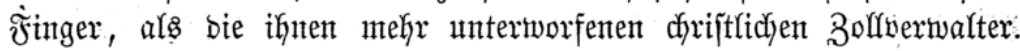
Ferner burch bie hohen Binjen, bie jie von ben $\mathfrak{B}$ ornehmen und Steringen

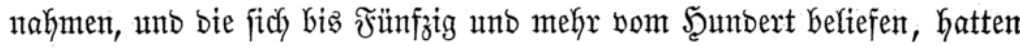
jie bent alfgemeinen $\mathfrak{b} a \tilde{B}$ gegen fich vermełrt; und wie bie Suben erjt an

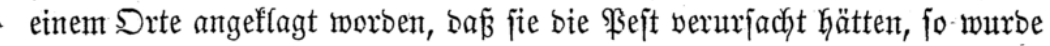

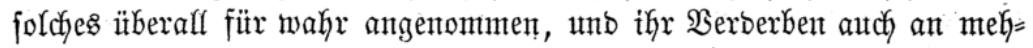
reren Drten bejchlofien. 'Bei ben geridytlidyen unterfutdyungen fing man mit faljdyen $\mathfrak{B} e\{d$ uldigungen und Martern an; und stes war Ginreidjent,

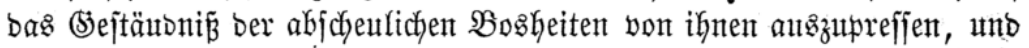
jocher Bosheiten, an welche bie Suben nie gebadyt hatten. Man bejdul=

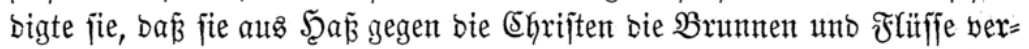

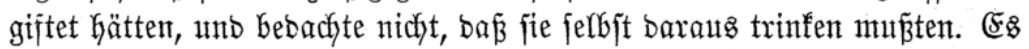

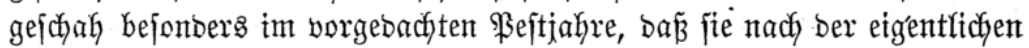
Bebeutung vogelfret erffärt unb von einem Seben, ber boshaft unt grau= fam genug war, in ber $\mathfrak{w h t h}$ unb heiligem (Eifer ermorbet ober autf auts: geplïnbert unb nacfent fortgejagt murben, ba fie benn vor Fetnger unb

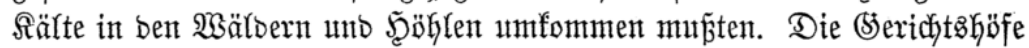

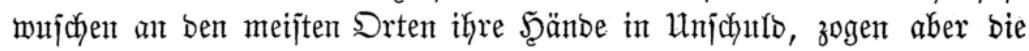

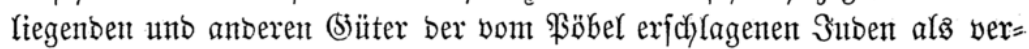
fallen ein. Deshalb tamen viele Magifträte unb verfjchiebene Fitriftent und

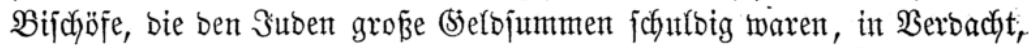

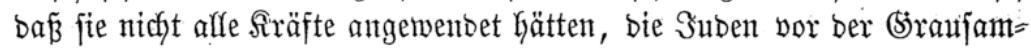

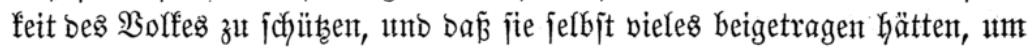
fie gänzlich zat vertifgen.

Sn ben meiften Stäbten unb auf bem Ranbe mutrben bie ungliüd =

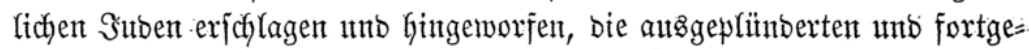

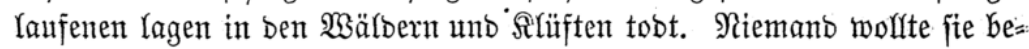
graben, und jie verurjachten nach bem Tobe burch (Seftank und Fäulntí eine wirffiche ßejt, für beren Urjache man fie frïher ohne Srund ange= geben 'hatte: In ben Stäbten, bie an Wafjer lagen, wurben, wie vor=

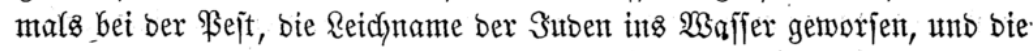
Seudye baburdy bermehrt und auggebreitet. In Spener ftedfte man bie

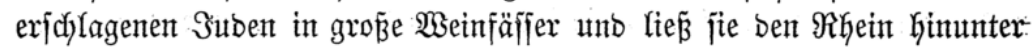
nach Şofland jchimimment."

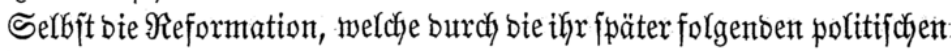

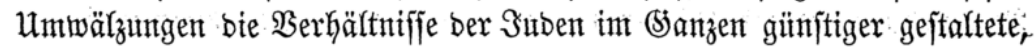


Gractite in benfelben unmittélbar feine $\mathfrak{B}$ eränberungen herbor, ba auch bie protejtantijchen Ranbegherren bas Eigenthumberecht an ben gebulbeten $\Im_{\mathfrak{H}}=$

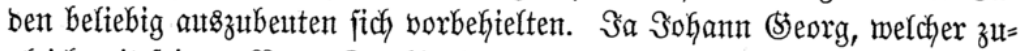

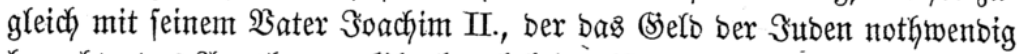

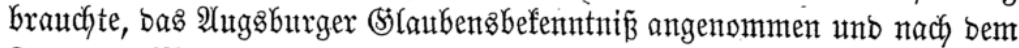
Tobe bes Marfgrafen Sohann bie jämmtlichen zux Surmart Branben= butrg gehörigen Ränoer für immer vereinigt hatte, begann 1571 jeine $\Re e=$

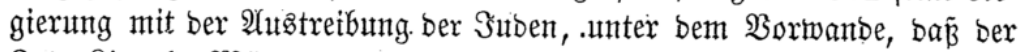

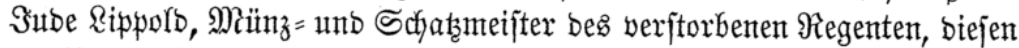
vergiftet habe. So wurben bie bamals aufgeregten Reibenjcyaften ber

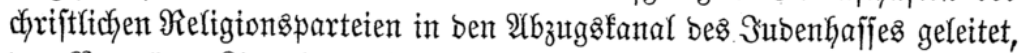
bas $\mathfrak{B}$ ermögen Rippolos, ohne irgent einen Bemeis feiner Schulb, beren

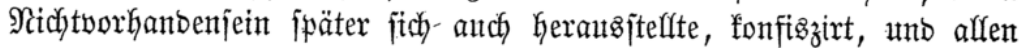

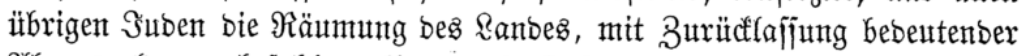

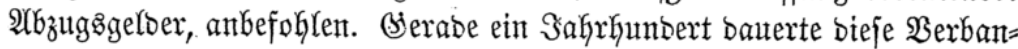
nung, benn erjt 1671 nahm ber grofe Surfürjt Friebrich Wilkelm bie auts ben faijerlichen Ranben, auf 2 ntrieb ber $\mathfrak{P f a f f e n}$, vertriebenen $\Im$ itben in feine Staaten wieber auf und ertheilte ifnen ein Schuthpribilegium, wel=

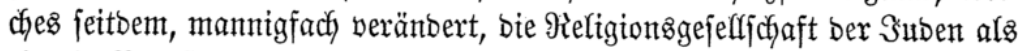

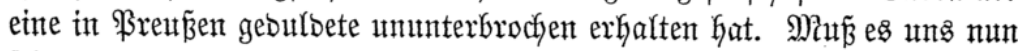

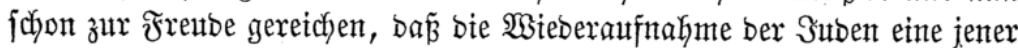
Mapregeln war, welche biejer (Stünber ber politifchen unb geiftigen Maadjt

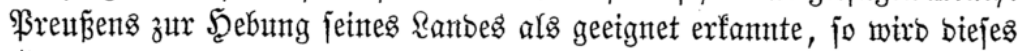

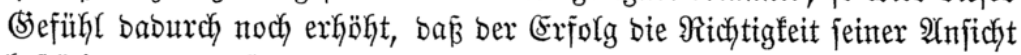

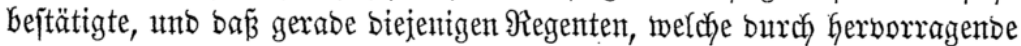

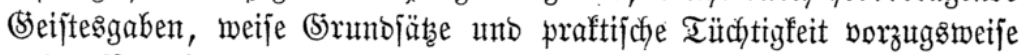
unjex $\mathfrak{B a t e r f a n t}$ feiner gegentwärtigen Steflung entgegenführten, auch ber Rage ifrer jübifchen Unterthanen ifyre bejonbere Átumerffamfeit fchenften, um fie burch fittliche Bereshung unb bürgerliche Erkebung immer mefr mit ben dyriftlicfen Ranbestinbern zut verjamelzen. Die Mittel entfprachen freilich nidyt immer bem beabjidytigten, ober body ant=

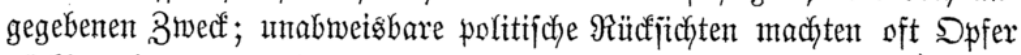

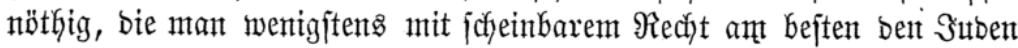
auferlegen fonnte, ja bie leţteren jelbjt jträubten jich zutweilen gegen ein

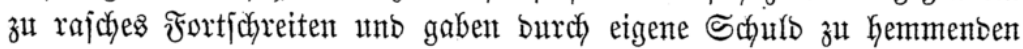
Serorbmungen פeranlafjung. Der Faben inber

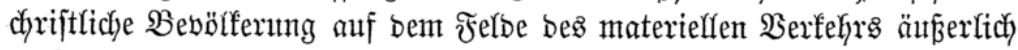
verbanb, warb allmälig burch bie gemeinfchaftliche unt gleichntäpige Ent= widfełunt auf bem geiftigen und fittlichen Siebiete zu einem immer engeren

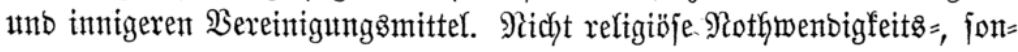




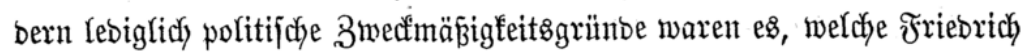

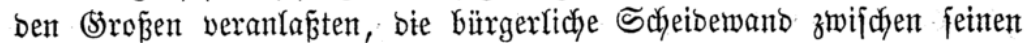
dyriftlicjen uno jübifichen Unterthanen aufredyt zu erhalten. Die (Emanzi= pation ber preupijichen Эuben war von jenter Zeit an nur eine Zeitfrage.

Friebridy ber (Strofe war, wie aus vielen feiner $\mathfrak{B r i e f e}$ und Rabinets= befehle Gervorgeht, nidhts wentger als ein Berächter bes (Ehriftenthums,

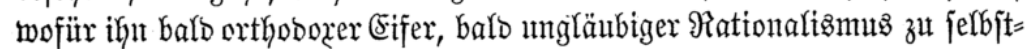
jüdytigen 3 wedfen autsgeben wollte. Dagegen machte er alferbings zwif fhen Der dyrifftichen Religion unt bem ifyr als Stüze bienenten firchlichent

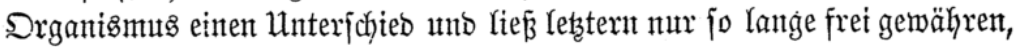
ałs er jeinem erfabenen 3 weed förberlich ober minbejtens nicht fchäblich

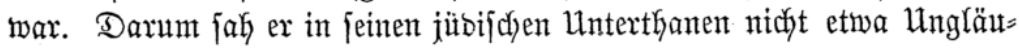
bige, bie er alz dyriftlictjer fïning zu verfolgen berechtigt ober gar ver= pflichtet fei, fonbern nur eine Religionsgefelffchaft, beren Dulbung und

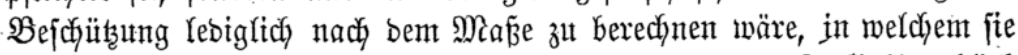
bem Ranbe nïtzlich zu werben vermöbdte. Das refigiöfe Btebiet blieb babei gleidyfam neutral, unb nur einzelne fird)liche (Einridfungen murben

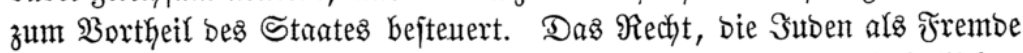
anzujehen unb zu behanbeln, war bamals, auf Srrund bes wejtphälifachen

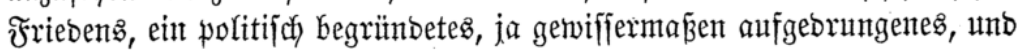
bie milbejte BBenutung beffelben bejtand unjtreitig barin, mit biefen Frem= ben einen Duldungs = unb Schutbertrig auf bem Boben bes gegenjeitigent

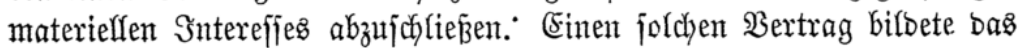
revibirte \$eneraljubenprivilegium vom 17. Ápril 1750.

Durch biejes (sejets wurben unter bent in Âffgemeinen afferbingz

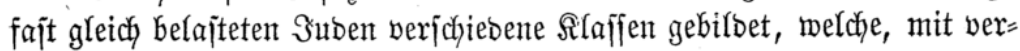
fajiebenen . Rechten begabt, gleidjfam brei Stänbe ausmachten, beren Gö̈bjter zwar immer nody unter bent niebrigiten ber carijtlidyen Staats= bitrger rangirte, aber feinen minber beborzugten \$)lanbenzbrübern gegen= über eine beneibensiverthe ariftofratifdje Stellung einnahnt. 3ur geiftigen

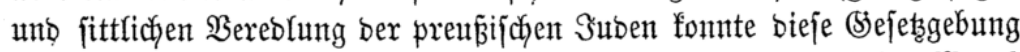

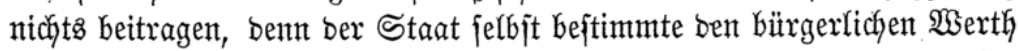

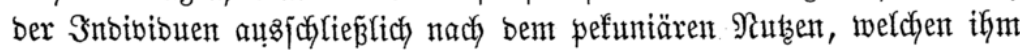

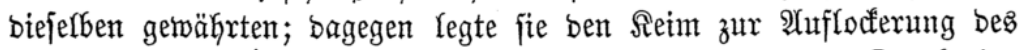

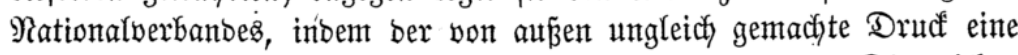
entiprectjente ungteidye Segenifpannung bon innen erzentgte. Die reidfen

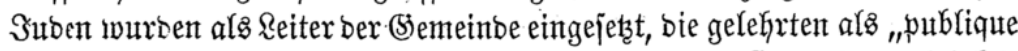

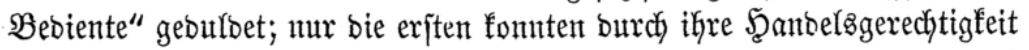
immer reidjer werben, und bas auf bieje Weife in einzelnen Familien jich aufhäufenoe $\mathfrak{B e r m o ̈ g e n ~ g r u ̈ n o e t e ~ e i n e ~ g l e i d y j a m ~ e r b f i c h e . ~ S ̧ e l b a r i j t o f r a t i e , ~}$ 


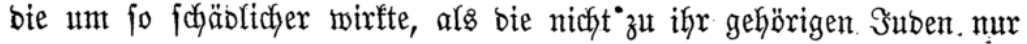
unter ifrem Schub̧e Dulbung unb Exịtenz erlangen fonnten. Währeno fo ein materielfes Moment in bie jübijchen $\mathfrak{B}$ erfältnifje einbrang, welches je nach feiner 2 (nwwenbung nütşlich ober fchäbrich mirfte, fiel zugleich ein

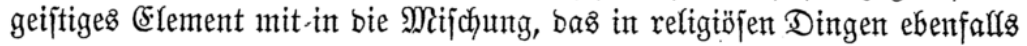

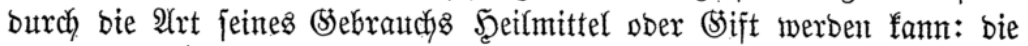

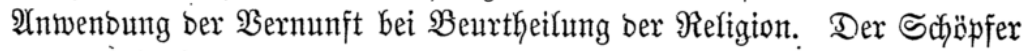
biejer für's Subenthum neuen $\Im$ raft twar Mojez Mendeläjohn, ber gerabe

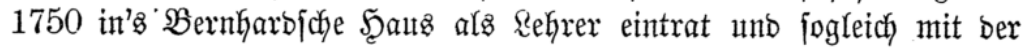

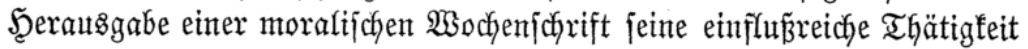
begann. Mlöge bies ßufammentreffen inmergin zufällig exfjyeinen, wir

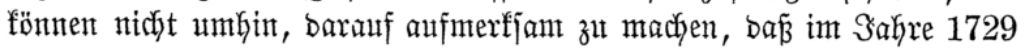

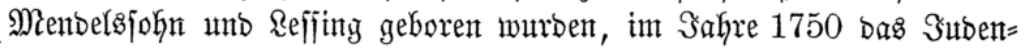
reglement und Mienbelşohnt łu wirfent anfingen, im Sahre 1786 aber

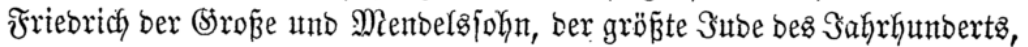
gejtorben jinto.

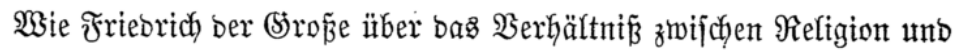

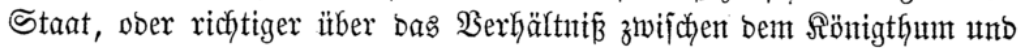
Rirchenthum bachte, ergiebt jich aus nachfolgenton betreffentoen 2 (eures rungen. Seine Schrift "über ben 9Hberglautben unb bie Religion" entet mit folgenten Säkzen:

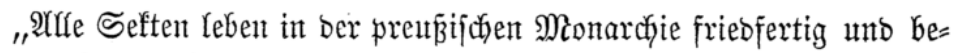
ftreben fich, zut Staatsmohlfahrt in gleidjem Maß̉e beizutragent. Es

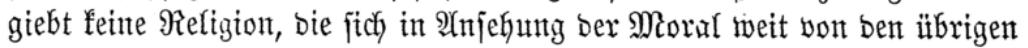
entfernte; fie fönnen folglidy ber Riegierung afle gleidh fein. Sie läßjt baker jebem bie Freifeit, auf weldyent 2 sege er will, zum Scinmel zut gehen. Went er intr eint guter $\mathfrak{B}$ ürger ijt, mehr verlangt man nidjt von

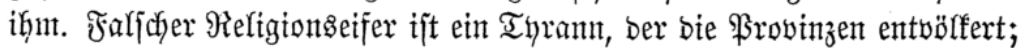
Toleranz aber eine zärtlichye Matter, bie fie pflegt unb brïkens macht."

Seinem ehemaligen Münbel ferner, bem ફ̧erzog Rarl Eutgent bon Würtemberg, ertheilt er folgenben "bäterlichen"

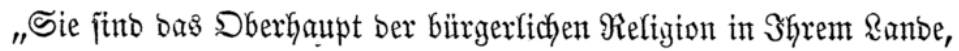

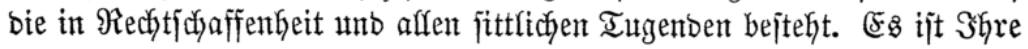

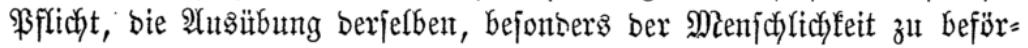

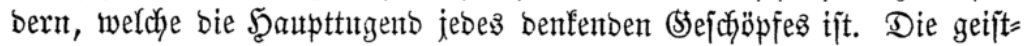

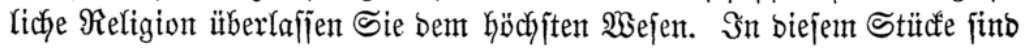
wix alle brint unt irren auf verfodjiebenen $\mathfrak{S e g e n .}$ Wer unter unz twäre

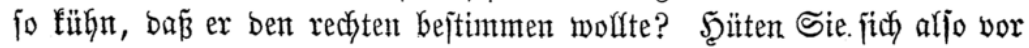

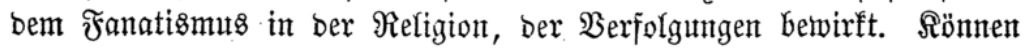


elẹtbe Sterbliche bem höchjten Wejen gefalfen, fo thun fie es burch Woblthaten, bie fie ben Menfichen ermeifen, nidfyt aber burch (Stemalt=

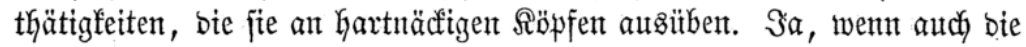

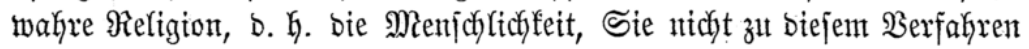
verbänbe, fo muß es body bie \$olitif thun."

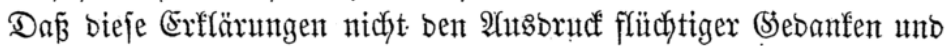

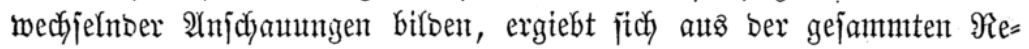

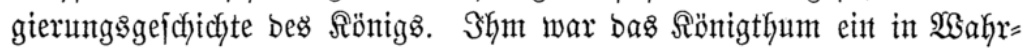
heit unb unmittelbar von \$sottes Snaben verliehentes unt baher burch ifn

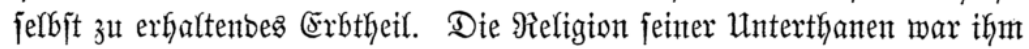
nidyt nur nicht gleidygültig, fonbern als (5rutno unb Boben alfer wahrhaft fittlichen Arräfte und Ihättgfeiten heilig unto untantajtbar. So weit bas Rirchenthum als Drganismus ber religiöjen Şantolungent uno (Empfin=. Duntgen biente ober fich betrachtete, Gielt er baffelbe nicht nur int Ehren, fonbern Yiez ifm auth feinen föntiglichen Schuts angebeihen. (5x bulbete

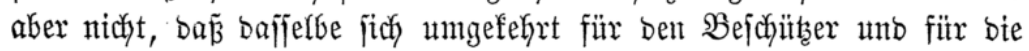
unentbehrliç) Stütze bes föniglichen Thrones uno ber föniglichen Macht

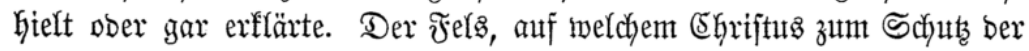

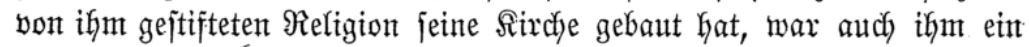

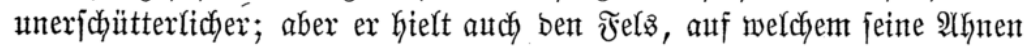
ben Söntgsthron gegrünbet hattent, für feft gentg, unt ben Schuts bes Sirchenfelfens entbehren zu fönnen. Und baj er Gierin fich nicht geirrt,

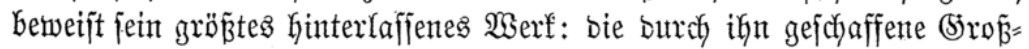

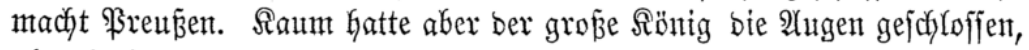
als bie immer madjame unb beobadjtende Rebentbuglerin ber föniglidjent Madjtodffommentheit jeinen mehr menjdjenfreundlichen als frafterfüfflent

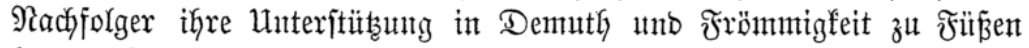

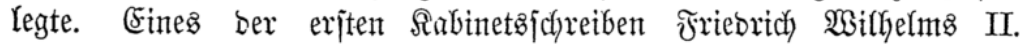
war bas nadjptehende an ben \$räjtbenten Freikerrn von Seyblits in Schlejien:

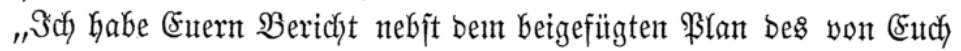

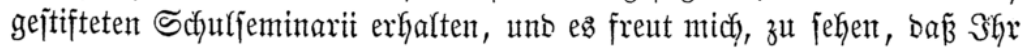

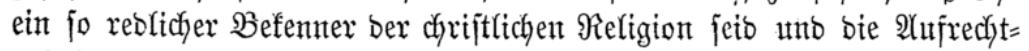

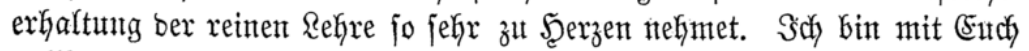
volffomment einerfei Meinung, baß̉ bie Srunbjätze bes EGriftentfums vor= nehmlich jungen (S)müthern mit Sorgfalt eingeprägt werben mïffen, ba=

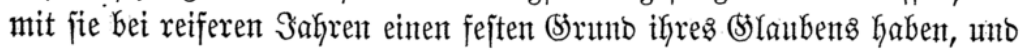

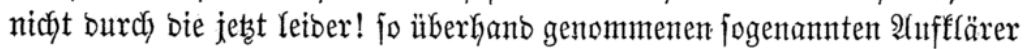
irre gefübrt und in ifger Religion wanfento gentadft werben. Sch haffe aflen

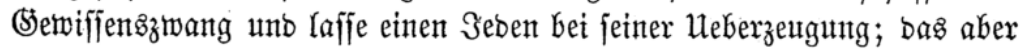




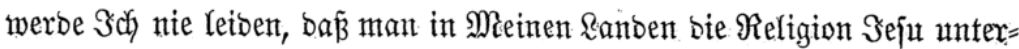

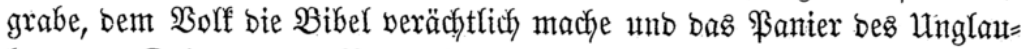

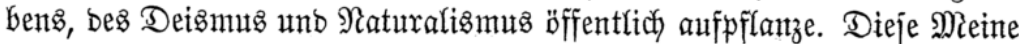

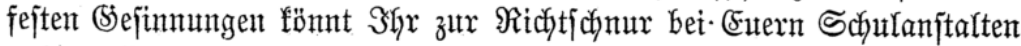
neh̆men."

Unt was bie Schule anf bieje Weije getehrt, jollte audy fpäter bie Sirche burch ifyren Einfluz befejtigen. So rajch bemächtigte fïh aber bas

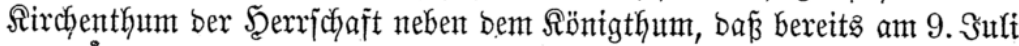

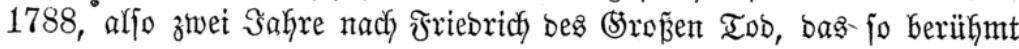

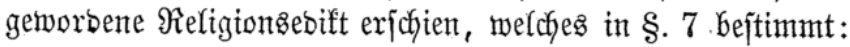

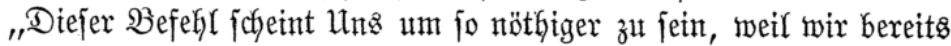
einige Эahre vor. Unjerer Thronbejteigung mit Reibmejen bemerft haben,

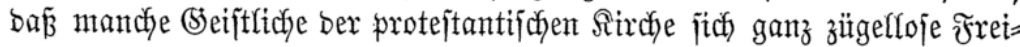

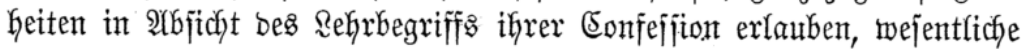
Stïcfe und Srunbwahrheiten ber protejtantifanen Sirche auts ber chrijt=

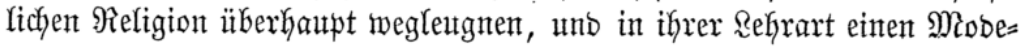
ton annehmen; ber bein Steift bes wahren Shriftenthums böflig zutwiber

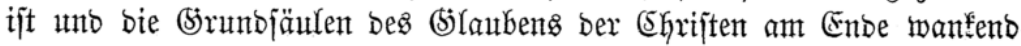
machen witrbe. Man entblöbet jïch nicht, bie elenben, längjt wiberlegten Srrthïmer ber Socinianer, Deijten, Maturafijten unb anberer Seften mefr wieberum aufatwärmen, und folche mit vieler Dreijtigfeit und $\mathfrak{U n}_{\mathfrak{n}}=$

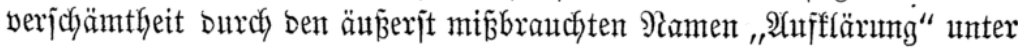

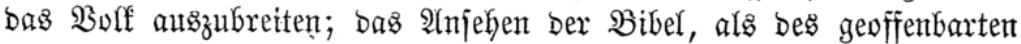

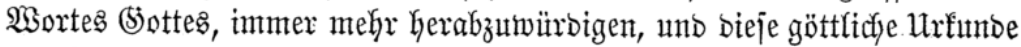

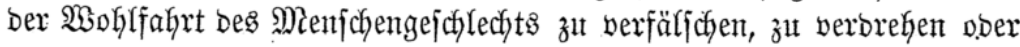

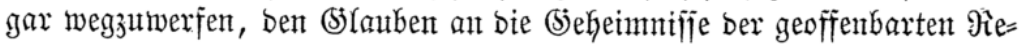

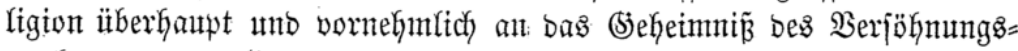

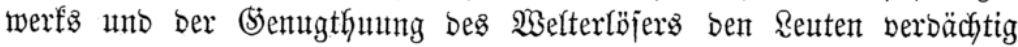
ober ïberflinffig, mitfint fie barin irre zu machen, unb anf bieje şeije

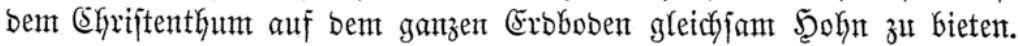

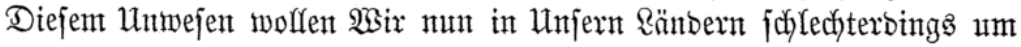

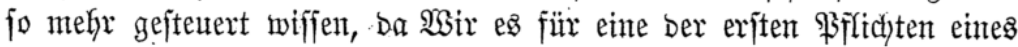

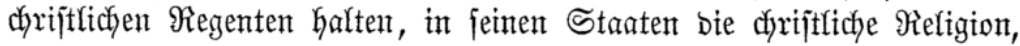

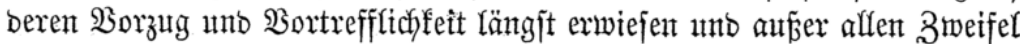

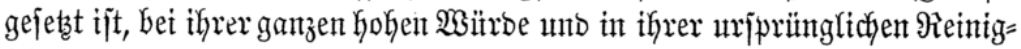
feit, fo wie fie in ber $\mathfrak{B}$ ibel gełehrt wirb, und nach oer Heberzentgung einer

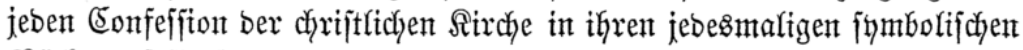

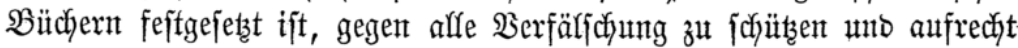

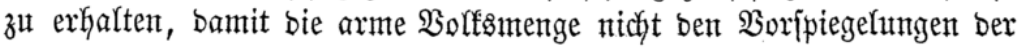
Mobelehrer preizgegeben, und baburch ben Mitfionen Unjerer guten 
Unterthanten bie Rufhe ihres Rebens unt ihr Iroft auf bem Sterbebette nicht gerautbt, unb fie aljo unglüfffich gemtacft werben."

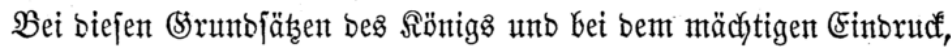

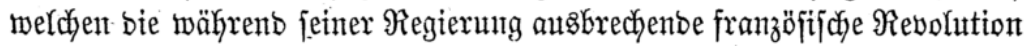

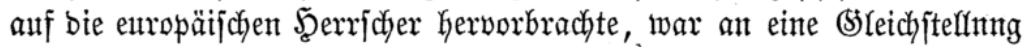
ber jübifdyen Unterthanent mit ben chriftlichen unt fo wentiger zut benfent,

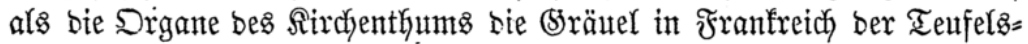

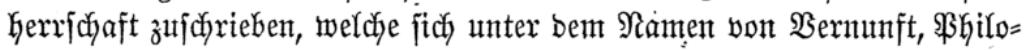

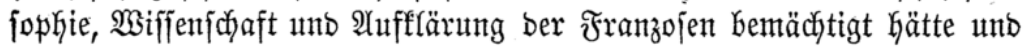
mit gleichen (Stefahren für Thyron and Sirche ïberalfhin einbringen werbe,

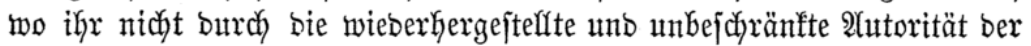
c)riftlichen Sirche ein unbefiegbarer Damm.entgegenjtege.

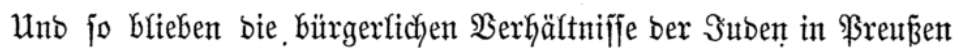

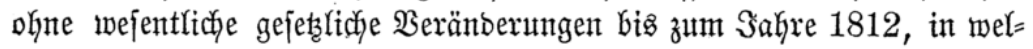
d)em bas (5bift vom 11. März erjojien.

"Mein ganzes Syjtem," jagte Şarbenberg in ber Serjammlung ber ftäntbifchen Deputirten am 23. Februar 1811, in welcher itber bie geeig= netjten Mittel zur $\mathfrak{B}$ efriebigung ber Bebürfniffe bes Staates berathfchlagt wutrbe, "berutht barauf, bå jeber Ginnofhner bes Staates, gänzlich fret,

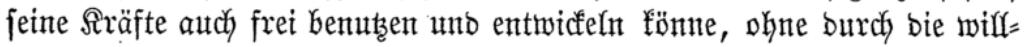

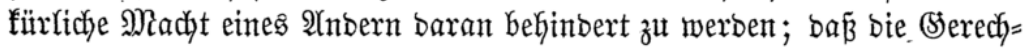

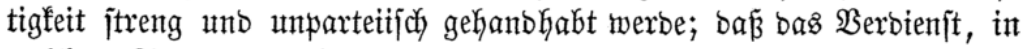
welchem Stande es fich fintoe, angehintort emporjtrebent fönne; unb ba

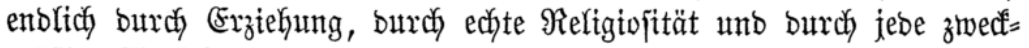

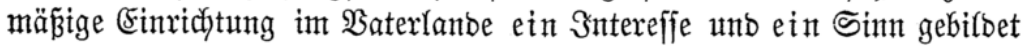

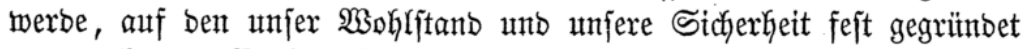
werben fann. (5:s bebarf für Sie feiner Schilberung bes exlittenen $\mathfrak{U n}=$

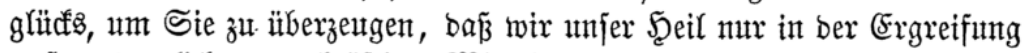
autEerorbentlidjer unt fräftiger Mittel finben fönnen. zum Trojte gereichen, bå bieje Mittel vorhanben fint, wenn wir fie, wie Mä̈ner, benen nicht zu flagen, aber zu hanbeln unb Dpfer nicht zut fóheuen geziemt, mit Mith ergreifen. Sie liegen aber feintegnegz affein in bem

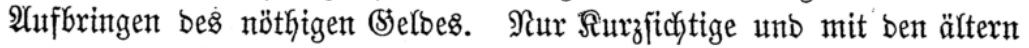
unt neurern Begebenheiten nicyt vertraute $\mathfrak{B}$ eobachter fönnten bies ver=

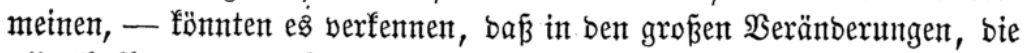
affenthalben um uns her vorgingen, laute 2 (ufforberungen liegen, niḑt zu

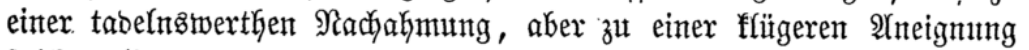
folcher Ssrunbjätze, Berfaffungen unb Einridytungen, weldye aus bem Fortidreiten bes menfdiliden Seiftes unb ben veränberten 
Infichten ber Dinge forgen, gegen bie bas श्रlte fich vergeblich zut exhalten jtrebt."

Ätฉ biejem Syjtem, welchem Prenken feine Wiebererbebung ver=

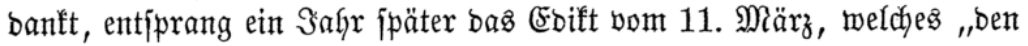

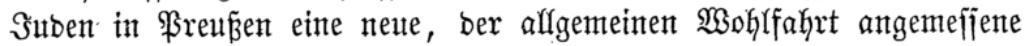
$\mathfrak{B}$ erfaff ung ertheilte" und in ben $\S \S .7$ it. 8 bejtimmte:

§. 7. Die für Finlänber zu achtenben Эuben follen, in fofern

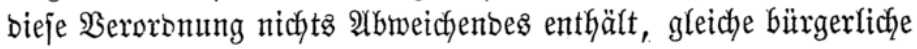

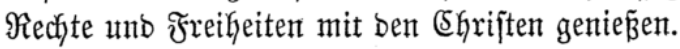

§. 8. Sie tönnen baher afabemifche Relyx= unb Schul=, autch

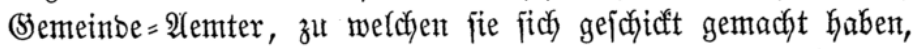
bertwalten.

Der Schwerpunft biefez (5bifts liegt barin, bä bafjelbe nicht ben

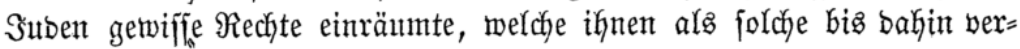

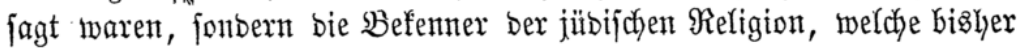
als Frembe nur gebulbet unb gejüjüţ̧ waren, für Einlänber erflärte,

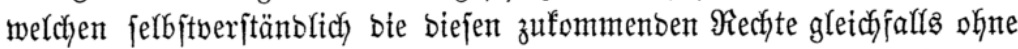

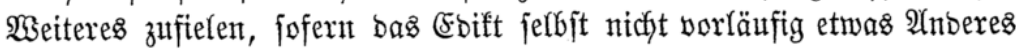

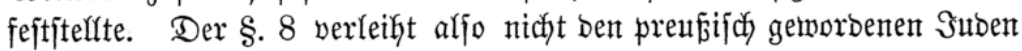

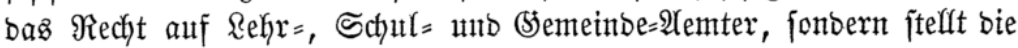
Befähigung zur Bertwaltung biejer 2 (emter burch bas Wort "Daker" Yebig= Yich) als eime ber viełen Sonjequenzen auf, welche zu ben 2 (ttributen ber (5inlänber gehören unb ben Suben gar nicht anbers twieber entzogen twer= ben fönnen, ałs wenn iłgre Qualifif́ation als Einlänber (\$. 7) in Frage gejtellt wirb.

Die Thatfache, bie fdyeinbar baş Stegentheil betweifen fönnte, möbte für biefe aufgejtelfte Behauptung bas fajlagenbjte Moment fein. Die

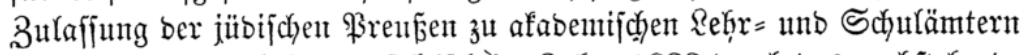

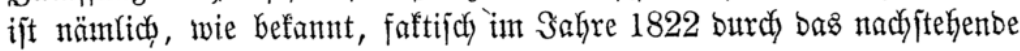
ßublifandum aufgehobent worben:

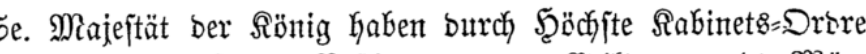

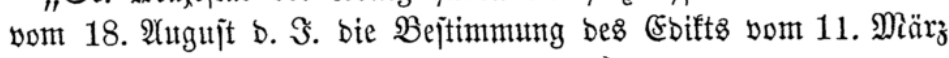
1812 §§. 7 anb 8,

wonnady bie für (sinlänber zut actytenben Sttben $z^{\mathfrak{u}}$ afabentifden

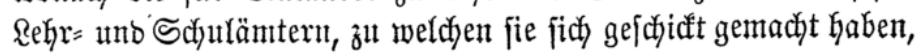
zugelaffent werben follen, 


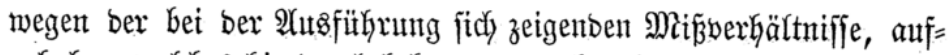
gehobent, weldyes hierburd befant gemacht wirb.

\section{Berrin, ben 4. Dezember 1822.}

Röniglictes Bjekeimes Staats= Minijterium.

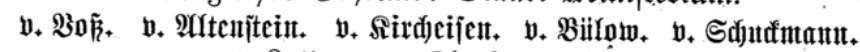

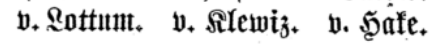

(5s ifit bereits bei ben Berhanblungen bes Eriten 2 ereinigten Rand=

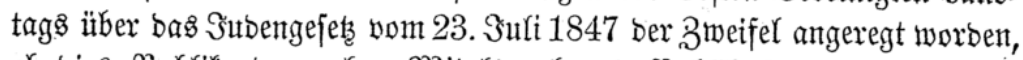

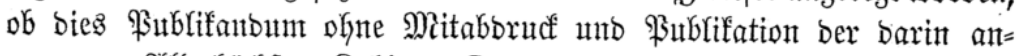

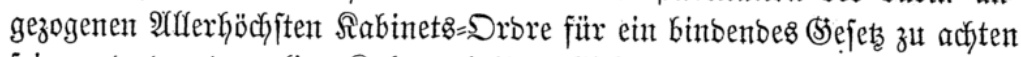

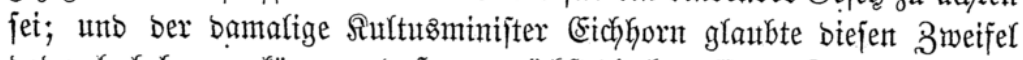

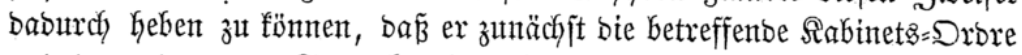

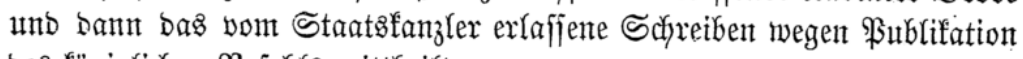
bes föniglichen $\mathfrak{B}$ efehls mittheilte.

Die Rabintets=Drbre lautet:

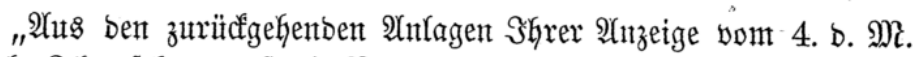

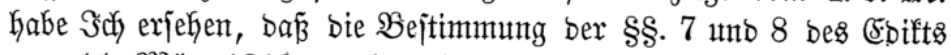
vom 11. Märr 1812, nach meldyer bie für (Eintänber zut achtenten Suben zut afabemifchen Rehr= und Schutämtern!, zut melchen fite fich gefdjifft gemacht haben, zugelaffent werben folfen, nicht, ofne grope

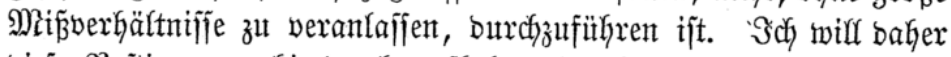

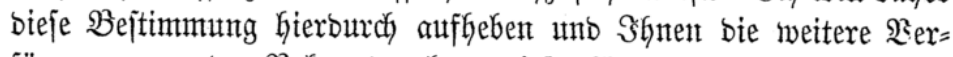

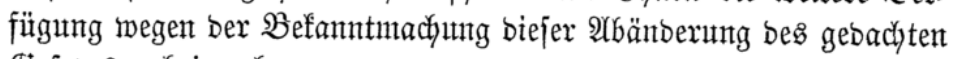
(S) efetzes antheimgebent.

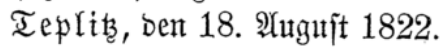

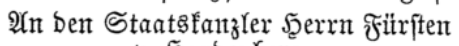
v. Şarbenberg.

(gez.) ซrriesrid) Miłleelnt.

Die 3ujendung biejer Rabints=Drore begleitete ber Stoatsfanzler mit folgentom Schreiben:

"Se. Majejtät ber Rönig haben burdy bie unterm 18. Nutguft c.

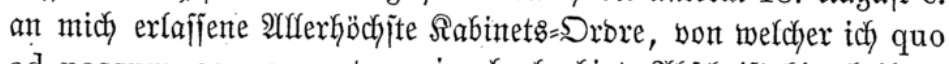
ad passum concernentem eine beglaubigte $\mathfrak{A} b$ fdyrift Gier beilege,

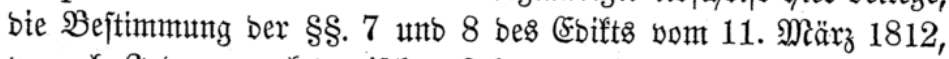

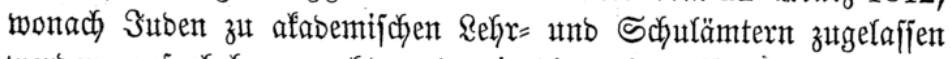

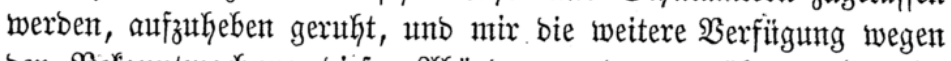

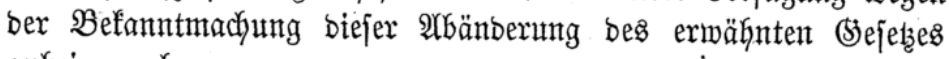
ankeimgegeben.

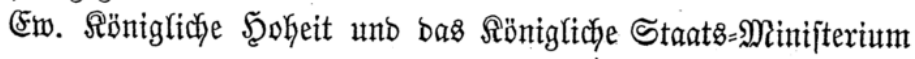


erjuthe idy hiernach gehorjamit uno ganz ergebenjt, jene angeoronete Befantmachung gefälligit zu bemirfen.

Berona, ben 19. Dftober 1822.

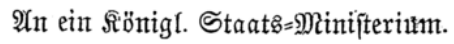

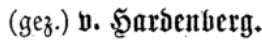

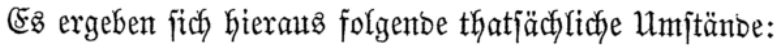

1) Die Sönigliche Sabinets=Srbre ift nicht an bas Staatsminifite= rium, jonbern an ben Staatgłanzler gerichtef, unb biejem nidyt befohlen, biejelbe in ber Bejetzammlunt befannt zu machen, jontoern sie weitere Berfügunt wegen ber $\mathfrak{B}$ ef anntmachung - nicht ber Rakineţ=Drbre -

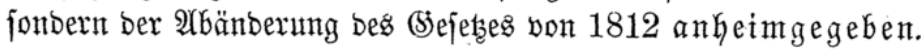

2) Dem Staatamtnifteriunt ift nicht bie betreffenbe fïnigliche $\Omega \mathfrak{\Omega a b}=$ nets= Drore yom Staatzfantler mitgetheilt, jonbern eine aus einer Sabinets=

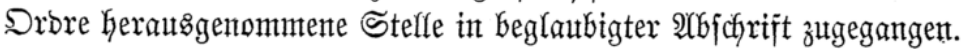

3) Äber auch bieje aus bem Bujammenthange herauggenommente

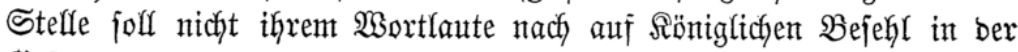
(5ejetziammlung publizirt merben, fonbern es wirb nur Se. Sïnigliche

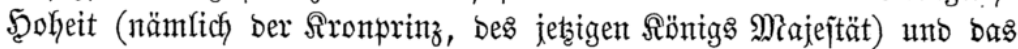
Staataminifterium gehorjamit und ganz exgebenjt exjudyt, bie angeorbuete $\mathfrak{b}$ efanntmadyug gefärligit zu bewirfen.

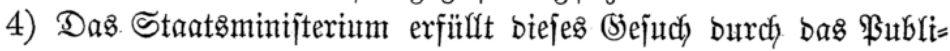
fanbum vom 4. Dezember in ber Stejetsjammlung, theilt aber nicfit etwa bie betreffende Sönigliche Sabinets=Drore mit, fonbern erffärt nur, was biejelbe ihrem 3nlyalte nach bejtimme.

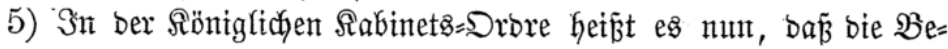

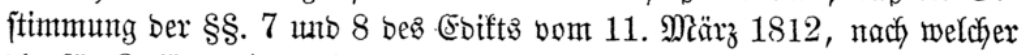

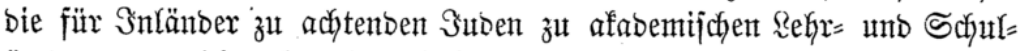

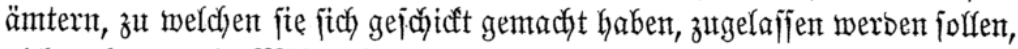

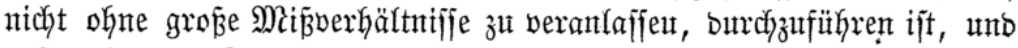

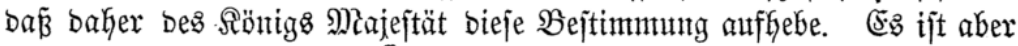

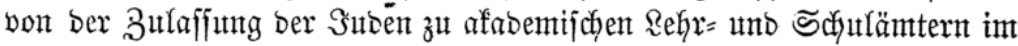

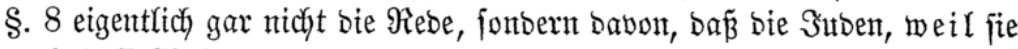

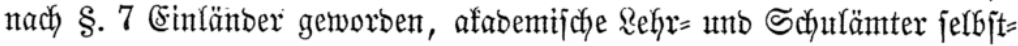
verjtänolich. verwalten tönnent. Solfen fie bies nicht mehr fönnen, jo

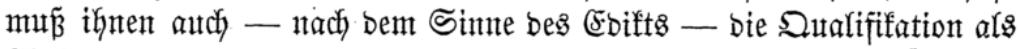
Finlänber wieber gentonment werben; unb jo erffärt ęి jich auch, warum ber $\S .7$ in bie $\Re a b i n t s=$ Drbre hereingezogen werben mufte.

Nicht baburch, bã eine Bejtimmung in ber Sejeţammlung $\mathfrak{a} b=$

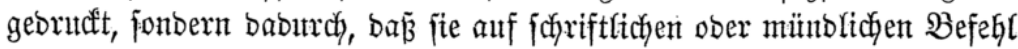
bes Rönigs in berfelben veröffentlidyt worben, wirb jie ein binbendes (s)e= 


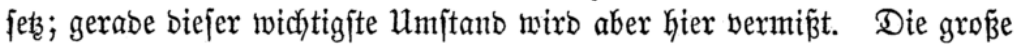

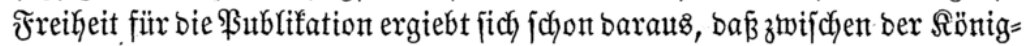

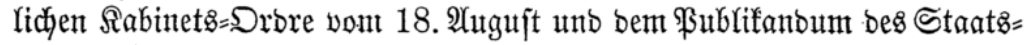
minifteriums vom 4. Dezember vier Menate liegen, eine Beit, welche

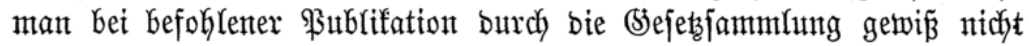
hätte verftreidyen laffent.

Die Sache nuti baher als fo liegend betrachtet merben: Der Staats= fanzler hatte an ben $\Re \ddot{n} n$ ig einen Beridyt erjtattet, in welchem er unter

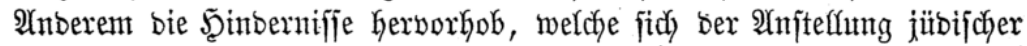

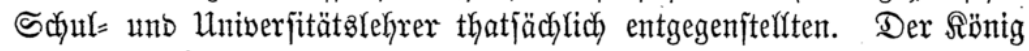
genehmigte ăuf (brund beffen, baß̉ eine befanntmachung erfolge, weldhe bie 2 uffhebung ber betreffenten $\mathfrak{B}$ ejtimmung im Ebift von 1812 mittheilte. Fis war aljo im eigentlichen Sinne nidyt bon einem nenen Sejets bie Rebe, fonbern nur von einer Sïnigl. Ermächtigung ber Âtbminiftratibbehärben, bie

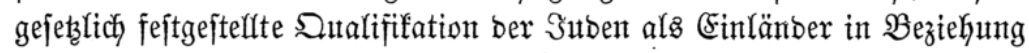
auf ihre B̧efähigung zu afabemifchen Rehr = und Schutü̈mtern nicht weiter zu berǚffichtigen uno bieje Ermädytigung befannt zu madyent. Şiermit war aber bem ganzen cobifte von 1812 fein fejter $\mathfrak{B}$ oben entzogen; unt

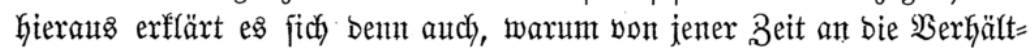

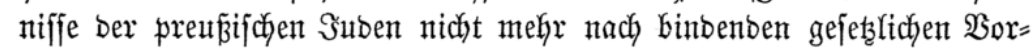

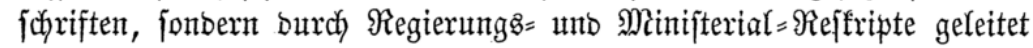
murben.

Was aber war benn in ber 3rwifdyenzeit. von 1812 bis 1822 vor= gegangen, um jene Maßaregel bes gered)ten Friebrich Wilfhelm III. erf(är=

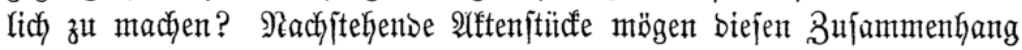
Gerjteffen.

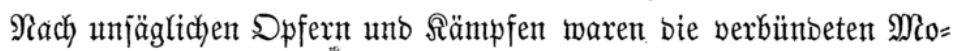
nardjen im Sult 1815 zum zmeitenmal fiegreich in \$aris eingezogen; unb noch bebor bajelbjt ber Friebe vom 20. Rovember abgejcylofjent wurbe;

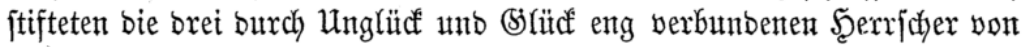

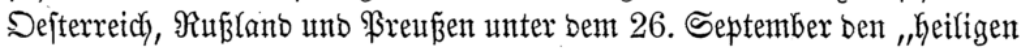
Bund", befjen Ur.funbe folgenbermaß̧en lautet:

„Şm Namen ber heifigen, untheifbaren Dreieinigfeit. Shre Maje=

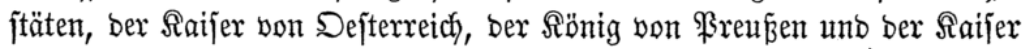

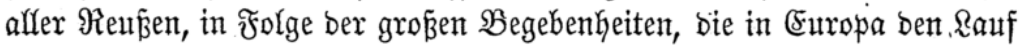

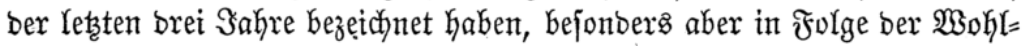

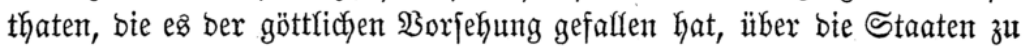

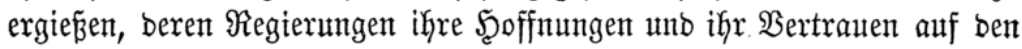
alleinigen (Sott jetzen, inbem fie bie innere Heberzengung fühlen, wie

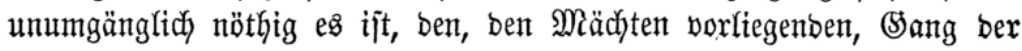




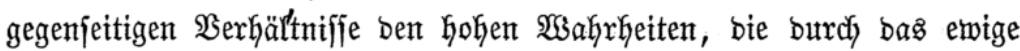

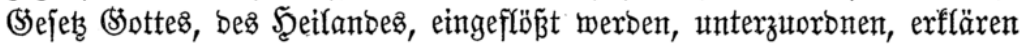

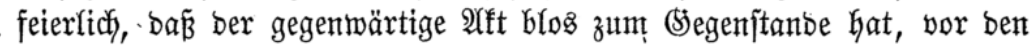

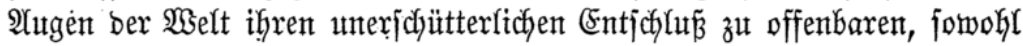
in ber Sermaltung ber ifnen anvertranten Staaten, als alt

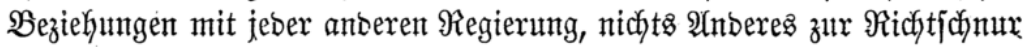

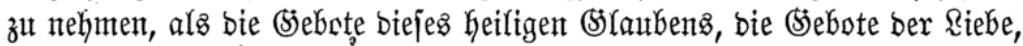

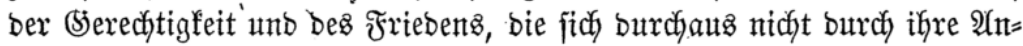

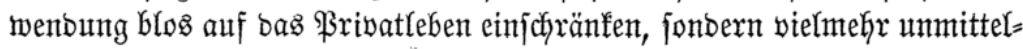

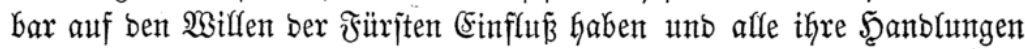

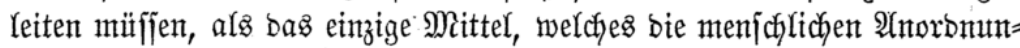

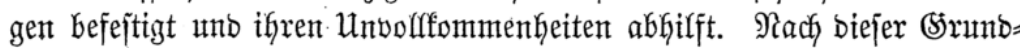
lage fint ifyre Majejtäten ïber folgenbe $\mathfrak{T}$ trtifel ïbereingefommen. 1) Den

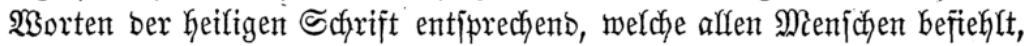
Brü̈ber zlt fein, werben bie brei fontrabirenben Monardjen, burch bie Banbe einer inahren unb inzertrennlichen Britberjafaft vereinigt, babei berbleiben und, fich als- Ranoslente betradjtent, in jebem Falfe und an jebem Drte einanber B̉eijtano, Şïlfe unb Unterjtïtsung leiften; in $\mathfrak{B}$ ezug auf ifye Unterthanen uno Truppen werben fie als Familientbäter biejelbent in eben bem Sieifte ber Brüberjdaft regieren, won weldyem jie für $\mathfrak{B}_{e}=$ wahrung ber Refigion, bes Friesents unb ber serechtigfeit bejeelt fint. 2) Diejem nach wirb bas einzige herrichente ßrinzip, fowohl zwijhyen ben erwähnten Mädyten, alz zwijod)en ifyren Unterthanen jein, einanber Dienjte

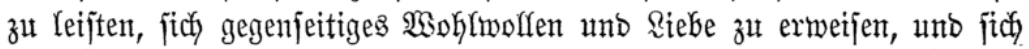
jämmtlich als eine umb biejerbe chriftliche Ration zu betrachten, indem 3) bie berbümbeten Fïrjten fich nicht anbers anjehen, als wont ber $\mathfrak{B o r}=$

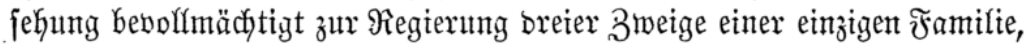

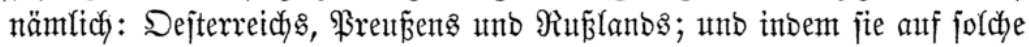

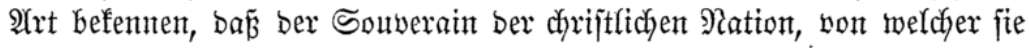
unt ifre Unterthanen einen Theil ausınadyen, eigentlidy niemant anbers ijt, als ber, bem bie Machyt eigentfyümlich gehört, ba blos in ifm bie

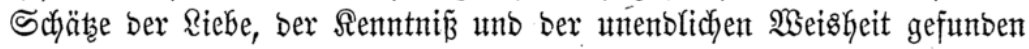

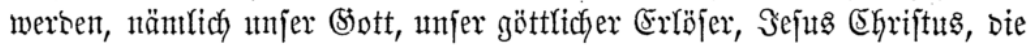

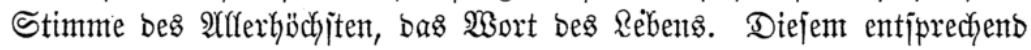
entpfehlen ifyre Majejtätent mit ber zärtlichjten Sorgfalt ihren Unterthanen,

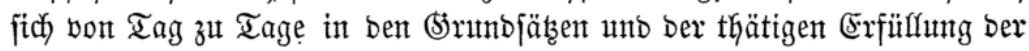
Bflichten zu befeitigen, in benen ber göttliche (Exlöfer bie Menfdyen unter= richtet hat, als bas einzige Mittel, ben Frieben zu gentefsen, ber aus bem guten (5erviffen entipringt, unb ber affein bauterkaft ift. 4) Iffe siejentigen Meächte, welche bie im gegentwärtigen 2 ffte auseinanbergefeţten Keiligen 
(5runtofätze feierlich anerfennen wolfen, und weldye fithlen, wie nöthig es

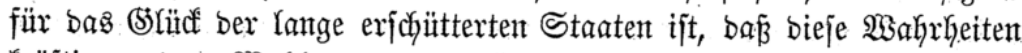

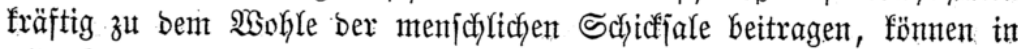
affer Riebe in biejent heifigen Bumb mit aufgentomment werben.

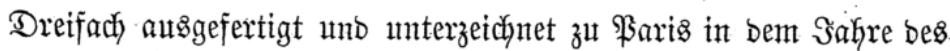
Segents 1815 , Dent $\frac{26}{14}$. September.

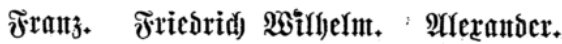

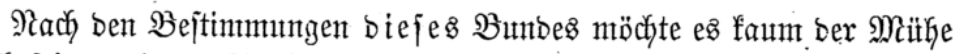
werth fein, auf Den $\mathfrak{A}$ rtifel 16 , Der einige Monate früher (ain 8 . Sunt 1815) unterzedcyneten beutichent Bumbesafte aufnterffant zu madjen, went

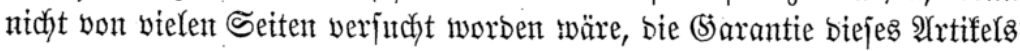

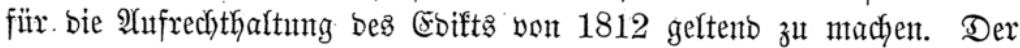
Artififel 16 lautet:

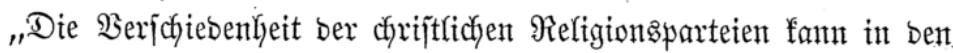

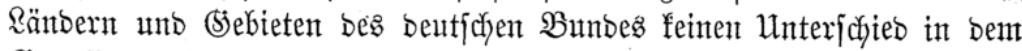

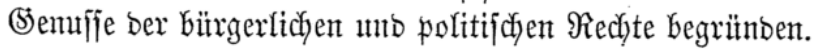

Die Bunbesverjanmlung wirb in Berathung ziełent, wie anf eine

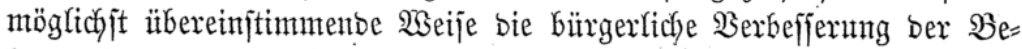
fenter bes jübifchen (5) faubens in Denticyland zu bemirfen fei, unb wie

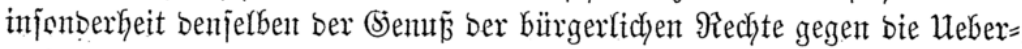
nahme affer Bürgerpffichten in ben Bumbesitaatent verfdyafft unt gefichert werben föme; jeooch werben ben Befennern biejes STaubens bis bafin

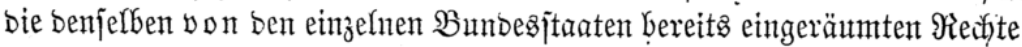
erfialten."

Der beutiche Bunbestag ward am 5. November 1816 in Franffurt

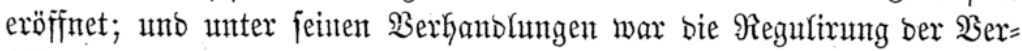

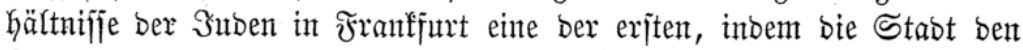

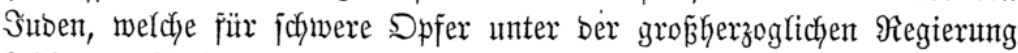

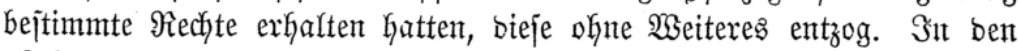
"Rebenzbilbern aus Dem Befreiungátriege". I. 183 ivirb ein Brief eines Staatsmannes an ben Srafen Münjter mitgetbeilt, welcher atts Wies= baben am 31. Dctober 1817 batirt ift unb nachjtehenbe ?iotiz enthält:

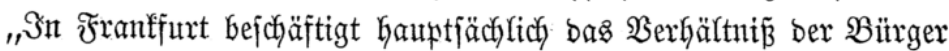

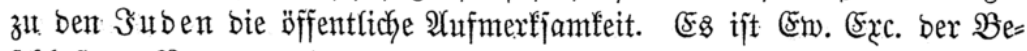

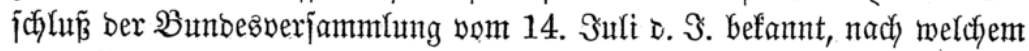

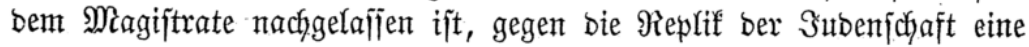

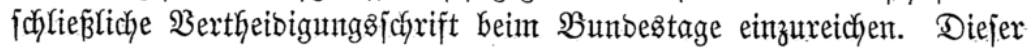
Beptimmung wax zugleidl die đilaufer angehängt, 
Dá̉ in biefer bei ber Bumbezberjammlung angebracten Sache weber in bem bermaligen Stanbe, noch im $\mathfrak{B}$ efits währent jolcher

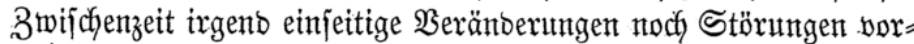
genommen twerben bürften.

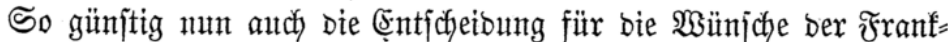
furter Bïrgerjchaft ift, indem baburch borläufitg bie $\mathfrak{B}$ erfïtgung bez Magi=

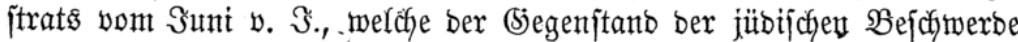

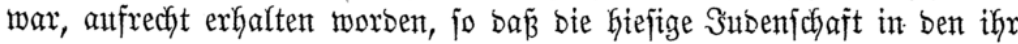

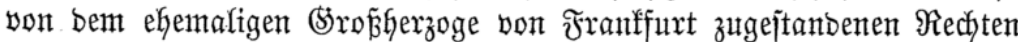
bebentent bejchränft bleibt, unb fo nothwendig und gerecht es gemí jebem

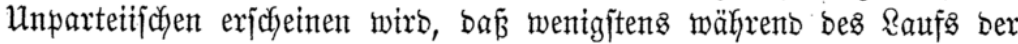
Berfjanthungen ber bermalige. Stand unt Befit burch weitere legiglato=

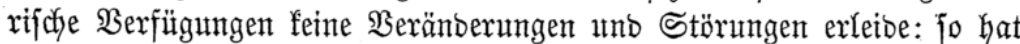

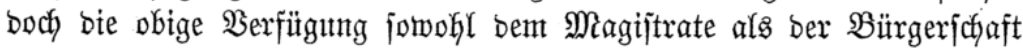

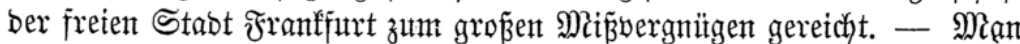
hat nämlich barin,

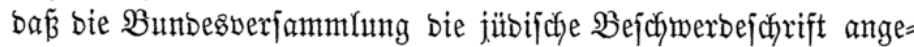
nomment und fich eine (Enticheibung vorbegalten, altch weitere legis= latorifiche Berfïgungen unterjagt hatte,

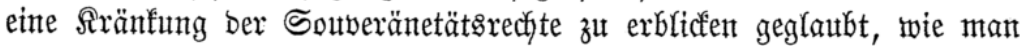
benn in $\Re$ epublifen unb fleinen Staaten immer eiferjü̈btiger auf bie ver=

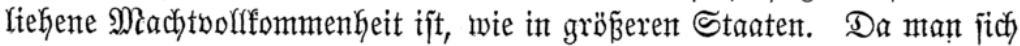
inbeffent bod fichentet, bie Rompetenz bes Bumbestags gerabe zu beztwei=

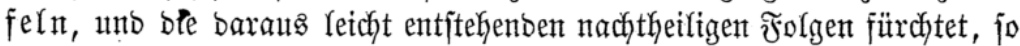
hat ber Magiftrat verjucht, fich mit ber hiefigen Subenjuaft ïber bie ihr fünftighin zu berleikenben $\Re$ echte zut vergleichen, unb ein nettes Statut in

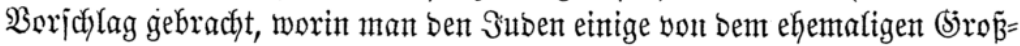
herzoge vont Franffurt zugejtanbene Rechte beftätigt, anbere aber aufge= Goben hat.

Bei ber grofien (Erbitterung, bie hier gegen bie Snben herridnt, hat inbeffen jenes Statut, wie es bem gejetggebenden Sörper zur berathung vorgelegt worbent, bie größ̧te unt lautefte Mifiß̧bilfigung erhalten, ja bie

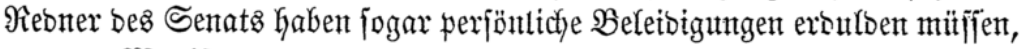
und ber Magifitrat, um nidjt gänzlich unpopulär zat merben, hat jidy ge=

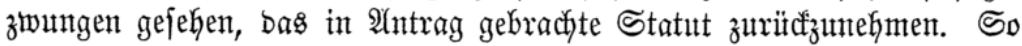

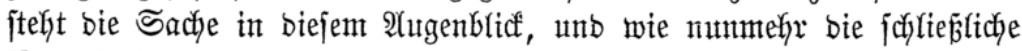

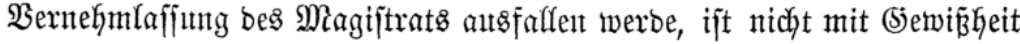

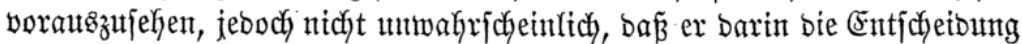
ber Bunbegverjammlung als nicht zu beren fompetenz gehörenb ablehnen werbe, ein Schritt, ber, went er exfolgt, nothwendig bie Sache ber Stabt 
jefyr verfalimmern muta. Die Ângelegenheit ber Subent wiro überhaupt mit einer gropen, gegenfeitigen Erbitterung betrieben, unb wenngleid) nidft

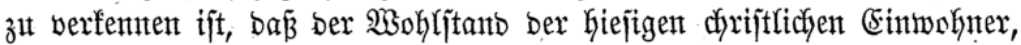
wollte nan ben Suben bie ifnent vom ehemaligen (5roßßherzoge von Frant:

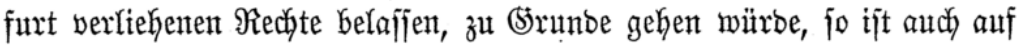

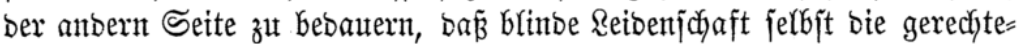

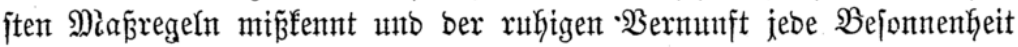
nimmt. Hebrigens aber érfreut man fich hier ber ben Suben im âffge=

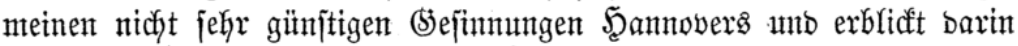

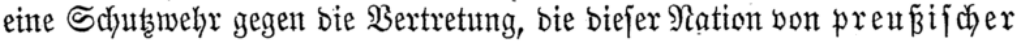
Seite angebeigt, und bie reiber jehr unreinen Triebfebern zugejdyrieben

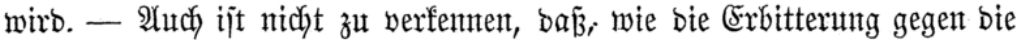

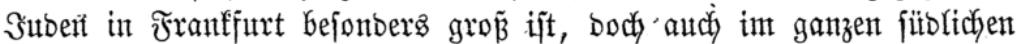

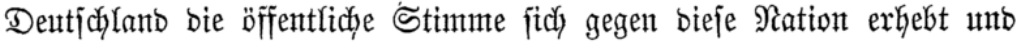

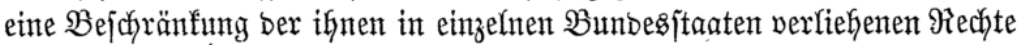
laut berlangt."

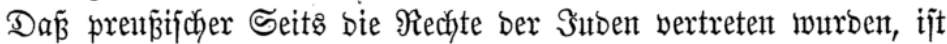
barum bon Snterefie, weil in

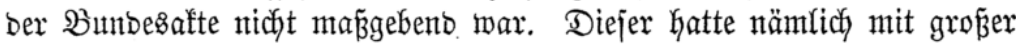

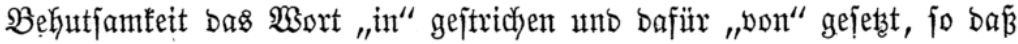
nicht bie in ben einzelnten $\mathfrak{B}$ undesfitaatent, fonbern mux bie von bent ein= zelnen $\mathfrak{B}$ unbeşfaaten ben Suben eingeräumten Rechte exhalten werben

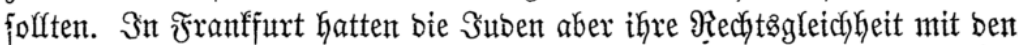
dyriftlidjen (Slaubensgenofien nidft bon bem neuen Bunbesjtaat befom=

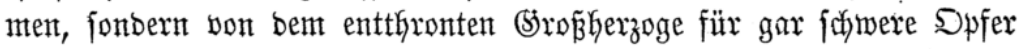
erfauft. Nan hatte ja auch \$rentien beim Friebents; genonnen, in weldyen unter ber Frembkerridjaft bie Suben böltig entan= zipirt worben waren; unt es ftant zu hoffen, bå ber gerechte Sïnig,

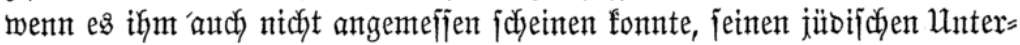
thanen ber netterworbenen \$rovinzen biejen Bollgenur ber bürgerlidjen

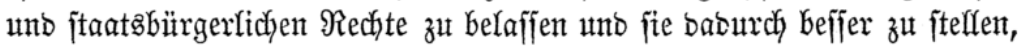

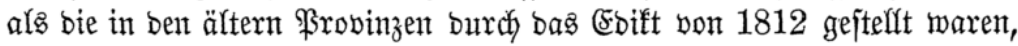

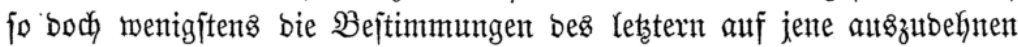
genteigt fein werbe. Dies wäre aber eine Fortjeţung besjentigen politijchen Syjtems gewejen, bem bas gebemütfigte unb verfleinerte \$rentent fo eben

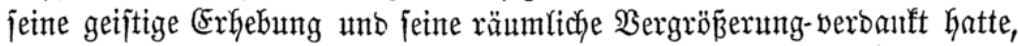

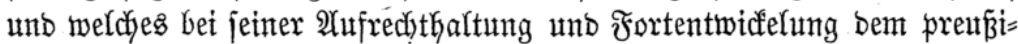

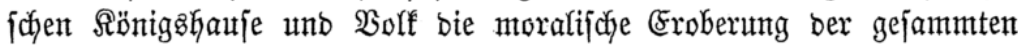

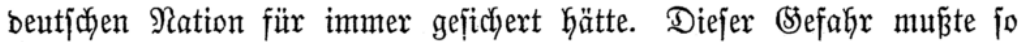
fräftig uno fo fdjleunig als möglid, von Seiten ber faljchen Freunbe ber 
Dhna ben; und es gab zu biejem Zwect wohl fein jidjereres Mittel, alz baß

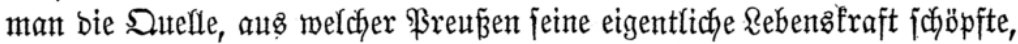
zu berjumpfen und bie ßulzabern, welche baffelbe mit einem affe Bslieber belebenben Strom burchbrangent, zu burchjachneiben verjud dyte.

2Uuf (semififens= umb Denffreifeit war bie Macht bes protejtantifden \$reufiens gegrünbet, unb bie Sraft biefer beiben Seeber wurbe in ber Beit

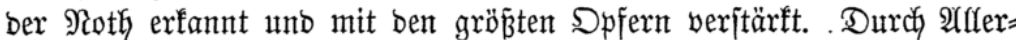

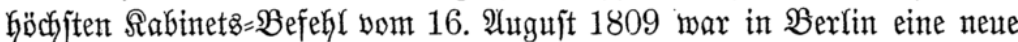
Unniberjität geftiftet, welche in Dftober 1810. iłgre Thätigfeit begann.

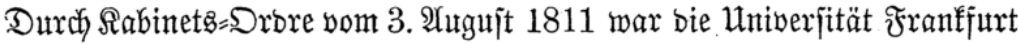
mit ber zu Breslau zut einer vereinigten uno baher befjer funbirten

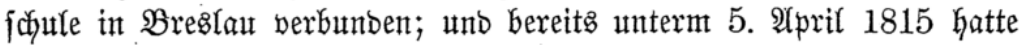
Friebridy Withelm III. in einem an bie (Fintwohner ber mit ber \$reu $\tilde{\beta} i=$

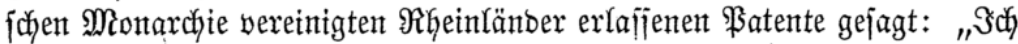

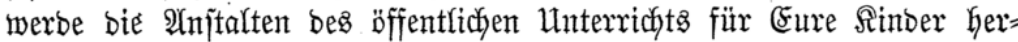
ftelfen, bie unter ber vorigen Regierung fo fehr vernachläfijigt wurben.

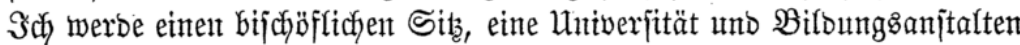

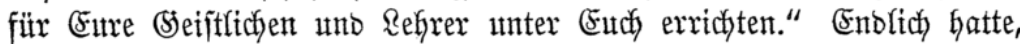

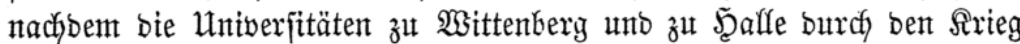
theils zeriprengt, theils aufgehoben morben waren, Se. Majeität ber

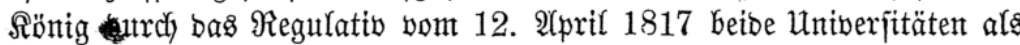

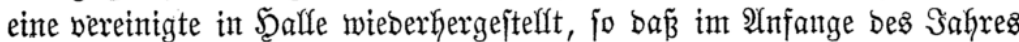

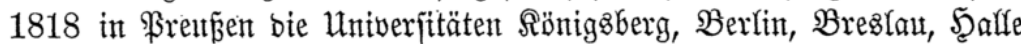
in volfer $\mathfrak{B}$ lütthe waren, bie Univerjität zat Mïnjter noch exijitirte, bie

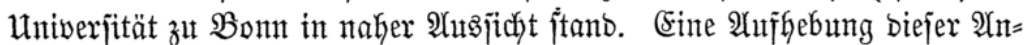

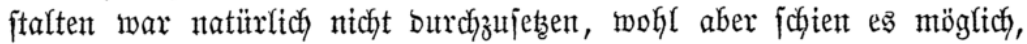

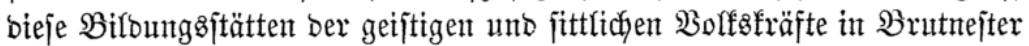
ber Berbummung und ber Berfinjterung umzutwanbeln. Belang biefer

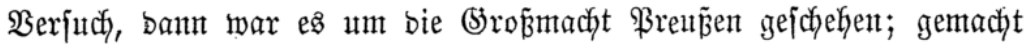
mupte er aber werben, und bie erjte Belegenkeit bazu bot ber-Geborjtehende

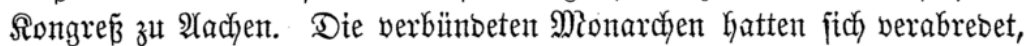

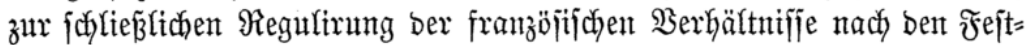

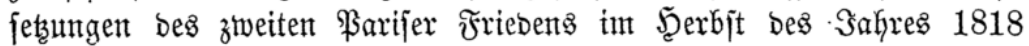

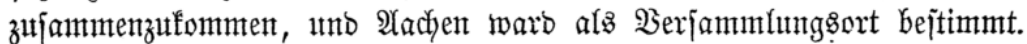

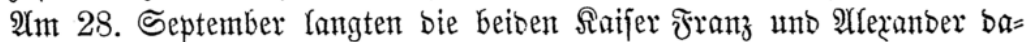

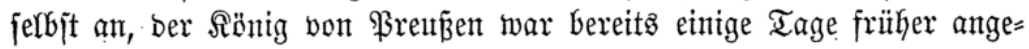
fommen. Englano und Franfreicy maren burch \$sejante vertretent.

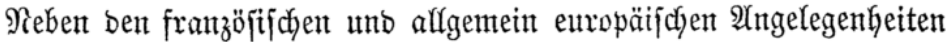

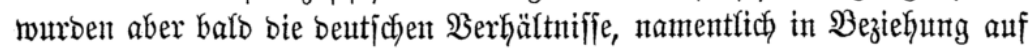




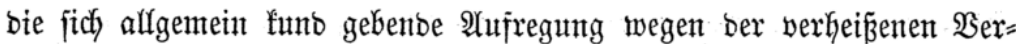

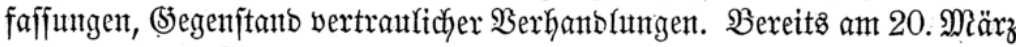

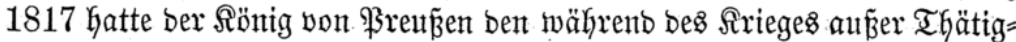
feit gejetzten Staatsrath auf's Reute begrimbet unb burch Rabinets= Drore

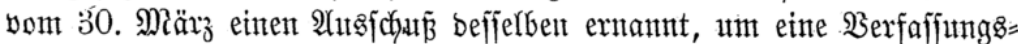
urfunbe nach ben in ber $\mathfrak{B e r o r b m u n g ~ v o m ~} 22$. Mai 1815 ausigefprodjenen

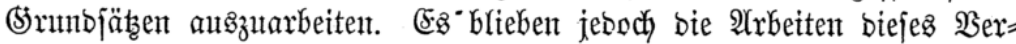

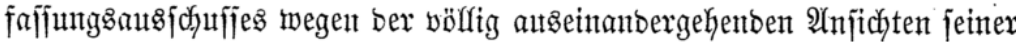
Mitglieber erfolgloz. Die Einten (Fürit Wittgenftein, Schudutnann, von Brodffaujen, von ber Sinejebedf und von Savigny) behaupteten, Freußen miiffje wegen feiner Rage ein Mititärjtaat bleiben, unb bazu bebürfe ęి vor allem eitter Einheit bes Entichluffes und einer Freikeit bes Şanbelns, welche burch jtänbijche Serjammlungen nur gehenmt unb gelähnt werben witrben. Die Átnbern (Sneifenaut, Boyen, Srolmann, Beyme, $\mathfrak{B} . \mathfrak{v}$. Şumbolbt, Stägemann und (Eich)horn) waren umgeféfyrt ber Meeinung:

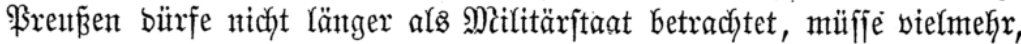

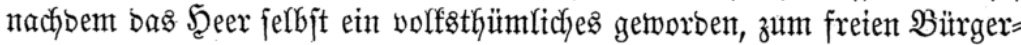

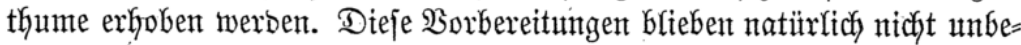

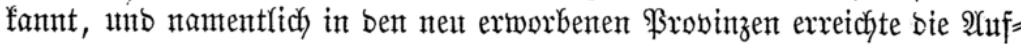
regung, um bie ફ̧inbernifje unt bie F̧inbernben z̆ bejeitigen, einen er= fdyredfenben (Stab. Das befannte $\mathfrak{3 a r t b u r g f e j t ~ v e r b r e i t e t e ~ b i e ~ A ̂ t r e g u n g ~}$ nach affen Theilen Dentjchlanbs unb namentlich nach ben Uniturjitäts= ftäbten, wo bie jungen Männer, welche bie Befreiung Deutfdhlandos vom

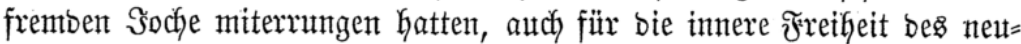
exjtanbenen beutjchen $\mathfrak{B a t e r l a n d s}$ glïhten unt jadwärmtent.

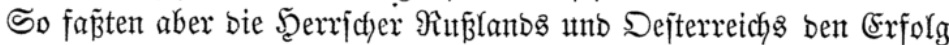
bes wiebererrungenen orriebens nicht auf; beibe wollten ben Drudf, welchen bie Frembkerrichaft auf ihre Miacht auggeitbt hatte, unb ber burch bie

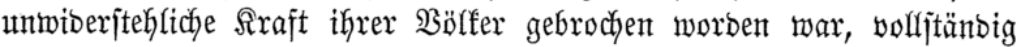

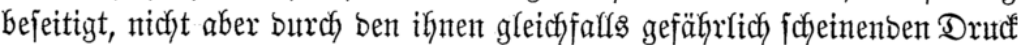

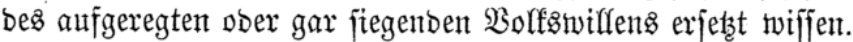

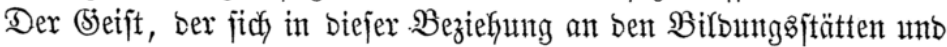

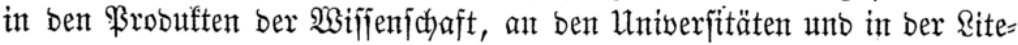
ratur, funb gab, exjchien baker alo berjenige reino, bent zunächjt ber ver=

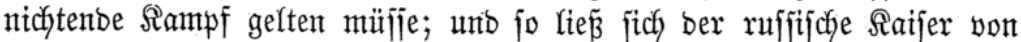
jeinem in $2(a c h e n$ antwejenben Staatzrath Stourbza ein hanbjofriftlidjes Mémoire (sur l'état actuel de l'Allemagne) ïberreidjen, in meldyem bie 3uftänbe Deutfd)lanos für traurig uno fo lang für hoffnungslos

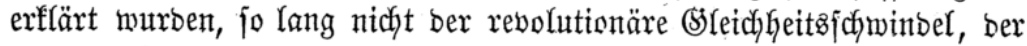

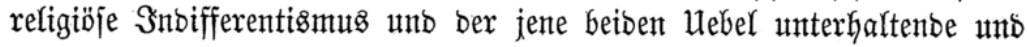


förbernbe 3uftand bes öffentlichen Unterridyts mit aller Sraft bejeitigt twürbent.

Die betreffenden Stelfen biefę Mémoire'z lauten:

„Les causes de l'agitation qui règne en Allemagne, et qui, tôt ou tard, pourrait devenir une explosion, sont:

1) Le déplacement universel des individus et des classes, fruit immédiat de la révolution;

2) Le vague et la désorganisation des idées religieuses, devenues le premier besoin de l'humanité souffrante, et par conséquent l'arme principale de la passion et de l'erreur;

3) Les vices toujours croissant de l'éducation publique, devenus énormes, et tels, que le système de législation et d'administration le plus parfait ne saurait leur servir de correctif.

C'est de ces trois sources majeurs qu'émanent en raison composée tous les maux qui affligent en ce moment l'Allemagne, et qui pourraient un .jour y bouleverser les droits, les conditions et les pouvoirs.

Ad Primum. Déplacement des autorités, des individus et des classes.

De cet ébranlement général, qui a été si prodigieux, qu’il a fait croire à un accroissement énorme de la population, malgré les dévastations et les guerres, sont dérivés:

1) Un désir vague d'activité qui doit être satisfait au-dedans, pour que cette activité ne s'épanche pas au-dehors;

2) Une tendance des classes éclairées vers l'unité politique de l'Allemagne;

3) Un mécontentement prononcé des classes inférieures, fatiguées de changer de maîtres, et courbées sous le poids d'une administration compliquée, plus onéreuse pour les peuples que féconde en résultats bienfaisans. Ces échafaudages, si peu proportionnés à la petitesse des édifices, constituent le legs que le régime français a fait à l'Allemagne.

Ad Secundum. Vague et désorganisation des idées religieuses.

En Allemagne plus que partout ailleurs, la science est de bonne foi; mais long temps reléguée dans la sphère des abstractions, elle est, plus que partout ailleurs, dénuée d'expérience. La religion, plus que partout ailleurs, y est devenue un besoin urgent; mais, à force de tâtonnemens, de rivalités et d'excès, elle est devenue un bien aussi précieux qu'indéfinissable. 
La réunion des églises réformées fournit une preuve de la vérité de notre assertion.

Lorsqu'on l'envisage comme un acte de fraternité et de paix, cette réunion mérite tous les éloges; mais, pour peu que l'on veuille $\mathrm{y}$ retrouver dès. à présent les caractères d'une réunion effective et mentale, on ne tarde pas à reconnaître que ce grand résultat ne peut être amené que par l'enseignement uniforme. d'une même doctrine, ainsi qu'il est question de l'introduire dans les pays de Nassau; car on ne saurait supposer que les généreux protecteurs de cette réunion puissent jamais confondre, en matière de religion, le principe conservateur de la tolérance chrétienne, avec les maximes funestes de l'indifférence.

Dans certaines parties de l'Allemagne, l'église chrétienne est livrée à un relâchement des disciplines au-dedans, qui offre le plus pénible contraste avec l'activité inquiète qu'elle manifeste au-dehors. Ailleurs, l'église n'est presque plus qu'une école. Sa faiblesse s'accorde mal avec le zèle inconsidéré des uns, et ne saurait tenir tête à l'animosité des autres. Partout les moeurs publiques, attaquées dans leurs sources, les institutions civiles désorganisées, vilipendées, imparfaites, 'appểllent à grands cris la religion, et soupirent après le raffermissement de son influence salutaire.

Ad Tertium. Vices de l'éducation publique devenus si énormes, que le système de législation et d'administration le plus parfait ne saurait leur servir decorrectif.

Cette dernière thèse, une fois développée, qui pourrait s'étonner encore de la grandeur des maux: récapitulés dans les deux précedentes, puisque le seul principe réparateur qui semblait pouvoir remédier au bouleversement des idées sociales et réligieuses, est lui-même le mal le plus invétéré de tous.

Pour juger du degré de perfection d'un gouvernement quelconque, il suffit d'observer l'influence qu'il exerce sur l'éducation publique. L'école rend témoignage au trône, et celui-ci atteste par le fait la bonté de l'éducation. L'antiquité tout entière rendit hommage à cette vérité fondamentale. Les constitutions des peuples anciens n'étaient que d'ingénieux systèmes de pédagogie, privés du flambeau de la religion chrétienne. Quelles qu'aient été leurs imperfections, le principe demeure immuable. Le berceau de Moïse, flottant sur les eaux du Nil, renfermait les destinées 
d'Israël; ou, en d'autres termes, le berceau des générations nais: santes devient le vaisseau de l'état.

Or, contemplons l'Allemagne sous ce point de vue important. , L'éducation préparatoire, quoique desorganisée par le malheur des temps, n'y est pas entièrement défectueuse; mais elle n'agit que sur cette majorité toujours passive qui n'a jamais fait les révolutions: d'ailleurs, tout aspire à étudier en Allemagne. De pauvres artisans se privent souvent du strict necessaire, pour réussir à perdre leurs enfans dans les universités. En effet, que sont-elles aujourd'hui, ces universités? Débris gothiques du moyen âge, incompatibles avec les institutions et les besoins du siècle où nous vivons; corporations sans objet qui forment un état dans le sein de l'état, elles sont animées d'un esprit de corps et de présomption héréditaire, qui ne sert qu’à égarer la jeunesse, à dénaturer l'esprit publique.

Répertoires de toutes les erreurs du siècle, les universités reproduisent et perpétuent toutes les doctrines mensongères, dont une funeste expérience a déjà désabusé la plupart de leurs contemporains. Elles sont maîtresses absolues de l'avenir d'une nation entière; et nul gouvernement ne leur demande compte de l'essence, de la méthode de leurs instructions. Les lettres, les sciences, le barreau, l'autel même, tout leur est confié, et rien ne garantit leur fidélité à administrer ce patrimoine des états. Livrées à une indiscipline totale, les universités sont tous les jours à la veille de se dissoudre; et si quelque chose les soutient encore, c'est, d'une part, l'attrait séducteur d'une liberté dite académique, et, de l'autre, l'étrange système de plusieurs gouvernemens d'Allemagne, qui s'obstinent à envisager une université comme une spéculation de finances propre à attirer du numéraire dans leur pays.

A ce prix, tout est licite dans les universités. La jeunesse, soustraite à l'empire des lois, se plonge dans tous les excès qui dérivent de la rébellion de l'esprit et de la corruption du coeur. Elle ne commence pas la carrière de la vie par un exercice d'obéissance, qui seul apprend à commander un jour; mais elle apprend à tout tenter, à tout se permettre dans l'âge de l'obéissance, afin de ne rien respecter, de tout bouleverser dans l'âge mûr. Chose incroyable! les états les plus démocratiques de l'antiquitétenaient inflexiblement à la discipline de la jeunesse; et ce sont, de nos jours, des états monarchiques qui émancipent 
l'homme de la nature, pour mieux discipliner l'homme de la. société."

Les instituteurs, à leur tour, enfans des mêmes principes et des mêmes écoles, ne considèrent, dans la carrière de l'enseignement, que leurs honoraires et leur popularité.

Entre de telles mains, la théologie est devenue l'antagoniste de la religion; l'herméneutique n'est plus que la profanation des saintes écritures; la médecine croit porter son scalpel jusque dans le sanctuaire de-l'âme, et la science du droit proclame le droit du plus fort. Les exceptions sont rares, et la vogue des professeurs dépend en grande partie de leur docilité à suivre le torrent. N'en est-ce pas assez pour tout subvertir? Et ces causes continuant à exister dans toute leur force, peut-on se flatter du retour d'un meilleur ordre de choses; et sur tout a-t-on le droit d'attendre que la paix et la concorde soient rétablies dans le système politique et social?

Il n'y a donc qu'une réforme radicale de l'éducation, qui puisse tarir la source du mạl et présager de méilleurs temps à 'l'Allemagne. Une foule de voix s'élèvent pour invoquer cette réforme si indispensable. L'accent d'une juste indignation se manifeste jusque dans le langage de plusieurs feuilles publiques, de plusieurs brochures publiées à la suite des troubles de Goettingue. Les voeux de la partie saine de la nation, quant à la réforme des universités, se réduisent aux articles suivans :

1) Suppression de tous les privilèges académiques, qui. n'étaient bons que dans le moyen âge, et qui sont incompatibles avec la situation présente des états.

2) En conséquence, substitution de la police,municipale à la police académique. L'étudiant n'est plus, aux yeux`de la loi, qu'un citoyen mineur, qui a ḋoit à quelque condescendance, mais non à l'impunité. La surveillance des, autorités civiles deviendra tout les jour moins nécessaire, lorsqu'elle aura cessé d'être une exception.

3) Fixation irrévocable du cours d'étude pour chaque vocation avouée; obligation de le suivre sans omission ni extension quelconque, sauf permission spéciale du sénat académique, qui autorise à suivre des cours accessoires ceux que leurs facultés rendent propres à embrasser une plus grande sphère de connaissances.

4) Distinction à établir entre les cours d'études prescrits aux indigènes et ceux qui sont réservés aux étrangers. 
5) Nullité des certificats délivrés à ceux qui se destinent à l'état ecclésiastique, dès que ces certificats ne sont pas accompagnés d'un brevet de bonne conduite donné par le sénat académique et l'autorité civile du lieu.

6) Le corps des professeurs, envisagé comme une assemblée délibérante, ne doit pas avoir le droit exclusif de se renouveler par ses propres suffrages; car des professeurs en corps ne choisissent que rarement leur égal, et jamais l'homme qui leur est supérieur. Leurs-suffrages doivent être entièrement subordonnés au vote décisif du gouvernement, dont l'intérêt n'est pas celui des individus.

Moyennant ces dispositions.fondamentales, on se trompe fort, ou tout prendrait une autre face dans les universités allemandes; surtout si les gouvernemens éclairés par une douloureuse expérience, abjuraient enfin le système dangereux qui les porte à ne voir dans une université que le véhicule de leurs finances, au lieu de l'envisager comme une institution, mère de toutes les institutions sociales, qui fonde le bonheur des peuples ou bouleverse tout leur avenir.

Le premier pas vers cette réforme religieuse, scientifique et administrative de l'éducation devrait consister dans l'application de ces principes à l'université de Bonn, encore naissante, objet des sollicitudes du gouvernement prussien. L'impiété proscrite de cette institution, et la discipline introduite dans son sein, serviraient aux autres académies d'avertissement et de modèle. Après six mois de clameurs, tout se tairait devant l'évidence; et les bons parens y feraient refluer de toute part la jeunesse.

Dieu, la religion, la vérité, l'expérience, la voix de la conscience et du devoir, le cri de l'humanité souffrante, le spectacle attendrissant de la génération actuelle, que le gouffre de la révolution menace encore d'engloutir, le salut de l'Allemagne et de l'Europe, l'avenir de cet univers que le glaive du Tout-puissant purifie lorsque le sceptre des roi ne peut le gouverner; tout appelle, tout réclame impérieusement le retour d'un meilleur ordre des choses dans cette Allemagne, où toutes les calamités se concentrent, dans cette Allemagne, où l'on délibère aujourd'hui sur les grands intérêts des sociétés humaines, comme naguère on $y$ combattait pour la cause de l'Europe et du genre humain."

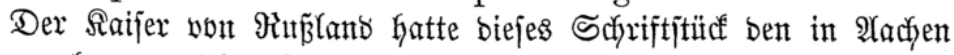

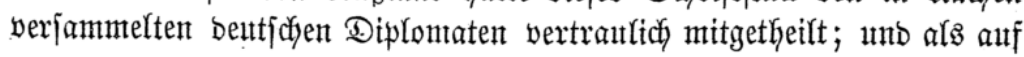




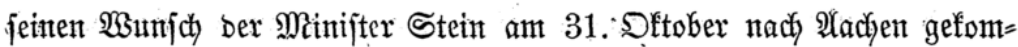
men war, wurbe auch biejer zu einer Mieinunggäunerung aufgeforbert. Diejer entfielt jich einer eingehenben $\mathfrak{B}$ eurtheilung, farach fich aber, wohl

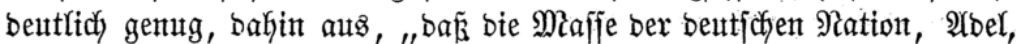

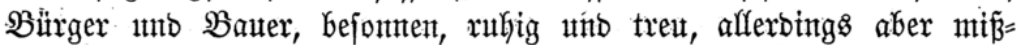

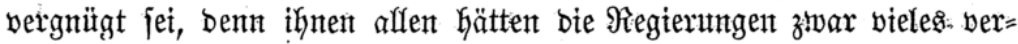
iprocken, aber wenig gefaltent."

Bor allem war es jeboch ber Siönig felbit, ber bie grofent Dienjte, wefche bie burch bie Univerjitäten wirfenben Rehrer und herangebilbeten

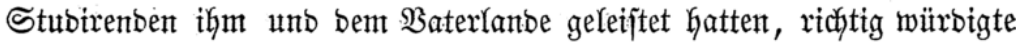

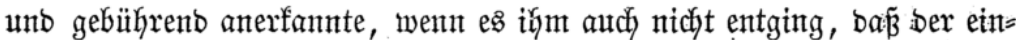
mal wach gerufene Thätigfeitzobrang, bemt es jetst an einem beftimmtent äufern Bielpunfte fehlte, bie in einem georbneten Staate nöthigen Stren=

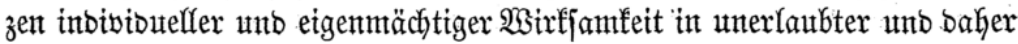

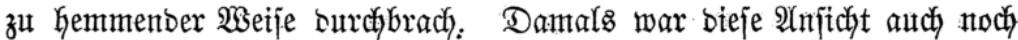

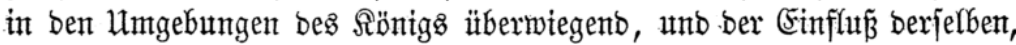

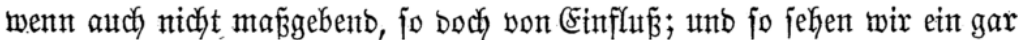
merfwürbiges 3 ujammentreffen in sem $\mathcal{U}$ mitanbe, baj gerabe in benjelben

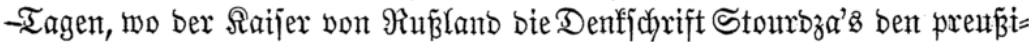

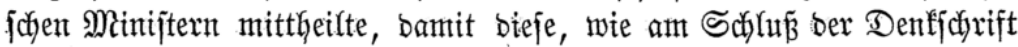

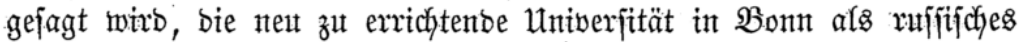
Mujterbild für bie übrigen preupiffłen Univerjitäten Kerjtellten, auf bie

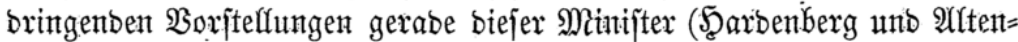

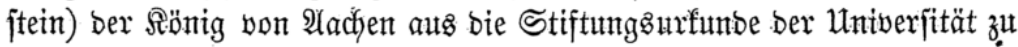

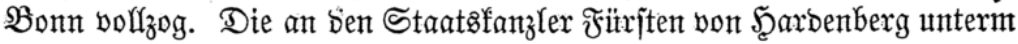

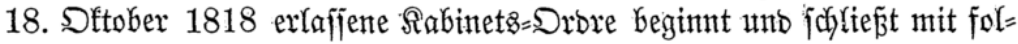
genten Sorten:

„Dem Bejtreben Meiner Borfahren in orer Regienung, burch jorg=

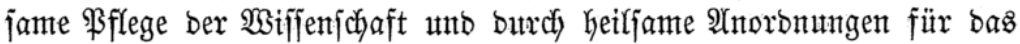

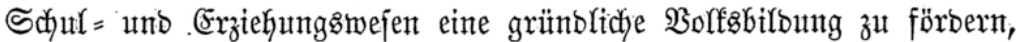

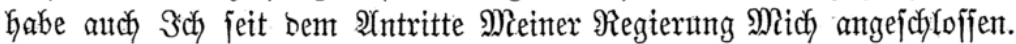

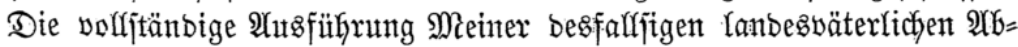

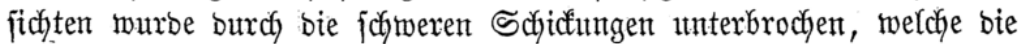
Borjefung über Midch unt Mein Ranb verbängte. Setzt aber, nachbem,

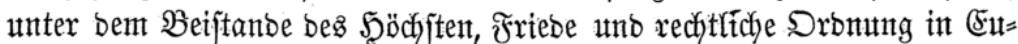

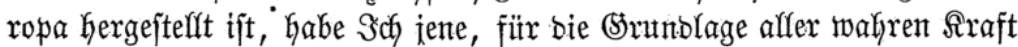

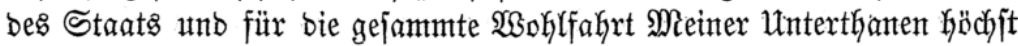
widytige 2 nntgelegenheit wieber aufgenommen, unb ernjtlidy bejchloffen, bas ganze offentliche Unterridyts= unb Bitbungsmejen in Meinen Ranben zu einem möglichjt bolffommenen, ber \$cokeit bes Siegenjtanbes entfprechenten 


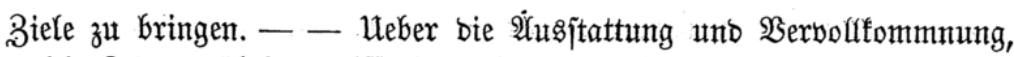

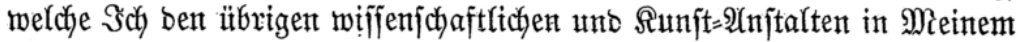
Reiche zu geben Wiflens bin, fonie über ben (Sirumbplan, nach welchem bas gejammte öffentliche untere unb höhere Unterrichtos= und $\mathfrak{B}$ ildungs: wejen in Meinen Ranben zu Einem, in jich jelbjt inbereinjtimmenten unb

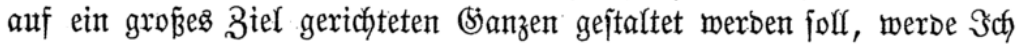
bas exforberliche Spezieflere, nach bem bon bem Staatmininijter $\mathfrak{v}$. Altenjtein eingereichten und von Mir gebifligten \$lane, exlaffen unb benjelben er=

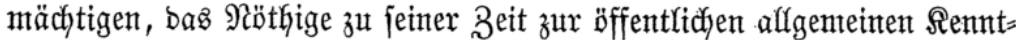

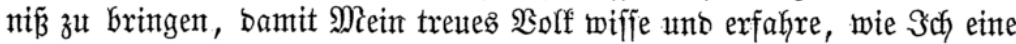

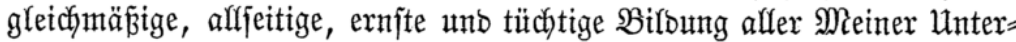
thanen mit lanbeşäterlidyer Riebe bezwedfe, unb folche als bas ficherjte Mittel betrachte, einem, ber wahren $\mathfrak{W}_{0}$ hlfahrt ber $\mathfrak{B o ̈ l f e r}$ jo höchjt nad)= theiligen, unrufigen und unfruchtbaren, Setriebe zuborzufommen unb bas Wohl untb (Sebeiken bes \$reutipifchen Staats hauptjächlich auf bie jorg= fältig geleitete Entwidfelung afler feiner geiftigen Siräfte auth fernerbjut zu grünben, gejonten bin."

Die Dunfelmänner jtutzten, gaben aber thre Brane feinesinegs auf, berjuchten es vielmehx, biefelben auf einem anbern Wege zut erreichen.

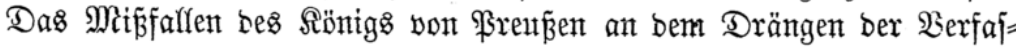
jungsfreunte lag in feiner ächt monarcfifichen Sejinnung und warb von

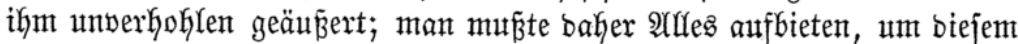

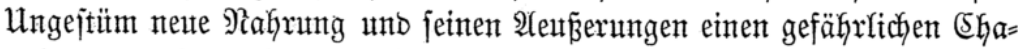

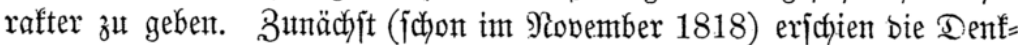

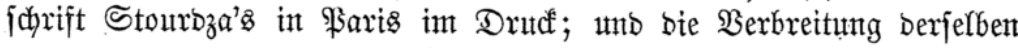
erzeugte unter ben beutfdyen (Selefyrten, Sdjriftiteflern and Stubirenten

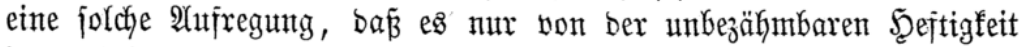

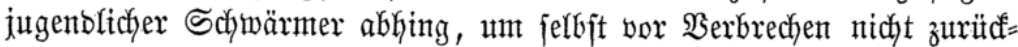

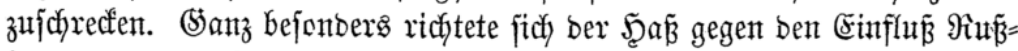
lantos; unt ba Sotzebte, ber bamals in Mannheim lebte, als ruffif djer Spion unt 2 gent angejehen wurbe, fo bejchloḡ ein Stubent aus Sena,

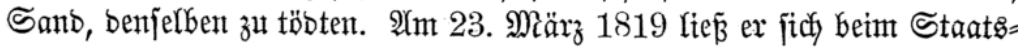

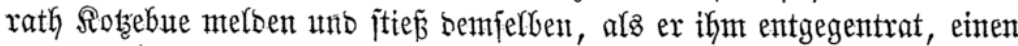

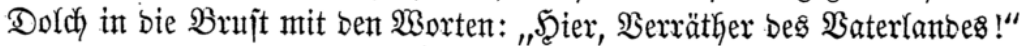

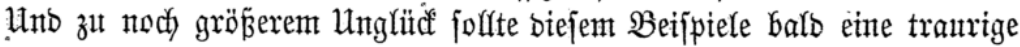

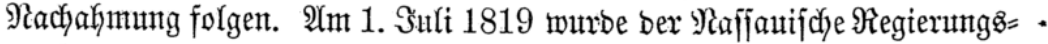

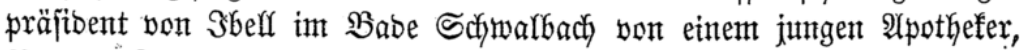

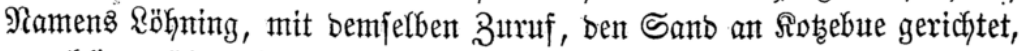
meutdylinga überfalfen.

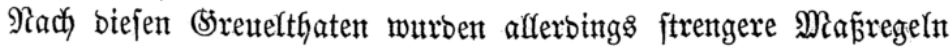


nöthig; man verwedyfelte aber, verleitent unb verleitet, bie Strenge mit ber (S)erechtigfeit, unt was einzelne verirrte ober jelbjt verbrecherijche junge Rente begangen, follte mun an ben ehrmürbigiten, in treuem Staatsbienjte, in

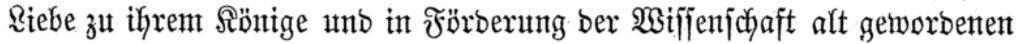
Miännern gerächt werben. Die ßolitif murbe \$olizei; uno jeber herbor = ragente Mann verbächtig, ber nidjt-bent neuen Syjtem ber Bebrïfuntg won obent unb bes Serbilismuts von unten vffen hulbigen wollte.

Şarbenberg war nicht mefx im Stanbe, mit bent wentigent (5etreuten

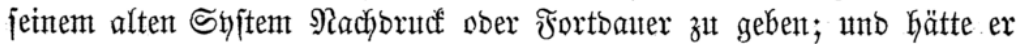

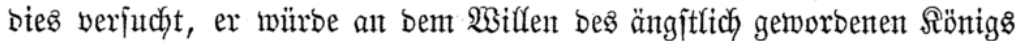
gejcheitert fein. (5x zog ez bor, jich ferbjt untreat zu werben unt mit ber

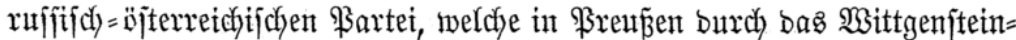
Sampt'iche Syjtem vertretent ivar, zunädjit in ein Sompromiz zut treten

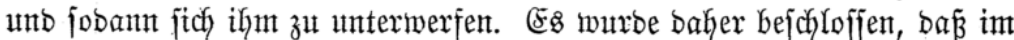

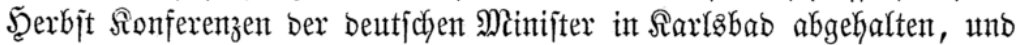

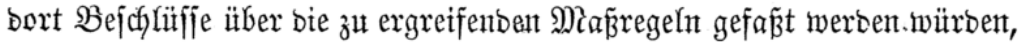
bie bant burch bie Bunbesverjammlung angentommen unb von bent bent= jachen ₹̛̈rjten fanftionirt werben folften.

Wie immer war auth hier bie Reaftion vor Alllem barauf bebacht, bie Rarlsbaber Berathungen burch bie Somöbie einer alfgemeinen $201 f$ = aufregung zu beeinfluffen; uno ba bie ultrantontane \$artet einerjeits bei

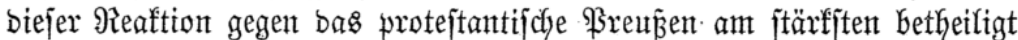

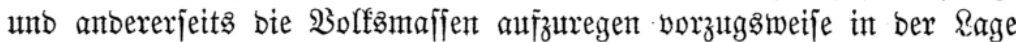
war, fo bot biejelbe milfig ifre Unteritütung an; und bas ifyr immer am nächjten liegente unb baher autch immer von ihr angemenbete Mittel be= jtand in einer improbifirten - Subenterfolgung. „23ährent bemnach bie

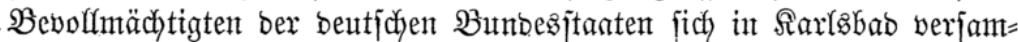

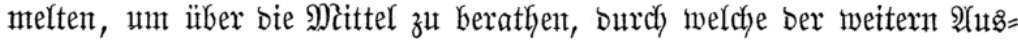

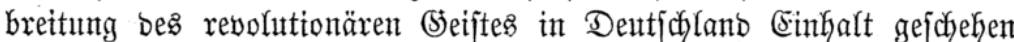

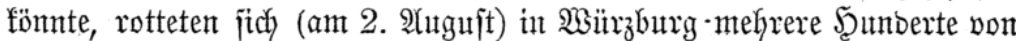
Menjchen aus bem niebrigiten Böbel zujammen, bie ohne irgent eine

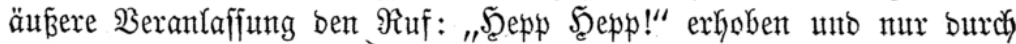

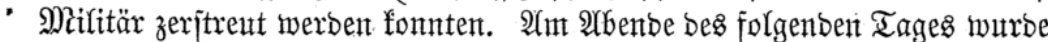
ber Rärm nody ärger, unb bie tobenben Şaufen warfen jeţt jadyon an

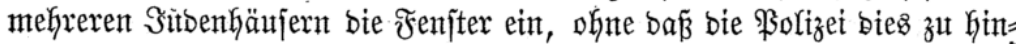

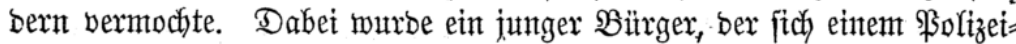

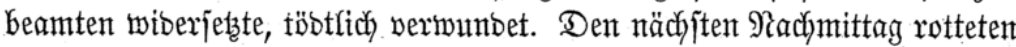
jich noch jtärfere Scaufen zujammen, zogen von einem Sttbenfiătje zum anbern und zertrümmerten ober berbarben in größ̈ter Gille Fenfter, säben,

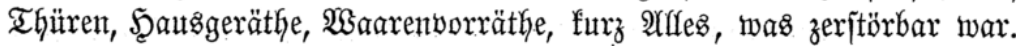




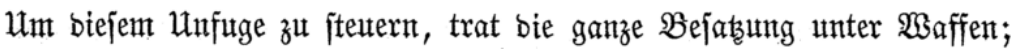
zaflreiche $\mathfrak{B}$ erfiftungen wurben vorgenommen, unb bem (sifer ber $\mathfrak{B} e=$

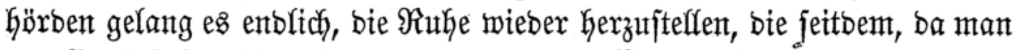
ben (Exnjt jah, nicht mieber gejtört wurbe. Wie ein Rauffeuter verbreitete

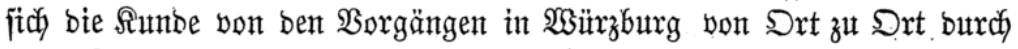

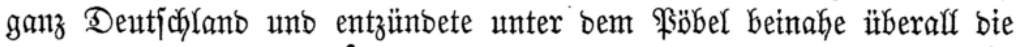

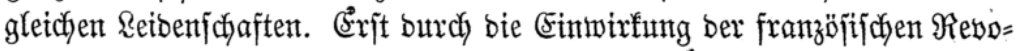
lution waren bie äuneren gejelfichaftliçen Unterjajeibungen, bie unter ber

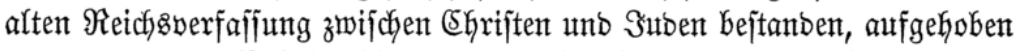

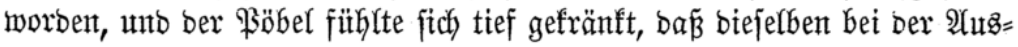
treibung ber Franzojent nicht in ifyrem volfen 1 mmfange wieber hergejtefft wurben. Die niebrigite @ifafje ber chriftlichen Bebölferungen, ber es oft an bem Nothwentigiten feflte, hatte in ber alten Beit body immer noch

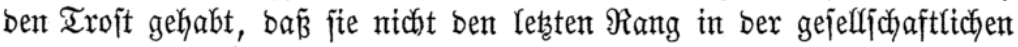

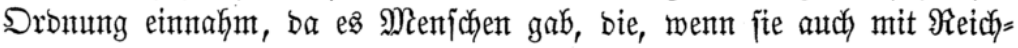
thümern ïberlabent waren und fich burch wiffenichaftliche Bildoung ober

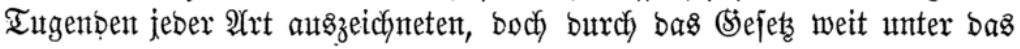
rokejte befitsloje Sejintel geftelft wurben. Man fonnte es bem Pöbel

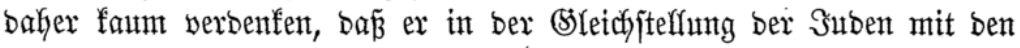

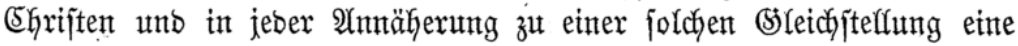
Sränflung feines gutten $\Re$ echtes fah; forberte boch ber $\mathfrak{A}$ loel jeine alten

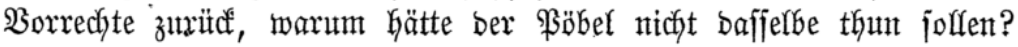
Sein Mäthlein, an ben Subent zut fühlen, war man unter foldhen $\mathfrak{U} m=$

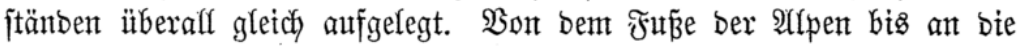

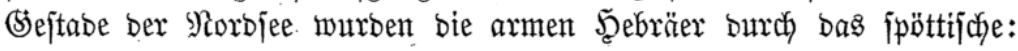

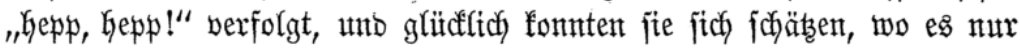
bet biejer Serfiphmung blieb. Sn Franffurt, Darmjtabt und Baireuth,

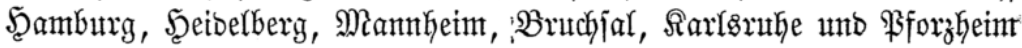

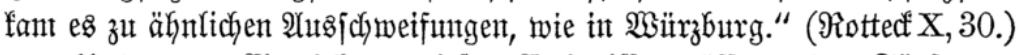

Unter ber Einmirfunt biejer Ereigniffe eröffnete ber F̌̈rrjt bon

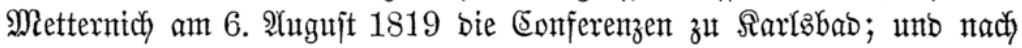

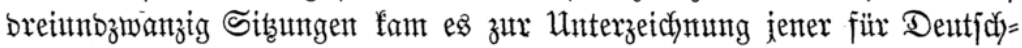

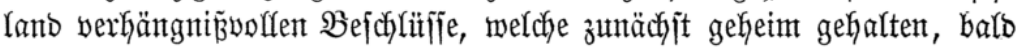
genuig aber, nämlich am 20. September, vom Bumbestag zu Franffurt

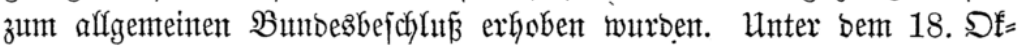

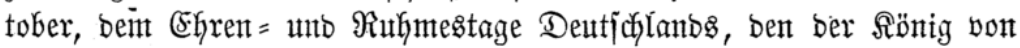

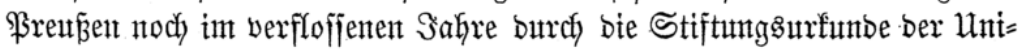

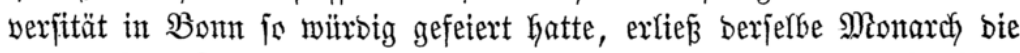

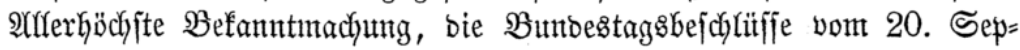
tember 1819 betreffent; into einen Monat fpäter erfffientent 


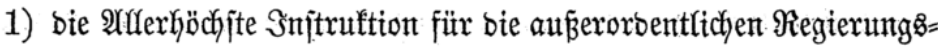
bebollmächtigten bet ben Univerjitäten, und

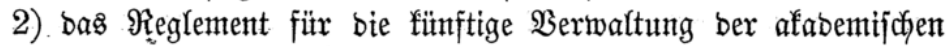

Disziplin und Polizeigenalt bet ben Untwerfitäten.

- Das leţtere beginnt mit folgenber Einteitung:

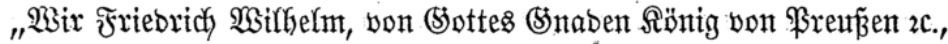
haben Uñ

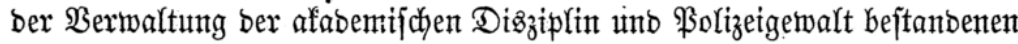
Einrichtungen nicht ïberall ben gemüntchten Erfolg gehabt haben. Die Reftoren unt Senatoren $\mathfrak{U}$ nf ferer Univerjitäten, in beren Şänben fich bis = Ger bie afabemif che Disziplin und \$olizeigetwalt fonzentrirte, jtanben nidjt

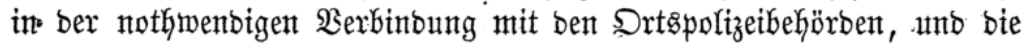

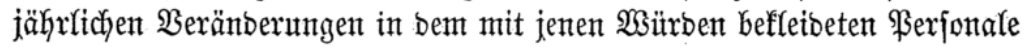
verfinberten eine gleidfförmige $\mathfrak{A}$ tsiübung ber bent Uniwerfitäten- ver= Iiekenen Disziplinargewalt. Wir haben baker bejdyloffen, bei jeber Unjerer Untberjitäten, jtatt bes bizkerigen Synbifłus, einen eigenent

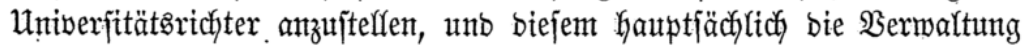
Der afabemifchen Disziplin unt $\Re_{0}$ olizeigetwalt zu ïbertragen. Demgemäß verorbnen $\mathfrak{W i r}$, indem $\mathfrak{W i r}$ alfe bem gegentwärtigen $\Re$ eglement wiber=

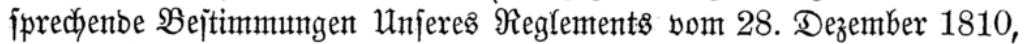

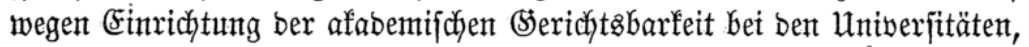
and ber Unjern Uniberfitäten bisher ertheilten Statuten Giexburdy ausbrüdrich abänbern und aufgeben, hiermit Fol genteg."

So warb Stourbza's פorjajlag zur Unterbrüdung ber \$reffe, ber

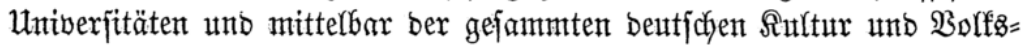

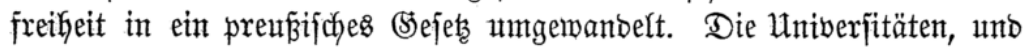
"Dieś mutá hier bejonbers hervorgehoben werben, vertoren, ungehört unt unberürffitytigt, ihre \$rivilegien unt Statuten. Der bentiche Stein, Den bie Branbungen ber Ariegesftürnte nidyt erjcjüttern gefonnt, unt

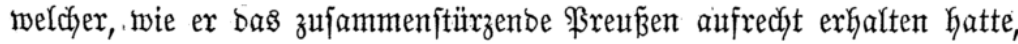
autch ben neuten $\mathfrak{A}$ uffbau zut jtütsen bereit, war, welchen enblich bie rutfififdjent Bäber zu 2Aachen zu ermetchen nicht vermodyt hatten, wurbe nut butrdy bie

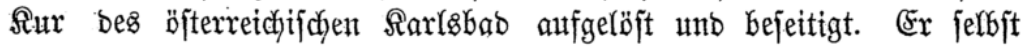
fchrieb barïber an Sumaroff in \$eterzburg:

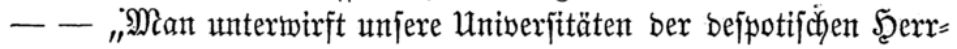

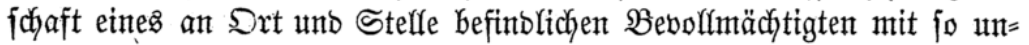

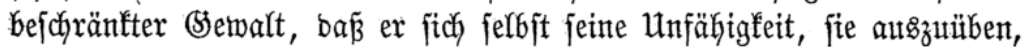
eingejtehen muß man unterwirft feiner 2 unficht bie Stubenten wie bie ßrofefforen, man beraubt beibe einer Unabbängigfeit, bie jenen für bie 


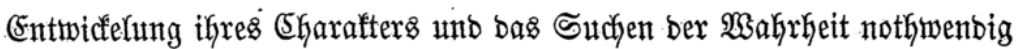

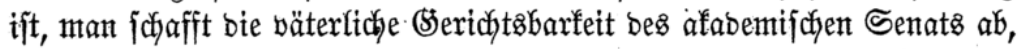
$\mathfrak{u m}$ an beren Stefle bie rohe unb trodene $\mathfrak{B e r f a h r u n g s a r t ~ e i n e s ~ ( B e r i c h t s : ~}$ mannes zut jetzen, und affe bieje $\mathscr{A}$ enderungen in ben miffenjichaftlidjen

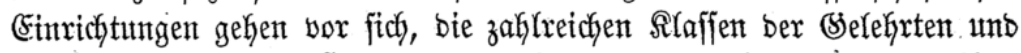

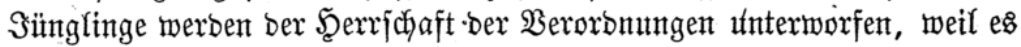
theils fidulbige, theils anworfichtige ober überjpannte Menfinen giebt;

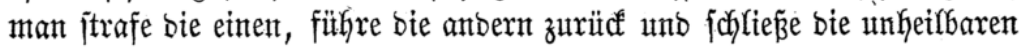
auts unb mache jie unichäblicty.

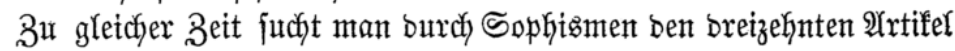

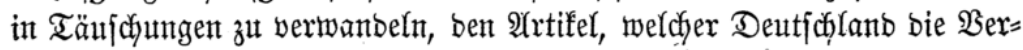

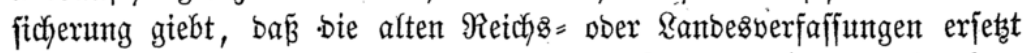
werben folfen burch ein, nady ber jetzigen Rage ber Sejeffjchaft abge=

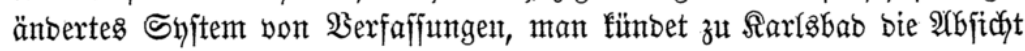

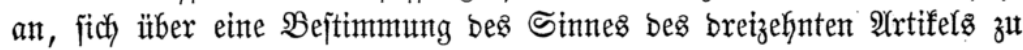
vereinigen, weldye auf alfe bie berjodiebenen beutjoyen Staaten anmentb= bar fein foll; wer fann num glauben, bã Dejterreich fich Stänbe geben

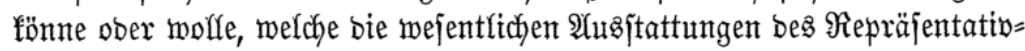
fyjtems, bie 3uftimmung zu ben $\mathfrak{A}$ uflagen unt sejetsen haben?

Fajt bie \$sejammtheit bes Bolfes wiff $\Re$ uhe, Dronung, Erhaltung ber alten Fürrjtenfäujer, aber zugleich) mittelz ber repräjentativen (Ein= richtungen eine Semähr gegen ben Misbrauth ber (Setwalt. Man muäte

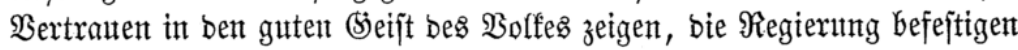
burch Sereinigung aller nationalen 3ntereffen um fie, bie Unrukefitifter ïberwact)en, bie fajlechten Söpfe entfernen, bie Sdyulbigen jtrafen - aber was werben bie britffenben Şemmungsimittel herborbringen unb bie Fort= bauter eines bureaufratijchen Seroronungsifyjtems, weldyes jeinen 2 (ntrieb empfängt von einem leeren, untwiffenben, winbmachenten nto an jeinten Talenten nicht żweifelnben Manu, unb einem Yeidytfinnigen, Yieberlichen,

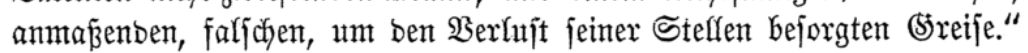
(\$Pers, Das Reben Steins V. 445.)

Die Geiben Frofefforen Dahlmann und Fald Yehnten bie Mitglied=

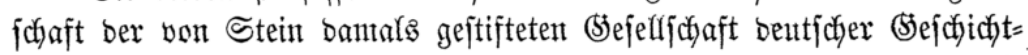
jabreiber in nadyjtehenben Sajreiben an ben \$seheimrath Büthler ab. ('Pert 1. c. S. 466-469.)

„Ster, ben 6. November. Seit bem Bumbestagsbejchluffe vom

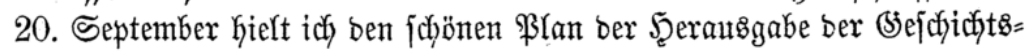
quelfen bes beutficten Mittelalters für aufgegeben; Denn ich hielt es für

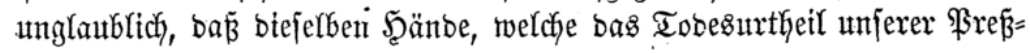




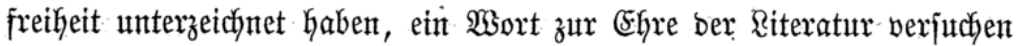

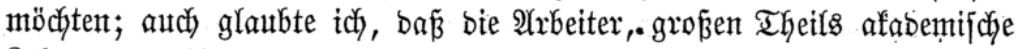
Sefjer ober ifnten verwant, wentig eifrig fein würben, fich unter bie Direftion von Männern zu ftelfen, burcly beren Mitwirfung ober $\mathfrak{Z}_{\mathfrak{H}=}$

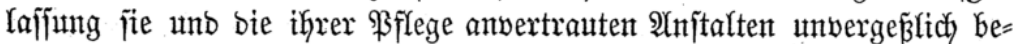
reibigt und herabgenürrbigt fint.

Setzt aber erfehe idy aus bem Briefe, mit bem midy (5iv. Sc. beefren,

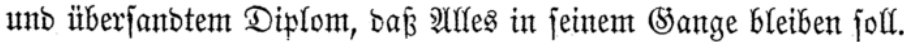

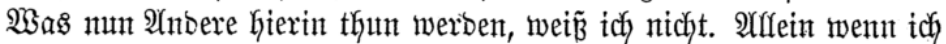
auf viele von bẹt Mä̈nnern fehe, welche jeţt zut ben offenbar verfolgten

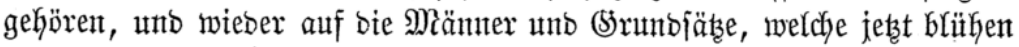

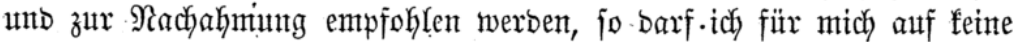

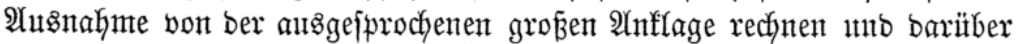

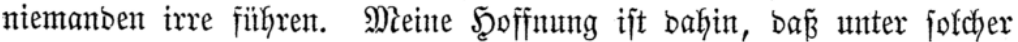

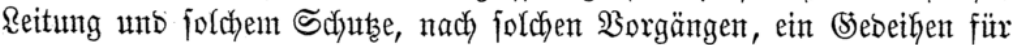

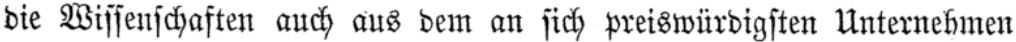
ermachjen fönne. Denn bas bejte Bjefingen fann niduts Erhekenbes

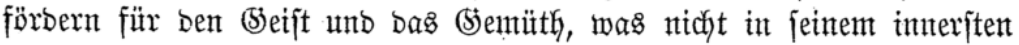

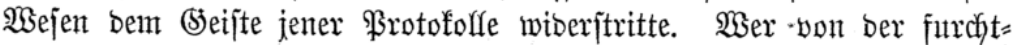

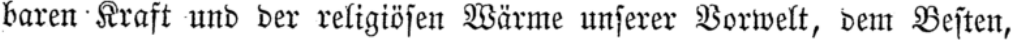
was fie bietet, ourchbrungen ift, wirb ex gelaffent bem 3uftanto zujehen

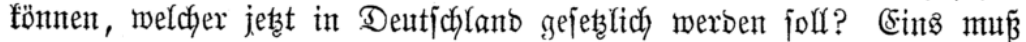

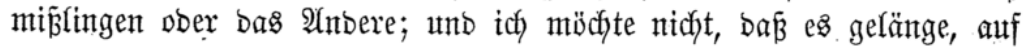

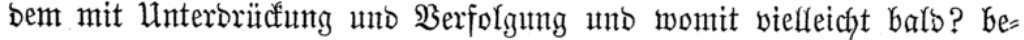
flectten Boben eble Friüchte ber $\mathfrak{3 i j f e n j d y a f t ~ b u r c h ~ g e b u n b e n t e ~ S ̦ a ̈ n b e ~ z u ~}$

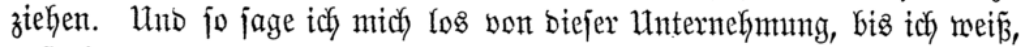

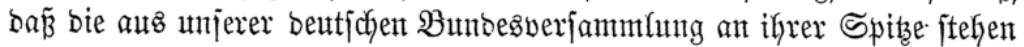
fich erffärt haben, feinen Theil haben zu wolfen an ben ltebel, welches jene Berfügungen unfehlbar über Deutjchlano bringen. Snbem idy biejes

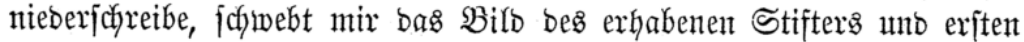

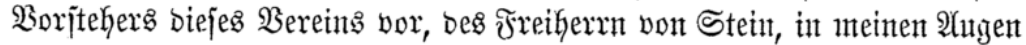
Desి gröp̧ten Staatomanns, weil er jeine Diplomatif. unter bie Berant=

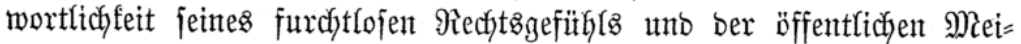
mung fterlyte.

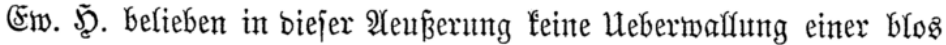

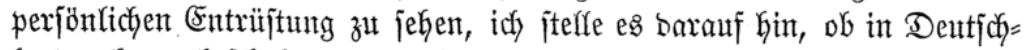
fant zefn unbejcholtene, bent Bregenitanbe gewachjene Miänner jint, bie biejes SEefühl nicht theilent. BBis bahin fente idy feinen einzigent. Schein=

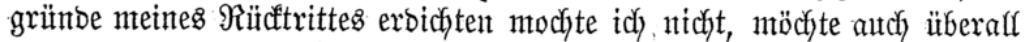

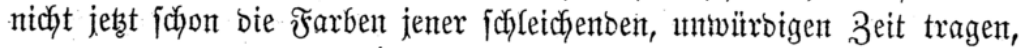


welche ficher eintritt, wenn bie \$̧andlungen bes Septembers, was ber Şimmel verfüte, Fortgang uno Bejtano geminnen."

Dahlmantu.

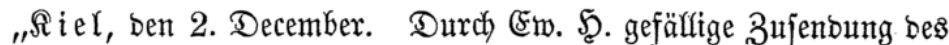

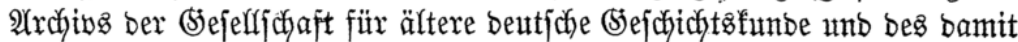

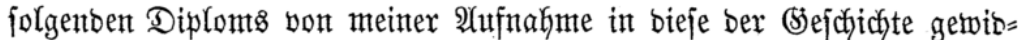
mete (sefellfichaft unterrichtet, hätte ich viefleidyt nicht fo lange jodweigen follen, als geidyehen ift. (5iemiź, idy erfenne bie mir miberfahrene Ehre bollfommen an. Âtuch würbe es mir fefr erfreulich fein, burch bie $\mathfrak{B e r}=$ bintung mit einer fo autgebreiteten (Sejellichaft für bie Bearbeitung

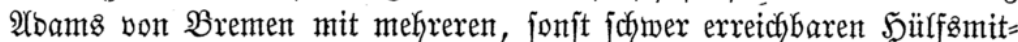

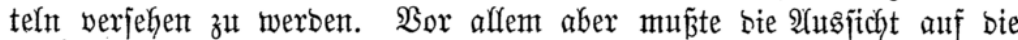
fünftigen Reiftungen einer jolchen Bejelljchaft freubig begeiftern, unb es fajt zum bentibenswerthen Rooje machen, als Mitglies in biejelbe aufge= nommen zat werben. Itngeadfet Gier num bie EFre in Serbinbung mit

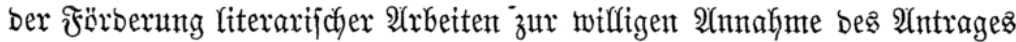

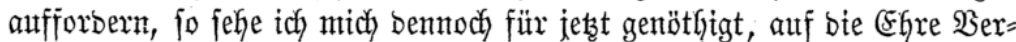
zicht zut Keiften, . unb fann nur für bie günjtige Mleinung von mir banfen, welche burch bie $\mathfrak{A}$ ufnahme in bie Bsefelfichaft beurfunbet wirb.

Die (Strünbe biejer ablehnenden (Erffärung habe ich nidjt nöthig,

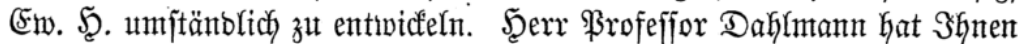

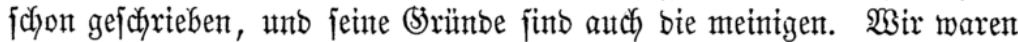

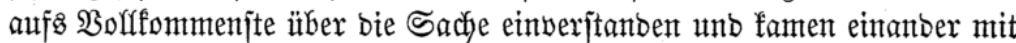

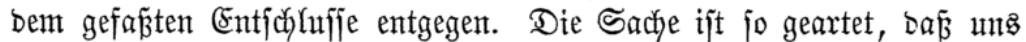
feine $\mathfrak{W a h l}$ iibrig blieb.

Die Schilberung ber beutifhen Uniberjitäten, welche von bent Bun= bestage ausigegangen, welcher vier Mitglieber ber Sentralbireftion beige=

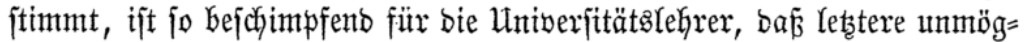

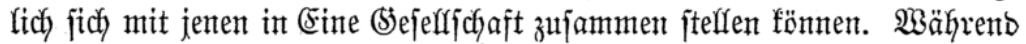

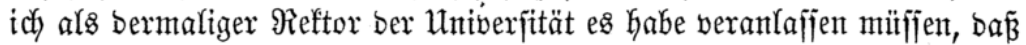
bas afabemifche Eonfifitorium bie hiejigen Rehrer vor unjerer Regierung rechtfertigte, währent bieje es anterfenut, bá jene Schilberung auj bieje

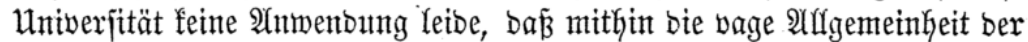

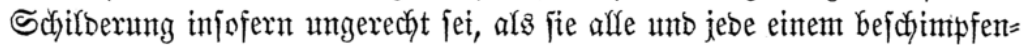

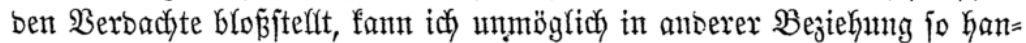

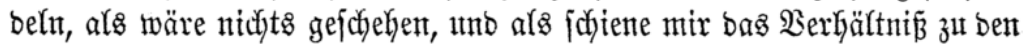
Mitgliebern ber Eentralbireftion ein freunblidjes. Sielfeidyt fehen jente Männer bie Sache gerabe fo an, wie unjer einer, unb miß̧billigen bas (5ejchehene, Gaben 


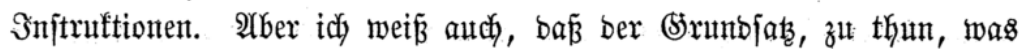
befohlen wirb, feine (5ränzen hat, und baß es wohl Fälle gebent fant, wo bie eigene Yebentige Heberzengung bem offizieffen (Sharafter nidyt unterzu= oronen ijt; unb. idh glaube, es wäre ant 20. September bie Zeit getwejen,

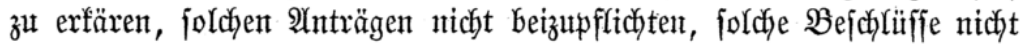
mit unterfachreiben zu wolfent.

Der jaymerzhafte Einbritct, ben jente Befdylitfje Kervorgebracht haben, ohne 3weifel alfenthalben wie hier im Rande, rechtfertigt vollfommen ben Wunf

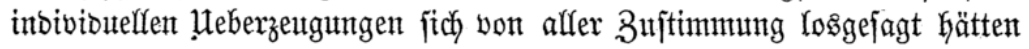
unt noch losfagen möchten. Sn ber That war bas nody meine Jevffnung,

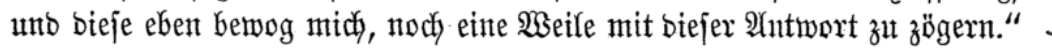

F́alta.

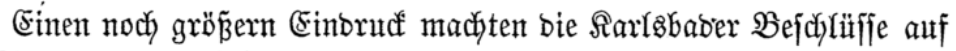
die Staatŝmänmer \$reuñens, bie baburch bie heilfame befejtigung feiner

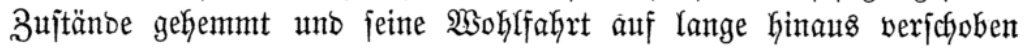
faken. Die Minifter Şumboldt, Boyen unto Beyme nahment bie Sache

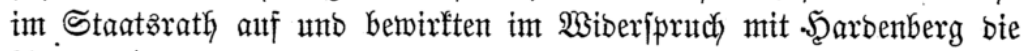

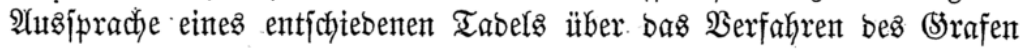

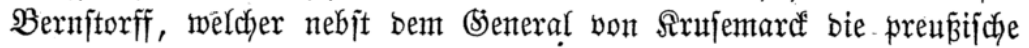

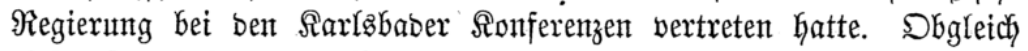

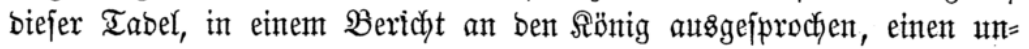

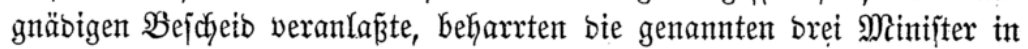

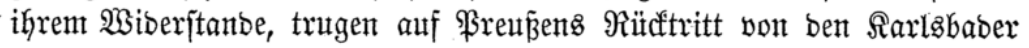
Beichlïfifen an unb bezeichneten babei zugleich bie Stelfung bes Staats=

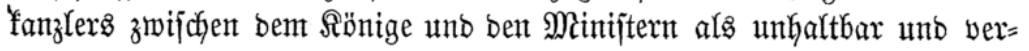
Derbfich. Şarbenberg. nahm nun jeine 3uflucht zut einer innigeren $\mathfrak{B e r}=$

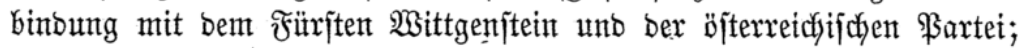
inter bem 25. Dezember unterzeidfnete ber $\Re$ önig Srolntanns und $\mathfrak{B}$ oyens

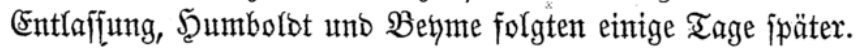

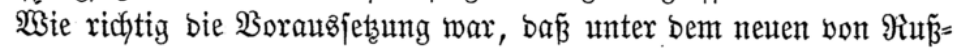
land empfohlenen, von Metternich unterftütsten und won (sents bis in bie feinjten Detailz ausgebildeten Syjtem ber intelfeftueflen Umétehr jebes Stre=

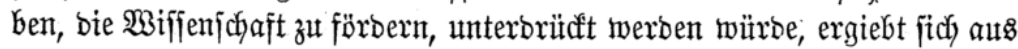

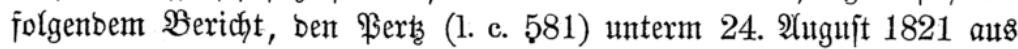
Wien an Stein erjtattete. Ex follte bajerbjt burch bie Bermittelung bon

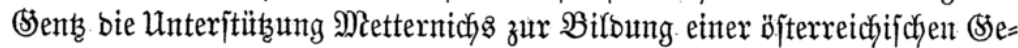
felfichaft beuticher Befchichtaforicher ermirfén unb hatte nach langem Soin=

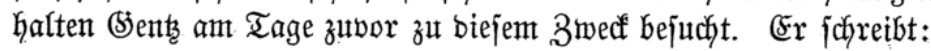


"Seftern (23. Atugujt 1821) fuhbr ich hinaus, und um 11 uhr begann bie Unterrebung, welche mir bas $\mathfrak{B} e r i$ tänoniñ über bie $\mathfrak{B}$ eurtheilung unje=

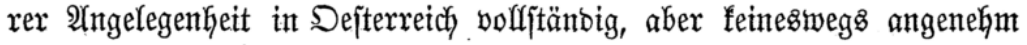

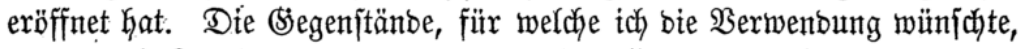
waren: 1) Theitnahme ber öfterreichifden (Selehrten, 2) ihre Bereint=

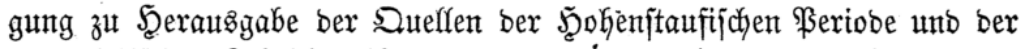
äjterreichifłjen Rofalchronifen unt Urfunben, 3) bie am Bundestage

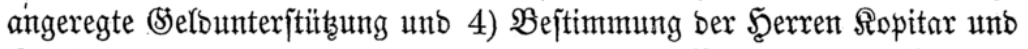
Snechtl — als ber beiben einzigen bazu fäbigen Männex - 子u Bearbei=

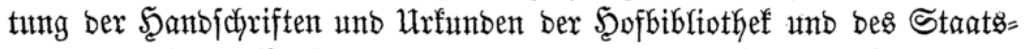
archinz nach ber $\mathfrak{B e r f u ̈ g u n g}$ Der Sentralsireftion. Şr. von Sients hatte Den Füriften fojon barüber gejprodjen und gab mir folgente, unter bent

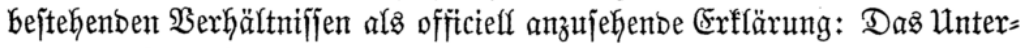
nehmen fei an ihm, ber neuten wifjenjchaftlichen Erjocheinungen wenig Beit

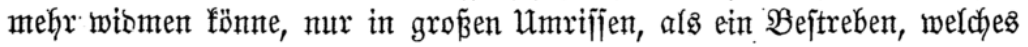
nach bem (5eifte ber Stifter mit grof̉er Thätigfeit geförbert merbe, bor= ïbergegangen; ber nächjte 3 wedf icheine Lobenşwerth, ber Exfolg, nach biejen $\mathfrak{B}$ orarbeiten und ben Berficherungen über bas bisher fidon Ex=

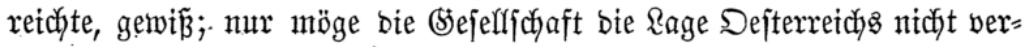
fement, welche won ber ber anbern beutjches Staaten burchaus verichieben

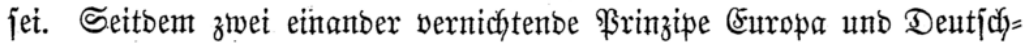

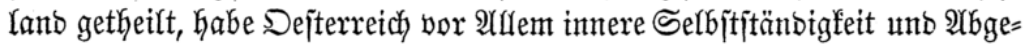

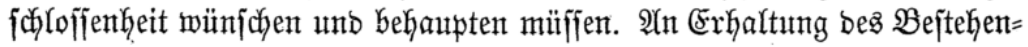
Den gebunbent, gleiche es einer belagerten Fejtung, wełche gegent ben unter

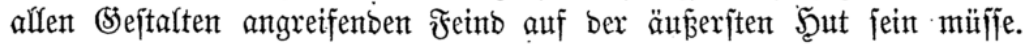

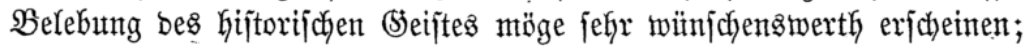

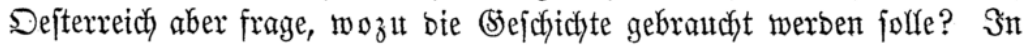
einer Beit, welche affes in Sift zu verwandeln wifie, gebe fie jo gut gegen,

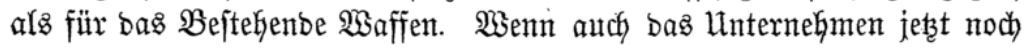
ohne weiteren 3'wecf fei, worauf er nach ber Unterrebung mit E. (E. Jut Uachen leben und jterben wolle, wemn auth ber perjönliche çGarafter bes Şerrn $\mathfrak{B i c e p r a ̈ j t b e n t e n , ~ F r e i k e r r n ~ v o n ~} \mathfrak{A}$ retin Exc. uno ber itbrigen Mit= glieber ber Eentralbireftion für bie näcdjte 3ufunft bag völligite פertranten einflöß̈e, fo jet bamit nod) feine Serfitherung für fpätere Beiten gegeben,

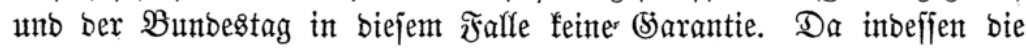
Bejorgniffe, welche bas Entifehen einer jo, bebeutenben Drganifation in Franffurt veranlafie, erjt nady beenbigten Borarbeiten, aljo vielleicht in

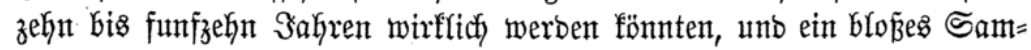

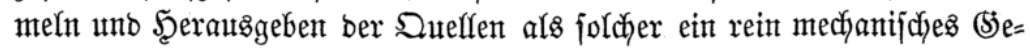
\{çäft fei, weldyes zwar nicht ohne vielfeitige Borfentniffe zu Stanbe 
fomme, aber feinerlet $\mathfrak{A}$ rt politifcher $\mathfrak{B}$ eziehung zeige, fo habe èr bem Fürjtent gerathen, jene, erft nach $\mathfrak{B}$ eiber Tobe eintretenben $\mathfrak{B}$ eforgniffe auf fich berukgen zu lafjen, unb bie Sache, in bie man einntal fo meit einge= gangen, autsufüüfren; meine Denffchrift Yiege fdjon in bemt \$ortefeutifle Sr. Durchlaucht zum mïnblichen Sortrage an ben ßaijer. Schon bá ber Fürjt münoliçen Sortrag barüber erjtatte, fönne mir zetgen, baß bie Sache feinesiwegs als politifh gleidghiltig betractitet merbe. Dent

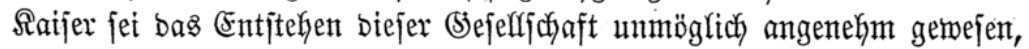

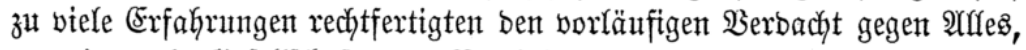
was jeţ̇t als (Sejellyd)aft ober Bereinigung auftrete; er habe fich baher

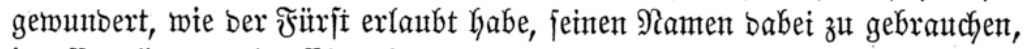

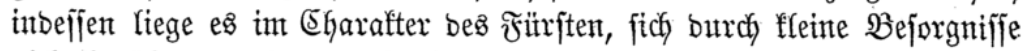

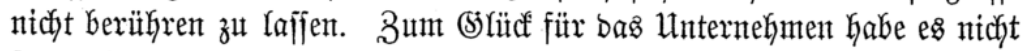
fpäter begonnen. So wentig ber Saijer bie Sache an jidy lobenzwerth

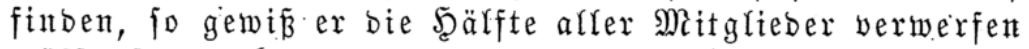

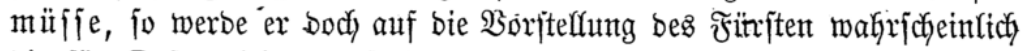
bie für Dejterreich vorgeichlagenen Thetfnefmer in Maffe genehmigen. Thue er es nidyt, jo nefme freilich bie Sache eine ganz anbere Wentung.

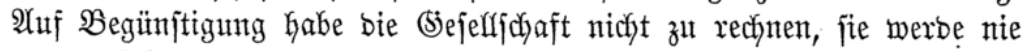
gern gejehen werben, aber alkb feine pojitiven ફ̧inberniffe finben. $\mathfrak{B} e=$ mutzung ber $\mathfrak{B}$ iblinthefen bleibe inmer geftattet; baß mix bas Staats=

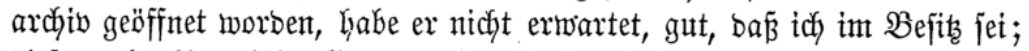

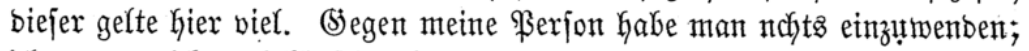

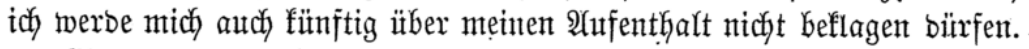

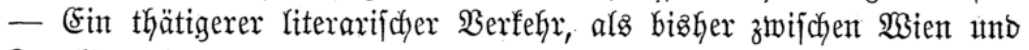

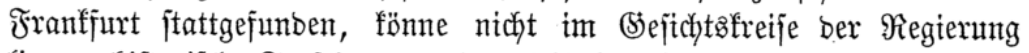

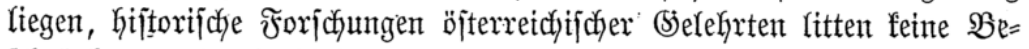

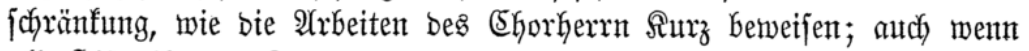

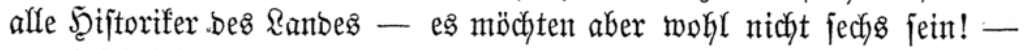
gemeinjchaftliche Unterjuthungen anjteflen, werfe Gerausgeben, ja felbjt mit einigem $\mathscr{A}$ uffeken von Zeit zu Zeit $\mathfrak{B}$ erjammlungen halten mollten,

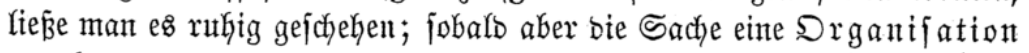

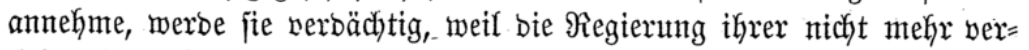

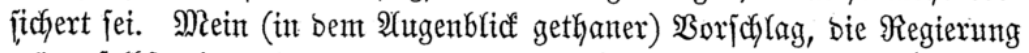

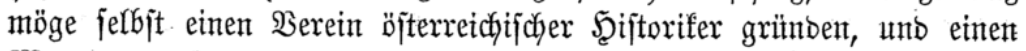
Mann, bem jie ganz vertraute, an bie Spitze fteffen, fei nicht ausfü̈hrbar, weil feiner berjentgen, weldhe bazu Fähigfeit unb bas $\mathfrak{B}$ ertrauten ber

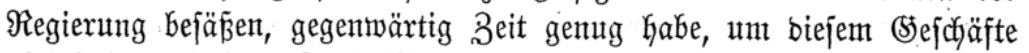
thätig vorzuftehen. Fürit Metternich, welcher fich mit $\mathfrak{B}$ ergin̈̈gen an bie Spitze jtellen merbe, habe bafür in einem Galben Sahre nidyt eine Stunbe; 


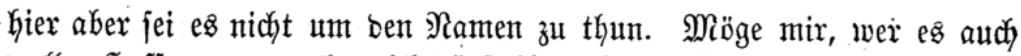

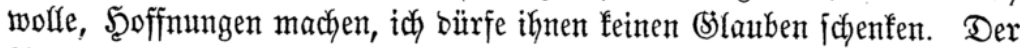

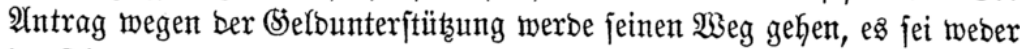

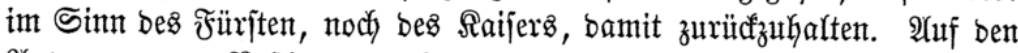
Antrag wegen Beftimmung faijerlicher Beamten zut ben $2(r b e i t e n$ ber

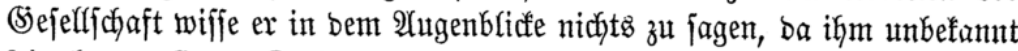

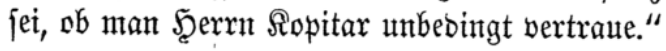

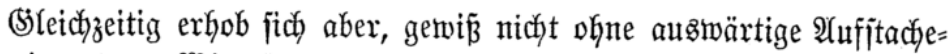

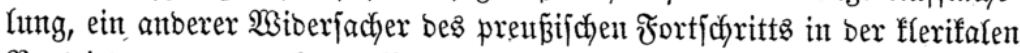
Bartei ber neuterworbenen Provinzen, welche bie Deit gefommen glaubte, um ifye frïher vernichtete Madyt wieberkerzuftelfen uno bie Sirche als Staat im Staat geltenl zu mactjen. Şier tritt num fofort ber Manu auf,

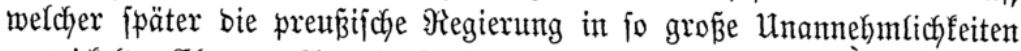

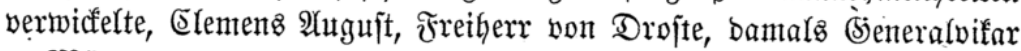

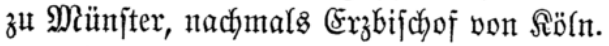

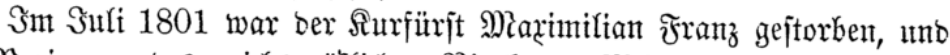
Lie Regierung Des reichşgräflichen Bisthums Münjter an bas Rapitel gefommen. $\mathfrak{A} \mathfrak{m}$ 9. Septbr. wurbe bie neue Sahl borgenommen unb fiel

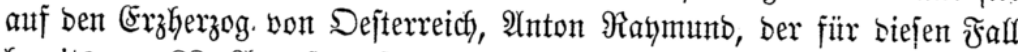
bereits am 22. 2Yugujt auf bent bamaligen Dombectyanten bon Spiegel,

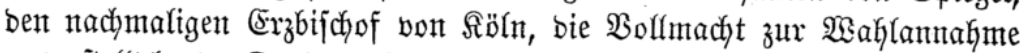

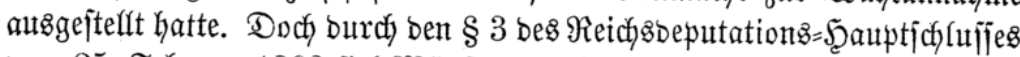

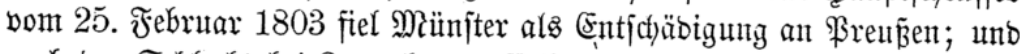

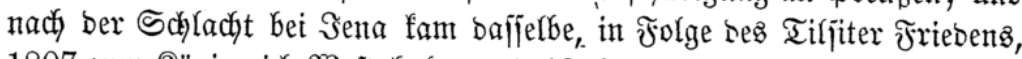

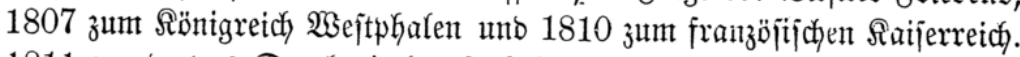
1811 wurbe bas Domfapitel aufgehoben, burch Defret vom 24. 24igujt 1812 aber wieber Gergejtellt, biz entblicty am 14. 24prif 1813 ber Dom= bechant yon Spiegel zum 2 ijofof von Mümiter burdy Rapoleon ernannt wurbe. Nur zwangşweife nahm er bieje Ernennung an, welcher ber $\mathfrak{B a p j t}$

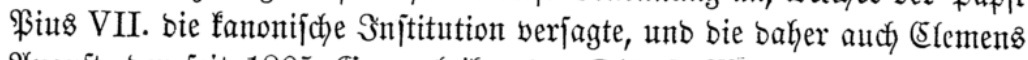

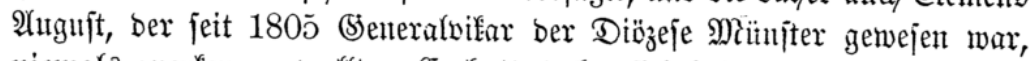
niemals anerfennen wollte. (Ex hatte baher fich beharrlich gemeigert, auf

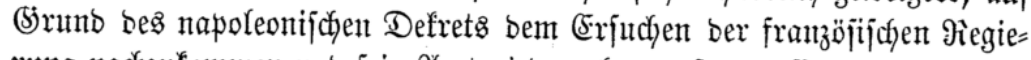
rung nad) zufommen und jein 2 (m) nieberzultegen, ftatt befien viefmehr aus eigener Machtwoflfommenkeit ben Freikern bon Spiegel jubjtituirt unb biejem bie Sertwaltung ber Diözeje ïberlajien. Saum war aber in

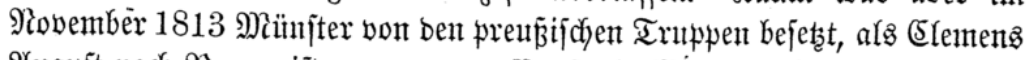

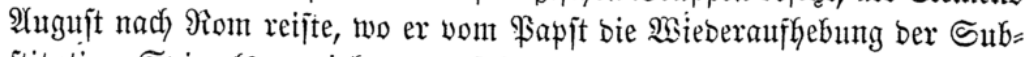
ftitution Spiegels ertwirfte, um fofort wieser felbjt bie Sierwaltung ju 


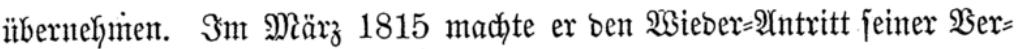
waltung als \$enteralwifar befannt und erffärte, weber bas "napoleonifche Sapitel," nody bie längere Fortjeţıng ber Subjtitutiont Spiegelz anzlt= erfennen; "nux bas alte Rapitel jei rechtabejtänbig,“ gegent bie $\mathfrak{B}$ ejchylitffe jebes anbern werbe er proteptiren. Das sapitel füfhylte fich natïrfich fier= burch gefränft unt veranlapste ben bamals hochgeadyteten unb felbit in

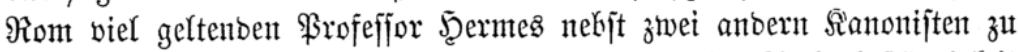

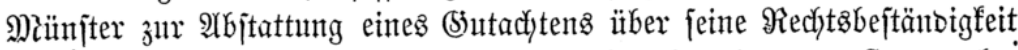

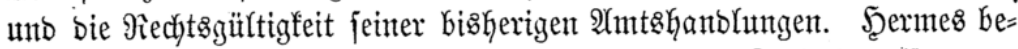
antwortete affe Fragen z̆l (5)unjten Spiegels und bes $\Re$ apitels, aljo gegen

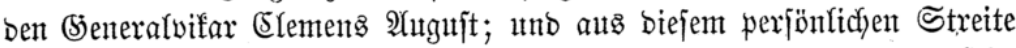
auf bemt (S)ebiete bes Sirchenrechts und ber firchlichen Diszziplin entwicfelte

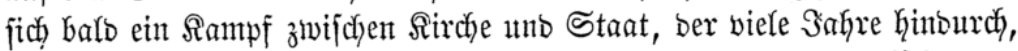

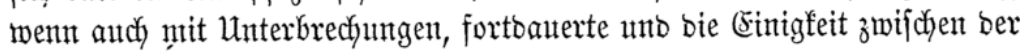
Regierung unb einem bebeutenben Theife ber fatholifhen Bevölferung zu

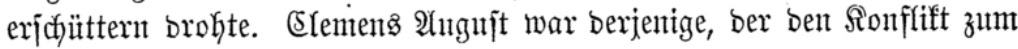
I(1186rud bradyte.

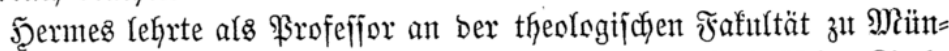
fter in einer $23 e i j e$, bie bon bem bisherigen Srjtem ber fatholijchen Sirche abwid); und jeine 1819 expdjientene Schrift "(sinleitung in bie dyriftfatho= lifiche Theologie" zeigte, ba

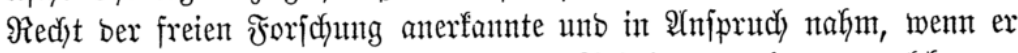

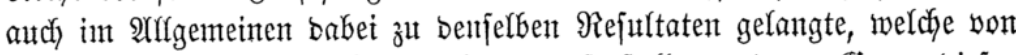
ben ïbrigent orthoboxent Rehrmethoben aufgefteflt wurben. Siegen siejen

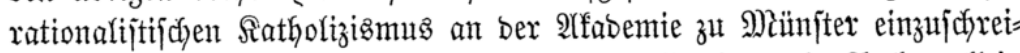

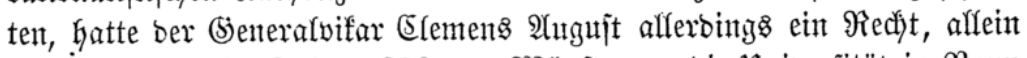

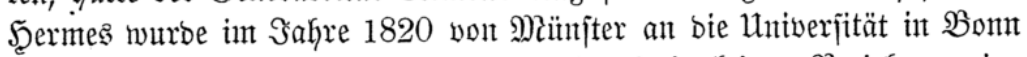

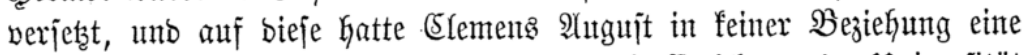

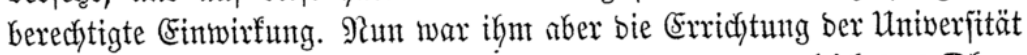

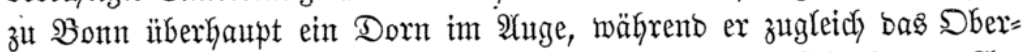

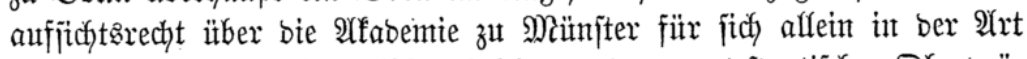

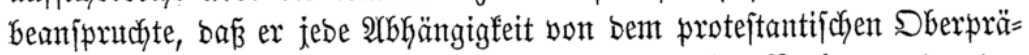

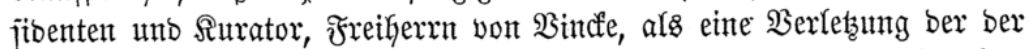

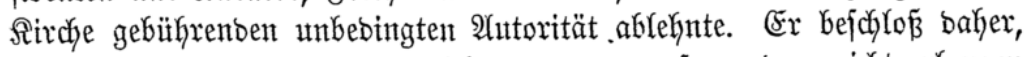
auf einem Ummege bas zu erreidyen, was er auf gerabem nidyt erlangen fonnte. Er verbot nämlich ben Theologen feiner Diözeje, fortan anber= roürts ars in Münjter felbit theologifdje Borlejungen zat hören. Den

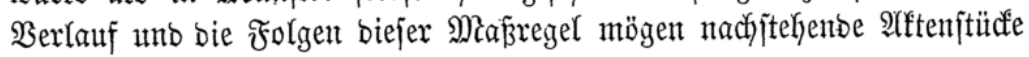
bartfun:

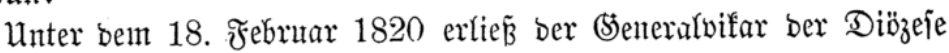




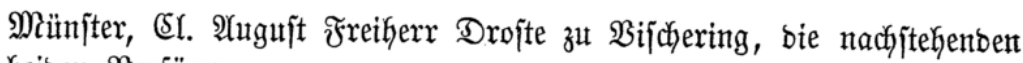
beiben $\mathfrak{B e r f u ̈ g u n g e n t : ~}$

\section{1. Ât fämmtlidye Theologen ber Diözefe.}

Wir finben uns veranlap̧t, ben Theologen hiefiger Diözes in Grin= nerung zu bringen, was fich freilich von jelbjt verjteht, bå̉ nämlich fein Theolog ohne Unjere Erlaubnis anberğwo, als hier, irgend einen 3weig

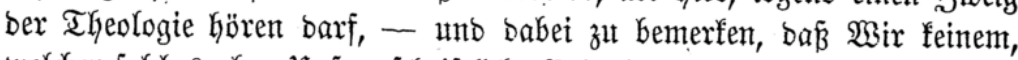

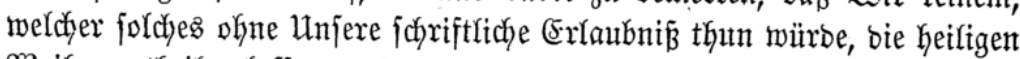
Weifen ertheilen lafjen werben.

Dieje Berfügunt foll bem Şerrn Defan ber theologijđdjen Fafultät

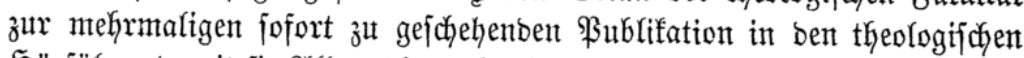
Scörjälen, santit fie Âffen, sie es betrifft, befannt werbe, und bamit fie int

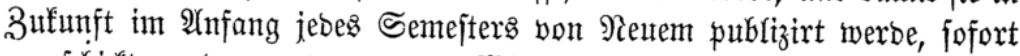
zugefdicift werben, und erwarten $\mathfrak{W i r}$ von erwähntem Scerrn Defan bie

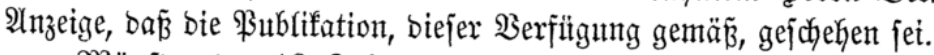

Miinfter, Den 18. Februar 1820.

\section{2. Ân ben Defan ber theologifäen Fafult ät.}

(5iw. Scodfwiurben exhalten hienteben bie meinerjeits unterm Geutigen Datum erlaffene Berfïtgung in Betreff ber ben Theologen Giefiger Diözes berbotenen Frequentiruth irgent einer theologifochen Borlejung auferkalb ber hiefigen Refranjtalt - mit bent 2 uftrage, biejelbe fofort zur mehr $=$ maligen. \$ublifation zut beförbern anto barüber bie $\mathfrak{A}_{n}$ eige ankero zu machen.

Mï̈tjter, bent 18. Februar 1820.

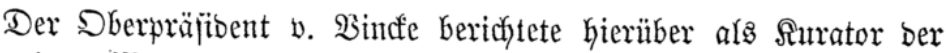
Alfabente zu Miünter an bas Minijterium, worauf biejes unterm 1. März Den Sieneralvifar zur Berantwortung aufforberte unb anf Burüdnahme

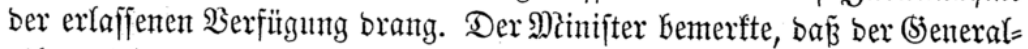
vifar nicht berecytigt gewejen fei, bie Freikeit ber Theologie Stubirenben

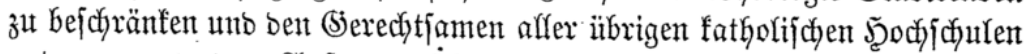
entgegen zu treten. Âtuerbem jei bie getroffene $\mathfrak{A}$ noromung neat unb baher

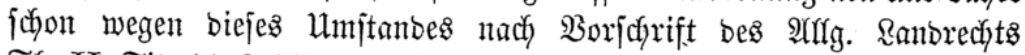

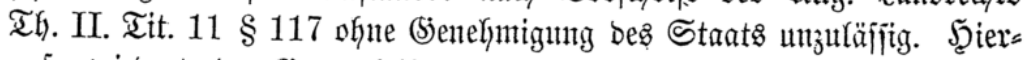
auf ertwieberte ber (5)eneralwifin burch) folgendes Antwortfdyreiben an ben Mcinifter von $\mathfrak{A}($ tenjtein. 
Şodgechrtefter Freiherr!

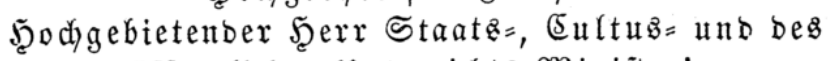 öffentriden Unterridyts Mintîter!}

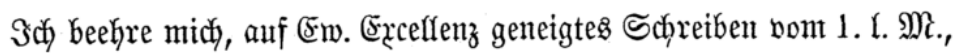

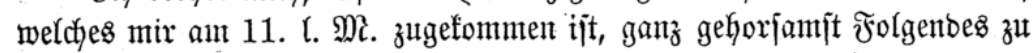
ermiebern.

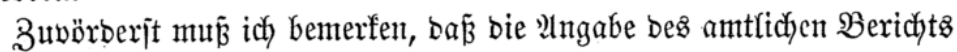
- ich habe bie fraglidye Serfügung anfchlagen lafjen - umrichtig ijt, bann aber bie Bemerfung beifügen, Daß̧ ber Seerr Dberpräjibent von.

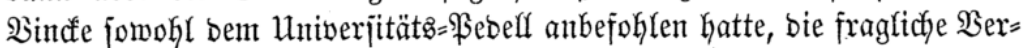
fürgung abzunefmen, weldyes aker, ba jie nidjt angejdylagen war, uidjt

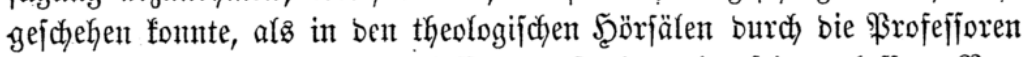
ber Theologie hat publiciren lafjen: baß bie meinerjeits erlaffene $\mathfrak{B} e x=$

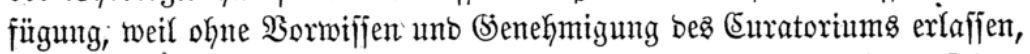
ohne $\mathfrak{\text { Sirfing }}$ jei - als wenn bie Frage: ob idy biejen ober jenten Then= logen weifen lafjen fönne, in irgend einer ß̉erbindung ftänbe mit bent

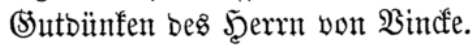

Das $\mathfrak{B}$ enehmen bes Serru Dberpräfibenten ift aber aus einem an= Dern, idu möchte jagen, ernjtern (Sejichtapunfte überaus umpajfent, intem es geeignet ijt, bas $\mathfrak{A}_{11}$ ehen ber geiftlidjen Dbrigfeit überhaut, insbejon= bere bet wentiger einfichtigen Theologen zu minbern; uno ba überbies ein

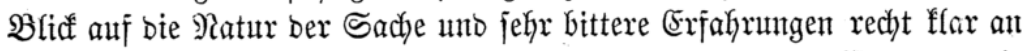
ben Iag legen, wie jehr bas Şeil bes Staates gefähroet ift, went bie

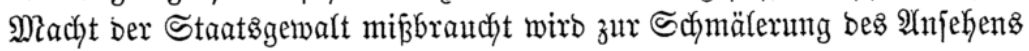
Der Sirchengemalt: fo brauche idf (5w. Exicellenz wohl nidyt einmal zu exjuchen, bem Şerrn Dberpräjioenten jein Benthmen wenigftens ernjtlich za berweijen.

(Ew. Excc. vermeinen, wohl in Sefolg eines ebenfalls irrigen Berichts,

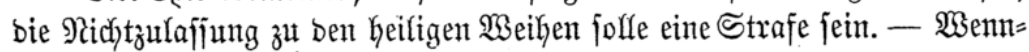
gleich) ber Ungehiorjam bes angehenten (Seiftlichen folche Strafe verbienen fönnte, fo ijt boch Gier Strafe nicht zu finben; benn meine Berfügung hat nux ben, jebem Unbefangenten leicht beritäntlichen, bie $\mathfrak{S a r n u n g}$ vor einer unaußbleiblichen natürlichen Folge enthaltenten Sim, $b a \tilde{\beta}$ ich anf bie Birbung foldjer Theologen, beren kefrer, Rernen und (Eonouite idy nidft

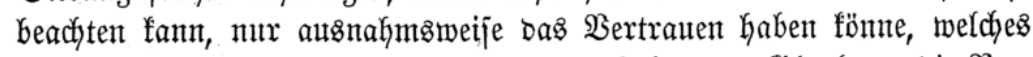

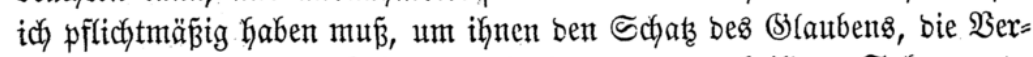

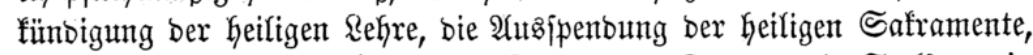

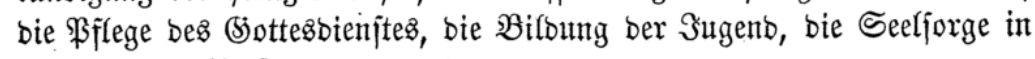
ifrem ganzen $\mathfrak{H}$ mfange anzuvertrauen. 
(5rw. Exceflenz hat man ferner beridytet, eine Erlaubniñ wie jene,

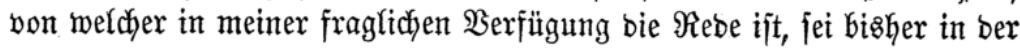
hiejigen Diözeje nicht erforberlich getwejen; ict) barf baher Erw. Exceflenz ganz gefyorjamjt erjuthen, fich von bem $\mathfrak{B}$ erichtjtêfler $\mathfrak{B}$ eweije biejer $\mathfrak{B} e=$ hauptung vorlegen zu laffen. Seitbem idy (Seneralvifar bin, haben einige

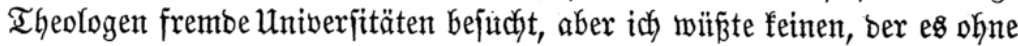

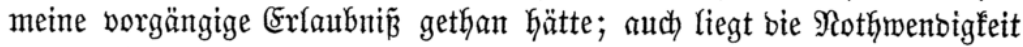

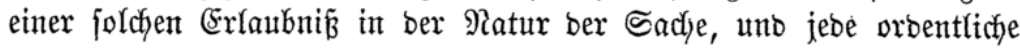
frembe Univerjität wärbe einen Theologen, meldjer eine foldje jodriftlidje Errlaubníz feines Droinarii nicht vorzeigen fönnte, nicht annehmen.

Uebrigens foll bas Sejagte unb bas zu Sagenbe nur zur Steuter ber Wahrheit, uno bamit En. Excellenz bie Rage ber Sache recht auffaffen

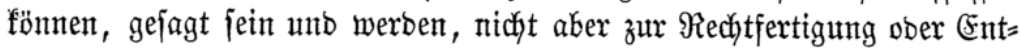

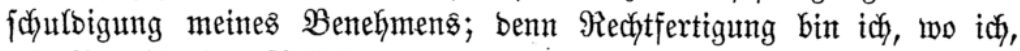

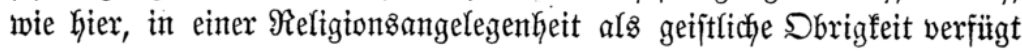

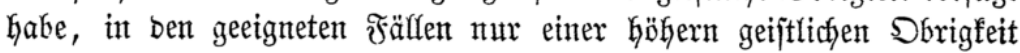
\{djulbig, uno ich bin weit entfernt, mich entichuldigen zu wollen, wo idy feft ïberzentgt bin, pflichtmäß̧ig gehanbelt zu haben.

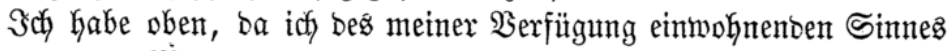

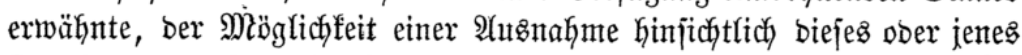

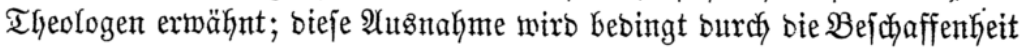
jowohl ber fremben Rehranitalten ïberhaut, als ber bajelbjt angejtefltent Rehrer, burch ben unter ben bort Rernenten herrifienden (5)eift uno burch

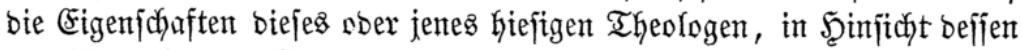
von $\mathfrak{A}$ uñnahme bie $\Re$ ebe ijt.

Nur bann, wenn idy auf bie Feftigfeit eines Giefigen Theologen mit

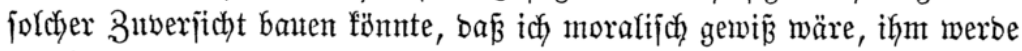

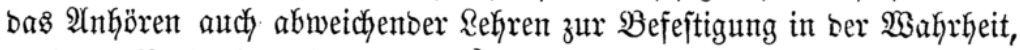

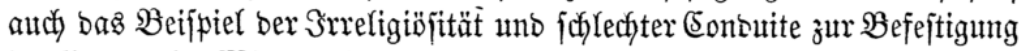

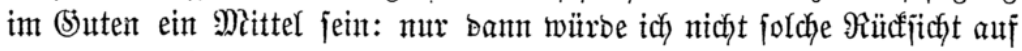
bie anbern, oben angeführten Bebingungen zu nehmen brauchen; wie jelten

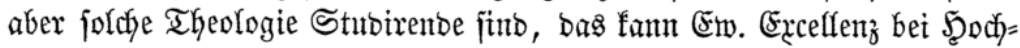

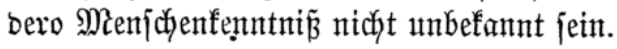

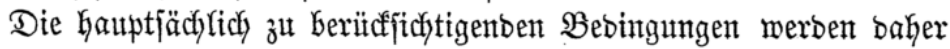
inmer jente fein, weldje jich auf bie fremben Rehranjtalten beziehen.

Scier aber barf idy mich auf Erw. Excellenz eigentes Urtheil bei Beant= wortung ber Frage: ob ich wohl ingent Butrauen haben faut unb. barf anf Rehranjtalten, wo nicht alfein bie 2 (njptalten ganz einjeitig von ber

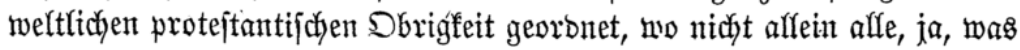

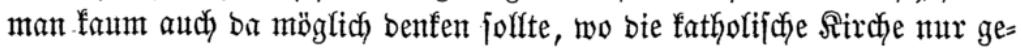


bulbet wäre, auch bie \$rofefforen ber fatholifdyen Theologie von jener protejtantifich $D$ brigfeit angejteflt werbent wollen, wo aljo bie ganze theo $=$ logifje Rehranjtalt extra nexum Ecclesiae ijt; wo nicht allein bie $\mathfrak{A} \mathfrak{n}=$ ftaltent, ihre Reyrer unt ber bort Gerrjchente Seijt mir unbefant fint, fonbern wo bie weltlidjen Dbrigfeiten es nöthig eradjtet haben, ifyre jelbjt= gejdyaffenen $\mathfrak{A}$ njtalten, bie von ihnen felbjt angejtellten ßrofefforen, bie Sonbutte ber bortigen Refrulinge in Sürveiflance zu fteflen?

Was itberbies insbefonbere bie Univerfität zut Bonn betrifft, fo ijt

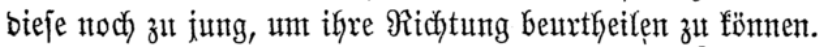

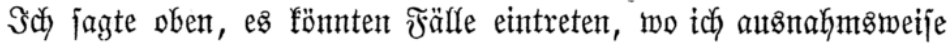
bas Stubiren ber Theologie auf fremben Rehramitalten erlauben bürfe;

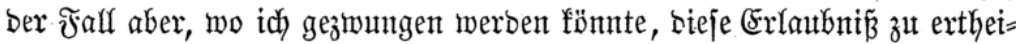

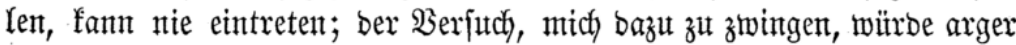

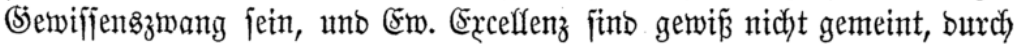

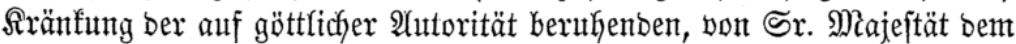
Sönige. anerfannten unb, infofern menfollidje (stewalt bas beöhere garan= tiren fant, garantirten Freiheit ber fatholijchen Sirchengewalt eine ver= meintliche Freiheit ber Stubirenton zu jodyütsen.

(5w. Excellenz füfren eine Stefle aut bem Âtfgemeinen Ranbrechte

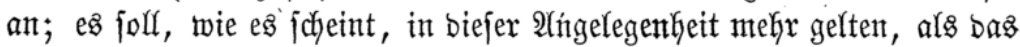
Siruchenrecht. Şierüber mus ich ganz gehorjamjt bemerfen:

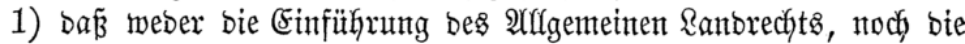
Begebenheit, wo fatholijche Ränber protejtantifchen Ranbesherren zugefalfen finb; bas in Deutficlant alfgemein gültige ßixcyentedyt aufheben fonnte; wo anbers verfahren wirb, ba tritt eben ber Falf ein, gegen welchen Der von Sr. Majeität Reichs $s=$ Deputations:

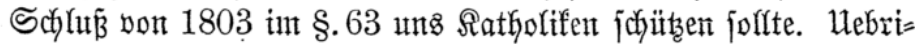
gens ift hier bie berufung auf bas Rirchenrecht nicht nötfig, in= Dem bie Keilige' Schrift beut(ich) ipricht;

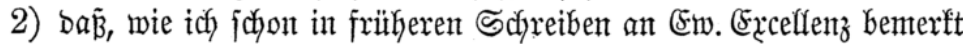
habe, mefrere Stelfen bes Affrgemeinen sanbrechts - unter $\mathfrak{A} n=$ berem auth bie angezogene Stefle - nicht ohne Stemifjenszanang und Эntoleranz auf ßatholifen angementet werben fönnen;

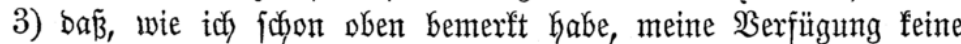

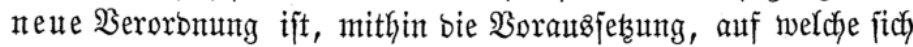
bie angezogene Stefle bez Ranbredyts bezieft, nicht einmal jtattfinbet;

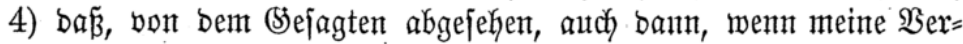
fügung eine neute $\mathfrak{B e r o r o m u n g ~ w a ̈ r e , ~ i c h ~ b e r p f l i c h t e t ~ g e t w e j e n ~ w a ̈ r e , ~}$ biejelbe z̆u erlajfen, uno ich nicht hätte vorläıfig bie, jonjt in man=

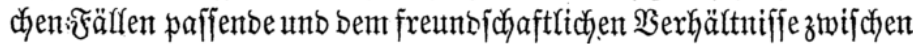


ber Rirche und ben Staaten angemefiene Frage: $0 \mathfrak{b}$ auth etwa

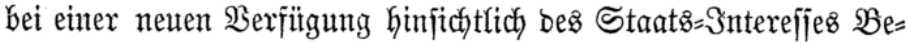
benffichfeiten obwalten? machen bïrfen.

(Fw. Excellenz twerben bas sub 4. Bemerfte, nach ernjttidjer (Erwägung bes Folgenben, jelbjt als ridhtig anerfennen milfjen. Beränberungen ber $\mathfrak{U m i t a ̈ n b e ~ m a c h e n ~ o f t ~ n e u e ~ B e r o r b m u t g e n ~ z u m ~ b r i n g e n b j t e n ~} \mathfrak{B}$ ebiixjnijīe, unb unter $\mathfrak{Y}$ noerm beshalb hat ber Şeiland feiner Sirche zwar eine unver= änberlidye $\mathfrak{B}$ erfafjut gegeben, aber mit berjelben in biejer fatfolijdyen Sirche Sbrigfeiten angeoronet ant bieje beauftragt, bie nötfigmerbenben Berfïgungen zut erlaffen.

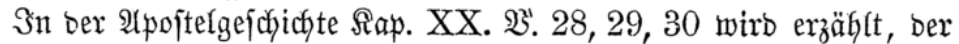

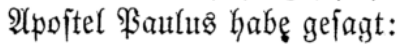

Attendite vobis, et universo gregi, in quo vos Spiritus sanctus posuit Episcopos regere Ecclesiam Dei, quam acquisivit sanguine suo. Ego scio, quoniam intrabunt post discessionem meam lupi rapaces in vos, non parcentes gregi. Et ex vobis ipsis exsurgent viri loquentes perversa, ut abducant discipulos post se etc.

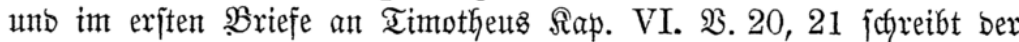
2lpoftel: O! Timothee, depositum custodi, devitans profanas vocum novitates et oppositiones falsi nominis scientiae, quam quidam promittentes, circa fidem exciderunt.

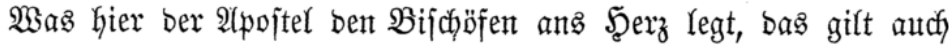

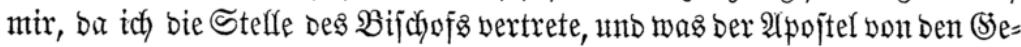

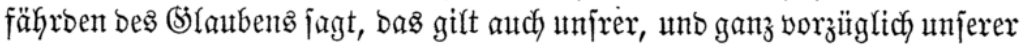
Zeit; bent es mag wohl faum eine Beit zut finben fein, wo jo viele waren, welche bas bem lejenben, hörentben unb lernbegierigen $\$$ hublifum bargeboten Gätten, was ber $\mathcal{A}$ pojtel profanas vocum novitates, oppositiones falsi nominis scientiae, perversa nennt; wo eine foldye babylnnifdye Ser= wirrung ber Begriffe jtattgefunben hätte, wo fo fehr Untfinn für Weisheit altógegeben und gefalten worben; wo bie Rüge, man fann jagen wiffen=

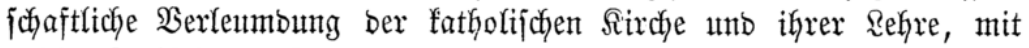
folcher ₹reigeit uno fo ungerïgt hätte ëffentlich auftreten fännen.

Es mag wohl fautm aud eine Beit getwejen fein, wo biejentigen, welche jelbjt ungläıbig getaufte Sceiben fint, wie ber 2(pojtel jagt, Sïnger fict nach, bas heipist mit jich ints Berberben zut ziehen jo begierig waren.

Wenn foldhe audy num, protejtantifichen ober itberhaupt sen Ranbes= Gerren einjtweilen nod zat jomeicheln, ben Schein antehmen, als eiferten fie für ben \$rotejtantismuts ober für bie Staatsgetwalt, jo wififen jie fehr.

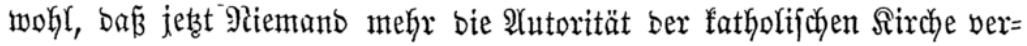


Iaffen wirb, unt fich ber $\mathscr{A}$ uttorität \&uthers ober (

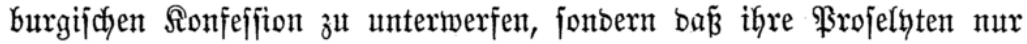
ber $\mathfrak{A}$ utorität ifyẹer eigenen $\mathfrak{B}$ ermunft, und zwar einzig biejer, ober berjelben in Erffärung ber $\mathfrak{B i b e l}$ hultbigen werbent. Sie wifjen fehr wohl, bå jie

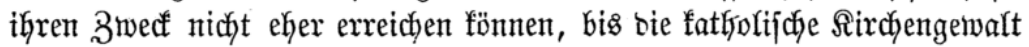
möglichjit gelähmt ift; baher ifnen fo wifffommen bie Erfinbung alfer jenter Rechte, welche bie Stantsgemalt über bie fatholifche Rirche haben jorf;

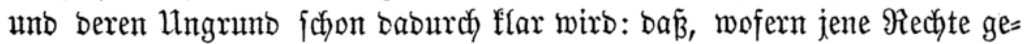
grünbet wären, bie âpoftel, welche vom heiligen \$seifte geleitet wurben,

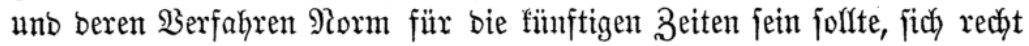
jehr gegen bie Staatiggewalt vergangen hätten.

Der Zwerf jenter getauften Şeisen ift aber eben.ber, weldyen ebent fie

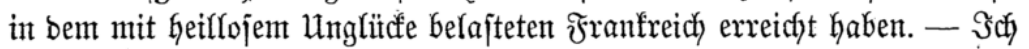

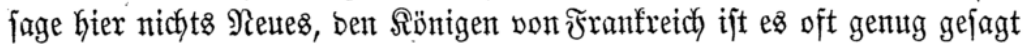
worben, aber fie haben nicht gehörig barauf geadjtet.

Wenn fchon biefes bie geiftlichen Dbrigfeiten zur verboppelten $\mathfrak{B a c h}=$

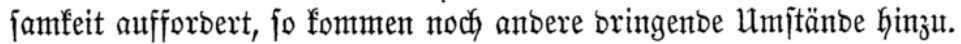

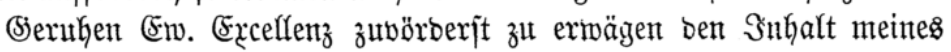

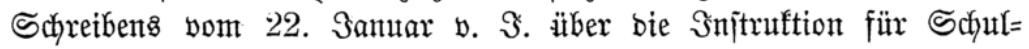
Injpeltoren, weldyem Sdyreiben autch jentes beigefügt war, bas idy unterm

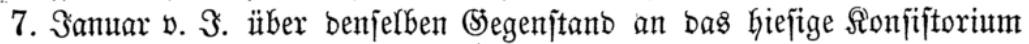
gerichtet hatte. Dann aber barf ich noch Folgendes beifügen.

Wie man zur Zeit ber Säcularifationt unt ber Frenibherrichaft Gin=

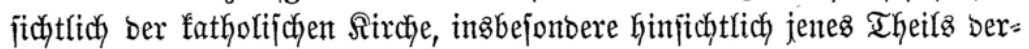
jelben, weldyer fich auf beutichem Boben befinbet, verfahren hat, bas ijt

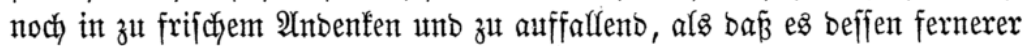

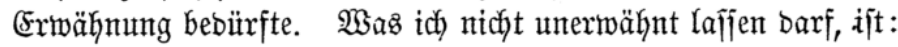

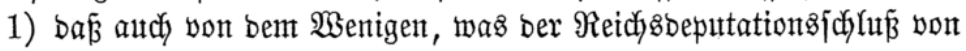

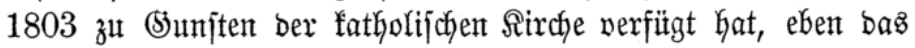
Sisejentlichjite uner rïllft geblieben ijt,

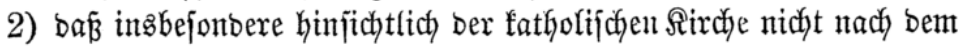
status quo von 1803, fonbern nach protejtantifđyen (S)unbjätzent verfahren mirb.

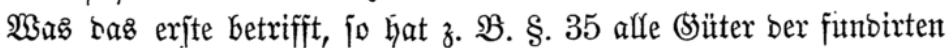

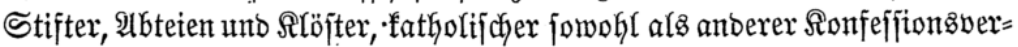
wanbten, ber freien unb yollen Dispofition ber Ranbesherren überlafjen, aber

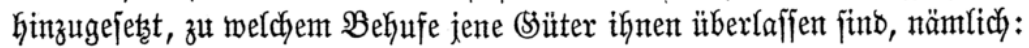
fowohl zum Behuf bez $\mathfrak{A}$ ufmandes für (5ottesbienft, Unterrichts:

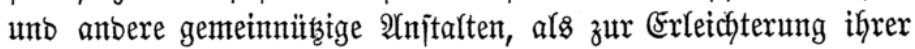
Finanzen, unt unter bem beftimnten $\mathfrak{B}$ orbehalten ber fejten unt 


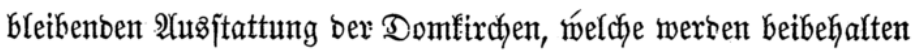
werben.

Wie mentig von biejem Theile bes vorliegenden §. exfülfet ijt, bas ift Ew. Exceflenz befannt, und nachbem mun jeit 1803 über 16 Jahre ver= floffen jino, ijt noch feine Domfirche botixt, noch haben bie Satholifen,

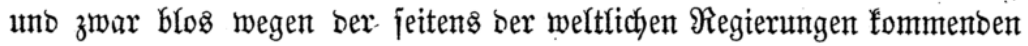
Şinbernifje, feine $\mathfrak{B}$ ifđüjpe.

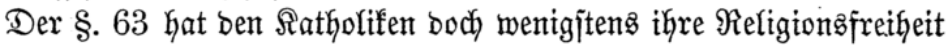
fitfyern wollen.

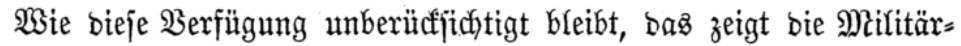
pflichtigfeit ber (seifitfichen und ber für biejen Stant fich bifloenten unb

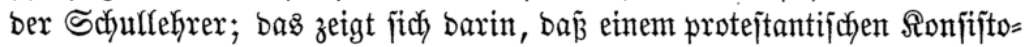
rium bas ganze Sdyutriejen unb einem protejtantifoten Suratorium jogar bie fatholijace Theologie unterworfen fein foll; bas zeigen bie Berkand= lungen über ben freien $\mathfrak{B}$ erfehr mit $\Re$ om, über $\mathfrak{A}$ njteflungen ber (seij̄t= lichen, über gemifidte (Ehen, ïber bas Schulwejen, ïber bas jogenannte

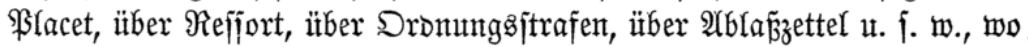
immer ich pflidy)tmäß̈ig unr bas erhalten wollte, was ber fatholifchen Sirche

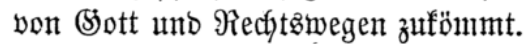

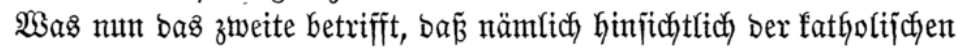
Sircfe nach protejtantifłyen (5rundojätsen verfahren wirb, fo ijt natïrlich,

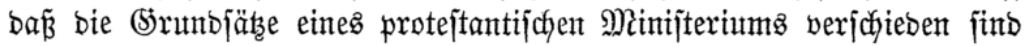
von jenten eitres fatholijchen Sirchent=Dbern. (Es ijt aud nicht zu ver= wumbern, bã Staatomaximen anjieht, welche bie fathol. Sirchen=Dbrigfeit als jefr ein=

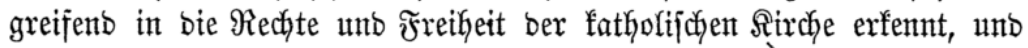

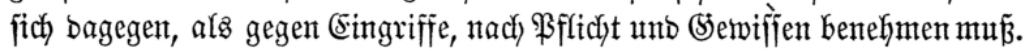

Die Frage: auf weldher Seite bie Wahrheit ijt? zut beantworten, bafïr fann bas protejtantifdye Minijterium nidft fompetent jein, unb bie Sompetenz ber fatholijachen Sirche wirb von jenem Minijterio nidgt an= erfannt. Es giebt baher nur ein Mittel, bem immerwährenten Zwie= fpalt zutvorzhtommen, nämlich biejes: jich fejt an ben statum quo

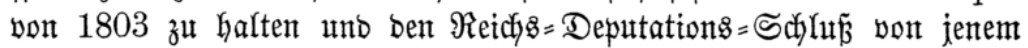
Sahre fofort auch in bem, was zu (\$) anjten ber Ratholifen ijt, in Er= fürllung zu bringent.

So lange aber anberz, fo lange wie bizher verfahren wirb - Em.

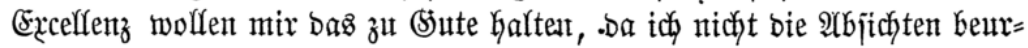

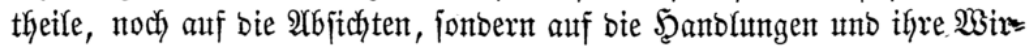
fungen jehe - jo lange fann idy mix nidht verheglen, bã bie fatholijche

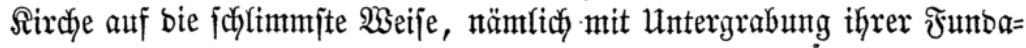




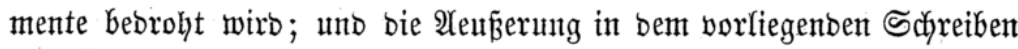
aiw. Exceffenz:

- inbem bie philojophifdye uno theologiface rafultät bem (seneral= vifariate nicht untergeorbnet iit, fontern in ber \$erjon bez Şerrn Dberpräfibenten ify befonberes amtfiches @uratoriunt hat, ohne - beffen Sortwiffen unt Beiftimmung weber an bie Defane, nod an bie Stubirenden felbjt ummittelfar etwas berfügt werben burfte fagt in anberen 13 orten: bá ber wejentlidjfte 3 weig ber Airchengewalt,

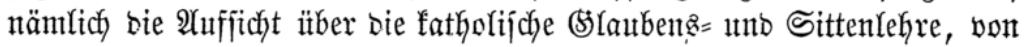
Dem fatholifchen $\mathfrak{B} i$ if

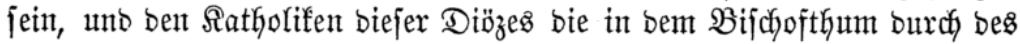
(Sottmenfdyen Stiftung ifinen verliegene Sidjerkeit ber Âtufredyterfyaltung ber reinen Refre nummefy ifnen genomment werbent jolle.

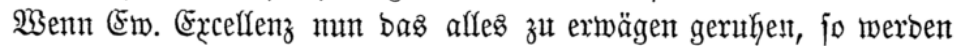

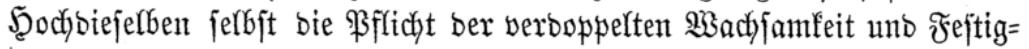
feit eines fatholifchen Sirchen $=$ D bern, insbefonbere auf bie Freiheit ber

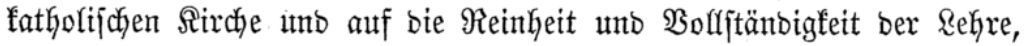
mitfin ganz befonbers auf biejenigen zut wachen, weldye befitimmt fint, bie andern burch \$ort und That zu belehren, anerfennen.

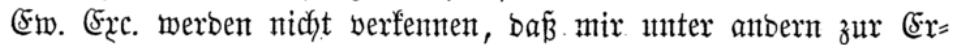

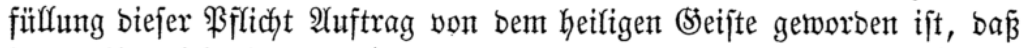

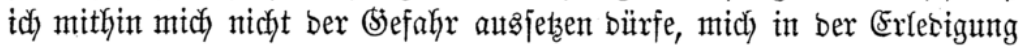
befferben Kinbern zu lafjen; biejes aber witrbe idh gethan haben, wenn ich borläuftig Kinfiçttlich meiner mehr erwähnten $\mathfrak{B}$ erfïgung an bie Theologen angefragt hätte.

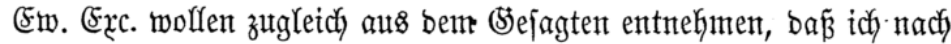
Pflicht uno \$setwiffen meiner fraglichen $\mathfrak{B e r f i t g u n g}$ allerbing mur unb bie an einzelne Iheologen ertheilte negative bejcheibung auf

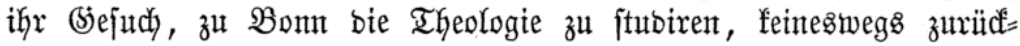
nehmen bari.

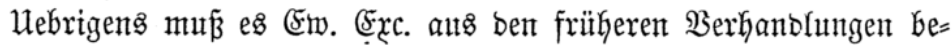

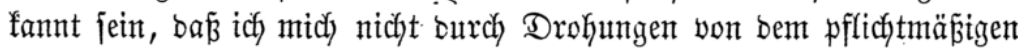
Benehmen ableiten laffe; mas aber bie Folgen betriffft, fo werbe nicht ich, ba idy nady Sfflidyt und Stemiffen hanble, foldye zut verantworten Kaben.

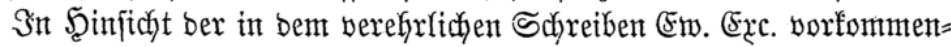

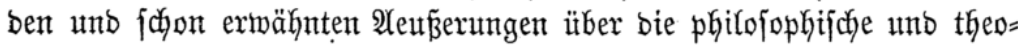

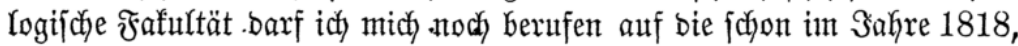
inzbejonbere aus Seranlaffung ber Dienft $=\Im n$ nftruftionen vom 23 . Dftober

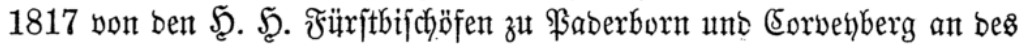

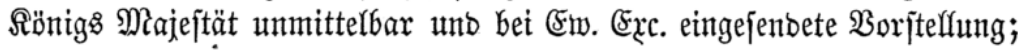




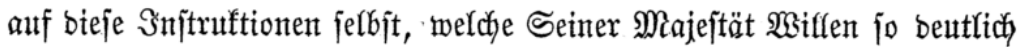

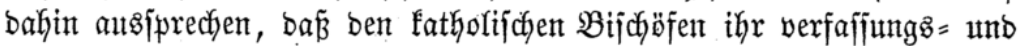

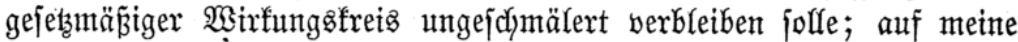
frühern Sdjreiben über biejen (segenftant, und ingbejonbere auf meine Borjteflungen ǘber jene Snjtruftionen.

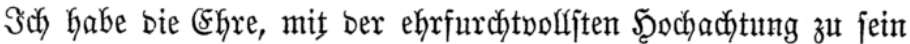

Mïnfter, am 21. März 1820.

(Fiw. Excellenz

ganz geforjamiter Diener

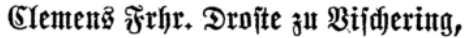
(5eneralbifar.

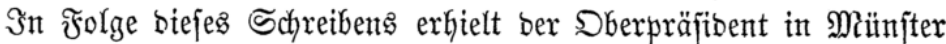

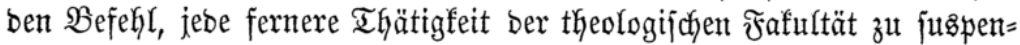

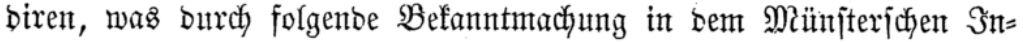

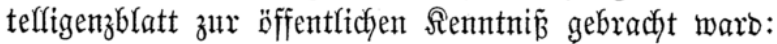

\section{$\mathfrak{B} \in \mathfrak{f} \mathfrak{a} \mathfrak{n} \mathfrak{n} \mathfrak{m} \mathfrak{a} \mathfrak{d}) \mathfrak{u} \mathfrak{n} g$.}

Sn Folge bes an bie Theologie Stubirenben Gierjelbjt ergangenen Berbots, anbere, als bie hiefigen theologifhen Sorlejungen zut bejuchen, woburch bie theologifoche frafultät in eine ganz unbefugte Dppojition mit

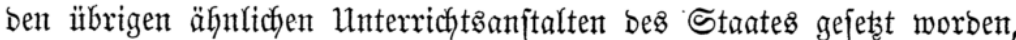
hat bas hohe Minifiterium ber geiftlichen unb Unterrichts-2lingelegenfyeiten

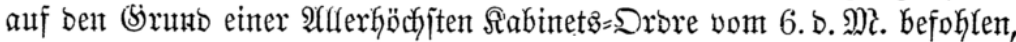
bis auf weitere $\mathfrak{B}$ erfügung jebe Thätigfeit ber hiefigen theologifden $\mathfrak{F} \mathfrak{a}=$

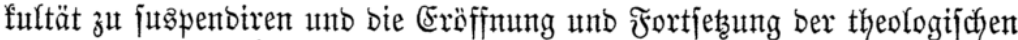
Borlejungen zu unterjagen.

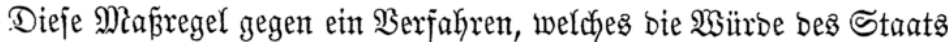
burchauts nicht zut buldoen gejtattet, ijt nidjt ofye vorkergegangene $\mathfrak{A} n=$ Görung ber Befjörbe, weldye bas oben genannte Serbot erlajfen hat, ver= fügt und ebent baburch bis jeţt verjpätet tworben; ba fich biejeltbe aber

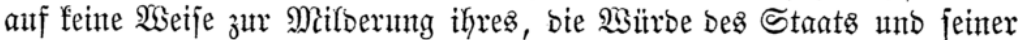
übrigen Rehranjtalten werletzenden Bentehmens betwegen lajien, fo mup̃te

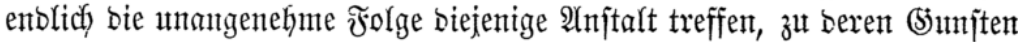
jene Berfïtgung erlajien war. Denn eine Rehranjtalt, neben welcher anbere

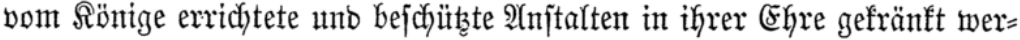
ben folfen, fann in biejer $\mathfrak{A}$ nmaf̧ung nicht gebulbet werben. Die weitere

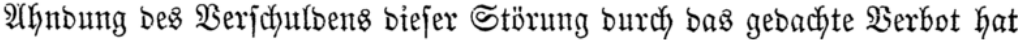
fich bie Gähere Behörbe vorbefalten.

(5: ift unt fo mefrr zut bebautern, baj ein trauriger 3 siberjtand, bei welchem für feinen audy nur irgent ein (Stervint erwachfen fant gerabe in

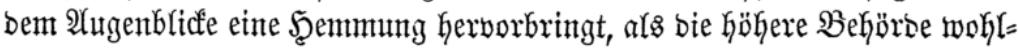




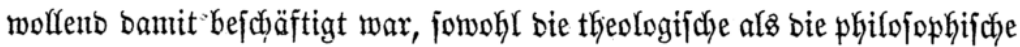

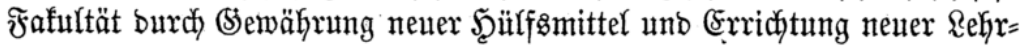

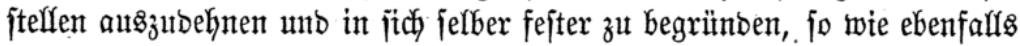

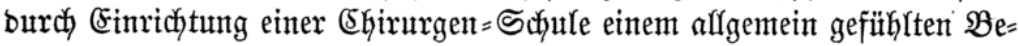

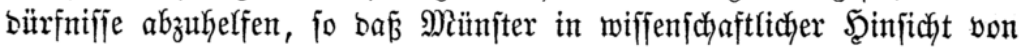
Reutem einen fejten Stanbpunft einutehmen uno behaupten fonnte.

Die philojophif

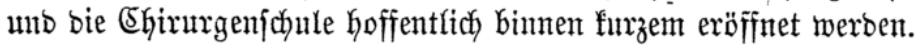

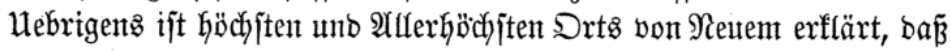
bas an bie Stubirenten erlafjene Berbot als aufgehoben zu betractiten jei, unt bá ber $\mathfrak{B} e$ ejuch ciner anbern Rehranjtalt fünftighin von feinen nach)= theiligen Folgen für fie fein merbe. Sie mögen fich überzengt halten, bå

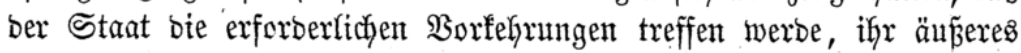

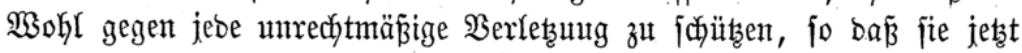
getrojt ben $\mathfrak{W}$ eg ter $\mathfrak{B}$ iloung verfolgen fönnen, welchen fie uno ifare $\mathfrak{A}$ gehörigen als ben angentefienen erachten werben.

$\mathfrak{M}$ ü ñ̂ter, ben 19. Alpril 1820 .

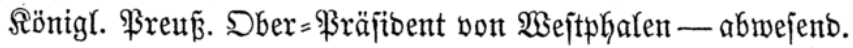
im 2 Uuftrage:

Der $\Re$ egierung $=\mathfrak{B i c e}=$ Fräjitbent v. Sa)ledtendahl.

Der $\Re$ egierungirath Rientib.

Erit nachbem ber Sieneralvifur jein 2 (lmt niebergelegt hatte, wurben

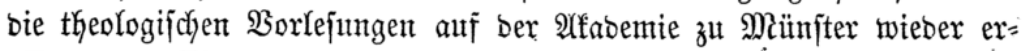

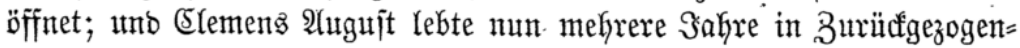

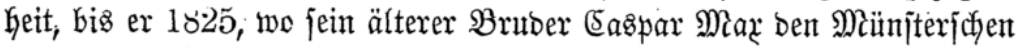
Bifdyofituthl bejtieg, zum Weihbifdy of beffelben ernannt murbe.

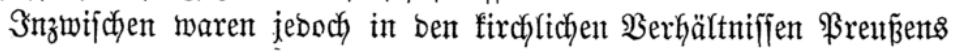
bebeutende Seränberungen vorgegangen, uno namentlich bie Bistgümer in ben neu erworbenen Brovinzen geregelt unb befintitio bejeşt worben. Die

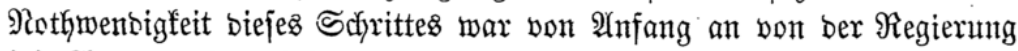

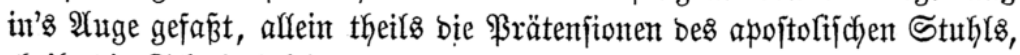
theifs bie Sdywierigfeiten, geeignete unb alfe Theile befriebigende ßerjön=

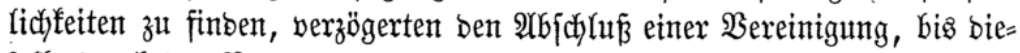
felfe burch ben $\mathfrak{B e r t r a g . v o m ~ 1 6 . ~ \Im u l f ~} 1821$ burch bie $\mathfrak{B u f f e}$, De salute animarum" zu Stanbe fam. Die Berhandhungen mit ber päpiftliçen

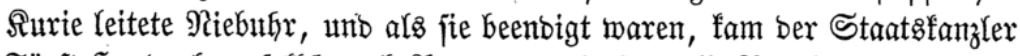

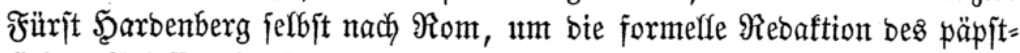

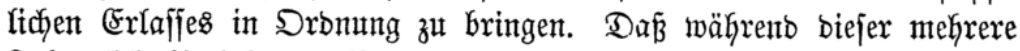

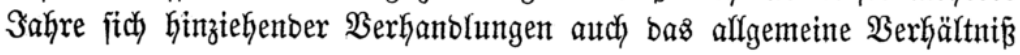


ztwijchen ber fathofijłyen Rirche und bem Staat bejprodyen, unb nament= Iidy bie Eintwirfung ber erjtern auf bie sBejeţung unb Beauffichtigung

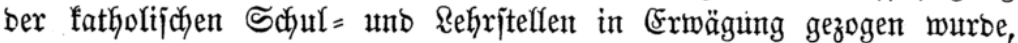

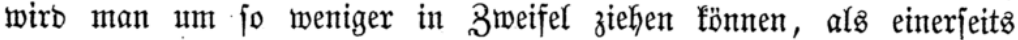

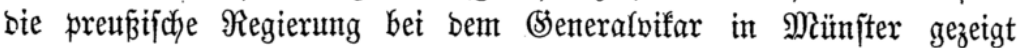
hatte, mit welcher Fejtigfeit ber Unterrichtâminifjter von ât tenjtein

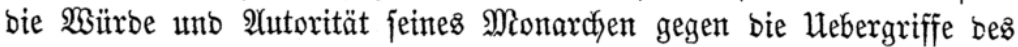

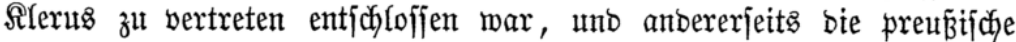

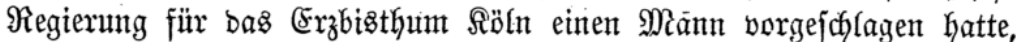

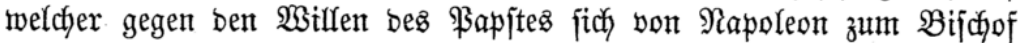

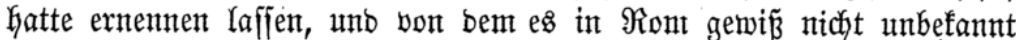

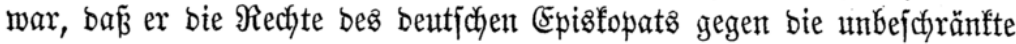
Monofratie bes päpjtfichen Stuhls gefichert wiffen wollte, ben Dom= bechanten Freikerrn von Spiegel zu Münjter. Eas finben jidh ïber alle

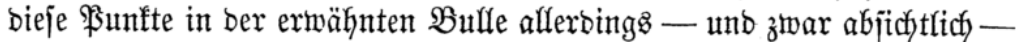

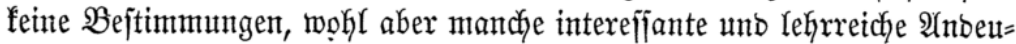
tungen in ben gleidfzeitigen $\Re$ orrefponbenzen Steinz mit ben betreffenten

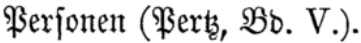

So fałreibt Stein bereits am 11. Miärz unb 17. Mai 1817 an (s)agern:

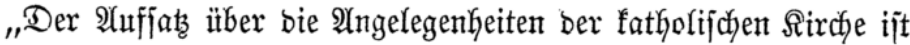
oberf(ächlich): - um jie beurtheifen zu fönnen, muß man mit bem

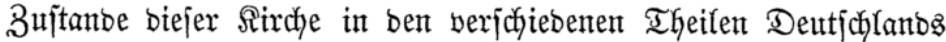
uns mit ber Stimmung ber Stemitther ifyrer Befenner vertraut jein.

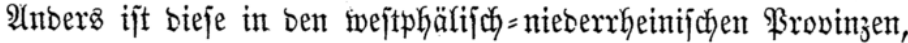
anbers in Ränbern, wo beibe $\Re$ eligionşparteien unter einanber ver= mengt und mit einanber in $\mathfrak{B}$ erïfrung leben.

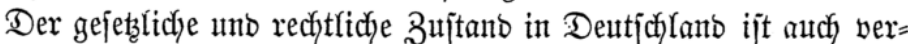

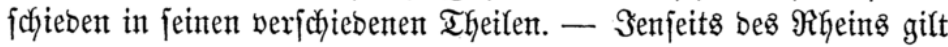

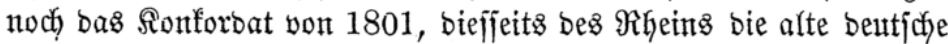

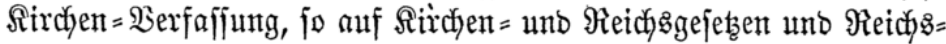
herfommen berutht.

Man münte zuterīt ben gegentwärtigen 3uitano ber fatholifajen "Sirche in Deutjchland genau barjtelfen, unb bann erjt läßjt jỉd bie Erage beantworten: weldae neue Einridytungen an bie Steffe ber untergegangenen alten erforbert biejer 3ujtand,

bebarf man eines bas ganze $\mathfrak{B} e r h a ̈ h t n i \tilde{\beta}$ ber Sirche zum Staat unt ifyen interen Buftant umfafjenben Ronforbats, ober mur einer Serabrebung mit bem $\mathfrak{B} a p j t$ über einzelne einer ફ̧ülfe bebürfente Stegenitänbe? 


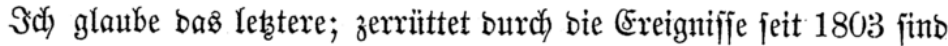
Gauptjäcylich bie Diözejan = Serhältniffe und bie $\mathfrak{B}$ erfajfung ber $\Re \mathfrak{a}=$

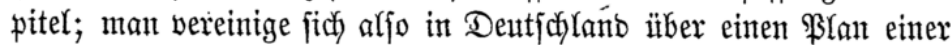

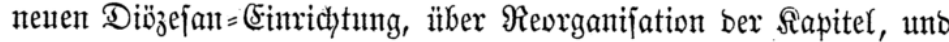

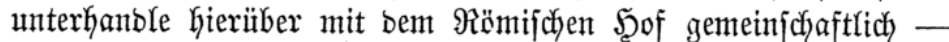

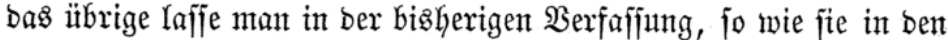
älteren \$๋ejeţen unb bent älteren Şerfommen begrïnbet ift, man be=

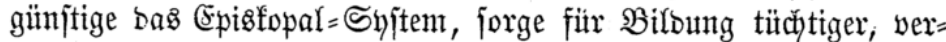

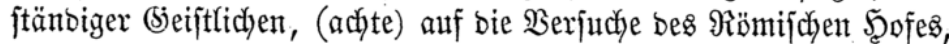

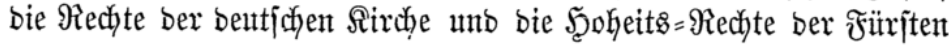

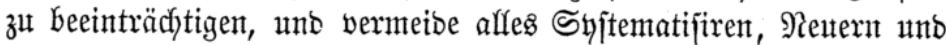

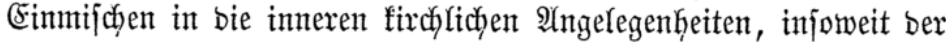
Staat nicht ein bejonberes Sntereffe hat, baran wegen ihres (Fin= flufjes auf bie bürgerliche Befellichaft Theil zu nefmen."

11. März 1817. (1. c. S. 144.)

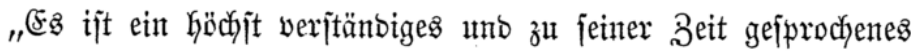

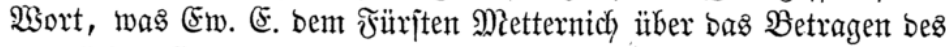

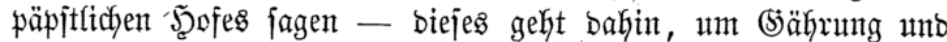
Bitterfeit zwifchen ben protejtantijchen Ranbeskerren unb fatholijchen Unterthanen zu erzengen unb zu unterhalten. Der päpjttliche Şof

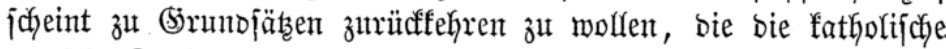
beutjche Sirthe längit aufgegeben ober gemilbert hatte; ind er hat burch bie Berrüttung ber gejeffjcyaftlichen Serfafiung ber Sirche,

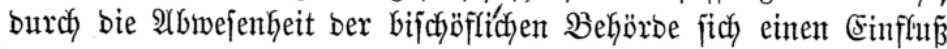
unb eine unmittelbare Einnirfung angemap̧t, bie ihm gar nicht zu=

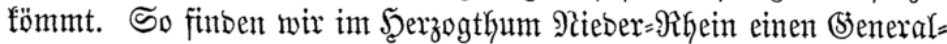

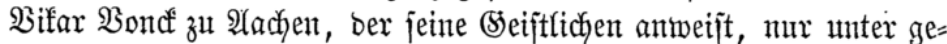

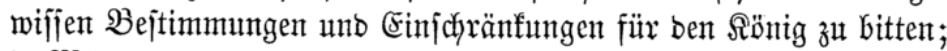
in Miunjter verbietet ber bumme und fanatijdye Sieneral = Bifar von Drojte ben Bieijtlichen, ingent einent $\mathfrak{2}$ nntheil an ber Einjegnung ber (5he zu nehmen, wenn nicht bie Ratholizität ber Sintber altßbebungen

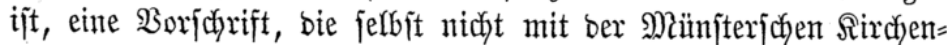

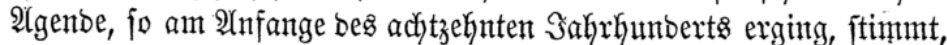
bie viel milber unb glimpflicher ijt.

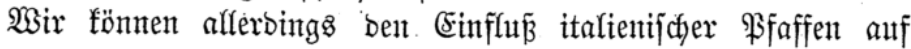

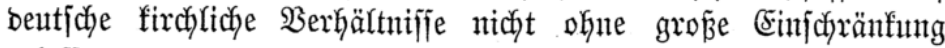
zulâfien.

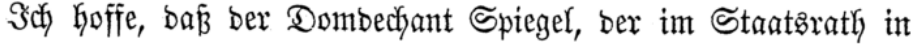
Berfin jizt, auf biefe Materien Einfluz haben wirb; er bejitzt bie 


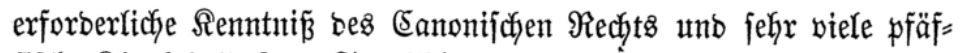
fif

ben 17. Mai 1817.

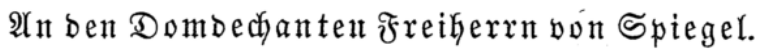

"(Em. Şochgeburen jehr verehrlicheś Schreiben erhielt idy gejtern. Uebereilen Sie fich nicht in \$hrem Urtheil über Dr. Schlofifer; ex ijt ein Miann von viefem (Steift, fehr entfernt, ein Ultramontaner zu

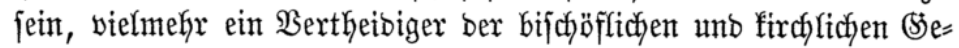

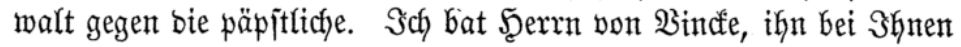

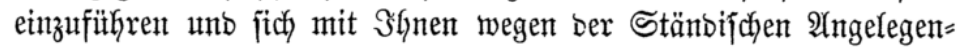
heiten zu befprectyen, worin er feit verflofjenem $\Im a \mathfrak{h}$ arbeitet." (l. c. ธ. 185.)

Den 27. Эanuar 1818.

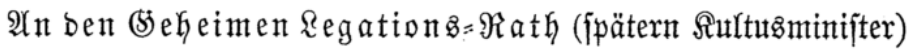
(Eid) horn:

"Die $\mathfrak{B}$ erhanblungen wegen ber $\mathfrak{A}$ ngelegenheiten ber fathodifchen : Sirche in Franfijurt find geidjlofien, bie leţten \$rotofolfe habe idy noch nicht erhalten. Wreben hat ben Intrag abgelehnt, ganz gebe idy bie F̧offnung nidyt auf.

(E⿱

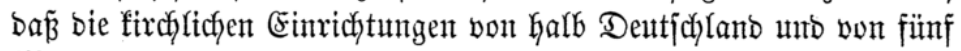
Millionen Bewohnern bez prenpijichen Staats gebilbet uno georbntet

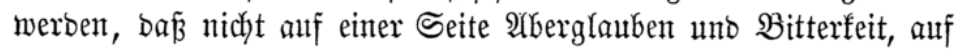

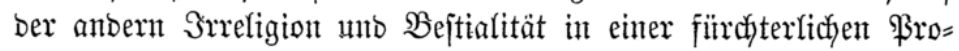
greffiton wadfje. Bründern fonnten wir bie Sirche, aber nidyts für ihre Erfaltung und Bereblung thun.

(Spiegel) ift ein Miann von \$eift unb \$ełehrjamfeit, \$ejdäfts=

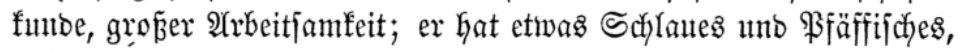

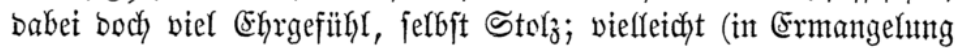

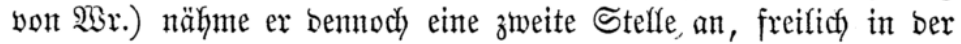

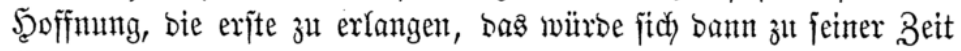
finbent.

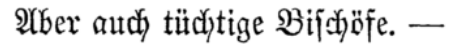

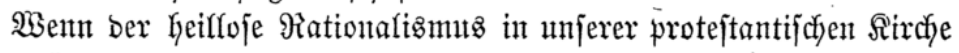

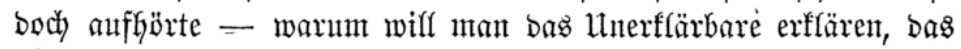

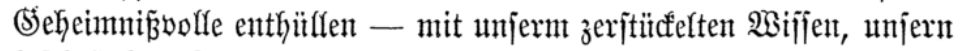
befac)ränften Siäften - wie wentg wir wiffen, wie wentig wir im Stande find, uns ferbít zu erfennen, forftent ms sody bie nenejten 
Wertbegebenheiten und auch) an uns felbjt bie (Explyeinungen bes Magnetiżnuts beléhren.

Eine Synobal= Berfajןung wirb unjere protejtantijchen aufgeflär $=$

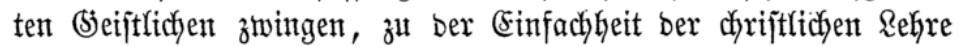

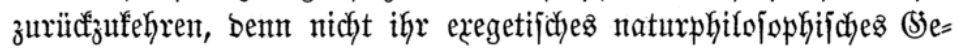

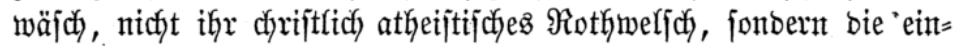

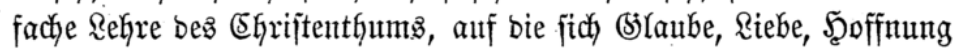

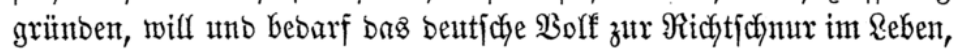

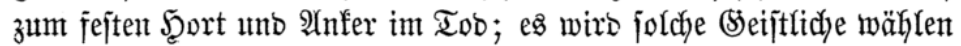
unt bon ben antern jidis abwenten.

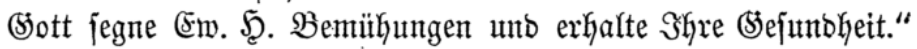
(1. c. S. 857.)

Den 22. Îpril 1818.

Эm Miärz 1821 war Stein zu feiner Erholung uno ber Staatz=

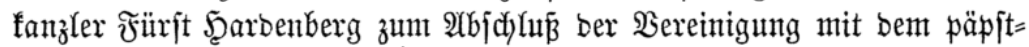

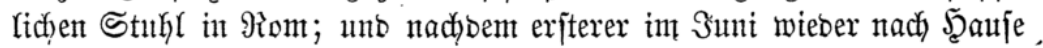

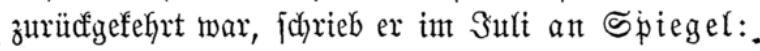

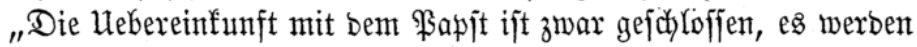

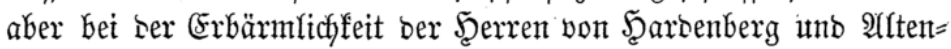
jtein bie Berabrebungen felbjt in mehreren Эahren nicht in bas Reben treten, baker es jofwer ift, worker zu bejtimmen, ob es alsbant rath= fam jei, eine hoke geiftlidje Stefle anzunehmen. Sjt aber alzbann bie Rage ber Sache gegen ben jetzigen Bujtant nidjt jehr veräntbert,

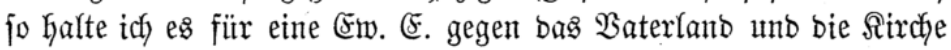

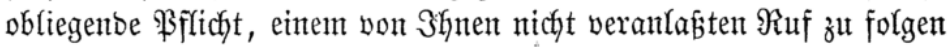

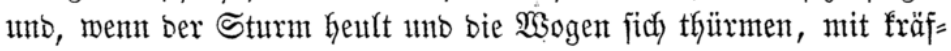
tiger unb funbiger Şand bas Stenerwber zu ergreifen, um an bem

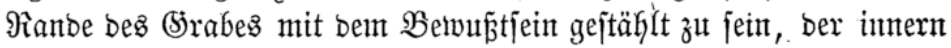

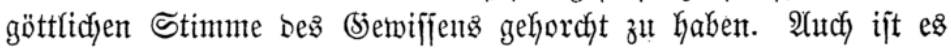

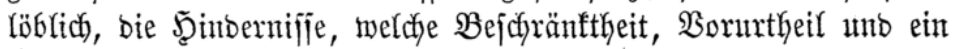

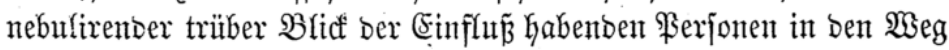

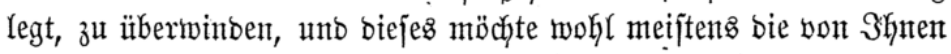

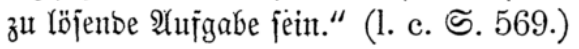

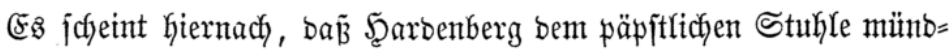

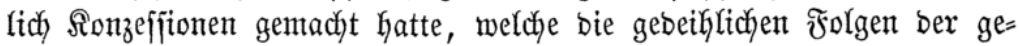
¡chlofijenen Ronvention gefähroeten; wentigitens barf man bies aus einem

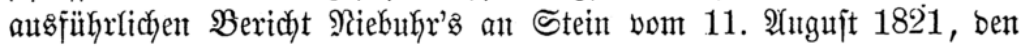

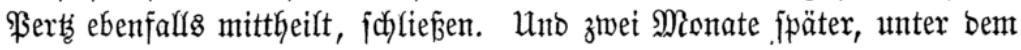

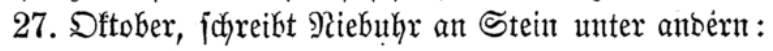




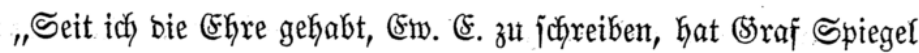
mich von feinen $\mathfrak{B}$ erhandlungen mit bem Minifterium in $\Re e n n t n i \tilde{B}$ gejetzt. $\Im$ dy bin in einige Berlegenheit gefommen, ba idy bie fïr ifn fobn gethanen Schritte habe zuritcttretent müiffen. Das ijt fehr

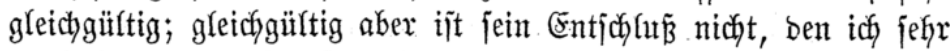
unglïfflich finbe. Fin fo welterfahrener Maun fonnte nicht glauben, bá er burch feine Schritte bei bem Minijter und Superminifter

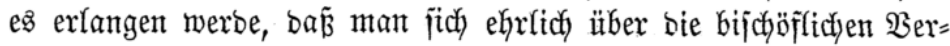

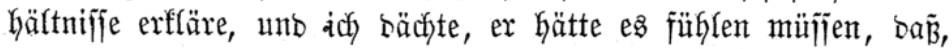
inbem er bieje Erinnerungen mit ber $\mathfrak{W}$ eigerung, jeine Penjion als Dombechant aufzugeben, verbant, ein jo böfer Schein gegen ifh ent=

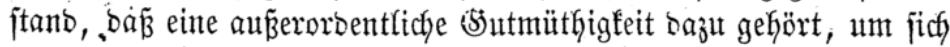

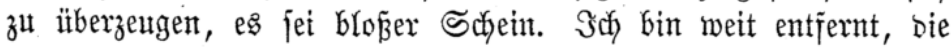
(5eiftlidffeit zut tabeln, welche jidy gegent bas ujurpirenbe Eingreifen bes Minijteriums mehrt; wenn man aber nidft blos fronbiren, fon= sern 3 wedfe erreidyen wifl, fo milïte man jeţt bie angebotenen Stél= len mit freimütf̧iger siffärung annebmen uno in ihrer Berwaltung

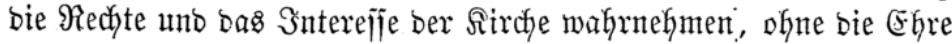

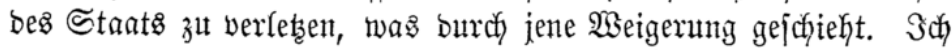

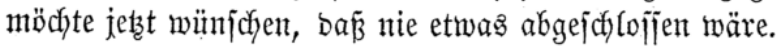

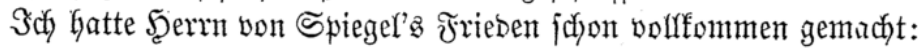
ber jefr eingenommene uno irritirte \$apjt jelbjt war - unb ijt es

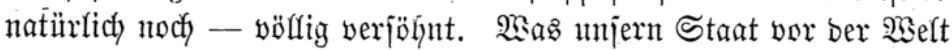

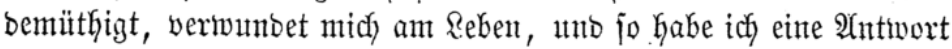
an Scern von Spiegel fajfirt und eine jweite nody nicht jut Stande bringen fönmen." (1. c. S. 624.)

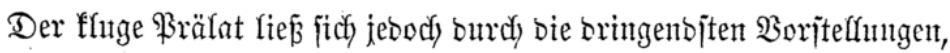
bie aud Stein ifm mieberholt machte, nicht betwegen, bent von ifhn einge=

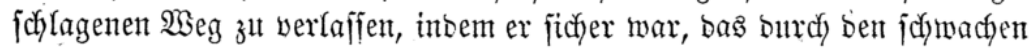
und nactgiebigen ફ̧arbenberg zut erreidjen, was er bei bem fräftigen unt

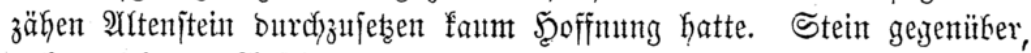

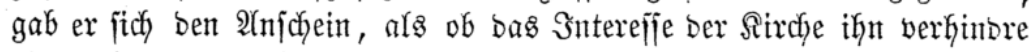

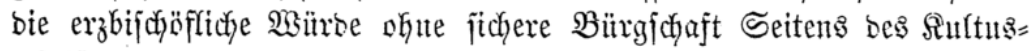
minifteriums anjunefymen. Denn unter bem 26. Februtar 1822 ridstete

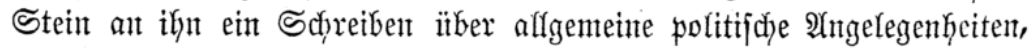
welches mit folgentoen Morten beginnt:

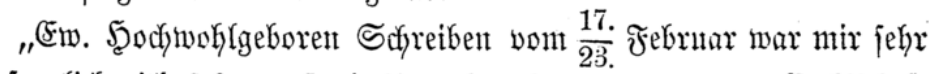

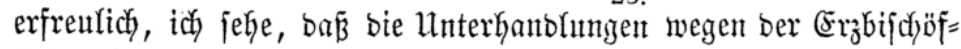
lichen Würbe noch fortbautern. - Wenn fidy bas geiftliche Departe= 
ment affein anf bas jus circa sacra befduränft, fich nidyt in bie

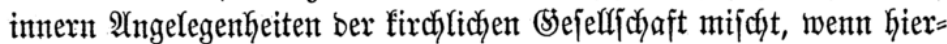

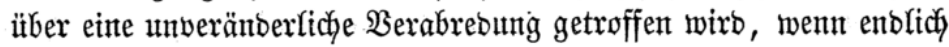
bie Searbeitung ber fatholijchen Sachen, jo atts bem jure circa sacra emaniren, einer auz ßatholifen bejtehenben Seftion bes geijt= licken Departements antwertraut wirb, jo jcyeint mir, bie Eollijionen

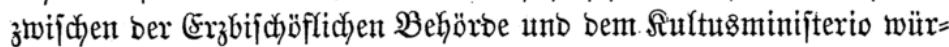
ben fo viel alz möglidy vermieben." (1. c. S. 645.)

Эn ber That aber hanbelte ez fich går nicht um bie Differenzen

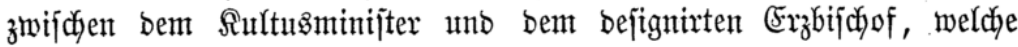
amtlich ausgegliden werben fonnten, fonbern um bie B̧efdywidytigung Pits VII., weldyer feinen Sroll gegen ben napoleonifchent Bifdyof nidyt unterbrücfen fonnte. Die Befeitigung biẹes Scinberniffes wurbe burch Jearbentberg perjönlich) unt im (Seheimen geleitet; und noch in einer Dent= jătift, welche Spiegel unter bem 6. Märr 1822 an ben Staatsłanzler richtete, jagt er zat feiner Entichulbigunts:

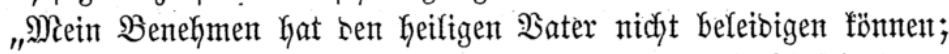

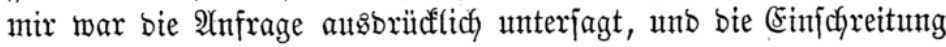

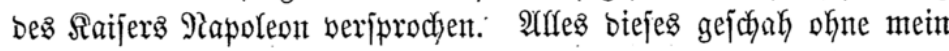

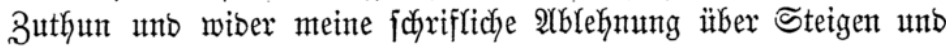
Fortrücten in ber geiftlichen Raufbahn."

Man mirb baher wohl faum fehlgreifen, wenn man annimmt, baź bieje Angelegenheit unmittelbar nach bem 6 . März 1822 von ந̧arbenberg in Dronung gebracht wurbe, unto baß ber Beridyt, ben berjelbe unterm

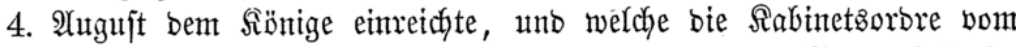

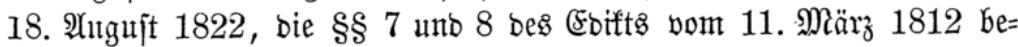
treffent, zur Folge hatte, jid in ber Scauptfacke auf bie firchlichen $\mathfrak{B e r}=$

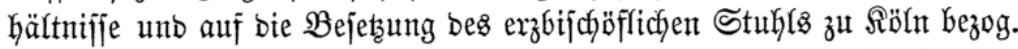
(E⿱

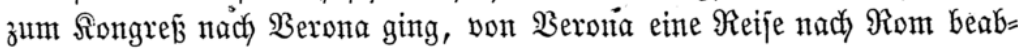
fichtigte, bie er bent auch wirffich unternahm.

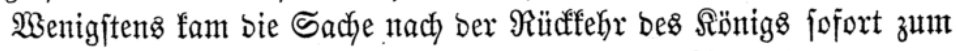

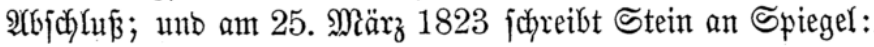

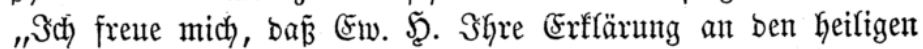

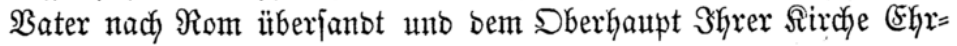

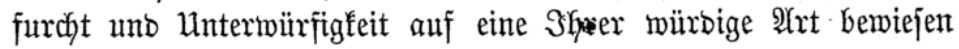
haben." (1. c. S. 807.) 
Fünfte Mtbtheilung.

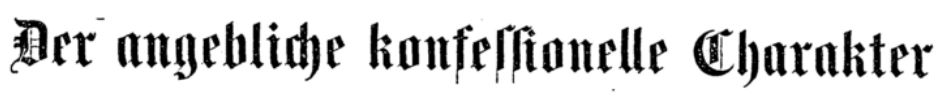

\author{
Der preuzijden Univerjitäten
}

auf Grund igrer Statuten. 

$\mathfrak{A}$

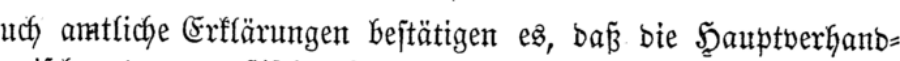

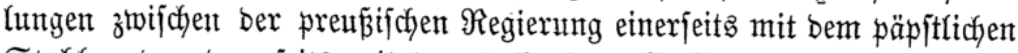

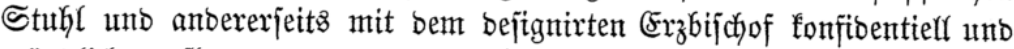

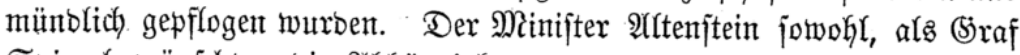

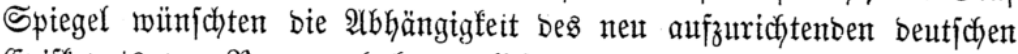

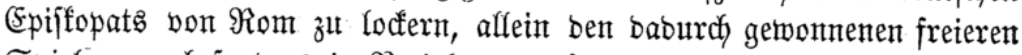
Spietraum, befonbers in Beziefung auf bie beiben Gerborragenden jtrei=

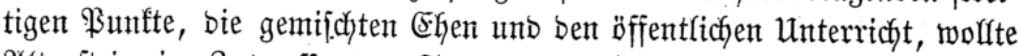
Y्ultenjtein in Intereffe des Staatz, Der Sraf Spiegel in bem jeiner

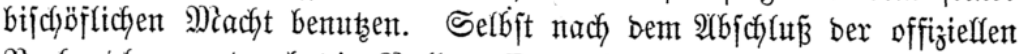
Berfanblungen burch bie Bulfe: „De salute animarum" blieben bie Şauptpunfte weiteren $\mathfrak{B e f p r e c h u n g e n ~ v o r b e h a l t e n , ~ u n o ~ n a m e n t l i c h ~ j o l l t e ~ b i e ~}$

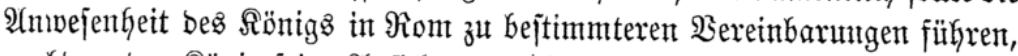

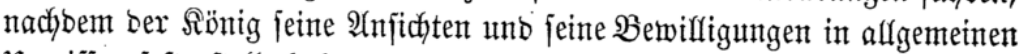
Unmiffen jejtgejtellt haben würbe.

Simmt man mun an, wie wix bereits angebentet haben, bafi jene

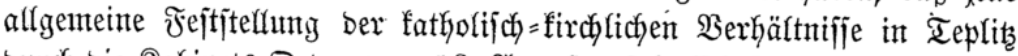

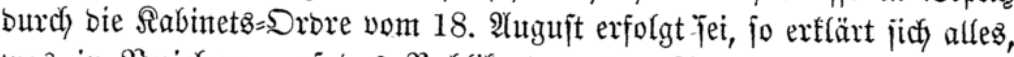

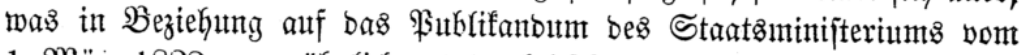

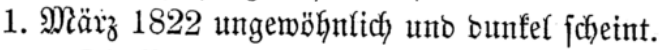

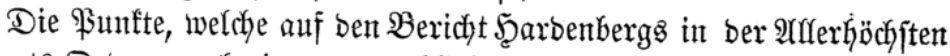
Rabinets=Drore genefymigt waren, blieben_geheim uno waren nur als $\Im_{n}=$ ftruftion für Den Staatgfanzler zu feiner Benulung bejtimmt. Wenn

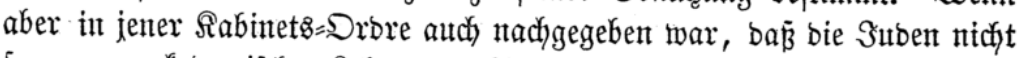

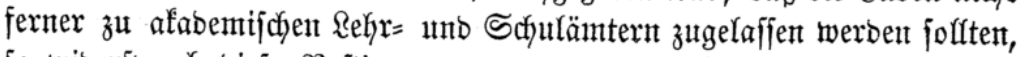
jo wiberiprady bieje Bejtimmung gerabezu bem (sejęze vom 11. März 1812, und eঞ mufite baker auf ingend eine Weije befant gemadyt werben, 


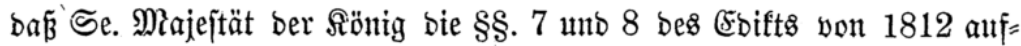

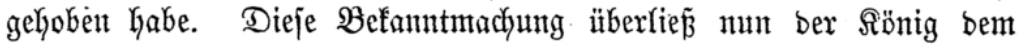
Staatsfinzler, welcher Gierzu fein anberes Mittel hatte, als aus ber ganzen

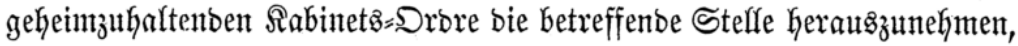

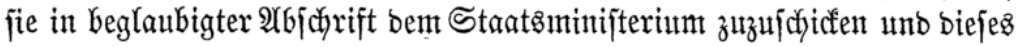
unt bie Befianntmadyung zut erjuchen. So ift bent ber in ber (bejess= gebung einzig bajtehenbe Fafl möglich und nothwentig geworben, baß sas Stantsminifterium, welchem eine vollitänoige $\Re a b i n e t s=$ Drore nicht mit= getheilt worben, ein einzelnes Stïff aus berjelben, nach einer iłm zutgefer=

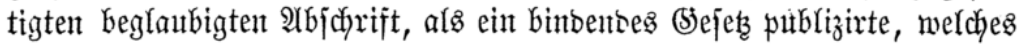

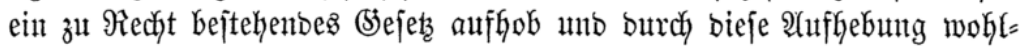

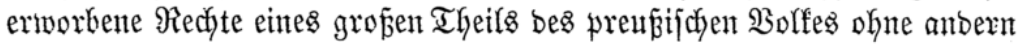

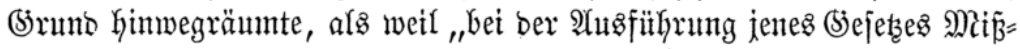
verjtänonifie jiłh gezeigt haben."

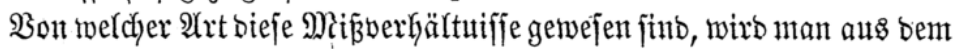
mitgetheilten gej dyidyttichen Material nakezu mit Sidjerheit errathen fönnen;

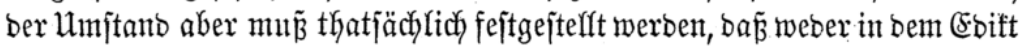
von 1812, welches ben Эuben bie befähigung zu afabemifchen Rehrämten

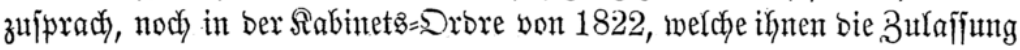

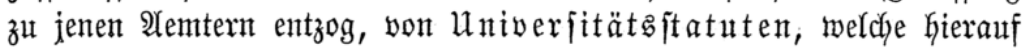

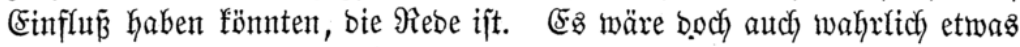
ganz $\mathfrak{A}$ bnormes, went ber (Sejełzgeber burdy bie Statuten einer Uniberjität, bie ex jeberzeit änbern fant, werhinbert fein jollte, allgemeine gejetzliche $\mathfrak{B} e=$

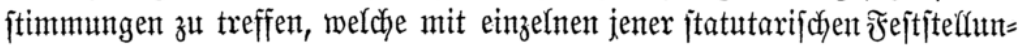

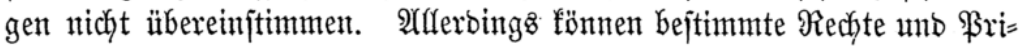
bilegien, weldhe einer phyjifdyen ober moralifdyen ßerjon lanbesherrlid verliehen worben, nidyt ohne 2 Seiteres burch ipätere gejeşliche $\mathfrak{B}$ ejtim= mungen, bie jich auf anbere Berfonen bezieken, alz aufgehobent eradjtet

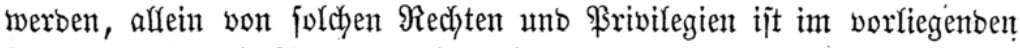

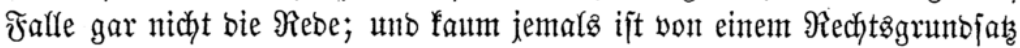

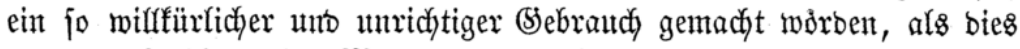

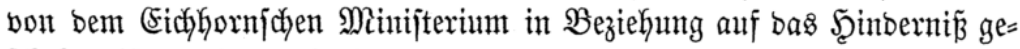

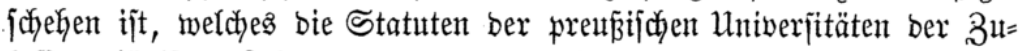
laffung jübijc)er Rehrer entgegenftelfen jollten.

Die Şervorkebung biefes \$ulftes Gat in einer faum erffärlicjen Weife bem Erjten Bereinigten Ranstag bei ber Berathung bes Эuben=

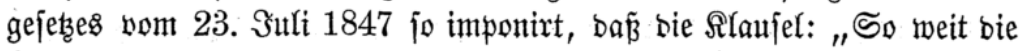
Statuten nicht entgegenjtehen" in bas Bejets aufgenommen wurbe unb

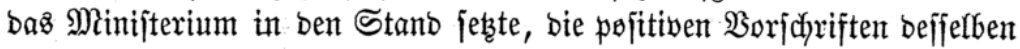
ïber bie Zulafjung ber Suben zu afabemijchen Rehrämtern volfjtänbig 
iflujorifach zu machen, ober boch wentigjtens bies zu verjuchen. War nämlich

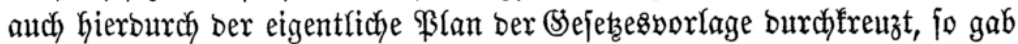
ifn body das (sich)hornjche Minifterium feinesmega auf; nur muste ber beabfichtigte. Zwect, beffen unmittelbare (Erreid)ung nach bem flaren 2 ort=

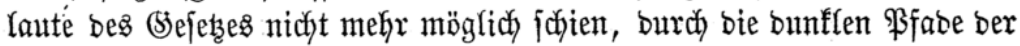
Berwaltung verfolgt werben. Was ber freie Zanbtag abgelehnt, bas jollten

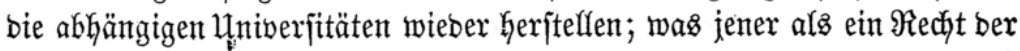

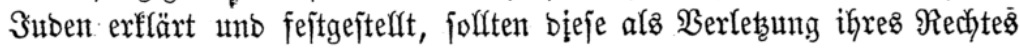

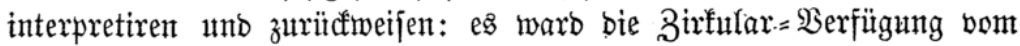
28. September erlajfen. Wir haben jowohl bieje, als bie auf Strund berjelben eingegangenen $\mathfrak{B o t a}$ ausführyrlich (S. 72-232) mitgetheilt, unb man hat gejẹgen, wie wentg bie Univerjitäten ben Wünjđyen bes Minijters entipractyen. Dá er jich baburch in jeinem weitern Berfahren nicjt

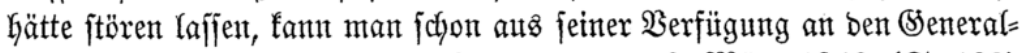

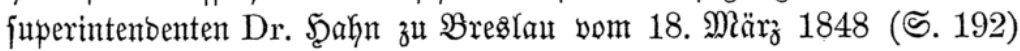
entnehmen; alfein ba er an bemielben Tage aus bem Minijterium fucjieb,

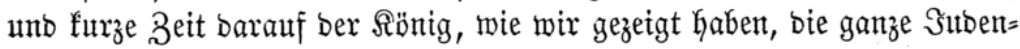
frage baburch 【öjte, baj er bie bürgerliche und politijule Scheibemano

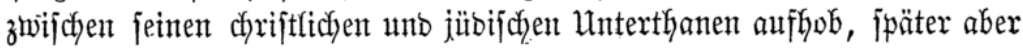

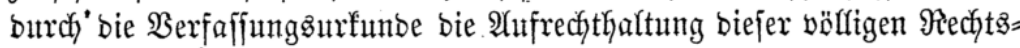
gleich heit fanftionirte unb gelobte: fo witrben bie Map̃regeln bes (Fid)=

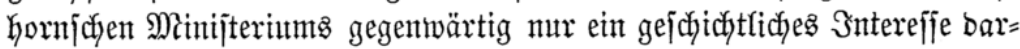
bieten, wenn nidyt gerabe bie afferjüngjte Beit mehrfach ben Betweis

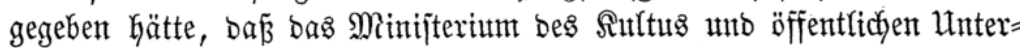

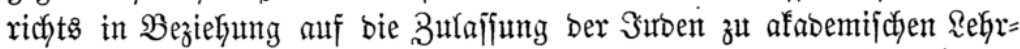
unb Schuläntern fich wieber auf ben Eidjhornichen Stanbpunft fiteift, ja

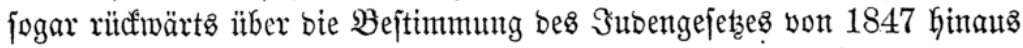

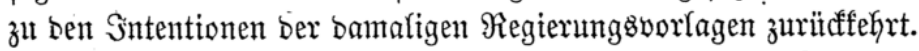

Wir haben barauf Gingemiefen, baß ber $\mathfrak{B}$ ereinigte Rantotag, wie ez volffomment in ber Dronung war, in einem (5efeţe für bie Suben bie gegenfeitigen Berhältnifje ber -verffyiebenen dyriftlidyen' Ronfeffionen auf

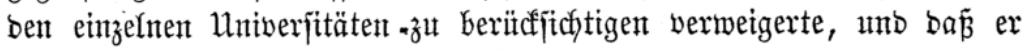

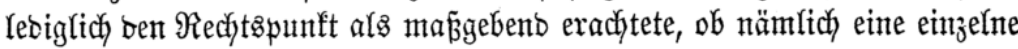

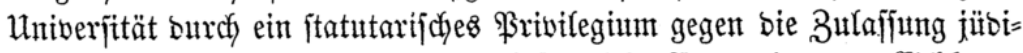

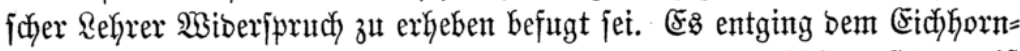

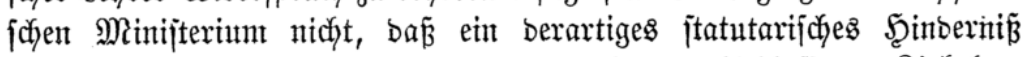
nirgento vorhanben jei; uno es bemerfte baker am Sdyluffe ber Birfutar= verfügung vom 28 . Septbr. 1847 ausobrürffict):

"Э̛̣lofern bie gegentuärtig geltenben Statuten einen hinreichen= ben $\mathfrak{A n h a l t}$ zur Beantwortung jener \$aunfte nidyt ergeben, ijt auf 
bie älteren Statuten umb Stiftungsిurfunben ber bortigen Utniver= fität zurü đ́fingehen."

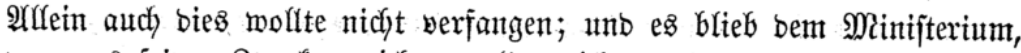

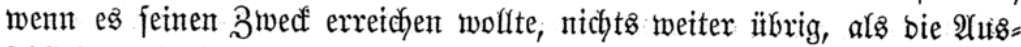

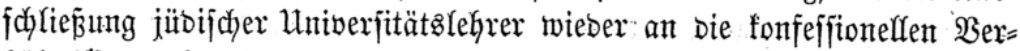

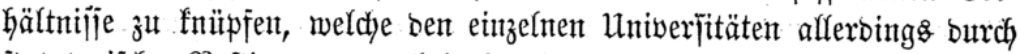
jtatutarijche Bejtimmungen beigelegt waren, nicht abẹr in Beziehung

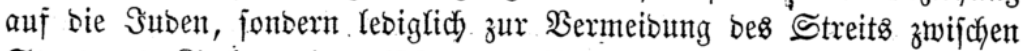

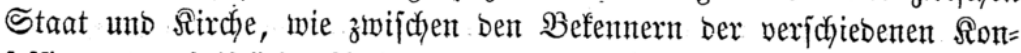

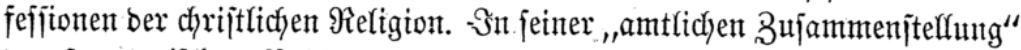

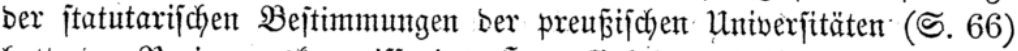

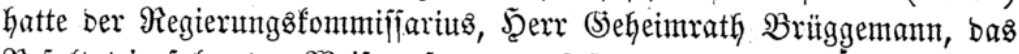
Rejultat in folgenber \$eije zujammengejajt:

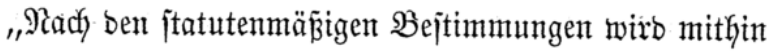

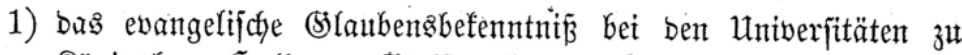

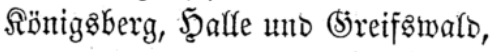

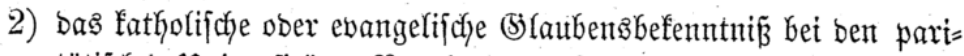

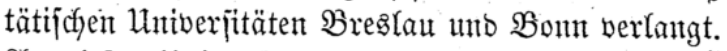

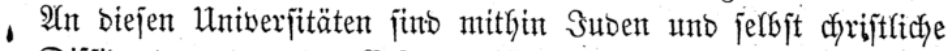
Dififibenten wegen bes (Exforbernifíes eines bejtimmten doriftlichen

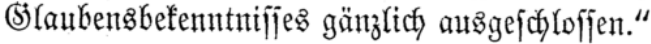

Unb eben weil bies ber Falf war, uno weil ber $\mathfrak{B}$ ereinigte Eanotag

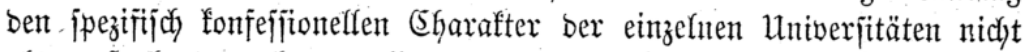

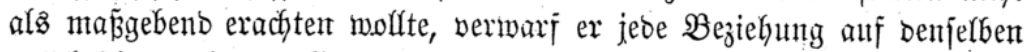

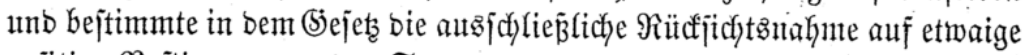
pojitive Beptimmungen ser Statuten.

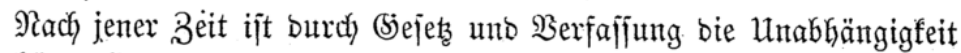

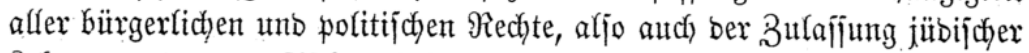
Refirer an ben preusijichen Univerjitäten, fejtgejtelft unb bejdyoren; bas

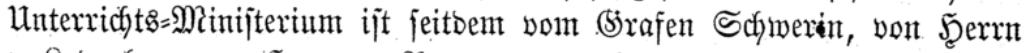
v. Rabenberg, von Serrn b. Faumer verwalțet worben, unb gegentwärtig

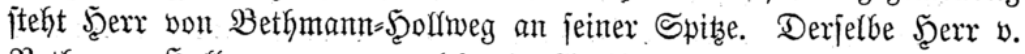

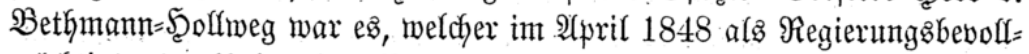
mächtigter ber Univerjität $\mathfrak{B}$ onn bie Sota ber Fafultüten, fo mie bas bes

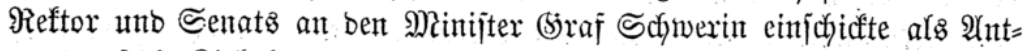
wort auf bie Zirfularberïgung vom 28. Septbr. 1847. Diejes (5ejammt= botum lautete (ธ. 227):

„Beibe von Dem hoken Minifterio ber Univerjität zux Beratfung vorgelegten Fragen: 
1) $\mathfrak{d}$ bie bejtehenoen Statuten unjerer Uniwerjität bie in bem stejęs

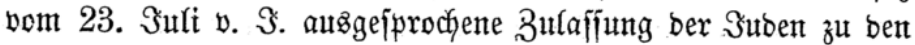
mebizinifchen, mathematifichen, naturmijienidjaftlichen, geographi=

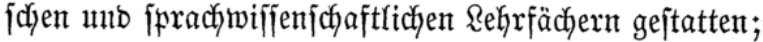

2) $\mathfrak{o b}$, wenn biez nicht ber Fall, eine Mlobififfation berjelben für zu= läffig uno angemeffen zu eractenten jei, fint yon ber überwiegenben Mehrkeit, jowohl ber einzelnen $\mathfrak{B}$ ota, alz ber (Siejammtgutadjten ber fünf Fafultäten bejaht morben.

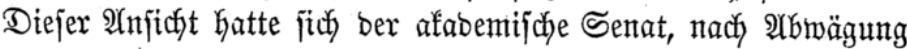
ber bafür unb bagegen geltent gemadjten Stritnbe, in münolictjer

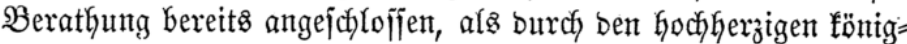

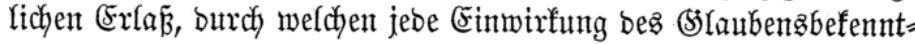

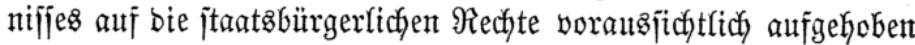
werben wirb, ber ganze Stanbpunft mit einem Sdjlage veräntbert,

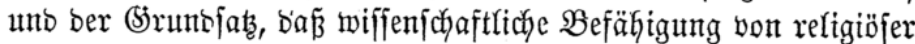
Ueberzeugung joblecththin unabhängig jein müjife, nach ber $\mathfrak{A} u f=$ fajfung ber entfchiebenen Mehrheit bes Senats in jeinem boflen Umiange anerfannt wurbe."

Man wiro jicts baher wohl bie ungenteine Senjation erffären fönnen,

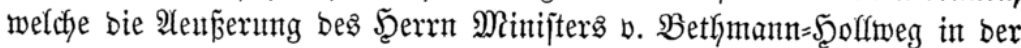

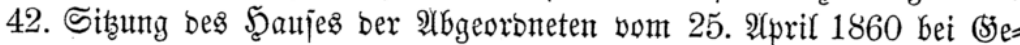

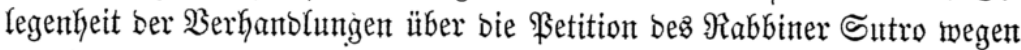

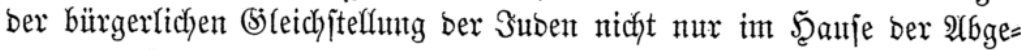
orbneten, fonbern im gejanmten $\mathfrak{3 a t e r l a n b e ~ h e r b o r g e r n f e n ~ h a t . ~ I n ~ e i n e r ~}$ (5rwiberung auf bie am borkergekenben Iage boin bem 2 bgeorbneten

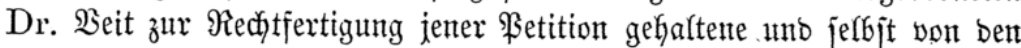

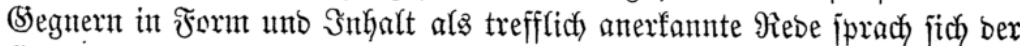

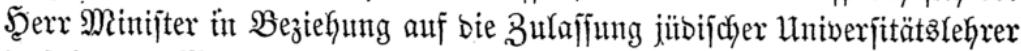
in folgentber $\mathfrak{B}$ eije atts:

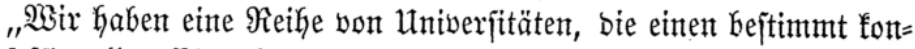
feffionelfen Sharafter an fich tragen, mehrere, bie bem evangeli= ¡chen $\mathfrak{B}$ efenutnin angehörent, eine, bie Âfabemie in Minnjter, weldye entichiebent fatholijch ijt. Wir Ģaben eine Untwerjität, weldje nach

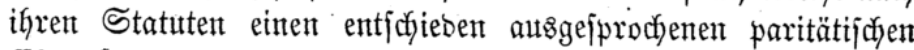

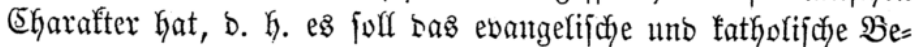

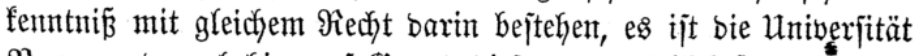

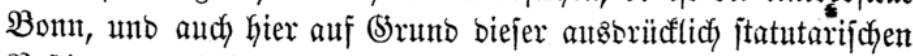
Bejtimmung halte ich bie $\mathfrak{A}$ njtellung jübijcher Regrer nidyt für zuläfifig. $\mathfrak{A}_{\mathfrak{n}}$ zwei $\mathfrak{A}$ njtalten, bie vermïge ifrer Statuten einten 
folchen fonfeffionellen EGarafter nicht an jidy tragen, ez fint bie . Univerfitäten Berlin mo Breslau, an biejen ijt eben beşGalb f́ein

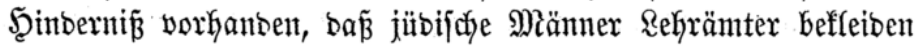
föınent."

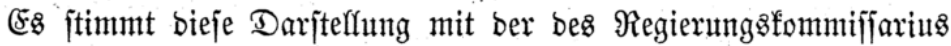

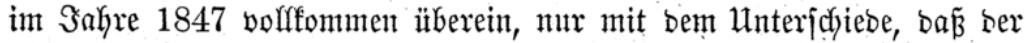

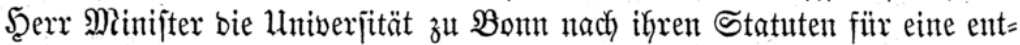

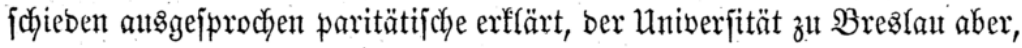
gleidffalls nady ihren Statuten, einen fonfeffionelfen (Eharafter abjpridyt

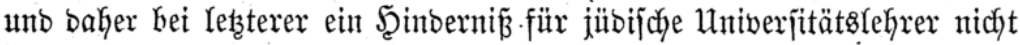

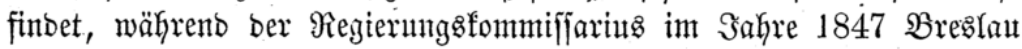
uno Bonn in biejer Beziefyung volffommen gleichjtelfte, uno zwar mit

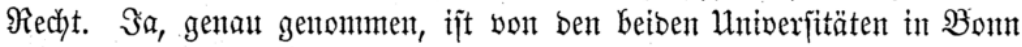
und Breslau gerabe bie leţtere im eigentlidyen Sinne bez Wortes eine

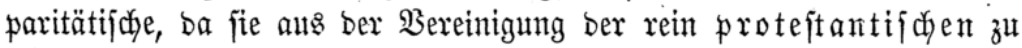

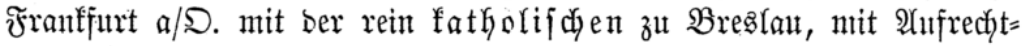
Galtung ber gleichen Berechtigung beiber, entitanben ift, unb baker ber

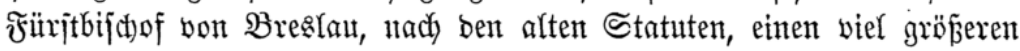
und jelfjtftänbigeren Einflũ alf bie $\mathfrak{B}$ ejeţung ber Refränter ber fatho=

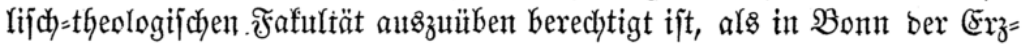

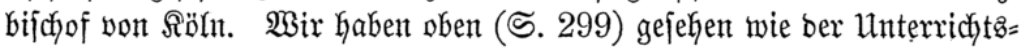

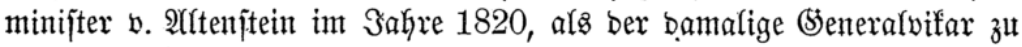
Miünjter, SClemens $\mathfrak{A}$ ugujt von Drojte, Den Theologen feiner Diözeje ber= bot, anberswo als in Münjter Theologie zu jtubiren, bie theologifche Fafultät bajelbjt jušpenbirte, und wie ber Şerr Bseneralvifar in Folge Deffen jein $\mathfrak{A} m$ t nieberlegte. (5benjo werben wir ppäter zeigen, wie berjelbe

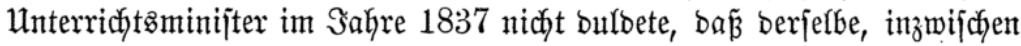

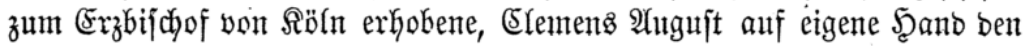
Stubirenben ber fatfyolijcyen Theologie unterjagte, folchen Borlejungen beizumohnen, beren Inhalt ber Seermes'ichen Rehre entnommen jei. भHber burch ein merfwürbiges $3 \mathfrak{i}$ anmentreffen murben an bemjelben Tage, an weldyem ber gegentwärtige Unterridjtaminifter ben fonfefiioneffen (5haraf= ter, welchen er für bie Univerfität in Bonn behauptete, für bie in Breglau in $\mathfrak{A}$ brebe ftellte, an bas jogenannte fđjwarze Brett ber Breslauter Univer= fität bie beiben nachfolgenben Befanntmachungen angefd)lagen:

- "Den Şerren (5ommilitonen erlaube idy mir anzuzeigen, baja ich) in

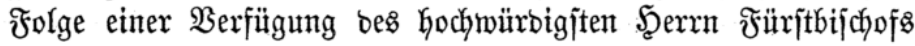
einftweilen $\mathfrak{B o r l}$ ejungen zu haltent verhintort bin, biz über ein in eintem ber päpjttlichen $\Re$ urie vorliegenten \$romentoria entwicfeltes 


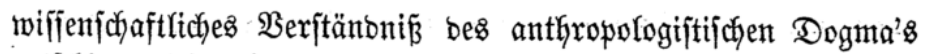
entichieben jein wirb.

Bresila

ßrofeffor Dr. Balber."

"Den Şerren Commilitonen, Stubiofen ber fatfolifdyent Fafultät, erlattbe ich mir anzuzeigen, baś ich nach einem - meine firch)liche Drthoboxie nicht beeinträchtigenben - Defrete bes hodymütrig= ften Şerrn Fitrift6ifdyofz feine Borlejungen mehr halten werbe.

$\mathfrak{B r e s} \mathfrak{l a} \mathfrak{u}$, ben 26. $\mathfrak{A}$ rril 1860.

Frofeffor Dr. Bittner."

Şalten wir uns jeboch einfacty an bie 2rrgumentation bes Şerrn

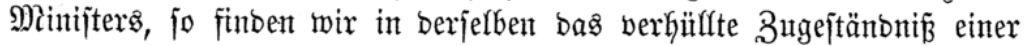

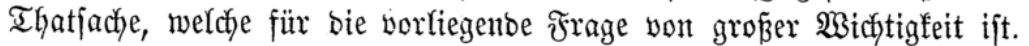

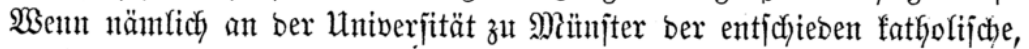

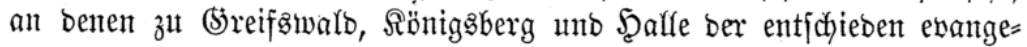
lifche, an ber zut Boun ber entichieben paritätifich=fonfeffitonelle (5harafter ber Statuten bie Bula ajjung jïbijcher Univerjitätzlehrer verbietet, in $\mathfrak{B e r}=$ fin unt Breakla bagegen, two bie Univerjitäten, wermöge ihrer Statuten

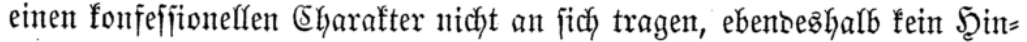

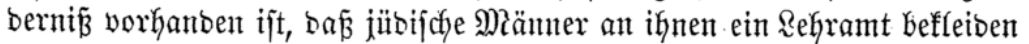
fömen": fo ijt es nicht ber reine- unb reinigenbe (seijt ber dyriftlichen

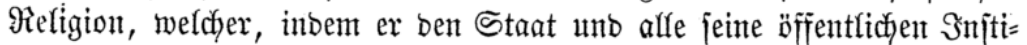

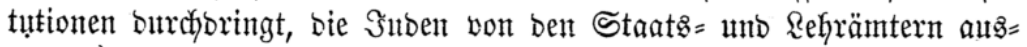
fd)ließst, fondern es ift bie trübe unb Getrübenbe SBerförperung ber erfabenen

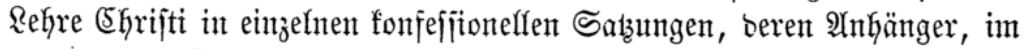
gegenfeitigen $\Re a m p f$ Kegriffen, fich burdy gegenfeitige Toleranz zu fdy wächen fürchten unt mur barin gemeinjchaftlich hanbeln, bá fie gegent bie Suben

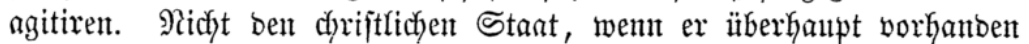
wäre, haben bie Sttben zut igrem Stegner; nut bie gefpaltenen unt ein= anter befämpfentent dyriftlidyen Sonfejfionen fint es, weldfe ber Exfluffi=

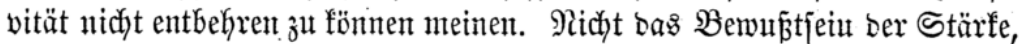

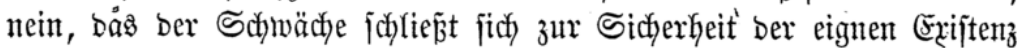
burch eine djinefifdye Miauer ab. Ulno fo hat bent ber Seerr Unterridyts=

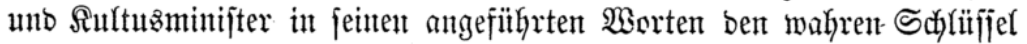

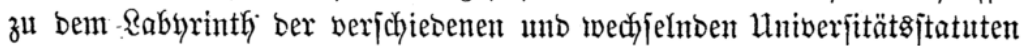
gegeben, währent in ben gleichzeitigen gejudidytlichen Ihatjactjen ber Arriabne= faben zu juctyen ift, weldyer unt burdy bie (Sänge beffelben zil Yeitent vermag.

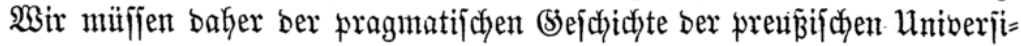


täten unb ifyer Statuten, fo weit biejerbe mit unjermt Stegenjtand zut=

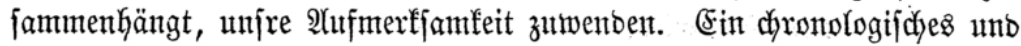

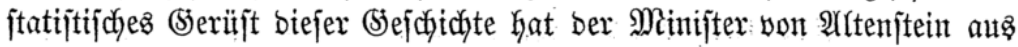
ben Afften burch $\mathfrak{B}$ eamte jeines Minijteriums nod funz vor feinem

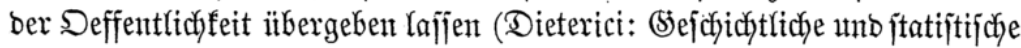

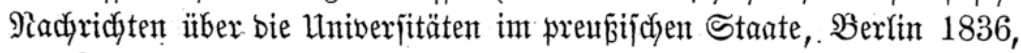

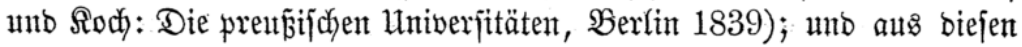

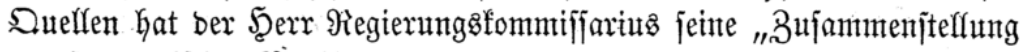

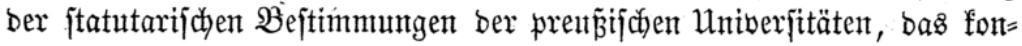

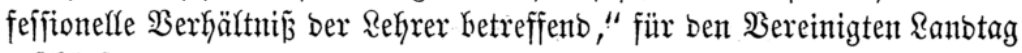
gejchöpft.

Arfein mit einzehten aus bem Bujanmenhange geriffenen unt ohne

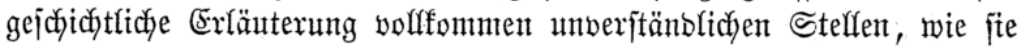
Dem Bereinigten Ranbtage mitgetheilt murben, ift nicht eine flare Dar= fteflung, jonbern eine noch gröpere Berbunfelung bes wahren Sadjwer= hältniffes zu erreidyen. Wir milffen uns baher erlauben, bie furzen

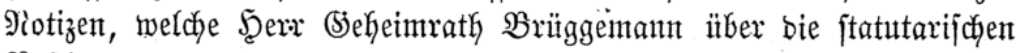
Bejtimmungen ber einzelnen prenßipichen Univerjitäten-gegeben, burch eine möglichjt gebrängte Darjteflung ber (bejdyidyte unb burch einen

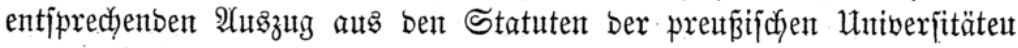

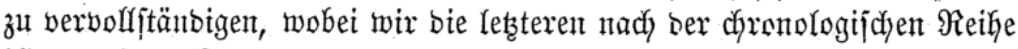

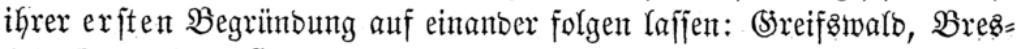

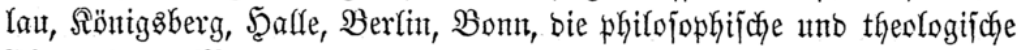

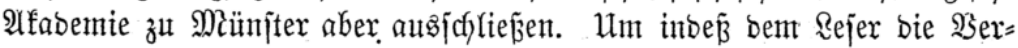

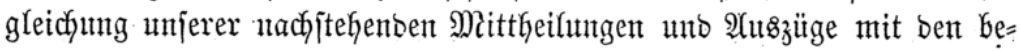
treffenben fragmentarifhen Bemerfungen bes Scern Steheimrath Brïgge

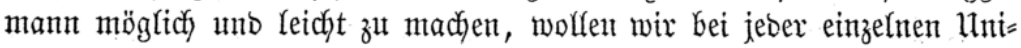

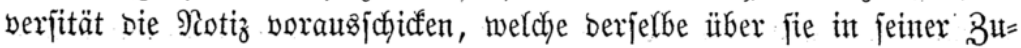

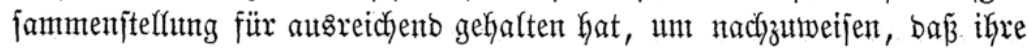
Statuten ber Bulafintüg jübijcher Rehrer entgegentitehen.

\section{Sireifșaldo,}

Şerr Seheimrath Brüggemann bemerft ïber biejelbe:

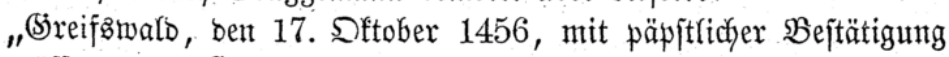
eröffnet, yon Şerzog \$hilipp. 1539 wieber hergejtelft.

Statuta von 1545

Deinde cum scholae omnis doctrinae honestae et virtutum officinae esse debeant, et praecipue opera danda sit, ut juventus ad pietatem adsuescat et doctrina christiana instruatur. - 
Nos igitur cum nihil perinde in hac schola nostra constituenda spectemus, quam ut Dei optimi maximi aeterni patris, Domini nostri Jesu Christi gloria tam propagetur quam illustretur.

Itaque statuimus, ut et professores et studiosi dominicis diebus sacris caeremoniis et concionibus diligenter intersint. - Quisque igitur professorum in templo suo loco - studiosi etiam suo adsint, sacras conciones audituri:-

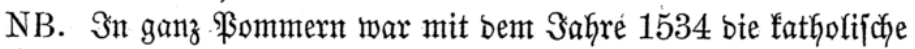
Rehre abgejchafft.

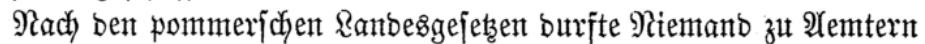
und Würben irgent einer $\mathfrak{A}$ rt zugetaffen werben, ber nidyt ber luthe= rifthen Ronfefition zugethan war. Suben wurben gar nicht im sanbe gebulbet. Der 9Regierungabebollmächtigte hält baher in einem $\mathfrak{B} e=$

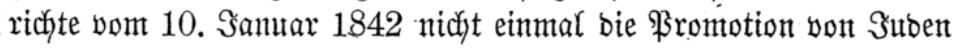

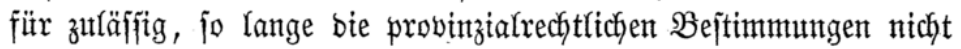
aufgehobent fint.

Dex neunte $\mathfrak{A}$ rtifel bes zu 2 Sient am 7. Sunt 1815 abgejchlojifenen Traftates bejtimmt: Sa Majesté le roi de Prusse s'engage à maintenir les établissemens, et notamment l'ácadémie de Greifswalde, dans leur état actuel."

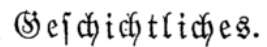

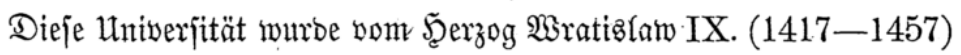

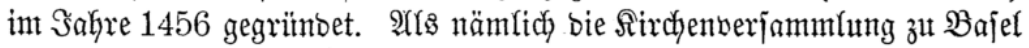

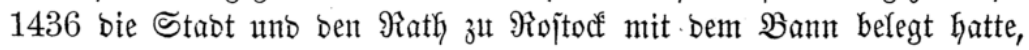

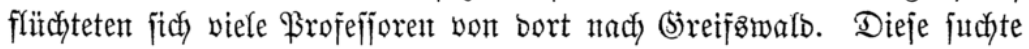
Wratislam bauterno zu gewinten, wobee ifn Gejonbers ber gelehrte Bitr=

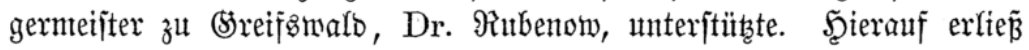
Wratialam feria secunda post festum Luciae virginis gloriosae, b. h. Montag ben 15 . Dezember 1455 eine vorfäufitge öffentfictje Erffä=

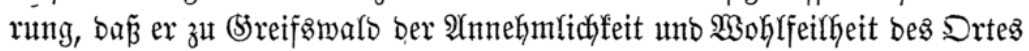
wegent eine Untwerjität zu grünben beabfichtige, ber bie ßrofonjules unb

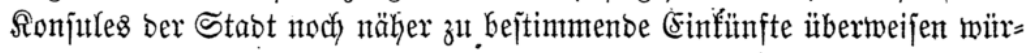
Dent, währent er jerbjt berjerben vier in ber 刃ähe von (5reifgrwarb belegene

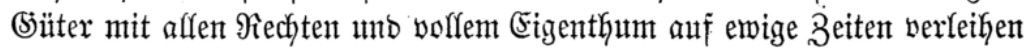
werbe, aut beren Einfünften jeber ßrofefior jährlich wentigitens 600 Florin beziehen fönne. Sollten jebody bie Rehrer gegen bie Berjitherung jeiner

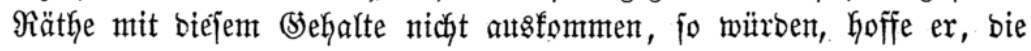

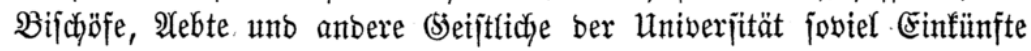


ïbertajfen, bap fie wie nur irgend eine anbere in Deutichland zut be= jtehen vermöbste. Şieranf bejtätigte \$apjt (Ealixt III., ber fadon vor= läufig bem Scerzog bie Zuftimmung zur (Errichtung ber Univerfität er= theilt, nadjoent er burch ben Bifchof Stephan von Branbenburg bie

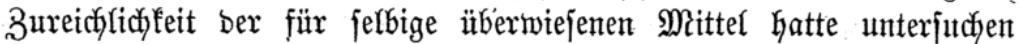
Iajien, fëterlich bie neue $\mathfrak{2}$ njtalt burch eine $\mathfrak{B u}$ tlle vom 29. Mat 1456,

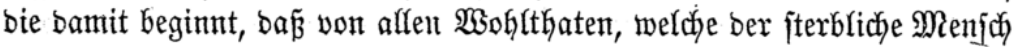
in biejem vergänglichen Reben von ber Snabe Stottes erfialten föme,

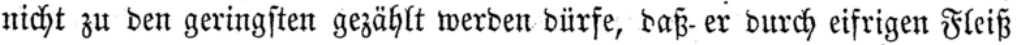

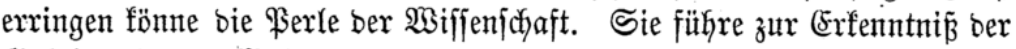

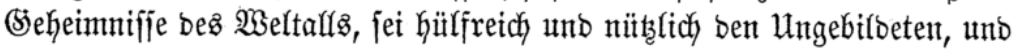
erhebe ben niebrig Seborenen zur hödjften Steffe. Der päpjttidye Stuhl habe baher immer begïnjtigt, wenn fromme ơürjten (Eimridytungen zur Erreichung jener Zwecfe bejchlofien. So bejtätige benn auth Salizt III. bie

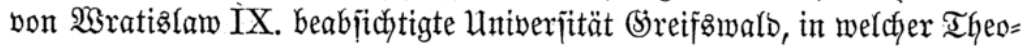

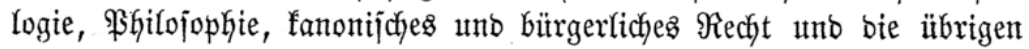
Rünjte und Wifijenfdaften gelejen merben jollten; auf weldyer Rehrer unt

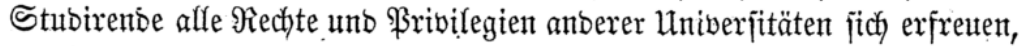
bie 23 ürben ber Doftoren uno Magijtex folften verfieken werben bïrfen; unb junge Reute, bie in Sreifäwald examinirt unb bejtanten feien, jollten überalf in bent betreffentoen Fächern, in benen je wirfen ober fehren woll =

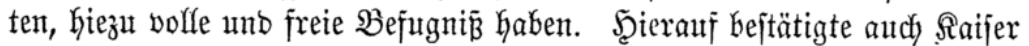

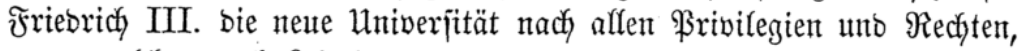
unter welchen autch Reipzig vergleichąweije aufgefütgrt wirb. Die förm=

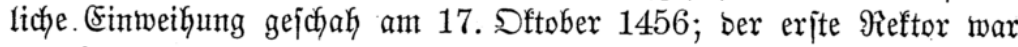
Der $\mathfrak{B u ̈ r g e r m e i f t e r ~ \Re u b e n o w . ~}$

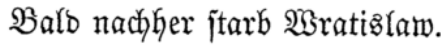

Die nur fdywach begrünbete Uniberjität blieb im funfzefnten $\Im a \mathfrak{a} \mathfrak{r}=$

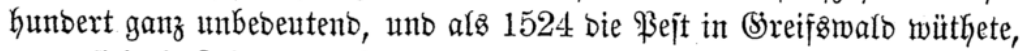
zogen jich bie Rehrer unb Rernenten fort, uno nament(ich nach $23 i t t e n b e r g$, wo \&uther aufgetreten war. Die Uniberjität hörte eine ßeit lang ganz

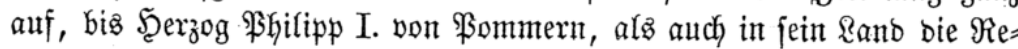
formation vorgebrungen war, wiewohl jie in \$reifžwalb jelbjt fich nux

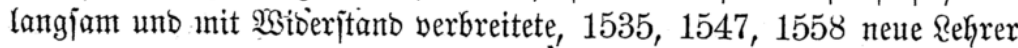

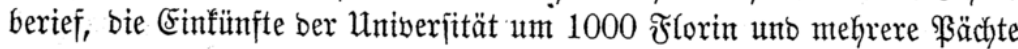
unt ફ̧ebungen jährlich vermehrte, bie Statuten berjelben revibirte unt neu aufitellte. Sie warb num eine rein evangelijche höhere Rehranjtalt. Enofich erfielt bie Univerfität burch Bogiala

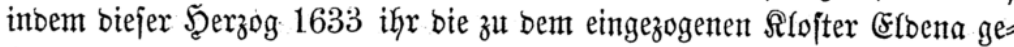

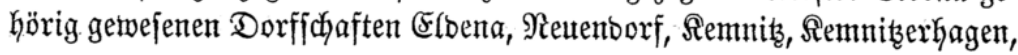




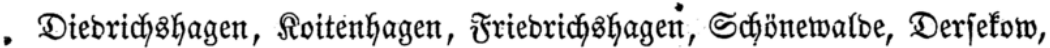

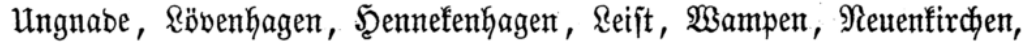

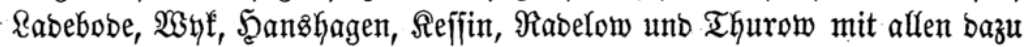

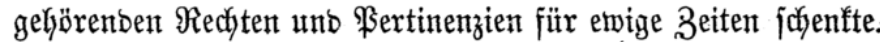

Bogizlaw XIV., ber leţte Weerzog \$ommerns, ftarb finberloz am

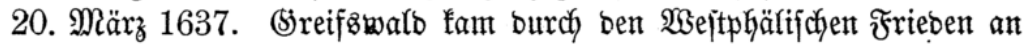
Sthmeben. Schon lange vorker hatten bie Schweden bie Stabt bejęzt,

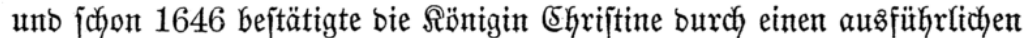

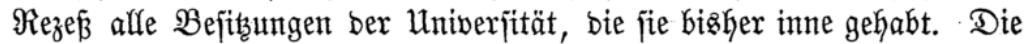

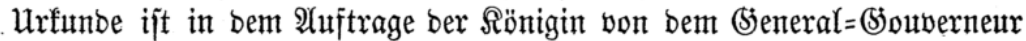
bon \$ommern, bem Felomaridhafl Reonharot Torjtenjohn, am 19. Sep= tember 1646 vollzogen.

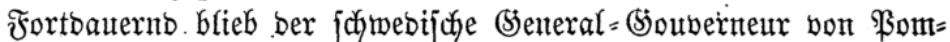

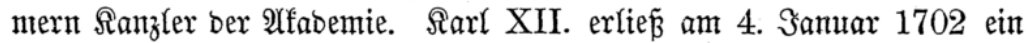
ausfübrhliches Reglement, worin er genau bejtimmte, in melchen Stumben

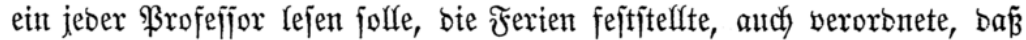

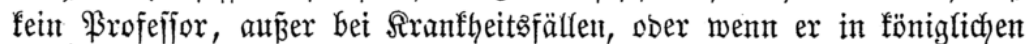

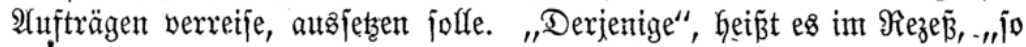

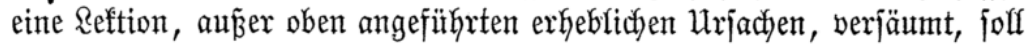
eine jebe verfäumte Reftion mit zwei I Ihalem bezahlen, wer aber zwölf Rettionez in einem Bierteljahy negligiret, foll won bem ganzen 2 iertel=

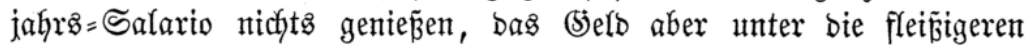

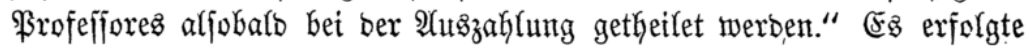

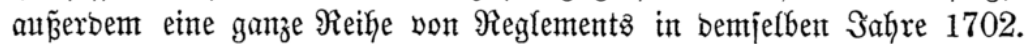
Dieje wurben nach)ger aḅgeänbert; ber lețte urb ausführliche $\Re e_{j} e \tilde{\beta}$ warb unter \$ujtab III. 1775 mit wenigen 2 bänberungen am 20. ซebruar 1795 beptätigt.

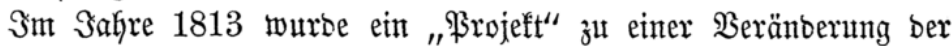

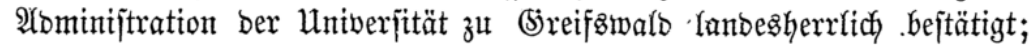
aber eine nette Epoche begann für biefelbe im Sahre 1815, wo jdye= bifac Sommern unter bie Scokeit ber preußifichen Srone fam. Unter bem

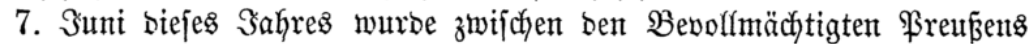

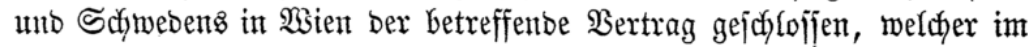

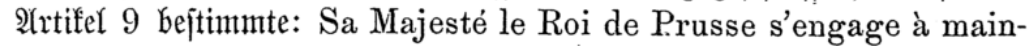
tenir les établissemens pieux et notamment l'académie de Greifswalde, dans leur état actuel, en les laissant jouir de tous leurs biens, fonds, capitaux et revenus actuels.

Der Traftat vom 7. Suni 1815, von meldyem ફ̧err Brü̈ggemann ipricht, war alfo lebiglicy ein $\mathfrak{B}$ ertrag zwijđłent ben Bebolfmächtigten

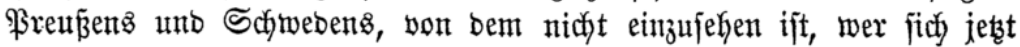


auf benfelben berufen fönute, wenn nidyt etwa Sdywebent. Wenn aber Seerr $\mathfrak{B r u ̈ g g e m a n n}$ Den 9 . Artiffer mit bent $\mathfrak{W o r t e n}$, dans leur état

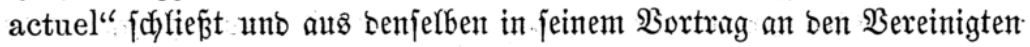
Ranbtag für \$rentien bie $\mathfrak{B}$ erpflichtung Kergeleitet lyat, von ber Univerjität

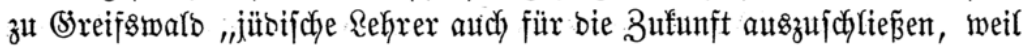
Se. Mlajejtät ber Rönig von \$reunen fich burdy jenen Traftat verpflichtet habe, bie arfabemie zu (5reifswald, wo bamals feine Suben lehrtent, in ihrem bamaligen 3 uftande zit erhalten“: fo hat er ben 9 . Ârtifel bes Sertrages volffommen unverjtänolich gemadyt, inbem ex ben erläuternoen Sđfluß̧ןat beffelbent: „en les laissant jouir de tous leurs biens, fonds capitaux et revenus actuels" weggelaffen hat: eine um fo auffaffenbere Weglafjung, als auth fdyon in bem mitgetheiften Satze bet bem Worte

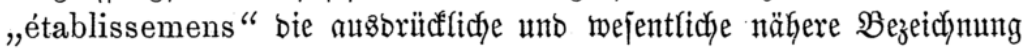
"pie ux" weggebrieben ijt.

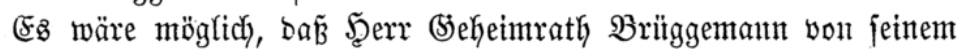

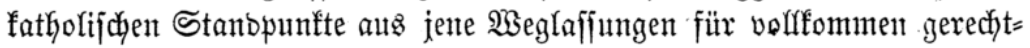

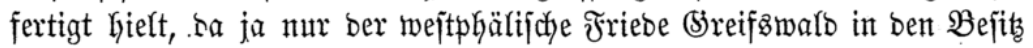
bes Schmebenfönigs gebradyt hatte, bie Stipulationen jenes Friebens aber vom päpittlidyen Stuhgl niemals anerf́annt worbent fint. Dann hätte ber

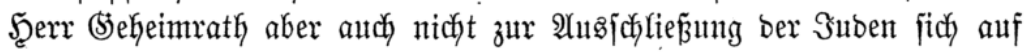

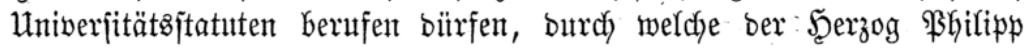

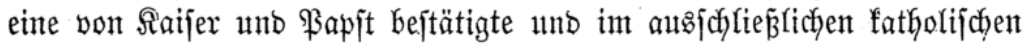

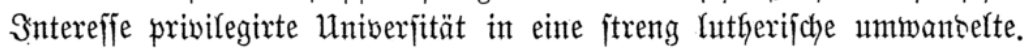

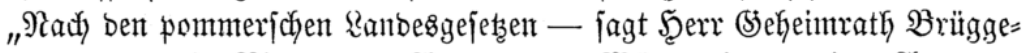

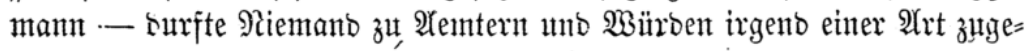

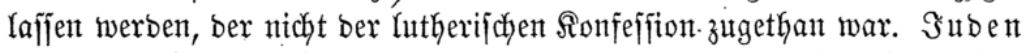

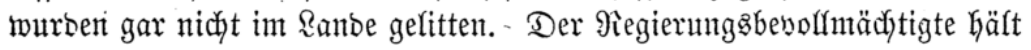
Daher in einem Beridyte vont 10. Samtar 1842 nicht eimmal bie Fro=

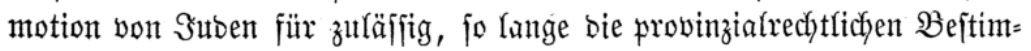

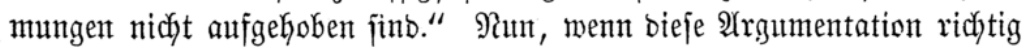

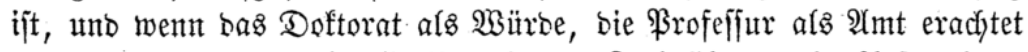

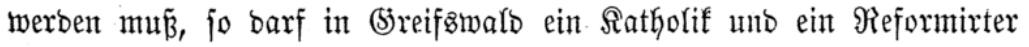
ebenjomentig wie ein Sube Doftor ober Srofeffor wertent.

Für uns aber, bie wir bie Srreifswaloer Untwerjitätżłatuten ohne Berïtffichtigung ifyer feinolichen Steflung gegen affe chrijttichen Son= feffionen zu (S)unften ber lutherifdyen betrad)ten unb lebiglich in $\mathfrak{B} e=$ ziehung auf biejentigen B̉ejtimmungen benuzen fönnen, weldye bie innere und ferbjtftänbige Berfaffung ber. Univerjität betreffen, bieten einzelne biejer Bejtimmungen afferbings einen himreichent intereffanten Эnhalt, um bịejelben mitzutheilen. Man wirb nämlid' aus benfelben entnehmen, 
wie bie bamaligen in bie Rirchenreformation eingehenten Füriten bas \$rinzip ber Souveräntät und Mlonarchie nicht vom heiligen römifchen Stuhl, fonbern unmittelbar von bem göttlicfen Wiflen, welcher biejez Brinzip ber ganzen lebenten :atur eingepflanzt hat, herleiteten, ja feinen

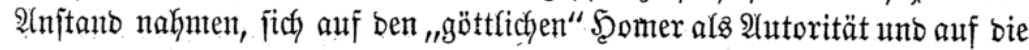
unvernünftigen Thiere als Dorbild zu berufen. Nidjt minber widhtig jind aber bie ßrivilegien, weldje jene Statuten bem afabemijdhen Rörper ver= leiken, von benen man aber - und aus guten Srünben - in feiner offi=

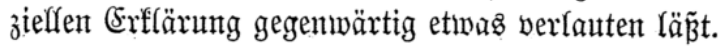

Die nadffolgenten Stellen werben für ben hier augejprodjenen

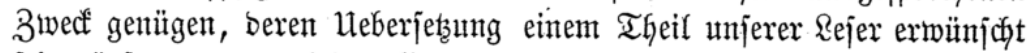
fein binrfte und aนs biejem Srunbe als. Note hinzugefügt wiro.

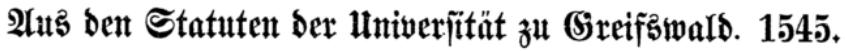

\section{Tit. I. De Rectore et ejus officio.*)}

I. Quemadmodum in omni republica opus est certa quadam disciplina, quae ex bene constitutis legibus, per bonos viros ad gloriam Dei illustrandam, hominumque in hac vita Societatem conservandam custodiatur: Ita in republica Scholastica, ubi imperitae juventutis vita, studia et mores informari debent, praecipue videtur hujuscemodi disciplina necessaria, vel ob eam causam, quod inde, velut ex semente, omnes respublicas succrescere videamus.

Quia vero non potest illa juventutis regendae ratio, citra legum optime conditarum auctoritatem, leges vero multo minus possunt sine Magistratu custodiri et conservari; operae pretium nos facturos speravimus, si huic nostrae Scholae Magistratum praeficeremus.: Gubernatorem sive Rectorem, qui leges simul et disciplinam bonorum virorum sibi conjunctorum, unanimi auxilio

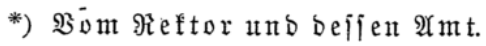

I. Wie in jebem georbneten Staate eine beftimmte Dişziplin nöthig ift, weräc nad) gut eingeridyteten (Sejetzen burd) tïd)tige Männer zur \$Berkerrfid)ung (5otte

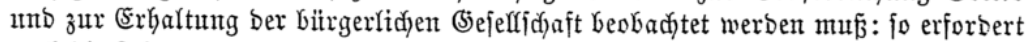
aud) Die Rehranjtalt, auf weldyer bie Stutbien unb Sitten ber unerfahrenten Sugenb gebilbet werben, eine älntide Dişziplin, fdon aus bem (5)unbe, weil wir baraus, wie aus einem Sament, alle Staaten fid) entwidfeln jehen.

Weil num aber bie Reitung Der Sugent ohne gejeţlidje $\mathfrak{A}$ utorität, unt bieje nie= berum nidjt oyne beftimmte vorgejetste behörbe geleitet unb erkalten werben fann,

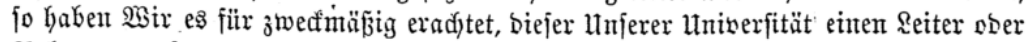

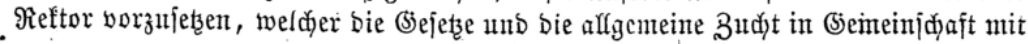


consilioque concordi tueretur. Deus enim ipse passim suo verbo testatur: nullam Politiam neque constitui neque conservari commode posse, nisi legum et Magistratus auctoritate confirmetur.

Quapropter a Paulo, merito dicitur Magistratus Dei ordinatio, quae videlicet ab ipso D'eo ad res divinas, pacem, justitiam et disciplinam, conservandas, instituta sit et approbata, quamque perennem et immutatam in hac hominum societate eadem velit ratione, qua corporum coelestium certos modos eorumque perpetuas vicissitudines nobis ob oculos positas, admirabili consilio, et nulli mortalium satis explorata sapientia gubernat, inque officio conservat ac tuetur.

Possent innumera commémorari praeclara testimonia, cum ex Philosophorum, tum etiam ex Sacrarum literarum monumentis, quae plane adfirment, et evidenter declarent, rerum publicarum gubernatores, perinde esse necessarios, atque aquam et ignem, et esse quasi nervum, quo omnes politice conserventur et eo augmententur; sed fortassis supervacaneum et ab instituto alienum fuerit, encomion rerum publicarum hoc loco prolixius prosequi.

II. Quod igitur ad nostram Academiam Gryphiswaldensem attinet, statuimus et sancimus, ut recepto aliarum Scholarum publicarum more, Rector aliquis electus summo Magistratus munere fungatur, cui omnes, quorum nomina in Album Academiae relata sunt, debitam obedientiam praestare in omnibus piis et honestis rebus debent. Videmus enim commodius plerumque respublicas

ben ihm beigegebenen Männern hanbhaben foll. Selbft (sott bezengt augbrüdfich) Git und wieber, bá fein Staat gegrünbet ober erhalten werben fömne, wenn er nidyt burd) bie Madjt ber (Sejetze unb ber Dbrigfeit bejeftigt twirb.

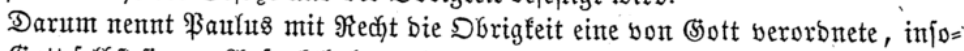

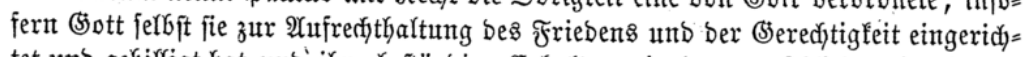

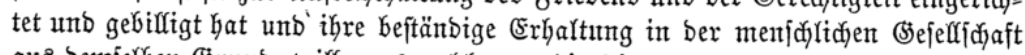

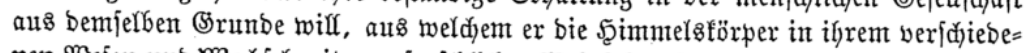

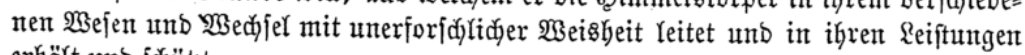
erkält unb jâdütşt.

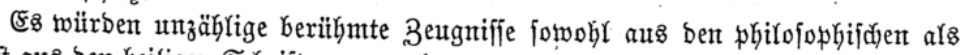
jelbft aus ben keiligen Sdyriften angegeben werben fönnen, weldje es beftätigen, baj

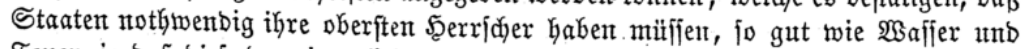

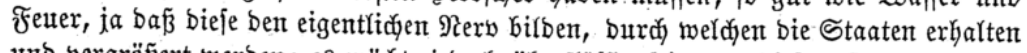
unb vergrößjert werben; es möd)te jebod' itberflüffig fein, an biejem Drte eine poli=

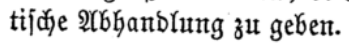

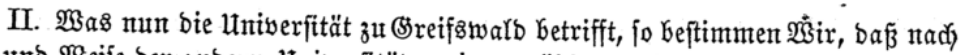
Art unb $\mathfrak{W}$ eije ber anbern Univerfitäten ein erwählter $\Re$ eftor bas bödjfte obrigfeit=

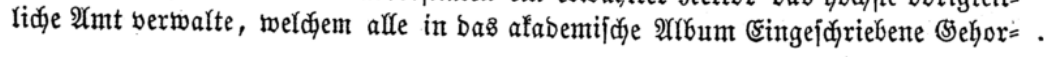


gubernari per Monarcham, qui tamen non ex suo unius arbitrio tyrannorum more, sed bonorum virorum judiciis et consiliis delegatum munus administret.

Cujus rei nos admonere possunt, gubernata hac ratione per multa saecula, in hanc usque aetatem, totius mundi longe potentissima regna, quae mutuo quodam Monarchiae imperio, divinitus instituto, sibi ordine successerunt, quemadmodum id historiae non tantum Ethnicorum, verum etiam sacrarum literarum mysteria, cum in multis aliis, tum Propheticis praecipue libris declarant.

Nec vero pulchrius aut utilius usquam Monarchia bene constituta reperiri potest: nimirum quae ad divinum et coeleste regnum quam proxime accedat. Atque hanc reipublicae formam vel in brutis animantibus Deus propositam nobis esse voluit: sicuti videmus apes unum agnoscere regem: greges et armenta unum habere ducem: Grues unam solam sequi iterato: unde non minus prudenter, quam graviter ab Homero dictum est: ovं

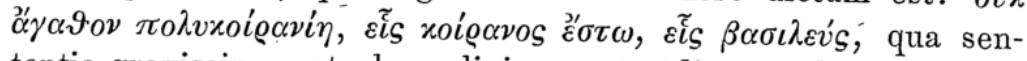
tentia gravissimus et plane divinus autor dicere voluit: felicissimam esse reipublicae administrationem, quae uni dumtaxat committatur.

\section{Statuta facultatis juridicae.}

Cap. I. De numero et qualitate facultistarum.

1. Tres facere collegium Ictus Neratius Priscus tradit, et tot sufficere, nec opus esse plures amplius adsciscere, longorum an-

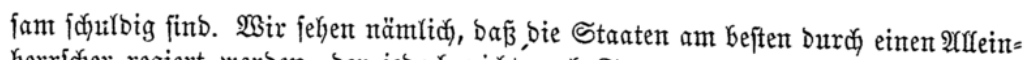

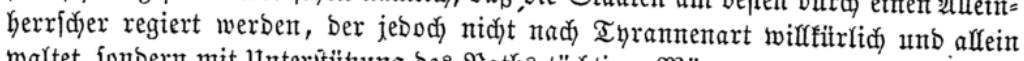

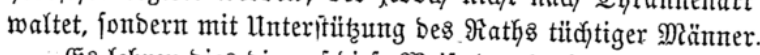

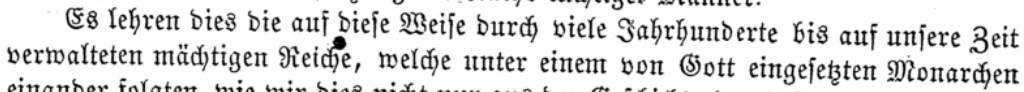

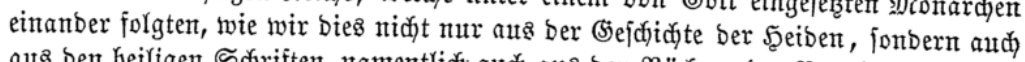

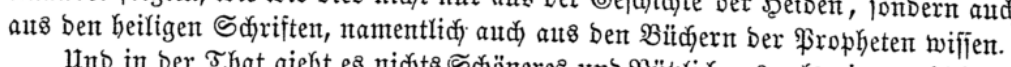

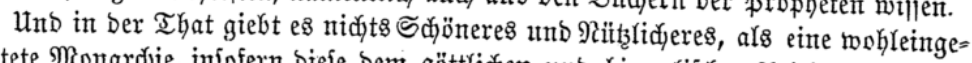

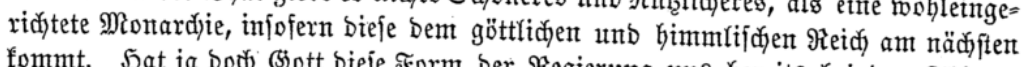

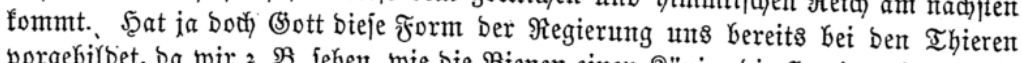

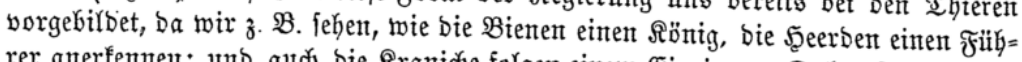

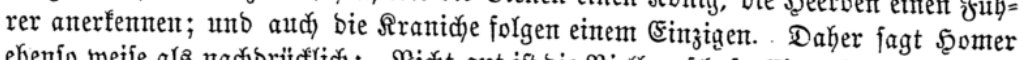

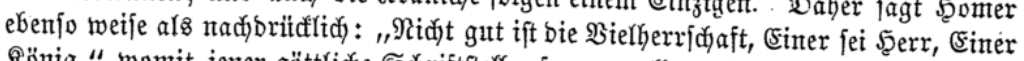

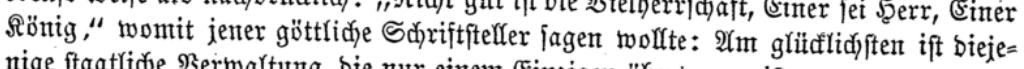
nige ftatlidje Berwaltung, bie nur einem Einzigen ïbertragen ift.

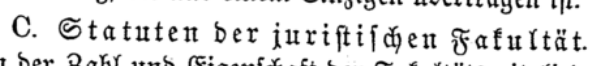

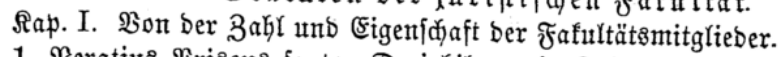

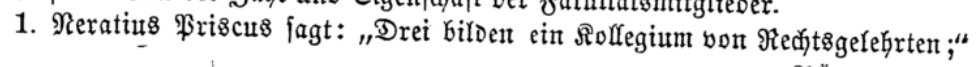


norum observantia, statuta nostrae academiae, novissimus recessus visitationis, et ordinationes academiae ordinant, eumque numerum nos ordinarie in posterum habituros, decernimus.

Cap. IV. De privilegio nominationis, et cooptandis in collegium facultatis, eorumque officio.

1. Nemo membrum nostrae facultatis esto, nisi juxta privilegium academiae concessum, et novissimo visitationis recessustabilitum, rite prius ad professoratum toti corpori academiae a membris facultatis nominatus, a toto corpore approbatus, cancellario academiae praesentatus, et a regeliteris, ut moris, vocatus, a magnifico domino rectore in numerum professorum, praevio juramento, sitreceptus.

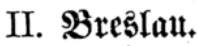

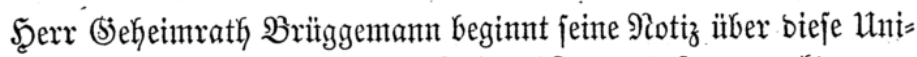
verjität mit beren (Exrichtung in Sahre 1811 und jagt, nachoem er

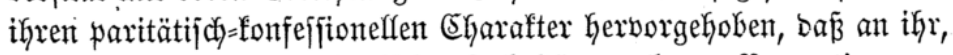

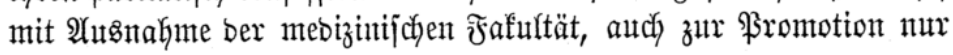
(5hrijten zugelajien werben bürfen.

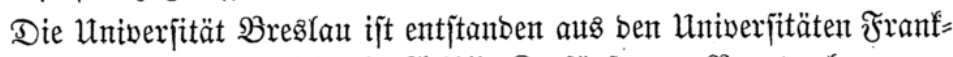

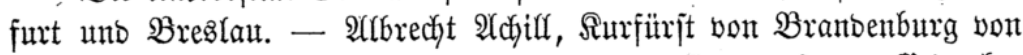

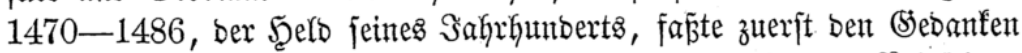
ber Erridutung einer Univerfität in Franffurt a. ๖. Soer. Bee jeinen

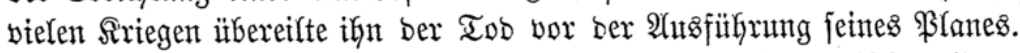

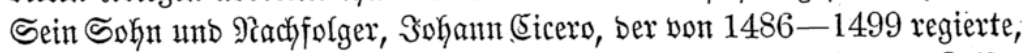
verfolgte ben \$lan jeines S3aters, unterfanbelte beshalb mit bem §aijer

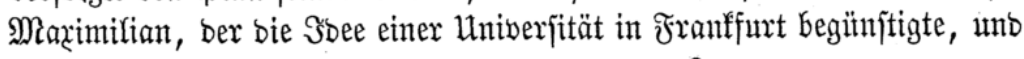

unb bafi in ber That fo viele genügen, mehr aber nidat nöthig find, hat eine langjäh= rige $\mathfrak{B}$ eobachtung bejtätigt, Der neuejte $\mathfrak{B}$ ifitations fo wolfen $\mathfrak{B i r}$ bieje $\mathfrak{Z}_{\text {ahl }}$ fütr bie 3 ufunft als bie gemöhnlidue fefthalten.

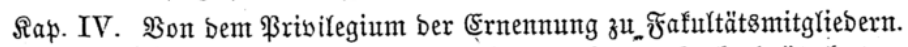

1. Niemanb barf als ein Mitglieb unjerer Fafultät betradtet

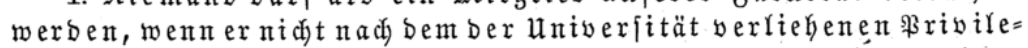
gium, wel des butr d) ben neueften zubor orbung mä

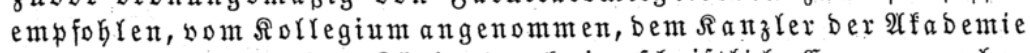

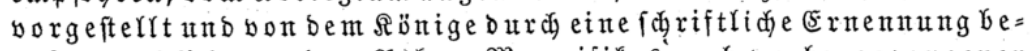
rufen, enbli won bem Meftor Magnififus na borkergegangener

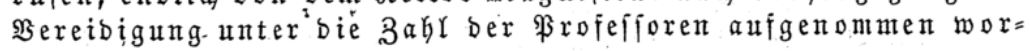
ben ift. 
warb bejonbers burch feinen Reibarzt, Simon jeines Borfabens angereizt. \$ijtoris twar \$rofefijor in Reipzig, won wo atts er ben Surrfüriten häufig bejuchte. - Er war mit bem \$rofejpor Pollich in Reipzig über bie Ratur ber venerijchen Sranfheit in einen Kefti= gen wifjenjchaftlictyen Streit gerathen unb jefnte fich beshalb von Reipzig

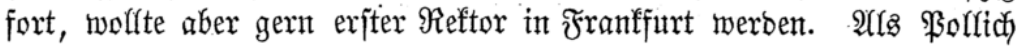

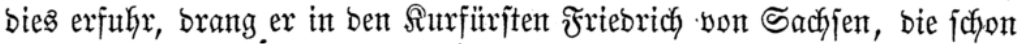

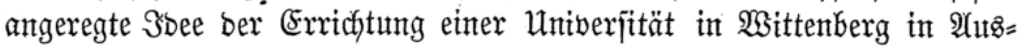
fïbrung zut bringen. Ex erreichte jeinen 3wedf; Wsittenberg warb 1502

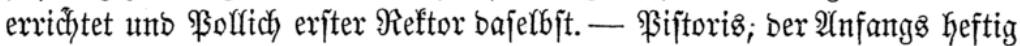

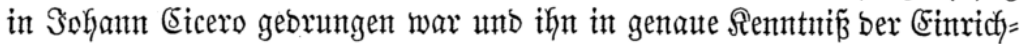

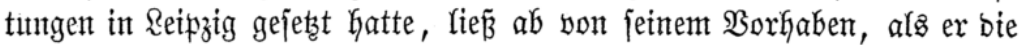
Bläne feines Feinbes gelingen jah, und wenngleidy Sohann (Sicero im

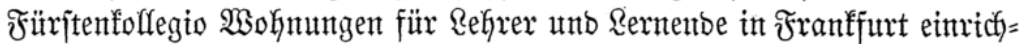

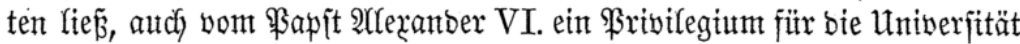

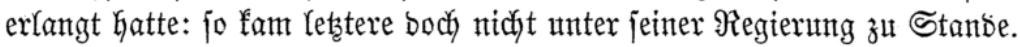

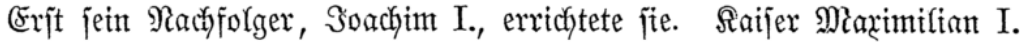
ertheilte bas ßrivilegium am 26. Dftober 1500; bie feierliche (sinweifung

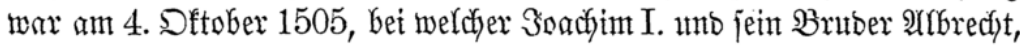

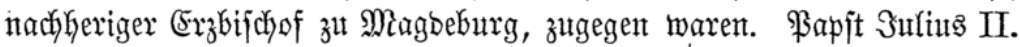

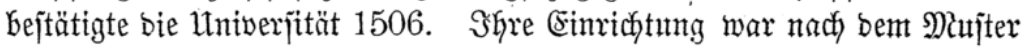
von Reipzig gejtaltet. Der Bifdyof von Rebus ward zum Sanzler ernant;

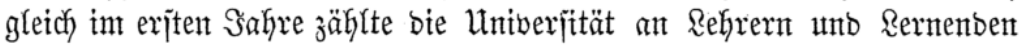

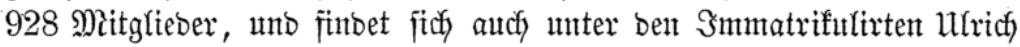

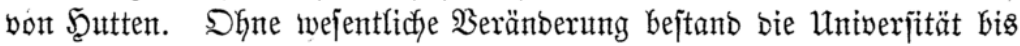
181.1.

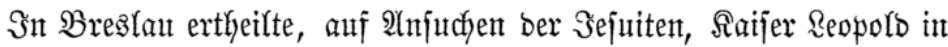
ber aurea bulla vom 21. 'Sltober 1702 bem Gejuttenfolfeginm bajelbjt bie Rechte einer volrffänbigen Uniwerfität. Sie jollte żwar nach jenter Urfimbe affe vier Fafultäten tmfaffen, hatte aber nie mehr als zwei, eine

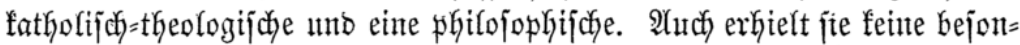
bere Dotation, es mitroen viefntefr bie Refrer nur aus bent Fonbs ber

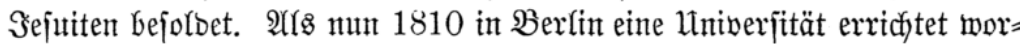

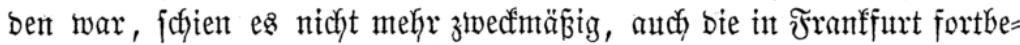

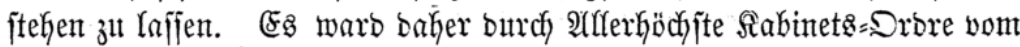

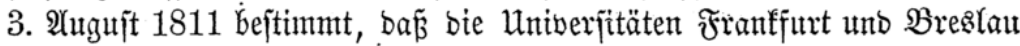

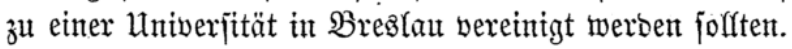

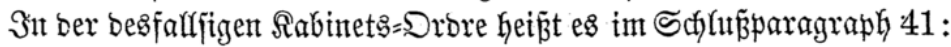

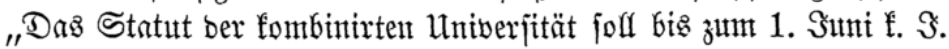
anf bie burch bas Departement bes öffentlidjen Unterridyts zu bejtintmente 
Weife entworfent unto Sr. Majeftät vorgelegt jein, bamit es mit bent 1. Dftober f. Э. in volle §raft treten fönne."

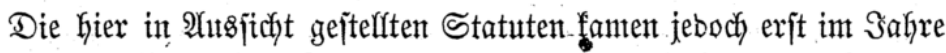

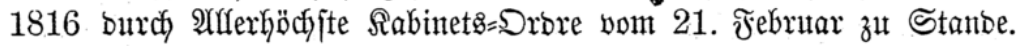

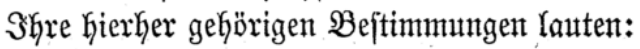

,'Wir Friebrich Wilfyelm, von (5ottes (5naben Rönig von \$reupen $2 c$.

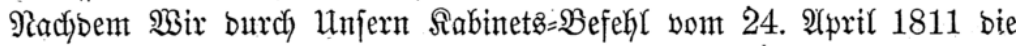

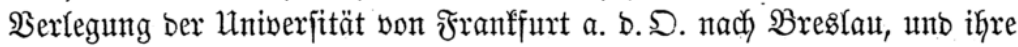

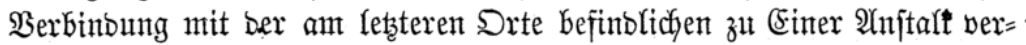
orbnet haben, auch bie Univerjität zu Breslaut jchon feit bem Mionat

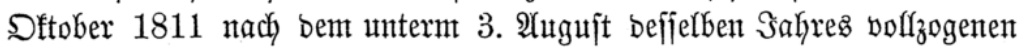
Bereinigungaplane, und ber unter gleichem Dato erlajfenen Rabinets= Drore in Thätigfeit ijt, jo wollen $\mathfrak{W}$ ir biejer Unjerer Untiverjität bie nach)= ftehenben, in bem $\$ .41$ gebachten Sereinigungaplans vorbehaltenen Sta $=$ tuten nunmehr Gierburch ertheilen, unb inbem $\mathfrak{B i r}$ jämmtliche Mitglieber ber Univerjität, jowie bie Behörben anmeifen, fich banach zu achten, wallen $\mathfrak{B i r}_{\text {bie }}$ früheren Statuten, fowohl ber vormaligen

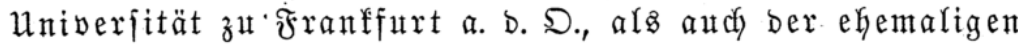

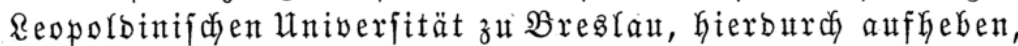

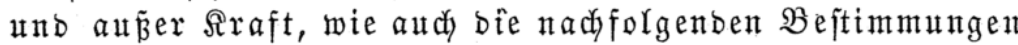
in allem, was bie Berfafing angeht, an bie Stelle bes oben erwähnten vorläufigen $\mathfrak{B}$ ereinigung gplang je势en.

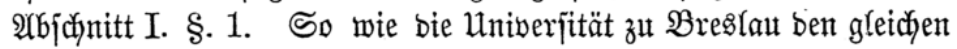

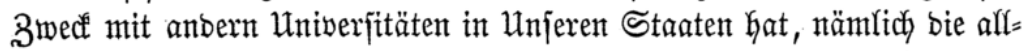
gemeine und bejonbere wiffenjafaftliche Billoung geförig vorbereiteter Sünglinge burch Sorlejungen unb anbere afabemifche Hefungen fort= zujetzen und jie zum Eintritt in bie verfchiebenen Bweige bes höheren

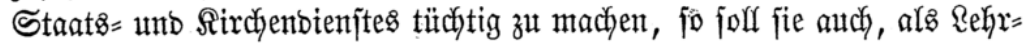
$\mathfrak{a n j t a l t ~ u n b ~ a l s ~ e i n e ~ p r i v i l e g i r t e ~ \Re o r p o r a t i o n ~ u n t e r ~ U n n j e r e m ~ R a n b e s ̧ u a ̈ t e r = ~}$

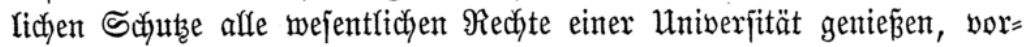

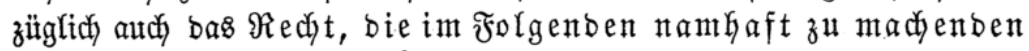
afabemijuen $\mathfrak{3}$ ürben zu ertheilen.

§.3. Die Unniverjität bejteht: 1) auż ber (Sejammtheit ber Rehrenten, fowohl ber von Unts unt Unjerem Minifterio bes Snnern berufenen unb angeftellten orbentlicyen unb aurerorbentlichen \$rofefforen, als aud aus ben of ne befondern $\mathfrak{B}$ eruf, aber mit Stenthmigung unb Ylutorität ber

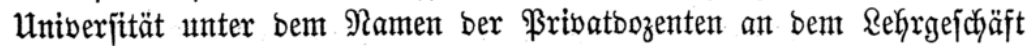
Theilnehmenben.

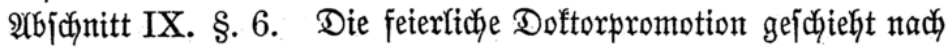


beenbigter Disputation von bem Defan ber Frafultät ober einem zu biejer Şanbling mit jeiner Eintuiffigung ernannten $\mathfrak{B r o}=$ Defan, nachoem bemt

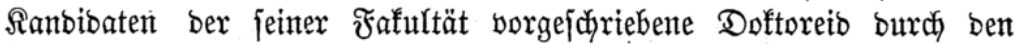
Sefretär ber U1niverjität vorgelejen und von iłm angenommen morben,

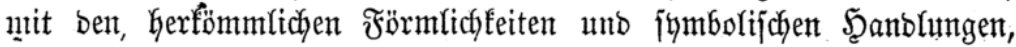

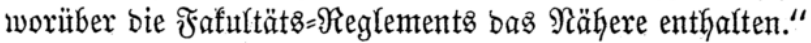

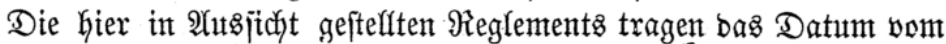

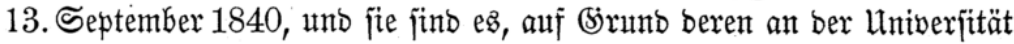

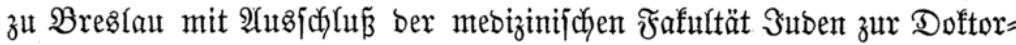

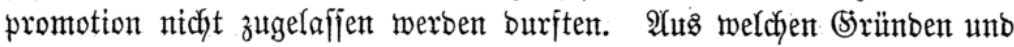

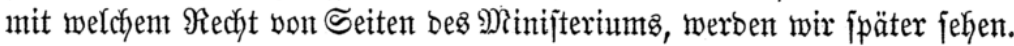
Soviel aber ergiebt jicty aus bem eben Mitgetheilten, bã bie gegentwärtige Untiverjität zu $\mathfrak{B}$ reģ

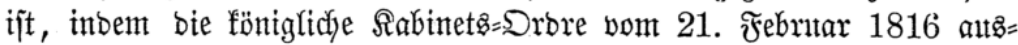
brüaffich fowohl ifye früheren Statuten, alz bie ber frïher jelbjtitänbigen unt 1811 mit ber Breslater verbunbenen Univerjität 孔̆ Franffurt auf́ = gehobent und beibent in ifrer neuten vereinigten Bejtalt eine vollfommen neute $\mathfrak{B e r f a f f i n g ~ u n t e r ~ b e r ~ B e z e i d y n u n g : ~ „ S t a t u t e n ~ b e r ~ \Re o ̈ n i g l i c h e n ~} \mathfrak{u n}$ i= verjität zut Breslau" verliełen hat. Dieje Statuten fint baher, fomeit fie nidfyt in gejeţlidy gültiger WSeife abgeänbert worben, für biejentgen Fragen má̧

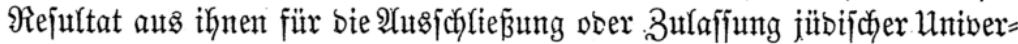

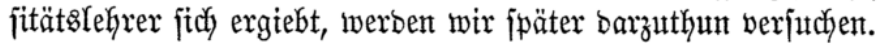

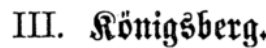

Şerr Sekeimrath Brïggemtann jagt:

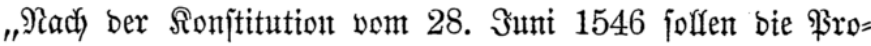
fefforen fatwören:

Ego juro - me amplecturum veram ac puram evangelii doctrinam quam uno spiritu ac voce una ecclesia Dei catholica profitetur, nec corrupturum doctrinam sacram ex philosophia.

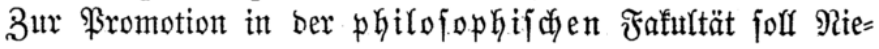
mant ztgelaffent werben: cujus mens polluta et fascinata (ver= ftricft) est falsis opinionibus et a consensu catholicae

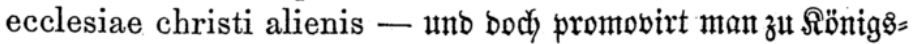
berg alth アrtiben.

Die neuen Statutent vom 4. Mai 1843 feł̧en $\$ .105$ fejt: 
Dex urfprüngliçen Stiftung gemäß fint bet ber Mntwerjitüt zu Rönigaberg nux Rehrer evangeltidyer Aonfeffion anzujtelfen."

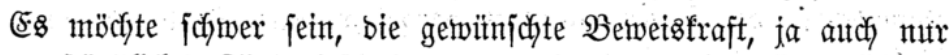

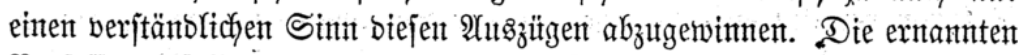

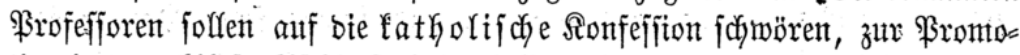
tion in ber phitojophifijen Fafultät folfen mur treute $\Re$ atholifen zugelajfen

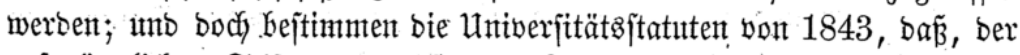

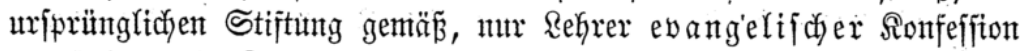

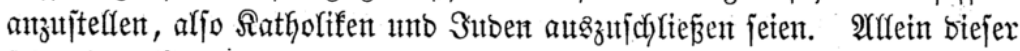

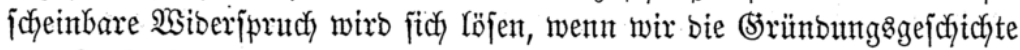
Der Sönigsberger Utniverjität int Bufammenthang mit jenen aus ifrex nothwenbigen Berbinbung geriffenten Steffen näher ins âtuge faffent.

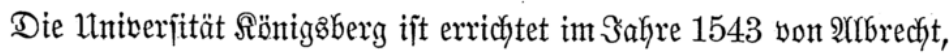
Marfgrafen zu Branbenburg, erjtem Seerzog in \$renfent. Diejer war

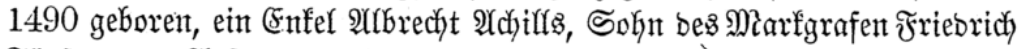

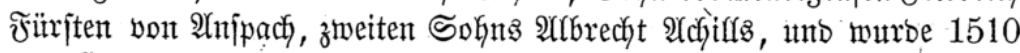

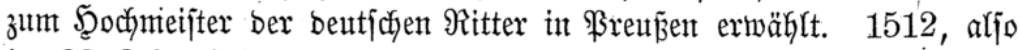
im 22. Rebensiabre, langte er mit einent prädytigen Bsefolge in \$irentíen

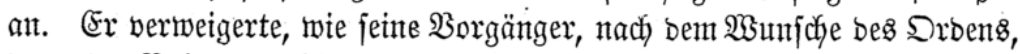
ber von $\Re_{0}$ len unabyängig fein wollte, bem Rönige Sigisimunt von \$olen ben Refnseid, worïber er mit \$olen in einent langwierigen Srieg

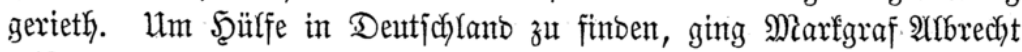

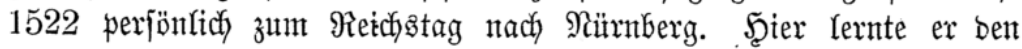

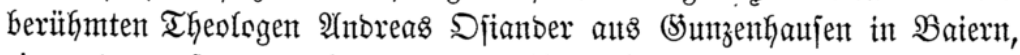
einen ber erjten unb bebeutenditen Schüfer \&uthers, fenten unt faut ourch ifn mit Spalatin und Ruther felbjt in Merbinbung. Marfgraf

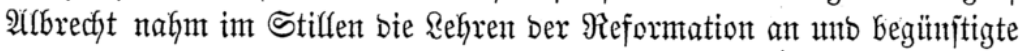

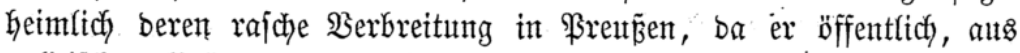

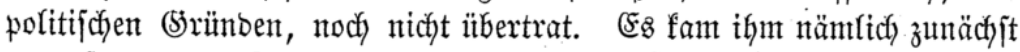

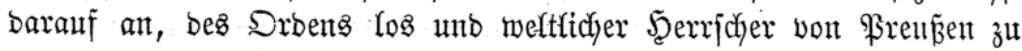

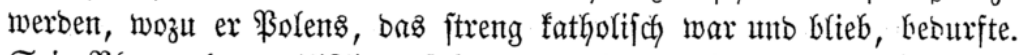
Sein $\mathfrak{B l a n}$ getang; 1525 berjöhnte er jich mit jeinem Dheim (Mutter=

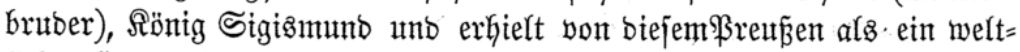
liches Şerzogthum zut Rehen fïr jich unb feine গachfommen. Die feierliche

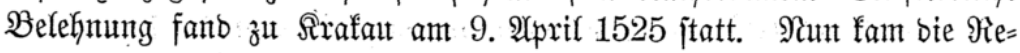

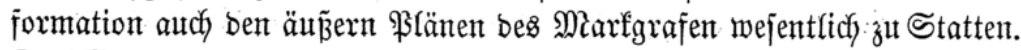
Der 3 iberjtand, ben unter anbern $14 m$ jänönen ber Droen wohl geleijtet

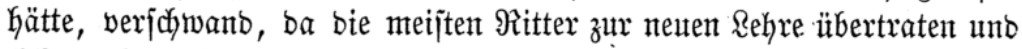

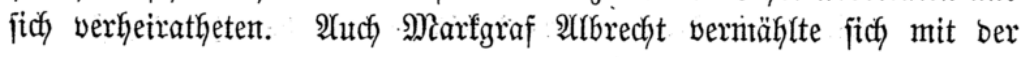




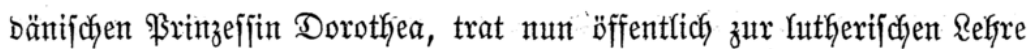
itber, nahm bemnächjt bie Âtagaburgifche Ronfeffion an, hob Stifte und

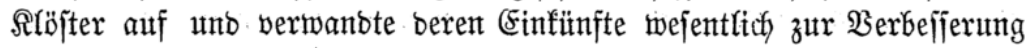

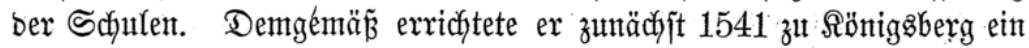

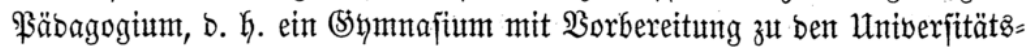

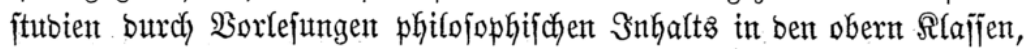

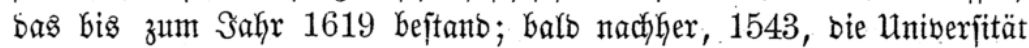
Rönigaberg jerbjt.

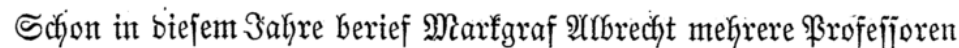

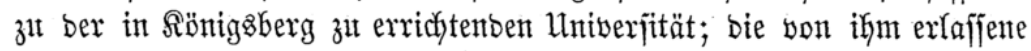
Funbationgantumbe jelbjt ift vom 20. Jult 1544.

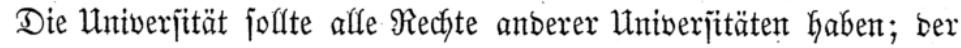
Marfgraf habe beshalb Einleitung getroffen, bie gemöhnlichen $\mathfrak{B}$ ejtä= tigungen ber Univerjitäten zu erhalten; vorläuftig werbe er Regrenbe uno Rernento mit eigener Macht gegen jebe Beeinträdytigung ifrer Rechte fdü̈tzen. Es joflten Regrer ber lateintichen, aud ber griechijdyen uno hebräiffyent Sprache (meil bieje Spractjen bie Ouellen ber firchlityen

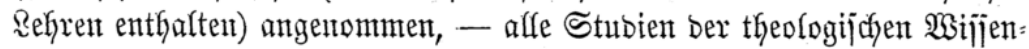

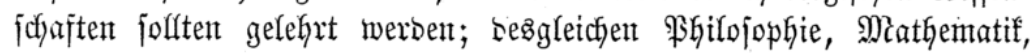

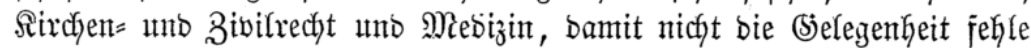
zux Erlernung ingent eines Theils ber Disziplinen, weldje in wohl ein= gerichteten Univerjitüten vorgetragen werben unb bas menjchliche Reben

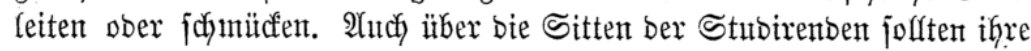
Borgejeţten wachen, benn von feinen andern Betweggrïnben jet ber Marf'= graf, wie er gegen ben Sdylup jagt, z̧ur Errichtung ber Univerijität bejtimmt

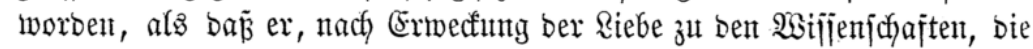

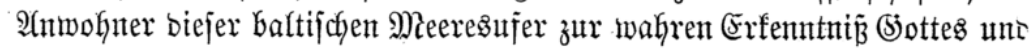
zur Einjicht ber Iugent hinanjühren wolle.

Die Untwerjität $\Re$ önigsberg war, nach bem Sinne bes Stifters, von

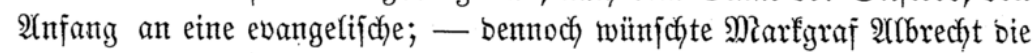
Bejtätigung ber Alfabemte burch ben \$apjt, bamit biefelbe bie \$romo:

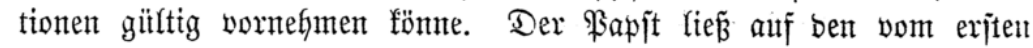

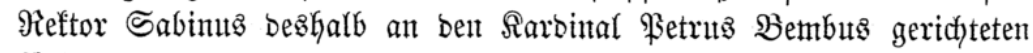

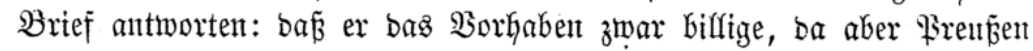

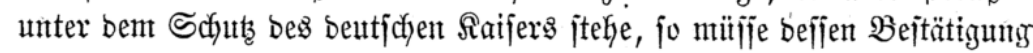
vorangehen. Dieje brieb aits, wenn gleich bie Univerjität, um jolche z̆lt

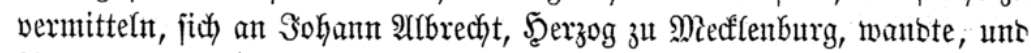

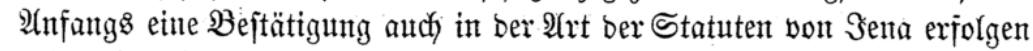
follte, jebody mit ber Bejđ)ränfung, bar bie Univerjität ßromotionen in 
Der theologifchen Fafultät nicht follte vornelymen bürfen. Dagegent

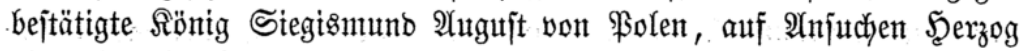

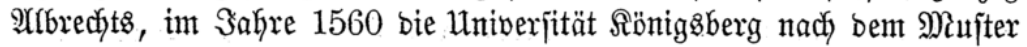

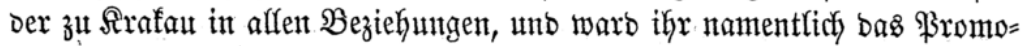
tionsredyt in allen Fafultäten auşbrüdfficd beigelegt.

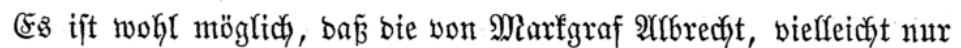
zum Schein, in fpätern Rebensijahren mehrfach gezeigte fohwanfente (5se= jünung in refigiöjer Bezieflung, uno bie in Bolen namentfich badurch

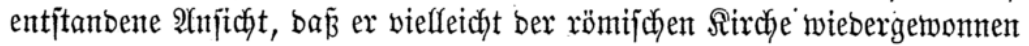
werben fönnte, bie Ertheilung ber Bejtätigung ber Untwerfität bei Siegias=

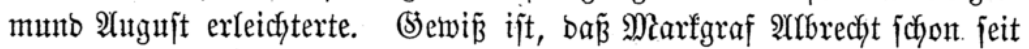

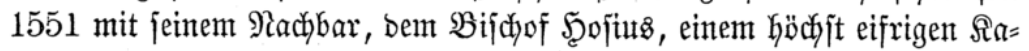

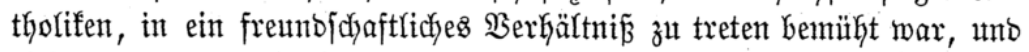
biejer nach bem Tobe Dïanberz 1552, ber einer ber erjten ßrojefforen in

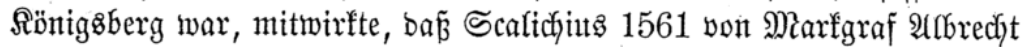
nach Söniggberg gerufen wurbe, ber, went er aud früher in Tïbingen

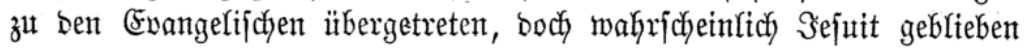

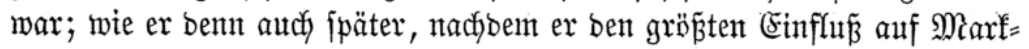

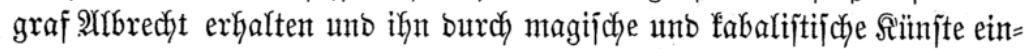

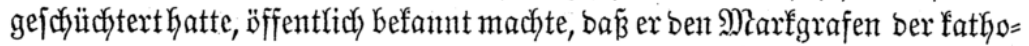

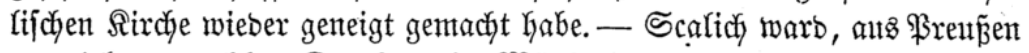
vertrieben, nachber Domberr in Münjter und ftarb 1574 in Danzig.

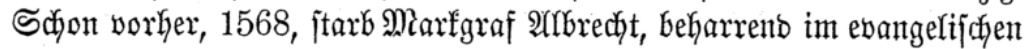
(biauben, im 78. Rebensiangre.

Das Sadjuerhältnin war bemnady folgendes:

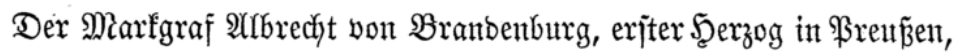

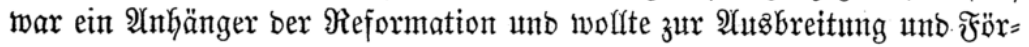
berung berfelben in Söniggberg eine Unniverjität grünton. Snjofern ber ipezififiche Sharafter ind bie eigentlidye Bebeutung einer Univerfität von jeher barin beftand, bå jie mit voller $\mathfrak{B}$ infjamfeit für bie ganze gełehrte Welt ben Doftorgrab in affen $\widetilde{a}$ fulttäten zu ertheilen bas unbejchränfte

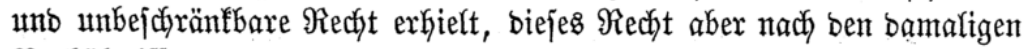

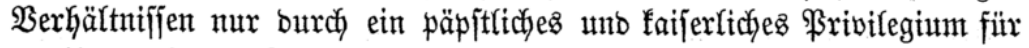

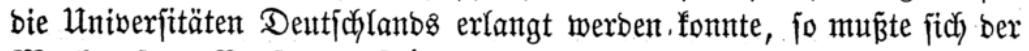

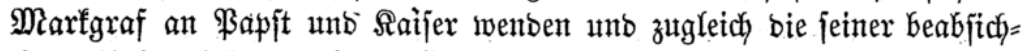

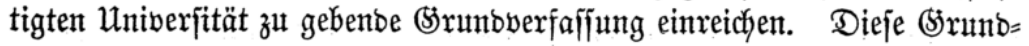
verfafiung ift $e^{2}$, num, welche in ber Ronjtitution von 1546 niebergelegt, unb aus welcher F̧err (Seheimrath Brïggemann einen Sats heraugigehoben hat, ber fich auf ben Schmur ber ßrofefforent bezieht. Diejer auf bie 


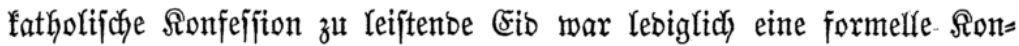

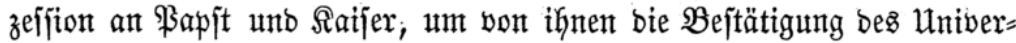
fitätaprivilegiums zut erhalten. Es exfolgte aber bie Bejtätigung nidjt,

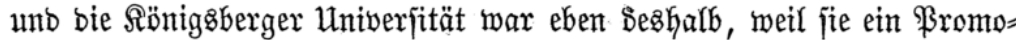
tionsrecht nicht hatte, leine Uniberjität, jonbern nux eine. Affabemie mit angejtellten Refrern.

Die zweite exzerpirte Stelle, nach weldyer zur Promotion in ber phi: lojophijchen Fafutltät mux Satholifen zutgelaffent werben jollten, jteht aber überhaupt in jenter Ronjtitution von $1546 \mathrm{gar}$ nidht; fie befindet ficd in bem

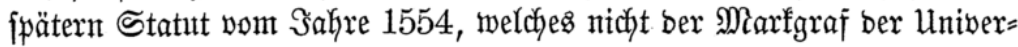
fität, jonbern bie philojophif che ₹afultät jich jelbjt gab, unb worin jie eben nur bas für bie Doftoren wieberholte, was in ber Ronjtitution von 1546 für bie \$rofefjoren vorgejchriebent war. IUffein bie Untwerjität erreichte

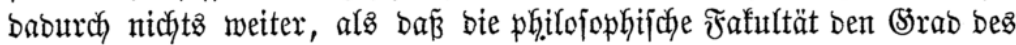

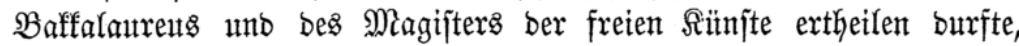
mährend bie Befugni in ben ïbrigen brei Frafurtäten Doftoren 孔 ernennen, ifyr unterjagt blieb. Plun wenbete fich ber Marffraf alz Scerzog in \$rentien an jeinen Rehnzherrn, ben R̈̈nig von \$olen; und biejer

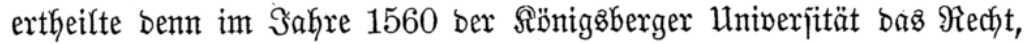
Doftoren in alfen vier Fafultäten zut freiren, woburd fie erjt zut einer wirffichen Utniverjität erfoben warb. Daker wurben benn autch erjt nady biejer Zeit, und zwar unter bem 17. Alugujt 1616, für bie juriftifdje, theo=

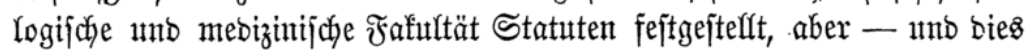
mut bejonbers herborgefoben werben - nidht bon bem Ranbesherrn, fon= Dern von jeber einzelnen Fafultüt aus eigner Madftwolffommenheit für jich ferbjt. Natr barauf war zut jehen, baj bie Statuten ber einzelnen Frafitl= täten nicht mit ber Şrumbverfafjung bes gejammten Univerfitätžtörpers

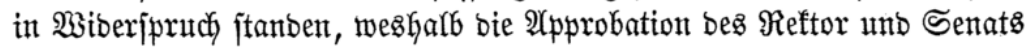
einzufolent war. Man wirb fehen, bas in biejent letztern, aus benen wir

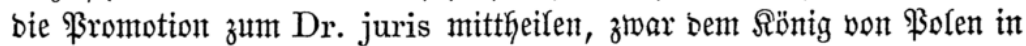
Dem Doftoreibe Danfbarfeit und treute 2(nhänglidjfeit angelobt, ber carijt=

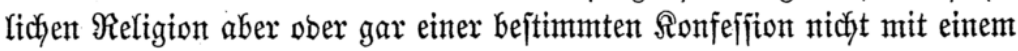

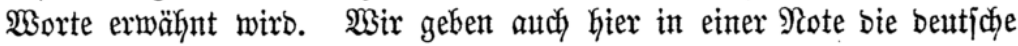
ueberjeţung. 
A. Constitutiones Academiae,Regiomontanae.

Bon 28. Sunt 1546.*)

\section{Juramentum Decanorum.}

Ego N. (hujus facultatis Decanus) juro, teste Deo, me Rectori praestiturum eam reverentiam, obedientiam ac fidem, quam legitimo Magistratui debeo: me ad eundem absque contumacia ac recusatione venturum, Reique publicae consilio semper praesto futurum, quandocunque vocabor. Nihil adversus illustrissimum Principem, Ducem Prussiae, hostiliter aut scelerate facturum, nihil in deliberationibus consideraturum, nisi pietatem, honestatem - et publicam utilitatem, nihil in cognoscendis et dijudicandis causis, nisi aequitatem. Me item nullas fanaticas opiniones ac sectas, sive Anabaptistarum sive Sacramentariorum hic probaturum ac defensurum esse, quinimo amplexurum me puram Evangelii doctrinam, quam nostra haec Ecclesia uno spiritu et una voce cum Ecclesia Dei catholica profitetur, nec carrupturum doctrinam sacram ex Philosophia, nec dissensurum a ministris Evangelii fingendis opinionibus. Nulla secreta concilii divulgaturum, rationes bona fide relaturúm ad aerarium, denique concordiam publicam conservaturum omni studio, nec ullius unquam aut factionis aut dissensionis autorem fore. - Hoc juramentum quoque Rectori praestabunt ommes, qui publici lectores et Assessores esse debent. Qui vero id semel praestiterint, denuo non jurabunt.

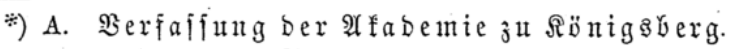

Der Sd)wur ber Def́ne.

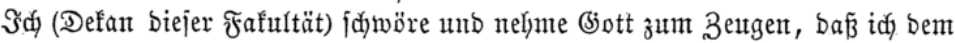

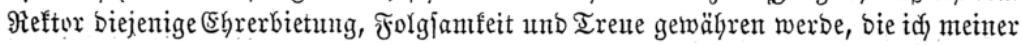

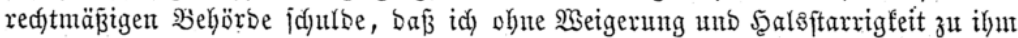

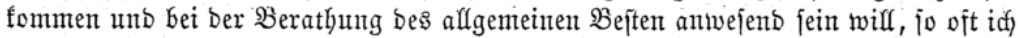

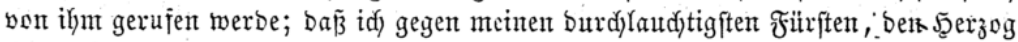

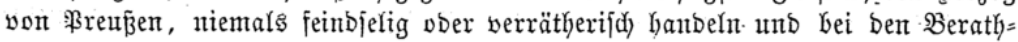

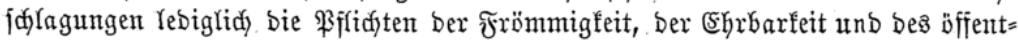

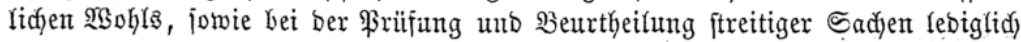

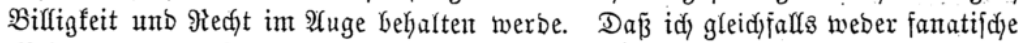
Meinungen, nod Seften bifligen und vertbeibigen, vielmehr ftets an ber reinen evan=

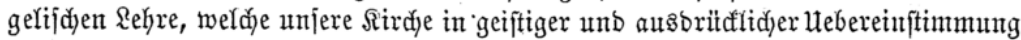

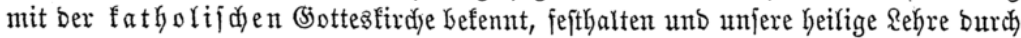
Phirofophie nidjt verftümmeln, nod aud burd, eigen gebilbete Mieinungen von bent

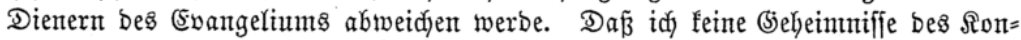

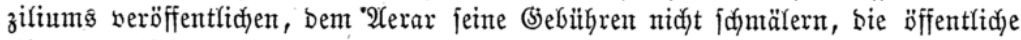
Eintradjt eifrigft bejörbern und feine ßarteiung ober Spaltung herbeifülyrent werbe. 


\section{B. Statuta Collegii Facultatis Artium et Philos ophiae de anno 1554 .}

Cap. XIII. De Gradibus.

Duplicem honorum contributionem in Scholis retineri multis de causis utile est, ut Júventus per artes vitae necessarias ordine ducatur, et discentium cura, industria et assiduitas acuatur et crescat. - Priori gradui a Laurea Antiquitas nomen indidit. Hujus honoris testimonium quicunque petituri sunt, annum ad minimum in hac Academia Regiomontana optimarum artium studiis operam navarint, et artium Professores attente et diligenter audierint necesse est, ut deinde de vita, moribus et doctrina judicium fieri possit. - Posterior est Magisterii gradus, qui eruditionem et judicium de rebus exquisitius requirit. Ad hujus igitur petitionem solidiorem Doctrinam, vitae modeste et bene actae testimonium Candidati adferant, nec admittantur ii, quorum mens polluta et fascinata est falsis opinionibus et a consensu Catholicae Ecclesiae Christi alienis, et in quorum moribus aliqua haeret turpitudo.

Cap. XVI. De Actu et Ritu Promotionis.

Poscente igitur publico Scholae Ministro singuli duobus digitis Sceptro impositis jurabunt: Amplecti se de singulis doctrinae

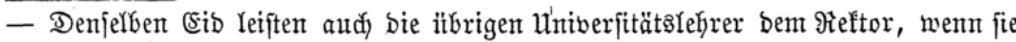
nidjt jadon einmal gejdyoren Gaben.

B. Statuten ber philojophifden $\mathfrak{F} \mathfrak{a} \mathfrak{f} \mathfrak{u}$ tä̈t bom Sahre 1554.

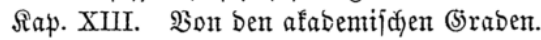

Die SBeibehaltung eines boppeltent (5rabes in ben afabemifden 93 ürben ift aus

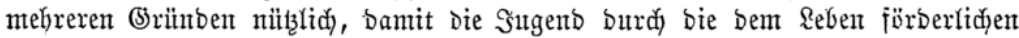

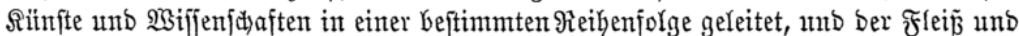
Sifer Der Rernenten angefpannt und vermehrt werbe. Fïr Den erften (5rab hat bas

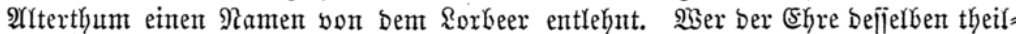

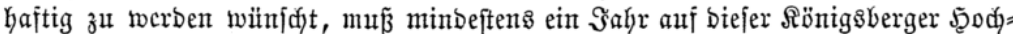

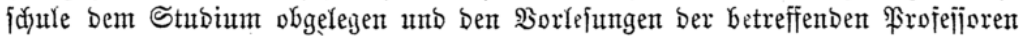
fleif̧ig beigewohnt haben, fo baß man itber feine Rebensmeije unb Renntnijie ein beftinmtes lattheil fälfen fann. Der zweite (5rad ift ber bes Miagifters und verlangt

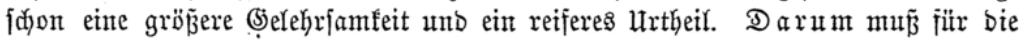

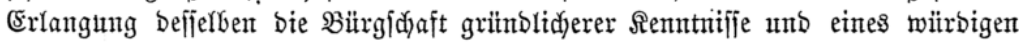
Rebenswandels geforbert, unb barf feiner zugelaffen werben, befien Beift burd,

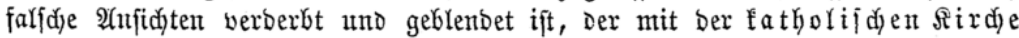
(Ehrifti fid) nidyt in volfer Hebereinftimmung befinbet, unb Deffen Sittlidffeit Den geringften $\mathfrak{F l e c \mathfrak { ~ } \text { hat. }}$

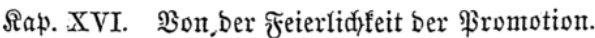

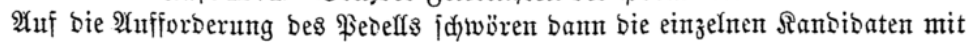

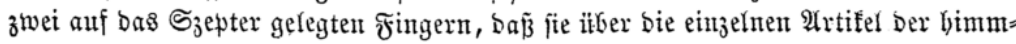


coelestis Articulis universum Scripturae Propheticae et Apostolicae Consensum, et praecipua Symbola cum his censentientia, et consentire in illud doctrinae genus, quod ex his constitutum, et anno tricesimo Imperatoriae Majestati Carolo V. sub titulo Augustanae Confessionis traditum, et deinceps in Apologia repetitum est, eo intellectu et sensu, qui cum universa Scriptura Prophetica et Apostolica congruit, et in hac agnita veritate adjuvante gratia Dei permansuros, publicam utilitatem Scholae promoturos, animi gratitudinem in Illustrissimum Borussiae Principem et Scholae hujus Professores, et inprimis in Decanum et Collegium Artisticum debita subjectione et observatione declaraturos, nec. denuo Magisterii titulum alibi repetituros. - Praestito Juramento a singulis, Decanus publica autoritate, qua fungitur, omnes et singulos liberalium artium Magistros pronunciet et proclamet. Et quia Vetustas addidit insignia, ea ordine conferat singulis. Primo det ipsis potestatem tenendae Cathedrae, h. e. tribuat eis jus in publicis Scholis, quas Academias vocant, profitendi et docendi Philosophiam, disputandi et declamandi. Deinde imponat ipsis rotundum pileum, quo ritu ipsos in libertatem asserat, ac participes faciat omnium Privilegiorum, quibus Caesares et Reges docentium coetus ornarunt. Tertio tribuat eis potestatem gestandi annulos aureos, quo ritu collocet eos in superioris ordinis dignitatem, et Nobiles pronunciet. Nam annulus Nobilium insigne est, et commonefactio de studiorum continuatione.

lifdjen Rebre in Hebereinftimmung mit Der prophetijdjen unb apoftolifjen Sdyriften

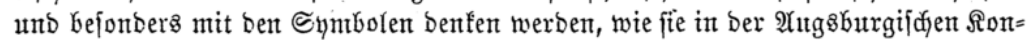

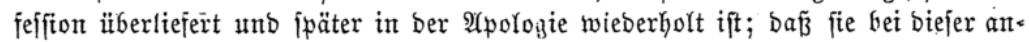
erf́anten $\mathfrak{W a h r h e i t ~ u n t e r ~ ( 5 ) o t t e s ~ g n a ̈ b i g e r ~ U n t e r f t i ̈ t z ̇ u n g ~ v e r h a r r e n , ~ b a s ~ a l f g e m e i n e ~}$

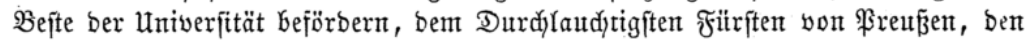
Brofejpren biejer Univerjität, unb bejonbers der philojophijdyen Fafultät, DantGar= feit unb iduulbigen (5jehorjam Yeiften, aud) nirgenbwo anbers ben Magiftertitel nad)=

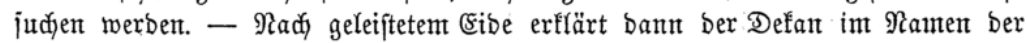
Dbrigfeit bie einzelnen Ranbibaten für Magifter ber freien Rïnfte. Utnb weil man

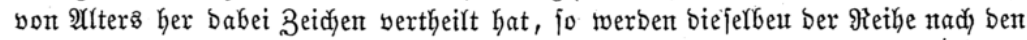

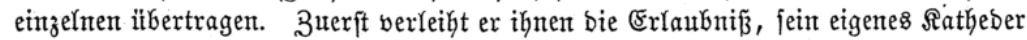
einzunehmen, b. h. er giebt ihnen bas $\Re$ edjt, in ben s̈ffentliden \&ehranfitalten bie $\mathfrak{B h} i=$ lojophie zu Yehren und Borträge zu halten. Dann fetzt er ifnen einen runben Scut auf, woburdy er fie gleid)jam für frei erflärt uno affer ßribilegien theilhaftig madyt,

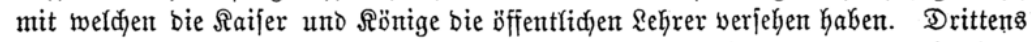

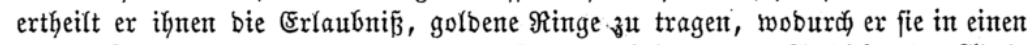

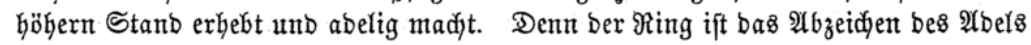
unb zugleid eine Mahnung zur Fortjetzung ber Stubient. 


\section{Statuta Facultatis Juridicae. De 17. August 1616.}

Cap. XIII. De Actu et Solemnibus Promotionis.

Actus ipse Promotionis constat initiis, progressu et exitu. Initia quidem alia peraguntur diebus aliquot actum ipsum antecedentibus, alia in ipso die promotionis. Diebus antecedentibus instituenda est invitatio, cum a Decano, tum ab ipsis Candidatis. Decanus quidem intimatione publica typis expressa, die Dominico actum proxime praecedente, significet, quibus personis honores Doctorales a Facultate Juridica sint decreti, et quo die executioni decretum hoc sit mandaturus, invitetque simul omnes omnium Ordinum Academicos, Proceres ac Cives, nec non bonos quosque ad actum illum spectandum, subjectis Quaestionibus, de quibus singulatim singuli Candidati sint dicturi, quoque Rectore, quoque Decano (si forsan alii quam Decano promovendi jus fecerit Facultas) actus sit peragendus. In Invitatione a Candidatis instituenda considerentur persona et modus. Personae invitantes principales quidem sunt ipsi Candidati, quorum si plures sint, primo et ultimo in Ordine hoc onus est injungendum. Sed adjungendi sunt his cum Orator aliquis, tum Pedelli. Personae invitandae sunt, inprimis Serenissimus Prussiae Princeps, Elector et Dominus noster Clementissimus, atque ejus vices in hoc Ducatu gerentes Illustres D. D. Domini Regentes. Deinde sunt Rector et Professores, nec non Ecclesiae Pastores cum Diaconis, item Consiliarii Principis, Assessores Consistorii, et alii in Aula Ordinis nostri amantes. Ex singulis oppidis Consules et rdinis

\section{Statuten Der juriftijüen Fafultät. \\ Bom 17. Yuguft 1616.}

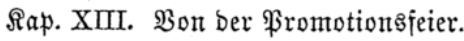

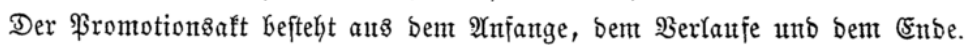

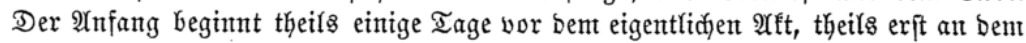
Promotionstage jelbft. Mehrere Tage vorker mus nämlid fowohl von Seiten be Defans, als von Seiten ber Ranbibaten eine Einlabung erfolgen. Der erftere läßjt 3ut biejent 3wedfe an bem Sonntage vor ber \$romotion gebrudt anjojlagen, weldjen Perfonen unb an weldyem Tage bie Doftorebren bon ber juriftijdjen faufultät ertheilt werben witrben, und labet zugleidy alle Mitglieber ber Affabemie, jowie bie $\mathfrak{B o r}=$

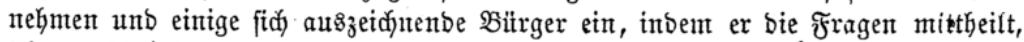
iiber weldye bie einzelten Ranbibaten ipredjen werben, jowie atdd, unter weldyem Reftor unb Defan ber Promotionsaft volfzogen werben wirb. Bei Der von ben Ranbibaten zu Yeiftenben জinlabung milffen, wenn ifyer viele fint, ber erfte unb letste

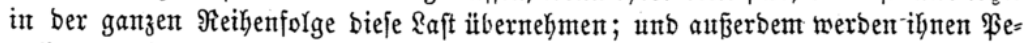

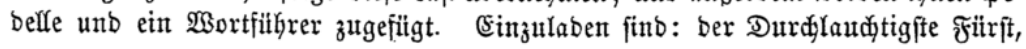


Senatorii Viri, et si qui adsint, docti Cives et peregrini non alieni a literis. Invitandi modus est, utPedelli veste solenne induti cum sceptris antecedant, et ab Oratore Candidatis adjuncto pro qualitate cujusque invitandi, nomine Decani Facultatis Juridicae, ad Actum doctorandorum honorifica invitatio instituatur. Ipso promotionis die hora septima matutina signum detur majori Campana in Ecclesia Cathedrali ad horae quadrantem, ut non solum invitatis, sed etiam ceteris de tempore promotionis constet. Quo. pulso absoluto addatur signum in Collegio. Interim invitati in aedibus Decani, aut alio loco destinato convenient ante octavam auditam. Quamprimum octava fuerit audita, candidati cum Oratore ingrediantur, et gratiis actis se in Collegium deduci petant. Ubi responsio finita, unus ex Pedellis schedulam legat a Rectore petitam, quo ordine singuli progrediantur. In hac pompa Tibicines praecedant, nec non pueri quidam elegantius vestiti cum facibus cereis. Hos subsequantur Illustrissimus Princeps, aut ejus Legatus, cui ex sinistro latere conjunctus sit Rector, deinde reliqui ordine in schedula praescripto. Posteaquam ad locum promotionis perventum est, Decanus, aut si forsan morbo vel alia de causa impediatur, Promotor actus initium faciat, habita Oratione praesenti negotio conveniente, quam pedetentim ad ipsos Doctorandos accommodet,ut commode antequam ad solennia accedat, jusjurandum ab illis exigat. Poscente igitur publico Scholae

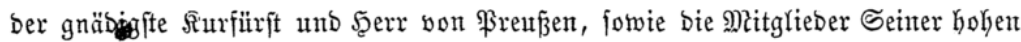

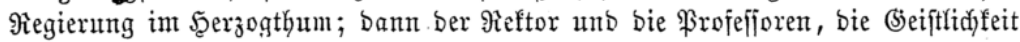

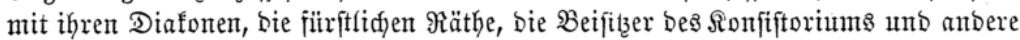

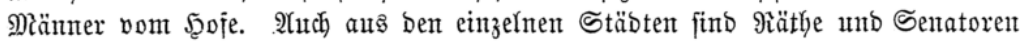
einzulaben, fomie etwa am Drt verwilenbe frembe (5)ilehrte. Die Fintabung ge=

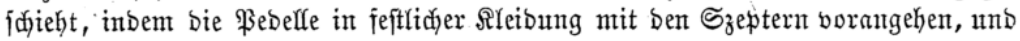
Der Den Rambibaten beigegebene $\mathfrak{S o r t j u ̈ h r e r ~ j e ~ n a d ) ~ D e m ~ S t a m b e ~ b e s ~ હ i n z u l a b e n b e n ~}$

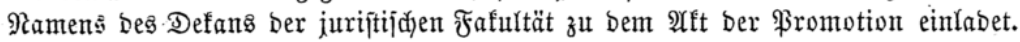

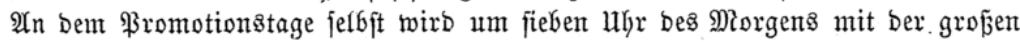

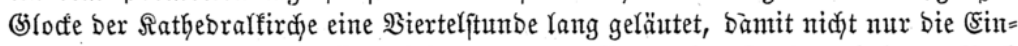

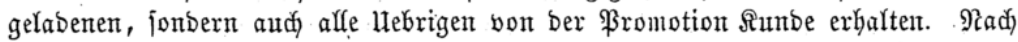

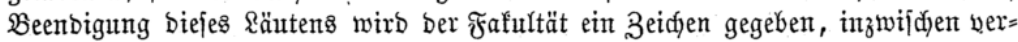

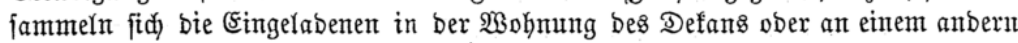
beftimmten Drte bis 8 uhr, unb jobarb es 8 uhr gejdlagen, fommen bie Ranbibaten

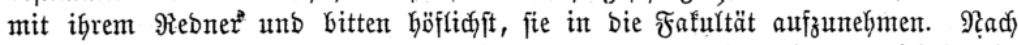

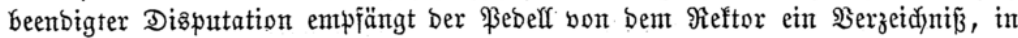

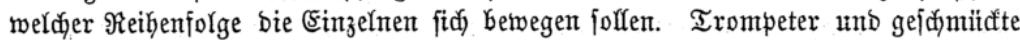

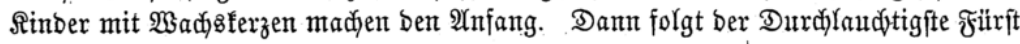


ministro singuli duobus digitis sceptro impositis jurabunt, Ornamenta doctrinae, posteaquam ea hodie acceperint, nequaquam amplius se petituros, nec ultro a quibuscunque oblata denuo recepturos, largitione illicita, profusioneve honoris hujus consequendi gratia nec usos se esse, nec posthac usuros; Sacrae Regiae Majestatis et Regni Poloniae, nec non Serenissimi Principis et Ducatus Prussiae ut et Academiae Regiomontanae praesertim Juridicae Facultatis commoda, utilitatem quovis loco, quocunque tempore pro virili curaturos; dignitatem comiter conservaturos; Decani et Collegii Ictorum mandatis et Constitutionibus sese obtemperaturos; Ornamenta honorum a Ictis tribui solita non collaturos, nec consensuros, ut tribuatur ei, quem ejus gradus decore indignum ex fide sua arbitrati fuerint, nec etiam communi autoritate probatum, sine consensu et roluntate Ordinis insignibus aucturos; per reliqua boni Viri officio, in Legibus potissimum interpretandis, de jure respondendo, profitendo, agendo, defendendo, judicando functuros, uti juris, aequitatis justitiaeque consultum facere oportet, et par est.

\section{IV. Şalle.}

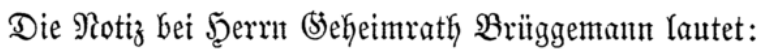

„Statuten von Surfürjt Frriebrich III. zu Branbenburg, ertheilt Dent 1 . Sutti 1694 .

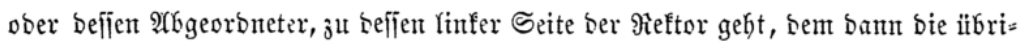

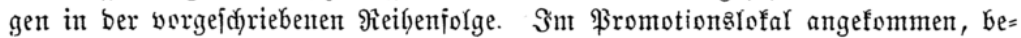

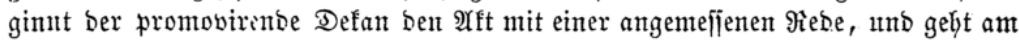

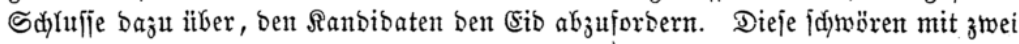

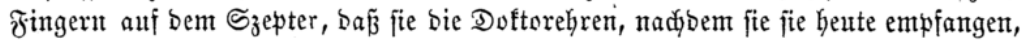

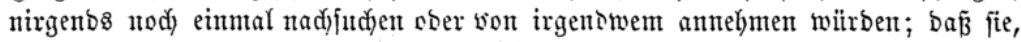

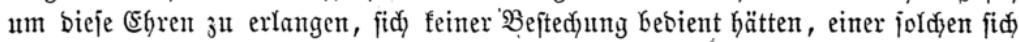

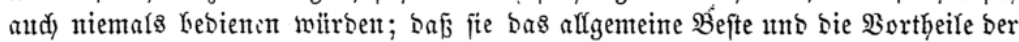

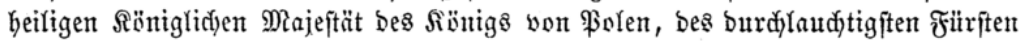

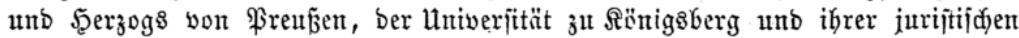

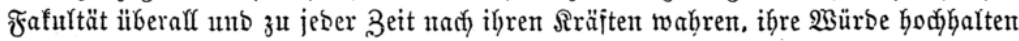

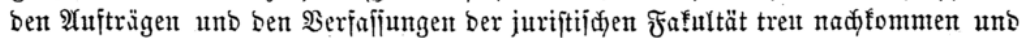

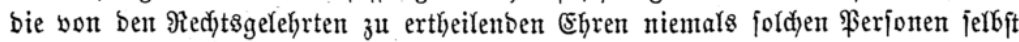
verleiken ober iibertragen Iafjen werben, bie fie eines foldhen Sd)mutfes fïr untwïroig

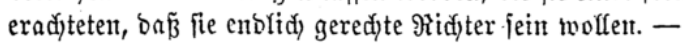

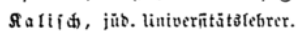


Praecipue autem consensus sit inter omnes et singulos professores in religioné christiana et doctrina evangelica, scriptis prophetarum et apostolorum et augustana confessione comprehensa.

Pariter ab omnibus christianae religioni et honestati contrariis opinionibus sibi temperent.

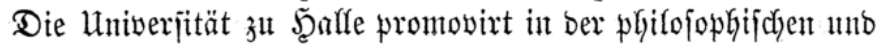

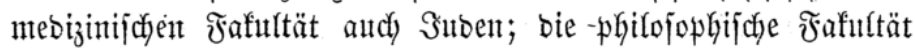
hält nad) ihrer 2(eunerunty vont 29. Dezember 1841 bie \$romotiont ber Subent in ber theologij(f)ent unb jurijtijachent Fafultät nicht fïr zulüjïig."

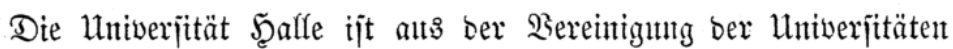
Şalle und $\mathfrak{3}$ ittenberg entitantoun.

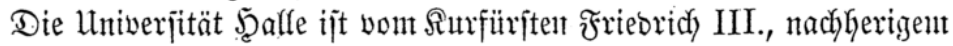

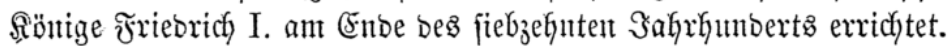

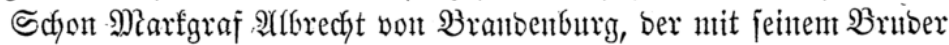

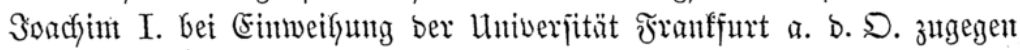
gewejen war, fajte als nach heriger (Erzbifchof wou Magbeburig bent Ent=

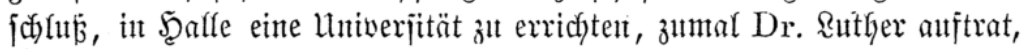

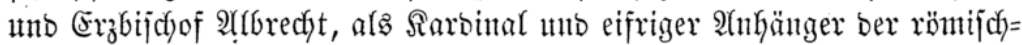

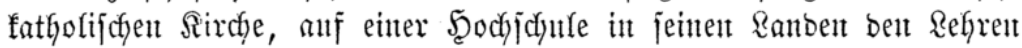

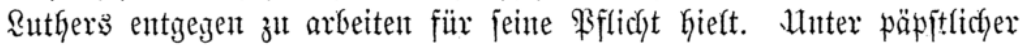
Alttorität bejtätigte ber Sarbinal Eanipeggi, als päpjttlicher Regat it

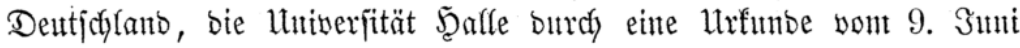

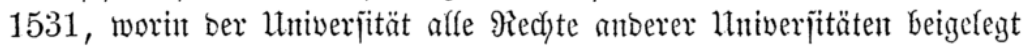
werbent: Doftorent, Mlagijter, Rizentiaten ju freirent. Sie follte Statutent gleid) Bologna haben.

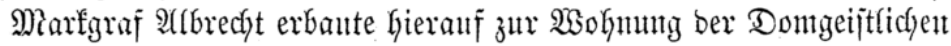
unb ber \$rofefijoren ber zut errichtenben Univerjität bas nody heute jtegente

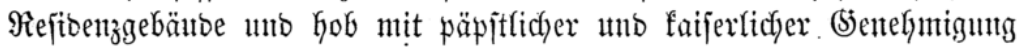

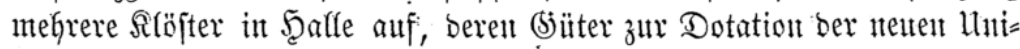

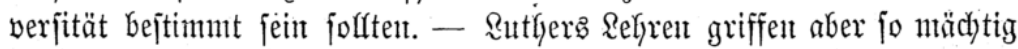

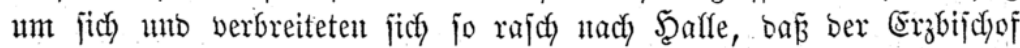

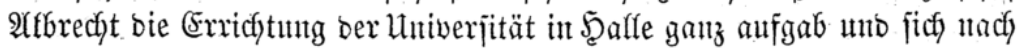

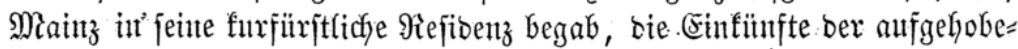

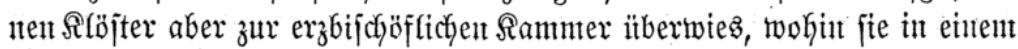

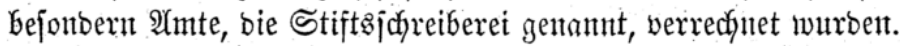

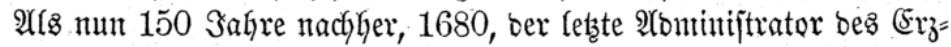

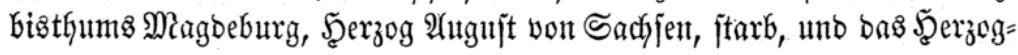




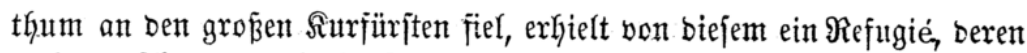
mefrere fđjon bamals in Dentichland Yebten, Ramenz Millé, genannt

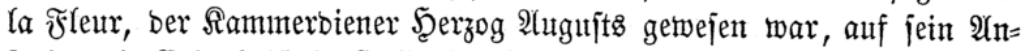

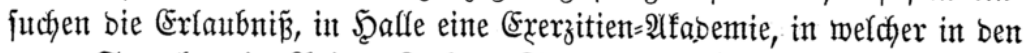

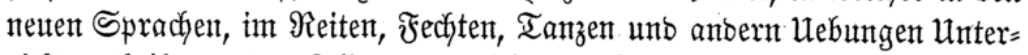

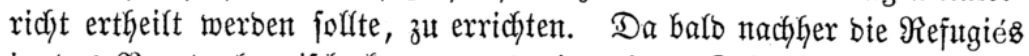
in bas Branbenburgijdye famen, unto eine eigene Rolonie berjelben nach

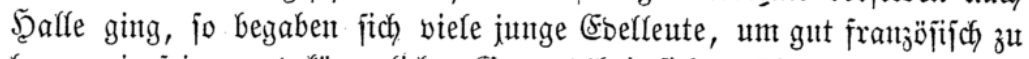
lernen, in jeiter uno förperfictyer (Semanbtheit jich) zu üben, auj bie Exer= zitien=2lffabemie nach ફ̧alle. Friebrich III. vertwanbette bieje 1689 in eine

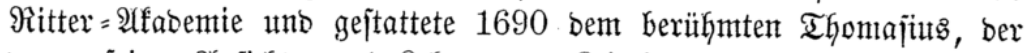
wegent feiner 2̂̃ufichten unt Rehren aus Reipzig vertriebent war, in Scalle

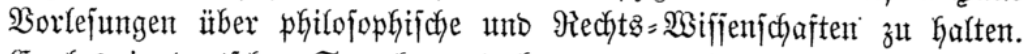
(Ex las in beutfcher Sprache und hatte ungemeinen Butlauf, weshalb

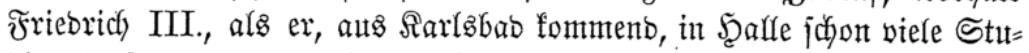
birente fanb, uno von jungen (Eollenten exjucht warb, eine proentfiche

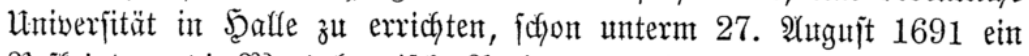

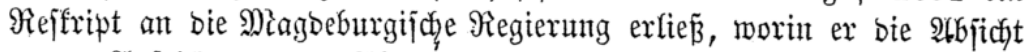

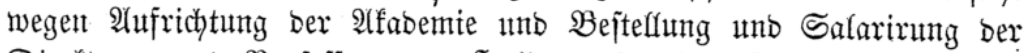

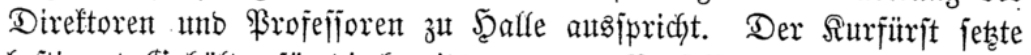
bejtimmte Siehälter für bie bereits ennanten \$rofefijoren aus: 500 Thaler für Thomajüts, 500 Thaler für ben Theologen Breithaupt, 250 Thaler

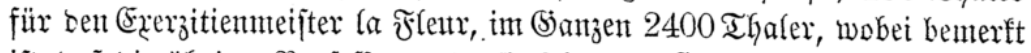

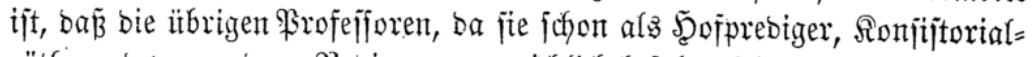
rätţe und von anbern Bebienungen reid)lidy bejoloet jeien, feiner (Siehälter

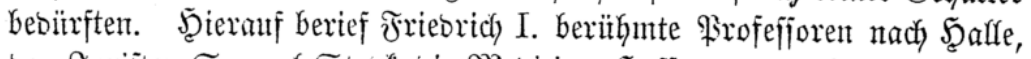

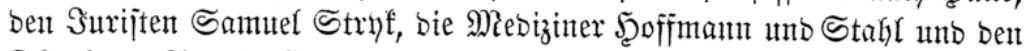

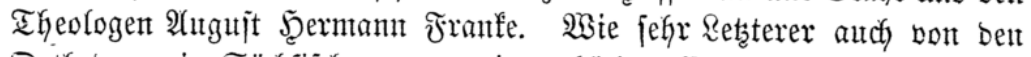
Drthodočen im Sächjif chen wergen eines thätigen (E) rijtenthums, bas burch gute (5ejunlsung unb gute 3 serfe jich hervortfite, angejeinbet warb, wenn

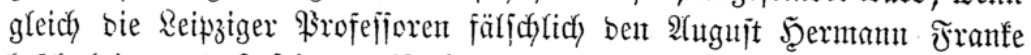

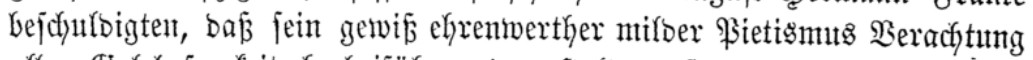

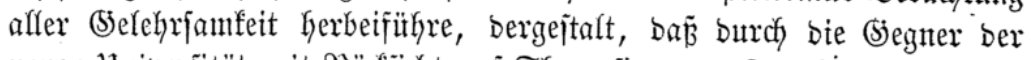

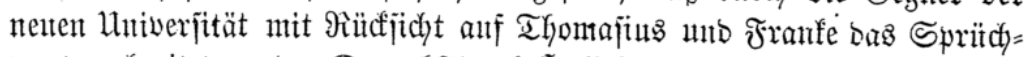
wort verbreitet warb: "Dit gehjt nach. Şalfe? - Galo mirjt ou als \$ietijt

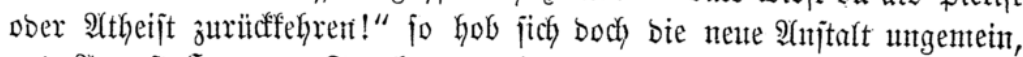

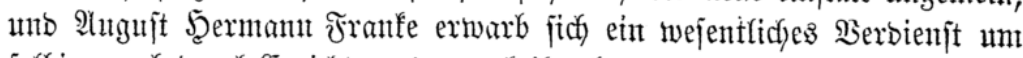
jelbige and burdy (Errid)tung ber nad) ihm benanntent frommen Stiftungen,

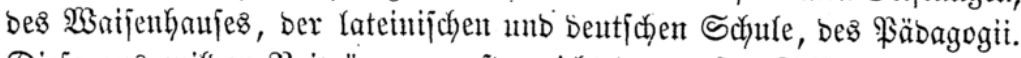
Dieje alts milben Beeiträgen juerît errichteten großjen Stiftungen waren 
mit ber Untwerjität fortbauterno in naher $\mathfrak{B}$ erbintoung unto verfchafftent jungen Theologen früh (Bjelegentheit, jich int Rehrfach zll üben, uno bie,

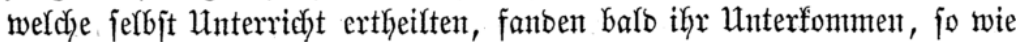
auch) ärmere Stubirente an ben Freitifuchen Theilunahme. - Saijer Reopolo

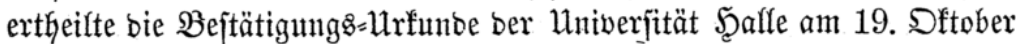
1693; unb hierauf warb am (Seburtstage bes Surfürjten, am 1. 3uli 1694,

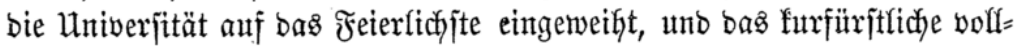

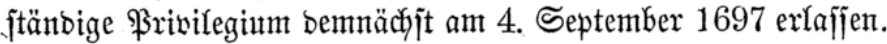

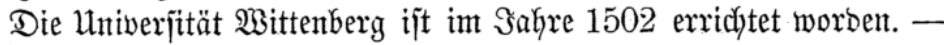

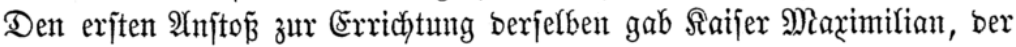

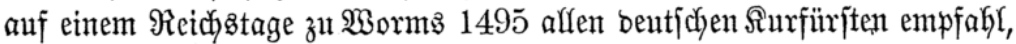

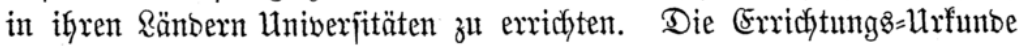

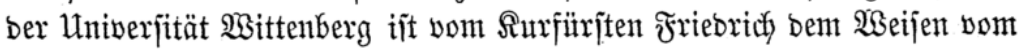
18. Dftober 1502 , an weldyem Tage jie aud eingemeift wurbe. Sdyon

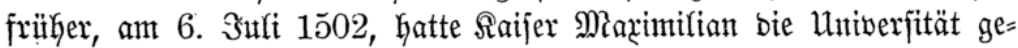

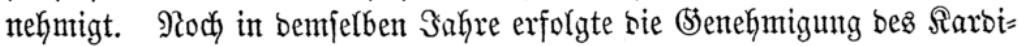

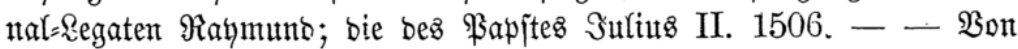

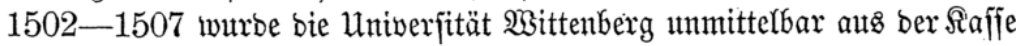
bes Surfüriłten unterfyalten; von 1507 an aber murbe bie Stiftsfirche mit

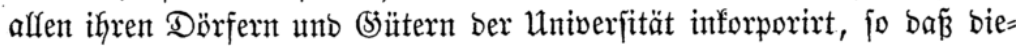
felbe von biejer Zeit an ighe Einnahme gänzlidy auts bem ifyr überwiejenen

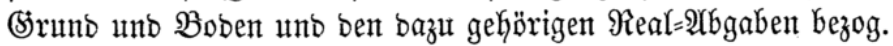

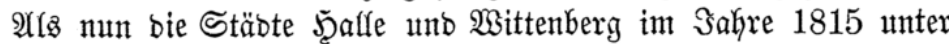

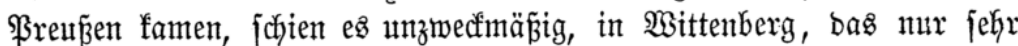
wenige Stubirentoe in ben Yetzten Dezennien gezäflt hatte, und wojelfít bie Unniberjität während ber Belagerung auseinanber gegangen war, eine bejontore Uuniverjität neben Berlin, Şalle, Breslau bejtehen zu laffen.

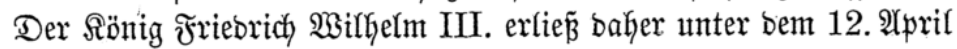
1817 ein

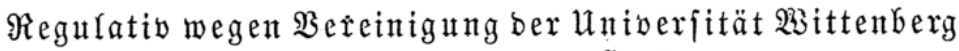
worin e\& heiß̧t: mit ber Univerfität $\mathfrak{T} \mathfrak{a} l \mathfrak{e}$,

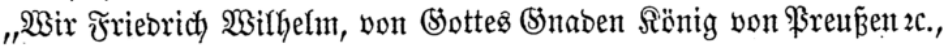
veroronen Gierburch, nachbem bie Univerjität burch ben $\Re$ rieg atz $\mathfrak{W}$ ittent=

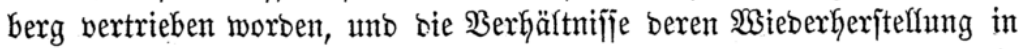

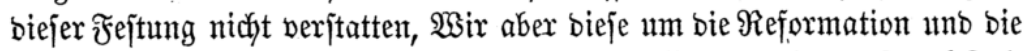

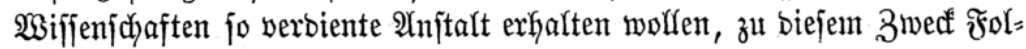
gentez:

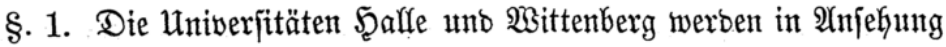

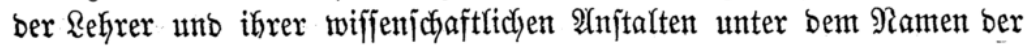




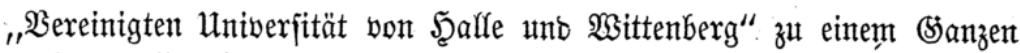
verbunben."

Die ftatutarifdyen Beftimmungen, welche für ben vortiegenben Begen= ftant von Intereffe fint, unt aus weldyen Feerr (seheimrath Britgge= mann einen einzelnen Sałz herauggerififen, lautten im Tex̌t uno in ber Ueberjetang:

\section{Statuten ber Friebrichs: Univerfität zat Şalle von Surfürft Friebrich III., 1. Iuli 1694**)}

Cap. I. De Corpore Academico, ejusque Membris.

$\S$ 1. Corpus Academicum Almae Eridericianae ex quatuor distinctis facultatibus constet, Theologica, Juridica, Medica et Philosophica, quarum quaelibet suis quidem gaudeat statutis, omnia tamen illarum Facultatum membra pacem inter se colant ac concordiam, nec altera Facultas alteram supprimere aut juribus ejus derogare intendat, sed potius omnis impendatur opera, quo singulis Professoribus et Facultatibus bene sit et membris probe junctis ac pro communi civium academicorum salute conspirantibus, universum corpus acadenicum floreat, et in dies majora capiat incrementa.

§ 2. Praecipue autem consensus sit inter omnes et singulos Professores in religione christiana et doctrina evangelica, Scriptis Prophetarum et Apostolorum, et Augustana Confessione comprehensa. Quod si vero circa controversias ad religionem pertinentes dubium uni alterive subortum, non mox alter in alterum invehatur publice, aut haereseos ipsum incuset, sed Prorectori

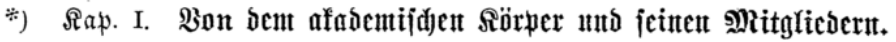

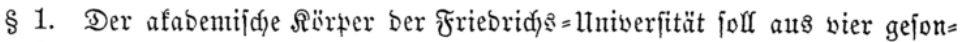
Derten Fafultäten, ber theologifdjen, juriftifdyen, mebizinijden unb philojophijoden, beftefen, bon weldyen jebe zwar befonbere Statuten erbalten wirb, bie aker alle unter fid) Frieben und (sintrad)t bewahren, und von benten feine bie anbere jut unter=

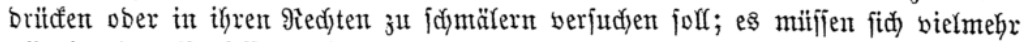

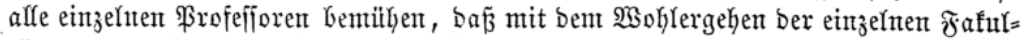

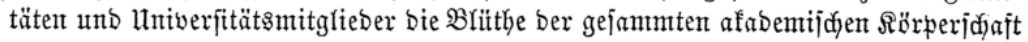
erhalten unb von $\mathfrak{T} a g$ ju $\mathfrak{T} a g$ vermebrt werbe.

§ 2. Befonbers mú unter Den einzelnen \$rofefjoren in Beziebuntg auf bie

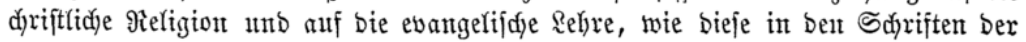

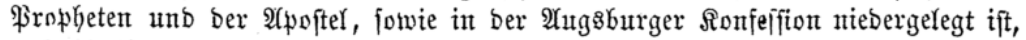
Hebereinfinmung vorhanben fein. Unt joute eine religiöje Rontroverje burdi einen biejem ober jenem fid aufbrängenten 3 weifel entfteben, fo fahre nidjt einer gleidy öffentlida) gegent ben anbern los, ober flage ihn wohl gar ber Retzeret an, madje vielmehr 
Academiae hoc significet, qui si rem componere nequeat, convocatis Theologiae non tantum, sed et aliarum Facultatum Professoribus ab illo, qui suspectus esse dicitur, declarationem opinionis suae petat, quae si ita comparata, ut doctrinae evangelicae conveniat, negotium inter dissentientes amice componatur; sin secus, causa ad Serenissimum et Potentissimum Electorem Brandenburg. referatur, quo ipse publica autoritate, quid facto opus sit, statuat.

ऽ 3. Porro unusquisque Professorum omnem impendet operam, ne sola doctrinae puritate nitatur, sed et vitae integritate morumque gravitate ac honestate exemplo possit esse illis, qui studiis hic operantur, nec Scandalum praebeat auditoribus, aut alia ratione ordini Profesșorio dedecori sit; sed hoc agat sedulo, ut sincerus Dei cultus morumque probitas inter Studiosos et verbis et facto promoveatur; sin secus fecerit, reliqui Professores hoc Prorectori referant, quo si ab hoc monitus, mores non mutaverit, res ad Concilium deferatur.

$\S$ 4. In ipsam autem Professorii muneris functione unusquisque fidelitatem et assiduitatem in docendo commendatam sibi habeat, quo Auditores metam sibi propositam eo felicius faciliusque contingant. Pariter ab omnibus christianae Religioni et honestati contrariis opinionibus sibi temperet, et spartam sibi commissam ita ornet, quo Deo et Principi justas commissi mu-

Tavon bem ßroreftor eine $\mathscr{2}$ zeige, ber, wenn er bie Sadje perjönlidy nidyt beilegen

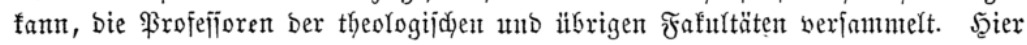

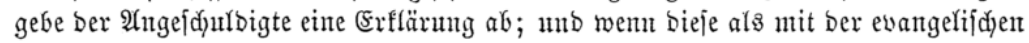

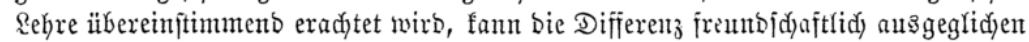

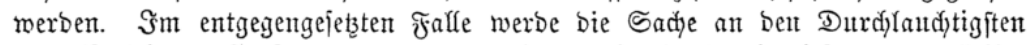
unb Mädjtigiten Rurfïrften von Branbenturg gebradjt, Damit biejer, was nüthig, veranlaije.

§ 3. Şeber.Profeffor fei außzerbem benüht, nidjt blos in jeiner \&ebre, fonbern aud) in feinem ganzen Rebensmanbel burdy Ernjt und (s)brbarfeit Denjenigen ein B̉eijpiel z̆ jein, weldje Den Stubien obliegen; er gebe jeinen Bubürern feine \$er= antaffung zun Sfanbal und madje bem Stande ber \$rofefforen feine Sdjanbe, wirfe vielmehr eifrig bahin, Dẩ aufrid)tige (5otteswerelyrung und wahrhafte Sitt= Yidjfeit unter ben Stubirenben in $\mathfrak{B o r t}$ und That geförbert werben. Şanbelt er anbers, fo Gaben bie ïbrigen Profejporen Dem \$roreftor barïber zut beridjten, Der Dann, ment feine perfönlidje Mahnung nidyt hilft, bie. Ȧngelegenlyeit vor ben Senat bringt.

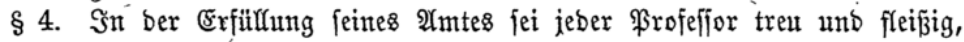

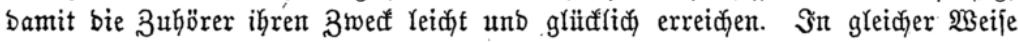

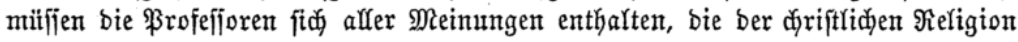
unb ber EGrenhaftigfeit wiberfpredjen, unb bas ihm anvertraute $\mathfrak{A m}$ io fübren, 
neris rationes reddere possit. Quid vero unicuivis in specie agendum incumbat, ex statutis cujusque Facultatis repetendum.

Cap. XII. De Legilus Academicis a Studiosis observandis.

$\S 1$. Unusquisque civium academicorum, cujuscunque status, Deum rite colat et se non verbo tantum, sed opere Christianum esse ostendat, initiumque sapientiae in timore Dei quaerat.

§ 2. Hoc fine publico cultui divino se non subtrahant, sed illi cum debita devotione intersint, et ab omnibus confabulationibus, ne alios in devotione turbent, semet abstineant, nec nisi finitis precibus ex templo discedant.

\$3. Privatis etiam precibus magna cum devotione incumbant et a Deo Spiritus sancti regimen in vita et studiis subinde expetant, probe perpendentes, si hoc ductore destituti, exitum studiorum se nunquam ex voto impetraturos, sed frustra tempus omne impensuros.

Statuta Facultatis Juridicae.

Cap. X. De Promotione Doctorum.

$\S 6$. His expeditis pergat promotor, non levis 'sed omnino magni momenti negotium esse ad Doctoris in utroque Jure adspirare gradum, dum non solus ille titulus, sed insimul Justitiae

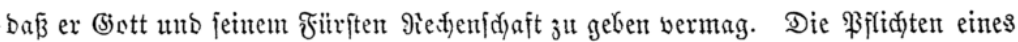
jeben im Eingelnen folfen in ben Kejonberen Fafultätş jatuten fejtgefterll werben.

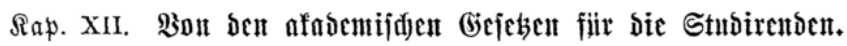

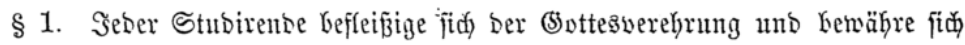

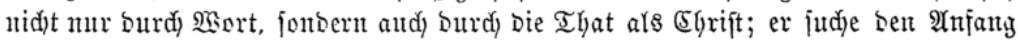
ser Sageigheit in ber (jotte\&furdyt.

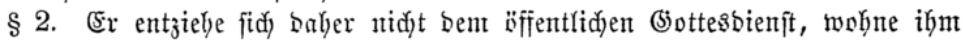

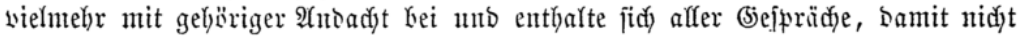

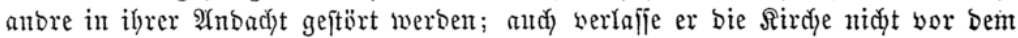

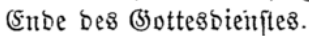

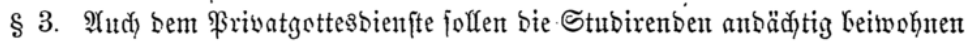
unt von Sott bie Reitung bes Keiligen (5eifites für ihr Reben und ihre Stubien er=

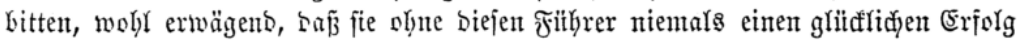
ihrer Stubien erreidyen, alle ihre ßeit vielmelyr verfieren werben.

\section{Statuten ìr jurifitird)en Enkultüt.}

\section{Rap. X. Bon ber Doftorpromotion.}

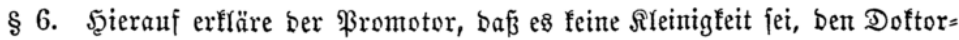

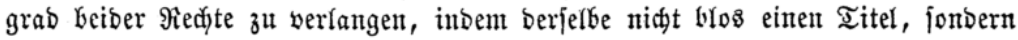


sacerdotium ipsi confertur, eaque propter omni studio doctoribus eo laborandum, ut quae ad honorem Dei et promovendam justitiam publicaeque rei salutem spectant, promte et ad conscientiae ductum conferant, quod ut eo certius faciant, solenni jurejurando ad hoc constringendos esse. Hoc fine promotor advocabit Actuarium facultatis, ut sacramenti formulam praelegat doctorandis.

§ 7. Formula Juramenti doctoratus: Ego N. N. juro, me Serenissimo Electori Brandenburg. fidelem futurum, commoda Electoralis Domus, ut et Academiae hujus pro viribus promoturum, collegio juridico debitam reverentiam exhibiturum, insigniaque doctoralia in nulla academia alia repetiturum. Praeterea si ad causas in foro agendas me contulero, aut alias de jure consultus fuero, nihil dolose, fraudulenter aut per calumniam acturum, sed justi regulas me ubique pro scientia et conscientia mea observaturum. Ita me Deus adiuvet.

\section{Statuta Facultatis Medicae.}

Cap. IV. De Promotionibus.

§ 8. Quoad gradum Licentiaturae (et Doctoralem) conferendum, in omnibus nos confirmamus cum Statutis facultatis Juridicae; nemo autem Candidatorum ad Licentiati vel Doctoris gradum adspirare debet, nisi prius praestiterit sequens juramentum:

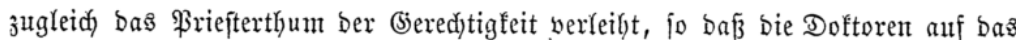
(Fifrigite fid) beftreben miiffien, alles, was fid) jur (5)bre (5ottes auf bie Förberung ber

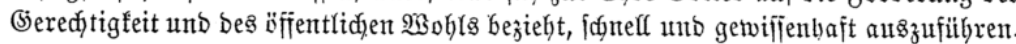
Un bies ju verfidjern, forfen fie einen feierlidjen (Fid leiften, weldyen ber \$romo= virenbe, unter ben Beiftand bes Fafultätsaftuars, ben Doftoranben laut vorlieft.

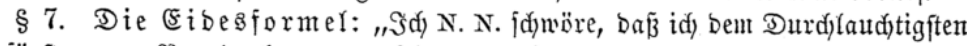

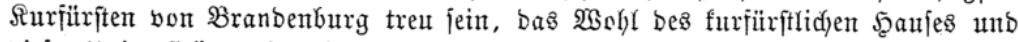
Diejer Univerfität nad) meinen Iräften förbern, Der jurifitidjen Fafultät bie jojul= Dige (5yrerbietung zoffen unb ben juriftifden Doftorgrab an feiner anbern Univerfität

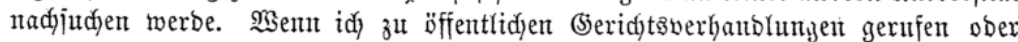

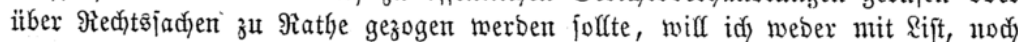
Betrug, nod) berleumberifd berfahren, jonbern ïberall bie (sieję̧e nady meinem bejten :

So wahr mir (5ott helfe!“

\section{Stüuten der medisinifit)en Enliultüt.}

Rap. IV. Bon bent Proutotionen.

§ 8. Der Rizentiaten = und Doftorgrab wirb ganz fo wie in ber juriftifjen

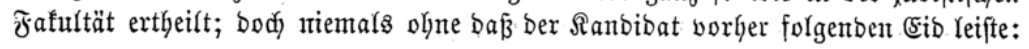


Ego N. N. juro, me Serenissimo Electori Brandenburgico fidelem futurum, commoda Electoralis Domus et Academiae hujus pro viribus adjuturum. Statutis Electoralibus et Facultati medicae reverentiam habiturum, gradumque Doctoralem nullibi, quam in hac Academia assumturum, et si ad ipsos aegros sanandos requisitus fuerim, nihil dolose, sed omnia circumspecte secundum conscientiam et regulas medicas acturum expediturumque, et non tam meum commodum, quam aegri sanitatem et salutem, sive pauper sive dives sit, quaesiturum. Ita me Deus adjuvet!

\section{Statuta facultatis Philosophicae.}

Cap. IV. De honoribus conferendis.

$\S 10$. Formula compromissionis a Candidatis praestanda adstringet eosdem ad promittendam pietatem et honestam vitam, studiorum continuationem, memoriam accepti hac solennitate beneficii et reverentiam erga Professores Academiae universos, maxime vero adversus illos, qui aliquid ad honores, quibus ornati sunt, contribuerunt.

\section{Berlin.}

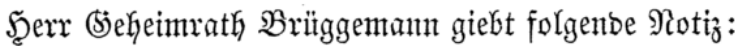

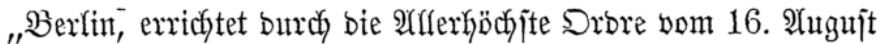
-1809. Die Statuten ber Univerfität fint vom 31. Dłtober 1816, bie Statuten ber einzelıen Fafultäten vom 29. Эanuar 1838.

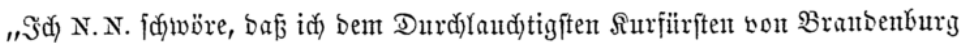

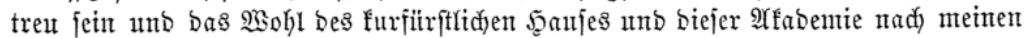

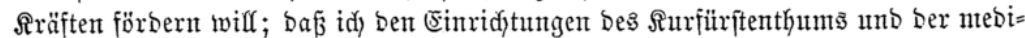

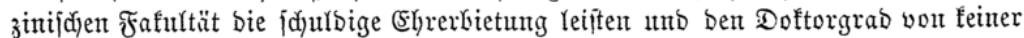

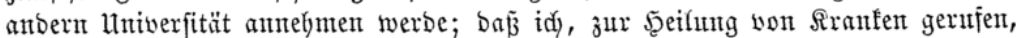

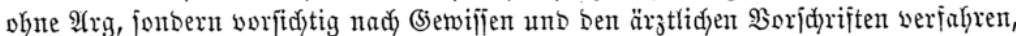

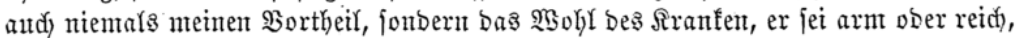
in $\mathfrak{A}$ inge haben werbe.

So wahr mir (5ott helfe!“

\section{Stututen. Jer philorophird)en faliultüt.}

Sap. IV. Bon ben afabcmijuch Eldren.

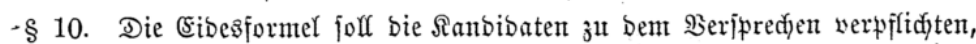

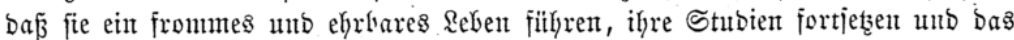
Inbenfen an bieje feier mit DanfGarfeit unib Ebrerbietung gegen bie Frojejioren ber utniwerfität ïberbaupt, bejonbers aber gegen biejentigen, weldje ju ben ihnen eben ertheilten afabemifjen (⿶)hren beigetragen haben, bewahren werben. 


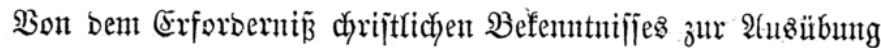
Des Rehrants ijt in ben Statuten nichts zu finben; in ben Sta= tuten ber Univerjität ijt mur als Zwedt angegeben, bie alfgenteine unb bejondere mififenfdyaftliche Bilbung gehörig vorbereiteter Süng= linge burdy Sior Yejungent und anbere afabemifdye Hebungen fortzlt= jeţent unb jie zum (Eintritt in bie verichiedenten 3weige bes häge ren Staats= unb Rirchenbienjtes tüdytig zu mádyen."

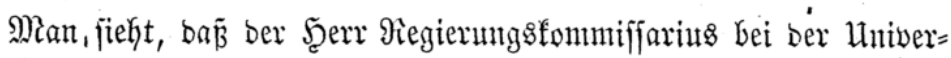

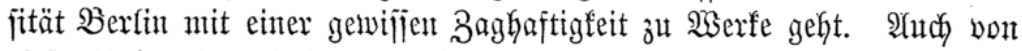
biejer Univerjität bie jübifchen Refyrer ausfdhließ̧en mollen, wäre gerabes=

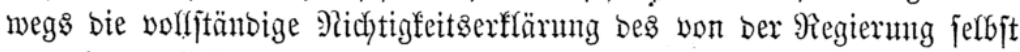
worgelegten (Biefetzes gewejen. Snt ber That aber wollte bas Minititerium

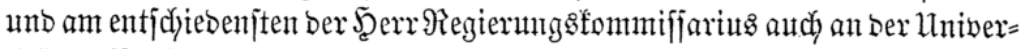

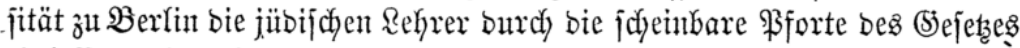

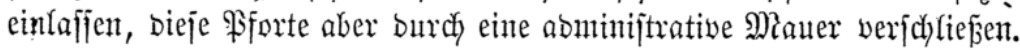
Denn bie . Sorbereitung ber Stubirenten jum Eintritt in bie verichiebenent 3weige bes höheren Staats = mo Sirchenbienjtes mürbe bod. wohl recht fïglich nur dyriftlicfen sefrern haben anvertrant werben bürfen. Und in ber That haben wir bei bent von ben einzelnen Univerjitäten abge= gebenen 2 otis gejehen, wie gar viele \$rofefforen, Şerr Stahl natürlich

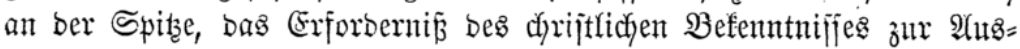
übung bes Reframtes mux barum in bent Statuten als nichtermähnt er=

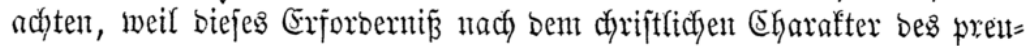

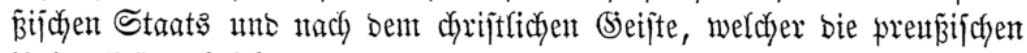
Univerjitäten beleben und burchbringen mitîfe, jich ganl von jerbjt berjtehe.

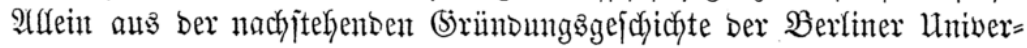

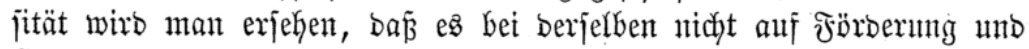

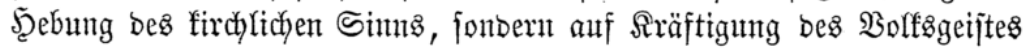
Durch möglidyjte Bermehrung unt Berbejierung ber Unterridytgntittel ant Unterridytanajtalten abgejeken war; unb bas balb nachlyer erjofienene

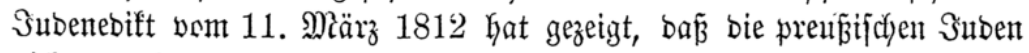

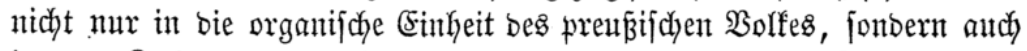

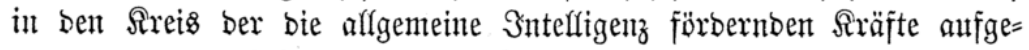

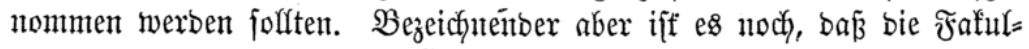
tätşłatuten von 1838, beren Scerr \$seheimrath Brüggemann mur obenfyin ermähnt, bei ben von ben Doftoren zu Yeijtenden Giben bie \$rromotion

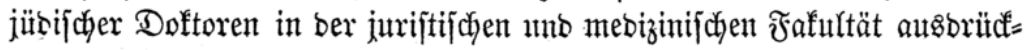
fich herworheben, in ber philojophifchen Fafulttät aber lebiglid, ein $\mathfrak{B e r}=$

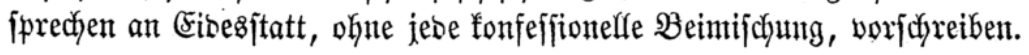




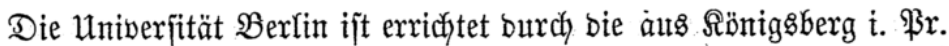

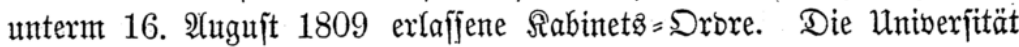

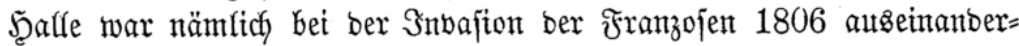
gefprengt, und fowohl bie Stubirenden, als viele \$rofefforen hatten bie 'Stabt verlajien. Der Schmerz Gierüber, Gejonbers als ber Säniz in einer ergreifenden \$roflamation vom 24. Suli 1807 jeine Unterthanen jenjeits

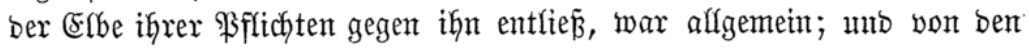

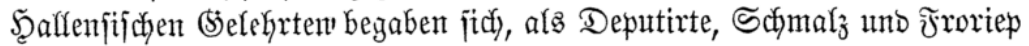

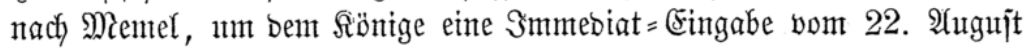
1807 zu übezreidyen, in meldjer um Errichtung einer neuen Univerjität in

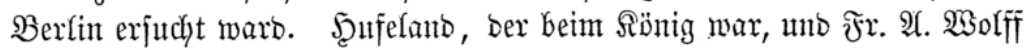

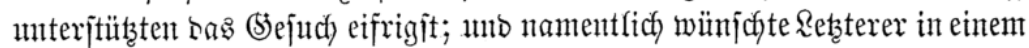
Schreiben an ben (Stroj̈tanjler Beyme eine balbige, wentgittens vorläufige

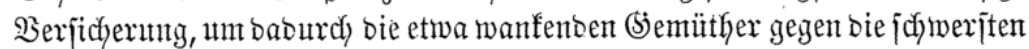

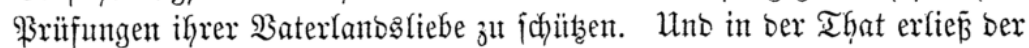
Rönig fónon unter bem 4. September 1807 in Memel an ben (Sjeheimtent

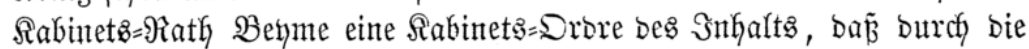

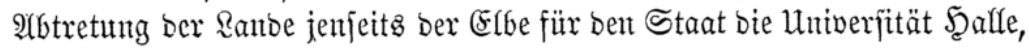
unt bamit bie widftigite uno volffommenjte allgemeine Refranjtalt, verlo=

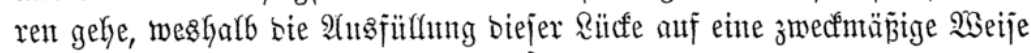
bei ber Reorganifation bes Staats ène ber eriten Sorgen jein müfie. Die Untverjitäten Franffut unb Sönigsberg feien bazı nicht geeignet,

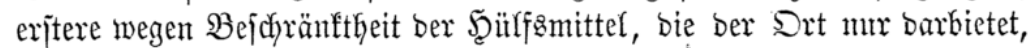

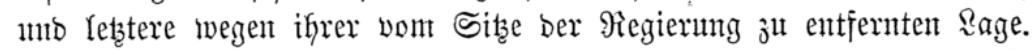

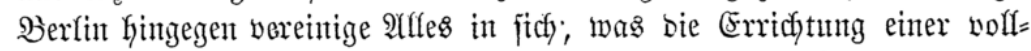
fonmenten, alfgemeinen Rehranjtalt mit bem minbejten Rojtenaujmante

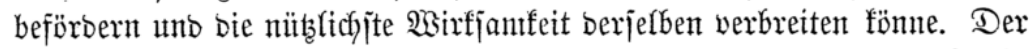
Rönig habe saher bejchlofien, eine joldhe alfgemeine Rebranjtalt in berfin

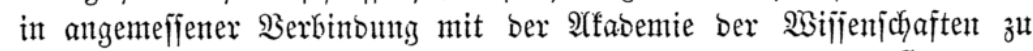
erridytent. Beynte jajrieb nun an bie \$rofejijoren Sdymaly, Şufeland,

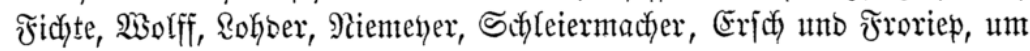

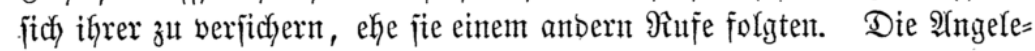
genkeit verzögerte jith) jebod), obwohl einzelne Borlejungen in Berlin ge=

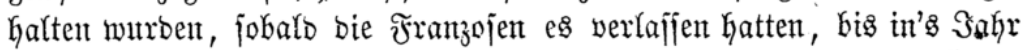
1809, wo jie bem bamaligen Stefeimen Staatarath \$ilfyelm von \$ृum= bolbt in jeiner Eigenfdjaft als (5)ef ber A(btheilung bes Minijteriums bes Snnern für ben äffentficyen Unterridyt mit übertragen murbe. Bereits unterm 12. Mai 1809 ïberreidyte berjelbe ben von ifhn eigenthänbig aus= gearbeiteten Эmmediatbericht, in welchem er baranf antrutg, in 'Berlin

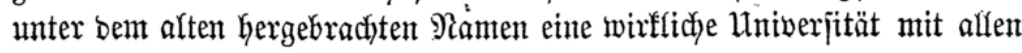


ify jufommenden $\mathfrak{A}$ ttributen zu errichten. "WBeit entfernt - jagt er in

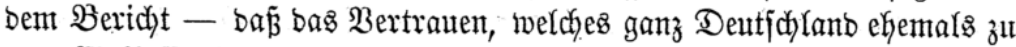

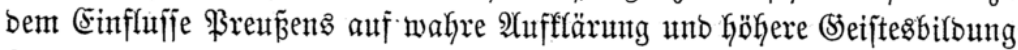
hegte, burch bie Yețten unglïdffichen (Ereignifje gejunfen jei, fo ijt es viel= mehr gejtiegen. Man habe gejehen, bas in affen neueren Staatbeinridy= tungen Sr. Majejtät ber Sinn Kerriche, welcher in jenem widytigiten alfer Borjüge aud ben hödjten Ziwed jeber Staatsvereinigung erfenne; man

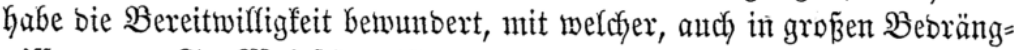

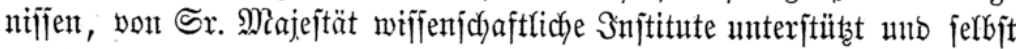
anjefnlid verbejiert worben jeien."

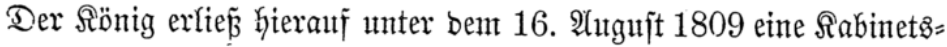

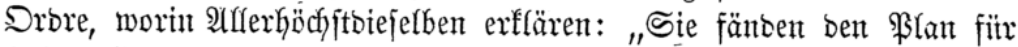

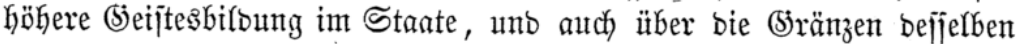

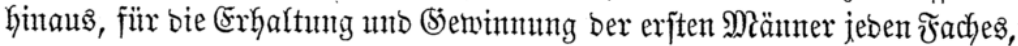

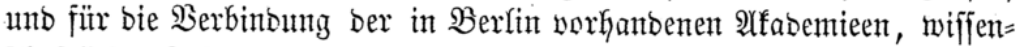
¡chaftlicyen Injtitute unb Sammlungen zu einem organif(y)en (5anzen, jo widjtig, bas jie bie Erridytung einer foldjen alfgemeinen Rehranjtălt, mit

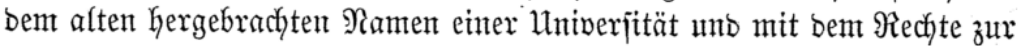

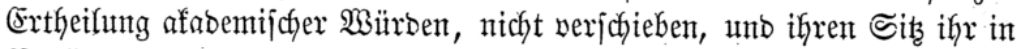
Berlin anmeijen wollten."

Sn Dftober 1810 wurbe bie Univerjität wirffiç eröffnet, uno

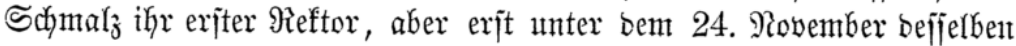

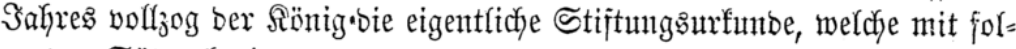
gentoen Sätşen beginnt:

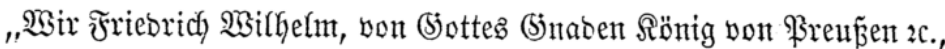
urfunten und erffären fiermit, uno in Siraft biejes lunjeres offenen Brie=

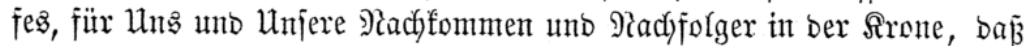
$\mathfrak{W} \mathfrak{i r}$, um ber zu Berfin eingerichteten höheren Rehranjtalt, welche unter

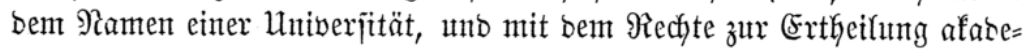

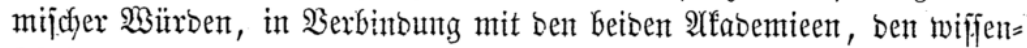
ichaftlichen Snjtituten und Sammlungen zu einem organifchen Sianjen vereint werben joll, ein eignes \$ebäube anzumeijen, in melchem bie Säle

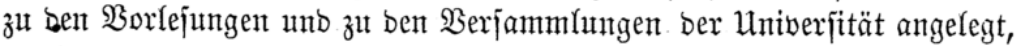

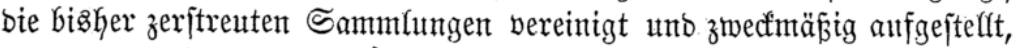

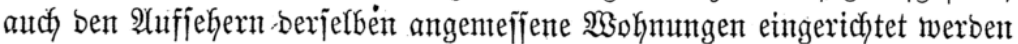

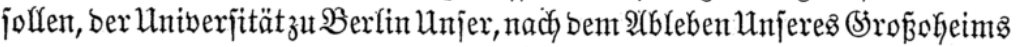

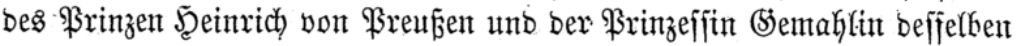

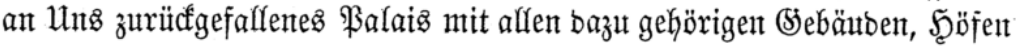
unb (Särtent, welches.bon bem Dpernplats, bem . Iupfergraben, ber Reţ̧ten= 


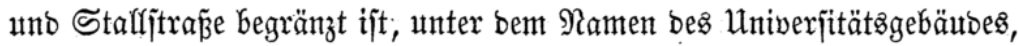
eigenthüumlidy zu jđhenfen, zu übergeben uno zu überlojjen, allergnäbigjt gerutht haben." -

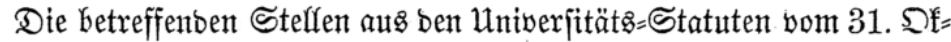
tober 1816 und bie vorgejdyriebenen Doftoreibe aus ben bejonbern Fufuls tätz=Statuten vom 29. Sanuar 1838 lauten wie folgt. Die Meberjeşung ber Doftoreibe geben wir in ber hinzugefiugten $\Re$ ote.

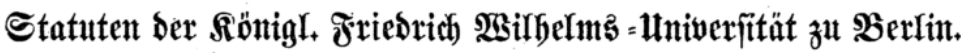

\author{
Som 31. Dftober 1816.
}

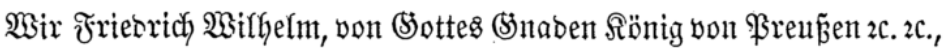
nachbem $\mathfrak{B i r}$ burch Unjern Sabinets = BBefehl vom 16. Alugujt 1809 eine Untwerjität zut Berlin gejtiftet haben, bieje auth bereits jeit ben Dftober 1810 in Thätigfeit ift: fo wollen $\mathfrak{B i r}$ berfelben mummehr, nadjbem bie Univerjität mit ifrem (S)utachten barüber vernommen worben, bie nach)= jtekenten, von Unjerm Minifiterium bes Snnern Unz vorgelegten Statu= ten Gierburch ertheilen, und inbem $\mathfrak{W} i r$ jämmtlidje Mlitglieber ber Mniver= jität, jorvie bie Behörben anweijer, fich barnach zu achten, wollen \$ir

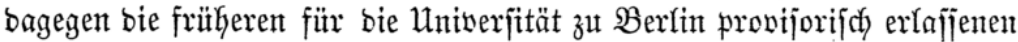

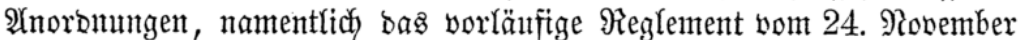
1810, Gierburch aufheben und außer ßraft jeţen.

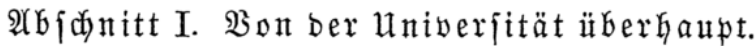

§. 1. Sorvie bie Univerjität z̆ $\mathfrak{b e r l i n}$ ben gleichen 3 weef hat mit anbern $\mathfrak{U n}$ niverjitäten in $\mathfrak{U n}$ jern Staaten, nämlich bie affgemeine unb be= jonbere wiffenifchaftliche Birbung gehörig vorbereiteter Sïnglinge burch Bortejungen unb anbere afabemifche Hebungen fortžufetzen; unb fie zum Eintritt in bie verjchiebenen Zweige bez hökeren Staats= unt Sirchen= Dienjtes tüdytig zu machent: fo joll jie aud jowohl als Rebranitalt und als eine privilegirte Rorporation unter Unjerem \&anbeşväterfichen Schutse,

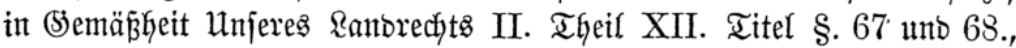
bie wejentlichen Rechte einer Untwerjität genieñen, vorzüglidy aud bas

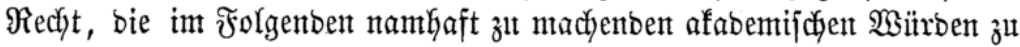
ertgeiten. Sie joll ein Siegel mit Unnjerem $\mathfrak{B}$ illoniffe führen, folches -in Wadyz aboructent bürjen, uno ijt in affen Stücfen unter bie unmittelbare

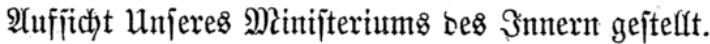

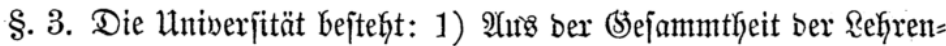

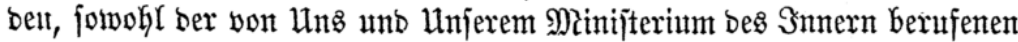

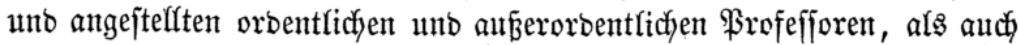

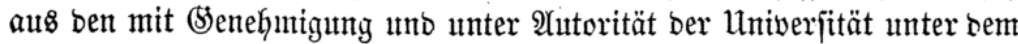


Mamen ber Privatbozenten an bem Rehrgejdäfte Theil nehmenten Reh=

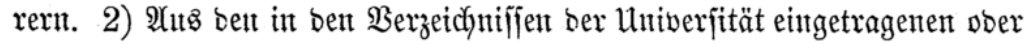

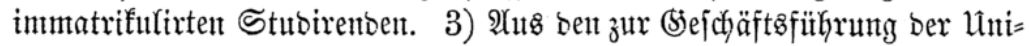

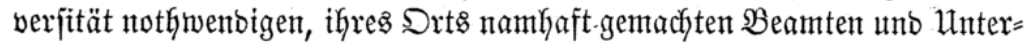
beamtelt.

\section{Statuten füt bie einzelten $\mathfrak{F} \mathfrak{a}$ fultüten.}

Som 29. Samuar 1838.

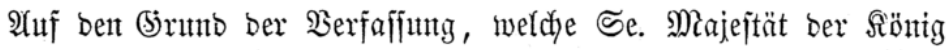
mittels ber Statutent vom 31. Dftober 1816 Der hiefigen Frieorich $\mathfrak{\text { Will }}$

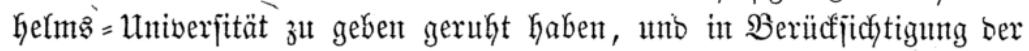
jpäteren @erorbmungen ertheilt bas Minifteriunt ber hiefigen . . . Faful= tät folgentbe Statuten:

\section{Die Doftoreibe.}

\section{A. Sponfion ber Doftoren ber Theologie.}

*) Postquam venerabilis in hacce Universitate Theologorum Ordo te S. S. Theologiae doctorem rite creare decrevit, ex mandato Ordinis ejusdemque nomine ego te ( $\mathfrak{B}$ or $=\mathfrak{m} b$. Buname) sollemniter interrogo, an fide data polliceri ac jurejurando confirmare constitueris: 1) te nihil a scriptis propheticis et apostolicis iisque omnibus, quae inde ad symbola ecclesiae cum oecumenica tum ad Augustanam praesertim confessionem manarunt, alienum neque ipsum docere aut spargere neque aliis docentibus affirmare vel commendare velle; 2) te gradus hujus dignitatem, quocumque locorum perveneris, eximia morum probitate atque gravitate sartam tectam tueri velle; 3) te gradum doctoris Theologiae ab hac Facultate impetratum alibi repetere nolle. - Haec igitur, priusquam Theologiae doctor publice renuntieris, ex animi sententia pollicere ac jurejurando confirma his verbis: „Has juramenti a me

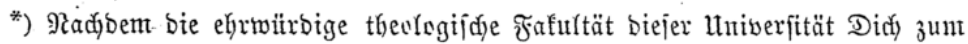
Doftor ber heiligen Theologie zu ermenten bejdlofijen hat, frage ith Dith in 2 uftrage

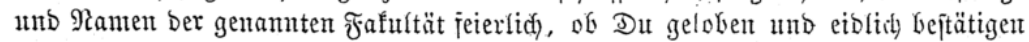

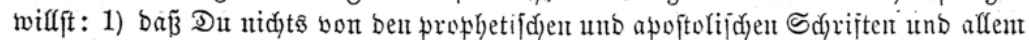

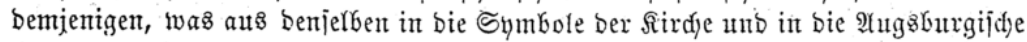

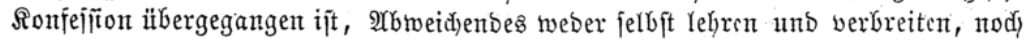

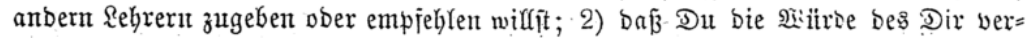
liehenen Doftorgrabes ïberall burd) Sittenreinheit und Rebensernft in (s)hen halten willft; 3) Dẩ, Dut ben theologijdjen Doftorgrab von feiner anbern Fafultät Dir wofleft verleifen laffen. - Bebor Dut alio feierfidy zum Doftor ber Theologie aus=

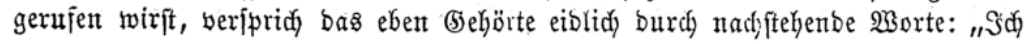


praestandi partes ego probe intellexi et me sancte servaturum promitto et juro. Sic me Deus adjuvet trinus et unus et sacrosanctum ejus evangelium."

\section{B. Sponfion ber Doftoren ber Redyte.}

*) Juret dominus Candidatus: 1) se gradum Doctoris in jure ab nulla alia facultate petiturum neque oblatum accepturum; 2) studiis juridicis et juri profitendo diligentem et adsiduam operam daturum; 3) in causis, in quibus judicare debeat, id solum, quod. justum et aequum est, secuturum, et sine favoris, odii aut ullius affectus inclinatione omnia recturum atque pronuntiaturum; 4) iis, qui de jure responsum petiverint, id ipsum ex intima conscientia, secundum jura et aequitatem daturum; 5 ) iis etiam, quorum causas agendas susceperit, patrocinium et defensionem, pauperibus aeque ac divitibus, sollerter et ex fide praestiturum, denique in profitendo, judicando, respondendo, postulando omnibusque iis, quae ad officium Doctoris in jure pertinent, omne propositum ad majorem Dei gloriam, ad promovendam justitiam, communem utilitatem et rei publicae conservationem directurum. - Der Sandi= bat Keiftet Gierauf ben Eit in folgentoer Weife: „Haec uti mihi praelecta sunt, me fideliter servaturum esse, ego ..... juro. Ita me Deus adjuvet et ejus sacrosanctum evangelium."“

Benterf ung. Bei ber \$romotion jübijcher Sanbibaten breibent bie Worte: „et ejus sacrosanctum evangelium“ weg.

Gabe bie einzelnen $\mathfrak{P u n f t e}$ bes mir abgeforberten Fibes volffomment veriftanton und jdyöre, fie treu ju beobadyten. So nahr mir ber oreieinige bott helfe uto jein bei= riges suangelium!"

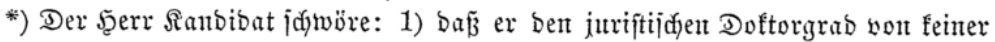

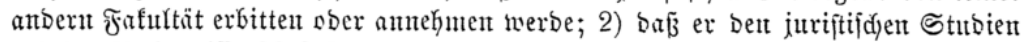

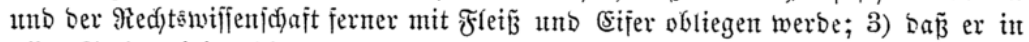
alfen Sadjen, bei weldjen er zu urtheifen hat, mur (Seredjtigfeit unb Biffigfeit im Aitge

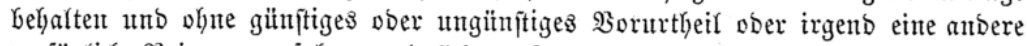

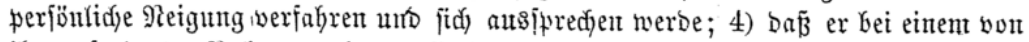

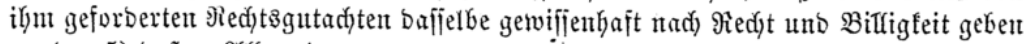

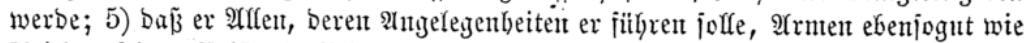
Fieidyen, feinten Beiftanto eifrig und tren Yeiften, entolidy in alfen Dingent, weldye zum

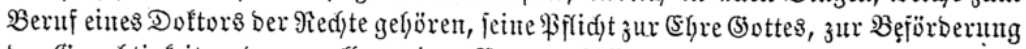
ber (s)eredytigfeit mlo jum affgemeinen Beften erfïflen werbe. - Der Ranbibat reiftet

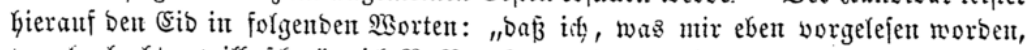
treu beobadjten wifl, idjwöre id) $\Re$. $\Re$. So nafr mir (5ott helfe mo jein heiliges Fvangelium! 


\section{Sponfion ber Doftoren ber Mebizin.}

*) Spondeo juroque, non mei me commodi causa medendi artem factitaturum, sed ut Dei gloriam celebrem, ut hominum tuear salutem, ut quantum queam ipsi doctrinae incrementi afferam; cuncta medici munia summa cum fide et religione quantaque valeam peritia et prudentia exsecuturum; laborantium cuivis, nullo discrimine aut delectu, ambitione nulla, sive sit inops sive dives, pari industria subyenturum; nullius unquam hominis vitam ancipiti tentaturum experimento; non ad vana aut sordida medicinae usum deflexurum; indefesso studio in exploranda cognoscendaque arte perseveraturum; socios artis humaniter, amiceque et uti ipsa artis - dignitas postulat tractaturum, promptissimoque animo neque ullo utilitatis propriae respectu quidquid possim facultatis cum illorum studiis in aegrotantium salutem consociaturum, omninoque id operam daturum, ut quam profiteor artem ad religionis sanctitatem adducam. Ita me Deus adjuvet et sacrosanctum ejus evangelium.

Bemerfung. Bei ber \$romotion jübijcher Sanbibatent wirb jtatt ber $\mathfrak{W o r t e : ~ „ I t a ~ m e ~ D e u s ~ a d j u v e t ~ e t ~ s a c r o s a n c t u m ~ e j u s ~ e v a n g e - ~}$ lium" gejetzt: „Ita me aeterna salute impertiat Deus."

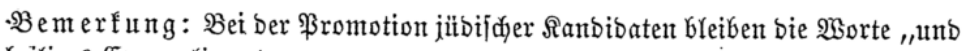
jein heiliges (5yangelium" weg.

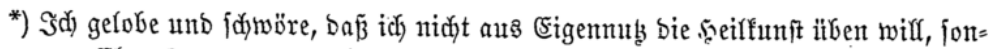

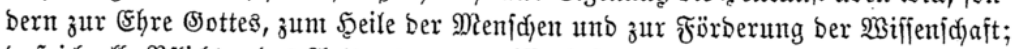

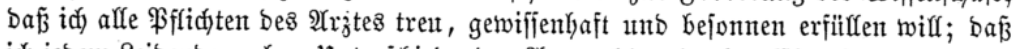

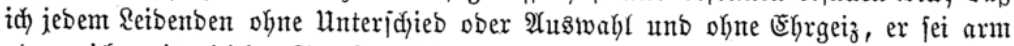

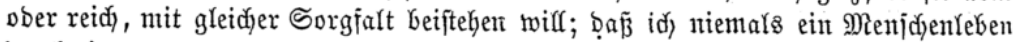

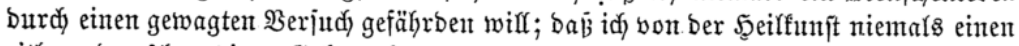
eitlen ober idjmutzigen (jebraudy madjen wiff; Dã

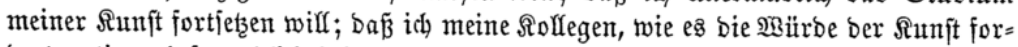

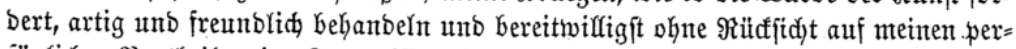

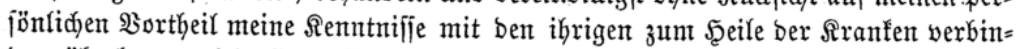

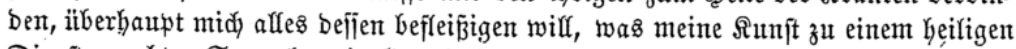
Dienfte madyt. So wahr mir (5)ott helfe und jein heiliges (5vangelium!

Bemerfung: Bei ber ßromotion jilbifjer Ranbibaten wirb ftatt Der $20 r t e:$ "So wahr mir Sott helfe unb jein Keiliges Evangelium" gejetzt: "So wahr mir (5ott Gelfe zur Seligfeit." 


\section{Sponfion ber Dottoren ber æhilofophie.}

*) Quandoquidem tu (nomen et gentilicium) posteaquam ab amplissimo in hacce Universitate Ordine Philosophorum petiisti, ut te magistrum artium liberalium et philosophiae doctorem rite creare, hujusque dignitatis honores jura et immunitates tibi impertire vellet, praestitis quae postulata erant omnibus, sacramento jam adigendus es; ex decreto Ordinis ejusdemque nomine ego te (nomen) sollemniter interrogo, an fide data polliceri et confirmare religiosissime constitueris, te artes honestas pro virili parte tueri, provehere atque ornare velle, non lucri causa, neque ad vanam captandam gloriolam, séd quo divinae veritatis lumen latius propagatum effulgeat; te quidquid ad verae religionis morumque bonorum incrementum facere possit, acturum sedulo, nec quidquam in eorum detrimentum sive omissurum sive perpetraturum; te nullius disciplinae placita frivole petulanterque lacessere aut sophistarum more captiosis rationibus labefactare, nec contra quam tibi persuasum sit, quidquam docere velle; te dignitatem magistri liberalium artium ac doctoris philosophiae neque prostituturum neque deformaturum moribus improbis; postremo te honorem hoc loco in te collatum ab aliis in alia Universitate non accepturum. - Haec igitur priusquam artium magister et philosophiae doctor publice renuntieris, ex animi sententia pollicere et confirma. - Der Doctorandus antwortet: Ex animi sententia data fide jurisjurandi loco polliceor et confirmo.

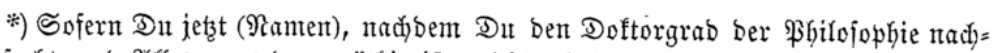

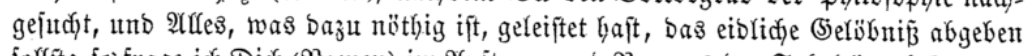

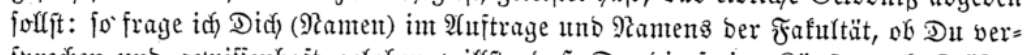

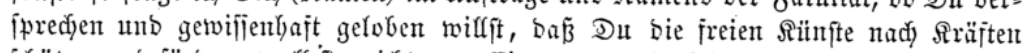

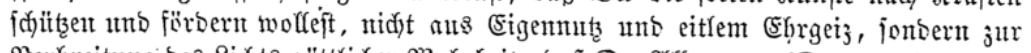

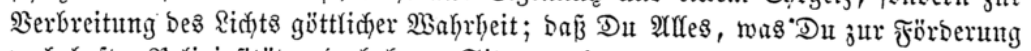

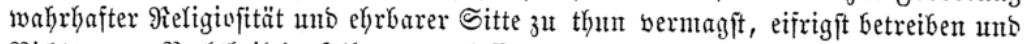

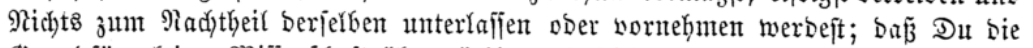

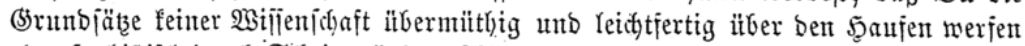

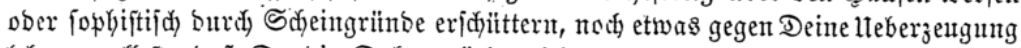

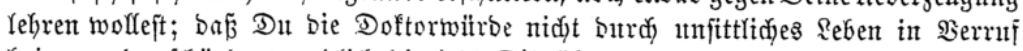
Gringen ober fdjänben, entid) bie jeb̧t Dir iibertragene (5)hre nidjt nodjmals von einer anbern Univerfität anmehmen wolleft. Dies verjprid unb gelobe, bebor Dut B̈ffentlid) zum Magifter Der Sïnfte utb zum Doftor Der Philojophie ausgerufen wirft.

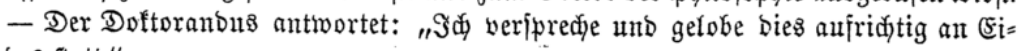
Desి ftatt." 


\section{VI. $\mathfrak{B} \mathfrak{n} \mathfrak{n}$.}

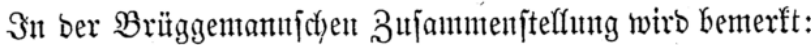

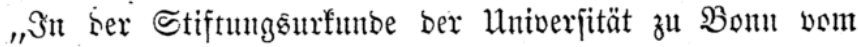
18. Dftober 1818 heipt es:

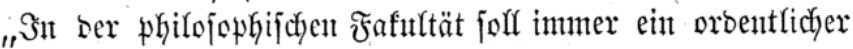
Frofeffor ber Bhitojophie won fatholijcher Sonfefition neben einem orbentfichen \$refcjfor ber \$rilojophie evangelifdyer Sonfeffion an= gejeţt, auferbem aber in feiner Fafuttlät, bie beibent theologifdhent autsgenommen, auf bie sionfefjion ber antuftellentent Refrer

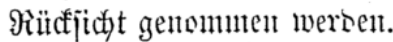

Es joll eil afabemifher (bottesbienft für jebe ber beiben Ronfeffionen befonders jtattfinben.

\section{Statuten vom 18. Dftober 1834.}

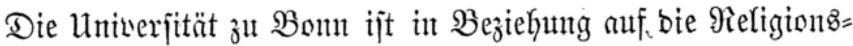

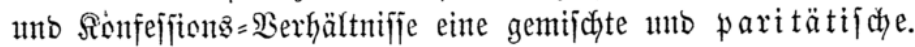
Эn ber juriftifden Fafultät joll wenigitens einer ber orbentlicyen Brofejioren fatholifacer Sonfeffion jein, ber bas Rehrfach beß $\mathfrak{f} a=$ tholijedyen Sirdyenredyts itbernehnen fann, ingleidjen foll in ber

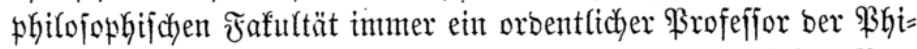
lojophie von fatholifdyer Sonfejfiton neben einem orbentfichen $\mathfrak{B r o}=$ fejfor evangelifcher Sinfejfion angejtellt, auferbem aber in feiner Fafultät, bie beizent theologifchen ansigenommen, auf bie $\operatorname{Ron} f e \uparrow=$ fionen ber anzuftelfenden Rehrer Rüdfficht genommen werben.

Für jebe ber beiben Ronfejfionen ift eit afabemifyer

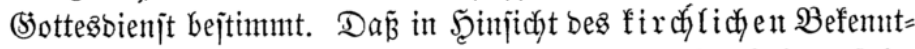

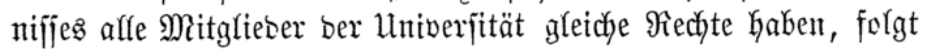
fdon aus unjern allgenteinen (biejetzen, wirb aber fier nod) bejon= Ders fejtgejetzt. (E⿱ glieber jich immer barant erinnern mögen, baß am meị̂ten bei einter

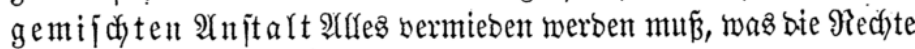
ber einen voer anbern $\Re$ onfeffion fränfen und in biejer $\mathfrak{B} e=$

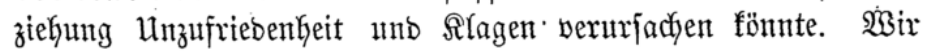
Kegen baher zu jämmtlidjen Rehrern bas Sertrauen, bas fie bei biejen Berbältniffen mit d)rijtlicher Riebe, mit Borficht uno zarter Schounng werfahren unb bet jeber (selegentheit auf $\mathfrak{B}$ eför=

" berung wedffelfeitiger 3ufriebenheit unb guter (Eintracht bebacht jein werben."

Die Sttlle, bie ber Seerr Regierunggłommiffaritz atts ben Statuten vom 18. Dftober 1834 anführt, ftefyt nicht in biefen, fonbern in ben vom 
Sïnige boflzogenen Statuten ber Siefammt:Uniberjität vom 1. September 1827, wo jie bie $\S \S .6,7$ uno 8 billbet.

Die Statuten bom 18. Dftober 1834 find für bie einzelnen Faful= täten gegeben unb lebiglich vom Minijterium auggegangen. Âtu leţteren hat Şerr (S)eheimrath Brüggemann irgento eine Stelle zu berntsen, fich nidyt veranlapit gefunben, aber auch auz erjteren gerabe biejentigen $\mathfrak{B} e j$ tim=

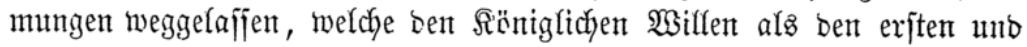

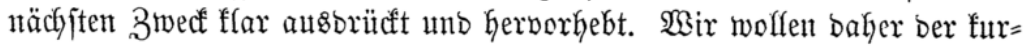

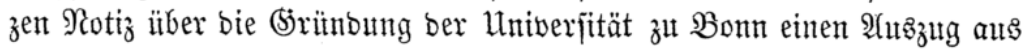
ber Stiftungsurfunbe vom 18. Dftober 1818, atts ben Huiverjitäts = Sta= tuten vom 1. September 1827 unb aus bent vom Minijteritm M(tenjtein fejtgejtellten Statuten ber einzelnen Fafulttäten vom 18. Dftober 1834 folgen lafien.

Sn bem aus Sien unterm 5. 2lpril 1815 an bie (sinwohner ber mit

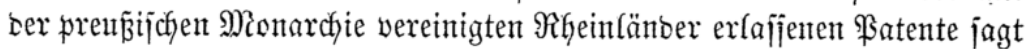

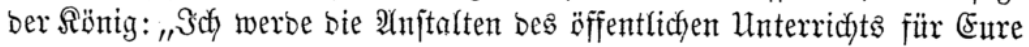

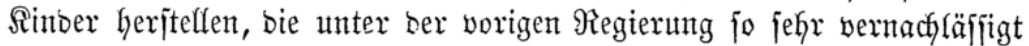

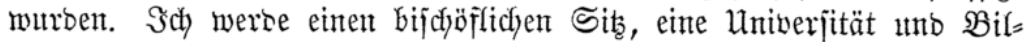

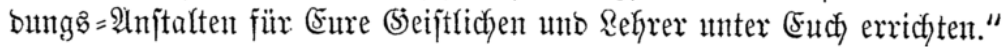

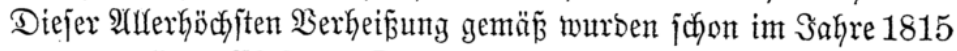
von bem bamaligen SGhef bes Departements für ben äffentlicfen 1 unter=

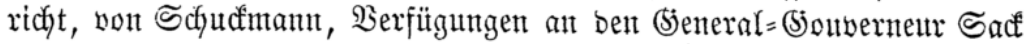

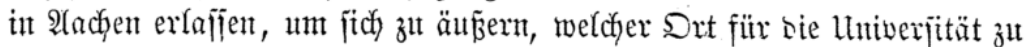
erwählen uno wie jolche zut errichten jei. - Es fonfurrirten bei ber $\mathfrak{W a h}$

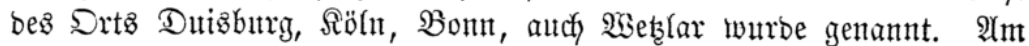

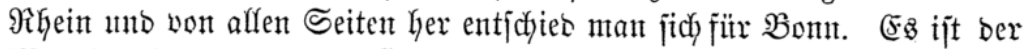
Mittelpunft ber mejtlichen ફ̧älfte ber jeţigen preupifichen Staaten. Seine

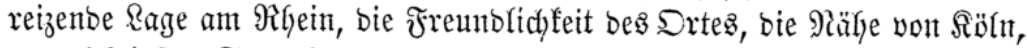

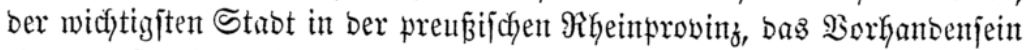

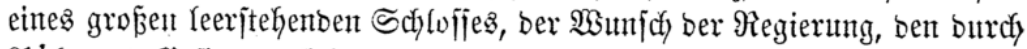

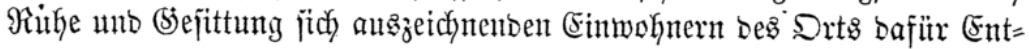

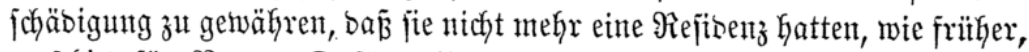

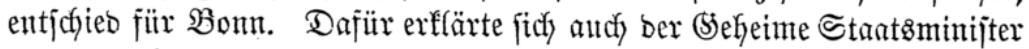

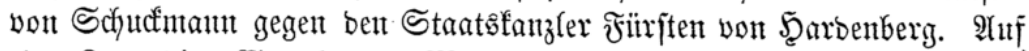

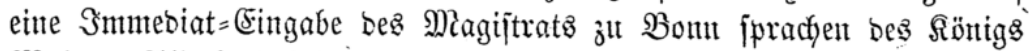

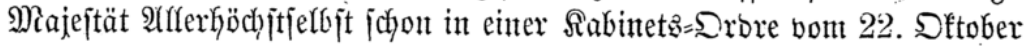

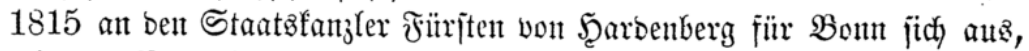

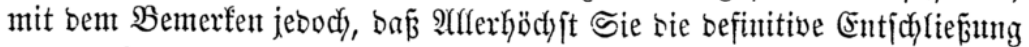

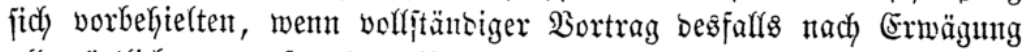
alfer örtlichen unb jonjtigen Sierbältniffe erjtattet fei. 


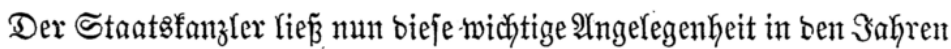
1815, 1816, 1817 nie aus ben 2Yugen. Nact) bem Seneral=\$ontwerneur

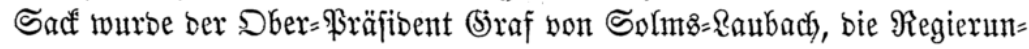
gen am Rhein, bie betheiligten Miagiftrăte, bie geiftlichen Behörben am

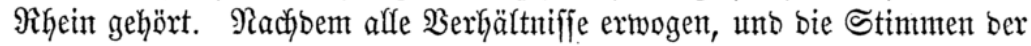

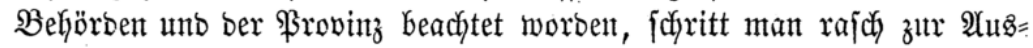
führiung.

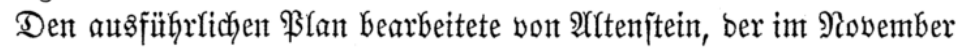

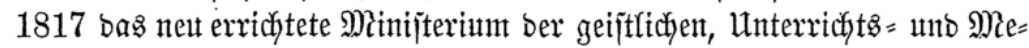
biżnal=92ngełegenheiten übernommen hatte. Der Rönig genehntigte ben= felben in eiter unter bem 26. Mai 1818 an ben Staatsfanzler extaffenen

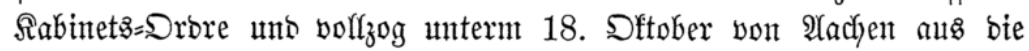

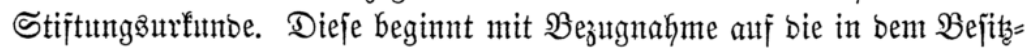

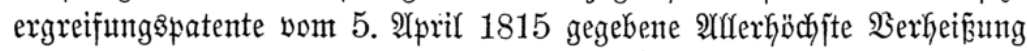

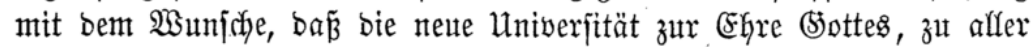

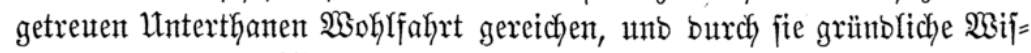
jenjidaft und gute Sitten in ber jtubirenben Sugento geförbert uno immer mehr affgemein verbreitet werben mögen. Die Schlöffer in Bonn unt Boppelsonf nebjt beren 3ubehör wurbent Kierauf ber Ulniwerjität afs Eigenthum überwiejen. Die Univerjität jodf, nach ber Stiftung\&unfuntoe,

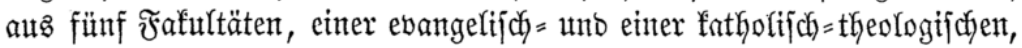
einer juriftijchen, einer mebizinif chen unt einer alfgemein mifjenjichaftliçyen ober phitojophifchen bejtehent. Die beiben theologifchen Fafultäten jolfen an $\Re a n g$ einanber gleich fein, aber in alfen Berbältnifjen, wo es auf ben

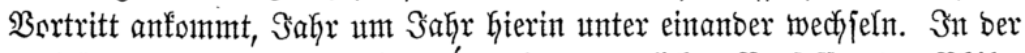

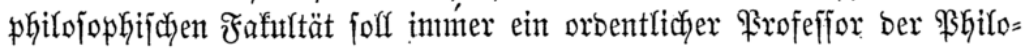

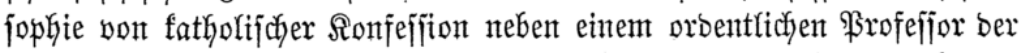

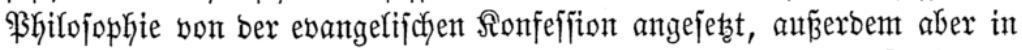
feiner Frafultät, bie beiben theologifchen autgenenommen, aiff bie Ronfejfion

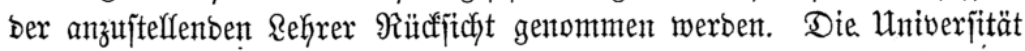

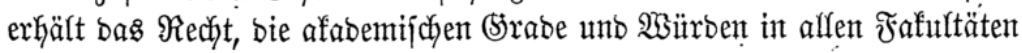

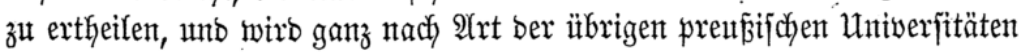
organifirt. Der $\& 13$ rautet mörtlich: "Die Ûniverjität wolfen $\mathfrak{W i x}$

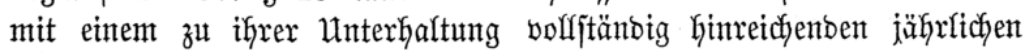
Finfommen mit Yanbesherrfidjer Mitroe auşjtatten, wie $\mathfrak{W i x}$ benn zur

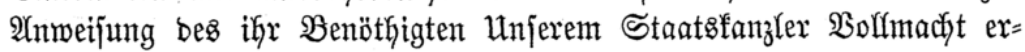
theilt haben." 


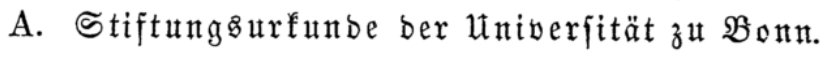

is om 18. Sftober 1818.

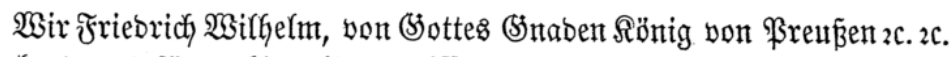
thun funt uno fügen fiermit 孔u mifjen:

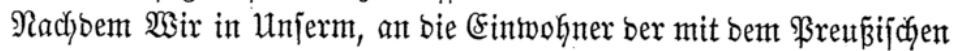

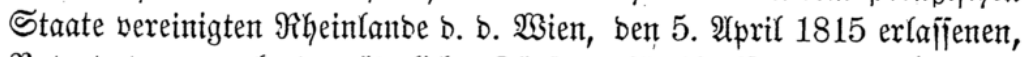

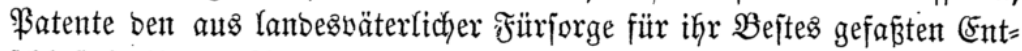

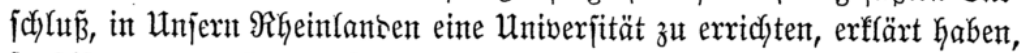
fo ftiftent und grünben $\mathfrak{W}$ ir nunmefr burch gegenwärtige Urfunbe bieje

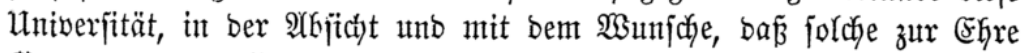

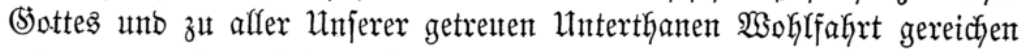

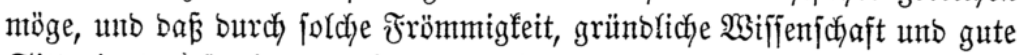
Sitte in ber futuirenten Sugent geförbert unt immer mefyr affgemein verbreitet merbe.

Wir bejtimmen bemnach anb verorbnen:

7). Das Refrwejen ber Univerfität wirb nady benferben Srunbjätzen,

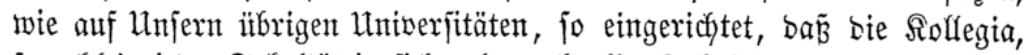
jowohl in jeber Fafuttät in jich, als aud afler Fafultäten, mit ben affge= meinn wiffenfchaftlichen $\mathfrak{B o r l}$ ejungen in ber philojophifichen Frafultät gehörig in einanber greifen unto burch iffe 2 thorbnung unt Folge felbjt ben Stu=

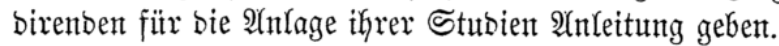

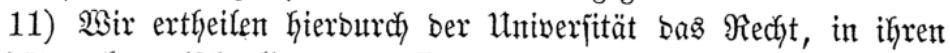
Fafultäten afabemif̧cye (Srabe unt Witrben, namentlich in ber philojophi= fchen Fafultüt bie (Srabe bes Magifiters unt Doftors, in ber mebizinifichen, nach erlangtem philojophijdjen Magiftergrabe, ben Sirab bes Doftors, in ber juriftifiten und ben beiben theologifchent Fufultüten bie Srabe bes

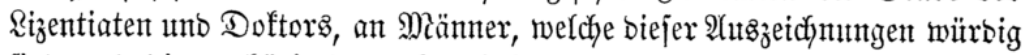

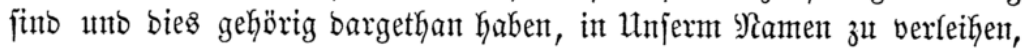

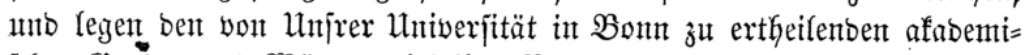

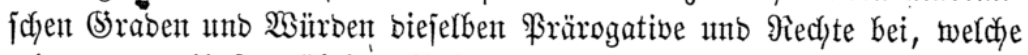
mit ben von Unjern ïbrigen Uniberjitüten verltehenen afabemijoyen \$ra= ben und Sürben verbunben fint.

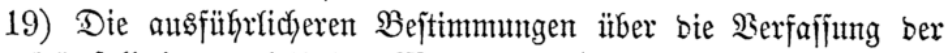
Univerjität folf ein, burch Unjern Minifiter ber geiftliçen unb unterridefts=

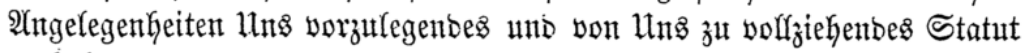
enthaltert. 


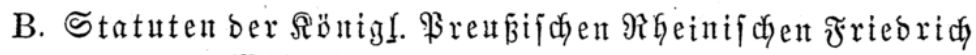
Wilkelms=univerjität z̆ boun.

\$on 1. September 1827.

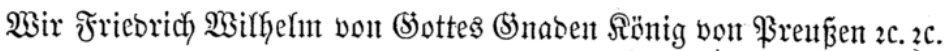

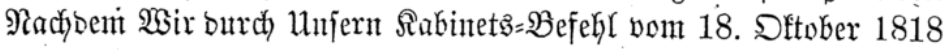

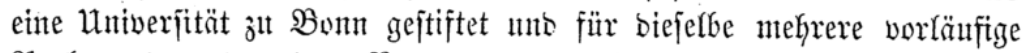

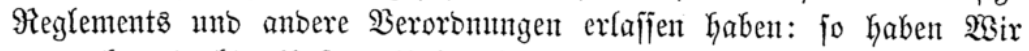
nummehr gebadfter Ulujerer Univerjität, weld) e mit ihrem (5) utady ten oarüber vernommen worben, auf ben Beridyt Unjeres Minifters oer geiftlichen, Unterridyts = unto Mebizinalangelegentheiten, nachjtehente

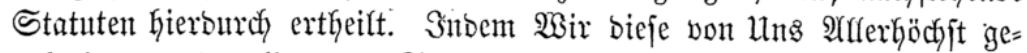
nefgmigten unb volfogenen Statuten Gierburd publiziren uno gebachter

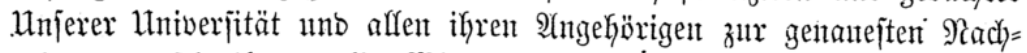

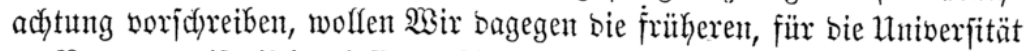

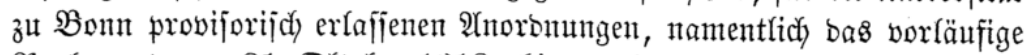

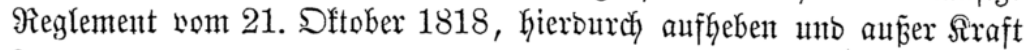
jeşent.

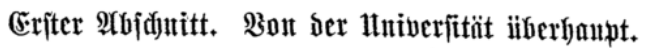

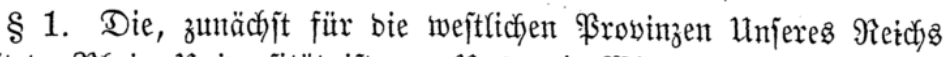

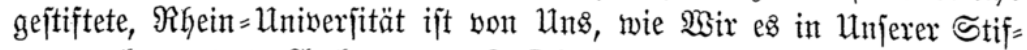

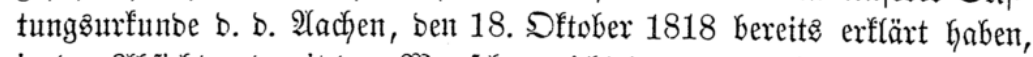

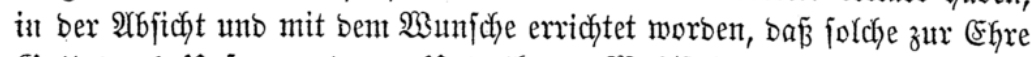

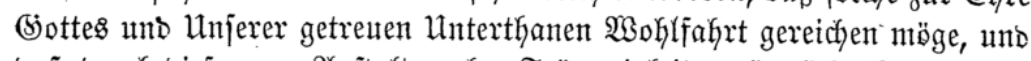

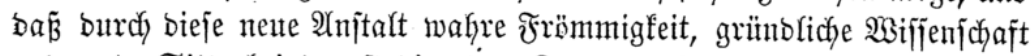

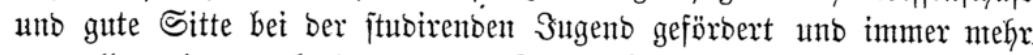
unb alfgemeiner verbreitet werbe. Snben $\mathfrak{W}$ ir bieje Erffärung hierburch

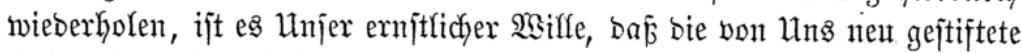

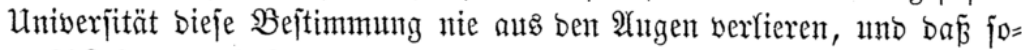
toogl Refrende als sernenbe ifren Beruf nie berfennen, jonbern denfelben,

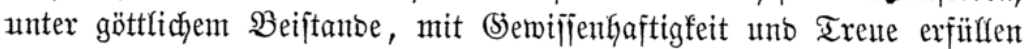
mögent.

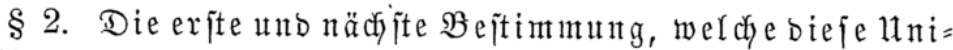
verjität mit anbern ähnlidyen Anjtalten gemein hat, ift: ba fie ein Staat injtitut jei, weldem bie wiffenjdyaftidye $\mathfrak{B} i l=$

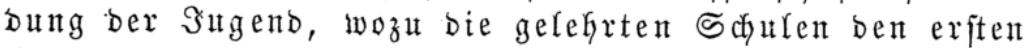
(5) rutb legen follen, im ganzen umfange unb. biz zum mög=

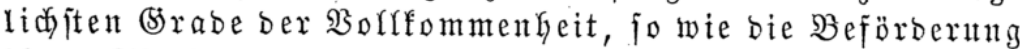

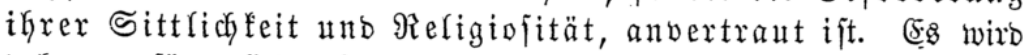
baker von jämmtliçen, bereits angejtellten uno fünftig noch anzujtefrentoen 


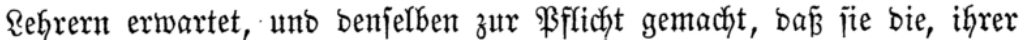

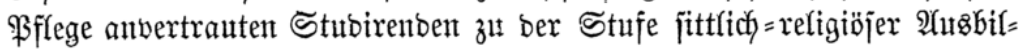
bung unb zu bemjentigen Strabe theoretijtyen und praftifjen Wifjens fïthren, fo wie in benjenigen trenten unb guten Befinnungen uno $\Re$ icd $=$ tungen befejtigen, weldje biejelbent zum (Eintritt in ben Dienjt ber $\Re$ irche uno bes Staatz, fowie in jeben Beruf befäfigen, woz̆ höhere mifjenjdaft=

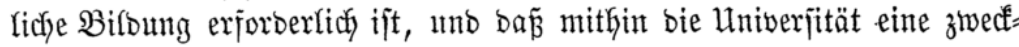

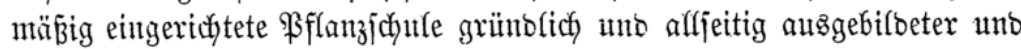
borbereiteter Staats = uno Rirchenbienter werbe. - Mit biejem, richtig verjtanbenen unb beförberten 3wed wiro fich ein anberer, nämlich bie 2 (us =

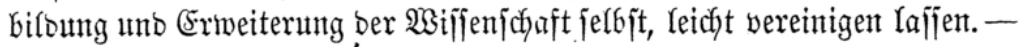
Wir habent baher zu jämmtlichen Rehrern bas gute Bertrauen, baß jie nicht

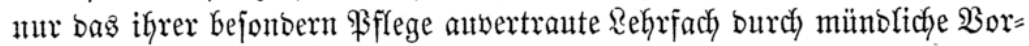
träge, burch afabentifche Hebungen uno Sdyriften nüthlich anbauen uno bereichern, fonbern auch für bas (S) jammtwifjent, weldyes bas Wejen einer Uniwerjität alı̇macht, eine heirfame Thätigfeit betweijen werben. Wir

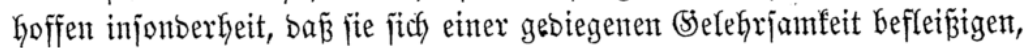

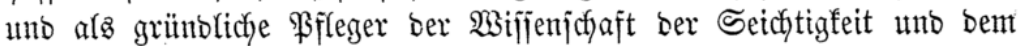

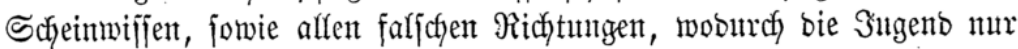
zu leidyt berblenbet unto irre geteitet wirb, fräftigit entgegen arbeiten werben.

\section{Statuten ber einzeluen $\widetilde{F} \mathfrak{f} \mathfrak{l}$ täten. פon 18. Dftober 1834 .}

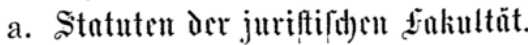

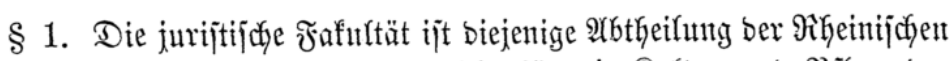

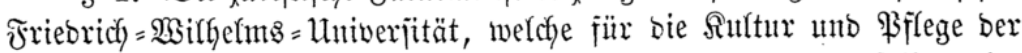

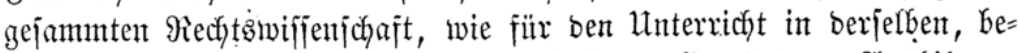

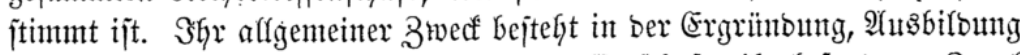

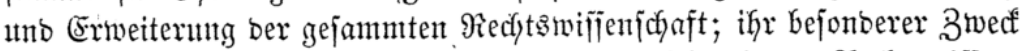

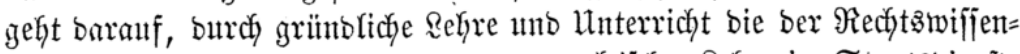
j(c)aft fich wibmenben Stubirenben zum praftijdyen Reben im Staatzbienjte wifienficyaftlich auszubifoen unt vorzubereiten.

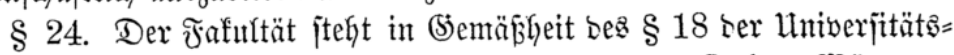

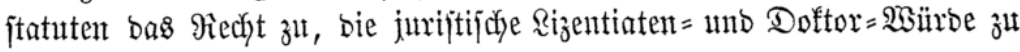
ertheilen.

$\S 40$. Die Fromotion wirb vont bent Defint ober beffent Stelfyer= treter verrichtet, welcher zut bent Enbe bent oberen Ratheber Getritt, während

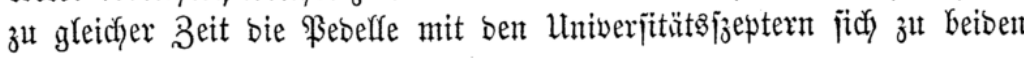




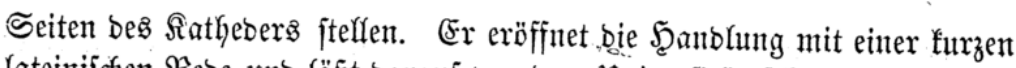

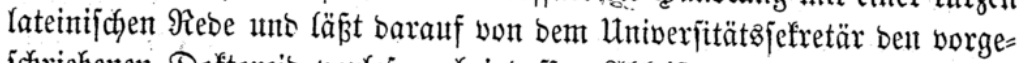
jufriebenten Doftoreib vorlejen, bei beffen Abreiftung ber Doftoranb bie

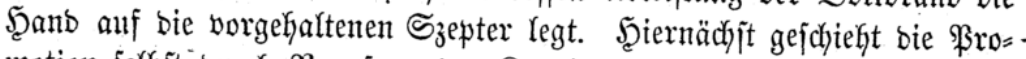

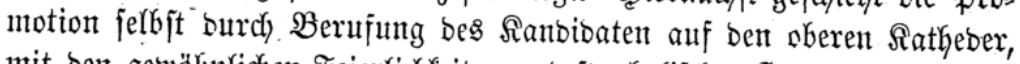

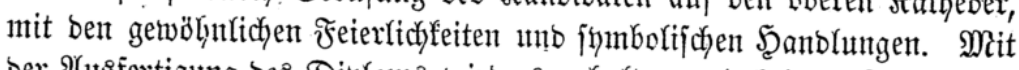

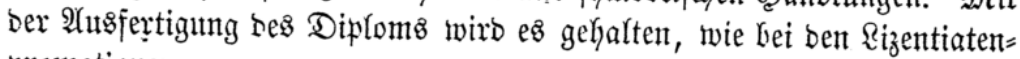
promotionen.

\section{b. Stututen der mrìizini(d)en fakkultät.}

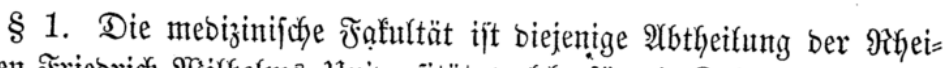

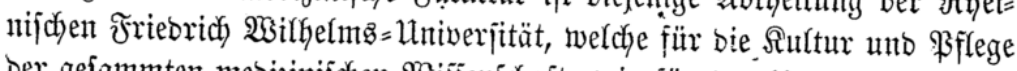
ber gefammten medizinifchen $\mathfrak{W}$ ifjenjchaft, wie für ben Unterridyt in ber= jelben, beftimmt ijt. $3 \mathfrak{k}$ allgemeiner Dwed bejteht in ber Ergrünoung,

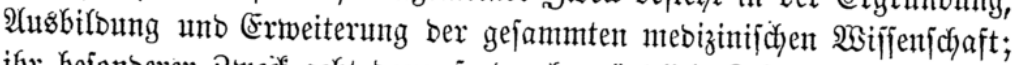

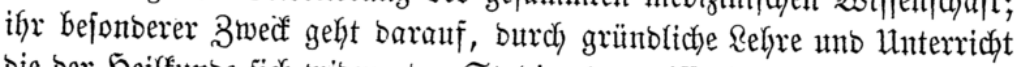

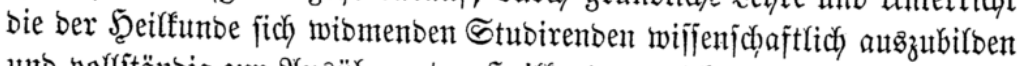

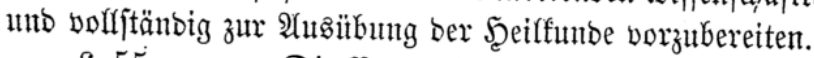

§ 55. - - Die \$romotion jelbjt wollziefyt ber Defan, inbem er, nach. Ëffentlicher Berichterftattung über bie borauggegangene Regitimation

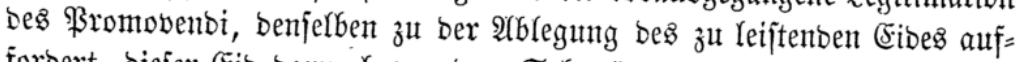
forbert, biefer (sib barnach von bem Sefretär ber Univerfität borgelejen, von bem \$romobento alf bie ifm vorgehaltenten sceptra academica

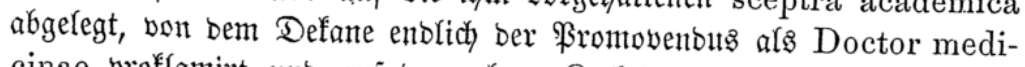
cinae proflamirt unt auf bem obern ßatheber mit ben Injignien ber Doftoruürbe ausgejtattet, auth. ify bas fonfirmirte Diplom itberrecicht

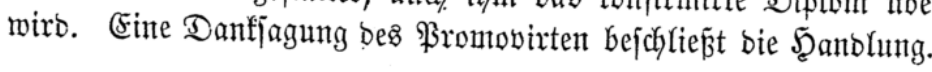

\section{c. Stututen der philofopbifthen falkultüt.}

$\S 1$. Die $\mathfrak{3 e j t i m m u n g ~ b e x ~ p h i l o j o p h i f c h e n ~ F a f u l t a ̈ t ~ i f t ~ e i n e ~ z m e i = ~}$

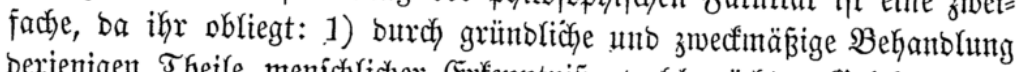

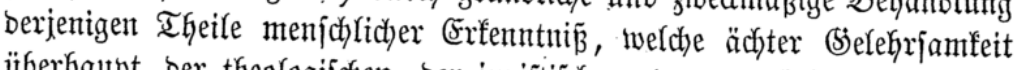
überhaupt, ber theologifdjen, ber jurijtijchen, ber mebiz̈nifdyen gleicher=

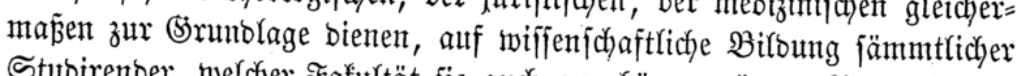
Stubirenber, welcfer Fafultät fie auch angehören mögen, hinzuarbeiten; 2) bie wifjenjichaftlictje 2 (1)

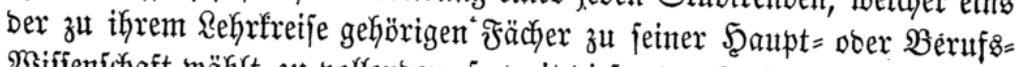
Wiffenjuchaft wählt, zu volfenben, fo weit biejes burch afabemijchen Unter= ridyt innerfarb ifyres $\mathfrak{B}$ ereiches zu betwerffitelfigen ift. 
§ 41. Der Doftorgrab, melcher höher ift alz ber Magij̈tergrab, folf eigentlich nur benent ertheilt werben, welchen bie erprobte Tüdytigfeit, als Refyrer iffres Faches aufzutreten, zugefprochen werben fann. - $\mathfrak{W e r}$

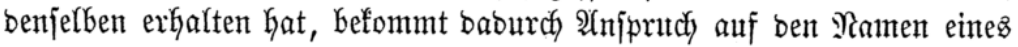

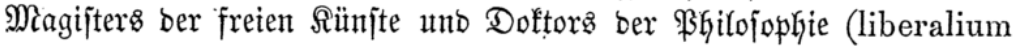
artium magistri et doctoris philosophiae).

§ 45. Die Fromotion mirb von bem Defan ber Fafultät ober jeinem Steffvertreter verrichtet, weldjer zut bem Enbe ben oberen Ratheber betritt, inbent zat gleicher Zeit bie Febelle mit ben Univerjitätşzeptern jidy zut

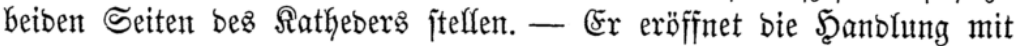

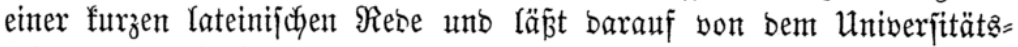
jefretär bem Doftoranben ben (ङib nach bem vorgejdyriebenen Formular vorlefen, wobei ber Doftorand bie Şand anf bie iłm freuz̆meije von ben

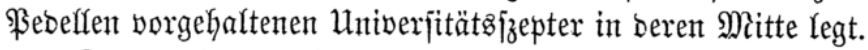

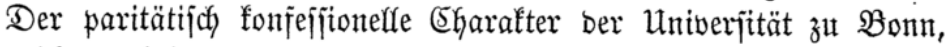
von weldyem übrigens in ber Stiftung wurfumbe von 1818 nod nitht bie Rebe ift, fonbern erjt in ben allgemeinen Uniberjitätsjtatuten von 1827

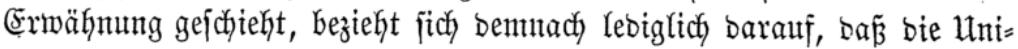
verjität żvei gejonberte unb gleidjberedjtigte theologīche Fafultäten bejitst, bon benen bie eine, nach ben Statuten won 1834 ,für bie Fultur unb

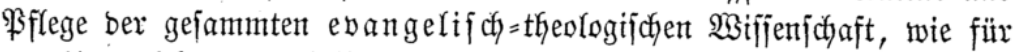
ben Unterricht in berfelben, bie anbere für bie Aultur uno

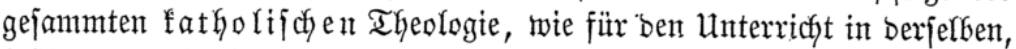

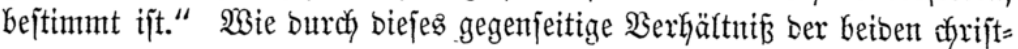

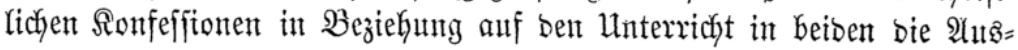

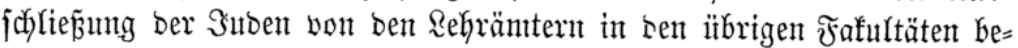
singt fein joll, ift nidjt einzujełent. Die Sache geminnt aber eine anbere

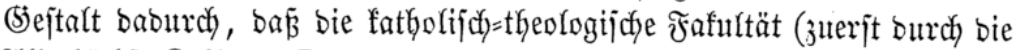

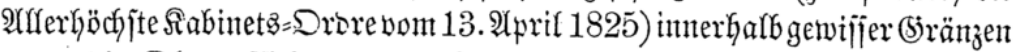

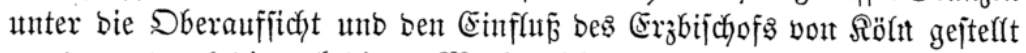
wurbe, woburch bie unbebingte Machtwofffonmentheit ber Staateregierung

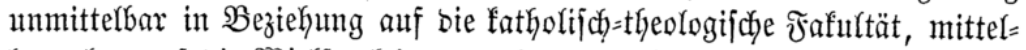

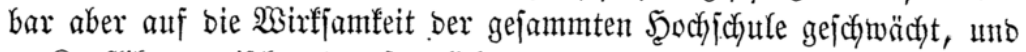

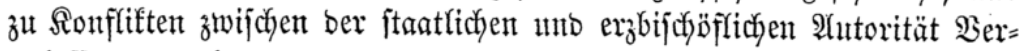
antafiung gegeben war.

Soldye Sionflifte fdyienten im Sahre 1834 burch bas frembliche $\mathfrak{B e r}=$

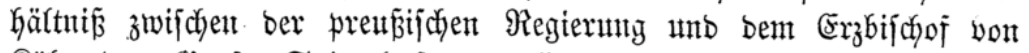

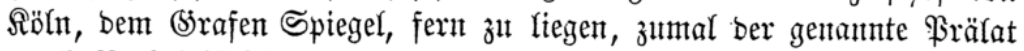

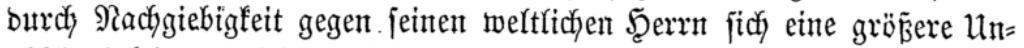
abhängigfeit von feinent firchlichen Dberkautpt anzuteignen geneigt war. 


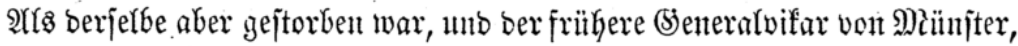

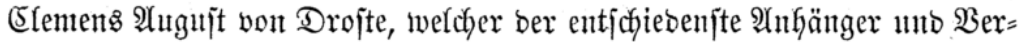
treter ber nubej dyränfltent ultramontanen Sirchenmadyt gebliebent war, ben erzbijdyöflichent Stubl bejtiegen hatte, brach jener Sonflift mit joldyer

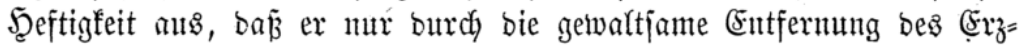
bijafofis unterbritfft werben fonnte. Altoererjeits war aber aud wieber ein Minijter vom fejten Sharafter $\mathfrak{A}($ ltenfteins erforberfidy, um burch einen

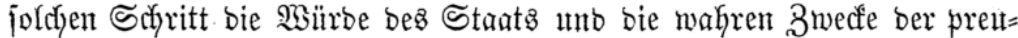

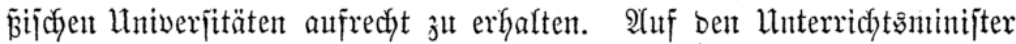

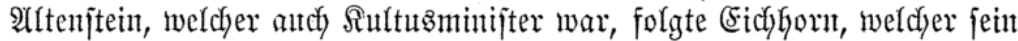

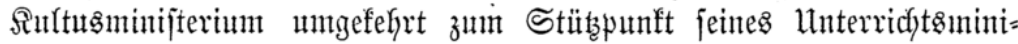

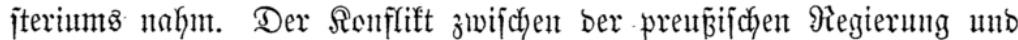

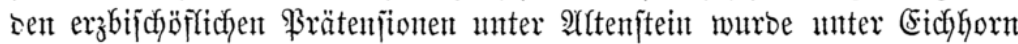

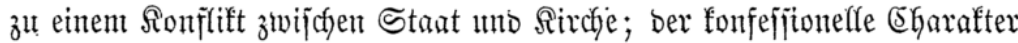
ber Untwerjitäten wurbe ourd) bent fonfeffionteflen (Eharafter bes (Eid)horn=

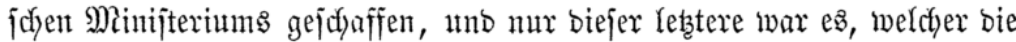

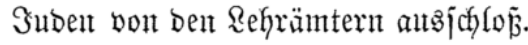


Sedyjte wrotheilung.

\section{Altenftein. and (Eid)orn ober}

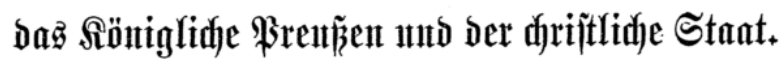





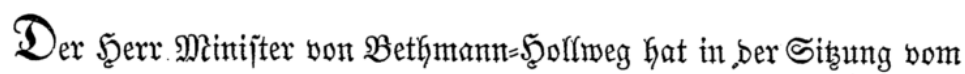
25. 2Lpril 1860 nidyt mur bent fonfeffitonelfent EGarafter ber preusiif dent

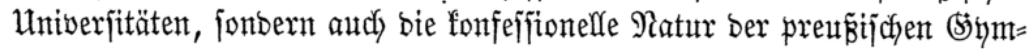

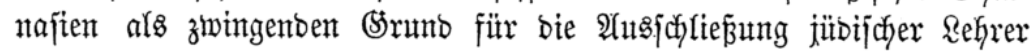
herworgefoben.

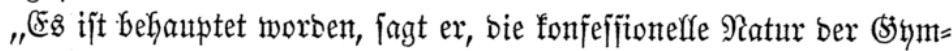
nafient, fofern fie netten $\mathfrak{H} r$ jprungs fei, batire won ber $\mathfrak{B}$ erwaltung bes

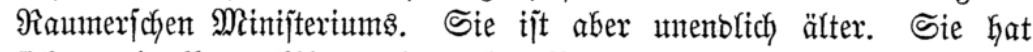

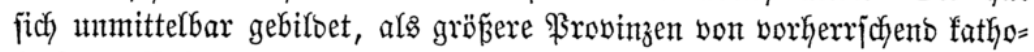

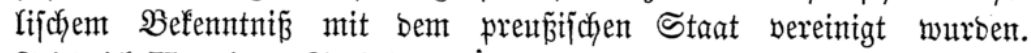

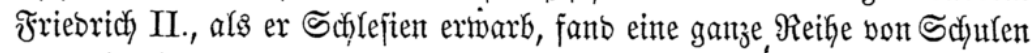

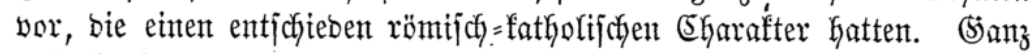

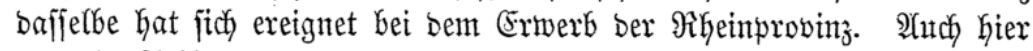

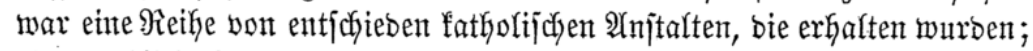

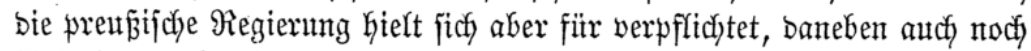

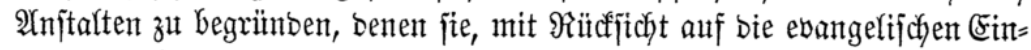

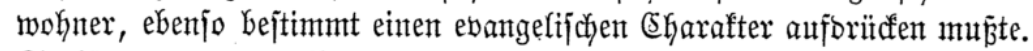

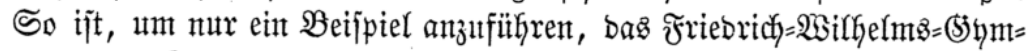
najium in $\Re \ddot{o} \mathfrak{n}$ entítanben."

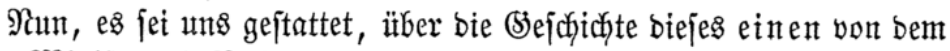

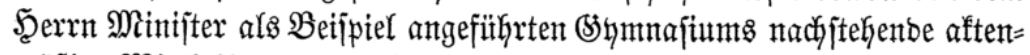
mäß̈ige Mittheilung zu madyent.

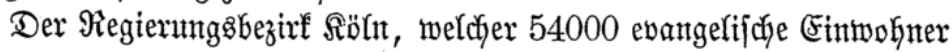
entfjielt, entbefyrte bei ber Befitergreifung burth \$rensent eines evan=

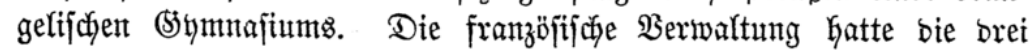




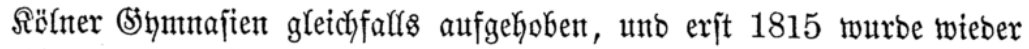
ein beutfches (Symnafum erridytet, weldyes fatholifach war unb bas

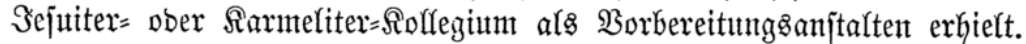

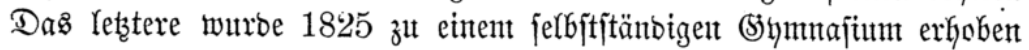

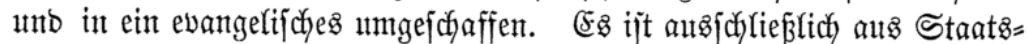
fonbs erridytet, inbemvon ben Fonbs ber ehemaligen Ä̈lnijachen (symnafien

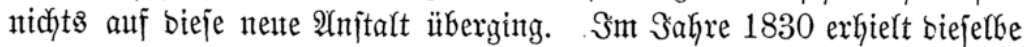

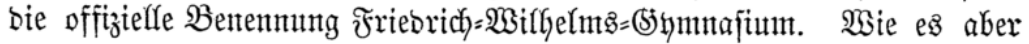
umt ifyent entichiebent ebangelijachen (Sharafter jtant, möge man aus nact)= jtehenben Datent entnehment.

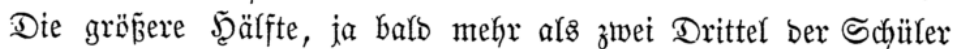

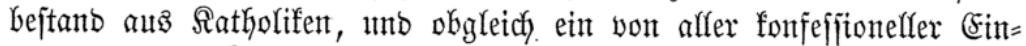
feitigfeit jich fern haltenber Direftor angejtellt wurbe, fo entrvidfelte fich

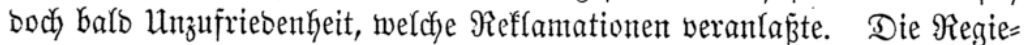
rung glaubte baher ben \$runbjats bes ebangelifd)=fonfeffionellent (5) arafters nicht fejthalten zu bürfen; bie Anjitalt wurbe faftifich eine gemifa)te (jinut=

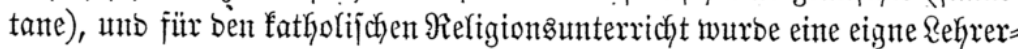
jtefle mit ziemtich Goher Bejoldung freirt. Diejer Refrer warb von ber

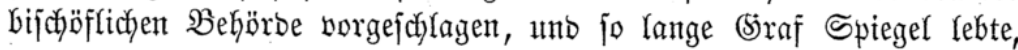

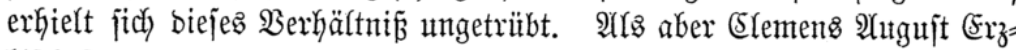
bijchof gemorben war, wollte er, ba er bag jogentante cbangeliface (sitnt= najum zu unterbrioffen nicht vermodyte, ifm baburdy bie fathofijdyen

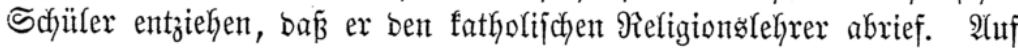

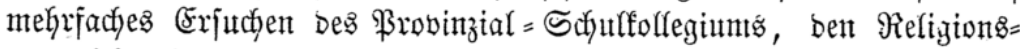
unterridgt einem anbern bon ifm gewählten (5seijtlichen zu ïbertragen,

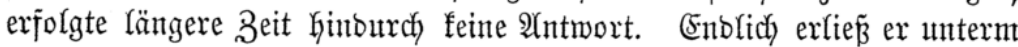
5. Эunt 1837 bas nachjtehenbe merfwürbige Schreiben, aus weldyem man bie Stellung erjehen wirb, weldye ber erzbijchöflidye Stuhl zu bent Unter= ricfitzanjalten bes Staats einzunefmen fich für beredytigt unb verpflichtet

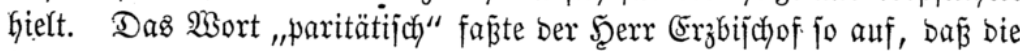

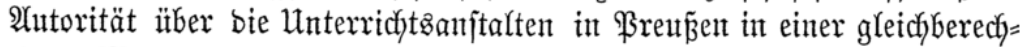
tigten Madjtuofffommenteit bes Staats einer= unb ber Sirche andererjeits zerfalle, ja, bá ber Stáat eigentlidy nur für bie Mittel uno bie $\mathfrak{A}$ njitalten,

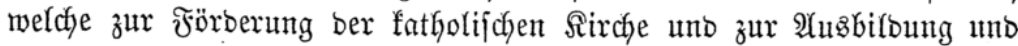
Berjorgung ber fathodijchen Bseiftlichen nöthig fino, zu jorgen, bagegent bie

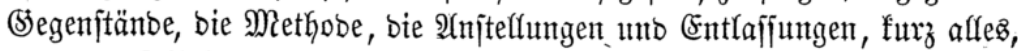

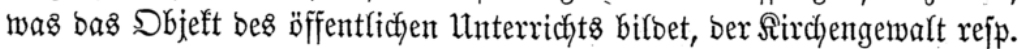
Dem bieje vertretentoen unb. bem päpjtficjen Stuhl aflein verantwortlichen Erzbijadof zu ïberlajjen habe.

Dabs erruähnte Schreiben bes Erzbijdyofa lautet: 


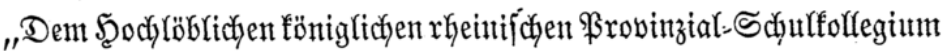

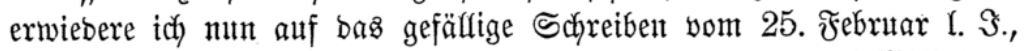

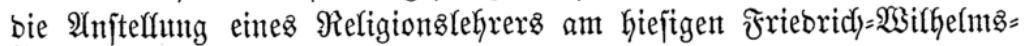

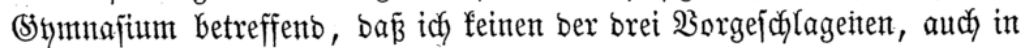

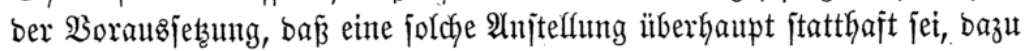
hergeben fönne. Waa ben Yanjent insbejonbere betrifft, fo hat er jeine

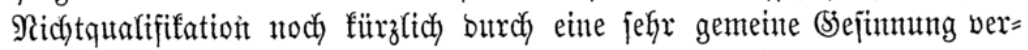

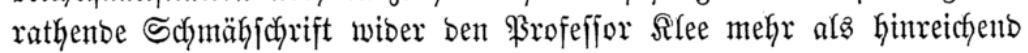
befunbet.

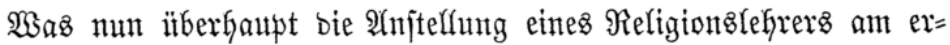

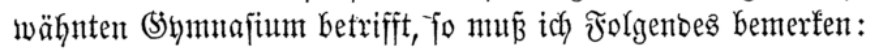

Sdyon zweimal ift ber Serfudy gemadyt worben, bem fraglidyen (5)ynnafum ben Sharafter uno bie Bejtimmung eines evangelijd)en (5y) najums zu geben; beibe Mal fam es feiner 2 ufflöjung nahe, weil bie

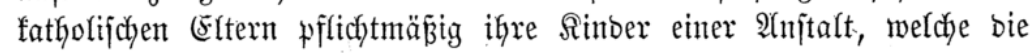

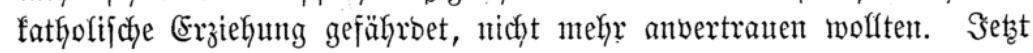

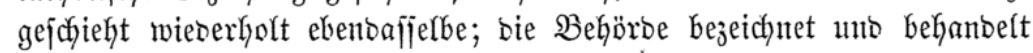

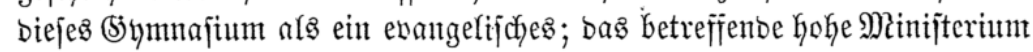
子. $\mathfrak{B}$. ridytet eine $\mathfrak{S e r f u ̈ g u m g ~ v o m ~ 3 0 . ~ S u l i ~} 1836$ an bie Direftion bes

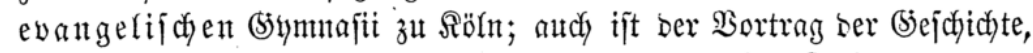
bent audy bie fatholifchent Schüler beiwohnen, in affen Sifajfen nur pro=

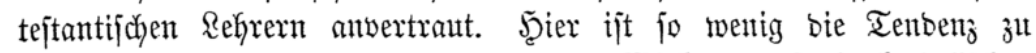
werfennen, als bie bavon zu erwartenbe \$irfung ali bie fatholijchen

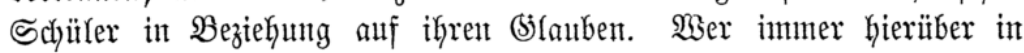
Zweifel wäre, brauthte nux in bent in ben Sdyulen eingefüfrten Sceibel=

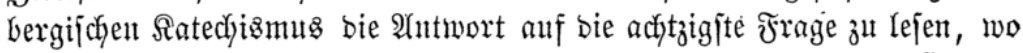

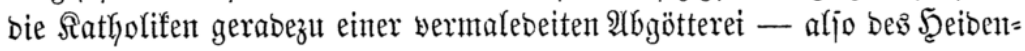
thums - bejantloigt werben. S3ie bas Gier ertwähnte Serjahren mit

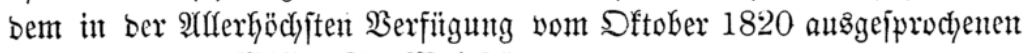
Âfergnäbigiten $\mathfrak{W i f l e n t}$ Sr. Majẹtät:

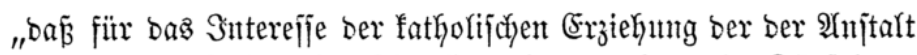

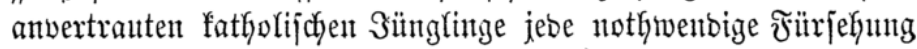
gefidyehen folle,"

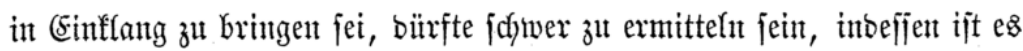

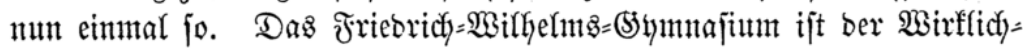

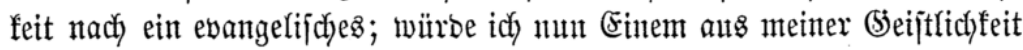

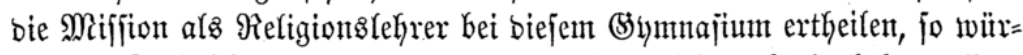
ben bie Sattyolifen, welche mit ber Sachlage nicht gehörig befannt fint, eben jenter Mifjion wegen bas fraglidye (Symnafium wentgítens für ein 


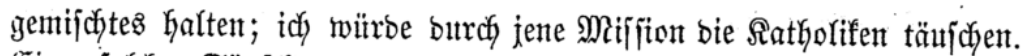

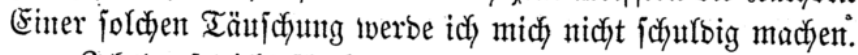

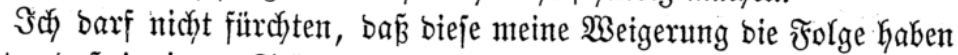

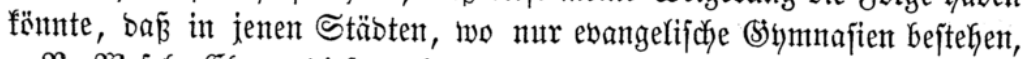

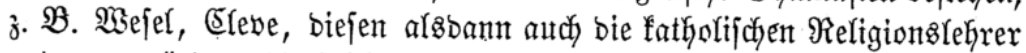
entzogent witroen, ba foldyes wiber (Serechtigfeit uno Bifltigfeit anjto

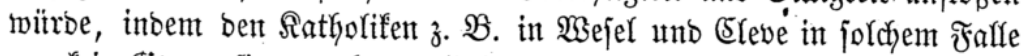
gar fein Bsymnafum mtehr zut Sebote jtehen mürbe, bent fie ifyre Sinber anvertralten fömtent. Diejer Falf aber wïrbe Gier nicht eintreten; auth würobe in (SIeichförmigfeit mit jentent Berfahren in jenten Stäbten, wo nur fatholifye (siymmajien, z. B. int Düfferborf, unto protejtantifche Religions=

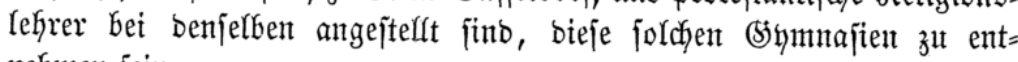
nefymen jein.

Wenn man mun bebenft, baj bie Zahl ber bie beiben hier bejtekenden (5iymajien, bavon bas eine fatholijd), bas andere, bas mehr befprochente evangelijus ijt, bejutchentoen fatholijchen Schjuler jich ant wentigitents 450 , Gingegen jene ber protejtantif(y)ent Schüler fich nutr aụf 75-80 beläuft:

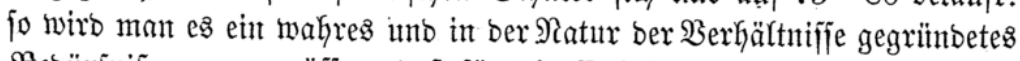

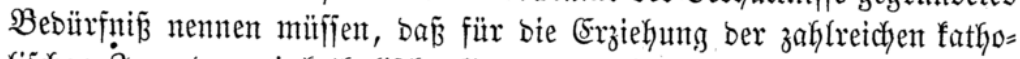

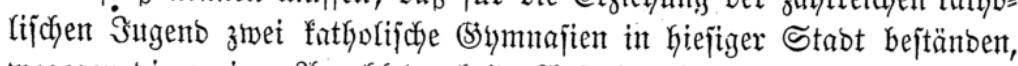
wogegen bie geringe $\mathfrak{A}_{\mathfrak{n}} \mathfrak{a h g}$ ber beibe $\mathfrak{A}$ njtalten befuchenden evangelifchent Schüler nicht bas $\mathfrak{B}$ ebürfni ermeifen bïrite. Das vorernähnte Bebürfnić hatte man auty in ber

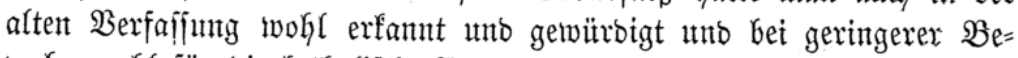
wohnerzahl für bie fatholijche Erziehung ber fatholifdyen Sttgent in Siön bret rein fatholijche (5y)mnafien gegrïnbet. Die Errichtung zweier fatho=

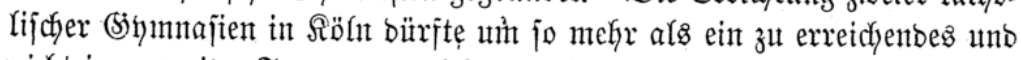

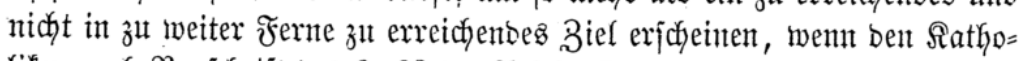

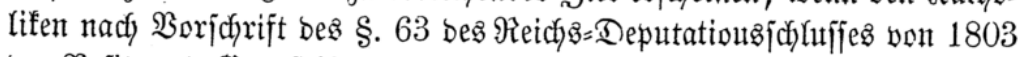

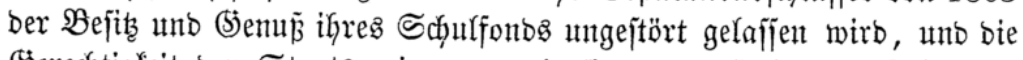
(Serechtigfeit ber Staataregiermutg, wie fie gegenwärtig bent Frriebrich= Wilfyelms = Sinmnajum zu jeinem Bejtande aus ber Staatsfajije 5000 Reichsthaler, welche ja urjprünglich ïberbaupt für bent höherent Unterricht

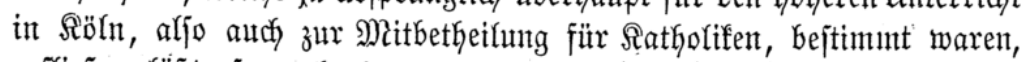

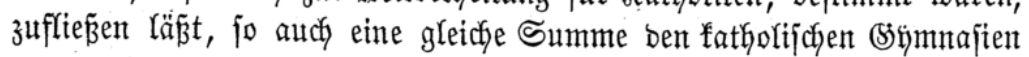
zutwentot.

Snbeffen biefes ijt in gegentwärtigen $\mathfrak{u}$ mifänben vieffeicht noch nicht

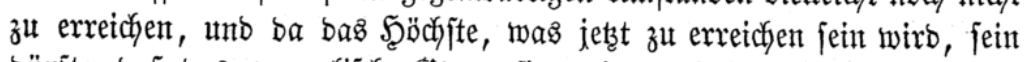

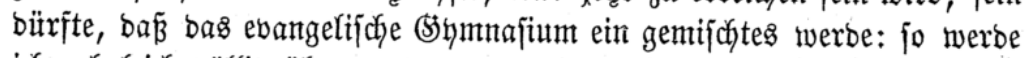

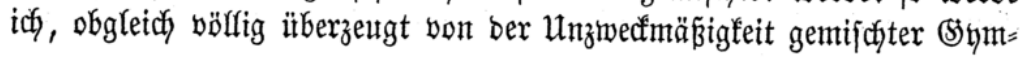




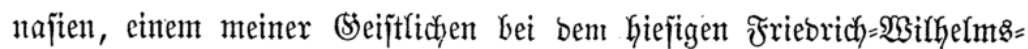
(5)ymnafium, falla jich nämlich bazu ein geeignefes Subjeft finben wiro, bie

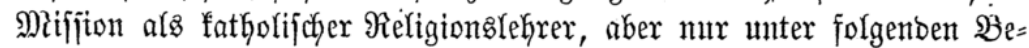
bingungen ertheilen:

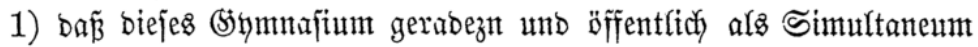
erffärt unb behanoelt werbe;

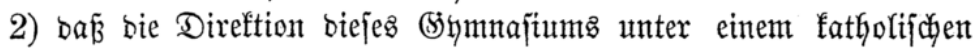
uno protejtantifanen Direftor mechjele;

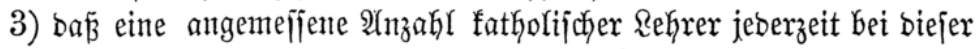
Inj talt in Wirffamfeit bleibe, und bas um jo megr, alz jelbjt in fatholifchen (symmajien, z. B. zu Düjjelborf, mehrere protejtan= tifiche Refrer fungiren;

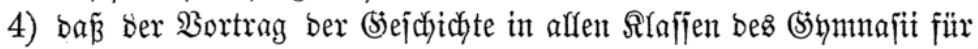
bie fatholifyen Schüler fatholijchen Rehreen, und zwar folchen anvertraut werbe, welche nidht alfein ber Benennung nach, fonbern

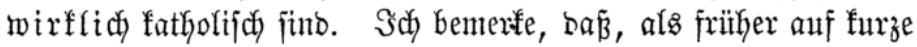
3eit Der Sortrag ber (Sejchichte im fraglichen (Symmafium fatho=

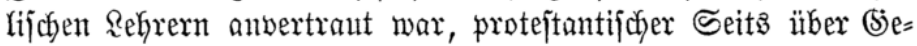
fähroung ber evangelifchen (Erziefung ber ebangelifłen Schüler geffagt wurbe.

Hebrigens fann idy nicht umbint, z̧t erffären:

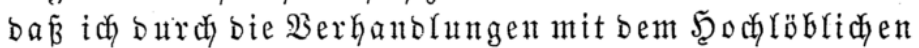
fäniglidyen $\Re$ hein= anz nidyt gleidfan jtirlfdweigend ober faftifd bie

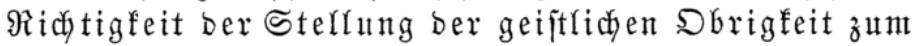
Schulwejen anerfennen wolle, es ijt mir vielmehr jehr flar,

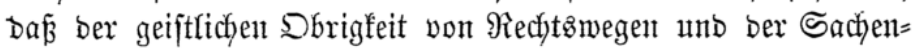
natur zufolge eine ganz andere Stellung gebiitgre.

イälıl, belt 5. Sunt 1837.

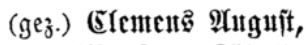

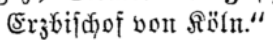

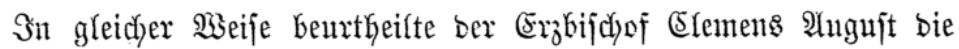
firchlidye, refpeftive feine Madytuofffommenfyeit über bie Rehre und bie Rehrer an ser paritätifç)en Univerjität in Bomn.

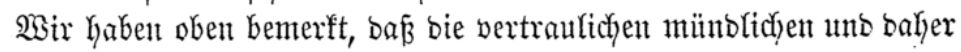
niemals befant gemorbenten Serkanblungen zwijdyen ber prentijacten Staatsregierung und bem Strafen Spiegel wegen feiner Hebernahme bes

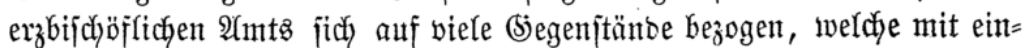

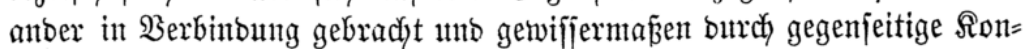
zeffitonten zutr 2 (t) 


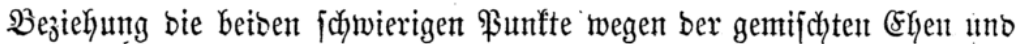

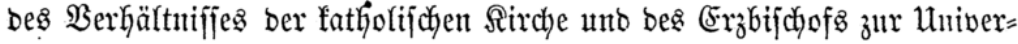

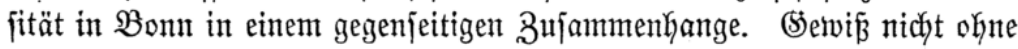

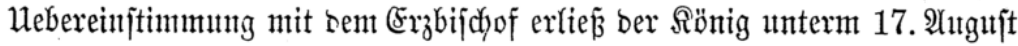
1825 bie $\Re a b i n e t s=$ Drbre, burdy welche bie Deflaration vom 21. Na=

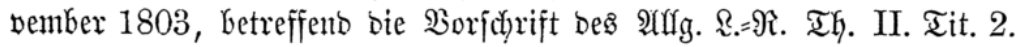

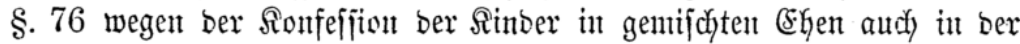

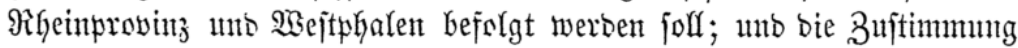

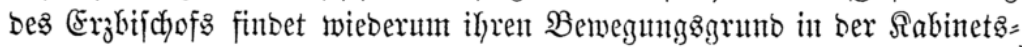

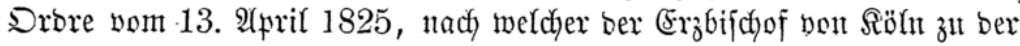

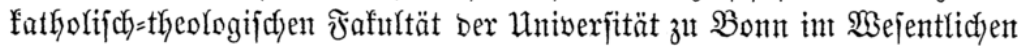
biejelbe Steflung einmehmen folf, in weldyer fich ber Füritbifichof von

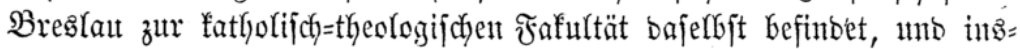
bejontere in Betreff ber 2 njitellung, Disziplin uno Entfernung ber Rehrer

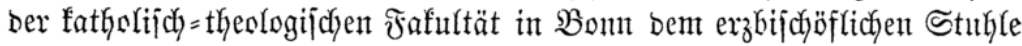
biejerben Befugnifje Geigelegt werben folfent, beren jidt) in biejer Bejiehung Der Fürjtbifdof bon Breslau erfreut. Die besfalffigent genauern $\mathfrak{B} e=$ jitimmungen joflten bem Minifterium überlaffen und feiner ßeit in bie

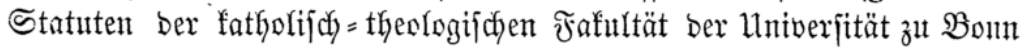

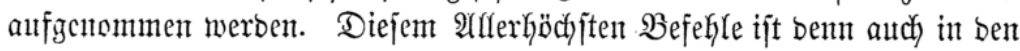
Statuten ber łatbolifch=theologijchen Fafultät vom 18. Oftober 1834

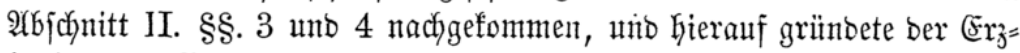
bifchof feine \$rrätenfionent unmittelbar, nachbem er im Sommer 1836 jein Amt angetretent hatte. Seine Şartnäcfigfeit mad)te befanntlich feine

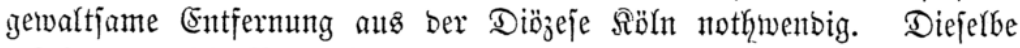
erfolgte am 20. November 1837 unb erregte, in Folge ultramontaner $\mathfrak{U}$ (gitationen, weldye namentlid) von $\mathfrak{B} e$ elgien ausgingen, ein fo alfgemeines

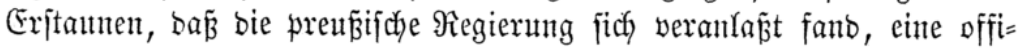
zielle "Darlegunt iłres

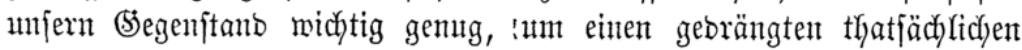

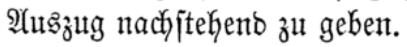

"Dentichlants Uluiverjitäten bilben eine ebenjo d)arafteriftifd)e (Eigen=

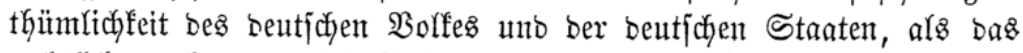

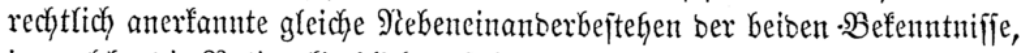

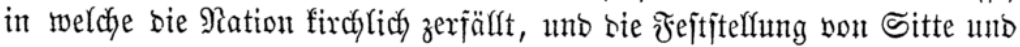

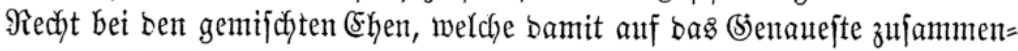

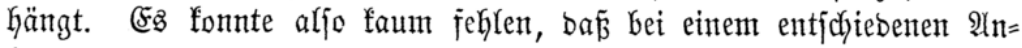
fämmfen gegen bie recfttich beftehenten BerGältniffe bes Staats zur fatho=

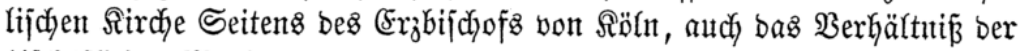

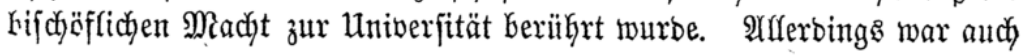




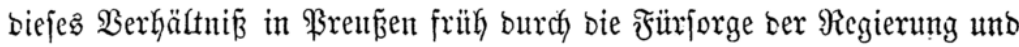

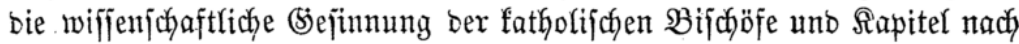

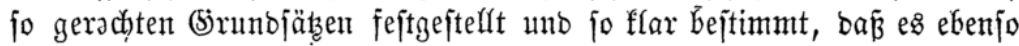
fdywer fofien, baffelbé nicht zu fennen, als es umittinzen zu mollen. Die Statuten ber Bonner Uniberjität werben genügen, bies urfundolich bar= jullegen. Die (5runbibee aller jener Anorbunngen ijt jehr einfad). Der

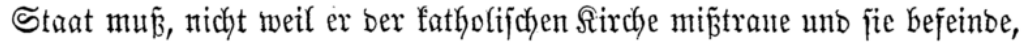
jonoern weil er jie in ihrer Wirffamfeit anerfannt hat unb redlidf in ihrem Bejtehen jchützen will, einen groß̉en 3ierth barauf legen, baß bie für bas

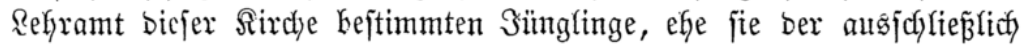
firchlichen Ergiefyung übergeben worben, einte alfgemeine Erziehung entwangen uno fich ber Gökern $\mathfrak{B}$ ilbung ber Ration theiffaftig madjen.

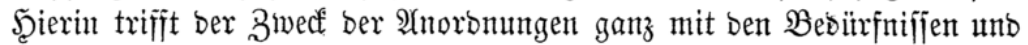

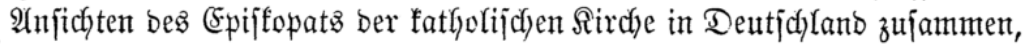

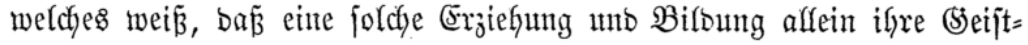
ficken befähigt, auf bie Stlaubenggenofijen unt Mitbürger weife uno erfolgreich einzumirfen unt jich ben gebüifrenten \$laţ in ber (jejellfchajt unt Siterntur zu fichern. Die höhere nationale Ergiehung beginnt mit bem Stymuafiun unt entigt mit ber Univerjität. Sn beiben Stabien

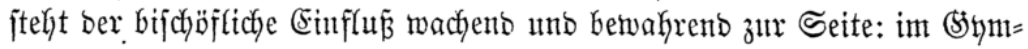

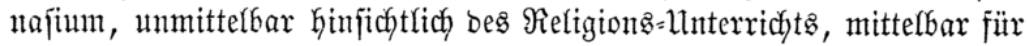
ben iibrigen, welchen außersem fatholifche Schulräthe reitent unb beauf= fichtigen; auf ber Univerfität jür bie gejammte theologijđye $\mathfrak{A}$ uśbilbung.

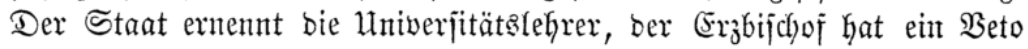
gegen biejentigen, weldhe er burch Rehre ober Reben biejes hohen $\mathfrak{A}$ mtes nicht würotig erachtet. Diejes Beto gilt vor ber Anjeflung unto nach Derjefben. So wie ber Erzbijchof bie Brofejioren an ber Staats= Univerjität rnidjt ernenut, fo fann er jie auch nidht abjeşen; aber fo wie

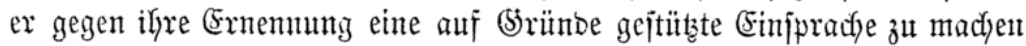

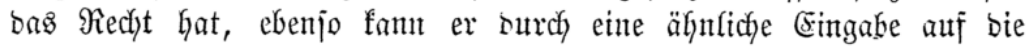

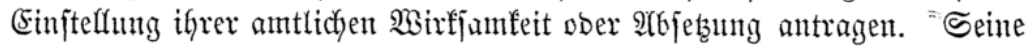
pojitive (5ivart bagegen tritt ein, wenn nach ber Univerjität, wie e\& alfge= meine beutjche Sitte ijt, bie fünftigen \$riejtex in's bijchäfliche Seminar

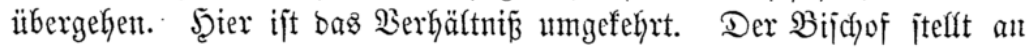

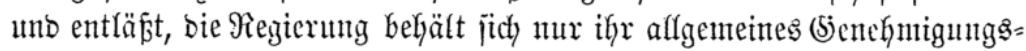
recht ber Anjteflung vor, bant fie in politijcher Beziefung ganz berufigt fein fönne. Son ber (Entlafjung nimmt jie, anjer int Falfe einer $\mathfrak{B} e=$

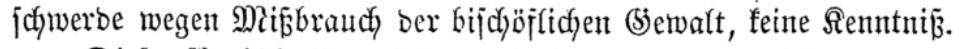

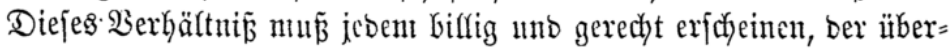

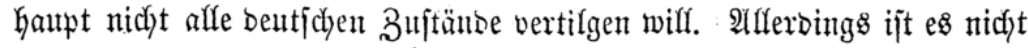




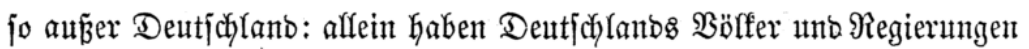

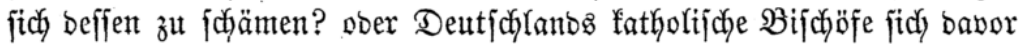
子̊l fürchtent?

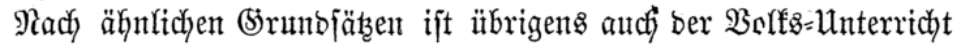

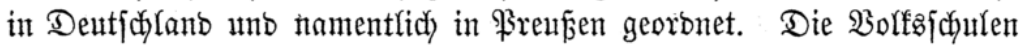

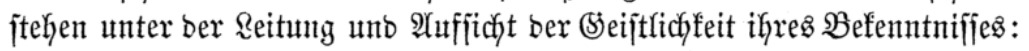
fïr bie Bifloung ber Refrer in ignen hat ber Staat grope Ânjtalten

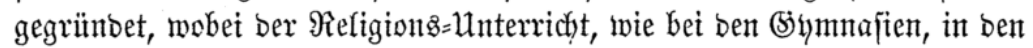

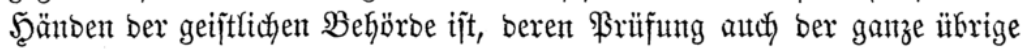
unterricht in jenen Seminarien offen Yiegt.

$\mathfrak{U n}$ z̆ ben Univerjitäten zurïd

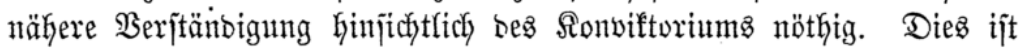
eine 2Unjtalt Für etroa jiebzig fatholijohe Stubirenbe, weldye ein gemein= fames Rebent führen uno babei, eben wie in ifren Stubien, unter Gejonberer.

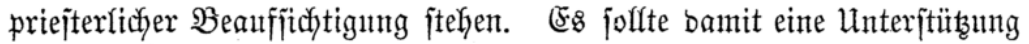
für bie Dïrftigeren gegeben, und bie jittlidf)=religiöje $\mathfrak{B}^{2}$ rbereitung zum

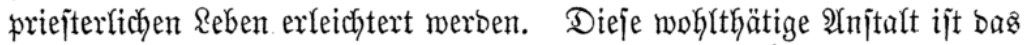

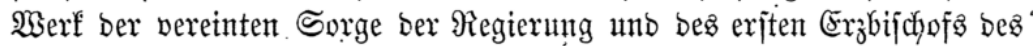

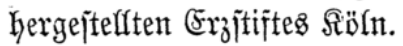

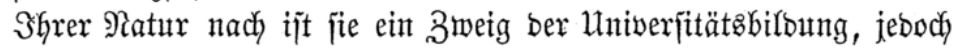
mit bejonberem geiftlichen Erziefungszzwedfe. Dffenbar fann fie aljo mur burch ein inniges und freunbichaftliches Bujammentwirfen ber Staats= unt ber bifchöflidjen Ssemalt bejtehen, fo twie fie baraus alfein herborgegangen ift.

Bergebens würbe man in ben baburch fejtgejtellten $\mathfrak{B}$ ejtimmungen

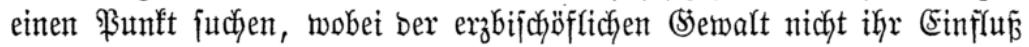

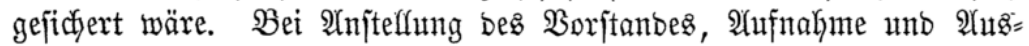

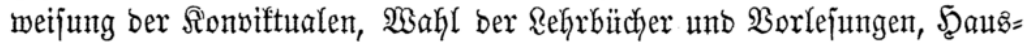
orbmung unb bergleidyen hat ber Erzbifdyof entweber eine Einfprache bent

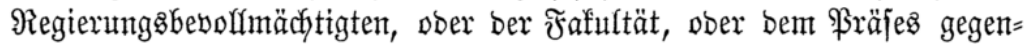

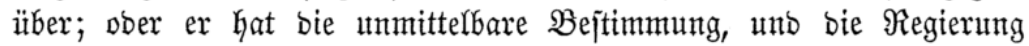
behält fich nur bie alfgemeine lanbegherrlidye (s)enehmigung vor. Die söjung ber Frage, ob ber eine ober ber anbere $\mathfrak{B u n f t}$ mehr burch pofitives Eingreifen bez Erzbifdyofs ober burch feine redytlidje Einfprache zu bejtimmen jei, hat man nach ben oben angebeuteten Struntojäłzen mit Biffigfeit und gegenjeitigem 2 ertrauten zut finben gejutht.

Sener Eintgung ging eine mehriährige Erfahrung vorker, unb weber

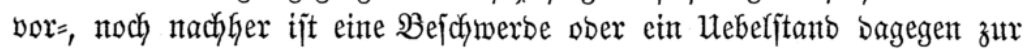
Spradje gefommen. Wer fönnte bei foldyer Behanblung ber Erziefungs: Untgelegentheiten jagen, bie fatholijche Sirche jei in ber Inedjtichaft bes Staats, unt eine joldye gemifuthte Befetggebung jei eine Erniebrigung fïr 
fie? Sollte man nicht vielmehr auf ber anbern Seite anzuerfennen haben,

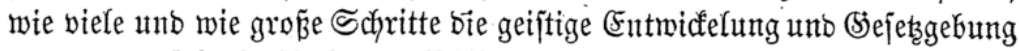

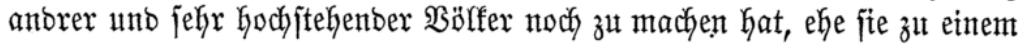

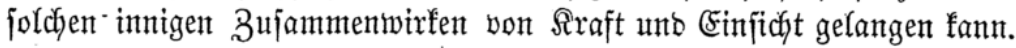

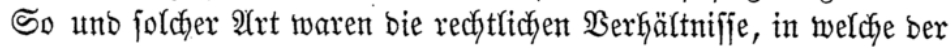

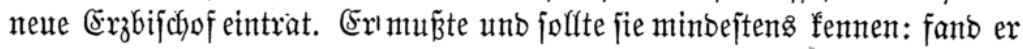

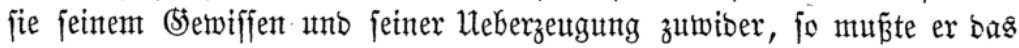

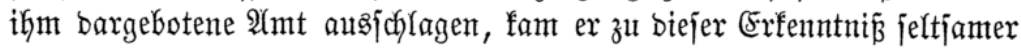

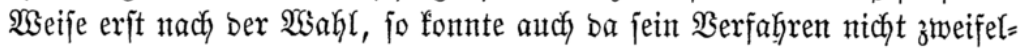

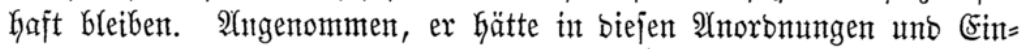

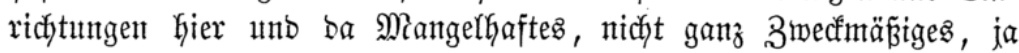
Semmentes ober gar ifan Berletzenbes gefunden, fo blieb ifym ber $\mathfrak{W} e g$ von Borjteffungen beim Miniftertum offen; war er mit ber Âtunahme nidyt zufrieben, fo ftant ifm frei: unmittelbar beim Ranbesherrn jeine Befdywerben anzubringen. Die Srunbjätze, weldye bie Regienung in

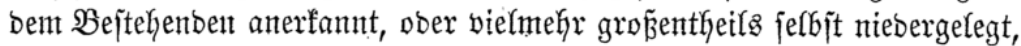

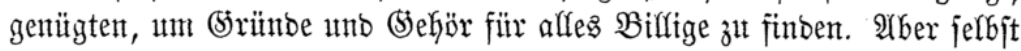

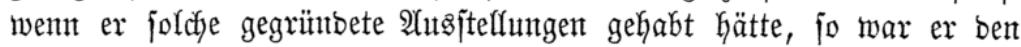

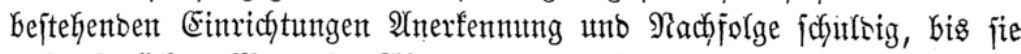

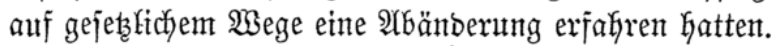

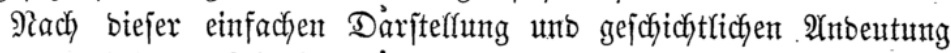

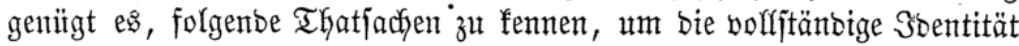
bes $\mathfrak{B}$ erfahrens bes Erzbijchofz in biejen Berfältniffen mit bemienigen einzufehen, weldes ber erjte Theil ber, Denffdrift in B̧eziehung auf bie

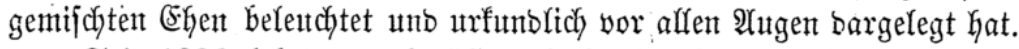

Seit 1820 lehrte ber berithmte fatholijale Theolog Seermes an ber

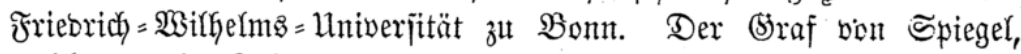

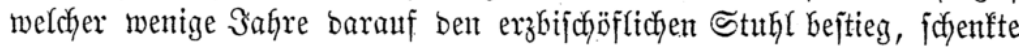
Den $\mathfrak{B}$ emühutngent jentes Mannes für bie \$̧ebung ber währent ber frant=

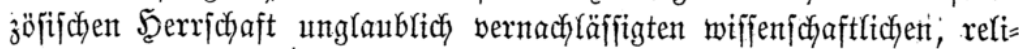

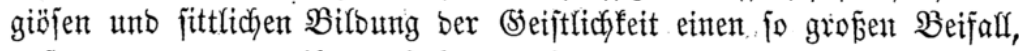

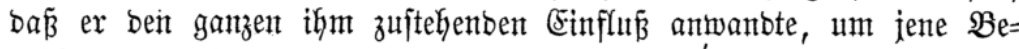

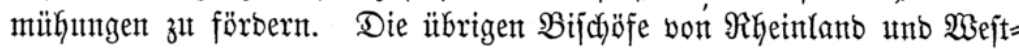
phałen jtanben ifm hierbet zur Seite: von feinem von ihnen warb ein

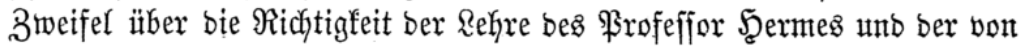
iłnt gebilbeten Männer laut.

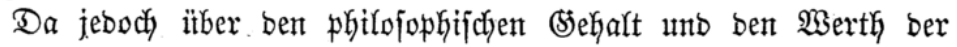

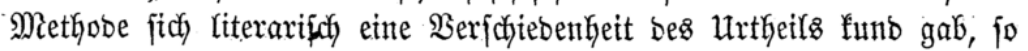

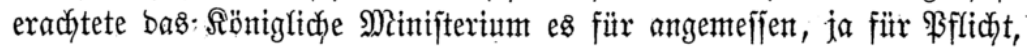

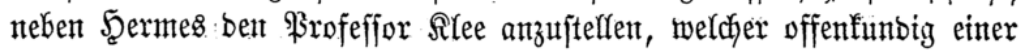




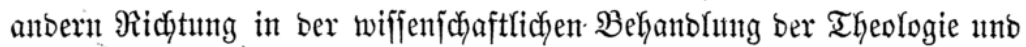
einer anbern Schule angehörte. Der Erabijchof werkehlte nidyt, weldhen

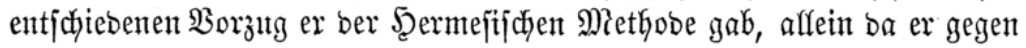

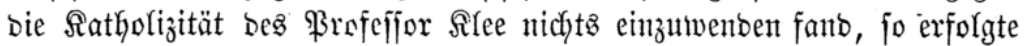

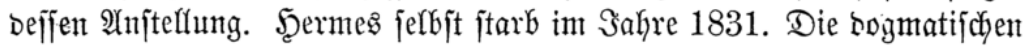
und moralifchen Borlejungen auf ber Univerjität brieben jeboch, mit $\mathfrak{A} u s=$ nafhne bes zuleţt genannten Refyrers, in bent J̧änben feiner Sdjüter unb Fremtube. Die Mekrheit ser fatholifchen Fafulttät B̧reslau, ber Fafultät in Münjter, ber bijchüflidjen @eminare ber ganzen Menardyie gehörten Derfelben Schule alt: eine grope 3 ahl ber Sapitultare und mehrere taufent

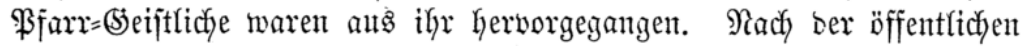
Stimme ift ifyr praftifches Sirfen im Eeelforgeramt im arffgemeinen mujterkaft uno belebend, unt warb als folches von ben Stemeinben anerfannt.

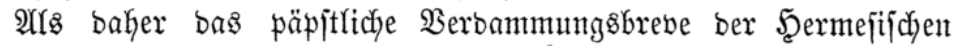
Sdyriftrn vom 26. September 1835 erfofien und zu Enbe bes アahres Dort befannt wars, muste nothwensig eine grope 2 ufregung in ber fatho=

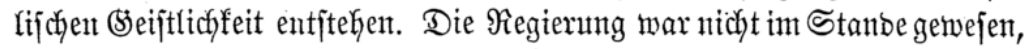
surch vorbereitente und vermittelnoe Maparegeln und Mittheilungen bieje AYufregung zu milbern, benn es mar ihr burchaus feine Sunbe von biejem grofien Sdyritte, bem erjten entjofiebenen Eingreifent Der oberjten Sirchent=

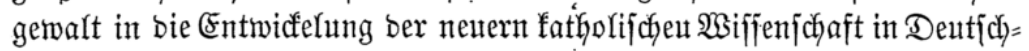
lant, gegeben worbent. Das Finzige, was̆ jie thun fonnte, war, fich jeber amtlichen $\mathfrak{B} e r$ öffentlichung zut enthalten. Seiner ber fatholifchen Ranbes= bifchöfe, ofne berent Urtheil unb Bujtimmung eine joldye SBefanntmachung

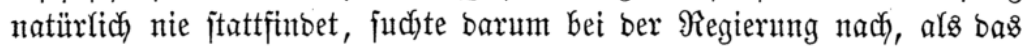
Dajein jenes Brebe befant geworben war. Bon mehreren angejehenten

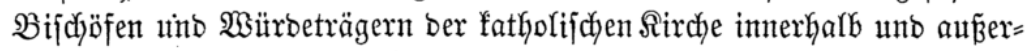

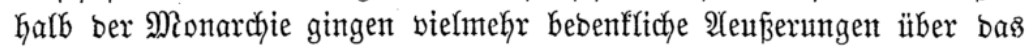
Brebe ein, beffen Faffung mit einer folchen Ungunjt bon ben Satholifen in

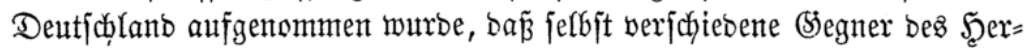
mejifchen Syjtems mit affer (Ehrerbietung gegen bas Sirchenoberhaupt fich in

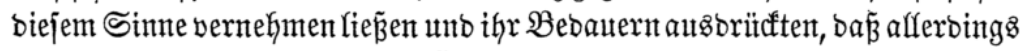
bas $\mathfrak{B e r b a m m u n g s u r t h e i l ~ b e r ~ S ̧ e r m e f i f ~ d j e n ~ S d j r i f t e n ~ i m ~ B r e b e ~ f l a r ~ a u s : ~}$ gefprochen, jonjt aber fdjwer baraus zu entnehmen jei, weldye sehren eigentlidy verbammt jeien? Weber in Bayern, nody in Dejterreidy, noch irgenbwo fonft in Deutjajland warb bas Breve, jobiel befannt ijt, publizirt.

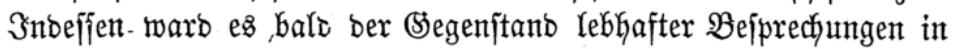

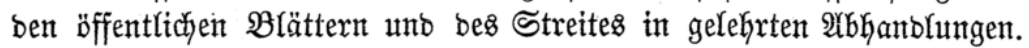
Dffenbar war arfo eine vorfäufige Maßaregel Ginfitutlich ber Borfejungen ber theologifđjen Frafultäten nothwentig. Es murbe beshalb fidon vor 


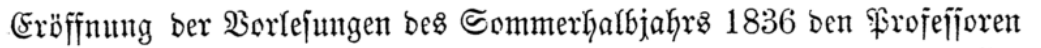

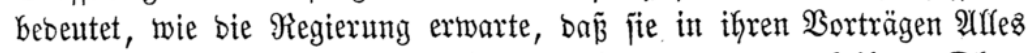
vermeiben wïrben, was bem offenfunbigen $\mathfrak{B}$ eroammungsurtheile bes $D$ ber= hautpts ifyer §irche entgegen jei. Diejer Errwartung famen bie 3ujagen

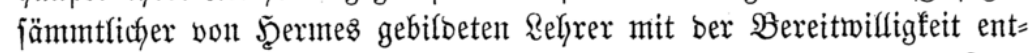

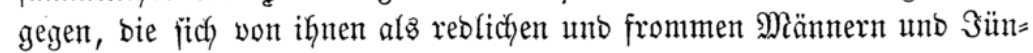

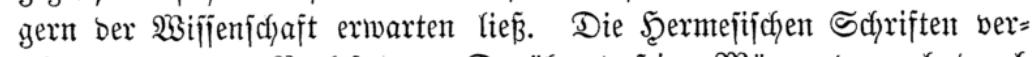

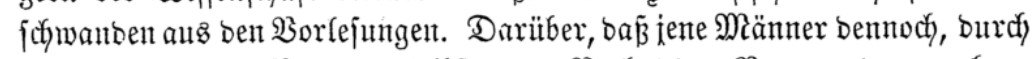

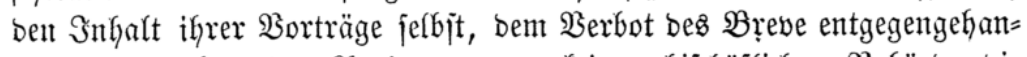

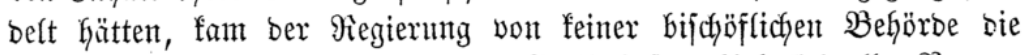

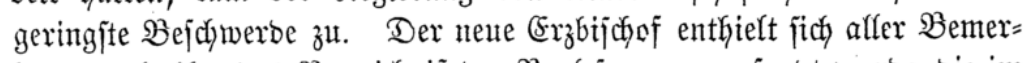

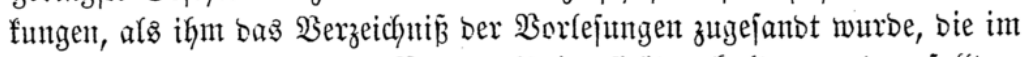
Winter 18:36/37 alf ber Bonner Univerjität gehalten werben follten. . So fanben bieje benn auch wie bisher ungejtört jtatt.

Aflein unterm 12. Sanuar 1837, in ber Mitte bez Minterhalbjahrs,

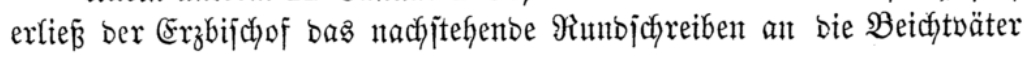
ber Stabt Bonn.

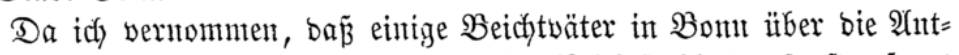
wort, bie fie zu geben haben, wem jie im Beichtiftuhl ober jonjt gefragt werben, ob man bie Schriften bes jeligen Profeffor Scermes Lefen bürfe, unt ob bie Theologen jenten Borlejungen beiwohnen bïrfen, in weldyen bie in jenen Sdyriften enthaltenen Behauptungen vorgetragent werben, in

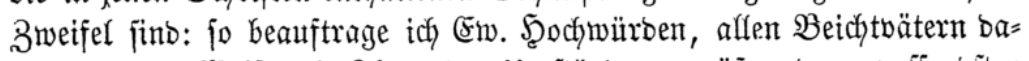

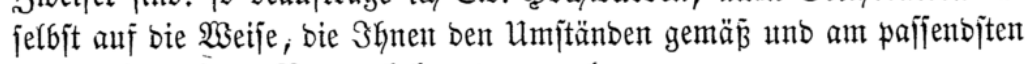

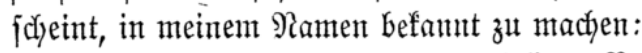

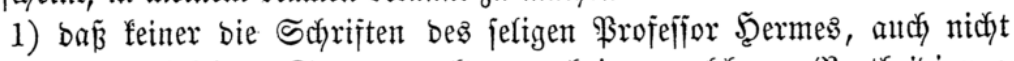
bie nach feinen Tobe gebrutften, nod jene, weldhe zur 23 ertheibigung

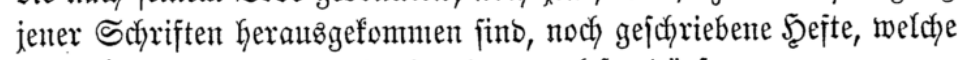
jenen Sçriften gemär gefertigt fịto, - lejen bürre;

2) Dá̧ fein Theolog Sorlejungent, beren Snhalt bent vbengenannten

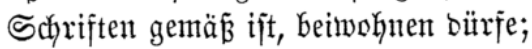

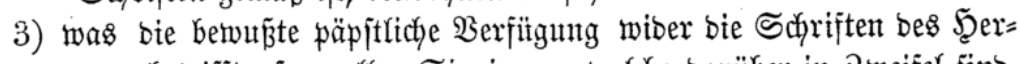
mes betrifft, fo wollen Sie jenten, welche barüber in $3^{\text {weifel fint, }}$

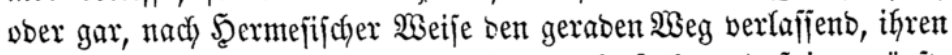

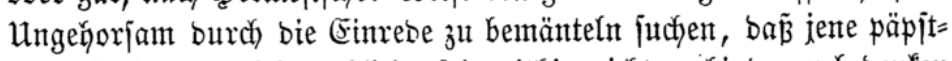

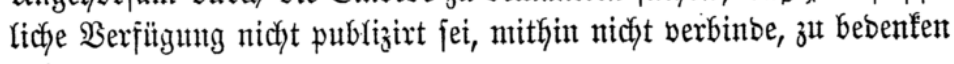
geben:

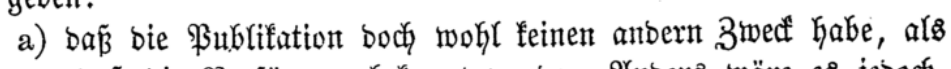

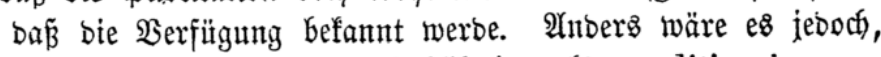
went ber Sejetggeber bie $\mathfrak{B u b l i f f a t i o n}$ als conditio sine qua 
non ber Berbinblidyfeit boridyriebe, wie biejes ber Fall bet bem (Sejeţe bes Sirchenrathes von Iribent: „, contra matrimonia clandestina" war;

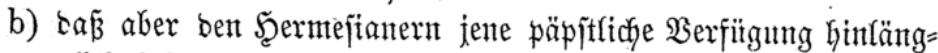
(ich) befannt ijt, zeigen ifre Sdyriften; ober man müpte einen Unterfichieb antebmen:

unter befant fein, um bas Dberfautpt ber Sirdje zut verböh= nett, uno

ùnter befannt feitt, um in Demuth zu gehorchen;

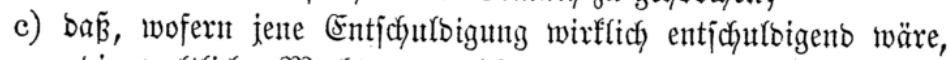
bie weltliche Madyt es butrdyats in ifyrer Macht hätte, bie Wirfjamfeit bes vom 5eetlanbe angeorbneten centri unitatis böllig zu Kenmen, was freilidy bent Seermejiantern, wie allent Seftirern, bie fidh nur vermittelfit ber weltlidyen Madyt, weldye.

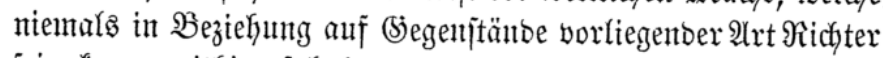
jein fam, mithin, fobald jie. Theil nimmt, Bartet ijt, Galten fönnen, niçt unlieb jein bürrfte. $\Re \ddot{l} \mathfrak{n}$, ben 12 . Samtar 1837.

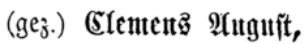

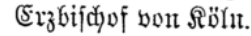

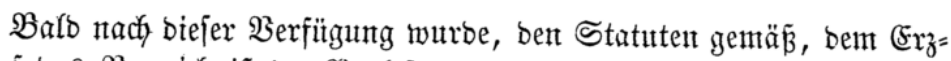

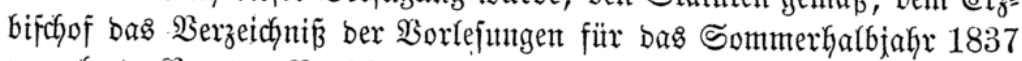
vorgelegt. Bont ben $\mathfrak{B o r l e j u n g e n t}$ eines ber $\mathfrak{B r o f e f f o r e n , ~ b e r ~ i ̈ b r i g e n s ~ n i d j t ~}$

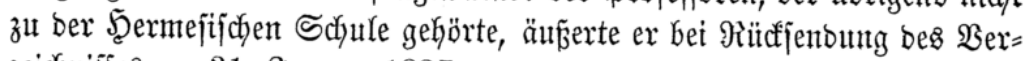
zeichnitijes an 31. Эanuar 1837:

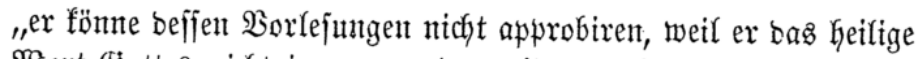
Wort (5ottez nicht immer, weber mit ber gebührenben Ehrerbie= tung, noch in (Steichförmigfeit mit bem Dogma behandle."

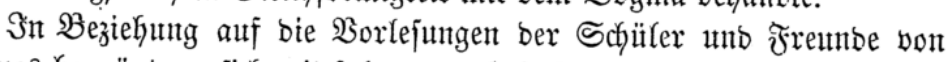
Sermes begntügte er jich) mit folgenben zwei Benterfingen:

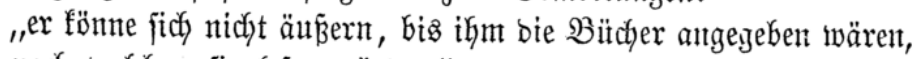
nach welchen jie lejent würben" uno, "er habe nichts zit erimtern, jofern bie $\mathfrak{B}$ orlẹ̣ung nur bas jei, was jie anfünbige."

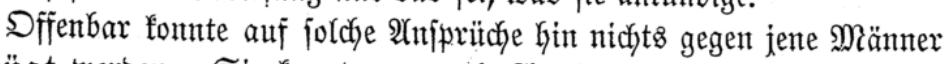
verfügt werben. Sie fonnten nux âs $\mathfrak{A}_{\mathfrak{n}}$ eidjen feinblicher Befinnung

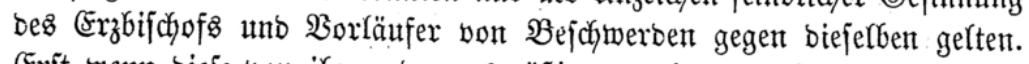

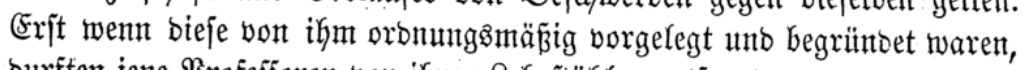
burften jene \$rofefforen won ifrent Regritüglen entfernt werbent.

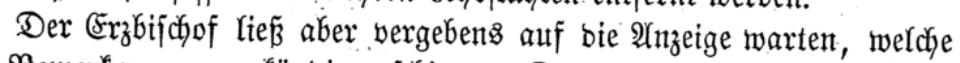
jene Bemerfungen anzufünbigen jchienten. Da ber $\Re$ egierung jeboch baran 


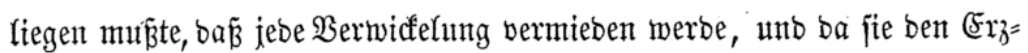

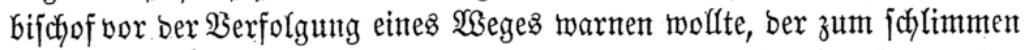

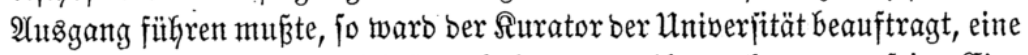

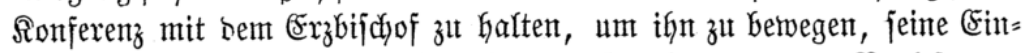

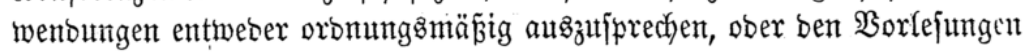
jener Männer nidyts in ben $\mathfrak{W e g}_{\text {zu }}$ Yegent.

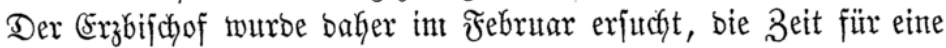

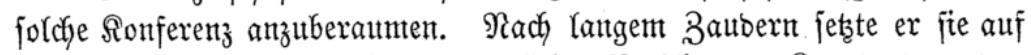
ben 19. März fejt. Nach bem amtfidyen Berichte bes Rurators murben ifm hierin, nach $\mathfrak{A}$ ttseinanberjetsung ber Strünbe, welche fein bisheriges

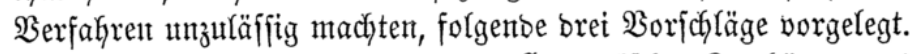

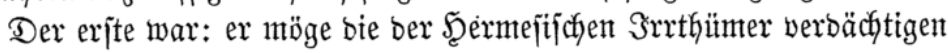
\$rofefforen bor jich laffen, bamit er fich baburdid bie Ueberzengung von ihrer äd)t fatholifchen (jefinnung ober bem Ssegentheile verichaffen fönnte.

Der (Erzbijadyof erffärte, er wolle mit jenen Männern in feine per= fönlidye Beriifyung treten, Kis bie Sache ausgeglichen jet.

So tratent bie Diterferien ein, ofne bá irgent eine Mittheilung vont

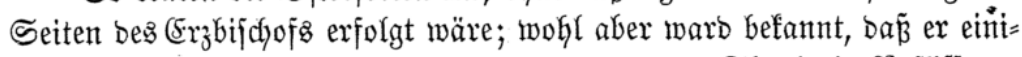
gen Stubirenben geidyrieben, es bürften von ber. Theologie Befliffenen

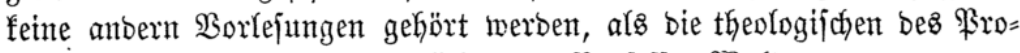

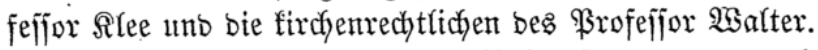

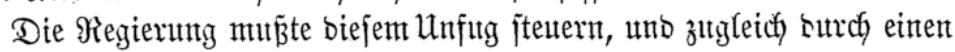

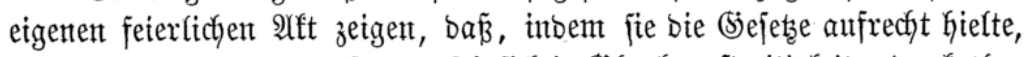

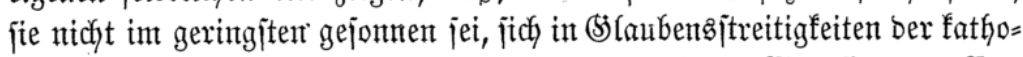

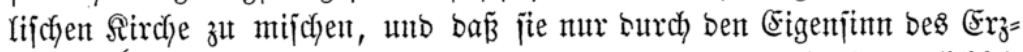

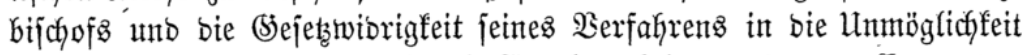

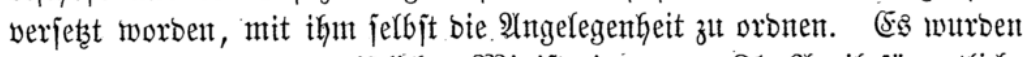

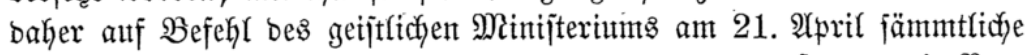

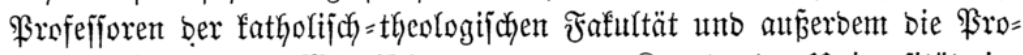

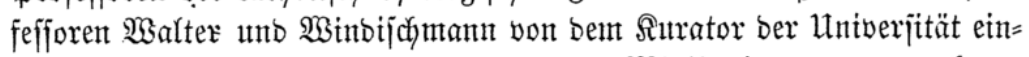

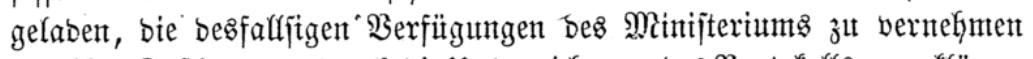
unt ifye 3uftimmung burch bie Unterzeidynung bes \$rotofolfs zu erffärent. Diejes Protofolf lautete:

Actum, $\mathfrak{B}$ onn, ben 21 . Ípril 1837 .

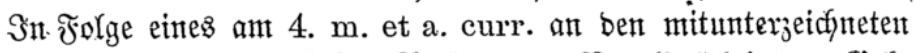

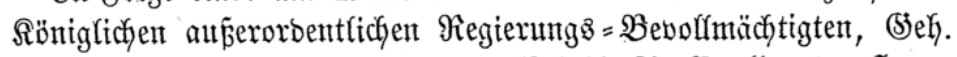

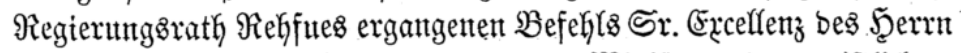

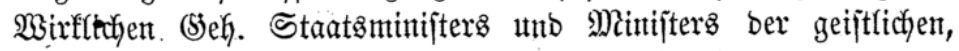

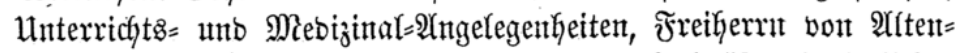
ftein, hat berjelbe Kente bie Brofefforen ber fatholif(t)=theologifanen 


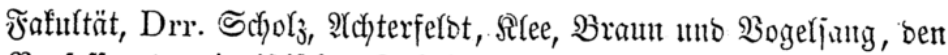

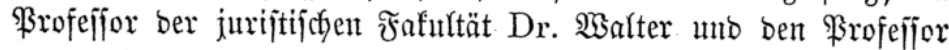

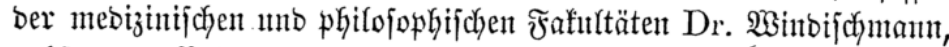
nebjt bem Srivatbozenten in ber fatholifdc=theologif chen Fafurtät

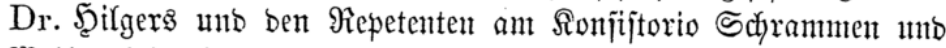

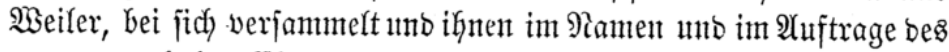
genanten hohen Eheis nachjtehenbe Eröffnung gemadyt:

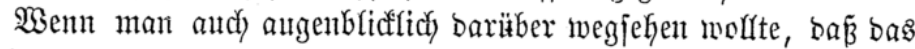
befannte päpjtlidye, gegen bie Schriften bes feligen Dr. Şermę gerichtete Breve ber Siöniglichen Stanteregierung weber in bem

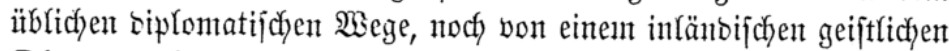

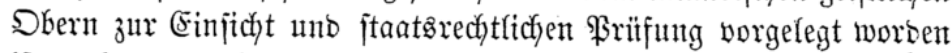
ift; baher es nady ausbritufficher Borfdyrift ber (Siejetse:

§. 118 bes 2 flfgemeinen Ranbrechts II. 11.

Loix organiques vom 26. Messidor IX. Tit. I. §. 1. bis bafin weber publizirt, nody volfogen werben fann, now überbaupt Sentand auj ben Grumb diejez Breves, blop beshalb, weil cr ein Schüler von Ştrmes getwejen ijt, ober befien Schriften uno Snjtem bis bahin borgetragen hat, in ber 2 lusïbung bes ifm an, vertrauten $\mathfrak{A m t e s}$ gefindert werten barf, fo liegt boch fowohl in ber Thatjactye, baj bejagtes Breve burch bie öffentlichen B̧ätter

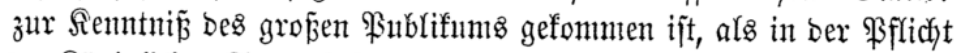

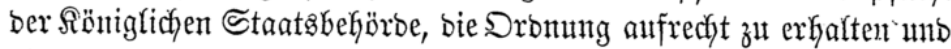

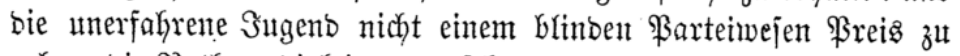
geben, bie Pothmentigfeit, vorzuleken:

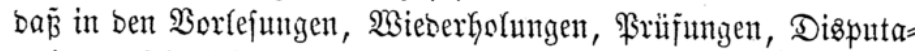

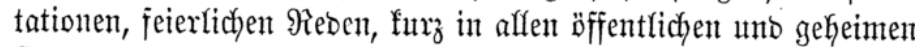
Şanblungent bes afabemifchen Rehramts, woz̆ autch bie Hebungen im Sionviftorium zat rechnen fint, jebe Errwähnung ber fier in Rebe jtehenben Schriftent bes Dr. Şermes uno ber biefelben betreffentent päpjitliçen Eenjuren uno $\mathfrak{B e r b o t e}$ vor ber Seanto gäız=

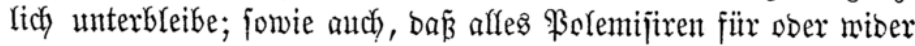
bas Şermejif che Syjtem überhaupt ober einzelne charafteriftijche Rehrjätze beffelben ernjtlidy vermieben werbe.

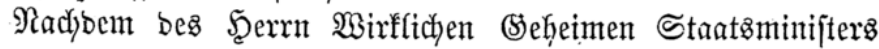

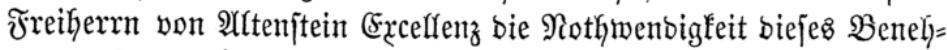
mens, fowohl wegen bex bejonbern Ehrerbietung, weldhe biejenigen, bie es angeht, bem apojtolijdyen Stukle jhuldig jinb; als megent ifrer Dbliegenheit, Den firchlichen Sinn ber S̈tgent zu pflegen,

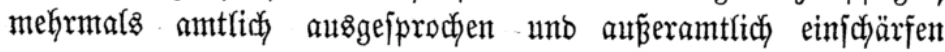




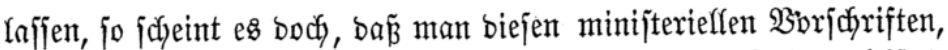

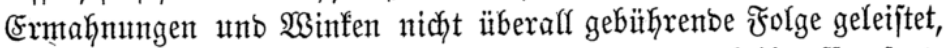

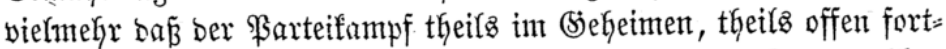
gejetzt morben ift, bis bie Sachen zu ben in Stabt und Ranb rucj)bar geworbenen Ungebührniffen gefommen fint, seren Bügelung und Utnterbrïffung gegenwärtig bie vorzüglidjite Sorge ber Sïniglidjen Staatsiregierung ausmacht.

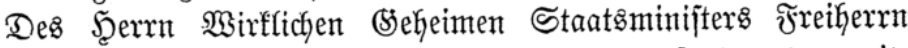
von 2̂ltenftein Excelfenz hat fich baranf betwogen gefunden, bem mit= unterzeichneten Regierungabbebollmächtigten zu befehlen, ben vor= genannten Seerrent ßrofefforen uno Dozenten zu eröffnen, wie Se. (5xcelfenz von benfelbent forbere unt mit' 3uberjicht erroarte:

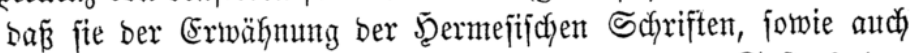
beren $\mathfrak{B}$ erfotez uno ber Bolemif fitr ober wiber bas Syjtent ober

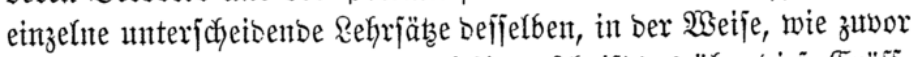
gejagt ijt, jich enthalten unb burch Unterjayrift bes äber bieje Erëffi=

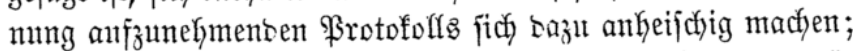

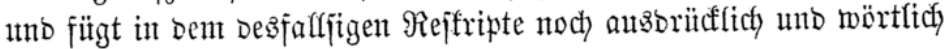
Ginzu:

mag einer itber bas QBerbanmungsbrebe und beffen Hripung ur=

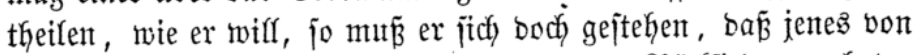

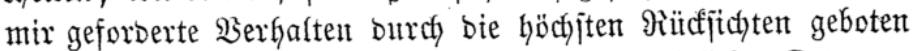
unb int 2 sejen jowohl ber religiöjen als ber rechtlichen Dronung begrïnbet ijt. Solfte baker, wiber meine Ertwartıng, Jemant jo

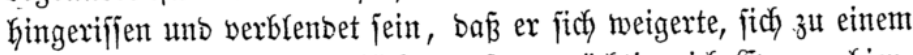
joldyen Berhalten jut verpflidyten, jo ermädytige ich (5w. zc. Kier= burch, benjelben zur Erffërung anf̧uforbern, ob ex fein $\mathfrak{A}$ mt nie= berzulegent geneigt jei, unb ¿abei zat erffären:

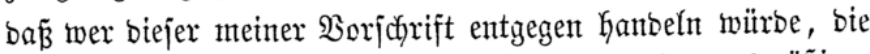
Suspenfion vom 2 (mte, uno im Sorgang vronungannäp̃igex

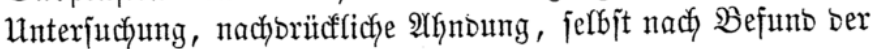

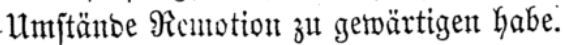

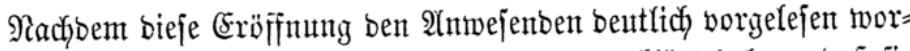

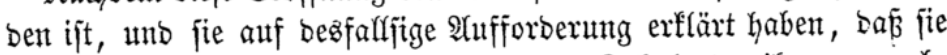
Arfes mohl verjtanden, jo gelobten fie, bem Inhalte ber ifynen gemadis= ten (Exöffunng getreulidy nadyzuleben, uno habent bieje Serjicherung burch ifre eigenhänbige Ramenzunterja)rift befräftigt.

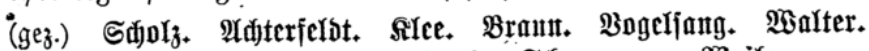

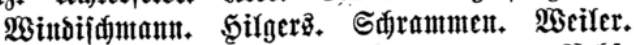

(gez.) volt 9ichfucz. 


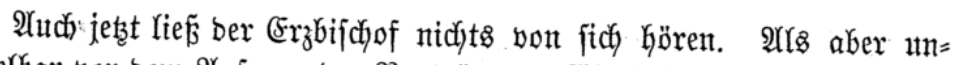

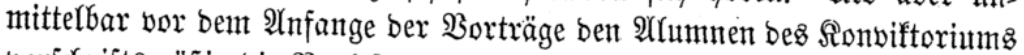
vorjchriftsmäß̈ig bie Borlejungen für bas neue Semejter bejtimmt werben

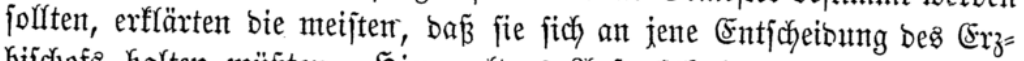

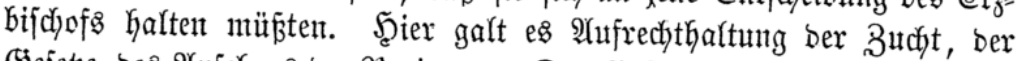

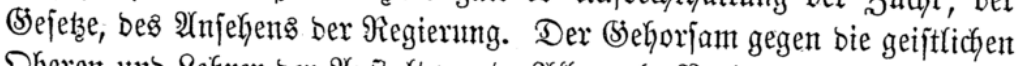
Dberent unb Refirer ber $\mathfrak{A}$ njtalt wurbe Affen alz Bebingung bes Bleibens in berjelfen geftellt. Die Folge war, baj won Siebzig nach und nach mełr als Sedjzig austraten; ein fdywerex Serlujt für bie Sirche, weldye bes Radywudfjes fehr bebarf, uno ein hartes Roos für bie jungen Mänter,

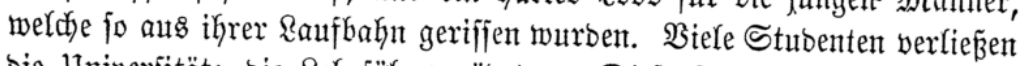
bie Univerjität: bie Rehriäle veröbeten. Dieje Folgen mufite ber Erz=

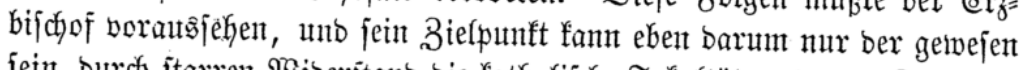
fein, Durch jtarren 2 Siberitano bie fatholifche Fafultät und bas ßonvifto=

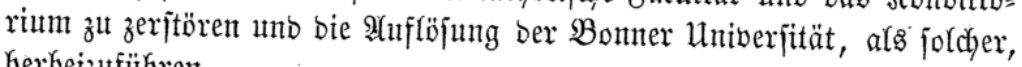
Gerbeizuführen.

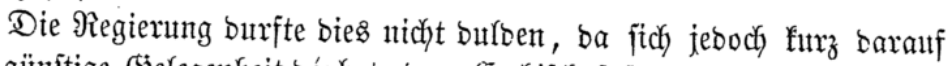

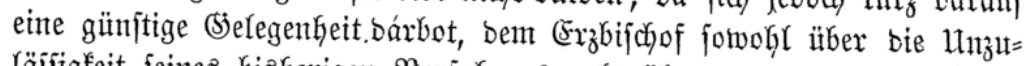
läjfitgfeit feines bisherigen Berfahrents, als ïber bent gutent Wiffen ber Regierung bie vertraulichjten. Berficherungen zu geben, jo wurbe aud

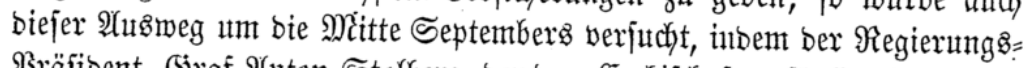

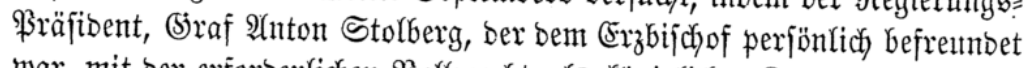
war, mit ber erforberlichen $\mathfrak{B o f f m a d f t}$ als föniglicfer Sommiffaritts ver=

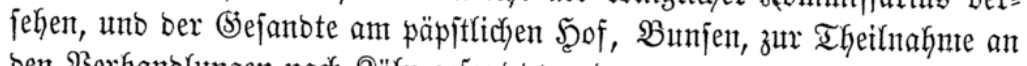
ben Berhanblungen nady $\Omega_{0}$ ln gefanbt wurbe.

Die Befpredyungen hatten einen freunbjofaftlichen (5harafter, ber. Ex $x_{3}$ bif

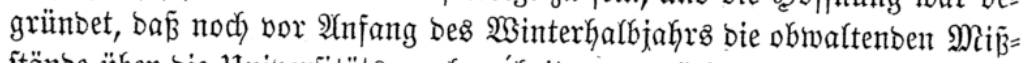
ftänbe über bie Unniverịitätzangelegeńtheit auşgeglichent jein würben. $\mathfrak{D a}$.

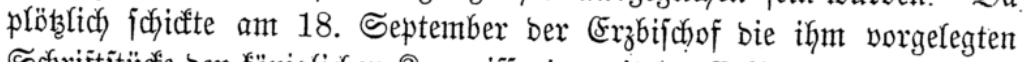

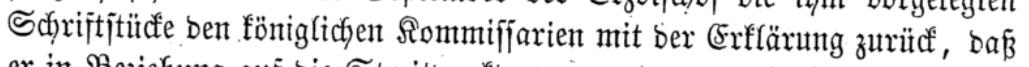
er in Beziehung auf bie Streitpunfte wegen ber gemifdytent. Ehen bei

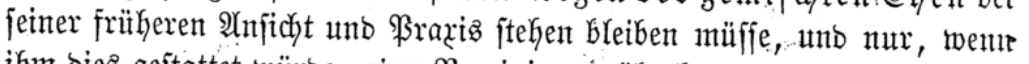
ifh bies geftattet mïrbe, eine Bereinigung überhaupt möglich, uno eine weitere Berkanblung zuläfïtg fet.

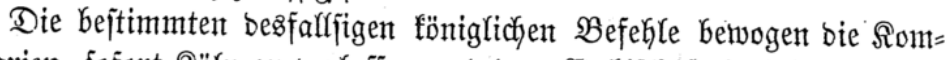

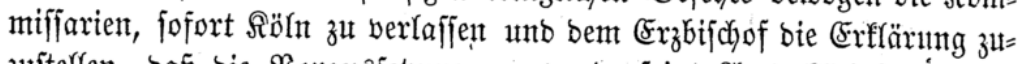

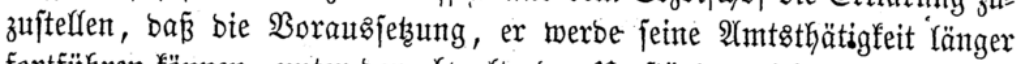
fortführen fönnen, unter ben obrwaltenben 14 mitänben nidgt meלy zutreffe, mit ifm alfo autch nidyt weiter verhanbelt werben fönne. 
Unter bem 24. Dttober forberte ber Minijter MAftenjtein ben Er $r=$ bijctof auf, jofort entweber feinen Sieforjam gegen bes Söniga Majejtät und bie Ranbesgejetse zu bezeugen, ober, wenn biez feinem (S)etwiffen wiber= jtrebe, bas Erzbistfum nieberzulegen. Und als ber (Erzbijchof unter bem 31. Dftober ablehnent antwortete, wurbe er am 20. Rovember 1837, bem

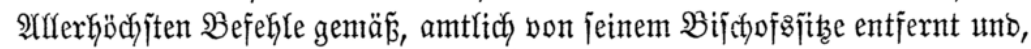
nach einer gerichtlidyen $\mathfrak{B e r h a n b l u n g ~ m i t ~ b e m ~ D k e r p r a ̈ f i b e n t e n ~ v o n ~} \mathfrak{B}$ obel=

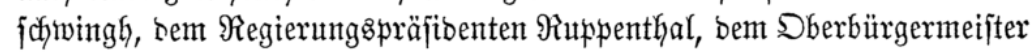
Steinberger unt bem Regierungårath Birf, nady Minben gebract, wo er bis auf $\mathfrak{W}$ eiteres internirt murbe."

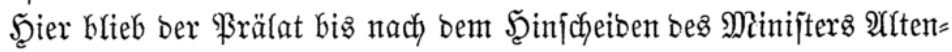

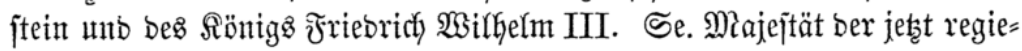

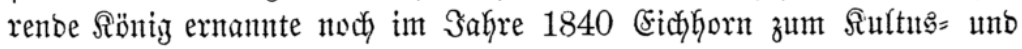

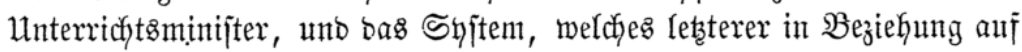

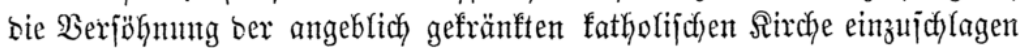

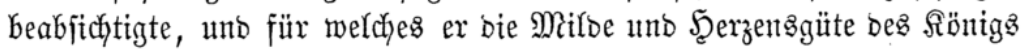
gemaun, gab fich fofort burch eine befanntmachung funb, welche er am 1. Sanuar 1841 erließ̄. Dicjelbe lautet:

„Se. Majejtät ber §önig, umjer affergnäbigiter Şerr, haben zu be=

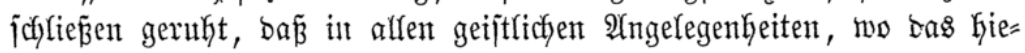

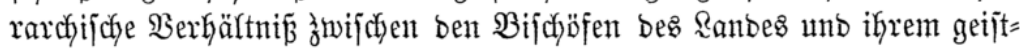

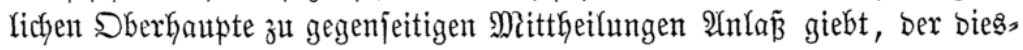
färfige Berfehr mit bem- römif̧den Stufle fortan frei von allen B̉efuränfungen ftattfinden fönne, uno bie Bermittelung beffelben

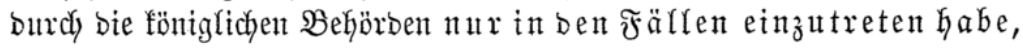
wo joldye von ben bijtÿfen ober bem römijchen Stugle jelbjt

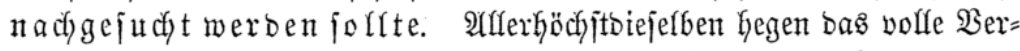

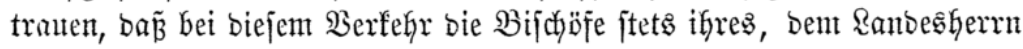
gereipteten Eibes ber Treut uno bes (Siehorjams eingesent jein, unb auth

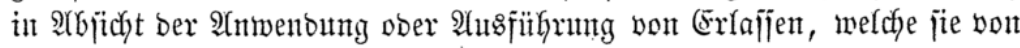

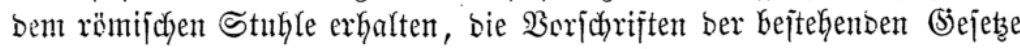

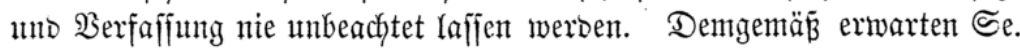
Majeftät von iłnen nicht nut bie jebesmalige $\mathfrak{A}$ nzeige von bem $\Im n=$ halte ber Saerhanblungen zwifyen ignen unb $\Re$ om, fonbern aud insbe=

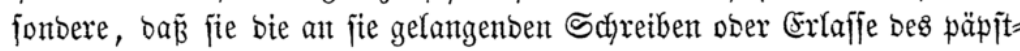

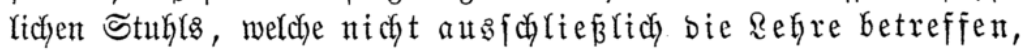
fonbern zugleidy ben Staat unts bie bürgerlidyen Berbältnifije, wenn auds nur mittelkar, Gerïfren, ofne bie vorangegangene 3ujtimumung ber welt= Cidjen Begörbe weber verfüntigen, nod) fonjt irgent in 2umenbung bringen.

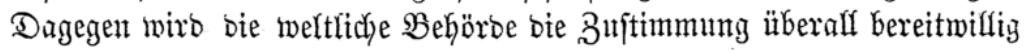


ertheiłen, wo bie Befaumtmadyung ober SYnwentung jener Sdyreibent uno

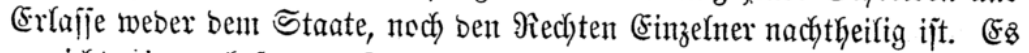

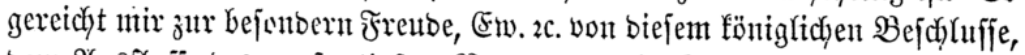

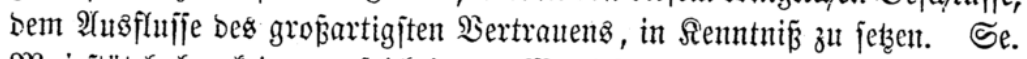

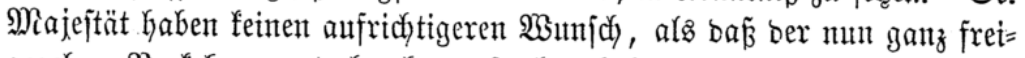

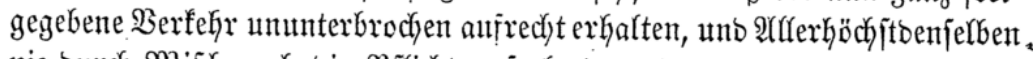

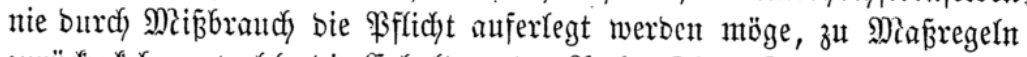

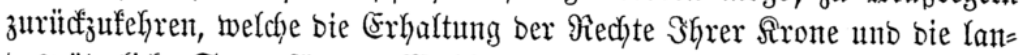

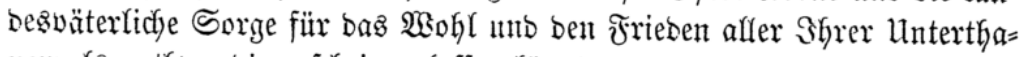
nen als notfhenbig erichcinen lafjen fönnte.

'Berlin, ben 1. Samuar 1841."

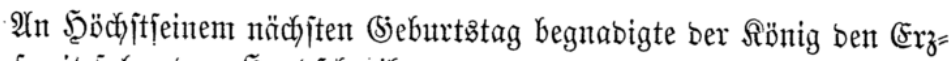
bijator mit folgentem $\mathfrak{S}$ andichreiben:

\section{Seodyüroiger Erzbifchof!}

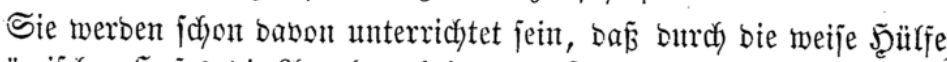

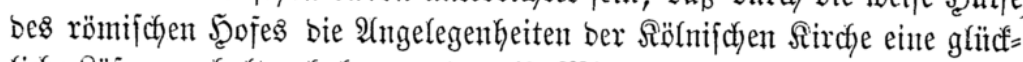

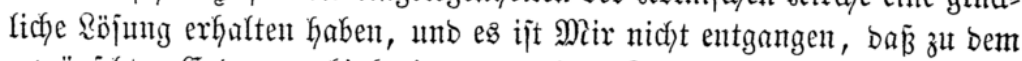
ermünjaten Enbe von bisherigen traurigen Sonfliften and Эhre Bereit=

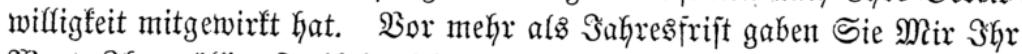

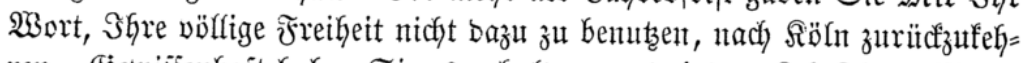

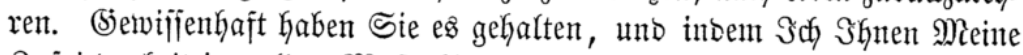

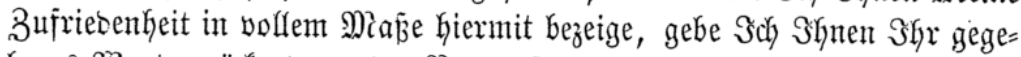

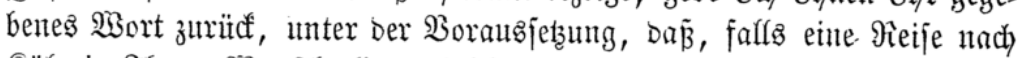

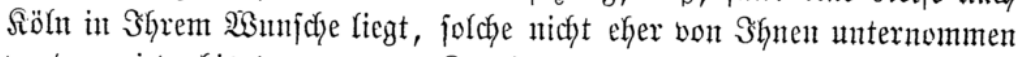
werben wiro, bis ber ernaumte Soabjutor bajelbjt eingetroffen ijt und bie

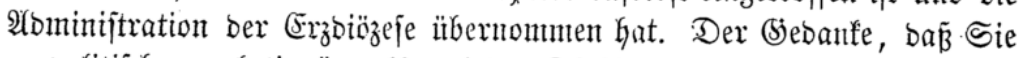

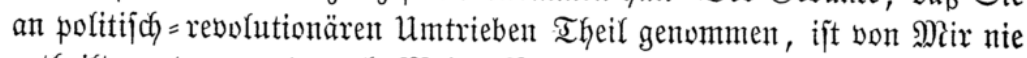
getfeilt worben, und auch Meine Beförben haben fchon frifher Beran=

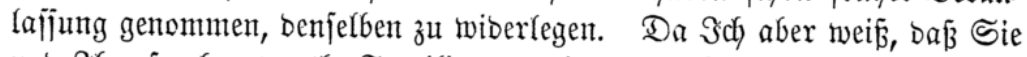

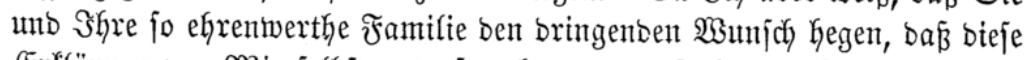

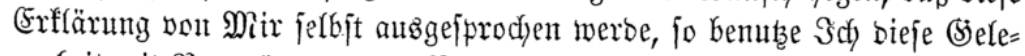

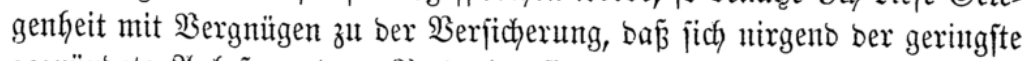

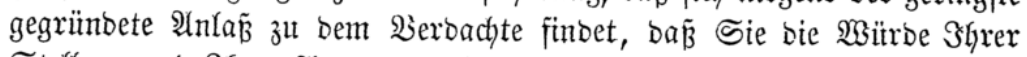

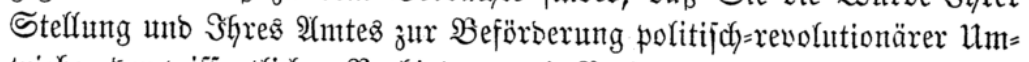
triebe ober wiffentlicken $\mathfrak{B}$ erbindung mit $\mathfrak{B}$ erjonen, bie foldje Brwecfe ver=

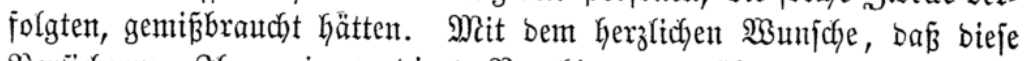

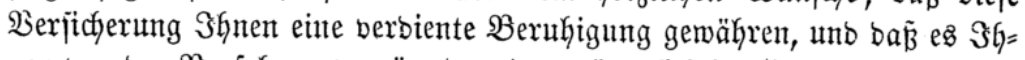
nen von ber Sorjehung vergönnt werbent möge, fich) im (\$enuffe eines ruhi= gen Alters bes wieberkergefteflten firchlichen Friebens noch lange zu 


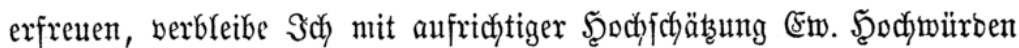
wohlgeneigter

Pareb, ben 15. Dftober 1841.

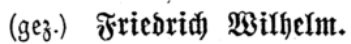

Die vollftänbige Beilegıng biejer $\mathfrak{2}$ ngelegenheit wurbe endlichy in ber Staatgzeitung vom 10. Samuar 1842 burd) nachjtehenbe offizielfe (Extflä= rung veröffentlicht:

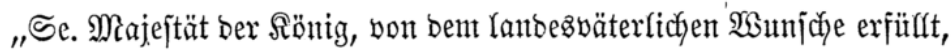

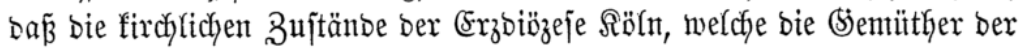

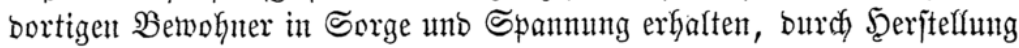

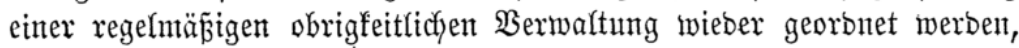

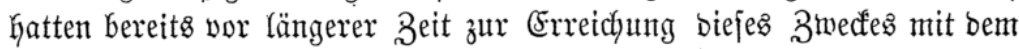
päpiftlichen Stuble Unterhanblungen anfnitpfen laffen. Durch gegenjei= tiges $\mathfrak{B}$ ertranen geförbert, haken bieje Unterhanblungen sas gemünjd)

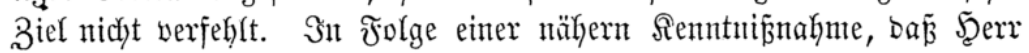

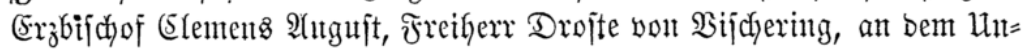

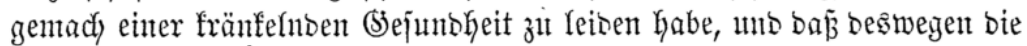

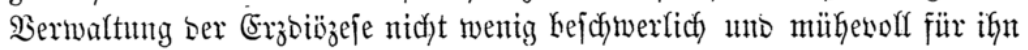

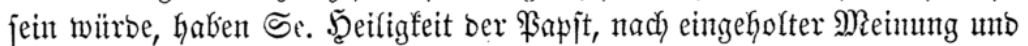

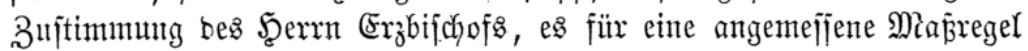

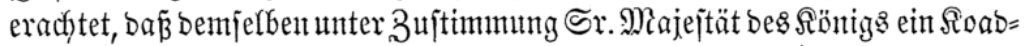

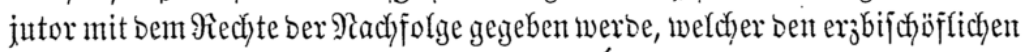
Sprentgel, fraft apojtolifłher Sollntadyt, zú verwalten habe. Demgemän

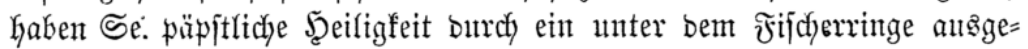
ftelltes Breve vom 24. September v. S., fraft apojtolifcher Machtwoll= fommenheit, bent Bifchof von Speyer, J̦ern Sohannes von Sseif̧el, ber wegen ber einfidytazolfen, bes alfgemeinen Sertrautens jich exfreuenten

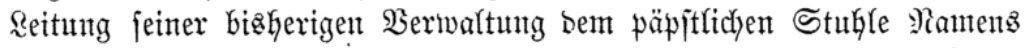

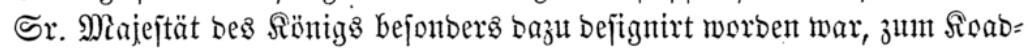

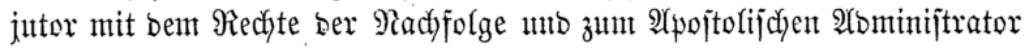
Der Exbiözeje Sïln mit alfen uno jeben nothwentigen und angemejienten

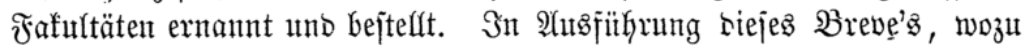

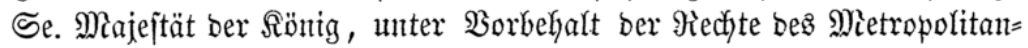

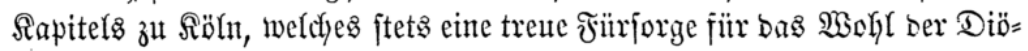

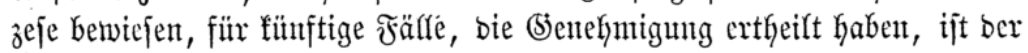

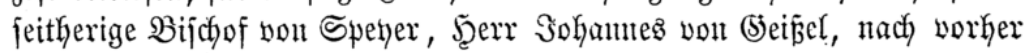

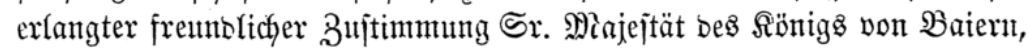

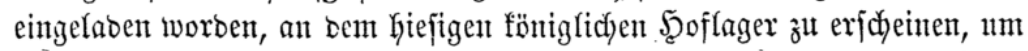

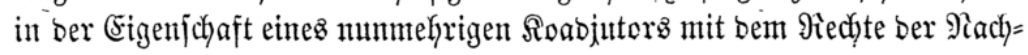




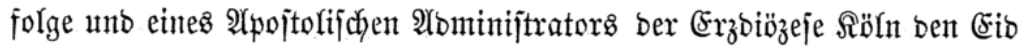
Der Treue unb Unterthänigfeit zu Keif́ten. Diejer Einlabung forgent, ijt

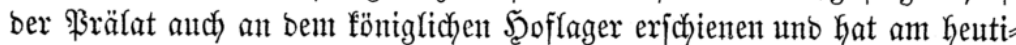

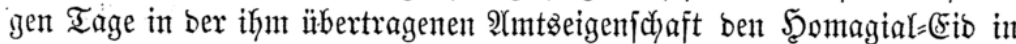

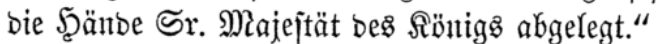

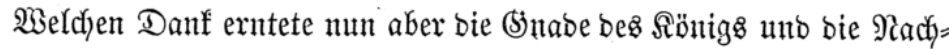

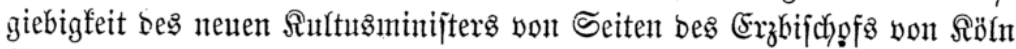

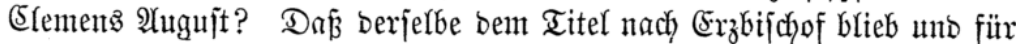
bie Dauter jeines Rebents burch einen Roabjutor vertreten wurbe, war

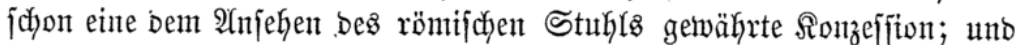
eş mag auch inmerhin angemeffen erjcheinen, wenn ber \$rälat ivährend feines zurütfigezogenen Rebens in Minben fich mit ber 2 Atzarbeitung einer

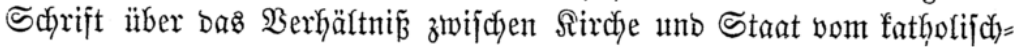

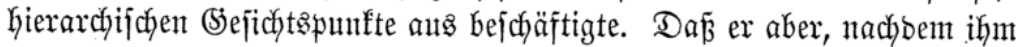

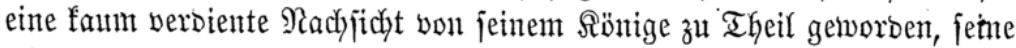

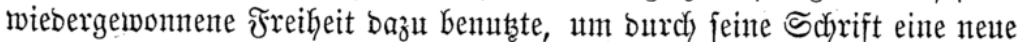

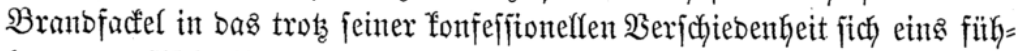

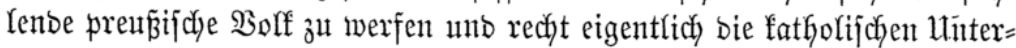

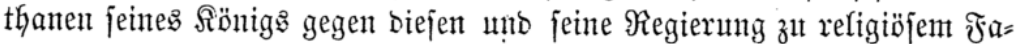
natisnus aufjuftacheln, wirft entweber auf ben perfönlichen (5harafter bes

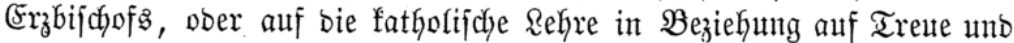

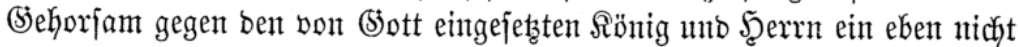
günjtiges Richt.

Diefe Schrift, welche ben Titel füfrt: „Iteber ben Frieben inter ber

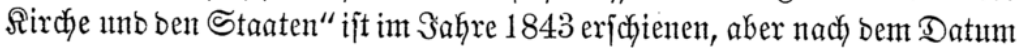

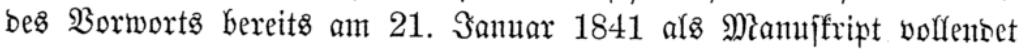

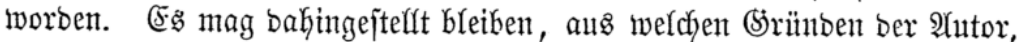

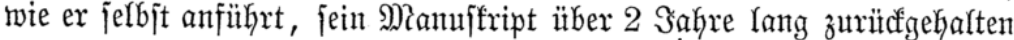

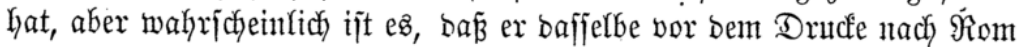

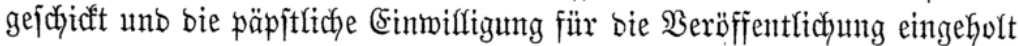

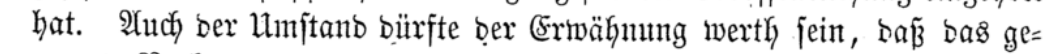
nannte $\mathfrak{B u d}$, um ber für Sdyriften von nidyt über 20 B̉ògen bamalz ge=

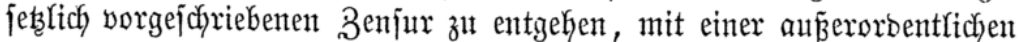
Raumberfdywentung gebructét unb baburch auf 20 Bogen unt eine Seite

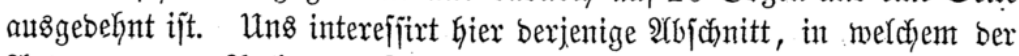

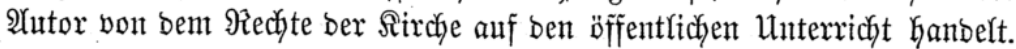

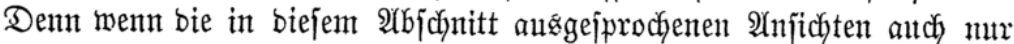
ben geringîten (Exfolg für fịch geminnen follten, bann ift es um bie Sntelfi=

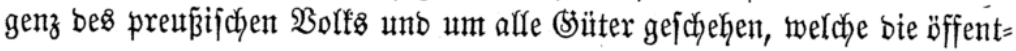




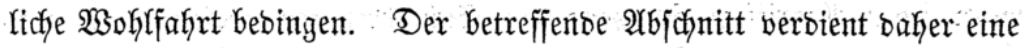
volrjtänbige Mittfjeilung. Er lautet:

VIII.

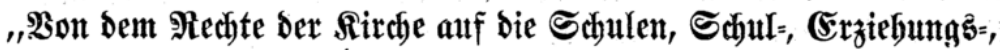 Billoungs = $\mathfrak{A n}$ italten.}

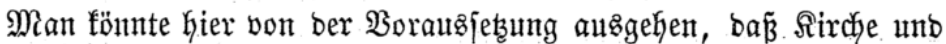

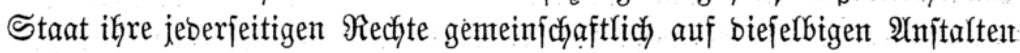

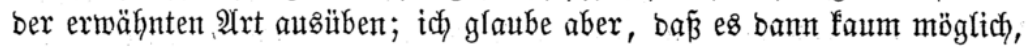
vbgleich umumgänglich nöthig jein mürbe, ben jebem Theile zufommenben

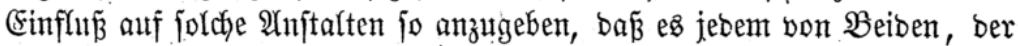
Sirche fowohl alz bem Staate, genïgen mürbe, und es würbe in praxi, weil bann ein gemifdyter Einfluß j itattfinben würbe, mehr ober weniger bie

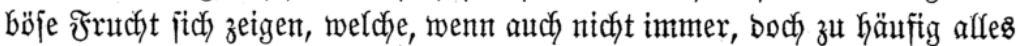
(S)emifuste -

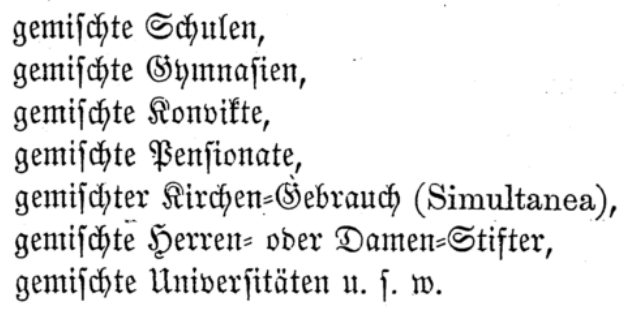

gemifudte Schulen, gemifobte (symunafien, gemifichte Sionvifte, gemifdyte Benjionate, gemifd)ter (irchen=(S)ebrauch) (Simultanea),

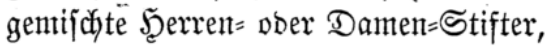
gemifichte Uniberjitäten u. j. w.

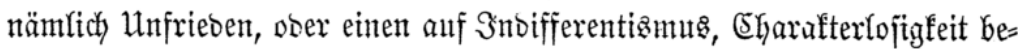

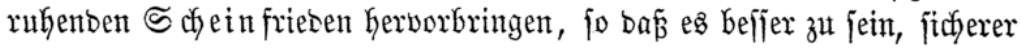

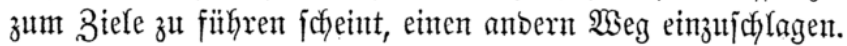

$\Im$ Gh habe nämrich bie Heberzeugung gewonnen, eine Heberzengung, bie fich mehr into mehr in mir befejtiget, bã hier riicht bie srage jei, twel=

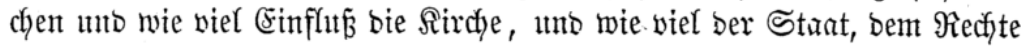

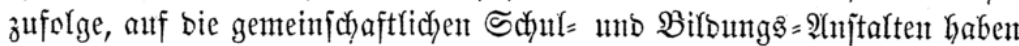

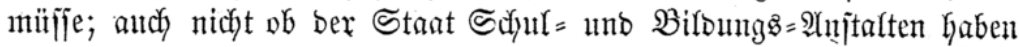
fönte, fonbern baf es auf bie Röpung ber Frage anfomme: ob nidjt aud

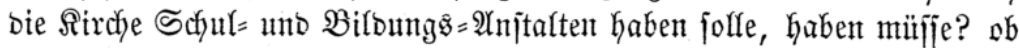

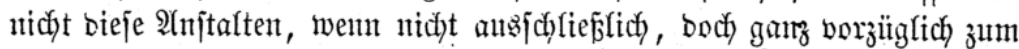
Bereiche ber Sirche gehören. Wir mitffen hier bie $\mathfrak{B} e$ jtimmung, ben $\mathfrak{B} e=$ ruf ber Sirdye, uno bie Beftimmung, ben Beruf ber Staaten erwägent uno

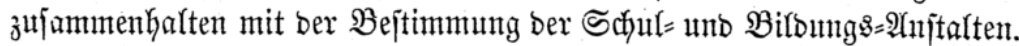

Die von \$ott angeorbnete Bejtimmung ber gefeffigen Berbinbungen unter Menjchen, bie wir Staaten nemen, ift offenbar bie: bas Recfyt, bie äuß

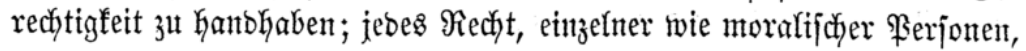




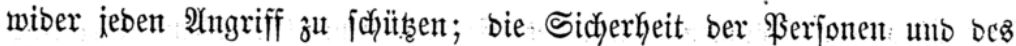
Eigenthums zut wahren; bas friedlide 3 ujammenfeben ber Unterthanen und

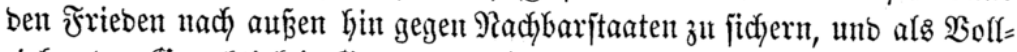

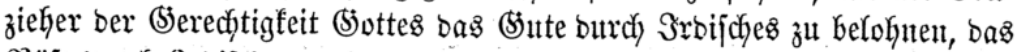
B̧öfe burch Srbijches zut bejtrafen.

Mir jayeint in biejer Bejtimuiutig ber Staaten ber Beruf, fich ben

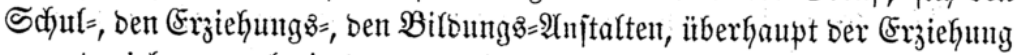
zu unterzieken, auch ein bazu zegebenter Âftrag nicht zu liegen; inbeffen fönnen wir, wenn man will, bấ bie Staatsgenalt auth unmittelbar uno

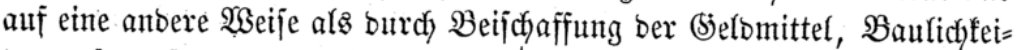
ten it. f. w. jorge, bas bafingejteflt jein lajjen. Die Kier zu beantwortente Frage ijt nidyt: ob uno intwiefern bem Stante bie Erziełung obliege, fon= bern in weldyem Berbältniffe bie Sdyule, bie Sdyul=, Erziehungş=, $\mathfrak{B} i l=$ Dungas=20njtalten zutr Sirche itehen.

Die アirche hat ganz eigentlich ben Beruf, bie Mienfdy heit zu erziehen,

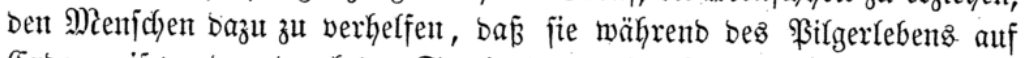
Erben reif werben, burch ben Tod in bas ewige Reben, in bie himmlifiche Seligfeit hineingeboren $3^{11}$ werben - bazu alfein ift bas Reben bes Mien=

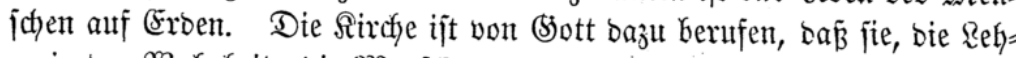

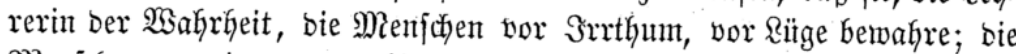
Menjajen von innen, wohin bie Staatzgewalt nicjt reichet, bie Reiben=

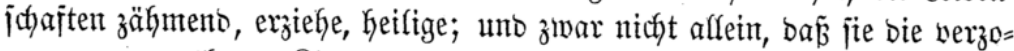
genen, ungerathenen Sinber wieber zuredyt bringe, jonbern jie zu bewo.hren,

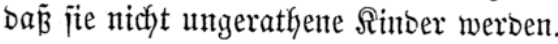

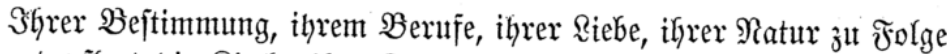
hegt unb pflegt bie Sirche ifye Sinber von ifprer Steburt an bis in oen Tob, bá fie vor jebem Schaben, vor jebem Srrthum, vor Unjittlichfeit,

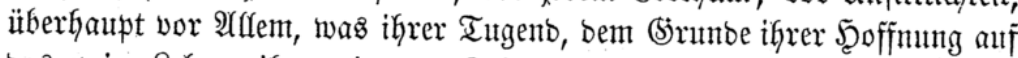
bas emige Reben, ifrem inneren Frieben, bem Frieben ber Seele. (jefahr

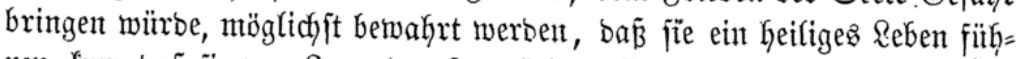

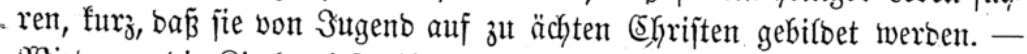
Wiro mun bie Rirche biejer ifrer Alufgabe gentïgen fömnen, wenn fie nicht

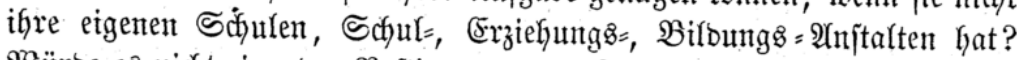

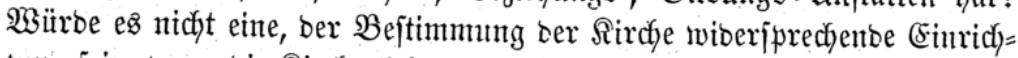

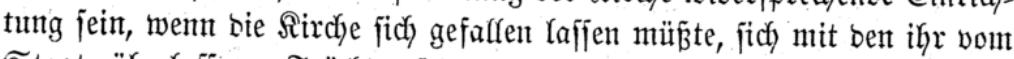
Staate überlaffenen Früdften jeines Erziehung =\$Baumes zu genügen.

(Stehent wir jeboch ein wentig in's Einzelne.

Die (5ymnajien und Broghmnafien faffe ich beibe unter bie Bezeidyung (5) mmajien zuammen. 


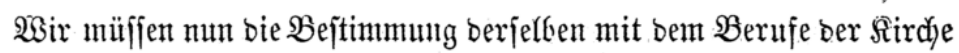
zujammen halten, um zut verjutchen, ob wir jenen, weldhe bie Simmnafien

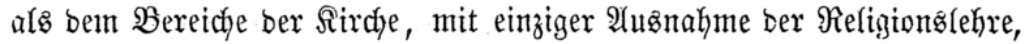
fremb, unb aflez Uebrige als bem Staate angehärent anjehen eine anbere Heberzengung beibringen fönnen.

Die (5ymmajial=Sdyüler haben noch fein bejtimmtes Fady, nody feinen

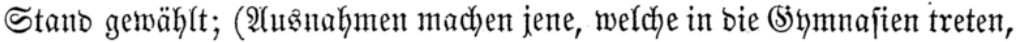
um nur einige Sdfuten mitzumachen, bann aber zu irgent einem (5emerbe

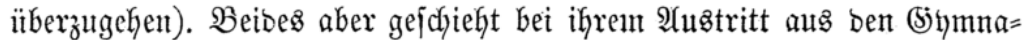

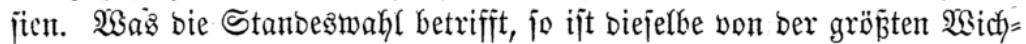
tigfeit, ba von ber Stanbesmafhl wohl ganz vorzüglich bas zettlidje $\mathfrak{W o h l}$

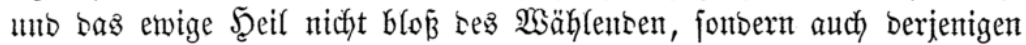
abgängt, mit welchen ber $\mathfrak{w a ̈ h l e n b e ~ b u r c h ~ j e i n e ~ S t a n b e s ł w a h l ~ w a ̈ h r e n t ~}$ jeines Rebens in bejonbere Berüfrung fommen wirb. Âd, oenfe id,

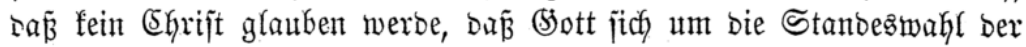

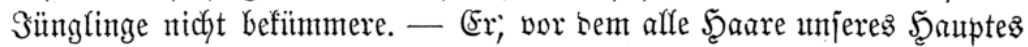
gezählet, find - Er, ohne befien $\mathfrak{B i l l e n}$ fein Sperling vom Dache fällt.

Die Sünglinge müjīen baker in ben Siłmnafien jo gebilset werben,

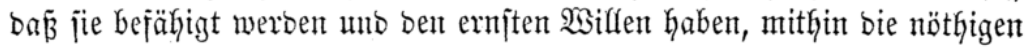
Mittel anwenben, zu erfennen, zu meldyen Stanbe fie bon \$jott berufen

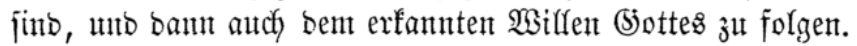

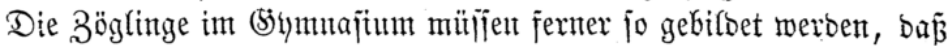
jie befähiget merben, ben mit bem gemählten ober ju mählcnben Stanbe

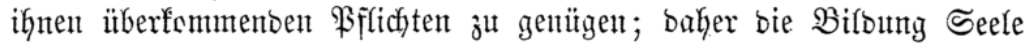

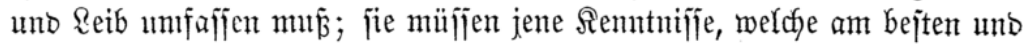
leidytejten in bem noch jugendficfen âter erlernt merben unto jebem, weldyen Stand immer er wählen möge, nütsen, erlernen. Die B̉iloung

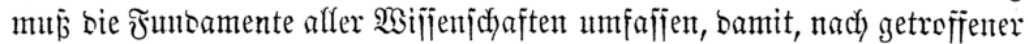

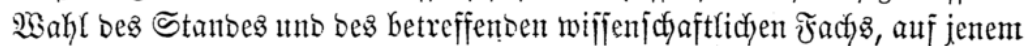
Funbamente fönne fortgebant iverben.

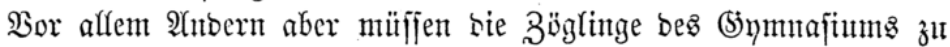
guten (5hrijten gebilbet werben; benn jonjt ijt alles nicht aflein unnübs,

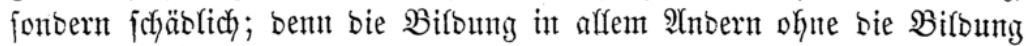
zum gutten (Éfriften madyt ben Mienfdyen zun (Sift ber Mitmenfichen.

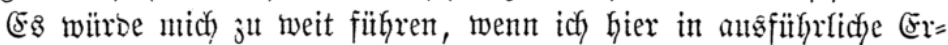
örterungen mich eitllaffen wolite; jeboch mur id bemerfen:

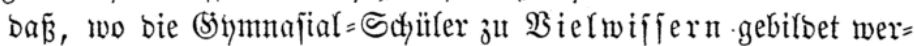

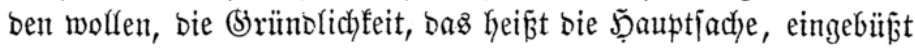
wiro, uno fie afferfei lernen, weldes fie nachber gar nidyt ge= brautchen fönnen; unb biejenigen, idy mag wohl jagen, wentigen 
jutngen Reute, weldye bie Strünolidyfeit mit bem $\mathfrak{B i e f ( w i f j e n ~ z u ~ v e r = ~}$ binten bas Talent haben, leicht bie Biejunbheit bes Rörperz ein=

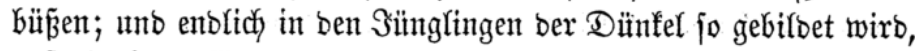
ba⿱ zu fein, alz alfe YYtnbern, unb glauben, fie feien mit bem Rernen fertig, ba boch baz eigentliche Rernen erit bann anfängt, unt eben was fie am meiften in ber \$ymmajialzeit zu erlernen haben,

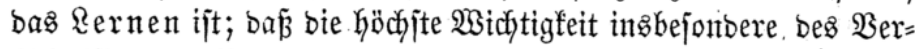

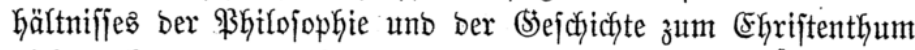

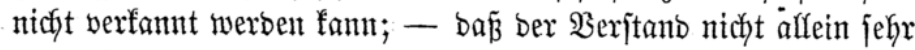
grïnolich unt jefr fonjequent benfen, jonbern anth jajweigen lernen müfffe.

Wenn wir nut bie eben angebeutete Beftimmung ber (5ymnajien mit bem Berufe ber ßirche - ben ganzen Menjchen zu erziehen zum guten

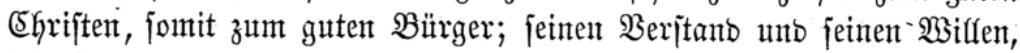

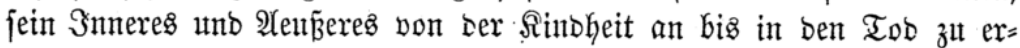
zieken, zu bilben - zujammenhalten, bann glaube idy, bie Forberung ber

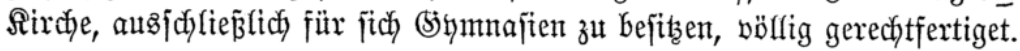

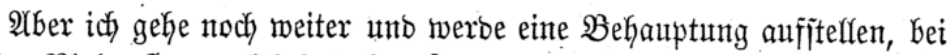
welcher $\mathfrak{B}$ ieler Şaare jich jträuben, 'weldje $\mathfrak{B}$ iele alz ein enormez $\mathfrak{P a r a}=$

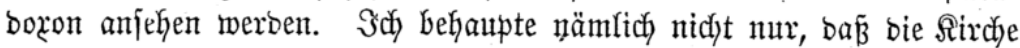

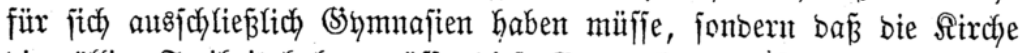

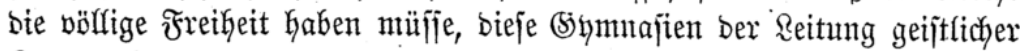

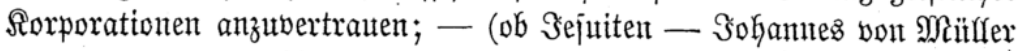

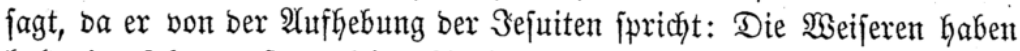

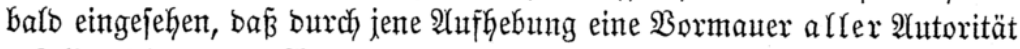
gefaffen fei - ober Anbere, barauf fömmt es fier nicht an) - ja idy be $=$

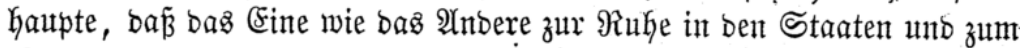

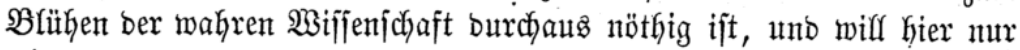
bemerfen, bá bäflige Sorgenfreiłeit in Beziehung auf bie Bebürfniffe Des Rebenż Der Regel nach conditio sine qua non ijt,

Damit fich einer ganz ber Wijfenjchaft, ober überhaupt jeinem Fache mibme - nicht Menjchen zu gefalfen, baker ifrer Berfehrtheit zu

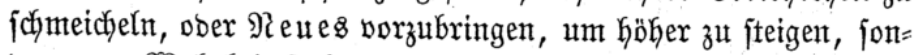
bern nur $\mathfrak{W a h r h e i t}$ fuche uno lehre; - bieje conditio sine qua non finbet in gut eingeridjteten Sorporationen ftatt.

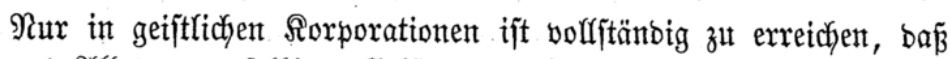

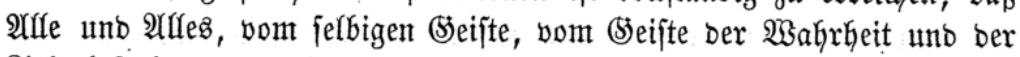

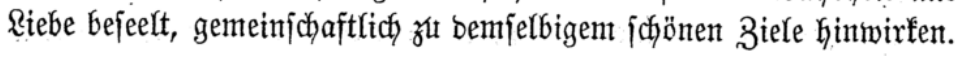




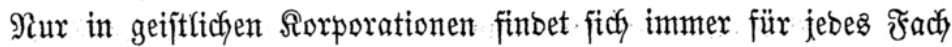

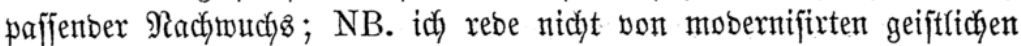

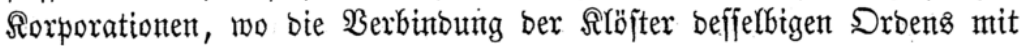
einanber und mit ifrem seneral nicht mefr jtattfinben joul.

Der Fladjheit unjerer Beit zu Siebe will id nur nod anfübren, baß̧ vermittelfyt geiftliçer Sorporationen mehr, aber mit viel wentger Rojten $=\mathfrak{A} u \mathfrak{f}$ wanb, erzielt : wirb - unt wenbe mich zu ben

Univerjitäten. Die Univerjitäten find für Sünglinge beftimmt, berent Erziehung, joviel antbere Menjohen bazu thun fönten, als fajt boll=

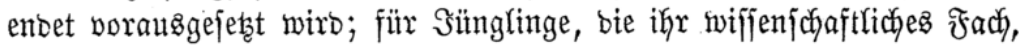
bem von ihnen getwähltent Berufe gemäß̈, gemählt haben.

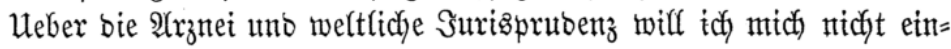

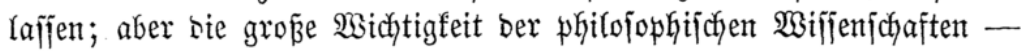

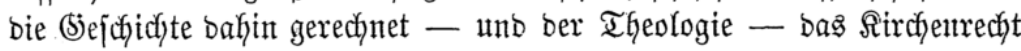

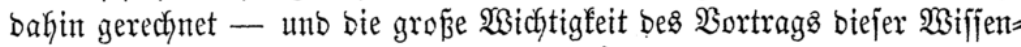

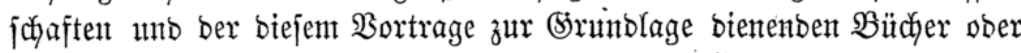

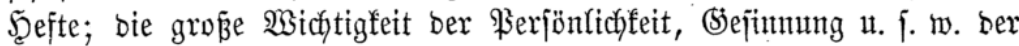
Srofeffioren und Rehrer und bes Eurators ber Univerjität, unb ber Sta

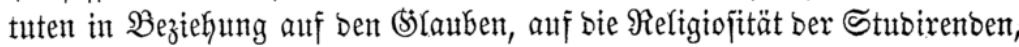

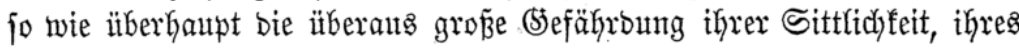

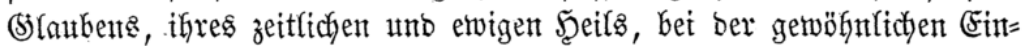

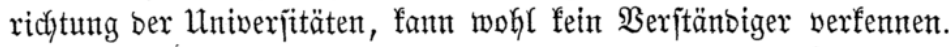

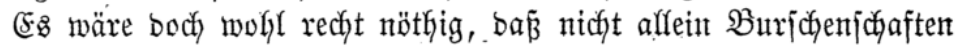
und was ben Staat, bas irbifche 930 bht in (5)efahr bringt, fonbern nebjt

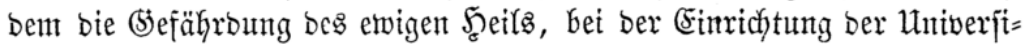

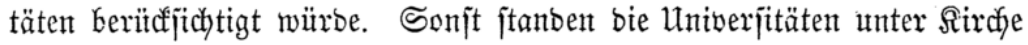

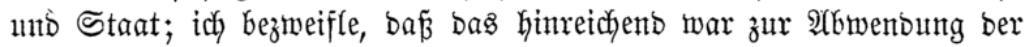

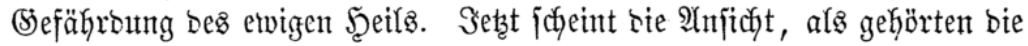

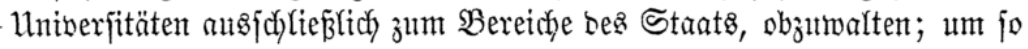

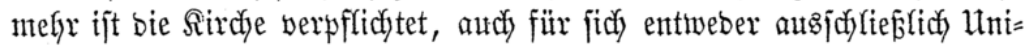
berijitäten zu reflamiren, ober wentigitens in Beziefung auf 2 (rfes, was bas envige Sceil gefähyrbet, ober bemt emigen Feile frommet.

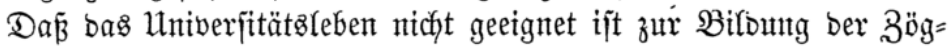

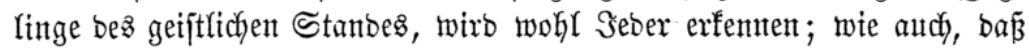
es bazıt nothwendig ber Seminarient bebïrfe.

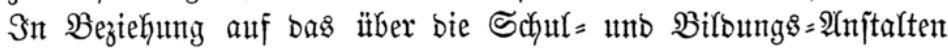

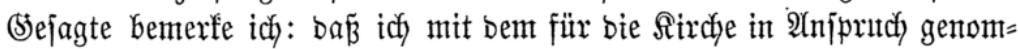

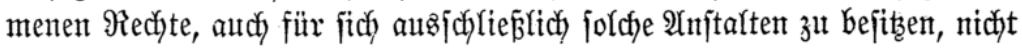

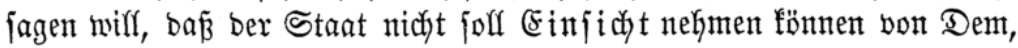

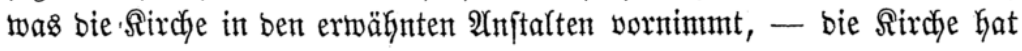




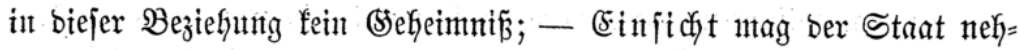
nten, aber nidyt 2ufficidst, nidyt Bormutnofdyaft.

Obgreidy bie Seminarien unter bie Bilbungs=29njtalten geförent, uno aljo feinem bejonbern 2lrtifel anzugehören jueinen, jo ijt boch biejer (s)egent=

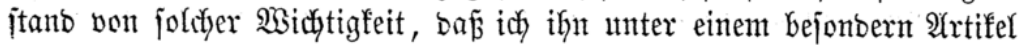
behantole."

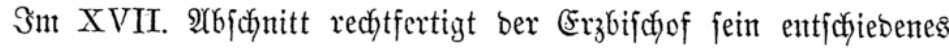

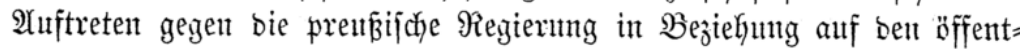
fichen Unterridyt, inoem er - natïrlich won jeinem Stantbunfte aus auf bie in ber friilyeren weltridyen (sefetzgebung anerfanten fiechte ber

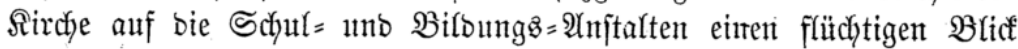
wirft. Ex jagt:

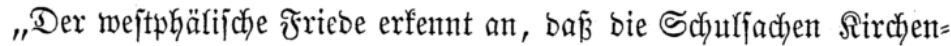
Untgelegentheit fint; bas heiṕt, er erfennt bas Bejtehente, was er vorfanb, ant, was er nicht berfennen fonnte.

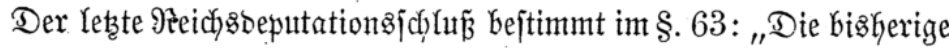

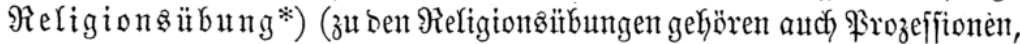
Walffahrten, b̈ffentliches $\mathfrak{B}$ erjehen ber Iranfen, säutent) eines jebent Ran=

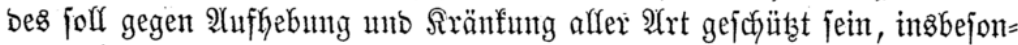

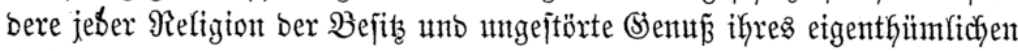

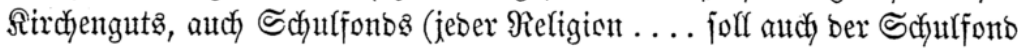

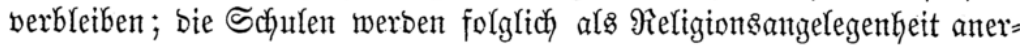
fant), nacty ber Borjanrift bes wejtphälifchen Friebens verbreiben. Dem

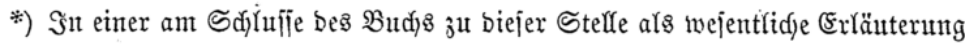

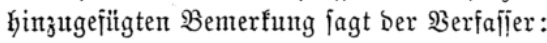

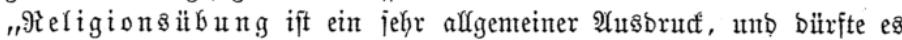
Biele geben, weldje barunter irrig mur ïfientlid)e, eigentlid, gottessienftlid genannte Şanblungen verítehen, - was in beziehung auj bieje, im $23 i b e r=$

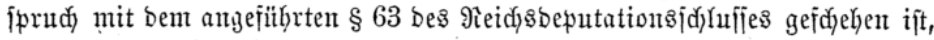
wiff idy hier nidyt weiter erörtern; aber gehört nidyt bie trene (5rfülfung ber

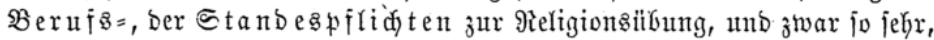

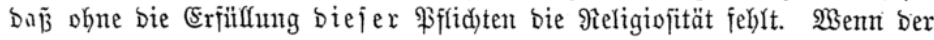

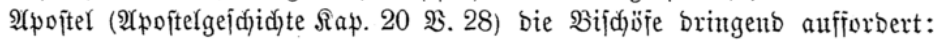
Attendite vobis et universo gregi, in quo vos Spiritus Sanctus posuit episcopos regere Ecclesiam Dei, quam acquisivit sanguine suo, fo gebört Dod) zuverläfifig

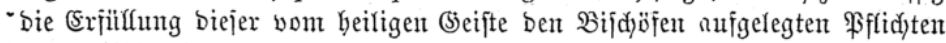

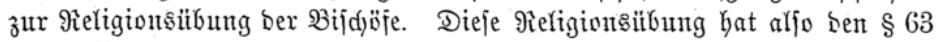

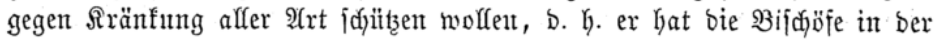

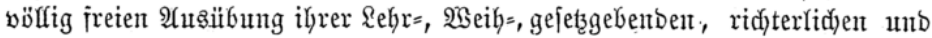

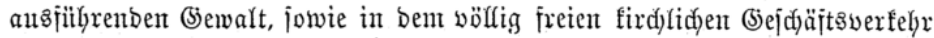

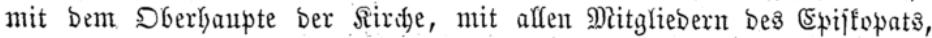

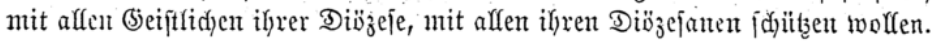




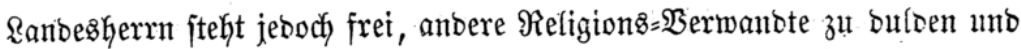

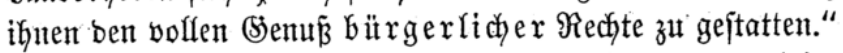

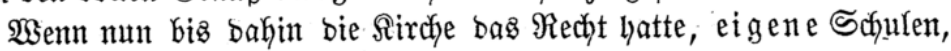
Schul= uno Bilbungganjtalten, nebit ben bazu gehörigen Fonbs zu haben,

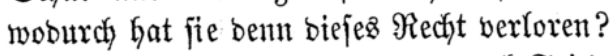

(5twa burch 2(btretungen, burch) Friebens = Schliujpe, bei welchen bie Sirche nicht gefragt worben, ober gegen weldhe fie protejtirt hat? Die pazifizirenben Theife founten bod wohl nicht abgeben ober abtreten, was fie nidht hatten? Doer etwa nach Dem (Eroberungarecht? Sönten aber wohl Rechte erobert werben, bie nidyt ba fino? Sonnte Bonaparte bergleidhen erobern unb baum abgeben? Âud) nimmt bie Staatagewalt ferkitrebento

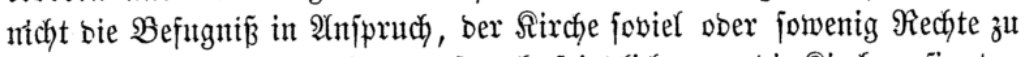
laffen ober zu nehmen, als ben sft redyt feindlich gegen bie Sirche gefinnten (s)elehrten gut bünfet?

Man wiro mir vielfeidyt hier worwerfen, idy ftreite, wie ber befaunte

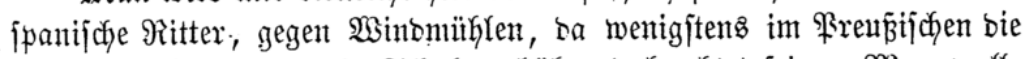
Rechte ber Sirche auf bie Sifule gebühyrento beadytet feient. Man wolle mir aber, ba ber (\$)egenjtant won ber höchjten Wisthtigfeit ijt unb, wie mir icheint, nidyt gehörig beachtet wiro, erlauben zu bemerfen, baś, wenigitens

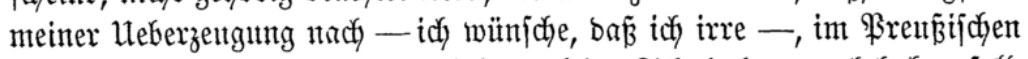

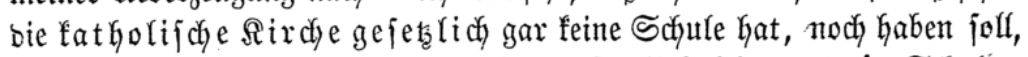
ba in \$rensen, nady meiner $\mathfrak{A n j i d y t , ~ g e j e t z l i d y ~ f e i n e ~ a n b e r n ~ S d y u t e n t , ~}$

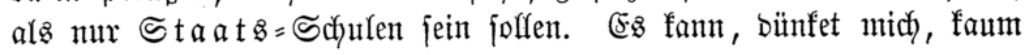
flaver, alz

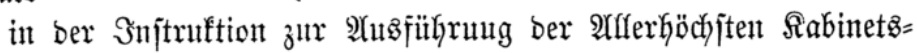
Orbre vom 16. Sunt 1834, bie Beauffichtigung ber \$rivatichuten,

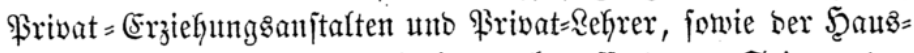
rebrer, Erzieher unto Ergieheriment betreffend - Seitens bes

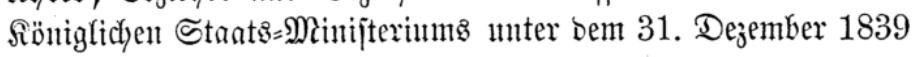
erlafien -

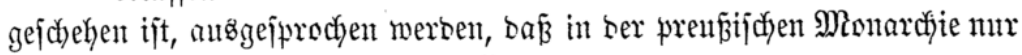

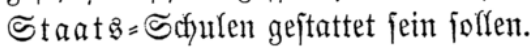

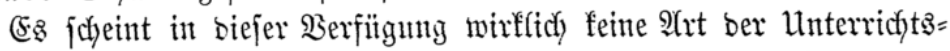

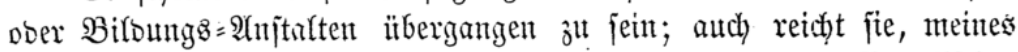

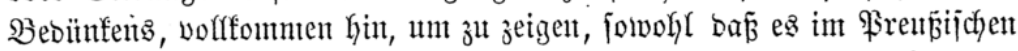
gar feine andern, als mur Staat $B=$ Sdhulen gebent folle, als auth umt jut

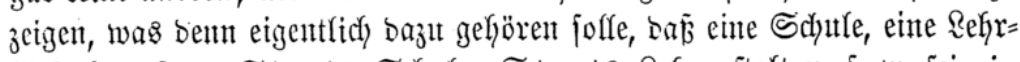

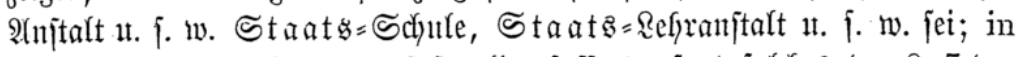
nuce, aber recht flar uno fajt allumfajfent, fagt joldyes ber $\$$. 7 ber erwähynten 3njtruftion; er fantet wïrtfich), nie folgt: 


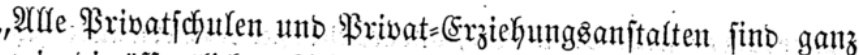
fo, wie bie öffentlichen Schutlen berjelben (Sattung, zunächjt ber

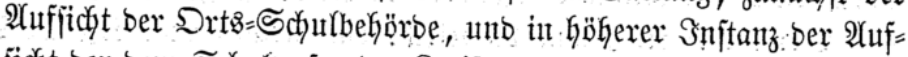

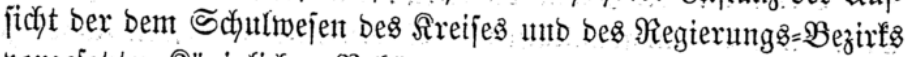

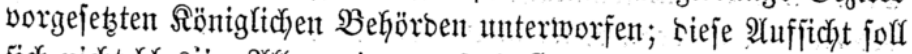

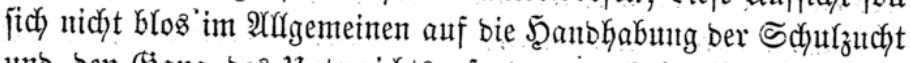
unb ben Stang bes Mnterrichts, fontern audy in Bejonbern auf bie (Eintchtung bes Rehriflans, bie Wahl ber Şüffalehrer, ber Rehrbücher unt Rehrmittel, bie Regrmethode, Schulgejeţe, bie : Zahl ber Ścjüler, unt jelbjt auf bas Rofale ber \$rivat= Schutent und Privat=Erziehungånitalten erjtredfen."

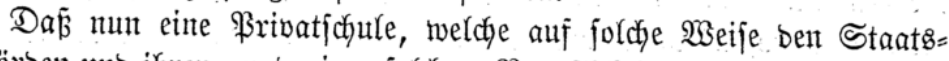

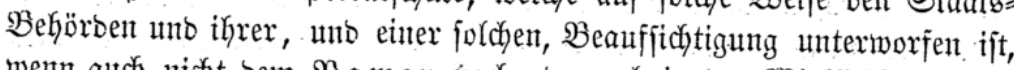
wenn audfy nidft bem $\Re$ a ment hady, bennoch in ber wirfficffeit in sie

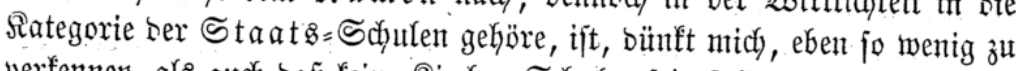

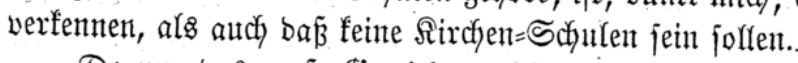

Da mul bas grof́e (Sjentidyt, welches bon Staatsinegen anf ben Befits bér fraglicyen Anjtalten gelegt wiro, unverfennbar ift, fo fant bas (5)ous= vernement unmöglich ber Sirche verübeln, bas aud fie eben fo groṕes

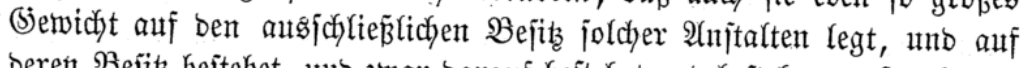

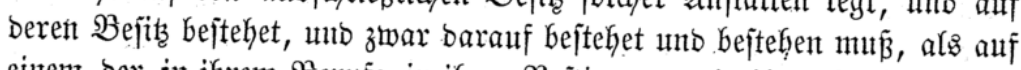
eintem ber in ihrem Berufe, in ifrer Bejtimmung, in ifyrer Selbjtitäntoig=

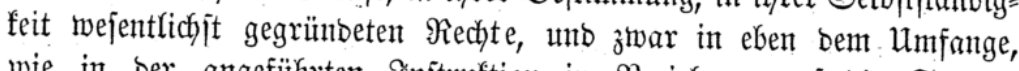
wie in ber angefïhrten Inftruftion in Beziehung auf bie Staats=

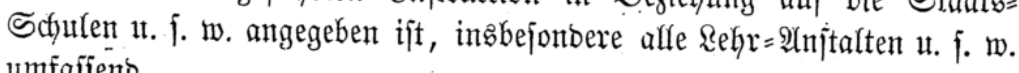
umfajpento.

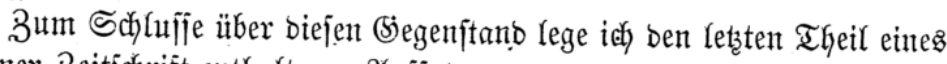

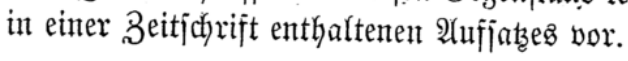

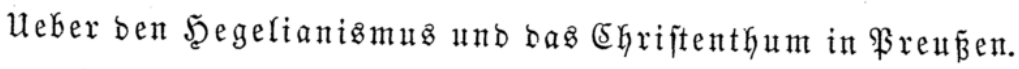

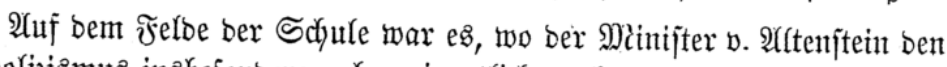

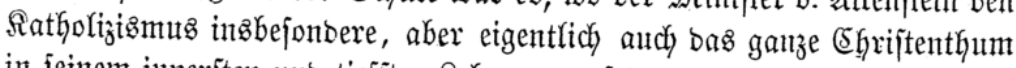
in jeinem innerjten und tiefïtent Reben zut zerfetzen unt zat vernidjten jtrebte.

(5r hatte fich nach und nach nidyt blos ber Univerjitäten, benn fiev bulbete er jebe Doftrin, jelbjt bie fatfolijdye, jonbern affer (Symmajien, högerer Schuten, entlich audy alfer nieberen Sdyulen in ber Stabt unt auf bem Ranbe böllig bemeijtert. Für bie geringite Dorffichule, wie für bas Symnafium, war ber Rehrplan genau vorgejdyrieben, bie Rehrbüdyer,

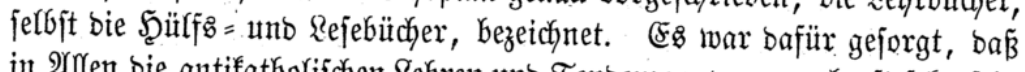
in 2 Wen bie antifatholifdjen rehren unb Tentenzen, wenn auth oft fehr fein 
verbectt, ausgefprochen unb verbreitet waren; aber nirgenos burfte besfalb ein offener $\mathfrak{A}$ ngriff gegen bie fatholifche Sirche ober bas (Shriftenthum workanben jein. Dabei war er jefr vorjichtig; fein alfgemeiner Rehrplaul für bie ganze Monardfie, nidyt ein= für affemal beftimmte Refrrbücher wurben vorgejdyreben, fonbern in jebem Regierungabezirfe war bies ver=

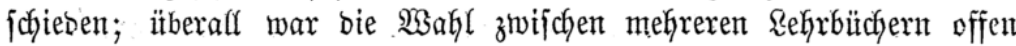

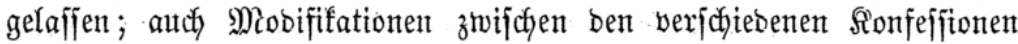
gejtellt. Mit Den Ratholifen waro sabei ungemein borjichtig verfahren; bie Speife twurbe jeben gereicht,-wie er fie eben vertragen fonnte.

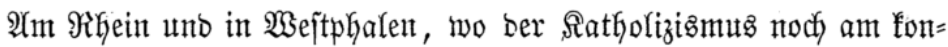

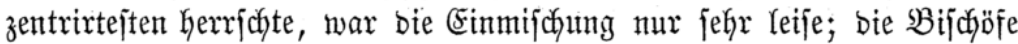
wurben befragt, ber Regrplan vorgelegt, nur burdh bie meltlidfen Piitanzen

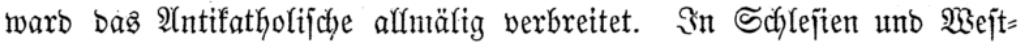
preußen ging man offener zu Werfe; eine Einmifdung ber Sirche in bie

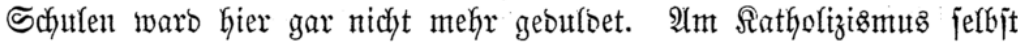
rïhrte man natïrlich nirgenos; aber pjeuto = fatholifdye Erbaumgs = uno

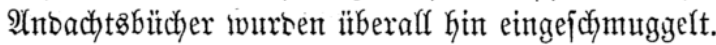

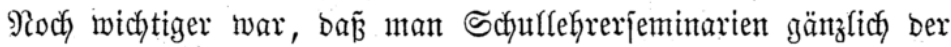

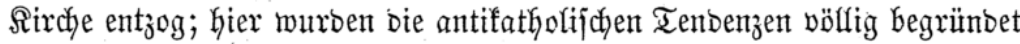
unt fejtgejteflt; won Gier atts verbreiteten jie jich als müntbliche Rehre, als mitnoliche Sommentare von viefleidyt jonjt unjdyuloigen uno nicht unfatho.

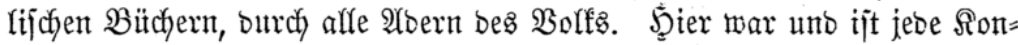

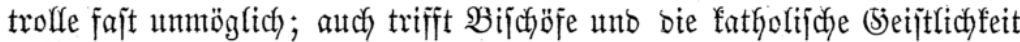

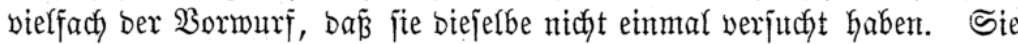

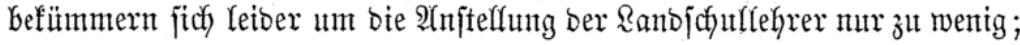
bet biejent aber ijt bie jogenannte Emanzipation bon ber Sirche eine fire

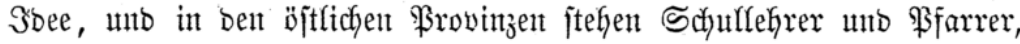
wenn fie nicht gerabe Beibe bie rationalijitifyent Simmpatfieen haben, fich häufig bireft in aflen Eintrirfungen entgegen. Den Rutheranern uno

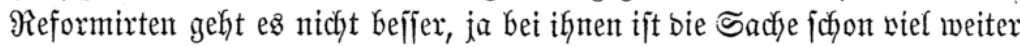

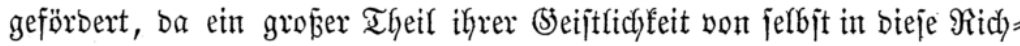
tungen feit lange eingegangent ift.

Rafjet uns nux bie Schule, jagte bas Minifterium Ât(tenjtein, bie Pracht eures äuñern Sottesobienjtes, eure äน

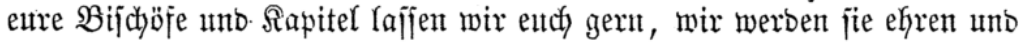

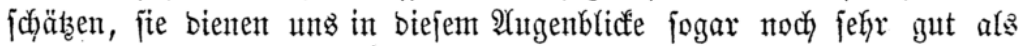
Dectmantèl unjere $\mathfrak{2}$ noronungen zut förbern, wir erfalten burch fie bie

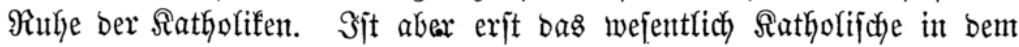

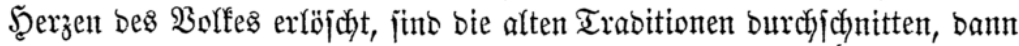




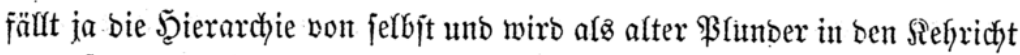
geworfen, um jertreten zlt werbell, ober Gÿdjitens unter ben übrigen Staats=

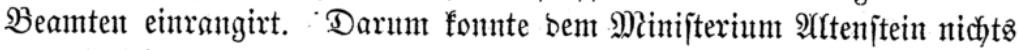
untermünffdter fommen, als, ber Streit über bie gemifdyten Ehen. Şier=

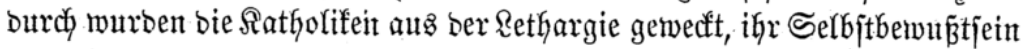
erwadyte, unb bas vorfichtig uno fein begrïnbete, fdyon halb aufgefiithrte (5ebäıtbe bes Şegeljchen Staaţ̧thums ijt auf einmal in Frage gejteflt. Darum fant ber Tod bes Minijters von Altenjtein im Sabre 1840 alferbings als ein bebeutentes, für Breunen provibentiefles Greignin ange= jekent werbent.

Wixb bas neue Minifterium in bemperben (5eijte und Sinne handeln, fo wirb ber $\mathbb{R}$ rieg anf Reben uno Tob mit ber

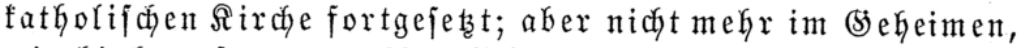
wie bisher, fonbern öfentlidy, benn bie Rathorifen miffen gegenwärtig fehr wohl, worauf es anfömmt, unb bie saien fajt nodbefjer als ber (Elerus. Uno jollte bas regententaus nid̆t einfehen, wie gefährlids es wäre, wenn bie fathorifde Rirdye im ßreufifden unterginge? Würbe nicht bie böllige ßer= jeţung bes \$rotejtantißnus unt fajt alles pojitiven Ehriftenthums bie

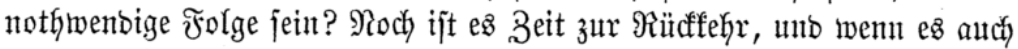

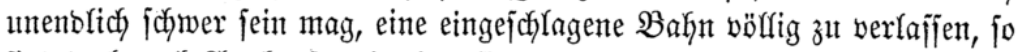

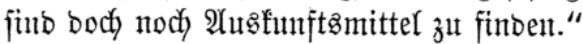

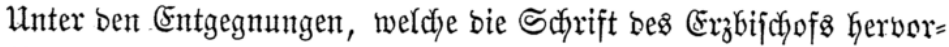

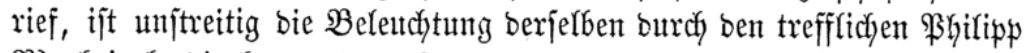
Markeinefe bie herborragentite unt umfaffendite. Sie befinbet fid in

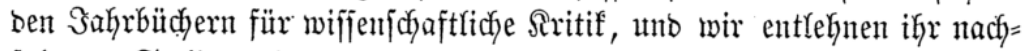

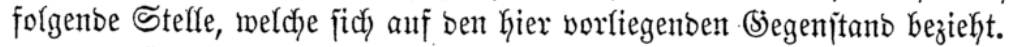

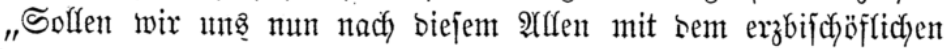

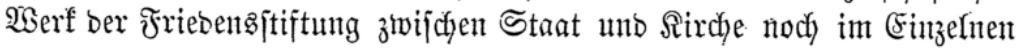

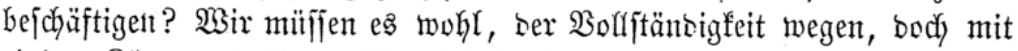

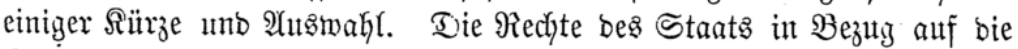

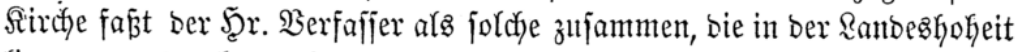
riegen unt burch bas jus circa sacra bejeiffnet finb. 2Allf bem Stant=

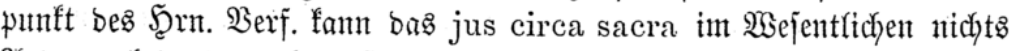

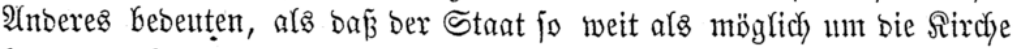

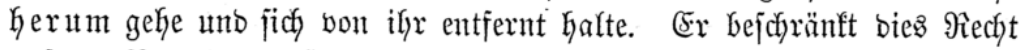

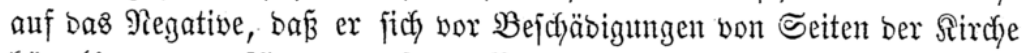
hüte (jus cavendi), unto auf bas \$ojitive, welches er aber nidyt jomohl

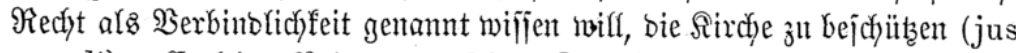
tuendi). (Ex̣ Leitet Beibes aus feiter Roorbination bes Staats uno ber 


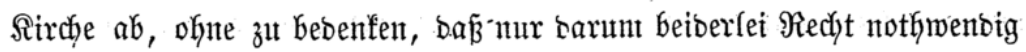
ift, weil bie Roorbination als biejes Yeere (S) Yeid)gemidyt, fo wie fie in's wirffiche Reben übergeht, und jidh gejdyidyttich erweifet, fofort in's Sdymant= fen geräth, bie Waagichale jich entweber nach ber einen, ober anbern Seite neigt, jomit als Soorbinatioit fidd aufhebt. Denn wenn fie eine wahre und wirffiche ober es (Ennjt mit ihr wäre, fo braudjte wahrlich ber Staat

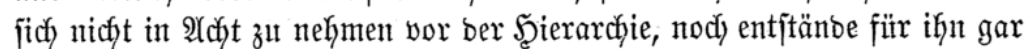

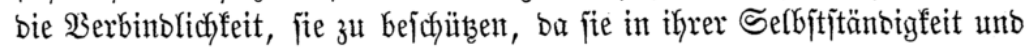
Unnbhängigfeit ohnehin genugfam im Stanbe ijt, jich felbjt zu vertheibigen

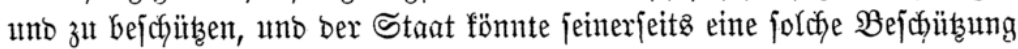
reidyt überfliiffitg madjen ourchy ein gerechtes Berhalten gegen bie Sirutye.

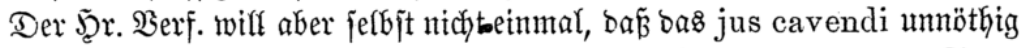
werbe, weil bies bịe Rirche in bie Unmöglichfeit jeţent mürbe, bem Staat zu juaben, unt jo aus ber Roorbination gleich wieber bie Suborbination unter bent Staat entjtänbe; aljo bie Miöglichfeit foll bleiben, aber bie Winffichfeit einer Bejđäbigung wiro als möglich gelentgnet, unt als joldbe Dinge, bie ben Staat gar nicht bejcjäbigen fömmen unb al: jolche

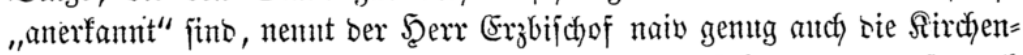
gejetze und bas Rirchentredyt. Sn Beziefung barauf fant unb barf, nad)

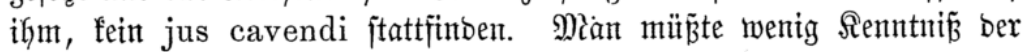

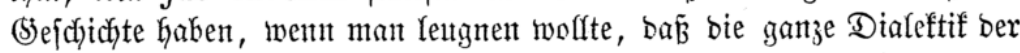

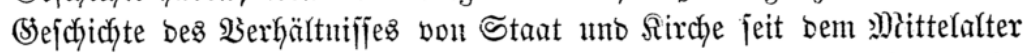

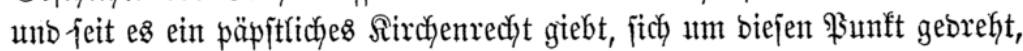
ber §lleruz gai viele Siejetze barin gemadyt hat, weldje mit jebem Staat, ber fich irgent felbjt begreift, unvereinbar fint, unb bie Notfmentigfeit eines jus cavendi von Seiten bes Staates Gimreichento motivirt haben.

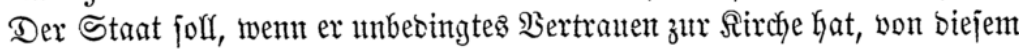

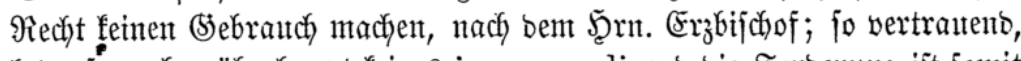
bebarf er aber itberkaupt feines jus cavendi uno bie forberung ift fomit eigentlich, er joll fich jorglos ber Disfretion ber Sirche iiberlaifen, utto

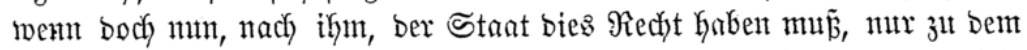

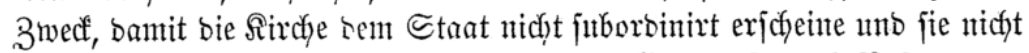

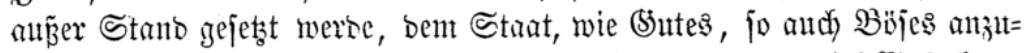
than (",wie wir Menfijen mun einmal jint,") fo wäre bas viel Einfachere,

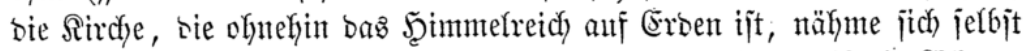

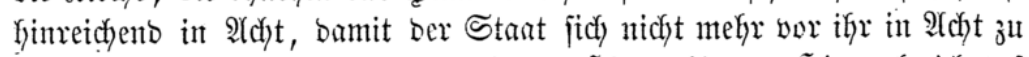

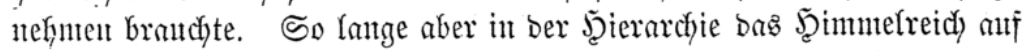
(Erbent noch nicht ganz evibent erfdyienen ijt, wirb mant bent Staat nicft verargen, wemt er es an ben nöthigen sirüfnuttionsmmafregefn nidyt fehlen

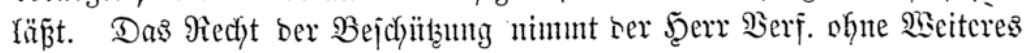


nurr als Serpflichtung bes Staats; ex führt aber nidyt bazu an, was bod

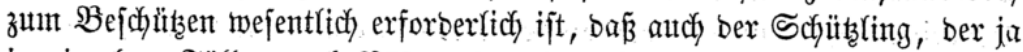
in einzelnen Färfen auth B̈öfes thun fann (,wie wir Menjchen mun ein= mal jino"), ftets in bent (Sränzent jeiter Befutgnifje breibe. Enolich, bamit

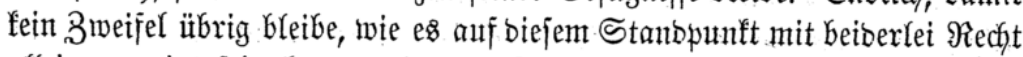
allein genteint fein fann, wirb ber Sirche, won wegen ber Soorbination,

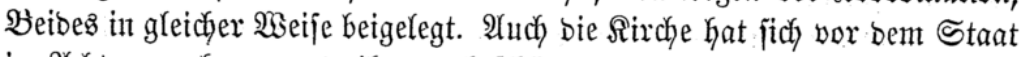

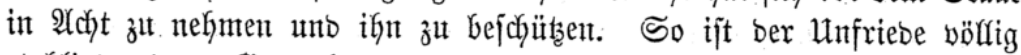
etablirt unt zur (5runblage bes Friebens gemacht. In ber Thut fam auf

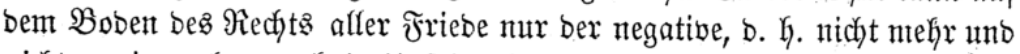

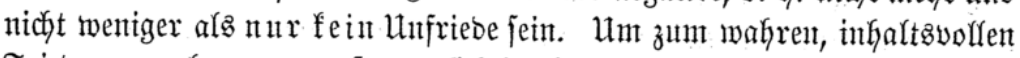

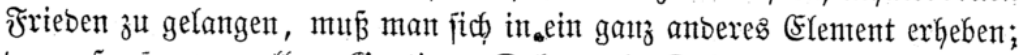
ba múz mä vor alfem (Siratians Defret, bie Defretalen (Gejonders bie falfyen), bie (Extravaganzent mo bas ganze corpus juris canonici bei Seite unt in Bergefjenbeit jtellen. Der Şerr Berf. geht weiter in feiner

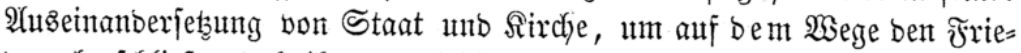

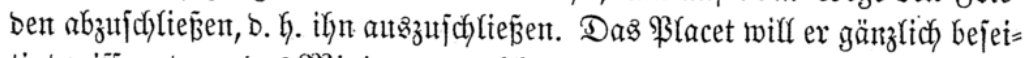
tigt mifijen; benu bas Mininum, welches er bavon zu(äpt, ijt nicht ber 9iebe werth. 2Auf bem (5runbe feiner Soorbination frägt er fogar: ob nicht aus bent

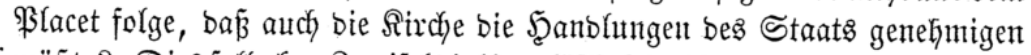

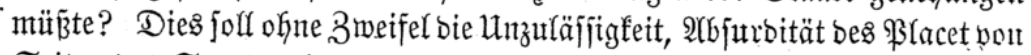
Seiten bezs Staatz zeigen; es zeigt aber zugleich, was uno wie viel ein

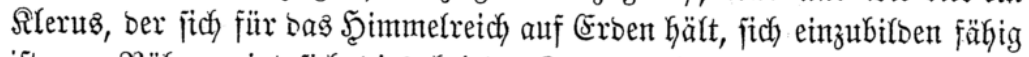
ijt. - Räher zeigt fid bies bei ber frage: wie es mit ben Sdyut= und

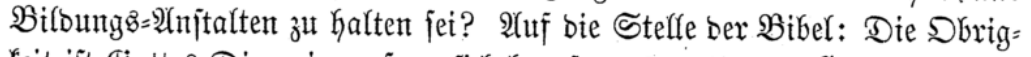

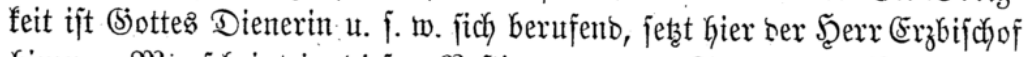
Ginzu: ,Mir fcheint in siejer Befitimmung ber Staaten ber Beruf, fich

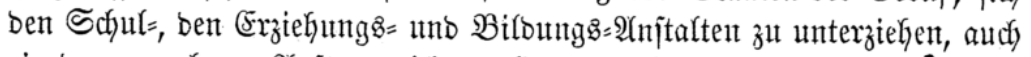

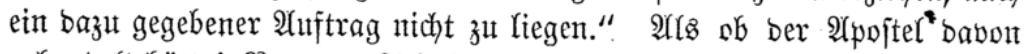

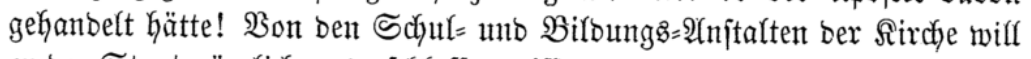
er ben Staat gänzlich auşgefdyloffent wifjen, unb was er weiter will, merft

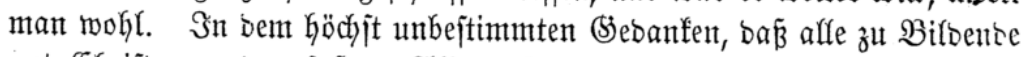

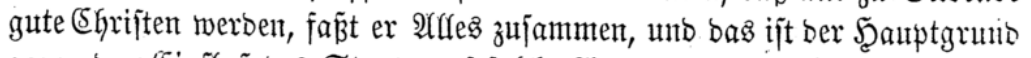

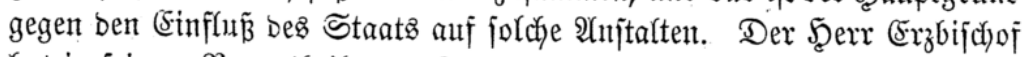
hat in feinem Borurtheil vom Staat, als einem undyriftlichen, noch eine fcheinbare Berechtigung zut feinem $\mathfrak{M r t h}$ eil. (Ex hat aber aud in ber pro=

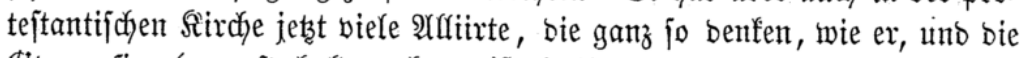

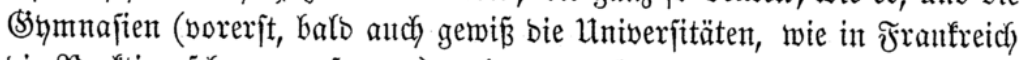
bie Reaftion fidyon angefangen), wie wenn fie bas bis jetzt nichyt gewejen

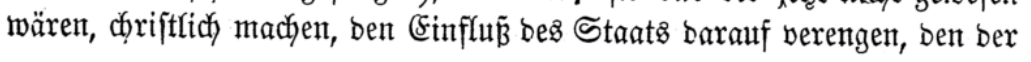




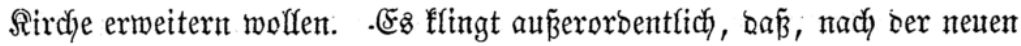
Theorie, ber Zwelf bes (5hriftenthums an ben 3ögfingen mur erreicht twer= ben foll unb nur fo erreidyt werben fann, bá bie Sirche jie in ihre Dbhut

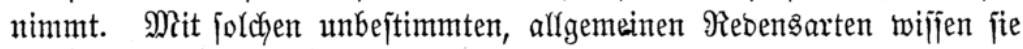
3t imtponiren; praftifich aber fommt es überaus fläglich) Geraus. Denn wiffen bieje audh, was überhautpt ber 3 wect bes Staats, was geiftige Frei=

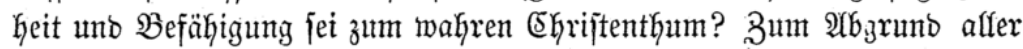
Bitloung uno (seifteşfreifeit wollen fie bas EGriftenthum machen uno bie= fen prachtooffen Ramen benutsen z̧ur Berbüfterung, zur Serbumpfung uno Serjumpfung bes \$eiftes. Sn bem unbejtimmten \$ebanfen bes ÇGrijten=

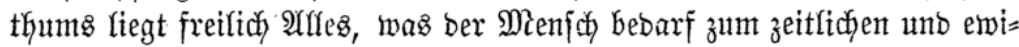

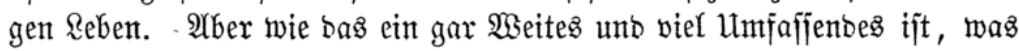

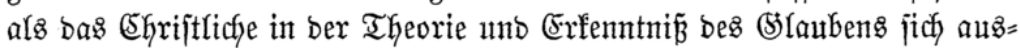
ejnanber zul legen hat, wo man nidjt mehr mit bem einfachen Namen bez

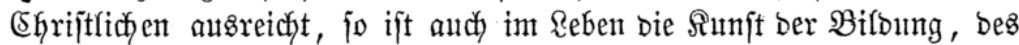

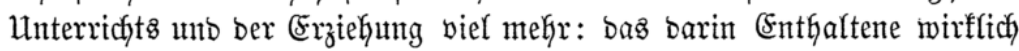

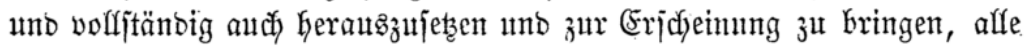
Elemente beffelben gehörig einanber unterğuronen, Mitter uno 3 weef in alfen Beziegungen zut unterfaceiben unb fo eine organifje (s)lieserung affer Bejtainbtheife eines wohlgeorbneten dyriftlichen Rebens zu erzengen, in ber

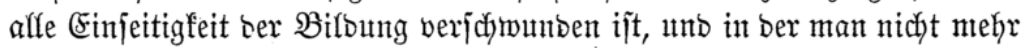
ras eine dyriftlidh, bas anbere und iibereinjitimmeno mit bent Şerrn Erzbijdyof benfen, einen großen Staat zu

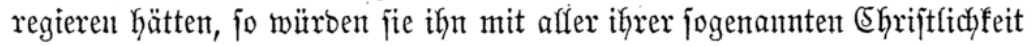
in furzer Seit fo herunterbringen, baj mur wenig noch won wahrer $\mathfrak{B i} i=$ Dung in ihm übrig bliebe, uno er in ben Sosmos bes eltropäifhen Staa=

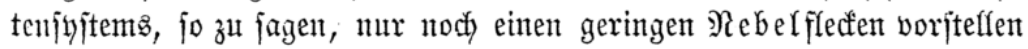
fönute.

Unifer Şerr SBerfaffer jtellt bei biejer Belegenheit eine Behauptung auf, bei ber, wie er felber fagt, Siełer Şaare fict jträıben werben, näm=

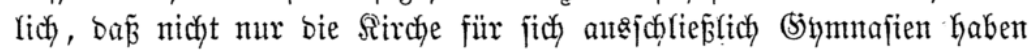
miiije (âs ob jie beren in preupijifyen Staat bisher nidyt gehabt hätte an

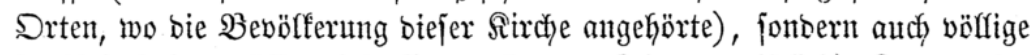
Jreikeit Kaben muiffe, biefe Ssymnafien ber Reitung geiftlicher Rorporatio=

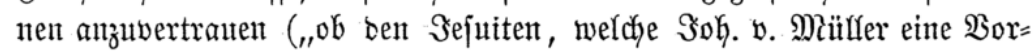

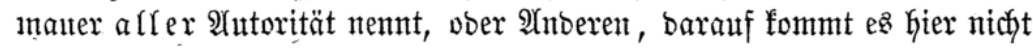
$\left.\mathfrak{a n}^{\prime \prime}\right)$. Wir fönnent barauf mur extwibern: wohl befomme es thr unt -

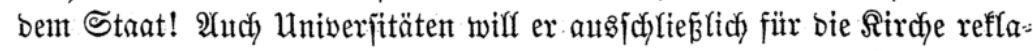

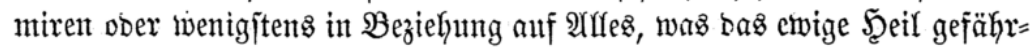

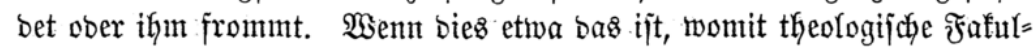




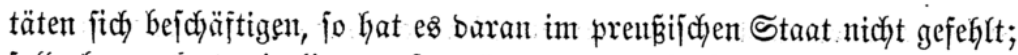
foll aber meljy barin liegen, fo würbe bas zugleich an Beiten erinnern, welche jetzt jujier alfgemein alz bie ber Barbarei gelten."

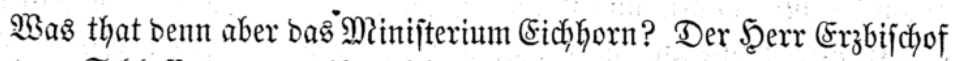

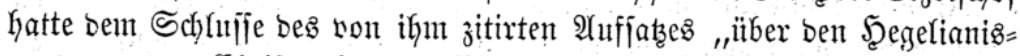

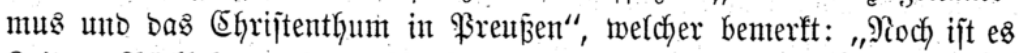

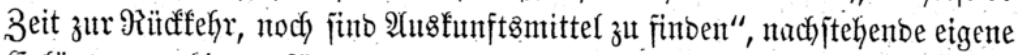
Erräuterung hinzugefügt:

"Ein ganz natïrlichés, Keichtes, sas bejte unt einzige gerechte

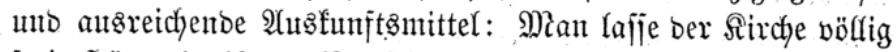

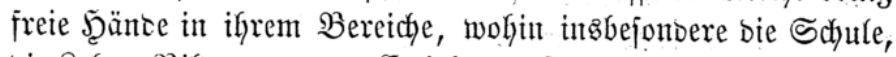

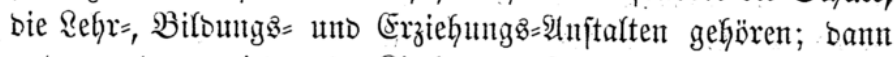
und nur bann wirb mter Sirche und Staut Friebe fein; bany unt nur baun wirb in ben Staaten Friebe fein; weir ber Friebe in ben Staaten auf ber (Sefinung ber Untertfanen be=

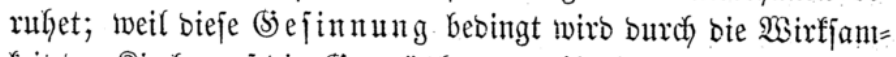

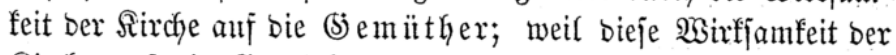
Sirche auf bie (s)emüther bebingt wirb burch bie Freikeit ber Sirche, bá jie jich in ifyrem Bereiche völlig frẹi bervegen fömne.

Sebes antere $\mathfrak{A}$ (to̊funftomittel beruhet mehr ober wentiger auf

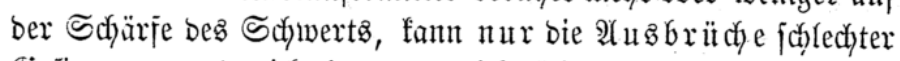
(5ejinnung, und nicht $i m m e x$, nidyt überall unb nur auf eite

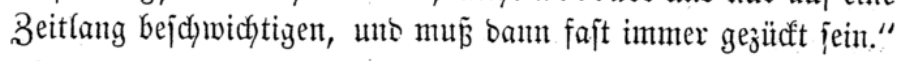

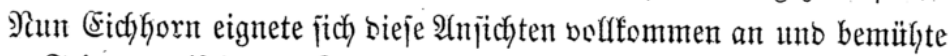

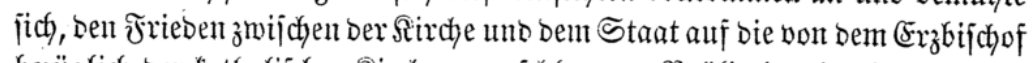

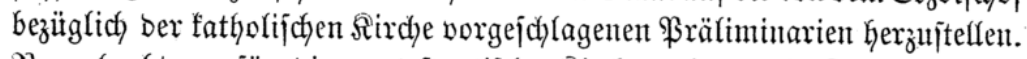
ঐur glaubte er für bie protejtantijche Sirtche, bie er als Sultusminifter 子u leiten hatte, biejelben günjtigen Bebingungen verlangen zu bürfen. Die

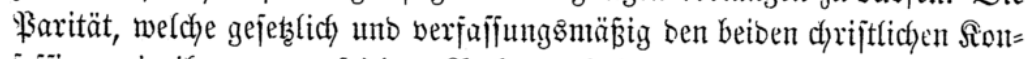

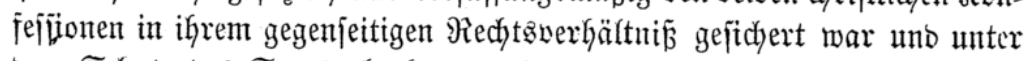
Dem Sđhukze bez Stautżoberfauptes jtano, verwanbelte er in eine $\mathfrak{B a r i t a ̈ t}$

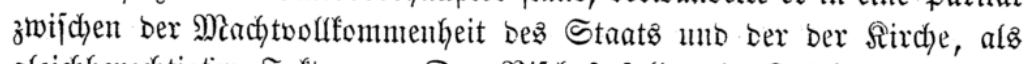

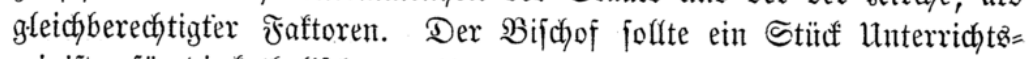

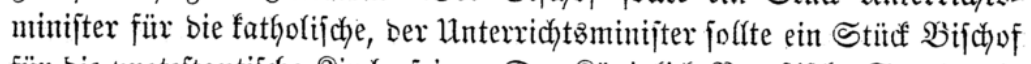

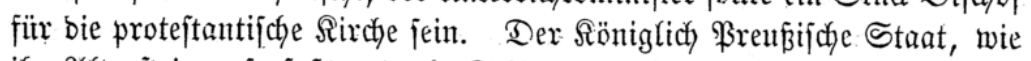

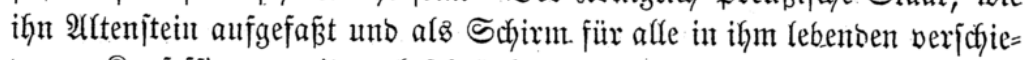
Denen ßonfeffionen mit unbejdyänfter Souveränetät auggerïjtet Katte, follte nady (Eid)horits Snjtem ein dyrijtlicher Staat merben, in melchem bie beiben dyriftlichen Sonfeffionen auf (5runt ihres gefdyloffenen Friebens 


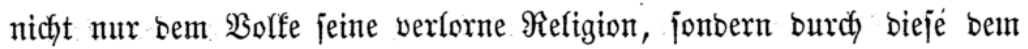
fï̈nig jein verlornes Bolf wiebergeben jollten.

Der $\mathfrak{W e g}$, ben er babei einjalug, uno bie Mittel, bie er zur (Errei=

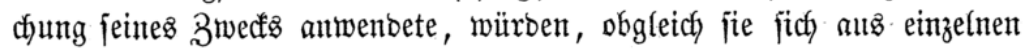

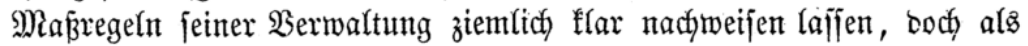

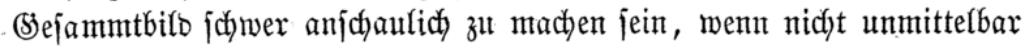

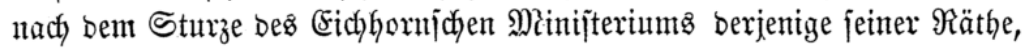
Dem er jeine Sntentionen unverkohlen mitgetheilt, uno ben er mit ben be= treffenten $\mathfrak{A}$ (uzarbeitungen vorzugsimeije betraut hatte, barïber einen aus: reichenbent $\mathfrak{A}_{4}$

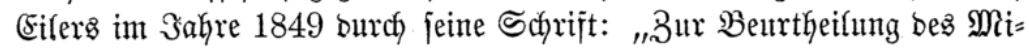
nijteriums Eichborn" gefchehen, soer wir bie unjern Begenjtand betreffen=

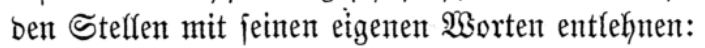

"(5) (eich nach ber Hebernahme bes Minijteriums bejchäftigte jich ber

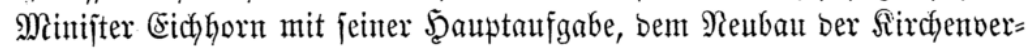
fajfung. Die Buverjicht, weldje ein reformatorifchez Unternehmen von jo

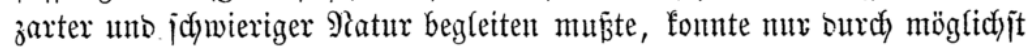

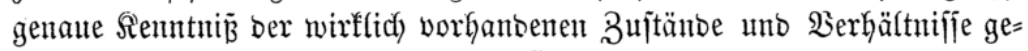
wonnent werben. Err Yegte baher bie Şanb nicht an's Werf ofne vorker

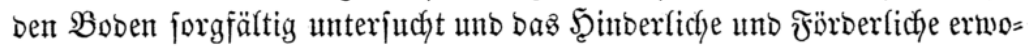
gen zu haben." (1. c. S. 67.)

, Neben ber Seerridyajt ber theologifdyen Shjiteme jener Beitphilojo=

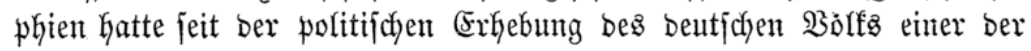

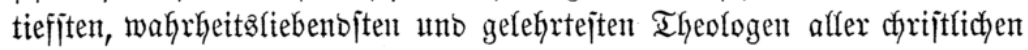

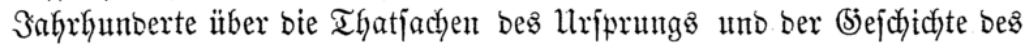
(5hrijtenthums ein \&idjt verbreitet, welches ben (Silautben an (Shrijtum auth) in ber gebilbeten $\mathfrak{B e l t}$ von ber Schmady ber Thorheit bejreite unb biejeni=

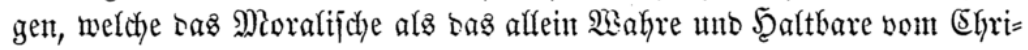
jtenthum abgeftreift, bas Uebrige ber Serad)tung preisgegeben hatten,

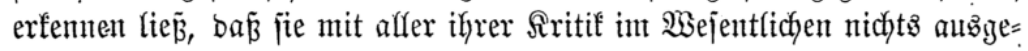
ridftet hatten. Şand in Şanb mit biejem tieferen refigiöfen, von feinent fonfeffionelfen ober bogmatifchen Borurtheile befangenen, (S)eijte fird)en=

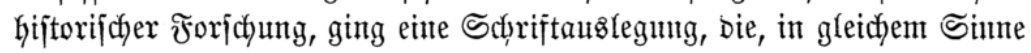

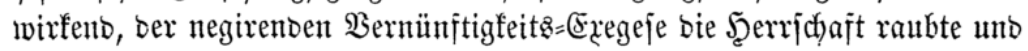
ber Theologie bes pojitiven dyriftlidfen (S) aubens ifren guten (5rumb nad)= wies. Îtn bieje fo geläuterten uno auf's 9eue betwährten theologijd)en

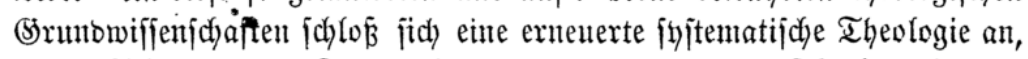
beren Schöpfer uno Träger balo bie vorkerridtenden Theologenbiloner wurben, welche auf bem ganzen (sebiete ber evangelifdyen Sirche eine Aluto= rität gewanmen, wie bie negirenten theologifchen \$otenzen jie nie gehabt. 
Der: Minifter Eichborn war ber Meinung, bạ biejer, bie ßhitojophie

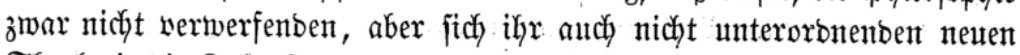
Theologie bie 3 ufunft ber evangelifdien $\Re$ irche gehöre, unb biefelbe baker,

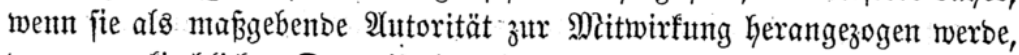
ber neuten firchlichen Drganifation eine bauterbafte theologifdye Srunblage geben werbe. Die Şautptmänner biejer Ridftung glänzten bereits auf

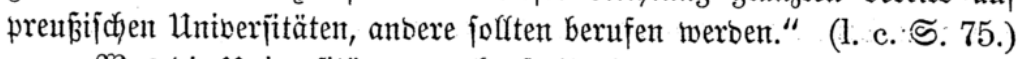

,'Was bie Univerfitäten angeht, fo ijt eine ber wid)tigitent $\mathfrak{A}$ ngelegen= heiten bie Bejeţung ber zur Errebigung fommenten Rebritühle. Die ge=

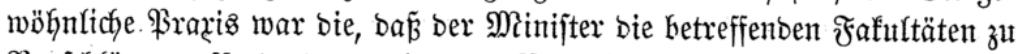

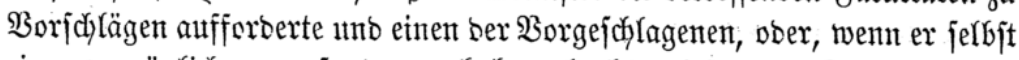
einen vorzüglickeren gefunben z̆ haben glaubte, biejen bem Я̈̈nige präjen=

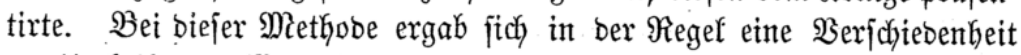

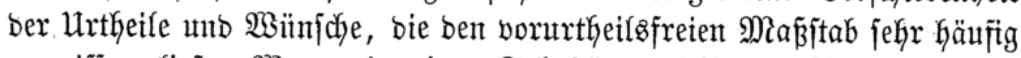

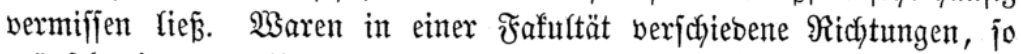
wïnjchte jebe berjelken jich burch ben neuen Rolfegen zu verjtärfen, und

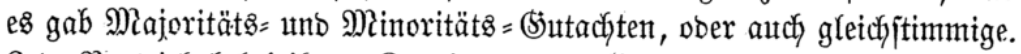

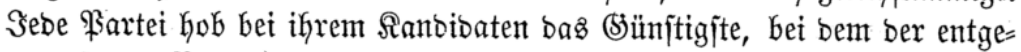
gengejetzten \$artet bas Ungünjtigjte herbor. Wie aud ber Minijter ent= fcheiben modyte, inmer erfdjien er als ßartei. গahm er auf feinen ber

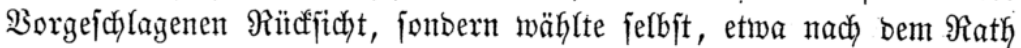
einer unbetheiligten Frafurtät, fo war meiftens bie unzufriebenkeit âtfer jein Sohnt, unto ber (Semählte hatte nicht jelten einen jchnerent Stant.

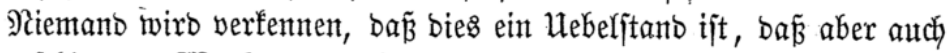

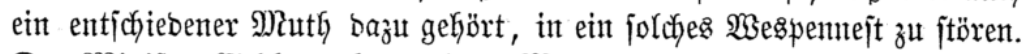
Der Minifter Eidhforn Gatte siejen Muth. Er war entichloffen, fowohl. für bie Befeţung ertebigter orbentlicher \$rofeffuren, alz aud für bie Seer=

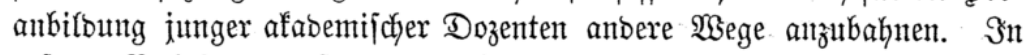
erjterer Beziełung muß̈te er zumächjt jelbjt \$artei nehmen, um fich vorker, vermöge ber ifm zujtehenten Machtwolffonmenheit, ber tïchtigiten \&ehrer zu verjithern. So murben Männer wie Stahl, Relfer und Ânbere beru= fen, zwar in voller Hebereinftimmung nit bem Rönige, aber nicht ofyne

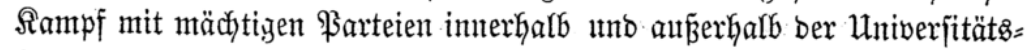
forporation.

Utm aljo bie einzelnen Frafultäten foviel unt jobalo als möglich burch

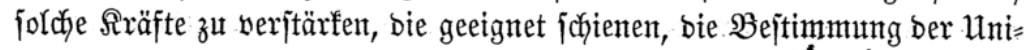

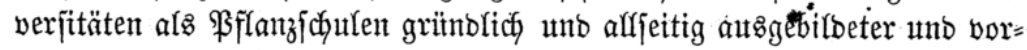
bereiteter Staata = unb Sirchenbiener zu fichern, befjielt ber Minifter (Eid)=

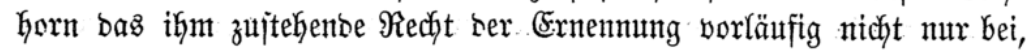
fonbern übte es jogar noch unabhängiger aus, ałs bies frïher geidjeben 
war. Seine YGjicht war aber, jobald biejer Zwect einigermazenen erreidyt fei, e ine ïber ben Fafultäten jtehenbe Behärbe, vielleiçt in geeigneter Berbinoung mit bem Dberid)ul=(5ollegium, uno für Theologen mit bem Dberconfiftorium, zu erridyten, ohue beren (Sitachten feine orbentlidye und

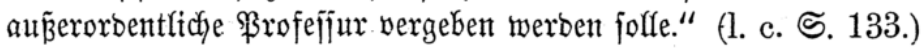

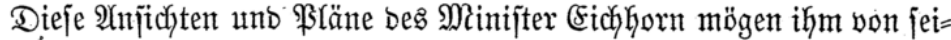

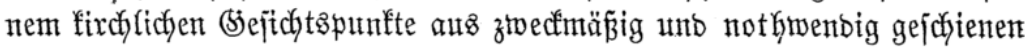
haben. Wo bleiben bent aber bie alten ehrwürbigen unb unantajtbaren lanbeaherrlidyen (5onjtiftutionen, Brivilegien uno Statuten ser Univerjitä=

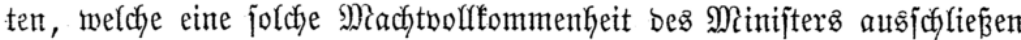

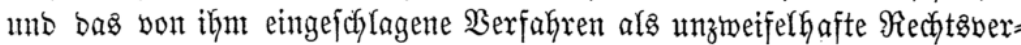
Yeţung erfcheinen lafjen? Die 2 (ntwort auf bieje Frage ijt in biejer Schrift bereitz gegeben. Seit ben Bunbesbejchlüfjen vom 20. Septbr. 1819 hat

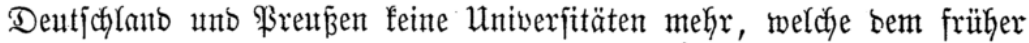
mit biejer Bezeidfunt verbunbenten Begriff entiprechen. Die früheren Privilegien und Statuten fint altsorituffich, foweit fie nicht etwa forpora= tive Eigenthumsrechte betreffen, aufgefoben, uno ber Minifter (Fid)horn hatte baher bolffomment frete Scand, burd) neute Statuten, fet es für eine $\mathfrak{U}$ niverjität überhautpt, fei $e B$ für bie einzelnen Fafulttäten berjelben $\mathfrak{B} e=$ jtimmungen fejtzujetsen, burch welche fein firchlicher $\Re$ eorganifationsplan in B̉eziehung auf bie ganze Stufenteiter bes öffentlichen Unterrichts in Frenfent vermirfficht werben follte.

Die $\mathfrak{A}$ th

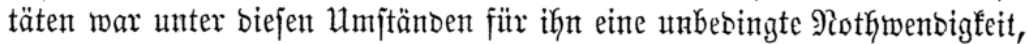

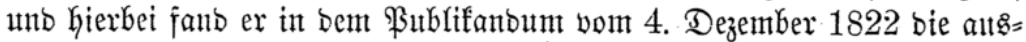
reidjente Unterftütşung. Âtrs aber bie bürgerlidfen Serbältniffe ber

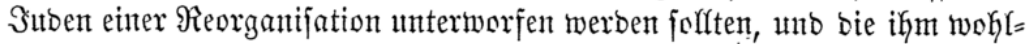
befannte Befinunng bez Rönigs, fowie sie öffentlidje Meeinung, bie Frejt=

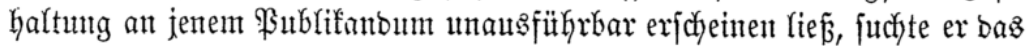
Ginfüllig geworbene Subengejeş burch einzelne Irümmer längit eingeftitrz=

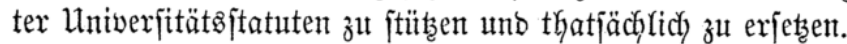

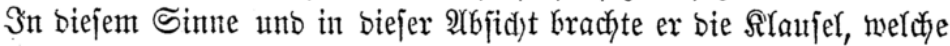
bent entgegenftehentoen fonfeffioneflen SGarafter ber einzelnen $\mathfrak{H}$ niverjitäten unb ifyer Statuten geltent macht, in bas Subengefets vom 23 . Sult 1847. Wie er aber bei ber (sjeltenbmadjung biejer Statuten, um fie für feinent

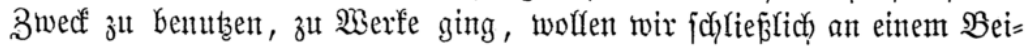

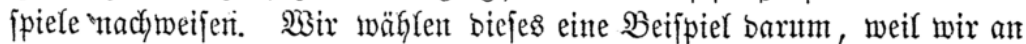
bemfelben zugleidy fehen werben, wie bas Shjtem (Eid)horns audy nach ber bejdyorenen unt in's Rebent getretenen Berfajiungsurfunte - mit ber furzen Unterbrectung Des Braf Schwerinfdyen unt von Rabenbergfdyen 


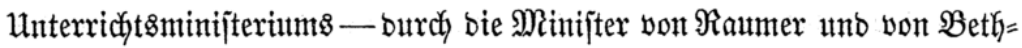
mann $=$ Şolfiweg fortgejeţt wirb.

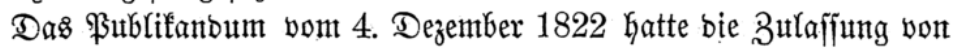

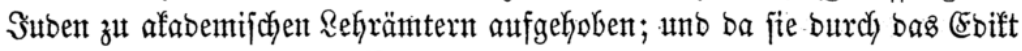
won 1812 bie unbebingte $\mathfrak{B}$ efäfiguntg bazu erkalten hatten, fo burfte bas

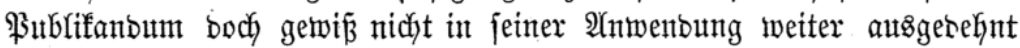

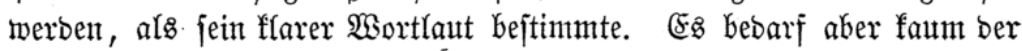

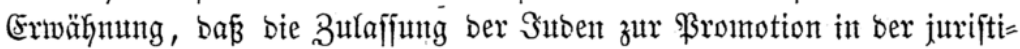

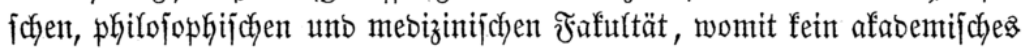
Reframt verbunben ijt, burch bas \$ublifanbum nidjt verboten war.

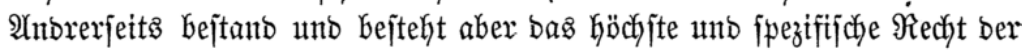

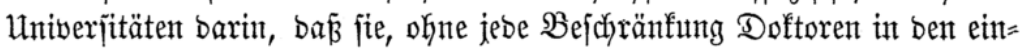
zetnen Fafurttäten unter ber $\mathfrak{A}$ utorität bes Ranbesherrn freiren bïrfen; ja,

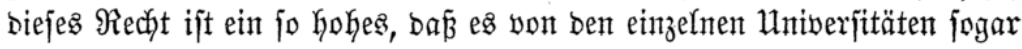

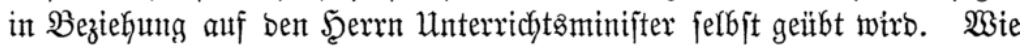
war es benn nun möglich, ben Suben aud bie Bulafjung zur Doftorpro= motion zut entziehen, ba bieje 3ulafjung lebiglich von bem (S)utbünfen ber Untverjitäten abłing? Nam, man madyte fich bie Sache baburch möglich,

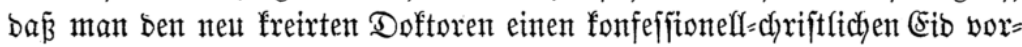
jajrieb unb baburch bie Univerjitäten, bie biejen (Fib afzunehmen hatten,

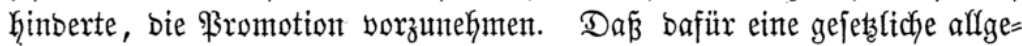

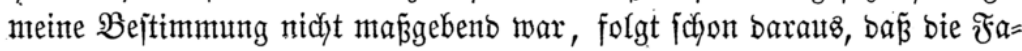

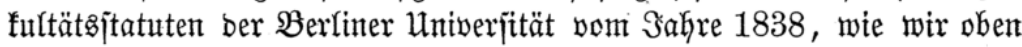

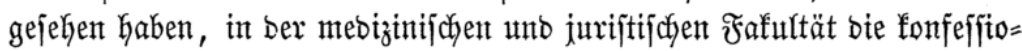

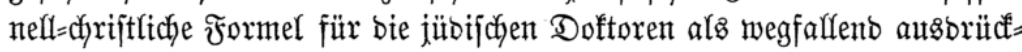
lich vorjachreiben, fïr bie Doftoren ber \$̧Gilojophie aber gar feine fon=

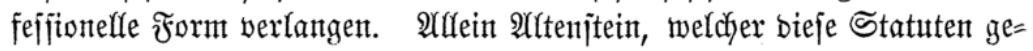
geben, ftarb barb barauf, und ber ihm folgenbe Minifter Eituhorn jorgte

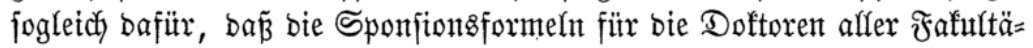

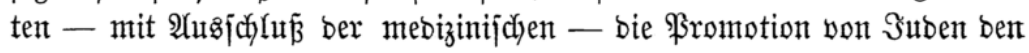

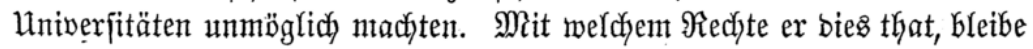
fier unerörtert, ba es fich aus bem (S) efagten himreichento entnehmen läß̈t; wenn ex aber fich babei auf alte, iłm unberleţrliche Statuten berief, wenn

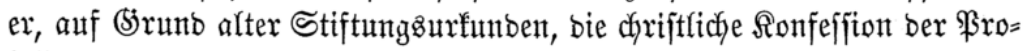
fefforen und ber zu freirenoen Dofteren beizubehalten fich für verpflichtet erffärte unb namentfiç) biefe Erffärung in $\mathfrak{B}$ eziełung anf bie Univerjität fiönigaberg geltent madhte, fo wolfen wir gernbe biejes 2 Beifpiel benutsen, 1um bie Thatjachen gegen ben Minifter iprectjen zu Kaffen.

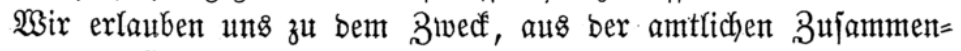
ftelfung. bes Seerrn (Seheimrath Brüggemann noch einmal bie Stelfe 
mitzutheifen, bie fich auf bie Univerjität ̊änigsberg bezicht. Sie lautet:

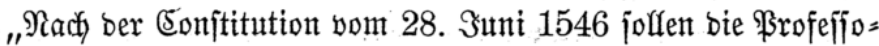
ren jojwören:

Ego juro - me amplecturum veram ac puram Evangelii doctrinam, quam uno spiritu ac voce una ecclesia Dei catholica profitetur, nec corrupturum doctrinam sacram ex philosophia.

3ur Fromotion in ber phitojophifichen Fafultät joll Niemanto zutgelaffent werben: cujus mens polluta et fascinata (beritricft) est falsis opinionibus - et a consensu catholicae ecclesiae Christi alienis - unb boch promobirt man zat アöniggaberg and Sttoent.

Die neuen Statuten yom 4. Maa 1843 jeţen §. 105 fejt:

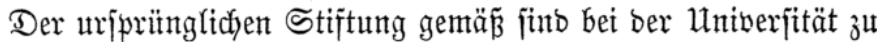
Rönigsberg unr Rehrer evangelifdyer Ronfeffiton anzultelfen."

Wären bieje Sonjtitutionten von 1546 überhautpt für bie Untwerjität

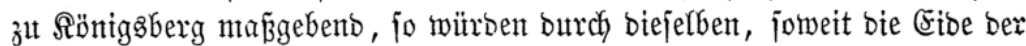
Brofefforen uno ber Doftoren ber \$Gilojophie einen fonfeffioneflen હGa= rafter haben, nidyt bie fatholifhen, fonbern gerabe umgefehrt bie evan= gelifdyen Regrer utto Doftoren ausigejchlofien; unto body folfen, ber ur=

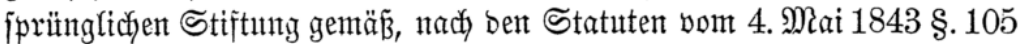
nur evangelifüe Refrer anzulftelfen jein. Die Sache riegt inber ganz

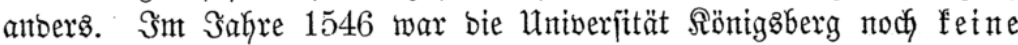

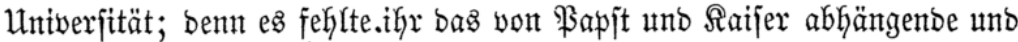
bamals verjagte Rechit, Doftoren zul freiren. Die Eibe anf bie fatho

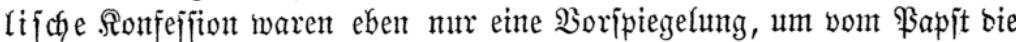

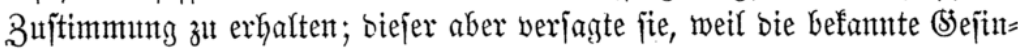

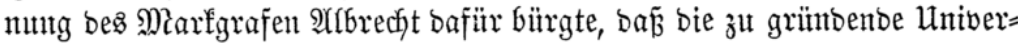
jität gegen bie fatholijaje uno fitr bie evangelifiche Sanfefjiton wirfen jollte. Erjt 1560 ertheilte ber Rönig von \$olen, als Refnnsherr bes Marfgrafen

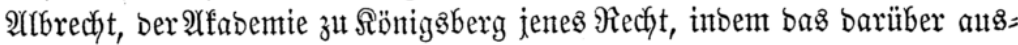
gefertigte Diplom folgenbe Bejtinmunt entfält: „Praeterea damus et concedimus Jus et potestatem promovendi in omnibus Facultatibus et ad omnes Scholasticos gradus, tum iis, qui in eadem Academia promoti erunt, universa Privilegia et praerogativas, quae iis, qui ceteris in Gymnasiis et Universitatibus promoventur, competunt competereve possunt consuetudine vel de jure."

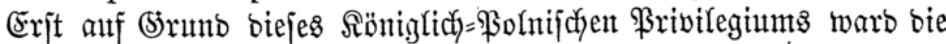

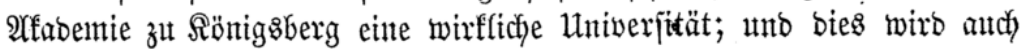




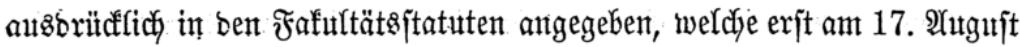
1616 von ben einzelnen Fafulttäten ausgearbeitet worben fint, unb zwar unter alfeiniger Alpprobation bes Reftor und Senats, wie biez bamalz zu

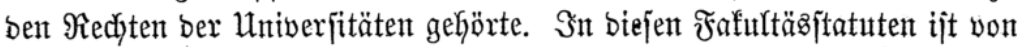

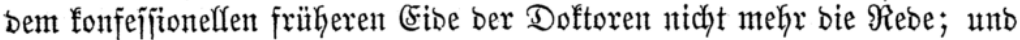
was bie Eibesformel ber \$rofefforen betrifft, jo ijt bieje - wie fie audd

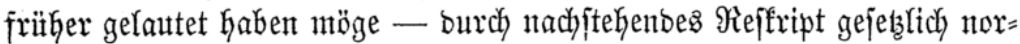

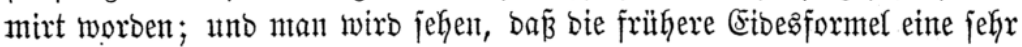
wejentliche Seränberunty erfahren hat.

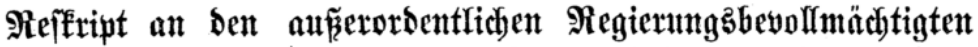 bei ber Hntwerfitüt Rönigsberg, Getreffent bie Sereibigutg bez Reftors, Der \$rofefīoren und der promovirten Doftoren unto Qiżentiaten.}

Som 14. Sanuar 1836.

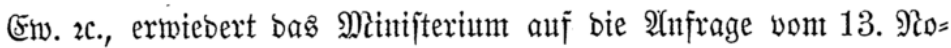

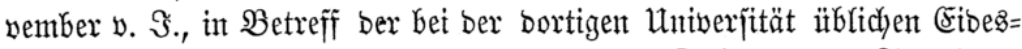

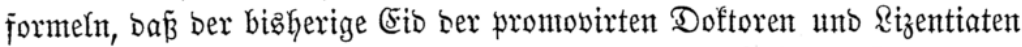

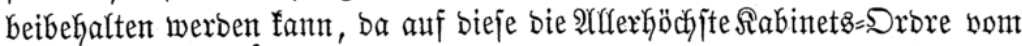

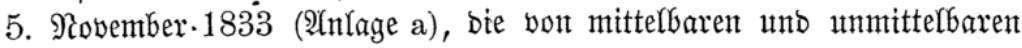
3ivifbeamten rebet, nicht zut bejiehen ijt; bodh finbet bas Minifiterium

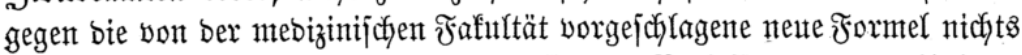

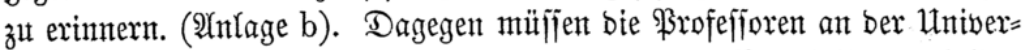

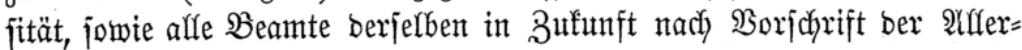

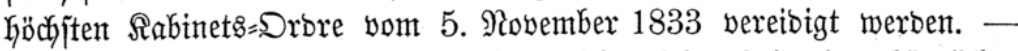
Ánbelangento entolich ben Broreftoreib, welcher jich auf ein eigenthitmliches Berkältnís grünbet und einen- wejentlichen Theil einer althergebrachten

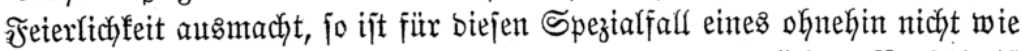

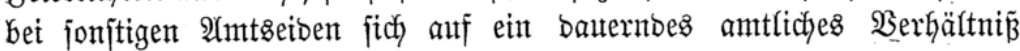
beziekenten Fibes, eine Anorbnung nicht in Frage gefommen, unt baher, bis eine jolche angeoronet wirb, bas bişherige Serfahren beizubehalten. ( $\mathfrak{A}$ thlage c.)

Berlin, ben 14. Sanuar 1836.

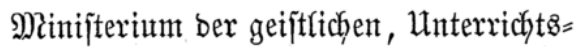
uno Mebizinal=2Angelegenheiten.

\section{Alutage a.}

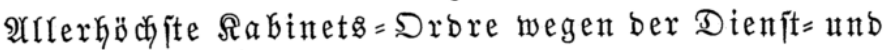

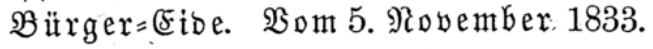

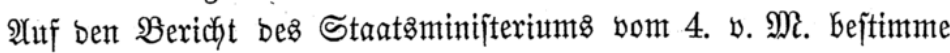

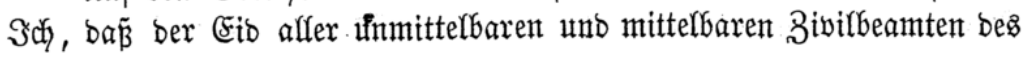




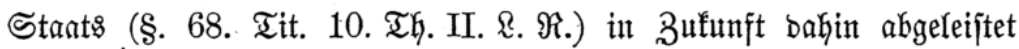
werben foif:

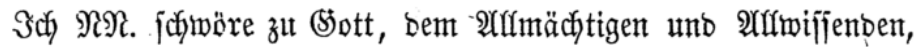

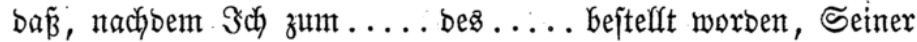

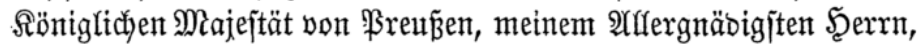
ich) unterthänig, treu uno geforjam jein, uno alle mir bermöge meines 2 (mtes obliegenden Pflichten nach meinem bejten Wifjen. uno (Sientiffen genau erfüffen wifl, fo mahr mix Sott helfe.

Эn Şeziehung auf bie Dienjteibe ber mittelbaren Staatsoiener tritt biejem Formular unabgeänbert biejenige (Eibeğnorm łinzu, mittels welcher

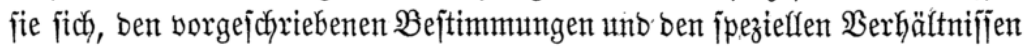
gemäß̈, Dem unmittelbaren Dienjtherrm zu verpflitdten haben. Bugleich verorbne $\Im \mathfrak{c h}$, ba

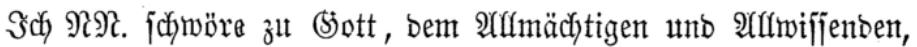

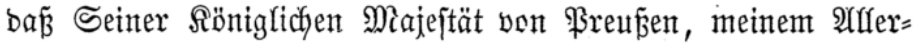
gnäbigiten Seerru, ich unterthänig, treu uno geforjant jein, meinen Borgejetzten willige Folge leiften, meine \$fflidyten alz Bürgex

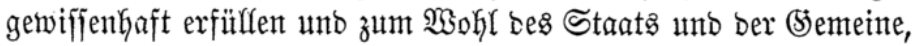
zu ber idy gehöre, nach alfen meinen Arạ̈ften mitwirfent will, fa wahr mir bott helfe u. f. w.

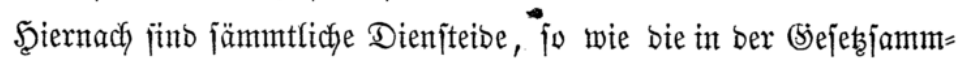
lung für 1831 S. 33 unb 1832 S. 184 uno 187 angegebenen Fibes=

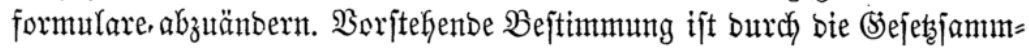
lung befannt z̆t machent.

Ber lin, Dett 5. November 1833.

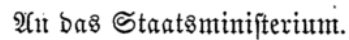

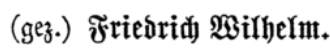

\section{$\mathfrak{A} \mathfrak{H} \mathfrak{H} \mathfrak{g} \mathfrak{g} \mathfrak{e}$ b.}

Doftoreib ber mebizinifhen Fafultät ber univerjität 子น $\Re \ddot{z}$ ing

Ego N. N. juro, me serenissimo ac potentissimo Regi Borussiae fidelem futurum, commoda Regiae Majestatts ejusque domus, ut et academiae hujus pro viribus promoturum; et si ad ipsos aegrotos sanandos requisitus fuerim, nihil dolose, sed omnia circumspecte secundum conscientiam et regulas medicas acturum, et non tam meum commodum, quam aegri sanitatem, sive pauper sive dives sit, quaesiturum esse. Ita me Deus adjuvet. 


\section{Âtrlage c.}

Proreftor=aio.

Prorector Magnificus jurabit, se velle omni cura ac diligentia et fide fungi suo officio, inprimis pietatem colere, paci et otio reipublicae studere, administrationem scholasticam sedulo, accurate, fideliter agere.

Die neuen Statuten vom 4. Mat 1843 jeţen aflerbings im §. 105

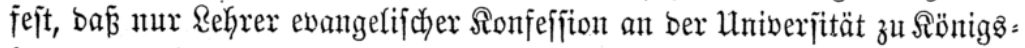
berg anzujteffen fint, affein über bie (bejejichte uno Bebeutung biejer $\mathfrak{B} e=$

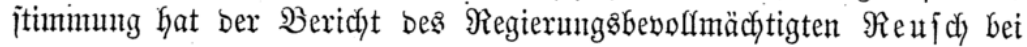

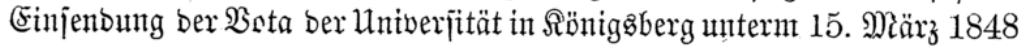

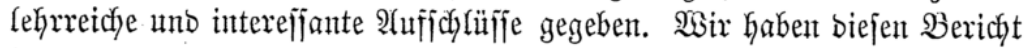
in ber zweiten ałbtheilung biejer Schrift $\mathbb{S}$. $214 \mathrm{ff}$. mitgetheilt unt wolfent ben Refer hier nur auf benfelben berweijen.

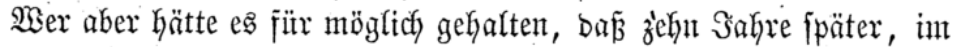
3ahre 1853, aljo nach Emantion ber bejdwornen Serfafjungsurfumbe

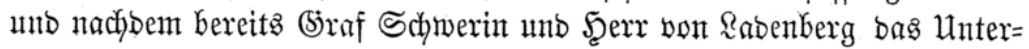

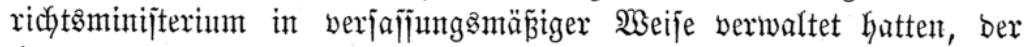

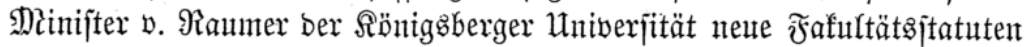

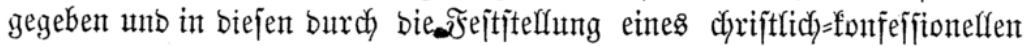

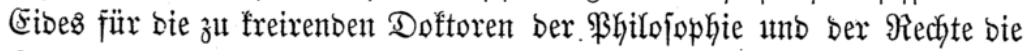

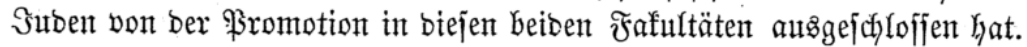
Nun Scerr $\mathfrak{v}$. Raumer Gatte feiner ganzen $\mathfrak{B}$ erwaltung ben fonfeffitoneffent

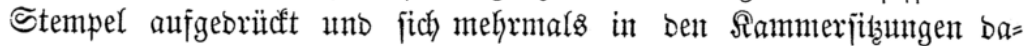

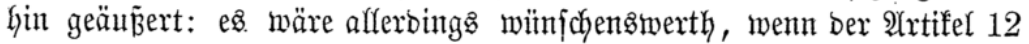

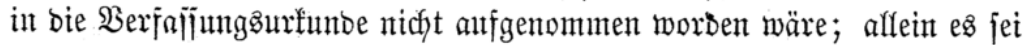

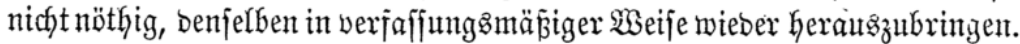

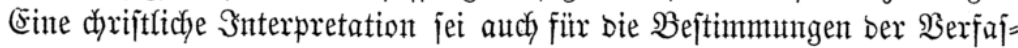
jungsinfunbe erfaubt unb geboten, und vermöge einer foldhen werbe bie

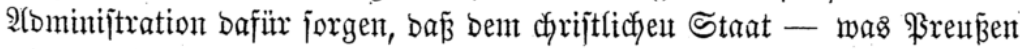

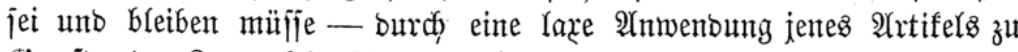

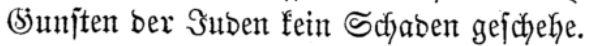

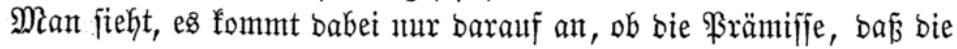

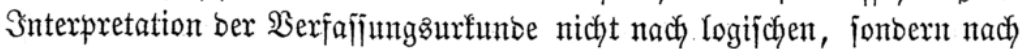

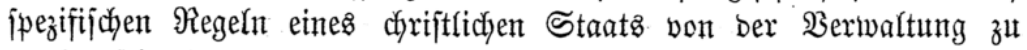
machen jei, als richtig zugegeben werben barf. Sjt jie bies, fo mus allez Uebrige als fonjequent gelten. Alnbers hat aber bas gegenwärtige Staats=

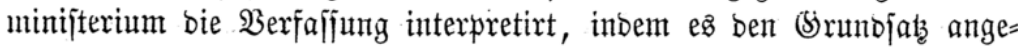

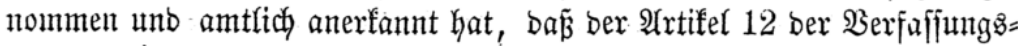


urfunbe bie Sraft eines bispofitiven, jofort wirfjamen Ssejeţes befize und

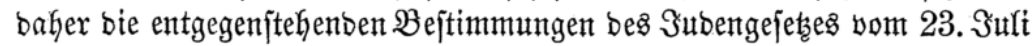
1847 aufgełoben habe. $\mathscr{A}$ uth ber Unterrichtominijter ijt biejem (5rumb= jaţe beigetretelt, hat aber bennod) - abgejehen von jeinen (Erflärungen

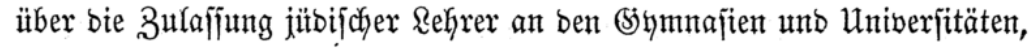

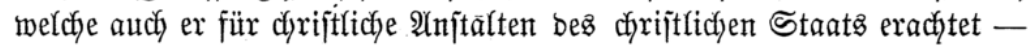

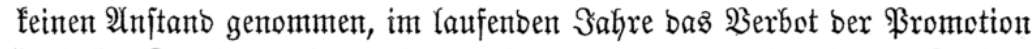

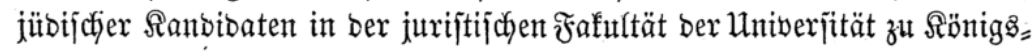
berg aufrecht zu halten. Er jelbjt hat feine besfaflfige Berfügung in bem von Scerrn (Steheimrath Stiehl amtlid) herauggegebenen "Sentralblatt für

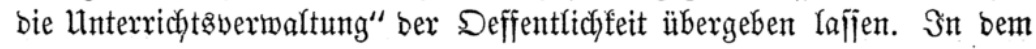

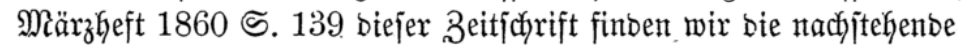

\section{Berfügung,}

bie Bromotion ber suben zu Doftoren ber Philofoptie betreffent.

(5m. 2 . erwiebere idh ergebenft auf ben gefälligen Bberidyt vom 29. v. M. unb $\Im$.

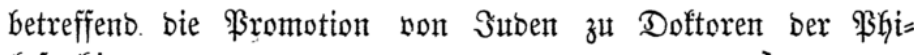
lofophie,

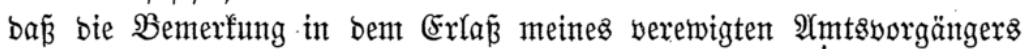
vom 20. Februar 1854 (u. 788), ę habe burch bie Fajijung, melche bem §. 63 Der Statuten für bie bortige philofophif che Fafultä̈t vom 15 . Dftober

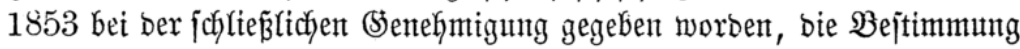

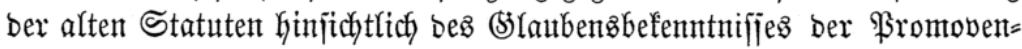
ben nicht abgeäntort werben jollent, auf einer irrigen Borauspełsung beruht. Der aftenmäß̧ige J̧ergang ber Sache ijt forgenber:

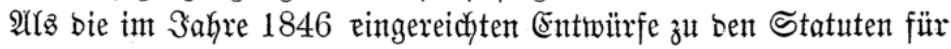
bie bortigen 4 Fafultäten mittełz biez̧eitigen Ertajfę bont 21. Dezember 1846 behufg nodymaliger untarbeitung remittirt wurben, warb ju

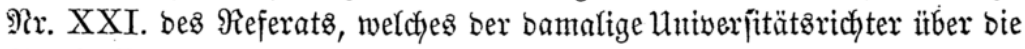

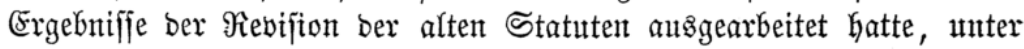
anberm bejtimmt, baß bei ber anbermeitigen $\Re$ ebaftion ber Statuten für

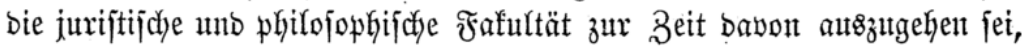

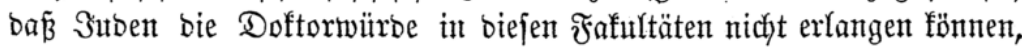

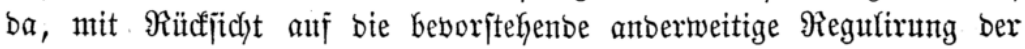

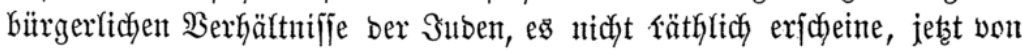
ben bejtehentoen Bejtimunungen abzutweidyen. Demgemän wat in ben mittera (5ww. zc. gefälfigen $\mathfrak{B e r i d y t s ~ v o m ~ 2 5 . ~ M a i ~} 1853$ vorgelegten umge= 


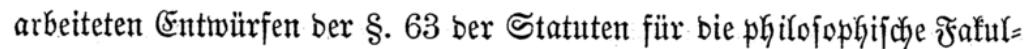
tät im Eingang bahin gefaßst:

"Wer fich um ben Doftorgrab bei ber Fafultät betwerben wifl, mùn jich zut chriftlichen ßeligion befennen."

(5m. zc. bemerften zu biejer $\mathfrak{B}$ eftimmung hinfid)trich bes phitofophifchen

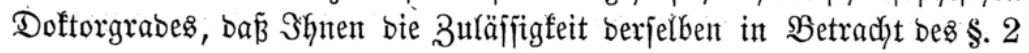

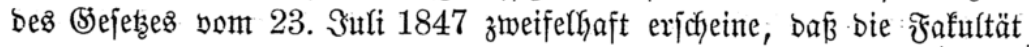

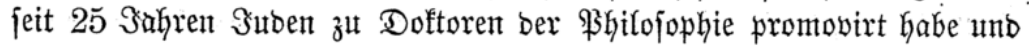

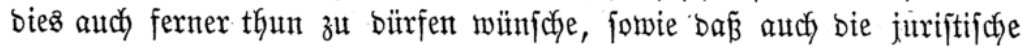

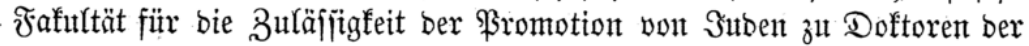

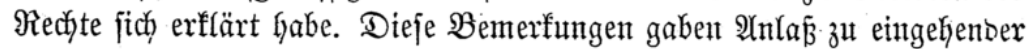

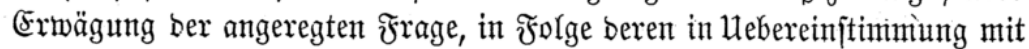

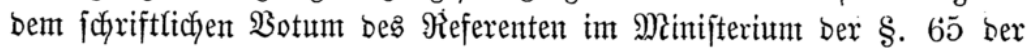
Statuten für bie jurijtifche Frafultät, weil jie mux Doctores juris utriusque freiren fanm, unveränbert gelaffen, bagegen im §. 63 ber

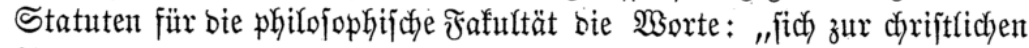
Religion befennen" gejtrichen wurben. Wenn beffen ungeachtet bie (sibes= formel im $\S .68$ biejer leţterent Statutẹn „Ita me Deus adjuvet et sacrosanctum ejus Evangelium" unveränbert gebliebent, unb nicht autch

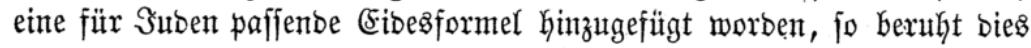
lebiglidy auf einem Berjełen bes Minifterialreferentent.

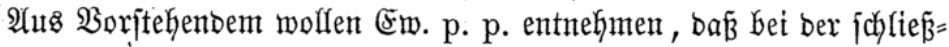
lichen Stenehmigung ber Statuten für bie bortige philojophifche Fafultät

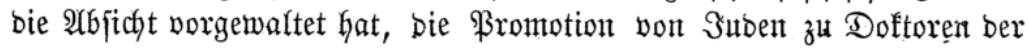

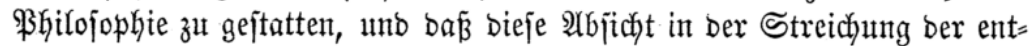

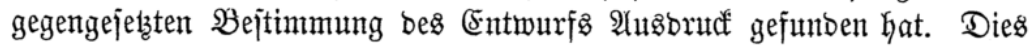
idjienen aud (5m. p. p. Damals vorausgejeţt zu haben, inbem Sie im Bericht vom 29. Dezember 1853 barauf antrugen, zu. bejtimmen, bá̧

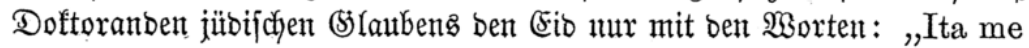
Deus adjuvet" ableiften bïrfent:

Şiernad, forwie in Berüffifidtigung ber in bem Bericht ber phitofo=

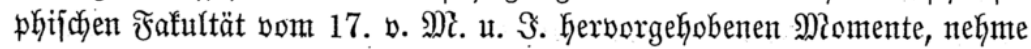
ich) nicht $\mathfrak{A} \mathfrak{n}$ fant, ber Fafultät nach ihrem 2 ntrage fortan autch bie $\mathfrak{B r o}=$ motion bon Suben zu Doftoren ber \$̧hilojophie hiermit zu gejtatten. Dex jübijhe Doftorand hat ben (5ib mit ben Morten: „Ita me Deus ad-

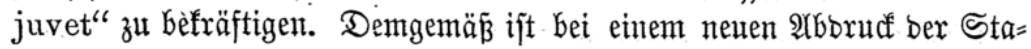
tuten ber philofophifchen Fafulttät bem §. 68 in einer $\mathfrak{A}$ tumerfung zum Terct bie $\mathfrak{B}$ ejtimmung Ginżuzufügen:

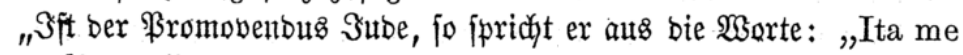
Deus adjuvet." 
(5m. p. p. exjutche ich ergebenft, hiernach gefälfigit bie Faturtät zu bejcheiben uno bas weiter Exforberliche zu veranlafjen.

Berlin, ben 21. Jamuar 1860. $\mathfrak{A} \mathfrak{n}$

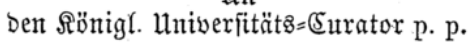

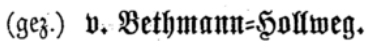

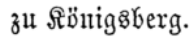

Wir mollen mit biejer $\mathfrak{B e r f u ̈ g u n g ~ u n j e r e ~ S c h r i f t ~ f a l t e p e n , ~ t r o t s ~ b e r = ~}$

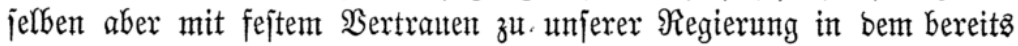
(Siegebenen bie Bürgichaft für bas nod) zu Erwartenbe erblicfent. Dic Wünlche, auth bie berechtigten, benvegen fich ichneller als bie Më̈glicffeit

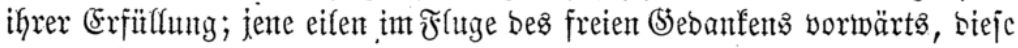

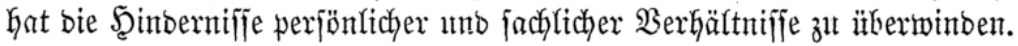

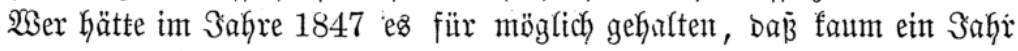
fpäter bas (5)efets vom 23. Suli antiquirt und burch eine \$erfaffungs: urfunbe erjetst fein würte, ja, bå̉ ber Mann, ber bies mit Entjojiebenkeit

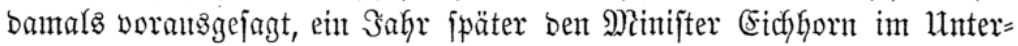

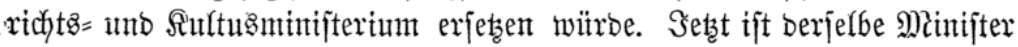
Des Sinnern, unt wenn er als folcher feine Treute gegen bie Berfajfung in

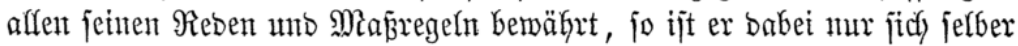

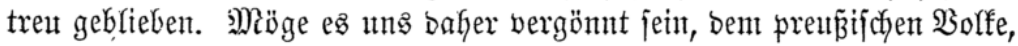
zu weldyent alth bie jübifichen Srenten als integrirenber unb untrennbarer Theil gefören, fudlieflidy bie Worte zu wieberkolen, welche ber Srraf Schwerin am 15. Jint 1847 bei ben Serhandlungen ïber bas biejets vom 23. Sult gegent baffelbe ausfpradh. Miögen fie uns aflen eine BB̈̈rgichaft

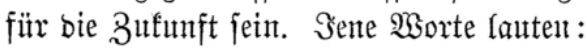

"Die (Segentwart ijt bas \$robuft ber Bergangenheit unt bie Träges rin ber Zuffunft; lajfen Sie uns baher nidyt bon ber Errungenfdyaft ber

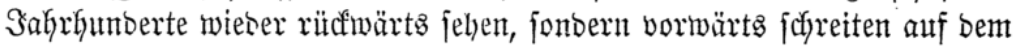
Wege, bent wir fafon bejajritten haben. Daz erforbert nidft mur ber Begriff bes Stuates, bas erforbert nod) mehr ber Begriff bes (Shriften= thumb. Eas ijt viel von bem dyriftlichen Staate gejprodhen, es ijt gejagt worben, bie @irche hätte ben Staat erzogen jur Mitnbigfeit. Wohlan, ge= ftehen wir bas zut. Bumächjt ift alferbings im Mittelalter bie Sirche bie Trägerin bes Staats getwejen; aber weil ber Stant mïnbiz getworben ift,

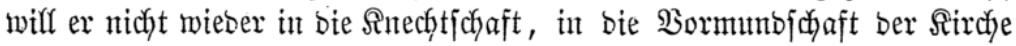
zuritưfgemiejen werben, barum will er jelbjtitüntbig bajtehen, will jeinen Begriff aus jich fẹtbit tweiter entwidéln unb bas Staatsbitrgerthum, bas Reben bes Staats, nidjt ber Sirche unterorbnen, fonbern nebent ber Sirche

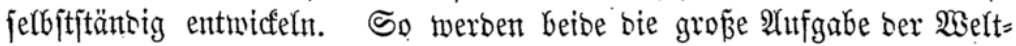

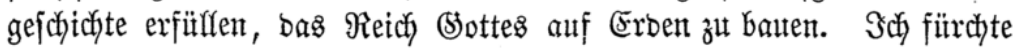

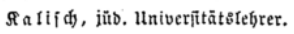




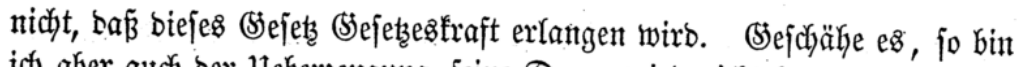
ich aber aud ber Ueberzengung, feine Dauer wirb nicht lange fein. Der

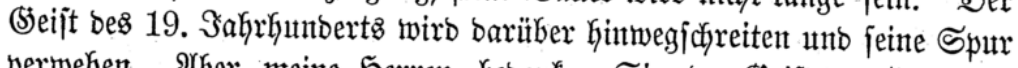

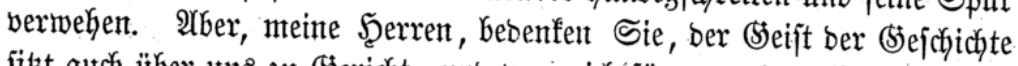

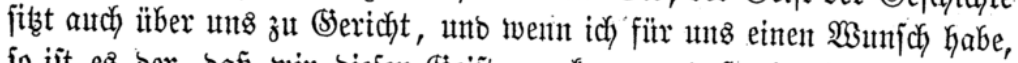

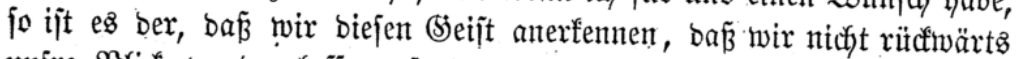

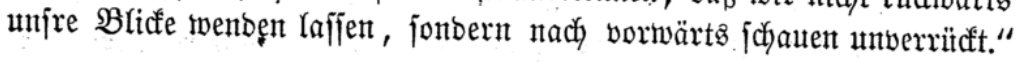

$4243 / 18$ 


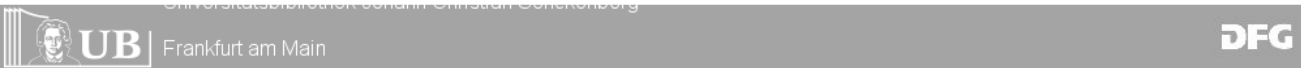

